\title{
Radiological Performance Assessment for the E-Area Vaults Disposal
} Facility

by

J. R. Cook

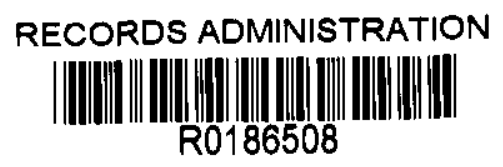

Westinghouse Savannah River Company

Savannah River Site

Aiken, South Carolina 29808

L. McDowell-Boyer

H. Holmes-Burns
A. D. $\mathrm{Yu}$
D. C. Kocher
E. L. Wilhite
K. E. Young

This paper was prepared in connection with work done under the above contract number with the U. S. Department of Energy. By acceptance of this paper, the publisher and/or recipient acknowledges the U. S.

Government's right to retain a nonexclusive, royalty-free license in and to any copyright covering this paper, along with the right to reproduce and to authorize others to reproduce all or part of the copyrighted paper. 


\section{DISCLAIMER}

This report was prepared as an account of work sponsored by an agency of the United States Government. Neither the United States Government nor any agency thereof, nor any of their employees, makes any warranty, express or implied, or assumes any legal liability or responsibility for the accuracy, completeness, or usefulness of any information, apparatus, product or process disclosed, or represents that its use would not infringe privately owned rights. Reference herein to otherwise does not necessarily constitute or imply its trade name, trademark, manufacturer, or the United States Government or any agency thereof. The vement, recommendation, or favoring by herein do not necessarily state or reflect those of the The views and opinions of authors expressed thereof.

This report has been reproduced directly from the best available copy.

Available for sale to the public, in paper, from: U.S. Department of Commerce, National Technical Information Service, 5285 Port Royal Road, Springfield, VA 22161, phone: (800) 553-6847,

fax: (703) 605-6900

email: orders@ntis.fedworld.gov

online ordering: http://www.ntis.gov/ordering.htm

Available electronically at http://www.doe.gov/bridge

Available for a processing fee to U.S. Department of Energy and its contractors, in paper, from:

U.S. Department of Energy, Office of Scientific and Technical Information, P.O. Box 62,

Oak Ridge, TN 37831-0062,

phone: (865)576-8401,

fax: (865)576-5728

email: reportsbadonis.osti.gov 
March 29, 2000

SRT-WED-2000-00032

To: Distribution

\section{SRS E-AREA LOW-LEVEL WASTE FACILITY PA REVISION (U)}

Per the discussion at last week's meeting of the DOE Low-Level Waste Disposal Facility Federal Review Group (LFRG), I am assisting Jane Talerico in sending copies of the revised Savannah River Site E-Area Low-Level Waste Facility performance assessment (WSRC-RP-94-218, Rev. 1) to LFRG members.

If you have any questions, please call.

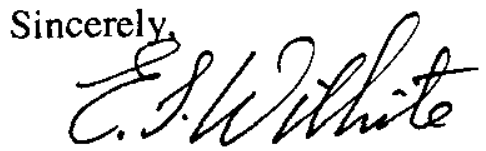

Elmer L. Wilhite

Advisory Scientist

Savannah River Technology Center

803-725-5800

Distribution:

Frank DiSanza, NVO

Joe Ginanni, NVO

Doug Hildebrand, RL

Randy Janke, $\mathrm{OH}$

Bill McMillan, ORO

Don Metzler, GJPO

Bill Noll, SR

Jim Orban, ALO

Andy Wallo, EH-41 
WSRC-RP-94-218

Revision 1

KEY WORDS: Performance Assessment

Waste Management

\section{RADIOLOGICAL PERFORMANCE ASSESSMENT FOR THE E-AREA LOW-LEVEL WASTE FACILITY}

Prepared by:

Laura McDowell-Boyer ${ }^{a}$

Andrew D. $\mathbf{Y u}^{\mathrm{a}}$

James R. Cook

David C. Kocher ${ }^{c}$

EImer L. Wilhite ${ }^{b}$

Heather Holmes-Burns ${ }^{d}$

Karen E. Young ${ }^{e}$

a Alara Environmental Analysis, Inc.

b Westinghouse Savannah River Company

c Oak Ridge National Laboratory

d BNFL Savannah River Company

e RCS Corporation, Inc.

January 31, 2000

Westinghouse Savannah River Company

Savannah River Site

Aiken, SC 29808

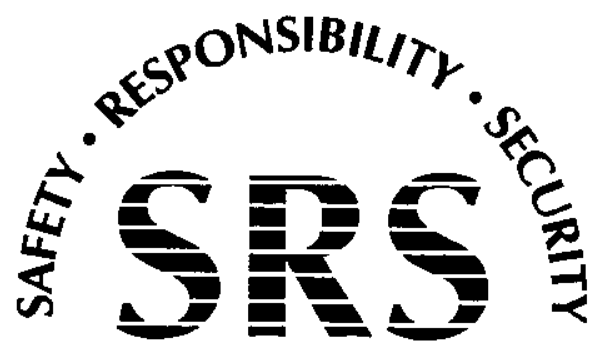




\section{REVIEWS AND APPROVALS}

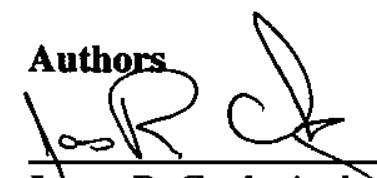

James R. Cook, Author

Waste Disposal and Environmental Development

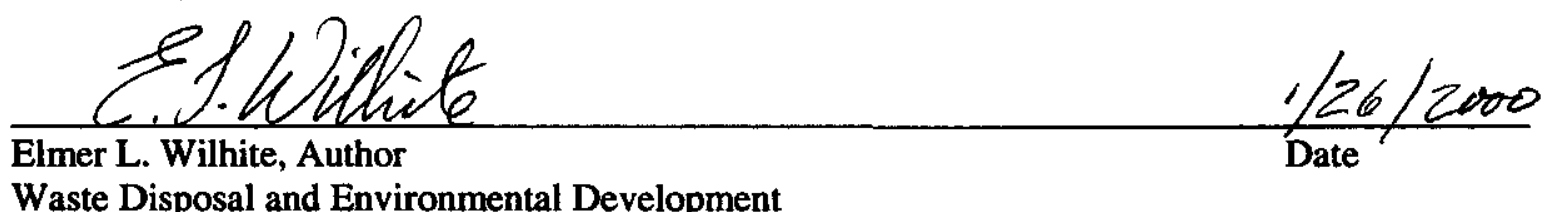

Waste Disposal and Environmental Development

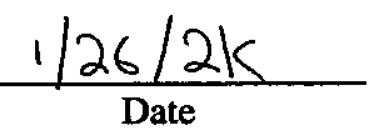

\section{Approvals/Review}

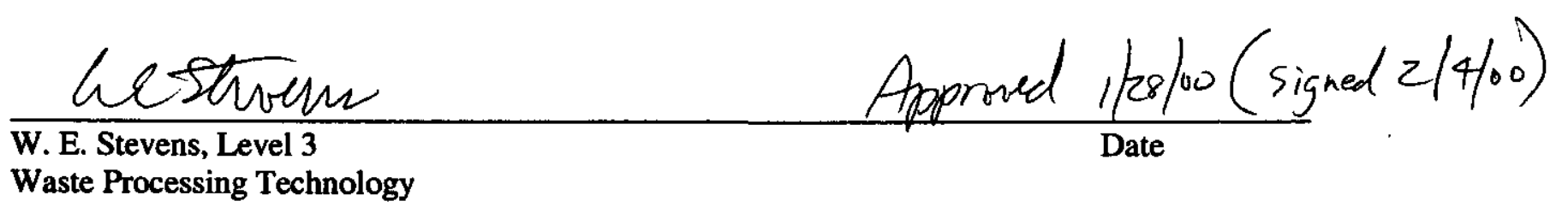

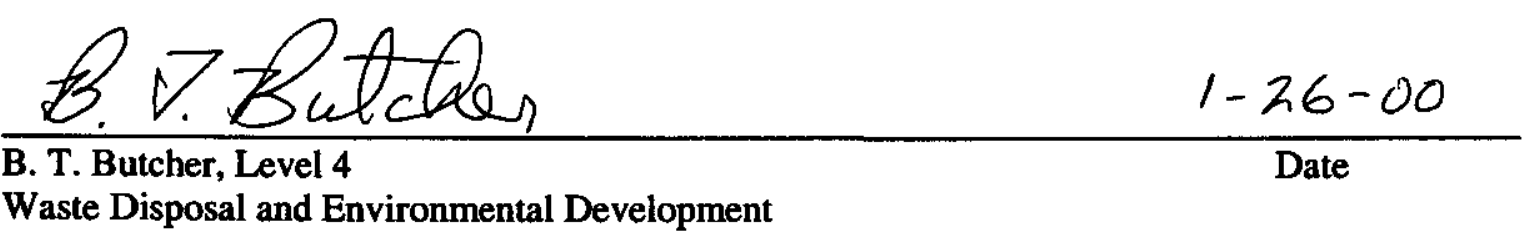

Waste Disposal and Environmental Development

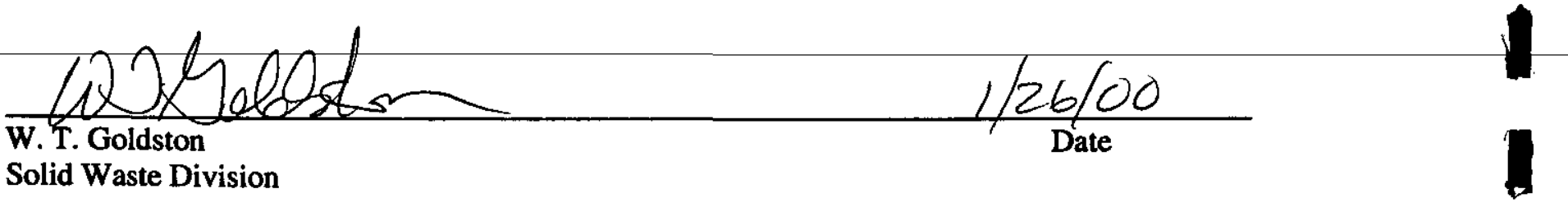

\section{Solid Waste Division}




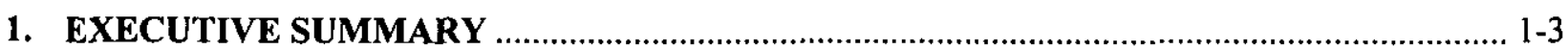

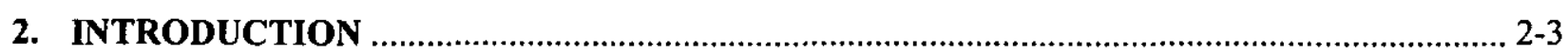

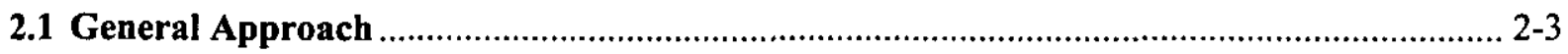

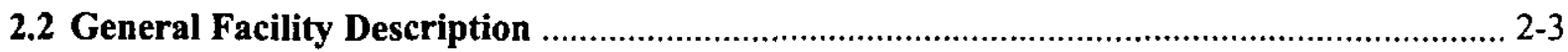

2.2.1 Low-Activity Waste Vaults.................................................................................. 2-4

2.2.1.1 General Description and Location.......................................................................... 2-4

2.2.1.2 Major Design Philosophy ................................................................................ 2-4

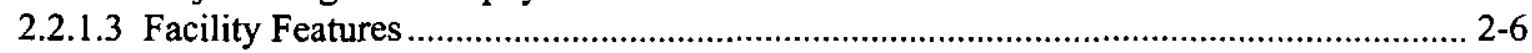

2.2.1.4 Disposal Concept Considerations and Movement of Waste Through the Facility .............................................................................................. 2-7

2.2.1.5 Waste Acceptance and Certification ................................................................... 2-7

2.2.1.6 Land Use Patterns .............................................................................................. 2-9

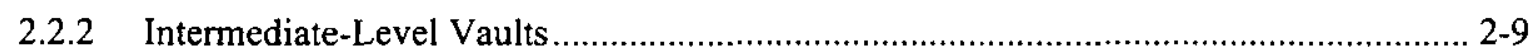

2.2.2.1 General Description and Location....................................................................... 2-9

2.2.2.2 Major Design Philosophy ............................................................................... 2-10

2.2.2.3 Facility Features........................................................................................ 2-12

2.2.2.4 Disposal Concept Considerations and Movement of Waste Through the Facility ...................................................................................... 2-12

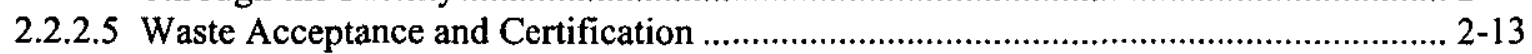

2.2.2.6 Land Use Patterns ............................................................................................. 2-13

2.2.3 Very-Low-Activity Waste Disposal Trenches …………............................................. 2-13

2.2.3.1 General Description and Location........................................................................ 2-13

2.2.3.2 Major Design Philosophy .................................................................................... 2-15

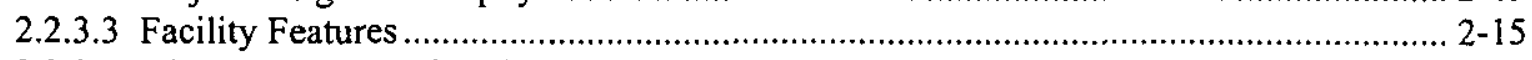

2.2.3.4 Disposal Concept Considerations and Movement of Waste

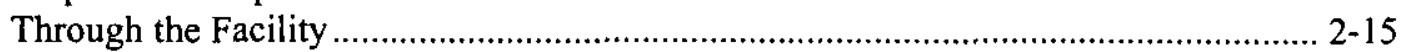

2.2.3.5 Waste Acceptance and Certification ..................................................................... 2-15

2.2.3.6 Land Use Patterns ....................................................................................... 2-15

2.2.4 Intimately-Mixed Cement-Stabilized Waste Disposal Trenches .................................. 2-16

2.2.4.1 General Description and Location.................................................................... 2-16

2.2.4.2 Major Design Philosophy............................................................................ 2-16

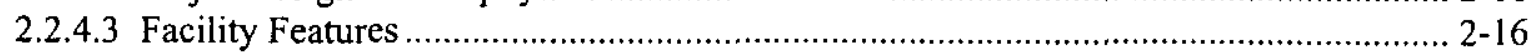

2.2.4.4 Disposal Concept Considerations and Movement of Waste

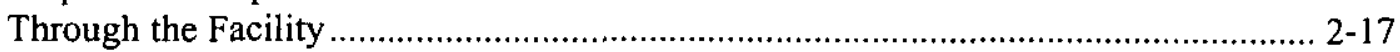

2.2.4.5 Waste Acceptance and Certification ..................................................................... 2-17

2.2.4.6 Land Use Patterns .......................................................................................... 2-17

2.2.5 Cement-Stabilized Encapsulated Waste Disposal Trenches ……………………….... 2-17

2.2.5.1 General Description and Location...................................................................... 2-17

2.2.5.2 Major Design Philosophy.............................................................................. 2-17

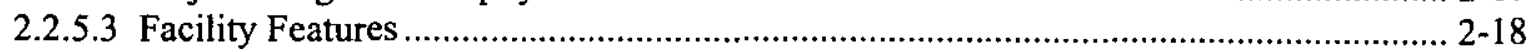




\section{CONTENTS (Cont'd.)}

2.2.5.4 Disposal Concept Considerations and Movement of Waste

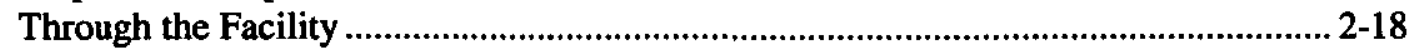

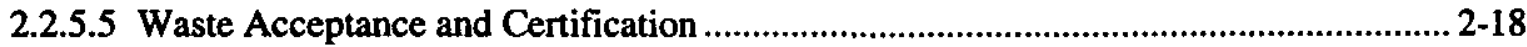

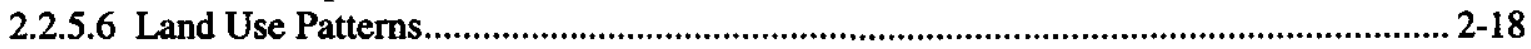

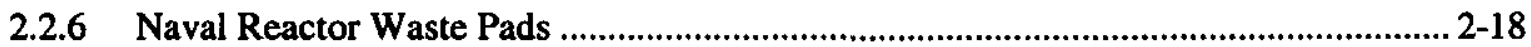

2.2.6.1 General Description and Location................................................................... 2-18

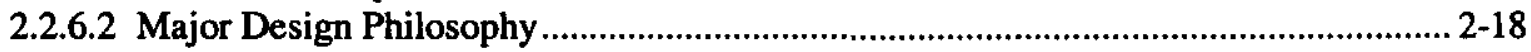

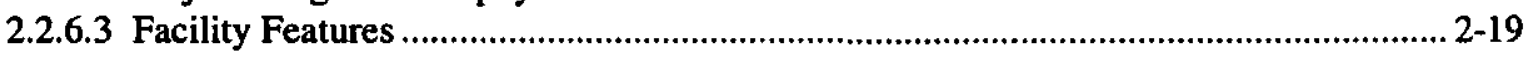

2.2.6.4 Disposal Concept Considerations and Movement of Waste

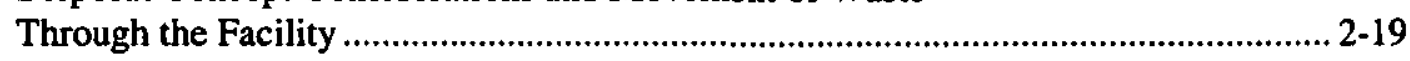

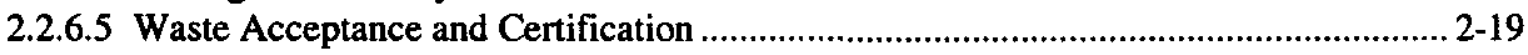

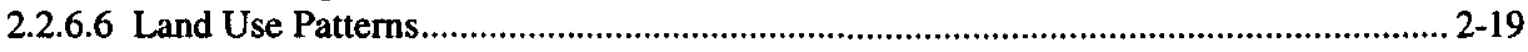

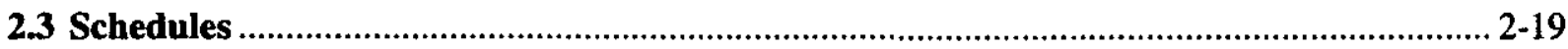

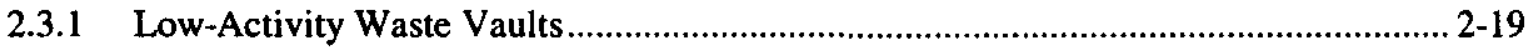

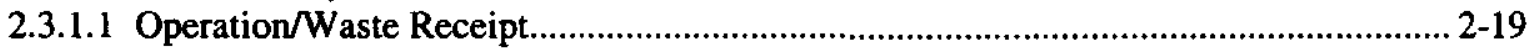

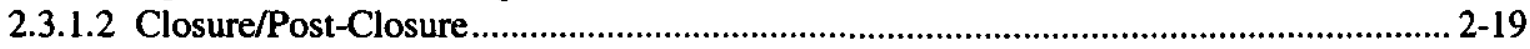

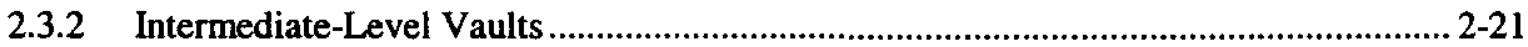

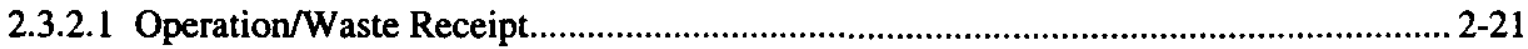

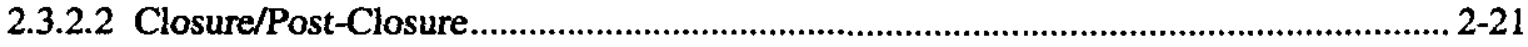

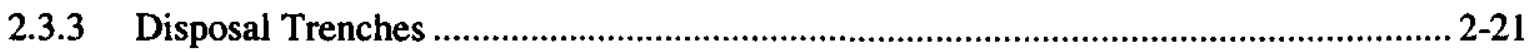

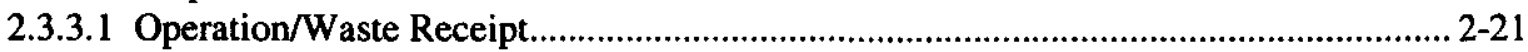

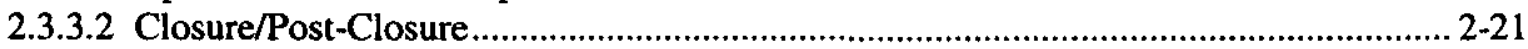

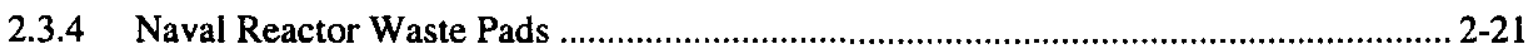

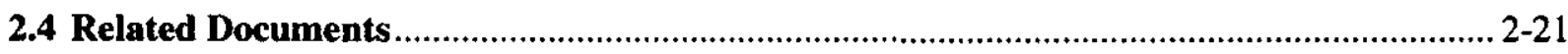

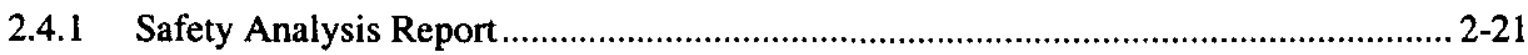

2.4.2 Groundwater Protection Management Program.................................................. 2-22

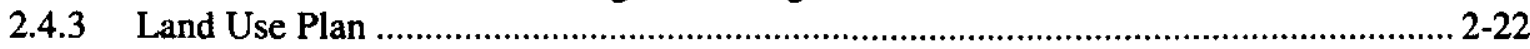

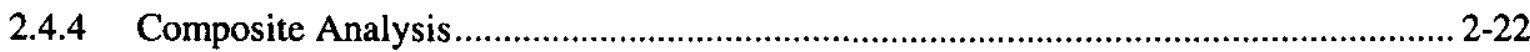

2.4.5 Saltstone Disposal Facility Performance Assessment and Closure Plan .................... 2-22

2.4.6 Waste Management Environmental Impact Statement ........................................... 2-23

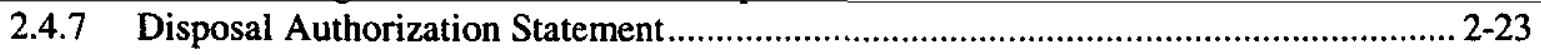

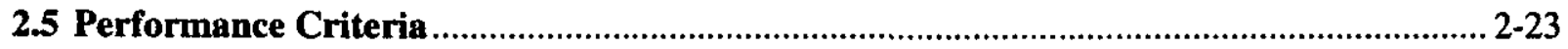

2.5.1 Public Protection Performance Objective .............................................................. 2-25

2.5.2 Water Resource Impact Assessment Requirement .................................................. 2-26

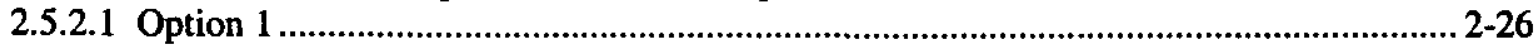

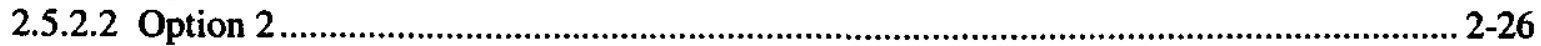

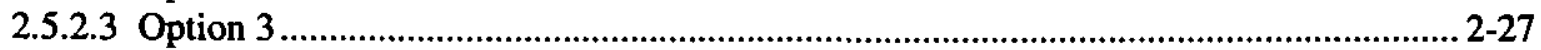

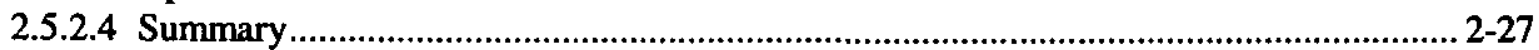

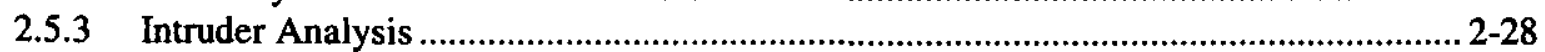




\section{CONTENTS (Cont'd.)}

2.6 Summary of Key Assessment Assumptions $2-28$

3. DISPOSAL FACILITY CHARACTERISTICS 3-3

3.1 Site Characteristics 3-3

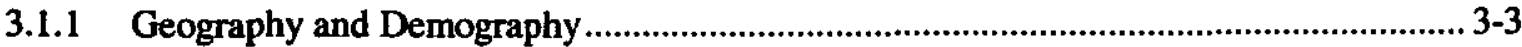

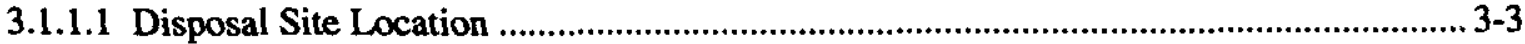

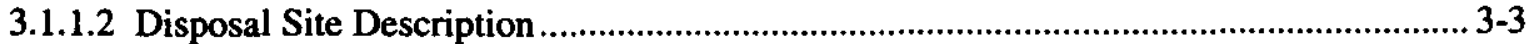

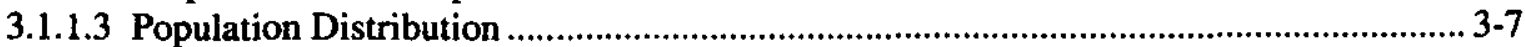

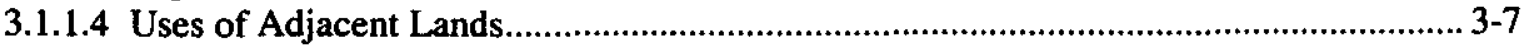

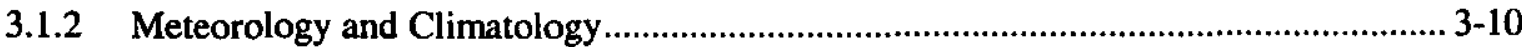

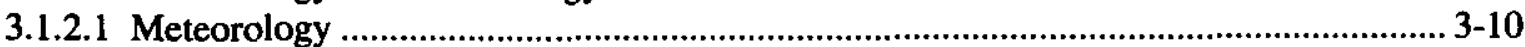

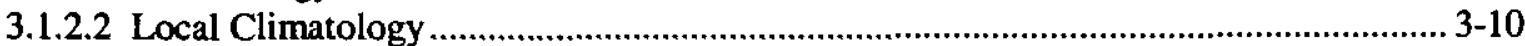

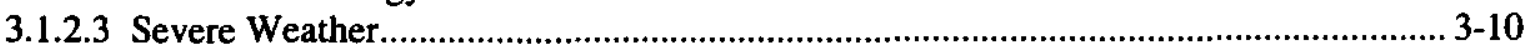

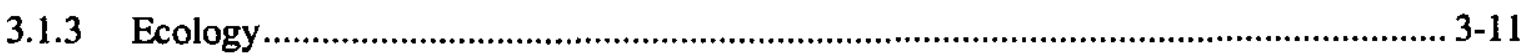

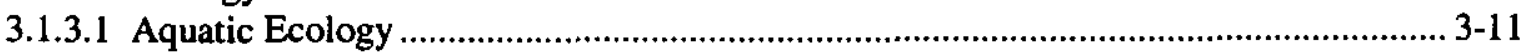

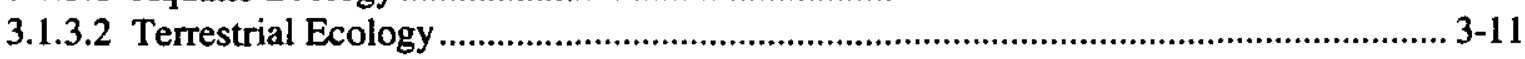

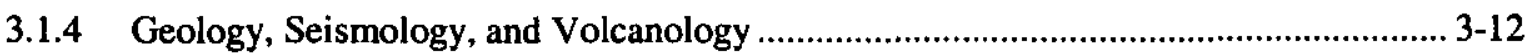

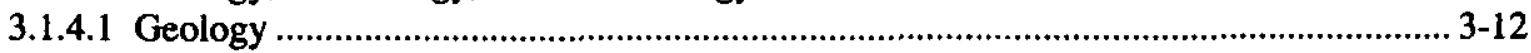

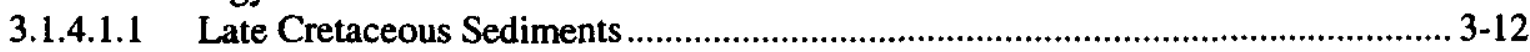

3.1.4.1.2 Paleocene-Eocene Black Mingo Group …............................................................ 3-14

3.1.4.1.3 Middle Eocene Orangeburg Group........................................................................ 3-14

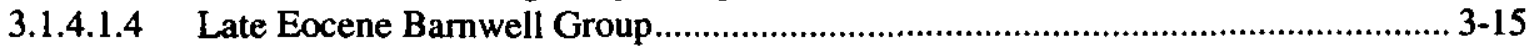

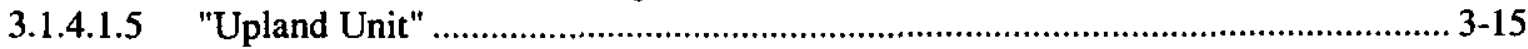

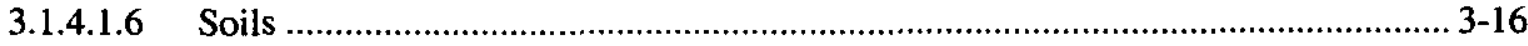

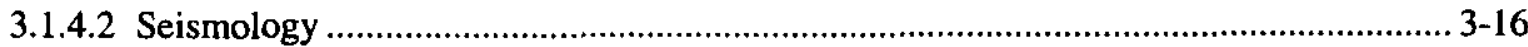

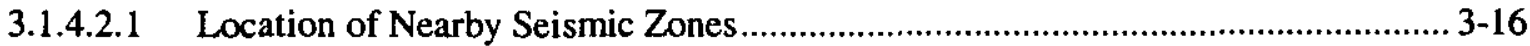

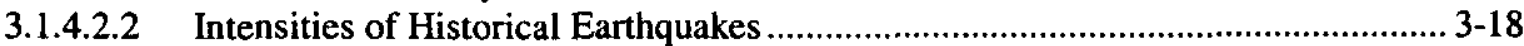

3.1.4.2.3 Projected Recurrence of Earthquakes .................................................................. 3-18

3.1.5 Hydrology

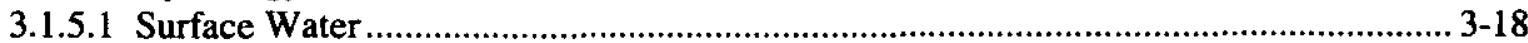

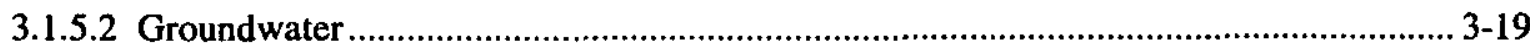

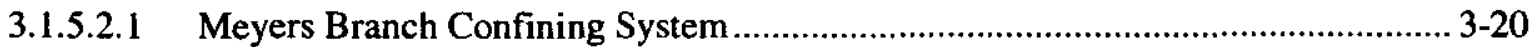

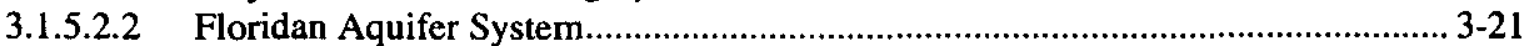

3.1.5.2.3 Hydrologic Characteristics of the Vadose Zone ............................................... 3-22

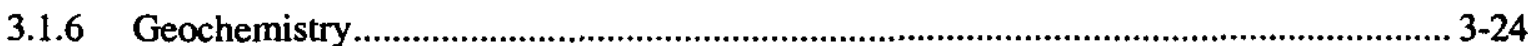

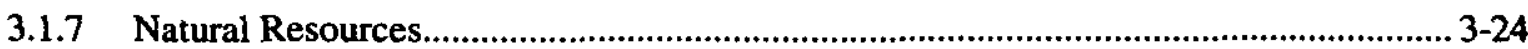

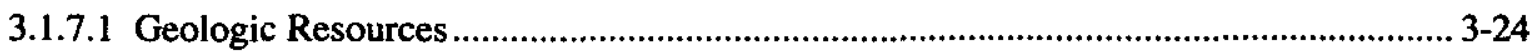

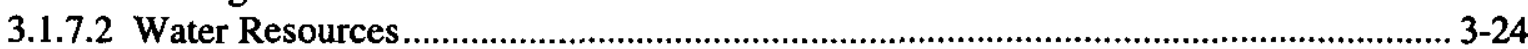

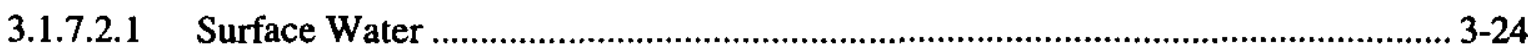

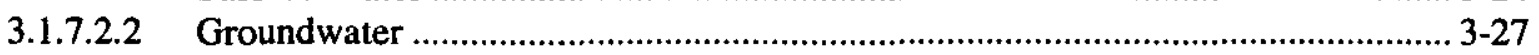


3.1.8 Natural Background Radiation ............................................................................. 3-27

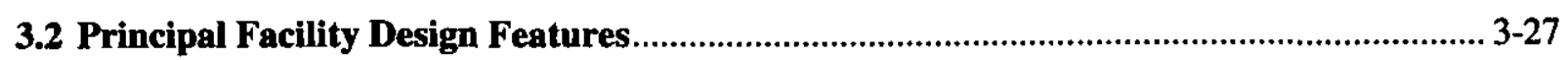

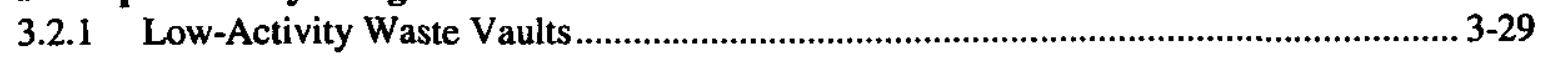

3.2.1.1 Water Infiltration and Disposal Unit Cover Integrity ............................................... 3-29

3.2.1.2 Structural Stability and Inadvertent Intruder Barrier ............................................... 3-31

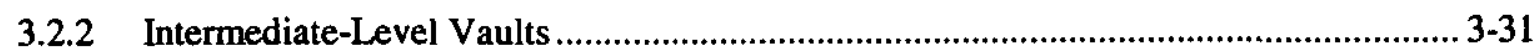

3.2.2.1 Water Infiltration and Disposal Unit Cover Integrity ................................................. 3-31

3.2.2.2 Structural Stability and Inadvertent Intruder Barrier ............................................... 3-31

3.2.3 Very-Low-Activity Waste Disposal Trenches ............................................................ 3-32

3.2.3.1 Water Infiltration and Disposal Unit Cover Integrity .............................................. 3-32

3.2.3.2 Structural Stability and Inadvertent Intruder Barrier .................................................. 3-32

3.2.4 Intimately-Mixed Cement-Stabilized Waste Disposal Trenches ................................ 3-33

3.2.4.1 Water Infiltration and Disposal Unit Cover Integrity ................................................. 3-33

3.2.4.2 Structural Stability and Inadvertent Intruder Barrier ............................................... 3-33

3.2.5 Cement-Stabilized Encapsulated Waste Disposal Trenches ....................................... 3-33

3.2.5.1 Water Infiltration and Disposal Unit Cover Integrity ............................................... 3-33

3.2.5.2 Structural Stability and Inadvertent Intruder Barrier ............................................... 3-33

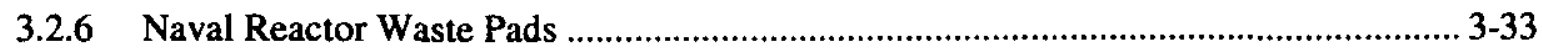

3.2.6.1 Water Infiltration and Disposal Unit Cover Integrity ............................................. 3-33

3.2.6.2 Structural Stability and Inadvertent Intruder Barrier .............................................. 3-33

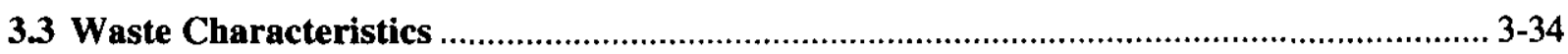

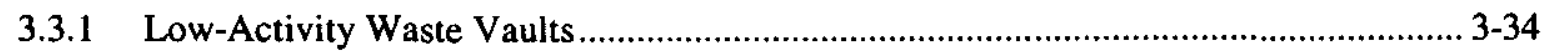

3.3.1.1 Waste Type/Chemical and Physical Form ............................................................. 3-34

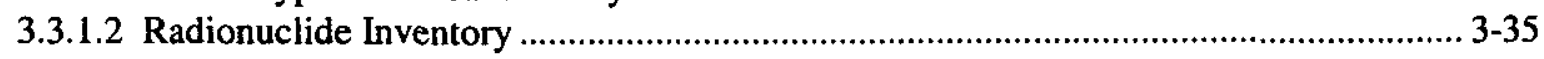

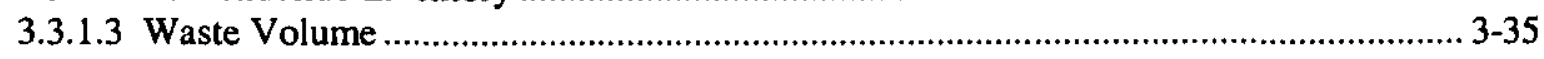

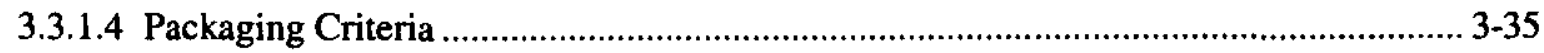

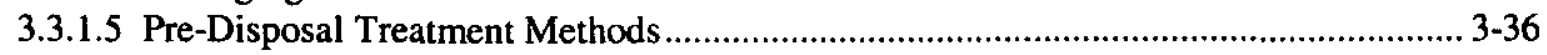

3.3.1.6 Waste Acceptance Restrictions ………… 3-36

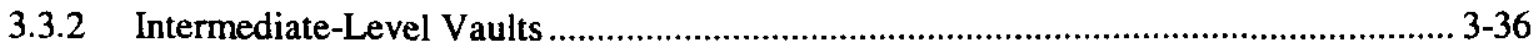

3.3.2.1 Waste Type/Chemical and Physical Form ............................................................. 3-36

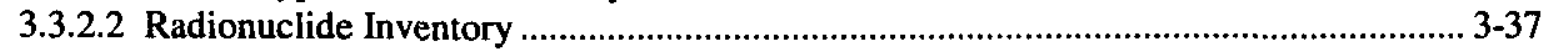

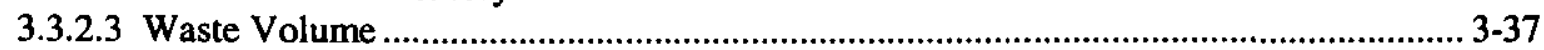

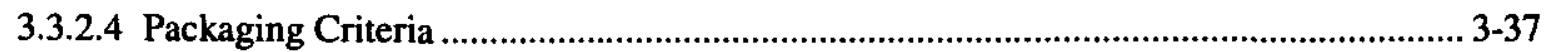

3.3.2.5 Pre-Disposal Treatment Methods ........................................................................ 3-37

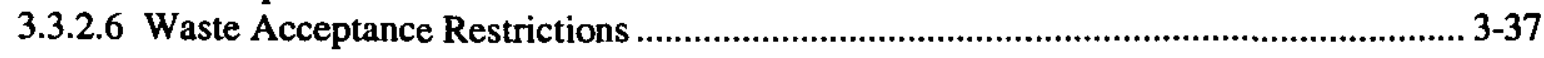

3.3.3 Very-Low-Activity Waste Disposal Trenches ....................................................... 3-37

3.3.3.1 Waste Type/Chemical and Physical Form ............................................................. 3-37 


\section{CONTENTS (Cont'd.)}

3.3.3.2 Radionuclide Inventory ................................................................................... 3-37

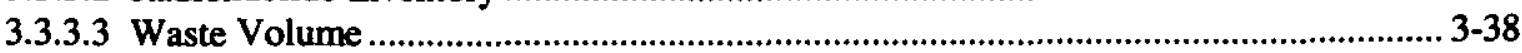

3.3.3.4 Packaging Criteria ................................................................................................. 3-38

3.3.3.5 Pre-Disposal Treatment Methods................................................................................. 3-38

3.3.3.6 Waste Acceptance Restrictions ..................................................................................... 3-38

3.3.4 Intimately-Mixed Cement-Stabilized Waste Disposal Trenches ................................... 3-38

3.3.4.1 Waste Type/Chemical and Physical Form …………................................................ 3-38

3.3.4.2 Radionuclide Inventory …………………………............................................... 3-38

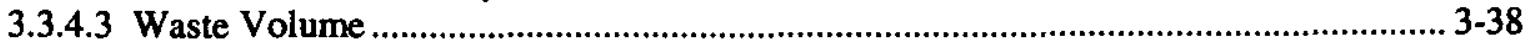

3.3.4.4 Packaging Criteria ............................................................................................. 3-39

3.3.4.5 Pre-Disposal Treatment Methods............................................................................ 3-39

3.3.4.6 Waste Acceptance Restrictions ................................................................................. 3-39

3.3.5 Disposal Trenches for Cement-Stabilized Encapsulated Waste ................................... 3-39

3.3.5.1 Waste Type/Chemical and Physical Form …………….............................................. 3-39

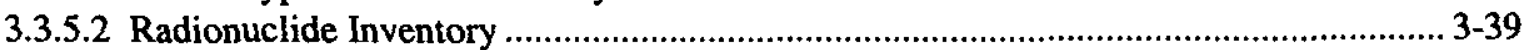

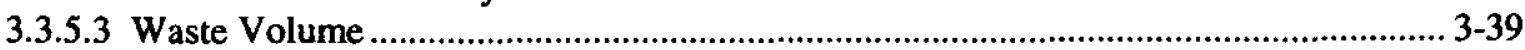

3.3.5.4 Packaging Criteria ............................................................................................ 3-39

3.3.5.5 Pre-Disposal Treatment Methods ....................................................................... 3-40

3.3.5.6 Waste Acceptance Restrictions ............................................................................. 3-40

3.3.6 Naval Reactor Waste Pads ......................................................................................40

3.3.6.1 Waste Type/Chemical and Physical Form …………........................................... 3-40

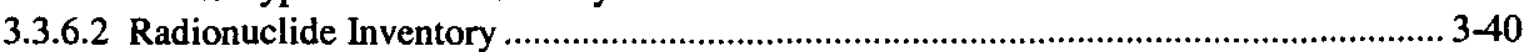

3.3.6.3 Waste Volume ........................................................................................ 3-40

3.3.6.4 Packaging Critería ……………………................................................................ 3-41

3.3.6.5 Pre-Disposal Treatment Methods ...............................................................................3-41

3.3.6.6 Waste Acceptance Restrictions ............................................................................... 3-41

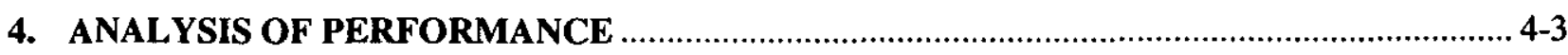

4.1 Source Terms

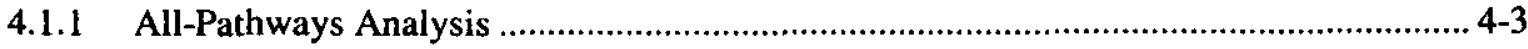

4.1.2 Air Pathways Analysis .........................................................................................4-4

4.1.2.1 ${ }^{3} \mathrm{H}$ and ${ }^{14} \mathrm{C}$ in Job Control Waste .......................................................................... 4-4

4.1.2.1.1 Trenches.................................................................................................... 4-4

4.1.2.1.2 LAW and IL Vaults .................................................................................. 4-4

4.1.2.2 ${ }^{3} \mathrm{H}$ Crucibles................................................................................................... 4-6

4.1.2.3 ${ }^{3} \mathrm{H}$ and ${ }^{14} \mathrm{C}$ in Naval Reactor Component Waste....................................................... 4-7

4.1.3 Water Resource Impacts Analysis ................................................................................. 4-7

4.1.3.1 Conceptual Model of the Source Term ................................................................ 4-7

4.1.3.1.1 Radionuclide Inventory .................................................................................... 4-8

4.1.3.1.2 Rate of Water Infiltration into Disposal Units.................................................... 4-10

4.1.3.1.3 Integrity of Barriers to Water Intrusion ………….............................................. 4-10 
4.1.3.1.4 Composition of Infiltrating Water ................................................................. 4-14

4.1.3.2 Estimated Releases of Radionuclides....................................................................... 4-15

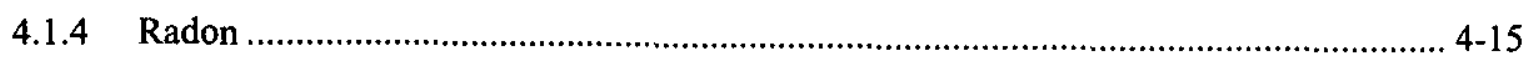

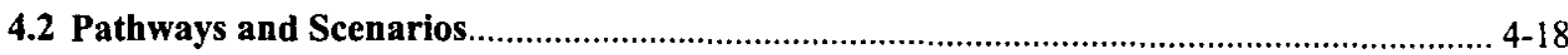

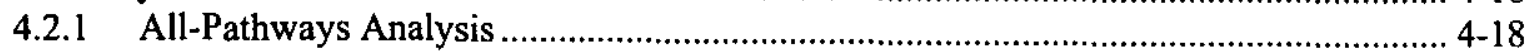

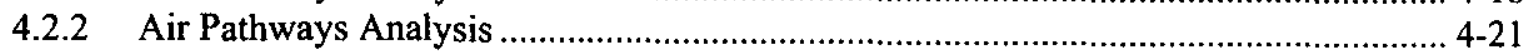

4.2.3 Water Resource Impacts Analysis......................................................................... 4-24

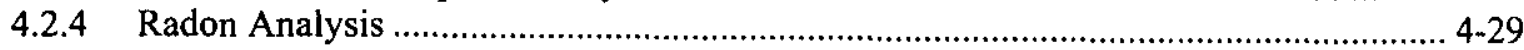

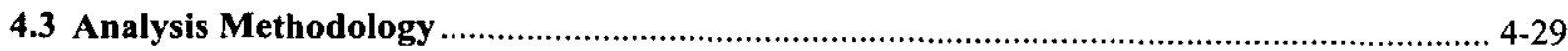

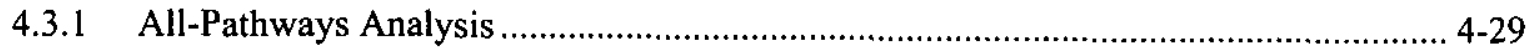

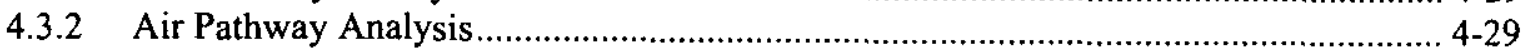

4.3.3 Water Resource Impacts Analysis........................................................................... 4-29

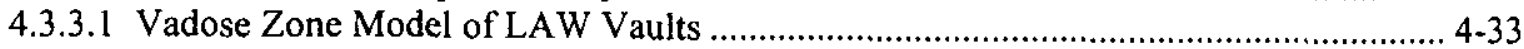

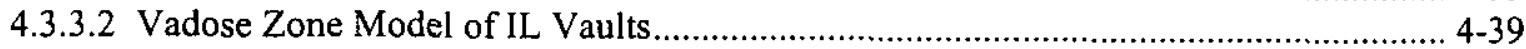

4.3.3.3 Vadose Zone Model of Slit Trenches...................................................................... 4-44

4.3.3.4 Naval Reactor Component Waste Units...................................................................... 4-49

4.3.3.5 Intimately-Mixed Cement-Stabilized Waste Units .................................................... 4-52

4.3.3.6 Cement-Stabilized Encapsulated Waste Units ......................................................... 4-57

4.3.3.7 Saturated Zone Model of E Area............................................................................ 4-57

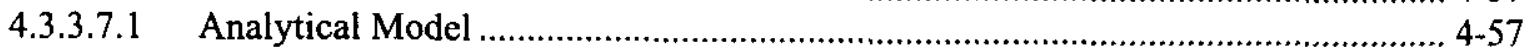

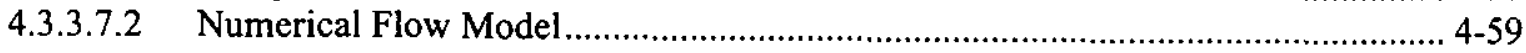

4.3.3.7.3 Numerical Transport Model ............................................................................ 4-60

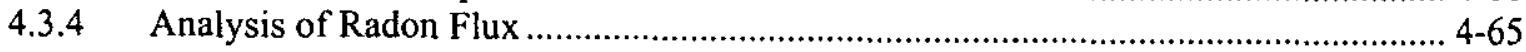

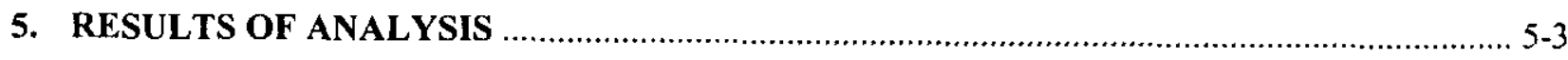

5.1 Results of All-Pathways Analysis and Water Resource Impacts Analysis ......................... 5-3

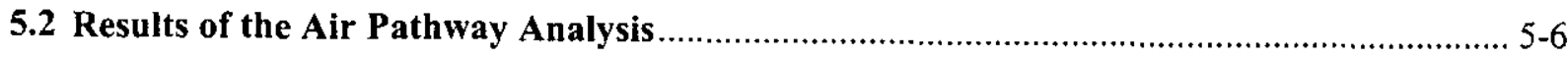

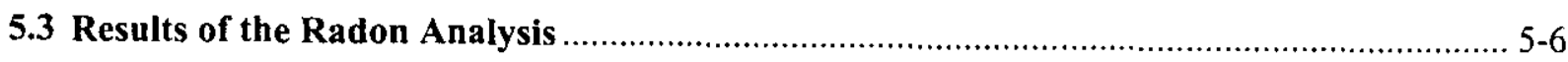

5.4 Results of the Sensitivity and Uncertainty Analysis ...................................................... 5-6

5.4.1 Sensitivity and Uncertainty Analysis of Near-Field and Groundwater Transport ............ 5-6

5.4 .2 Sensitivity of Results to Assessment Assumptions ................................................ 5-34

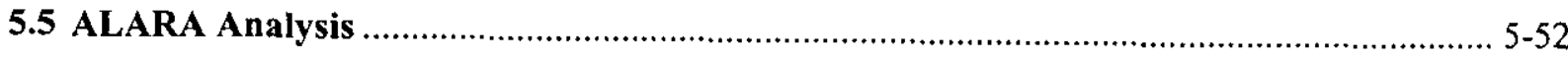

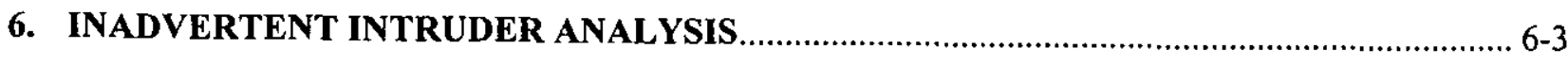

6.1 Exposure Scenarios for Inadvertent Intruders ...................................................................... 6-3

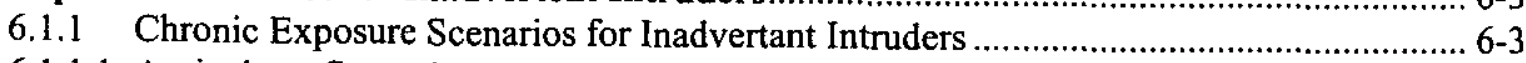

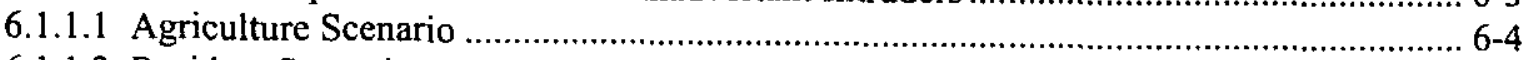

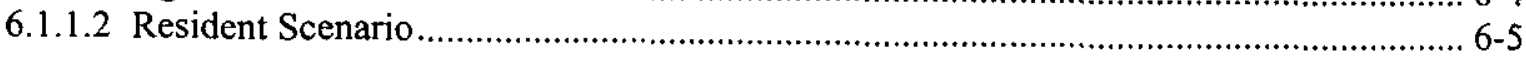




\section{CONTENTS (Cont'd.)}

6.1.1.3 Comparison of Agriculture and Resident Scenarios .................................................6-6

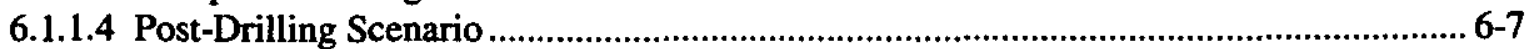

6.1.1.5 Comparison of Agriculture and Post-Drilling Scenarios .............................................. 6-7

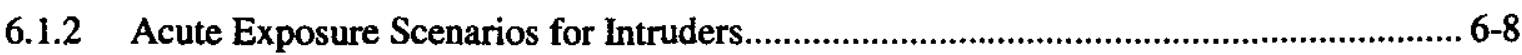

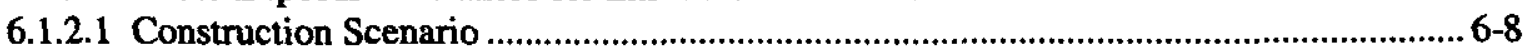

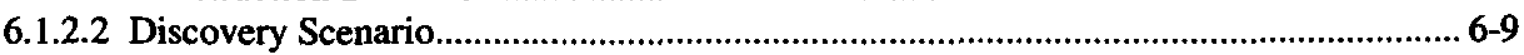

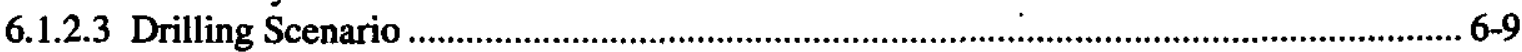

6.1.2.4 Summary of Acute Exposure Scenarios ...................................................................... 6-10

6.1.3 Summary of Exposure Scenarios for Inadvertant Intruders ...................................... 6-10

6.2 Screening of Radionuclides for Intruder Dose Analysis................................................ 6-10

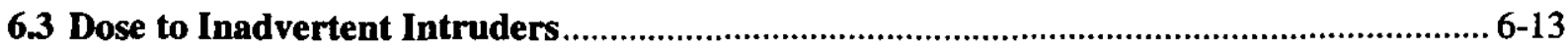

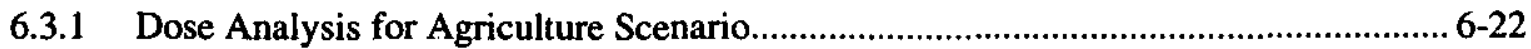

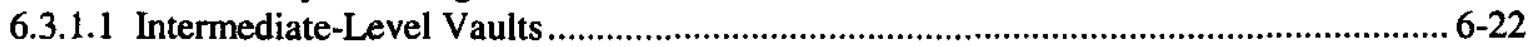

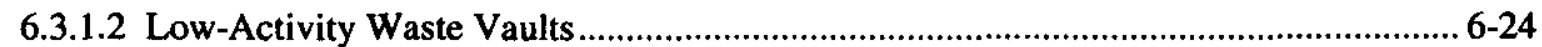

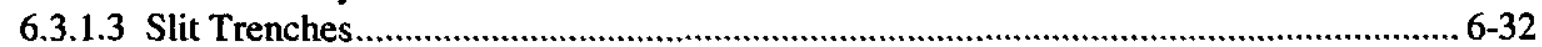

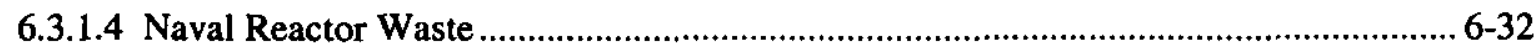

6.3.1.5 Intimately-Mixed Cement-Stabilized Waste Units...................................................6-36

6.3.1.6 Cement-Stabilized Encapsulated Waste Units .......................................................... 6-42

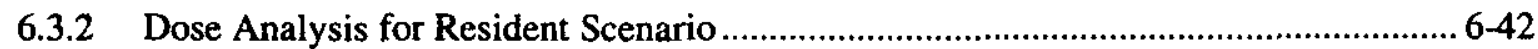

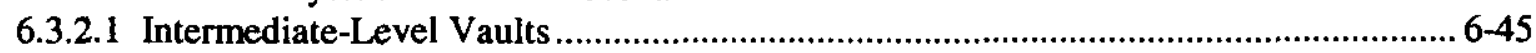

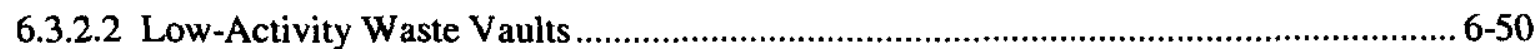

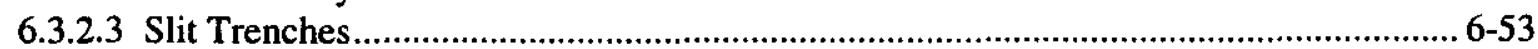

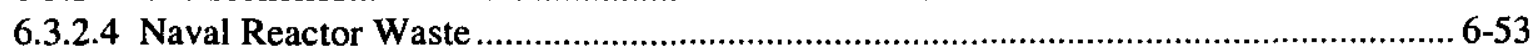

6.3.2.5 Intimately-Mixed Cement-Stabilized Waste Units.................................................. 6-57

6.3.2.6 Cement-Stabilized Encapsulated Waste Units ...................................................... 6-57

6.3.3 Dose Analysis for Post-Drilling Scenario .............................................................. 6-57

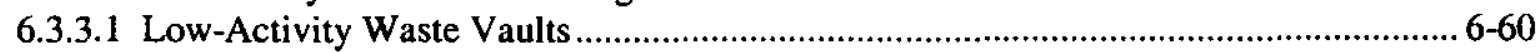

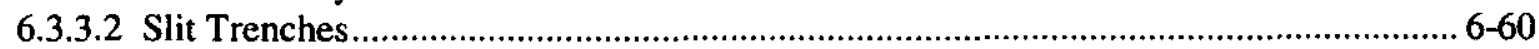

6.3.3.3 Intimately-Mixed Cement-Stabilized Waste Units.................................................. 6-60

6.3.3.4 Cement-Stabilized Encapsulated Waste Units ...................................................... 6-68

6.4 Sensitivity and Uncertainty in Dose Models for Inadvertent Intruders ........................ 6-68

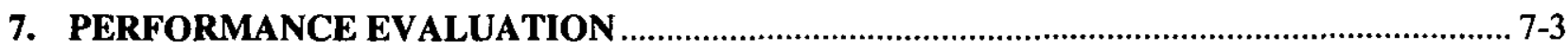

7.1 Comparison of Results to Performance Objectives ....................................................... 7-3

7.2 Impact of this PA Revision on the SRS Composite Analysis........................................... 7-15

7.3 Use of Performance Assessment Results ..................................................................... 
7.4 Further Work 7-16

7.41 Monitoring. 7-16

7.3.2 Test and Research. 7-16

8. QUALITY ASSURANCE 8-3

9. LIST OF PREPARERS

10. REFERENCES

APPENDIX A PROJECTED INVENTORY OF E-AREA LOW LEVEL WASTE FACILITY

APPENDIX B COMPUTER CODES B-1

APPENDIX C SUPPORTING DETAILS OF MODELS AND ASSUMPTIONS C-1 APPENDIX D VAULT DEGRADATION STUDY D-1 APPENDIX E GEOCHEMICAL INTERACTIONS E-1 APPENDIX F SOFTWARE QA PLAN F-1 APPENDIX G RESULTS OF FLOW AND TRANSPORT MODELING G-1 APPENDIX H SENSITIVITY/UNCERTAINTY ANALYSIS FOR GROUNDWATER $\mathrm{H}-1$ 
Figure 2.2-1

Figure 2.2-2

Figure 2.2-3

Figure 2.2-4

Figure 2.2-5

Figure 3.1-1

Figure 3.1-2

Figure 3.1-3

Figure 3.1-4

Figure 3.1-5

Figure 3.1-6

Figure 3.1-7

Figure 3.2-1

Figure 3.3-1

Figure 3.3-2

Figure 4.2-1

Figure 4.3-1

Figure 4.3-2

Figure 4.3-3

Figure 4.3-4

Figure 4.3-5

Figure 4.3-6

Figure 4.3-7

Figure 4.3-8

Figure 4.3-9

Figure 4.3-10

Figure 5.4-1
Projected Layout of the E-Area Low-Level Waste Facility

Typical Section Through a Low-Activity Waste Vault Cell.............................. 2-8

Arrangement of the Intermediate Level Non-Tritium and

Intermediate Level Tritium Vaults

Conceptual Drawings of Trench and Vault Disposal Units ........................... 2-14

Conceptual Layout of 100 Naval Reactor Waste

Disposal Containers.

$2-20$

Location of Savannah River Site and Adjacent Study Area ............................ 3-4

Facility Location Map of the SRS, Showing Surface Drainage ........................ 3-5

Location of the General Separations Area .................................................. 3-6

Comparison of Lithostratigraphic and Hydrostratigraphic

Units at the SRS

Seismic Zones in the Vicinity of the SRS ................................................... 3-17

Illustration of Flow Directions in General Separations Area ......................... 3-23

Major Sources of Radiation Exposure in the Vicinity of SRS ....................... 3-28

Vault Closure Concept (intact cover system) ................................................. 3-30

Conceptual Naval Reactor Waste Disposal Cask............................................. 3-43

Proposed Layout of NR Waste Disposal Area .............................................. 3-44

Pathways to Human Receptors from Subsurface Radionuclides ..................... 4-19

Flow Diagram of Computer Codes ........................................................... 4-34

Conceptual Model of LAW Vault ................................................................ 4-35

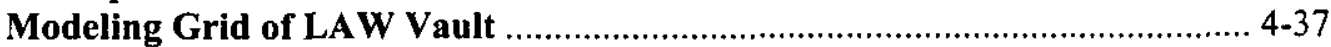

Conceptual Model of IL Vault ........................................................................ 4-42

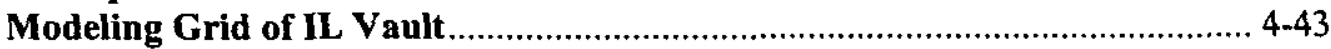

Conceptual Model of Trench Disposal Unit ................................................. 4-47

Modeling Grid of Trench Disposal Unit ................................................... 4-48

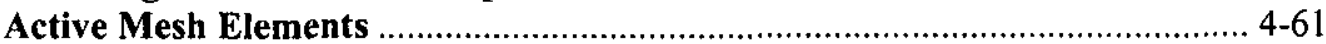

Typical Cross-Section of Stratigraphy-Conforming

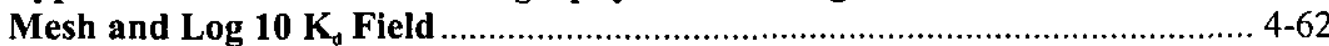

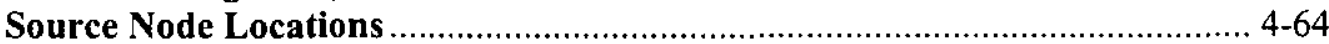

Cumulative Distribution Function of Maximum Groundwater

Concentration of ${ }^{9} \mathrm{Tc}$ 
Table 2.5-1

Table 3.1-1

Table 3.1-2

Table 3.1-3

Table 3.1-4

Table 3.1-5

Table 3.2-1

Table 3.3-1

Table 4.1-1

Table 4.1-2

Table 4.1-3

Table 4.1-4

Table 4.1-5

Table 4.1-6

Table 4.2-1

Table 4.2-2

Table 4.2-3

Table 4.3-1

Table 4.3-2

Table 4.3-3

Table 4,3-4

Table 4.3-5

Table 4.3-6

Table 4.3-7

Table 4.3-8
Performance Objectives, Assessment Requirements and

Points of Compliance. 2-24

Population Distribution and Percent Region of Influence

(\%ROI) for Counties and Selected Communities..

Population Projections and Percent Region of Influence

(\%ROI)

Hydrostratigraphic Nomenclature.

Water Quality on the Savannah River Upstrean and Downstream from

SRS (Calendar Year 1996).

Water Quality in Selected SRS Streams

3-26

Values for Hydraulic Properties of Vault Closure Design

3-31

Forecast of Naval Reactor Waste Components for E-Area

LLWF Disposal .

Release Fractions for ${ }^{3} \mathrm{H}$ and ${ }^{14} \mathrm{C}$

Parameters Used in Screening of Radionuclide Inventories

for E-Area Low-Level Waste Facility Disposal Units and

Lists of Radionuclides for Further Analysis with Respect

to Off-Site Public Exposures

Summary of Degradation Scenarios for E-Area Low

Level Waste Facility Disposal Units

Radionuclides

Solubility Limits for Plutonium and Uranium

Diffusion Coefficients Assumed for Mass Transport Simulations

Parameters used in Air Dose Calculations

Dose Factors for the Air Pathway

Groundwater Corresponding to Different Options for

Groundwater Protection Requirement.

Comparison of MCLs and Allowable Groundwater

Concentrations Based on the $\mathbf{2 5}$ mrem per Year Performance

Objective for Off-Site Individuals.

Estimated Peak Fractional Flux to the Water Table for

Radionuclides Disposed of in E-Area LAW Vaults

Estimated Peak Fractional Flux to the Water Table for

Radionuclides Disposed of in E-Area IL Vaults $4-45$

Estimated Peak Fractional Flux to the Water Table for

Radionuclides Disposed of in E-Area Slit Trenches

Estimated Peak Fractional Flux to the Water Table for

Radionuclides Disposed of in E-Area Naval Reactor Pads.

Estimated Peak Fractional Flux to the Water Table for

Radionuclides Disposed of in E-Area Intimately-Mixed

Cement-Stabilized Waste

Estimated Peak Fractional Flux to the Water Table for

Radionuclides Disposed of in E-Area Cement-Stabilized

Encapsulated Waste. 4-58 
Table 4.3-9

Table 5.1-1

Table 5.1-2

Table 5.1-3

Table 5.1-4

Table 5.1-5

Table 5.1-6

Table 5.1-7

Table 5.1-8

Table 5.1-9

Table 5.1-10

Table 5.1-11

Table 5.1-12

Table 5.1-13

Table 5.2-1

Table 5.3-1

Table 5.4-1

Table 5.4-2

Table 5.4-3

Table 5.4-4

Table 5.4-5

Table 5.4-6

Table 5.4-7

Table 5.4-8

Table 5.4-9
${ }^{234}$ U Disposal Limits Based on Radon Release Rates 4-66 Annual EDEs from Drinking Water Pathway per Unit Concentration of Radionuclides in Water. 5-4 Peak Groundwater Concentrations for the LAW Vault Simulations per Ci of Each Radionuclide in 2 Vaults $5-7$ Peak Groundwater Concentrations for the IL Vault Simulations per Ci of Each Radionuclide in 2 Vaults $5-9$ Peak Groundwater Concentrations for the Slit Trench Simulations per Ci of Each Radionuclide in 10 Trenches. $5-11$ Peak Groundwater Concentrations for the Naval Reactor Pad Simulations per $\mathrm{C} i$ of Each Radionuclide in 100 Containers

Peak Groundwater Concentrations for the Intimately-Mixed

Cement-Stabilized Waste Simulations - per $\mathrm{Ci}$ of Each

Radionuclide in 10 Trenches.

Peak Groundwater Concentrations for the Cement-Stabilized

Encapsulated Waste Simulations - per $\mathrm{Ci}$ of Each Radionuclide in 10 Trenches $5-17$

Calculated Inventory Limits for the LAW Vaults ......................................... 5-18

Calculated Inventory Limits for the IL Vaults ........................................... 5-20

Calculated Inventory Limits for the Slit Trenches …................................. 5-22

Calculated Inventory Limits for the Naval Reactor Pad Waste ...................... 5-24

Calculated Inventory Limits for the Trenches Containing

Intimately-Mixed Cement-Stabilized Waste $5-26$

Calculated Inventory Limits for the Trenches Containing

Cement-Stabilized Encapsulated Waste ….................................................... 5-28

Results of the Air Pathway Analysis ............................................................ 5-30

${ }^{234}$ U Disposal Limits Based on Radon Release Rates ................................... 5-30

Important Parameters and Assumptions Used in Calculating

Groundwater Concentrations.

Effect of Increase on Infiltration Rate after Roof Failure of the LAW

Vault

Effect of Increase in Infiltration Rate After Failure

(Subsidence) of the Slit Trench....

Effect of Time of Placement of Moisture Barrier on Flux to the Water table for Slit Trenches

Effect of Location of Compliance Point on Peak Groundwater

Concentrations Projected for LAW Vaults, IL Vaults, and Slit

Trenches within 10,000 Years After Closure

Sensitivity of Groundwater-Based Inventory Limits for the LAW Vault to Time of Assessment

Sensitivity of Groundwater-Based Inventory Limits for the IL Vaults to Time of Assessment

Sensitivity of Groundwater-Based Inventory Limits for the Slit Trenches to Time of Assessment

Sensitivity of Groundwater-Based Inventory Limits for the Naval Reactor Pad to Time of Assessment $5-45$ 
Table 5.4-10

Table 5.4-11

Table 5.5-1

Table 6.2-1

Table 6.3-1

Table 6.3-2

Table 6.3-3

Table 6.3-4

Table 6.3-5

Table 6.3-6

Table 6.3-7

Table 6.3-8

Table 6.3-9

Table 6.3-10

Table 6.3-11

Table 6.3-12

Table 6.3-13

Table 6.3-14

Table 6.3-15

Table 6.3-16
Sensitivity of Groundwater-Based Inventory Limits for Trenches Containing Intimately-Mixed Cement-Stabilized Waste to Time of Assessment. $5-47$

Sensitivity of Groundwater-Based Inventory Limits for Trenches Containing Cement-Stabilized Encapsulated Waste to Time of Assessment.

Maximum Flux of Significant Radionuclides to the Water

Table from Sources Draining to Upper Three Runs .

Parameters used in Screening Radionuclide Inventories for

E-Area Low Level Waste Facility Disposal Units, and Lists of

Radionuclides for Further Analysis.

Annual EDEs per Unit Concentration of Radionuclides

in Disposal Units from all Exposure Pathways for

Agriculture Scenario

Annual EDEs per Unit Concentration of Radionuclides

in Disposal Units for Resident Scenario.

Annual EDEs per Unit Concentration of Radionuclides

in Exhumed Waste for Post-Drilling Scenario....

Geometrical Reduction Factors (G) used in Dose Analyses

for Inadvertent Intruders.

Intruder-Based Radionuclide Disposal Limits for IL Vaults - Agriculture

Scenario at 20,000 Years

Intruder-Based Radionuclide Disposal Limits for LAW Vaults -

Agriculture Scenario at 5,000 Years

Intruder-Based Radionuclide Disposal Limits for Slit

Trenches - Agriculture Scenario at 700 Years

Intruder-Based Radionuclide Disposal Limits for Naval

Reactor Waste - Agriculture Scenario at 10,000 Years

Intruder-based Radionuclide Disposal Limits for Intimately-Mixed

Cement-Stabilized Waste Trenches - Agriculture Scenario at 700 Years

Intruder-Based Radionuclide Disposal Limits for Cement-Stabilized

Encapsulated Waste Trenches - Agriculture Scenario at 700 Years.

Intruder-Based Radionuclide Disposal Limits for IL

Vaults - Resident Scenario at 100 Years

Intruder-Based Radionuclide Disposal Limits for IL

Vaults - Resident Scenario at 10,000 Years.

6.48

Intruder-Based Radionuclide Disposal Limits for LAW

Vaults - Resident Scenario at 100 Years.

Intruder-Based Radionuclide Disposal Limits for Slit Trenches -

Resident Scenario at 100 Years

Intruder-Based Radionuclide Disposal Limits for

Intimately-Mixed Cement-Stabilized Waste - Resident

Scenario at 100 Years

Intruder-Based Radionuclide Disposal Limits for

Cement-Stabilized Encapsulated Waste - Resident Scenario

at 100 Years 
Table 6.3-17 Intruder-Based Radionuclide Disposal Limits for LAW

Vaults - Post-Drilling Scenario at 3,000 Years. 6-61

Table 6.3-18

Intruder-Based Radionuclide Disposal Limits for Slit

Trenches - Post-Drilling Scenario at 100 Years

Table 6.3-19

Intruder-Based Radionuclide Disposal Limits for Intimately-Mixed Cement-Stabilized Waste - Post-Drilling

Scenario at 300 Years.

Table 6.3-20

Intruder-Based Radionuclide Disposal Limits for

Cement-Stabilized Encapsulated Waste - Post-Drilling

Scenario at 300 Years.

Table 6.4-1

Parameters used in Calculating SDCFs for Intruder Dose

Analyses, by Exposure Scenarios

Table 6.4-2

Table 7.1-1

Radionuclides for Which Projected Inventories are

Greater Than or Equal to $1 / \mathbf{1 0 0 0}^{\text {th }}$ of the Calculated

Inventory Limits for the LAW Vaults and $1 / 100,000^{\text {th }}$ of the

Calculated Inventory Limits for the Slit Trenches

Inventory Limits for LAW Vaults; Limiting Pathway;

Comparison to Projected Inventory.

Table 7.1-2

Inventory Limits for IL Vaults; Limiting Pathway;

Comparison to Projected Inventory.

Table 7.1-3

Inventory Limits for Slit Trenches; Limiting Pathway;

Comparison to Projected Inventory.

Table 7.1-4

Inventory Limits for Naval Reactor Pad Waste; Limiting

Pathway; Comparison to Projected Inventory

Table 7.1-5

Inventory Limits for Intimately-Mixed Cement-Stabilized

Waste Trenches; Limiting Pathway; Comparison to Projected

Inventory

Table 7.1-6

Inventory Limits for Cement-Stabilized Encapsulated Waste

Trenches; Limiting Pathway; Comparison to

Projected Inventory 
ACRONYMS

\begin{tabular}{|c|c|}
\hline ALARA & As Low As Reasonably Achievable \\
\hline ARAR & Applicable or Relevant and Appropriate Requirement \\
\hline ASME & American Society of Mechanical Engineers \\
\hline AT & Advanced Tensiometers \\
\hline $\mathrm{CA}$ & Composite Analysis \\
\hline CERCLA & $\begin{array}{l}\text { Comprehensive Environmental Response, Compensation, } \\
\text { and Liability Act }\end{array}$ \\
\hline CFR & Code of Federal Regulations \\
\hline CIF & Consolidated Incinerator Facility \\
\hline CSEW & Cement-Stabilized Encapsulated-Waste \\
\hline CSRA & Central Savannah River Area \\
\hline DOE & U.S. Department of Energy \\
\hline DWS & Drinking Water Standard \\
\hline EDE & Effective Dose Equivalent \\
\hline $\mathrm{EH}$ & U.S. Department of Energy Office of Environment, Safety, and Health \\
\hline EIS & Environmental Impact Statement \\
\hline EMOP & E-Area Monitoring Program \\
\hline EPA & U.S. Environmental Protection Agency \\
\hline FY & Fiscal Year \\
\hline HLW & High-Level Waste \\
\hline ICRP & International Commission on Radiological Protection \\
\hline IL & Intermediate-Level \\
\hline ILNT & Intermediate-Level Non-Tritium \\
\hline ILT & Intermediate-Level Tritium \\
\hline JCW & Job Control Waste \\
\hline LAW & Low-Activity Waste \\
\hline LLW & Low-Level Waste \\
\hline LLWF & Low-Level Waste Facility \\
\hline $\mathrm{MCL}$ & Maximum Contaminant Level \\
\hline MMI & Modified Mercalli Intensity \\
\hline MPC & Maximum Permissible Concentration \\
\hline NCRP & National Council on Radiation Protection and Measurements \\
\hline NPDES & National Pollutant Discharge Elimination System \\
\hline NPL & National Priorities List \\
\hline NQA & Nuclear Quality Assurance \\
\hline NRC & Nuclear Regulatory Commission \\
\hline NWS & National Weather Service \\
\hline PA & Performance Assessment \\
\hline QA & Quality Assurance \\
\hline ROI & Region of Influence \\
\hline SAR & Safety Analysis Report \\
\hline SCDHEC & South Carolina Department of Health and Environmental Control \\
\hline SDCF & Scenario Dose Conversion Factor \\
\hline SRS & Savannah River Site \\
\hline
\end{tabular}


LIST OF ACRONYMS AND ABBREVIATIONS (Cont'd.)

SRTC

TDR

Savannah River Technology Center

TRU

Time-Domain Reflectometers

TSR

Transuranic

USGS

VZMS

WAC

Technical Safety Requirement

U.S. Geological Survey

Vadose Zone Monitoring System

Waste Acceptance Criteria

WITS

Waste Information Tracking System

WSRC

Westinghouse Savannah River Company

\section{ABBREVIATIONS}

$\begin{array}{ll}\rho_{\mathrm{b}} & \text { bulk density } \\ \mu \mathrm{g} & \text { microgram } \\ \mathrm{Bq} & \text { Becquerel } \\ \mathrm{cc} & \text { cubic centimeters } \\ \mathrm{cfs} & \text { cubic feet per second } \\ \mathrm{cm} & \text { centimeter } \\ \mathrm{d} & \text { day } \\ \mathrm{F} & \text { Fahrenheit } \\ \mathrm{ft} & \text { foot } \\ \mathrm{g} & \text { gram } \\ \mathrm{gal} & \text { gallon } \\ \mathrm{hr} & \text { hour } \\ \mathrm{K} & \text { Kelvin } \\ \mathrm{kg} & \text { kilogram } \\ \mathrm{km} & \text { kilometer } \\ \mathrm{L} & \text { liter } \\ \mathrm{lb} & \text { pound } \\ \mathrm{m} & \text { meter } \\ \mathrm{mL} & \text { milliliter } \\ \mathrm{mrem} & \text { millirem } \\ \mathrm{msl} & \text { mean sea level } \\ \mathrm{nCi} & \text { nanocurie } \\ \mathrm{pCi} & \text { picocurie } \\ \mathrm{s} & \text { second } \\ \mathrm{Sv} & \text { Sievert } \\ \mathrm{yr} & \text { year } \\ \mathrm{m} & \end{array}$


THIS PAGE INTENTIONALLY LEFT BLANK 


\section{SECTION 1}

EXECUTIVE SUMMARY 
THIS PAGE INTENTIONALLY LEFT BLANK

Rev. 1 


\section{EXECUTIVE SUMMARY}

This report is the first revision to "Radiological Performance Assessment for the E-Area Vaults Disposal Facility, Revision 0", which was issued in April 1994 and received conditional DOE approval in September 1994. The title of this report has been changed to conform to the current name of the facility. The revision incorporates improved groundwater modeling methodology, which includes a large data base of site specific geotechnical data, and Special Analyses on disposal of cement-based wasteforms and naval wastes, issued after publication of Revision 0 .

This performance assessment for the Savannah River Site E-Area Low-Level Waste Facility was prepared to meet the performance assessment requirements of Chapter IV of the U.S. Department of Energy Order 435.1. The Order specifies that a performance assessment should provide reasonable assurance that a lowlevel waste disposal facility will comply with the performance objectives of the Order. The performance objectives require that: 1) Dose to representative members of the public shall not exceed $25 \mathrm{mrem}$ in a year total effective dose equivalent from all exposure pathways, excluding the dose from radon and its progeny in air; 2) Dose to representative members of the public via the air pathway shall not exceed 10 mrem in a year total effective dose equivalent, excluding the dose from radon and its progeny; and 3 ) Release of radon shall be less than an average flux of $20 \mathrm{pCi} / \mathrm{m}^{2} / \mathrm{s}$ at the surface of the disposal facility; alternatively, a limit of $0.5 \mathrm{pCi} / \mathrm{L}$ of air may be applied at the boundary of the facility. The Order also requires, for purposes of establishing limits on radionuclides that may be disposed near-surface, assessments of impacts to water resources and to hypothetical inadvertent intruders.

The E-Area Low-Level Waste Facility, located on a 200-acre site immediately north of the former low-level waste burial site (i.e., 643-7E), provides disposal capacity for solid, low-level, non-hazardous radioactive waste. As presently planned, this facility will contain the following: two large concrete vaults for lowactivity waste; two large concrete vaults for intermediate-level non-tritium and tritium waste; ten unlined trenches for disposal of very low activity waste; ten unlined trenches for disposal of intimately-mixed cement-stabilized waste; ten unlined trenches for disposal of cement-stabilized encapsulated waste; and one gravel pad for disposal of up to 100 Naval Reactor Component waste containers.

The long-term performance of the engineered features of the disposal units in the E-Area Low-Level Waste Facility is key to estimating the transport of radionuclides into the environment at E-Area. Therefore, degradation of these features, including moisture barriers, concrete vaults, and concrete wasteforms, was addressed in this assessment. A special study was conducted by an independent engineering firm to study the degradation mechanisms and their effects on the integrity of the vault systems. The results of this study estimated the time required for cracking of the vaults and collapse of the roof structures.

To evaluate the long-term performance of the E-Area Low-Level Waste Facility, site-specific conceptual models were developed to consider: 1) exposure pathways and scenarios of potential importance; 2) potential releases from the facility to the environment; 3 ) effects of degradation of engineered features; and 4) transport in the environment to a designated point of compliance. For evaluation of doses to off-site members of the public and water resource impacts, the point of compliance is assumed to be the point of highest concentration in groundwater or air more than $100 \mathrm{~m}$ from the disposed waste. For evaluation of doses to inadvertent intruders, the point of compliance is located at the point of highest concentration of radionuclides after a 100-year institutional control period following closure of the facility. 
This performance assessment was used as a means to determine the allowable radionuclide concentrations and inventories in each type of disposal unit. Allowable inventory limits were calculated by comparison of estimated groundwater concentrations or off-site and intruder doses with limits on groundwater concentrations or doses as set forth in the performance objectives. The calculated inventory limits were then compared with the 20-year projected inventories for each type of disposal unit, to evaluate whether reasonable assurance is provided that the performance objectives will be met. The calculated inventory limits will be used to revise waste acceptance criteria for the E-Area Low-Level Waste Facility.

The great majority of calculated inventory limits for the six types of disposal units of the E-Area LowLevel Waste Facility will allow disposal of the projected inventories for these units, according to the performance evaluation conducted in this performance assessment. In general, calculated inventory limits are more than two orders of magnitude greater than the projected inventories. For the few radionuclides showing a projected inventory greater than the calculated limits $\left({ }^{3} \mathbf{H}\right.$ in the intimately-mixed cementstabilized waste, ${ }^{99} \mathrm{Tc}$, and ${ }^{129} \mathrm{I}$ in the cement-stabilized encapsulated waste, and ${ }^{59} \mathrm{Ni}$ in the Naval Reactor pad), continued implementation of waste acceptance procedures (e.g., Waste Acceptance Criteria, waste characterization, waste certification, computerized waste information and tracking system) will ensure that waste accepted for disposal will not exceed radionuclide inventory or concentration limits.

To ensure disposal capacity for the entire projected waste inventory, waste packages exceeding Waste Acceptance Criteria for trench disposal could be disposed in one of the types of vault. With the exception of ${ }^{129} \mathrm{I}$, the intimately-mixed cement-stabilized and the cement-stabilized encapsulated waste exceeding the Low Activity Waste vault limits can be accommodated in the IL vault. The ${ }^{129}$ I inventory projected for the cement-stabilized encapsulated waste exceeds the limit for the IL vault. Further investigation of this waste stream is needed to refine the projected ${ }^{129} I$ inventory. Additionally, the performance assessment analyses could be revised to remove conservatism so that all of the waste projected for trench or Naval Reactor pad disposal can be accommodated. 
THIS PAGE INTENTIONALLY LEFT BLANK 


\section{INTRODUCTION}

This Radiological Performance Assessment (PA) is for the currently active low-level radioactive waste disposal facility at the Savannah River Site (SRS). This facility is known as the E-Area Low-Level Waste Facility (LLWF).

\subsection{General Approach}

This report is the first revision to "Radiological Performance Assessment for the E-Area Vaults Disposal Facility, Revision 0", which was issued in April 1994 and received conditional DOE approval in September 1994. The title of this report has been changed to conform to the current name of the facility. The revision incorporates improved groundwater modeling methodology, which includes a large data base of site specific geotechnical data, and Special Analyses on disposal of cement-based wasteforms and naval wastes, issued after publication of Revision 0 .

The overall content of this PA was developed using the U.S. Department of Energy's (DOE) requirements and guidance for performance assessment specified in DOE Order 435.1. Considerations made to limit the length of the document while completely addressing all requirements include the use of screening methodologies, where appropriate. For example, radionuclides were screened to determine those most likely to contribute to dose under the specific scenarios chosen for review (Sections 4.1.3 and 6.2). In addition, exposure scenarios evaluated in Section 6 were reviewed to determine which provided the maximum exposure to individuals and detailed evaluation was focused on those scenarios in order to streamline the document.

Whenever possible, supporting information such as meteorological data and environmental information, is provided in general terms to meet the need of this document with references provided for access to additional details. This practice aids with streamlining and maximizes consistency.

The level of technical detail presented in the report, along with the Appendices is sufficient to allow a reviewer to reproduce the results of the PA calculations. Where appropriate, intermediate results are given in the PA, for example, the flux of radionuclides to the water table are presented in tables and plots, which are an intermediate result in the calculation of groundwater concentrations at the point of compliance.

The Appendices in the PA include detailed supporting information. In some cases these are separate reports, such as Appendix D on vault degradation. In other cases, such as Appendix A on projected inventories, large data sets are compiled.

\subsection{General Facility Description}

The E-Area LLWF is the site for low-level radioactive waste disposal and storage at the SRS. The EArea LLWF has been designed to manage all LLW resulting from SRS operations for the next 20 years.

The E-Area LLWF is intended to provide containment to reduce radionuclide migration from disposed LLW forms. Low-level waste will be disposed of in concrete vaults and trenches. There are two types of vaults: the Low-Activity Waste (LAW) Vaults and the Intermediate-Level (IL) Vaults. In addition, the EArea trenches and the Naval Reactor Waste Pads are also within the E-Area LLWF. This Performance Assessment also addresses two types of enhanced trench disposal: Intimately Mixed Cement Stabilized waste forms, such as Ashcrete and Blowcrete resulting from the operation of the Consolidated Incinerator Facility, and Cement-Stabilized Encapsulated Waste, where wasteforms would be disposed of in trenches 
surrounded by a grout or other cementitious material. Over the life of the E-Area LLWF additional disposal units will be constructed as needed.

The E-Area LLWF site is located on a 200 -acre site immediately north of the former LLW burial site. Only 100 acres have been developed at this time (Fig. 2.2-1); the additional 100 acres will allow for expansion of the LLW disposal capacity, as needed. The nearest SRS boundary to the E-Area LLWF is about $11 \mathrm{~km}$ to the west. The E-Area LLWF is in a relatively level highland region of SRS at about $90 \mathrm{~m}$ $(300 \mathrm{ft})$ above $\mathrm{msl}$.

For the purposes of this PA, it has been assumed that 100 acres would provide disposal capacity for 20 years of SRS operations, which would include two IL Vaults, two LAW Vaults and ten each of the three types of the trench disposal units.

\subsubsection{Low-Activity Waste Vaults}

\subsubsection{General Description and Location}

Each LAW Vauit consists of three major subdivisions (modules) with each module containing four cells. Each three-module vault provides approximately $4.8 \times 10^{4} \mathrm{~m}^{3}(1,700,000$ cubic feet $)$ of waste disposal capacity that will accommodate more than $12,000 \mathrm{~B}-25$ boxes (waste containers). The base of the LAW Vault is at an average elevation of $84.4 \mathrm{~m}(280 \mathrm{ft})$ above msl. The potential source of radionuclides to the E-Area environment and to an inadvertent intruder posed by these trenches is evaluated in this PA and radionuclide limits for disposal of waste in such trenches are provided.

\subsubsection{Major Design Philosophy}

Many design features have been incorporated into the operation of the vaults for the performance of important functions. These functions include structural design resistance and water removal provisions, and are described in this section. The LAW Vaults are designed for disposal of low-activity waste contained in metal containers. Each vault has three distinct phases of operation and construction as described below:

1) Operating Phase - Waste will be placed in the vault cell by means of forklift trucks. The interior wall access openings will allow personnel passage from the operating cell to a vacant nonoperating cell or from the last operating cell to outside.

2) Interim Closure Phase - After the individual cells are filled with wastes, all of the external wall openings (i.e., access openings and exhaust fan openings) are formed and filled with reinforced concrete to provide continuous, structurally sound walls to isolate the cell from the environment.

3) Final Closure Phase - When all the vaults have been filled with waste and interim closure has been completed, the vaults are ready for final closure. LAW Vault final closure consists of placing an earthen cover with an engineered, clay cap over the entire vault area.

The LAW Vault is classified as a Hazard Category 3 facility (WSRC 1996a). However, the vaults were designed to meet the requirements of a Maximum Resistance (High Hazard) structure during the interim and final closure phases. The LAW Vault satisfies the criteria for classification as a Standard Resistance (General Use) structure. 


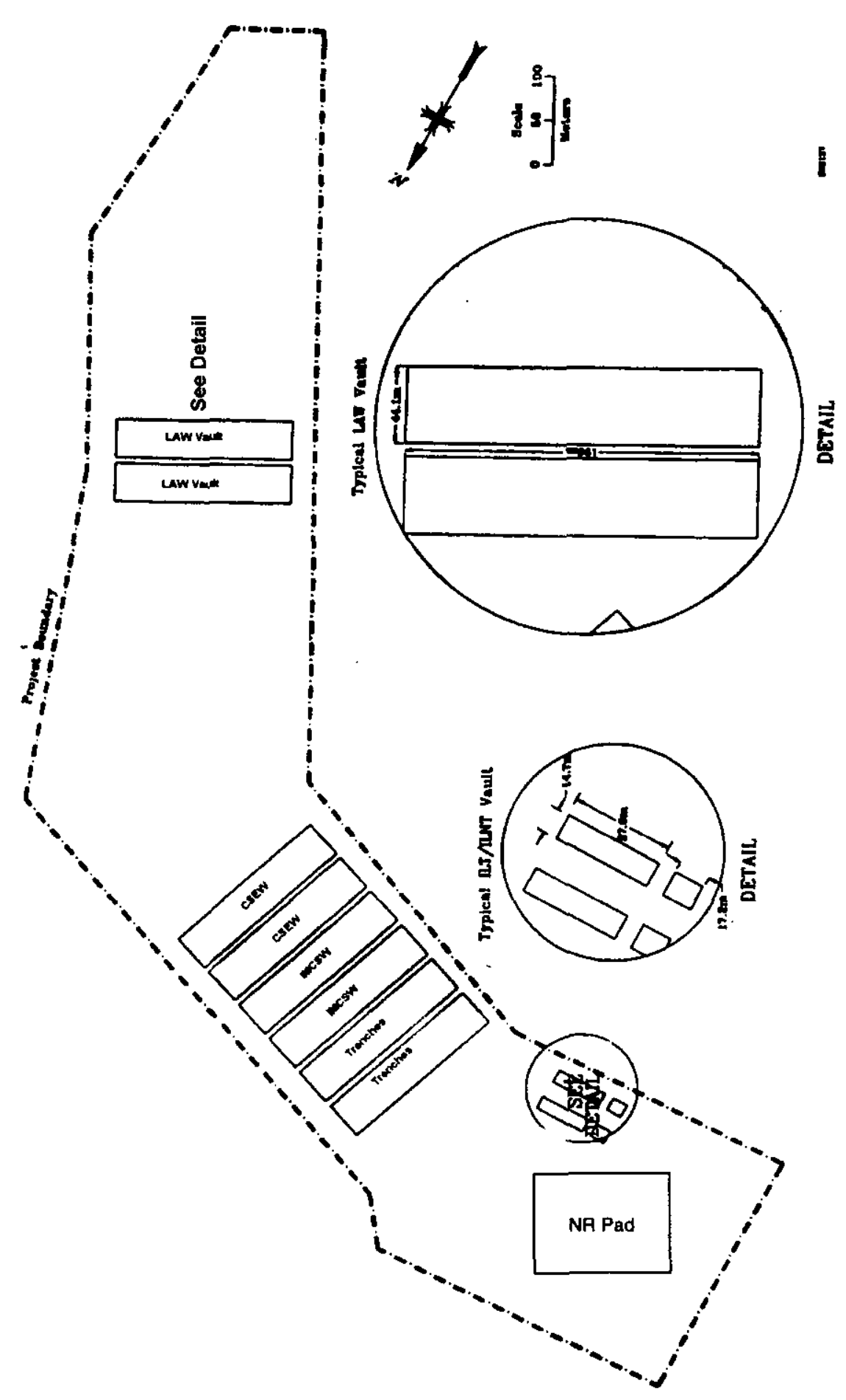

Figure 2.2-1. Projected Layout of the E-Area Low-Level Waste Facility 
The LAW Vaults were designed and constructed to be maximum resistance structures after closure. In accordance with Site Specification 7096, a maximum resistance structure shall be designed to withstand a 0.2 g earthquake event.

The overall design of the LAW Vaults provides structurally sound and water resistant containment of the waste containers. Water infiltrating the vault and contacting the waste is undesirable. The following provisions exist for water removal:

- Any rainwater that may enter a working cell directly through the access opening or by way of handling equipment, drains on the sloped floor to a collection trench and is routed to a sump. The sump is checked both periodically and after every hard rain either visually or by using a portable conductivity probe. Water is pumped out, if necessary, to either drums or a portable tank. Prior to pumping, however, sump water must be sampled and analyzed for radioactivity. If it is determined that the water is not contaminated, it is released. If it is determined that the water is contaminated, the water is shipped to the Effluent Treatment Facility for treatment. This drainage system is filled with grout upon final closure of the vault.

- The watertight roof is drained by a rain gutter/downspout system that remains in place up to final vault closure. During operation, downspout runoff is routed to a subsurface drainage pipe system that empties away from the facility into a ditch that empties into a sedimentation basin. After interim closure, the downspouts will remain operational. After final closure, the cap will mitigate the amount of water reaching the facility.

- The sub-drainage system collects water from under and around each vauit and routes it to separate manholes where it drains out the bottom of the manhole. This system remains functional after vault closure.

- Adequate drainage around each vault is provided to prevent localized flooding.

The LAW Vault has a permanent 41-centimeter (16-inch) thick, poured-in-place concrete roof to prevent the infiltration of rainwater and is constructed on poured-in-place concrete pads with side-walls. When the vaults are filled to capacity, a closure cap would be used to cover the concrete roof to further reduce the infiltration of water. Each cell within the vault has a means of collecting and removing water that may enter the vault, as described above.

\subsubsection{Facility Features}

The LAW Vault is a concrete structure approximately 200 meters ( 643 feet) long by approximately 44 meters (145 feet) wide by approximately 8 meters $(27$ feet) deep. Each vault contains 12 cells with approximately 48,500 cubic meters $(170,000$ cubic feet $)$ of usable waste disposal capacity. End, side, and interior walls of each module are 0.61 meters $(2$ feet $)$ thick. The LAW Vault walls are structurally mated to the $0.8 \mathrm{~m}$ (30-inch) thick footer that is continuous under all cells within each module. Adjacent walls between modules are separated by a $5-\mathrm{cm}(2-\mathrm{in})$ expansion gap. The base slab is $0.3-\mathrm{m}(1-\mathrm{ft})$ thick, and is set on footings under each exterior and interior wall junction. The base slab is supported on a layer of crushed stone that varies in thickness from $1.1 \mathrm{~m}(3.5 \mathrm{ft})$ at the center to $2.3 \mathrm{~m}(7.5 \mathrm{ft})$ at each lateral edge. Crushed stone is placed on compacted backfill. Two personnel openings are provided in each vault interior wall, between cells, and in one outside wall of each vault. The access openings are provided to allow personnel passage from the operating cell to a vacant non-operating cell and from the last operating cell directly to the outside. For each double interior wall, doorways are in each wall between modules. The interior access openings are located approximately $15 \mathrm{~m}(50 \mathrm{ft})$ apart and $15 \mathrm{~m}(50 \mathrm{ft})$ from each end 
wall. The interior access openings can be equipped with doors during cell operation. Upon cell closure, the access openings will be sealed.

The outer wall of each of the 12 cells in the vault has a 7.9-m (26-ft) wide access opening extending from the floor slab to the roof. This access opening allows entry by forklift trucks for waste container placement. The top of each opening is wood-framed and faced with exterior grade plywood to make the opening approximately 20 feet high. A metal roll-up door provides weather protection for the cell and may be used on new cells or left off completely. The roll-up door is raised manually when access to the vault cell is required. This access opening will be filled with reinforced concrete and mated with the vault at interim closure

A reinforced concrete roof slab is supported by pre-cast concrete beams. The beams extend between each cross wall for the length of the vault. The end walls of each module have recessed beam seats to support the beam ends. Bearing pads fastened to the top of interior walls allow beam ends to rest on the walls. Fig. 2.2-2 illustrates a typical cross section through a LAW Vault cell. The 8.9-cm (3.5-in) thick, pre-cast concrete deck panels are sloped and installed directly on the roof beams to provide a base for the $41-\mathrm{cm}$ (16-in) thick, cast-in-place concrete roof slabs. The roof slab has $5.1-\mathrm{cm}(2$-in) wide expansion joints between module walls. Each expansion joint has flashing installed to provide waterproofing. The roof slab is covered with a bonded in-place layer of fiberboard insulation and a layer of waterproof membrane roofing.

\subsubsection{Disposal Concept Considerations and Movement of Waste Through the Facility}

Low-activity waste is containerized and stacked in the LAW Vault using an extendible boom forklift. Low-activity waste is packaged in various approved steel containers (e.g., B-25 and B-12 Boxes and Department of Transportation-approved drums).

Prior to emplacement of waste into a LAW Vault, each waste container and its accompanying waste characterization documentation is examined by Solid Waste Management personnel. Solid Waste Management personnel verify the generator packaging and documentation for each container received. Waste containers are surveyed at the entrance. The radiation levels emitted through the container and smearable surface contamination are measured and compared to the Generators documentation. Any container that does not meet the Waste Acceptance Criteria (WAC) is treated as a nonconformance and is not accepted for disposal.

Waste containers are positioned within each disposal unit. Orderly stacking of the containerized waste results in the most efficient use of disposal and storage volume. Waste emplacement to the operating LAW Vault cell is through an access opening that allows waste handling forklift trucks to enter. Lowactivity waste arrives at the LAW vaults via truck according to a pre-planned schedule. The waste containers are off-loaded from the delivery truck with a forklift and are driven into the operating cell. The waste containers are positioned and stacked in a preplanned configuration that minimizes the free space between containers.

\subsubsection{Waste Acceptance and Certification}

All LAW and ILW is subject to the WAC of the 1S Procedure Manual (WSRC 1997a). The 1S Manual procedure, WAC 2.02, Rev. 1, Low Level Waste Characterization Requirements, provides requirements associated with the development of suitable methodologies for characterization of waste packages. This procedure establishes the basis to ensure that all LLW packages presented to Solid Waste for treatment, 


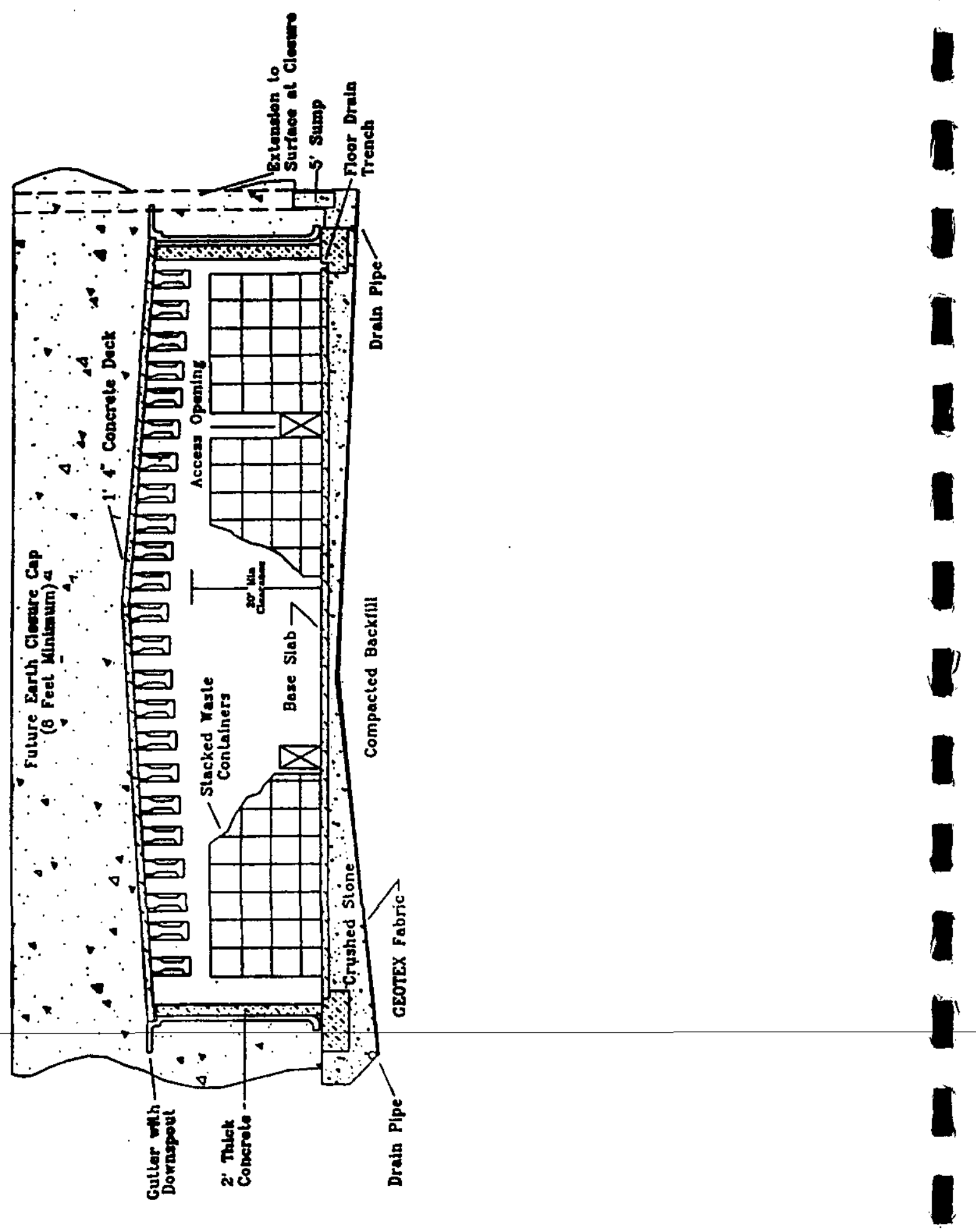

Figure 2.2-2. Typical Section Through a Low-Activity Waste Vault Cell 
storage, or disposal have been characterized by the generator to reasonably represent the physical, chemical and radiological contents of the waste package with sufficient accuracy to permit proper segregation, treatment, storage and disposal.

According to procedure WAC 2.02 , generators must periodically validate the radionuclide content and distribution in their waste streams after their initial certification. The purpose of periodic validation is to demonstrate that the waste stream distribution of the important radionuclides (i.e., those constrained by the WAC) has not changed significantly. The radionuclide content and distribution of all routinely generated SRS waste streams shall be reviewed and validated at least every two years.

The SRS certification procedure requires the generator to characterize the waste using laboratory analysis of representative samples. The procedure also requires that a facility sampling plan be used which ensures that samples are representative of the contaminated waste stream and are consistent and appropriate for each waste stream. After sample analysis results are screened the remaining data shall be evaluated to consider:

- radionuclides identified in the data set compared to historic data sets, and reported values compared to historic sample data for the same waste stream,

- comparisons between in-house analysis results (if available) and independent laboratory results,

- scaling factor ranges relative to similar waste streams and historic data, and

- specific radionuclide results adequately account for gross analysis results.

The procedure indicates that sampling and analysis is the preferred method of characterization where it can be used. However, some waste streams can not be adequately characterized through use of sample and analysis techniques; therefore, process knowledge is appropriate and necessary.

Process knowledge includes available knowledge of the physical, chemical, and radiological properties of the materials involved in the process that generates the waste, the effect of all aspects of the process on the materials, associated process stream and product specifications, and administrative controls. Sources of process knowledge include historical operating and inventory records, analysis results, direct assay results, technical reports, documents and drawings specifying process areas and equipment, process equipment manuals, process stream or product specifications, documented mass balance information and procedures. A radioisotopic distribution for a waste stream determined by process knowledge shall initially be validated using sampling and analysis of representative waste stream samples.

\subsubsection{Land Use Patterns}

As described in Section 3.1.1.4, the use of land adjacent to the SRS is primarily agricultural.

\subsubsection{Intermediate-Level Vaults}

\subsubsection{General Description and Location}

For the purposes of this PA, it has been assumed that 100 acres would provide disposal capacity for 20 years of operations, which would include 2 IL Vaults. At this time, one IL Vault has been constructed. The general location of the existing IL Vault within the E-Area LLWF is shown in Fig. 2.2-1. 
The IL Vault is subdivided into the Intermediate-Level Non-Tritium (ILNT) Vault and the IntermediateLevel Tritium (ILT) Vauit. The ILT Vault will be used for disposal and storage of tritium-bearing waste, packed in 10-gallon drums, or spent tritium extraction crucibles from which almost all the tritium has been removed, and tritium job control waste (JCW). The ILT Vault is similar in design to the ILNT Vault. Both utilize the same crane for waste container handling, they are immediately adjacent and closed as a single unit. The ILT Vault is structurally identical to the ILNT Vault, except for length and depth. The ILT Vault consists of two cells or subdivided sections within the vault structure and provides approximately $1.6 \times 10^{3} \mathrm{~m}^{3}$ (56,000 cubic feet) of waste disposal capacity (Fig. 2.2-3). As originally conceived, one cell in the ILT Vault would be fitted with a silo system to permit the disposal of tritium crucibles. The ILNT Vault consists of seven cells within the vault structure and provides approximately $5.7 \times 10^{3} \mathrm{~m}^{3}$ (approximately 200,000 cubic feet) of waste disposal capacity (Fig. 2.2-3). The base of the IL Vault is at an average elevation of $78 \mathrm{~m}(260 \mathrm{ft})$ above msl. The potential source of radionuclides to the E-Area environment and to an inadvertent intruder posed by these trenches is evaluated in this PA and radionuclide limits for disposal of waste in such trenches are provided.

\subsubsection{Major Design Philosophy}

There are features that have been incorporated into the design of the IL Vault for specific functions. These functions, which include water removal provisions and radiation shielding, are described in this section.

1) Water Removal Provisions - The floor of each cell slopes to a drain which runs to a sump in the base slab for each ceil. Any water accumulating in the sump can be monitored and removed through a $0.15-\mathrm{m}$ diameter riser pipe at the top of the wall. Any water that collects under the vault will flow to dry wells between the ILNT Vault and the ILT Vault. Access to the dry well is through a man-hole at grade level.

Each cell is also provided with a metal rain cover that is installed over each cell when not operating to minimize the infiltration of rain.

All concrete joints include a waterstop seal that is continuous around all corners and intersections. All exterior concrete surfaces exposed to soil are coated with tar-based waterproofing. Rain covers are provided to minimize the entry of rainfall into a cell, and to direct the rain water on to the ground for runoff. A rain cover is available for use on each cell. The rain cover is a roof-truss-type of steel structure that fits around the cell walls to completely cover the cell opening. The roof of the rain cover is slightly sloped, from the center to each lateral edge, to allow water drainage. Water from within a cell is collected in a sump by the in-cell drainage system. The raincover consists of a roofing membrane and metal deck on steel framing. Each rain cover includes stacking posts to allow one cover to be temporarily placed on top of another during cell operations. The rain covers are positioned by a crane.

2) Radiation Shielding - During operations, each cell can be covered with reinforced concrete slabs, known as shielding tees, to reduce the radiation level at the edge of the vault. The profile of these slabs is in the shape of the letter " $T$ " so that they can be interlocked to provide $0.5 \mathrm{~m}$ of shielding.

The IL Vault is classified as a Hazard Category 3 Facility (WSRC 1996a). However, the vaults were designed to meet the requirements of a Maximum Resistance (High Hazard) structure during the interim and final closure phases. The IL Vault satisfies the criteria for classification as a Standard Resistance (General Use) structure. 


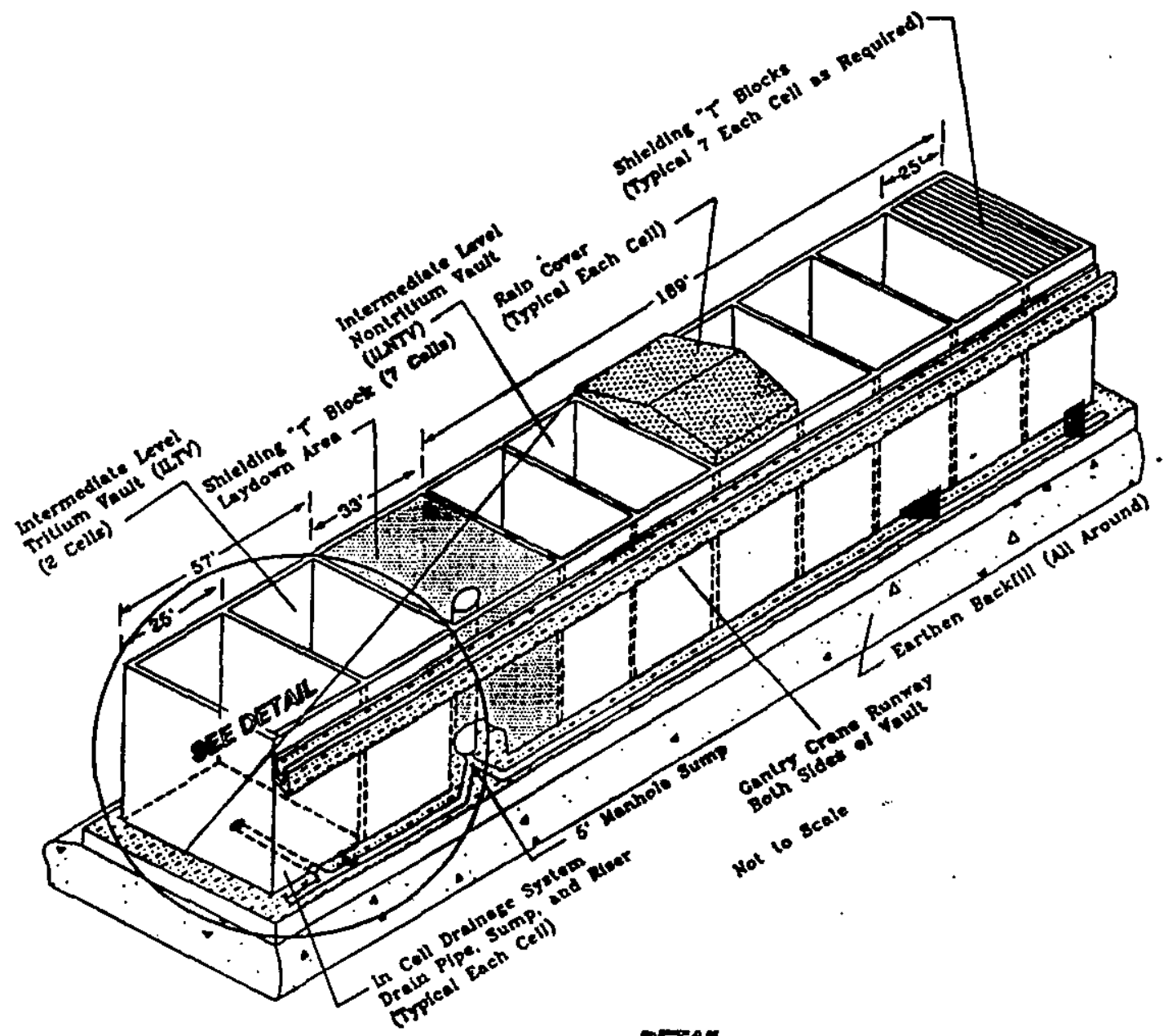

DETAR

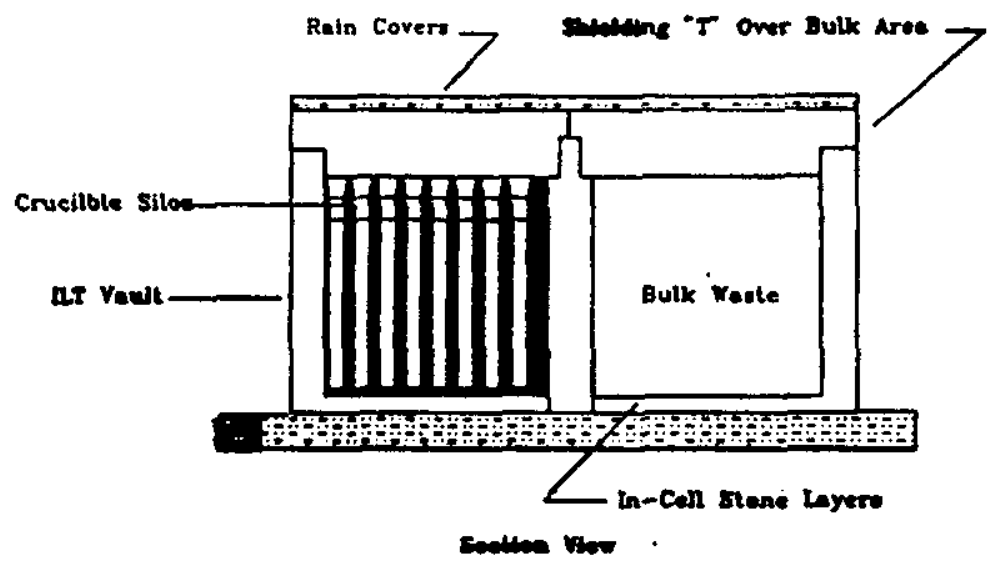

Figure 2.2-3. Arrangement of the Intermediate Level Non-Tritium and Intermediate Level Tritium Vaults 
As documented in the Structural Design Criteria (S2889-306-25-0) the IL Vault was designed and constructed to be maximum resistance structures after closure. In accordance with Site Specification 7096, a maximum resistance structure shall be designed to withstand a $0.2 \mathrm{~g}$ earthquake event.

Each IL Vault has three distinct phases of operation and construction as described below:

1) Operating Phase - This phase involves waste emplacement. As each layer of waste containers is completed, grout is poured around and over the containers to form a new working surface for emplacement of the next layer.

2) Interim Closure Phase - After the final layer of waste containers is placed into the cell, a final layer of grout is placed in the cell and is leveled at the wall ledges used to support the shielding slabs. A permanent roof slab of reinforced concrete is then emplaced to cover the nine IL Vault cells. The slab is then covered with fiberboard and a layer of waterproof membrane roofing.

3) Final Closure Phase - This phase will be performed after all vaults are interim-closed. Final closure consists of placing an earthen cover with an engineered clay cap over the entire E-Area LLWF.

\subsubsection{Facility Features}

At this time, one IL Vault has been constructed, consisting of one ILNT vault and one ILT vault. It is assumed that future IL vaults will be constructed in a combined single vault configuration of nine cells housing both ILT and ILNT waste. The vault construction would be identical to the IL Vaults. The usable capacity of each vault would be approximately 5,300 cubic meters $\left(1.87 \times 10^{5}\right.$ cubic feet $)$.

The ILNT Vault is a below-grade, reinforced concrete structure approximately 58 meters (189 feet) long, 15 meters (48 feet) wide, and 9 meters ( 29 feet) deep with a seven-cell configuration (see Fig. 2.2-3). Exterior walls are 0.76 meters (2-1/2 feet) thick; and interior walls forming the cells are 0.46 meter $(1-1 / 2$ feet) thick. Walls are structurally mated to a base slab which is approximately 0.76 meter $(2-1 / 2)$ thick and extends past the outside of the exterior walls approximately 0.6 meter ( 2 feet). The base slab is supported on two layers of crushed stone placed on compacted subgrade. All concrete construction joints are located at defined control joints, with no horizontal joints in any vertical wall. All concrete joints include a waterstop seal that is continuous around all comers and intersections. All exterior concrete surfaces exposed to soil are coated with tar-based waterproofing.

The ILT Vault consists of two cells with a combined length of approximately $17 \mathrm{~m}(57 \mathrm{ft})$. One cell is identical to the ILNT Vault cells. The other ILT Vault cell is $0.6 \mathrm{~m}(2 \mathrm{ft})$ deeper and has been fitted with a silo storage system designed to house tritium crucibles (see Fig. 2.2-3). This cell is equipped with 142 silos, for tritium crucibles and tritium reservoirs. After a crucible has been placed in a silo, a l-m thick shielding plug is installed to reduce radiation exposure from the disposed crucible. The crucibles are contained in overpacks. The ILT Vault has approximately 400 cubic meters (14,000 cubic feet) of usable waste disposal capacity.

\subsubsection{Disposal Concept Considerations and Movement of Waste Through the Facility}

Shielding blocks and rain covers are provided during cell loading operations. Reinforced concrete blocks are positioned across the width of a cell to provide personnel shielding from the radioactive materials within the cell. The raincover is a roof-truss-type of steel structure that fits around the cells' walls to completely cover the cell opening. Rain covers are installed on a cell until interim closure is accomplished. 
IL solid wastes are divided into tritium and non-tritium bearing fractions, and disposed of separately in the ILT Vault or ILNT Vault. When a vault is being filled with waste, a crane removes the raincover from the designated cell. Next the crane will remove any T-blocks that may be installed in the designated cell. Waste is placed into the cell by the crane from the waste transport vehicle. The T-blocks are reinstalled and the rain covers put back into place. Waste containers placed in an IL vault cell are encapsulated in grout. Successive grout layers are cured before installing additional waste containers. After the final waste is placed into the cell, a final layer of grout is placed in the cell and is leveled at the wall ledges used to support the T-blocks. A permanent roof slab of reinforced concrete that completely covers the vault cells will be installed after the cells in a vault have been filled. Final closure would be performed after vaults were filled by placing an earthen cover with an engineered clay cap over the entire vault area.

The ILT Vault will receive waste in the same manner as the ILNT Vault. The ILT Vault is used for disposal of tritium-bearing waste, packed in either crucibles or 10-gallon containers, and tritium JCW. The crucible silo system is designed to receive overpacked tritium waste containers. Each silo is approximately $46 \mathrm{~cm}(18 \mathrm{in})$ in diameter and $6.1 \mathrm{~m}(20 \mathrm{ft})$ long. The silo system consists of approximately $14250-\mathrm{cm}$ - (20-in-) diameter cylinders, uniformly placed and aligned to form a vertical grid. Each silo is provided with a separate concrete shielding plug. A permanent roof slab is installed at the time of interim closure. The ILT Vault cell operation is the same as that described for the ILNT Vault except that T-blocks are not required for ILT Vault cells containing the silo system. The individual shielding plugs provide radiation shielding.

\subsubsection{Waste Acceptance and Certification}

See Section 2.2.1.5.

\subsubsection{Land Use Patterns}

As described in Section 3.1.1.4, the use of land adjacent to the SRS is primarily agricultural.

\subsubsection{Very-Low-Activity Waste Disposal Trenches}

\subsubsection{General Description and Location}

Between 2800 and $3600 \mathrm{~m}^{3}$ of soil and rubble from regulated areas is designated as contaminated soil at the SRS annually (Cook 1991). In addition large volumes of debris and rubble from environmental restoration and building decommissioning will be generated. Non-vault disposal of a portion of this waste, as well as other very low activity waste such as job control waste, in below-grade trenches has been approved for the E-Area LLWF. These trenches have inventory limits established in the performance assessment and will be used to minimize the use of valuable concrete vault space. Any waste that meets the WAC based on this PA for these disposal units and the Waste Management Safety Analysis Report (SAR) (WSRC 1996a) is suitable for disposal in the Very-Low-Activity Waste Disposal Trenches. These disposal units are referred to as "slit trenches" in this PA.

Ten below-grade trenches are considered in this PA for the E-Area LLWF. The dimensions of each trench are $6 \mathrm{~m}$ wide by $200 \mathrm{~m}$ long by $6 \mathrm{~m}$ deep. Therefore, five below-grade trenches have the surface area equal to that of a LAW Vault. The conceptual layout of one set of trenches is shown in Fig. 2.2-4. The waste is placed in the trenches to a depth of $4.8 \mathrm{~m}$, allowing for $1.2 \mathrm{~m}$ of a clean soil (i.e., backfill) cover in the trenches. This clean soil is in addition to the final soil and clay cover that will overlay the trenches when final closure of the E-Area LLWF occurs. No engineered barriers exist beneath the 


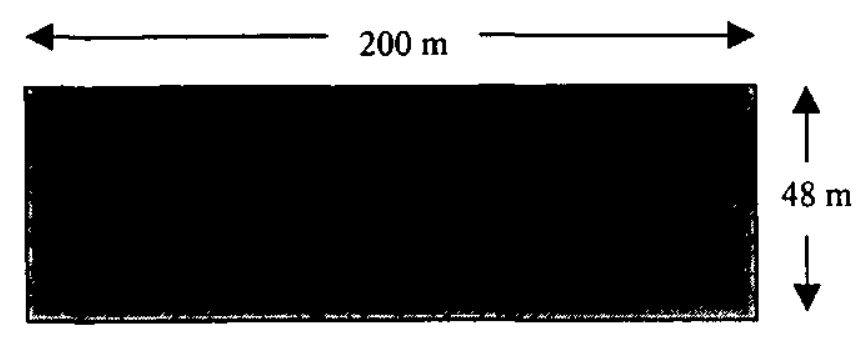

LAW Vault Plan View

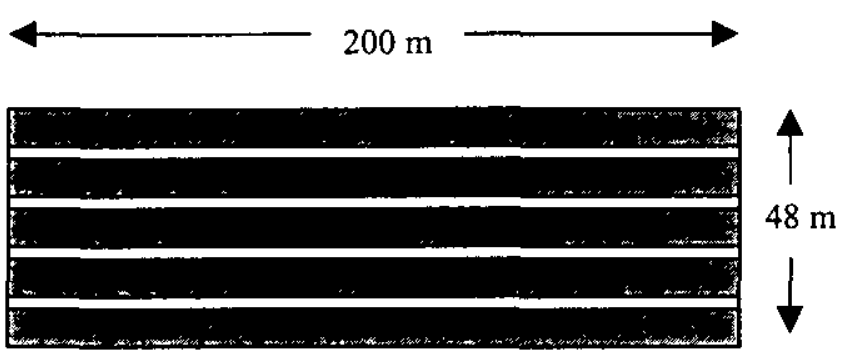

Trench disposal Unit Plan View
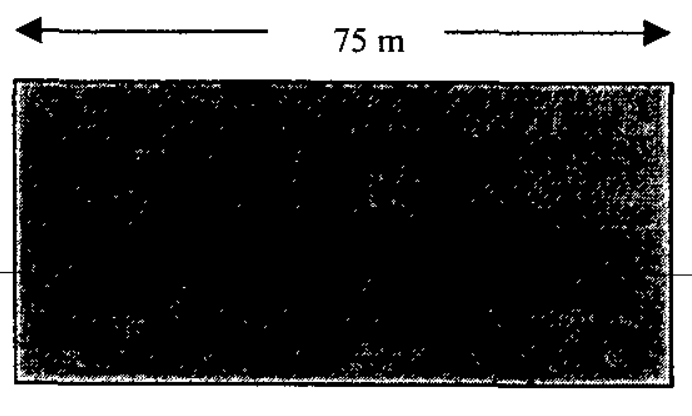

IL Vault Plan View

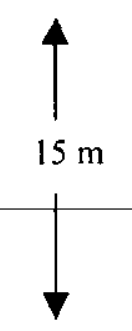

IL Vault Cross Section

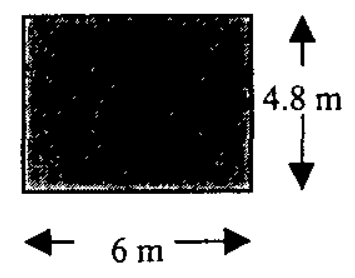

Trench Disposal Unit Cross Section

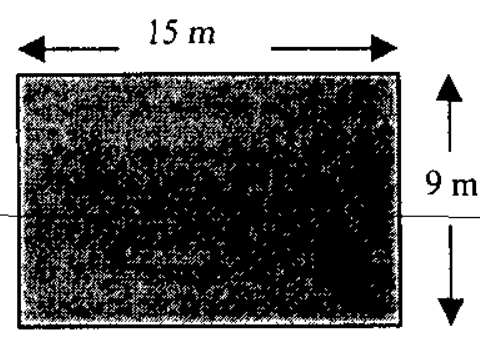

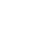

Figure 2.2-4. Conceptual Drawings of Trench and Vault Disposal Units 


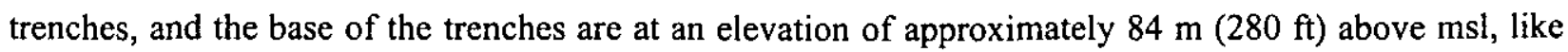
the LAW Vaults. The potential source of radionuclides to the E-Area environment and to an inadvertent intruder posed by these trenches is evaluated in this PA and radionuclide limits for disposal of waste in such trenches are provided.

\subsubsection{Major Design Philosophy}

Specific design measures were applied to the disposal trenches to enhance safe operation, as described below:

1) Wastes, disposed in earthen trenches, are protected from contact with water-saturated soil. All trenches maintain a nominal 25 feet of undisturbed soil between the trench bottom and the permanent ground water table.

2) Waste containers inside the trenches are covered with soil to reduce the potential for radiation exposure, fire and wind-blown contamination. Backfill is added to reduce the surface radiation rate. Backfill provides an earthen cover of approximately 4 feet. Where necessary, soil is added to counteract subsidence of the backfill.

3) Deep-rooted plant systems are not permitted to develop on top of the backfilled trenches.

4) Trenches are located in areas remote from standing ground water.

5) Trenches are located in areas where topography is conducive to level trenching and controlled surface water runoff.

\subsubsection{Facility Features}

The approximate dimensions of the trenches are as follows: The width of a trench is $6 \mathrm{~m}$ (20 feet), and the trench is $200 \mathrm{~m}$ ( $656 \mathrm{feet})$ long. The depth of a trench is $6.1 \mathrm{~m}$ (20 feet) deep, but the top $1.2 \mathrm{~m}$ ( 4 feet) of each trench will be filled with clean soil. The disposal capacity of each of the five disposal trenches is approximately $57600 \mathrm{~m}^{3}\left(203,000 \mathrm{ft}^{3}\right)$.

Waste to date has been soil, wood and debris, though any waste meeting the WAC for these disposal units can be disposed of in the Very-Low-Activity Disposal Trenches. Waste is typically transported to the trenches in lined, reusable containers (i.e., dumpsters and skip pans).

\subsubsection{Disposal Concept Considerations and Movement of Waste Through the Facility}

See Sections 2.2.3.1 through 2.2.3.3.

\subsubsection{Waste Acceptance and Certification}

See Section 2.2.1.5

\subsubsection{Land Use Patterns}

As described in Section 3.1.1.4, the use of land adjacent to the SRS is primarily agricultural. 


\subsubsection{Intimately-Mixed Cement-Stabilized Waste Disposal Trenches}

\subsubsection{General Description and Location}

Operation of the Consolidated Incinerator Facility at SRS produces a solid waste (ash) and a liquid waste (blowdown from the off-gas system). These waste materials are blended with cement to produce more stable wasteforms known as Ashcrete and Blowcrete. The cement-based wasteforms are drummed and disposed in below-grade trenches. These trenches have inventory limits established in this PA and will be used to minimize the use of valuable concrete vault space. Any wasteform that consists of liquid or particulate contamination blended with cement to form a solid that also meets the WAC based on this portion of the PA for these disposal units and the Waste Management SAR (WSRC 1996a) is suitable for trench disposal.

Ten below-grade trenches are considered in this PA for the E-Area LLWF. The dimensions of each trench are $6 \mathrm{~m}$ wide by $200 \mathrm{~m}$ long by $6 \mathrm{~m}$ deep. Therefore, five below-grade trenches have the surface area equal to that of a LAW Vault. The conceptual layout of one set of five trenches is shown in Fig. 2.24. The waste is placed in the trenches to a depth of $4.8 \mathrm{~m}$, allowing for $1.2 \mathrm{~m}$ of a clean soil cover in the trenches. This clean soil is in addition to the final soil and clay cover that will overlay the trenches when final closure of the E-Area LLWF occurs. No engineered barriers exist beneath the trenches, and the base of the trenches are at an elevation of approximately $84 \mathrm{~m}(280 \mathrm{ft})$ above msl, like the LAW Vaults. The potential source of radionuclides to the E-Area environment and to an inadvertent intruder posed by these trenches is evaluated in this PA and radionuclide limits for disposal of waste in such trenches are provided.

\subsubsection{Major Design Philosophy}

Specific design measures were applied to the disposal trenches to enhance safe operation, as described below:

1) The wasteform is a stable solid that limits infiltration of water to the contamination and reduces the potential for future subsidence.

2) Wastes, disposed in earthen trenches, are protected from contact with water-saturated soil. All trenches maintain a nominal 25 feet of undisturbed soil between the trench bottom and the permanent ground water table.

3) Wastes containers inside the trenches are covered with soil to reduce the potential for radiation exposure, fire and wind-blown contamination. Backfill is added to reduce the surface radiation rate. Backfill provides an earthen cover of approximately 4 feet.

4) Deep-rooted plant systems are not permitted to develop on top of the backfilled trenches.

5) Trenches are located in areas remote from standing ground water.

6) Trenches are located in areas where topography is conducive to level trenching and controlled surface water runoff.

\subsubsection{Facility Features}

The approximate dimensions of the trenches are as follows: The width of a trench is $6 \mathrm{~m}$ (20 feet), and the trench is $200 \mathrm{~m}$ ( $656 \mathrm{feet})$ long. The depth of a trench is $6.1 \mathrm{~m}$ (20 feet) deep, but the top $1.2 \mathrm{~m}$ ( 4 feet) of 
soil in each trench will be filled with clean soil. The disposal capacity of each of the five disposal trenches is approximately $57,000 \mathrm{~m}^{3}\left(186,000 \mathrm{ft}^{3}\right)$.

The waste will consist of 55-gallon drums filled with a solidified cement-based wasteform.

\subsubsection{Disposal Concept Considerations and Movement of Waste Through the Facility}

See Sections 2.2.3.1 through 2.2.3.3.

\subsubsection{Waste Acceptance and Certification}

See Section 2.2.1.5

\subsubsection{Land Use Patterns}

As described in Section 3.1.1.4, the use of land adjacent to the SRS is primarily agricultural.

\subsubsection{Cement-Stabilized Encapsulated Waste Disposal Trenches}

\subsubsection{General Description and Location}

Operations at SRS occasionally produce items of large equipment that have either failed or become obsolete, and therefore are considered waste. Disposal of these items in vaults can be operationally difficult due to their large size. This PA examines trench disposal of wasteforms encapsulated by grout or other cementitious backfill as an alternative to vault disposal. Any solid wasteform that meets the WAC based on this portion of the PA for these disposal units and the Waste Management SAR (WSRC 1996a) is suitable for trench disposal.

Ten below-grade trenches are considered in this PA for the E-Area LLWF. The dimensions of each trench are $6 \mathrm{~m}$ wide by $200 \mathrm{~m}$ long by $6 \mathrm{~m}$ deep. Therefore, five below-grade trenches have the surface area equal to that of a LAW Vault. The conceptual layout of one set of trenches is shown in Fig. 2.2-4. A base of grout or other cementitious backfill is first emplaced in the trench bottom, then the waste is placed in the trench. Grout or other cementitious material is then poured or pumped around and over the waste to a depth of $4.8 \mathrm{~m}$, allowing for $1.2 \mathrm{~m}$ of a clean soil cover in the trenches. This clean soil is in addition to the final soil and clay cover that will overlay the trenches when final closure of the E-Area LLWF occurs. No engineered barriers exist beneath the trenches, and the base of the trenches are at an elevation of approximately $84 \mathrm{~m}(280 \mathrm{ft})$ above msl, like the LAW Vaults. The potential source of radionuclides to the E-Area environment and to an inadvertent intruder posed by these trenches is evaluated in this PA and radionuclide limits for disposal of waste in such trenches are provided.

\subsubsection{Major Design Philosophy}

Specific design measures were applied to the disposal trenches to enhance safe operation, as described below:

1) The wasteform is completely encapsulated by a stable solid that limits infiltration of water to the contamination and reduces the potential for future subsidence.

2) Wastes, disposed in earthen trenches, are protected from contact with water-saturated soil. All trenches maintain a nominal 25 feet of undisturbed soil between the trench bottom and the permanent ground water table. 
3) Wastes containers inside the trenches are surrounded by grout or other cementitious backfill and covered with soil to reduce the potential for radiation exposure, fire and wind-blown contamination. Backfill can be added to reduce the surface radiation rate. Backfill provides an earthen cover of approximately 4 feet.

4) Deep-rooted plant systems are not permitted to develop on top of the backfilled trenches.

5) Trenches are located in areas remote from standing ground water.

6) Trenches are located in areas where topography is conducive to level trenching and controlled surface water runoff.

\subsubsection{Facility Features}

The approximate dimensions of the trenches are as follows: The width of a trench is $6 \mathrm{~m} \mathrm{(20} \mathrm{feet),} \mathrm{and} \mathrm{the}$ trench is $200 \mathrm{~m}$ ( $656 \mathrm{feet}$ ) long. The depth of a trench is $6.1 \mathrm{~m}$ ( 20 feet) deep, but the top $1.2 \mathrm{~m}$ ( 4 feet) of each trench will be filled with clean soil. The disposal capacity of each of the five disposal trenches is approximately $57,000 \mathrm{~m}^{3}\left(186,000 \mathrm{ft}^{3}\right)$.

The waste will consist of large equipment encapsulated in grout or other cementitious backfill.

\subsubsection{Disposal Concept Considerations and Movement of Waste Through the Facility}

See Sections 2.2.3.1 through 2.2.3.3.

\subsubsection{Waste Acceptance and Certification}

See Section 2.2.1.5

\subsubsection{Land Use Patterns}

As described in Section 3.1.1.4, the use of land adjacent to the SRS is primarily agricultural.

\subsubsection{Naval Reactor Waste Pads}

\subsubsection{General Description and Location}

The Naval Reactor Waste Pad is within the boundary of the E-Area LLWF (See Fig. 2.2-1). This pad is where large pieces of activated metal naval reactor components (typieally eneased in heavily shielded shipping containers) are disposed. The waste consists of core barrels, adapter flanges, closure heads and other similar equipment.

\subsubsection{Major Design Philosophy}

Specific design measures were applied to the Naval Reactor Waste Pad to enhance safe operation, as described below:

1) Components are protected from contact with water by the heavy disposal casks.

2) The disposal casks provide radiation shielding to protect operations personnel. 


\subsubsection{Facility Features}

An area of approximately $43 \mathrm{~m}$ by $43 \mathrm{~m}$ has been designated for the Naval Reactor Waste Pad. This provides capacity for 100 disposal casks.

\subsubsection{Disposal Concept Considerations and Movement of Waste Through the Facility}

In this PA, it is assumed that up to 100 disposal casks containing Naval Reactor waste will be disposed of in $E$ Area at grade. The quantity of 100 was used to provide some buffer above the currently projected 65 components so that future shipments of similar Naval Reactor wastes would not require a modification of this PA or necessitate conducting a new PA addendum. For waste placement, Savannah River Technology Center (SRTC) recommends vertical placement of the components in a $10 \times 10$ array, with centers of the containers equally-spaced (Fig. 2.2-5), to minimize the exposure profile of the Naval Reactor Waste to infiltrating water. Actual waste placement and layout may vary depending on actual waste/container configuration; it may be more practical to dispose of waste containers on their sides. Given the dimensions of the conceptual Knolls Atomic Power Laboratory Core Barrel/Thermal Shield waste container provided in Fig. 2.2-5, the minimum area for disposal of 100 casks is about $1,024 \mathrm{~m}^{2}$, which corresponds to the area required if the 100 casks are placed immediately adjacent to each other in any type of rectangular arrangement. Since it is likely that there will be a spacing between casks at the time of disposal, the layout assumed for this assessment is shown in Fig. 2.2-5, with a spacing between casks of $1 \mathrm{~m}$. Thus, the overall disposal area is estimated to be $43 \mathrm{~m} \mathrm{x} 43 \mathrm{~m}$, or $1849 \mathrm{~m}^{2}$. (The groundwater modeling nodes are relatively coarse compared to the size of the Naval Reactor Pad. Thus, the groundwater modeling results are not very sensitive to the size of the Naval Reactor Pad.)

\subsubsection{Waste Acceptance and Certification}

See Section 2.2.1.5.

\subsubsection{Land Use Pattems}

As described in Section 3.1.1.4, the use of land adjacent to the SRS is primarily agricultural.

\subsection{Schedules}

\subsubsection{Low-Activity Waste Vaults}

\subsubsection{Operation/Waste Receipt}

At this time, one LAW Vault has been constructed. The next vault is projected to be constructed by Fiscal Year (FY) 2010 based on the current waste forecast and the use of the sorting and segregation facility.

\subsubsection{Closure/Post-Closure}

The entire E-Area LLWF will be closed at the time the second vault has been filled, which is currently estimated to occur in FY14. 


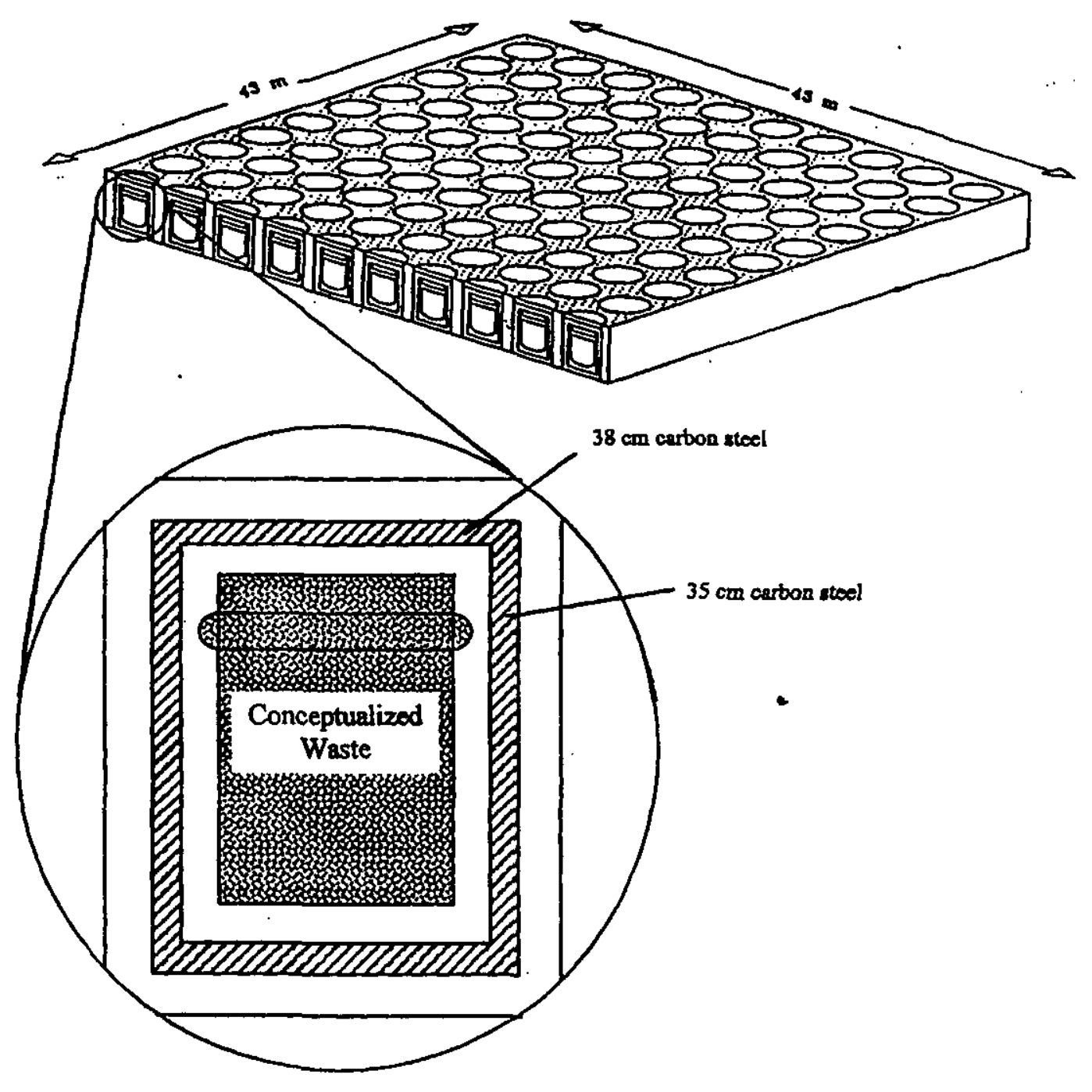

Dimensions $3.2 \mathrm{~m} \times 5.4 \mathrm{~m}$

Figure 2.2-5. Conceptual Layout of 100 Naval Reactor Waste Disposal Containers 


\subsubsection{Intermediate-Level Vaults}

\subsubsection{Operation/Waste Receipt}

At this time, one IL Vault has been constructed. The next vault is projected to be constructed in FY04 based on the current waste forecast.

\subsubsection{Closure/Post-Closure}

The entire E-Area LLWF will be closed at the time the second vault has been filled, which is currently estimated to occur in FY14.

\subsubsection{Disposal Trenches}

\subsubsection{Operation/Waste Receipt}

The five disposal trenches for very-low-activity waste that make up one LAW Vault footprint are estimated to last approximately 5 to 7 years. The current set of five trenches is estimated to last between 3 and 4.5 more years (i.e., after FY02). After these trenches are filled, up to 4 more sets of trenches may be utilized for waste disposal.

Disposal units for enhanced trench disposal, i.e., Intimately-Mixed Cement-Stabilized waste and CementStabilized Encapsulated waste, will be built as needed.

\subsubsection{Closure/Post-Closure}

The entire E-Area LLWF will be closed by FY14.

\subsubsection{Naval Reactor Waste Pads}

This facility will continue to operate until the components are "mounded in place." The entire E-Area LLWF will be closed by FY14.

\subsection{Related Documents}

This revised PA has been prepared within the regulatory context of LLW management per DOE Order 435.1 (DOE 1999) and associated guidance (DOE 1996). The PA is influenced by and has an influence on other documents that are discussed in this section.

\subsubsection{Safety Analysis Report}

The E-Area LLWF is identified as a Hazard Category 3 non-reactor nuclear facility (WSRC 1996a). Although the SAR and the PA focus on different time periods (the SAR is focused on the operational and closure periods, the PA is focused on the post-closure period), there is a considerable degree of overlap in the information presented in the two documents. Both must incorporate features of the environmental setting, and the facility design and operation. The results of the SAR, as well as those of the PA, are reflected in the WAC (WSRC 1997a). In fact, the SAR is the most restrictive analysis for more radionuclides (e.g., criticality concerns for fissile isotopes such as ${ }^{239} \mathrm{Pu}$ ) than is the PA. 


\subsubsection{Groundwater Protection Management Program}

The plan for protection of groundwater at SRS is documented in the SRS Groundwater Protection Management Program (WSRC 1996b). The hydrogeologic information utilized in this revision of the EArea LLWF is consistent with that in the groundwater protection program. The groundwater protection program is focused on those activities regulated by external agencies (i.e., the State of South Carolina and the U.S. Environmental Protection Agency [EPA]). The E-Area LLWF is not regulated by the State of South Carolina or the EPA; rather, it is regulated by DOE through DOE Order 435.1 (DOE 1999). Additionally, the SRS had not entered into any formal agreement applicable to groundwater protection with respect to the E-Area LLWF. However, consistent with guidance for preparing the PA (DOE 1996), the requirement of DOE Order 435.1 to assess impacts to water resources has been interpreted as meaning that concentrations of radioactive contaminants should not exceed standards for public drinking water supplies established by the EPA. This interpretation is consistent with the SRS groundwater protection program.

\subsubsection{Land Use Plan}

The SRS Future Use Plan (DOE 1998a) indicates that the current SRS boundaries will remain unchanged. The land will remain under the ownership of the federal government, consistent with the site's designation as a National Environmental Research Park. Thus, no member of the public would have unrestricted access to the E-Area LLWF. Nonetheless, per the requirements of DOE 435.1, this revised PA has used the point of maximum calculated dose or concentration, outside a $100-\mathrm{m}$ buffer zone surrounding the disposed waste, as the point of assessment. For the inadvertent intruder calculations, the assumed period of active institutional control was limited to 100 -years.

\subsubsection{Composite Analysis}

A Composite Analysis (CA) (WSRC 1997b) has been completed to assess the potential impacts to hypothetical members of the public from residual radioactive material that may be left at the SRS when operations are complete. The CA concluded that the impacts of the operating low-level radioactive waste disposal facilities, the E-Area LLWF and the Saltstone facility, are negligible contributors to calculated doses. Thus, the CA will not influence WAC for the E-Area LLWF. The CA will be revised, as appropriate, to incorporate relevant material from this revision of the PA.

\subsubsection{Saltstone Disposal Facility Performance Assessment and Closure Plan}

The SRS has two operating LLW disposal facilities, the E-Area LLWF and the Saltstone disposal facility. The performance of the Saltstone disposal facility was assessed in the Saltstone PA (WSRC 1992b). In the Saltstone PA, as in this revised PA for the E-Area LLWF, a closure plan had not been prepared. Rather, a closure concept was analyzed. Subsequent to issuing the Saltstone PA, a closure plan for the Saltstone disposal facility was developed to ensure that the functional performance of the proposed closure concept can be achieved through the use of established civil engineering practices for closure of landfill sites (General Engineering Laboratories 1995).

The Saltstone closure plan (General Engineering Laboratories 1995) concluded that the conceptual closure analyzed in the Saltstone PA, which is very similar to that analyzed in this PA revision, is technically and economically feasible using demonstrated techniques. The addendum also concluded that the conceptual closure is rather conservative. 


\subsubsection{Waste Management Environmental Impact Statement}

SRS has prepared an Environmental Impact Statement (EIS) for waste management (DOE 1995). The EIS considered continued disposal of LLW in the 643-7E disposal facility (i.e., the former LLW burial site; disposal in this site has now ceased) and disposal in the E-Area LLWF. The analyses presented in this revised PA are consistent with the EIS.

\subsubsection{Disposal Authorization Statement}

On September 28, 1999 DOE Headquarters issued the Disposal Authorization Statement (DAS) for lowlevel waste disposal in the E-Area and Saltstone disposal facilities. The DAS serves as the "license" under which SRS may dispose of low-level waste at the two disposal facilities. The performance assessments for the facilities, the composite analysis, and information developed during and subsequent to the review of these documents (e.g., addenda to the PAs and CA) form the basis for the DAS. Changes in disposal operations, such as the development of new disposal technology (e.g.., CSEW in trenches) are appropriate, if the changes conform to the PA/CA maintenance requirements.

\subsection{Performance Criteria}

The specific performance objectives for solid waste disposal in E Area are contained in DOE Order 435.1 (DOE 1999):

Performance Objectives. Low-level waste disposal facilities shall be sited, designed, operated, maintained, and closed so that a reasonable expectation exists that the following performance objectives will be met for waste disposed of after September 26, 1988:

(a) Dose to representative members of the public shall not exceed $25 \mathrm{mrem}(0.25 \mathrm{mSv})$ in a year total effective dose equivalent from all exposure pathways, excluding the dose from radon and its progeny in air.

(b) Dose to representative members of the public via the air pathway shall not exceed 10 mrem $(0.10$ $\mathrm{mSv}$ ) in a year total effective dose equivalent, excluding the dose from radon and its progeny.

(c) Release of radon shall be less than an average flux of $20 \mathrm{pCi} / \mathrm{m}^{2} / \mathrm{s}\left(0.74 \mathrm{~Bq} / \mathrm{m}^{2} / \mathrm{s}\right)$ at the surface of the disposal facility. Alternatively, a limit of $0.5 \mathrm{pCi} / \mathrm{L}(0.0185 \mathrm{~Bq} / \mathrm{L})$ of air may be applied at the boundary of the facility.

In addition to the performance objectives, the Order requires, for purposes of establishing limits on the concentrations of radionuclides that may be disposed of near-surface, an assessment of impacts to water resources and to hypothetical persons assumed to inadvertently intrude for a temporary period into the low-level waste disposal facility.

In this PA, the point of assessment for protection of the public and for the assessment of impacts to water resources is taken to be that location more than $100 \mathrm{~m}$ from any disposed waste at which the projected dose or projected concentrations of contaminants in groundwater are the highest. Although this point of assessment is conservative, given the SRS land-use plan which foresees no unrestricted public access, it is consistent with DOE 435.1.

Table 2.5-1 lays out the performance measures and the associated points of compliance. 
Table 2.5-1 Performance Objectives, Assessment Requirements, and Points of Compliance

\begin{tabular}{|c|c|c|}
\hline $\begin{array}{l}\text { Performance } \\
\text { Objective }^{1}\end{array}$ & Measure & Point of Compliance \\
\hline All pathways & $\begin{array}{l}\leq 25 \text { mrem in a year, not including } \\
\text { doses from radon and progeny }\end{array}$ & $\begin{array}{l}\text { Point of highest projected dose or } \\
\text { concentration beyond a } 100 \text {-meter } \\
\text { buffer zone surrounding the } \\
\text { disposed waste. }\end{array}$ \\
\hline Air pathway & $\begin{array}{l}\leq 10 \text { mrem in a year, not including } \\
\text { doses from radon and progeny }\end{array}$ & $\begin{array}{l}\text { Point of highest projected dose or } \\
\text { concentration beyond a } 100 \text {-meter } \\
\text { buffer zone surrounding the } \\
\text { disposed waste. }\end{array}$ \\
\hline \multirow[t]{3}{*}{ Radon } & either & \\
\hline & $\begin{array}{l}\text { (1) an average flux of } \\
\leq 20 \mathrm{pCi} / \mathrm{m}^{2} / \mathrm{s} \text {, or }\end{array}$ & Disposal facility surface \\
\hline & $\begin{array}{l}\text { (2) an air concentration of } \\
\leq 0.5 \mathrm{pCi} / \mathrm{L}\end{array}$ & $\begin{array}{l}\text { Point of highest projected dose or } \\
\text { concentration beyond a } 100 \text {-meter } \\
\text { buffer zone surrounding the } \\
\text { disposed waste. }\end{array}$ \\
\hline $\begin{array}{l}\text { Assessment } \\
\text { Requirement }^{2}\end{array}$ & Measure & Point of Compliance \\
\hline \multirow[t]{2}{*}{$\begin{array}{l}\text { Hypothetical } \\
\text { inadvertent intruder }\end{array}$} & $\begin{array}{l}100 \text { mrem in a year from chronic } \\
\text { exposure }\end{array}$ & Disposal facility \\
\hline & 500 mrem from a single event & Disposal facility \\
\hline $\begin{array}{l}\text { Impact on Water } \\
\text { Resources }\end{array}$ & $\begin{array}{l}\text { The SRS interpretation is that } \\
\text { concentrations of radioactive } \\
\text { contaminants should not exceed } \\
\text { standards for public drinking water } \\
\text { supplies established by the EPA ( } 40 \\
\text { CFR Part 141). }\end{array}$ & $\begin{array}{l}\text { Point of highest projected dose or } \\
\text { concentration beyond a } 100 \text { meter } \\
\text { buffer zone surrounding the } \\
\text { disposed waste. }\end{array}$ \\
\hline
\end{tabular}

1. DOE Order 435.1 requires that low-level waste disposal facilities shall be sited, designed, operated, maintained, and closed so that a reasonable expectation exists that the performance objectives will be met for waste disposed of after September 26, 1988.

2. DOE Order 435.1 also requires that the performance assessment include, for purposes of establishing limits on radionuclides that may be disposed of near-surface, an assessment of the impacts on water resources and an assessment of impacts calculated for a hypothetical person assumed to inadvertently intrude for a temporary period into the low-level waste disposal facility. 
DOE Order 435.1 states that "The performance assessment shall include calculations for a 1,000-year period after closure of potential doses to representative future members of the public and potential releases from the facility to provide a reasonable expectation that the performance objectives identified in this Chapter are not exceeded as a result of operation and closure of the facility." The guidance for DOE Order 435.1 states "The sensitivity/uncertainty analysis should include the calculation of maximum impact of the disposal facility beyond the 1,000 year period used for the compliance period, regardless of the time at which the maximum occurs."

However, a more conservative approach than that required by DOE Order 435.1 has been taken in this PA with respect to the time period for compliance with the performance objectives and requirements:

1) The performance objectives for protection of off-site members of the public, and the performance measures for the analysis of impacts on inadvertent intruders and water resources are applied for 10,000 years after disposal. The 10,000-year period was selected to be consistent with PA guidance from the Nuclear Regulatory Commission (NRC) (NRC 1997).

2) If calculated doses to off-site members of the public or inadvertent intruders or calculated contaminant levels in groundwater do not attain their maximum values during the 10,000-year compliance period, the estimates of the peak values and the times at which they occur are obtained and presented. The largest value within the 10,000 year period following closure of the facility is used to assess compliance.

Compliance with the requirement to assess impacts on water resources is interpreted at the SRS as meaning that concentrations of radioactive contaminants at any points of compliance should not exceed standards for public drinking water supplies established by the EPA (40 CFR Part 141).

Specific interpretation and application of the performance objectives and requirements listed above are further discussed below with respect to protection of the public, impacts on water resources, and impacts on inadvertent intruders.

\subsubsection{Public Protection Performance Objective}

Protection of the public according to the stated performance objectives requires that calculated annual dose to a hypothetical future member of the public shall not exceed 25 mrem total EDE from all exposure pathways. "All exposure pathways" includes all modes of exposure, including the air pathway, but excluding exposures to radon and short-lived progeny. Furthermore, calculated dose via the air pathway is not to exceed $10 \mathrm{mrem} / \mathrm{yr}$ total EDE, again excluding dose from radon and short-lived progeny. The point of compliance, as stated earlier, is the point of highest calculated dose beyond a 100 -meter buffer zone surrounding the waste.

Radon is addressed separately, with separate applicable limits. In most cases, the limit for radon should be an average ground surface emanation rate of $20 \mathrm{pCi} / \mathrm{m}^{2} / \mathrm{s}$, which applies in the E-Area PA. (An alternative limit may apply in special cases, which involve disposal of material that radiologically resembles uranium or thorium mill tailings, in which case an incremental increase in the air concentration of radon of $0.5 \mathrm{pCi} / \mathrm{l}$ at the point of public access (i.e., beyond a 100-meter buffer zone surrounding the disposed waste) should be applied). 


\subsubsection{Water Resource Impact Assessment Requirement}

DOE Order 435.1 does not specify either dose or concentration limits for radionuclides in water. Therefore, there is some ambiguity in applying the requirement even though, as described previously, it is interpreted as requiring that concentrations of contaminants in groundwater should not exceed values specified in EPA standards for public drinking water supplies (40 CFR Part 141).

In the PA for the E-Area LLWF, three different options for specifying maximum contaminant levels (MCLs) of radionuclides in groundwater are considered. The three options, each of which is consistent with EPA standards for radioactivity in drinking water, are described below.

\subsubsection{Option 1}

In the first option, the MCLs for radionuclides in groundwater are those specified in current EPA standards for radioactivity in drinking water, which were promulgated in 1976 . The current standards include: 1) a limit on concentration of $5 \mathrm{pCi} / \mathrm{L}$ for ${ }^{226} \mathrm{Ra}$ and ${ }^{228} \mathrm{Ra}$ combined; 2) a limit on concentration of $15 \mathrm{pCi} / \mathrm{L}$ for gross alpha-particle activity, including ${ }^{226} \mathrm{Ra}$ but excluding radon and uranium; and 3) a limit on dose equivalent to whole body or any organ of 4 mrem per year from all man-made beta/gamma-emitting radionuclides. The current standards also specify that the concentration of any man-made beta/gammaemitting radionuclide causing a dose equivalent of $4 \mathrm{mrem}$ to whole body or any organ shall be calculated on the basis of a drinking water intake of $2 \mathrm{~L} /$ day and data for converting activity intakes of radionuclides to dose published by the U.S. Department of Commerce (DOC) (1963), except the MCLs are given as $20,000 \mathrm{pCi} / \mathrm{L}$ for tritium $\left({ }^{3} \mathrm{H}\right)$ and $8 \mathrm{pCi} / \mathrm{L}$ for ${ }^{90} \mathrm{Sr}$.

A possible drawback of the approach specified by the EPA for calculating MCLs for beta/gamma-emitting radionuclides is that the concentration limits in water corresponding to a dose equivalent to whole body or any organ of $4 \mathrm{mrem}$ are based on internal dosimetry data (DOC 1963) which is now outdated. The dosimetric and metabolic models for radionuclides used to obtain the data in the Department of Commerce report essentially are those recommended in the International Commission on Radiological Protection's (ICRP) Publication 2 (ICRP 1959), but these data have been superseded by data based on the models in ICRP Publication 30 (1979). Although the more recent internal dosimetry data developed by the ICRP have been adopted for use by the EPA (Eckerman et al. 1988) and DOE (1988), these data have not yet been incorporated in the EPA standards for radioactivity in drinking water. Because these standards use outdated internal dosimetry data for beta/gamma-emitting radionuclides, the MCLs for most radionuclides calculated as specified by the EPA would not correspond to the specified limit on dose equivalent of 4 mrem to whole body or any organ. This consideration leads to the second option for the performance objective adopted for use in this analysis.

\subsubsection{Option 2}

In the second option, the EPA's current MCLs of $5 \mathrm{pCi} / \mathrm{L}$ for ${ }^{226} \mathrm{Ra}$ and ${ }^{228} \mathrm{Ra}$ combined and $15 \mathrm{pCi} / \mathrm{L}$ for gross alpha-particle activity, including ${ }^{226} \mathrm{Ra}$ but excluding radon and uranium, and the limit on dose equivalent of $4 \mathrm{mrem}$ per year to whole body or any organ from all man-made beta/gamma-emitting radionuclides are retained. However, the dose limit for any beta/gamma-emitting radionuclide is converted to a concentration limit using the internal dosimetry data from ICRP Publication 30 (1979) that has been adopted for use by the DOE (1988). Thus, for beta/gamma-emitting radionuclides, the second option uses the same primary standard (i.e., dose limit) as the current EPA standards, but the secondary standards (i.e., concentration limits) are based on up-to-date internal dosimetry data; and, in this option, the MCLs for all beta/gamma-emitting radionuclides correspond, based on the best available information, to the dose limit of 4 mrem per year to whole body or any organ. 


\subsubsection{Option 3}

In the third option, the MCLs for radionuclides in groundwater are those specified in the EPA's proposed revisions of the drinking water standards (DWS) for radionuclides (EPA 1991). The proposed standards include: 1) separate limits on concentration of $20 \mathrm{pCi} / \mathrm{L}$ for ${ }^{226} \mathrm{Ra}$ and ${ }^{228} \mathrm{Ra}$; 2) a limit on concentration of 20 $\mu \mathrm{g} / \mathrm{L}$ for uranium, 3) a limit on concentration of $15 \mathrm{pCi} / \mathrm{L}$ for gross alpha-particle activity, excluding ${ }^{226} \mathrm{Ra}$, uranium, and ${ }^{222} \mathrm{Rn}$; and 4 ) a limit on EDE of 4 mrem per year for all beta/gamma-emitting radionuclides. The proposed concentration limit for uranium is based on prevention of chemical toxicity in the kidney, rather than limitation of radiation dose, and corresponds to an activity concentration of $14 \mathrm{pCi} / \mathrm{L}$ for naturally occurring uranium with its normal isotopic abundances. The proposed standards also include a concentration limit of $300 \mathrm{pCi} / \mathrm{L}$ for ${ }^{222} \mathrm{Rn}$, but the Energy Policy Act of 1992 directs the EPA not to issue a standard for radon in drinking water at the present time. Final revisions of the DWS for radionuclides have not yet been promulgated.

The proposed revisions of the DWS for radionuclides described above differ from the current standards in two respects that are potentially important for this PA. First, the proposed revisions include an MCL for uranium, whereas uranium is unregulated in current standards. Second, the proposed revisions include a limit on EDE for beta/gamma-emitting radionuclides, whereas the dose limit in current standards applies to whole body or any organ. For radionuclides that preferentially irradiate only one or a few body organs (e.g., ${ }^{129} \mathrm{I},{ }^{239} \mathrm{Pu}$ ) a limit on EDE of 4 mrem corresponds to a considerably different MCL than a limit on dose equivalent of 4 mrem to whole body or any organ, even when the same dosimetric and metabolic model is used. Internal dosimetry data based on ICRP Publication 30 (1979) presumably would be used to convert the dose limit of 4 mrem EDE to radionuclide-specific MCLs.

\subsubsection{Summary}

Three different options for specifying the performance measure for assessing impacts on groundwater resources have been used in this analysis. These options are summarized as follows:

1) Current EPA standards for radionuclides in drinking water, including the method prescribed by the EPA for calculating MCLs for beta/gamma-emitting radionuclides based on internal dosimetry data from ICRP Publication 2 (1959) and the specified MCLs for ${ }^{3} \mathrm{H}$ and ${ }^{90} \mathrm{Sr}$;

2) Current EPA standards for radionuclides in drinking water, except all MCLs for beta/gammaemitting radionuclides are calculated from the prescribed dose limit using updated internal dosimetry data based on ICRP Publication 30 (1979); and

3) Proposed revisions of the EPA standards for radionuclides in drinking water, with MCLs for beta/gamma-emitting radionuclides calculated using internal dosimetry data based on ICRP Publication 30 (1979), except no standard for radon is assumed.

Option 1 will be used in this PA to assess compliance with requirement to assess impacts to water resources; for uranium, a compliance limit of $20 \mu \mathrm{g} / \mathrm{L}$ from Option 3 will be used. The SRS is one of the DOE sites designated as being on the National Priorities List (NPL) by the Comprehensive Environmental Response, Compensation, and Liability Act (CERCLA) (40 CFR 300). As a result, all groundwater at SRS is regulated by CERCLA. Under CERCLA, the MCLs promulgated under the Safe Drinking Water Act (40 CFR 141) are used as applicable or relevant and appropriate requirements (ARARs). Thus, even though they use out-dated dose methodology, the current MCLs (Option 1) should be used for compliance. Where the current MCLs do not specify a limit (as in the case of uranium), a proposed MCL can be used as an ARAR. Thus the compliance limit for uranium is $20 \mu \mathrm{g} / \mathrm{L}$. In most, but not all, cases Option 1 produces the most restrictive MCLs (see Table 3.2-1). 


\subsubsection{Intruder Analysis}

The assessment of impacts to hypothetical persons who are assumed to intrude into the E-Area LLWF requires that calculated annual total EDE to such individuals not exceed 100 mrem for chronic exposure scenarios. For acute exposure scenarios, calculated doses are not to exceed 500 mrem total EDE. Institutional controls are assumed to be effective in deterring intrusion for at least 100 years following closure of the facility. Passive controls, in the form of engineered barriers or features of the site, can be claimed as further deterrents to intrusion.

In general, the chronic exposure scenarios address all reasonable pathways. Consumption of groundwater and crop irrigation are exposure pathways that are excluded from the intruder analysis; impacts of groundwater contamination are evaluated separately in the PA in the all-pathways analysis and the water resource impacts analysis. Doses from short-lived radon progeny are not addressed for similar reasons.

\subsection{Summary of Key Assessment Assumptions}

For protection of the public and the assessment of impacts to water resources, exposure pathways involving direct ingestion of groundwater and release of volatile radionuclides to the atmosphere are the pathways of dominant concern for the E-Area LLWF PA (see Section. 4). For the intruder analysis, there is no clear dominance of exposure pathways and scenarios, and doses for a given unit vary greatly by radionuclide and the state of engineered barriers (see Section. 6).

Assumptions of greatest importance to the projection of groundwater concentrations are those that affect the projection of release from the waste forms and subsequent transport to the point of compliance. Release from the waste forms is a strong function of the amount of water infiltrating the disposal unit, the manner in which radionuclides are bound to the waste, physical/chemical sorption properties of individual radionuclides, solubility of the radionuclides, and the presence of engineered barriers to water flow. The amount of infiltrating water and hydraulic properties of the soil matrix are important to the estimation of the transport to the water table; however, over long periods of time, when steady-state conditions are approached, hydraulic properties become less important because the flow rate becomes controlled by the rate water infiltrates to the waste zone. Ultimately, groundwater concentrations are a function of the rate radionuclides reach the water table, which are affected by the parameters listed above, and of the hydraulic properties of the aquifer matrix. Simulation of these important processes requires a number of generally simplifying assumptions. Those that most affect the projected groundwater concentrations are: 1) vault degradation is assumed to occur in instantaneous steps, rather than gradually; at the projected earliest time of cracking and roof failure; 2) moisture barriers are assumed to fail as soon as waste forms begin to degrade, or at the end of the institutional control period (100 years) for slit trenches; 3 ) sorption is assumed to be adequately represented by non-site-specific sorption coefficients $\left(\mathrm{K}_{\phi} \mathrm{s}\right)$ for many radionuclides and materials; 4) with the exception of the naval reactor waste and the solubility-limited uranium and plutonium isotopes in wastes that are either cement-stabilized or disposed of in concrete vaults, all other radionuclides are assumed to exist as surface contamination, and are available for transport; and 5) the depth of nodes in the simulation domain used for the groundwater transport simulations is assumed to be adequately small to avoid introducing unrealistic dilution of the radionuclides reaching the water table.

Assumptions of greatest importance to the estimation of dose resulting from release of volatile radionuclides to air have to do with the rate at which volatile radionuclides are released to the atmosphere and the time at which the releases occur. 
For estimation of dose to inadvertent intruders, exposure scenario definitions (assumptions) are perhaps most critical to the performance analysis. Probably the most important assumptions are: 1) the inadvertent intruder has no knowledge of prior waste activities at the site: 2) the intruder will build a home or drill a well at the location of disposal units, rather than in uncontaminated areas; 3 ) the intruder excavates or drills at the earliest time possible relative to degradation estimates for the various materials; and 4) exhumed waste is mixed with uncontaminated soil, and a garden is planted in the resulting mix. These important assumptions tend to maximize calculated dose to the intruder, and thus provide a pessimistic evaluation of performance of the facility with respect to impacts on intruders. 
THIS PAGE INTENTIONALLY LEFT BLANK 


\section{SECTION 3}

\section{DISPOSAL FACILITY CHARACTERISTICS}


THIS PAGE INTENTIONALLY LEFT BLANK

Rev. 1 


\section{DISPOSAL FACILITY CHARACTERISTICS}

\subsection{Site Characteristics}

Evaluation of radionuclide transport from the E-Area LLWF, and of human exposure resulting from release of radionuclides to the environment, requires careful consideration of factors affecting transport processes and exposure potential. Topographic features and hydrogeologic characteristics strongly affect the direction and flow of radionuclides potentially released from the disposal site. Projected land use and population distributions affect the estimation of human exposure. In this section, the relevant natural and demographic characteristics of the E-Area site and surrounding area are discussed.

\subsubsection{Geography and Demography}

\subsubsection{Disposal Site Location}

The SRS occupies about $780 \mathrm{~km}^{2}$ in Aiken, Barnwell, and Allendale Counties on the Upper Atlantic Coastal Plain of southwestern South Carolina (Fig. 3.1-1). The center of the SRS is approximately $36 \mathrm{~km}$ southeast of Augusta, GA; $32 \mathrm{~km}$ south of Aiken, SC; $160 \mathrm{~km}$ from the Atlantic Coast; and is bounded on the southwest by the Savannah River for about $28 \mathrm{~km}$. The Fall Line, which separates the Atlantic Coastal Plain physiographic province from the Piedmont physiographic province, is approximately $50 \mathrm{~km}$ northwest of the central SRS.

Prominent geographic features within $80 \mathrm{~km}$ of the SRS are the Savannah River, Thurmond Lake, Par Pond, and L Lake. The Savannah River forms the southwest boundary of the SRS. Thurmond Lake is the largest nearby public recreational area. This reservoir is on the Savannah River and is about $64 \mathrm{~km}$ upstream of the center of the SRS. Par Pond is an $11 \mathrm{~km}^{2}$ former reactor cooling water impoundment that lies in the eastern sector of the SRS. L Lake is a $4 \mathrm{~km}^{2}$ former reactor cooling water impoundment that lies in the southern sector of the SRS (Fig. 3.1-2).

The E-Area LLWF is located in the central region of the SRS known as the General Separations Area (GSA) (Fig. 3.1-3). The disposal site consists of approximately $0.8 \mathrm{~km}^{2}$ (200 acres) and is situated immediately north of the former Low-Level Waste (LLW) burial grounds. Construction of the E-Area LLWF began in October 1989. Planned construction covers an elbow-shaped, cleared area of $0.4 \mathrm{~km}^{2}$ (100 acres), curving to the northwest on an interfluvial plateau.

\subsubsection{Disposal Site Description}

The elevation of the SRS ranges from $24 \mathrm{~m}$ above msl (ASL) at the Savannah River to about $122 \mathrm{~m}$ ASL in the upper northwest portion of the site. The Pleistocene Coastal terraces and the Aiken Plateau form two distinct physiographic subregions at the SRS (WSRC 1992a). The Pleistocene Coastal terraces are below $82 \mathrm{~m}$ in elevation, with the lowest terrace constituting the present flood plain of the Savannah River and the higher terraces characterized by gently rolling topography. The relatively flat Aiken Plateau occurs above $82 \mathrm{~m}$.

The Aiken Plateau is dissected by numerous streams. Because of the large number of tributaries to small streams on the SRS, no location on the site is far from a flowing stream, most of which drain to the Savannah River. 


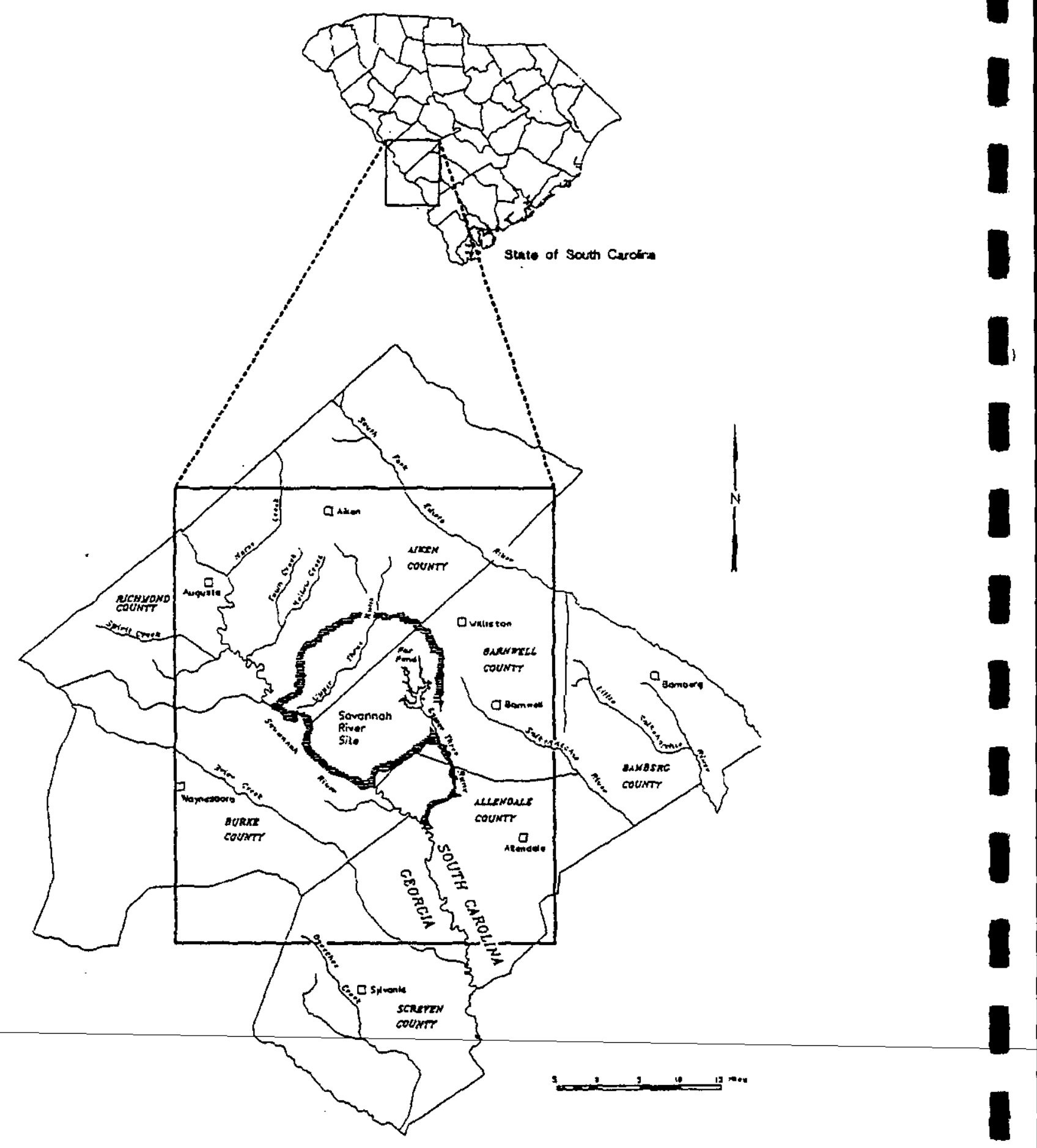

Figure 3.1-1 Location of Savannah River Site and Adjacent Study Area 


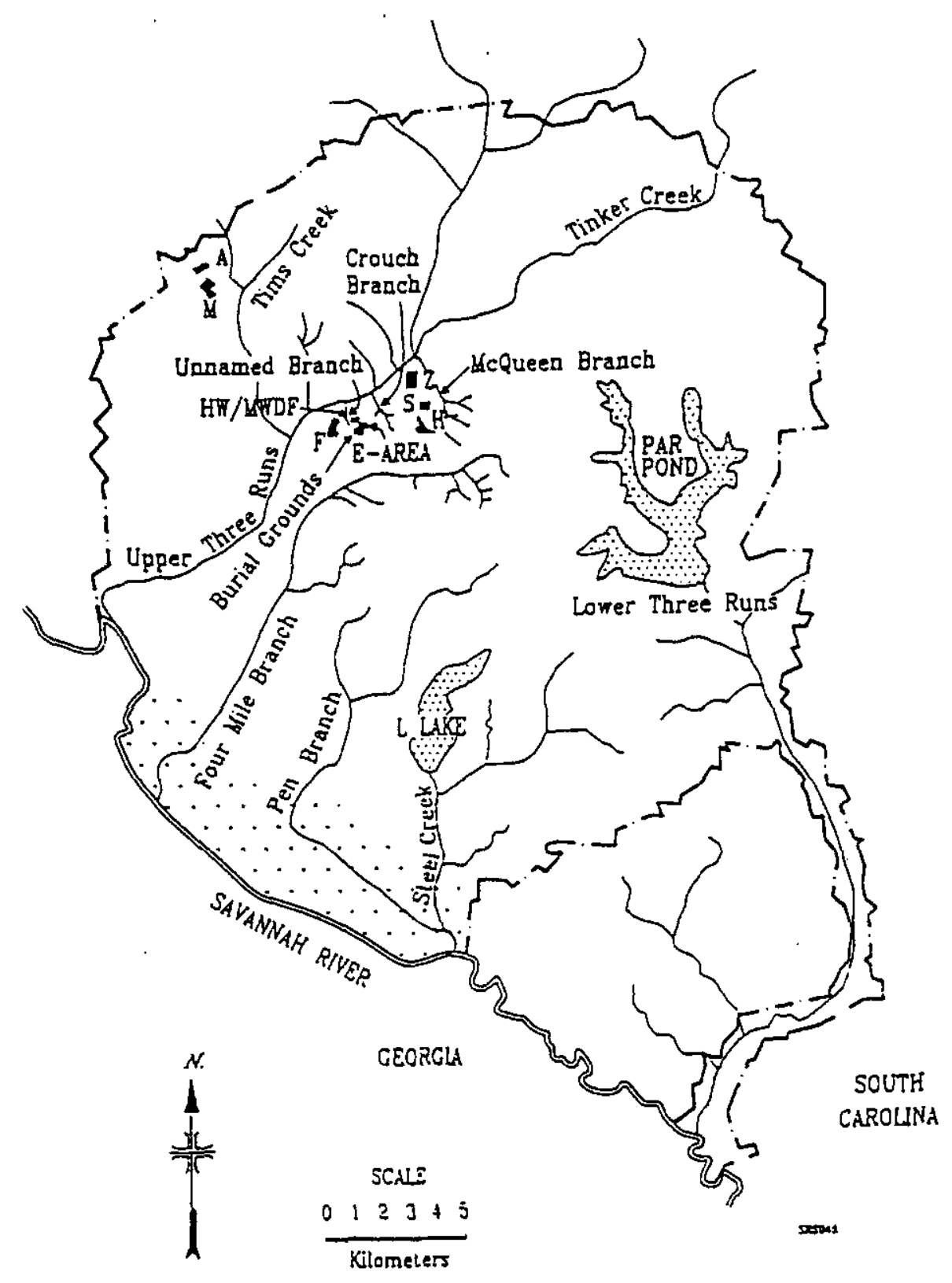

Figure 3.1-2 Facility Location Map of the SRS Showing Surface Drainage 


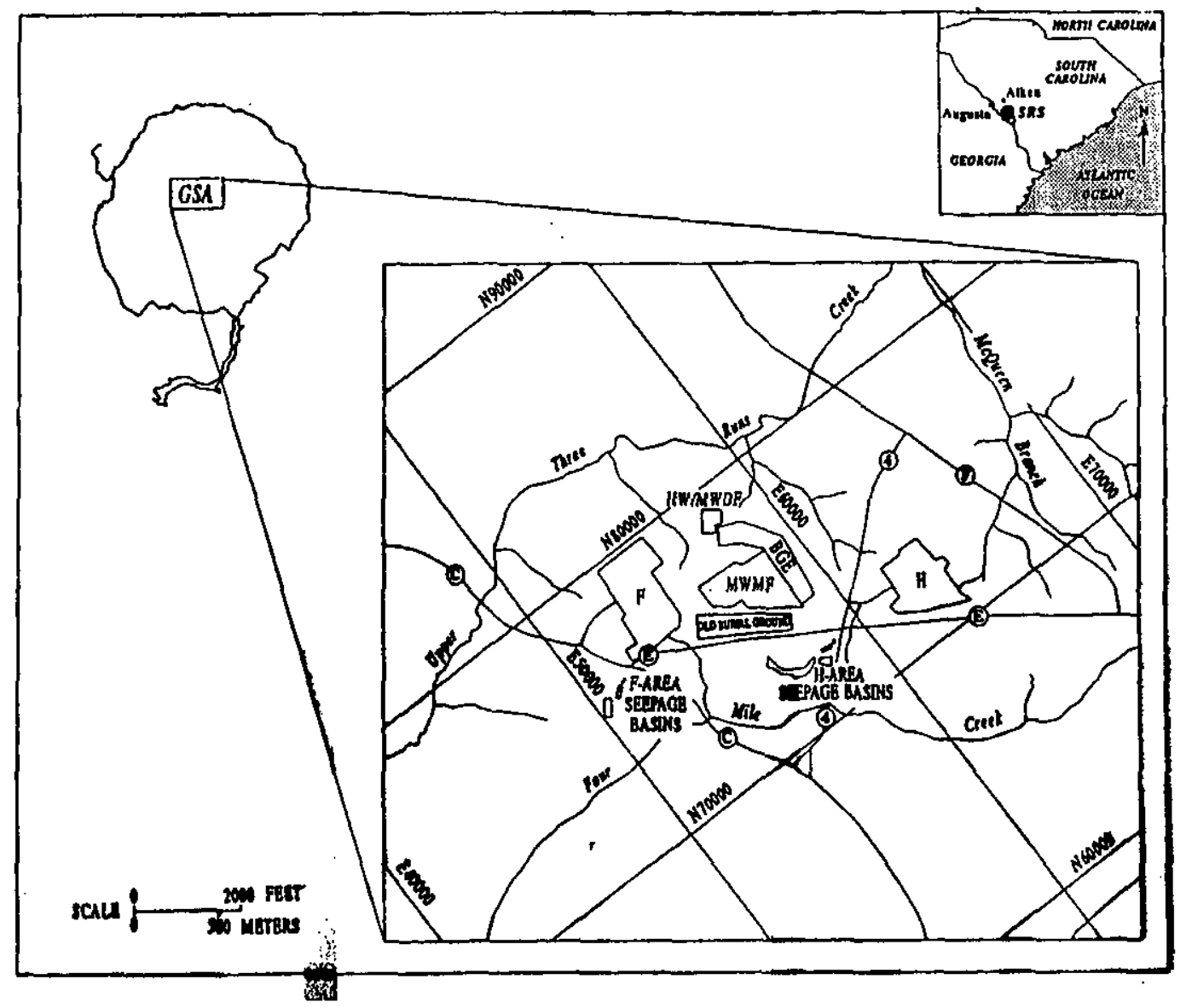

Figure 3.1-3 Location of the General Separations Area 
The E-Area site has low to moderate topographic relief and is drained by several perennial streams (Fig. 3.1-3). It slopes from an elevation of about $88 \mathrm{~m}$ in the southernmost corner to an elevation of $76 \mathrm{~m}$ in the northernmost corner. The site is bordered by three streams with several intermittent streams present within the area boundary. Runoff is to the north toward Upper Three Runs, to the east toward Crouch Branch, and to the west toward an unnamed branch. Upper Three Runs is approximately $760 \mathrm{~m}$ north of the facility boundary. The nearest perennial stream is approximately $370 \mathrm{~m}$ northeast of the boundary.

The dominant vegetation on the SRS is forest, with types ranging from scrub oak communities on the driest areas to bald cypress and black gum in the swamps. Pine forests cover more area than any other forest type. Land utilization presently is about 56 percent in pine forests, 35 percent in hardwoods, 7 percent in SRS facilities and open fields, and 2 percent in water (WSRC 1992a).

Except for three roadways and a railway that are near the edge of the SRS, public access to the SRS is restricted to guided tours, controlled deer hunts, and authorized environmental studies. Fig. 3.1-2 shows the major areas at the SRS and their location within the site boundary. The major production areas located at the site include: Raw Materials (M Area), Separations ( $\mathrm{F}$ and $\mathrm{H}$ Areas), Waste Management Operations (E, F, and H Areas), and Defense Waste Processing (S and Z Areas) (WSRC 1992a). Administrative and support services, the Savannah River Technology Center, and the Savannah River Ecology Laboratory are located in A Area.

\subsubsection{Population Distribution}

Based on state and federal agency surveys and trends, the estimated 1994 population in the region of influence was 457,824. More than 89 percent lived in Aiken (28.8 percent), Columbia (17.5 percent), and Richmond (42.8 percent) counties (Table $3.1-1$ ). The population in the region grew at an average annual growth rate of 1.2 percent during the 1980s and slowed to a less than 1 percent rate between 1990 and 1994. The positive net immigration that occurred in the region was consistent with population growth in Georgia and South Carolina. Columbia County experienced the greatest increase, 146 percent total net increase. Aiken County was second with a 53 percent total net increase. Over the same period, however, Bamberg, Barnwell, and Richmond counties experienced a net loss of population.

Population projections indicate that the overall population in the region should continue to grow until about 2040. Three counties-Allendale, Bamberg, and Barnwell-should experience little growth after 2000, while the others should increase consistently (Table 3.1-2). Columbia County will continue to show a significant upward growth pattern (DOE 1998b).

\subsubsection{Uses of Adjacent Lands}

In the area adjacent to the SRS, less than 8 percent of the existing land is devoted to urban and built-up uses. Most such uses are in and around the cities of Augusta and Aiken. Agriculture accounts for about 21 percent of total land use; forests, wetlands, water bodies, and unclassified, predominantly rural, lands account for about 70 percent.

The projected future land uses of the area adjacent to the SRS are similar to existing patterns. Developed urban land is projected to increase by 2 percent in the next 20 years. The largest percentage of this growth is expected to occur in Aiken and Columbia Counties as a result of the expansion of the Augusta metropolitan area (DOE 1987). 
Table 3.1-1 Population Distribution and Percent of Region of Influence (\%ROI) For Counties and Selected Communities

\begin{tabular}{crr}
\hline Jurisdiction & 1994 Population & $1994 \%$ ROI \\
\hline South Carolina & $3,663,990$ & \\
Aiken County & 132,060 & 28.8 \\
Aiken & 24,930 & 5.4 \\
Jackson & 1,880 & 0.4 \\
New Ellenton & 2,490 & 0.5 \\
North Augusta & 17,610 & 3.8 \\
Allendale County & 11,690 & 2.6 \\
Bamberg County & 16,700 & 3.6 \\
Barnwell County & 21,420 & 4.7 \\
Barnwell & 5,600 & 1.2 \\
Georgia & $7,055,340$ & \\
Columbia County & 79,920 & 17.5 \\
Augusta/Richmond & 196,030 & 42.8 \\
County & & \\
Six-county total & & \\
United States & & \\
\hline
\end{tabular}


Table 3.1-2 Population Projections and Percent of Region of Influence (\% ROI)

\begin{tabular}{|c|c|c|c|c|c|c|}
\hline \multirow[b]{2}{*}{ Jurisdiction } & \multicolumn{2}{|l|}{2000} & \multicolumn{2}{|l|}{2010} & \multicolumn{2}{|l|}{2020} \\
\hline & Population & $\% \mathrm{ROI}$ & Population & $\% \mathrm{ROI}$ & Population & $\% \mathrm{ROI}$ \\
\hline \multicolumn{7}{|l|}{ South Carolina } \\
\hline Aiken County & 133,760 & 26.81 & 145,800 & 26.35 & 156,590 & 26.22 \\
\hline Allendale County & 12,960 & 2.60 & 14,130 & 2.55 & 15,180 & 2.54 \\
\hline Bamberg County & 18,690 & 3.75 & 20,380 & 3.68 & 21,880 & 3.66 \\
\hline Barnwell County & 22,440 & 4.50 & 24,460 & 4.42 & 26,270 & 4.40 \\
\hline \multicolumn{7}{|l|}{ Georgia } \\
\hline Columbia County & 80,290 & 16.10 & 90,010 & 16.27 & 97,390 & 16.31 \\
\hline Richmond County & 230,700 & 46.25 & 258,610 & 46.73 & 279,820 & 46.86 \\
\hline Six-county total & 498,850 & 100 & 533,390 & 100 & 597,130 & 100 \\
\hline
\end{tabular}

\begin{tabular}{lrrrr}
\hline & \multicolumn{2}{l}{2030} & \multicolumn{2}{l}{2040} \\
\cline { 2 - 5 } Jurisdiction & Population & \% ROI & Population & \% ROI \\
\hline South Carolina & & & & \\
$\quad$ Aiken County & 168,180 & 26.19 & 180,620 & 26.07 \\
$\quad$ Allendale County & 16,300 & 2.54 & 17,510 & 2.53 \\
Bamberg County & 23,500 & 3.66 & 25,240 & 3.64 \\
$\quad$ Barnwell County & 28,220 & 4.39 & 30,310 & 4.37 \\
& & & & \\
Georgia & & & & 16.46 \\
$\quad$ Columbia County & 105,376 & 16.41 & 114,020 & 16.93 \\
$\quad$ Richmond County & 300,526 & 46.80 & 325,170 & 46.9 \\
& & & & \\
Six-county total & 642,098 & 100 & 692,860 & 100 \\
\hline
\end{tabular}

a. DOE $1998 \mathrm{~b}$ 


\subsubsection{Meteorology and Climatology}

\subsubsection{Meteorology}

The southeastern U.S. has a humid, subtropical climate characterized by relatively short, mild winters and long, warm, and humid summers. Summer-like weather typically lasts from May through September, when the area is subject to the persistent presence of the Atlantic subtropical anticyclone (i.e., the 'Bermuda' high). The humid conditions often result in scattered afternoon thunderstorms. Average seasonal rainfall is usually lowest during the fall.

The weather is changeable during the winter as mid-latitude low-pressure systems and fronts migrate through the region. Measurable snowfall is rare. Spring is characterized by a higher frequency of tornadoes and severe thunderstorms than the other seasons. During spring, temperatures are mild and the humidity is relatively low.

\subsubsection{Local Climatology}

Sources of data used to characterize the climatology of the SRS consist of a standard instrument shelter in A Area (temperature, humidity, and rainfall for 1961 to 1994), the Central Climatology Meteorological Facility near N Area (temperature, humidity, and precipitation for 1995-1996), and the H-Area meteorological tower (winds and atmospheric stability).

The average annual temperature at the SRS is $64.7^{\circ} \mathrm{F}$. July is the warmest month of the year with an average daily maximum of $92^{\circ} \mathrm{F}$ and an average daily minimum near $72^{\circ} \mathrm{F}$. January is the coldest month with an average daily high around $56^{\circ} \mathrm{F}$ and an average daily low of $36^{\circ} \mathrm{F}$. Temperature extremes recorded at the SRS since 1961 are $107^{\circ} \mathrm{F}$ in July 1986 and $-3^{\circ} \mathrm{F}$ in January 1985.

Annual precipitation averages 49.5 inches. Summer is the wettest season of the year with an average monthly rainfall of 5.2 inches. Fall is the driest season with an average monthly rainfall of 3.3 inches. Relative humidity averages 70 percent annually with an average daily maximum of 91 percent and an average daily minimum of 45 percent.

Winds are most frequently from the northeast and southwest sectors. Measurements of turbulence are used to determine whether the atmosphere has relatively high, moderate, or low potential to disperse airborne pollutants (commonly identified as unstable, neutral, or stable atmospheric conditions, respectively). Generally, SRS atmospheric conditions were categorized as unstable 56 percent of the time (DOE 1998b).

Meteorological data are critical input to atmospheric transport and dose models that are used to estimate the effects of releases from SRS facilities. The atmospheric transport and dose modeling performed for this PA is based upon a 5-year average meteorological dataset from the period 1987 to 1991 . This is the most recently quality-assured meteorological database for the SRS.

\subsubsection{Severe Weather}

An average of 54 thunderstorm days per year was observed at the National Weather Service (NWS) Augusta, GA, office during the period 1951-1995. About half of the thunderstorms occurred during the summer. Since operations began at the SRS, ten confirmed tornadoes have occurred on or in close proximity to the site. Several of these tornadoes were estimated to have winds up to 150 miles per hour, and did considerable damage to forested areas of the SRS. None caused damage to structures. Tornado 
statistics (Ramsdell and Andrews 1986) indicate that the average frequency of a tornado striking any single point on the site is $7.11 \times 10^{-5}$ per year or about once every 14,000 years.

The highest sustained wind recorded at the Augusta NWS Office is 82 miles per hour. The maximum 100 -year straight-line wind speed for the SRS area has been estimated to be 107 miles per hour. Straightline winds are produced by hurricanes, thunderstorms, and strong winter storms. Hurricanes struck South Carolina 36 times during the period 1700 to 1992, an average recurrence frequency of once every 8 years. A hurricane force wind of 75 miles per hour has been observed at SRS only once, during Hurricane Gracie in 1959.

\subsubsection{Ecology}

\subsubsection{Aquatic Ecology}

Flora in the Savannah River basin and in creeks on the SRS is diverse and seasonally variable. Several species of diatoms, green algae, yellow-green algae, and blue-green algae are present. In seasonally flooded areas, bald cypress and tupelo gum thrive. In less severely flooded areas, oak, maple, ash, sweet gum, ironwood, and other species less tolerant of flooding are found. In the river swamp formed by the Savannah River in the vicinity of the SRS, herbaceous growth is sparse. A number of macrophytes, such as cattail and milfoil, are found in areas receiving sufficient sunlight.

The fish communities in the Savannah River and in creeks on the SRS are very diverse. Redbreast sunfish, spotted sucker, channel catfish, and flat bullhead are the dominant species. Sunfish, crappies, darters, minnows, American shad, and striped bass are also abundant.

Macroinvertebrate communities are largely comprised of true flies, mayflies, caddisflies, stoneflies, and beetles. Leaf litter input is high, but is rapidly broken down by macroinvertebrate shredders. The Asiatic clam is found in the Savannah River and its larger tributary streams.

\subsubsection{Terrestrial Ecology}

Prior to its acquisition by the U. S. Government in 1951, approximately one-third of the SRS was cropland, about half was forested, and the remainder was floodplain and swamp. Since that time, the U. $S$. Forest Service has reclaimed many previously disturbed areas through natural plant succession or by planting pine trees. As was noted in Section 3.1.1.2, 91 percent is now pine or hardwood forests, with the remaining 9 percent divided between SRS facilities and water bodies.

A variety of vascular plants exist on the site. Scrub oak communities cover the drier sandy areas, which include predominantly longleaf pine, turkey oak, bluejack oak, blackjack oak, dwarf post oak, three awngrass, and huckleberry (DOE 1987). On the more fertile, dry uplands, white oak, post oak, southern red oak, mockernut hickory, pignut hickory, and loblolly pine predominate, with an understory of sparkleberry, holly, greenbriar, and poison ivy. Pine trees cover more area than any other tree genus.

The heterogeneity of the vegetation on the SRS supports a diverse wildife population. Several species of reptiles and amphibians are present due to the variety of aquatic and terrestrial habitats. These include snakes, frogs, toads, salamanders, turtles, lizards, and alligators. More than 213 species of birds have been identified on the SRS. Burrowing animals at the SRS include: Peromyscus polionotus, known commonly as the Old Field Mouse; Blarine brevicauda, known as the short tail shrew; Scalopus aquiticus, known as the eastern mole; Pogonomyrmex badius, known as the harvester ant; Dorymyrmex pyramicus, known as the pyramid ant; and earthworms (Briese and Smith 1974; Davenport 1964; Golley and Gentry 1964; Smith 1971; Van Pelt 1966). 


\subsubsection{Geology, Seismology, and Volcanology}

Regional and local information on the geologic and seismic characteristics of the E-Area disposal site are presented in this section. Because the SRS is not located within a region of active plate tectonics characterized by volcanism, volcanology is not an issue of concern in this PA, and thus further discussion of this topic is omitted from the following discussion.

\subsubsection{Geology}

The surface of the Upper Atlantic Coastal Plain on which the SRS is located slopes gently seaward. The province is underlain by a seaward dipping wedge of unconsolidated and semi-consolidated sediments that extends from the Fall Line to the seaward edge of the continental shelf. Sediment thickness increases from zero at the Fall Line, where the crystalline Piedmont province gives way to the Coastal Plain, to more than $1.2 \mathrm{~km}$ near the coast of South Carolina. The SRS is underlain by about 180 to $370 \mathrm{~m}$ of Coastal Plain sediments. These sediments vary in age from Late Cretaceous to Miocene and are divided into several groups based principally on age and lithology. A brief discussion of these groups follows. The presence and approximate thicknesses of the sediments in the vicinity of E Area are also provided. An in-depth treatment of the stratigraphy of the SRS is given in a recent report by the State of South Carolina's Department of Natural Resources (Aadland et al. 1995).

\subsection{Late Cretaceous Sediments}

The Late Cretaceous sediments include, from oldest to youngest, the Cape Fear Formation and the three formations of the Lumbee Group: the Middendorf, Black Creek, and Steel Creek Formations (Fig. 3.1-4). These sediments are approximately $210 \mathrm{~m}$ thick at the center of the SRS, near E Area. The lowermost Cape Fear Formation rests on a thin veneer of saprolitic bedrock, which defines the surface of the crystalline and sedimentary basement rock. This formation is composed of poorly sorted silty-to-clayey quartz sands and interbedded clays. Bedding thicknesses range from 1.5 to $6 \mathrm{~m}$, with sand beds being thicker than clay beds. The formation is about $9 \mathrm{~m}$ thick at the northwestern boundary of the SRS, and it increases to more than $55 \mathrm{~m}$ near the southeastern boundary (WSRC 1992a). This formation has not been observed to outcrop in the vicinity of the SRS.

The thickness of the Lumbee Group, which overlies the Cape Fear Formation, varies across the SRS from $120 \mathrm{~m}$ in the northwest to more than $230 \mathrm{~m}$ near the southeastern boundary (WSRC 1992a). The Middendorf Formation, which directly overlies the Cape Fear Formation, is composed mostly of medium and coarse quartz sand that is cleaner and less indurated than the underlying sediments. Clay casts and pebbly zones occur in several places in the Middendorf Formation. A clay zone up to $24 \mathrm{~m}$ thick forms the top of this formation over much of the SRS. In total, the Middendorf Formation ranges from approximately 40 to $55 \mathrm{~m}$ thick from the northwestern to southeastern boundary of the SRS. Outcrops of this formation have been identified northwest of the SRS.

The Black Creek Formation consists of quartz sands, silts, and clays. The lower section consists of fineto coarse-grained sands with layers of pebbles and clay casts. The upper section changes in composition as it crosses the SRS from northwest to southeast, from massive clay to silty sand with interbeds of clay. Thickness of the Black Creek Formation under the SRS ranges from $34 \mathrm{~m}$ in the northwest to $76 \mathrm{~m}$ in the southeast (WSRC 1992a). Outcropping in the vicinity of the SRS has not been confirmed. 


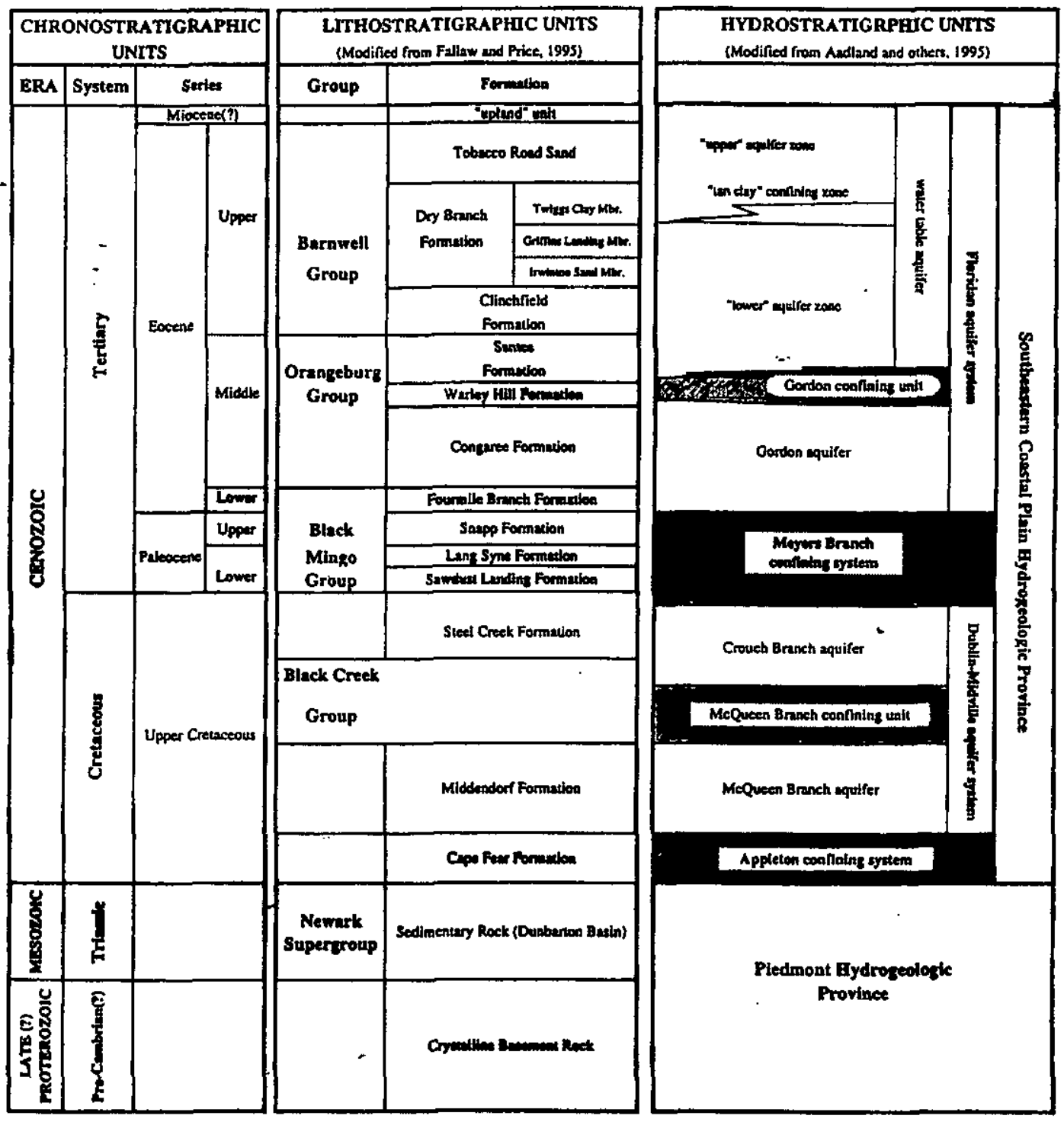

Figure 3.1-4 Comparison of Lithostratigraphic and Hydrostratigraphic Units at the SRS 
The uppermost formation in the Lumbee Group is the Steel Creek Formation (previously referred to as the Peedee Formation), which consists of fine-grained sandstone and siltstone with marine

fossils. This formation is comparable in age, but lithologically distinct, from the Peedee Formation in southwestern South Carolina. The lower portion of this formation consists of fine- to coarse- grained quartz sand and silty sand, with a pebble-rich zone at its base. Pebbly zones and clay casts are common throughout the lower portion of the Steel Creek Formation. The upper portion of this formation is a clay that varies from more than $15 \mathrm{~m}$ to less than $1 \mathrm{~m}$ in thickness at the SRS. The Steel Creek Formation is about $34 \mathrm{~m}$ thick at the northwestern SRS boundary and about $40 \mathrm{~m}$ thick at the southeastern boundary (WSRC 1992a). No nearby outcropping has been identified.

\subsection{Paleocene-Eocene Black Mingo Group}

Paleocene-Early Eocene sediments make up the Black Mingo Group (Fig. 3.1-4). In E Area, this group consists of the Early Paleocene Lang Syne/Sawdust Landing Formations, the Late Paleocene Snapp Formation, and the Early Eocene Fourmile Formation. This group is about $21 \mathrm{~m}$ thick at the northwestern SRS boundary, thickens to about $46 \mathrm{~m}$ near the southeastern boundary, and is about $210 \mathrm{~m}$ thick at the coast (WSRC 1992a).

The Lang Syne/Sawdust Landing Formations together are equivalent to the lithologic unit previously referred to as the Ellenton Formation (Siple 1967). These formations, treated as a single unit due to difficulty in mapping them separately (Aadland et al. 1995), consist mostly of gray, poorly sorted, micaceous, lignitic, silty and clayey quartz sand interbedded with gray clays. They are approximately $12 \mathrm{~m}$ thick at the northwestern boundary of the SRS and thicken to about $30 \mathrm{~m}$ near the southeastern boundary. These formations outcrop about four miles northwest of the SRS.

The deposits near the SRS that are time-equivalent to the Williamsburg Formation differ from the type Williamsburg and are designated as the Snapp Formation. The sediments are typically silty, medium- to coarse-grained quartz sand interbedded with clay. The Snapp Formation pinches out at the northwestern SRS boundary and thickens to about $15 \mathrm{~m}$ near the southeastern boundary. In E Area, the distribution of the Snapp Formation is sporadic, not continuous.

Sand immediately overlying the Snapp Formation is identified as the Fourmile Formation. The wellsorted sand of this formation is an average of $9 \mathrm{~m}$ in thickness. Clay beds near the middle and top of the formation are a few feet thick. In $\mathrm{E}$ Area, this formation may not be continuous.

\subsection{Middle Eocene Orangeburg Group}

The middle Eocene sediments make up the Orangeburg Group, which in E Area consists of the lower middle Eocene Congaree Formation, the upper middle Eocene Warley Hill Formation, and the late middle Eocene Tinker/Santee Limestone Formation (Fig. 3.1-4). The sediments thicken from about $30 \mathrm{~m}$ at the northwestern SRS boundary to about $49 \mathrm{~m}$ near the southeastern boundary (Aadland et al. 1995). The dip of the upper surface of this formation is about $.002 \mathrm{~m} / \mathrm{m}$ to the southeast across the site. The Orangeburg Group is about $100 \mathrm{~m}$ thick at the coast. The group outcrops at lower elevations in many places near and on the SRS.

The Congaree Formation consists of fine to coarse, well-sorted and rounded quartz sands. Thin clay laminae occur throughout, as do small pebble zones. The sand is glauconitic in places. The formation is about $26 \mathrm{~m}$ thick at the center of the SRS (Smits et al. 1997). 
The Warley Hill Formation, made up of glauconitic sand and green clay beds and thus previously referred to as the "green clay," overlies the Congaree Formation. This formation is generally 3 to $6 \mathrm{~m}$ in thickness. However, northwest of E Area, the Warley Hill Formation is missing or very thin, such that the overlying Tinker/Santee Formation rests unconformably on the Congaree Formation.

The Tinker/Santee Formation consists of calcilutite, calcarenite, shelly limestone, calcareous sands and clays, and micritic limestone. The sands are glauconitic in places and fine- to medium-grained. The sediments comprising this formation have been referred to in the past as the Santee Limestone, McBean, and Lisbon Formations and indicate deposition in shallow marine environments. The Tinker/Santee Formation is about 12 to $15 \mathrm{~m}$ thick in the center of E Area (Smits et al. 1997). In places where the Warley Hill Formation is absent, the Tinker/Santee Formation rests directly on the Congaree Formation.

\subsection{Late Eocene Barnwell Group}

The Late Eocene sediments make up the Barnwell Group, which consists of the Clinchfield, Dry Branch, and Tobacco Road Sand (Fig. 3.1-4). The Clinchfield Formation, the oldest of the three, is made up of quartz sand, limestone, calcareous sand, and clay. It is generally identified only when the contrasting carbonates of the overlying Dry Branch and underlying Tinker/Santee Formations are present, with the sand of the Clinchfield Formation sandwiched between them. It has been identified at several areas within the SRS, where it is up to $8 \mathrm{~m}$ thick, but is indistinguishable in the central regions of the SRS, near E Area.

The Dry Branch Formation consists of three distinguishable members: the Twiggs Clay Member, the Griffins Landing Member, and the Irwinton Sand Member. The Twiggs Clay Member is not mapable as a continuous unit within the SRS, but lithologically similar clay is present at various levels within this formation. The tan, light gray, and brown clay of the Twiggs Clay Member has previously been referred to as the "tan clay" at the SRS. The Griffins Landing Member is up to $15 \mathrm{~m}$ thick in the southeastern part of the SRS. This member consists mostly of calcilutite and calcarenite, calcareous quartz sand, and slightly calcareous clay. It occurs sporadically and pinches out in the center of the SRS. The remainder of the Dry Branch Formation within the SRS is made up of the Irwinton Sand Member, which is composed of moderately sorted quartz sand, with interlaminated clays abundant in places. Clay beds of this member have also been referred to as the "tan clay" at the SRS. The Irwinton Sand is about $12 \mathrm{~m}$ thick at the northwestern SRS boundary and thickens to $21 \mathrm{~m}$ near the southeastern boundary. It outcrops in many places around and within the SRS.

The Tobacco Road Sand overlies the Dry Branch Formation. This formation consists of moderately to poorly sorted quartz sands, interspersed with pebble layers and clay laminae. The sediments have the characteristics of a shallow marine deposit. The upper surface of this formation is irregular due to an incision that accompanied deposition of the overlying "Upland Unit" and later erosion. The thickness is variable as a result of erosive processes, but is at least $15 \mathrm{~m}$ in places (WSRC 1992a).

\subsubsection{5 "Upland Unit"}

The "Upland Unit" is an informal stratigraphic term applied to terrestrial deposits that occur at higher elevations in some places in the southwestern South Carolina Coastal Plain (Fig. 3.1-4). This unit overlies the Barnwell Group in the Upper Coastal Plain of western South Carolina, on which the SRS is located. This unit occurs at the surface at higher elevations in many places around and within the SRS, but it is not present at all higher elevations. The sediments are poorly sorted, clayey-to-silty sands, with lenses and layers of conglomerates, pebbly sands, and clays. Clay casts are abundant. The "Upland Unit" is up to $21 \mathrm{~m}$ thick in parts of the SRS. Much of this unit corresponds to the Hawthorne Formation and the Tertiary alluvial gravels identified in previous documents (INTERA 1986). 


\subsection{Soils}

Most of the soils at the SRS are sandy over a loamy or clayey subsoil. The distribution of soil types is very much influenced by the creeks on the site, with colluvial deposits on hill-tops and hillsides giving way to alluvium in valley bottoms (Dennehy et al. 1989). Road cuts and excavations on interstream areas near the SRS commonly expose a deeply developed soil profile. Two horizons are apparent. The A horizon may be up to $3 \mathrm{~m}$ thick and typically consists of structureless fine- to medium-grained quartz sand, and the lower B horizon, which may be from 0.6 to $3 \mathrm{~m}$ in thickness, contains iron and aluminum compounds leached from the overlying material.

Weathering effects are evident. In some areas, intense weathering has produced tensional soil fractures as a result of volume reduction. These fractures are dominant features in shallow exposures such as drainage ditches or roadside embankments. Average soil erosion rates for the area surrounding the SRS, much of which is cropland, range from 1.5 to $2.0 \mathrm{~kg} / \mathrm{m}^{2} / \mathrm{yr}^{1}$ (USDA 1985). Employing the Universal Soil Loss Equation to predict erosion at the SRS under different vegetative conditions, Horton and Wilhite (1978) estimate that the presence of natural successional forests would reduce erosion by a factor of 400 to 500 over cropland erosion.

\subsubsection{Seismology}

The susceptibility of the SRS, and particularly E Area, to seismic motion is of interest to establish if E Area is suitable for waste disposal. Seismic events could result in cracking of the encapsulating material. Cracking could be fairly severe if liquefaction of supporting soils were to take place. However, liquefaction of supporting soils is not considered to be a potential problem at the SRS based on a review of previous studies at the SRS (URS/Blume 1982). Below is a discussion of seismic zones that are known to exist in the vicinity of the SRS and the expected intensity associated with seismic activity in these zones at the SRS.

\subsection{Location of Nearby Seismic Zones}

The SRS is located in the interior of the North American plate. In the past 200 years, the nearest zones of concentrated seismic activity in the region have been centered in the Charleston-Summerville area of South Carolina and near Bowman, SC, which is $60 \mathrm{~km}$ northwest of Summerville, SC (Fig. 3.1-5). Recent seismic activity in the Charleston area, probably including the earthquake of 1886, has originated largely or entirely in the basement beneath the Coastal Plain sediments. The seismicity in the Charleston area is believed to occur at the intersection of the Ashley River fault and the Woodstock fault, at minimum depths of $4 \mathrm{~km}$ and $8 \mathrm{~km}$, respectively. Seismicity associated with the Bowman seismic zone occurs along a border fault of a buried Triassic basin, extending to a depth of about $6 \mathrm{~km}$ (WSRC 1992a).

Underlying the Coastal Plain sediments of the central and southern portions of the SRS is a TriassicJurassic rift basin within the crystalline basement. This basin, called the Dunbarton Triassic basin, is located in the Aiken Plateau, about $50 \mathrm{~km}$ southeast of the Fall Line (Fig. 3.1-5). Associated with this basin on the SRS are at least two faults; the northern border fault and a parallel fault, the Pen Branch fault, which may coincide with the border fault. These faults do not extend upward into post-Oligocene sediments at the SRS.

Faulting has also been recognized in sediments as young as Oligocene in the Atlantic Coastal Plain sediments of South Carolina. Faulting has been postulated to occur in these sediments based on structure-contour mapping of the Eocene-Oligocene unconformity, which lies between 30 and $61 \mathrm{~m}$ below the surface, in the vicinity of Charleston, and about $100 \mathrm{~km}$ from the SRS. A shallow fault, 


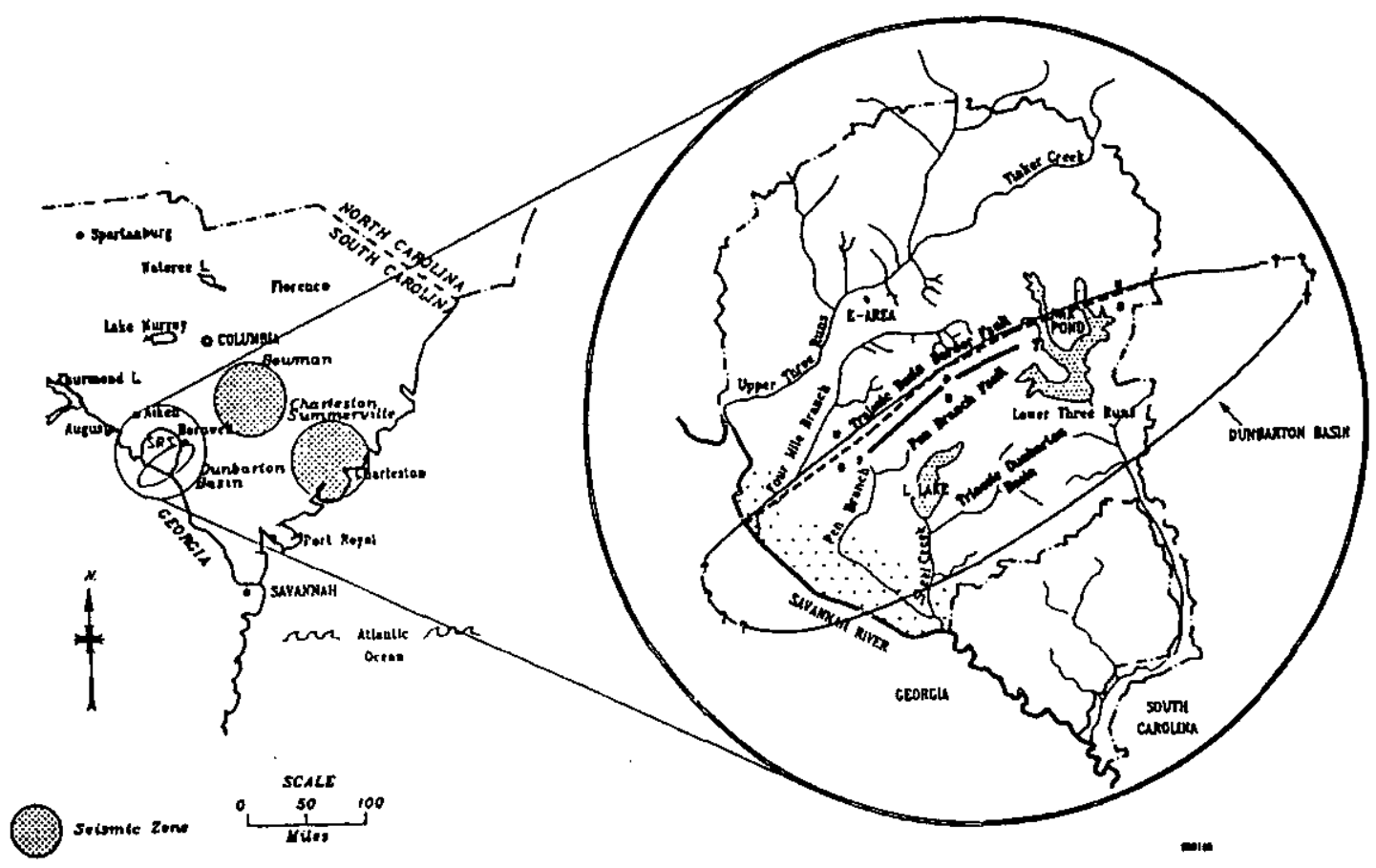

Figure 3.1-5 Seismic Zones in the Vicinity of the SRS 
associated with a 16-km wide graben of Oligocene and Miocene rocks which crosses beneath the Savannah River from Georgia into South Carolina, is postulated about $56 \mathrm{~km}$ southeast of the SRS. It is not currently possible to relate these shallow faults to modern earthquakes that occur at depths greater than about $2 \mathrm{~km}$.

\subsection{Intensities of Historical Earthquakes}

The largest known earthquake to affect the site region was the Charleston earthquake of 1886 . This Modified Mercalli Intensity (MMI) X earthquake struck Charleston SC, on August 31, 1886 . The greatest intensity felt at the SRS has been estimated at MMI VI-VII (felt by all; everyone runs outdoors; damage negligible in buildings of good structure, but considerable in poorly built structures) as a result of the Charleston earthquake (WSRC 1992a). Minor tremors from aftershocks of the 1886 Charleston event were also felt in the area where the SRS is now located. Intensities of these tremors were estimated to be equal to or less than MMI IV.

Seismic activity producing earthquakes of estimated MMI up to V to VII has been present in the Bowman area (about $95 \mathrm{~km}$ northeast of SRS) over the last 200 years (WSRC 1992a). These earthquakes produced acceleration at the SRS of less than 0.1 times the earth's gravitational acceleration (Stephenson 1993). An earthquake (MMI VIII) that struck Union County, SC, about $160 \mathrm{~km}$ north-northeast of the SRS in 1913 was felt at Aiken (6 km north-northwest of SRS) with an MMI of II-III (vibration indoors like a passing truck).

Two earthquakes of MMI III or less have occurred with epicentral locations within the boundaries of the SRS (Stephenson et al. 1985; Stephenson 1988). An MMI III earthquake occurred in June 1985 at the SRS, as did an MMI I-II earthquake in August 1988. Neither of the earthquakes triggered the seismic alarms at the SRS facilities, which are triggered when ground accelerations equal or exceed .002 times the earth's gravitational acceleration. The epicenters of these earthquakes appear to be located within about six miles of the intersection of a northwest-trending fault and the northeast-trending border fault at the northern edge of the Dunbarton Triassic basin and are relatively shallow (1 to $3 \mathrm{~km}$ below the earth's surface).

\subsection{Projected Recurrence of Earthquakes}

According to Bollinger et al. (1989), the recurrence interval for a Charleston-size shock (MMI X) for the Charleston area and for the Coastal Plain is on the order of 1,000 years, at the 95 percent confidence level. A recurrence of the 1886 Charleston earthquake would result in an intensity of MMI VII at the SRS (URS/Blume 1982). Recurrence of earthquakes associated with other known seismic zones in the region are not expected to be of greater intensity nor cause greater shaking at the SRS (WSRC 1992a).

\subsubsection{Hydrology}

\subsubsection{Surface Water}

The Savannah River cuts a broad valley approximately $76 \mathrm{~m}$ deep through the Aiken Plateau, on which most of the SRS sits. The Savannah River Swamp lies in the floodplain along the Savannah River and averages about $2.4 \mathrm{~km}$ wide. Upper Three Runs, Fourmile Branch, Tinker Creek, Pen Branch, Steel Creek, and Lower Three Runs (Fig. 3.1-2) are the major tributaries of the Savannah River that occur on the SRS. Three breaches of the natural levee occur at the confluences of the Savannah River with Beaver Dam Creek, Fourmile Branch, and Steel Creek, allowing discharge of these streams to the river. During swamp flooding, water from Beaver Dam Creek and Fourmile Branch flows through the swamp that 
parallels the river and combines with the Pen Branch flow. Pen Branch joins Steel Creek about $0.8 \mathrm{~km}$ above its mouth.

Surface water is held in artificial impoundments and natural wetlands on the Aiken Plateau. Par Pond, the largest impoundment on the SRS, is located in the eastern part of the SRS, covering about $11 \mathrm{~km}^{2}$. A second impoundment, L Lake, lies in the southern portion of SRS and covers approximately $4 \mathrm{~km}^{2}$. The waters drain from Par Pond and L Lake to the south via Lower Three Runs and Steel Creek, respectively, into the Savannah River. Lowland and upland marshes and natural and man-made basins on the SRS retain water intermittently.

Near the SRS, the flow of the Savannah River has been stabilized by the construction of upstream reservoirs. The yearly average flow is approximately $300 \mathrm{~m}^{3} / \mathrm{s}(10,400 \mathrm{cfs})$ at the point where Highway 301 crosses the river (approximately $20 \mathrm{~km}$ downstream of the site; Hayes and Marter 1991). Based on data collected from 1954 to 1988 , the minimum average annual flow rate at this location was $150 \mathrm{~m}^{3} / \mathrm{s}$ $(5,200 \mathrm{cfs})$ in 1988 . From the SRS, river water usually reaches the coast in five to six days but may take as few as three days. At the Beaufort-Jasper water treatment plant, approximately $160 \mathrm{~km}$ downstream of the site, the average annual flow rate is estimated to be approximately $450 \mathrm{~m}^{3} / \mathrm{s}(15,800 \mathrm{cfs})$.

The watershed of Upper Three Runs drains about $500 \mathrm{~km}^{2}$ of the Upper Coastal Plain northeast of the Savannah River. Significant tributaries to this creek are Tinker Creek, which is a headwaters branch that comes in northeast of E Area, and Tims Branch, which connects up west of E Area (Fig. 3.1-2). There are no lakes or flow control structures on Upper Three Runs or its tributaries. The stream channel has a low gradient and is meandering. Its floodplain ranges in width from 0.4 to $1.6 \mathrm{~km}$ and is heavily forested with hardwoods.

Upper Three Runs is gauged by the U. S. Geological Survey (USGS 1997a) about $14 \mathrm{~km}$ above the confluence with the Savannah River, just above Road C. This location is of interest in this analysis because it is just west of $\mathrm{E}$ Area and thus is a point through which radionuclides potentially discharged to Upper Three Runs and tributaries in E Area would pass. The average annual flow at this location, as measured by the USGS (USGS 1997a) between 1989 and 1992, was approximately $6.2 \mathrm{~m}^{3} / \mathrm{s}(220 \mathrm{cfs})$. During the driest of the four years of measurement, the average flow was $4.8 \mathrm{~m}^{3} / \mathrm{s}(170 \mathrm{cfs})$. These flow rates reflect contributions of upstream tributaries, including McQueen Branch and others that receive groundwater discharges from E Area. All of the major streams at SRS, including Upper Three Runs and Fourmile Branch, receive groundwater discharge and are gaining streams.

Fourmile Branch has been gauged in the vicinity of E Area (USGS 1997b), approximately $10 \mathrm{~km}$ from its confluence with the Savannah River. Data were collected at this gauging station for approximately four years (1985 through 1988). These data indicate an average annual flow of $0.40 \mathrm{~m}^{3} / \mathrm{s}(14 \mathrm{cfs})$ at this location. A minimum annual flow rate during the gauging period of approximately $0.34 \mathrm{~m}^{3} / \mathrm{s}(12 \mathrm{cfs})$ was measured in 1988.

\subsubsection{Groundwater}

A discussion of groundwater hydrology must consider all the aquifers and confining units that affect the subsurface distribution of contaminants potentially released from the E-Area LLWF. In this report, the discussion of groundwater hydrology is restricted to hydrostratigraphic units above the Meyers Branch confining system because units below that system are considered protected from contamination. Justification for this assumption is given in the subsection entitled "Meyers Branch Confining System" below. 
The nomenclature used in this report to identify hydrostratigraphic units is consistent with Aadland et al. (1995). Two different alphanumeric systems of hydrostratigraphic nomenclature were utilized in the Zand original E-Area Performance Assessments. These systems are listed in Table 3.1-3, along with the present nomenclature. The "common" names listed in this table are names that have historically been used for the hydrostratigraphic units and that are utilized in many older documents on this subject. These units, and their hydrologic properties, are defined and described below.

Potentiometric surfaces and particle tracking data provided in the discussion of flow modeling (Section 4.3.3) support this interpretation of E-Area hydrology.

\subsection{Meyers Branch Confining System}

The Meyers Branch confining system overlies the Dublin and Dublin-Midville aquifer systems (Fig. 3.14). Sediments of this Late Cretaceous-Paleocene system correspond to the lignitic clays and interbedded sands of the upper Steel Creek Formation and the laminated clays and shale of the Lang Syne/Sawdust Landing and Snapp Formations. At the SRS, the Meyers Branch system consists of a single hydrostratigraphic unit, the Crouch Branch confining unit, which includes several thick and relatively continuous (over several miles) clay beds. East of E Area, the Meyers Branch confining system is $41 \mathrm{~m}$ thick, $21 \mathrm{~m}$ of which is clay beds. The Crouch Branch confining unit constitutes the Meyers Branch confining system over much of the SRS, ranging in thickness from $17 \mathrm{~m}$ to $56 \mathrm{~m}$. The updip limit of the Meyers Branch confining system, where the system is no longer a regional confining system, occurs north of the intersection of McQueen Branch and Upper Three Runs streams and runs approximately east to west. North of the updip limit, the Crouch Branch confining unit continues and is considered part of the Floridan-Midville aquifer system (in which all aquifer units above and including the McQueen Branch aquifer are considered layered parts of one aquifer system).

Table 3.1-3 Hydrostratigraphic Nomenclature

\begin{tabular}{|c|c|c|c|}
\hline $\begin{array}{l}\text { Nomenclature of Aadland et } \\
\text { al. } 1995 \\
\end{array}$ & E-Area Nomenclature & $\begin{array}{c}\text { Z-Area } \\
\text { Nomenclature }\end{array}$ & $\begin{array}{c}\text { Common } \\
\text { Nomenclature }\end{array}$ \\
\hline Floridan Aquifer System & Aquifer System II & & \\
\hline \multicolumn{4}{|l|}{ Upper Three Runs aquifer } \\
\hline "upper" zone & Aquifer unit IIB, zone 2 & Zone $7 \mathrm{c} / 8$ & Water table unit \\
\hline "tan clay" zone & Confining unit IIB $\mathrm{II}_{1}-\mathrm{IIB}_{2}$ & Zone $7 b$ & Tan clay \\
\hline "lower" zone & Aquifer unit IIB, zone 1 & Zone 6/7a & Barnwell/McBean \\
\hline Gordon confining unit & Confining unit IIA-IIB & Zone $5 b$ & Green clay \\
\hline Gordon aquifer & Aquifer unit IIA & Zone $5 \mathrm{a}$ & Congaree \\
\hline $\begin{array}{l}\text { Meyers Branch Confining } \\
\text { System }\end{array}$ & Confining System I-II & Zone 4 & Ellenton clays \\
\hline
\end{tabular}


Areas of the SRS which are adjacent to the Savannah River flood plain and the Upper Three Runs drainage systems, including E-Area, exhibit an "upward" gradient across the Crouch Branch confining unit (Fig. 3.1-4). Hydraulic heads in the underlying Crouch Branch aquifer are higher than those in the overlying Gordon aquifer in these areas, due to the incisement of the overlying aquifer by these two river systems. This area of upward gradient encompasses all of E Area. The magnitude of the upward gradient is about 5 meters in the vicinity of E-Area, but the low transmissivity of the Meyers Branch Confining System results in a low water flux into the Gordon Aquifer. Thus, in E Area, the confining nature of the Crouch Branch confining unit along with the head-reversal phenomenon, provides a natural protection of aquifers beneath the Floridan aquifer system from contamination.

\subsection{Floridan Aquifer System}

Because of relative hydrologic isolation due to the Meyers Branch confining system, only the Floridan aquifer system is of interest in the performance assessment and special analysis of potential groundwater contamination from operations at E Area. The Floridan aquifer system is comprised of the lowermost Gordon aquifer unit, the Gordon confining unit, and the uppermost Upper Three Runs aquifer unit, which contains the water table.

Gordon Aquifer Unit. The Gordon aquifer unit overlies the Crouch Branch confining system and is approximately $23 \mathrm{~m}$ thick at E Area. The aquifer consists of sandy parts of the Late Paleocene-Early Eocene Snapp, Fourmile, and Congaree Formations. Sands and clayey sands of the Gordon aquifer unit are largely yellow to orange in color and consist of fine- to coarse-grained, subangular to subrounded quartz. The sands range from well to poorly sorted. Locally-confining clay beds are present, as are pebbly zones. The unit dips at 1.5 to $1.7 \mathrm{~m} / \mathrm{km}$ to the south and southeast and thickens in the western portion of E Area and to a minor extent to the southeast (WSRC 1992a).

The hydraulic gradient in the Gordon aquifer across the SRS is generally from northeast to southwest, averaging $0.9 \mathrm{~m} / \mathrm{km}$, towards the Savannah River. However, the potentiometric surface (Aadland et al. 1995) indicates considerable deflection of the contours due to incisement of aquifer sediments by Upper Three Runs, such that flow from E Area is westerly. Potentiometric surfaces demonstrating this trend are provided in Section 4.3.3 of this report. Based on measurements and modeling (Aadland et al. 1995), an average horizontal hydraulic conductivity of $1 \times 10^{-2} \mathrm{~m} / \mathrm{s}$ is reported for this unit.

Gordon Confining Unit. The Gordon confining unit separates the underlying Gordon aquifer unit from the Upper Three Runs aquifer unit. This confining unit is informally known as the "green clay." It is comprised of the fine-grained glauconitic sand and clay beds of the Middle Eocene Warley Hill Formation and the micritic limestone of the Tinker/Santee Formation. Thickness of the Gordon confining unit in the vicinity of the SRS varies from 1.5 to $25 \mathrm{~m}$. In the vicinity of $\mathrm{E}$ Area, it is from 0.6 to $9 \mathrm{~m}$ thick. Recent studies indicate the unit is composed of several lenses of green and gray clay that thicken, thin, and pinch out abruptly. Extensive carbonate sediments associated with areas of thin or truncated clay beds are present in E Area.

Leakance coefficients, estimated from modeling and pump tests, indicate an updip limit of the Gordon confining unit at the SRS that runs southwest to northeast along Upper Three Runs and Tinker Creek. Southeast of this limit, leakances are relatively low except in areas associated with extensive faulting. Laboratory- and model-derived vertical hydraulic conductivities in E Area are on the order of $5 \times 10^{-10}$ $\mathrm{m} / \mathrm{s}$ (Aadland et al. 1995), suggesting that the Gordon confining unit is an effective aquitard in this region. Horizontal hydraulic conductivities ranging from $1.4 \times 10^{-10}$ to $1.6 \times 10^{-9} \mathrm{~m} / \mathrm{s}$ have been determined from laboratory tests. A map of hydraulic head differences across the Gordon confining unit (Aadland et al. 1995) shows an downward gradient in the vicinity of Upper Three Runs and the Savannah River. 
Upper Three Runs Aquifer Unit. The Upper Three Runs aquifer unit overlies the Gordon confining unit and is the water table unit. This unit includes the sandy sediments of the Tinker/Santee Formation and all the heterogeneous sediments in the Late Eocene Barnwell Group. In the center of the SRS, the aquifer unit is $40 \mathrm{~m}$ thick. In $\mathrm{E}$ Area, the aquifer unit is divided into three hydrostratigraphic zones with respect to hydraulic properties (Aadland et al. 1995): a "lower" zone, a "tan clay" locally-confining zone, and an "upper" aquifer zone (the water table zone).

In E Area, the "lower" aquifer zone occurs between the overlying "tan clay" confining zone and the Gordon confining unit. It consists of sand, clayey sand, and calcareous sand of the Tinker/Santee Formation and of the lower part of the Dry Branch Formation. Groundwater that leaks across the "tan clay" confining zone recharges this zone. Most of the recharge water moves laterally toward the bounding streams that incise this zone; the remainder flows vertically downward across the Gordon confining unit. Hydraulic conductivity of the "lower" zone has been estimated for the E-Area vicinity by several methods: slug tests, pumping tests, minipermeameter test, and sieve analyses. Average values for the various methods range from $3 \times 10^{-6} \mathrm{~m} / \mathrm{s}$ to $6 \times 10^{-4} \mathrm{~m} / \mathrm{s}$. The lower values are based on pumping tests, and the higher values are based on sieve analyses. The large discrepancy between the two methods suggests that large-scale heterogeneities, not sample-in-sieve-analysis techniques, are important in determining conductivity.

The "tan clay" confining zone is a leaky confining zone, ranging in thickness from 0 to $10 \mathrm{~m}$ throughout the E-Area vicinity. The average thickness is about $3 \mathrm{~m}$. The clay beds of this confining zone, when present, generally support a head difference (up to $5 \mathrm{~m}$ ) in E Area between the "upper" and "lower" aquifer zones of the Upper Three Runs aquifer unit and thus retard the movement of water downward across this zone. Laboratory analyses of undisturbed samples of the "tan clay" confining zone yielded a range of hydraulic conductivities from $6 \times 10^{-11}$ to $5 \times 10^{-7} \mathrm{~m} / \mathrm{s}$ in the horizontal direction and $1 \times 10^{-11}$ to $4 \times 10^{-7} \mathrm{~m} / \mathrm{s}$ in the vertical direction (Aadland et al. 1995).

In E Area, the "upper" aquifer zone consists of the silty sands of the Irwinton Sand Member of the Dry Branch Formation overlain by the clayey sands of the Tobacco Road Formation. The water table occurs in the "upper" zone. This zone overlies the "tan clay" confining zone, when present, or the "lower" aquifer zone when the confining zone is absent. Units below the "upper" aquifer zone is always saturated, so the "upper" aquifer is not a perched system. Slug tests, minipermeameter tests, pumping tests, and sieve analyses have been used to estimate hydraulic conductivity of the "upper" zone in the vicinity of E Area (Aadland et al. 1995). The average hydraulic conductivity estimates for the "upper" aquifer zone ranged from $2 \times 10^{-6}$ to $5 \times 10^{-4} \mathrm{~m} / \mathrm{s}$ for the various methods.

Three streams on site, Upper Three Runs to the north of E Area, McQueen Branch (a tributary of Upper Three Runs) to the northeast, and Fourmile Branch to the south, are natural boundaries to groundwater flow in the Upper Three Runs aquifer unit. All creeks cut into this, and thus groundwater is either intercepted by the creeks or recharges the underlying Gordon aquifer unit. A groundwater divide occurs in this water table unit due to the influence of these streams. Figure 3.1-6 is a cross section through the General Separations Area illustrating the flow directions through the various aquifer and aquitard units.

\subsection{Hydrologic Characteristics of the Vadose Zone}

The vadose zone extends from the ground surface downward to the water table. Hydraulic characteristics of unsaturated soil in E Area were most recently investigated by Core Laboratories, Inc., in Carollton, Texas (Yu et al. 1993). Capillary pressure vs. water saturation relationships and relative permeability vs. 


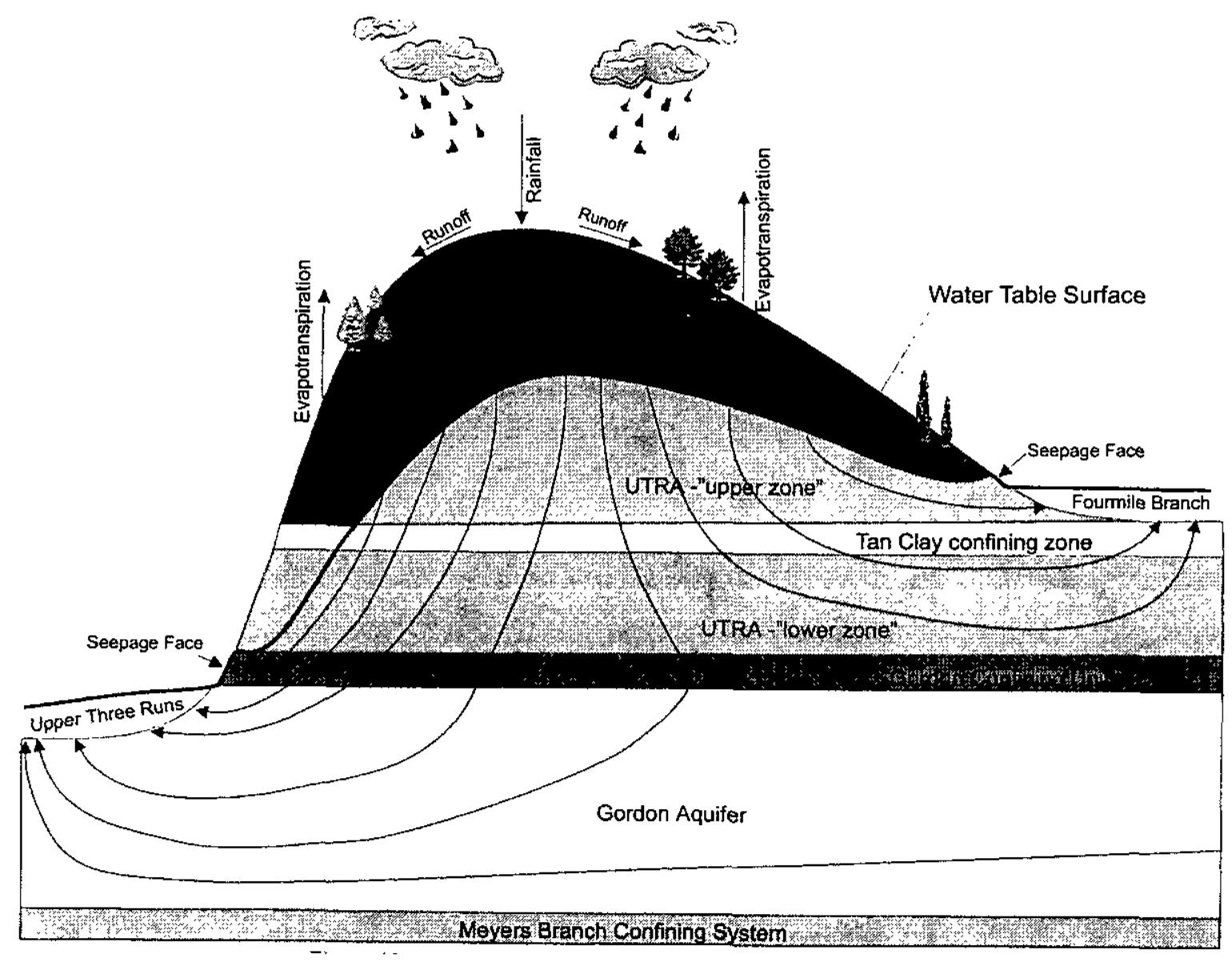

Figure 3.1-6 Illustration of Flow Directions in General Separations Area 
water saturation relationships were developed for field samples of topsoil, gravel, two clays, sand, and backfill to provide a range of analyses for various vadose zone materials found, or planned for use, in the E-Area LLWF. Saturated hydraulic conductivity of topsoils were measured to be on the order of $10^{-5} \mathrm{~m} / \mathrm{s}$, with porosity on the order of 0.40 . Saturated hydraulic conductivity of gravels and clays were measured to be on the order of $10^{-1}$ and $10^{-8} \mathrm{~m} / \mathrm{s}$, respectively, with respective porosities of 0.38 and 0.56 .

\subsubsection{Geochemistry}

Geochemical aspects of the disposal site are not evaluated nor used directly in assessing radionuclide migration. Rather, site-specific sorption coefficients, which are affected by $\mathrm{pH}$ and other geochemical conditions, are used when available. Geochemical modeling conducted for the E-Area Performance Assessment (Appendix E) is restricted to the vault environment and thus is not pertinent to the present discussion of disposal site characteristics.

\subsubsection{Natural Resources}

\subsubsection{Geologic Resources}

The only material of significance as a geologic resource in the vicinity of the SRS is kaolin clay. About 90 percent of the U. S. production of kaolin at one time came from a district in Georgia and South Carolina that includes Aiken County. Commercial deposits occur as lenses in the Lang Syne Formation along the Fall Line bordering the northwestern edge of the Coastal Plain (Bates 1969).

At $\mathrm{E}$ Area, the Lang Syne Formation is at a depth greater than $100 \mathrm{~m}$ from the ground surface, making commercial exploration unlikely due to the large amount of overburden that would have to be removed to exploit a deposit.

\subsubsection{Water Resources}

The South Carolina Department of Health and Environmental Control (SCDHEC) has been delegated authority by the EPA to implement and enforce the requirements of the Clean Water Act for the State of South Carolina. SCDHEC therefore is responsible for maintaining the chemical and biological integrity of all state waters, including those on federal reservations such as SRS. It does this by enforcing a system of water quality standards and by regulating all point-source discharges through the National Pollutant Discharge Elimination System (NPDES) program. SCDHEC is the principal regulatory authority for water quality issues on the SRS.

\subsection{Surface Water}

The Savannah River is the principal surface water system associated with the SRS. Five of its major tributaries (Upper Three Runs, Fourmile Branch, Pen Branch, Steel Creek, and Lower Three Runs) flow through and drain the SRS (Fig. 3.1-2). Mean annual flow at river mile 187.4, approximately 12 miles south of Augusta, GA, during the period 1984 to 1996 was 16,580 cubic feet per second (USGS 1997c). The Savannah River serves as a domestic and industrial water source for the SRS and several downstream communities (the cities of Port Wentworth and Savannah in Georgia and Beaufort and Jasper counties in South Carolina). The intakes for these downstream water systems are located at river miles 29 and 39.2, respectively. In addition, the Vogtle Electric Generating Plant, located across the river from the SRS, uses the Savannah River for cooling water, withdrawing an average of $46 \mathrm{cfs}$. Table 3.1-4 characterizes Savannah River water quality both up- and downstream of the SRS. Table 3.1-5 characterizes water quality in SRS streams. 
Table 3.1-4 Water Quality in the Savannah River Upstream and Downstream from SRS (Calendar Year 1996) $)^{2, b}$

\begin{tabular}{|c|c|c|c|c|c|c|}
\hline \multirow[b]{2}{*}{ Parameter } & \multirow{2}{*}{$\begin{array}{l}\text { Unit of } \\
\text { measure }^{c}\end{array}$} & \multirow{2}{*}{$\begin{array}{l}\mathrm{MCL}^{\mathrm{d}, e} \text { or } \\
\mathrm{DCG}^{\mathrm{f}}\end{array}$} & \multicolumn{2}{|c|}{ Upstream } & \multicolumn{2}{|c|}{ Downstream } \\
\hline & & & Minimum & Maximum $^{\mathrm{g}}$ & Minimum & Maximum \\
\hline Aluminum & $\mathrm{mg} / \mathrm{L}$ & $0.05-0.2^{\mathrm{b}}$ & 0.15 & 0.71 & 0.16 & 79 \\
\hline Ammonia & $\mathrm{mg} / \mathrm{L}$ & $N A^{i j}$ & ND & 0.27 & ND & 0.33 \\
\hline Cadmium & $\mathrm{mg} / \mathrm{L}$ & $0.005^{d}$ & $\mathrm{ND}^{\mathrm{k}}$ & ND & ND & ND \\
\hline Chemical oxygen demand & $\mathrm{mg} / \mathrm{L}$ & NA & ND & 22 & ND & 20 \\
\hline Chloride & $\mathrm{mg} / \mathrm{L}$ & $250^{\mathrm{h}}$ & 4 & 9 & 4 & 9 \\
\hline Chromium & $\mathrm{mg} / \mathrm{L}$ & $0.1^{\mathrm{d}}$ & ND & $\mathrm{ND}$ & ND & 0.011 \\
\hline Copper & $\mathrm{mg} / \mathrm{L}$ & $1.3^{1}$ & ND & ND & ND & ND \\
\hline Dissolved oxygen & $\mathrm{mg} / \mathrm{L}$ & $>5.0^{\mathrm{m}}$ & 6.4 & 11.5 & 6.2 & 13 \\
\hline Fecal coliform & colonies/.1L & $1,000^{\mathrm{m}}$ & $\mathrm{Nr}^{\mathrm{n}}$ & 300 & $\mathrm{Nr}^{\mathrm{n}}$ & 1,100 \\
\hline Gross alpha radioactivity & $\mathrm{pCi} / \mathrm{L}$ & $15^{\mathrm{d}}$ & $<0.62^{\circ}$ & 0.75 & $<0.62^{\circ}$ & 0.97 \\
\hline Lead & $\mathrm{mg} / \mathrm{L}$ & $0.015^{1}$ & ND & ND & ND & ND \\
\hline Mercury & $\mathrm{mg} / \mathrm{L}$ & $0.002^{\mathrm{d}, e}$ & ND & 0.0005 & ND & 0.0003 \\
\hline Nickel & $\mathrm{mg} / \mathrm{L}$ & $0.1^{\mathrm{d}}$ & ND & ND & ND & ND \\
\hline Nitrite/nitrate (as N) & $\mathrm{mg} / \mathrm{L}$ & $10^{d}$ & 0.24 & 0.47 & 0.24 & 0.51 \\
\hline $\begin{array}{l}\text { Nonvolatile (dissolved) } \\
\text { beta radioactivity }\end{array}$ & $\mathrm{pCi} / \mathrm{L}$ & $50^{\mathrm{d}}$ & $<1.6$ & 3.6 & $<1.6$ & 2.8 \\
\hline $\mathrm{pH}$ & $\mathrm{pH}$ units & $6.5-8.5^{\mathrm{h}}$ & 5.8 & 6.8 & 5.5 & 7 \\
\hline Phosphate & $\mathrm{mg} / \mathrm{L}$ & $\mathrm{NA}$ & ND & ND & ND & ND \\
\hline Sulfate & $\mathrm{mg} / \mathrm{L}$ & $250^{\mathrm{h}}$ & 4 & 9 & 5 & 10 \\
\hline Suspended solids & $\mathrm{mg} / \mathrm{L}$ & NA & 6 & 36 & 8 & 23 \\
\hline Temperature & ${ }^{\circ} \mathrm{F}$ & $90^{p}$ & 44 & 76 & 42 & 78 \\
\hline Total dissolved solids & $m g / L$ & $500^{\mathrm{h}}$ & 51 & 72 & 58 & 76 \\
\hline Tritium & $\mathrm{pCi} / \mathrm{L}$ & $20,000^{\mathrm{d}, \mathrm{e}}$ & $<410$ & 450 & 520 & 2,200 \\
\hline Zinc & $\mathrm{mg} / \mathrm{L}$ & $5^{\mathrm{h}}$ & ND & 0.029 & ND & 0.046 \\
\hline
\end{tabular}

a. Source: Arnett and Mamatey (1997).

b. Parameters are those DOE routinely measures as a regulatory requirement or as part of ongoing monitoring programs.

c. $\mathrm{mg} / \mathrm{L}=$ milligrams per liter; a measure of concentration equivalent to the weight/volume ratio. $\mathrm{pCi} / \mathrm{L}=$ picocuries per liter; a picocurie is a unit of radioactivity; one trillionth of a curie.

d. Maximum Contaminant Level (MCL), EPA National Primary Drinking Water Standards (40 CFR Part 141).

e. Maximum Contaminant Level (MCL), SCDHEC (1976).

f. DOE Derived Concentration Guides (DCGs) for water (DOE Order 5400.5, "Radiation Protection for the Public and the Environment"). DCG values are based on committed effective dose of 100 millirem per year for consistency with drinking water MCL of 4 millirem per year.

g. Minimum concentrations of samples. The maximum listed concentration is the highest single result found during one sampling event.

h. Secondary Maximum Contaminant Level (SMCL). EPA National Secondary Drinking Water Regulations (40 CFR Part 143).

i. $\quad$ NA $=$ none applicable.

j. Dependent upon $\mathrm{pH}$ and temperature.

k. $\mathrm{ND}=$ none detected.

1. Action level for lead and copper.

$\mathrm{m}$. WQS = water quality standard.

n. Only fecal coliform bacteria exceedances are reported.

o. Less than $(<)$ indicates concentration below lower limit of detection (LLD).

p. Shall not exceed weekly average of $32.2^{\circ} \mathrm{C}\left(90^{\circ} \mathrm{F}\right)$ after mixing nor rise more than $2.8^{\circ} \mathrm{C}\left(5^{\circ} \mathrm{F}\right)$ in 1 week unless appropriate temperature criterion mixing zone has been established. 
Table 3.1-5 Water Quality in Selected SRS Streams

\begin{tabular}{|c|c|c|c|c|c|c|c|}
\hline Sampling location & Tempe & ture $\left({ }^{\circ} \mathrm{F}\right)$ & $\mathrm{pH}$ & $\begin{array}{l}\text { Dissolved } \\
\text { oxygen } \\
(\mathrm{mg} / \mathrm{L}) \\
\end{array}$ & $\begin{array}{l}\text { Specific } \\
\text { conductance } \\
(\mu \mathrm{S} / \mathrm{cm}) \\
\end{array}$ & $\begin{array}{l}\text { Turbidity } \\
\text { (NTU) }\end{array}$ & $\begin{array}{l}\text { Total } \\
\text { suspended } \\
\text { solids } \\
(\mathrm{mg} / \mathrm{L})\end{array}$ \\
\hline \multirow{2}{*}{$\begin{array}{l}\text { Upper Three Runs at } \\
\text { Road A } A^{a}(1996)\end{array}$} & Mean & 63 & 6.35 & 8.21 & 24.3 & 13.55 & 13.33 \\
\hline & Range & $45.3-74.3$ & $6-7$ & $6.5-12.7$ & $21-29$ & $3.2-65$ & $3-51$ \\
\hline \multirow{2}{*}{$\begin{array}{l}\text { Upper Three Runs at } \\
\text { Road A } A^{b}(1987-1991)\end{array}$} & Mean & 66.7 & 6.08 & 8.36 & 24.5 & 5.24 & 10 \\
\hline & Range & NA & NA & $4.9-12$ & $3.0-41$ & $1.0-22$ & $2-97$ \\
\hline \multirow{2}{*}{$\begin{array}{l}\text { Upper Three Runs at } \\
\text { Road } 8-1^{2}(1996)\end{array}$} & Mean & 61.5 & 6.03 & 8.29 & 48.2 & 5.60 & 9 \\
\hline & Range & $49.6-71.2$ & $5.3-6.8$ & $5.2-10.2$ & $3-140$ & $1.6-11$ & $2-15$ \\
\hline \multirow{2}{*}{$\begin{array}{l}\text { Crouch Branch at Road } 4^{\mathrm{a}} \\
\text { (1996) }\end{array}$} & Mean & 64.9 & 6.06 & 7.13 & 37.9 & 26.23 & 16 \\
\hline & Range & $46.4-76.6$ & $5.4-6.4$ & $5.2-8.5$ & $22-50$ & $3.4-130$ & $4-76$ \\
\hline \multirow{2}{*}{$\begin{array}{l}\text { Lower Three Runs at } \\
\text { Patterson Mill }{ }^{\mathrm{a}}(1996)\end{array}$} & Mean & 64 & 6.29 & 7.49 & 84.5 & 4.28 & 9 \\
\hline & Range & $49.3-80.6$ & $6-7$ & $5.8-10.6$ & $60-120$ & $1.2-9.8$ & $2-24$ \\
\hline \multirow{2}{*}{$\begin{array}{l}\text { Lower Three Runs at } \\
\text { Patterson Mill }{ }^{b} \text { (1987- } \\
\text { 1991) }\end{array}$} & Mean & 64.4 & NA & 8.0 & 75 & 2.8 & 5 \\
\hline & Range & $45.9-84.2$ & $5.9-7.4$ & $5.8-11$ & $13-140$ & $0.94-38$ & $1-34$ \\
\hline
\end{tabular}

$\mathrm{NA}=$ Not available.

a. Arnett (1997).

b. Wike et al. (1994). 


\subsection{Groundwater}

Within 20 miles of the SRS, there are more than 56 major municipal, industrial, or agricultural groundwater users that consume approximately 36 million gallons of water per day (WSRC 1997b). Total SRS groundwater (domestic and process water) use ranges from 9 to 12 million gallons per day (WSRC 1997b; Amett and Mamatey 1996). At the SRS, only the deeper aquifers (Crouch Branch and McQueen Branch) are used as groundwater sources (Figure 3.1-4).

Under most of the SRS, the quality of groundwater is considered to be good. The pH for SRS groundwater ranges from 4.9 to 7.7 and the water is generally soft (DOE 1997a). Concentrations of dissolved and suspended solids are low, but iron concentrations are elevated in some of the aquifers (DOE 1995). At the SRS, approximately 5 to 10 percent of the shallow aquifer system has been contaminated with tritium, industrial solvents, metals, and other chemicals (Arnett et al. 1993).

\subsubsection{Natural Background Radiation}

All human beings are exposed to sources of ionizing radiation that include naturally occurring and manmade sources. The average dose contribution estimates from various sources to individuals were obtained from the Savannah River Environmental Report for 1996 (Arnett et al. 1997). On average, a person living in the Central Savannah River Area (CSRA) receives an annual radiation dose of $359 \mathrm{mrem}$. The average dose contributions from the various radiation sources to individuals in the CSRA are given in Fig. 3.1-7.

The major source of radiation exposure to an average member of the public in the CSRA is attributed to naturally occurring radiation. This naturally occurring radiation is often referred to as natural background radiation. Natural sources of radiation include cosmic radiation from outer space, cosmogenic radionuclides formed by interaction of cosmic radiation with elements in the earth's atmosphere, terrestrial radiation from natural radioactive materials in the ground, radiation from radionuclides occurring naturally in the body, and inhaled or ingested radionuclides of natural origin. The amount of exposure individuals receive depends on their location. The average annual dose to people in the U.S. from cosmic radiation is 27 mrem per year.

The major contributors to the annual EDE for internal radionuclides are the short-lived decay products of radon (mostly ${ }^{222} \mathrm{Rn}$ ), which contribute an average EDE of about 200 mrem per year. The average EDE from other internal radionuclides is about 40 mrem per year, which is predominantly attributed to the naturally occurring radioactive isotope of potassium, ${ }^{40} \mathrm{~K}$. A wide range of consumer products also contain sources of ionizing radiation. The U.S. average annual EDE to an individual from consumer products is about 10 mrem (Arnett et al. 1997). Radiation is an important tool of diagnostic medicine and cancer treatment. The average annual EDE to all individuals from all medical examinations, including diagnostic $\mathrm{x}$-rays and nuclear medicine procedures, is $53 \mathrm{mrem}$.

\subsection{Principal Facility Design Features}

One of the key objectives of any closure of a waste disposal site is to limit moisture flux through the waste, thus minimizing contamination of the underlying groundwater. Because the E-Area LLWF is designed as a controlled release facility, proper closure to meet the objective of limiting moisture through the waste will be an integral part of long-term acceptability of the disposal site. Because backfilling and final closure of the E-Area LLWF will be delayed for several years, a detailed closure design has not been fully developed for the E-Area LLWF. Thus an integral part of the E-Area LLWF PA required that a closure concept be described and subsequently tested in models that simulate the performance characteristics of the proposed closure concept. 


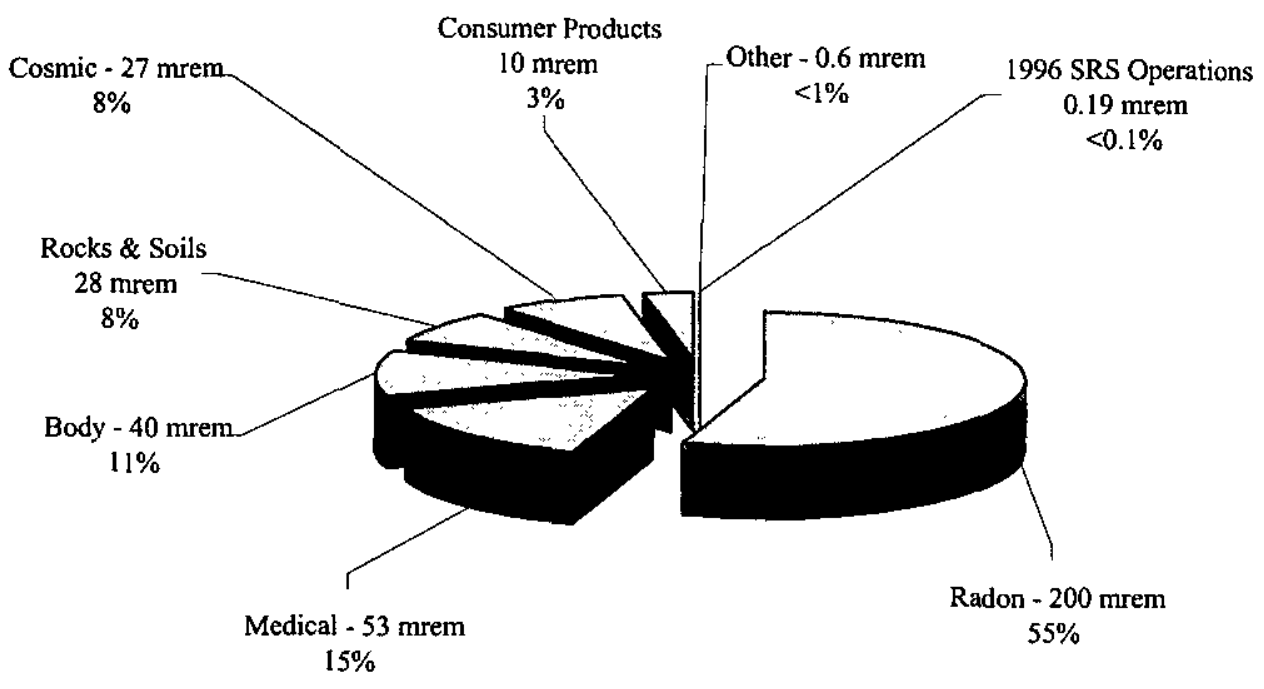

Figure 3.1-7 Major Sources of Radiation Exposure in the Vicinity of SRS 


\subsubsection{Low-Activity Waste Vaults}

\subsubsection{Water Infiltration and Disposal Unit Cover Integrity}

Each of the LAW Vaults will be closed in stages. Individual cells would be closed, then the entire vault area would be closed. Low-activity waste vault final closure consists of placing an earthen cover with an engineered clay cap over the entire vault area.

Closure concept developed for this assessment are illustrated in Fig. 3.2-1. Closure operations will begin when an individual cell is filled with waste and the concrete roof of the vault has been installed. The lighting and ventilation fixtures will be removed and the cell opening will be sealed with reinforced concrete. The reinforcing steel will be tied into the reinforcing steel of the vault itself, forming a unified structure. Near the end of the active disposal period of the E-Area LLWF, (i.e., after most or all of the vaults and trenches have been constructed and filled and the individual cell or trenches closed), backfill will be placed around and over the disposal units.

At least $0.9 \mathrm{~m}$ of backfill will be placed around the top of the vaults. This layer of will serve to establish slopes for the overlying layers so that infiltrating water will tend to flow down the slope and away from the vaults, limiting the amount of infiltration into the vaults themselves. Above this layer of backfill, a laterally extensive moisture barrier will be installed. This moisture barrier will consist of $0.76 \mathrm{~m}$ of clay and an overlying layer of $0.3 \mathrm{~m}$ of gravel. A geotextile fabric will be placed on the gravel layer, and a second backfill layer, approximately $0.76-\mathrm{m}$ thick, will be placed over the moisture barrier. Finally, a $0.15-\mathrm{m}$ layer of topsoil will be placed on the top layer of backfill. This sequence of layers provides a minimum of $2.9 \mathrm{~m}$ of cover for each vault.

Final closure of the E-Area LLWF will be accomplished by constructing a drainage system and revegetating the site. The drainage system will consist of a system of rip-rap lined ditches that intercept the gravel layer of the moisture barrier. These ditches will divert surface runoff and water intercepted by the moisture barrier away from the disposal site. The drainage ditches will be constructed between rows of vaults and around the perimeter of the E-Area LLWF.

The topsoil will be revegetated with bamboo. A study conducted by the USDA Soil Conservation Service (Salvo and Cook 1993) has shown that the two species of bamboo (Phyllostachys bissetii and Phyllostachys rubromarginata) will quickly establish a dense ground cover which will prevent the growth of pine trees, the most deeply rooted naturally occurring plant type at SRS. Bamboo is a shallow-rooted climax species which evapotranspirates year-round in the SRS climate, thus, removing a large amount of moisture from the soil and decreasing the infiltration into the underlying disposal system.

Performance requirements for the closure concept are expressed in terms of hydraulic properties for the various soil layers (Thompson 1991). These properties are listed in Table 3.2-1. The topsoil and upper backfill layer serve to store and distribute infiltrating water. These layers intercept incoming water and redirect a significant portion in the horizontal direction to drainage ditches installed at the E-Area LLWF. Computer simulations of flow through the cover show that the gravel drainage layer will carry away a major portion of the water that would normally infiltrate at the E-Area LLWF $(40 \mathrm{~cm} / \mathrm{yr})$. 


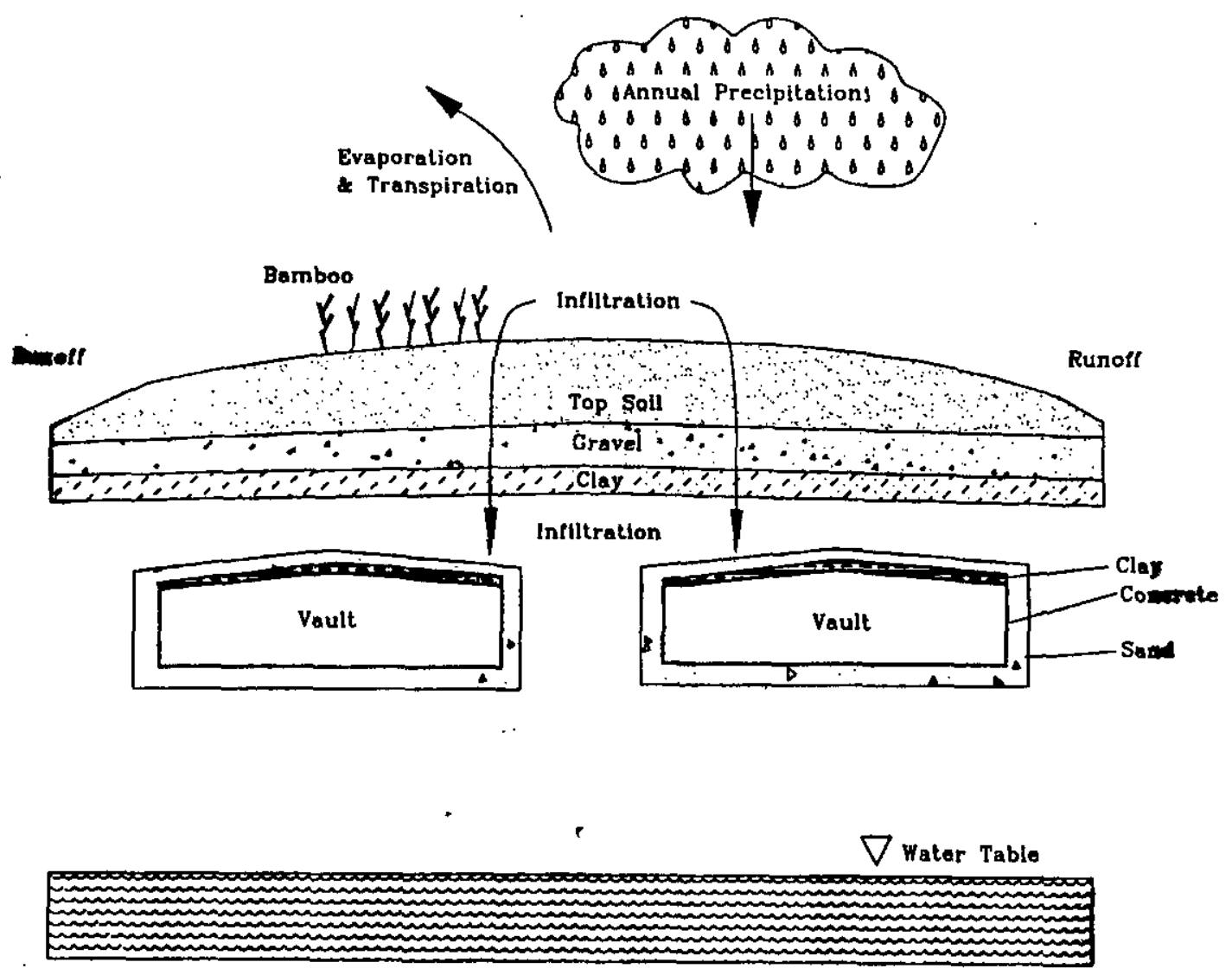

Figure 3.2-1. Vault Closure Concept (intact cover system) 
Table 3.2-1 Values for Hydraulic Properties of Vault Closure Design

\begin{tabular}{ll}
\hline & Hydraulic \\
Layer Description & Conductivity $(\mathrm{m} / \mathrm{s})$ \\
\hline Clay & $1.0 \times 10^{-9}$ \\
Gravel & $5.0 \times 10^{-3}$ \\
Backfill & $1.0 \times 10^{-7}$ \\
\hline
\end{tabular}

\subsubsection{Structural Stability and Inadvertent Intruder Barrier}

The LAW vault features that promote structural stability until roof collapse (See Section 4.1.3.1 and Appendix D) are:

- The vaults are on-grade, reinforced concrete structures within an excavated area. The walls are structurally mated to a 30 -inch footer that is continuous under all cells in each module. The vaults have no liners attached to them. The vaults are designed to withstand Design Basis Accident loads and therefore, assure continued structural stability.

- Upon filling the cells with waste, the exterior access opening is sealed with cast-in-place concrete to form a continuous wall.

The entire vault is covered with a reinforced concrete roof slab, supported on pre-cast concrete beams. The roof slab will be covered with a bonded-in-place layer of fiberboard insulation and a layer of waterproof membrane roofing. The roof slab and pre-cast beams ensure structural stability for about 3,000 years (Appendix D). They also provide a barrier to intrusion for this time period because normal residential construction and well drilling equipment used in the vicinity of the SRS is not capable of penetrating the roof structure.

The final closure for the LAWV consists of placing an earthen cover with an engineered clay cap over the entire LAWV area. Voids are present on the cells of the LAW vaults during and after filling. Approximately 50 percent of the vault volume is void space (Appendix $C$ ). However, these voids do not impact the structural stability of the LAW vaults until the walls and roof weaken to the point of collapse.

The potential for increased infiltration due to subsidence at the time of roof collapse is addressed in this PA in Section 5.3.

\subsubsection{Intermediate-Level Vaults}

\subsubsection{Water Infiltration and Disposal Unit Cover Integrity}

The closure concept for the IL vaults is identical to that for the LAW vaults (see Section 3.2.1.1).

\subsubsection{Structural Stability and Inadvertent Intruder Barrier}

The IL Vaults include features that promote structural stability are:

- The vaults are below-grade reinforced concrete structures. All walls are structurally mated to $21 / 2$-foot thick concrete slabs that extend approximately 2 feet beyond the outside of the exterior 
walls. The vaults are designed to withstand loads imposed by Design Basis Accidents and therefore, assure continued structural stability.

- Waste is containerized in engineered metal containers before being brought to the vault. The containers are stacked in layers. After a layer of waste containers is placed in a cell, grout will be poured to encapsulate the containers and form a surface for emplacement of the next layer of containers.

- After being filled with waste and layers or grout, the vault will be covered with a top layer of grout. A thick (thickness varies from 2-feet -3 inches to 3 -feet -2 inches) reinforced concrete roof slab will completely cover all nine cells of the IL Vault. The roof slab will extend over and around the cell-wall stubs and will be covered with a bonded-in-place layer of fiberboard insulation and layer of waterproof membrane roofing. Structural stability of the IL vault roof is expected for about 1,050 years (Appendix D). The roof and grout layer provide both a barrier to water infiltration and intrusion before this time period.

The confinement features for the IL tritium portion of the IL vault is the same as that for the ILNT portion. The ILT portion has two cells, one of which will dispose of tritium crucibles in silos. The silo system consists of vertical cylinders that are grouted in place, thus providing stabilization and shielding.

\subsubsection{Very-Low-Activity Waste Disposal Trenches}

\subsubsection{Water Infiltration and Disposal Unit Cover Integrity}

Final closure of the disposal trenches will be consistent with that described for the LAW vaults (Section 3.2.1.1). For the purposes of this assessment, the cap system used in the E-Area LLWF closure concept (Fig. 3.2-1) is assumed. Briefly, approximately $0.9 \mathrm{~m}$ of native backfill is assumed to be placed over the filled trenches (which themselves include $1.2 \mathrm{~m}$ of clean soil at the top), over which a laterally extensive moisture barrier is assumed to be placed. The moisture barrier consists of $0.76 \mathrm{~m}$ of clay overlain by $0.3 \mathrm{~m}$ of gravel and a geotextile fabric. Over this moisture barrier, $0.76 \mathrm{~m}$ of backfill is assumed, followed by $0.15 \mathrm{~m}$ of topsoil. As a result, a minimum of $2.9 \mathrm{~m}$ of cover material is assumed to overlie the disposal trenches at closure. Revegetation and drainage ditches are assumed to constitute final closure, for the purposes of stabilizing soil, preventing pine tree growth, and diverting excess water from the gravel layer.

\subsubsection{Structural Stability and Inadvertent Intruder Barrier}

The disposal trenches do not have features that limit infiltration of water or human intrusion. The cover system described in Section 3.2.3.1 provides some of these features, while assumed to be intact. Water infiltration is limited by the clay/gravel layer, and intrusion is limited by the depth to waste (approximately $4 \mathrm{~m}$, taking into account the $2.9-\mathrm{m}$ cover and $1.2-\mathrm{m}$ of clean soil overlaying the waste).

Voids may occur when readily-degradable materials, such as wood products, are reduced in volume by natural processes. Subsidence in the trenches may occur at this time, which is likely to occur within the period of active institutional control (i.e., within 100 years after closure). It is assumed in this assessment that damage to the cover system due to subsidence will be repaired during this time. A sensitivity analysis (Section 5.3) was also conducted to evaluate the effect of increased infiltration due to subsidence on disposal trench performance. 


\subsubsection{Intimately-Mixed Cement-Stabilized Waste Disposal Trenches}

\subsubsection{Water Infiltration and Disposal Unit Cover Integrity}

The cover for these trenches containing intimately-mixed cement-stabilized waste is identical to that described in Section 3.2.3.1 for the trench disposal units.

\subsubsection{Structural stability and Inadvertent Intruder Barrier}

The intimately-mixed cement-stabilized wasteform is likely to maintain its structural stability for 300 years (Section 4.1.3.1), thus limiting infiltration of water through and prohibiting human intrusion into the waste. The cover system described in Section 3.2.3.1, while intact, will also limit water infiltration.

\subsubsection{Cement-Stabilized Encapsulated Waste Disposal Trenches}

\subsubsection{Water Infiltration and Disposal Unit Cover Integrity}

The cover for these trenches containing cement-stabilized encapsulated waste is also identical to that described in Section 3.2.3.1 for the trench disposal units.

\subsubsection{Structural Stability and Inadvertent Intruder Barrier}

The cement-stabilized encapsulated wasteform is likely to maintain its structural stability for 300 years (Section 4.1.3.1), thus limiting infiltration of water through and prohibiting human intrusion into the waste. The cover system described in Section 3.2.3.1, while intact, will also limit water infiltration.

\subsubsection{Naval Reactor Waste Pads}

\subsubsection{Water Infiltration and Disposal Unit Cover Integrity}

The Naval Reactor waste disposal casks or containers will be placed within the E-Area LLWF boundary, and therefore final closure will be similar to that for the entire facility see Section 3.2.1.1). Briefly, 0.9-m of backfill from the Burma Road borrow pit is assumed to be placed over at-grade casks, above which a laterally extensive moisture barrier is assumed to be placed. The moisture barrier consists of $0.76 \mathrm{~m}$ of clay overlain by $0.3 \mathrm{~m}$ of gravel and a geotextile fabric. Over this moisture barrier, $0.76 \mathrm{~m}$ of backfill is assumed, followed by $0.15 \mathrm{~m}$ of topsoil. As a result, a minimum of $2.9 \mathrm{~m}$ of cover material is assumed to overlie the NR disposal casks at closure. Re-vegetation and drainage ditches are assumed to constitute final closure, and are intended to stabilize soil against erosion, prevent pine tree growth and divert excess water from the gravel layer.

\subsubsection{Structural Stability and Inadvertent Intruder Barrier}

Strength requirements of the Naval Reactor waste containers are such that they must remain intact while transporting Naval Reactor components, which have a density of 7,700-8,000 kg/m $\mathrm{m}^{3}\left(480-500 \mathrm{lbs} / \mathrm{ft}^{3}\right)$. Thus it is expected that these containers will support a soil/clay overburden with a density of $960-1,600$ $\mathrm{kg} / \mathrm{m}^{3}\left(60-100 \mathrm{lbs} / \mathrm{ft}^{3}\right)$. The gasketed containers are also designed to deter water infiltration for a considerable time period after institutional control has ceased. It is assumed that container breach may occur as early as 750 years (Section 4.1.3.1) in the PA. However, the nature of the containers and wasteform are such that intrusion is not likely for at least 10,000 years; the time it would take to corrode the steel containers and wasteform sufficiently to allow contact with the radionuclides which largely exist as activation products incorporated in the metal matrix of the waste components (Section 6.3.1.4). 


\subsection{Waste Characteristics}

Low-level radioactive solid waste may be segregated by the Waste Generator into seven categories. The disposition of waste containers in the E-Area LLWF will be based on this segregation. The waste categories are as follows:

1) Low-activity waste

2) Intermediate-level tritium waste

3) Intermediate-level non-tritium waste

5) E-Area trench waste

6) Naval Reactor Components

7) Intimately-mixed cement-stabilized waste

8) Cement-stabilized encapsulated waste

Low-activity waste and intermediate-level waste will be disposed of in the designated vaults; trenches will take soil, rubble wood and job control waste, and concrete waste forms (intimately-mixed cementstabilized waste and cement-stabilized encapsulated waste); and Naval Reactor components will be disposed of in the pad in the E-Area LLWF.

Estimated radionuclide inventories for each of the disposal units are shown in Appendix A. For those disposal units that have an operational history (i.e., LAW vault, IL vault, and slit trenches), the actual inventory as of 6/1/98 was used to develop a concentration value for each radionuclide; the concentrations were then applied to the forecasted waste volume to estimate the forecasted inventory. For the NR pad, the projected inventory was derived from forecasted waste volumes provided by DOE-NR. For the intimately-mixed cement-stabilized waste, projections of the volume of waste to be processed through the Consolidated Incinerator and radionuclide inventory data on those waste types from waste emplaced in the LAW vault were used to develop the projected inventory for five of these trenches. The inventory for the cement-stabilized encapsulated waste was derived from information available on currently stored equipment that are candidates for such disposal.

\subsubsection{Low-Activity Waste Vaults}

\subsubsection{Waste Type/ Chemical and Physical Form}

The LAW will include job control waste, scrap metal, and contaminated soil and rubble. Job control waste will consist of potentially contaminated protective clothing including plastic suits, shoe covers, lab coats, and plastic sheeting. Scrap metal will be contaminated tools, process equipment, and laboratory equipment. Soil and rubble will be generated from demolition and cleanup activities. Historically, the majority of this waste has been generated by the HLW tank farms. Larger volumes of waste disposed at E-Area LLWF are anticipated from environmental restoration activities as facilities are decommissioned and old waste sites are remediated.

The radioactive content of LAW is primarily fission products from the tank farms and Separations. Waste contaminated with uranium will be received from M-Area. Waste will also be received from offsite facilities, which will have a variety of radionuclides. 


\subsubsection{Radionuclide Inventory}

The radiation dose rate measured at $5 \mathrm{~cm}$ from the surface of an unshielded container is less than 200 $\mathrm{mR} / \mathrm{hr}$ for containers destined for the E-Area LLWF (LAW Vault). The transuranic activity concentration for the LAW Vault is less than $100 \mathrm{nCi} / \mathrm{g}$ of alpha activity.

The 20-year projected inventory for the two LAW vaults planned for the E-Area LLWF is given in Appendix A.

\subsubsection{Waste Volume}

The LAW vault provides approximately $4.8 \times 10^{4} \mathrm{~m}^{3}$ of LAW capacity (Section 2.2.1.1). Provided that inventory limits are not exceeded, waste volumes may approach that capacity for both LAW vaults during the period of operation of these units.

\subsubsection{Packaging Criteria}

All LLW is subject to the packaging requirements of the 1S Manual. Most of the LAW will be received in standard $1.2 \times 1.2 \times 1.8 \mathrm{~m}$ metal containers (B25 boxes), but some waste will also be received in standard $0.6 \times 1.2 \times 1.8 \mathrm{~m}$ containers (B12 boxes) or 210 -L drums. The LAW may also be received in non-standard engineered concrete or metal containers. These containers shall be pre-approved by Solid Waste Management prior to their receipt at the E-Area LLWF.

Many different containers will be received at the E-Area LLWF. However, all containers are required by the Technical Safety Requirements (TSRs) to be engineered concrete or metal containers that have been approved by Solid Waste. A procedure has been written that defines this approval process and requires Solid Waste Management Engineering, Solid Waste Management Operations, and Solid Waste Management Maintenance to concur that the container can be safely handled, will not impair vault space utilization, and will satisfactorily contain the waste contents.

The B25 and B12 are carbon steel boxes that have been used in the past for waste disposal in the SWDF. The boxes are similar in construction with the exception of size. The B25 is a $2.5 \mathrm{~m}^{3}$ container that is approximately $1.2 \mathrm{~m}$ high, $1.2 \mathrm{~m}$ wide, and $1.8 \mathrm{~m}$ long. It is typically constructed of 14-gauge carbon steel $(1.9 \mathrm{~mm})$ but some B25s are constructed of 12-gauge carbon steel $(2.6 \mathrm{~mm})$ to allow use in the compactor. The B12 is a $1.3 \mathrm{~m}^{3}$ container that is approximately $0.6 \mathrm{~m}$ high, $1.2 \mathrm{~m}$ wide, and $1.8 \mathrm{~m}$ long and is typically constructed of 12-gauge carbon steel.

The B12 and B25 containers are constructed with a rubber-gasket seal between the lid and the container conforming to ASTM-D-1056 with a gasket compression of 20 to 30 percent. The interior and exterior of each container is coated with a zinc chromate primer. The exteriors are given an additional coating of alkyd enamel and a finish coat of paint conforming to ASTM-D-16-75.

A variety of drums, corresponding to international drum specifications, will also be received as standard containers. Use of these containers is restricted to situations where use of a B25 is not practical. Drums will be banded together and banded to a fire-resistant pallet prior to shipment to the E-Area LLWF.

Non-Standard Container - For waste that cannot be placed in a standard container, specific size and weight limits have been specified. Maximum dimensions for containers in the LAWV are $4.3 \mathrm{~m}$ high $\times$ $7.3 \mathrm{~m}$ wide $\times 15.2 \mathrm{~m}$ long. The maximum dimensions for containers in the Intermediate Level Vaults are 
$7.3 \mathrm{~m}$ high $\times 10.7 \mathrm{~m}$ long $\times 6.1 \mathrm{~m}$ wide. The maximum uniform load on the vault floor cannot exceed $4.9 \times 10^{6} \mathrm{~kg} / \mathrm{m}^{2}$ for the IL Vaults and $2.8 \times 10^{6} \mathrm{~kg} / \mathrm{m}^{2}$ for the LAW Vaults.

\subsubsection{Pre-Disposal Treatment Methods}

All LAW containers, upon receipt at the EADF, are opened, and the contents are sorted into incinerable, compactible, and non-incinerable non-compactible fractions in the sorting and segregation facility. Incinerables are sent to the Consolidated Incinerator Facility, the resulting residue is disposed as intimately-mixed, cement-stabilized waste. The compactible fraction is compressed in a super-compactor prior to disposal.

\subsubsection{Waste Acceptance Restrictions}

Waste acceptance for disposal in the LAW vaults must conform to criteria put forth in the SRS WAC (WSRC 1997a).

\subsubsection{Intermediate-Level Vaults}

\subsubsection{Waste Type/ Chemical and Physical Form}

The IL Vault will be used for disposal of IL waste. Intermediate-level waste consists of job control waste, scrap hardware, and contaminated soil and rubble. Job control waste is primarily highly contaminated lab coats, plastic suits, shoe covers, plastic sheeting, etc. This material is assumed to be combustible and is contaminated primarily with fission products. Scrap hardware consists of reactor hardware, reactor fuel and target fittings, jumpers, and used canyon and tank farm equipment contaminated with fission products and/or induced activity.

All of the IL waste will be packaged in engineered metal or concrete containers that have been approved by Solid Waste Management. The containers will be remotely placed into the vault in layers. IL waste containers will be grouted in place to provide better waste isolation, reduce dose to operators, and improve stacking of additional containers.

Tritiated waste will be disposed in the ILT portion of the IL vault.. This portion consists of two cells, one for each of the two subcategories of tritiated waste. Tritium crucibles will be disposed in the first cell. This wasteform is generated by the tritium facilities in the process used to recover tritium from target assemblies. The crucibles will be over-packed into a stainless-steel container that is about $0.5 \mathrm{~m}$ in diameter and $6.1 \mathrm{~m}$ in length. The crucible cell is specially designed with vertical silos to receive waste. All other tritiated waste will be disposed of in the bulk tritiated waste cell. This waste will consist of job control waste and used process equipment that is contaminated with tritium. Bulk tritiated waste will be disposed in engineered metal or concrete containers.

Depending on the origin of this waste, it can contain either fission products or induced activity contamination. The induced activity waste will be mostly metal reactor hardware and fittings that have been exposed to a high neutron field. This waste generates a high radiation field but the activity is fairly immobile due to the metal matrix. Job control waste and process piping from Separations and High Level Waste Management will be contaminated with fission products. These fission products will be both loose and fixed surface contamination.

The large majority of activity in this waste will be tritium. However, ${ }^{60} \mathrm{Co}$ and ${ }^{65} \mathrm{Zn}$ will also be present due to the activation of impurities during tritium production. 


\subsubsection{Radionuclide Inventory}

Waste is categorized as IL if the radiation dose rate measured at $5 \mathrm{~cm}$ from the surface unshielded container is greater than $200 \mathrm{mR} / \mathrm{hr}$. Also, the transuranium element alpha activity concentration is less than $10 \mathrm{nCi} / \mathrm{g}$.

The 20-year projected inventory for the two IL vaults planned for the E-Area LLWF is given in Appendix A.

\subsubsection{Waste Volume}

The IL vault provides approximately $5.7 \times 10^{3} \mathrm{~m}^{3}$ of waste capacity for ILNT waste and $1.6 \times 10^{3} \mathrm{~m}^{3}$ for ILT waste (Section 2.2.2.1). Provided that inventory limits are not exceeded, waste volumes may approach that capacity for both IL vaults during the period of operation of these units.

\subsubsection{Packaging Criteria}

All LLW is subject to the packaging requirements of the 1S Manual. Thus, the bulk of the waste received by the E-Area LLWF, is containerized by the Waste Generator in B-25 or B-12 Engineered metal boxes, or in 55-gallon drums. Tritium crucibles will be packaged in a stainless steel overpack container. The overpack will be an $0.46-\mathrm{m}$ diameter pipe which is approximately $6.1 \mathrm{~m}$ long. The lid will be sealed to the overpack with a compression O-ring. The O-ring will not prevent off-gassing of tritium in the ILTV crucible silos. The ILTV is designed to receive 142 of these tritium crucible overpacks.

\subsubsection{Pre-Disposal Treatment Methods}

No pre-disposal treatment methods are currently planned for IL waste.

\subsubsection{Waste Acceptance Restrictions}

Waste acceptance for disposal in the IL vaults must conform to criteria put forth in the SRS WAC (WSRC 1997a).

\subsubsection{Very-Low-Activity Waste Disposal Trenches}

\subsubsection{Waste Type/ Chemical and Physical Form}

Waste destined for trench disposal can generally be described as contaminated soil, rubble, wood debris and job control waste (Section 2.2.3.1). Levels of radioactivity are generally lower than for waste destined for vault disposal.

\subsubsection{Radionuclide Inventory}

The 20-year projected inventory for ten trenches planned for the E-Area LLWF is given in Appendix A. 


\subsubsection{Waste Volume}

The volume capacity of each trench is $5760 \mathrm{~m}^{3}$ (from Fig. 2.2-4, $200 \mathrm{~m} \mathrm{x} 6 \mathrm{~m} \mathrm{x} 4.8 \mathrm{~m}$ ). Therefore the capacity of ten trenches is $5.7 \times 10^{4} \mathrm{~m}^{3}$.

\subsubsection{Packaging Criteria}

No packaging criteria apply to the waste destined for very-low activity trench disposal.

\subsubsection{Pre-Disposal Treatment Methods}

Containerized waste will be considered for pretreatment in the sorting and segregation facility (see Section 3.3.1.5).

\subsubsection{Waste Acceptance Restrictions}

Waste acceptance for disposal in trenches must conform to criteria put for in the SRS WAC (WSRC 1997b).

\subsubsection{Intimately-Mixed Cement-Stabilized Waste Disposal Trenches}

The Savannah River Site is considering the possibility of direct trench disposal of cement-solidified wasteforms. These wasteforms will be produced by blending solid or liquid waste products with cement or by encapsulating a solid form within a cement product, forming a solid waste form with physical and chemical stability. The nature of the waste form and the very low levels of radioactivity expected in the waste make trench disposal a cost-effective alternative to emplacement in the E-Area Vaults.

\subsubsection{Waste Type/Chemical and Physical Form}

The Consolidated Incinerator Facility (CIF) is designed to treat hazardous, mixed, and low-level radioactive waste by destroying organic compounds and reducing the volume of contaminated combustible materials. The air pollution control system for the CIF employs a water quench and steam atomized scrubber which collect salt, ash and trace metals in the liquid they use. To minimize waste, scrubber condensate will be used as make-up water in the quench. Water is recirculated in the quench until a predetermined amount of suspended solids or dissolved salts are present. This liquid, called blowdown, will be pumped to storage tanks prior to treatment and disposal. Both blowdown and the ash residual from the incineration process constitute the waste destined for the intimately-mixed cementstabilized waste trenches. Physical characteristics of the cementitious wasteform are discussed in Section 3.3.4.5.

\subsubsection{Radionuclide Inventory}

The 20-year projected inventory for the intimately-mixed cement-stabilized waste planned for disposal in ten E-Area LLWF trenches is given in Appendix A.

\subsubsection{Waste Volume}

The volume capacity of each trench is $5760 \mathrm{~m}^{3}$ (from Fig. $2.2-4,200 \mathrm{~m} \mathrm{x} 6 \mathrm{~m} \mathrm{x} 4.8 \mathrm{~m}$ ). Therefore the capacity of ten trenches is $5.7 \times 10^{4} \mathrm{~m}^{3}$. 


\subsubsection{Packaging Criteria}

The cementitious wasteform will be solidified in 55-gallon carbon steel drums. No other packaging criteria have been specified at this time.

\subsubsection{Pre-Disposal Treatment Methods}

The blowdown and ash residual from the incineration process will be stabilized with Portland cement in the ashcrete processor, which produces drums of solidified waste. Extensive studies have been carried out to optimize stabilization of both the ash (Fisher 1994a) and blowdown (Fisher 1995) and to produce acceptable wasteforms.

Tests to determine the permeability of the cementitious wasteform were conducted at the University of South Carolina. Three wasteform samples were used with the results varying from $3.0 \times 10^{-11} \mathrm{~m} / \mathrm{s}$ to $7.3 \times 10^{-14} \mathrm{~m} / \mathrm{s}$ (Meadows 1997).

Results of tests of the compressive strength of this wasteform have varied from 1571 to 5220 psi (Fisher 1994b), all of which are much higher that the 500 psi recommendation by the NRC (NRC 1991).

\subsubsection{Waste Acceptance Restrictions}

Waste acceptance for disposal in the trenches designated to receive intimately-mixed cement-stabilized waste must conform to criteria put forth in the SRS WAC (WSRC 1997a).

\subsubsection{Disposal Trenches for Cement-Stabilized Encapsulated Waste}

\subsubsection{Waste Type/Chemical and Physical Form}

In general, large equipment contaminated with radioactive materials will constitute the type of waste destined for disposal in these trenches. Any solid wasteform, however, that meets the WAC which will be based on the results of this PA, will be suitable for disposal as an encapsulated wasteform.

\subsubsection{Radionuclide Inventory}

The 20-year projected inventory for the cement-stabilized encapsulated waste planned for disposal in ten E-Area LLWF trenches is given in Appendix A.

\subsubsection{Waste Volume}

The volume capacity of each trench is $5760 \mathrm{~m}^{3}$ (from Fig. $2.2-4,200 \mathrm{~m} \mathrm{x} 6 \mathrm{~m} \mathrm{x} 4.8 \mathrm{~m}$ ). Therefore the capacity of ten trenches is $5.7 \times 10^{4} \mathrm{~m}^{3}$.

\subsubsection{Packaging Criteria}

Wasteforms encapsulated in grout will be placed directly in the designated trenches. No packaging criteria apply to waste destined for these trenches. 


\subsubsection{Pre-Disposal Treatment Methods}

Waste destined for these trenches will be encapsulated by grout or other cementitious backfill as an alternative to vault disposal (Section 2.2.5.1). Specific methods and criteria for encapsulation are not yet developed.

\subsubsection{Waste Acceptance Restrictions}

Waste acceptance for disposal in the trenches designated to receive cement-stabilized encapsulated waste must conform to criteria put forth in the SRS WAC (WSRC 1997a).

\subsubsection{Naval Reactor Waste Pads}

Heavily shielded shipping/disposal casks containing Naval Reactor (NR) waste components are planned to be disposed of at the Naval Reactor Pad, within the fenced 100-acre boundary of the E-Area LLWF, at the Savannah River Site. Large quantities of activation products are associated with the metal matrix of the waste forms within the disposal containers. Lesser amounts of radioactive contaminants are present in "crud" corrosion products.

\subsubsection{Waste Type/ Chemical and Physical Form}

Within the E-Area LLWF, disposal of up to 100 stainless steel casks containing naval reactor (NR) components is proposed. The Naval Reactor component waste is composed of activated metals and can include control rods, control rod drive mechanisms, resin vessels, adapter flanges, and similar equipment. The high shielding shipping/disposal containers reduce the safety risks involved in the disposal of Naval Reactor component wastes.

Naval Reactor waste consists of a variety of solid activated metal naval nuclear reactor components, including core barrels/thermal shields (CB/TS), adapter flanges, closure heads, holddown (HD) barrels, pumps and other similar equipment. Certain components are also covered with a thin layer of adherent corrosion products, referred to as "crud", which is rich in radionuclide contamination. Bettis Atomic Power Laboratory has identified sixty-five (65) NR waste components that have been or are planned to be delivered to SRS for disposal (Bettis 1995a,b). These waste components include Bettis Core Barrels with Thermal Shields (CB/TS), holddown (HD) barrels, Bettis heads, Bettis adapter flanges, Bettis shrouds, Bettis pumps, KAPL CB/TS, and KAPL Heads. Volumes of the metal waste components range between 1.05 and $7.05 \mathrm{~m}^{3}$ for each component. Most waste components also contain some water, with the maximum amount averaging about $9.5 \times 10^{-3} \mathrm{~m}^{3}(2.5 \mathrm{gal})$. More detailed configurational descriptions of the NR waste components are not available because of the classified nature of this information.

\subsubsection{Radionuclide Inventory}

The 20-year projected inventory of radionuclides for 100 naval reactor component waste containers is listed in Appendix A.

\subsubsection{Waste Volume}

Naval reactor core barrels and reactor components are to be disposed of on gravel pads in the E-Area LLWF. The gravel pads have a total storage capacity of 697 square meters $(7,500$ square feet). At least 65 containers are planned for disposal at the E-Area LLWF, although up to 100 containers may be delivered. The metal volume of the waste is approximately $3.5 \mathrm{~m}^{3}$ per container. 


\subsubsection{Packaging Criteria}

There is no standard Naval Reactor Component waste disposal container due to the variety of waste components. The actual container configuration, thickness, material of construction and closure method may be tailored to the characteristics of the Naval Reactor waste component at the time of disposal. Table 3.3.-1 shows that the planned or proposed containers for Naval Reactor waste disposal are mostly composed of carbon steel or low-alloy steel and closed by a gasket or a weld. A simplified cross-section of the KAPL CB/TS conceptual disposal container (a representative type of container according to Bettis) is illustrated in Fig. 3.3-1. The assumed thickness of the container is based on estimates shielding requirements (by Bettis) for abounding KAPL CB/TS radionuclide inventory. From Fig. 3.3-1, the overall containerized waste volume is about $43 \mathrm{~m}^{3}$.

The proposed layout of the containers is shown in Fig. 3.3-2. The life expectancy and shielding capacity of the shipping/disposal casks are determined by the specifications of the containers. A detail of the proposed NR waste package is shown in Fig. 3.3-2, showing the outside dimensions of $3.2 \mathrm{~m}$ in diameter and $5.4 \mathrm{~m}$ high..

\subsubsection{Pre-Disposal Treatment Methods}

The offsite generator is responsible for any pre-disposal treatment methods prior to shipment to SRS.

\subsubsection{Waste Acceptance Restrictions}

Waste acceptance for disposal on the Naval Reactor Waste pad must conform to criteria put forth in the SRS WAC (WSRC 1997a). 
Table 3.3-1 Forecast of Naval Reactor Waste Components for E-Area LLWF Disposal

\begin{tabular}{|c|c|c|c|c|c|c|c|c|c|}
\hline Description: & $\begin{array}{l}\text { Bettis } \\
\text { CB/TS }\end{array}$ & $\begin{array}{l}\text { Bettis } \\
\text { HD } \\
\text { Barrels }\end{array}$ & $\begin{array}{l}\text { Bettis } \\
\text { Head/CP }\end{array}$ & $\begin{array}{l}\text { Bettis } \\
\text { Adapter } \\
\text { Flange }\end{array}$ & $\begin{array}{l}\text { Bettis } \\
\text { Shrouds }\end{array}$ & $\begin{array}{l}\text { Bettis } \\
\text { Pump }\end{array}$ & $\begin{array}{l}\text { Bettis } \\
\text { Barrel }\end{array}$ & $\begin{array}{l}\text { KAPL } \\
\text { CB/TS }\end{array}$ & $\begin{array}{l}\text { KAPL } \\
\text { Head }\end{array}$ \\
\hline $\begin{array}{l}\text { Number of } \\
\text { units }^{1}\end{array}$ & 8 & 8 & 2 & 10 & 2 & 2 & 1 & 16 & 16 \\
\hline $\begin{array}{l}\text { Gross Weight } \\
\text { (lb.) }\end{array}$ & 241000 & 159070 & 152600 & 87710 & 26090 & 111350 & 290065 & 360000 & 78000 \\
\hline \multicolumn{10}{|l|}{ Component } \\
\hline $\begin{array}{l}\text { Component } \\
\text { weight (lb.) }\end{array}$ & 61000 & 59710 & 121920 & 42910 & 18090 & 90130 & 60065 & 72000 & 47000 \\
\hline $\begin{array}{l}\text { Component } \\
\text { volume }\left(\mathrm{ft}^{3}\right)\end{array}$ & 125 & 122 & 249 & 86 & 37 & 184 & 123 & 147 & 96 \\
\hline $\begin{array}{l}\text { Component } \\
\text { Alloy }^{3}\end{array}$ & 304 s.s. & Inconel & $\begin{array}{l}\text { Carbon } \\
\text { steel }\end{array}$ & $\begin{array}{l}\text { Carbon } \\
\text { Steel }\end{array}$ & Inconel & $\begin{array}{l}\text { Carbon } \\
\text { steel }\end{array}$ & Inconel & $\begin{array}{l}\text { Inconel/ } \\
\text { Zircaloy }\end{array}$ & $\begin{array}{l}\text { Inconel } \\
\text { clad } \\
\text { c. steel }\end{array}$ \\
\hline $\begin{array}{l}\text { Max water } \\
\text { (gals) }\end{array}$ & 1 & 5 & 13.5 & 0.4 & 1.5 & 8 & 8 & 3.5 & 0 \\
\hline \multicolumn{10}{|l|}{ Container } \\
\hline $\begin{array}{l}\text { Container } \\
\text { weight (lb.) }\end{array}$ & 180000 & 99360 & 30680 & 44800 & 8000 & 21220 & 230000 & 288000 & 31000 \\
\hline $\begin{array}{l}\text { Thinnest } \\
\text { Thickness } \\
\text { of container } \\
\text { (in) }\end{array}$ & 5.2 & 4 & 0 & 0 & 0 & 0 & 1.25 & 1.64 & $\underline{0}$ \\
\hline $\begin{array}{l}\text { Container } \\
\text { alloy }\end{array}$ & $\begin{array}{l}\text { Carbon } \\
\text { steel }\end{array}$ & HY -80 & $\begin{array}{l}\text { Carbon } \\
\text { steel }\end{array}$ & $\begin{array}{l}\text { Carbon } \\
\text { Steel }\end{array}$ & $\begin{array}{l}\text { Carbon } \\
\text { steel }\end{array}$ & $\begin{array}{l}\text { Carbon } \\
\text { steel }\end{array}$ & $\begin{array}{l}\text { Carbon } \\
\text { steel }\end{array}$ & $\begin{array}{l}\text { Carbon } \\
\text { steel }\end{array}$ & $\begin{array}{l}\text { Carbon } \\
\text { steel }\end{array}$ \\
\hline $\begin{array}{l}\text { Type of } \\
\text { container } \\
\text { closure } \\
\end{array}$ & $\begin{array}{l}\text { Full pen } \\
\text { weld }\end{array}$ & $\begin{array}{l}\text { Full } \\
\text { Pen } \\
\text { weld } \\
\end{array}$ & Gasket & Gasket $^{2}$ & Gasket & Gasket & $\begin{array}{l}\text { Full } \\
\text { Pen } \\
\text { weld } \\
\end{array}$ & $\begin{array}{l}\text { Full Pen } \\
\text { weld }\end{array}$ & Gasket \\
\hline
\end{tabular}

Notes:

1. Includes components recently shipped and identified as above ground ( $8 \mathrm{CB} / \mathrm{TS}+8 \mathrm{HD}$ Barrels +8 Adap. Flanges)

2. Eight of the Adap. Flange containers were welded shut. The remainder two will be rubber gasketed and bolted.

3. Alloy shown is major alloy of construction.

4. Zero indicates gasketed and bolted closure. 


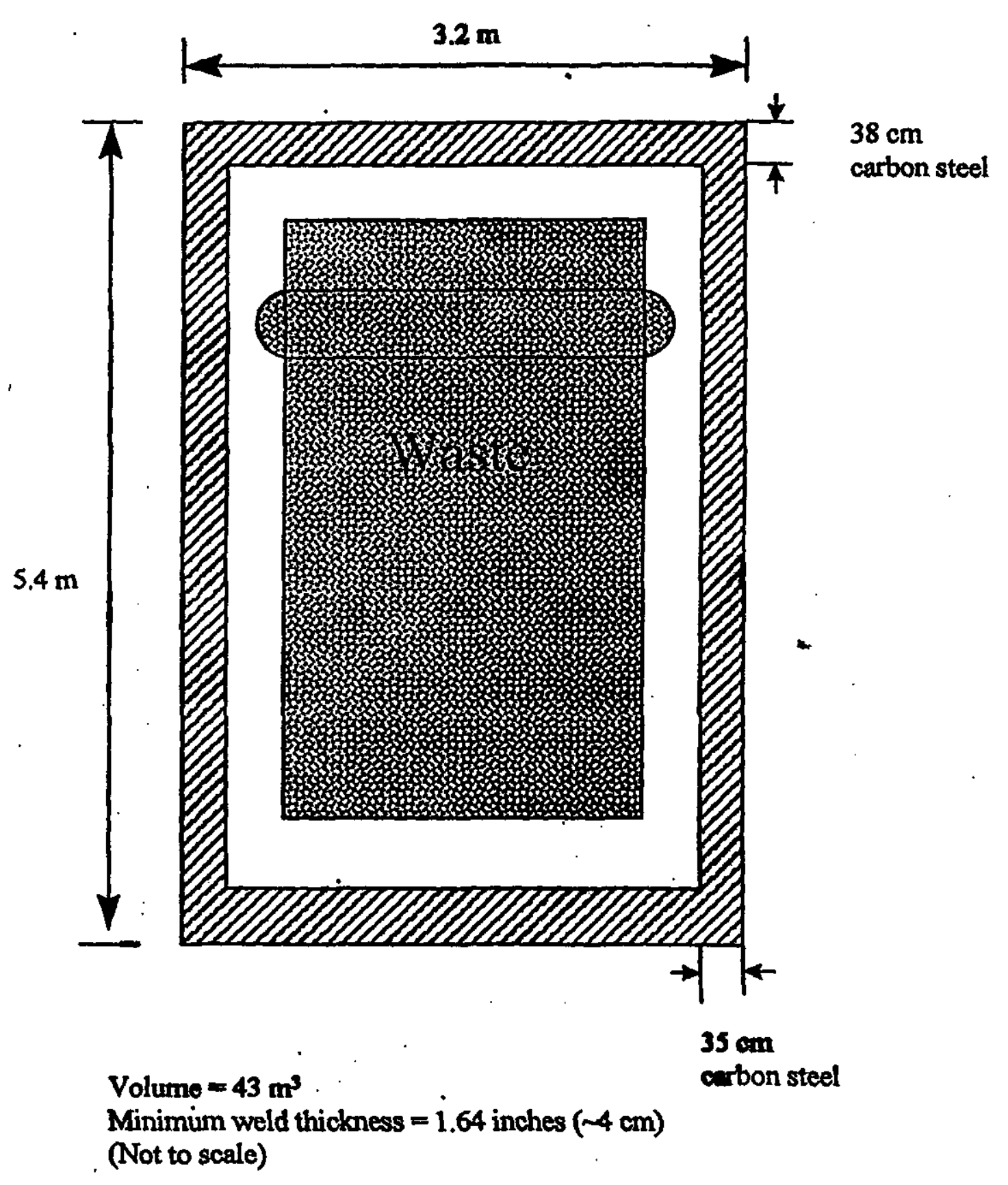

Figure 3.3-1. Conceptual Naval Reactor Waste Disposal Cask 


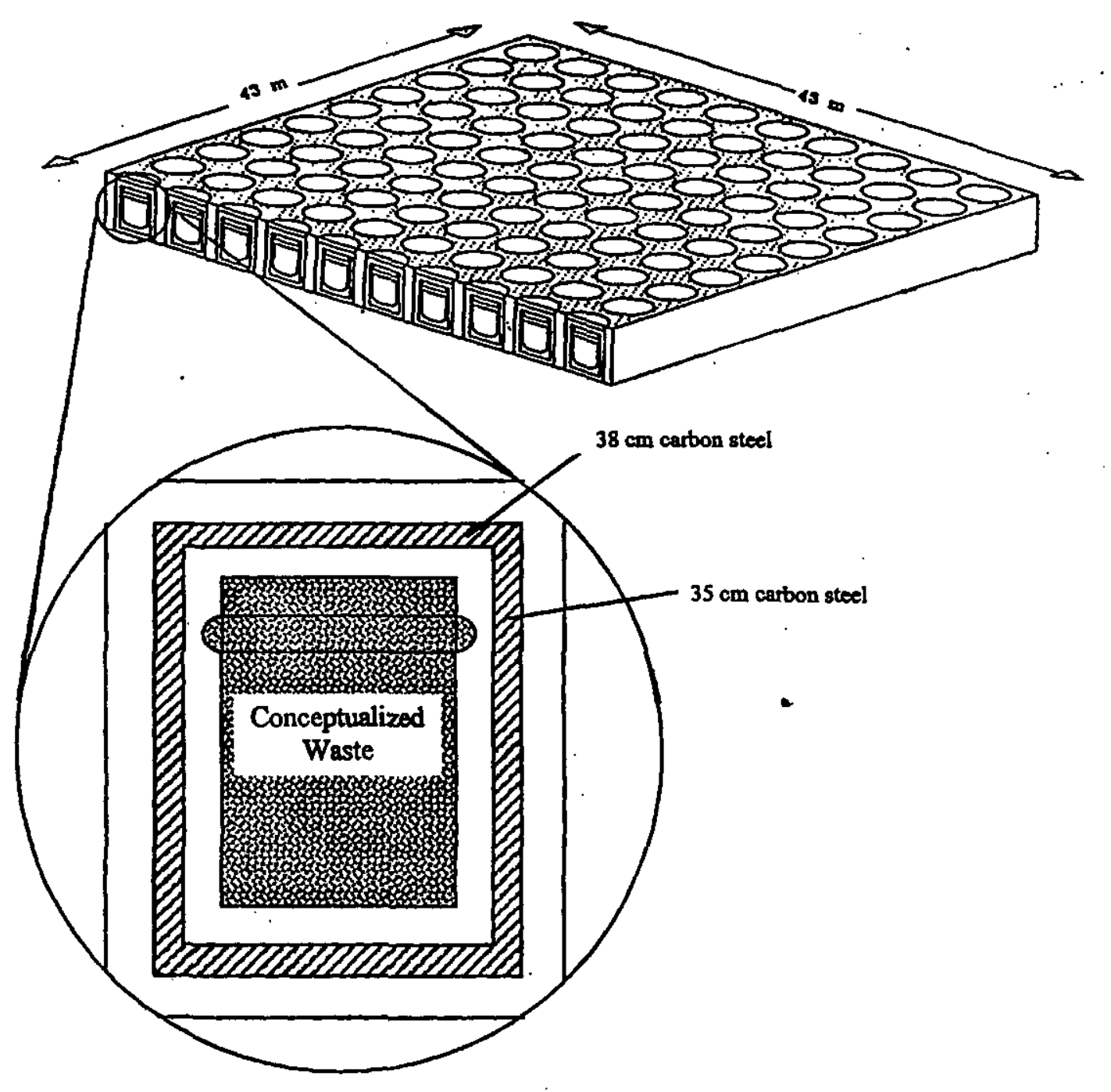

Dimensions $3.2 \mathrm{~m} \times 5.4 \mathrm{~m}$

Figure 3.3.2. Proposed Layout of NR Waste Disposal Area 


\section{SECTION 4}

ANALYSIS OF PERFORMANCE 
THIS PAGE INTENTIONALLY LEFT BLANK

Rev. 1

January 31,2000 


\section{ANALYSIS OF PERFORMANCE}

The methods used to analyze the long-term performance of the E-Area LLWF are described in this chapter. Source term development is addressed in Sect 4.1, where a discussion of potential mechanisms of contaminant release from the disposal units, and of potential mechanisms responsible for loss of integrity of the engineered barriers for each unit type is provided. In this section, the screening process used to identify potentially significant radionuclides in each disposal unit type is also described.

In Section 4.2, potentially significant pathways to exposure and exposure scenarios for off-site members of the public are described. Screening of scenarios and pathways are also discussed in this section, as are receptor locations for subsequent analysis.

Finally, in Section 4.3, the conceptual models developed to analyze the fate and transport of potentially significant radionuclides released from the E-Area LLWF for the pathways identified in Section 4.2 are described. Computational methods used to evaluate the models are also discussed.

\subsection{Source Terms}

In this section, mechanisms and factors which affect the rate of potential release of radionuclides from the E-Area LLWF disposal units to the environment are discussed. Screening techniques used to focus analyses on significant radionuclides and processes are also described. Once significant radionuclides and processes are identified, conceptual models for release from waste forms and disposal units are presented. These models address releases from initially intact disposal units and releases from units after degradation of engineered barriers has occurred. Simulation models and assumed values of parameters used in the models are discussed. Calculated releases to the environment over time are provided.

\subsubsection{All-Pathways Analysis}

In an all-pathways analysis, the potential for air, groundwater (above or below the water table), surface water, and soil to carry radionuclides from E-Area to off-site locations is considered. The source term analysis for a disposal facility considers how radionuclides might be directly released to these four media. The description of pathways and scenarios for the all-pathways analysis (Section 4.2.1) considers how radionuclides released to a medium may be transported within and between media to locations where human exposure may take place.

The E-Area disposal units are subsurface units, with overlying soil extending in excess of $2 \mathrm{~m}$ from the top of the units to the ground surface when closure is complete. Release to the subsurface soil surrounding the waste units, as a result of diffusion and convection, is probable. Direct release of radionuclides from the disposal units to overlying surface soil, air, or nearby surface water is highly unlikely, except for release of volatile radiological components of waste (i.e., tritium, ${ }^{14} \mathrm{C}$ and radon), which are addressed in Section 4.1.2. While erosion of cropland in the vicinity of the SRS is on the order of $0.08 \mathrm{~cm} / \mathrm{y}$ (from Section 3.1.4.1, assuming a soil matrix density of $2650 \mathrm{~kg} / \mathrm{m}^{3}$ ), the presence of a final vegetative cover will lower the erosion potential in a manner similar to that of a successional forest, which is estimated to lower erosion by a factor of 400 to 500 (Section 3.1.4.1). Thus, uncovering of the vaults or trenches by natural processes during the first 10,000 years after disposal is not expected. The final vegetative cover will be a climax species which prevents the growth of deeply-rooted pine trees native to the area and limits other types of biointrusion (see Section 4.2.1), such that significant movement of nonvolatile radionuclides upwards toward the soil surface is also unlikely. Therefore, the source term analysis focuses on the source of radionuclides released to the groundwater in the vadose, or unsaturated, zone. With this focus, development of the source term for both the all-pathways analysis and the water-resource impacts analysis will be identical, and is described in Section 4.1.3 below. 


\subsubsection{Air Pathways Analysis}

The air pathway analysis addresses potential emission of volatile radionuclides from the E-Area LLWF. Screening analyses (Cook and Wilhite 1998) show that only HTO (tritiated water vapor), HT and ${ }^{14} \mathrm{C}$ could produce doses of concern via the air pathway. In this section the release mechanisms used in the air pathway analysis are described for different types of waste forms containing ${ }^{3} \mathrm{H}$. Doses from HT are neglected because the dose conversion factor for HT is three orders of magnitude less than that for HTO.

\subsubsection{1 ${ }^{3} \mathrm{H}$ and ${ }^{14} \mathrm{C}$ in Job Control Waste}

For Job Control Waste (JCW), typically packaged in double plastic bags and placed inside a steel disposal box, no credit is assumed in this PA for any containment of gaseous forms of ${ }^{3} \mathrm{H}$ or ${ }^{14} \mathrm{C}$, i.e., the entire volatile inventory is assumed to be released in one year. Once released from the waste form, the volatile radionuclides must migrate to the ground surface to enter the atmospheric pathway. Downward movement caused by infiltrating water is neglected. The fraction of the disposed inventory that is available for atmospheric transport (i.e., that is volatile) is calculated differently for each disposal unit considered. Results are presented in Table 4.1-1.

\subsection{Trenches}

For trench disposal (including all wasteforms destined for trench disposal), all of the ${ }^{3} \mathrm{H}$ and ${ }^{14} \mathrm{C}$ in a group of 2 sets of five trenches (i.e., 10 trenches) is assumed to be available for atmospheric transport at the time of disposal. That is, the ratio of the curies released into the atmospheric pathway to the curies disposed is unity (Table 4.1-1). This leads to a maximum estimate of release.

\subsection{LAW and IL Vaults}

For the LAW and IL vaults, the analysis of the ${ }^{3} \mathrm{H}$ and ${ }^{14} \mathrm{C}$ source term to the atmosphere considers the partitioning of ${ }^{3} \mathrm{H}$ and ${ }^{14} \mathrm{C}$ between the volatile water vapor phase, and pore water in the vaults, the nonvolatile phase.

Table 4.1-1. Release Fractions for ${ }^{3} \mathrm{H}$ and ${ }^{14} \mathrm{C}$

\begin{tabular}{|c|c|c|}
\hline & ${ }^{3} \mathrm{H}(\mathrm{Ci} / \mathrm{yr} / \mathrm{Ci})$ & ${ }^{14} \mathrm{C}(\mathrm{Ci} / \mathrm{yr} / \mathrm{Ci})$ \\
\hline $\begin{array}{r}\text { Job Control Waste } \\
10 \text { Trenches }\end{array}$ & (n) & 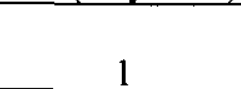 \\
\hline $\begin{array}{l}1 \text { LAW Vault } \\
1 \text { IL Vault } \\
\end{array}$ & $\begin{array}{l}5.6 \times 10^{-4} \\
3.2 \times 10^{-4} \\
\end{array}$ & $\begin{array}{l}1 \\
1\end{array}$ \\
\hline Crucibles (1 vault) & $8.9 \times 10^{-9}$ & -- \\
\hline $\begin{array}{l}\text { Naval Reactor Component } \\
\text { Waste ( } 100 \text { containers) }\end{array}$ & 1 & $3.0 \times 10^{-5}$ \\
\hline
\end{tabular}


Since ${ }^{3} \mathrm{H}$ in the vapor form is derived from the concentrations in the pore water, the ratio of the concentration in the vapor form to that in the water phase can be determined as follows:

$$
\mathrm{H}=\frac{C_{\text {vapor }}\left(\mathrm{g} / \mathrm{m}^{3} \text { of air }\right)}{C_{\text {water }}\left(\mathrm{g} / \mathrm{m}^{3} \text { of water }\right)}
$$

The concentration of water in air at $10^{\circ} \mathrm{C}$ and 100 percent relative humidity can be determined as follows:

$$
\mathrm{C}\left(\mathrm{g} / \mathrm{m}^{3}\right)=\frac{A v p}{R x T} \times M W
$$

where

$$
\begin{array}{lll}
A v p & = & \text { actual vapor pressure }(0.012 \text { bars }), \\
R & = & \text { gas constant }\left(8.314 \times 10^{-5} \mathrm{bar} \mathrm{m}^{3} \mathrm{~mol}^{-1} \mathrm{~K}^{-1}\right), \\
T & = & \text { temperature }\left(283^{0} \mathrm{~K}\right), \\
M W & = & \text { molecular weight }\left(18 \mathrm{~g} \mathrm{~mol}^{-1}\right)
\end{array}
$$

This results in a water concentration in the air of $9.2 \mathrm{~g} \mathrm{~m}^{-3}$. Assuming that concentration of ${ }^{3} \mathrm{H}$ in water is equal to the concentration in the vapor:

$$
\frac{1 C i}{m_{(H 2 O)}^{3}} \times \frac{1 m_{(H 2 O)}^{3}}{10^{6} g_{(H 2 O)}} \times \frac{9.2 g_{(H 2 O)}}{m_{(\text {air })}^{3}}=\frac{9.2 \times 10^{-6} C i^{3} H}{m_{(\text {air })}^{3}}
$$

Therefore,

$$
\mathrm{H}=\frac{9.2 \times 10^{-6} \mathrm{Ci} / \mathrm{m}_{(\text {air })}^{3}}{1 \mathrm{Ci} / \mathrm{m}_{(\mathrm{H} 2 O)}^{3}}
$$

Using this relationship, the ${ }^{3} \mathrm{H}$ concentration in the vapor phase can be determined from the concentration in the water phase in the vault.

Assuming that this is the ${ }^{3} \mathrm{H}$ concentration in the vapor phase at the top surface of the vault, then the flux at the ground surface is given by:

$$
\mathrm{J}=D\left(\frac{C_{0}}{x}\right) \times L_{\text {vault }} \times W_{\text {vault }}
$$

where

$$
\begin{array}{lll}
J & = & \text { annual flux at the soil surface, } \mathrm{Ci} \mathrm{r}^{-1}, \\
D & = & \text { diffusion coefficient in air, } 754 \mathrm{~m}^{2} \mathrm{yr}^{-1},(\mathrm{CRC} \mathrm{1981}), \\
C_{o} & = & \text { source concentration in the vapor phase, } \mathrm{Ci} \mathrm{m}{ }^{-3}, \\
x & = & \text { soil thickness, } 1 \mathrm{~m}
\end{array}
$$




$$
\begin{array}{lll}
\mathrm{L}_{\text {vault }}= & \text { Length of vault, } \mathrm{m} \\
\mathrm{W}_{\text {vault }}= & \text { Width of vault, } \mathrm{m}
\end{array}
$$

For the LAW vaults, using a volume of $7.2 \times 10^{4} \mathrm{~m}^{3}$ (i.e., one vault), a porosity of 0.5 and an inventory of $1 \mathrm{Ci}$, the water concentration is $1.4 \times 10^{-5} \mathrm{Ci} / \mathrm{m}^{3}$. This gives a vapor concentration of $1.3 \times 10^{-10} \mathrm{Ci} / \mathrm{m}^{3}$. Using a cover thickness of $3 \mathrm{~m}$, a tritium diffusion rate of $754 \mathrm{~m}^{2} / \mathrm{yr}$ (CRC 1981), a length of $200 \mathrm{~m}$ and a width of $44 \mathrm{~m}$ gives an annual release rate of $5.6 \times 10^{-4} \mathrm{Ci} / \mathrm{yr}$.

For the IL vault, using a volume of $9.9 \times 10^{3} \mathrm{~m}^{3}$ (i.e., one vault), a porosity of 0.5 and an inventory of 1 $\mathrm{Ci}$ gives a water concentration of $2.0 \times 10^{-4} \mathrm{Ci} / \mathrm{m}^{3}$. This results in a vapor concentration of $1.9 \times 10^{-9}$ $\mathrm{Ci} / \mathrm{m}^{3}$. Using a cover thickness of $5 \mathrm{~m}$, a tritium diffusion rate of $754 \mathrm{~m}^{2} / \mathrm{yr}$ (CRC 1981), a length of $75 \mathrm{~m}$ and a width of $15 \mathrm{~m}$ gives an annual release rate of $3.2 \times 10^{-4} \mathrm{Ci} / \mathrm{yr}$.

A similar analysis for ${ }^{14} \mathrm{C}$ waste forms for the LAW and IL vaults shows that the annual release fraction is unity, because the partitioning between the water and vapor phases cannot be considered. This is reflected in Table 4.1-1.

\subsubsection{2 ${ }^{3} \mathrm{H}$ Crucibles}

Wastes containing more than incidental amounts of ${ }^{3} \mathrm{H}$ are generally disposed of in specially designed packages. One of these special packages, known as a ${ }^{3} \mathrm{H}$ Crucible, was taken as the representative waste package for wastes containing higher amounts of ${ }^{3} \mathrm{H}$. Most high ${ }^{3} \mathrm{H}$ waste packages consist of a tightly sealed waste form within welded steel containers. ${ }^{3} \mathrm{H}$ Crucibles are made of carbon steel and contain a $\mathrm{Li}$ $\mathrm{Al}$ alloy material from which ${ }^{3} \mathrm{H}$ has been extracted. Since the early 1980 's, ${ }^{3} \mathrm{H}$ Crucibles have been sealed using an epoxy cap. This waste form is conservatively used in the air pathway analysis to represent all higher integrity ${ }^{3} \mathrm{H}$ waste forms.

Orebaugh and Wallace (1989) evaluated the release of ${ }^{3} \mathrm{H}$ from the crucibles for various scenarios including: Case I, a ${ }^{3} \mathrm{H}$ crucible sealed with moist air inside; Case II, plug shrinkage vents the crucible to moist air; Case III, vented crucibles stored in an unvented concrete vault; and Case IV, Case III with an engineered vent. This study evaluated the impact of the corrosion reaction between $\mathrm{Al}$ and $\mathrm{H}_{2} \mathrm{O}$ producing $\mathrm{H}_{2}$ gas. The study provides ${ }^{3} \mathrm{H}$ flux rates from the crucibles, which were used in this PA to determine the impact to the intruder and off-site individuals from tritiated water vapor released from the E-Area LLWF ILT vaults. Modeling results for Case III of this study were used in which vented crucibles are stored in a sealed concrete vault. This assumes that the vault is not ventilated, therefore, the source of HTO would be maximized in the vault. The epoxy plugged crucibles are assumed to vent due to shrinkage of the plug. Nearly saturated vault walls were assumed requiring an aqueous diffusion pathway. Wet vault walls were assumed to ensure saturated air at all times in the vault.

The Orebaugh and Wallace (1989) study assumed that: 1) the air in the vault is always water saturated;2) all 250 plugged crucibles, each containing $500 \mathrm{Ci}$ of ${ }^{3} \mathrm{H}$, are releasing hydrogen and ${ }^{3} \mathrm{H}$ to the vault (NOTE: presently only 142 crucibles are planned per vault making this analysis conservative); and 3 ) hydrogen diffuses out of the vault through an aqueous pathway (i.e., saturated concrete). The hydrogen and ${ }^{3} \mathrm{H}$ diffuse out of the crucibles into the vault, and gradually increase the concentration of both species in the vault atmosphere. The concentration in the soil is assumed to always be zero. The flux through all the vault walls at the time of the maximum ${ }^{3} \mathrm{H}$ concentration in the vault air was less than $1 \mathrm{mCi} / \mathrm{yr}$.

Using the upper bound flux estimate of $1 \mathrm{mCi} / \mathrm{yr}$ gives an annual release fraction of:

$1 \mathrm{mCi} / \mathrm{yr} /(250$ crucibles $* 500 \mathrm{Ci} /$ crucible $* 1000 \mathrm{mCi} / \mathrm{Ci})=8.0 \times 10^{-9} / \mathrm{yr}$. 
This fractional release is listed in Table 4.1-1, along with the fractional releases for the JCW.

\subsubsection{3 ${ }^{3} \mathrm{H}$ and ${ }^{14} \mathrm{C}$ in Naval Reactor Component Waste}

To estimate fluxes of potentially volatile radionuclides, ${ }^{3} \mathrm{H}$ and ${ }^{14} \mathrm{C}$, from the Naval Reactor wastes, two approaches are taken. For ${ }^{3} \mathrm{H}$, it is conservatively assumed that all of this radionuclide is in a volatile form, and is available for transport. Thus, the fractional release in one year is unity. This is similar to the assumption used for the trench waste (Section 4.1.2.1.1). For ${ }^{14} \mathrm{C}$, the corrosion rate of the waste form is taken into consideration, based on the fact that the great majcrity of the ${ }^{14} \mathrm{C}$ in the waste will initially be in the form of activated metal, due to the high content of activated stainless steel in the waste.

Corrosion rates of Inconel and Zircaloy, the two representative alloys found in the Naval Reactor Component wastes, are described in Appendix C.1.2.6. Briefly, corrosion rates for Inconel and Zircaloy are $5 \times 10^{-5}$ and $5 \times 10^{-6} \mathrm{~cm} / \mathrm{yr}$, respectively. Six different types of typical components were analyzed, each with different thicknesses, and thus different fractional corrosion and release rates. Data are provided describing the distribution of ${ }^{14} \mathrm{C}$ between the two different alloys. Thus, it is possible to estimate the fractional release of ${ }^{14} \mathrm{C}$ from the activated metal. The results are as follows.

For Inconel, with which $12 \%$ of the ${ }^{14} \mathrm{C}$ is associated (Table C. $1-6$ of Appendix C), the fractional release of ${ }^{14} \mathrm{C}$ is at most $2 \times 10^{-4} \mathrm{yr}^{-1}$ (Table C.1-7). For Zircaloy, with which $88 \%$ of the ${ }^{14} \mathrm{C}$ is associated (Table C.1-6), the fractional release of ${ }^{14} \mathrm{C}$ is at most $1 \times 10^{-5} \mathrm{yr}^{-1}$ (Table C.1-7). Thus, the maximum release of ${ }^{14} \mathrm{C}$ from activated metals in a given year based on this method of estimation is $0.12\left(2 \times 10^{-4}\right)+0.88$ $\left(1 \times 10^{-5}\right)$, or $3 \times 10^{-5} \mathrm{Ci} / \mathrm{yr}$ per $\mathrm{Ci}$ in activated metal. This estimated release rate is included in Table 4.1-1.

\subsubsection{Water Resource Impacts Analysis}

The source term analysis for water resource impacts addresses the potential release of radionuclides from the various waste forms to be disposed of in the E-Area disposal units to the vadose zone surrounding the vaults and trenches of this facility. Release may occur when water contacts the waste and radionuclides are leached from the waste form, or when radionuclides diffuse out of the units. The source term analysis requires development of a conceptual model to represent mechanisms of release and factors affecting the rate of release.

\subsubsection{Conceptual Model of the Source Term}

The rate of release for any particular radionuclide to the subsurface will be a function of:

- the quantity of that radionuclide initially disposed of (i.e., radionuclide inventory),

- the rate of water infiltration into disposal units, which depends on the long-term integrity of barriers to water intrusion,

- the composition of infiltrating water contacting waste, and

- the physical form, solubility, sorptive, and diffusive behavior of the radionuclide (i.e., physical/chemical characteristics).

Each of these parameters are discussed below, as they relate to mechanisms of release and the conceptual model to simulate these processes. 


\subsection{Radionuclide Inventory}

One purpose of the PA is to determine the allowable inventory of radionuclides for each type of waste disposal unit based on consideration of water resource impacts analysis requirements, protection of offsite members of the public, and analysis of impacts on inadvertent intruders; another is to estimate compliance with performance objectives based on the projected inventory for each of the radionuclides in the various waste disposal units. Projected inventories for each disposal unit were described in Section 3.3, and are listed in Appendix A.

Although a potentially large number of radionuclides may be disposed of in each unit (Appendix A), a small fraction of these radionuclides will contribute the majority of the dose. Shorter-lived and/or highly sorbing radionuclides may decay to insignificant levels before human exposures occur. In order to identify radionuclides that will be insignificant to the total potential dose associated with the E-Area disposal facility, and thereby focus the remaining analysis on the potentially significant radionuclides, the list of nuclides in the projected inventories was screened. The screening methodology addresses potential dose associated with water resource impacts and inadvertent intruders separately, because radionuclides important to inadvertent intruders may not be important to water resource impacts. The remainder of this discussion on screening is pertinent to water resource impacts; screening of the projected inventory with respect to intruder doses is described in Section 6.

Many radionuclides decay significantly during transport in the subsurface, due to short half-lives or high sorption potential, such that allowable inventories greatly exceed any imaginable inventory in a disposal unit. Screening calculations, used to identify radionuclides that do not decay significantly during transport, were carried out on a large suite of radionuclides which may be encountered during disposal operations.

Screening was accomplished with spreadsheet calculations, described in detail in Cook (1998). The methodology described in NCRP Report 123 (NCRP 1996), applicable to disposal of radionuclides in the ground, was followed. This approach may be summarized as follows. In order to relate dose to consumption of contaminated groundwater, a concentration of each radionuclide in groundwater is estimated. The average concentration of each radionuclide in the pore water of each disposal unit (assuming an initial inventory of one $\mathrm{Ci}$ ) during the first year of disposal is calculated, and then adjusted to account for leaching and radiological decay that may occur during travel to a point of interest (e.g., compliance point). The waste is assumed to be a material similar to soil. Travel time to the point of interest is estimated to be 5 years for a nonsorbing radionuclide, which is conservative with respect to actual travel times from the waste to the point of compliance for water resource impacts in this assessment. For sorbing radionuclides, a correction to the travel time is made to account for retardation of the contaminant plume. Plume spreading caused by diffusive and dispersive mechanisms is ignored, which further lends conservatism to the estimated concentration. For these calculations, porosity of the waste is assumed to be 0.3 for all units, and dry bulk density $\left(\rho_{b}\right)$ is assumed to be $1.5 \mathrm{~g} / \mathrm{ml}$; both reasonable values for soil. An average annual infiltration rate of $40 \mathrm{~cm} / \mathrm{y}$ (Appendix $C$ ) is assumed, based on site-specific data (i.e., reduction in infiltration into waste units due to moisture barriers is neglected). Sorption coefficients $\left(\mathrm{K}_{\mathrm{d}}\right.$ 's) were taken from Sheppard and Thibault $(1990)$ and the NCRP Report 123 (NCRP 1996). Disposal unit-specific parameters assumed for these screening calculations are listed in Table 4.1-2.

Doses to individuals ingesting groundwater are calculated by multiplying the calculated concentration in water by radionuclide-specific dose factors $(\mathrm{mrem} / \mathrm{Ci})$ and by a $730 \mathrm{~L} /$ year assumed ingestion rate. The results are expressed as mrem/year per $\mathrm{Ci}$ of each radionuclide disposed of in each unit (e.g., vault or trench). These doses are then multiplied by $10^{7}$ curies to see the dose effect of disposing of 10 million curies of each radionuclide. The factor of $10^{7}$ was selected because it represents the total number of 
Table 4.1-2 Parameters Used in Screening of Radionuclide Inventories for E-Area Low-Level Waste Facility Disposal Units and Lists of Radionuclides for Further Analysis with Respect to Off-Site Public Exposures

\begin{tabular}{|c|c|c|c|}
\hline $\begin{array}{l}\text { Type of } \\
\text { Disposal Unit }\end{array}$ & $\begin{array}{l}\text { Depth of } \\
\text { Waste in } \\
\text { Disposal Unit } \\
\text { (m) }\end{array}$ & $\begin{array}{l}\text { Area of Waste } \\
\text { in Disposal } \\
\text { Unit }\left(\mathrm{m}^{2}\right)\end{array}$ & $\begin{array}{c}\text { Radionuclides Identified as Potentially Significant } \\
\text { Contributors to Dose Related to Water Resource } \\
\text { Impacts Analysis }\end{array}$ \\
\hline LAW Vaults & 3 & 8624 & $\begin{array}{l}{ }^{3} \mathrm{H},{ }^{14} \mathrm{C},{ }^{59} \mathrm{Ni},{ }^{79} \mathrm{Se},{ }^{87} \mathrm{Rb},{ }^{90} \mathrm{Sr}+\mathrm{d},{ }^{93} \mathrm{Zr}+\mathrm{d},{ }^{94} \mathrm{Nb},{ }^{99} \mathrm{Tc}, \\
{ }^{107} \mathrm{Pd},{ }^{126} \mathrm{Sn}+\mathrm{d},{ }^{129} \mathrm{I},{ }^{135} \mathrm{Cs},{ }^{232} \mathrm{Th}+\mathrm{d},{ }^{232} \mathrm{U}+\mathrm{d},{ }^{233} \mathrm{U}+\mathrm{d}, \\
{ }^{234} \mathrm{U}+\mathrm{d},{ }^{235} \mathrm{U}+\mathrm{d},{ }^{236} \mathrm{U},{ }^{237} \mathrm{~Np},{ }^{238} \mathrm{U}+\mathrm{d},{ }^{238} \mathrm{Pu}+\mathrm{d},{ }^{239} \mathrm{Pu}+\mathrm{d}, \\
{ }^{240} \mathrm{Cu} \\
{ }^{240} \mathrm{Pu}+\mathrm{d},{ }^{241} \mathrm{Pu} \mathrm{d},{ }^{242} \mathrm{Pu}+\mathrm{d},{ }^{244} \mathrm{Pu},{ }^{241} \mathrm{Am}+\mathrm{d},{ }^{243} \mathrm{Am}+\mathrm{d}, \\
{ }^{244} \mathrm{Cm}+\mathrm{d},{ }^{245} \mathrm{Cm}+\mathrm{d},{ }^{246} \mathrm{Cm},{ }^{247} \mathrm{Cm}+\mathrm{d},{ }^{248} \mathrm{Cm}+\mathrm{d}, \\
{ }^{249} \mathrm{Cf}+\mathrm{d},{ }^{252} \mathrm{Cf}+\mathrm{d}\end{array}$ \\
\hline IL Vaults & 6 & 728 & $\begin{array}{l}{ }^{3} \mathrm{H},{ }^{14} \mathrm{C},{ }^{59} \mathrm{Ni},{ }^{79} \mathrm{Se},{ }^{90} \mathrm{Sr}+\mathrm{d},{ }^{93} \mathrm{Zr}+\mathrm{d},{ }^{99} \mathrm{Tc},{ }^{107} \mathrm{Pd}, \\
{ }^{226} \mathrm{Sn}+\mathrm{d},{ }^{129} \mathrm{I},{ }^{135} \mathrm{Cs},{ }^{232} \mathrm{Th}+\mathrm{d},{ }^{232} \mathrm{U}+\mathrm{d},{ }^{233} \mathrm{U}+\mathrm{d},{ }^{234} \mathrm{U}+\mathrm{d}, \\
{ }^{235} \mathrm{U}+\mathrm{d},{ }^{236} \mathrm{U},{ }^{237} \mathrm{~Np},{ }^{238} \mathrm{U}+\mathrm{d},{ }^{238} \mathrm{Pu}+\mathrm{d},{ }^{239} \mathrm{Pu}+\mathrm{d}, \\
{ }^{240} \mathrm{Pu}+\mathrm{d},{ }^{241} \mathrm{Pu}+\mathrm{d},{ }^{242} \mathrm{Pu}+\mathrm{d},{ }^{244} \mathrm{Pu},{ }^{241} \mathrm{Am}+\mathrm{d},{ }^{243} \mathrm{Am}+\mathrm{d}, \\
{ }^{244} \mathrm{Cm}+\mathrm{d},{ }^{245} \mathrm{Cm}+\mathrm{d},{ }^{246} \mathrm{Cm},{ }^{247} \mathrm{Cm}+\mathrm{d},{ }^{248} \mathrm{Cm}+\mathrm{d}, \\
{ }^{249} \mathrm{Cf}+\mathrm{d},{ }^{252} \mathrm{Cf}+\mathrm{d}\end{array}$ \\
\hline Slit Trenches & 4.8 & 1200 & $\begin{array}{l}{ }^{3} \mathrm{H},{ }^{14} \mathrm{C},{ }^{59}{ }^{5 i},{ }^{79} \mathrm{Se},{ }^{87} \mathrm{Rb},{ }^{90} \mathrm{Sr}+\mathrm{d},{ }^{93} \mathrm{Zr}+\mathrm{d},{ }^{99} \mathrm{Tc},{ }^{107} \mathrm{Pd}, \\
{ }^{123} \mathrm{Sn}+\mathrm{d},{ }^{129} \mathrm{I},{ }^{135} \mathrm{Cs},{ }^{230} \mathrm{Th}+\mathrm{d},{ }^{232} \mathrm{Th}+\mathrm{d},{ }^{232} \mathrm{U}+\mathrm{d}, \\
{ }^{233} \mathrm{U}+\mathrm{d},{ }^{234} \mathrm{U}+\mathrm{d},{ }^{235} \mathrm{U}+\mathrm{d},{ }^{236} \mathrm{U},{ }^{237} \mathrm{~Np},{ }^{238} \mathrm{U}+\mathrm{d},{ }^{238} \mathrm{Pu}+\mathrm{d}, \\
{ }^{239} \mathrm{Pu}+\mathrm{d},{ }^{240} \mathrm{Pu}+\mathrm{d},{ }^{241} \mathrm{Pu}+\mathrm{d},{ }^{242}{ }^{244} \mathrm{Pu}+\mathrm{d},{ }^{244} \mathrm{Pu},{ }^{241} \mathrm{Am}+\mathrm{d}, \\
{ }^{243} \mathrm{Am}+\mathrm{d},{ }^{242} \mathrm{Cm}+\mathrm{d},{ }^{244} \mathrm{Cm}+\mathrm{d},{ }^{245} \mathrm{Cm}+\mathrm{d},{ }^{246} \mathrm{Cm}, \\
{ }^{247} \mathrm{Cm}+\mathrm{d},{ }^{248} \mathrm{Cm}+\mathrm{d},{ }^{249} \mathrm{Bk}+\mathrm{d},{ }^{249} \mathrm{Cf}+\mathrm{d},{ }^{252} \mathrm{Cf}+\mathrm{d}\end{array}$ \\
\hline $\begin{array}{l}\text { Intimately- } \\
\text { mixed } \\
\text { Cement- } \\
\text { stabilized } \\
\text { Waste Units }^{\mathbf{a}}\end{array}$ & 4.8 & 1200 & $\begin{array}{l}{ }^{3} \mathrm{H},{ }^{14} \mathrm{C},{ }^{59} \mathrm{Ni},{ }^{79} \mathrm{Se},{ }^{87} \mathrm{Rb},{ }^{90} \mathrm{Sr}+\mathrm{d},{ }^{93} \mathrm{Zr}+\mathrm{d},{ }^{94} \mathrm{Nb},{ }^{99} \mathrm{Tc}, \\
{ }^{107} \mathrm{Pd},{ }^{126} \mathrm{Sn}+\mathrm{d},{ }^{129} \mathrm{~d},{ }^{135} \mathrm{Cs},{ }^{232} \mathrm{Th}+\mathrm{d},{ }^{232} \mathrm{U}+\mathrm{d},{ }^{233} \mathrm{U}+\mathrm{d}, \\
{ }^{234} \mathrm{U}+\mathrm{d},{ }^{235} \mathrm{U}+\mathrm{d},{ }^{236} \mathrm{U},{ }^{237} \mathrm{~Np},{ }^{238} \mathrm{U}+\mathrm{d},{ }^{238} \mathrm{Pu}+\mathrm{d},{ }^{239} \mathrm{Pu}+\mathrm{d}, \\
{ }^{240} \mathrm{O},{ }^{244} \mathrm{Pu}+\mathrm{d},{ }^{241} \mathrm{Pu}+\mathrm{d},{ }^{242} \mathrm{Pu}+\mathrm{d},{ }^{244} \mathrm{Pu},{ }^{241} \mathrm{Am}+\mathrm{d},{ }^{243} \mathrm{Am}+\mathrm{d}, \\
{ }^{244} \mathrm{Cm}+\mathrm{d},{ }^{245} \mathrm{Cm}+\mathrm{d},{ }^{246} \mathrm{Cm},{ }^{247} \mathrm{Cm}+\mathrm{d},{ }^{248} \mathrm{Cm}+\mathrm{d}, \\
{ }^{249} \mathrm{Cf}+\mathrm{d},{ }^{252} \mathrm{Cf}+\mathrm{d}\end{array}$ \\
\hline $\begin{array}{l}\text { Cement- } \\
\text { stabilized } \\
\text { Encapsulated } \\
\text { Waste Units } \\
\end{array}$ & 4.8 & 1200 & $\begin{array}{l}{ }^{3} \mathrm{H},{ }^{59} \mathrm{Ni},{ }^{79} \mathrm{Se},{ }^{90} \mathrm{Sr}+\mathrm{d},{ }^{93} \mathrm{Zr}+\mathrm{d},{ }^{99} \mathrm{Tc},{ }^{107} \mathrm{Pd},{ }^{126} \mathrm{Sn}+\mathrm{d}, \\
{ }^{129} \mathrm{I},{ }^{135} \mathrm{Cs},{ }^{232} \mathrm{U}+\mathrm{d},{ }^{233} \mathrm{U}+\mathrm{d},{ }^{234} \mathrm{U}+\mathrm{d},{ }^{235} \mathrm{U}+\mathrm{d},{ }^{236} \mathrm{U}, \\
{ }^{238} \mathrm{U}+\mathrm{d},{ }^{238} \mathrm{Pu}+\mathrm{d},{ }^{239} \mathrm{Pu}+\mathrm{d},{ }^{240} \mathrm{Pu}+\mathrm{d},{ }^{242} \mathrm{Pu}+\mathrm{d}\end{array}$ \\
\hline $\begin{array}{l}\text { Naval Reactor } \\
\text { Components }\end{array}$ & 4.7 & $1850^{b}$ & $\begin{array}{l}{ }^{3} \mathrm{H},{ }^{14} \mathrm{C},{ }^{59} \mathrm{Ni},{ }^{79} \mathrm{Se},{ }^{90} \mathrm{Sr}+\mathrm{d},{ }^{93} \mathrm{Zr}+\mathrm{d},{ }^{94} \mathrm{Nb},{ }^{99} \mathrm{Tc},{ }^{107} \mathrm{Pd}, \\
{ }^{126} \mathrm{Sn}+\mathrm{d},{ }^{129} \mathrm{I},{ }^{135} \mathrm{Cs},{ }^{232} \mathrm{Th}+\mathrm{d},{ }^{232} \mathrm{U}+\mathrm{d},{ }^{234} \mathrm{U}+\mathrm{d},{ }^{235} \mathrm{U}+\mathrm{d}, \\
\\
{ }^{236} \mathrm{U},{ }^{237} \mathrm{~Np},{ }^{238} \mathrm{U}+\mathrm{d},{ }^{238} \mathrm{Pu}+\mathrm{d},{ }^{239} \mathrm{Pu}+\mathrm{d},{ }^{240} \mathrm{Pu}+\mathrm{d}, \\
{ }^{241} \mathrm{Pu}+\mathrm{d},{ }^{242} \mathrm{Pu}+\mathrm{d},{ }^{244} \mathrm{Pu},{ }^{241} \mathrm{Am}+\mathrm{d},{ }^{243} \mathrm{Am}+\mathrm{d}, \\
{ }^{244} \mathrm{Cm}+\mathrm{d},{ }^{245} \mathrm{Cm}+\mathrm{d},{ }^{246} \mathrm{Cm},{ }^{247} \mathrm{Cm}+\mathrm{d},{ }^{248} \mathrm{Cm}+\mathrm{d}, \\
{ }^{249} \mathrm{Cf}+\mathrm{d}\end{array}$ \\
\hline
\end{tabular}

Starting list of radionuclides (i.e., before screening) assumed to be the same as that for the LAW vaults.

b Corresponds to an area taken up by 100 casks. 
curies, of all radionuclides combined, that has been disposed in LLW at SRS over 40 years of operation. The effect of this factor is to scale the estimated doses to a total disposal unit inventory that is greater than projected inventories, to provide a very conservative upper bound on dose. Radionuclides for which calculated doses are less that $1 / 100$ of the $4 \mathrm{mrem} / \mathrm{yr}$ limit for water resource impacts (i.e., less than 0.04 $\mathrm{mrem} / \mathrm{yr}$ ) are then considered to be screened from further consideration in this assessment.

A departure from the NCRP screening methodology occurred in how radioactive progeny were handled in the analysis. Instead of directly incorporating the daughter ingrowth into the spreadsheet calculations, each radionuclide in the inventory lists for each disposal unit was evaluated individually with respect to the potential for producing daughters of radiological significance. A table of radionuclides with significant long-lived daughters in NCRP Report 123 was consulted to select radionuclides for which further analysis was required, whether or not the parent radionuclide might be screened by the methodology described above. The lists of radionuclides of potential significance with respect to water resource impacts, including those with potentially significant daughters noted by " $+d "$, are given in Table 4.1-2 for each type of disposal unit in the E-Area LLWF.

\subsection{Rate of Water Infiltration into Disposal Units}

Release of radionuclides from waste is triggered by contact with water which has seeped into the waste disposal units from the surrounding vadose zone. The rate of water infiltration into the disposal units is a function of the infiltration rate of rainwater into the subsurface and the efficiency of engineered barriers which serve to divert water away from the waste in the disposal units. Boxes or other containers used to facilitate placement of waste into disposal units are not considered reliable barriers to water infiltration.

The conceptual model of water infiltration into the vaults considers the types of engineered barriers (e. g., moisture barriers, vaults, grouted waste forms) associated with the various disposal unit types (Section 3.2). Infiltration through these barriers is simulated using the numerical code PORFLOW (Appendix B), which provides estimates of rates of transport of water through the subsurface soil, engineered barriers, and waste forms to the water table. More in-depth descriptions of the simulation domains used and assumptions made to estimate this transport is provided in Section 4.3.3.

\subsection{Integrity of Barriers to Water Intrusion}

Degradation of engineered barriers is expected to occur over time, thus increasing the influx of water to the wastes. Degradation will affect infiltration barriers, which are constructed for all units, and concrete vaults, containers, and cementitious or solid metal waste forms, which are present in some units.

Infiltration barrier degradation. Degradation of the infiltration barrier (clay/gravel drain system) is expected to occur by a number of natural processes. Potential processes include erosion, intrusion by plants and animals, and external events such as settling or slumping or a seismic event. These processes will reduce the effectiveness of the cover in limiting the vertical moisture flux.

As presently conceived in the closure concept (Section 3.2.2), shallow-rooted bamboo will be planted on the disposal site and a system of drainage ditches will be constructed to handle surface runoff and diverted infiltration. During the period of active institutional control it is assumed that periodic site inspection would reveal any degradation of the overlying cover and drainage system and corrective actions would be taken. Cover degradation during the institutional control period is therefore likely to be minimal. Sheet erosion will occur, but the final vegetative cover would minimize the effects of this disturbance. 
Retum of the SRS land to unrestricted use at the end of the active institutional control period may result in a usage conversion to agricultural practices, consistent with past and current land use in the SRS vicinity. Row crop farming, which is consistent with historical practices in the vicinity, would increase the erosive effects of precipitation. Soil erosion rates for cropland in the vicinity of the SRS are on the order of $2 \mathrm{~kg} \mathrm{~m}^{-2} \mathrm{yr}^{-1}$ (Section 3.1.4.1). Erosion is reduced several hundred fold if a dense vegetative cover is present (Section 3.1.4.1). This suggests that there will be little erosion as long as the final vegetative layer has not been cleared. However, if the final vegetative layer is cleared, the cover may be eroded down to the gravel layer in as little as $\mathbf{6 5 0}$ years. Erosion of the gravel layer is difficult to predict. In this analysis, the following assumptions were made regarding degradation of the infiltration barrier:

- for the LAW and IL vaults, it is assumed that the cover remains fully functional until the roof of the vaults fails and thus, no longer provide support for the cover. At this time, the permeability of the gravel and clay materials are assumed to be the same as that of the top soil and backfill soil, respectively.

- for the slit trenches, degradation of the cover to the properties of the top soil and backfill soil is assumed to occur at the time institutional control ends, in lieu of support by a cementitious waste form or vault.

- for the intimately-mixed cement-stabilized waste, the cement-stabilized encapsulated waste, and the naval reactor waste, the moisture barrier is assumed to remain intact until waste form failure (at 300 years for all except the naval reactor waste, for which the container is projected to fail at 750 years). At the time of failure, the cover is assumed to degrade to the properties of the top soil and backfill soil.

Vault degradation. The concrete vaults are expected to degrade slowly through a combination of physical, chemical, and mechanical processes (Walton et al. 1990). Physical and mechanical degradation processes that produce cracking are of primary concern, because of the concomitant increase in permeability. Shrinkage cracks occur as a result of the temperature cycling during curing of concrete structures, and thus are present before the facility closure cover is constructed. This allows for filling of the outer portion of the cracks, in the vault walls or roof, with epoxy prior to closure. Cracking can occur after the vaults have been covered as a result of degradation of the epoxy used to fill shrinkage cracks, foundation settling, or rebar expansion due to corrosion. Eventually, structural failure (collapse) of the vault roofs may occur.

The principal chemical processes that disrupt the integrity of concrete structures are: sulfate attack, carbonation, calcium hydroxide leaching, and rebar corrosion. The effects of these processes on vault degradation have been analyzed using a methodology described in Walton, et al. (1990). The analysis of chemical degradation effects and concomitant structural impacts are discussed in detail in Appendix D. The results of this analysis indicated that cracks completely penetrating the LAW vault roofs are most likely to occur around 1,400 years, and not before 575 years for the $\mathbb{L}$ vaults. Vault failure was defined as structural collapse of the vaults. This was estimated to occur at approximately 3,100 years and 1,050 years for the LAW vaults and IL vaults, respectively. The degradation scenarios assumed for these vaults utilize these estimates for times that degradation and failure of the vaults occur.

At roof failure, the waste compartment for the LAW vaults is assumed to have the hydraulic properties of top soil, which is more permeable than the surrounding native soil. The more permeable zone is assumed to occur because void spaces exist in the LAW vaults before failure. However, for the IL vaults, in which voids are filled in with grout., the hydraulic characteristics of the waste compartment are assumed to mimic those of native soil after roof failure. 
Cement-stabilized waste form degradation. Degradation of the intimately-mixed cement-stabilized waste form, cement-stabilized encapsulated waste form, and the enhanced waste form, all of which are surrounded by copious amounts of grout, was not evaluated rigorously in this PA. Instead, these waste forms were assumed to remain intact for 300 years, based on the Nuclear Regulatory Commission's use of 300 years as the period of time for which credit can be taken for stabilized Class B wasteforms (NRC 1981) At the time of failure and beyond, the waste form and any encapsulating cement is assumed to degrade (i.e., increase in permeability) to the hydraulic properties of native soil, which surrounds the waste.

Naval reactor container and waste degradation. There is no standard NR waste disposal container due to the variety of NR Waste components. The actual container configuration, thickness, material of construction and closure method may be tailored to the characteristics of the NR waste component at the time of disposal. Planned or proposed containers for NR waste disposal are mostly composed of carbon steel or low-alloy steel and closed by a gasket or a weld (Section 3.3.5.4).

Based on data and recommendations of Bettis Atomic Power Laboratory (Bettis 1995a), a typical disposal container may be assumed to be intact for 750 years, at which time the weld may be corroded through and water may enter and leave the container. This assumption is based on a minimum weld thickness of $4 \mathrm{~cm}$, and a corrosion rate of about $4.2 \times 10^{-3} \mathrm{~cm} / \mathrm{yr}$ for carbon steel (based on a literature survey by Bettis), and the assumption that the weld material corrodes at a rate similar to that of carbon steel. Before 750 years, the container is assumed to be intact and there is no contaminant release. After container breach, the container is assumed to provide no deterrent to leaching of the contents, and the waste is assumed to have the hydraulic properties of the top soil, which is more permeable than the surrounding native soil. The more permeable waste zone is assumed to occur due to the initial presence of voids within the NR containers.

The degradation scenarios for the various waste disposal units are summarized in Table 4.1-3.

Subsidence is an issue that must be considered for all waste disposal units at E-Area. Subsidence of the land surface may occur when wood product waste, or other readily-degraded material, is broken down to a form that decreases the waste volume significantly. Subsidence may also occur at the time of roof collapse of vaults which have significant void spaces in the waste compartment, as is encountered in the LAW vaults. Although subsidence is a temporary condition, due to the natural infilling of depressions that occurs over time in disturbed areas, the potential effect on the influx of water into the disposal units must be considered. For the waste disposal trenches containing up to $40 \%$ wood products (slit trenches), subsidence is most likely to occur within a few tens of years from the time of closure due to the rapid degradation of wood products in a humid environment. Because the Savannah River Site will be under institutional control during the time period of possible subsidence, it is assumed in this assessment that controls will be in place to quickly correct any subsidence that occurs in the slit trenches.

Subsidence caused by failure of the concrete LAW vaults is not likely to occur during the institutional control period, however. In fact, subsidence of this type of structure is not likely to occur before 3,100 years according to the analysis in Appendix D. Therefore, only slowly-decaying and more stronglysorbing radionuclides will be present in the LAW vaults during the period of time that subsidence, and thus increased infiltration, may occur. Because subsidence is believed to only temporarily increase infiltration, until natural erosive processes work to even the landscape again, it is not likely that the effect of leaching of strongly-sorbing radionuclides during this time period will be significant. However, a sensitivity study on the significance of a relatively brief period of increased infiltration was conducted in order to test this belief. The results of this study are presented in Section 5.3. 
Table 4.1-3 Summary of Degradation Scenarios for E-Area Low Level Waste Facility Disposal Units

\begin{tabular}{|c|c|c|c|c|c|c|c|}
\hline \multirow[b]{2}{*}{$\begin{array}{c}\text { Type of } \\
\text { Disposal Unit }\end{array}$} & \multicolumn{2}{|c|}{ Pre-closure phase } & \multirow{2}{*}{$\begin{array}{l}\text { Intact Phase } \\
\text { Time of } \\
\text { occurrence } \\
\text { (yr) }\end{array}$} & \multicolumn{2}{|c|}{ Degraded Phase } & \multicolumn{2}{|c|}{ Failed Phase } \\
\hline & $\begin{array}{c}\text { Time of } \\
\text { occurrence } \\
\text { (yr) }\end{array}$ & $\begin{array}{l}\text { Character- } \\
\text { istics }\end{array}$ & & $\begin{array}{c}\text { Time of } \\
\text { occurrence } \\
(y r)\end{array}$ & $\begin{array}{l}\text { Character- } \\
\text { istics }\end{array}$ & $\begin{array}{c}\text { Time of } \\
\text { occurrence } \\
\text { (yr) }\end{array}$ & $\begin{array}{l}\text { Character- } \\
\text { istics }\end{array}$ \\
\hline LAW Vaults & NA & & $0-1400$ & $1400-3100$ & $\begin{array}{c}\text { vaults } \\
\text { cracked }\end{array}$ & $\begin{array}{l}3100 \text { and } \\
\text { up }\end{array}$ & $\begin{array}{l}\text { moisture } \\
\text { barrier } \\
\text { failure; } \\
\text { roof } \\
\text { failure }\end{array}$ \\
\hline IL Vaults & NA & & $0-575$ & $575-1050$ & $\begin{array}{c}\text { vaults } \\
\text { cracked }\end{array}$ & $\begin{array}{l}1050 \text { and } \\
\text { up }\end{array}$ & $\begin{array}{l}\text { moisture } \\
\text { barrier } \\
\text { failure; } \\
\text { roof } \\
\text { failure }\end{array}$ \\
\hline Slit Trenches & $0-25$ & $\begin{array}{c}\text { No } \\
\text { moisture } \\
\text { barrier }\end{array}$ & $25-125$ & $\overline{\mathrm{NA}}$ & & 125 and up & $\begin{array}{c}\text { moisture } \\
\text { barrier } \\
\text { failure }\end{array}$ \\
\hline $\begin{array}{l}\text { Intimately- } \\
\text { mixed } \\
\text { Cement- } \\
\text { stabilized } \\
\text { Waste Units }\end{array}$ & NA & & $0-300$ & $\overline{\mathrm{NA}}$ & & 300 and up & $\begin{array}{l}\text { moisture } \\
\text { barrier } \\
\text { failure; } \\
\text { wasteform } \\
\text { failure }\end{array}$ \\
\hline $\begin{array}{l}\text { Cement- } \\
\text { stabilized } \\
\text { Encapsulated } \\
\text { Waste Units }\end{array}$ & NA & & $0-300$ & $\overline{\mathrm{NA}}$ & & 300 and up & $\begin{array}{l}\text { moisture } \\
\text { barrier } \\
\text { failure; } \\
\text { wasteform } \\
\text { failure }\end{array}$ \\
\hline $\begin{array}{l}\text { Naval } \\
\text { Reactor } \\
\text { Components }\end{array}$ & $\mathrm{NA}$ & & $0-750$ & NA & & 750 and up & $\begin{array}{l}\text { Moisture } \\
\text { barrier } \\
\text { failure; } \\
\text { container } \\
\text { failure }\end{array}$ \\
\hline
\end{tabular}




\subsection{Composition of Infiltrating Water}

The composition of water infiltrating the disposal units will potentially affect the solubility or sorptive characteristics of radionuclides in the wastes. Water which has infiltrated disposal units consisting of vaults and/or containing cementitious waste forms will have a composition which reflects the interaction of concrete pore water with vadose zone water. The presence of $\mathrm{CO}_{2}$ gas in the soil and calcite present as a weathering product in the cement will buffer the $\mathrm{pH}$ of the vault water to between 7 and 8 . Water which has entered units without cementitious components will have a composition more similar to that of vadose zone water. Corrosion products of metals that are present in the disposal units, arising either from waste containers or surface contaminated wastes, may also be present in the water contacting wastes.

\section{Physical/chemical characteristics}

The physical and chemical form of radionuclides disposed of in E Area will vary according to the form the radionuclide is in when disposed of, and conditions in the disposal unit which may cause a change in form over time. Waste records are not sufficiently complete to accurately assign a form to each radionuclide in all units at the time of disposal, and considerable uncertainty exists regarding conditions in the units over time that may cause a change of form. Therefore, assumptions regarding chemical and physical form are based on limited available information derived from consideration of the probable water composition in the waste disposal units, discussed above. Conservative assumptions are generally made regarding physical and chemical form that tend to overestimate the mobility of radionuclides from the disposal units, and thus overestimate the concentrations in groundwater.

With the exception of radionuclides known to be present as activation products in naval reactor (NR) wastes, radionuclides are assumed to be present as surface contamination that is leached according to laws governing solubility and sorption. Wastes are represented as porous media, thus maximizing the surface area of the waste potentially exposed to infiltrating water. For the analysis pertinent to water resource impacts, radionuclides that have volatile forms (e.g., H-3 and C-14) are assumed to be completely soluble in water, despite the fact that a separate analysis is done (Section 4.1.2) which assumes a fraction of these radionuclides is volatile.

For waste disposed of in steel boxes, or otherwise closely associated with steel, but not grouted, sorption onto corrosion products of steel was assumed to reduce aqueous concentrations of radionuclides present within this waste. The LAW vaults, cement-stabilized encapsulated waste, and naval reactor waste will contain waste which falls into this category. Geochemical calculations of sorption coefficients $\left(\mathrm{K}_{d} \mathrm{~s}\right)$ for many of the radionuclides in waste destined for the LAW vaults are described in Appendix E. These coefficients are also applied to the cement-stabilized encapsulated waste and naval reactor waste. Although waste destined for the $\mathrm{IL}$ vaults and enhanced waste units may also contain corrosion products of steel over time, the presence of large quantities of cement grout used in these units will likely control the sorption characteristics of radionuclides in the waste.

Aqueous concentrations of radionuclides in Naval Reactor wastes are not initially governed by sorption processes or solubility limits; less that $0.1 \%$ of the radionuclide inventory in these waste components is in the form of surface contamination (Bettis 1995b). Thus, release of radionuclides from the Naval Reactor waste form to the aqueous phase will be largely governed by the corrosion rate of the metal matrix. Once released by corrosion, radionuclides from Naval Reactor wastes are expected to behave similarly to those in other waste forms, according to their sorption characteristics. Equations for release rate based on a corrosion analysis of NR wastes are provided in Appendix C. 
The sorption coefficients $\left(\mathrm{K}_{d} s\right)$ assumed in the analyses of release from waste forms are listed in Table 4.1-4. Selection of $K_{d} s$ was made according to the following rationale. Site-specific values of soil $K_{d} s$ are considered most appropriate; when available, they were used. Next, the comprehensive listing of default values by Sheppard and Thibault (1990) was consulted for $K_{d} s$ in soil and clay. The sandy soil $K_{d}$ was selected for "soil" because this value tends to be lower than for other soil types, and thus is conservative (i.e., may overestimate radionuclide mobility) with respect to water resource impacts. For a few radionuclides not listed by Sheppard and Thibault, the NCRP Publication 123 was consulted (1996). For concrete, a listing of $\mathrm{K}_{d} \mathrm{~s}$ by Bradbury and Sarott (1995) was consulted. For waste in which corrosion products are expected to affect sorption, $K_{d} s$ were developed in Appendix $E$ (Geochemistry). For slit trench waste, the effects of wood degradation products on sorption are accounted for in some elemental $K_{d} s$ based on an analysis by Serkiz and Myers (1996). For isotopes of $U$ and Pu, limits on solubility of these elements in cementitious waste forms, or in the walls and floors of concrete vaults, where the $\mathrm{pH}$ is expected to be in excess of 7 , are assumed to affect availability for transport. The solubility limits assumed are developed in Appendix E (Geochemistry) and listed in Table 4.1-5.

Diffusion of radionuclides through porous media is a potentially important means of release from some of the E-Area waste disposal facilities, because engineered barriers limit convective transport when intact. For a given porous material, it is reasonable to assume that apparent diffusion coefficients (molecular diffusion coefficients corrected for tortuosity of the porous medium) are similar for all radionuclides because molecular diffusivities in water do not vary significantly. Apparent diffusion coefficients will vary, however, between porous materials due to differences in tortuosity. Tortuosity cannot be measured directly, but apparent diffusion coefficients have been obtained empirically for conservative (nonsorbing, nonreactive, nondecaying) compounds. Apparent diffusion coefficients assumed for the various porous materials encountered are listed in Table 4.1-6. Calculation of diffusional release is part of the mass transport simulations described in Section 4.3 .3 below.

\subsubsection{Estimated Releases of Radionuclides}

Computational analysis of the release of radionuclides from the waste to the surrounding vadose, or unsaturated, zone environment of the E-Area LLWF disposal units is an integral part of the total analysis of transport from the waste to the point of compliance for water resource impacts. This total analysis is described in detail in Section 4.3.3. A separate accounting of quantity of radionuclides released from the waste forms before transport in the vadose zone is not readily available. However, the fractional release of radionuclides to the saturated zone (i.e., fraction of original inventory released as a function of time) is readily available, and both tabulated and graphical output of the results of these calculations are provided in Section 4.3.3.

\subsubsection{Radon}

Radon is assumed to be released through the ground surface from decay of disposed ${ }^{234} \mathrm{U}$. 
Table 4.1-4 Elemental Sorption Coefficients $\left(K_{d} s\right)$ for E-Area Radionuclides

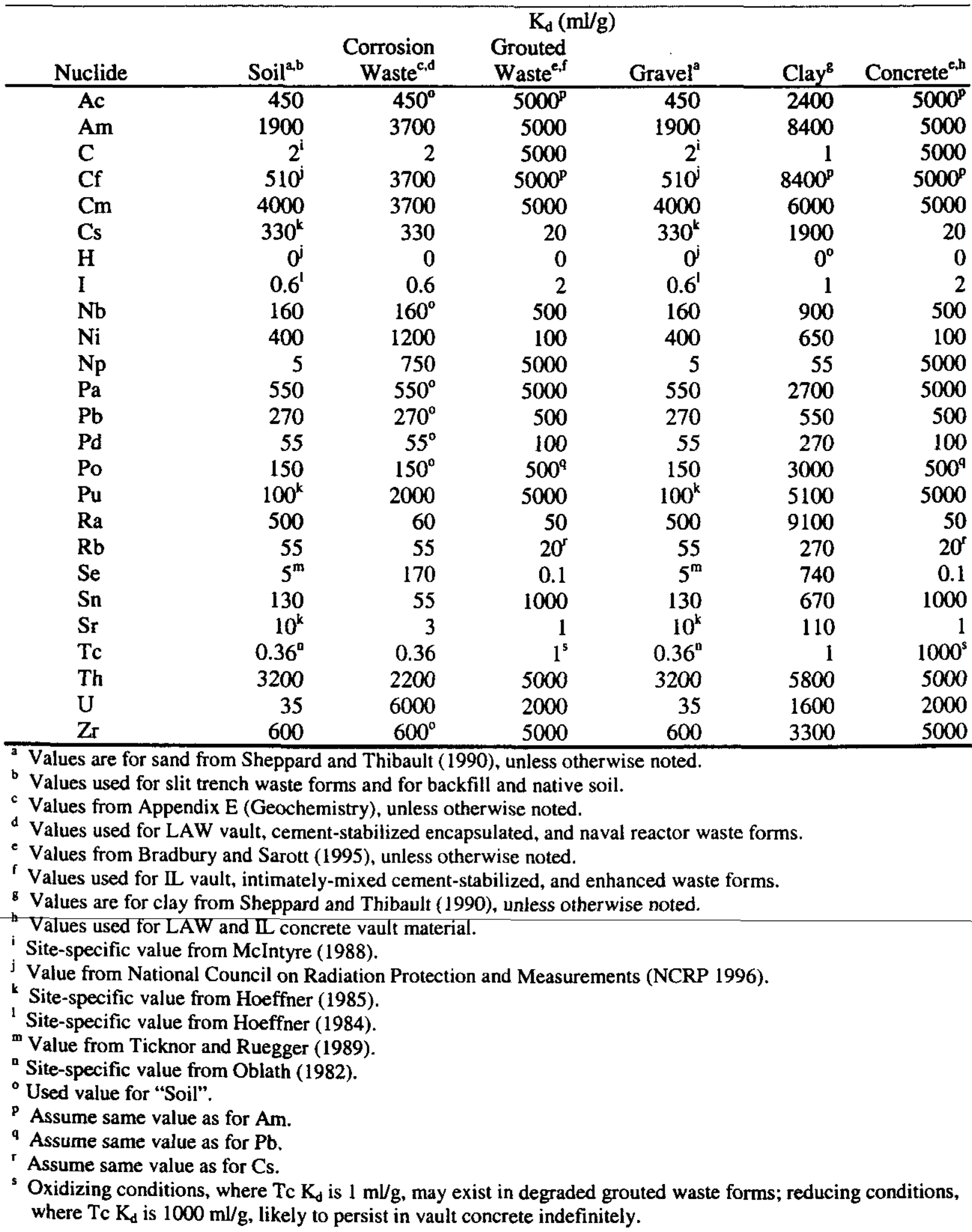


Table 4.1-5 Solubility Limits for Plutonium and Uranium.

\begin{tabular}{clc}
\hline & \multicolumn{2}{c}{ Solubility Limit } \\
Element & $\mathrm{g} / \mathrm{cc}$ \\
\hline $\mathrm{Pu}$ & $4.4 \times 10^{-13}$ & $1.1 \times 10^{-13}$ \\
$\mathrm{U}$ & $3 \times 10^{-10}$ & $7.0 \times 10^{-11}$ \\
\hline
\end{tabular}

Table 4.1-6 Diffusion Coefficients Assumed for Mass Transport Simulations

\begin{tabular}{|c|c|c|}
\hline Material & $\begin{array}{l}\text { Apparent Diffusivity } \\
\left(\mathrm{cm}^{2} / \mathrm{s}\right)\end{array}$ & Source \\
\hline Top soil, Native soil & $5 \times 10^{-6}$ & Freeze and Cherry, 1979 \\
\hline Gravel & $1 \times 10^{-5}$ & $\begin{array}{l}\text { assumed equal to molecular diffusivity without } \\
\text { tortuosity correction }\end{array}$ \\
\hline Clay & $1.5 \times 10^{-6}$ & a \\
\hline Backfill & $5 \times 10^{-6}$ & assumed same as for top soil and native soil \\
\hline $\begin{array}{l}\text { Concrete and } \\
\text { cementitious waste }\end{array}$ & $1 \times 10^{-8}$ & (personal communication, C. A. Langton 1997) \\
\hline $\begin{array}{l}\text { Non-cementitious } \\
\text { Waste }\end{array}$ & $5 \times 10^{-6}$ & assumed same as for top soil and native soil \\
\hline
\end{tabular}




\subsection{Pathways and Scenarios}

The source term analysis in Section 4.1 provides estimates of release of radionuclides from the waste disposal units to the immediate environment. These releases are considered in this section with respect to how radionuclides might be further dispersed and ultimately lead to exposures to off-site members of the public. In order to evaluate exposures in terms of performance objectives stated (Section 2.5), significant pathways and scenarios relevant to estimating exposures for the all-pathways analysis, the air pathway analysis, and the water resource impacts analysis must be identified.

\subsubsection{All-Pathways Analysis}

In order to evaluate the potential sources of off-site contamination, numerous pathways to human exposure from buried LLW are considered. A generalized diagram of pathways to human receptors from a subsurface source of radionuclides is shown in Fig. 4.2-1. Arrows (both broken and solid) represent pathways of radionuclide movement from the source, between compartments (represented by boxes), and eventually to a human receptor. The pathways identified in this figure are for sources undisturbed by human intrusion. Pathways pertinent to intruder exposures are addressed separately in this PA in Section 6.

For a subsurface source, radionuclides may be leached by infiltrating water into underlying aquifers or isolated perched water zones, they may diffuse in the air-filled voids in the soil to the ground surface, or they may be moved to the surface (cover) soil by burrowing animals or deep tree roots. Radionuclides that are leached to groundwater may be ingested by humans directly, transported to the ground surface as a result of irrigation with groundwater, or they may eventually reach surface water at locations where there are seeps or streams.

The arrow leading directly from the "Groundwater" box in Fig. 4.2-1 to the human receptor is solid, indicating that this pathway is considered a potentially significant route of human exposure in this analysis. Radionuclides may move through groundwater either as dissolved constituents or in a suspended colloidal form. Colloidal migration is a very dynamic process. As suspended colloids encounter slight changes in water chemistry or flow rate along a flow path, they may either deposit on the immobile soil surfaces, or become mobilized. Therefore, colloidal transport in natural aquifer media can be viewed as a process with attributes similar to those governing sorption and desorption of elements and compounds. Colloidal forms are not explicitly addressed in this analysis for two reasons, discussed below.

First, colloidal forms are not directly addressed in this analysis because reliable means of predicting sitespecific colloidal influences on solute migration are not available. The types of colloids present are not readily measured, and thus the sorptive potential and stability of the colloids cannot be predicted. Second, colloids migrate according to complex physical and chemical immobilization and remobilization mechanisms. These mechanisms are not easily determined in non-idealized media such as natural aquifer materials. Because of these and other uncertainties, many conservative assumptions are used in the performance assessment to assure that these indeterminate effects attributable to colloids will not have a significant influence on the results. 


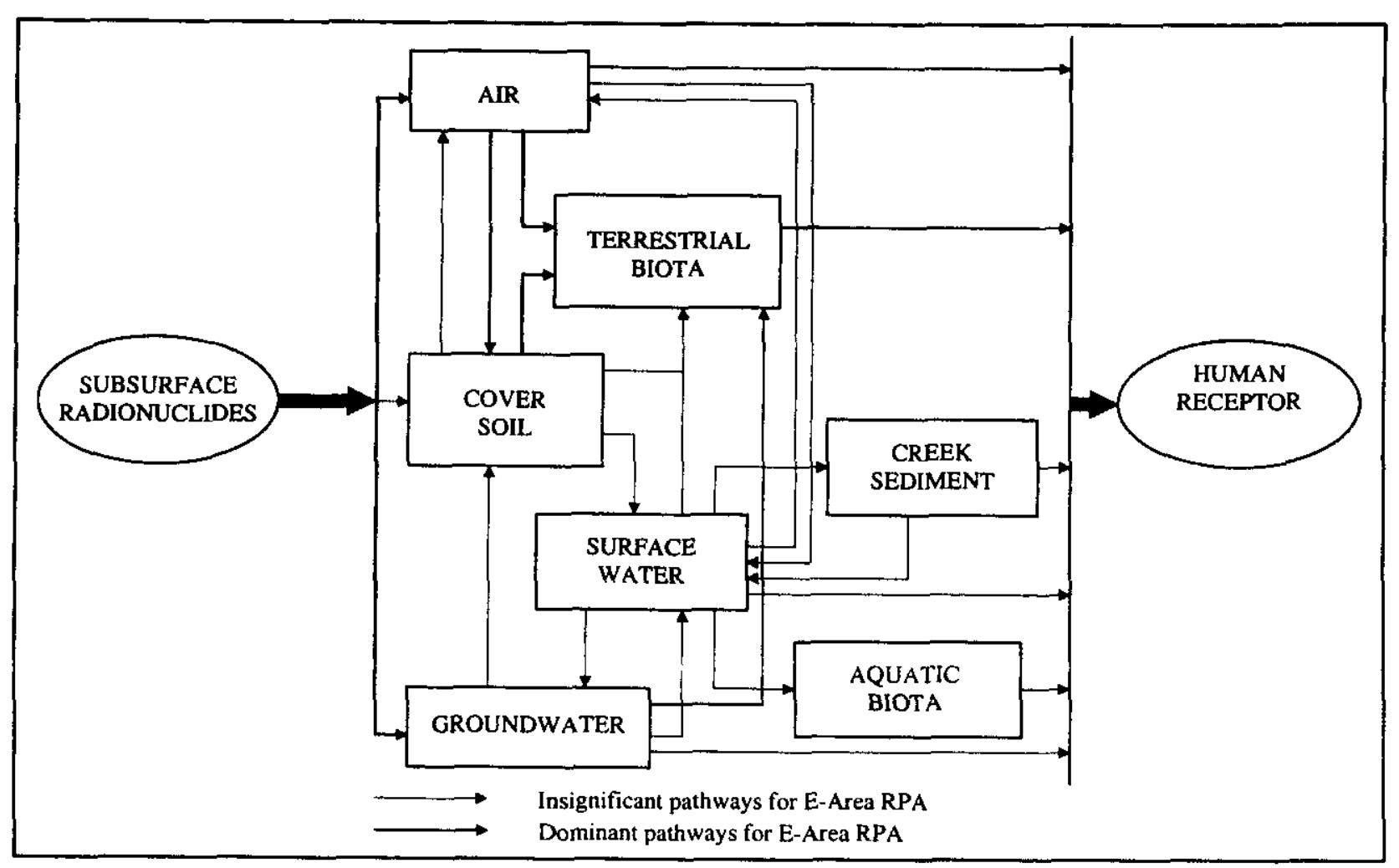

Figure 4.2-1. Pathways to Human Receptors from Subsurface Radionuclides. 
For liquid transport computations used in this analysis, a sorption coefficient, normally referred to as a $\mathrm{K}_{\mathrm{d}}$, is used to partition a radionuclide between the solid and liquid phases. Coefficients for each radionuclide are empirically determined, and are calculated from experimental tests that either measure "liquid phase" and solid phase concentrations of radionuclides, or measure the retardation that occurs as a result of reversible sorption processes when liquid constituents move through a porous medium. "Liquid phase" in both of these measurements is defined as that portion of the experimental media that passes through a filter of a specified pore size. Because of this definition, the "liquid phase" may actually contain some colloidal solid material that also passes through the filter. This colloidal material is very sorptive because the particles are small with a very high surface to volume ratio. Thus, an experimentally determined $\mathrm{K}_{\mathrm{d}}$ may include the colloidal fraction passing through the filter, and may underestimate the true sorption potential of the porous media that is being tested. Because an experimental $K_{d}$ may yield a liquid phase concentration that is greater than or equal to the true solubility of a radionuclide due to the presence of colloids, calculated doses from liquid pathways will always be conservative.

As depicted in Fig. 4.2-1, radionuclides in groundwater may also exchange with surface water, via discharge and recharge, and with cover soil, via irrigation. These two pathways are considered relatively insignificant (as indicated by the broken arrows) in this PA for the following reasons.

The streams on the SRS are gaining streams; therefore, groundwater is not recharged by the streams and radionuclides discharged to the streams will not contaminate groundwater in locations downstream from E-Area. This is indicated in Figure 4.2-1 by the broken line leaving the "Surface Water" compartment and entering the "Groundwater" compartment. Groundwater from beneath the GSA does discharge to local streams on the SRS (shown by a broken arrow leaving "Groundwater" and entering "Surface Water"); however, dilution is considerable in the nearby creeks. Groundwater in the vicinity of the disposal units is expected, therefore, to exceed surface water concentrations by orders of magnitude; thus, direct ingestion of groundwater will result in exposures exceeding those arising from less direct routes of exposure through aquatic food chains. For this reason, surface-water pathways (including those involving aquatic biota and creek sediment) were dropped from further consideration as potentially significant pathways to exposure.

Irrigation of cover soil by groundwater is practiced only occasionally in the SRS region, due to abundant precipitation during the growing season (Murphy 1990). Furthermore, groundwater under the SRS is intercepted by on-site surface water streams rather than flowing off-site, thus restricting the region of potential groundwater contamination. Therefore, groundwater irrigation, indicated in Fig. 4.2-1 by a broken arrow between the "Groundwater" and "Cover Soil" compartments, is not an important pathway to cover soil, and ultimately to human exposure.

Volatile radionuclides that diffuse to the ground surface may be transported in air and eventually inhaled by humans. This pathway is shown in Fig. 4.2-1 by a solid arrow from the subsurface radionuclide compartment to the air compartment. Volatile radionuclides may also exchange with the cover soil and terrestrial biota compartments. Deposition on cover soil and plant surfaces leads to exposure via ingestion of crops, milk or beef.

Based on the discussion above, only two sets of transport pathways are considered to be of significant consequence to exposures of off-site members of the public, and are considered further in this PA. These pathways, indicated by solid arrows in Fig. 4.2-1, include: 1) leaching of the wasteform resulting in contamination of groundwater local to E-Area, and both direct ingestion of that groundwater and ingestion of meat and milk arising from cattle that drink the contaminated groundwater; and 2) release of volatile radionuclides to air, subsequent contamination of agricultural soil, crops, and animals, inhalation of air and ingestion of food products contaminated by volatile radionuclides. The assessment of the 
release of volatile radionuclides to air is addressed in Section 4.2.2. Therefore, the remaining pathway of concem in the all-pathways analysis is the pathway involving groundwater.

The nearest location from the disposal site for off-site members of the public depends on the time after disposal. During the period of active institutional control, i.e., for the first 100 years after facility closure, off-site members of the public are assumed to be located no closer to the disposal site than the present boundary of the SRS. However, after active institutional control ceases, off-site members of the public could be located as close as $100 \mathrm{~m}$ from any of the E-Area disposal units. Because of such factors as 1) the desigat and closure concept for the disposal units that are intended to inhibit infiltration of precipitation, 2) the considerable distance from the disposal site to the present boundary of the SRS, and 3) the expected discharge of contaminated groundwater to surface streams within the SRS and the considerable dilution in radionuclide concentrations provided by such discharge, it is reasonable to conclude that the dose analysis for off-site members of the public can focus on exposure pathways resulting from use of contaminated groundwater at distances from the disposal units as close as $100 \mathrm{~m}$ for the time period after active institutional control ceases. Thus, in the dose analysis for the groundwater pathway, an off-site member of the public is assumed to use water from a well for domestic purposes, and the well is assumed to be at the location at least $100 \mathrm{~m}$ from the disposal units where the maximum concentrations of radionuclides in groundwater are predicted to occur after loss of active institutional control.

A 100-m buffer zone, outside of which are the points of compliance with respect to an all-pathways analysis, is defined for each grouping of disposal units of each type. There are two LAW vaults in a grouping, two $\mathbb{L}$ vaults in a grouping, ten slit trenches in a grouping, ten intimately-mixed cementstabilized waste trenches in a grouping, ten cement-stabilized encapsulated waste trenches in a grouping and 100 naval reactor containers in one grouping. Thus, there are six points of compliance that are evaluated in this PA.

\subsubsection{Air Pathways Analysis}

Human exposure calculations related to the air pathway include six pathways; plume shine, ground deposition, inhalation, vegetation consumption, milk consumption and meat consumption. Parameter selection was made to maximize the calculated dose. The parameters are given in Table 4.2-1.

Two points and times of exposure were used in the analysis. For the first 100 years, the minimum time for which institutional control will be maintained, the point of maximum exposure will be at the SRS boundary, about $11 \mathrm{~km}$ north of E-Area. Doses were also calculated at a point $100 \mathrm{~m}$ from the E-Area Disposal Facility at 100 years after closure.

The dose limit used in the air pathway analysis is $10 \mathrm{mrem} / \mathrm{yr}$, effective dose equivalent, as required by 40 CFR 61.

The air pathway analysis gave the results in Table 4.2-2. 
Table 4.2-1. Parameters Used in Air Dose Calculations

\begin{tabular}{|l|l|}
\hline Relative Concentration (X/Q): & $1.70 \mathrm{E}-04\left(\mathrm{sec} / \mathrm{m}^{3}\right)$ \\
\hline Decayed X/Q: & $1.70 \mathrm{E}-04\left(\mathrm{sec} / \mathrm{m}^{3}\right)$ \\
\hline Depleted X/Q: & $1.70 \mathrm{E}-04\left(\mathrm{sec} / \mathrm{m}^{3}\right)$ \\
\hline Relative Deposition (D/Q): & $5.20 \mathrm{E}-07\left(1 / \mathrm{m}^{2}\right)$ \\
\hline Distance to Receptor: & $100(\mathrm{~m})$ \\
\hline Vegetable Consumption: & $276(\mathrm{~kg} / \mathrm{yr})$ \\
\hline Leafy Vegetable Consumption: & $43(\mathrm{~kg} / \mathrm{yr})$ \\
\hline Milk Consumption: & $230(\mathrm{~L} / \mathrm{yr})$ \\
\hline Meat Consumption: & $81(\mathrm{~kg} / \mathrm{yr})$ \\
\hline Origin of Milk: & $\mathrm{cow}$ \\
\hline Deposition Buildup Time: & $25(\mathrm{yr})$ \\
\hline Breathing Rate: & $8,000\left(\mathrm{~m}^{3} / \mathrm{yr}\right)$ \\
\hline Elemental Iodine Fraction: & 1 \\
\hline Absolute Humidity: & $0.0114\left(\mathrm{~kg} / \mathrm{m}^{3}\right)$ \\
\hline Tritium Plant-to-Air Ratio: & 0.5 \\
\hline Shielding Factor: & 0.23 \\
\hline Fraction of Year C-14 Released: & 1 \\
\hline Retained Fraction (iodine): & 1 \\
\hline Retained Fraction (particulates): & 0.2 \\
\hline Weathering Rate Constant: & $18.1(1 / \mathrm{yr})$ \\
\hline Crop Exposure Time: & $0.164(\mathrm{yr})$ \\
\hline Pasture Grass Exposure Time: & $0.0822(\mathrm{yr})$ \\
\hline Pasture Grass Productivity: & $1.8\left(\mathrm{~kg} / \mathrm{m}^{2}\right)$ \\
\hline Produce Productivity: & $0.7\left(\mathrm{~kg} / \mathrm{m}^{2}\right)$ \\
\hline Surface Soil Density (15 cm): & $240\left(\mathrm{~kg} / \mathrm{m}^{2}\right)$ \\
\hline Pasture Grass Holdup Time: & $0(\mathrm{yrs})$ \\
\hline Stored Feed Holdup Time: & $0.247(\mathrm{yrs})$ \\
\hline Leafy Vegetable Holdup Time: & $0.00274(\mathrm{yrs})$ \\
\hline Produce Holdup Time: & $0.164(\mathrm{yrs})$ \\
\hline Milk Cattle Feed Consumption: & $44(\mathrm{~kg} / \mathrm{day})$ \\
\hline Beef Cattle Feed Consumption: & $44(\mathrm{~kg} / \mathrm{day})$ \\
\hline Feed-Milk-Man Transport Time: & $0.00548(\mathrm{yr})$ \\
\hline Fraction of Year on Pasture (beef): & 1 \\
\hline Fraction of Year on Pasture (milk): & \\
\hline Fraction Intake from Pasture (beef): & $0.0164(\mathrm{yr})$ \\
\hline Fraction Intake from Pasture (milk): & 0.76 \\
\hline Slaughter to Consumption Time: & 0.75 \\
\hline Fraction of Produce from Garden: & 0.56 \\
\hline Fraction of Leafy Vegetables from Garden: & \\
\hline a MAXIGASP default & \\
\hline Hamby 1991 & \\
\hline HRC 1977 & \\
\hline & \\
\hline Hamby and Bauer 1994 & \\
\hline
\end{tabular}


Table 4.2-2. Dose Factors for the Air Pathway

\begin{tabular}{|c|c|c|}
\hline Radionuclide & $\begin{array}{c}\mathbf{1 0 0} \text { m Location } \\
\text { (mrem/Ci Released) }\end{array}$ & $\begin{array}{c}\text { Site Boundary Location } \\
\text { (mrem/Ci Released) }\end{array}$ \\
\hline${ }^{3} \mathrm{H}$ & $8.5 \times 10^{-3}$ & $2.4 \times 10^{-6}$ \\
\hline${ }^{14} \mathrm{C}$ & 3.8 & $1.0 \times 10^{-3}$ \\
\hline
\end{tabular}




\subsubsection{Water Resource Impacts Analysis}

Pathways to human exposure related to the water resource impacts analysis are limited to consideration of direct ingestion of groundwater. The points of compliance for water resource impacts analysis are identical to those described in Section 4.2.1 for the all-pathways analysis. At these points of compliance, the performance measure described in Section 2.5.2 is assumed. Briefly, because there is some ambiguity in selecting particular numerical standards for radioactivity in drinking water to be applied to groundwater impacts, three different options for specifying the performance measure are used in this analysis:

1) Current EPA standards for radionuclides in drinking water (40 CFR Part 141), including (a) the method prescribed in the standards for calculating MCLs for beta/gamma-emitting radionuclides from the specified dose limit based on internal dosimetry data from ICRP Publication 2 (1959), as tabulated by the Department of Commerce (1963), and (b) the specified MCLs for ${ }^{3} \mathrm{H}$ and ${ }^{90} \mathrm{Sr}$;

2) Current EPA standards for radionuclides in drinking water, except all MCLs for beta/gammaemitting radionuclides are calculated from the specified dose limit using internal dosimetry data based on ICRP Publication 30 (1979); and

3) Proposed revisions of the EPA standards for radionuclides in drinking water (EPA 1991), with all MCLs for beta/gamma-emitting radionuclides calculated using internal dosimetry data based on ICRP Publication 30 (1979), except no standard for radon is assumed.

For all options, the performance objective is assumed to apply for 10,000 years after disposal (see Section 2.5.2). Some of the differences among the three options are summarized as follows.

All options specify concentration limits, rather than dose limits, for alpha-emitting radionuclides. The concentration limits for radium in the third option are higher than the first two options, and the third option is the only one that contains a limit for uranium.

In all options, a limit on dose equivalent is used to define limits on concentrations of beta/gamma-emitting radionuclides in water, but the resulting MCLs are different for all three options. The first two options use the same dose limit for whole body or any organ, but the internal dosimetry data used to obtain the MCLs from the dose limit differ substantially for most radionuclides. The third option differs from the first two in that a limit on EDE, rather than dose equivalent to whole body or any organ, is used. Thus, for most radionuclides, the resulting MCLs for the third option are substantially higher than the values for the first two options.

The MCLs for the three options for specifying the performance objective for ground-water impacts are given in Table 4.2-3. For all radionuclides except uranium in the third option, the MCLs are given in units of $\mathrm{pCi} / \mathrm{L}$ to facilitate comparisons of the different options, even though the primary standard for beta/gamma-emitting radionuclides in all options is a dose limit rather than a limit on concentration. For naturally occurring uranium with its normal isotopic abundances, the MCL of $20 \mu \mathrm{g} / \mathrm{L}$ corresponds to an activity concentration of $14 \mathrm{pCi} / \mathrm{L}$.

For all alpha-emitting radionuclides, the MCLs in Table 4.2-3 are obtained directly from current EPA standards for radioactivity in drinking water (40 CFR Part 141) or the proposed revisions of the standards (EPA 1991). The MCLs for beta/gamma-emitting radionuclides for the different options are obtained as described below. 
Table 4.2-3. Maximum Contaminant Levels for Radionuclides in Groundwater Corresponding to Different Options for Groundwater Impacts Requirement $t^{a}$

\begin{tabular}{|c|c|c|c|}
\hline Radionuclide & Option $1^{b}$ & Option $2^{b}$ & Option $3^{b, c}$ \\
\hline $\mathrm{H}-3$ & 20,000 & 90,000 & 60,900 \\
\hline C-14 & 6,400 & 2,600 & 3,200 \\
\hline $\mathrm{Ni}-59$ & 530 & 5,500 & 27,000 \\
\hline $\mathrm{Se}-79$ & $\ldots$ & 110 & $660^{d}$ \\
\hline $\mathrm{Rb}-87$ & 270 & 390 & 501 \\
\hline Sr-90 & 8 & 3 & 42 \\
\hline Mo-93 & $\cdots$ & 820 & $4,200^{d}$ \\
\hline $\mathrm{Zr}-93$ & 2,100 & 160 & 5,100 \\
\hline $\mathrm{Nb}-93 \mathrm{~m}$ & 1,100 & 1,000 & 10,500 \\
\hline $\mathrm{Nb}-94$ & ---- & 130 & 707 \\
\hline Tc-99 & 800 & 420 & 3,800 \\
\hline Pd-107 & $\ldots$ & 3,200 & 37,000 \\
\hline Sn-126 & ---- & 30 & 290 \\
\hline I- 129 & 0.5 & 0.6 & 21 \\
\hline Cs- 135 & 800 & 800 & 790 \\
\hline $\mathrm{Pb}-210$ & 0.3 & 0.07 & 1 \\
\hline $\mathrm{Ra}-225$ & --- & 0.82 & 9 \\
\hline $\mathrm{Ra}-226$ & 5 & 5 & 20 \\
\hline Th-234 & 59 & 34 & $420^{\circ}$ \\
\hline$N p-239$ & 300 & 170 & $1,900^{\mathrm{d}}$ \\
\hline Uranium & $\cdots$ & $\cdots--$ & $20^{\mathrm{e}}$ \\
\hline $\mathrm{Am}-242 \mathrm{~m}$ & $\cdots$ & 0.074 & 1.27 \\
\hline Other Alpha ${ }^{\mathbf{f}}$ & 15 & 15 & 15 \\
\hline
\end{tabular}

${ }^{a}$ Different options are described in Section 2.5.2 and Section 4.2.3.

${ }^{b}$ Values are in units of $\mathrm{pCi} / \mathrm{L}$, unless otherwise noted.

c Value calculated by EPA (1991), unless otherwise noted.

${ }^{d}$ Value calculated using ingestion dose conversion factor (DCF) from DOE compilation (U.S. DOE 1988).

e Value is in units of $\mu \mathrm{g} / \mathrm{L}$.

$f$ Adjusted gross alpha emitters (excluding Ra-226, U, and Rn-222). 
For the first option, the MCLs for ${ }^{3} \mathrm{H}$ and ${ }^{90} \mathrm{Sr}$ are the values specified in the current EPA standards. For any other beta/gamma-emitting radionuclide, the MCL is obtained, as specified in the current EPA standards, from the limit on dose equivalent of 4 mrem per year to whole body or any organ using the maximum permissible concentration (MPC) in water for an exposure time of $168 \mathrm{~h}$ obtained from a Department of Commerce (1963) tabulation. These MPCs apply to occupational exposure and are based on limits on dose equivalent of $5 \mathrm{rem}$ per year to whole body or gonads, $30 \mathrm{rem}$ per year to thyroid, or $15 \mathrm{rem}$ per year to any other organ, whichever is more restrictive. Thus, the MCL in groundwater is obtained from the MPC in water by multiplying by the ratio of the applicable dose limit in the DWS to the dose limit used to obtain the MPC. For example, for ${ }^{99} \mathrm{Tc}$, which has the lower large intestine as the organ receiving the highest dose, the MPC in water for $168 \mathrm{~h}$ exposure in the Department of Commerce (1963) tabulation is multiplied by the factor $0.004 / 15$ to obtain the MCL in groundwater.

For the second option, the MCL in groundwater for any beta/gamma-emitting radionuclide is obtained from (1) the dose limit of 4 mrem per year to whole body or any organ specified in the current EPA standards, (2) an assumed intake of contaminated water of $2 \mathrm{~L} / \mathrm{d}(730 \mathrm{~L} /$ year $)$, as also specified in the EPA standards, and (3) the dose per unit intake to whole body or the organ receiving the highest dose obtained from the DOE (1988c) compilation of internal DCFs, which are based on the dosimetric and metabolic models of ICRP Publication 30 (1979).

For the third option, the MCL in groundwater for most beta/gamma-emitting radionuclides is the value given by the EPA (1991). In a few cases, a value was not estimated by the EPA but is obtained from the limit on EDE of 4 mrem per year (EPA 1991), a water intake of $2 \mathrm{~L} / \mathrm{d}$, and the EDE per unit intake obtained from the DOE (1988) compilation.

In comparing the second and third options for calculating MCLs for beta/gamma-emitting radionuclides, the change from a limit on dose equivalent to whole body or any organ to the same numerical limit on EDE results in substantial increases in the MCL in most cases. Again, essentially the same internal dosimetry models are used for both options.

As described in the present discussion and Section 4.2.1, concentrations of radionuclides in groundwater at any location more than $100 \mathrm{~m}$ from the location of disposal units are limited by two performance objectives: 1) a maximum EDE of 25 mrem per year from all exposure pathways involving use of contaminated water and 2) various options for limiting dose from consumption of drinking water only or concentrations of radionuclides in groundwater. The first performance objective assumes that use of contaminated groundwater is the only significant source of exposure for off-site members of the public. The question then arises as to which of the two performance objectives would be the more restrictive, i.e., would result in lower limits on acceptable concentrations of radionuclides in groundwater and, thus, in waste in the E-Area LLWF. A related question concerns whether exposure pathways other than ingestion of drinking water would contribute significantly to the dose from all exposure pathways.

In order to address the relative importance of the two performance objectives given above that apply to use of contaminated groundwater, the dose from direct ingestion of contaminated water must be compared to the dose from the pathways involving ingestion of milk and meat from dairy and beef cattle that drink contaminated water. For purposes of this analysis, the dose limit from drinking water only for beta/gammaemitting radionuclides is assumed to be 4 mrem per year EDE, as in the third option for the performance measure for groundwater impacts. With this choice, the same dosimetric quantity is used in the performance measures for all-pathways and for drinking water only, but the results do not depend greatly on the choice of dose limits. 
For direct ingestion of radionuclides in drinking water, the dose to an exposed individual is given by

$$
\mathrm{H}_{w} \quad=\mathrm{C}_{\mathrm{w}} \mathrm{U}_{\mathrm{w}} \mathrm{DCF}_{\mathrm{ing}}
$$

where

$\mathrm{H}_{\mathrm{w}} \quad=\mathrm{EDE}$ from drinking water pathway (rem/year),

$\mathrm{C}_{\mathrm{w}} \quad=$ radionuclide concentration in ground water $(\mu \mathrm{Ci} / \mathrm{L})$,

$\mathrm{U}_{\mathrm{w}} \quad=$ consumption of drinking water $(\mathrm{L} /$ year $)$, and

$\mathrm{DCF}_{\text {ing }}=\mathrm{EDE}$ per unit activity of a radionuclide ingested, i.e., the ingestion dose conversion factor $(\mathrm{rem} / \mu \mathrm{Ci})$.

In determining compliance with the groundwater impacts requirement, a consumption rate of drinking water of $730 \mathrm{~L} /$ year (i.e., $2 \mathrm{~L} / \mathrm{d}$ ) is used. Therefore, the dose from direct consumption of contaminated groundwater is given by

$$
\mathrm{H}_{\mathrm{w}}(\mathrm{rem} / \text { year })=(730 \mathrm{~L} / \mathrm{y}) \mathrm{C}_{\mathrm{w}}(\mu \mathrm{Ci} / \mathrm{L}) \mathrm{DCF} \mathrm{Fing}_{\text {ing }}(\mathrm{rem} / \mu \mathrm{Ci}) .
$$

The doses from ingestion of milk ( $m$ ) and meat ( $f$ ) from cattle that drink contaminated groundwater are given by

$$
\begin{aligned}
& H_{m}=C_{m} U_{m} D C F_{i n g}, \\
& H_{f}=C_{f} U_{f} D C F_{i n g},
\end{aligned}
$$

respectively, where

$$
\begin{aligned}
& \mathrm{H}_{m}, \mathrm{H}_{\mathrm{f}}=\text { EDE from milk or meat intakes (rem/year), } \\
& \mathrm{C}_{\mathrm{m}}, \mathrm{C}_{\mathrm{f}}=\text { radionuclide concentration in milk }(\mu \mathrm{Ci} / \mathrm{L}) \text { or meat }(\mu \mathrm{Ci} / \mathrm{kg}), \\
& \mathrm{U}_{\mathrm{m}}, \mathrm{U}_{\mathrm{f}}=\text { consumption rate of milk }(\mathrm{L} / \text { year }) \text { or meat }(\mathrm{kg} / \text { year }), \text { and } \\
& \mathrm{DCF}_{\text {ing }}=\text { ingestion dose conversion factor }(\mathrm{rem} / \mu \mathrm{Ci}) .
\end{aligned}
$$

Dairy and beef cattle are assumed to drink only contaminated groundwater, and the radionuclide concentrations in milk and meat are given by

$$
\begin{aligned}
& \mathrm{C}_{\mathrm{m}}=\mathrm{C}_{\mathrm{w}} \mathrm{Q}_{\mathrm{m}} \mathrm{F}_{\mathrm{m}}, \\
& \mathrm{C}_{\mathrm{f}}=\mathrm{C}_{\mathrm{w}} \mathrm{Q}_{\mathrm{f}} \mathrm{F}_{\mathrm{f}},
\end{aligned}
$$

respectively, where

$$
\begin{aligned}
& \mathrm{C}_{\mathrm{w}}=\quad \text { radionuclide concentration in groundwater }(\mu \mathrm{Ci} / \mathrm{L}) \text {, } \\
& \mathrm{Q}_{\mathrm{m}}, \mathrm{Q}_{\mathfrak{f}}=\quad \text { consumption rate of water by dairy or beef cattle }(\mathrm{L} / \mathrm{d}) \text {, and } \\
& \mathrm{F}_{\mathrm{m}}, \mathrm{F}_{\mathrm{f}}=\text { ratio of equilibrium radionuclide concentration in milk }(\mu \mathrm{Ci} / \mathrm{L}) \text { or meat }(\mu \mathrm{Ci} / \mathrm{kg}) \text { to } \\
& \text { daily intake by dairy or beef cattle }(\mu \mathrm{Ci} / \mathrm{d}) \text {. }
\end{aligned}
$$


In implementing the model for the milk and meat pathways, a consumption rate of water by dairy and beef cattle of $60 \mathrm{~L} / \mathrm{d}$ and $50 \mathrm{~L} / \mathrm{d}$, respectively, and a consumption rate of milk and meat by an exposed individual of $110 \mathrm{~L}$ year and $90 \mathrm{~kg} /$ year, respectively, are used (NRC 1977). If the transfer coefficients for the milk and meat pathways $\left(F_{m}\right.$ and $\left.F_{f}\right)$ recommended by Baes et al. (1984) are used, the following comparison of the dose from the drinking water pathway and the doses from the milk and meat pathways is obtained. The dose from the drinking water pathway exceeds the dose from the milk and meat pathways by about a factor of 10 for ${ }^{99} \mathrm{Tc}$, a factor of 3 for ${ }^{126} \mathrm{Sn}$, a factor of 5 for ${ }^{137} \mathrm{Cs}$, and 5 orders of magnitude for ${ }^{239} \mathrm{Pu}$.

The analysis presented above illustrates that the dose from direct ingestion of drinking water is expected to be considerably greater than the dose from ingestion of milk and meat obtained from dairy and beef cattle that drink contaminated water from the same source. This conclusion is expected to apply to all radionuclides that could be present in the E-Area LLWF.

This comparative analysis can be summarized as follows. First, for all beta/gamma-emitting radionuclides, the performance measure for groundwater impacts - i.e., a dose limit of either 4 mrem per year to whole body or any organ or 4 mrem per year EDE from the drinking water pathway only - should be more restrictive than the performance objective for protection of off-site members of the public - i.e., a dose limit of 25 mrem per year EDE from all exposure pathways - because the dose from the drinking water pathway only is expected to be greater than the dose from the milk and meat pathways combined. Thus, if the performance measure for groundwater impacts is met, then the performance objective for protection of off-site individuals also will be met without the need for analysis of the dose from exposure pathways other than drinking water.

Second, for alpha-emitting radionuclides, the performance measure for groundwater impacts, which is expressed in terms of concentration limits rather than limits on dose equivalent, may result in doses from the drinking water pathway only that exceed the performance objective for protection of off-site members of the public. For example, the current MCL for ${ }^{239} \mathrm{Pu}$ in groundwater of $15 \mathrm{pCi} / \mathrm{L}$ (see Table 4.2-3) corresponds to an EDE of nearly 50 mrem per year, assuming consumption of $2 \mathrm{~L} / \mathrm{d}$ of water and the ingestion DCF for ${ }^{239} \mathrm{Pu}$ given in Table C.3-2. In these cases, the dose limit in the performance objective for off-site individuals would be more restrictive and, in principle, the contributions to the dose from exposure pathways other than drinking water would need to be considered in demonstrating compliance with the performance objective. However, the contribution from the meat and milk pathways is expected to be no more than a few tens of percent of the contribution from ingestion of groundwater, and should be much less for many radionuclides, in which case the other pathways essentially can be neglected in estimating dose. That is, in cases where the performance objective for off-site individuals from all potentially-significant exposure pathways applies, demonstration of compliance with the performance objective reasonably need to take into account only the dose from the drinking water pathway. In other cases where the MCL for an alpha-emitting radionuctide conesponds to a dose less than the performance objective for off-site individuals, compliance with the MCL would ensure that the dose limit for all exposure pathways would be met without need for further analysis.

Therefore, the general conclusion from this analysis is that only the drinking water pathway needs to be considered for off-site releases of radionuclides in groundwater. In cases where the MCL in groundwater corresponds to a dose equivalent less than the performance objective for off-site individuals of 25 mrem per year from all exposure pathways, compliance with the MCL would ensure that the dose to off-site individuals would be substantially less than the performance objective. In cases where the MCL in groundwater corresponds to a dose equivalent greater than the performance objective for off-site individuals, the dose from all potentially-significant exposure pathways other than drinking water would be insignificant compared with the dose from the drinking water pathway, particularly when the uncertainties 
in estimating maximum concentrations of radionuclides in groundwater at locations more than $100 \mathrm{~m}$ from any disposal units are taken into account.

\subsubsection{Radon Analysis}

The pathway for radon release is decay of parent material, assumed to be ${ }^{234} \mathrm{U}$, and upward diffusion of radon gas to the ground surface.

\subsection{Analysis Methodology}

The conceptual models developed for analyzing potential transport for radionuclides from the waste disposal units of E-Area to the points of compliance associated with the performance objectives of the PA are described in this section. Methods used to implement these models, assumptions made in implementation, and justification for the assumptions are also discussed.

\subsubsection{All-Pathways Analysis}

Based on the discussion in Section 4.2.3, the only exposure pathway of concern for the all-pathways analysis, in addition to the air pathway analysis in Section 4.3.2, is the pathway involving direct ingestion of groundwater. In large part, the analysis of this pathway is identical to that for the water-resource impacts analysis, and thus is described in Section 4.3.3. Doses to the off-site members of the public resulting from ingestion of contaminated groundwater beyond the $100-\mathrm{m}$ buffer zone around all disposal units were not directly estimated. Rather, comparisons of maximum projected groundwater concentrations with the more restrictive of either MCLs (Table 4.2-3) or allowable concentrations based on the 25-mrem per year performance objective were made. The allowable concentrations were calculated by dividing the 25 mrem per year value by the EDE per unit concentration in drinking water (Table C.3-5, Appendix C.3). A composite listing of MCLs and allowable concentrations based on the $25 \mathrm{mrem} / \mathrm{yr}$ limit is given in Table 4.3-1.

\subsubsection{Air Pathway Analysis}

Doses for unit releases of ${ }^{3} \mathrm{H}$ and ${ }^{14} \mathrm{C}$ were calculated at the site boundary (Simpkins and Carlton 1998) using the MAXIGASP computer program (Hamby 1995). Doses for unit releases at the E-Area boundary were calculated (Simpkins 1998) using the MAXINE spreadsheet (Hamby 1994) that implements the MAXIGASP methodology. The results are shown in Table 4.3-2.

\subsubsection{Water Resource Impacts Analysis}

The analysis for water resource impacts requires that transport of radionuclides from the waste disposal units to the compliance points for groundwater impacts analysis (Section 2.5.2) be simulated. To carry out these simulations, conceptual models were developed representing the disposal units and surrounding vadose zone to facilitate computation of radionuclide transport to groundwater. A conceptual model for transport in the saturated zone was also developed. The conceptual models define how features of the disposal units and the subsurface environment are represented in the numerical models used to carry out the transport simulations. The key assumptions and values of parameters assumed for this analysis are described below. 
Table 4.3-1 Comparison of MCLs and Allowable Groundwater Concentrations Based on the $\mathbf{2 5}$ mrem per Year Performance Objective for Off-Site Individuals

\begin{tabular}{|c|c|c|}
\hline Radionuclide & $\mathrm{MCL},{ }^{a} \mathrm{pCi} / \mathrm{L}$ & Allowable Concentration Based on 25 mrem per year, $\mathrm{pCi} / \mathrm{L}^{6}$ \\
\hline $\mathbf{H}-\mathbf{3}$ & 20,000 & 540,000 \\
\hline C-14 & 6,400 & 16,000 \\
\hline $\mathrm{Ni}-59$ & 530 & 160,000 \\
\hline $\mathrm{Se}-79$ & $660^{c}$ & 4,100 \\
\hline Rb-87 & 270 & 7,100 \\
\hline Sr-90 & 8 & 250 \\
\hline Mo-93 & $4,200^{c}$ & 26,000 \\
\hline $\mathrm{Zr}-93$ & 2,100 & 16,000 \\
\hline $\mathrm{Nb}-94$ & $707^{c}$ & 6,800 \\
\hline Tc-99 & 800 & 26,000 \\
\hline Pd-107 & $37,000^{c}$ & 250,000 \\
\hline Sn-126 & $290^{c}$ & 1,900 \\
\hline $\mathrm{I}-129$ & 0.5 & 130 \\
\hline Cs- 135 & 800 & 4,800 \\
\hline $\mathrm{Pb}-210$ & 0.3 & 6.8 \\
\hline Po-210 & 15 & 21 \\
\hline $\mathrm{Ra}-223$ & 15 & 63 \\
\hline $\mathrm{Ra}-224$ & 15 & 93 \\
\hline Ra-225 & $9^{c}$ & 83 \\
\hline $\mathrm{Ra}-226$ & 5 & 31 \\
\hline Ac- 227 & 5.3 & 2.5 \\
\hline Th-227 & 15 & 960 \\
\hline $\mathrm{Ra}-228$ & 5 & 28 \\
\hline Th-228 & 15 & 89 \\
\hline Th-229 & 15 & 9.6 \\
\hline Th-230 & 15 & 64 \\
\hline $\mathrm{Pa}-231$ & 2.4 & 3.1 \\
\hline Th-232 & 15 & 13 \\
\hline
\end{tabular}


Table 4.3-1 Comparison of MCLs and Allowable Groundwater Concentrations Based on the $\mathbf{2 5}$ mrem per Year Performance Objective for Off-Site Individuals

\begin{tabular}{|c|c|c|}
\hline Radionuclide & $\mathrm{MCL},{ }^{a} \mathrm{pCi} / \mathrm{L}$ & Allowable Concentration Based on 25 mrem per year, $\mathrm{pCi} / \mathrm{L}^{6}$ \\
\hline $\mathrm{U}-232$ & $\begin{array}{c}430,000,000 \\
(20 \mu \mathrm{g} / \mathrm{L})^{\mathrm{c}}\end{array}$ & 26 \\
\hline U-233 & $\begin{array}{c}190,000 \\
(20 \mu \mathrm{g} / \mathrm{L})^{\mathrm{c}}\end{array}$ & 125 \\
\hline Th-234 & 59 & 2,600 \\
\hline $\mathrm{U}-234$ & $\begin{array}{c}124,000 \\
(20 \mu \mathrm{g} / \mathrm{L})^{\mathrm{c}}\end{array}$ & 132 \\
\hline U-235 & $\begin{array}{c}428 \\
(20 \mu \mathrm{g} / \mathrm{L})^{\mathrm{c}}\end{array}$ & 139 \\
\hline U-236 & $\begin{array}{c}1,270 \\
(20 \mu \mathrm{g} / \mathrm{L})^{\mathrm{c}}\end{array}$ & 139 \\
\hline Np-237 & 15 & 8.9 \\
\hline U-238 & $\begin{array}{c}6.66 \\
(20 \mu \mathrm{g} / \mathrm{L})^{\mathrm{c}}\end{array}$ & 139 \\
\hline Pu-238 & 15 & 8.9 \\
\hline Np-239 & 300 & 12,000 \\
\hline Pu-239 & 15 & 8.1 \\
\hline $\mathrm{Pu}-240$ & 15 & 8.1 \\
\hline $\mathrm{Pu}-242$ & 15 & 8.3 \\
\hline Am-243 & 15 & 7.6 \\
\hline $\mathrm{Pu}-244$ & 15 & 8.6 \\
\hline $\mathrm{Cm}-245$ & 15 & 7.6 \\
\hline $\mathrm{Cm}-246$ & 15 & 7.6 \\
\hline $\mathrm{Cm}-247$ & 15 & 8.3 \\
\hline $\mathrm{Cm}-248$ & 15 & 2.1 \\
\hline Cf-249 & 15 & 7.4 \\
\hline
\end{tabular}

aption 1, Table 4.2-1, unless otherwise noted.

b Calculated from Table C.3-5; potentially-significant short-lived daughters are accounted for.

c Option 3, Table 4.2-1. 
Table 4.3-2. Dose for Unit Release via the Air Pathway

\begin{tabular}{l|l|l}
\hline & Dose for Unit Release (mrem/Ci) \\
\hline Radionuclide & 100 meters & SRS Boundary \\
\hline${ }^{3} \mathrm{H}$ (oxide) & $8.5 \times 10^{-3}$ & $2.4 \times 10^{-6}$ \\
\hline${ }^{14} \mathrm{C}$ & 3.8 & $1.0 \times 10^{-3}$ \\
\hline
\end{tabular}


Conceptual models of radionuclide transport are of two main types: models describing vadose, or unsaturated, zone transport (which include transport through disposal unit barriers); and a model describing transport through the saturated zone beneath the water table to the point of compliance. The vadose zone models are unique for each type of disposal unit with significantly different design characteristics that influence the flow of water and transport of radionuclides through the materials present. Thus, these models will be discussed by unit. The saturated zone model represents the aquifer units underneath all of the disposal units; therefore, only one model is needed for the entire facility.

Implementation of the conceptual models with computer codes required the use of two groundwater codes. The PORFLOW code was used to simulate flow and transport in the vadose zone, and mass transport in the saturated zone. The FACT code was used to simulate flow in the saturated zone, as this code has already been calibrated for the E-Area site.

A flow diagram of how the codes are used together in the water resource impacts analysis is shown in Figure 4.3-1. Inventory estimates and screening calculations are described in Sect. 4.1.3.1. Vadose zone flow and transport of radionuclides of potential significance are evaluated with the PORFLOW code. Results of these simulations provide radionuclide flux to the water table. The FACT code is used in the saturated zone to develop a flow field in that zone, which is characterized by flow velocity and direction for each grid block in the simulation domain. The PORFLOW code reads this flow field as well as the radionuclide fluxes to the water table, and uses this data in simulating transport of radionuclides in the saturated zone. The saturated zone implementation of PORFLOW provides radionuclide concentrations in groundwater for the simulation domain.

The results of the saturated zone model simulations are reported in terms of maximum groundwater concentrations at the eight points of compliance per $\mathrm{Ci}$ of each radionuclide disposed of in each type of waste unit (i.e., 2 LAW vaults, 2 IL vaults, 10 trenches, one Naval Reactor pad of 100 containers). These concentrations are then compared to MCLs and to allowable concentrations based on the 25-mrem allpathways performance objective, when the latter are more restrictive than MCLs (see Section 4.2.3). This comparison yields inventory limits for each radionuclide in each waste unit, which are reported in Section 5 .

\subsubsection{Vadose Zone Model of LAW Vaults}

Release of radionuclides from the LAW vaults to the vadose zone will occur when water enters the vaults, contacts the waste, dissolves or desorbs radionuclides, and subsequently exits the vaults (Section 4.1.3). Diffusion may also occur at this time. The factors affecting this release are the rates of water movement through the vaults and waste and the solubility, sorption, and decay characteristics of the radionuclides. Once in the surrounding vadose zone, transport of radionuclides will be influenced by the same factors.

The conceptual model of the LAW vaults considers movement of water and radionuclides through the vadose zone and waste disposal units in 2-dimensions. The 2-dimensional model represents a transverse section through a LAW vault and the surrounding porous media, as shown in Fig. 4.3-2. Analysis in 2dimensions is sufficient for this problem, because releases along the length of the vaults are expected to be uniform except at each end of a vault. Releases from the end-planes of the vaults are expected to be insignificant relative to releases from the combined areas represented by the bottoms and sides of the vaults, and thus no corrections are made to account for these releases. The results in 2-dimensions, which assume a unit width in the third dimension, are readily adapted to 3-dimensions. 


\section{Radionuclides to Water Table}

Groundwater

Flow
Radionuclide

Transport

\section{PORFLOW \\ FACT \\ PORFLOW}

Figure 4.3-1 Flow Diagram of Computer Codes 


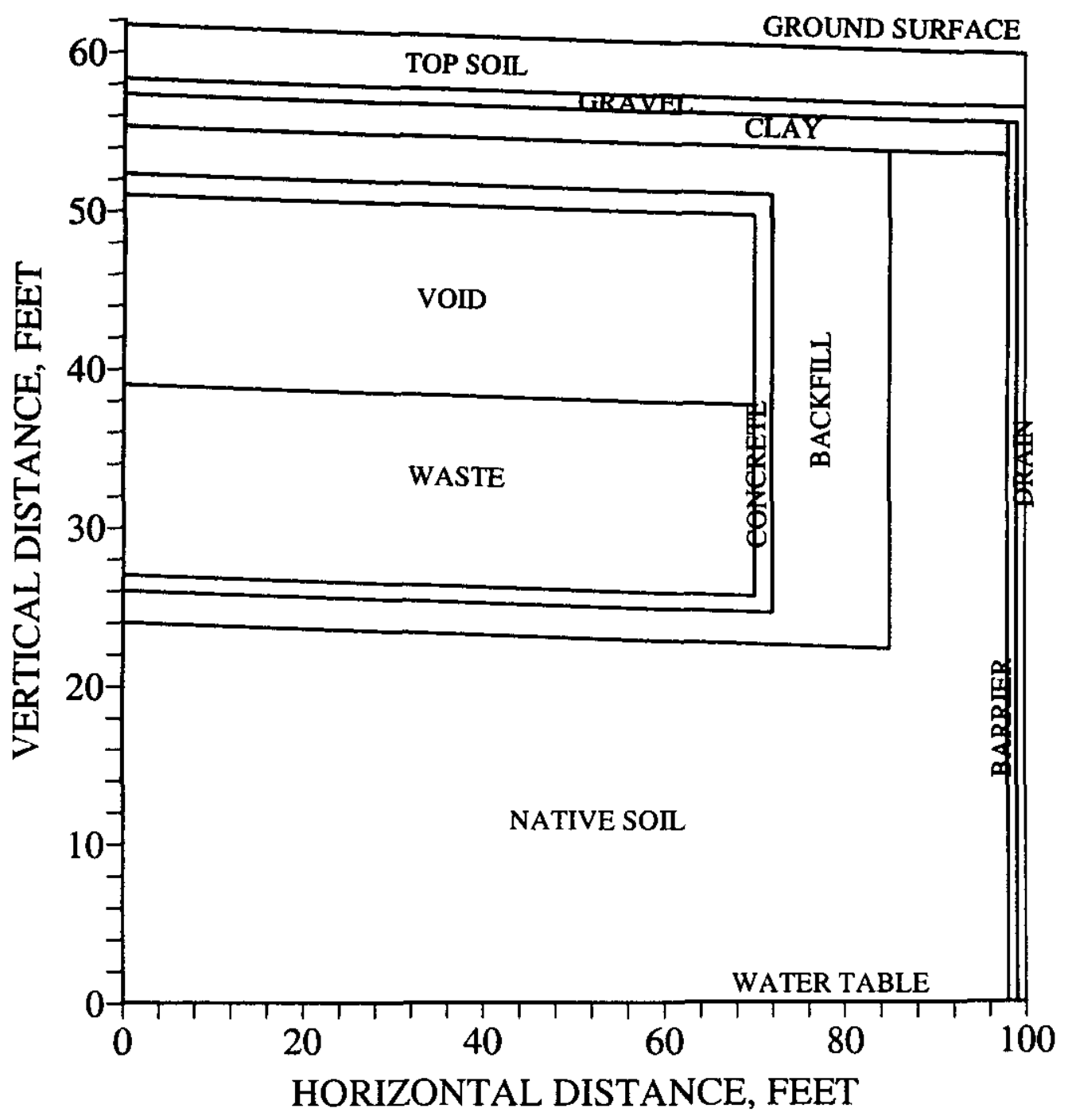

Figure 4.3-2. Conceptual Model of LAW Vault 
The upper part of the domain of the LAW vault conceptual model is the ground surface (Fig 4.3-2). The lower part of the domain is the water table. Directly beneath the ground surface is top soil, underlain by the sloped (2\% grade) gravel and clay layers of the infiltration barrier. Water prohibited from infiltrating by the clay layer is assumed to flow to a conceptual drain, representing any means of diverting water from the vaults. It is assumed that drainage around individual vaults is sufficient to carry excluded water away from the vaults during the time that the infiltration barrier is intact. Underneath the infiltration barrier is the backfill used to fill under, to the sides, and over the constructed and filled vaults. Finally, the concrete roof, walls, and floor of the vaults are represented, as well as the waste placed in the vaults and the resulting voids. The floor of the vaults are represented at approximately $7.6 \mathrm{~m}(25 \mathrm{feet})$ above the water table. Since the waste containers are expected to corrode and lose their integrity much faster than the vault, it was assumed that upon placement of the waste in the vault, the containment boxes are completely corroded and compacted, leaving the majority of the void space above the waste. This assumption results in more concentrated waste at the point nearest release (the bottom of the vault). The estimated effective height of the waste zone and void zone are developed in Appendix C.

The barrier at the right side of the LAW vaults domain, just left of the drain, represents a location far enough from the vaults that flow is expected to be vertical and unaffected by the flow of water diverted around the low permeability vaults. No lateral flow is expected at this location and an imaginary barrier was put in place so that water from the conceptual drain does not reenter the domain at this point. The left side of the LAW vault domain is a line of symmetry and is located midway through the transverse section of the LAW vault. Flow at this point is expected to be vertical, and thus flow on either side can be assumed to be symmetrical.

The conceptual model for the LAW vault depicted in Fig. 4.3-2 defines the vertical and lateral extent of the simulation domain used to perform flow and mass transport computations. The domain was discretized into 2900 small elements (a $50 \times 58$ grid) for which the flow and transport equations are solved numerically (Fig. 4.3-3). The PORFLOW code (Appendix B) was used for flow and transport simulations.

In order to solve the flow equations, it was necessary to specify boundary conditions and hydraulic properties of the materials present in the simulation domain. The top of the domain is a constant flux boundary, where net infiltration (rainfall less evapotranspiration and other losses) is applied. An infiltration rate of $40 \mathrm{~cm} / \mathrm{yr}$ is assumed (Appendix C). The bottom of the domain is a constant head boundary, maintained by the presence of the water table. The left and right boundaries are no flow boundaries, where flow is essentially vertical and parallel to these boundaries, as described above.

Since the void and waste in the LAW vault are not continuous porous media, they require special consideration. At first glance, it seems reasonable to assume the void is a very conductive material such as gravel, and the waste is a somewhat less conductive material. However, this scenario poses a very difficult numerical problem during the intact phase since adjacent to these unsaturated, conductive materials is a material (concrete) of high saturation and very low hydraulic conductivity. Since the vault itself is nearly saturated at steady-state (which is assumed for the simulations), any additional water entering the vault at the top will cause an equivalent amount of water to enter the waste in the lower-half of the vault almost instantaneously. This process can be simulated by assuming the void and waste are also saturated concrete materials, but with a much higher porosity than concrete. (Sorptive properties of radionuclides in the waste are assumed to be those for corrosion products of the metal waste containers, rather than those for concrete). These assumptions do not significantly affect the estimated release of radionuclides during the period of time the vault floors and walls are intact, because the controlling factor 


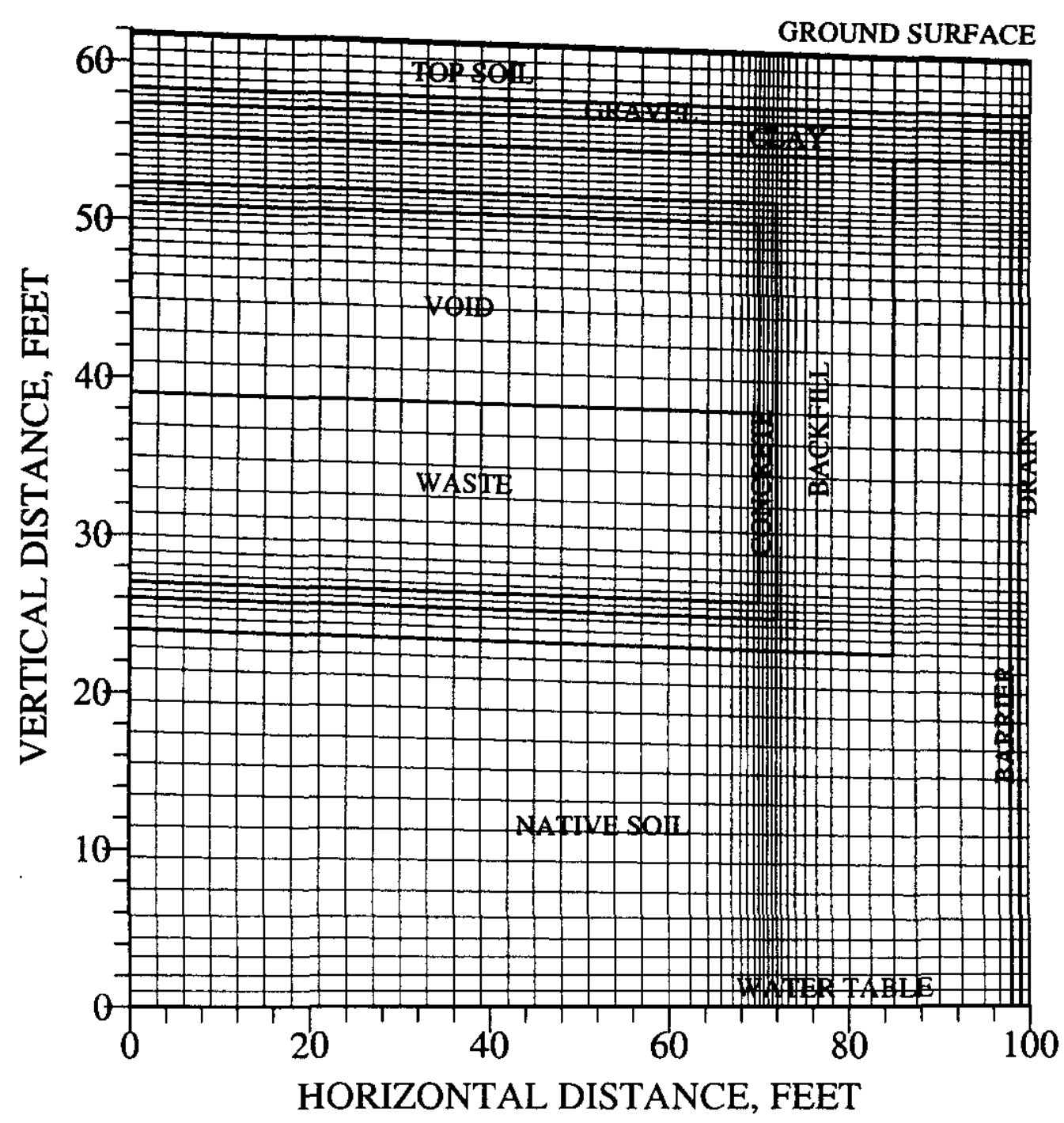

Figure 4.3-3. Modeling Grid of LAW Vault 
for release is the hydraulic conductivity of the lower portion of the vault; i.e., the concrete floor and walls. In other words, flow out of the vault is not affected by the hydraulic properties of the material assumed for the void or the waste.

Hydraulic properties of the materials present in the simulation domain were assigned according to a complex rationale described in Appendix C. Assignment of these properties requires spatial averaging, such that each of these materials is treated as if they are homogeneous and isotropic porous media. These properties change with time, according to the degree of degradation assumed to have occurred in the vaults. For the LAW vaults, three different conditions occur over time (Table 4.1.2, Section 4.1.3): the intact condition, occurring from the time of closure to 1400 years post-closure; the degraded condition, occurring between 1400 and 3100 years post-closure; and the failed condition, occurring after roof failure, which is estimated to occur at 3100 years post-closure (Appendix D). Table C.1-1 lists the hydraulic conductivity, porosity, and type of moisture characteristic curve assumed for each material under these three conditions.

Simulations of flow were carried out to steady state for the three conditions defined for the LAW vaults using the hydraulic properties listed in Table C.1-1. Velocity profiles for the simulation domain are provided in Appendix $\mathrm{F}$ for the intact, degraded, and failed scenarios, respectively. During the intact phase, the gravel drain is very effective at removing water from the system, as is apparent in the relatively small velocity vectors beneath the infiltration barrier.

Mass transport simulations were run using the steady-state flow fields generated for all three scenarios, and were based on an initial activity of $1 \mathrm{Ci}$ of each radionuclide present in two LAW vaults. Boundary conditions for mass transport are assumed as follows: at the top and bottom of the domain, a concentration of zero was assigned, which corresponds to the assumption that contaminants reaching either boundary are rapidly swept away from the vicinity of contact. This assumption serves to maximize the simulated diffusive flux through the domain, which is driven by concentration gradients, and thus, is conservative. At the sides of the domain, no-flux boundaries were assigned, consistent with the no flow boundaries at these locations.

Radioactive daughter ingrowth is accounted for explicitly in the PORFLOW code. The Kds listed in Tabie 4.1-4 were used for each radionuclide and radioactive daughter product. Apparent diffusion coefficients from Table 4.1-6 were assumed. Longitudinal and transverse dispersivities were assumed to be zero $\mathrm{cm}$. This assumption may delay simulated arrival of the leading edge of a plume at the water table slightly, but is conservative because the plume is more concentrated by neglecting dispersion. Estimated fluxes at the water table are reported as $\mathrm{Ci} / \mathrm{yr}$ at the water table per $\mathrm{Ci}$ initially in the disposal unit. These reporting units facilitate calculation of inventory limits, and are readily scaled to the initial inventory of each radionuclide listed in Appendix A. The radionuclides for which results are provided are those listed in Table 4.1-2 (Section 4.1.3.1), which include only those radionuelides which were not screened from consideration according to the screening methods described in that section. In a few cases, the radionuclide listed is not important because of a combination of its half-life, sorption characteristics, and/or dose conversion factor; however, the longer-lived daughters are potentially important. For these radionuclides $\left({ }^{241} \mathrm{Pu},{ }^{241} \mathrm{Am},{ }^{244} \mathrm{Cm}\right.$, and $\left.{ }^{252} \mathrm{Cf}\right)$, the parent radionuclide is assumed to decay completely to the first longer-lived daughter of potential significance instantaneously. The initial activity of the first daughter, per $\mathrm{Ci}$ of original parent inventory, is calculated from:

$$
A_{d 0}=\frac{\lambda_{d}}{\lambda_{p}}
$$


where $\lambda_{d}$ and $\lambda_{p}$ are the decay constants $\left(0.693 / T_{1 / 2}\right)$ of the daughter and parent radionuclides, respectively. Fractional fluxes of the daughters, simulated using PORFLOW per $\mathrm{Ci}$ of first daughter in a chain, can be related back to an initial inventory of the parent of one $\mathrm{Ci}$ through this relationship.

Peak fractional fluxes to the water table for all radionuclides simulated for the LAW vaults are given in Table 4.3-3. The peak for ${ }^{3} \mathrm{H}$ occurs during the intact scenario for the LAW vaults. Although more water passes through the vaults during the degraded phases, the initial inventory of ${ }^{3} \mathrm{H}$ has decayed significantly before degradation occurs. The peaks for ${ }^{90} \mathrm{Sr}$ and ${ }^{129} \mathrm{I}$ occur during the degraded scenario, when cracking of the vaults has occurred. Thus roof failure (at 3100 yeais) is not a factor in determining peak release of these three radionuclides. Peak releases for the remaining radionuclides occur after roof failure, and occur after 10,000 years for many radionuclides.

\subsubsection{Vadose Zone Model of IL Vaults}

The conceptual model of the IL vaults (Fig. 4.3-4) is very similar to that of the LAW vaults (Fig. 4.3-2). Again, a 2-dimensional model represents a transverse section through an IL vault and the surrounding porous media. Assumptions of symmetry and corrections for end planes are also valid approaches for simulating flow and mass transport through the IL vaults and the surrounding vadose zone.

As with the LAW vault model, the upper part of the IL vault domain is the ground surface; the lower part is the water table. Directly beneath the ground surface is the top soil, underlain by the sloped gravel and clay layers of the infiltration barrier. Again, it is assumed that drainage around individual vaults is sufficient to carry excluded water away from the vaults while the infiltration barrier is intact (100 years). Backfill surrounds the $\mathbb{L}$ vaults similar to the $L A W$ vaults. The floors of the $\mathbb{I}$ vaults are assumed to be $7.6 \mathrm{~m}$ ( 25 feet) above the water table. Representation of waste within the concrete Il vaults is different than that for the LAW vaults because the $\mathbb{L}$ waste is to be grouted in place or enclosed in concrete. Because the limiting material for flow is the grout, which is assumed to degrade, and have hydraulic properties similar to concrete, the entire waste volume was assumed to be radionuclide-contaminated grout. Although voids will exist where tritium crucibles and other waste forms are present, release from the vaults during the intact phase will be controlled by the low-conductivity concrete materials. The IL vault domain is discretized into the grid shown in Fig. 4.3-5.

Hydraulic properties of the materials present in the IL vault simulation design are described in Appendix C. For the IL vaults, the intact conditions is assumed to occur from the time of closure to 575 years postclosure (Section 4.1.3). The degraded condition, when cracking of the vaults and waste form lowers their hydraulic conductivity, is assumed to occur between 575 and 1050 years post-closure. Roof failure is estimated to occur at 1050 years post-closure, and the failed condition is assumed to persist from that time on. Table C.1-2 lists the hydraulic conductivity, porosity, and type of moisture characteristic curve assumed for each material under these three conditions. 
Table 4.3-3. Estimated Peak Fractional Flux to the Water Table for Radionuclides Disposed of in E-Area LAW Vaults

\begin{tabular}{|c|c|c|}
\hline Radionuclide & $\begin{array}{l}\text { Peak flux to water table } \\
\text { Ci/yr } \\
\end{array}$ & $\begin{array}{c}\text { Time of peak flux } \\
y \mathbf{y}\end{array}$ \\
\hline $\mathrm{H}-3$ & $3.10 \mathrm{E}-12$ & $1.20 \mathrm{E}+02$ \\
\hline C-14 & $1.90 \mathrm{E}-04$ & $4.02 E+03$ \\
\hline $\mathrm{Ni}-59$ & $6.55 \mathrm{E}-05$ & $1.08 \mathrm{E}+04$ \\
\hline Se-79 & $4.62 \mathrm{E}-04$ & $5.87 \mathrm{E}+03$ \\
\hline Rb-87 & $1.41 \mathrm{E}-03$ & $4.01 E+03$ \\
\hline Sr-90 & $1.50 \mathrm{E}-24$ & $1.80 \mathrm{E}+03$ \\
\hline $\mathrm{Zr}-93$ & $1.16 \mathrm{E}-04$ & $1.68 E+04$ \\
\hline $\mathrm{Nb}-93 \mathrm{~m}$ & $4.35 \mathrm{E}-04$ & $1.68 \mathrm{E}+04$ \\
\hline $\mathrm{Nb}-94$ & $3.96 \mathrm{E}-04$ & $6.28 E+03$ \\
\hline Tc-99 & $1.51 \mathrm{E}-03$ & $3.23 E+03$ \\
\hline Pd-107 & $1.42 \mathrm{E}-03$ & $4.07 E+03$ \\
\hline $\mathrm{Sn}-126$ & $7.10 \mathrm{E}-04$ & $5.84 \mathrm{E}+03$ \\
\hline I-129 & $1.06 \mathrm{E}-02$ & $1.51 \mathrm{E}+03$ \\
\hline Cs-135 & $2.44 \mathrm{E}-04$ & $9.38 \mathrm{E}+03$ \\
\hline Th-232 & $3.61 \mathrm{E}-05$ & $6.78 \mathrm{E}+04$ \\
\hline Ra-228 & $2.31 \mathrm{E}-04$ & $6.74 \mathrm{E}+04$ \\
\hline Th-228 & $3.59 \mathrm{E}-05$ & $6.74 E+04$ \\
\hline Ra-224 & $2.30 \mathrm{E}-04$ & $6.76 \mathrm{E}+04$ \\
\hline $\mathrm{U}-232$ & $2.64 \mathrm{E}-20$ & $3.73 E+03$ \\
\hline Th-228 & $2.91 \mathrm{E}-22$ & $3.74 E+03$ \\
\hline $\mathrm{Ra}-224$ & $1.86 \mathrm{E}-21$ & $3.74 \mathrm{E}+03$ \\
\hline $\mathrm{U}-233$ & $6.22 \mathrm{E}-14$ & $1.09 \mathrm{E}+05$ \\
\hline Th-229 & $5.85 \mathrm{E}-07$ & $7.02 \mathrm{E}+04$ \\
\hline $\mathrm{Ra}-225$ & $3.74 \mathrm{E}-06$ & $7.04 \mathrm{E}+04$ \\
\hline U-234 & $4.06 \mathrm{E}-14$ & $8.58 E+04$ \\
\hline Th-230 & 4.77E-06 & $9.10 \mathrm{E}+04$ \\
\hline $\mathrm{Ra}-226$ & $3.34 \mathrm{E}-05$ & $8.38 E+04$ \\
\hline $\mathrm{Pb}-210$ & $6.20 \mathrm{E}-05$ & $8.26 \mathrm{E}+04$ \\
\hline Po-210 & $1.11 \mathrm{E}-04$ & $8.22 \mathrm{E}+04$ \\
\hline $\mathrm{U}-235$ & $1.52 \mathrm{E}-14$ & $1.08 \mathrm{E}+04$ \\
\hline $\mathrm{Pa}-231$ & $1.77 \mathrm{E}-05$ & $1.88 \mathrm{E}+04$ \\
\hline Ac- 227 & $2.17 \mathrm{E}-05$ & $1.88 \mathrm{E}+04$ \\
\hline $\mathrm{Th}-227$ & $3.05 \mathrm{E}-06$ & $1.88 \mathrm{E}+04$ \\
\hline $\mathrm{Ra}-223$ & $1.96 \mathrm{E}-05$ & $1.88 \mathrm{E}+04$ \\
\hline U-236 & $1.52 \mathrm{E}-14$ & $1.08 \mathrm{E}+04$ \\
\hline Np-237 & $2.15 \mathrm{E}-05$ & $4.28 \mathrm{E}+03$ \\
\hline U-238 & $1.50 \mathrm{E}-14$ & $1.08 \mathrm{E}+04$ \\
\hline Th-234 & $1.65 \mathrm{E}-16$ & $1.08 \mathrm{E}+04$ \\
\hline U-234 & $6.17 \mathrm{E}-14$ & $1.06 \mathrm{E}+04$ \\
\hline $\mathrm{Pu}-238$ & $5.71 \mathrm{E}-21$ & $1.12 \mathrm{E}+04$ \\
\hline U-234 & $4.05 \mathrm{E}-14$ & $9.85 \mathrm{E}+03$ \\
\hline $\mathrm{Pu}-239$ & $5.54 \mathrm{E}-16$ & $1.08 E+05$ \\
\hline U-235 & $1.42 \mathrm{E}-17$ & $1.02 \mathrm{E}+05$ \\
\hline $\mathrm{Pu}-240$ & $1.63 \mathrm{E}-15$ & $9.32 \mathrm{E}+04$ \\
\hline U-236 & $4.26 \mathrm{E}-16$ & $8.50 \mathrm{E}+04$ \\
\hline
\end{tabular}


Table 4.3-3. Estimated Peak Fractional Flux to the Water Table for Radionuclides Disposed of in E-Area LAW Vaults

\begin{tabular}{|c|c|c|}
\hline Radionuclide & $\begin{array}{c}\text { Peak flux to water table } \\
\mathrm{Ci} / \mathrm{yr}\end{array}$ & $\begin{array}{c}\text { Time of peak flux } \\
\text { yr }\end{array}$ \\
\hline Am-241 & $\ldots a^{a}$ & \\
\hline Np-237 & $6.1 \mathrm{E}-08^{\mathrm{a}}$ & $4.28 \mathrm{E}+03$ \\
\hline $\mathrm{Pu}-241$ & .... b & \\
\hline Am-241 & $---{ }^{b}$ & \\
\hline $\mathrm{Np}-237$ & 2.0E- $-09^{\mathrm{b}}$ & $4.28 E+03$ \\
\hline Pu-242 & $1.34 \mathrm{E}-16$ & $1.20 \mathrm{E}+04$ \\
\hline U-238 & $2.23 E-18$ & $1.01 \mathrm{E}+05$ \\
\hline Am-243 & $5.72 \mathrm{E}-07$ & $3.56 \mathrm{E}+04$ \\
\hline Np-239 & $2.07 \mathrm{E}-04$ & $3.54 \mathrm{E}+04$ \\
\hline Pu-239 & $3.96 \mathrm{E}-06$ & $1.34 \mathrm{E}+04$ \\
\hline $\mathrm{Pu}-244$ & $1.17 \mathrm{E}-16$ & $1.20 E+04$ \\
\hline $\mathrm{Cm}-244$ & $-c^{-}$ & \\
\hline $\mathrm{Pu}-240$ & $4.4 \mathrm{E}-18^{\mathrm{c}}$ & $9.32 E+04$ \\
\hline U-236 & $1.2 \mathrm{E}-18^{\mathrm{c}}$ & $8.50 \mathrm{E}+04$ \\
\hline $\mathrm{Cm}-245$ & $6.80 \mathrm{E}-08$ & $6.12 \mathrm{E}+04$ \\
\hline Pu-241 & $2.90 \mathrm{E}-06$ & $6.02 \mathrm{E}+04$ \\
\hline Am-241 & $1.71 \mathrm{E}-07$ & $5.90 \mathrm{E}+04$ \\
\hline Np-237 & $2.28 \mathrm{E}-07$ & $7.97 \mathrm{E}+03$ \\
\hline $\mathrm{Cm}-246$ & $1.79 \mathrm{E}-09$ & $5.06 \mathrm{E}+04$ \\
\hline $\mathrm{Cm}-247$ & $2.15 \mathrm{E}-05$ & $8.32 \mathrm{E}+04$ \\
\hline Am-243 & $4.06 \mathrm{E}-05$ & $7.46 \mathrm{E}+04$ \\
\hline Np-239 & $1.47 \mathrm{E}-02$ & $7.38 \mathrm{E}+04$ \\
\hline Pu-239 & $2.89 \mathrm{E}-05$ & $3.72 \mathrm{E}+04$ \\
\hline $\mathrm{Cm}-248$ & $1.84 \mathrm{E}-05$ & $8.26 \mathrm{E}+04$ \\
\hline $\mathrm{Pu}-244$ & $8.85 \mathrm{E}-09$ & $3.34 E+04$ \\
\hline Cf-249 & $1.48 \mathrm{E}-14$ & $8.13 E+03$ \\
\hline $\mathrm{Cm}-245$ & $2.92 \mathrm{E}-09$ & $6.10 \mathrm{E}+04$ \\
\hline $\mathrm{Pu}-241$ & $1.25 \mathrm{E}-07$ & $6.02 E+04$ \\
\hline Am-241 & $7.34 \mathrm{E}-09$ & $5.90 \mathrm{E}+04$ \\
\hline $\mathrm{Np}-237$ & $9.74 \mathrm{E}-09$ & $8.23 E+03$ \\
\hline $\mathrm{Cf}-252$ & $\ldots{ }^{d}$ & \\
\hline $\mathrm{Cm}-248$ & $1.4 \mathrm{E}-10^{\mathrm{d}}$ & $8.26 \mathrm{E}+04$ \\
\hline $\mathrm{Pu}-244$ & $6.9 \mathrm{E}-14^{\mathrm{d}}$ & $3.34 \mathrm{E}+04$ \\
\hline \multicolumn{3}{|c|}{$\begin{array}{l}\text { Am-241 not potentially significant; value calculated for daughter assumes all } \mathrm{Am}-241\left(\mathrm{~T}_{1 / 2}=\right. \\
432 \mathrm{yr}) \text { decays instantaneously to Np-234 before transport. } \\
\mathrm{Pu}-241 \text { and } \mathrm{Am}-241 \text { not potentially significant; value calculated for daughter assumes all Pu- } \\
241\left(\mathrm{~T}_{12}=14.4 \mathrm{yr}\right) \text { decays instantaneously to } \mathrm{Np}-237 \text { before transport. } \\
\mathrm{Cm}-244 \text { not potentially significant; value calculated for daughter assumes all } \mathrm{Cm}-244\left(\mathrm{~T}_{1 / 2}=18\right. \\
\mathrm{yr} \text { decays instantaneously to Pu- } 240 \text { before transport. } \\
\text { Cf-252 not potentially significant; value calculated for daughter assumes all } \mathrm{Cf}-252\left(\mathrm{~T}_{1 / 2}=\right. \\
2.64 \mathrm{yr}) \text { decays instantaneously to } \mathrm{Cm}-248 \text { before transport. }\end{array}$} \\
\hline
\end{tabular}




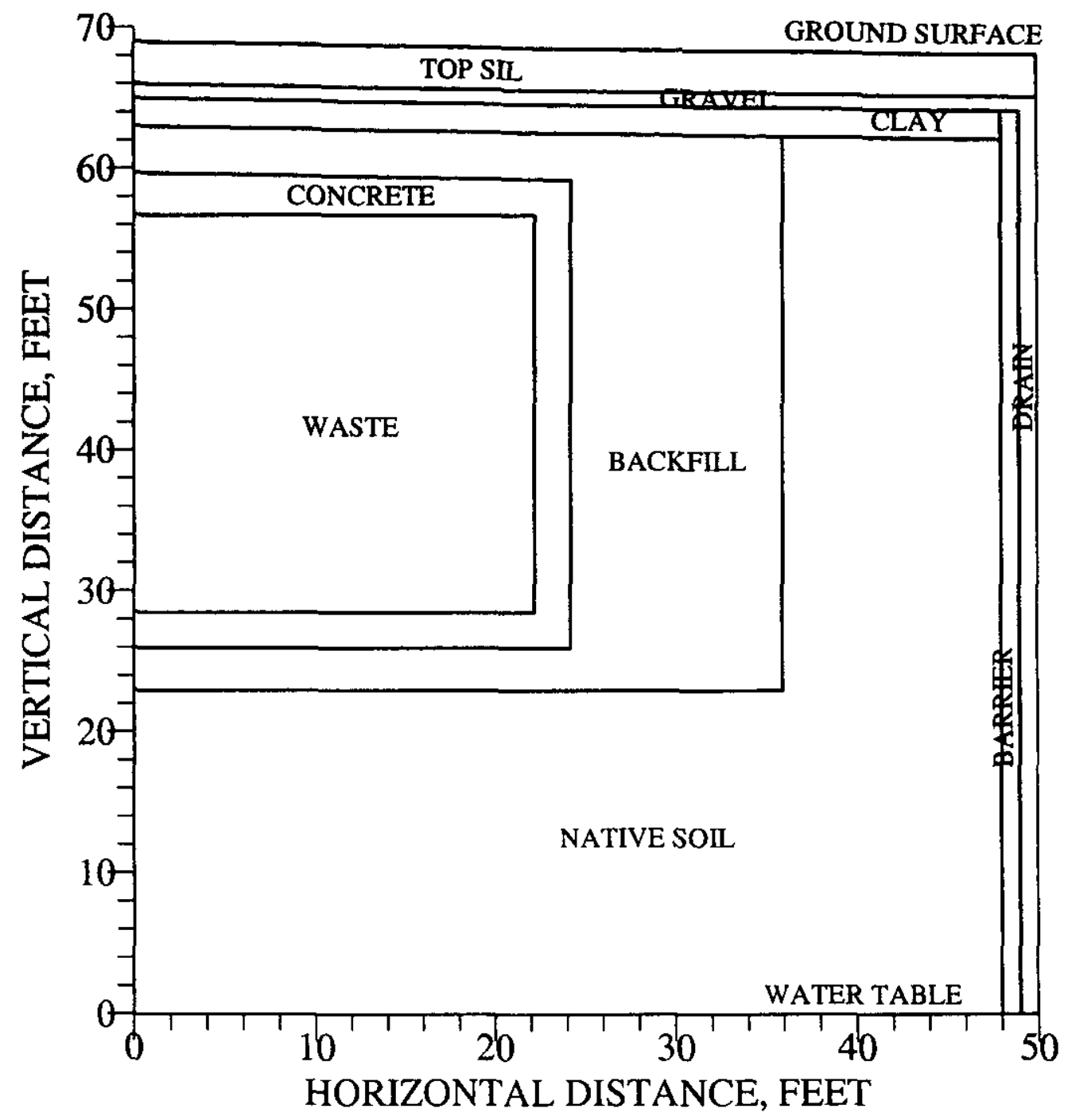

Figure 4.3-4. Conceptual Model of IL Vault 


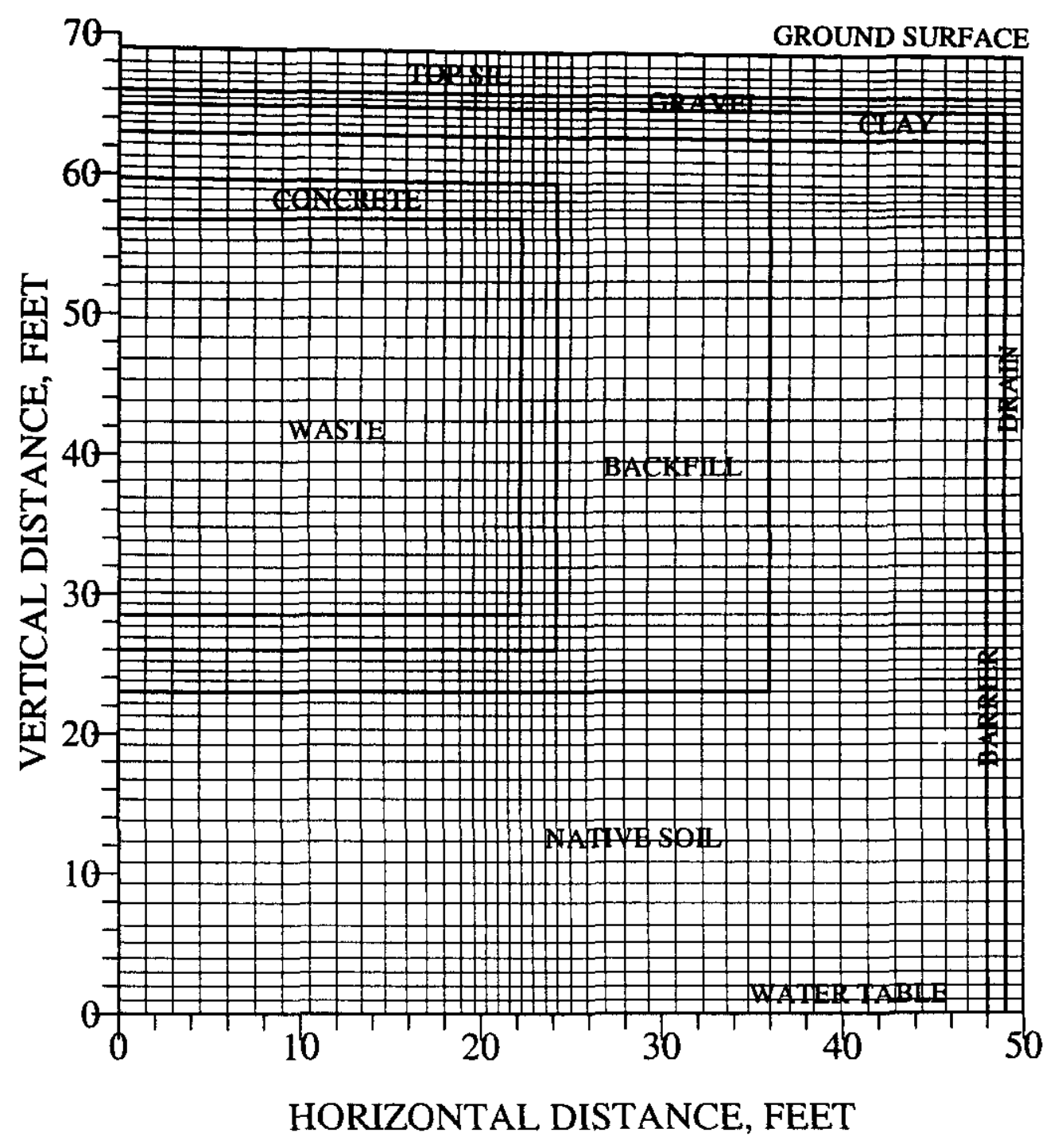

Figure 4.3-5. Modeling Grid of IL Vault 
Simulations of flow and transport were carried out for the $\mathbb{L}$ vaults using the PORFLOW code (Appendix B). Steady-state flow fields generated by PORFLOW for each scenario (i.e., intact, degraded, failed) were used to predict fractional fluxes at the water table in the manner described for the LAW vaults. The list of radionuclides for which fluxes at the water table were simulated is given in Table 4.1-2, and was derived from the screening procedure described in Section 4.1.3.1. Radioactive daughter ingrowth is accounted for in the manner explained for the LAW vault analysis.

Peak fractional fluxes to the water table for all $\mathrm{IL}$ vault radionuclides simulated are given in Table 4.3-4. As with the LAW vaults, the peak for ${ }^{3} \mathrm{H}$ occurs while the vaults are assumed to be intact. Peak fluxes for ${ }^{129} \mathrm{I}$ and ${ }^{90} \mathrm{Sr}$ occur soon after roof failure. Peak fluxes for all other radionuclides occur much later after roof failure, which is estimated to occur at 1050 years. Peak releases for many radionuclides occur after 10,000 years.

\subsubsection{Vadose Zone Model of Slit Trenches}

Release of radionuclides disposed of in the slit trenches to the vadose zone will occur when water enters the trenches and contacts the waste. The slit trenches will be covered with an infiltration barrier only when all trenches are filled. Thus, over the first 25 years, waste may be placed in these trenches and covered with only backfill soil. The exact time of waste placement is not known. Therefore, it is assumed in this assessment that all of the waste is placed in the trenches at 25 years prior to closure, and 25 years later an infiltration barrier is placed on all of the slit trenches. This is a conservative assumption from the standpoint of groundwater resource impacts analysis, because longer periods of exposure to unmitigated infiltration will increase the total quantity of relatively mobile radionuclides leached from the trench wastes.

The conceptual model of the slit trenches, showing the gravel and clay layers of the infiltration barrier in place is shown in Fig. 4.3-6. The trenches are conceptualized as rectangular compartments in two dimensions, with clean backfill placed on top of the trenches to bring them up to the level of the excavated area. The depth of waste in the trenches is assumed to be approximately $4.6 \mathrm{~m}$ ( 15 feet), and the bottom of the trench is approximately $7.6 \mathrm{~m}$ (25 feet) above the water table. A layer of backfill is placed over the clean backfill in the trench, and the sloped clay and gravel layer (a $2 \%$ grade assumed) overlies the backfill. At the top of the domain is the ground surface; at the bottom is the water table.

The right side of the slit trench domain is a drain/barrier combination, which functions as described for the LAW vaults. The left side of the domain represents the midpoint between two trenches, and is assumed to be a no-flow boundary where flow is vertical and parallel to the boundary. The discretized domain used for simulation of flow and transport is shown in Fig. 4.3-7. This $50 \times 34$ grid contains 1700 elements of unit thickness.

Hydraulic properties assumed for the waste, backfill, clay, gravel, top soil and native soil are described in Appendix C. Table C.1-3 lists the assumed hydraulic conductivities, porosities, and moisture characteristic curves for these materials. The waste is assigned hydraulic properties equivalent to that of backfill, for lack of more precise waste characterization. Much of the waste will indeed be soil, and thus this is a reasonable assumption. 
Table 4.3-4. Estimated Peak Fractional Flux to the Water Table for Radionuclides Disposed of in E-Area IL Vaults

\begin{tabular}{|c|c|c|}
\hline Radionuclide & $\begin{array}{c}\text { Peak flux to water table } \\
\mathrm{Ci} / \mathrm{yr}\end{array}$ & $\begin{array}{c}\text { Time of peak flux } \\
\text { yr }\end{array}$ \\
\hline $\mathrm{H}-3$ & $2.04 \mathrm{E}-16$ & $1.16 \mathrm{E}+02$ \\
\hline C-14 & $6.78 \mathrm{E}-07$ & $1.00 \mathrm{E}+04$ \\
\hline $\mathrm{Ni}-59$ & $1.80 \mathrm{E}-04$ & $1.06 \mathrm{E}+04$ \\
\hline Se-79 & $5.28 \mathrm{E}-04$ & $3.93 E+03$ \\
\hline Sr-90 & $7.31 \mathrm{E}-16$ & $1.23 E+03$ \\
\hline Tc-99 & $2.98 \mathrm{E}-04$ & $2.81 \mathrm{E}+03$ \\
\hline $\mathrm{Sn}-126$ & $3.07 \mathrm{E}-05$ & $1.14 E+04$ \\
\hline I- 129 & $1.63 \mathrm{E}-02$ & $1.10 \mathrm{E}+03$ \\
\hline Cs-135 & $2.74 \mathrm{E}-04$ & $7.73 E+03$ \\
\hline Th-232 & $6.43 \mathrm{E}-06$ & $1.09 E+05$ \\
\hline $\mathrm{Ra}-228$ & 4.11E-05 & $1.09 \mathrm{E}+05$ \\
\hline Th-228 & $6.40 \mathrm{E}-06$ & $1.09 \mathrm{E}+05$ \\
\hline $\mathrm{Ra}-224$ & $4.10 \mathrm{E}-05$ & $1.09 E+05$ \\
\hline $\mathrm{U}-232$ & $1.31 \mathrm{E}-17$ & $2.04 \mathrm{E}+03$ \\
\hline Th-228 & $1.45 \mathrm{E}-19$ & $2.03 E+03$ \\
\hline $\mathrm{Ra}-224$ & $9.26 \mathrm{E}-19$ & $2.03 E+03$ \\
\hline $\mathrm{U}-233$ & $1.76 \mathrm{E}-14$ & $1.09 \mathrm{E}+05$ \\
\hline Th-229 & $1.07 \mathrm{E}-08$ & $1.01 E+05$ \\
\hline $\mathrm{Ra}-225$ & $6.82 \mathrm{E}-08$ & $1.02 \mathrm{E}+05$ \\
\hline $\mathrm{U}-234$ & $1.16 \mathrm{E}-14$ & $1.09 \mathrm{E}+05$ \\
\hline Th-230 & $8.32 \mathrm{E}-07$ & $1.09 \mathrm{E}+05$ \\
\hline Ra-226 & $1.02 \mathrm{E}-05$ & $1.09 \mathrm{E}+05$ \\
\hline $\mathrm{Pb}-210$ & $1.91 \mathrm{E}-05$ & $1.09 \mathrm{E}+05$ \\
\hline Po-210 & $3.43 \mathrm{E}-05$ & $1.09 \mathrm{E}+05$ \\
\hline U-235 & $4.11 \mathrm{E}-18$ & $1.09 \mathrm{E}+05$ \\
\hline $\mathrm{Pa}-231$ & $3.41 \mathrm{E}-06$ & $1.09 \mathrm{E}+05$ \\
\hline Ac -227 & $4.19 \mathrm{E}-06$ & $1.09 \mathrm{E}+05$ \\
\hline Th-227 & $5.89 \mathrm{E}-07$ & $1.09 E+05$ \\
\hline Ra-223 & $3.77 \mathrm{E}-06$ & $1.09 E+05$ \\
\hline U-236 & $1.23 \mathrm{E}-16$ & $1.06 \mathrm{E}+05$ \\
\hline Np-237 & $4.16 \mathrm{E}-06$ & $1.52 \mathrm{E}+04$ \\
\hline U-238 & $6.44 E-19$ & $1.09 \mathrm{E}+05$ \\
\hline Th-234 & $7.10 \mathrm{E}-21$ & $1.09 \mathrm{E}+05$ \\
\hline U-234 & $1.17 \mathrm{E}-14$ & $1.09 E+05$ \\
\hline $\mathrm{Pu}-238$ & $7.92 \mathrm{E}-24$ & $3.30 \mathrm{E}+03$ \\
\hline $\mathrm{U}-234$ & $1.01 \mathrm{E}-14$ & $1.04 E+04$ \\
\hline Pu-239 & $1.16 \mathrm{E}-16$ & $1.09 \mathrm{E}+05$ \\
\hline U-235 & $4.11 \mathrm{E}-18$ & $1.09 E+05$ \\
\hline $\mathrm{Pu}-240$ & $1.69 \mathrm{E}-16$ & $1.09 \mathrm{E}+05$ \\
\hline U-236 & $1.23 \mathrm{E}-16$ & $1.09 E+05$ \\
\hline Am-241 & ${ }_{-}{ }^{\mathrm{a}}$ & \\
\hline Np-237 & $8.40 \mathrm{E}-10^{\mathrm{a}}$ & $1.52 \mathrm{E}+04$ \\
\hline $\mathrm{Pu}-241$ & - b & \\
\hline Am-241 & $\ldots$ & \\
\hline
\end{tabular}


Table 4.3-4. Estimated Peak Fractional Flux to the Water Table for Radionuclides Disposed of in E-Area IL Vaults

\begin{tabular}{|c|c|c|}
\hline Radionuclide & $\begin{array}{c}\text { Peak flux to water table } \\
\mathrm{Ci} / \mathrm{yr}\end{array}$ & $\begin{array}{c}\text { Time of peak flux } \\
\text { yr }\end{array}$ \\
\hline Np-237 & $2.80 \mathrm{E}-11$ & $1.52 \mathrm{E}+04$ \\
\hline Pu-242 & $1.09 \mathrm{E}-17$ & $1.09 E+05$ \\
\hline $\mathrm{U}-238$ & $6.45 \mathrm{E}-19$ & $1.09 E+05$ \\
\hline Am-243 & $2.79 \mathrm{E}-08$ & $4.84 E+04$ \\
\hline Np-239 & $1.01 \mathrm{E}-05$ & $4.80 \mathrm{E}+04$ \\
\hline Pu-239 & $2.08 \mathrm{E}-07$ & $2.48 \mathrm{E}+04$ \\
\hline $\mathrm{Pu}-244$ & $5.23 \mathrm{E}-20$ & $1.09 E+05$ \\
\hline $\mathrm{Cm}-244$ & $\begin{array}{c}J .2 J D-20 \\
\ldots \ldots\end{array}$ & \\
\hline Pu-240 & $4.65 \mathrm{E}-19^{\mathrm{c}}$ & $1.09 E+05$ \\
\hline $\mathrm{U}-236$ & $3.39 \mathrm{E}-19^{\mathrm{c}}$ & $1.09 \mathrm{E}+05$ \\
\hline $\mathrm{Cm}-245$ & $2.33 \mathrm{E}-09$ & $7.80 E+04$ \\
\hline Pu-241 & $9.94 \mathrm{E}-08$ & $7.76 \mathrm{E}+04$ \\
\hline Am-241 & $5.86 \mathrm{E}-09$ & $7.68 \mathrm{E}+04$ \\
\hline $\mathrm{Np}-237$ & $2.74 E-08$ & $4.28 \mathrm{E}+04$ \\
\hline $\mathrm{Cm}-247$ & $5.22 \mathrm{E}-06$ & $1.09 \mathrm{E}+05$ \\
\hline Am-243 & $1.21 \mathrm{E}-05$ & $1.09 \mathrm{E}+05$ \\
\hline Np-239 & $4.38 \mathrm{E}-03$ & $1.09 \mathrm{E}+05$ \\
\hline Pu-239 & $1.25 \mathrm{E}-05$ & $1.09 E+05$ \\
\hline $\mathrm{Cf}-249$ & $9.48 \mathrm{E}-17$ & $7.78 \mathrm{E}+03$ \\
\hline $\mathrm{Cm}-245$ & $1.00 \mathrm{E}-10$ & $7.86 \mathrm{E}+04$ \\
\hline Pu-241 & $4.27 \mathrm{E}-09$ & $7.74 \mathrm{E}+04$ \\
\hline Am-241 & $2.52 \mathrm{E}-10$ & $7.70 \mathrm{E}+04$ \\
\hline Np-237 & $1.13 E-09$ & $4.20 \mathrm{E}+04$ \\
\hline $\mathrm{Cf}-252$ & -..- & \\
\hline $\mathrm{Cm}-248$ & (needed) $)^{d}$ & \\
\hline $\mathrm{Pu}-244$ & (needed) $)^{d}$ & \\
\hline
\end{tabular}

a Am-24l not potentially significant; value calculated for daughter assumes all Am-241 $\left(\mathrm{T}_{1 / 2}=432 \mathrm{yr}\right)$ decays instantaneously to $\mathrm{Np}-237$ before transport.

b Pu-241 and Am-241 not potentially significant; value calculated for daughter assumes all Pu-24l $\left(\mathrm{T}_{12}=\right.$ $14.4 \mathrm{yr}$ ) decays instantaneously to $\mathrm{Np}-237$ before transport.

c $\mathrm{Cm}-244$ not potentially significant; value calculated for daughter assumes all Cm-244 $\left(\mathrm{T}_{1 / 2}=18 \mathrm{yr}\right)$ decays instantaneously to $\mathrm{Pu}-240$ before transport.

d Cf-252 not potentially significant; value calculated for daughter assumes all Cf-252 $\left(\mathrm{T}_{1 / 2}=2.64 \mathrm{yr}\right)$ decays instantaneously to $\mathrm{Cm}-248$ before transport. 


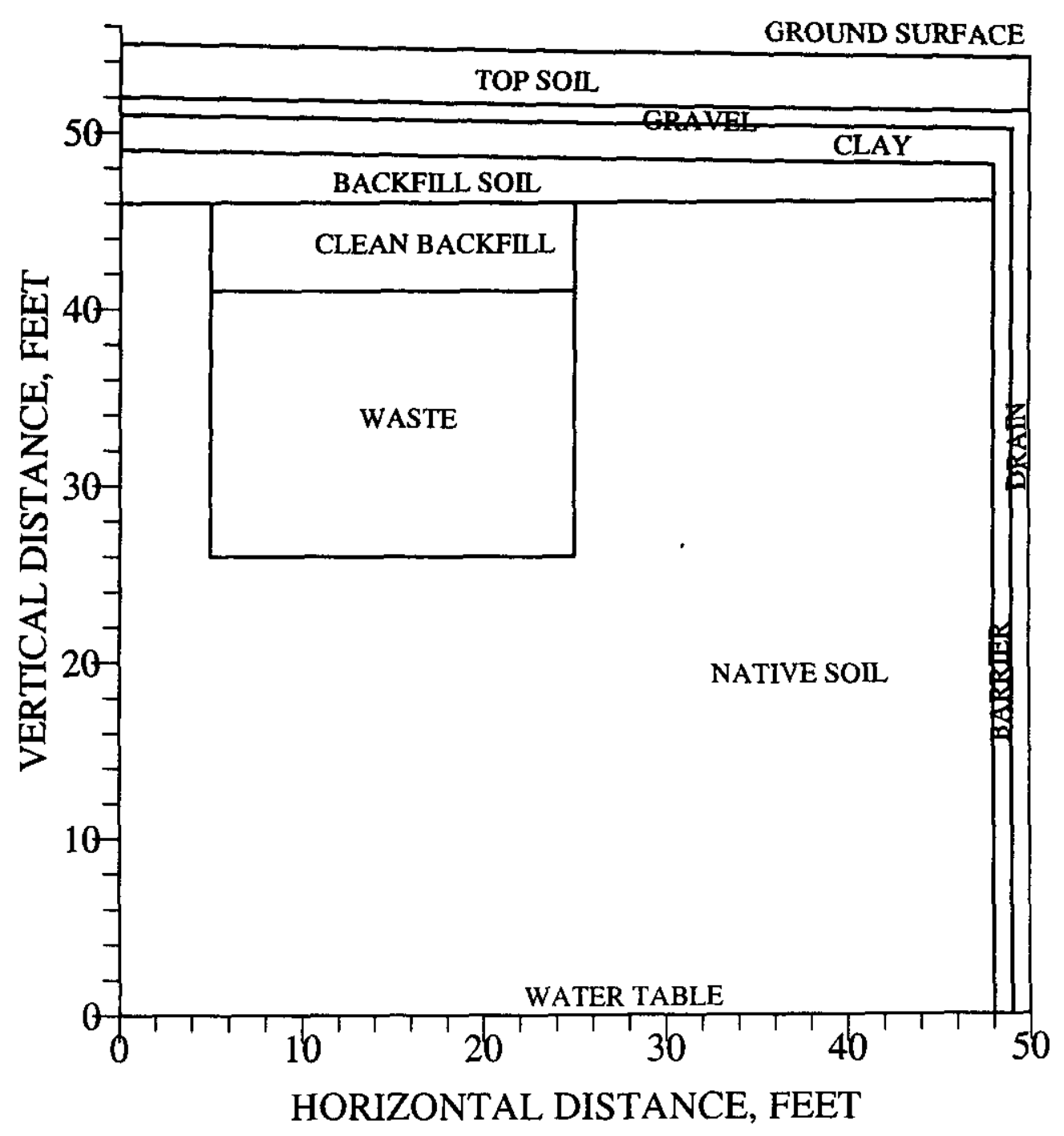

Figure 4.3-6. Conceptual Model of Trench Disposal Unit 


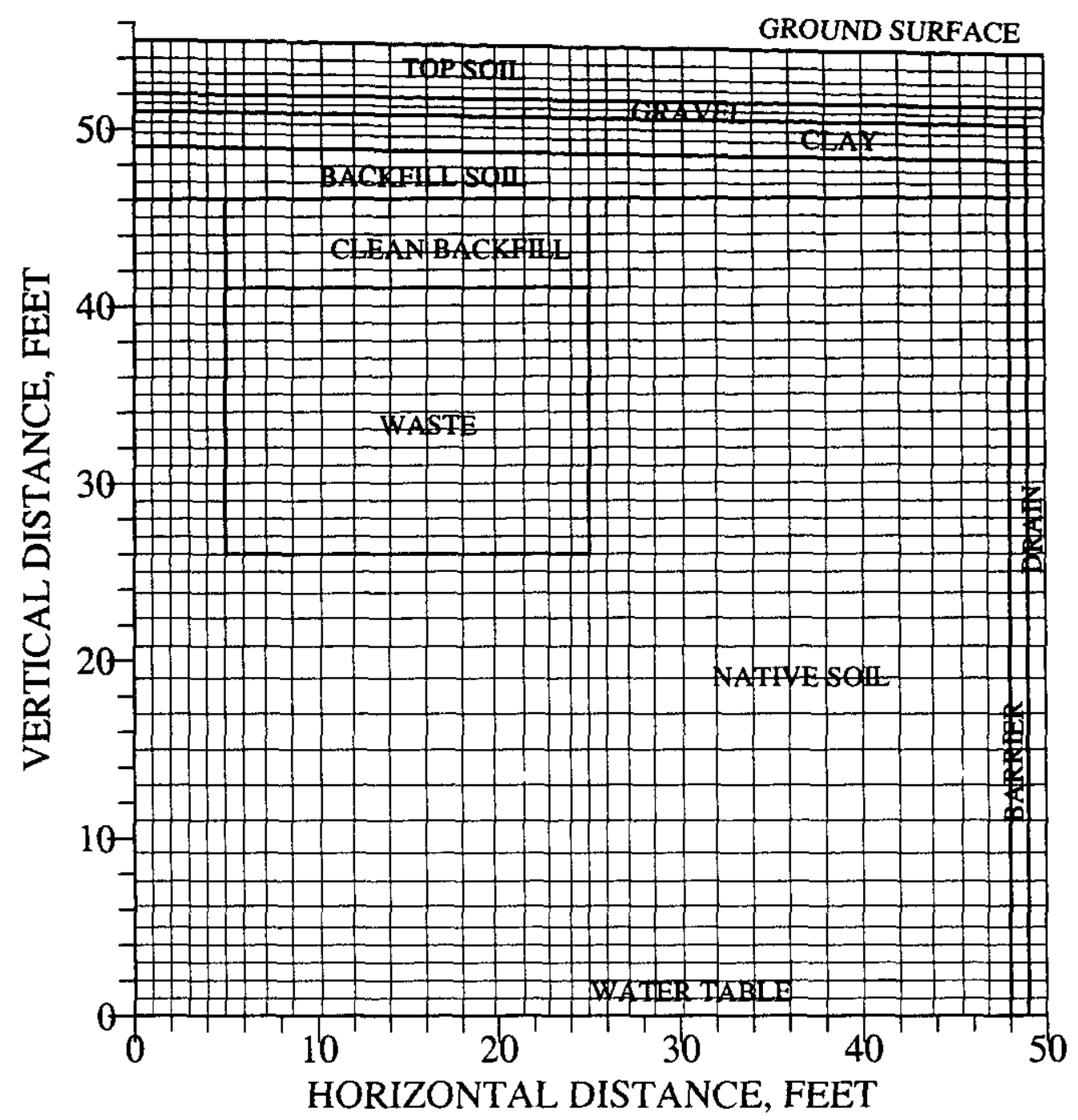

Figure 4.3-7. Modeling Grid of Trench Disposal Unit 
Infiltration at the top of the domain is assumed to be $40 \mathrm{~cm} / \mathrm{yr}$ (Appendix C). A steady-state flow field was generated using PORFLOW (Appendix B) for the 25-year period before closure of the trenches when the infiltration barrier is absent, and for the time beyond 100 years post-closure, when the infiltration barrier is assumed to have failed (Section 4.1.3). When the infiltration barrier is in place and intact, another steady-state flow field is generated using PORFLOW (Appendix B).

Mass transport simulations were run using the steady-state flow fields generated for the three discrete periods of time (the 25 years leading to closure, from closure to 100 years post-closure, and from 100 years post-closure and beyond). These PORFLOW simulations were based on an initial activity of $1 \mathrm{Ci}$ of each radionuclide present in two groups of five slit trenches (i.e., one Ci distributed over 10 trenches). Again, radioactive daughter ingrowth was accounted for explicitly in the PORFLOW code. The $K_{d} s$ listed in Table $4.1-4$ for soil were used for the waste and underlying soils. Longitudinal and transverse dispersivities were assumed to be zero $\mathrm{cm}$. Fractional fluxes $(\mathrm{Ci} / \mathrm{yr}-\mathrm{Ci}$ initially disposed of in each trench) at the water table were calculated for each radionuclide listed in the inventory for the slit trenches (Appendix A) with the exception of those radionuclides screened from consideration based on the procedures described in Section 4.1.3.1.

Peak fractional fluxes to the water table for all radionuclides simulated for the slit trenches are given in Table 4.3-5. In the absence of vaults, peak fluxes at the water table occur much earlier for many radionulcides (tritium peaks in 7 years). Highly-sorbing radionuclides (e.g., Th isotopes) still peak after 10,000 years.

\subsubsection{Naval Reactor Component Waste Units}

Release of radionuclides from the NR waste to the surrounding unsaturated soils of the vadose zone will occur when the integrity of the disposal containers is breached (Section 4.1.3.1). The rate of release will be controlled by the quantity of infiltrating water contacting the waste and the availability of radionuclides for transport. Flow of water through the NR waste is limited by the amount of infiltration through the moisture barrier, and hydraulic characteristics of the waste and surrounding soil. The availability of radionuclides for transport is a function of the degree of corrosion of the activated metal in the NR waste (Section 4.1.3.1 and Appendix C).

The conceptual model is very similar to that of the slit trenches, because release is not modeled until containment is assumed to be breached. Thus, visualization of the waste in a trench-type disposal unit is sufficient. As with the conceptual models described earlier, the upper part of the domain of the NR waste conceptual model is the ground surface; the lower part is the water table (see Fig. 4.3-6). The infiltration barrier lies beneath the top soil, as in previously-described models. Underneath the infiltration barrier clay is backfill used to fill around and over the disposal casks. The bottom of the waste zone is assumed to lie at approximately $7.6 \mathrm{~m}(25 \mathrm{feet})$ above the water table.

Hydraulic properties assumed for the waste, backfill, clay, gravel, top soil, and native soil are described in Appendix C. Table C.I-4 lists the assumed hydraulic conductivities, porosities, and moisture characteristic curves for these materials. Since simulation of mass transport is only done after container integrity is breached, at 750 years, all other materials are assumed to have degraded at that time to properties like those described for the failed trenches (Table C.1-3). Thus, the steady-state flow field used for simulating mass transport from the naval reactor components waste is very much like the flow field for the failed trenches. 
Table 4.3-5. Estimated Peak Fractional Flux to the Water Table for Radionuclides Disposed of in E-Area Slit Trenches

\begin{tabular}{|c|c|c|}
\hline Radionuclide & $\begin{array}{c}\text { Peak flux to water table } \\
\mathrm{Ci} / \mathrm{yr}\end{array}$ & $\begin{array}{c}\text { Time of peak flux } \\
y \mathrm{r}\end{array}$ \\
\hline $\mathrm{H}-3$ & $1.56 \mathrm{E}-01$ & $6.91 \mathrm{E}+00$ \\
\hline C-14 & $3.09 \mathrm{E}-02$ & $1.55 E+02$ \\
\hline $\mathrm{Ni}-59$ & $1.98 \mathrm{E}-04$ & $6.85 \mathrm{E}+03$ \\
\hline Se-79 & $5.23 E-04$ & $2.80 \mathrm{E}+03$ \\
\hline $\mathrm{Rb}-87$ & $1.46 \mathrm{E}-03$ & $1.12 \mathrm{E}+03$ \\
\hline Sr-90 & $9.15 \mathrm{E}-06$ & $2.66 \mathrm{E}+02$ \\
\hline $\mathrm{Zr}-93$ & $1.34 \mathrm{E}-04$ & $1.08 \mathrm{E}+04$ \\
\hline $\mathrm{Nb}-93 \mathrm{~m}$ & $5.01 \mathrm{E}-04$ & $1.08 \mathrm{E}+04$ \\
\hline Tc-99 & $1.00 \mathrm{E}-01$ & $1.62 \mathrm{E}+01$ \\
\hline Pd-107 & $1.52 \mathrm{E}-03$ & $1.06 \mathrm{E}+03$ \\
\hline Sn-126 & $6.11 \mathrm{E}-04$ & $2.45 \mathrm{E}+03$ \\
\hline I -129 & 7.27E-02 & $2.24 \mathrm{E}+01$ \\
\hline Cs- 135 & $2.45 \mathrm{E}-04$ & $5.96 \mathrm{E}+03$ \\
\hline Th-232 & $2.53 \mathrm{E}-05$ & $5.70 \mathrm{E}+04$ \\
\hline Ra-228 & $1.62 \mathrm{E}-04$ & $5.74 \mathrm{E}+04$ \\
\hline Th-228 & $2.52 \mathrm{E}-05$ & $5.74 E+04$ \\
\hline $\mathrm{Ra}-224$ & $1.61 \mathrm{E}-04$ & $5.68 \mathrm{E}+04$ \\
\hline $\mathrm{U}-232$ & $6.12 \mathrm{E}-06$ & $5.55 \mathrm{E}+02$ \\
\hline Th-228 & $6.74 \mathrm{E}-08$ & $5.65 \mathrm{E}+02$ \\
\hline $\mathrm{Ra}-224$ & $4.32 \mathrm{E}-07$ & $5.65 E+02$ \\
\hline $\mathrm{U}-233$ & $2.42 \mathrm{E}-03$ & $7.15 \mathrm{E}+02$ \\
\hline Th-229 & $9.83 \mathrm{E}-07$ & $1.72 \mathrm{E}+03$ \\
\hline $\mathrm{Ra}-225$ & $6.26 \mathrm{E}-06$ & $1.40 \mathrm{E}+03$ \\
\hline $\mathrm{U}-234$ & $2.42 \mathrm{E}-03$ & $7.15 \mathrm{E}+02$ \\
\hline Th-230 & $1.05 \mathrm{E}-07$ & $2.13 \mathrm{E}+03$ \\
\hline $\mathrm{Ra}-226$ & $6.42 \mathrm{E}-07$ & $9.07 \mathrm{E}+03$ \\
\hline $\mathrm{Pb}-210$ & $1.19 \mathrm{E}-06$ & $9.02 \mathrm{E}+03$ \\
\hline Po-210 & $2.14 \mathrm{E}-06$ & $8.97 \mathrm{E}+03$ \\
\hline U-235 & $2.43 \mathrm{E}-03$ & $7.15 \mathrm{E}+02$ \\
\hline $\mathrm{Pa}-23 \mathrm{I}$ & $1.45 \mathrm{E}-06$ & $1.50 \mathrm{E}+03$ \\
\hline Ac- -227 & $1.77 \mathrm{E}-06$ & $1.45 \mathrm{E}+03$ \\
\hline Th-227 & $2.46 \mathrm{E}-07$ & $1.38 \mathrm{E}+03$ \\
\hline $\mathrm{Ra}-223$ & $1.57 \mathrm{E}-06$ & $1.37 E+03$ \\
\hline U-236 & $2.43 \mathrm{E}-03$ & $7.15 \mathrm{E}+02$ \\
\hline $\mathrm{Np}-237$ & $1.50 \mathrm{E}-02$ & $2.15 \mathrm{E}+02$ \\
\hline U-238 & $2.43 \mathrm{E}-03$ & $7.15 \mathrm{E}+02$ \\
\hline Th-234 & $2.68 \mathrm{E}-05$ & $7.15 \mathrm{E}+02$ \\
\hline U-234 & $4.98 \mathrm{E}-06$ & $7.45 \mathrm{E}+02$ \\
\hline $\mathrm{Pu}-238$ & $1.59 \mathrm{E}-08$ & $1.09 \mathrm{E}+03$ \\
\hline U-234 & $7.84 \mathrm{E}-07$ & $7.45 \mathrm{E}+02$ \\
\hline Pu-239 & $7.87 \mathrm{E}-04$ & $1.84 \mathrm{E}+03$ \\
\hline U-235 & $1.40 \mathrm{E}-09$ & $1.17 \mathrm{E}+03$ \\
\hline $\mathrm{Pu}-240$ & $6.84 \mathrm{E}-04$ & $1.81 E+03$ \\
\hline $\mathrm{U}-236$ & $3.96 \mathrm{E}-08$ & $1.13 \mathrm{E}+03$ \\
\hline
\end{tabular}


Table 4.3-5. Estimated Peak Fractional Flux to the Water Table for Radionuclides Disposed of in E-Area Slit Trenches

\begin{tabular}{|c|c|c|}
\hline Radionuclide & $\begin{array}{l}\text { Peak flux to water table } \\
\mathrm{Ci} / \mathrm{yr}\end{array}$ & $\begin{array}{c}\text { Time of peak flux } \\
y \mathrm{yr}\end{array}$ \\
\hline Am-241 & $--^{a}$ & \\
\hline Np-237 & $3.03 \mathrm{E}-06^{\mathrm{a}}$ & $2.15 \mathrm{E}+02$ \\
\hline $\mathrm{Pu}-241$ & -.. b & \\
\hline Am-241 & ----' & \\
\hline Np-237 & $1.01 \mathrm{E}-07^{\mathrm{b}}$ & $2.15 \mathrm{E}+02$ \\
\hline $\mathrm{Pu}-242$ & $8.26 \mathrm{E}-04$ & $1.84 E+03$ \\
\hline U-238 & $2.24 \mathrm{E}-10$ & $1.22 \mathrm{E}+03$ \\
\hline Am-243 & $2.84 \mathrm{E}-06$ & $2.70 \mathrm{E}+04$ \\
\hline Np-239 & $1.03 \mathrm{E}-03$ & $2.70 \mathrm{E}+04$ \\
\hline Pu-239 & $2.51 \mathrm{E}-05$ & $2.99 E+03$ \\
\hline $\mathrm{Pu}-244$ & $8.29 \mathrm{E}-04$ & $1.84 \mathrm{E}+03$ \\
\hline $\mathrm{Cm}-242$ & $--^{c}$ & \\
\hline $\mathrm{U}-234$ & $1.62 \mathrm{E}-06^{\mathrm{c}}$ & $7.15 \mathrm{E}+02$ \\
\hline $\mathrm{Cm}-244$ & $-{ }^{d}$ & \\
\hline $\mathrm{Pu}-240$ & $1.89 \mathrm{E}-06^{\mathrm{d}}$ & $1.81 E+03$ \\
\hline U-236 & $1.09 \mathrm{E}-10^{\mathrm{d}}$ & $1.13 E+03$ \\
\hline $\mathrm{Cm}-245$ & $3.86 \mathrm{E}-10$ & $1.84 \mathrm{E}+04$ \\
\hline $\mathrm{Pu}-241$ & $3.07 \mathrm{E}-08$ & $1.84 E+04$ \\
\hline Am-241 & $2.91 \mathrm{E}-09$ & $1.84 \mathrm{E}+04$ \\
\hline $\mathrm{Np}-237$ & $3.74 \mathrm{E}-07$ & $2.09 \mathrm{E}+03$ \\
\hline $\mathrm{Cm}-246$ & $8.16 \mathrm{E}-14$ & $1.00 \mathrm{E}+04$ \\
\hline $\mathrm{Cm}-247$ & $2.20 \mathrm{E}-05$ & $6.72 \mathrm{E}+04$ \\
\hline Am-243 & 4.11E-05 & $5.90 \mathrm{E}+04$ \\
\hline$N p-239$ & $1.49 \mathrm{E}-02$ & $5.92 \mathrm{E}+04$ \\
\hline $\mathrm{Pu}-239$ & $3.43 \mathrm{E}-05$ & $3.12 \mathrm{E}+04$ \\
\hline $\mathrm{Cm}-248$ & $1.93 \mathrm{E}-05$ & $6.64 E+04$ \\
\hline Pu-244 & $1.16 \mathrm{E}-08$ & $1.10 \mathrm{E}+04$ \\
\hline $\mathrm{Bk}-249$ & $\ldots$ & \\
\hline Cf-249 & $1.31 \mathrm{E}-12^{\mathrm{e}}$ & $4.70 \mathrm{E}+03$ \\
\hline $\mathrm{Cf}-249$ & $5.21 \mathrm{E}-10$ & $4.70 \mathrm{E}+03$ \\
\hline C $\mathrm{Cm}-245$ & $2.45 \mathrm{E}-10$ & $1.84 \mathrm{E}+04$ \\
\hline $\mathrm{Pu}-241$ & $1.28 \mathrm{E}-08$ & $1.84 \mathrm{E}+04$ \\
\hline Am-241 & $9.05 \mathrm{E}-10$ & $1.84 E+04$ \\
\hline $\mathrm{Np}-237$ & $1.13 \mathrm{E}-08$ & $2.97 \mathrm{E}+03$ \\
\hline $\mathrm{Cf}-252$ & $\ldots f$ & \\
\hline $\mathrm{Cm}-248$ & $1.50 \mathrm{E}-10^{\mathrm{f}}$ & $6.64 \mathrm{E}+04$ \\
\hline $\mathrm{Pu}-244$ & $9.03 \mathrm{E}-14$ & $1.10 \mathrm{E}+04$ \\
\hline \multicolumn{3}{|c|}{$\begin{array}{l}\text { Am-241 not potentially significant; value calculated for daughter assumes all Am-241 }\left(\mathrm{T}_{1 / 2}=432 \mathrm{yr}\right) \text { decays } \\
\text { instantaneously to Np-237 before transport. } \\
\text { Pu-241 and Am-241 not potentially significant; value calculated for daughter assumes all Pu-241 }\left(\mathrm{T}_{1 / 2}=14.4\right. \\
\mathrm{yr}) \text { decays instantaneously to Np-237 before transport. } \\
\mathrm{Cm}-242 \text { not potentially significant; value calculated for daughter assumes all } \mathrm{Cm}-242\left(\mathrm{~T}_{1 / 2}=0.45 \mathrm{yr}\right) \text { decays } \\
\text { instantaneously to U-234 before transport. } \\
\text { Cm-244 not potentially significant; value calculated for daughter assumes all Cm-244 }\left(\mathrm{T}_{\mathrm{l} / 2}=18 \mathrm{yr}\right) \text { decays } \\
\text { instantaneously to Pu-240 before transport. } \\
\text { Bk-249 not potentially significant; value calculated for daughter assumes all Bk-249 }\left(\mathrm{T}_{1 / 2}=0.88 \mathrm{yr}\right) \text { decays } \\
\text { instantaneously to Cf-249 before transport. } \\
\text { Cf-252 not potentially significant; value calculated for daughter assumes all Cf-252 }\left(\mathrm{T}_{1 / 2}=2.64 \mathrm{yr}\right) \text { decays } \\
\text { instantaneously to Cm-248 before transport. }\end{array}$} \\
\hline
\end{tabular}


A steady-state flow field was developed for the discretized grid shown in Fig. 4.3-7. Mass transport simulations were run using this steady-state flow field. As with other disposal units, the PORFLOW simulations assumed an initial activity of $1 \mathrm{Ci}$ for each radionuclide listed in the NR inventory (i.e., one $\mathrm{Ci}$ distributed over 100 containers). Because radionuclides only become available for leaching as the activated metal waste form corrodes, an additional source specification reflecting this limited availability over time is made. Fractional fluxes ( $\mathrm{Ci} / \mathrm{yr}-\mathrm{Ci}$ initially disposed of in the $\mathrm{Pad}$ ) at the water table were calculated for each radionuclide listed in the inventory for the NR components (Appendix A), that was not screened from consideration based on the procedures described in Section 4.1.3.1. Radioactive daughter ingrowth is handled explicitly by the PORFLOW code.

Peak fractional fluxes to the water table for all radionuclides simulated for the NR components are given in Table 4.3-6.

\subsubsection{Intimately-Mixed Cement-Stabilized Waste Units}

Intimately-mixed cement-stabilized waste forms, disposed of in slit trenches, are conceptualized in a manner similar to that of the waste forms in the IL vaults around which grout is poured. The sorption behavior of radionuclides in both of these types of waste disposal units will be controlled by the presence of the surrounding grout. A distinguishing feature of the conceptual model for intimately-mixed waste forms from that of the IL vaults is, however, that contact with water will not be controlled by the presence of concrete vaults in the first 575 years. Therefore, degradation of the waste form (Section 4.1.3.1) is assumed to occur much earlier ( 300 years), and contact with water will be greater in the non-degraded state, due to the higher conductivity of the grout as opposed to that of the concrete used in construction of the vaults.

The 2-dimensional domain of the conceptual model representing the intimately-mixed cement-stabilized waste form looks very much like that of the slit trenches (Fig. 4.3-6), and is discretized in a similar manner (Fig. 4.3-7). One difference between the slit trench domain and the intimately-mixed waste form model domain is found in the hydraulic and sorption properties assigned to the waste zone. Hydraulic properties assumed for the conceptual model of the intimately-mixed cement stabilized waste units are listed in Table C.1-6, and sorption properties are listed in Table 4.1-4. The other difference is that the infiltration barrier is assumed to be in place as soon as the cement-stabilized waste form is placed in the trench. This assumption was made to facilitate analysis. Assuming the barrier is not in place for 25 years (as is done for the slit trenches) is not meaningful because the hydraulic properties of the waste form itself control the influx of water through the waste during the first 300 years of analysis, after which the cement is assumed to have degraded.

The PORFLOW code was used to develop steady-state flow fields, representing flow of water through the waste and surrounding vadose zone, both before and after waste form degradation. Mass transport simulations using PORFLOW provided fractional fluxes ( $\mathrm{Ci} / \mathrm{yr}-\mathrm{Ci}$ initially disposed of in ten trenches) at the water table for each radionuclide listed in Table 4.1-2 for the intimately-mixed cement-stabilized waste form.

Peak fractional fluxes to the water table for all radionuclides simulated for the intimately-mixed cementstabilized waste units are given in Table 4.3-7. The peak for ${ }^{3} \mathrm{H}$ occurs during the period of time the waste is assumed to be intact. Although more water passes through the waste units during the failed phases, the initial inventory of ${ }^{3} \mathrm{H}$ has decayed significantly before failure occurs (300 years). Peak fluxes for many radionuclides occur after 10,000 years. 
Table 4.3-6. Estimated Peak Fractional Flux to the Water Table for Radionuclides Disposed of in E-Area Naval Reactor Pads

\begin{tabular}{|c|c|c|}
\hline Radionuclide & $\begin{array}{l}\text { Peak flux to water table } \\
\mathrm{Ci} / \mathrm{yr}\end{array}$ & $\begin{array}{c}\text { Time of Peak flux } \\
y \mathrm{yr}\end{array}$ \\
\hline $\mathrm{H}-3$ & $1.25 \mathrm{E}-23$ & $7.70 \mathrm{E}+02$ \\
\hline C-14 & $1.47 \mathrm{E}-05$ & $9.30 \mathrm{E}+02$ \\
\hline $\mathrm{Ni}-59$ & $4.18 \mathrm{E}-05$ & $1.23 E+04$ \\
\hline $\mathrm{Se}-79$ & $5.79 \mathrm{E}-05$ & $6.92 \mathrm{E}+03$ \\
\hline Sr-90 & $9.66 \mathrm{E}-15$ & $9.50 \mathrm{E}+02$ \\
\hline Mo-93 & $4.95 \mathrm{E}-05$ & $1.18 \mathrm{E}+03$ \\
\hline Zr-93 & $8.13 \mathrm{E}-06$ & $1.76 \mathrm{E}+04$ \\
\hline $\mathrm{Nb}-93 \mathrm{~m}$ & $1.97 \mathrm{E}-10$ & $1.58 \mathrm{E}+04$ \\
\hline Тc-99 & $5.02 \mathrm{E}-05$ & $8.40 \mathrm{E}+02$ \\
\hline $\mathrm{Sn}-126$ & $5.98 \mathrm{E}-05$ & $6.86 \mathrm{E}+03$ \\
\hline $1-129$ & $6.46 \mathrm{E}-05$ & $5.51 \mathrm{E}+03$ \\
\hline Cs- 135 & $5.42 \mathrm{E}-05$ & $9.88 \mathrm{E}+03$ \\
\hline Th-232 & $9.33 \mathrm{E}-06$ & $6.93 E+04$ \\
\hline $\mathrm{Ra}-228$ & $8.60 \mathrm{E}-15$ & $8.76 \mathrm{E}+04$ \\
\hline Th-228 & $5.04 \mathrm{E}-16$ & $8.58 \mathrm{E}+04$ \\
\hline $\mathrm{Ra}-224$ & $3.51 \mathrm{E}-17$ & $7.34 \mathrm{E}+04$ \\
\hline U-232 & $1.08 \mathrm{E}-12$ & $1.35 \mathrm{E}+03$ \\
\hline Th-228 & $3.15 \mathrm{E}-16$ & $1.36 \mathrm{E}+03$ \\
\hline $\mathrm{Ra}-224$ & $1.04 \mathrm{E}-17$ & $1.36 \mathrm{E}+03$ \\
\hline $\mathrm{U}-234$ & $2.81 \mathrm{E}-05$ & $1.05 \mathrm{E}+04$ \\
\hline Th-230 & $6.11 \mathrm{E}-08$ & $8.57 \mathrm{E}+04$ \\
\hline $\mathrm{Ra}-226$ & $8.25 E-09$ & $7.73 E+04$ \\
\hline $\mathrm{Pb}-210$ & $3.83 \mathrm{E}-10$ & $6.62 E+04$ \\
\hline Po-210 & $9.67 \mathrm{E}-12$ & $7.01 \mathrm{E}+04$ \\
\hline $\mathrm{U}-235$ & $2.89 \mathrm{E}-05$ & $1.05 \mathrm{E}+04$ \\
\hline $\mathrm{Pa}-231$ & $2.08 \mathrm{E}-10$ & $2.01 \mathrm{E}+04$ \\
\hline $\mathrm{Ac}-227$ & $2.52 \mathrm{E}-14$ & $1.00 \mathrm{E}+04$ \\
\hline Th-227 & $5.71 \mathrm{E}-17$ & $1.91 \mathrm{E}+04$ \\
\hline $\mathrm{Ra}-223$ & $2.19 E-16$ & $2.00 \mathrm{E}+04$ \\
\hline U-236 & $2.90 \mathrm{E}-05$ & $1.06 \mathrm{E}+04$ \\
\hline $\mathrm{Np}-237$ & $6.44 \mathrm{E}-05$ & $5.61 \mathrm{E}+03$ \\
\hline U-238 & $2.89 \mathrm{E}-05$ & $1.05 E+04$ \\
\hline Th-234 & $4.72 \mathrm{E}-18$ & $1.07 E+04$ \\
\hline U-234 & $4.01 \mathrm{E}-11$ & $1.53 E+04$ \\
\hline $\mathrm{Pu}-238$ & $5.61 \mathrm{E}-15$ & $1.90 \mathrm{E}+03$ \\
\hline U-234 & $4.01 \mathrm{E}-10$ & $1.80 \mathrm{E}+03$ \\
\hline $\mathrm{Pu}-239$ & $7.41 \mathrm{E}-06$ & $9.19 E+03$ \\
\hline U-235 & 8.59E-07 & $1.10 \mathrm{E}+04$ \\
\hline $\mathrm{Pu}-240$ & $3.85 \mathrm{E}-06$ & $8.35 \mathrm{E}+03$ \\
\hline U-236 & $1.71 \mathrm{E}-06$ & $9.86 \mathrm{E}+03$ \\
\hline Am-241 & --. ${ }^{\mathrm{a}}$ & \\
\hline Np-237 & $1.30 \mathrm{E}-08^{\mathrm{a}}$ & $5.61 \mathrm{E}+03$ \\
\hline $\mathrm{Pu}-241$ & - & \\
\hline Am-241 & $---{ }^{b}$ & \\
\hline Np-237 & $4.33 \mathrm{E}-10^{b}$ & $5.61 \mathrm{E}+03$ \\
\hline
\end{tabular}


Table 4.3-6. Estimated Peak Fractional Flux to the Water Table for Radionuclides Disposed of in E-Area Naval Reactor Pads

\begin{tabular}{|c|c|c|}
\hline Radionuclide & $\begin{array}{c}\text { Peak flux to water table } \\
\mathrm{Ci} / \mathrm{yr}\end{array}$ & $\begin{array}{c}\text { Time of Peak flux } \\
\mathrm{yr}\end{array}$ \\
\hline $\mathrm{Pu}-242$ & $9.68 \mathrm{E}-06$ & $1.10 \mathrm{E}+04$ \\
\hline U-238 & $6.93 \mathrm{E}-08$ & $1.10 \mathrm{E}+04$ \\
\hline Am-243 & $4.87 E-07$ & $3.63 E+04$ \\
\hline $\mathrm{Np}-239$ & $6.93 \mathrm{E}-08$ & $1,10 \mathrm{E}+04$ \\
\hline $\mathrm{Pu}-239$ & $4.01 E-11$ & $1.53 E+04$ \\
\hline Pu-244 & $9.81 \mathrm{E}-06$ & $1.00 \mathrm{E}+04$ \\
\hline $\mathrm{Cm}-242$ & $\ldots{ }^{c}$ & \\
\hline $\mathrm{U}-234$ & $5.17 \mathrm{E}-11^{\mathrm{c}}$ & $1.05 E+04$ \\
\hline $\mathrm{Cm}-244$ & $--^{\mathrm{d}}$ & \\
\hline Pu-240 & $1.06 \mathrm{E}-08^{\mathrm{d}}$ & $8.35 \mathrm{E}+03$ \\
\hline$U-236$ & 4.71E-09 & $9.86 \mathrm{E}+03$ \\
\hline $\mathrm{Cm}-245$ & $2.05 \mathrm{E}-08$ & $7.46 \mathrm{E}+04$ \\
\hline $\mathrm{Pu}-241$ & $2.50 \mathrm{E}-09$ & $6.55 E+04$ \\
\hline Am-241 & $4.82 \mathrm{E}-09$ & $6.28 \mathrm{E}+04$ \\
\hline Np-237 & $1.75 \mathrm{E}-05$ & $8.12 E+03$ \\
\hline $\mathrm{Cm}-246$ & $3.64 \mathrm{E}-12$ & $9.75 \mathrm{E}+04$ \\
\hline $\mathrm{Cm}-247$ & $6.42 \mathrm{E}-06$ & $9.12 \mathrm{E}+04$ \\
\hline Am-243 & $5.57 \mathrm{E}-09$ & $8.34 \mathrm{E}+04$ \\
\hline $\mathrm{Np}-239$ & 1.35E-12 & $8.97 \mathrm{E}+04$ \\
\hline Pu-239 & $5.46 \mathrm{E}-09$ & $8.55 E+04$ \\
\hline $\mathrm{Cm}-248$ & $5.02 \mathrm{E}-06$ & $9.29 \mathrm{E}+04$ \\
\hline $\mathrm{Pu}-244$ & $7.88 \mathrm{E}-07$ & $1.00 \mathrm{E}+04$ \\
\hline Cf-249 & $6.15 \mathrm{E}-13$ & $5.84 \mathrm{E}+03$ \\
\hline $\mathrm{Cm}-245$ & $7.31 \mathrm{E}-11$ & $9.03 E+04$ \\
\hline Pu-241 & $8.28 \mathrm{E}-12$ & $8.57 \mathrm{E}+04$ \\
\hline Am-24l & $3.46 \mathrm{E}-12$ & $9.66 \mathrm{E}+04$ \\
\hline $\mathrm{Np}-237$ & $5.55 \mathrm{E}-07$ & $5.20 \mathrm{E}+03$ \\
\hline \multicolumn{3}{|c|}{$\begin{array}{l}\text { Am-241 not potentially significant; value calculated for daughter assumes all } \mathrm{Am}-241\left(\mathrm{~T}_{1 / 2}=\right. \\
432 \mathrm{yr}) \text { decays instantaneously to Np-237 before transport. } \\
\mathrm{Pu}-241 \text { and Am-241 not potentially significant; value calculated for daughter assumes all Pu- } \\
\left.241 \text { ( } \mathrm{T}_{\mathrm{l} / 2}=14.4 \mathrm{yr}\right) \text { decays instantaneously to Np-237 before transport. } \\
\mathrm{Cm}-242 \text { not potentially significant; value calculated for daughter assumes all } \mathrm{Cm}-242\left(\mathrm{~T}_{1 / 2}=\right. \\
0.45 \mathrm{yr}) \text { decays instantaneously to U-234 before transport. } \\
\mathrm{Cm}-244 \text { not potentially significant; value calculated for daughter assumes all } \mathrm{Cm}-244\left(\mathrm{~T}_{1 / 2}=18\right. \\
\mathrm{yr}) \text { decays instantaneously to Pu- } 240 \text { before transport. }\end{array}$} \\
\hline
\end{tabular}


Table 4.3-7. Estimated Peak Fractional Flux to the Water Table for Radionuclides Disposed of in E-Area Intimately-Mixed CementStabilized Waste

\begin{tabular}{|c|c|c|}
\hline Radionuclide & $\begin{array}{c}\text { Peak flux to water table } \\
\mathrm{Ci} / \mathrm{yr}\end{array}$ & $\begin{array}{c}\text { Time of peak flux } \\
\mathrm{yr}\end{array}$ \\
\hline $\mathrm{H}-3$ & $2.58 \mathrm{E}-09$ & $6.61 \mathrm{E}+01$ \\
\hline C-14 & $1.23 \mathrm{E}-05$ & $4.00 \mathrm{E}+02$ \\
\hline $\mathrm{Ni}-59$ & $1.80 \mathrm{E}-04$ & $9.05 E+03$ \\
\hline Se-79 & $5.12 \mathrm{E}-04$ & $3.29 \mathrm{E}+03$ \\
\hline $\mathrm{Rb}-87$ & $1.35 \mathrm{E}-03$ & $1.58 \mathrm{E} \div 03$ \\
\hline Sr-90 & $1.56 \mathrm{E}-07$ & $4.40 E+02$ \\
\hline Zr-93 & $1.27 \mathrm{E}-05$ & $2.18 \mathrm{E}+04$ \\
\hline $\mathrm{Nb}-93 \mathrm{~m}$ & $4.76 \mathrm{E}-05$ & $2.32 \mathrm{E}+04$ \\
\hline $\mathrm{Nb}-94$ & $1.04 \mathrm{E}-04$ & $5.56 \mathrm{E}+03$ \\
\hline Tc-99 & $4.67 \mathrm{E}-02$ & $3.30 \mathrm{E}+02$ \\
\hline Pd-107 & $6.19 \mathrm{E}-04$ & $2.12 E+03$ \\
\hline $\mathrm{Sn}-126$ & $6.14 \mathrm{E}-05$ & $4.61 \mathrm{E}+03$ \\
\hline $\mathrm{I}-129$ & $2.95 \mathrm{E}-02$ & $3.40 \mathrm{E}+02$ \\
\hline Cs-135 & $2.43 \mathrm{E}-04$ & $7.01 \mathrm{E}+03$ \\
\hline Th-232 & $1.21 \mathrm{E}-05$ & $1.01 \mathrm{E}+05$ \\
\hline $\mathrm{Ra}-228$ & $7.75 \mathrm{E}-05$ & $1.00 \mathrm{E}+05$ \\
\hline Th-228 & $1.21 \mathrm{E}-05$ & $1.01 \mathrm{E}+05$ \\
\hline $\mathrm{Ra}-224$ & $7.73 \mathrm{E}-05$ & $1.01 \mathrm{E}+05$ \\
\hline $\mathrm{U}-232$ & $8.93 \mathrm{E}-14$ & $1.17 \mathrm{E}+03$ \\
\hline Th-228 & $9.82 \mathrm{E}-16$ & $1.75 \mathrm{E}+03$ \\
\hline $\mathrm{Ra}-224$ & $6.31 \mathrm{E}-15$ & $1.17 \mathrm{E}+03$ \\
\hline U-233 & $1.63 \mathrm{E}-14$ & $8.41 \mathrm{E}+03$ \\
\hline Th-229 & $1.58 \mathrm{E}-08$ & $6.04 \mathrm{E}+04$ \\
\hline $\mathrm{Ra}-225$ & $1.01 \mathrm{E}-07$ & $5.98 \mathrm{E}+04$ \\
\hline $\mathrm{U}-234$ & $1.06 \mathrm{E}-14$ & $1.00 \mathrm{E}+04$ \\
\hline Th-230 & $4.59 \mathrm{E}-07$ & $9.44 \mathrm{E}+04$ \\
\hline $\mathrm{Ra}-226$ & $3.20 \mathrm{E}-06$ & $8.28 \mathrm{E}+04$ \\
\hline $\mathrm{Pb}-210$ & $5.94 \mathrm{E}-06$ & $8.18 E+04$ \\
\hline Po-210 & $1.07 \mathrm{E}-05$ & $8.20 \mathrm{E}+04$ \\
\hline $\mathrm{U}-235$ & $3.70 \mathrm{E}-18$ & $9.45 E+03$ \\
\hline $\mathrm{Pa}-231$ & $1.76 \mathrm{E}-06$ & $2.42 E+04$ \\
\hline $\mathrm{Ac}-227$ & $2.16 \mathrm{E}-06$ & $2.40 \mathrm{E}+04$ \\
\hline Th-227 & $3.05 \mathrm{E}-07$ & $2.42 \mathrm{E}+04$ \\
\hline $\mathrm{Ra}-223$ & $1.95 \mathrm{E}-06$ & $2.40 \mathrm{E}+04$ \\
\hline U-236 & $1.11 \mathrm{E}-16$ & $1.00 \mathrm{E}+04$ \\
\hline Np-237 & $1.29 \mathrm{E}-05$ & $9.51 \mathrm{E}+03$ \\
\hline U-238 & $5.81 \mathrm{E}-19$ & $1.00 \mathrm{E}+04$ \\
\hline Th-234 & $6.40 \mathrm{E}-21$ & $1.00 E+04$ \\
\hline U-234 & $3.51 \mathrm{E}-12$ & $1.00 \mathrm{E}+04$ \\
\hline $\mathrm{Pu}-238$ & $3.53 \mathrm{E}-19$ & $2.08 E+03$ \\
\hline U-234 & $1.06 \mathrm{E}-14$ & $1.00 \mathrm{E}+04$ \\
\hline Pu-239 & $1.49 \mathrm{E}-16$ & $1.00 \mathrm{E}+04$ \\
\hline U-235 & $3.70 \mathrm{E}-18$ & $9.88 \mathrm{E}+03$ \\
\hline
\end{tabular}


Table 4.3-7. Estimated Peak Fractional Flux to the Water Table for Radionuclides Disposed of in E-Area Intimately-Mixed CementStabilized Waste

\begin{tabular}{|c|c|c|}
\hline Radionuclide & $\begin{array}{l}\text { Peak flux to water table } \\
\mathrm{Ci} / \mathrm{yr}\end{array}$ & $\begin{array}{c}\text { Time of peak flux } \\
y \mathrm{r}\end{array}$ \\
\hline $\mathrm{Pu}-240$ & $4.67 \mathrm{E}-16$ & $1.00 \mathrm{E}+04$ \\
\hline $\mathrm{U}-236$ & $1.11 \mathrm{E}-16$ & $1.00 \mathrm{E}+04$ \\
\hline Am-241 & $--^{a}$ & \\
\hline $\mathrm{Np}-237$ & $2.60 \mathrm{E}-09^{\mathrm{a}}$ & $9.51 E+03$ \\
\hline Pu-241 & $\ldots$ & \\
\hline $\mathrm{Am}-241$ & $\ldots{ }^{b}$ & \\
\hline Np-237 & $8.68 \mathrm{E}-11^{b}$ & $9.51 \mathrm{E}+03$ \\
\hline $\mathrm{Pu}-242$ & $1.01 \mathrm{E}-17$ & $1.00 \mathrm{E}+04$ \\
\hline U-238 & $5.81 \mathrm{E}-19$ & $1.00 E+04$ \\
\hline $\mathrm{Am}-243$ & $1.58 \mathrm{E}-07$ & $3.84 \mathrm{E}+04$ \\
\hline Np-239 & $5.72 \mathrm{E}-05$ & $3.84 \mathrm{E}+04$ \\
\hline $\mathrm{Pu}-239$ & $1.37 \mathrm{E}-06$ & $1.30 \mathrm{E}+04$ \\
\hline $\mathrm{Pu}-244$ & $4.72 \mathrm{E}-20$ & $1.00 \mathrm{E}+04$ \\
\hline $\mathrm{Cm}-244$ & $\ldots$ & \\
\hline $\mathrm{Pu}-240$ & $1.29 \mathrm{E}-18^{\mathrm{c}}$ & $1.00 \mathrm{E}+04$ \\
\hline U-236 & $3.06 \mathrm{E}-19^{\mathrm{c}}$ & $1.00 \mathrm{E}+04$ \\
\hline $\mathrm{Cm}-245$ & $1.08 \mathrm{E}-08$ & $6.70 \mathrm{E}+04$ \\
\hline $\mathrm{Pu}-241$ & $4.62 \mathrm{E}-07$ & $6.62 \mathrm{E}+04$ \\
\hline Am-24l & $2.72 \mathrm{E}-08$ & $6.52 \mathrm{E}+04$ \\
\hline Np-237 & $5.84 \mathrm{E}-08$ & $2.44 \mathrm{E}+04$ \\
\hline $\mathrm{Cm}-246$ & $2.18 \mathrm{E}-10$ & $5.30 E+04$ \\
\hline $\mathrm{Cm}-247$ & $1.11 \mathrm{E}-05$ & $1.09 E+05$ \\
\hline Am-243 & $2.31 \mathrm{E}-05$ & $1.08 E+05$ \\
\hline $\mathrm{Np}-239$ & $8.34 \mathrm{E}-03$ & $1.08 \mathrm{E}+05$ \\
\hline Pu-239 & $2.10 \mathrm{E}-05$ & $7.74 E+04$ \\
\hline $\mathrm{Cm}-248$ & $8.97 \mathrm{E}-06$ & $1.09 E+05$ \\
\hline $\mathrm{Pu}-244$ & $6.19 \mathrm{E}-09$ & $7.72 \mathrm{E}+04$ \\
\hline $\mathrm{Cf}-249$ & $1.05 \mathrm{E}-12$ & $5.36 \mathrm{E}+03$ \\
\hline $\mathrm{Cm}-245$ & $4.66 \mathrm{E}-10$ & $6.68 \mathrm{E}+04$ \\
\hline $\mathrm{Pu}-241$ & $1.99 \mathrm{E}-08$ & $6.60 \mathrm{E}+04$ \\
\hline Am-24l & $1.17 \mathrm{E}-09$ & $6.52 \mathrm{E}+04$ \\
\hline Np-237 & $2.42 \mathrm{E}-09$ & $2.38 E+04$ \\
\hline $\mathrm{Cf}-252$ & $\ldots d$ & \\
\hline $\mathrm{Cm}-248$ & $6.98 \mathrm{E}-11^{d}$ & $1.09 E+05$ \\
\hline Pu-244 & $4.82 \mathrm{E}-14^{\mathrm{d}}$ & $7.72 E+04$ \\
\hline \multicolumn{3}{|c|}{$\begin{array}{l}\text { Am-24l not potentially significant; value calculated for daughter assumes all } \mathrm{Am}-241\left(\mathrm{~T}_{\mathrm{1} / 2}=432\right. \\
\mathrm{yr}) \text { decays instantaneously to } \mathrm{Np}-234 \text { before transport. } \\
\mathrm{Pu}-241 \text { and Am-241 not potentially significant; value calculated for daughter assumes all } \mathrm{Pu}-241 \\
\left(\mathrm{~T}_{1 / 2}=14.4 \mathrm{yr}\right) \text { decays instantaneously to Np-237 before transport. } \\
\text { Cm-244 not potentially significant; value calculated for daughter assumes all } \mathrm{Cm}-244\left(\mathrm{~T}_{1 / 2}=18\right. \\
\text { yr) decays instantaneously to } \mathrm{Pu}-240 \text { before transport. } \\
\text { d } \mathrm{Cf}-252 \text { not potentially significant; value calculated for daughter assumes all } \mathrm{Cf}-252\left(\mathrm{~T}_{1 / 2}=2.64\right. \\
\text { yr) decays instantaneously to } \mathrm{Cm}-248 \text { before transport. }\end{array}$} \\
\hline
\end{tabular}




\subsubsection{Cement-Stabilized Encapsulated Waste Units}

Cement-stabilized encapsulated waste forms (for example, large metal equipment), disposed of in slit trenches, are conceptualized in a manner similar to that of the LAW vault waste forms. The waste compartment, surrounded by a concrete cocoon, is considered to be predominantly corrosion products of the metal equipment. The sorption behavior of radionuclides in the waste compartment of both of these types of waste disposal units will be controlled by the presence of these corrosion products. Unlike the LAW vaults, however, degradation of the encapsulating concrete (Section 4.1.3.1) is assumed to occur at 300 years because of the absence of the thicker-walled vaults. Contact with water is assumed to be greater in the non-degraded state also, due to the higher conductivity of the grout as opposed to that of the concrete used in construction of the vaults.

The 2-dimensional domain of the conceptual model representing the cement-stabilized encapsulated waste units again looks very much like that of the slit trenches (Fig. 4.3-6 and Fig. 4.3-7). One difference between the slit trench domain and the encapsulated waste unit model domain is found in the hydraulic and sorption properties assigned to the waste zone. Hydraulic properties assumed for the conceptual model of the cement-stabilized encapsulated waste units are listed in Table C.1-7, and sorption properties are listed in Table 4.1-4. The other difference is that the infiltration barrier is assumed to be in place as soon as the encapsulated waste units are placed in the trench. As with the intimately-mixed waste form, this assumption was made to facilitate analysis. The hydraulic properties of the concrete cocoon control the influx of water through the waste during the first 300 years of analysis, after which the cement is assumed to have degraded.

The PORFLOW code was used to develop steady-state flow fields, representing flow through the waste and surrounding vadose zone, both before and after waste form degradation. Mass transport simulations using PORFLOW provided fractional fluxes (Ci/yr-Ci initially disposed of in ten trenches) at the water table for each radionuclide listed in Table 4.1-2 for the cement-stabilized encapsulated waste units.

Peak fractional fluxes to the water table for all radionuclides simulated for the cement-stabilized encapsulated waste units are given in Table 4.3-8.

\subsubsection{Saturated Zone Model of E-Area}

\subsection{Analytical Model}

In order to calculate peak groundwater concentrations at the points of compliance for the all-pathways analysis and water resource impacts analysis, transport in the saturated zone of radionuclides leached from the waste disposal units and reaching the water table must be evaluated. Before doing so, however, an analytical method was developed for estimating maximum groundwater concentrations based on peak fractional fluxes (Tables 4.3-2 through 4.3-7). These estimates were used to screen from further analysis radionuclides for which comparisons of the estimated peak groundwater concentrations with MCLs and allowable concentrations based on the $25 \mathrm{mrem} / \mathrm{yr}$ limit result in inventory limits that are orders of magnitude greater than the projected inventories provided for each type of unit in Appendix A. The analytical estimates were also used to estimate peak groundwater concentrations when these peaks are believed to occur beyond 10,000 years after closure of the facilities. 
Table 4.3-8 Estimated Peak Fractional Flux to the Water Table for Radionuclides Disposed of in E-Area Cement-Stabilized Encapsulated Waste

\begin{tabular}{|c|c|c|}
\hline Radionuclide & $\begin{array}{l}\text { Peak Flux to water table } \\
\mathrm{Ci} / \mathrm{yr}\end{array}$ & $\begin{array}{c}\text { Time of peak flux } \\
y \mathrm{y}\end{array}$ \\
\hline $\mathrm{H}-3$ & $2.34 \mathrm{E}-11$ & $3.20 \mathrm{E}+02$ \\
\hline $\mathrm{Ni}-59$ & $1.91 \mathrm{E}-04$ & $7.78 \mathrm{E}+03$ \\
\hline Se-79 & $5.67 \mathrm{E}-04$ & $2.88 E+03$ \\
\hline Sr-90 & $1.56 \mathrm{E}-07$ & $4.40 \mathrm{E}+02$ \\
\hline Zr-93 & $1.25 \mathrm{E}-04$ & $2.50 \mathrm{E}+03$ \\
\hline $\mathrm{Nb}-93 \mathrm{~m}$ & $4.68 \mathrm{E}-04$ & $2.30 \mathrm{E}+03$ \\
\hline Tc-99 & $7.01 \mathrm{E}-02$ & $3.20 \mathrm{E}+02$ \\
\hline $\mathrm{Sn}-126$ & $5.81 \mathrm{E}-04$ & $2.76 \mathrm{E}+03$ \\
\hline I-129 & $7.51 \mathrm{E}-02$ & $3.20 \mathrm{E}+02$ \\
\hline Cs-135 & $2.10 \mathrm{E}-04$ & $6.98 \mathrm{E}+03$ \\
\hline U-232 & $1.75 E-14$ & $1.81 E+03$ \\
\hline Th-228 & $1.92 \mathrm{E}-16$ & $1.83 E+03$ \\
\hline Ra-224 & $1.23 \mathrm{E}-15$ & $1.84 \mathrm{E}+03$ \\
\hline U-233 & $2.92 \mathrm{E}-14$ & $9.35 \mathrm{E}+04$ \\
\hline Th-229 & $6.43 \mathrm{E}-07$ & $6.03 E+04$ \\
\hline $\mathrm{Ra}-225$ & $4.10 \mathrm{E}-06$ & $6.11 E+04$ \\
\hline $\mathrm{U}-234$ & $1.90 \mathrm{E}-14$ & $9.67 \mathrm{E}+04$ \\
\hline Th-230 & $4.67 \mathrm{E}-06$ & $8.45 E+04$ \\
\hline $\mathrm{Ra}-226$ & $3.27 \mathrm{E}-05$ & $7.49 \mathrm{E}+04$ \\
\hline $\mathrm{Pb}-210$ & $6.08 \mathrm{E}-05$ & $7.51 \mathrm{E}+04$ \\
\hline Po-210 & $1.09 \mathrm{E}-04$ & $7.43 E+04$ \\
\hline U-235 & $6.66 \mathrm{E}-18$ & $7.57 \mathrm{E}+04$ \\
\hline $\mathrm{Pa}-231$ & $1.64 \mathrm{E}-05$ & $9.93 E+04$ \\
\hline Ac- 227 & $2.01 \mathrm{E}-05$ & $9.89 \mathrm{E}+04$ \\
\hline Th-227 & $2.83 \mathrm{E}-06$ & $9.13 E+04$ \\
\hline $\mathrm{Ra}-223$ & $1.81 \mathrm{E}-05$ & $9.77 \mathrm{E}+04$ \\
\hline$U-236$ & $1.98 \mathrm{E}-16$ & $9.99 E+03$ \\
\hline $\mathrm{U}-238$ & $1.04 \mathrm{E}-18$ & $5.71 E+04$ \\
\hline Th-234 & $1.15 \mathrm{E}-20$ & $9.73 \mathrm{E}+04$ \\
\hline $\mathrm{U}-234$ & $2.94 \mathrm{E}-14$ & $9.01 \mathrm{E}+02$ \\
\hline $\mathrm{Pu}-238$ & $4.69 \mathrm{E}-19$ & $3.42 E+03$ \\
\hline U-234 & $1.88 \mathrm{E}-14$ & $9.96 \mathrm{E}+03$ \\
\hline Pu-239 & $2.64 \mathrm{E}-16$ & $9.72 E+03$ \\
\hline $\mathrm{U}-235$ & $7.56 \mathrm{E}-18$ & $9.01 \mathrm{E}+02$ \\
\hline $\mathrm{Pu}-240$ & $8.04 \mathrm{E}-16$ & $9.86 \mathrm{E}+03$ \\
\hline U-236 & $2.26 \mathrm{E}-16$ & $2.50 \mathrm{E}+03$ \\
\hline$A m-241$ & $\ldots{ }^{a}$ & \\
\hline $\mathrm{Np}-237$ & $7.21 \mathrm{E}-08^{\mathrm{a}}$ & $1.55 \mathrm{E}+03$ \\
\hline $\mathrm{Pu}-241$ & $\ldots \mathrm{b}$ & \\
\hline Am-241 & $\ldots{ }^{b}$ & \\
\hline Np-237 & $2.40 \mathrm{E}-09^{\mathrm{b}}$ & $1.55 \mathrm{E}+03$ \\
\hline $\mathrm{Pu}-242$ & $1.81 \mathrm{E}-17$ & $9.32 \mathrm{E}+03$ \\
\hline $\mathrm{U}-238$ & $1.20 \mathrm{E}-18$ & $9.01 \mathrm{E}+02$ \\
\hline $\begin{array}{l}\text { Am-241 not po } \\
\text { yr) decays inst: } \\
\text { Pu-241 and An } \\
\left(\mathrm{T}_{1 / 2}=14.4 \mathrm{yr}\right)\end{array}$ & $\begin{array}{l}\text { ficant; value calculated for } \\
\mathrm{Np}-234 \text { before transport } \\
\text { entially significant; value cal } \\
\text { taneously to } \mathrm{Np}-237 \text { before }\end{array}$ & $\begin{array}{l}\text { ssumes all Am-241 }\left(\mathrm{T}_{1 / 2}=432\right. \\
\text { daughter assumes all } \mathrm{Pu}-241\end{array}$ \\
\hline
\end{tabular}


The simplified analytical estimate of peak groundwater concentration is conservative; thus, it is likely to overestimate concentrations at the point of compliance for assessing impact on the public and water resources. In the analytical model, the peak flux, in $\mathrm{Ci} / \mathrm{yr}$ per $\mathrm{Ci}$ disposed of in each type of disposal unit, as calculated by PORFLOW, is initially distributed in a volume beneath each grouping of disposal units (Sect 4.2.1). (This volume is comparable to the volume of the nodes that lie beneath the units in the saturated zone model that was ultimately developed, and is described below.) The initial distribution of radionuclides within that volume ignores sorption that may occur on the aquifer matrix or dispersive processes that may spread the plume across many more nodes in the saturated zone model. Decay and retardation (due to sorptive processes) are subsequently accounted for in calculating a peak groundwater concentration (in $\mathrm{pCi} / \mathrm{L}$ per $\mathrm{Ci}$ disposed of in each grouping of disposal units) and time of peak concentration with this simplified analytical estimate. The disposal unit groups are 2 LAW vaults, 2 IL vaults, 10 trenches of each type, and $1 \mathrm{NR}$ pad with 100 containers. More complete documentation of this analytical method is provided in Appendix C.2.1.

Estimated inventory limits for each grouping of disposal units may be derived by dividing the MCL or allowable concentration based on the $25 \mathrm{mrem} / \mathrm{yr}$ performance objective (Table $4.3-1$ ), the more restrictive (i.e., smaller) of the two, by the normalized peak groundwater concentration derived from the analytical method. This estimated inventory limit is expected to be an underestimate (and thus conservative), because the peak groundwater concentration is overestimated by the analytical method. Radionuclides for which the projected inventories (Appendix A) are considerably less than the conservatively-estimated inventory limit were screened from further analysis at this point, and the conservative peak groundwater concentration and inventory limit are presented in Section 5 as the final results of the analysis.

Radionuclides for which projected inventories are not considerably less than the inventory limit estimated via the conservative analytical model were submitted for more detailed groundwater transport analysis. There are two main components to this more detailed analysis: 1) development and simulation of a saturated flow model; and 2) development and simulation of a contaminant transport model for the saturated zone.

\subsection{Numerical Flow Model}

The first of these components was addressed through development of a three-dimensional model of groundwater flow beneath E-Area. The E-Area model simulates groundwater flow within the area bounded by Fourmile Branch on the south, Upper Three Runs on the north, F Area on the west, and McQueen Branch on the east (Figure 3.1-2), from ground surface to the bottom of the Gordon aquifer (Figure 4.3-8). The aquifer system potentially impacted by radionuclides released from sources in E-Area is the Floridan aquifer system (Section 3.1.5.2), which is comprised of two aquifer units: the Upper Three Runs aquifer unit and the Gordon aquifer unit. Boundary conditions for the two aquifer units of concern in this analysis were defined according to the following rationale. From the discussion in Section 3.1.5.2, most of the groundwater from the Upper Three Runs aquifer unit discharges to Upper Three Runs, Fourmile Branch and McQueen Branch. Because these streams incise this unit, the remaining groundwater moves downward across the Gordon confining unit. Therefore, these streams provide natural boundary conditions for most of the UTR aquifer unit, and were prescribed as discharge regions in the groundwater model. On the west side of the unit, hydraulic head values from a contour map of measured groundwater elevations are prescribed in lieu of natural flow boundary conditions.

Hydraulic head measurements indicate that the Gordon aquifer discharges fully to Upper Three Runs in the vicinity of E-Area; therefore, a discharge boundary condition is specified over the north face of the model, along Upper Three Runs. Lacking natural boundary conditions, hydraulic heads are specified over the west, south and east faces of the model within the Gordon aquifer. Areas of groundwater recharge 
and discharge consistent with computed hydraulic head at ground surface are computed as part of the model solution using a combined recharge/drain boundary condition. In areas where the computed head lies below ground elevation, recharge occurs. Recharge to the water table is specified at an average rate of $0.37 \mathrm{~m} / \mathrm{yr}(14.4 \mathrm{in} / \mathrm{yr})$ over the entire model surface area. Various man-made features (e.g., basins) provide additional recharge in localized areas, which are specified. Groundwater discharges to surface water in regions where the computed head is above ground elevation.

The areal resolution of the model grid is $61 \mathrm{~m}$ (200 ft) on a side except in peripheral areas (Figure 4.3-8). There are 108 elements along the east-west axis, and 77 finite-elements along the north-south axis. The vertical resolution varies depending on hydrogeologic unit and terrain/hydrostratigraphic surface variations (Figure 4.3-9). A more detailed description of the simulation domain for the saturated zone is given in Appendix C.2.

Hydraulic conductivity values in the model are based directly on a large characterization database comprised of approximately 100 pumping and 500 slug test data points, approximately 250 laboratory permeability measurements, and approximately 40,000 lithology data records. The saturated flow model is assumed to be heterogeneous with respect to conductivity within hydrogeologic units (see Appendix C.2). The average horizontal conductivities in the "upper" Upper Three Runs aquifer zone, "lower" UTR aquifer zone, and Gordon aquifer unit are $3.4 \times 10^{-5}, 3.3 \times 10^{-5}$, and $1.3 \times 10^{-4} \mathrm{~m} / \mathrm{s}(9.6,9.3$, and $38 \mathrm{ft} / \mathrm{d})$, respectively. The average vertical conductivities for the "tan clay" confining zone and the Gordon confining unit are $2.2 \times 10^{-8}$ and $3.5 \times 10^{-11} \mathrm{~m} / \mathrm{s}\left(6.3 \times 10^{-3}\right.$ and $\left.1.0 \times 10^{-5} \mathrm{ft} / \mathrm{d}\right)$, respectively.

The FACT code (Appendix B) was used to implement the model of the saturated zone described above. Calibration of this model (described more fully in Appendix C.2) involved comparison of simulated hydraulic head and discharge rates at the streams to measured head data and stream baseflow measurements, respectively. In general, these comparisons indicated that the simulation results reproduce the head gradients in the respective aquifer units fairly well, and thus provide a reasonable estimate of flow directions and rates in these units.

The hydrologic model described above was used to generate an average steady-state flow field for EArea. This flow field describes the quantity and rate of flow of water between elements in the model grid, and is utilized in the transport model described below to predict movement of radionuclides from their point of contact with the water table through the groundwater to the points of interest in the vicinity of EArea.

\subsection{Numerical Transport Model}

Transport simulations using PORFLOW were accomplished using the simulation grid established for the E-Area saturated flow model described above. This allowed incorporation of the steady-state flow field computed using the FACT code in the transport simulations. The 200 -foot by 200 -foot grid block size was an appropriate size for the transport simulations, because this grid size was approximately the same size, or smaller, than the "footprint" of each disposal unit. Thus, unnecessary dilution was not introduced. For the disposal units covering a larger area than a grid block, more than one grid block is assigned to the disposal unit. 


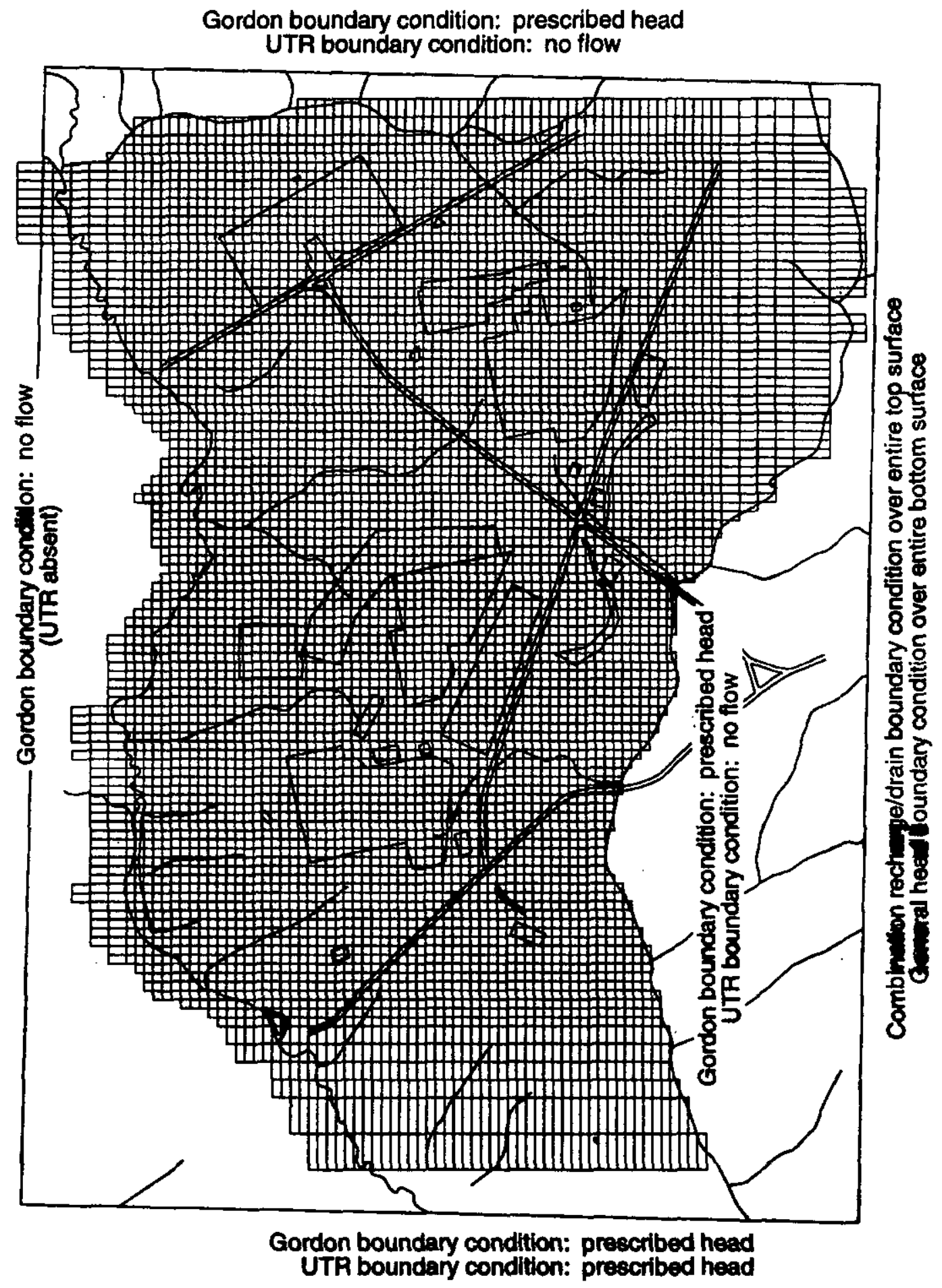

Figure 4.3-8 Active Mesh Elements 


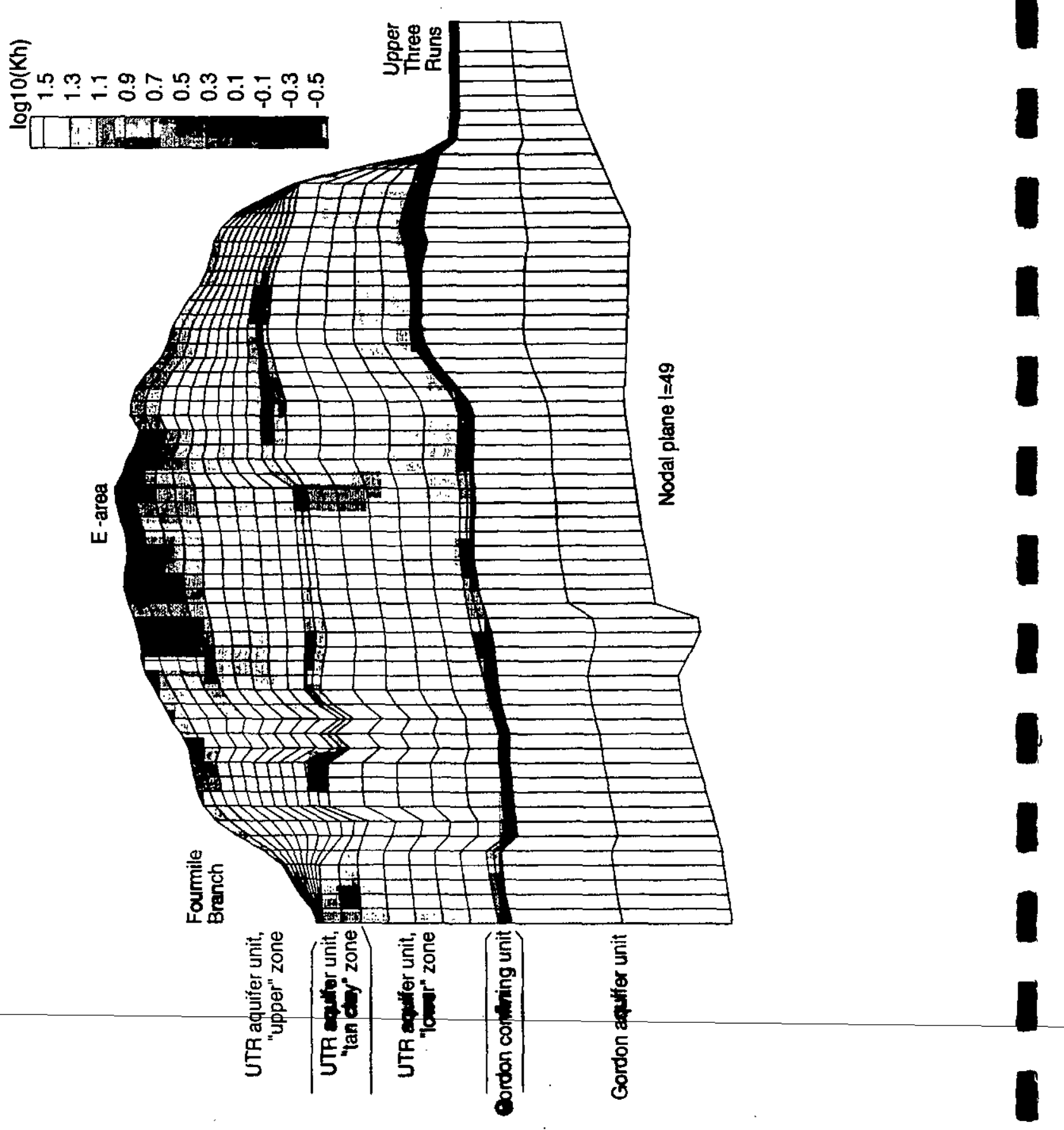

Figure 4.3-9 Typical Cross-Section of Stratigraphy-Conforming Mesh and $\log 10 \mathrm{~K}_{\mathrm{d}}$ Field 
The source locations identified for each set of disposal units were interpreted in terms of this simulation grid. The number of units of each type represented on this grid for the E-Area LLWF are as follows: 1) 2 LAW vaults; 2) 2 IL vaults; 3) 10 slit trenches; 4) 10 trenches containing intimately-mixed cementstabilized waste; 5) 10 trenches containing cement-stabilized encapsulated waste; and 6) one naval reactor pad with 100 containers. A plan view, showing elements into which radionuclides were introduced as sources at the water table is shown in Figure 4.3-10. Source nodes are also shown for the adjacent 643-7E facility (Appendix J), representing: 1) 2 ELLT and 14 slit trenches; 2) one enhanced waste trench and 20 enhanced waste boreholes; and 3) one naval reactor pad with 42 containers. The source terms from the vadose zone, described earlier in this section, are specified in the transport model as fractional fluxes to the water table, in $\mathrm{Ci} / \mathrm{yr}$ per $\mathrm{Ci}$ disposed of in a disposal unit grouping of a given type (e.g., $2 \mathrm{LAW}$ vaults), as a function of time. The curves describing flux to the water table for each radionuclide are shown graphically in Appendix G.

As with the vadose zone transport simulations, transport of radionuclides introduced to the saturated zone under E-Area occurs as a result of advective and dispersive processes, but is hindered by sorptive and radioactive decay processes. Dispersion, caused by diffusion of solute molecules and mechanical mixing, is simulated by PORFLOW in the advection-dispersion equation. Required inputs are apparent diffusion coefficients for dissolved constituents (which account not only for diffusion in water but also tortuosity of the porous medium) and hydrodynamic dispersion coefficients. In this analysis, the value of the apparent diffusion coefficient was assumed to be $5 \times 10^{-6} \mathrm{~cm}^{2} / \mathrm{s}$ for all radionuclides; a reasonable value based on an average diffusion coefficient for major ions in waste at $25^{\circ} \mathrm{C} \mathrm{of} 10^{-5} \mathrm{~cm}^{2} / \mathrm{s}$, and a tortuosity factor of 0.1 , which is within the commonly observed range of 0.5 to 0.01 (Freeze and Cherry 1979). Further refinement of this assumption was not necessary because advective transport in groundwater is the dominant means of transport. For this analysis, mechanical dispersion was neglected, and thus hydrodynamic dispersion coefficients were set to zero. Although mechanical dispersion may result in the dilute portion of a plume reaching a particular location somewhat earlier in time, neglect of this process is not expected to lead to underestimates of radionuclide concentrations because the time period over which the assessment is carried out is sufficient for the more concentrated portion of the plume to arrive at the point of compliance. The peak groundwater concentration is based on this more concentrated portion; not on the more diffuse concentrations at the edges of the plume. Neglect of dispersion will lead to an underestimate of dilution of the plume, and thus an overestimate of potential peak groundwater concentrations.

Sorption coefficients listed in Table 4.1-4 for soil and clay were used in the PORFLOW simulations of radionuclide transport in groundwater. These values are site-specific when possible, and are average values from literature sources when necessary. Sorption coefficients for soil were applied in this analysis when the vertical hydraulic conductivity $\left(\mathrm{K}_{v}\right)$ of the media in a grid element is greater than or equal to $1 \times 10^{-9} \mathrm{~m} / \mathrm{s}$; a clay $\mathrm{K}_{\mathrm{d}}$ is used when the $\mathrm{K}_{\mathrm{v}}$ is less than $1.0 \times 10^{-9} \mathrm{~m} / \mathrm{s}$. The criteria of $1 \times 10^{-9} \mathrm{~m} / \mathrm{s}$ for $\mathrm{K}_{\mathrm{v}}$ corresponds to a 50 percent mud fraction in aquifer sediments; lower values of $K_{v}$ correspond to mud fractions greater than 50 percent. This value was selected based on the knowledge that grid elements representing the Gordon confining unit, which is the only continuous confining unit in the hydrologic units of concern, are generally characterized by a $\mathrm{K}_{\mathrm{v}}$ of less than $1 \times 10^{-9} \mathrm{~m} / \mathrm{s}$. Thus, the higher sorption capacity of clay is accounted for only in this confining unit, even though intermittent clay lenses exist in other hydrologic units. This adds conservatism to the transport modeling, by neglecting the greater sorption capacity of non-contiguous clays in the hydrologic units. 


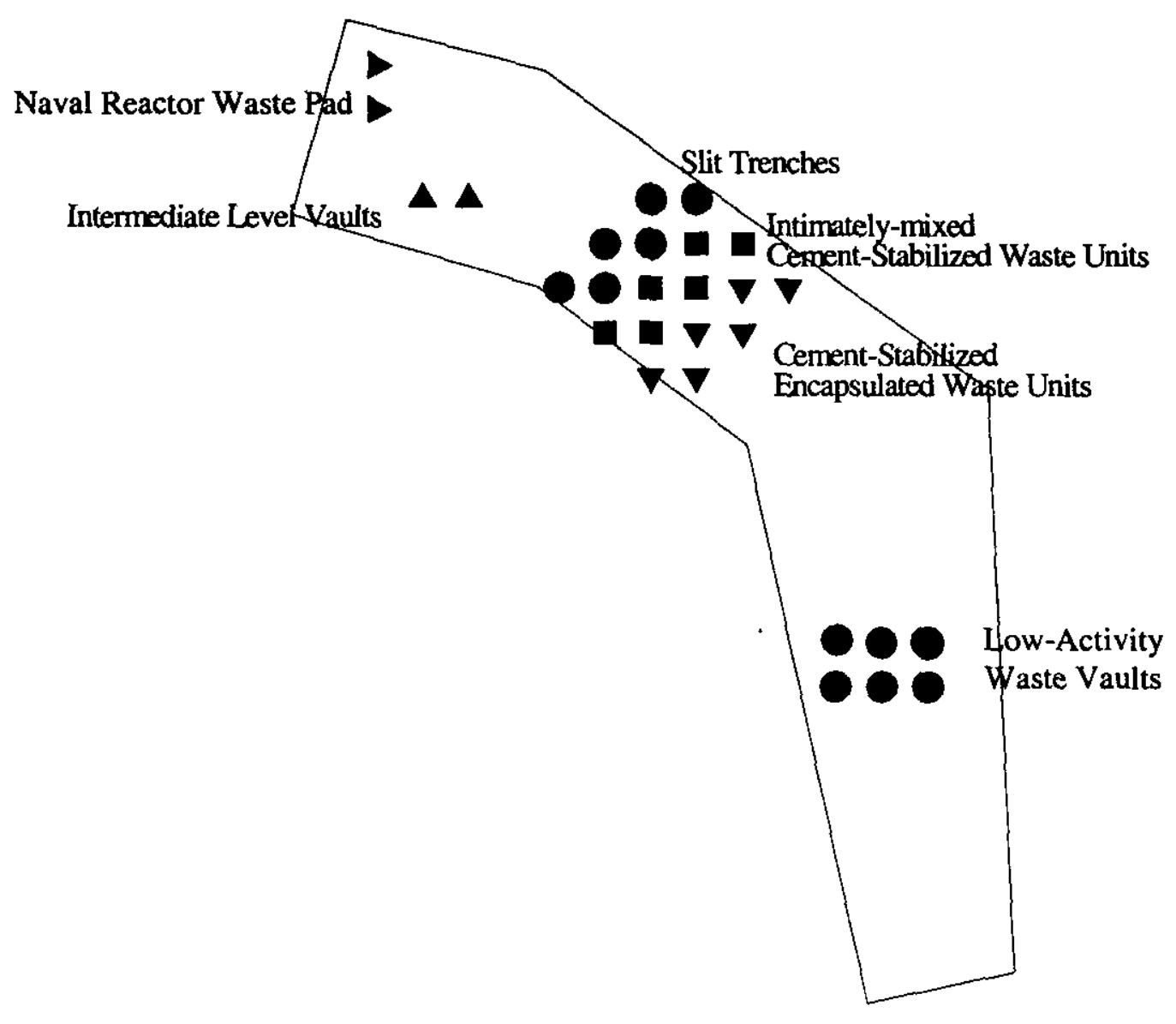

Figure 4.3-10 Source Node Locations 
Characteristics of the porous media underlying E Area which must be specified for the mass transport simulations include density and porosity of the media. Particle density of the media is a property used by the simulation code PORFLOW to calculate retardation based on the sorption coefficient, or $\mathrm{K}_{\mathrm{d}}$. Porosity $(n)$ is related to particle density $\left(\rho_{s}\right)$ according to (Freeze and Cherry 1979):

$$
n=1-\frac{\rho_{b}}{\rho_{s}}
$$

where $\rho_{b}$ is bulk density (i.e., oven-dried mass of a matrix sample divided by field volume). A bulk density of approximately $1600 \mathrm{~kg} / \mathrm{m}^{3}$ is reported for the SRS (Looney et al. 1987), although this value can be expected to vary throughout the different formations underlying the SRS. The total porosity of SRS sediments have been found to range from 0.4 to 0.6 (Looney et al. 1987). Assuming a porosity of 0.4 , a matrix density of approximately $2670 \mathrm{~kg} / \mathrm{m}^{3}$ can be derived from equation $4.3-1$, which is in agreement with the average value of $2650 \mathrm{~kg} / \mathrm{m}^{3}$ provided by Freeze and Cherry (1979) for mineral soils. Thus, this average value of $2650 \mathrm{~kg} / \mathrm{m}^{3}$ was used as a representative value in the PORFLOW simulations.

Although porosities can be expected to vary between sand and clay sediments, sands tend to have lower porosity than clays at the SRS (Looney et al. 1987), and sands dominate the sediment distribution. Diffusional porosity, which is the term found in the advection-dispersion equation for simulating mass transport and is defined as the ratio of the volume of pores that participate in diffusion to the total matrix volume, is expected to be somewhat less than the total porosity but slightly greater than the effective porosity. The results of a modeling study of tritium migration from the Old Burial Ground at E-Area indicated an effective porosity of 0.23 based on calibration efforts (Flach et al. 1996). Therefore, a diffusional porosity of 0.25 was assumed for this analysis for all lithologies. One would expect diffusional porosity to be somewhat less in tighter lithologies; however, the error introduced by ignoring differential diffusional properties was deemed insignificant because the importance of convective transport greatly outweighs that of diffusive transport in saturated media.

Separate simulations of the radionuclide plumes originating from each type of disposal unit were carried out for up to 10,000 years. Time steps were selected to preserve numerical stability and satisfy mass balance requirements on a grid element-by-grid element basis. A test was done to identify the point of maximum concentration in groundwater outside of the $100-\mathrm{m}$ buffer zone surrounding each set of disposal units (e.g., surrounding the two LAW vaults). Output of the simulations was in terms of normalized groundwater concentration at this identified point of maximum concentration for each radionuclide simulated and each disposal unit type. Groundwater concentrations were normalized to one $\mathrm{Ci}$ of activity of each radionuclide disposed of in all disposal units of a given type (i.e., 2 LAW vaults). The results of the transport simulations are provided in Section 5 and Appendix G.

\subsubsection{Analysis of Radon Flux}

The release of radon from each of the disposal units was calculated using the PORFLOW code. Besides having the capability to model groundwater flow and transport, the PORFLOW code can also model radioactive decay and diffusion. The case that was modeled was that of a failed disposal unit at 10,000 years. At 10,000 years all of the disposal units considered in this study are assumed to be indistinguishable from each other. The waste is assumed to have a uniform distribution of ${ }^{234} \mathrm{U}$. A $100-\mathrm{cm}$ thick layer of soil was assumed to cover the waste in the failed trench disposal units and a 200-cm thick layer was assumed to cover the vault disposal units.. A unit concentration of ${ }^{234} \mathrm{U}$ was allowed to decay for 10,000 years through the intermediate daughters, ${ }^{230} \mathrm{Th}$ and ${ }^{226} \mathrm{Ra}$, producing ${ }^{222} \mathrm{Rn}$. The radon 
was allowed to diffuse upward as it was produced, and the flux of radon emanating from the top of the $100-\mathrm{cm}$ soil cover was calculated. The parameters used in this calculation were:

$\begin{array}{ll}{ }^{222} \mathrm{Rn} \text { Half Life: } & 1.05 \times 10^{-2} \text { year (3.8 days) } \\ { }^{226} \mathrm{Ra} \text { Half Life: } & 1.62 \times 10^{3} \text { year } \\ { }^{230} \mathrm{Th} \text { Half Life: } & 7.70 \times 10^{4} \text { year } \\ { }^{234} \mathrm{U} \text { Half Life: } & 2.45 \times 10^{5} \text { year } \\ \text { Diffusivity of Radon: } & 2 \times 10^{6} \mathrm{~cm}^{2} / \text { year } \\ \text { Density of waste and soil } & 1.6 \mathrm{~g} / \mathrm{cm}^{3} \\ \text { Effective porosity } & 0.1\end{array}$

The PORFLOW simulation results gives a radon flux of $1.6 \times 10^{-6}$ moles per $\mathrm{cm}^{3} /$ year from the trench disposal units and $1.0 \times 10^{-6}$ moles per $\mathrm{cm}^{3} /$ year from the vault disposal units. In order to compare this with a performance objective of $20 \mathrm{pCi} / \mathrm{m}^{2}-\mathrm{s}$, the following unit conversion was made for trench units:

$$
\begin{aligned}
1 \mathrm{~mol} / \mathrm{cm}^{3} & =1.6 \times 10^{-6} \mathrm{~mol} / \mathrm{cm}^{2}-\mathrm{yr} * 222 \mathrm{~g} / \mathrm{mol}^{*} 1.5 \times 10^{5} \mathrm{Ci} / \mathrm{g}=5.3 \times 10^{1} \mathrm{Ci} / \mathrm{cm}^{2}-\mathrm{yr} \\
& =5.3 \times 10^{1} \mathrm{Ci} / \mathrm{cm}^{2}-\mathrm{yr}^{*} 10^{12} \mathrm{pCi} / \mathrm{Ci} * 10^{4} \mathrm{~cm}^{2} / \mathrm{m}^{2} * 3.2 \times 10^{-8} \mathrm{yr} / \mathrm{s} \\
& =1.7 \times 10^{10} \mathrm{pCi} / \mathrm{m}^{2}-\mathrm{s}
\end{aligned}
$$

For the vault disposal units, the same exercise yields a result of $1.1 \times 10^{10} \mathrm{pCi} / \mathrm{m}^{2}-\mathrm{s}$.

Since we now know that $1 \mathrm{~mol} / \mathrm{cm}^{3}$ of ${ }^{234} \mathrm{U}$ will produce a radon flux of $1.7 \times 10^{10} \mathrm{pCi} / \mathrm{m}^{2}-\mathrm{yr}$ from trench disposal units and $1.1 \times 10^{10} \mathrm{pCi} / \mathrm{m}^{2}$-s from vault units, a simple ratio can be used to determine the ${ }^{234} \mathrm{U}$ concentration, in $\mathrm{Ci} / \mathrm{m}^{3}$, that will produce a ${ }^{222} \mathrm{Rn}$ flux of $20 \mathrm{pCi} / \mathrm{m}^{2}-\mathrm{s}$, ignoring transport of ${ }^{234} \mathrm{U}$ away from the disposal facility by water. For trench disposal units this is:

$$
\begin{aligned}
& { }^{234} \mathrm{U} \mathrm{mol} / \mathrm{cm}^{3} / 1 \mathrm{~mol} / \mathrm{cm}^{3}=20 \mathrm{pCi} / \mathrm{m}^{2}-\mathrm{s} / 1.7 \times 10^{10} \mathrm{pCi} / \mathrm{m}^{2}-\mathrm{s} \\
& { }^{234} \mathrm{U}=1.2 \times 10^{-9} \mathrm{~mol} / \mathrm{cm}^{3} * 234 \mathrm{~g} / \mathrm{mol}^{*} 6.2 \times 10^{-3} \mathrm{Ci} / \mathrm{g}^{*} 10^{6} \mathrm{~cm}^{-3} / \mathrm{m}^{3} \\
& { }^{234} \mathrm{U}=1.7 \times 10^{-3} \mathrm{Ci} / \mathrm{m}^{3}
\end{aligned}
$$

and for vault disposal units this is:

$$
\begin{aligned}
& { }^{234} \mathrm{U} \mathrm{mol} / \mathrm{cm}^{3} / 1 \mathrm{~mol} / \mathrm{cm}^{3}=20 \mathrm{pCi} / \mathrm{m}^{2}-\mathrm{s} / 1.1 \times 10^{10} \mathrm{pCi} / \mathrm{m}^{2}-\mathrm{s} \\
& { }^{234} \mathrm{U}=1.8 \times 10^{-9} \mathrm{~mol} / \mathrm{cm}^{3} * 234 \mathrm{~g} / \mathrm{mol}^{3} * 6.2 \times 10^{-3} \mathrm{Ci} / \mathrm{g} * 10^{6} \mathrm{~cm}^{-3} / \mathrm{m}^{3} \\
& { }^{234} \mathrm{U}=2.6 \times 10^{-3} \mathrm{Ci} / \mathrm{m}^{3}
\end{aligned}
$$

Since we now know that $1.7 \times 10^{-3} \mathrm{Ci} / \mathrm{m}^{3}$ of ${ }^{234} \mathrm{U}$ will produce a radon flux of $20 \mathrm{pCi} / \mathrm{m}^{2}-\mathrm{sec}$, multiplying this factor by the volume of each disposal unit, in $\mathrm{m}^{3}$, will give the disposal limit for ${ }^{234} \mathrm{U}$ in curies. The results are given in Table 4.3-9.

Table 4.3-9 $\quad{ }^{234} \mathrm{U}$ Disposal Limits Based on Radon Release Rates

\begin{tabular}{|c|c|c|}
\hline Disposal unit & Volume $\left(\mathrm{m}^{3}\right)$ & ${ }^{234} \mathrm{U}$ limit (Ci/unit) \\
\hline LAW Vault & $4.8 \times 10^{4}$ & 125 \\
\hline IL Vault & $5.9 \times 10^{3}$ & 15 \\
\hline Trench units & $2.6 \times 10^{4}$ & 8.8 \\
\hline
\end{tabular}




\section{SECTION 5}

\section{RESULTS OF ANALYSIS}


THIS PAGE INTENTIONALLY LEFT BLANK

Rev. 1 


\section{RESULTS OF ANALYSIS}

In this section, the results of the analysis of performance of the waste disposal units in the E-Area LLWF are presented. As described in Section 4.2, the analyses focus on ingestion of radionuclides in groundwater for the all-pathways and water resource impacts analysis, and on inhalation of volatile radionuclides for the air pathways analysis. In Section 5.1, projected groundwater concentrations and calculated inventory limits used in evaluating performance with respect to the performance objective for protection of the public and the performance measure for the analysis of impacts on water resources (Ssction 2.5) are presented. In Section 5.2, calculated doses for the air pathway analysis are provided. In Section 5.3, the results of sensitivity and uncertainty analyses are discussed, for the purpose of gaining perspective on the meaning of the results in Section 5.1 and 5.2. Finally, in Sect 5.4, application of the As Low As Reasonably Achievable (ALARA) process to the design and operation of the E-Area LLWF is discussed.

\subsection{Results of All-Pathways Analysis and Water Resource Impacts Analysis}

It was established in Section 4.2 that the only significant pathway of concern for the all-pathways analysis is groundwater ingestion, with the endpoint of the analysis being evaluation of dose. For the water resource impacts analysis, the endpoint of the analysis is estimated groundwater concentrations at the same compliance point as that used in evaluating protection of the public; the point of highest concentration outside a $100-\mathrm{m}$ buffer zone around disposal units. The performance objective of 25 mrem/yr for protection of the public can readily be converted to an allowable groundwater concentration limit, by dividing the $25 \mathrm{mrem} / \mathrm{yr}$ limit by the effective dose equivalent of any given radionuclide per unit concentration in groundwater (Table 5.1-1). Therefore, the endpoints of the performance objective for protection of the public and the performance measure for analysis of impacts on water resources can be expressed in terms of groundwater concentration in this PA. The following discussion addresses the results of the all-pathways analysis and water resource impacts analysis together, as the same calculated groundwater concentrations can be used to evaluate the two performance objectives.

The methods for calculating groundwater concentrations at the compliance point for protection of the public and impacts on water resources were described in Section 4.3. Briefly, groundwater concentrations at the compliance point were calculated by using the vadose zone models (simulated with PORFLOW) to calculate contaminant flux to the water table as a function of time. Fractional fluxes ( $\mathrm{Ci} / \mathrm{yr}$ per $\mathrm{Ci}$ disposed) were estimated, and used as the source term to the saturated zone model. Groundwater concentrations ( $\mathrm{pCi} / \mathrm{L}$ per $\mathrm{Ci}$ disposed) were then calculated either using the PORFLOW computer code, or using an analytical model. The analytical model used is a screening-level model that is conservative, and thus over estimates ultimate groundwater concentrations at the point of compliance (Appendix C.2). The results of this model were retained as the projected groundwater concentration for radionuclides with very low projected inventories (Appendix A) compared to the calculated inventory limits (based on the analytical model). Results of the PORFLOW analyses are shown graphically in Appendix G.

The groundwater concentrations presented in this section are in normalized units, to facilitate computation of inventory limits for each type of disposal unit. Ultimately, the more restrictive of either the MCLs (in $\mathrm{pCi} / \mathrm{L}$ ) or allowable concentrations (in $\mathrm{pCi} / \mathrm{L}$ ) based on the $25 \mathrm{mrem} / \mathrm{yr}$ performance objective can be divided by the normalized groundwater concentrations to derive an inventory limit. Calculated inventory limits, based on the peak groundwater concentrations, are also presented in this section. 
Table 5.1-1 Annual EDEs From Drinking Water Pathway per Unit Concentration of Radionuclides in Water

\begin{tabular}{|c|c|}
\hline Radionuclide $^{a, b}$ & $\begin{array}{c}\mathrm{EDE} \\
\mathrm{rem} / \mathrm{yr} \text { per } \mu \mathrm{Ci} / \mathrm{L}\end{array}$ \\
\hline $\mathrm{H}-3$ & $4.6 \mathrm{E}-02$ \\
\hline C-14 & $1.5 \mathrm{E}+00$ \\
\hline $\mathrm{Ni}-59$ & $1.5 \mathrm{E}-01$ \\
\hline $\mathrm{Se}-79$ & $6.1 E+00$ \\
\hline $\mathrm{Rb}-87$ & $3.5 E+00$ \\
\hline $\mathrm{Sr}-90+\mathrm{d}$ & $1.0 \mathrm{E}+02$ \\
\hline Mo-93 & $9.5 \mathrm{E}-01$ \\
\hline $\mathrm{Zr}-93+\mathrm{d}$ & $1.6 \mathrm{E}+00$ \\
\hline $\mathrm{Nb}-94$ & $3.7 E+00$ \\
\hline Tc-99 & $9.5 \mathrm{E}-01$ \\
\hline Pd-107 & $1.0 \mathrm{E}-01$ \\
\hline $\mathrm{Sn}-126+d$ & $1.3 E+01$ \\
\hline $\mathrm{I}-129$ & $2.0 \mathrm{E}+02$ \\
\hline Cs- 135 & $5.2 E+00$ \\
\hline Th-230 & $3.9 E+02$ \\
\hline $\mathrm{Ra}-226+\mathrm{d}$ & $8.0 \mathrm{E}+02$ \\
\hline $\mathrm{Pb}-210$ & $3.7 \mathrm{E}+03$ \\
\hline Po-210 & $1.2 \mathrm{E}+03$ \\
\hline Th-232 & $2.0 \mathrm{E}+03$ \\
\hline $\mathrm{Ra}-228+\mathrm{d}$ & $8.8 E+02$ \\
\hline Th-228 & $2.8 \mathrm{E}+02$ \\
\hline $\mathrm{Ra}-224+\mathrm{d}$ & $2.7 \mathrm{E}+02$ \\
\hline $\mathrm{U}-232$ & $9.5 E+02$ \\
\hline Th-228 & $2.8 \mathrm{E}+02$ \\
\hline $\mathrm{Ra}-224+\mathrm{d}$ & $2.7 \mathrm{E}+02$ \\
\hline U-233 & $2.0 \mathrm{E}+02$ \\
\hline Th-229 & $2.6 \mathrm{E}+03$ \\
\hline $\mathrm{Ra}-225+\mathrm{d}$ & $3.0 \mathrm{E}+02$ \\
\hline $\mathrm{U}-234$ & $1.9 E+02$ \\
\hline Th- 230 & $3.9 E+02$ \\
\hline $\mathrm{Ra}-226+\mathrm{d}$ & $8.0 \mathrm{E}+02$ \\
\hline $\mathrm{Pb}-210$ & $3.7 E+03$ \\
\hline Po-210 & $1.2 \mathrm{E}+03$ \\
\hline$U-235+d$ & $1.8 E+02$ \\
\hline $\mathrm{Pa}-231$ & $8.0 \mathrm{E}+03$ \\
\hline Ac- -227 & $1.0 \mathrm{E}+04$ \\
\hline Th-227 & $2.6 \mathrm{E}+01$ \\
\hline $\mathrm{Ra}-223+\mathrm{d}$ & $4.0 \mathrm{E}+02$ \\
\hline U-236 & $1.8 \mathrm{E}+02$ \\
\hline U-238 & $1.7 \mathrm{E}+02$ \\
\hline Th-234 +d & $9.5 \mathrm{E}+00$ \\
\hline $\mathrm{Np}-237+\mathrm{d}$ & $2.8 E+03$ \\
\hline Pu-238 & $2.8 \mathrm{E}+03$ \\
\hline U-234 & $1.9 \mathrm{E}+02$ \\
\hline
\end{tabular}


Table 5.1-1 Annual EDEs From Drinking Water Pathway per Unit Concentration of Radionuclides in Water

\begin{tabular}{|c|c|}
\hline Radionuclide ${ }^{a, b}$ & $\begin{array}{c}\text { EDE } \\
\mathrm{rem} / \mathrm{yr} \text { per } \mu \mathrm{Ci} / \mathrm{L}\end{array}$ \\
\hline $\mathrm{Pu}-239$ & $3.1 \mathrm{E}+03$ \\
\hline $\mathrm{U}-235$ & $1.8 \mathrm{E}+02$ \\
\hline $\mathrm{Pu}-240$ & $3.1 \mathrm{E}+03$ \\
\hline U-236 & $1.8 \mathrm{E}+02$ \\
\hline $\mathrm{Pu}-241$ & $6.3 E+01$ \\
\hline Am-241 & $3.3 E+03$ \\
\hline$N p-237+d$ & $2.8 E+03$ \\
\hline $\mathrm{Pu}-242$ & $3.0 \mathrm{E}+03$ \\
\hline U-238 & $1.7 \mathrm{E}+02$ \\
\hline $\mathrm{Pu}-244+\mathrm{d}$ & $2.9 \mathrm{E}+03$ \\
\hline Am-241 & $3.3 E+03$ \\
\hline $\mathrm{Np}-237+\mathrm{d}$ & $2.8 \mathrm{E}+03$ \\
\hline$A m-242 m+d$ & $3.1 \mathrm{E}+03$ \\
\hline $\mathrm{Pu}-238$ & $2.8 E+03$ \\
\hline U-234 & $1.9 E+02$ \\
\hline$A m-243+d$ & $3.3 E+03$ \\
\hline $\mathrm{Pu}-239$ & $3.1 E+03$ \\
\hline $\mathrm{Cm}-242$ & $8.0 \mathrm{E}+01$ \\
\hline Pu-238 & $2.8 \mathrm{E}+03$ \\
\hline U-234 & $1.9 \mathrm{E}+02$ \\
\hline $\mathrm{Cm}-245$ & $3.3 E+03$ \\
\hline $\mathrm{Pu}-241$ & $6.3 E+01$ \\
\hline $\mathrm{Am}-241$ & $3.3 E+03$ \\
\hline $\mathrm{Np}-237+\mathrm{d}$ & $2.8 \mathrm{E}+03$ \\
\hline $\mathrm{Cm}-246$ & $3.3 E+03$ \\
\hline $\mathrm{Cm}-247+\mathrm{d}$ & $3.0 \mathrm{E}+03$ \\
\hline Am-243 & $3.3 \mathrm{E}+03$ \\
\hline $\mathrm{Np}-239$ & $2.1 \mathrm{E}+00$ \\
\hline Pu-239 & $3.1 E+03$ \\
\hline $\mathrm{Cm}-248$ & $1.2 E+04$ \\
\hline $\mathrm{Pu}-244$ & $2.7 \mathrm{E}+03$ \\
\hline $\mathrm{Bk}-249$ & $4.4 E+00$ \\
\hline Cf-249 & $3.4 \mathrm{E}+03$ \\
\hline $\mathrm{Cm}-245$ & $3.3 E+03$ \\
\hline Cf -249 & $3.4 E+03$ \\
\hline $\mathrm{Cm}-245$ & $3.3 \mathrm{E}+03$ \\
\hline $\mathrm{Pu}-241$ & $6.3 \mathrm{E}+01$ \\
\hline $\mathrm{Am}-241$ & $3.3 E+03$ \\
\hline $\mathrm{Np}-237+\mathrm{d}$ & $2.8 \mathrm{E}+03$ \\
\hline $\mathrm{Cf}-252$ & $6.9 E+02$ \\
\hline $\mathrm{Cm}-248$ & $1.1 E+04$ \\
\hline
\end{tabular}


Tables 5.1-2 through 5.1-7 provide the maximum projected groundwater concentrations of radionuclides at the compliance point for protection of the public and water resource impacts analysis, normalized to a one-Ci source of each radionuclide listed in the inventory (Appendix A) for each type of disposal unit on the source grid (Fig. 4.3-9). Thus, groundwater concentrations are based on disposal of one Ci of each radionuclide in two LAW vaults, two IL vaults, ten slit trenches, ten trenches containing intimately-mixed cement-stabilized waste, and ten trenches containing cement-stabilized encapsulated waste. For the naval reactor waste, groundwater concentrations are reported per $\mathrm{Ci}$ of each radionuclide in a pad containing 100 casks. The compliance point is specific for each type of disposal unit, as long as the units of a given type are immediately adjacent to each other. When peak concentrations were simulated to occur after 10,000 years, both the 10,000-year concentration and the peak concentration are provided, because the performance evaluation for the PA is based on the peak groundwater concentration up to 10,000 years. Peaks beyond 10,000 years are provided only for additional information, and are estimated using the analytical model (Appendix C.2) rather than PORFLOW. In Tables 5.1-8 through 5.1-13, calculated inventory limits based on the peak groundwater concentrations up to 10,000 years are given. These limits are derived as indicated in the tables, and are based on a one-Ci disposal in a single vault (i.e., LAW, II), in a set of five trenches of a particular type (i.e., cement-stabilized encapsulated waste), and in one Naval Reactor pad (i.e., 100 containers).

\subsection{Results of the Air Pathway Analysis}

Table 5.2-1 presents the results of the air pathway analysis described in Section 4.1.2.

\subsection{Results of the Radon Analysis}

Table 5.3-1 presents the results of the radon flux analysis described in section 4.1.4.

\subsection{Results of the Sensitivity and Uncertainty Analysis}

To interpret the results provided in previous sections, parameters and assumptions to which the results are most sensitive must be identified. The uncertainty associated with these parameters and assumptions must also be considered to determine the degree of confidence in the calculated results. A rigorous quantitative analysis of uncertainty is desirable, but such an analysis is not possible for all aspects of the analyses conducted for this PA due to: 1) limits of our knowledge with respect to certain physical and functional characteristics or processes; 2 ) the inability to predict conditions in the future, especially beyond several decades; and 3) the inability to quantify uncertainty associated with the definition of a particular scenario. This last type of uncertainty can dominate the overall uncertainty in some cases.

\subsubsection{Sensitivity and Uncertainty Analysis of Near-Field and Groundwater Transport}

The endpoint of the all-pathways analysis and water resource impacts analysis in this PA is groundwater concentration. Calculated concentrations are compared to the more restrictive of either EPA's MCLs, or allowable concentrations based on the $25 \mathrm{mrem} / \mathrm{yr}$ limit for off-site exposures. Therefore, factors that affect the estimation of groundwater concentration are the focus of the sensitivity and uncertainty analysis discussed in this section. These factors include those that influence the availability of radionuclides for transport in water (e.g., $\mathrm{K}_{d} \mathrm{~s}$, solubilities, corrosion rates of activated metals), those that influence the rate of water flow through the source zone (e.g., presence and state of engineered barriers), and those that influence transport and dilution in groundwater (e.g., dispersion). 
Table 5.1-2 Peak Groundwater Concentrations for the LAW Vault Simulations per $\mathrm{Ci}$ of Each Radionuclide in 2 Vaults

\begin{tabular}{|c|c|c|c|}
\hline Radionuclide & $\begin{array}{l}\text { Peak up to } 10,000 \text { years } \\
\text { pCi/L-Ci }\end{array}$ & $\begin{array}{c}\text { Peak after } 10,000 \text { years }^{b} \\
\text { pCi/L-Ci }\end{array}$ & $\begin{array}{c}\text { Time of peak } \\
\mathrm{yr}\end{array}$ \\
\hline $\mathrm{H}-3$ & $9.48 \mathrm{E}-08$ & na & $1.26 \mathrm{E}+02$ \\
\hline C-14 & $9.24 E+00$ & na & $4.20 \mathrm{E}+03$ \\
\hline $\mathrm{Ni}-59$ & 2.51E-03 & $3.76 \mathrm{E}+01$ & $1.73 \mathrm{E}+04$ \\
\hline $\mathrm{Se}-79$ & $3.29 \mathrm{E}+00$ & $2.65 \mathrm{E}+02$ & $8.32 \mathrm{E}+03^{\mathrm{d}}$ \\
\hline $\mathrm{Rb}-87$ & $8.06 \mathrm{E}+02^{\mathrm{b}}$ & na & $4.91 E+03$ \\
\hline $\mathrm{Sr}-90$ & $8.62 \mathrm{E}-19^{\mathrm{b}}$ & na & $1.97 \mathrm{E}+03$ \\
\hline $\mathrm{Zr}-93$ & $2.54 \mathrm{E}+00^{\mathrm{b}}$ & $6.68 \mathrm{E}+01$ & $2.66 \mathrm{E}+04$ \\
\hline $\mathrm{Nb}-94$ & $2.27 \mathrm{E}+02^{\mathrm{b}}$ & na & $8.89 \mathrm{E}+03$ \\
\hline Тc-99 & $7.50 \mathrm{E}+01$ & na & $3.27 \mathrm{E}+03$ \\
\hline Pd-107 & $8.16 \mathrm{E}+02^{b}$ & na & $4.97 \mathrm{E}+03$ \\
\hline $\mathrm{Sn}-126$ & $6.33 \mathrm{E}+00$ & $4.07 \mathrm{E}+02$ & $7.96 \mathrm{E}+03^{\mathrm{d}}$ \\
\hline$I-129$ & $4.10 E+02$ & па & $1.57 \mathrm{E}+03$ \\
\hline Cs- 135 & $1.30 \mathrm{E}+02^{\mathrm{b}}$ & $1.40 E+02$ & $1.48 \mathrm{E}+04$ \\
\hline Th-232 & $9.23 \mathrm{E}-10^{b}$ & $2.07 \mathrm{E}+01$ & $1.20 \mathrm{E}+05$ \\
\hline $\mathrm{Ra}-228$ & $6.60 \mathrm{E}-09^{\mathrm{b}}$ & $1.32 E+02$ & $7.57 \mathrm{E}+04$ \\
\hline Th-228 & $1.03 \mathrm{E}-09^{b}$ & $2.06 \mathrm{E}+01$ & $7.57 E+04$ \\
\hline $\mathrm{Ra}-224$ & $6.58 \mathrm{E}-09^{b}$ & $1.32 \mathrm{E}+02$ & $7.59 E+04$ \\
\hline $\mathrm{U}-232$ & $0.00 \mathrm{E}+00^{\mathrm{b}}$ & $1.51 \mathrm{E}-14$ & $1.20 \mathrm{E}+04$ \\
\hline Th-228 & $0.00 \mathrm{E}+00^{\mathrm{b}}$ & $1.67 \mathrm{E}-16$ & $1.20 \mathrm{E}+04$ \\
\hline $\mathrm{Ra}-224$ & $0.00 \mathrm{E}+00^{\mathrm{b}}$ & $1.07 \mathrm{E}-15$ & $1.20 \mathrm{E}+04$ \\
\hline $\mathrm{U}-233$ & $3.56 \mathrm{E}-08^{\mathrm{b}}$ & $3.56 \mathrm{E}-08$ & $1.17 \mathrm{E}+05$ \\
\hline Th-229 & $5.00 \mathrm{E}-10^{\mathrm{b}}$ & $3.36 \mathrm{E}-01$ & $7.85 \mathrm{E}+04$ \\
\hline $\mathrm{Ra}-225$ & $3.19 \mathrm{E}-09^{\mathrm{b}}$ & $2.14 \mathrm{E}+00$ & $7.87 \mathrm{E}+04$ \\
\hline $\mathrm{U}-234$ & $1.91 \mathrm{E}-09$ & $2.32 \mathrm{E}-08$ & $9.41 \mathrm{E}+04$ \\
\hline Th-230 & $6.82 \mathrm{E}-13$ & $2.74 \mathrm{E}+00$ & $9.93 E+04$ \\
\hline $\mathrm{Ra}-226$ & $2.30 \mathrm{E}-06$ & $1.91 \mathrm{E}+01$ & $9.21 E+04$ \\
\hline $\mathrm{Pb}-210$ & $4.53 \mathrm{E}-06$ & $3.56 \mathrm{E}+01$ & $9.09 E+04$ \\
\hline Po-210 & $8.16 \mathrm{E}-06$ & $6.39 E+01$ & $9.05 E+04$ \\
\hline U-235 & $6.89 \mathrm{E}-13$ & 8.69E-09 & $1.91 E+04$ \\
\hline $\mathrm{Pa}-231$ & $5.23 \mathrm{E}-06$ & $1.01 \mathrm{E}+01$ & $2.71 E+04$ \\
\hline Ac- 227 & $6.46 \mathrm{E}-06$ & $1.24 \mathrm{E}+01$ & $2.71 E+04$ \\
\hline Th-227 & $9.08 \mathrm{E}-07$ & $1.75 E+00$ & $2.71 E+04$ \\
\hline $\mathrm{Ra}-223$ & $5.82 \mathrm{E}-06$ & $1.12 \mathrm{E}+01$ & $2.71 E+04$ \\
\hline U-236 & $2.44 \mathrm{E}-10^{\mathrm{b}}$ & $8.74 E-09$ & $1.91 E+04$ \\
\hline Np-237 & $1.05 E+00$ & na & $4.72 E+03$ \\
\hline U-238 & $1.27 \mathrm{E}-12^{\mathrm{b}}$ & $8.59 \mathrm{E}-09$ & $1.91 \mathrm{E}+04$ \\
\hline Th-234 & $1.41 \mathrm{E}-14^{\mathrm{b}}$ & $9.47 \mathrm{E}-11$ & $1.91 \mathrm{E}+04$ \\
\hline U-234 & $3.50 \mathrm{E}-08^{\mathrm{b}}$ & $3.54 \mathrm{E}-08$ & $1.89 \mathrm{E}+04$ \\
\hline Pu-238 & $0.00 \mathrm{E}+00^{\mathrm{b}}$ & $3.27 \mathrm{E}-15$ & $1.95 E+04$ \\
\hline U-234 & $2.32 \mathrm{E}-08^{\mathrm{b}}$ & $2.32 \mathrm{E}-08$ & $1.82 \mathrm{E}+04$ \\
\hline Pu-239 & $3.12 \mathrm{E}-10^{\mathrm{b}}$ & $3.18 \mathrm{E}-10$ & $1.16 \mathrm{E}+05$ \\
\hline U-235 & $8.12 \mathrm{E}-12^{\mathrm{b}}$ & $8.13 E-12$ & $1.11 E+05$ \\
\hline Pu-240 & $9.22 \mathrm{E}-10^{b}$ & $9.32 \mathrm{E}-10$ & $1.02 \mathrm{E}+05$ \\
\hline U-236 & $2.44 \mathrm{E}-10^{\mathrm{b}}$ & $2.44 \mathrm{E}-10$ & $9.33 E+04$ \\
\hline Am-241 & $\ldots c^{c}$ & $\ldots{ }^{c}$ & \\
\hline Np-237 & $2.12 \mathrm{E}-04$ & na & $4.72 E+03$ \\
\hline
\end{tabular}

Rev. 1 
Table 5.1-2 Peak Groundwater Concentrations for the LAW Vault Simulations per $\mathrm{Ci}$ of Each Radionuclide in 2 Vaults

\begin{tabular}{|c|c|c|c|}
\hline Radionuclide & $\begin{array}{l}\text { Peak up to } 10,000 \text { years }^{2} \\
\mathrm{pCi} / \mathrm{L}-\mathrm{Ci}\end{array}$ & $\begin{array}{c}\text { Peak after } 10,000 \text { years }^{b} \\
\text { pCi/L-Ci }\end{array}$ & $\begin{array}{c}\text { Time of peak } \\
y \mathrm{r}\end{array}$ \\
\hline $\mathrm{Pu}-24 \mathrm{I}$ & $\ldots{ }^{c}$ & $\ldots{ }^{c}$ & \\
\hline Am-241 & $\ldots{ }^{c}$ & $--^{c}$ & \\
\hline Np-237 & $7.07 \mathrm{E}-06$ & na & $4.72 \mathrm{E}+03$ \\
\hline $\mathrm{Pu}-242$ & $2.18 \mathrm{E}-11^{\mathrm{b}}$ & $7.68 \mathrm{E}-11$ & $2.03 E+04$ \\
\hline $\mathrm{U}-238$ & $1.27 \mathrm{E}-12^{\mathrm{b}}$ & $1.28 \mathrm{E}-12$ & $1.09 \mathrm{E}+05$ \\
\hline Am-243 & $4.28 \mathrm{E}-07^{b}$ & $3.28 \mathrm{E}-01$ & $4.39 \mathrm{E}+04$ \\
\hline Np-239 & $1.56 \mathrm{E}-04^{\mathrm{b}}$ & $1.19 E+02$ & $4.37 \mathrm{E}+04$ \\
\hline $\mathrm{Pu}-239$ & $1.69 \mathrm{E}+00^{\mathrm{b}}$ & $2.27 \mathrm{E}+00$ & $2.17 \mathrm{E}+04$ \\
\hline $\mathrm{Pu}-244$ & $1.04 \mathrm{E}-13^{\mathrm{b}}$ & $6.71 \mathrm{E}-11$ & $2.03 E+04$ \\
\hline $\mathrm{Cm}-245$ & $7.60 \mathrm{E}-12^{\mathrm{b}}$ & $3.90 \mathrm{E}-02$ & $6.95 \mathrm{E}+04$ \\
\hline Pu-241 & $3.88 \mathrm{E}-08^{\mathrm{b}}$ & $1.67 \mathrm{E}+00$ & $6.85 E+04$ \\
\hline Am-241 & $9.90 \mathrm{E}-09^{\mathrm{b}}$ & $9.81 \mathrm{E}-02$ & $6.73 E+04$ \\
\hline $\mathrm{Np}-237$ & $1.22 \mathrm{E}-01^{\mathrm{b}}$ & $1.31 \mathrm{E}-01$ & $1.63 E+04$ \\
\hline $\mathrm{Cm}-246$ & $3.93 \mathrm{E}-12^{\mathrm{b}}$ & $1.02 \mathrm{E}-03$ & $5.89 E+04$ \\
\hline $\mathrm{Cm}-247$ & $1.72 \mathrm{E}-11^{\mathrm{b}}$ & $1.24 \mathrm{E}+01$ & $9.15 E+04$ \\
\hline Am-243 & $2.68 \mathrm{E}-07^{\mathrm{b}}$ & $2.33 E+01$ & $8.29 \mathrm{E}+04$ \\
\hline Np-239 & $9.76 \mathrm{E}-05^{\mathrm{b}}$ & $8.42 E+03$ & $8.21 E+04$ \\
\hline Pu-239 & $2.44 \mathrm{E}+00^{\mathrm{b}}$ & $1.66 \mathrm{E}+01$ & $4.55 \mathrm{E}+04$ \\
\hline $\mathrm{Cm}-248$ & $1.69 \mathrm{E}-11^{\mathrm{b}}$ & $1.05 \mathrm{E}+01$ & $9.09 E+04$ \\
\hline Pu-244 & $1.11 \mathrm{E}-03^{\mathrm{b}}$ & $5.07 \mathrm{E}-03$ & $4.17 E+04$ \\
\hline Cf -249 & $3.29 \mathrm{E}-09^{\mathrm{b}}$ & $8.49 \mathrm{E}-09$ & $1.64 E+04$ \\
\hline $\mathrm{Cm}-245$ & $4.03 \mathrm{E}-10^{\mathrm{b}}$ & $1.67 \mathrm{E}-03$ & $6.93 E+04$ \\
\hline $\mathrm{Pu}-241$ & $2.26 \mathrm{E}-08^{\mathrm{b}}$ & $7.14 \mathrm{E}-02$ & $6.85 E+04$ \\
\hline Am-24I & $1.74 \mathrm{E}-09^{b}$ & $4.21 \mathrm{E}-03$ & $6.73 E+04$ \\
\hline Np-237 & $5.21 \mathrm{E}-03^{\mathrm{b}}$ & $5.58 \mathrm{E}-03$ & $1.65 E+04$ \\
\hline $\mathrm{Cf}-252$ & $\ldots{ }^{c}$ & $\ldots c^{c}$ & \\
\hline $\mathrm{Cm}-248$ & $1.32 \mathrm{E}-16^{\mathrm{b}}$ & $8.17 E-05$ & $9.09 E+04$ \\
\hline $\mathrm{Pu}-244$ & $8.64 \mathrm{E}-09^{\mathrm{b}}$ & $3.95 \mathrm{E}-08$ & $4.17 \mathrm{E}+04$ \\
\hline \multicolumn{4}{|c|}{$\begin{array}{l}\text { Estimated with PORFLOW, unless otherwise noted. } \\
\text { Estimated with the analytical model in Appendix C.2; values tend to be overestimates due to conservative } \\
\text { nature of model; "na" indicates peak occurred before } 10,000 \text { years. } \\
\text { Radionuclide was screened; only radioactive daughters are of potential significance } \\
\text { Peak estimated with analytical method occurred before } 10,000 \text { years due to conservative nature of model, } \\
\text { resulting in underestimates of travel time to compliance point. }\end{array}$} \\
\hline
\end{tabular}


Table 5.1-3 Peak Groundwater Concentrations for the IL Vault Simulations per Ci of Each Radionuclide in 2 Vaults

\begin{tabular}{|c|c|c|c|}
\hline Radionuclide & $\begin{array}{l}\text { Peak up to } 10,000 \text { years }{ }^{2} \\
\text { pCi/L-Ci }\end{array}$ & $\begin{array}{c}\text { Peak after } 10,000 \text { years }{ }^{b} \\
\text { pCi/L-Ci }\end{array}$ & $\begin{array}{c}\text { Time of peak } \\
y r\end{array}$ \\
\hline $\mathrm{H}-3$ & $1.07 \mathrm{E}-11$ & na & $1.17 \mathrm{E}+02$ \\
\hline C-14 & $4.11 \mathrm{E}-02$ & na & $1.00 \mathrm{E}+04$ \\
\hline $\mathrm{Ni}-59$ & $5.04 \mathrm{E}-01$ & $5.35 E+01$ & $1.47 \mathrm{E}+04$ \\
\hline $\mathrm{Se}-79$ & $1.20 \mathrm{E}+01$ & na & $6.58 \mathrm{E}+03$ \\
\hline Sr-90 & $2.17 \mathrm{E}-10^{\mathrm{b}}$ & na & $1.33 \mathrm{E}+03$ \\
\hline $\mathrm{Zr}-93$ & $1.02 \mathrm{E}-03^{\mathrm{b}}$ & $1.93 E+00$ & $6.01 E+04$ \\
\hline Tc-99 & $1.82 \mathrm{E}+01$ & na & $2.78 \mathrm{E}+03$ \\
\hline Sn- 126 & $1.29 \mathrm{E}+00$ & $9.11 \mathrm{E}+00$ & $1.27 \mathrm{E}+04$ \\
\hline I-129 & $9.66 \mathrm{E}+02$ & na & $1.12 E+03$ \\
\hline Cs-135 & $3.63 \mathrm{E}+00$ & $8.13 \mathrm{E}+01$ & $1.11 \mathrm{E}+04$ \\
\hline Th-232 & $7.76 \mathrm{E}-15^{\mathrm{b}}$ & $1.91 E+00$ & $1.41 \mathrm{E}+0 \mathrm{~S}$ \\
\hline $\mathrm{Ra}-228$ & $5.56 \mathrm{E}-14^{\mathrm{b}}$ & $1.22 \mathrm{E}+01$ & $1.14 \mathrm{E}+05$ \\
\hline Th-228 & $8.67 \mathrm{E}-15^{b}$ & $1.90 \mathrm{E}+00$ & $1.14 \mathrm{E}+05$ \\
\hline $\mathrm{Ra}-224$ & $5.55 \mathrm{E}-14^{\mathrm{b}}$ & $1.22 \mathrm{E}+01$ & $1.14 \mathrm{E}+05$ \\
\hline $\mathrm{U}-232$ & $3.89 \mathrm{E}-12^{\mathrm{b}}$ & na & $7.20 \mathrm{E}+03$ \\
\hline Th-228 & $4.29 \mathrm{E}-14^{\mathrm{b}}$ & na & $7.19 E+03$ \\
\hline $\mathrm{Ra}-224$ & $2.75 \mathrm{E}-13^{\mathrm{b}}$ & na & $7.19 E+03$ \\
\hline $\mathrm{U}-233$ & $4.48 \mathrm{E}-09^{\mathrm{b}}$ & $5.24 \mathrm{E}-09$ & $1.14 E+05$ \\
\hline Th-229 & $1.49 \mathrm{E}-11^{\mathrm{b}}$ & $3.17 \mathrm{E}-03$ & $1.06 \mathrm{E}+05$ \\
\hline $\mathrm{Ra}-225$ & $9.50 \mathrm{E}-11^{b}$ & $2.02 \mathrm{E}-02$ & $1.07 \mathrm{E}+05$ \\
\hline $\mathrm{U}-234$ & $5.69 \mathrm{E}-10$ & $3.44 \mathrm{E}-09$ & $1.14 \mathrm{E}+05$ \\
\hline Th-230 & $1.93 \mathrm{E}-13$ & $2.47 \mathrm{E}-01$ & $1.14 \mathrm{E}+05$ \\
\hline $\mathrm{Ra}-226$ & $3.08 \mathrm{E}-05$ & $3.02 E+00$ & $1.14 \mathrm{E}+05$ \\
\hline $\mathrm{Pb}-210$ & $6.02 \mathrm{E}-05$ & $5.66 \mathrm{E}+00$ & $1.14 E+05$ \\
\hline Po-210 & $1.08 \mathrm{E}-04$ & $1.02 E+01$ & $1.14 \mathrm{E}+05$ \\
\hline$U-235$ & $2.01 E-13$ & $1.22 \mathrm{E}-12$ & $1.14 E+05$ \\
\hline $\mathrm{Pa}-231$ & $8.25 \mathrm{E}-08$ & $1.01 E+00$ & $1.14 \mathrm{E}+05$ \\
\hline Ac-227 & $1.02 \mathrm{E}-07$ & $1.24 \mathrm{E}+00$ & $1.14 \mathrm{E}+05$ \\
\hline Th-227 & $1.43 \mathrm{E}-08$ & $1.75 \mathrm{E}-01$ & $1.14 E+05$ \\
\hline $\mathrm{Ra}-223$ & $9.18 \mathrm{E}-08$ & $1.12 \mathrm{E}+00$ & $1.14 \mathrm{E}+05$ \\
\hline U-236 & $3.12 \mathrm{E}-11^{\mathrm{b}}$ & $3.66 \mathrm{E}-11$ & $1.11 \mathrm{E}+05$ \\
\hline Np-237 & $1.34 \mathrm{E}-01$ & $1.24 \mathrm{E}+00$ & $2.04 E+04$ \\
\hline U-238 & $1.63 \mathrm{E}-13^{\mathrm{b}}$ & $1.91 \mathrm{E}-13$ & $1.14 \mathrm{E}+05$ \\
\hline Th-234 & $1.80 \mathrm{E}-15^{\mathrm{b}}$ & $2.11 E-15$ & $1.14 \mathrm{E}+05$ \\
\hline U-234 & $3.29 \mathrm{E}-09^{\mathrm{b}}$ & $3.47 \mathrm{E}-09$ & $1.14 \mathrm{E}+05$ \\
\hline $\mathrm{Pu}-238$ & $2.35 \mathrm{E}-18^{\mathrm{b}}$ & na & $8.46 \mathrm{E}+03$ \\
\hline U-234 & $2.95 \mathrm{E}-09^{b}$ & $3.00 \mathrm{E}-09$ & $1.56 \mathrm{E}+04$ \\
\hline $\mathrm{Pu}-239$ & $9.41 \mathrm{E}-12^{\mathrm{b}}$ & $3.46 \mathrm{E}-11$ & $1.14 \mathrm{E}+05$ \\
\hline U-235 & $1.04 \mathrm{E}-12^{b}$ & $1.22 \mathrm{E}-12$ & $1.14 \mathrm{E}+05$ \\
\hline $\mathrm{Pu}-240$ & $2.08 \mathrm{E}-11^{\mathrm{b}}$ & $5.01 \mathrm{E}-11$ & $1.14 \mathrm{E}+05$ \\
\hline U-236 & $3.13 \mathrm{E}-11^{\mathrm{b}}$ & $3.66 \mathrm{E}-11$ & $1.14 E+05$ \\
\hline Am-241 & $\ldots$ & $-c^{c}$ & \\
\hline $\mathrm{Np}-237$ & $2.71 \mathrm{E}-05$ & $2.50 \mathrm{E}-04$ & $2.04 E+04$ \\
\hline $\mathrm{Pu}-241$ & -...c & $\ldots c$ & \\
\hline Am-241 & -.-_c & $\ldots-^{\mathfrak{c}}$ & \\
\hline Np-237 & $9.02 \mathrm{E}-07$ & $8.34 \mathrm{E}-06$ & $2.04 \mathrm{E}+04$ \\
\hline
\end{tabular}


Table 5.1-3 Peak Groundwater Concentrations for the IL Vault Simulations per Ci of Each Radionuclide in 2 Vaults

\begin{tabular}{|c|c|c|c|}
\hline Radionuclide & $\begin{array}{c}\text { Peak up to } 10,000 \text { years }{ }^{2} \\
\text { pCi/L-Ci }\end{array}$ & $\begin{array}{c}\text { Peak after } 10,000 \text { years } \\
\text { pCi/L-Ci }\end{array}$ & $\begin{array}{c}\text { Time of peak } \\
\mathrm{yr}\end{array}$ \\
\hline $\mathrm{Pu}-242$ & $7.19 \mathrm{E}-13^{\mathrm{b}}$ & $3.24 \mathrm{E}-12$ & $1.14 \mathrm{E}+05$ \\
\hline $\mathrm{U}-238$ & $1.63 \mathrm{E}-13^{\mathrm{b}}$ & $1.91 \mathrm{E}-13$ & $1.14 \mathrm{E}+05$ \\
\hline $\mathrm{Am}-243$ & $4.29 \mathrm{E}-11^{\mathrm{b}}$ & $8.28 \mathrm{E}-03$ & $5.36 \mathrm{E}+04$ \\
\hline Np-239 & $1.29 \mathrm{E}-02^{\mathrm{b}}$ & $3.00 \mathrm{E}+00$ & $5.32 \mathrm{E}+04$ \\
\hline Pu-239 & $8.60 \mathrm{E}-05^{\mathrm{b}}$ & $6.17 \mathrm{E}-02$ & $3.00 \mathrm{E}+04$ \\
\hline Pu-244 & $3.41 \mathrm{E}-15^{\mathrm{b}}$ & $1.55 \mathrm{E}-14$ & $1.14 \mathrm{E}+05$ \\
\hline $\mathrm{Cm}-244$ & $\ldots{ }^{c}$ & $-c^{c}$ & \\
\hline $\mathrm{Pu}-240$ & $5.76 \mathrm{E}-14^{b}$ & $1.39 \mathrm{E}-13$ & $1.14 E+05$ \\
\hline $\mathrm{U}-236$ & $8.67 \mathrm{E}-14^{b}$ & $1.01 \mathrm{E}-13$ & $1.14 \mathrm{E}+05$ \\
\hline $\mathrm{Cm}-245$ & $4.45 \mathrm{E}-17^{\mathrm{b}}$ & $6.91 \mathrm{E}-04$ & $8.32 E+04$ \\
\hline $\mathrm{Pu}-241$ & $8.43 \mathrm{E}-13^{b}$ & $2.95 \mathrm{E}-02$ & $8.28 E+04$ \\
\hline Am-241 & $2.46 \mathrm{E}-13^{\mathrm{b}}$ & $1.74 \mathrm{E}-03$ & $8.20 \mathrm{E}+04$ \\
\hline Np-237 & $1.70 \mathrm{E}-03^{\mathrm{b}}$ & $8.13 \mathrm{E}-03$ & $4.80 \mathrm{E}+04$ \\
\hline $\mathrm{Cm}-246$ & $2.30 \mathrm{E}-17^{\mathrm{b}}$ & $6.66 \mathrm{E}-06$ & $6.86 \mathrm{E}+04$ \\
\hline $\mathrm{Cm}-247$ & $1.01 \mathrm{E}-16^{\mathrm{b}}$ & $1.55 E+00$ & $1.14 \mathrm{E}+05$ \\
\hline Am-243 & $1.66 \mathrm{E}-11^{\mathrm{b}}$ & $3.59 \mathrm{E}+00$ & $1.14 \mathrm{E}+05$ \\
\hline $\mathrm{Np}-239$ & $6.05 \mathrm{E}-09^{\mathrm{b}}$ & $1.30 \mathrm{E}+03$ & $1.14 E+05$ \\
\hline Pu-239 & $1.48 \mathrm{E}-02^{b}$ & $3.72 E+00$ & $1.14 \mathrm{E}+05$ \\
\hline $\mathrm{Cm}-248$ & $9.90 \mathrm{E}-17^{\mathrm{b}}$ & $1.25 \mathrm{E}+00$ & $1.14 \mathrm{E}+05$ \\
\hline Pu-244 & $8.35 \mathrm{E}-06^{\mathrm{b}}$ & $1.06 \mathrm{E}-03$ & $1.14 \mathrm{E}+05$ \\
\hline Cf-249 & $1.06 \mathrm{E}-11^{\mathrm{b}}$ & $2.81 \mathrm{E}-11$ & $1.29 \mathrm{E}+04$ \\
\hline Cm-245 & $1.70 \mathrm{E}-12^{\mathrm{b}}$ & $2.97 \mathrm{E}-05$ & $8.38 \mathrm{E}+04$ \\
\hline $\mathrm{Pu}-241$ & $8.82 \mathrm{E}-11^{\mathrm{b}}$ & $1.27 \mathrm{E}-03$ & $8.26 \mathrm{E}+04$ \\
\hline Am-241 & $5.70 \mathrm{E}-12^{\mathrm{b}}$ & $7.48 \mathrm{E}-05$ & $8.22 \mathrm{E}+04$ \\
\hline Np-237 & $6.83 E-05^{b}$ & $3.36 \mathrm{E}-04$ & $4.72 \mathrm{E}+04$ \\
\hline Cf- 252 & ${ }^{2}$ & c & \\
\hline $\mathrm{Cm}-248$ & $7.39 \mathrm{E}-22^{\mathrm{b}}$ & $9.36 E+06$ & $1.14 \mathrm{E}+05$ \\
\hline $\mathrm{Pu}-244$ & $6.24 \mathrm{E}-11^{\mathrm{b}}$ & $7,94 \mathrm{E}-09$ & $1.14 \mathrm{E}+05$ \\
\hline
\end{tabular}

Estimated with PORFLOW, unless otherwise noted.

b Estimated with the analytical model in Appendix C.2; values tend to be overestimates due to conservative nature of model; "na" indicates peak occurred before 10,000 years.

c Radionuclide was screened; only radioactive daughters are of potential significance 
Table 5.1-4 Peak Groundwater Concentrations for the Slit Trench Simulations per Ci of Each Radionuclide in 10 Trenches

\begin{tabular}{|c|c|c|c|}
\hline Radionuclide & $\begin{array}{c}\text { Peak up to } 10,000 \text { years }^{\mathrm{a}} \\
\mathrm{pCi} / \mathrm{L}\end{array}$ & $\begin{array}{c}\text { Peak after } 10,000 \text { years }^{b} \\
\mathrm{pCi} / \mathrm{L}-\mathrm{Ci}\end{array}$ & $\begin{array}{c}\text { Time of peak } \\
\mathrm{yr}\end{array}$ \\
\hline $\mathrm{H}-3$ & $1.59 \mathrm{E}+03$ & $\mathrm{Na}$ & $9.00 \mathrm{E}+00$ \\
\hline C-14 & $2.17 \mathrm{E}+02$ & na & $1.80 \mathrm{E}+02$ \\
\hline $\mathrm{Ni}-59$ & $9.32 \mathrm{E}-01$ & $5.87 \mathrm{E}+01$ & $1.09 \mathrm{E}+04$ \\
\hline $\mathrm{Se}-79$ & $2.97 \mathrm{E}+00$ & na & $4.70 \mathrm{E}+03$ \\
\hline Rb-87 & $4.33 \mathrm{E}+02^{\mathrm{b}}$ & na & $1.67 \mathrm{E}+03$ \\
\hline Sr-90 & $7.05 \mathrm{E}-03$ & na & $3.20 \mathrm{E}+02$ \\
\hline $\mathrm{Zr}-93$ & $3.79 E+01^{b}$ & $3.98 \mathrm{E}+01$ & $1.69 \mathrm{E}+04$ \\
\hline Tc-99 & $7.32 \mathrm{E}+02$ & na & $2.00 \mathrm{E}+01$ \\
\hline Pd-107 & $4.52 \mathrm{E}+02^{\mathrm{b}}$ & na & $1.61 \mathrm{E}+03$ \\
\hline Sn-126 & $3.50 \mathrm{E}+00$ & na & $4.10 \mathrm{E}+03$ \\
\hline $\mathrm{I}-129$ & $4.77 \mathrm{E}+02$ & na & $2.90 \mathrm{E}+01$ \\
\hline Cs-135 & $1.41 \mathrm{E}+00$ & $7.27 \mathrm{E}+01$ & $9.30 \mathrm{E}+03^{\mathrm{d}}$ \\
\hline Th-232 & $5.08 \mathrm{E}-07^{\mathrm{b}}$ & $7.51 \mathrm{E}+00$ & $6.22 E+04$ \\
\hline Ra-228 & $3.48 \mathrm{E}-06^{\mathrm{b}}$ & $4.80 \mathrm{E}+01$ & $6.26 \mathrm{E}+04$ \\
\hline Th-228 & $5.42 \mathrm{E}-07^{\mathrm{b}}$ & $7.48 \mathrm{E}+00$ & $6.26 \mathrm{E}+04$ \\
\hline $\mathrm{Ra}-224$ & $3.47 \mathrm{E}-06^{\mathrm{b}}$ & $4.79 E+01$ & $6.20 \mathrm{E}+04$ \\
\hline$U-232$ & $1.81 \mathrm{E}+00^{\mathrm{b}}$ & na & $5.72 E+03$ \\
\hline Th-228 & $2.00 \mathrm{E}-02^{\mathrm{b}}$ & na & $5.73 E+03$ \\
\hline $\mathrm{Ra}-224$ & $1.28 \mathrm{E}-01^{\mathrm{b}}$ & na & $5.73 E+03$ \\
\hline $\mathrm{U}-233$ & $7.19 \mathrm{E}+02^{\mathrm{b}}$ & $7.19 \mathrm{E}+02$ & $5.88 \mathrm{E}+03$ \\
\hline Th-229 & $2.92 \mathrm{E}-01^{\mathrm{b}}$ & $2.92 \mathrm{E}-01$ & $6.88 E+03$ \\
\hline Ra-225 & $1.86 \mathrm{E}+00^{\mathrm{b}}$ & $1.86 \mathrm{E}+00$ & $6.56 \mathrm{E}+03$ \\
\hline U-234 & $1.39 E+01$ & na & $1.17 \mathrm{E}+03$ \\
\hline Th-230 & $4.22 \mathrm{E}-03$ & $3.11 \mathrm{E}-02$ & $7.29 \mathrm{E}+03^{\mathrm{d}}$ \\
\hline $\mathrm{Ra}-226$ & $2.39 \mathrm{E}-02$ & $1.90 \mathrm{E}-01$ & $1.42 E+04$ \\
\hline Pb-210 & $4.41 \mathrm{E}-02$ & $3.53 \mathrm{E}-01$ & $1.42 \mathrm{E}+04$ \\
\hline Po-210 & $7.94 \mathrm{E}-02$ & $6.34 \mathrm{E}-01$ & $1.42 \mathrm{E}+04$ \\
\hline U-235 & $1.40 \mathrm{E}+01$ & na & $1.17 \mathrm{E}+03$ \\
\hline $\mathrm{Pa}-231$ & $5.11 \mathrm{E}-02$ & na & $8.30 \mathrm{E}+03$ \\
\hline Ac- 227 & $6.27 \mathrm{E}-02$ & na & $8.32 \mathrm{E}+03$ \\
\hline Th-227 & $8.82 E-03$ & na & $8.32 \mathrm{E}+03$ \\
\hline Ra-223 & $5.64 \mathrm{E}-02$ & na & $8.32 \mathrm{E}+03$ \\
\hline U-236 & $7.21 E+02^{b}$ & na & $5.88 \mathrm{E}+03$ \\
\hline $\mathrm{Np}-237$ & $9.23 E+01$ & na & $2.80 \mathrm{E}+02$ \\
\hline $\mathrm{U}-238$ & $1.41 \mathrm{E}+01$ & na & $1.17 \mathrm{E}+03$ \\
\hline Th-234 & $1.54 \mathrm{E}-01$ & na & $1.17 \mathrm{E}+03$ \\
\hline U-234 & $4.88 \mathrm{E}-02$ & na & $1.32 E+03$ \\
\hline $\mathrm{Pu}-238$ & $4.71 \mathrm{E}-03^{\mathrm{b}}$ & na & $6.25 E+03$ \\
\hline U-234 & $2.33 \mathrm{E}-01^{\mathrm{b}}$ & na & $5.91 E+03$ \\
\hline Pu-239 & $4.36 \mathrm{E}+00$ & na & $3.10 \mathrm{E}+03$ \\
\hline U-235 & $2.16 \mathrm{E}-05$ & na & $2.85 \mathrm{E}+03$ \\
\hline $\mathrm{Pu}-240$ & $3.47 \mathrm{E}+00$ & na & $3.02 \mathrm{E}+03$ \\
\hline U-236 & $6.01 E-04$ & na & $2.60 \mathrm{E}+03$ \\
\hline Am-241 & $-{ }_{-}^{c}$ & & \\
\hline Np-237 & $1.86 \mathrm{E}-02$ & na & $2.80 \mathrm{E}+02$ \\
\hline
\end{tabular}


Table 5.1-4 Peak Groundwater Concentrations for the Slit Trench Simulations per Ci of Each Radionuclide in 10 Trenches

\begin{tabular}{|c|c|c|c|}
\hline Radionuclide & $\begin{array}{c}\text { Peak up to } 10,000 \text { years } \\
\text { pCi/L }\end{array}$ & $\begin{array}{c}\text { Peak after } 10,000 \text { years } \\
\text { pCi } / \mathrm{L}-\mathrm{Ci}\end{array}$ & $\begin{array}{c}\text { Time of peak } \\
y r\end{array}$ \\
\hline Pu-241 & $--^{c}$ & & \\
\hline Am-241 & $--^{c}$ & & \\
\hline Np-237 & $6.21 \mathrm{E}-04$ & na & $2.80 E+02$ \\
\hline $\mathrm{Pu}-242$ & $2.45 \mathrm{E}+02^{b}$ & na & $7.00 \mathrm{E}+03$ \\
\hline U-238 & $6.65 \mathrm{E}-05^{\mathrm{b}}$ & na & $6.38 \mathrm{E}+03$ \\
\hline Am-243 & $1.47 \mathrm{E}-03^{b}$ & $8.42 \mathrm{E}-01$ & $3.22 E+04$ \\
\hline Np-239 & $5.34 \mathrm{E}-01^{b}$ & $3.05 E+02$ & $3.22 \mathrm{E}+04$ \\
\hline Pu-239 & $4.52 \mathrm{E}+00^{b}$ & $7.43 \mathrm{E}+00$ & $8.15 E+03$ \\
\hline $\mathrm{Pu}-244$ & $2.46 \mathrm{E}+02^{\mathrm{b}}$ & na & $7.00 \mathrm{E}+03$ \\
\hline $\mathrm{Cm}-242+\mathrm{d}$ & $2.42 \mathrm{E}-05^{\mathrm{b}}$ & na & $6.25 \mathrm{E}+03$ \\
\hline $\mathrm{Cm}-244$ & $---{ }^{c}$ & & \\
\hline Pu-240 & $9.50 \mathrm{E}-03^{\mathrm{b}}$ & na & $2.93 E+03$ \\
\hline $\mathrm{U}-236$ & $1.54 \mathrm{E}-06^{\mathrm{b}}$ & na & $2.77 \mathrm{E}+03$ \\
\hline $\mathrm{Cm}-245$ & $4.68 \mathrm{E}-08^{\mathrm{b}}$ & $1.15 \mathrm{E}-04$ & $2.36 \mathrm{E}+04$ \\
\hline $\mathrm{Pu}-241$ & $1.65 \mathrm{E}-05^{\mathrm{b}}$ & $9.12 E-03$ & $2.36 \mathrm{E}+04$ \\
\hline Am-241 & $3.10 \mathrm{E}-06^{\mathrm{b}}$ & 8.63E-04 & $2.36 \mathrm{E}+04$ \\
\hline Np-237 & $1.11 \mathrm{E}-01^{\mathrm{b}}$ & na & $7.25 E+03$ \\
\hline $\mathrm{Cm}-246$ & $2.42 \mathrm{E}-08^{\mathrm{b}}$ & $2.42 \mathrm{E}-08$ & $1.52 \mathrm{E}+04$ \\
\hline $\mathrm{Cm}-247$ & $1.06 \mathrm{E}-07^{b}$ & $6.52 E+00$ & $7.24 \mathrm{E}+04$ \\
\hline$A m-243$ & $3.21 \mathrm{E}-04^{\mathrm{b}}$ & $1.22 \mathrm{E}+01$ & $6.42 \mathrm{E}+04$ \\
\hline Np-239 & $1.17 \mathrm{E}-01^{\mathrm{b}}$ & $4.41 E+03$ & $6.44 E+04$ \\
\hline Pu-239 & $5.69 \mathrm{E}+00^{\mathrm{b}}$ & $1.02 \mathrm{E}+01$ & $3.64 E+04$ \\
\hline $\mathrm{Cm}-248$ & $1.04 \mathrm{E}-07^{\mathrm{b}}$ & $5.73 E+00$ & $7.16 \mathrm{E}+04$ \\
\hline $\mathrm{Pu}-244$ & $3.44 \mathrm{E}-03^{\mathrm{b}}$ & $3.44 \mathrm{E}-03$ & $1.62 E+04$ \\
\hline$B k-249+d$ & $3.89 \mathrm{E}-07^{b}$ & na & $9.86 \mathrm{E}+03$ \\
\hline Cf-249 & $1.55 \mathrm{E}-04^{\mathrm{b}}$ & na & $9.86 E+03$ \\
\hline $\mathrm{Cm}-245$ & $1.38 \mathrm{E}-05^{\mathrm{b}}$ & $7.28 \mathrm{E}-05$ & $2.36 E+04$ \\
\hline $\mathrm{Pu}-241$ & $7.12 \mathrm{E}-04^{\mathrm{b}}$ & $3.81 \mathrm{E}-03$ & $2.36 \mathrm{E}+04$ \\
\hline Am-241 & $4.95 \mathrm{E}-05^{\mathrm{b}}$ & $2.68 \mathrm{E}-04$ & $2.36 \mathrm{E}+04$ \\
\hline $\mathrm{Np}-237$ & $3.36 \mathrm{E}-03^{b}$ & na & $8.13 E+03$ \\
\hline$C f-250+d$ & $6.66 \mathrm{E}-11^{\mathrm{b}}$ & $6.66 \mathrm{E}-11$ & $1.52 E+04$ \\
\hline Cf-252 & $---c^{-}$ & & \\
\hline $\mathrm{Cm}-248$ & $8.10 \mathrm{E}-13^{\mathrm{b}}$ & $4.46 \mathrm{E}-05$ & $7.16 \mathrm{E}+04$ \\
\hline Pu-244 & $2.68 \mathrm{E}-08^{\mathrm{b}}$ & $2.68 \mathrm{E}-08$ & $1.62 \mathrm{E}+04$ \\
\hline
\end{tabular}

Estimated with PORFLOW, untess otherwise noted.

bstimated with the analytical model in Appendix C.2; values tend to be overestimates due to conservative nature of model; "na" indicates peak occurred before 10,000 years.

c Radionuclide was screened; only radioactive daughters are of potential significance.

d Peak estimated with analytical method occurred before 10,000 years due to conservative nature of model, resulting in underestimates of travel time to compliance point. 
Table 5.1-5 Peak Groundwater Concentrations for the Naval Reactor Pad Simulations per $\mathrm{Ci}$ of each Radionuclide in 100 Containers

\begin{tabular}{|c|c|c|c|}
\hline Radionuclide & $\begin{array}{l}\text { Peak up to } 10,000 \text { years }^{\mathrm{a}} \\
\mathrm{pCi} / \mathrm{L}\end{array}$ & $\begin{array}{c}\text { Peak after } 10,000 \text { years } \\
\text { pCi } / \mathrm{L}-\mathrm{C} i\end{array}$ & $\begin{array}{c}\text { Time of peak } \\
y \mathbf{y r}\end{array}$ \\
\hline $\mathrm{H}-3$ & $1.8 \mathrm{E}-18^{b}$ & na & $7.7 \mathrm{E}+02$ \\
\hline C-14 & $2.3 \mathrm{E}+00$ & na & $9.8 \mathrm{E}+02$ \\
\hline $\mathrm{Ni}-59$ & $3.2 \mathrm{E}-01$ & $9.3 E+00$ & $1.6 \mathrm{E}+04$ \\
\hline $\mathrm{Se}-79$ & $7.7 \mathrm{E}+00$ & na & $9.0 \mathrm{E}+03$ \\
\hline $\mathrm{Sr}-90+\mathrm{d}$ & $2.2 \mathrm{E}-09^{b}$ & na & $1.0 \mathrm{E}+03$ \\
\hline Mo-93 & $7.1 \mathrm{E}+00$ & na & $1.5 E+03$ \\
\hline $\mathrm{Zr}-93+\mathrm{d}$ & $3.7 \mathrm{E}-03$ & $1.8 \mathrm{E}+00$ & $2.3 \mathrm{E}+04$ \\
\hline $\mathrm{Nb}-94$ & $5.2 \mathrm{E}+00$ & na & $9.1 \mathrm{E}+03$ \\
\hline Tc-99 & $7.8 \mathrm{E}+00$ & na & $8.5 E+02$ \\
\hline Sn-126+d & $8.3 \mathrm{E}+00$ & na & $8.3 E+03$ \\
\hline $\mathrm{I}-129$ & $1.0 \mathrm{E}+01$ & na & $5.5 E+03$ \\
\hline Cs-135 & $2.0 \mathrm{E}+00$ & $1.2 \mathrm{E}+01$ & $1.3 E+04$ \\
\hline Th-232 & $7.6 \mathrm{E}-09^{\mathrm{b}}$ & $2.1 E+00$ & $9.7 \mathrm{E}+04$ \\
\hline $\mathrm{Ra}-228$ & $2.2 \mathrm{E}-17^{\mathrm{b}}$ & $1.9 \mathrm{E}-09$ & $9.2 \mathrm{E}+04$ \\
\hline Th-228 & $1.1 \mathrm{E}-18^{\mathrm{b}}$ & $1.1 \mathrm{E}-10$ & $9.0 \mathrm{E}+04$ \\
\hline $\mathrm{Ra}-224$ & $3.7 \mathrm{E}-20^{\mathrm{b}}$ & $7.9 \mathrm{E}-12$ & $7.8 \mathrm{E}+04$ \\
\hline U-232 & $2.4 \mathrm{E}-07^{\mathrm{b}}$ & na & $5.7 \mathrm{E}+03$ \\
\hline Th-228 & $7.0 \mathrm{E}-11^{\mathrm{b}}$ & na & $5.7 E+03$ \\
\hline Ra-224 & $2.3 \mathrm{E}-12^{\mathrm{b}}$ & na & $5.7 E+03$ \\
\hline U-234 & $4.0 \mathrm{E}+00$ & $6.3 \mathrm{E}+00$ & $1.5 \mathrm{E}+04$ \\
\hline Th-230 & $1.9 \mathrm{E}-03$ & $1.4 \mathrm{E}-02$ & $9.0 \mathrm{E}+04$ \\
\hline $\mathrm{Ra}-226$ & 7.3E-03 & $1.8 \mathrm{E}-03$ & $8.2 \mathrm{E}+04$ \\
\hline $\mathrm{Pb}-210$ & $1.3 \mathrm{E}-02$ & $8.6 \mathrm{E}-05$ & $7.1 E+04$ \\
\hline Po-210 & $2.4 \mathrm{E}-02$ & $2.2 \mathrm{E}-06$ & $7.5 E+04$ \\
\hline U-235 & $4.1 E+00$ & $6.5 \mathrm{E}+00$ & $1.5 \mathrm{E}+04$ \\
\hline $\mathrm{Pa}-231$ & $2.3 \mathrm{E}-02$ & 4.7E-05 & $2.5 \mathrm{E}+04$ \\
\hline Ac- -227 & $2.9 E-02$ & $5.6 \mathrm{E}-09$ & $1.4 \mathrm{E}+04$ \\
\hline Th-227 & $4.0 \mathrm{E}-03$ & $1.3 \mathrm{E}-11$ & $2.3 \mathrm{E}+04$ \\
\hline Ra-223 & $2.6 \mathrm{E}-02$ & $4.9 \mathrm{E}-11$ & $2.4 \mathrm{E}+04$ \\
\hline U-236 & $4.1 E+00$ & $6.5 \mathrm{E}+00$ & $1.5 E+04$ \\
\hline $\mathrm{Np}-237$ & $1.0 \mathrm{E}+01$ & na & $5.7 E+03$ \\
\hline$U-238$ & $4.1 E+00$ & $6.5 E+00$ & $1.5 \mathrm{E}+04$ \\
\hline Th-234 & $4.5 E-02$ & $1.1 \mathrm{E}-12$ & $1.5 \mathrm{E}+04$ \\
\hline U-234 & $9.3 \mathrm{E}-03$ & 9.0 E-06 & $2.0 \mathrm{E}+04$ \\
\hline Pu-238 & $1.3 \mathrm{E}-09^{\mathrm{b}}$ & na & $6.3 \mathrm{E}+03$ \\
\hline U-234 & $9.0 \mathrm{E}-05^{b}$ & na & $6.2 E+03$ \\
\hline Pu-239 & $1.0 \mathrm{E}+00$ & $1.7 \mathrm{E}+00$ & $1.4 E+04$ \\
\hline $\mathrm{U}-235$ & $1.3 \mathrm{E}-01$ & $1.9 \mathrm{E}-01$ & $1.5 \mathrm{E}+04$ \\
\hline $\mathrm{Pu}-240$ & $4.8 \mathrm{E}-01$ & na & $9.6 \mathrm{E}+03$ \\
\hline U-236 & $2.6 \mathrm{E}-01$ & $3.8 \mathrm{E}-01$ & $1.4 \mathrm{E}+04$ \\
\hline Am-241 & $---{ }^{c}$ & & \\
\hline Np-237 & $2.0 \mathrm{E}-03$ & na & $5.7 \mathrm{E}+03$ \\
\hline $\mathrm{Pu}-241$ &.$-^{c}$ & & \\
\hline Am-241 & $--^{c}$ & & \\
\hline Np-237 & $6.7 \mathrm{E}-05$ & na & $5.7 \mathrm{E}+03$ \\
\hline
\end{tabular}


Table 5.1-5 Peak Groundwater Concentrations for the Naval Reactor Pad Simulations per $\mathrm{Ci}$ of each Radionuclide in 100 Containers

\begin{tabular}{|c|c|c|c|}
\hline Radionuclide & $\begin{array}{l}\text { Peak up to } 10,000 \text { years }{ }^{a} \\
\text { pCi } / \mathrm{L}\end{array}$ & $\begin{array}{c}\text { Peak after } 10,000 \text { years }^{b} \\
\text { pCi/L-Ci }\end{array}$ & $\begin{array}{c}\text { Time of peak } \\
\mathrm{yr}\end{array}$ \\
\hline $\mathrm{Pu}-242$ & $1.4 \mathrm{E}+00$ & $2.2 \mathrm{E}+00$ & $1.5 \mathrm{E}+04$ \\
\hline $\mathrm{U}-238$ & $9.8 \mathrm{E}-03$ & $1.6 \mathrm{E}-02$ & $1.5 \mathrm{E}+04$ \\
\hline Am-243 & $3.0 \mathrm{E}-06^{\mathrm{b}}$ & $1.1 \mathrm{E}-01$ & $4.1 E+04$ \\
\hline $\mathrm{Np}-239$ & $1.5 \mathrm{E}-02^{\mathrm{b}}$ & $1.6 \mathrm{E}-02$ & $1.5 \mathrm{E}+04$ \\
\hline $\mathrm{Pu}-239$ & $5.4 \mathrm{E}-06^{\mathrm{b}}$ & $9.0 \mathrm{E}-06$ & $2.0 \mathrm{E}+04$ \\
\hline $\mathrm{Pu}-244$ & $1.4 \mathrm{E}+00$ & $2.2 \mathrm{E}+00$ & $1.4 \mathrm{E}+04$ \\
\hline $\mathrm{Cm}-244$ & $---{ }^{c}$ & & \\
\hline Pu-240 & $1.3 \mathrm{E}-03$ & na & $9.6 \mathrm{E}+03$ \\
\hline U-236 & $7.3 E-04$ & $1.1 \mathrm{E}-03$ & $1.4 \mathrm{E}+04$ \\
\hline $\mathrm{Cm}-245$ & $3.5 \mathrm{E}-16$ & $4.6 \mathrm{E}-03$ & $7.9 \mathrm{E}+04$ \\
\hline $\mathrm{Pu}-241$ & $7.6 \mathrm{E}-14$ & $5.6 \mathrm{E}-04$ & $7.0 \mathrm{E}+04$ \\
\hline Am-241 & $1.8 \mathrm{E}-14$ & $1.1 \mathrm{E}-03$ & $6.7 \mathrm{E}+04$ \\
\hline Np-237 & $2.7 \mathrm{E}+00$ & $3.9 \mathrm{E}+00$ & $8.2 E+03$ \\
\hline $\mathrm{Cm}-246$ & $1.7 \mathrm{E}-16$ & $8.1 E-07$ & $1.0 \mathrm{E}+05$ \\
\hline $\mathrm{Cm}-247$ & $1.4 \mathrm{E}-10^{\mathrm{b}}$ & $1.4 \mathrm{E}+00$ & $9.6 \mathrm{E}+04$ \\
\hline Am-243 & $2.9 \mathrm{E}-10^{\mathrm{b}}$ & $1.3 \mathrm{E}-03$ & $8.8 E+04$ \\
\hline Np-239 & $9.0 \mathrm{E}-14^{\mathrm{b}}$ & $3.0 \mathrm{E}-07$ & $9.4 \mathrm{E}+04$ \\
\hline $\mathrm{Pu}-239$ & $1.1 \mathrm{E}-03^{\mathrm{b}}$ & $1.2 \mathrm{E}-03$ & $9.0 \mathrm{E}+04$ \\
\hline $\mathrm{Cm}-248$ & $1.4 \mathrm{E}-10^{\mathrm{b}}$ & $1.1 \mathrm{E}+00$ & $9.7 \mathrm{E}+04$ \\
\hline $\mathrm{Pu}-244$ & $1.8 \mathrm{E}-01^{\mathrm{b}}$ & $1.8 \mathrm{E}-01$ & $1.4 \mathrm{E}+04$ \\
\hline $\mathrm{Cf}-249$ & $3.4 \mathrm{E}-09^{\mathrm{b}}$ & $1.4 \mathrm{E}-07$ & $1.0 \mathrm{E}+04$ \\
\hline $\mathrm{Cm}-245$ & $2.7 \mathrm{E}-07^{\mathrm{b}}$ & $1.6 \mathrm{E}-05$ & $9.5 E+04$ \\
\hline $\mathrm{Pu}-241$ & $2.3 \mathrm{E}-08^{\mathrm{b}}$ & $1.9 \mathrm{E}-06$ & $9.4 \mathrm{E}+04$ \\
\hline $\mathrm{Am}-241$ & $4.9 \mathrm{E}-08^{b}$ & $7.7 \mathrm{E}-07$ & $1.0 \mathrm{E}+05$ \\
\hline Np-237 & $7.8 \mathrm{E}-02^{\mathrm{b}}$ & na & $9.6 \mathrm{E}+03$ \\
\hline
\end{tabular}



Table 5.1-6 Peak Groundwater Concentrations for the Intimately-Mixed Cement-Stabilized Waste Simulations - per Ci of Each Radionuclide in 10 Trenches

\begin{tabular}{|c|c|c|c|}
\hline Radionuclide & $\begin{array}{l}\text { Peak up to } 10,000 \text { years }{ }^{a} \\
\mathrm{pCi} / \mathrm{L}\end{array}$ & $\begin{array}{c}\text { Peak after } 10,000 \text { years }^{b} \\
\text { pCi/L-Ci }\end{array}$ & $\begin{array}{c}\text { Time of peak } \\
y r\end{array}$ \\
\hline $\mathrm{H}-3$ & $6.35 \mathrm{E}-05$ & na & $7.30 \mathrm{E}+01$ \\
\hline$C-14$ & $4.36 \mathrm{E}-01$ & na & $7.10 \mathrm{E}+02$ \\
\hline $\mathrm{Ni}-59$ & $5.58 \mathrm{E}-01$ & $5.33 \mathrm{E}+01$ & $1.31 \mathrm{E}+04$ \\
\hline $\mathrm{Se}-79$ & $1.84 \mathrm{E}+01$ & na & $3.58 \mathrm{E}+03$ \\
\hline $\mathrm{Rb}-87$ & $4.00 \mathrm{E}+02^{\mathrm{b}}$ & na & $2.14 \mathrm{E}+03$ \\
\hline Sr-90 & $7.83 \mathrm{E}-06$ & na & $5.61 \mathrm{E}+02$ \\
\hline Zr-93 & $6.32 \mathrm{E}-01^{\mathrm{b}}$ & $3.77 \mathrm{E}+00$ & $2.79 E+04$ \\
\hline $\mathrm{Nb}-94$ & $3.10 \mathrm{E}+01^{\mathrm{b}}$ & na & $7.18 \mathrm{E}+03$ \\
\hline Тc-99 & $1.03 E+03$ & na & $3.50 \mathrm{E}+02$ \\
\hline Pd-107 & $1.84 \mathrm{E}+02^{\mathrm{b}}$ & na & $2.68 \mathrm{E}+03$ \\
\hline Sn-126 & $1.16 \mathrm{E}+00$ & $1.82 \mathrm{E}+01$ & $5.93 \mathrm{E}+03^{d}$ \\
\hline $1-129$ & $6.12 \mathrm{E}+02$ & na & $3.70 \mathrm{E}+02$ \\
\hline Cs- 135 & $1.97 \mathrm{E}+0 \mathrm{l}^{\mathrm{b}}$ & $7.22 \mathrm{E}+01$ & $1.04 \mathrm{E}+04$ \\
\hline Th-232 & $2.00 \mathrm{E}-09^{\mathrm{b}}$ & $3.60 \mathrm{E}+00$ & $1.33 \mathrm{E}+05$ \\
\hline $\mathrm{Ra}-228$ & $1.38 \mathrm{E}-08^{\mathrm{b}}$ & $2.30 \mathrm{E}+01$ & $1.05 \mathrm{E}+05$ \\
\hline Th- 228 & $2.15 \mathrm{E}-09^{\mathrm{b}}$ & $3.58 \mathrm{E}+00$ & $1.06 \mathrm{E}+05$ \\
\hline $\mathrm{Ra}-224$ & $1.38 \mathrm{E}-08^{\mathrm{b}}$ & $2.29 \mathrm{E}+01$ & $1.06 \mathrm{E}+05$ \\
\hline$U-232$ & $2.65 \mathrm{E}-08^{\mathrm{b}}$ & na & $6.33 \mathrm{E}+03$ \\
\hline Th-228 & $2.91 \mathrm{E}-10^{\mathrm{b}}$ & na & $6.91 E+03$ \\
\hline $\mathrm{Ra}-224$ & $1.87 \mathrm{E}-09^{\mathrm{b}}$ & na & $6.33 E+03$ \\
\hline $\mathrm{U}-233$ & $4.82 \mathrm{E}-09^{\mathrm{b}}$ & $4.83 \mathrm{E}-09$ & $1.36 \mathrm{E}+04$ \\
\hline Th-229 & $9.87 \mathrm{E}-11^{\mathrm{b}}$ & $4.68 \mathrm{E}-03$ & $6.56 \mathrm{E}+04$ \\
\hline $\mathrm{Ra}-225$ & $6.30 \mathrm{E}-10^{\mathrm{b}}$ & $2.99 \mathrm{E}-02$ & $6.50 \mathrm{E}+04$ \\
\hline $\mathrm{U}-234$ & $3.88 \mathrm{E}-10$ & na & $1.00 \mathrm{E}+04$ \\
\hline Th-230 & $2.58 \mathrm{E}-13$ & $1.36 \mathrm{E}-01$ & $9.96 \mathrm{E}+04$ \\
\hline $\mathrm{Ra}-226$ & $2.55 \mathrm{E}-05$ & $9.48 \mathrm{E}-01$ & $8.80 E+04$ \\
\hline $\mathrm{Pb}-210$ & $4.96 \mathrm{E}-05$ & $1.76 \mathrm{E}+00$ & $8.70 E+04$ \\
\hline Po-210 & $8.93 E-05$ & $3.17 \mathrm{E}+00$ & $8.72 E+04$ \\
\hline U-235 & $1.36 \mathrm{E}-13$ & na & $1.00 \mathrm{E}+04$ \\
\hline $\mathrm{Pa}-231$ & $3.24 \mathrm{E}-05$ & $5.23 \mathrm{E}-01$ & $2.94 \mathrm{E}+04$ \\
\hline Ac- 227 & $4.00 \mathrm{E}-05$ & $6.42 \mathrm{E}-01$ & $2.92 \mathrm{E}+04$ \\
\hline Th-227 & $5.63 \mathrm{E}-05$ & $9.04 \mathrm{E}-02$ & $2.94 \mathrm{E}+04$ \\
\hline $\mathrm{Ra}-223$ & 3.60E-05 & $5.79 \mathrm{E}-01$ & $2.92 \mathrm{E}+04$ \\
\hline$U-236$ & $3.30 \mathrm{E}-11^{\mathrm{b}}$ & $3.30 \mathrm{E}-11$ & $1.00 \mathrm{E}+04$ \\
\hline $\mathrm{Np}-237$ & $4.75 \mathrm{E}-01$ & na & $9.96 \mathrm{E}+03$ \\
\hline U-238 & $1.72 \mathrm{E}-13^{\mathrm{b}}$ & na & $1.00 \mathrm{E}+04$ \\
\hline Th-234 & $1.90 \mathrm{E}-15^{\mathrm{b}}$ & na & $1.00 \mathrm{E}+04$ \\
\hline U-234 & $1.04 \mathrm{E}-06^{\mathrm{b}}$ & na & $1.00 \mathrm{E}+04$ \\
\hline $\mathrm{Pu}-238$ & $1.05 \mathrm{E}-13^{\mathrm{b}}$ & na & $7.24 \mathrm{E}+03$ \\
\hline U-234 & $3.15 \mathrm{E}-09^{\mathrm{b}}$ & na & $1.00 \mathrm{E}+04$ \\
\hline $\mathrm{Pu}-239$ & $4.41 \mathrm{E}-11^{b}$ & na & $1.00 \mathrm{E}+04$ \\
\hline U-235 & $1.10 \mathrm{E}-12^{\mathrm{b}}$ & na & $1.00 \mathrm{E}+04$ \\
\hline $\mathrm{Pu}-240$ & $1.39 \mathrm{E}-10^{\mathrm{b}}$ & na & $1.00 \mathrm{E}+04$ \\
\hline U-236 & $3.30 \mathrm{E}-11^{\mathrm{b}}$ & na & $1.00 \mathrm{E}+04$ \\
\hline
\end{tabular}




\begin{tabular}{|c|c|c|c|}
\hline Table 5.1-6 & $\begin{array}{l}\text { Peak Groundwater Co } \\
\text { Cement-Stabilized Waste } \\
\text { in } 10 \text { Trenches }\end{array}$ & $\begin{array}{l}\text { entrations for the I } \\
\text { mulations - per } \mathrm{Ci} \text { of } \mathrm{E} \text { ? }\end{array}$ & $\begin{array}{l}\text { mately-Mixed } \\
\text { Radionuclide }\end{array}$ \\
\hline Radionuclide & $\begin{array}{c}\text { Peak up to } 10,000 \text { years }{ }^{a} \\
\text { pCi/L }\end{array}$ & $\begin{array}{c}\text { Peak after } 10,000 \text { years } \\
\text { pCi/L-Ci }\end{array}$ & $\begin{array}{c}\text { Time of peak } \\
y r\end{array}$ \\
\hline Am-241 & $--^{c}$ & & \\
\hline $\mathrm{Np}-237$ & $9.59 \mathrm{E}-05$ & na & $9.96 \mathrm{E}+03$ \\
\hline $\mathrm{Pu}-241$ & $\ldots{ }^{c}$ & & \\
\hline Am-241 & $\ldots$ c $^{\mathbf{c}}$ & & \\
\hline $\mathrm{Np}-237$ & $3.20 \mathrm{E}-06$ & na & $9.96 E+03$ \\
\hline $\mathrm{Pu}-242$ & $2.99 \mathrm{E}-12^{\mathrm{b}}$ & na & $1.00 \mathrm{E}+04$ \\
\hline $\mathrm{U}-238$ & $1.72 \mathrm{E}-13^{\mathrm{b}}$ & na & $1.00 \mathrm{E}+04$ \\
\hline Am-243 & $1.64 \mathrm{E}-06^{\mathrm{b}}$ & $4.69 \mathrm{E}-02$ & $4.36 \mathrm{E}+04$ \\
\hline Np-239 & $1.72 \mathrm{E}-13^{\mathrm{b}}$ & $1.70 \mathrm{E}+01$ & $4.36 \mathrm{E}+04$ \\
\hline Pu-239 & $1.04 \mathrm{E}-06^{\mathrm{b}}$ & 4.07E-01 & $1.82 \mathrm{E}+04$ \\
\hline $\mathrm{Pu}-244$ & $1.40 \mathrm{E}-14^{\mathrm{b}}$ & na & $1.00 \mathrm{E}+04$ \\
\hline $\mathrm{Cm}-244$ & $-c^{c}$ & & \\
\hline $\mathrm{Pu}-240$ & $3.85 \mathrm{E}-13^{b}$ & na & $1.00 \mathrm{E}+04$ \\
\hline U-236 & $9.14 \mathrm{E}-14^{\mathrm{b}}$ & na & $1.00 \mathrm{E}+04$ \\
\hline $\mathrm{Cm}-245$ & $2.65 \mathrm{E}-11^{\mathrm{b}}$ & $3.21 E-03$ & $7.22 \mathrm{E}+04$ \\
\hline Pu-241 & $1.42 \mathrm{E}-08^{\mathrm{b}}$ & $1.37 E-01$ & $7.14 \mathrm{E}+04$ \\
\hline Am-241 & $3.05 \mathrm{E}-09^{\mathrm{b}}$ & $8.08 \mathrm{E}-03$ & $7.04 \mathrm{E}+04$ \\
\hline Np-237 & $1.37 \mathrm{E}-02^{\mathrm{b}}$ & $1.73 E-02$ & $2.96 E+04$ \\
\hline $\mathrm{Cm}-246$ & $1.37 \mathrm{E}-11^{\mathrm{b}}$ & $6.46 \mathrm{E}-05$ & $5.82 E+04$ \\
\hline $\mathrm{Cm}-247$ & $6.01 \mathrm{E}-11^{\mathrm{b}}$ & $3.29 \mathrm{E}+00$ & $1.14 \mathrm{E}+05$ \\
\hline Am-243 & $3.88 \mathrm{E}-07^{\mathrm{b}}$ & $6.84 E+00$ & $1.14 \mathrm{E}+05$ \\
\hline $\mathrm{Np}-239$ & $1.41 \mathrm{E}-04^{\mathrm{b}}$ & $2.48 \mathrm{E}+03$ & $1.14 \mathrm{E}+05$ \\
\hline Pu-239 & $4.38 \mathrm{E}-0 \mathrm{1}^{\mathrm{b}}$ & $6.24 E+00$ & $8.26 E+04$ \\
\hline $\mathrm{Cm}-248$ & $5.89 \mathrm{E}-11^{\mathrm{b}}$ & $2.66 \mathrm{E}+00$ & $1.14 \mathrm{E}+05$ \\
\hline $\mathrm{Pu}-244$ & $2.51 \mathrm{E}-04^{\mathrm{b}}$ & $1.84 \mathrm{E}-03$ & $8.24 E+04$ \\
\hline Cf- 249 & $3.65 \mathrm{E}-09^{b}$ & $3.12 \mathrm{E}-07$ & $1.05 E+04$ \\
\hline $\mathrm{Cm}-245$ & $2.75 \mathrm{E}-08^{\mathrm{b}}$ & $1.38 \mathrm{E}-04$ & $7.20 E+04$ \\
\hline Pu-241 & $1.42 \mathrm{E}-06^{\mathrm{b}}$ & $5.91 \mathrm{E}-03$ & $7.12 \mathrm{E}+04$ \\
\hline Am-241 & $9.84 \mathrm{E}-08^{\mathrm{b}}$ & $3.48 \mathrm{E}-04$ & $7.04 \mathrm{E}+04$ \\
\hline $\mathrm{Np}-237$ & $5.61 \mathrm{E}-04^{\mathrm{b}}$ & $7.18 \mathrm{E}-04$ & $2.90 \mathrm{E}+04$ \\
\hline Cf- 252 & $\ldots c^{c}$ & & \\
\hline Cm-248 & $4.59 \mathrm{E}-16^{\mathrm{b}}$ & $2.07 \mathrm{E}-05$ & $1.14 E+05$ \\
\hline $\mathrm{Pu}-244$ & $1.95 \mathrm{E}-09^{\mathrm{b}}$ & $1.43 \mathrm{E}-08$ & $8.24 E+04$ \\
\hline
\end{tabular}

a Estimated with PORFLOW, unless otherwise noted.

bstimated with the analytical model in Appendix C.2; values tend to be overestimates due to conservative nature of model; "na" indicates peak occurred before 10,000 years.

${ }^{c}$ Radionuclide was screened; only radioactive daughters are of potential significance.

d Peak estimated with analytical method occurred before 10,000 years due to conservative nature of model, resulting in underestimates of travel time to compliance point. 
Table 5.1-7 Peak Groundwater Concentrations for the Cement-Stabilized Encapsulated Waste Simulations - per Ci of Each Radionuclide in 10 trenches

\begin{tabular}{|c|c|c|c|}
\hline Radionuclide & $\begin{array}{c}\text { Peak up to } 10,000 \text { years } \\
\text { pCi } / \mathrm{L}\end{array}$ & $\begin{array}{c}\text { Peak after } 10,000 \text { years }^{b} \\
\text { pCi/L-Ci }\end{array}$ & $\begin{array}{c}\text { Time of peak } \\
y r\end{array}$ \\
\hline $\mathrm{H}-3$ & $6.50 \mathrm{E}-07$ & na & $3.23 \mathrm{E}+02$ \\
\hline $\mathrm{Ni}-59$ & $5.97 \mathrm{E}-02$ & $1.32 \mathrm{E}+02$ & $1.33 E+04$ \\
\hline $\mathrm{Se}-79$ & $4.27 \mathrm{E}+00$ & na & $9.67 \mathrm{E}+03$ \\
\hline Sr-90 & $7.83 \mathrm{E}-06$ & na & $5.61 E+02$ \\
\hline Zr-93 & $6.60 \mathrm{E}+01^{b}$ & $8.68 \mathrm{E}+01$ & $1.08 E+04$ \\
\hline Tc-99 & $1.33 E+03$ & na & $3.40 \mathrm{E}+02$ \\
\hline Pd-107 & $1.09 \mathrm{E}+03^{\mathrm{b}}$ & na & $2.05 E+03$ \\
\hline Sn- 126 & $4.78 \mathrm{E}+00$ & na & $8.52 E+03$ \\
\hline I-129 & $1.15 \mathrm{E}+03$ & na & $3.50 E+02$ \\
\hline Cs- 135 & $1.98 \mathrm{E}+01^{b}$ & $1.46 \mathrm{E}+02$ & $1.16 \mathrm{E}+04$ \\
\hline $\mathrm{U}-232$ & $1.21 \mathrm{E}-08^{\mathrm{b}}$ & na & $8.90 E+03$ \\
\hline Th-228 & $1.33 \mathrm{E}-10^{\mathrm{b}}$ & na & $8.92 E+03$ \\
\hline $\mathrm{Ra}-224$ & $8.51 \mathrm{E}-10^{\mathrm{b}}$ & na & $8.93 \mathrm{E}+03$ \\
\hline $\mathrm{U}-233$ & $1.99 \mathrm{E}-08^{b}$ & $2.02 \mathrm{E}-08$ & $1.01 \mathrm{E}+05$ \\
\hline Th-229 & $2.73 \mathrm{E}-08^{\mathrm{b}}$ & $4.45 \mathrm{E}-01$ & $6.74 \mathrm{E}+04$ \\
\hline $\mathrm{Ra}-225$ & $1.75 \mathrm{E}-07^{\mathrm{b}}$ & $2.84 \mathrm{E}+00$ & $6.82 E+04$ \\
\hline $\mathrm{U}-234$ & $8.02 \mathrm{E}-10$ & $1.32 \mathrm{E}-08$ & $1.04 \mathrm{E}+05$ \\
\hline Th-230 & $3.52 \mathrm{E}-13$ & $3.23 \mathrm{E}+00$ & $9.16 \mathrm{E}+04$ \\
\hline $\mathrm{Ra}-226$ & $2.30 \mathrm{E}-06$ & $2.27 \mathrm{E}+01$ & $8.20 \mathrm{E}+04$ \\
\hline $\mathrm{Pb}-210$ & $4.49 \mathrm{E}-06$ & $4.21 E+01$ & $8.22 \mathrm{E}+04$ \\
\hline Po-210 & 8.08E-06 & $7.57 \mathrm{E}+01$ & $8.14 E+04$ \\
\hline U-235 & $2.80 \mathrm{E}-13$ & $4.61 \mathrm{E}-12$ & $8.28 \mathrm{E}+04$ \\
\hline $\mathrm{Pa}-231$ & $6.05 \mathrm{E}-05$ & $1.13 E+01$ & $1.06 \mathrm{E}+05$ \\
\hline Ac- 227 & $7.47 \mathrm{E}-05$ & $1.39 E+01$ & $1.06 \mathrm{E}+05$ \\
\hline Th-227 & $1.05 \mathrm{E}-05$ & $1.96 \bar{E}+00$ & $9.84 E+04$ \\
\hline $\mathrm{Ra}-223$ & $6.73 \mathrm{E}-05$ & $1.25 \mathrm{E}+01$ & $1.05 E+05$ \\
\hline $\mathrm{U}-236$ & $1.37 \mathrm{E}-10$ & $1.37 \mathrm{E}-10$ & $1.71 E+04$ \\
\hline $\mathrm{U}-238$ & $7.16 \mathrm{E}-13^{\mathrm{b}}$ & $7.23 \mathrm{E}-13$ & $6.42 E+04$ \\
\hline Th-234 & $7.88 \mathrm{E}-15^{b}$ & $7.97 \mathrm{E}-15$ & $1.04 \mathrm{E}+05$ \\
\hline U-234 & $2.04 \mathrm{E}-08^{\mathrm{b}}$ & na & $7.99 \mathrm{E}+03$ \\
\hline Pu-238 & $0.00 \mathrm{E}+00^{\mathrm{b}}$ & $3.25 \mathrm{E}-13$ & $1.05 \mathrm{E}+04$ \\
\hline U-234 & $1.30 \mathrm{E}-08^{\mathrm{b}}$ & $1.30 \mathrm{E}-08$ & $1.71 E+04$ \\
\hline Pu-239 & $1.83 \mathrm{E}-10^{\mathrm{b}}$ & $1.83 E-10$ & $1.68 \mathrm{E}+04$ \\
\hline U-235 & $5.24 \mathrm{E}-12^{\mathrm{b}}$ & na & $7.99 E+03$ \\
\hline $\mathrm{Pu}-240$ & $5.57 \mathrm{E}-10^{\mathrm{b}}$ & $5.57 \mathrm{E}-10$ & $1.70 E+04$ \\
\hline $\mathrm{U}-236$ & $1.56 \mathrm{E}-10^{\mathrm{b}}$ & na & $9.59 E+03$ \\
\hline$A m-241$ & $-{ }_{-}{ }^{c}$ & & \\
\hline Np-237 & $3.21 \mathrm{E}-03^{\mathrm{b}}$ & na & $1.86 \mathrm{E}+03$ \\
\hline $\mathrm{Pu}-241$ & $-{ }_{--{ }^{-}}$ & & \\
\hline Am-241 & $---{ }^{c}$ & & \\
\hline Np-237 & $1.74 \mathrm{E}-04^{\mathrm{b}}$ & na & $1.86 \mathrm{E}+03$ \\
\hline $\mathrm{Pu}-242$ & $1.25 \mathrm{E}-11$ & $1.25 \mathrm{E}-11$ & $1.64 E+04$ \\
\hline $\mathrm{U}-238$ & $8.30 \mathrm{E}-13$ & na & $7.99 E+03$ \\
\hline
\end{tabular}


Table 5.1-8 Calculated Inventory Limits for the LAW Vaults

\begin{tabular}{|c|c|c|c|}
\hline Radionuclide $^{\mathrm{a}}$ & $\begin{array}{c}\text { Concentration limit } \\
\mathrm{pCi} / \mathrm{L}\end{array}$ & $\begin{array}{l}\text { Peak groundwater } \\
\text { concentration up to } \\
10,000 \text { years }{ }^{\mathrm{c}} \\
\mathrm{pCi} / \mathrm{L}-\mathrm{Ci}\end{array}$ & $\begin{array}{c}\text { Calculated inventory } \\
\text { limit }^{d} \\
\mathrm{Ci} / \text { vault }\end{array}$ \\
\hline $\mathrm{H}-3$ & $2.00 \mathrm{E}+04$ & $9.5 \mathrm{E}-08$ & $1.1 \mathrm{E}+11$ \\
\hline C-14 & $6.40 \mathrm{E}+03$ & $9.2 \mathrm{E}+00$ & $3.5 \mathrm{E}+02$ \\
\hline $\mathrm{Ni}-59$ & $5.30 \mathrm{E}+02$ & $2.5 \mathrm{E}-03$ & $1.1 \mathrm{E}+05$ \\
\hline Se-79 & $6.60 \mathrm{E}+02$ & $2.5 \mathrm{E}+00$ & $1.3 \mathrm{E}+02$ \\
\hline $\mathrm{Rb}-87$ & $2.70 \mathrm{E}+02$ & $8.1 E+02$ & $1.7 \mathrm{E}-01$ \\
\hline Sr-90+d & $8.00 \mathrm{E}+00$ & $8.6 \mathrm{E}-19$ & $4.6 \mathrm{E}+18$ \\
\hline $\mathrm{Zr}-93+\mathrm{d}$ & $2.10 \mathrm{E}+03$ & $2.5 \mathrm{E}+00$ & $4.1 E+02$ \\
\hline $\mathrm{Nb}-94$ & $1.30 \mathrm{E}+02$ & $2.3 \mathrm{E}+02$ & $2.9 \mathrm{E}-01$ \\
\hline Tc-99 & $8.00 \mathrm{E}+02$ & $7.5 \mathrm{E}+01$ & $5.3 \mathrm{E}+00$ \\
\hline Pd-107 & $3.66 \mathrm{E}+04$ & $8.2 E+02$ & $2.2 \mathrm{E}+01$ \\
\hline $\mathrm{Sn}-126+d$ & $2.90 \mathrm{E}+02$ & $4.8 \mathrm{E}+00$ & $3.0 \mathrm{E}+01$ \\
\hline $\mathrm{I}-129$ & $5.00 \mathrm{E}-01$ & $4.1 E+02$ & $6.1 \mathrm{E}-04$ \\
\hline Cs- 135 & $8.00 \mathrm{E}+02$ & $1.3 \mathrm{E}+02$ & $3.1 E+00$ \\
\hline Th-232 & $1.30 \mathrm{E}+01$ & $9.2 \mathrm{E}-10$ & $7.0 \mathrm{E}+09$ \\
\hline $\mathrm{Ra}-228$ & $5.00 \mathrm{E}+00$ & $6.6 \mathrm{E}-09$ & $3.8 \mathrm{E}+08$ \\
\hline Th-228 & $1.50 \mathrm{E}+01$ & $1.0 \mathrm{E}-09$ & $7.3 \mathrm{E}+09$ \\
\hline $\mathrm{Ra}-224$ & $1.50 \mathrm{E}+01$ & $6.6 \mathrm{E}-09$ & $1.1 \mathrm{E}+09$ \\
\hline $\mathrm{U}-232$ & $2.60 \mathrm{E}+01$ & $0.0 \mathrm{E}+00$ & no limit ${ }^{e}$ \\
\hline Th-228 & $1.50 \mathrm{E}+01$ & $0.0 \mathrm{E}+00$ & \\
\hline $\mathrm{Ra}-224$ & $1.50 \mathrm{E}+01$ & $0.0 \mathrm{E}+00$ & \\
\hline$U-233$ & $1.25 \mathrm{E}+02$ & $3.6 \mathrm{E}-08$ & $1.4 \mathrm{E}+09$ \\
\hline Th-229 & $9.60 \mathrm{E}+00$ & $5.0 \mathrm{E}-10$ & \\
\hline $\mathrm{Ra}-225$ & $9.00 \mathrm{E}+00$ & $3.2 E-09$ & \\
\hline$U-234$ & $1.32 E+02$ & $1.9 \mathrm{E}-09$ & $3.3 E+04$ \\
\hline Th-230 & $1.50 \mathrm{E}+01$ & $6.8 \mathrm{E}-13$ & \\
\hline $\mathrm{Ra}-226$ & $5.00 \mathrm{E}+00$ & $2.3 \mathrm{E}-06$ & \\
\hline $\mathrm{Pb}-210$ & $3.00 \mathrm{E}-01$ & $4.5 \mathrm{E}-06$ & \\
\hline Po-210 & $1.50 \mathrm{E}+01$ & $8.2 \mathrm{E}-06$ & \\
\hline U-235 & $1.39 E+02$ & $6.9 \mathrm{E}-13$ & $3.0 \mathrm{E}+05$ \\
\hline $\mathrm{Pa}-231$ & $3.10 \mathrm{E}+00$ & $5.2 \mathrm{E}-06$ & \\
\hline Ac- 227 & $2.50 \mathrm{E}+00$ & $6.5 \mathrm{E}-06$ & \\
\hline Th -227 & $1.50 \mathrm{E}+01$ & $9.1 \mathrm{E}-07$ & \\
\hline $\mathrm{Ra}-223$ & $1.50 \mathrm{E}+01$ & $5.8 \mathrm{E}-06$ & \\
\hline U-236 & $1.39 E+02$ & $2.4 E-10$ & $2.8 \mathrm{E}+11$ \\
\hline $\mathrm{Np}-237$ & $8.90 \mathrm{E}+00$ & $1.1 \mathrm{E}+00$ & $4.2 \mathrm{E}+00$ \\
\hline U-238 & $6.66 \mathrm{E}+00$ & $1.3 \mathrm{E}-12$ & $1.9 E+09$ \\
\hline Th-234 & $5.90 \mathrm{E}+01$ & $1.4 \mathrm{E}-14$ & \\
\hline U-234 & $1.32 \mathrm{E}+02$ & $3.5 \mathrm{E}-08$ & \\
\hline $\mathrm{Pu}-238$ & $8.90 \mathrm{E}+00$ & $0.0 \mathrm{E}+00$ & $2.8 E+09$ \\
\hline U-234 & $1.32 \mathrm{E}+02$ & $2.3 \mathrm{E}-08$ & \\
\hline Pu-239 & $8.10 \mathrm{E}+00$ & $3.1 \mathrm{E}-10$ & $1.3 \mathrm{E}+10$ \\
\hline $\mathrm{U}-235$ & $1.39 \mathrm{E}+02$ & $8.1 \mathrm{E}-12$ & \\
\hline $\mathrm{Pu}-240$ & $8.10 \mathrm{E}+00$ & $9.2 \mathrm{E}-10$ & $4.4 \mathrm{E}+09$ \\
\hline \multirow[t]{2}{*}{$\mathrm{U}-236$} & $1.39 E+02$ & $2.4 \mathrm{E}-10$ & \\
\hline & & Rev. 1 & January 31,2000 \\
\hline
\end{tabular}


Table 5.1-8 Calculated Inventory Limits for the LAW Vaults

\begin{tabular}{|c|c|c|c|}
\hline Radionuclide $^{\text {a }}$ & $\begin{array}{c}\text { Concentration limit }{ }^{\mathrm{b}} \\
\mathrm{pCi} / \mathrm{L}\end{array}$ & $\begin{array}{l}\text { Peak groundwater } \\
\text { concentration up to } \\
10,000 \text { years }{ }^{c} \\
\mathrm{pCi} / \mathrm{L}-\mathrm{Ci}\end{array}$ & $\begin{array}{c}\text { Calculated inventory } \\
\text { limit }^{d} \\
\mathrm{Ci} / \text { vault }\end{array}$ \\
\hline Am-241 & $7.60 \mathrm{E}+00$ & screened $^{f}$ & $2.1 \mathrm{E}+04$ \\
\hline Np-237 & $8.90 \mathrm{E}+00$ & $2.1 \mathrm{E}-04$ & \\
\hline $\mathrm{Pu}-24 \mathrm{l}$ & $5.30 \mathrm{E}+02$ & screened $^{f}$ & $6.3 \mathrm{E}+05$ \\
\hline Am-241 & $7.60 \mathrm{E}+00$ & screened $^{f}$ & \\
\hline Np-237 & $8.90 \mathrm{E}+00$ & 7.1E-06 & \\
\hline Pu-242 & $8.30 \mathrm{E}+00$ & $2.2 \mathrm{E}-11$ & $1.9 \mathrm{E}+11$ \\
\hline U-238 & $1.39 \mathrm{E}+02$ & $1.3 \mathrm{E}-12$ & \\
\hline $\mathrm{Am}-243$ & $7.60 \mathrm{E}+00$ & 4.3E-07 & $2.4 \mathrm{E}+00$ \\
\hline $\mathrm{Np}-239$ & $3.00 \mathrm{E}+02$ & $1.6 \mathrm{E}-04$ & \\
\hline $\mathrm{Pu}-239$ & $8.10 \mathrm{E}+00$ & $1.7 \mathrm{E}+00$ & \\
\hline $\mathrm{Pu}-244$ & $8.60 \mathrm{E}+00$ & $1.0 \mathrm{E}-13$ & $4.1 E+13$ \\
\hline $\mathrm{Cm}-244$ & $1.50 \mathrm{E}+01$ & screened ${ }^{\mathrm{f}}$ & $1.6 \mathrm{E}+12$ \\
\hline $\mathrm{Pu}-240$ & $8.10 \mathrm{E}+00$ & $2.6 \mathrm{E}-12$ & \\
\hline U-236 & $1.39 E+02$ & $6.8 \mathrm{E}-13$ & \\
\hline $\mathrm{Cm}-245$ & $7.60 \mathrm{E}+00$ & $7.6 \mathrm{E}-12$ & $3.6 \mathrm{E}+01$ \\
\hline $\mathrm{Pu}-241$ & $5.30 \mathrm{E}+02$ & $3.9 \mathrm{E}-08$ & \\
\hline Am-241 & $7.60 \mathrm{E}+00$ & $9.9 \mathrm{E}-09$ & \\
\hline $\mathrm{Np}-237$ & $8.90 \mathrm{E}+00$ & $1.2 \mathrm{E}-01$ & \\
\hline $\mathrm{Cm}-246$ & $7.60 \mathrm{E}+00$ & $3.9 \mathrm{E}-12$ & $9.7 \mathrm{E}+11$ \\
\hline $\mathrm{Cm}-247$ & $8.30 \mathrm{E}+00$ & $1.7 \mathrm{E}-11$ & $1.7 \mathrm{E}+00$ \\
\hline Am-243 & $7.60 \mathrm{E}+00$ & $2.7 E-07$ & \\
\hline$N p-239$ & $3.00 \mathrm{E}+02$ & $9.8 \mathrm{E}-05$ & \\
\hline $\mathrm{Pu}-239$ & $8.10 E+00$ & $2.4 \mathrm{E}+00$ & \\
\hline $\mathrm{Cm}-248$ & $2.10 \mathrm{E}+00$ & $1.7 \mathrm{E}-11$ & $3.9 \mathrm{E}+03$ \\
\hline $\mathrm{Pu}-244$ & $8.60 E+00$ & $1.1 \mathrm{E}-03$ & \\
\hline Cf-249 & $7.40 \mathrm{E}+00$ & $3.3 \mathrm{E}-09$ & $8.5 E+02$ \\
\hline $\mathrm{Cm}-245$ & $7.60 \mathrm{E}+00$ & $4.0 \mathrm{E}-10$ & \\
\hline $\mathrm{Pu}-241$ & $5.30 \mathrm{E}+02$ & $2.3 \mathrm{E}-08$ & \\
\hline Am-241 & $7.60 \mathrm{E}+00$ & $1.7 \mathrm{E}-09$ & \\
\hline Np-237 & $8.90 \mathrm{E}+00$ & $5.2 \mathrm{E}-03$ & \\
\hline $\mathrm{Cf}-252$ & $1.50 \mathrm{E}+01$ & screened ${ }^{f}$ & $5.0 \mathrm{E}+08$ \\
\hline $\mathrm{Cm}-248$ & $2.10 \mathrm{E}+00$ & $1.3 \mathrm{E}-16$ & $5.0 \mathrm{E}+08$ \\
\hline $\mathrm{Pu}-244$ & $8.60 \mathrm{E}+00$ & 8.6E-09 & $5.0 \mathrm{E}+08$ \\
\hline \multicolumn{4}{|c|}{$\begin{array}{l}\text { "+d" indicates short- and/or long-lived radioactive daughters are considered in the analysis. } \\
\text { The more restrictive of either the MCL or the allowable concentration based on a } 25 \mathrm{mrem} / \mathrm{yr} \text { performance } \\
\text { objective (Table } 4.3-1 \text { ) } \\
\text { Peak concentration is per Ci disposed of in two LAW vaults. } \\
\text { Calculated by dividing the "Concentration limit" by the "Peak groundwater concentration", and dividing by } 2 \\
\text { to normalize to one vault. For radionuclides with daughters, the lower limit calculated by this method for all } \\
\text { radionuclides in the decay chain is the one reported as the inventory limit. } \\
\text { "No limit" refers to the fact that no significant groundwater concentration was calculated during the 10,000- } \\
\text { year time period; thus, no limit can be calculated. } \\
\text { Inventory limit is based on radioactive daughter(s) only; parent was screened from consideration (Section 4.1). }\end{array}$} \\
\hline
\end{tabular}


Table 5.1-9 Calculated Inventory Limits for the IL Vaults

\begin{tabular}{|c|c|c|c|}
\hline Radionuclide & $\begin{array}{c}\text { Concentration limit }^{b} \\
\mathrm{pC} / \mathrm{L}\end{array}$ & $\begin{array}{l}\text { Peak groundwater } \\
\text { concentration up to } \\
10,000 \text { years c } \\
\text { pCi/L-Ci }\end{array}$ & $\begin{array}{c}\text { Calculated inventory } \\
\text { limit }^{d} \\
\mathrm{Ci} / \text { vault }\end{array}$ \\
\hline $\mathrm{H}-3$ & $2.00 \mathrm{E}+04$ & $1.07 \mathrm{E}-11$ & $9.35 \mathrm{E}+14$ \\
\hline C-14 & $6.40 \mathrm{E}+03$ & $4.11 \mathrm{E}-02$ & $7.79 \mathrm{E}+04$ \\
\hline $\mathrm{Ni}-59$ & $5.30 \mathrm{E}+02$ & $5.04 \mathrm{E}-01$ & $5.26 \mathrm{E}+02$ \\
\hline $\mathrm{Se}-79$ & $6.60 E+02$ & $1.19 \mathrm{E}+01$ & $2.77 \mathrm{E}+01$ \\
\hline Rb-87 & $2.70 \mathrm{E}+02$ & na & \\
\hline Sr-90+d & $8.00 \mathrm{E}+00$ & $2.17 \mathrm{E}-10$ & $1.84 \mathrm{E}+10$ \\
\hline Mo-93 & $8.20 \mathrm{E}+02$ & na & \\
\hline $\mathrm{Zr}-93+\mathrm{d}$ & $2.10 \mathrm{E}+03$ & $1.02 \mathrm{E}-03$ & $1.03 E+06$ \\
\hline Tc-99 & $8.00 \mathrm{E}+02$ & $1.82 \mathrm{E}+01$ & $2.20 \mathrm{E}+01$ \\
\hline$S n-126+d$ & $2.90 \mathrm{E}+02$ & $1.29 \mathrm{E}+00$ & $1.12 \mathrm{E}+02$ \\
\hline $\mathrm{I}-129$ & $5.00 \mathrm{E}-01$ & $9.66 \mathrm{E}+02$ & $2.59 \mathrm{E}-04$ \\
\hline Cs-135 & $8.00 E+02$ & $3.63 E+00$ & $1.10 \mathrm{E}+02$ \\
\hline Th-232 & $1.30 \mathrm{E}+01$ & $7.76 \mathrm{E}-15$ & $4.50 \mathrm{E}+13$ \\
\hline $\mathrm{Ra}-228$ & $5.00 \mathrm{E}+00$ & $5.56 \mathrm{E}-14$ & \\
\hline Th-228 & $1.50 \mathrm{E}+01$ & $8.67 \mathrm{E}-15$ & . \\
\hline $\mathrm{Ra}-224$ & $1.50 \mathrm{E}+01$ & $5.55 \mathrm{E}-14$ & ${ }^{*}$ \\
\hline $\mathrm{U}-232$ & $2.60 \mathrm{E}+01$ & $3.89 \mathrm{E}-12$ & \\
\hline Th-228 & $1.50 \mathrm{E}+01$ & $4.29 \mathrm{E}-14$ & \\
\hline Ra-224 & $1.50 \mathrm{E}+01$ & $2.75 \mathrm{E}-13$ & \\
\hline U-233 & $1.25 E+02$ & $4.48 \mathrm{E}-09$ & $4.74 \mathrm{E}+10$ \\
\hline Th-229 & $9.60 \mathrm{E}+00$ & $1.49 \mathrm{E}-11$ & \\
\hline Ra-225 & $9.00 \mathrm{E}+00$ & $9.50 \mathrm{E}-11$ & \\
\hline U-234 & $1.32 E+02$ & $5.69 \mathrm{E}-10$ & $2.49 \mathrm{E}+03$ \\
\hline Th-230 & $1.50 \mathrm{E}+01$ & $1.93 \mathrm{E}-13$ & \\
\hline Ra-226 & $5.00 \mathrm{E}+00$ & $3.08 \mathrm{E}-05$ & \\
\hline $\mathrm{Pb}-210$ & $3.00 \mathrm{E}-01$ & $6.02 \mathrm{E}-05$ & \\
\hline Po-210 & $1.50 \mathrm{E}+01$ & $1.08 \mathrm{E}-04$ & \\
\hline $\mathrm{U}-235$ & $1.39 E+02$ & $2.01 \mathrm{E}-13$ & $1.88 \mathrm{E}+07$ \\
\hline $\mathrm{Pa}-231$ & $3.10 \mathrm{E}+00$ & $8.25 \mathrm{E}-08$ & \\
\hline Ac- 227 & $2.50 \mathrm{E}+00$ & $1.02 \mathrm{E}-07$ & \\
\hline Th-227 & $1.50 \mathrm{E}+01$ & $1.43 \mathrm{E}-08$ & \\
\hline Ra-223 & $1.50 \mathrm{E}+01$ & $9.18 E-08$ & \\
\hline U-236 & $1.39 E+02$ & $3.12 \mathrm{E}-11$ & $2.23 E+12$ \\
\hline Np-237 & $8.90 \mathrm{E}+00$ & $1.34 \mathrm{E}-01$ & $3.32 \mathrm{E}+01$ \\
\hline U-238 & $6.66 \mathrm{E}+00$ & $1.63 \mathrm{E}-13$ & $2.01 E+10$ \\
\hline Th-234 & $5.90 E+01$ & $1.80 \mathrm{E}-15$ & \\
\hline U-234 & $1.32 E+02$ & $3.29 \mathrm{E}-09$ & \\
\hline $\mathrm{Pu}-238$ & $8.90 \mathrm{E}+00$ & $2.35 \mathrm{E}-18$ & $2.24 E+10$ \\
\hline U-234 & $1.32 \mathrm{E}+02$ & $2.95 \mathrm{E}-09$ & \\
\hline Pu-239 & $8.10 \mathrm{E}+00$ & $9.41 \mathrm{E}-12$ & $4.30 \mathrm{E}+11$ \\
\hline U-235 & $1.39 E+02$ & $1.04 \mathrm{E}-12$ & \\
\hline $\mathrm{Pu}-240$ & $8.10 \mathrm{E}+00$ & $2.08 \mathrm{E}-11$ & $1.95 \mathrm{E}+11$ \\
\hline U-236 & $1.39 \mathrm{E}+02$ & $3.13 \mathrm{E}-11$ & \\
\hline
\end{tabular}


Table 5.1-9 Calculated Inventory Limits for the IL Vaults

\begin{tabular}{|c|c|c|c|}
\hline Radionuclide & $\begin{array}{c}\text { Concentration limit } \\
\mathrm{pCi} / \mathrm{L}\end{array}$ & $\begin{array}{l}\text { Peak groundwater } \\
\text { concentration up to } \\
10,000 \text { years } \\
\text { pCi/L-Ci }\end{array}$ & $\begin{array}{c}\text { Calculated inventory } \\
\text { limit }^{\mathrm{d}} \\
\mathrm{Ci} / \text { vault }^{2}\end{array}$ \\
\hline $\mathrm{Am}-241$ & $7.60 \mathrm{E}+00$ & screened $^{e}$ & $1.65 \mathrm{E}+05$ \\
\hline Np-237 & $8.90 \mathrm{E}+00$ & $2.71 \mathrm{E}-05$ & \\
\hline $\mathrm{Pu}-241$ & $5.30 \mathrm{E}+02$ & screened $^{e}$ & $4.94 \mathrm{E}+06$ \\
\hline Am-24l & $7.60 \mathrm{E}+00$ & screened $^{e}$ & \\
\hline $\mathrm{Np}-237$ & $8.90 \mathrm{E}+00$ & $9.02 \mathrm{E}-07$ & \\
\hline $\mathrm{Pu}-242$ & $8.30 E+00$ & $7.19 \mathrm{E}-13$ & $5.77 \mathrm{E}+12$ \\
\hline U-238 & $1.39 \mathrm{E}+02$ & $1.63 \mathrm{E}-13$ & \\
\hline Am-243 & $7.60 \mathrm{E}+00$ & $4.29 \mathrm{E}-11$ & $4.71 \mathrm{E}+04$ \\
\hline Np-239 & $3.00 \mathrm{E}+02$ & $1.29 \mathrm{E}-02$ & \\
\hline $\mathrm{Pu}-239$ & $8.10 \mathrm{E}+00$ & $8.60 \mathrm{E}-05$ & \\
\hline $\mathrm{Pu}-244$ & $8.60 \mathrm{E}+00$ & $3.41 \mathrm{E}-15$ & $1.26 \mathrm{E}+15$ \\
\hline $\mathrm{Cm}-244$ & $1.50 \mathrm{E}+01$ & screened $^{\mathrm{e}}$ & \\
\hline $\mathrm{Pu}-240$ & $8.10 \mathrm{E}+00$ & $5.76 \mathrm{E}-14$ & \\
\hline U-236 & $1.39 E+02$ & $8.67 \mathrm{E}-14$ & \\
\hline $\mathrm{Cm}-245$ & $7.60 \mathrm{E}+00$ & $4.45 \mathrm{E}-17$ & $2.62 \mathrm{E}+03$ \\
\hline $\mathrm{Pu}-241$ & $5.30 \mathrm{E}+02$ & $8.43 \mathrm{E}-13$ & \\
\hline Am-241 & $7.60 \mathrm{E}+00$ & $2.46 \mathrm{E}-13$ & \\
\hline Np-237 & $8.90 \mathrm{E}+00$ & $1.70 \mathrm{E}-03$ & \\
\hline $\mathrm{Cm}-246$ & $7.60 \mathrm{E}+00$ & $2.30 \mathrm{E}-17$ & $1.65 \mathrm{E}+17$ \\
\hline $\mathrm{Cm}-247$ & $8.30 \mathrm{E}+00$ & $1.01 \mathrm{E}-16$ & $2.74 \mathrm{E}+02$ \\
\hline Am-243 & $7.60 \mathrm{E}+00$ & $1.66 \mathrm{E}-11$ & \\
\hline Np-239 & $3.00 \mathrm{E}+02$ & $6.05 \mathrm{E}-09$ & \\
\hline $\mathrm{Pu}-239$ & $8.10 \mathrm{E}+00$ & $1.48 \mathrm{E}-02$ & \\
\hline $\mathrm{Cm}-248$ & $2.10 \mathrm{E}+00$ & $9.90 \mathrm{E}-17$ & $5.15 E+05$ \\
\hline $\mathrm{Pu}-244$ & $8.60 \mathrm{E}+00$ & $8.35 \mathrm{E}-06$ & \\
\hline Cf-249 & $7.40 \mathrm{E}+00$ & $1.06 \mathrm{E}-11$ & $6.52 \mathrm{E}+04$ \\
\hline $\mathrm{Cm}-245$ & $7.60 \mathrm{E}+00$ & $1.70 \mathrm{E}-12$ & \\
\hline Pu-241 & $5.30 \mathrm{E}+02$ & $8.82 \mathrm{E}-11$ & \\
\hline Am-241 & $7.60 \mathrm{E}+00$ & $5.70 \mathrm{E}-12$ & \\
\hline Np-237 & $8.90 \mathrm{E}+00$ & $6.83 \mathrm{E}-05$ & \\
\hline$C f-252$ & $1.50 \mathrm{E}+01$ & screened $^{\mathrm{e}}$ & \\
\hline $\mathrm{Cm}-248$ & $2.10 \mathrm{E}+00$ & $7.39 \mathrm{E}-22$ & $6.89 E+10$ \\
\hline $\mathrm{Pu}-244$ & $8.60 \mathrm{E}+00$ & $6.24 \mathrm{E}-11$ & \\
\hline \multicolumn{4}{|c|}{$\begin{array}{l}\text { "+d" indicates short- and/or long-lived radioactive daughters are considered in the analysis. } \\
\text { The more restrictive of either the MCL or the allowable concentration based on a } 25 \text { mrem/yr performance } \\
\text { objective (Table 4.3-1) } \\
\text { Peak concentration is per Ci disposed of in two IL vaults. } \\
\text { Calculated by dividing the "Concentration limit" by the "Peak groundwater concentration", and dividing by } 2 \text { to } \\
\text { normalize to one vault. For radionuclides with daughters, the lower limit calculated by this method for all } \\
\text { radionuclides in the decay chain is the one reported as the inventory limit. } \\
\text { Inventory limit is based on radioactive daughter(s) only; parent was screened from consideration (Section 4.1). }\end{array}$} \\
\hline
\end{tabular}


Table 5.1-10 Calculated Inventory Limits for the Slit Trenches

\begin{tabular}{|c|c|c|c|}
\hline Radionuclide $^{\text {a }}$ & $\begin{array}{c}\text { Concentration limit } \\
\mathrm{pCi} / \mathrm{L}\end{array}$ & $\begin{array}{l}\text { Peak groundwater } \\
\text { concentration up to } \\
10,000 \text { years } \\
\text { pCi/L }\end{array}$ & $\begin{array}{c}\text { Calculated inventory } \\
\text { limit }^{d} \\
\mathrm{Ci} / 5 \text { trenches }\end{array}$ \\
\hline $\mathrm{H}-3$ & $2.00 \mathrm{E}+04$ & $1.59 \mathrm{E}+03$ & $6.29 \mathrm{E}+00$ \\
\hline C-14 & $6.40 \mathrm{E}+03$ & $2.17 \mathrm{E}+02$ & $1.47 \mathrm{E}+01$ \\
\hline $\mathrm{Ni}-59$ & $5.30 \mathrm{E}+02$ & $9.32 \mathrm{E}-01$ & $2.84 \mathrm{E}+02$ \\
\hline $\mathrm{Se}-79$ & $6.60 \mathrm{E}+02$ & $2.97 \mathrm{E}+00$ & $1.11 \mathrm{E}+02$ \\
\hline Rb-87 & $2.70 \mathrm{E}+02$ & $4.33 E+02$ & $3.12 \mathrm{E}-01$ \\
\hline Sr-90 +d & $8.00 \mathrm{E}+00$ & $7.05 \mathrm{E}-03$ & $5.67 \mathrm{E}+02$ \\
\hline $\mathrm{Zr}-93+\mathrm{d}$ & $2.10 \mathrm{E}+03$ & $3.79 E+01$ & $2.77 \mathrm{E}+01$ \\
\hline Tc-99 & $8.00 \mathrm{E}+02$ & $7.32 E+02$ & $5.46 \mathrm{E}-01$ \\
\hline Pd-107 & $3.66 \mathrm{E}+04$ & $4.52 E+02$ & $4.05 E+01$ \\
\hline Sn-126+d & $2.90 \mathrm{E}+02$ & $3.50 \mathrm{E}+00$ & $4.14 \mathrm{E}+01$ \\
\hline I-129 & $5.00 \mathrm{E}-01$ & $4.77 E+02$ & $5.24 \mathrm{E}-04$ \\
\hline Cs- 135 & $8.00 \mathrm{E}+02$ & $1.41 E+00$ & $2.84 \mathrm{E}+02$ \\
\hline Th-232 & $1.30 \mathrm{E}+01$ & $5.08 \mathrm{E}-07$ & $7.18 \mathrm{E}+05$ \\
\hline $\mathrm{Ra}-228$ & $5.00 \mathrm{E}+00$ & $3.48 \mathrm{E}-06$ & \\
\hline Th-228 & $1.50 \mathrm{E}+01$ & $5.42 \mathrm{E}-07$ & \\
\hline Ra-224 & $1.50 \mathrm{E}+01$ & $3.47 \mathrm{E}-06$ & \\
\hline $\mathrm{U}-232$ & $2.60 \mathrm{E}+01$ & $1.81 \mathrm{E}+00$ & $1.44 \mathrm{E}+01$ \\
\hline Th-228 & $1.50 \mathrm{E}+01$ & $2.00 \mathrm{E}-02$ & \\
\hline $\mathrm{Ra}-224$ & $1.50 \mathrm{E}+01$ & $1.28 \mathrm{E}-01$ & \\
\hline U-233 & $1.25 E+02$ & $7.19 E+02$ & $2.42 \mathrm{E}+00$ \\
\hline Th-229 & $9.60 \mathrm{E}+00$ & $2.92 \mathrm{E}-01$ & \\
\hline Ra-225 & $9.00 \mathrm{E}+00$ & $1.86 \mathrm{E}+00$ & \\
\hline $\mathrm{U}-234$ & $1.32 E+02$ & $1.39 \mathrm{E}+01$ & $3.40 \mathrm{E}+00$ \\
\hline Th-230 & $1.50 \mathrm{E}+01$ & $4.22 \mathrm{E}-03$ & \\
\hline $\mathrm{Ra}-226$ & $5.00 \mathrm{E}+00$ & $2.39 \mathrm{E}-02$ & \\
\hline $\mathrm{Pb}-210$ & $3.00 \mathrm{E}-01$ & $4.41 \mathrm{E}-02$ & \\
\hline Po-210 & $1.50 \mathrm{E}+01$ & $7.94 \mathrm{E}-02$ & \\
\hline $\mathrm{U}-235$ & $1.39 E+02$ & $1.40 E+01$ & $4.96 \mathrm{E}+00$ \\
\hline $\mathrm{Pa}-231$ & $3.10 \mathrm{E}+00$ & $5.11 \mathrm{E}-02$ & \\
\hline Ac- -227 & $2.50 \mathrm{E}+00$ & $6.27 \mathrm{E}-02$ & \\
\hline Th-227 & $1.50 \mathrm{E}+01$ & $8.82 \mathrm{E}-03$ & \\
\hline Ra-223 & $1.50 E+01$ & $5.64 \mathrm{E}-02$ & \\
\hline $\mathrm{U}-236$ & $1.39 E+02$ & $7.21 \mathrm{E}+02$ & $9.64 \mathrm{E}-02$ \\
\hline Np-237 & $8.90 \mathrm{E}+00$ & $9.23 \mathrm{E}+01$ & $4.82 \mathrm{E}-02$ \\
\hline$U-238$ & $6.66 E+00$ & $1.41 E+01$ & $2.36 \mathrm{E}-01$ \\
\hline Th-234 & $5.90 \mathrm{E}+01$ & $1.54 \mathrm{E}-01$ & \\
\hline U-234 & $1.32 \mathrm{E}+02$ & $4.88 \mathrm{E}-02$ & \\
\hline Pu-238 & $8.90 E+00$ & $4.71 \mathrm{E}-03$ & $2.83 E+02$ \\
\hline $\mathrm{U}-234$ & $1.32 E+02$ & $2.33 \mathrm{E}-01$ & \\
\hline Pu-239 & 8.10E+00 & $4.36 \mathrm{E}+00$ & $9.29 \mathrm{E}-01$ \\
\hline U-235 & $1.39 \mathrm{E}+02$ & $2.16 \mathrm{E}-05$ & \\
\hline Pu-240 & $8.10 E+00$ & $3.47 \mathrm{E}+00$ & $1.17 \mathrm{E}+00$ \\
\hline $\mathrm{U}-236$ & $1.39 E+02$ & $6.01 \mathrm{E}-04$ & \\
\hline
\end{tabular}


Table 5.1-10 Calculated Inventory Limits for the Slit Trenches

\begin{tabular}{|c|c|c|c|}
\hline Radionuclide $^{\mathrm{a}}$ & $\begin{array}{c}\text { Concentration limit }{ }^{b} \\
\mathrm{pCi} / \mathrm{L}\end{array}$ & $\begin{array}{l}\text { Peak groundwater } \\
\text { concentration up to } \\
10,000 \text { years }{ }^{c} \\
\text { pCi/L }\end{array}$ & $\begin{array}{c}\text { Calculated inventory } \\
\text { limit }{ }^{d} \\
\text { Ci } / 5 \text { trenches }\end{array}$ \\
\hline Am-24l & $7.60 \mathrm{E}+00$ & screened $^{e}$ & $2.39 \mathrm{E}+02$ \\
\hline Np-237 & $8.90 \mathrm{E}+00$ & $1.86 \mathrm{E}-02$ & \\
\hline $\mathrm{Pu}-241$ & $5.30 \mathrm{E}+02$ & screened $^{e}$ & $7.16 \mathrm{E}+03$ \\
\hline Am-241 & $7.60 \mathrm{E}+00$ & screened $^{e}$ & \\
\hline Np-237 & $8.90 \mathrm{E}+00$ & $6.21 \mathrm{E}-04$ & \\
\hline $\mathrm{Pu}-242$ & $8.30 E+00$ & $2.45 \mathrm{E}+02$ & $1.69 \mathrm{E}-02$ \\
\hline $\mathrm{U}-238$ & $1.39 \mathrm{E}+02$ & $6.65 \mathrm{E}-05$ & \\
\hline $\mathrm{Am}-243$ & $7.60 \mathrm{E}+00$ & $1.47 \mathrm{E}-03$ & $8.96 \mathrm{E}-01$ \\
\hline $\mathrm{Np}-239$ & $3.00 \mathrm{E}+02$ & $5.34 \mathrm{E}-01$ & \\
\hline Pu-239 & $8.10 \mathrm{E}+00$ & $4.52 \mathrm{E}+00$ & \\
\hline $\mathrm{Pu}-244$ & $8.60 \mathrm{E}+00$ & $2.46 \mathrm{E}+02$ & $1.75 \mathrm{E}-02$ \\
\hline $\mathrm{Cm}-242+\mathrm{d}$ & $8.90 \mathrm{E}+00$ & $2.42 \mathrm{E}-05$ & $1.84 \mathrm{E}+05$ \\
\hline $\mathrm{Cm}-244$ & $1.50 \mathrm{E}+01$ & screened ${ }^{e}$ & $4.26 \mathrm{E}+02$ \\
\hline Pu-240 & $8.10 \mathrm{E}+00$ & $9.50 \mathrm{E}-03$ & \\
\hline U-236 & $1.39 \mathrm{E}+02$ & $1.54 \mathrm{E}-06$ & \\
\hline $\mathrm{Cm}-245$ & $7.60 \mathrm{E}+00$ & $4.68 \mathrm{E}-08$ & $4.01 E+01$ \\
\hline Pu-241 & $5.30 \mathrm{E}+02$ & $1.65 \mathrm{E}-05$ & \\
\hline Am-241 & $7.60 \mathrm{E}+00$ & $3.10 \mathrm{E}-06$ & \\
\hline $\mathrm{Np}-237$ & $8.90 \mathrm{E}+00$ & $1.11 \mathrm{E}-01$ & \\
\hline $\mathrm{Cm}-246$ & $7.60 \mathrm{E}+00$ & $2.42 \mathrm{E}-08$ & $1.57 \mathrm{E}+08$ \\
\hline $\mathrm{Cm}-247$ & $8.30 \mathrm{E}+00$ & $1.06 \mathrm{E}-07$ & $7.12 \mathrm{E}-01$ \\
\hline $\mathrm{Am}-243$ & $7.60 \mathrm{E}+00$ & $3.21 \mathrm{E}-04$ & \\
\hline $\mathrm{Np}-239$ & $3.00 \mathrm{E}+02$ & $1.17 \mathrm{E}-01$ & \\
\hline Pu-239 & $8.10 \mathrm{E}+00$ & $5.69 \mathrm{E}+00$ & \\
\hline $\mathrm{Cm}-248$ & $2.10 \mathrm{E}+00$ & $1.04 \mathrm{E}-07$ & $1.25 E+03$ \\
\hline Pu-244 & $8.60 \mathrm{E}+00$ & $3.44 \mathrm{E}-03$ & \\
\hline$B k-249+d$ & $7.40 \mathrm{E}+00^{\mathrm{f}}$ & $3.89 \mathrm{E}-07$ & $9.51 E+06$ \\
\hline Cf-249 & $7.40 \mathrm{E}+00$ & $1.55 \mathrm{E}-04$ & $1.32 E+03$ \\
\hline $\mathrm{Cm}-245$ & $7.60 \mathrm{E}+00$ & $1.38 \mathrm{E}-05$ & \\
\hline $\mathrm{Pu}-241$ & $5.30 \mathrm{E}+02$ & $7.12 \mathrm{E}-04$ & \\
\hline Am-241 & $7.60 \mathrm{E}+00$ & $4.95 \mathrm{E}-05$ & \\
\hline Np-237 & $8.90 \mathrm{E}+00$ & $3.36 \mathrm{E}-03$ & \\
\hline $\mathrm{Cf}-252$ & $1.50 \mathrm{E}+01$ & screened $^{\mathrm{e}}$ & $1.61 \mathrm{E}+08$ \\
\hline $\mathrm{Cm}-248$ & $2.10 \mathrm{E}+00$ & $8.10 \mathrm{E}-13$ & \\
\hline $\mathrm{Pu}-244$ & $8.60 \mathrm{E}+00$ & $2.68 \mathrm{E}-08$ & \\
\hline \multicolumn{4}{|c|}{$\begin{array}{l}\text { " }+\mathrm{d} \text { " indicates short- and/or long-lived radioactive daughters are considered in the analysis. } \\
\text { The more restrictive of either the MCL or the allowable concentration based on a } 25 \mathrm{mrem} / \mathrm{yr} \text { performance } \\
\text { objective (Table } 4.3-1 \text { ) } \\
\text { d Peak concentration is per Ci disposed of in ten slit trenches. } \\
\text { d Calculated by dividing the "Concentration limit" by the "Peak groundwater concentration", and dividing by } 2 \\
\text { to normalize to five trenches. For radionuclides with daughters, the lower limit calculated by this method for } \\
\text { all radionuclides in the decay chain is the one reported as the inventory limit. } \\
\text { " Inventory limit is based on radioactive daughter(s) only; parent was screened from consideration (Section 4.1) } \\
\text { Concentration limit is based on that of radiologically-significant daughter }\end{array}$} \\
\hline
\end{tabular}


Table 5.1-11 Calculated Inventory Limits for the Naval Reactor Pad Waste

\begin{tabular}{|c|c|c|c|}
\hline Radionuclide $^{\mathbf{a}}$ & $\begin{array}{c}\text { Concentration limit }^{b} \\
\mathrm{pCi} / \mathrm{L}\end{array}$ & $\begin{array}{c}\text { Peak groundwater } \\
\text { concentration up to } \\
10,000 \text { years } \\
\text { pCi } / \mathrm{L}\end{array}$ & $\begin{array}{l}\text { Calculated inventory } \\
\text { limit }^{d} \\
\mathrm{Ci} / \text { pad }\end{array}$ \\
\hline $\mathrm{H}-3$ & $2.00 \mathrm{E}+04$ & $1.8 \mathrm{E}-18$ & $1.1 \mathrm{E}+22$ \\
\hline C-14 & $6.40 \mathrm{E}+03$ & $2.3 \mathrm{E}+00$ & $2.8 \mathrm{E}+03$ \\
\hline $\mathrm{Ni}-59$ & $5.30 \mathrm{E}+02$ & $3.2 \mathrm{E}-01$ & $1.7 \mathrm{E}+03$ \\
\hline $\mathrm{Se}-79$ & $6.60 \mathrm{E}+02$ & $7.7 \mathrm{E}+00$ & $8.6 \mathrm{E}+01$ \\
\hline $\mathrm{Sr}-90+\mathrm{d}$ & $8.00 \mathrm{E}+00$ & $2.2 \mathrm{E}-09$ & $3.7 \mathrm{E}+09$ \\
\hline Mo-93 & $8.20 \mathrm{E}+02$ & $7.1 \mathrm{E}+00$ & $1.2 \mathrm{E}+02$ \\
\hline $\mathrm{Zr}-93+\mathrm{d}$ & $2.10 \mathrm{E}+03$ & $3.7 \mathrm{E}-03$ & $5.7 \mathrm{E}+05$ \\
\hline Nb-94 & $1.30 \mathrm{E}+02$ & $5.2 \mathrm{E}+00$ & $2.5 \mathrm{E}+01$ \\
\hline Tc-99 & $8.00 \mathrm{E}+02$ & $7.8 \mathrm{E}+00$ & $1.0 \mathrm{E}+02$ \\
\hline$S n-126+d$ & $2.90 \mathrm{E}+02$ & $8.3 E+00$ & $3.5 \mathrm{E}+01$ \\
\hline I- 129 & $5.00 \mathrm{E}-01$ & $1.0 \mathrm{E}+01$ & $5.0 \mathrm{E}-02$ \\
\hline Cs-135 & $8.00 \mathrm{E}+02$ & $2.0 \mathrm{E}+00$ & $4.0 \mathrm{E}+02$ \\
\hline Th-232 & $1.30 \mathrm{E}+01$ & $7.6 \mathrm{E}-09$ & $1.7 \mathrm{E}+09$ \\
\hline Ra-228 & $5.00 \mathrm{E}+00$ & $2.2 \mathrm{E}-17$ & \\
\hline Th-228 & $1.50 \mathrm{E}+01$ & $1.1 \mathrm{E}-18$ & \\
\hline Ra-224 & $1.50 \mathrm{E}+01$ & $3.7 \mathrm{E}-20$ & \\
\hline U-232 & $2.60 \mathrm{E}+01$ & $2.4 \mathrm{E}-07$ & $1.1 \mathrm{E}+08$ \\
\hline Th-228 & $1.50 \mathrm{E}+01$ & $7.0 \mathrm{E}-11$ & \\
\hline Ra-224 & $1.50 \mathrm{E}+01$ & $2.3 \mathrm{E}-12$ & \\
\hline U-234 & $1.32 \mathrm{E}+02$ & $4.0 \mathrm{E}+00$ & $2.3 \mathrm{E}+01$ \\
\hline Th-230 & $1.50 \mathrm{E}+01$ & $1.9 \mathrm{E}-03$ & \\
\hline Ra-226 & $5.00 \mathrm{E}+00$ & $7.3 \mathrm{E}-03$ & \\
\hline $\mathrm{Pb}-210$ & $3.00 \mathrm{E}-01$ & $1.3 \mathrm{E}-02$ & \\
\hline Po-210 & $1.50 \mathrm{E}+01$ & $2.4 \mathrm{E}-02$ & \\
\hline U-235 & $1.39 \mathrm{E}+02$ & 4.1E+00 & $3.4 \mathrm{E}+01$ \\
\hline $\mathrm{Pa}-231$ & $3.10 E+00$ & $2.3 \mathrm{E}-02$ & \\
\hline Ac-227 & $2.50 \mathrm{E}+00$ & $2.9 \mathrm{E}-02$ & \\
\hline Th-227 & $1.50 \mathrm{E}+01$ & $4.0 \mathrm{E}-03$ & \\
\hline $\mathrm{Ra}-223$ & $1.50 \mathrm{E}+01$ & $2.6 \mathrm{E}-02$ & \\
\hline $\mathrm{U}-236$ & $1.39 E+02$ & $4.1 E+00$ & $3.4 \mathrm{E}+01$ \\
\hline Np-237 & $8.90 E+00$ & $1.0 \mathrm{E}+01$ & $8.9 \mathrm{E}-01$ \\
\hline $\mathrm{U}-238$ & $6.66 E+00$ & $4.1 E+00$ & $1.6 \mathrm{E}+00$ \\
\hline Th-234 & $5.90 \mathrm{E}+01$ & $4.5 \mathrm{E}-02$ & \\
\hline $\mathrm{U}-234$ & $1.32 \mathrm{E}+02$ & $9.3 \mathrm{E}-03$ & \\
\hline Pu-238 & $8.90 E+00$ & $1.3 \mathrm{E}-09$ & $1.5 \mathrm{E}+06$ \\
\hline U-234 & $1.32 \mathrm{E}+02$ & $9.0 \mathrm{E}-05$ & \\
\hline Pu-239 & $8.10 \mathrm{E}+00$ & $1.0 \mathrm{E}+00$ & $7.9 \mathrm{E}+00$ \\
\hline $\mathrm{U}-235$ & $1.39 E+02$ & $1.3 \mathrm{E}-01$ & \\
\hline Pu-240 & $8.10 \mathrm{E}+00$ & 4.8E-01 & $1.7 \mathrm{E}+01$ \\
\hline $\mathrm{U}-236$ & $1.39 E+02$ & $2.6 \mathrm{E}-01$ & \\
\hline Am-241 & $7.60 \mathrm{E}+00$ & screened $^{e}$ & $4.4 \mathrm{E}+03$ \\
\hline \multirow[t]{2}{*}{ Np-237 } & $8.90 E+00$ & $2.0 \mathrm{E}-03$ & \\
\hline & & Rev. 1 & January 31,2000 \\
\hline
\end{tabular}


Table 5.1-11 Calculated Inventory Limits for the Naval Reactor Pad Waste

\begin{tabular}{|c|c|c|c|}
\hline Radionuclide $^{\text {a }}$ & $\begin{array}{c}\text { Concentration limit } \\
\mathrm{pC} / \mathrm{L}\end{array}$ & $\begin{array}{c}\text { Peak groundwater } \\
\text { concentration up to } \\
10,000 \text { years } \\
\text { pCi/L }\end{array}$ & $\begin{array}{l}\text { Calculated inventory } \\
\text { limit }^{d} \\
\mathrm{Ci} / \mathrm{pad}^{\mathrm{d}}\end{array}$ \\
\hline $\mathrm{Pu}-241$ & $5.30 \mathrm{E}+02$ & screened $^{c}$ & $1.3 \mathrm{E}+05$ \\
\hline Am-241 & $7.60 \mathrm{E}+00$ & screened $^{\mathrm{e}}$ & \\
\hline Np-237 & $8.90 \mathrm{E}+00$ & $6.7 \mathrm{E}-05$ & \\
\hline $\mathrm{Pu}-242$ & $8.30 \mathrm{E}+00$ & $1.4 \mathrm{E}+00$ & $6.1 \mathrm{E}+00$ \\
\hline U-238 & $1.39 \mathrm{E}+02$ & $9.8 \mathrm{E}-03$ & \\
\hline$A m-243$ & $7.60 \mathrm{E}+00$ & $3.0 \mathrm{E}-06$ & $1.5 \mathrm{E}+06$ \\
\hline Np-239 & $3.00 \mathrm{E}+02$ & $1.5 \mathrm{E}-02$ & \\
\hline Pu-239 & $8.10 \mathrm{E}+00$ & $5.4 \mathrm{E}-06$ & \\
\hline Pu-244 & $8.60 \mathrm{E}+00$ & $1.4 \mathrm{E}+00$ & $6.2 \mathrm{E}+00$ \\
\hline $\mathrm{Cm}-244$ & $1.50 \mathrm{E}+01$ & screened $^{\mathrm{e}}$ & $6.1 E+03$ \\
\hline $\mathrm{Pu}-240$ & $8.10 \mathrm{E}+00$ & $1.3 \mathrm{E}-03$ & \\
\hline U-236 & $1.39 \mathrm{E}+02$ & 7.3E-04 & \\
\hline $\mathrm{Cm}-245$ & $7.60 \mathrm{E}+00$ & $3.5 \mathrm{E}-16$ & $3.3 \mathrm{E}+00$ \\
\hline $\mathrm{Pu}-241$ & $5.30 \mathrm{E}+02$ & $7.6 \mathrm{E}-14$ & \\
\hline Am-241 & $7.60 \mathrm{E}+00$ & $1.8 \mathrm{E}-14$ & \\
\hline Np-237 & $8.90 \mathrm{E}+00$ & $2.7 \mathrm{E}+00$ & \\
\hline $\mathrm{Cm}-246$ & $7.60 \mathrm{E}+00$ & $1.7 \mathrm{E}-16$ & $4.4 \mathrm{E}+16$ \\
\hline $\mathrm{Cm}-247$ & $8.30 \mathrm{E}+00$ & $1.4 \mathrm{E}-10$ & $7.7 \mathrm{E}+03$ \\
\hline Am-243 & $7.60 \mathrm{E}+00$ & $2.9 \mathrm{E}-10$ & \\
\hline Np-239 & $3.00 \mathrm{E}+02$ & $9.0 \mathrm{E}-14$ & \\
\hline Pu-239 & $8.10 \mathrm{E}+00$ & $1.1 \mathrm{E}-03$ & \\
\hline $\mathrm{Cm}-248$ & $2.10 \mathrm{E}+00$ & $1.4 \mathrm{E}-10$ & $4.9 \mathrm{E}+01$ \\
\hline $\mathrm{Pu}-244$ & $8.60 \mathrm{E}+00$ & $1.8 \mathrm{E}-01$ & \\
\hline Cf-249 & $7.40 \mathrm{E}+00$ & $3.4 \mathrm{E}-09$ & $1.1 \mathrm{E}+02$ \\
\hline $\mathrm{Cm}-245$ & $7.60 \mathrm{E}+00$ & $2.7 \mathrm{E}-07$ & \\
\hline $\mathrm{Pu}-241$ & $5.30 \mathrm{E}+02$ & $2.3 \mathrm{E}-08$ & \\
\hline Am-241 & $7.60 \mathrm{E}+00$ & $4.9 \mathrm{E}-08$ & \\
\hline Np-237 & $8.90 \mathrm{E}+00$ & $7.8 \mathrm{E}-02$ & \\
\hline \multicolumn{4}{|c|}{$\begin{array}{l}\text { " }+\mathrm{d} \text { " indicates short- and/or long-lived radioactive daughters are considered in the analysis. } \\
\text { The more restrictive of either the MCL or the allowable concentration based on a } 25 \mathrm{mrem} / \mathrm{yr} \text { performance } \\
\text { objective (Table 4.3-1) } \\
\text { Peak concentration is per Ci disposed of in } 100 \text { naval reactor waste containers in one pad. } \\
\text { Calculated by dividing the "Concentration limit" by the "Peak groundwater concentration". For radionuclides } \\
\text { with daughters, the lower limit calculated by this method for all radionuclides in the decay chain is the one } \\
\text { reported as the inventory limit. } \\
\text { Inventory limit is based on radioactive daughter(s) only; parent was screened from consideration (Section } 4.1 \text { ) }\end{array}$} \\
\hline
\end{tabular}


Table 5.1-12 Calculated Inventory Limits for the Trenches Containing Intimately-Mixed Cement-Stabilized Waste

\begin{tabular}{|c|c|c|c|}
\hline Radionuclide $^{\text {a }}$ & $\begin{array}{c}\text { Concentration limit } \\
\mathrm{pC} / \mathrm{L}\end{array}$ & $\begin{array}{l}\text { Peak groundwater } \\
\text { concentration up to } \\
10,000 \text { years } \\
\text { pCi } / \mathrm{L}\end{array}$ & $\begin{array}{c}\text { Calculated inventory } \\
\text { limit }^{d} \\
\text { Ci } / 5 \text { trenches }\end{array}$ \\
\hline $\mathrm{H}-3$ & $2.00 \mathrm{E}+04$ & $6.35 \mathrm{E}-05$ & $1.57 \mathrm{E}+08$ \\
\hline C-14 & $6.40 \mathrm{E}+03$ & $4.36 \mathrm{E}-01$ & $7.34 \mathrm{E}+03$ \\
\hline $\mathrm{Ni}-59$ & $5.30 \mathrm{E}+02$ & $5.58 \mathrm{E}-01$ & $4.75 \mathrm{E}+02$ \\
\hline $\mathrm{Se}-79$ & $6.60 \mathrm{E}+02$ & $1.84 \mathrm{E}+01$ & $1.79 \mathrm{E}+01$ \\
\hline Rb-87 & $2.70 \mathrm{E}+02$ & $4.00 \mathrm{E}+02$ & $3.38 \mathrm{E}-01$ \\
\hline Sr-90+d & $8.00 \mathrm{E}+00$ & $7.83 \mathrm{E}-06$ & $2.56 \mathrm{E}+05$ \\
\hline $\mathrm{Zr}-93+\mathrm{d}$ & $2.10 \mathrm{E}+03$ & $6.32 \mathrm{E}-01$ & $1.66 \mathrm{E}+03$ \\
\hline $\mathrm{Nb}-94$ & $1.30 \mathrm{E}+02$ & $3.10 \mathrm{E}+01$ & $2.10 \mathrm{E}+00$ \\
\hline Tc-99 & $8.00 \mathrm{E}+02$ & $1.03 E+03$ & $3.88 \mathrm{E}-01$ \\
\hline Pd-107 & $3.66 \mathrm{E}+04$ & $1.84 \mathrm{E}+02$ & $9.95 \mathrm{E}+01$ \\
\hline$S n-126+d$ & $2.90 \mathrm{E}+02$ & $1.16 \mathrm{E}+01$ & $1.25 \mathrm{E}+02$ \\
\hline $1-129$ & $5.00 \mathrm{E}-01$ & $6.12 E+02$ & $4.08 \mathrm{E}-04$ \\
\hline Cs- 135 & $8.00 \mathrm{E}+02$ & $1.97 \mathrm{E}+01$ & $2.03 E+01$ \\
\hline Th-232 & $1.30 \mathrm{E}+01$ & $2.00 \mathrm{E}-09$ & $1.81 E+08$ \\
\hline Ra-228 & $5.00 \mathrm{E}+00$ & $1.38 \mathrm{E}-08$ & \\
\hline Th-228 & $1.50 \mathrm{E}+01$ & $2.15 \mathrm{E}-09$ & \\
\hline Ra-224 & $1.50 \mathrm{E}+01$ & $1.38 \mathrm{E}-08$ & \\
\hline $\mathrm{U}-232$ & $2.60 \mathrm{E}+01$ & $2.65 \mathrm{E}-08$ & $4.91 E+08$ \\
\hline Th-228 & $1.50 \mathrm{E}+01$ & $2.91 \mathrm{E}-10$ & \\
\hline Ra-224 & $1.50 \mathrm{E}+01$ & $1.87 \mathrm{E}-09$ & \\
\hline $\mathrm{U}-233$ & $1.25 \mathrm{E}+02$ & $4.82 \mathrm{E}-09$ & $7.14 \mathrm{E}+09$ \\
\hline Th-229 & $9.60 \mathrm{E}+00$ & $9.87 \mathrm{E}-11$ & \\
\hline $\mathrm{Ra}-225$ & $9.00 \mathrm{E}+00$ & $6.30 \mathrm{E}-10$ & \\
\hline $\mathrm{U}-234$ & $1.32 \mathrm{E}+02$ & $3.88 \mathrm{E}-10$ & $3.02 \mathrm{E}+03$ \\
\hline Th-230 & $1.50 \mathrm{E}+01$ & $2.58 \mathrm{E}-13$ & \\
\hline $\mathrm{Ra}-226$ & $5.00 \mathrm{E}+00$ & $2.55 \mathrm{E}-0.5$ & \\
\hline $\mathrm{Pb}-210$ & $3.00 \mathrm{E}-01$ & $4.96 \mathrm{E}-05$ & \\
\hline Po-210 & $1.50 \mathrm{E}+01$ & $8.93 \mathrm{E}-05$ & \\
\hline U-235 & $1.39 E+02$ & $1.36 \mathrm{E}-13$ & $3.13 E+04$ \\
\hline $\mathrm{Pa}-231$ & $3.10 \mathrm{E}+00$ & $3.24 \mathrm{E}-05$ & \\
\hline Ac- 227 & $2.50 \mathrm{E}+00$ & $4.00 \mathrm{E}-05$ & \\
\hline Th-227 & $1.50 \mathrm{E}+01$ & $5.63 E-05$ & \\
\hline Ra-223 & $1.50 \mathrm{E}+01$ & $3.60 \mathrm{E}-05$ & \\
\hline U-236 & $1.39 E+02$ & $3.30 \mathrm{E}-11$ & $2.11 \mathrm{E}+12$ \\
\hline Np-237 & $8.90 \mathrm{E}+00$ & $4.75 \mathrm{E}-01$ & $9.37 \mathrm{E}+00$ \\
\hline U-238 & $6.66 \mathrm{E}+00$ & $1.72 \mathrm{E}-13$ & $6.35 E+07$ \\
\hline Th-234 & $5.90 \mathrm{E}+01$ & $1.90 \mathrm{E}-15$ & \\
\hline U-234 & $1.32 \mathrm{E}+02$ & $1.04 \mathrm{E}-06$ & \\
\hline Pu-238 & $8.90 \mathrm{E}+00$ & $1.05 \mathrm{E}-13$ & $2.10 \mathrm{E}+10$ \\
\hline U-234 & $1.32 \mathrm{E}+02$ & $3.15 \mathrm{E}-09$ & \\
\hline $\mathrm{Pu}-239$ & $8.10 \mathrm{E}+00$ & $4.41 \mathrm{E}-11$ & $9.18 \mathrm{E}+10$ \\
\hline U-235 & $1.39 \mathrm{E}+02$ & $1.10 \mathrm{E}-12$ & \\
\hline
\end{tabular}


Table 5.1-12 Calculated Inventory Limits for the Trenches Containing Intimately-Mixed Cement-Stabilized Waste

\begin{tabular}{|c|c|c|c|}
\hline Radionuclide $^{\text {a }}$ & $\begin{array}{c}\text { Concentration limit } \\
\mathrm{pCi} / \mathrm{L}\end{array}$ & $\begin{array}{l}\text { Peak groundwater } \\
\text { concentration up to } \\
10,000 \text { years } \\
\text { pCi/L }\end{array}$ & $\begin{array}{c}\text { Calculated inventory } \\
\text { limit }{ }^{\mathrm{d}} \\
\mathrm{Ci} / 5 \text { trenches }\end{array}$ \\
\hline Pu-240 & $8.10 \mathrm{E}+00$ & $1.39 \mathrm{E}-10$ & $2.91 \mathrm{E}+10$ \\
\hline U-236 & $1.39 E+02$ & 3.30E-11 & \\
\hline Am-241 & $7.60 \mathrm{E}+00$ & -...e & $4.64 E+04$ \\
\hline Np-237 & $8.90 E+00$ & 9.59E-05 & \\
\hline Pu-241 & $5.30 \mathrm{E}+02$ & $--e^{e}$ & $1.39 \mathrm{E}+06$ \\
\hline Am-241 & $7.60 \mathrm{E}+00$ & --. & \\
\hline Np-237 & $8.90 \mathrm{E}+00$ & $3.20 \mathrm{E}-06$ & \\
\hline $\mathrm{Pu}-242$ & $8.30 \mathrm{E}+00$ & $2.99 \mathrm{E}-12$ & $1.39 \mathrm{E}+12$ \\
\hline U-238 & $1.39 \mathrm{E}+02$ & 1.72E-13 & \\
\hline Am-243 & $7.60 \mathrm{E}+00$ & $1.64 \mathrm{E}-06$ & $2.32 \mathrm{E}+06$ \\
\hline Np-239 & $3.00 \mathrm{E}+02$ & $1.72 E-13$ & \\
\hline Pu-239 & $8.10 \mathrm{E}+00$ & $1.04 \mathrm{E}-06$ & \\
\hline $\mathrm{Pu}-244$ & $8.60 \mathrm{E}+00$ & $1.40 \mathrm{E}-14$ & $3.07 \mathrm{E}+14$ \\
\hline $\mathrm{Cm}-244$ & $1.50 \mathrm{E}+01$ & $-\ldots{ }^{e}$ & $1.05 E+13$ \\
\hline $\mathrm{Pu}-240$ & $8.10 \mathrm{E}+00$ & $3.85 \mathrm{E}-13$ & \\
\hline U-236 & $1.39 \mathrm{E}+02$ & $9.14 \mathrm{E}-14$ & \\
\hline $\mathrm{Cm}-245$ & $7.60 \mathrm{E}+00$ & $2.65 \mathrm{E}-11$ & $3.25 \mathrm{E}+02$ \\
\hline $\mathrm{Pu}-241$ & $5.30 \mathrm{E}+02$ & $1.42 \mathrm{E}-08$ & \\
\hline Am-241 & $7.60 \mathrm{E}+00$ & $3.05 \mathrm{E}-09$ & \\
\hline Np-237 & $8.90 \mathrm{E}+00$ & $1.37 \mathrm{E}-02$ & \\
\hline $\mathrm{Cm}-246$ & $7.60 \mathrm{E}+00$ & $1.37 \mathrm{E}-11$ & $2.77 \mathrm{E}+11$ \\
\hline $\mathrm{Cm}-247$ & $8.30 \mathrm{E}+00$ & $6.01 \mathrm{E}-11$ & $9.25 \mathrm{E}+00$ \\
\hline Am-243 & $7.60 \mathrm{E}+00$ & $3.88 \mathrm{E}-07$ & \\
\hline Np-239 & $3.00 \mathrm{E}+02$ & $1.41 \mathrm{E}-04$ & \\
\hline Pu-239 & $8.10 \mathrm{E}+00$ & $4.38 \mathrm{E}-01$ & \\
\hline $\mathrm{Cm}-248$ & $2.10 \mathrm{E}+00$ & $5.89 \mathrm{E}-11$ & $1.71 \mathrm{E}+04$ \\
\hline Pu-244 & $8.60 E+00$ & $2.51 \mathrm{E}-04$ & \\
\hline Cf-249 & $7.40 \mathrm{E}+00$ & $3.65 \mathrm{E}-09$ & $7.93 E+03$ \\
\hline $\mathrm{Cm}-245$ & $7.60 \mathrm{E}+00$ & $2.75 \mathrm{E}-08$ & \\
\hline Pu-241 & $5.30 \mathrm{E}+02$ & $1.42 \mathrm{E}-06$ & \\
\hline Am-241 & $7.60 E+00$ & $9.84 \mathrm{E}-08$ & \\
\hline $\mathrm{Np}-237$ & $8.90 \mathrm{E}+00$ & $5.61 \mathrm{E}-04$ & \\
\hline $\mathrm{Cf}-252$ & $1.50 \mathrm{E}+01$ & --.e & $2.20 \mathrm{E}+09$ \\
\hline $\mathrm{Cm}-248$ & $2.10 \mathrm{E}+00$ & $4.59 \mathrm{E}-16$ & \\
\hline $\mathrm{Pu}-244$ & $8.60 \mathrm{E}+00$ & $1.95 \mathrm{E}-09$ & \\
\hline \multicolumn{4}{|c|}{$\begin{array}{l}\text { "+d" indicates short- and/or long-lived radioactive daughters are considered in the analysis. } \\
\text { The more restrictive of either the MCL or the allowable concentration based on a } 25 \mathrm{mrem} / \mathrm{yr} \text { performance } \\
\text { objective (Table 4.3-1) } \\
\text { Peak concentration is per Ci disposed of in ten trenches. } \\
\text { Calculated by dividing the "Concentration limit" by the "Peak groundwater concentration", and dividing by } 2 \\
\text { to normalize to five trenches. For radionuclides with daughters, the lower limit calculated by this method for } \\
\text { all radionuclides in the decay chain is the one reported as the inventory limit. } \\
\text { Inventory limit is based on radioactive daughter(s) only; parent was screened from consideration (Section 4). }\end{array}$} \\
\hline
\end{tabular}


Table 5.1-13 Calculated Inventory Limits for the Trenches Containing Cement-Stabilized Encapsulated Waste

\begin{tabular}{|c|c|c|c|}
\hline Radionuclide $^{\text {a }}$ & $\begin{array}{c}\text { Concentration limit }{ }^{b} \\
\mathrm{pCi} / \mathrm{L}\end{array}$ & $\begin{array}{l}\text { Peak groundwater } \\
\text { concentration up to } \\
10,000 \text { years }{ }^{c} \\
\text { pCi/L }\end{array}$ & $\begin{array}{c}\text { Calculated inventory } \\
\text { limit }^{\mathrm{d}} \\
\text { Ci/ } 5 \text { trenches }\end{array}$ \\
\hline $\mathrm{H}-3$ & $2.0 \mathrm{E}+04$ & $6.5 \mathrm{E}-07$ & $1.5 \mathrm{E}+10$ \\
\hline $\mathrm{Ni}-59$ & $5.3 \mathrm{E}+02$ & $6.0 \mathrm{E}-02$ & $4.4 \mathrm{E}+03$ \\
\hline Se-79 & $6.6 \mathrm{E}+02$ & $4.3 \mathrm{E}+00$ & $7.7 \mathrm{E}+01$ \\
\hline Sr-90+d & $8.0 \mathrm{E}+00$ & $5.8 \mathrm{E}-06$ & $2.6 \mathrm{E}+05$ \\
\hline $\mathrm{Zr}-93+\mathrm{d}$ & $2.1 \mathrm{E}+03$ & $6.6 \mathrm{E}+01$ & $1.6 \mathrm{E}+01$ \\
\hline Tc-99 & $8.0 \mathrm{E}+02$ & $1.3 \mathrm{E}+03$ & $3.0 \mathrm{E}-01$ \\
\hline Pd-107 & $3.7 E+04$ & $1.1 \mathrm{E}+03$ & $1.7 E+01$ \\
\hline $\mathrm{Sn}-126+\mathrm{d}$ & $2.9 \mathrm{E}+02$ & $4.8 \mathrm{E}+00$ & $3.0 \mathrm{E}+01$ \\
\hline $1-129$ & $5.0 \mathrm{E}-01$ & $1.2 E+03$ & $2.2 \mathrm{E}-04$ \\
\hline Cs-135 & $8.0 \mathrm{E}+02$ & $2.0 \mathrm{E}+01$ & $2.0 \mathrm{E}+01$ \\
\hline $\mathrm{U}-232$ & $2.6 \mathrm{E}+01$ & $1.2 \mathrm{E}-08$ & $1.1 \mathrm{E}+09$ \\
\hline Th-228 & $1.5 \mathrm{E}+01$ & $1.3 \mathrm{E}-10$ & \\
\hline $\mathrm{Ra}-224$ & $1.5 \mathrm{E}+01$ & $8.5 \mathrm{E}-10$ & \\
\hline $\mathrm{U}-233$ & $1.3 \mathrm{E}+02$ & $2.0 \mathrm{E}-08$ & $2.6 \mathrm{E}+07$ \\
\hline Th-229 & $9.6 \mathrm{E}+00$ & $2.7 \mathrm{E}-08$ & \\
\hline $\mathrm{Ra}-225$ & $9.0 \mathrm{E}+00$ & $1.8 \mathrm{E}-07$ & \\
\hline $\mathrm{U}-234$ & $1.3 E+02$ & $8.0 \mathrm{E}-10$ & $3.3 \mathrm{E}+04$ \\
\hline Th-230 & $1.5 E+01$ & $3.5 E-13$ & \\
\hline $\mathrm{Ra}-226$ & $5.0 \mathrm{E}+00$ & $2.3 \mathrm{E}-06$ & \\
\hline $\mathrm{Pb}-210$ & $3.0 \mathrm{E}-01$ & $4.5 \mathrm{E}-06$ & \\
\hline Po-210 & $1.5 \mathrm{E}+01$ & $8.1 \mathrm{E}-06$ & \\
\hline U-235 & $1.4 \mathrm{E}+02$ & $2.8 \mathrm{E}-13$ & $1.7 \mathrm{E}+04$ \\
\hline $\mathrm{Pa}-231$ & $3.1 \mathrm{E}+00$ & $6.1 \mathrm{E}-05$ & \\
\hline Ac- -227 & $2.5 \mathrm{E}+00$ & $7.5 \mathrm{E}-05$ & \\
\hline Th-227 & $1.5 E+01$ & $1.1 \mathrm{E}-05$ & \\
\hline Ra-223 & $1.5 \mathrm{E}+01$ & $6.7 \mathrm{E}-05$ & \\
\hline$U-236$ & $1.4 \mathrm{E}+02$ & $1.4 \mathrm{E}-10$ & $5.1 E+11$ \\
\hline U-238 & $6.7 \mathrm{E}+00$ & $7.2 \mathrm{E}-13$ & $3.2 \mathrm{E}+09$ \\
\hline Th-234 & $5.9 \mathrm{E}+01$ & $7.9 \mathrm{E}-15$ & \\
\hline U-234 & $1.3 \mathrm{E}+02$ & $2.0 \mathrm{E}-08$ & \\
\hline $\mathrm{Pu}-238$ & $8.9 \mathrm{E}+00$ & $0.0 \mathrm{E}+00$ & $5.1 E+09$ \\
\hline $\mathrm{U}-234$ & $1.3 \mathrm{E}+02$ & $1.3 E-08$ & \\
\hline $\mathrm{Pu}-239$ & $8.1 \mathrm{E}+00$ & $1.8 \mathrm{E}-10$ & $2.2 \mathrm{E}+10$ \\
\hline U-235 & $1.4 \mathrm{E}+02$ & $5.2 \mathrm{E}-12$ & \\
\hline $\mathrm{Pu}-240$ & $8.1 \mathrm{E}+00$ & $5.6 \mathrm{E}-10$ & $7.3 E+09$ \\
\hline U-236 & $1.4 \mathrm{E}+02$ & 1.6E-10 & \\
\hline Am-24I & $7.6 \mathrm{E}+00$ & screened $^{e}$ & $1.4 \mathrm{E}+03$ \\
\hline Np-237 & $8.9 \mathrm{E}+00$ & $3.2 \mathrm{E}-03$ & \\
\hline $\mathrm{Pu}-241$ & $5.3 \mathrm{E}+02$ & screened $^{e}$ & $2.6 \mathrm{E}+04$ \\
\hline Am-241 & $7.6 \mathrm{E}+00$ & screened $^{\mathrm{e}}$ & \\
\hline $\mathrm{Np}-237$ & $8.9 \mathrm{E}+00$ & $1.7 E-04$ & \\
\hline $\mathrm{Pu}-242$ & $8.3 \mathrm{E}+00$ & $1.3 \mathrm{E}-11$ & $3.3 \mathrm{E}+11$ \\
\hline U-238 & $1.4 E+02$ & $8.3 E-13$ & \\
\hline
\end{tabular}


a " $+d$ " indicates short- and/or long-lived radioactive daughters are considered in the analysis.

b The more restrictive of either the MCL or the allowable concentration based on a $25 \mathrm{mrem} / \mathrm{yr}$ performance objective (Table 4,3-1)

c Peak concentration is per $\mathrm{Ci}$ disposed of in ten trenches.

"Calculated by dividing the "Concentration limit" by the "Peak groundwater concentration", and dividing by 2 to normalize to five trenches. For radionuclides with daughters, the lower limit calculated by this method for all radionuclides in the decay chain is the one reported as the inventory limit.

c Inventory limit is based on radioactive daughter(s) only; parent was screened from consideration (Section 4.1). 
Table 5.2-1. Results of the Air Pathway Analysis

\begin{tabular}{|c|c|c|c|}
\hline & $\begin{array}{c}\text { Inventory Limit } \\
\text { Based on } \\
\text { Location } 100 \mathrm{~m} \\
\text { from Waste after } \\
100 \text { Year } \\
\text { Institution } \\
\text { Control Period } \\
\text { (Ci/disposal Unit) }\end{array}$ & $\begin{array}{c}\text { Inventory Limit } \\
\text { Based on Location } \\
\text { at SRS Boundary } \\
\text { before } 100 \text { year } \\
\text { Institution Control } \\
\text { Period } \\
\text { (Ci/disposal Unit) }\end{array}$ & $\begin{array}{l}\text { Inventory Limit } \\
\text { Based on Air } \\
\text { Pathway } \\
\text { (Ci/disposal Unit) }\end{array}$ \\
\hline \multicolumn{4}{|l|}{$\mathrm{H}-3$} \\
\hline 5 Trenches $^{+}$ & $3.2 \mathrm{E}+05$ & $4.2 \mathrm{E}+06$ & $3.2 \mathrm{E}+05$ \\
\hline Crucibles (1 vauit) & $4.1 \mathrm{E}+13$ & $5.2 \mathrm{E}+14$ & $4.1 E+13$ \\
\hline $1 \mathrm{LAW}$ Vault JCW & $6.4 \mathrm{E}+07$ & $8.2 \mathrm{E}+08$ & $6.4 \mathrm{E}+07$ \\
\hline 1 IL Vault JCW & $5.5 \bar{E}+07$ & $7.1 \mathrm{E}+08$ & $5.5 \mathrm{E}+07$ \\
\hline \multicolumn{4}{|l|}{$\mathrm{C}-14$} \\
\hline 5 Trenches $^{+}$ & 2.7 & $1.0 \mathrm{E}+04$ & 2.7 \\
\hline 1 LAW Vault JCW & 2.7 & $1.0 \mathrm{E}+04$ & 2.7 \\
\hline 1 IL Vault JCW & 2.7 & $1.0 \mathrm{E}+04$ & 2.7 \\
\hline \multicolumn{4}{|l|}{$\mathrm{U}-234$ based on $\mathrm{Rn}-222^{\circ}$} \\
\hline 5 Trenches $^{+}$ & 44 & & 9.8 \\
\hline 1 LAW Vault & 125 & & 125 \\
\hline 1 IL Vault & 15 & & 15 \\
\hline
\end{tabular}

+ Includes Waste in Grout and Intimately Mixed Cement Based Wasteforms

* Based on radon flux limit of $20 \mathrm{pCi} / \mathrm{m}^{2}$-sec

Table 5.3-1 $\quad{ }^{234}$ U Disposal Limits Based on Radon Release Rates

\begin{tabular}{|l|l|}
\hline Disposal unit & ${ }^{234} \mathrm{U}$ limit \\
\hline LAW Vault & $250 \mathrm{Ci}$ per two vaults \\
\hline IL Vault & $30 \mathrm{Ci}$ per two vaults \\
\hline Trench units & $88 \mathrm{Ci}$ per 10 disposal trenches \\
\hline
\end{tabular}


Table 5.4-1 lists important parameters and assumptions made in estimating groundwater concentrations for this report. In the last column of this table, comments are provided which address the conservatism of the assumed parameter value and/or the uncertainty in the parameter. For highly uncertain parameters, such as timing of failure events, $\mathrm{K}_{\mathrm{d}} \mathrm{s}$, and hydrodynamic dispersion, parameter values were chosen which tend to maximize groundwater concentration. Hydraulic conductivities in the saturated zone, however, were selected in a manner dictated by the calibration procedure; in order to obtain a pressure head distribution, and thus flow field, that represents measured field values for the E-Area location.

Certain modeling decisions, such as boundary condition specification, simulation time steps, or even computer code selection, are not included in Table 5.3-1 because, although they may affect the results, they are not "parameters" that are subject to random variations in natural systems. Most such decisions are based on the considerable experience of the modeler, such that there is a high level of confidence that the assumptions made are most appropriate, and valid, for the system being modeled.

From Table 5.4-1, it is evident that reasonably average, or best-estimate, values were selected for parameters that were not expected to range over orders of magnitude. However, for parameters for which values are considered highly uncertain and for which probability distributions are unknown, values were selected that were likely to maximize predicted groundwater concentrations; these values can be considered "upper bound." Because there are several parameters that fall into this latter category, it is expected that the groundwater concentrations presented in Section 5.1 are overestimates of actual concentrations that will occur, and that the inventory limits based on these concentrations are thus conservative. Attempts to further maximize the predicted concentrations, for the purpose of defining an "upper bound" on the concentrations, would likely lead to implausible results because of the alreadyexisting conservatism. Therefore, while uncertainty does exist in the groundwater concentrations presented in Section 5.1, it is likely that the values reported are "upper bound" values in the realm of reasonability. It is not reasonable to attempt to quantify an absolute upper bound in this case, due to the considerable uncertainty in many of the important parameters and the inability to develop a probability distribution for these parameters.

The remainder of this discussion of sensitivity and uncertainty is devoted to sensitivity and uncertainty analyses that were conducted on isolated parameters used in the computer simulations of flow and transport from the disposed waste to the compliance point. These studies provide insight into the relative importance of certain parameters and assumptions made in deriving the groundwater concentrations in Section 5.1.

In this PA, fractional fluxes of radionuclides to the water table were simulated in the near-field model with PORFLOW (Section 4.3.3 and Appendix B) and used as a source to the saturated zone transport model (also simulated with PORFLOW) to estimate groundwater concentrations as a function of time and distance from the E-Area LLWF. The FACT code (Section 4.3.3 and Appendix B) was used to generate the saturated flow field (i.e., flow velocity and direction for grid elements within the simulation domain) used by PORFLOW to estimate groundwater concentration profiles. Sensitivity and uncertainty analysis of PORFLOW used to evaluate groundwater concentrations resulting from release of radionuclides from vaultcontained low-level waste was done in earlier studies, and is reviewed below. Parameters studied were infiltration rates; hydraulic and diffusive properties of the porous materials; $K_{d} s$; and timing of vault cracking and roof failure. In the present study, the following additional parameters were selected for sensitivity analysis: infiltration rate (changes due to subsidence); time of placement of moisture barriers on trenches; and the point of assessment for compliance with performance objectives. 
Table 5.4-1 Important Parameters and Assumptions Used in Calculating Groundwater Concentrations

\begin{tabular}{lll}
\hline Parameter Description & Parameter Value Assumed & Comments \\
\hline
\end{tabular}

Factors affecting water flow through waste:

Infiltration rate at surface $\quad 40 \mathrm{~cm} / \mathrm{yr}$

Failure history for moisture barrier

Failure history for waste form or engineered barrier

Hydraulic conductivities and moisture characteristic curves for all materials in waste zone and vadose zone
At the time of waste form failure, 300 years

Complete failure occurs at 300 years

Based on both field- and laboratory-derived values, with emphasis on more recently-derived values that reflect better data acquisition technologies
On the upper end of a range of annual average estimates ( 22 to $45 \mathrm{~cm} / \mathrm{yr}$ ); extremes of 10 $\mathrm{cm} / \mathrm{yr}$ and $81 \mathrm{~cm} / \mathrm{yr}$ have been measured

After institutional control period, moisture barrier is conservatively assumed to be non-functional as soon as engineered waste forms fail; large uncertainty

Chose conservative basis for the assumed failure times (Section 4.1.3.1.3, Appendix D); large uncertainty

Chose average values for all media based largely on laboratory-derived values

Factors affecting release of radionuclides from waste:

\section{$\mathrm{K}_{\mathrm{d}} \mathrm{s}$}

Site-specific when available; most from Sheppard and Thiebault when site-specific values not available
Chose average values for sand, which are generally higher than for other media, and thus overestimate desorption from waste; large uncertainty 
Table 5.4-1 Important Parameters and Assumptions Used in Calculating Groundwater Concentrations

\begin{tabular}{|c|c|c|}
\hline Parameter Description & Parameter Value Assumed & Comments \\
\hline Apparent diffusivities & $\begin{array}{l}\text { Range from } 10^{-8} \text { to } 10^{-5} \mathrm{~cm}^{2} / \mathrm{s} \\
\text { for various materials }\end{array}$ & $\begin{array}{l}\text { Best-estimate values used for } \\
\text { each material; error for } \\
\text { intermediate values is likely to } \\
\text { be less than one order of } \\
\text { magnitude }\end{array}$ \\
\hline Solubilities & $\begin{array}{l}4.4 \times 10^{-13} \mathrm{M} \text { for } \mathrm{Pu} \\
3 \times 10^{-10} \mathrm{M} \text { for } \mathrm{U}\end{array}$ & $\begin{array}{l}\text { For Pu and } \mathrm{U} \text { isotopes only; } \\
\text { best-estimate values assuming } \\
\text { a pH in excess of } 7 \text { due to } \\
\text { cement encapsulation }\end{array}$ \\
\hline $\begin{array}{l}\text { Corrosion rate of activated } \\
\text { metals }\end{array}$ & $\begin{array}{l}2 \times 10^{-6} \text { to } 2 \times 10^{-5} \mathrm{in} / \mathrm{yr} \text { for } \\
\text { Zircaloy and Inconel, } \\
\text { respectively }\end{array}$ & $\begin{array}{l}\text { Conservative estimates; } \\
\text { particularly that for Zircaloy } \\
\text { which is reported to be orders } \\
\text { of magnitude below that of } \\
\text { Inconel; large uncertainty }\end{array}$ \\
\hline
\end{tabular}

Factors affecting transport and dilution of plume in the saturated zone:

Simulation grid block size 200 ' by 200 ' grid size for saturated zone

Hydraulic conductivities of Based on both field- and aquifers and confining laboratory-derived values, units with emphasis on more recently-derived values that reflect better data acquisition technologies

Hydrodynamic dispersion $\quad 0$

Point of assessment for groundwater compliance
Chosen to minimize artificial dilution (a close match to the size of the base of the disposal units)

Chose average values for all media based on both field- and laboratory-derived values individual measurements can vary over several orders of magnitude

Chosen to minimize dispersive effects, and thus conservatively concentrate plume; large uncertainty

Based on interim guidance 
The sensitivity of, and uncertainty in, PORFLOW simulations of vault-contained low-level radioactive waste were evaluated in the Z-Area PA (WSRC 1992b) with respect to variable infiltration rates and hydraulic and diffusive properties of the waste form, vaults, and soil. The results indicated a low sensitivity to infiltration rate, due to the flux-controlling nature of the low-conductivity concrete materials, and a high sensitivity to hydraulic conductivity, especially to that of the material with the lowest conductivity. Sensitivity to hydraulic conductivity of low-permeability concrete decreases with increasing half-live; longer-lived radionuclides are available for transport after vault failure occurs, and thus are less sensitive to the hydraulic conductivity of intact concrete.

A sensitivity and uncertainty analysis of an earlier version of the model used in this PA for the IL vaults was conducted before the present work was initiated. The PORFLOW simulations of the IL vault system were evaluated in terms of the movement of ${ }^{99} \mathrm{Tc}$ from the vault area through the vadose zone and in the aquifer. This earlier study focused on the sensitivity and uncertainty in model results with respect to the $\mathrm{K}_{d} \mathrm{~s}$ in the waste form, concrete and soil of the unsaturated zone, and with respect to timing of two different types of vault failure: roof cracking and roof collapse. Details of this study are provided in Appendix $\mathrm{H}$, and the results are summarized below.

The analysis of the influence of $\mathrm{K}_{\mathrm{d}}$ and timing parameters (Appendix $\mathrm{H}$ ) together resulted in specification of distributions and bounds on values of five factors for the PORFLOW simulations in this analysis. The results of the sensitivity analysis indicated that the peak groundwater concentration was most sensitive to the concrete $\mathrm{K}_{d}$ assumed for ${ }^{99} \mathrm{Tc}$ (accounting for 96 percent of the response variability). This is likely due to the fact that concrete $K_{d} s$ specified were orders of magnitude larger than the waste or soil $K_{d} s$ for ${ }^{99} \mathrm{Tc}$, such that retardation in the concrete is the controlling geochemical factor in the simulations. The time that the peak occurred was also fairly sensitive to the time assumed between vault cracking and roof collapse. The amount of variability, or uncertainty, in the ${ }^{99} \mathrm{Tc}$ results was rather low for the range of parameter values tested. Calculated 95 percent tolerance limits indicated peak groundwater concentrations ranging between 0.008 and $0.192 \mathrm{pCi} / \mathrm{cc}$ per $\mathrm{Ci}$ of ${ }^{99} \mathrm{Tc}$ in the IL vaults, while the time of the peak ranged from 780 to 5500 years with 95 percent confidence. The peak groundwater concentration of ${ }^{99} \mathrm{Tc}$ in this earlier study was calculated to be $0.04 \mathrm{pCi} / \mathrm{cc}$ per $\mathrm{Ci}$ in the IL vaults, occurring at 1800 years, which is approximately the midpoint of these distributions. A cumulative distribution function of the maximum groundwater concentrations calculated in the uncertainty analysis (Fig. 5.4-1) indicated that although 50 percent of the calculated peak groundwater concentrations appear to exceed the $0.04 \mathrm{pCi} / \mathrm{cc}$ per $\mathrm{Ci}$ inventory, less than 10 percent exceed $0.1 \mathrm{pCi} / \mathrm{cc}$ per $\mathrm{Ci}$. Thus, large errors are not expected despite the large distributions assumed for the $\mathrm{K}_{\mathrm{d}}$ and timing parameters.

\subsubsection{Sensitivity of Results to Assessment Assumptions}

Subsidence of the ground surface due to failure of the LAW vault roofs or decay of wood products in the slit trenches may result in a short-term increase in infiltration into the LAW vault or slit trench waste. A study of the effects of subsidence, and thus increased infiltration, on fractional releases to the saturated zone, as simulated by PORFLOW, was conducted. Infiltration rates of $120 \mathrm{~cm} / \mathrm{yr}, 80 \mathrm{~cm} / \mathrm{yr}$, and the normal infiltration rate of $40 \mathrm{~cm} / \mathrm{yr}$ (in the absence of a moisture barrier) were considered, after failure of these units was assumed to occur. For the LAW vaults, this is at 3100 years, the earliest time of roof collapse. For the slit trenches, this is assumed to occur at 100 years, at the end of the institutional control period. The results of this analysis are presented in Tables $5.4-2$ and 5.4-3, for four radionuclides: ${ }^{14} \mathrm{C}-14$ (fairly mobile in soil, sorbing in concrete, moderate half-life), ${ }^{59} \mathrm{Ni}-59$ (highly sorbing in all media, long half-life), ${ }^{99} \mathrm{Tc}$ (mobile in soil, sorbing in concrete, long half-life), and ${ }^{129} \mathrm{I}$ (fairly mobile in all media, long half-life). These results indicate, as expected, that increased infiltration due to subsidence only affects results for those radionuclides that peak after the time of failure. Mobile radionuclides, such as ${ }^{129} \mathrm{I}$ in the LAW vaults, and ${ }^{129} \mathrm{I}$ and ${ }^{99} \mathrm{Tc}$ in the slit trenches, are not affected by the increased infiltration. For radionuclides that peak after failure, when 

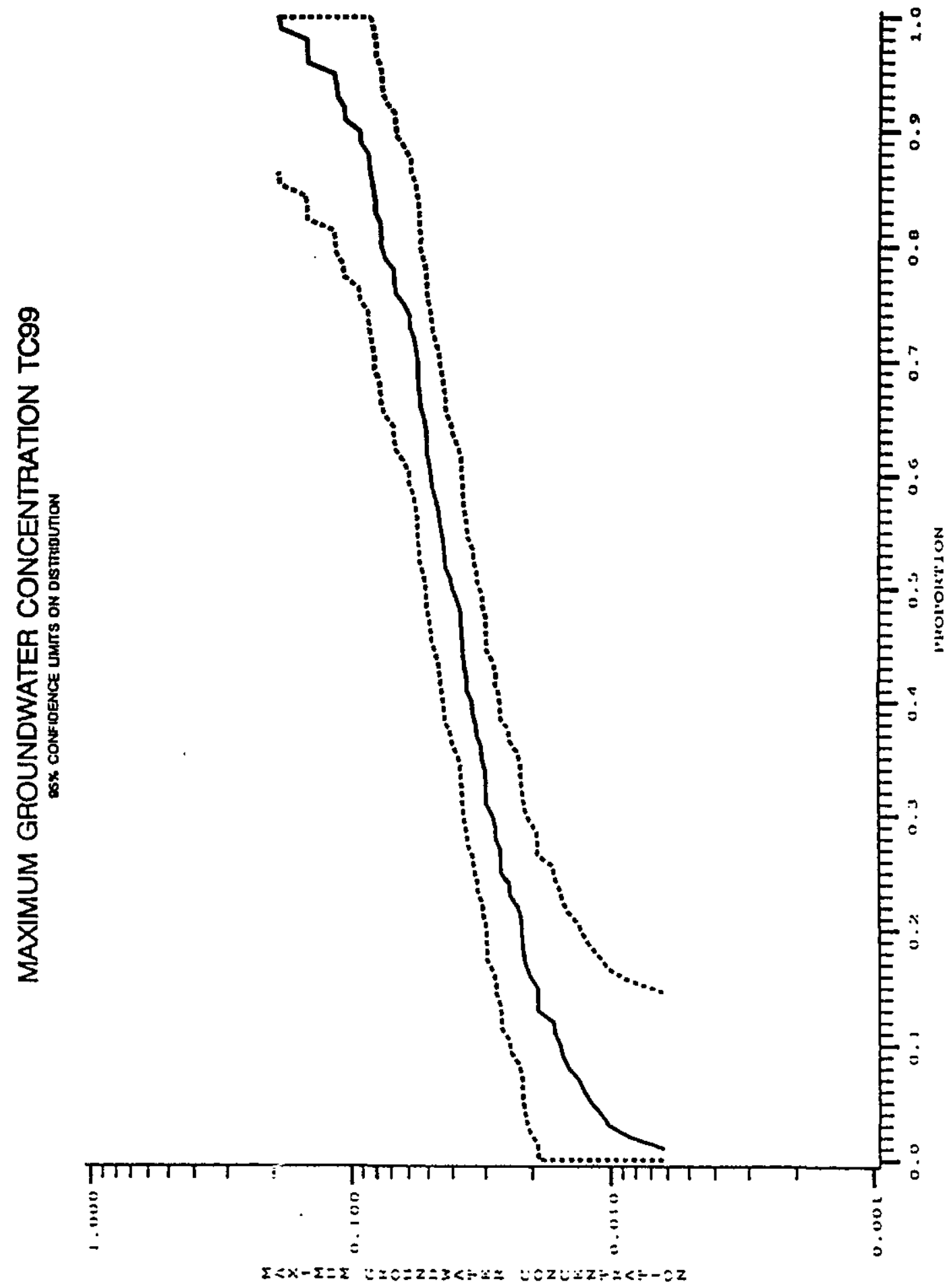

Figure 5.4-1. Cumulative Distribution Function of Maximum Groundwater Concentration of ${ }^{99} \mathrm{Tc}$ 
Table 5.4-2 Effect of Increase in Infiltration Rate after Roof Failure of the LAW Vault

\begin{tabular}{lcccccc}
\hline \multirow{2}{*}{ Nuclides } & \multicolumn{2}{c}{$40 \mathrm{~cm} / \mathrm{yr}$} & \multicolumn{2}{c}{$80 \mathrm{~cm} / \mathrm{yr}$} & \multicolumn{2}{c}{$120 \mathrm{~cm} / \mathrm{yr}$} \\
& $\begin{array}{l}\text { Peak Flux } \\
\text { fraction/yr }\end{array}$ & Peak Time & Pr & Peak Flux & Peak Time & \multicolumn{2}{c}{ Peak Flux } & Peak Time \\
& fraction/yr & yr & fraction/yr & yr \\
\hline C-14 & $1.90 \mathrm{E}-04$ & 4020 & $3.05 \mathrm{E}-04$ & 3670 & $4.96 \mathrm{E}-04$ & 3520 \\
Ni-59 & $6.55 \mathrm{E}-05$ & 10800 & $1.15 \mathrm{E}-04$ & 7620 & $1.55 \mathrm{E}-04$ & 6230 \\
Tc-99 & $1.51 \mathrm{E}-03$ & 3230 & $2.64 \mathrm{E}-03$ & 3180 & $3.67 \mathrm{E}-03$ & 3160 \\
$\mathrm{I}-129$ & $1.06 \mathrm{E}-02$ & 1510 & $1.06 \mathrm{E}-02$ & 1510 & $1.06 \mathrm{E}-02$ & 1510 \\
\hline
\end{tabular}

Table 5.4-3 Effect of Increase in Infiltration Rate after Failure (subsidence) of the Slit Trench

\begin{tabular}{lcccccc}
\multirow{2}{*}{ Nuclides } & \multicolumn{2}{c}{$40 \mathrm{~cm} / \mathrm{yr}$} & \multicolumn{2}{c}{$80 \mathrm{~cm} / \mathrm{yr}$} & \multicolumn{2}{c}{$120 \mathrm{~cm} / \mathrm{yr}$} \\
& $\begin{array}{c}\text { Peak Flux } \\
\text { fraction/yr }\end{array}$ & Peak Time & Pr & Peak Flux & Peak Time & \multicolumn{2}{c}{ Peak Flux } & Peak Time \\
& fraction/yr & yr & fraction/yr & $\mathrm{yr}$ \\
\hline C-14 & $3.09 \mathrm{E}-02$ & 155 & $5.21 \mathrm{E}-02$ & 145 & $5.1 \mathrm{E}-02$ & 145 \\
Ni-59 & $1.98 \mathrm{E}-04$ & 6850 & $3.60 \mathrm{E}-04$ & 3770 & $3.60 \mathrm{E}-04$ & 3770 \\
Tc-99 & $1.00 \mathrm{E}-01$ & 16.2 & $1.00 \mathrm{E}-01$ & 16.2 & $1.00 \mathrm{E}-01$ & 16.2 \\
$\mathrm{I}-129$ & $7.27 \mathrm{E}-02$ & 22.4 & $7.27 \mathrm{E}-02$ & 22.4 & $7.27 \mathrm{E}-02$ & 22.4 \\
\hline
\end{tabular}


infiltration may increase, the peak flux increases by less than a factor of three for an increase in infiltration from $40 \mathrm{~cm} / \mathrm{yr}$ to $120 \mathrm{~cm} / \mathrm{yr}$.

The time of placement of the moisture barriers on slit trenches is a potentially important parameter with respect to performance of the trenches for mobile radionuclides such as tritium. Delayed placement of the barrier, which may occur when the time to fill the trenches is extended out in time, may lead to undesirable leaching of mobile radionuclides. Therefore, a study was conducted to analyze the sensitivity of the PORFLOW model to the time of moisture barrier placement: immediate placement (i.e., trenches are filled and capped in a time much shorter than one year); and placement an average of 25 years after the trench is filled. The results of this analysis are provided in Table 5.4-4 for five radionuclides: ${ }^{3} \mathrm{H}$ (mobile, shortlived), ${ }^{14} \mathrm{C}$ (fairly mobile, moderate half-life), ${ }^{59} \mathrm{Ni}$ (strongly sorbing, long half-life), ${ }^{99} \mathrm{Tc}$ (mobile, long halflife), and ${ }^{129} \mathrm{I}$ (mobile, long half-life). The results indicate that for mobile, short-lived radionuclides like ${ }^{3} \mathrm{H}$, immediate capping considerably reduces the peak flux to the water table, and ultimately the groundwater concentration at the compliance point. In this particular case, immediate capping reduced the peak tritium flux by four orders of magnitude. For long-lived radionuclides, whether sorbing or mobile, the results are fairly insensitive to the time of capping, because most of the radionuclide remains in the slit trench until the assumed cap failure at 100 years.

Table 5.4-4 Effect of Time of Placement of Moisture Barrier on Flux to the Water Table for Slit Trenches

\begin{tabular}{|c|c|c|c|c|}
\hline \multirow[b]{2}{*}{ Nuclides } & \multicolumn{2}{|c|}{ Capped at time 0} & \multicolumn{2}{|c|}{ Capped after 25 years } \\
\hline & $\begin{array}{l}\text { Peak Flux } \\
\text { fraction/year }\end{array}$ & $\begin{array}{c}\text { Peak Time } \\
\text { year }\end{array}$ & $\begin{array}{l}\text { Peak Flux } \\
\text { fraction/year }\end{array}$ & $\begin{array}{c}\text { Peak Time } \\
\text { year }\end{array}$ \\
\hline H-3 & $1.54 \mathrm{E}-05$ & 120 & $1.56 \mathrm{E}-01$ & 6.9 \\
\hline $\mathrm{C}-14$ & $2.93 \mathrm{E}-02$ & 150 & $3.09 \mathrm{E}-02$ & 155 \\
\hline $\mathrm{Ni}-59$ & $1.90 \mathrm{E}-04$ & 7180 & $1.98 \mathrm{E}-04$ & 6850 \\
\hline Тc-99 & $6.17 \mathrm{E}-02$ & 120 & $1.00 \mathrm{E}-01$ & 16.2 \\
\hline $1-129$ & $6.60 \mathrm{E}-02$ & 120 & $7.27 \mathrm{E}-02$ & 22.4 \\
\hline
\end{tabular}

Finally, the sensitivity of the groundwater concentration analysis to the point of assessment was studied. Groundwater concentrations directly under the disposal units, peak concentrations outside of a $100-\mathrm{m}$ buffer zone, and concentrations at seeplines near the creeks which dissect E-Area were evaluated. For the IL vaults, LAW vaults, and slit trenches, groundwater concentrations at these three locations are presented in Table 5.4-5. Results for four radionuclides were evaluated: ${ }^{3} \mathrm{H}$ (mobile, short-lived), ${ }^{14} \mathrm{C}$ (fairly mobile, moderate half-life), ${ }^{59} \mathrm{Ni}$ (strongly sorbing, long half-life), and ${ }^{99} \mathrm{Tc}$ (low mobility in cement, high mobility in soil, long half-life). Peak groundwater concentrations were evaluated out to 10,000 years after facility closure. Two generalizations can be made from the data in Table 5.4-4. First, the influence of the location of the point of compliance is greater in this analysis for strongly-sorbing radionuclides such as ${ }^{59} \mathrm{Ni}$, mainly due to retardation of the plume. Points of compliance far from the source show a much larger difference between peak concentration at the $100-\mathrm{m}$ well and at the seepline during a 10,000-year time of assessment for these slow-moving radionuclides. Second, the influence of the location of the point of compliance is greater for short-lived radionuclides than for longer-lived radionuclides with similar sorption characteristics.

The sensitivity of calculated disposal limits for each disposal unit considered in this analysis on the time of compliance was investigated. is shown in tables 5.3-6 through 5.3-11. The Performance Assessment Team working on this analysis chose to not follow the guidance for DOE Order 435.1 with respect to the time of assessment. Instead of the recommended time of 1,000 years, the team decided to use 10,000 years. Over the longer time period more radionuclides arrive at the hypothetical well 100 meters down gradient of the 
Table 5.4-5 Effect of Location of Compliance Point on Peak Groundwater

Concentrations Projected for LAW Vaults, IL Vaults, and Slit Trenches within 10,000 Years after Closure

\begin{tabular}{lcccccc}
\hline LAW vault & \multicolumn{2}{c}{ Source Node } & \multicolumn{2}{c}{100 -meter Well } & \multicolumn{2}{c}{ Seepline } \\
& Peak Conc. & Peak Time & Peak Conc. & Peak Time & Peak Conc. & Peak Time \\
Nuclides & $\mathrm{pCi} / \mathrm{L}$ & year & $\mathrm{pCi} / \mathrm{L}$ & year & $\mathrm{pCi} / \mathrm{L}$ & year \\
\hline $\mathrm{H}-3$ & $3.57 \mathrm{E}-07$ & 123 & $4.48 \mathrm{E}-08$ & 126 & $8.75 \mathrm{E}-11$ & 152 \\
$\mathrm{C}-14$ & $2.48 \mathrm{E}+01$ & 4060 & $9.24 \mathrm{E}+00$ & 4200 & $3.15 \mathrm{E}-02$ & 4610 \\
$\mathrm{Ni}-59$ & $1.56 \mathrm{E}+00$ & 10000 & $2.51 \mathrm{E}-03$ & 10000 & $1.41 \mathrm{E}-21$ & 10000 \\
$\mathrm{Tc}-99$ & $1.98 \mathrm{E}+02$ & 3240 & $7.54 \mathrm{E}+01$ & 3270 & $2.67 \mathrm{E}-01$ & 3380
\end{tabular}

IL vault

Source Node 100-meter Well Seepline Peak Conc. Peak Time Peak Conc. Peak Time Pcak Conc. Peak Time

$\begin{array}{lcccccc}\text { Nuclides } & \text { pCi/L } & \text { year } & \text { pCi/L } & \text { year } & \text { pCi/L } & \text { year } \\ \text { H-3 } & 2.57 \mathrm{E}-11 & 115 & 1.07 \mathrm{E}-11 & 117 & 3.76 \mathrm{E}-15 & 134 \\ \mathrm{C}-14 & 9.01 \mathrm{E}-02 & 10000 & 4.11 \mathrm{E}-02 & 10000 & 3.37 \mathrm{E}-05 & 10000 \\ \mathrm{Ni}-59 & 9.57 \mathrm{E}+00 & 10000 & 5.04 \mathrm{E}-01 & 10000 & 1.21 \mathrm{E}-18 & 10000 \\ \text { Tc-99 } & 3.97 \mathrm{E}+01 & 2770 & 1.82 \mathrm{E}+01 & 2780 & 1.58 \mathrm{E}-02 & 2910\end{array}$

\section{SLIT trench}

Source Node

100-meter Well Peak Conc. Peak Time Peak Conc. Peak Time Peak Conc. Peak Time

\begin{tabular}{lcccccc} 
Nuclides & $\mathrm{pCi} / \mathrm{L}$ & year & $\mathrm{pCi} / \mathrm{L}$ & year & $\mathrm{pCi} / \mathrm{L}$ & year \\
\hline $\mathrm{H}-3$ & $1.48 \mathrm{E}+04$ & 8.0 & $1.59 \mathrm{E}+03$ & 9.0 & $4.48 \mathrm{E}+01$ & 19.0 \\
$\mathrm{C}-14$ & $2.24 \mathrm{E}+03$ & 170 & $2.17 \mathrm{E}+02$ & 180 & $7.31 \mathrm{E}+00$ & 325 \\
$\mathrm{Ni}-59$ & $1.15 \mathrm{E}+01$ & 8940 & $7.08 \mathrm{E}-01$ & 8940 & $5.58 \mathrm{E}-08$ & 8940 \\
$\mathrm{Tc}-99$ & $8.42 \mathrm{E}+03$ & 20.0 & $7.32 \mathrm{E}+02$ & 20.0 & $3.15 \mathrm{E}+01$ & 70.0
\end{tabular}


Table 5.4-6 Sensitivity of Groundwater-Based Inventory Limits for the LAW Vaults to Time of Assessment

\begin{tabular}{|c|c|c|c|c|c|}
\hline Radionuclide ${ }^{a}$ & $\begin{array}{c}\text { Concentration } \\
\operatorname{limit}^{b} \\
\mathrm{pCi} / \mathrm{L}\end{array}$ & $\begin{array}{c}\text { Peak } \\
\text { groundwater } \\
\text { concentration } \\
\text { up to } \\
1,000 \text { years } \\
\text { pCi } / \mathrm{L}-\mathrm{Ci} \\
\end{array}$ & $\begin{array}{c}\text { Calculated } \\
\text { inventory } \\
\text { limit based on } \\
1,000 \text { year Time } \\
\text { of Compliance } \\
\text { Ci/vault } \\
\end{array}$ & $\begin{array}{c}\text { Peak } \\
\text { groundwater } \\
\text { concentration } \\
\text { up to } \\
10,000 \text { years } \\
\text { pCi/L-Ci } \\
\end{array}$ & $\begin{array}{c}\text { Calculated } \\
\text { inventory } \\
\text { limit based on } \\
10,000 \text { year Time } \\
\text { of Compliance } \\
\mathrm{Ci} / \text { vault }\end{array}$ \\
\hline $\mathrm{H}-3$ & $2.00 \mathrm{E}+04$ & $9.5 \mathrm{E}-08$ & $1.1 \mathrm{E}+11$ & $9.5 \mathrm{E}-08$ & $1.1 \mathrm{E}+11$ \\
\hline C-14 & $6.40 \mathrm{E}+03$ & $2.3 \mathrm{E}-02$ & $1.4 \mathrm{E}+05$ & $9.2 \mathrm{E}+00$ & $3.5 \mathrm{E}+02$ \\
\hline $\mathrm{Ni}-59$ & $5.30 \mathrm{E}+02$ & $0.0 \mathrm{E}+00$ & no $\operatorname{limit}^{e}$ & $2.5 \mathrm{E}-03$ & $1.1 E+05$ \\
\hline $\mathrm{Se}-79$ & $6.60 \mathrm{E}+02$ & $0.0 \mathrm{E}+00$ & no limit ${ }^{\mathrm{e}}$ & $2.5 E+00$ & $1.3 E+02$ \\
\hline $\mathrm{Rb}-87$ & $2.70 \mathrm{E}+02$ & $0.0 \mathrm{E}+00$ & no limit $^{e}$ & $8.1 E+02$ & $1.7 \mathrm{E}-01$ \\
\hline Sr-90 +d & $8.00 \mathrm{E}+00$ & $0.0 \mathrm{E}+00$ & no $\operatorname{limit}^{e}$ & $8.6 \mathrm{E}-19$ & $4.6 \mathrm{E}+18$ \\
\hline $\mathrm{Zr}-93+\mathrm{d}$ & $2.10 \mathrm{E}+03$ & $0.0 \mathrm{E}+00$ & no $\operatorname{limit}^{\mathrm{e}}$ & $2.5 \mathrm{E}+00$ & $4.1 \mathrm{E}+02$ \\
\hline $\mathrm{Nb}-94$ & $1.30 \mathrm{E}+02$ & $0.0 \mathrm{E}+00$ & no $\operatorname{limit}^{\mathrm{e}}$ & $2.3 \mathrm{E}+02$ & $2.9 \mathrm{E}-01$ \\
\hline Tc-99 & $8.00 \mathrm{E}+02$ & $0.0 \mathrm{E}+00$ & no limit ${ }^{e}$ & $7.5 E+01$ & $5.3 \mathrm{E}+00$ \\
\hline Pd-107 & $3.66 \mathrm{E}+04$ & $0.0 \mathrm{E}+00$ & no $\operatorname{limit}^{\mathrm{e}}$ & $8.2 \mathrm{E}+02$ & $2.2 \mathrm{E}+0 \mathrm{l}$ \\
\hline$S n-126+d$ & $2.90 \mathrm{E}+02$ & $0.0 \mathrm{E}+00$ & no $\operatorname{limit}^{\mathrm{e}}$ & $4.8 \mathrm{E}+00$ & $3.0 \mathrm{E}+01$ \\
\hline I-129 & $5.00 \mathrm{E}-01$ & $6.1 \mathrm{E}+00$ & $4.1 \mathrm{E}-02$ & $4.1 E+02$ & $6.1 \mathrm{E}-04$ \\
\hline Cs- 135 & $8.00 \mathrm{E}+02$ & $0.0 \mathrm{E}+00$ & no limit ${ }^{e}$ & $1.3 \mathrm{E}+02$ & $3.1 E+00$ \\
\hline Th-232 & $1.30 \mathrm{E}+01$ & $0.0 \mathrm{E}+00$ & no limit ${ }^{e}$ & $9.2 \mathrm{E}-10$ & $7.0 \mathrm{E}+09$ \\
\hline Ra-228 & $5.00 \mathrm{E}+00$ & $0.0 \mathrm{E}+00$ & & $6.6 \mathrm{E}-09$ & $3.8 \mathrm{E}+08$ \\
\hline Th-228 & $1.50 \mathrm{E}+01$ & $0.0 \mathrm{E}+00$ & & $1.0 \mathrm{E}-09$ & $7.3 E+09$ \\
\hline Ra-224 & $1.50 \mathrm{E}+01$ & $0.0 \mathrm{E}+00$ & & $6.6 \mathrm{E}-09$ & $1.1 \mathrm{E}+09$ \\
\hline U-232 & $2.60 \mathrm{E}+01$ & $0.0 \mathrm{E}+00$ & no $\operatorname{limit}^{\mathrm{e}}$ & $0.0 \mathrm{E}+00$ & no limit ${ }^{\mathrm{e}}$ \\
\hline Th-228 & $1.50 \mathrm{E}+01$ & $0.0 \mathrm{E}+00$ & & $0.0 \mathrm{E}+00$ & \\
\hline $\mathrm{Ra}-224$ & $1.50 \mathrm{E}+01$ & $0.0 \mathrm{E}+00$ & & $0.0 \mathrm{E}+00$ & \\
\hline U-233 & $1.25 \mathrm{E}+02$ & $0.0 \mathrm{E}+00$ & no $\operatorname{limit}^{c}$ & $3.6 \mathrm{E}-08$ & $1.4 \mathrm{E}+09$ \\
\hline Th-229 & $9.60 \mathrm{E}+00$ & $0.0 \mathrm{E}+00$ & & $5.0 \mathrm{E}-10$ & \\
\hline $\mathrm{Ra}-225$ & $9.00 \mathrm{E}+00$ & $0.0 \mathrm{E}+00$ & & $3.2 \mathrm{E}-09$ & \\
\hline U-234 & $1.32 \mathrm{E}+02$ & $0.0 \mathrm{E}+00$ & no $\operatorname{limit}^{\mathfrak{e}}$ & $1.9 \mathrm{E}-09$ & $3.3 \mathrm{E}+04$ \\
\hline Th-230 & $1.50 \mathrm{E}+01$ & $0.0 \mathrm{E}+00$ & & $6.8 \mathrm{E}-13$ & \\
\hline $\mathrm{Ra}-226$ & $5.00 \mathrm{E}+00$ & $0.0 \mathrm{E}+00$ & & $2.3 \mathrm{E}-06$ & \\
\hline $\mathrm{Pb}-210$ & $3.00 \mathrm{E}-01$ & $0.0 \mathrm{E}+00$ & & $4.5 \mathrm{E}-06$ & \\
\hline Po-210 & $1.50 \mathrm{E}+01$ & $0.0 \mathrm{E}+00$ & & $8.2 \mathrm{E}-06$ & \\
\hline U-235 & $1.39 \mathrm{E}+02$ & $0.0 \mathrm{E}+00$ & no $\operatorname{limit}^{\mathrm{e}}$ & $6.9 \mathrm{E}-13$ & $3.0 \mathrm{E}+05$ \\
\hline $\mathrm{Pa}-231$ & $3.10 \mathrm{E}+00$ & $0.0 \mathrm{E}+00$ & & $5.2 \mathrm{E}-06$ & \\
\hline Ac -227 & $2.50 \mathrm{E}+00$ & $0.0 \mathrm{E}+00$ & & $6.5 \mathrm{E}-06$ & \\
\hline Th-227 & $1.50 \mathrm{E}+01$ & $0.0 \mathrm{E}+00$ & & $9.1 \mathrm{E}-07$ & \\
\hline $\mathrm{Ra}-223$ & $1.50 \mathrm{E}+01$ & $0.0 \mathrm{E}+00$ & & $5.8 \mathrm{E}-06$ & \\
\hline U-236 & $1.39 \mathrm{E}+02$ & $0.0 \mathrm{E}+00$ & no $\operatorname{limit}^{\mathrm{e}}$ & $2.4 \mathrm{E}-10$ & $2.8 \mathrm{E}+11$ \\
\hline Np-237 & $8.90 \mathrm{E}+00$ & $2.4 \mathrm{E}-04$ & $1.9 \mathrm{E}+04$ & $1.1 \mathrm{E}+00$ & $4.2 E+00$ \\
\hline U-238 & $6.66 \mathrm{E}+00$ & $0.0 \mathrm{E}+00$ & no limit ${ }^{e}$ & $1.3 \mathrm{E}-12$ & $1.9 \mathrm{E}+09$ \\
\hline Th-234 & $5.90 \mathrm{E}+01$ & $0.0 \mathrm{E}+00$ & & $1.4 \mathrm{E}-14$ & \\
\hline U-234 & $1.32 \mathrm{E}+02$ & $0.0 \mathrm{E}+00$ & & $3.5 \mathrm{E}-08$ & \\
\hline $\mathrm{Pu}-238$ & $8.90 \mathrm{E}+00$ & $0.0 \mathrm{E}+00$ & no limit ${ }^{e}$ & $0.0 \mathrm{E}+00$ & $2.8 \mathrm{E}+09$ \\
\hline U-234 & $1.32 \mathrm{E}+02$ & $0.0 \mathrm{E}+00$ & & $2.3 \mathrm{E}-08$ & \\
\hline Pu-239 & $8.10 \mathrm{E}+00$ & $0.0 \mathrm{E}+00$ & no $\operatorname{limit}^{\mathrm{e}}$ & $3.1 \mathrm{E}-10$ & 1. $3 \mathrm{E}+10$ \\
\hline U-235 & $1.39 \mathrm{E}+02$ & $0.0 \mathrm{E}+00$ & & $8.1 \mathrm{E}-12$ & \\
\hline
\end{tabular}


Table 5.4-7 Sensitivity of Groundwater-Based Inventory Limits for the IL Vaults to Time of Assessment

\begin{tabular}{|c|c|c|c|c|c|}
\hline Radionuclide & $\begin{array}{l}\text { Concentration } \\
\operatorname{limit}^{b} \\
\mathrm{pCi} / \mathrm{L}\end{array}$ & $\begin{array}{c}\text { Peak } \\
\text { groundwater } \\
\text { concentration } \\
\text { up to } \\
1,000 \text { years }{ }^{c} \\
\text { pCi/L-Ci }\end{array}$ & $\begin{array}{c}\text { Calculated } \\
\text { inventory limit } \\
\text { based on } 1,000 \\
\text { year Time of } \\
\text { Compliance } \\
\text { Ci/vault }\end{array}$ & $\begin{array}{c}\text { Peak } \\
\text { groundwater } \\
\text { concentration } \\
\text { up to } \\
10,000 \text { years } \\
\text { pCi/L-Ci }\end{array}$ & $\begin{array}{c}\text { Calculated } \\
\text { inventory limit } \\
\text { based on } 10,000 \\
\text { year Time of } \\
\text { Compliance } \\
\text { Ci/vault }\end{array}$ \\
\hline $\mathrm{H}-3$ & $2.00 \mathrm{E}+04$ & $1.07 \mathrm{E}-11$ & $9.35 \mathrm{E}+14$ & $1.07 \mathrm{E}-11$ & $9.35 \mathrm{E}+14$ \\
\hline$C-14$ & $6.40 E+03$ & $2.3 \mathrm{E}-04$ & $1.4 \mathrm{E}+07$ & $4.11 \mathrm{E}-02$ & $7.79 \mathrm{E}+04$ \\
\hline $\mathrm{Ni}-59$ & $5.30 \mathrm{E}+02$ & $1.9 \mathrm{E}-03$ & $1.4 E+05$ & $5.04 \mathrm{E}-01$ & $5.26 \mathrm{E}+02$ \\
\hline Se-79 & $6.60 \mathrm{E}+02$ & $0.0 \mathrm{E}+00$ & no limit ${ }^{e}$ & $1.19 \mathrm{E}+01$ & $2.77 \mathrm{E}+01$ \\
\hline Sr-90 +d & $8.00 \mathrm{E}+00$ & $0.0 \mathrm{E}+00$ & no $\operatorname{limit}^{\mathrm{e}}$ & $2.17 \mathrm{E}-10$ & $1.84 \mathrm{E}+10$ \\
\hline $\mathrm{Zr}-93+\mathrm{d}$ & $2.10 \mathrm{E}+03$ & $0.0 \mathrm{E}+00$ & no $\operatorname{limit}^{e}$ & $1.02 \mathrm{E}-03$ & $1.03 E+06$ \\
\hline Tc-99 & $8.00 \mathrm{E}+02$ & $2.1 \mathrm{E}-02$ & no limit ${ }^{e}$ & $1.82 \mathrm{E}+01$ & $2.20 \mathrm{E}+01$ \\
\hline Sn- $126+d$ & $2.90 \mathrm{E}+02$ & $8.0 \mathrm{E}-04$ & $1.8 \mathrm{E}+05$ & $1.29 \mathrm{E}+00$ & $1.12 \mathrm{E}+02$ \\
\hline I-129 & $5.00 \mathrm{E}-01$ & $4.0 \mathrm{E}-05$ & $6.25 E+03$ & $9.66 \mathrm{E}+02$ & $2.59 \mathrm{E}-04$ \\
\hline Cs-135 & $8.00 \mathrm{E}+02$ & $6.6 \mathrm{E}-03$ & $6.0 \mathrm{E}+04$ & $3.63 E+00$ & $1.10 \mathrm{E}+02$ \\
\hline Th-232 & $1.30 \mathrm{E}+01$ & $0.0 \mathrm{E}+00$ & no $\operatorname{limit}^{\mathrm{e}}$ & $7.76 \mathrm{E}-15$ & $4.50 \mathrm{E}+13$ \\
\hline $\mathrm{Ra}-228$ & $5.00 \mathrm{E}+00$ & $0.0 \mathrm{E}+00$ & & $5.56 \mathrm{E}-14$ & \\
\hline Th-228 & $1.50 \mathrm{E}+01$ & $0.0 \mathrm{E}+00$ & & $8.67 \mathrm{E}-15$ & \\
\hline $\mathrm{Ra}-224$ & $1.50 \mathrm{E}+0 \mathrm{I}$ & $0.0 \mathrm{E}+00$ & & $5.55 \mathrm{E}-14$ & \\
\hline U-232 & $2.60 \mathrm{E}+01$ & $0.0 \mathrm{E}+00$ & no limit ${ }^{e}$ & $3.89 \mathrm{E}-12$ & \\
\hline Th-228 & $1.50 \mathrm{E}+01$ & $0.0 \mathrm{E}+00$ & & $4.29 \mathrm{E}-14$ & \\
\hline $\mathrm{Ra}-224$ & $1.50 \mathrm{E}+01$ & $0.0 E+00$ & & $2.75 \mathrm{E}-13$ & \\
\hline U-233 & $1.25 \mathrm{E}+02$ & $0.0 \mathrm{E}+00$ & no limit ${ }^{\mathrm{e}}$ & 4.48E-09 & $4.74 \mathrm{E}+10$ \\
\hline Th-229 & $9.60 \mathrm{E}+00$ & $0.0 \mathrm{E}+00$ & & $1.49 \mathrm{E}-11$ & \\
\hline Ra-225 & $9.00 \mathrm{E}+00$ & $0.0 \mathrm{E}+00$ & & $9.50 \mathrm{E}-11$ & \\
\hline $\mathrm{U}-234$ & $1.32 \mathrm{E}+02$ & $0.0 \mathrm{E}+00$ & no $\operatorname{limit}^{e}$ & $5.69 \mathrm{E}-10$ & $2.49 \mathrm{E}+03$ \\
\hline Th-230 & $1.50 E+01$ & $0.0 E+00$ & & $1.93 \mathrm{E}-13$ & \\
\hline $\mathrm{Ra}-226$ & $5.00 \mathrm{E}+00$ & $0.0 \mathrm{E}+00$ & & $3.08 \mathrm{E}-05$ & \\
\hline $\mathrm{Pb}-210$ & $3.00 \mathrm{E}-01$ & $0.0 \mathrm{E}+00$ & & $6.02 \mathrm{E}-05$ & \\
\hline Po-210 & $1.50 \mathrm{E}+01$ & $0.0 \mathrm{E}+00$ & & $1.08 \mathrm{E}-04$ & \\
\hline $\mathrm{U}-235$ & $1.39 \mathrm{E}+02$ & $0.0 \mathrm{E}+00$ & no $\operatorname{limit}^{\mathrm{e}}$ & $2.01 \mathrm{E}-13$ & $1.88 \mathrm{E}+07$ \\
\hline $\mathrm{Pa}-231$ & $3.10 \mathrm{E}+00$ & $0.0 \mathrm{E}+00$ & & $8.25 E-08$ & \\
\hline Ac- 227 & $2.50 \mathrm{E}+00$ & $0.0 \mathrm{E}+00$ & & $1.02 \mathrm{E}-07$ & \\
\hline Th-227 & $1.50 \mathrm{E}+01$ & $0.0 \mathrm{E}+00$ & & $1.43 \mathrm{E}-08$ & \\
\hline Ra-223 & $1.50 \mathrm{E}+01$ & $0.0 \mathrm{E}+00$ & & $9.18 \mathrm{E}-08$ & \\
\hline U-236 & $1.39 \mathrm{E}+02$ & $0.0 \mathrm{E}+00$ & no limit ${ }^{e}$ & $3.12 \mathrm{E}-11$ & $2.23 E+12$ \\
\hline Np-237 & $8.90 \mathrm{E}+00$ & $3.4 E-04$ & $1.3 E+04$ & $1.34 \mathrm{E}-01$ & $3.32 E+01$ \\
\hline U-238 & $6.66 \mathrm{E}+00$ & $0.0 \mathrm{E}+00$ & no $\operatorname{limit}^{e}$ & $1.63 \mathrm{E}-13$ & $2.01 E+10$ \\
\hline Th-234 & $5.90 \mathrm{E}+01$ & $0.0 \mathrm{E}+00$ & & $1.80 \mathrm{E}-15$ & \\
\hline $\mathrm{U}-234$ & $1.32 \mathrm{E}+02$ & $0.0 \mathrm{E}+00$ & & $3.29 \mathrm{E}-09$ & \\
\hline $\mathrm{Pu}-238$ & $8.90 \mathrm{E}+00$ & $0.0 \mathrm{E}+00$ & no limit ${ }^{e}$ & $2.35 \mathrm{E}-18$ & $2.24 \mathrm{E}+10$ \\
\hline U-234 & $1.32 \mathrm{E}+02$ & $0.0 \mathrm{E}+00$ & & $2.95 \mathrm{E}-09$ & \\
\hline Pu-239 & $8.10 \mathrm{E}+00$ & $0.0 \mathrm{E}+00$ & no $\operatorname{limit}^{e}$ & $9.41 \mathrm{E}-12$ & $4.30 \mathrm{E}+11$ \\
\hline U-235 & $1.39 \mathrm{E}+02$ & $0.0 \mathrm{E}+00$ & & $1.04 \mathrm{E}-12$ & \\
\hline $\mathrm{Pu}-240$ & $8.10 \mathrm{E}+00$ & $0.0 \mathrm{E}+00$ & no $\operatorname{limit}^{e}$ & $2.08 \mathrm{E}-11$ & $1.95 \mathrm{E}+11$ \\
\hline U-236 & $1.39 \mathrm{E}+02$ & $0.0 \mathrm{E}+00$ & & $3.13 \mathrm{E}-11$ & \\
\hline
\end{tabular}


Table 5.4.8 Sensitivity of Groundwater-Based Inventory Limits for the Slit Trenches to Time of Assessment

\begin{tabular}{|c|c|c|c|c|c|}
\hline Radionuclide $^{\mathbf{a}}$ & $\begin{array}{c}\text { Concentration } \\
\operatorname{limit}^{b} \\
\mathrm{pCi} / \mathrm{L}\end{array}$ & $\begin{array}{c}\text { Peak } \\
\text { groundwater } \\
\text { concentration } \\
\text { up to } \\
1,000 \text { years } \\
\text { pCi/L }\end{array}$ & $\begin{array}{c}\text { Calculated } \\
\text { inventory limit } \\
\text { based on } 1,000 \\
\text { year Time of } \\
\text { Compliance } \\
\text { Ci/5 trenches }\end{array}$ & $\begin{array}{c}\text { Peak } \\
\text { groundwater } \\
\text { concentration } \\
\text { up to } \\
10,000 \text { years } \\
\text { pCi } / \mathrm{L}\end{array}$ & $\begin{array}{c}\text { Calculated } \\
\text { inventory limit } \\
\text { based on } 10,000 \\
\text { year Time of } \\
\text { Compliance } \\
\text { Ci/5 trenches }\end{array}$ \\
\hline $\mathrm{H}-3$ & $2.00 \mathrm{E}+04$ & $1.59 \mathrm{E}+03$ & $6.29 E+00$ & $1.59 \mathrm{E}+03$ & $6.29 \mathrm{E}+00$ \\
\hline$C-14$ & $6.40 \mathrm{E}+03$ & $2.17 \mathrm{E}+02$ & $1.47 \mathrm{E}+01$ & $2.17 \mathrm{E}+02$ & $1.47 \mathrm{E}+01$ \\
\hline Ni-59 & $5.30 \mathrm{E}+02$ & $1.04 \mathrm{E}-03$ & $2.6 \mathrm{E}+05$ & $9.32 \mathrm{E}-01$ & $2.84 \mathrm{E}+02$ \\
\hline $\mathrm{Se}-79$ & $6.60 E+02$ & $0.0 \mathrm{E}+00$ & no limit ${ }^{e}$ & $2.97 \mathrm{E}+00$ & $1.11 \mathrm{E}+02$ \\
\hline Sr-90+d & $8.00 \mathrm{E}+00$ & $7.05 \mathrm{E}-03$ & $5.67 \mathrm{E}+02$ & $7.05 \mathrm{E}-03$ & $5.67 \mathrm{E}+02$ \\
\hline$Z_{r}-93+d$ & $2.10 \mathrm{E}+03$ & & no limit ${ }^{e}$ & $3.79 \mathrm{E}+01$ & $2.77 \mathrm{E}+01$ \\
\hline Tc-99 & $8.00 \mathrm{E}+02$ & $7.32 \mathrm{E}+02$ & $5.46 \mathrm{E}-01$ & $7.32 \mathrm{E}+02$ & $5.46 \mathrm{E}-01$ \\
\hline Pd-107 & $3.66 \mathrm{E}+04$ & & no $\operatorname{limit}^{\mathrm{e}}$ & $4.52 \mathrm{E}+02$ & $4.05 E+01$ \\
\hline Sn-126+d & $2.90 \mathrm{E}+02$ & $0.0 \mathrm{E}+00$ & no limit ${ }^{e}$ & $3.50 \mathrm{E}+00$ & $4.14 \mathrm{E}+01$ \\
\hline I-129 & $5.00 \mathrm{E}-01$ & $4.77 \mathrm{E}+02$ & $5.24 \mathrm{E}-04$ & $4.77 \mathrm{E}+02$ & $5.24 \mathrm{E}-04$ \\
\hline Cs-135 & $8.00 \mathrm{E}+02$ & $3.47 \mathrm{E}-03$ & $1.2 \mathrm{E}+05$ & $1.41 \mathrm{E}+00$ & $2.84 \mathrm{E}+02$ \\
\hline Th-232 & $1.30 \mathrm{E}+01$ & $0.0 \mathrm{E}+00$ & no limit & $5.08 \mathrm{E}-07$ & $7.18 \mathrm{E}+05$ \\
\hline Ra-228 & $5.00 \mathrm{E}+00$ & $0.0 \mathrm{E}+00$ & & $3.48 \mathrm{E}-06$ & \\
\hline Th-228 & $1.50 \mathrm{E}+01$ & $0.0 \mathrm{E}+00$ & & $5.42 \mathrm{E}-07$ & \\
\hline$R a-224$ & $1.50 \mathrm{E}+01$ & $0.0 \mathrm{E}+00$ & & $3.47 \mathrm{E}-06$ & \\
\hline $\mathrm{U}-232$ & $2.60 \mathrm{E}+01$ & & no limit ${ }^{e}$ & $1.81 \mathrm{E}+00$ & $1.44 \mathrm{E}+01$ \\
\hline Th-228 & $1.50 \mathrm{E}+01$ & & & $2.00 \mathrm{E}-02$ & \\
\hline Ra-224 & $1.50 \mathrm{E}+01$ & & & $1.28 \mathrm{E}-01$ & \\
\hline U-233 & $1.25 \mathrm{E}+02$ & & no $\operatorname{limit}^{e}$ & $7.19 \mathrm{E}+02$ & $2.42 \mathrm{E}+00$ \\
\hline Th-229 & $9.60 \mathrm{E}+00$ & & & $2.92 \mathrm{E}-01$ & \\
\hline $\mathrm{Ra}-225$ & $9.00 \mathrm{E}+00$ & & & $1.86 \mathrm{E}+00$ & \\
\hline U-234 & $1.32 E+02$ & $1.22 E+01$ & $3.9 E+00$ & $1.39 E+01$ & $3.40 \mathrm{E}+00$ \\
\hline Th-230 & $1.50 \mathrm{E}+01$ & $2.43 \mathrm{E}-04$ & & $4.22 \mathrm{E}-03$ & \\
\hline Ra-226 & $5.00 \mathrm{E}+00$ & $9.56 \mathrm{E}-05$ & & $2.39 \mathrm{E}-02$ & \\
\hline $\mathrm{Pb}-210$ & $3.00 \mathrm{E}-01$ & $1.46 \mathrm{E}-04$ & & $4.41 \mathrm{E}-02$ & \\
\hline Po-210 & $1.50 \mathrm{E}+01$ & $2.63 \mathrm{E}-04$ & & $7.94 \mathrm{E}-02$ & \\
\hline$U-235$ & $1.39 \mathrm{E}+02$ & $1.22 \mathrm{E}+01$ & $5.7 \mathrm{E}+\infty 0$ & $1.40 \mathrm{E}+01$ & $4.96 \mathrm{E}+00$ \\
\hline $\mathrm{Pa}-231$ & $3.10 E+00$ & $3.50 \mathrm{E}-03$ & & $5.11 \mathrm{E}-02$ & \\
\hline Ac- 227 & $2.50 \mathrm{E}+00$ & $3.70 \mathrm{E}-03$ & & $6.27 \mathrm{E}-02$ & \\
\hline Th-227 & $1.50 \mathrm{E}+01$ & $5.21 \mathrm{E}-04$ & & $8.82 E-03$ & \\
\hline Ra-223 & $1.50 \mathrm{E}+01$ & $3.34 \mathrm{E}-03$ & & $5.64 \mathrm{E}-02$ & \\
\hline$U-236$ & $1.39 \mathrm{E}+02$ & & no limit ${ }^{e}$ & $7.21 \mathrm{E}+02$ & $9.64 \mathrm{E}-02$ \\
\hline Np-237 & $8.90 \mathrm{E}+00$ & $9.23 \mathrm{E}+01$ & $4.8 \mathrm{E}-02$ & $9.23 \mathrm{E}+01$ & $4.82 E-02$ \\
\hline U-238 & $6.66 \mathrm{E}+00$ & $1.23 \mathrm{E}+01$ & $2.7 \mathrm{E}-01$ & $1.41 \mathrm{E}+01$ & $2.36 \mathrm{E}-01$ \\
\hline Th-234 & $5.90 \mathrm{E}+01$ & $1.34 \mathrm{E}-01$ & & $1.54 \mathrm{E}-01$ & \\
\hline U-234 & $1.32 E+02$ & $3.46 \mathrm{E}-02$ & & $4.88 \mathrm{E}-02$ & \\
\hline Pu-238 & $8.90 E+00$ & & no limit ${ }^{e}$ & $4.71 \mathrm{E}-03$ & $2.83 E+02$ \\
\hline U-234 & $1.32 \mathrm{E}+02$ & & & $2.33 \mathrm{E}-01$ & \\
\hline $\mathrm{Pu}-239$ & $8.10 \mathrm{E}+00$ & $5.18 \mathrm{E}-03$ & no limit ${ }^{e}$ & $4.36 \mathrm{E}+00$ & $9.29 \mathrm{E}-01$ \\
\hline U-235 & $1.39 E+02$ & $8.32 \mathrm{E}-07$ & & $2.16 \mathrm{E}-05$ & \\
\hline $\mathrm{Pu}-240$ & $8.10 \mathrm{E}+00$ & $2.28 \mathrm{E}-03$ & $1.5 E+02$ & $3.47 \mathrm{E}+00$ & $1.17 \mathrm{E}+00$ \\
\hline U-236 & $1.39 E+02$ & 4.81E-06 & & $6.01 \mathrm{E}-04$ & \\
\hline
\end{tabular}


Table 5.4.8 Sensitivity of Groundwater-Based Inventory Limits for the Slit Trenches to Time of Assessment

\begin{tabular}{|c|c|c|c|c|c|}
\hline Radionuclide $^{\text {a }}$ & $\begin{array}{l}\text { Concentration } \\
\operatorname{limit}^{\mathrm{b}} \\
\mathrm{pCi} / \mathrm{L}\end{array}$ & $\begin{array}{c}\text { Peak } \\
\text { groundwater } \\
\text { concentration } \\
\text { up to } \\
1,000 \text { years } \\
\text { pCi } / \mathrm{L}\end{array}$ & $\begin{array}{c}\text { Calculated } \\
\text { inventory limit } \\
\text { based on } 1,000 \\
\text { year Time of } \\
\text { Compliance } \\
\mathrm{Ci} / 5 \text { trenches }\end{array}$ & $\begin{array}{c}\text { Peak } \\
\text { groundwater } \\
\text { concentration } \\
\text { up to } \\
10,000 \text { years } \\
\text { pCi/L }\end{array}$ & $\begin{array}{c}\text { Calculated } \\
\text { inventory limit } \\
\text { based on } 10,000 \\
\text { year Time of } \\
\text { Compliance } \\
\text { Ci } / 5 \text { trenches }\end{array}$ \\
\hline Am-241 & $7.60 \mathrm{E}+00$ & screened $^{t}$ & no limit $^{e}$ & screened $^{f}$ & $2.39 \mathrm{E}+02$ \\
\hline Np-237 & $8.90 \mathrm{E}+00$ & & & $1.86 \mathrm{E}-02$ & \\
\hline Pu-241 & $5.30 \mathrm{E}+02$ & screened $^{\text {f }}$ & no $\operatorname{limit}^{e}$ & screened $^{\mathrm{f}}$ & $7.16 E+03$ \\
\hline Am-241 & $7.60 \mathrm{E}+00$ & screened ${ }^{f}$ & & screened $^{f}$ & \\
\hline Np-237 & $8.90 \mathrm{E}+00$ & & & $6.21 \mathrm{E}-04$ & \\
\hline $\mathrm{Pu}-242$ & $8.30 \mathrm{E}+00$ & & no limit ${ }^{e}$ & $2.45 \mathrm{E}+02$ & $1.69 \mathrm{E}-02$ \\
\hline $\mathrm{U}-238$ & $1.39 E+02$ & & & $6.65 \mathrm{E}-05$ & \\
\hline Am-243 & $7.60 \mathrm{E}+00$ & & no limit ${ }^{c}$ & $1.47 \mathrm{E}-03$ & $8.96 \mathrm{E}-01$ \\
\hline $\mathrm{Np}-239$ & $3.00 \mathrm{E}+02$ & & & $5.34 \mathrm{E}-01$ & \\
\hline Pu-239 & $8.10 E+00$ & & & $4.52 \mathrm{E}+00$ & \\
\hline $\mathrm{Pu}-244$ & $8.60 \mathrm{E}+00$ & & no limit ${ }^{e}$ & $2.46 \mathrm{E}+02$ & $1.75 \mathrm{E}-02$ \\
\hline $\mathrm{Cm}-242+\mathrm{d}$ & $8.90 E+00$ & & no limit ${ }^{e}$ & $2.42 \mathrm{E}-05$ & $1.84 \mathrm{E}+05$ \\
\hline $\mathrm{Cm}-244$ & $1.50 \mathrm{E}+01$ & screened $^{f}$ & no limit ${ }^{\mathrm{e}}$ & screened & $4.26 E+02$ \\
\hline $\mathrm{Pu}-240$ & $8.10 \mathrm{E}+00$ & & & $9.50 \mathrm{E}-03$ & \\
\hline U-236 & $1.39 E+02$ & & & $1.54 E-06$ & \\
\hline $\mathrm{Cm}-245$ & $7.60 \mathrm{E}+00$ & & no limit ${ }^{e}$ & $4.68 \mathrm{E}-08$ & $4.01 E+01$ \\
\hline Pu-241 & $5.30 E+02$ & & & $1.65 \mathrm{E}-05$ & \\
\hline Am-241 & $7.60 \mathrm{E}+00$ & & & $3.10 \mathrm{E}-06$ & \\
\hline Np-237 & $8.90 E+00$ & & & $1.11 \mathrm{E}-01$ & \\
\hline $\mathrm{Cm}-246$ & $7.60 \mathrm{E}+00$ & & no limit ${ }^{e}$ & $2.42 \mathrm{E}-08$ & $1.57 \mathrm{E}+08$ \\
\hline $\mathrm{Cm}-247$ & $8.30 E+00$ & & no limit ${ }^{e}$ & $1.06 \mathrm{E}-07$ & $7.12 \mathrm{E}-01$ \\
\hline Am-243 & $7.60 \mathrm{E}+00$ & & & $3.21 \mathrm{E}-04$ & \\
\hline $\mathrm{Np}-239$ & $3.00 \mathrm{E}+02$ & & & $1.17 \mathrm{E}-01$ & \\
\hline Pu-239 & $8.10 E+00$ & & & $5.69 E+00$ & \\
\hline $\mathrm{Cm}-248$ & $2.10 \mathrm{E}+00$ & & no limit ${ }^{e}$ & $1.04 \mathrm{E}-07$ & $1.25 E+03$ \\
\hline Pu-244 & $8.60 E+00$ & & & $3.44 \mathrm{E}-03$ & \\
\hline$B k-249+d$ & $7.40 \mathrm{E}+00^{f}$ & & no limit ${ }^{e}$ & $3.89 \mathrm{E}-07$ & $9.5 \mathrm{IE}+06$ \\
\hline$C f-249$ & $7.40 \mathrm{E}+00$ & & no limit ${ }^{e}$ & $1.55 \mathrm{E}-04$ & $1.32 E+03$ \\
\hline $\mathrm{Cm}-245$ & $7.60 E+00$ & & & $1.38 \mathrm{E}-05$ & \\
\hline $\mathrm{Pu}-241$ & $5.30 E+02$ & & & $7.12 \mathrm{E}-04$ & \\
\hline Am-241 & $7.60 \mathrm{E}+00$ & & & $4.95 \mathrm{E}-05$ & \\
\hline$N p-237$ & $8.90 \mathrm{E}+00$ & & & $3.36 \mathrm{E}-03$ & \\
\hline Cf- 252 & $1.50 \mathrm{E}+01$ & screened $^{f}$ & no limit ${ }^{e}$ & screened ${ }^{\mathrm{f}}$ & $1.61 E+08$ \\
\hline $\mathrm{Cm}-248$ & $2.10 \mathrm{E}+00$ & & & $8.10 \mathrm{E}-13$ & \\
\hline $\mathrm{Pu}_{\mathrm{u}-244}$ & $8.60 \mathrm{E}+00$ & & & $2.68 \mathrm{E}-08$ & \\
\hline \multicolumn{6}{|c|}{$\begin{array}{l}\text { "+d" indicates short- and/or long-lived radioactive daughters are considered in the analysis. } \\
\text { The more restrictive of either the MCL or the allowable concentration based on } 25 \text { mrem/yr } \\
\text { Peak concentration is per Ci disposed of in ten slit trenches. } \\
\text { Calculated by dividing the "Concentration limit" by the "Peak groundwater concentration", and dividing by } 2 \text { to normalize to } \\
\text { five trenches. For radionuclides with daughters, the lower limit calculated by this method for all radionuclides in the decay } \\
\text { chain is the one reported as the inventory limit. } \\
\text { "No limit" refers to the fact that no significant groundwater concentration was calculated during the time period of interest; thus, } \\
\text { no limit can be calculated. } \\
\text { Inventory limit is based on radioactive daughter(s) only; parent was screened from consideration }\end{array}$} \\
\hline
\end{tabular}


Table 5.4.9 Sensitivity of Groundwater-Based Inventory Limits for the Naval Reactor Pad to Time of Assessment

\begin{tabular}{|c|c|c|c|c|c|}
\hline Radionuclide $^{\text {a }}$ & $\begin{array}{c}\text { Concentration } \\
\text { limit }^{b} \\
\mathrm{pCi} / \mathrm{L}\end{array}$ & $\begin{array}{c}\text { Peak } \\
\text { groundwater } \\
\text { concentration } \\
\text { up to } \\
1,000 \text { years } \\
\text { pCi } / L\end{array}$ & $\begin{array}{c}\text { Calculated } \\
\text { inventory } \\
\text { limit based } \\
\text { on } 1,000 \text { year } \\
\text { Time of } \\
\text { Compliance } \\
\text { Ci/gad }\end{array}$ & $\begin{array}{c}\text { Peak } \\
\text { groundwater } \\
\text { concentration } \\
\text { up to } \\
10,000 \text { years } \\
\text { pCi/L }\end{array}$ & $\begin{array}{c}\text { Calculated } \\
\text { inventory limit } \\
\text { based on } \\
10,000 \text { year } \\
\text { Time of } \\
\text { Compliance } \\
\text { Ci/pad }\end{array}$ \\
\hline $\mathrm{H}-3$ & $2.00 \mathrm{E}+04$ & $1.8 \mathrm{E}-18$ & $1.1 \mathrm{E}+22$ & $1.8 \mathrm{E}-18$ & $1.1 \mathrm{E}+22$ \\
\hline C-14 & $6.40 \mathrm{E}+03$ & $2.3 E+00$ & $2.8 \mathrm{E}+03$ & $2.3 E+00$ & $2.8 E+03$ \\
\hline $\mathrm{Ni}-59$ & $5.30 \mathrm{E}+02$ & $0.0 \mathrm{E}+00$ & no limit ${ }^{c}$ & $3.2 \mathrm{E}-01$ & $1.7 \mathrm{E}+03$ \\
\hline Se-79 & $6.60 \mathrm{E}+02$ & $0.0 \mathrm{E}+00$ & no $\operatorname{limit}^{e}$ & $7.7 \mathrm{E}+00$ & $8.6 \mathrm{E}+01$ \\
\hline Sr $-90+d$ & $8.00 E+00$ & $2.2 \mathrm{E}-09$ & $3.7 E+09$ & 2.2E-09 & $3.7 \mathrm{E}+09$ \\
\hline Mo-93 & $8.20 E+02$ & & no limit ${ }^{e}$ & $7.1 \mathrm{E}+00$ & $1.2 \mathrm{E}+02$ \\
\hline $\mathrm{Zr}-93+\mathrm{d}$ & $2.10 \mathrm{E}+03$ & $0.0 \mathrm{E}+00$ & no limit ${ }^{e}$ & $3.7 \mathrm{E}-03$ & $5.7 E+05$ \\
\hline $\mathrm{Nb}-94$ & $1.30 \mathrm{E}+02$ & $0.0 \mathrm{E}+00$ & no $\operatorname{limit}^{e}$ & $5.2 \mathrm{E}+00$ & $2.5 \mathrm{E}+01$ \\
\hline Tc-99 & $8.00 \mathrm{E}+02$ & $7.8 \mathrm{E}+00$ & $1.0 \mathrm{E}+02$ & $7.8 \mathrm{E}+00$ & $1.0 \mathrm{E}+02$ \\
\hline$S n-126+d$ & $2.90 \mathrm{E}+02$ & $0.0 \mathrm{E}+00$ & no limit ${ }^{e}$ & $8.3 E+00$ & $3.5 \mathrm{E}+01$ \\
\hline $1-129$ & $5.00 \mathrm{E}-01$ & $9.98 E+00$ & $5.0 \mathrm{E}-02$ & $1.0 \mathrm{E}+01$ & $5.0 \mathrm{E}-02$ \\
\hline Cs- 135 & $8.00 E+02$ & $0.0 \mathrm{E}+00$ & no limit ${ }^{\mathrm{e}}$ & $2.0 \mathrm{E}+00$ & $4.0 \mathrm{E}+02$ \\
\hline Th-232 & $1.30 \mathrm{E}+01$ & $0.0 \mathrm{E}+00$ & no limit ${ }^{e}$ & $7.6 \mathrm{E}-09$ & $1.7 \mathrm{E}+09$ \\
\hline Ra-228 & $5.00 \mathrm{E}+00$ & $0.0 \mathrm{E}+00$ & & 2.2E-17 & \\
\hline Th-228 & $1.50 \mathrm{E}+01$ & $0.0 \mathrm{E}+00$ & & $1.1 \mathrm{E}-18$ & \\
\hline Ra-224 & $1.50 \mathrm{E}+01$ & $0.0 \mathrm{E}+00$ & & $3.7 E-20$ & \\
\hline $\mathrm{U}-232$ & $2.60 \mathrm{E}+01$ & & no limit ${ }^{e}$ & $2.4 \mathrm{E}-07$ & $1.1 \mathrm{E}+08$ \\
\hline Th-228 & $1.50 \mathrm{E}+01$ & & & $7.0 \mathrm{E}-11$ & \\
\hline $\mathrm{Ra}-224$ & $1.50 \mathrm{E}+01$ & & & $2.3 \mathrm{E}-12$ & \\
\hline$U-234$ & $1.32 \mathrm{E}+02$ & $0.0 \mathrm{E}+\infty 0$ & no limit ${ }^{e}$ & $4.0 \mathrm{E}+00$ & $2.3 \mathrm{E}+01$ \\
\hline Th-230 & $1.50 \mathrm{E}+01$ & $0.0 \mathrm{E}+00$ & & $1.9 \mathrm{E}-03$ & \\
\hline $\mathrm{Ra}-226$ & $5.00 \mathrm{E}+00$ & $0.0 \mathrm{E}+00$ & & 7.3E-03 & \\
\hline $\mathrm{Pb}-210$ & $3.00 \mathrm{E}-01$ & $0.0 \mathrm{E}+00$ & & $1.3 \mathrm{E}-02$ & \\
\hline Po-210 & $1.50 \mathrm{E}+01$ & $0.0 \mathrm{E}+00$ & & $2.4 \mathrm{E}-02$ & \\
\hline $\mathrm{U}-235$ & $1.39 E+02$ & $0.0 \mathrm{E}+00$ & no $\operatorname{limit}^{\mathrm{e}}$ & 4.1E+00 & $3.4 \mathrm{E}+01$ \\
\hline $\mathrm{Pa}-231$ & $3.10 \mathrm{E}+00$ & $0.0 \mathrm{E}+00$ & & $2.3 \mathrm{E}-02$ & \\
\hline Ac- -227 & $2.50 \mathrm{E}+00$ & $0.0 \mathrm{E}+00$ & & $2.9 \mathrm{E}-02$ & \\
\hline Th-227 & $1.50 \mathrm{E}+01$ & $0.0 \mathrm{E}+00$ & & $4.0 \mathrm{E}-03$ & \\
\hline $\mathrm{Ra}-223$ & $1.50 \mathrm{E}+01$ & $0.0 \mathrm{E}+00$ & & $2.6 \mathrm{E}-02$ & \\
\hline U-236 & $1.39 \mathrm{E}+02$ & $0.0 \mathrm{E}+00$ & no limit ${ }^{e}$ & $4.1 \mathrm{E}+00$ & $3.4 \mathrm{E}+01$ \\
\hline Np-237 & $8.90 \mathrm{E}+00$ & $3.92 E-01$ & $2.3 \mathrm{E}+01$ & $1.0 \mathrm{E}+01$ & $8.9 \mathrm{E}-01$ \\
\hline U-238 & $6.66 \mathrm{E}+00$ & $0.0 \mathrm{E}+00$ & no limit ${ }^{e}$ & $4.1 E+00$ & $1.6 \mathrm{E}+00$ \\
\hline Th-234 & $5.90 \mathrm{E}+01$ & $0.0 \mathrm{E}+00$ & & $4.5 \mathrm{E}-02$ & \\
\hline U-234 & $1.32 \mathrm{E}+02$ & $0.0 \mathrm{E}+00$ & & $9.3 \mathrm{E}-03$ & \\
\hline $\mathrm{Pu}-238$ & $8.90 \mathrm{E}+00$ & $0.0 \mathrm{E}+00$ & no limit ${ }^{e}$ & $1.3 \mathrm{E}-09$ & $1.5 \mathrm{E}+06$ \\
\hline $\mathrm{U}-234$ & $1.32 E+02$ & $0.0 \mathrm{E}+00$ & & $9.0 \mathrm{E}-05$ & \\
\hline $\mathrm{Pu}-239$ & $8.10 \mathrm{E}+00$ & $0.0 \mathrm{E}+00$ & no limit ${ }^{e}$ & $1.0 \mathrm{E}+00$ & $7.9 \mathrm{E}+00$ \\
\hline U-235 & $1.39 E+02$ & $0.0 \mathrm{E}+00$ & & $1.3 \mathrm{E}-01$ & \\
\hline
\end{tabular}


Table 5.4.9 Sensitivity of Groundwater-Based Inventory Limits for the Naval Reactor Pad to Time of Assessment

\begin{tabular}{|c|c|c|c|c|c|}
\hline Radionuclide $^{\text {a }}$ & $\begin{array}{c}\text { Concentration } \\
\text { limit }^{\mathrm{b}} \\
\mathrm{pC} / \mathrm{L}\end{array}$ & $\begin{array}{c}\text { Peak } \\
\text { groundwater } \\
\text { concentration } \\
\text { up to } \\
1,000 \text { years } \\
\text { pCi } / \mathrm{L}\end{array}$ & $\begin{array}{c}\text { Calculated } \\
\text { inventory } \\
\text { limit based } \\
\text { on } 1,000 \text { year } \\
\text { Time of } \\
\text { Compliance } \\
\text { Ci/pad }\end{array}$ & $\begin{array}{c}\text { Peak } \\
\text { groundwater } \\
\text { concentration } \\
\text { up to } \\
10,000 \text { years } \\
\text { pCi/L }\end{array}$ & $\begin{array}{c}\text { Calculated } \\
\text { inventory limit } \\
\text { based on } \\
10,000 \text { year } \\
\text { Time of } \\
\text { Compliance } \\
\mathrm{Ci} / \mathrm{pad}\end{array}$ \\
\hline $\mathrm{Pu}-240$ & $8.10 \mathrm{E}+00$ & $0.0 \mathrm{E}+00$ & no limit $^{e}$ & $4.8 \mathrm{E}-01$ & $1.7 \mathrm{E}+01$ \\
\hline U-236 & $1.39 E+02$ & $0.0 \mathrm{E}+00$ & & $2.6 \mathrm{E}-01$ & \\
\hline Am-241 & $7.60 \mathrm{E}+00$ & screened $^{\mathrm{f}}$ & no limit ${ }^{e}$ & screened ${ }^{f}$ & $4.4 \mathrm{E}+03$ \\
\hline Np-237 & $8.90 E+00$ & $0.0 \mathrm{E}+00$ & & $2.0 E-03$ & \\
\hline $\mathrm{Pu}-241$ & $5.30 \mathrm{E}+02$ & screened $^{\mathrm{f}}$ & no limit ${ }^{e}$ & screened & $1.3 E+05$ \\
\hline Am-241 & 7. $60 \mathrm{E}+00$ & screened $^{f}$ & & screened ${ }^{f}$ & \\
\hline Np-237 & $8.90 \mathrm{E}+00$ & $0.0 \mathrm{E}+00$ & & $6.7 \mathrm{E}-05$ & \\
\hline $\mathrm{Pu}-242$ & $8.30 \mathrm{E}+00$ & $0.0 \mathrm{E}+00$ & no limit ${ }^{e}$ & $1.4 \mathrm{E}+00$ & $6.1 E+00$ \\
\hline U-238 & $1.39 \mathrm{E}+02$ & $0.0 \mathrm{E}+00$ & & $9.8 \mathrm{E}-03$ & \\
\hline Am-243 & $7.60 \mathrm{E}+00$ & $0.0 \mathrm{E}+00$ & no limit ${ }^{e}$ & $3.0 \mathrm{E}-06$ & $1.5 \mathrm{E}+06$ \\
\hline Np-239 & $3.00 \mathrm{E}+02$ & $0.0 \mathrm{E}+00$ & & $1.5 \mathrm{E}-02$ & \\
\hline Pu-239 & $8.10 E+00$ & $0.0 \mathrm{E}+00$ & & $5.4 \mathrm{E}-06$ & \\
\hline$P u-244$ & $8.60 E+00$ & $0.0 \mathrm{E}+00$ & no limit ${ }^{e}$ & $1.4 E+00$ & $6.2 \mathrm{E}+00$ \\
\hline $\mathrm{Cm}-244$ & $1.50 \mathrm{E}+01$ & screened $^{f}$ & no limit ${ }^{e}$ & screened ${ }^{f}$ & $6.1 E+03$ \\
\hline Pu-240 & $8.10 \mathrm{E}+00$ & $0.0 \mathrm{E}+00$ & & $1.3 \mathrm{E}-03$ & \\
\hline U-236 & $1.39 \mathrm{E}+02$ & $0.0 \mathrm{E}+00$ & & 7.3E-04 & \\
\hline $\mathrm{Cm}-245$ & $7.60 \mathrm{E}+00$ & $0.0 \mathrm{E}+00$ & no limit ${ }^{e}$ & $3.5 E-16$ & $3.3 E+00$ \\
\hline $\mathrm{Pu}-241$ & $5.30 \mathrm{E}+02$ & $0.0 \mathrm{E}+00$ & & $7.6 \mathrm{E}-14$ & \\
\hline Am-241 & $7.60 \mathrm{E}+00$ & $0.0 \mathrm{E}+00$ & & $1.8 \mathrm{E}-14$ & \\
\hline Np-237 & $8.90 \mathrm{E}+00$ & $0.0 \mathrm{E}+00$ & & $2.7 E+00$ & \\
\hline $\mathrm{Cm}-246$ & $7.60 \mathrm{E}+00$ & $0.0 \mathrm{E}+00$ & no $\operatorname{limit}^{e}$ & $1.7 \mathrm{E}-16$ & $4.4 E+16$ \\
\hline $\mathrm{Cm}-247$ & $8.30 \mathrm{E}+00$ & $0.0 \mathrm{E}+00$ & no limit ${ }^{e}$ & $1.4 \mathrm{E}-10$ & $7.7 \mathrm{E}+03$ \\
\hline Am-243 & $7.60 \mathrm{E}+00$ & $0.0 \mathrm{E}+00$ & & $2.9 \mathrm{E}-10$ & \\
\hline Np-239 & $3.00 \mathrm{E}+02$ & $0.0 \mathrm{E}+00$ & & $9.0 \mathrm{E}-14$ & \\
\hline Pu-239 & $8.10 \mathrm{E}+00$ & $0.0 \mathrm{E}+00$ & & $1.1 \mathrm{E}-03$ & \\
\hline $\mathrm{Cm}-248$ & $2.10 \mathrm{E}+00$ & $0.0 \mathrm{E}+00$ & no limit ${ }^{e}$ & $1.4 \mathrm{E}-10$ & $4.9 \mathrm{E}+01$ \\
\hline Pu-244 & $8.60 \mathrm{E}+00$ & $0.0 E+00$ & & $1.8 \mathrm{E}-01$ & \\
\hline Cf-249 & $7.40 \mathrm{E}+00$ & $0.0 \mathrm{E}+00$ & no limit ${ }^{e}$ & $3.4 \mathrm{E}-09$ & $1.1 E+02$ \\
\hline $\mathrm{Cm}-245$ & $7.60 \mathrm{E}+00$ & $0.0 \mathrm{E}+00$ & & $2.7 E-07$ & \\
\hline $\mathrm{Pu}-241$ & $5.30 \mathrm{E}+02$ & $0.0 \mathrm{E}+00$ & & $2.3 \mathrm{E}-08$ & \\
\hline Am-241 & $7.60 \mathrm{E}+00$ & $0.0 \mathrm{E}+00$ & & $4.9 \mathrm{E}-08$ & \\
\hline $\mathrm{Np}-237$ & $8.90 \mathrm{E}+00$ & $0.0 \mathrm{E}+00$ & & $7.8 \mathrm{E}-02$ & \\
\hline \multicolumn{6}{|c|}{$\begin{array}{l}\text { "+d" indicates short- and/or long-lived radioactive daughters are considered in the analysis. } \\
\text { The more restrictive of either the MCL or the allowable concentration based on a } 25 \text { marem/yr performance objective (Table } \\
4.3-1 \text { ) } \\
\text { Peak concentration is per Ci disposed of in } 100 \text { naval reactor waste containers in one pad. } \\
\text { Calculated by dividing the "Concentration limit" by the "Peak groundwater concentration". For radionuclides with } \\
\text { daughters, the lower limit calculated by this method for all radionuclides in the decay chain is the one reported as the } \\
\text { inventory limit. } \\
\text { "No limit" refers to the fact that no significant groundwater concentration was calculated during the time period of interest: } \\
\text { thus, no limit can be calculated. } \\
\text { Inventory limit is based on radioactive daughter(s) only; parent was screened from consideration (Section 4.1). }\end{array}$} \\
\hline
\end{tabular}


Table 5.4-10 Sensitivity of Groundwater-Based Inventory Limits for Trenches Containing Intimately-Mixed Cement-Stabilized Waste to Time of Assessment

\begin{tabular}{|c|c|c|c|c|c|}
\hline Radionuclide $^{\text {a }}$ & $\begin{array}{c}\text { Concentration } \\
\operatorname{limit}^{b} \\
\mathrm{pCi} / \mathrm{L}\end{array}$ & $\begin{array}{c}\text { Peak } \\
\text { groundwater } \\
\text { concentration } \\
\text { up to } \\
1,000 \text { years } \\
\text { pCi } / \mathrm{L}\end{array}$ & $\begin{array}{c}\text { Calculated } \\
\text { inventory limit } \\
\text { based on } 1,000 \\
\text { year Time of } \\
\text { Compliance } \\
\mathrm{Ci} / 5 \text { trenches }\end{array}$ & $\begin{array}{c}\text { Peak } \\
\text { groundwater } \\
\text { concentration } \\
\text { up to } \\
10,000 \text { years } \\
\text { pCi } / \mathrm{L}\end{array}$ & $\begin{array}{c}\text { Calculated } \\
\text { inventory limit } \\
\text { based on } 1,000 \\
\text { year Time of } \\
\text { Compliance } \\
\text { Ci/5 trenches }\end{array}$ \\
\hline $\mathrm{H}-3$ & $2.00 \mathrm{E}+04$ & $6.35 \mathrm{E}-05$ & $1.57 \mathrm{E}+08$ & $6.35 \mathrm{E}-05$ & $1.57 \mathrm{E}+08$ \\
\hline C-14 & $6.40 \mathrm{E}+03$ & $4.36 \mathrm{E}-01$ & $7.34 \mathrm{E}+03$ & $4.36 \mathrm{E}-01$ & $7.34 \mathrm{E}+03$ \\
\hline $\mathrm{Ni}-59$ & $5.30 \mathrm{E}+02$ & $0.0 \mathrm{E}+00$ & no limit ${ }^{e}$ & $5.58 \mathrm{E}-01$ & $4.75 E+02$ \\
\hline $\mathrm{Se}-79$ & $6.60 \mathrm{E}+02$ & $0.0 \mathrm{E}+00$ & no limit ${ }^{e}$ & $1.84 E+01$ & $1.79 \mathrm{E}+01$ \\
\hline Sr-90 +d & $8.00 E+00$ & $7.83 \mathrm{E}-06$ & $5.11 E+05$ & $7.83 \mathrm{E}-06$ & $5.11 E+05$ \\
\hline$Z_{r-93}+d$ & $2.10 \mathrm{E}+03$ & & no limit & $6.32 \mathrm{E}-01$ & $1.66 \mathrm{E}+03$ \\
\hline $\mathrm{Nb}-94$ & $1.30 \mathrm{E}+02$ & & no limit ${ }^{e}$ & $3.10 \mathrm{E}+01$ & $2.10 \mathrm{E}+00$ \\
\hline Tc-99 & $8.00 \mathrm{E}+02$ & $1.03 E+03$ & $3.88 \mathrm{E}-01$ & $1.03 E+03$ & $3.88 \mathrm{E}-01$ \\
\hline Pd-107 & $3.66 \mathrm{E}+04$ & & no limit & $1.84 \mathrm{E}+02$ & $9.95 E+01$ \\
\hline Sn-126+d & $2.90 \mathrm{E}+02$ & $0.0 \mathrm{E}+00$ & no limit ${ }^{e}$ & $1.16 \mathrm{E}+01$ & $1.25 \mathrm{E}+02$ \\
\hline I-129 & $5.00 \mathrm{E}-01$ & $6.12 E+02$ & $4.08 \mathrm{E}-04$ & $6.12 \mathrm{E}+02$ & $4.08 \mathrm{E}-04$ \\
\hline Cs-135 & $8.00 \mathrm{E}+02$ & $0.0 \mathrm{E}+00$ & no limit ${ }^{e}$ & $1.97 \mathrm{E}+01$ & $2.03 E+01$ \\
\hline Th-232 & $1.30 \mathrm{E}+01$ & $0.0 \mathrm{E}+00$ & no limit ${ }^{\circ}$ & $2.00 \mathrm{E}-09$ & $1.81 E+08$ \\
\hline Ra-228 & $5.00 \mathrm{E}+00$ & $0.0 \mathrm{E}+00$ & & $1.38 \mathrm{E}-08$ & \\
\hline Th-228 & $1.50 \mathrm{E}+01$ & $0.0 \mathrm{E}+00$ & & $2.15 \mathrm{E}-09$ & \\
\hline $\mathrm{Ra}-224$ & $1.50 \mathrm{E}+01$ & $0.0 \mathrm{E}+00$ & & $1.38 \mathrm{E}-08$ & \\
\hline U-232 & $2.60 \mathrm{E}+01$ & & no limit ${ }^{c}$ & $2.65 \mathrm{E}-08$ & $4.91 E+08$ \\
\hline Th-228 & $1.50 \mathrm{E}+01$ & & & $2.91 \mathrm{E}-10$ & \\
\hline Ra-224 & $1.50 \mathrm{E}+01$ & & & $1.87 \mathrm{E}-09$ & \\
\hline $\mathrm{U}-233$ & $1.25 \mathrm{E}+02$ & & no $\operatorname{limit}^{\mathrm{e}}$ & $4.82 \mathrm{E}-09$ & $7.14 \mathrm{E}+09$ \\
\hline Th-229 & $9.60 \mathrm{E}+00$ & & & $9.87 \mathrm{E}-11$ & \\
\hline $\mathrm{Ra}-225$ & $9.00 \mathrm{E}+00$ & & & $6.30 \mathrm{E}-10$ & \\
\hline U-234 & $1.32 \mathrm{E}+02$ & $4.31 \mathrm{E}-13$ & $2.7 E+06$ & $3.88 \mathrm{E}-10$ & $3.02 E+03$ \\
\hline Th-230 & $1.50 \mathrm{E}+01$ & $3.37 \mathrm{E}-17$ & & $2.58 \mathrm{E}-13$ & \\
\hline $\mathrm{Ra}-226$ & $5.00 \mathrm{E}+00$ & $3.95 \mathrm{E}-10$ & & $2.55 \mathrm{E}-05$ & \\
\hline $\mathrm{Pb}-210$ & $3.00 \mathrm{E}-01$ & $1.51 \mathrm{E}-09$ & & $4.96 \mathrm{E}-05$ & \\
\hline Po-210 & $1.50 \mathrm{E}+01$ & $2.28 \mathrm{E}-09$ & & 8.93E-05 & \\
\hline $\mathrm{U}-235$ & $1.39 \mathrm{E}+02$ & $5.80 \mathrm{E}-16$ & $7.3 \mathrm{E}+06$ & $1.36 \mathrm{E}-13$ & $3.13 E+04$ \\
\hline $\mathrm{Pa}-231$ & $3.10 \mathrm{E}+00$ & $1.59 \mathrm{E}-09$ & & $3.24 \mathrm{E}-05$ & \\
\hline Ac- 227 & $2.50 \mathrm{E}+00$ & $1.60 \mathrm{E}-09$ & & $4.00 \mathrm{E}-05$ & \\
\hline Th-227 & $1.50 \mathrm{E}+01$ & $1.93 \mathrm{E}-10$ & & $5.63 \mathrm{E}-05$ & \\
\hline $\mathrm{Ra}-223$ & $1.50 \mathrm{E}+01$ & $1.63 \mathrm{E}-09$ & & $3.60 \mathrm{E}-05$ & \\
\hline $\mathrm{U}-236$ & $1.39 \mathrm{E}+02$ & & no limit ${ }^{e}$ & $3.30 \mathrm{E}-11$ & $2.11 \mathrm{E}+12$ \\
\hline Np-237 & $8.90 \mathrm{E}+00$ & $4.48 \mathrm{E}-01$ & $9.9 \mathrm{E}+00$ & $4.75 \mathrm{E}-01$ & $9.37 \mathrm{E}+00$ \\
\hline U-238 & $6.66 \mathrm{E}+00$ & & no limit ${ }^{e}$ & $1.72 \mathrm{E}-13$ & $6.35 E+07$ \\
\hline Th-234 & $5.90 \mathrm{E}+01$ & & & $1.90 \mathrm{E}-15$ & \\
\hline U-234 & $1.32 \mathrm{E}+02$ & & & $1.04 \mathrm{E}-06$ & \\
\hline $\mathrm{Pu}-238$ & $8.90 \mathrm{E}+00$ & & no $\operatorname{limit}^{\mathrm{e}}$ & $1.05 \mathrm{E}-13$ & $2.10 \mathrm{E}+10$ \\
\hline U-234 & $1.32 \mathrm{E}+02$ & & & $3.15 \mathrm{E}-09$ & \\
\hline
\end{tabular}


Table 5.4-10 Sensitivity of Groundwater-Based Inventory Limits for Trenches Containing Intimately-Mixed Cement-Stabilized Waste to Time of Assessment

\begin{tabular}{|c|c|c|c|c|c|}
\hline Radionuclide $^{3}$ & $\begin{array}{c}\begin{array}{c}\text { Concentration } \\
\text { limit }^{\mathrm{b}} \\
\mathrm{pCi} / \mathrm{L} \\
\end{array} \\
\end{array}$ & $\begin{array}{c}\text { Peak } \\
\text { groundwater } \\
\text { concentration } \\
\text { up to } \\
1,000 \text { years } \\
\text { pCi/L } \\
\end{array}$ & $\begin{array}{c}\text { Calculated } \\
\text { inventory limit } \\
\text { based on } 1,000 \\
\text { year Time of } \\
\text { Compliance } \\
\text { Ci/ } / 5 \text { trenches }\end{array}$ & $\begin{array}{c}\text { Peak } \\
\text { groundwater } \\
\text { concentration } \\
\text { up to } \\
10,000 \text { years } \\
\text { pCi/L } \\
\end{array}$ & $\begin{array}{c}\text { Calculated } \\
\text { inventory limit } \\
\text { based on } 1,000 \\
\text { year Time of } \\
\text { Compliance } \\
\text { Ci/5 trenches }\end{array}$ \\
\hline $\mathrm{Pu}-239$ & $8.10 \mathrm{E}+00$ & & no limit ${ }^{e}$ & $4.41 \mathrm{E}-11$ & $9.18 \mathrm{E}+10$ \\
\hline $\mathrm{U}-235$ & $1.39 \mathrm{E}+02$ & & & $1.10 \mathrm{E}-12$ & \\
\hline $\mathrm{Pu}-240$ & $8.10 \mathrm{E}+00$ & & no limit ${ }^{e}$ & $1.39 \mathrm{E}-10$ & $2.91 E+10$ \\
\hline U-236 & $1.39 \mathrm{E}+02$ & & & $3.30 \mathrm{E}-11$ & \\
\hline Am-241 & $7.60 \mathrm{E}+00$ & & no $\operatorname{limit}^{e}$ & $-\mathrm{ff}^{\mathrm{f}}$ & $4.64 \mathrm{E}+04$ \\
\hline Np-237 & $8.90 \mathrm{E}+00$ & & & $9.59 \mathrm{E}-05$ & \\
\hline $\mathrm{Pu}-241$ & $5.30 \mathrm{E}+02$ & & no limit ${ }^{c}$ & ---- & $1.39 \mathrm{E}+06$ \\
\hline Am-241 & $7.60 \mathrm{E}+00$ & & & $---{ }^{f}$ & \\
\hline Np-237 & $8.90 \mathrm{E}+00$ & & & $3.20 \mathrm{E}-06$ & \\
\hline $\mathrm{Pu}-242$ & $8.30 E+00$ & & no limit ${ }^{e}$ & $2.99 \mathrm{E}-12$ & $1.39 E+12$ \\
\hline U-238 & $1.39 \mathrm{E}+02$ & & & $1.72 \mathrm{E}-13$ & \\
\hline Am-243 & $7.60 E+00$ & & no limit & $1.64 \mathrm{E}-06$ & $2.32 E+06$ \\
\hline Np-239 & $3.00 \mathrm{E}+02$ & & & $1.72 \mathrm{E}-13$ & \\
\hline Pu-239 & $8.10 E+00$ & & & $1.04 \mathrm{E}-06$ & \\
\hline $\mathrm{Pu}-244$ & $8.60 \mathrm{E}+00$ & & no limit ${ }^{e}$ & $1.40 \mathrm{E}-14$ & 3.07E+14 \\
\hline $\mathrm{Cm}-244$ & $1.50 \mathrm{E}+01$ & & no limit ${ }^{e}$ & ---- & $1.05 E+13$ \\
\hline $\mathrm{Pu}-240$ & $8.10 \mathrm{E}+00$ & & & $3.85 \mathrm{E}-13$ & \\
\hline U.236 & $1.39 E+02$ & & & $9.14 E-14$ & \\
\hline $\mathrm{Cm}-245$ & $7.60 \mathrm{E}+00$ & & no limit ${ }^{e}$ & $2.65 \mathrm{E}-11$ & $3.25 \mathrm{E}+02$ \\
\hline $\mathrm{Pu}-241$ & $5.30 \mathrm{E}+02$ & & & $1.42 \mathrm{E}-08$ & \\
\hline Am-241 & $7.60 \mathrm{E}+00$ & & & $3.05 \mathrm{E}-09$ & \\
\hline $\mathrm{Np}-237$ & $8.90 E+00$ & & & $1.37 E-02$ & \\
\hline $\mathrm{Cm}-246$ & $7.60 \mathrm{E}+00$ & & no limit ${ }^{c}$ & $1.37 \mathrm{E}-11$ & $2.77 \mathrm{E}+11$ \\
\hline $\mathrm{Cm}-247$ & $8.30 E+00$ & & no limit ${ }^{\mathrm{e}}$ & $6.01 E-11$ & $9.25 E+00$ \\
\hline Am-243 & $7.60 \mathrm{E}+00$ & & & $3.88 \mathrm{E}-07$ & \\
\hline Np-239 & $3.00 \mathrm{E}+02$ & & & $1.41 E-04$ & \\
\hline Pu-239 & $8.10 \mathrm{E}+00$ & & & $4.38 \mathrm{E}-01$ & \\
\hline $\mathrm{Cm}-248$ & $2.10 \mathrm{E}+00$ & & no limit ${ }^{e}$ & $5.89 \mathrm{E}-11$ & $1.71 E+04$ \\
\hline $\mathrm{Pu}-244$ & $8.60 \mathrm{E}+00$ & & & $2.51 \mathrm{E}-04$ & \\
\hline Cf-249 & $7.40 \mathrm{E}+00$ & & no limit $^{e}$ & $3.65 E-09$ & $7.93 E+03$ \\
\hline $\mathrm{Cm}-245$ & $7.60 \mathrm{E}+00$ & & & $2.75 \mathrm{E}-08$ & \\
\hline $\mathrm{Pu}-24 \mathrm{I}$ & $5.30 \mathrm{E}+02$ & & & $1.42 \mathrm{E}-06$ & \\
\hline Am-241 & $7.60 \mathrm{E}+00$ & & & $9.84 \mathrm{E}-08$ & \\
\hline $\mathrm{Np}-237$ & $8.90 \mathrm{E}+00$ & & & $5.61 \mathrm{E}-04$ & \\
\hline Cf-252 & $1.50 \mathrm{E}+01$ & & no limit ${ }^{e}$ & $-{ }^{f}$ & $2.20 \mathrm{E}+09$ \\
\hline $\mathrm{Cm}-248$ & $2.10 \mathrm{E}+00$ & & & $4.59 \mathrm{E}-16$ & \\
\hline $\mathrm{Pu}-244$ & $8.60 \mathrm{E}+00$ & & & $1.95 \mathrm{E}-09$ & \\
\hline
\end{tabular}


"Calculated by dividing the "Concentration limit" by the "Peak ground water concentration", and dividing by 2 to normalize to five trenches. For radionuclides with daughters, the lower limit calculated by this method for all radionuclides in the decay chain is the one reported as the inventory limit.

- "No limit" refers to the fact that no significant groundwater concentration was calculated during the time period of interest; thus, no limit can be calculated.

Inventory limit is based on radioactive daughter(s) only; parent was screened from consideration 
Table 5.4-11 Sensitivity of Groundwater-Based Inventory Limits for Trenches Containing Cement-Stabilized Encapsulated Waste to Time of Assessment

\begin{tabular}{|c|c|c|c|c|c|}
\hline Radionuclide $^{a}$ & $\begin{array}{c}\text { Concentration } \\
\text { limit }^{\mathrm{b}} \\
\mathrm{pCi} / \mathrm{L}\end{array}$ & $\begin{array}{c}\text { Peak } \\
\text { groundwater } \\
\text { concentration } \\
\text { up to } \\
1,000 \text { years } \\
\text { pCi } / \mathrm{L}\end{array}$ & $\begin{array}{c}\text { Calculated } \\
\text { inventory } \\
\text { limit based on } \\
1,000 \text { year } \\
\text { Time of } \\
\text { Compliance } \\
\text { Ci/ } 5 \text { trenches }\end{array}$ & $\begin{array}{c}\text { Peak } \\
\text { groundwater } \\
\text { concentration } \\
\text { up to } \\
10,000 \text { years } \\
\text { pCi/L } \\
\end{array}$ & $\begin{array}{c}\text { Calculated } \\
\text { inventory } \\
\text { limit based } \\
\text { on } 10,000 \\
\text { year Time of } \\
\text { Compliance } \\
\text { Ci/ } 5 \text { trenches } \\
\end{array}$ \\
\hline H-3 & $2.0 \mathrm{E}+04$ & $6.5 \mathrm{E}-07$ & $1.5 \mathrm{E}+10$ & $6.5 \mathrm{E}-07$ & $1.5 \mathrm{E}+10$ \\
\hline C-14 & $6.4 \mathrm{E}+03$ & $4.4 \mathrm{E}-01$ & $7.3 E+03$ & $4.4 E-01$ & $7.3 \mathrm{E}+03$ \\
\hline $\mathrm{Ni}-59$ & $5.3 E+02$ & $0.0 \mathrm{E}+00$ & no limit ${ }^{e}$ & $6.0 \mathrm{E}-02$ & $4.4 \mathrm{E}+03$ \\
\hline $\mathrm{Se}-79$ & $6.6 \mathrm{E}+02$ & $0.0 \mathrm{E}+00$ & no limit ${ }^{e}$ & $4.3 E+00$ & $7.7 \mathrm{E}+01$ \\
\hline Sr-90+d & $8.0 \mathrm{E}+00$ & $5.8 \mathrm{E}-06$ & $5.1 \mathrm{E}+05$ & $5.8 \mathrm{E}-06$ & $5.1 E+05$ \\
\hline $\mathrm{Zr}-93+d$ & $2.1 \mathrm{E}+03$ & $0.0 \mathrm{E}+00$ & no limit ${ }^{e}$ & $6.6 \mathrm{E}+01$ & $1.6 E+01$ \\
\hline Tc-99 & $8.0 \mathrm{E}+02$ & $1.3 \mathrm{E}+03$ & $3.0 \mathrm{E}-01$ & $1.3 \mathrm{E}+03$ & $3.0 \mathrm{E}-01$ \\
\hline Pd-107 & $3.7 \mathrm{E}+04$ & & no limit ${ }^{e}$ & $1.1 E+03$ & $1.7 E+01$ \\
\hline Sn-126+d & $2.9 \mathrm{E}+02$ & $0.0 \mathrm{E}+00$ & no limit ${ }^{e}$ & $4.8 E+\infty 0$ & $3.0 \mathrm{E}+01$ \\
\hline I- 129 & $5.0 \mathrm{E}-01$ & $1.2 \mathrm{E}+03$ & $2.2 \mathrm{E}-04$ & $1.2 \mathrm{E}+03$ & $2.2 \mathrm{E}-04$ \\
\hline Cs-135 & $8.0 \mathrm{E}+02$ & $0.0 \mathrm{E}+00$ & no limit ${ }^{e}$ & $2.0 \mathrm{E}+01$ & $2.0 \mathrm{E}+01$ \\
\hline $\mathrm{U}-232$ & $2.6 \mathrm{E}+01$ & & no limit ${ }^{e}$ & $1.2 \mathrm{E}-08$ & $1.1 E+09$ \\
\hline Th-228 & $1.5 \mathrm{E}+01$ & & & $1.3 \mathrm{E}-10$ & \\
\hline Ra-224 & $1.5 \mathrm{E}+01$ & & & $8.5 E-10$ & \\
\hline U-233 & $1.3 \mathrm{E}+02$ & & no limit $^{e}$ & $2.0 \mathrm{E}-08$ & $2.6 \mathrm{E}+07$ \\
\hline Th-229 & $9.6 \mathrm{E}+00$ & & & 2.7E-08 & \\
\hline Ra-225 & $9.0 \mathrm{E}+00$ & & & $1.8 \mathrm{E}-07$ & \\
\hline U-234 & $1.3 E+02$ & $0.0 \mathrm{E}+00$ & no limit ${ }^{e}$ & $8.0 \mathrm{E}-10$ & $3.3 E+04$ \\
\hline Th-230 & $1.5 \mathrm{E}+01$ & $0.0 \mathrm{E}+00$ & & $3.5 \mathrm{E}-13$ & \\
\hline $\mathrm{Ra}-226$ & $5.0 \mathrm{E}+00$ & $0.0 \mathrm{E}+00$ & & $2.3 \mathrm{E}-06$ & \\
\hline $\mathrm{Pb}-210$ & $3.0 \mathrm{E}-01$ & $0.0 \mathrm{E}+00$ & & $4.5 \mathrm{E}-06$ & \\
\hline Po-210 & $1.5 \mathrm{E}+01$ & $0.0 \mathrm{E}+00$ & & $8.1 E-06$ & \\
\hline U-235 & $1.4 \mathrm{E}+02$ & $1.3 \mathrm{E}-16$ & $3.7 E+07$ & $2.8 \mathrm{E}-13$ & $1.7 \mathrm{E}+04$ \\
\hline $\mathrm{Pa}-231$ & $3.1 E+00$ & 4. $1 E-08$ & & $6.1 E-05$ & \\
\hline Ac- -227 & $2.5 \mathrm{E}+00$ & $3.8 \mathrm{E}-08$ & & $7.5 \mathrm{E}-05$ & \\
\hline Th-227 & $1.5 \mathrm{E}+01$ & $7.0 \mathrm{E}-09$ & & $1.1 \mathrm{E}-05$ & \\
\hline $\mathrm{Ra}-223$ & $1.5 \mathrm{E}+01$ & $7.9 \mathrm{E}-08$ & & $6.7 \mathrm{E}-05$ & \\
\hline$U-236$ & $1.4 \mathrm{E}+02$ & & no limit & $1.4 \mathrm{E}-10$ & $5.1 E+11$ \\
\hline $\mathrm{Np}-237$ & $8.9 \mathrm{E}+00$ & $4.5 \mathrm{E}-01$ & $1.0 \mathrm{E}+01$ & $4.8 \mathrm{E}-01$ & $9.4 \mathrm{E}+00$ \\
\hline$U-238$ & $6.7 E+00$ & & no limit ${ }^{e}$ & $7.2 \mathrm{E}-13$ & $3.2 \mathrm{E}+09$ \\
\hline Th-234 & $5.9 \mathrm{E}+01$ & & & $7.9 \mathrm{E}-15$ & \\
\hline U-234 & $1.3 E+02$ & & & $2.0 \mathrm{E}-08$ & \\
\hline $\mathrm{Pu}-238$ & $8.9 \mathrm{E}+00$ & & no limit ${ }^{e}$ & $0.0 \mathrm{E}+00$ & $5.1 \mathrm{E}+09$ \\
\hline U-234 & 1. $3 \mathrm{E}+02$ & & & $1.3 \mathrm{E}-08$ & \\
\hline Pu-239 & $8.1 E+00$ & & no limit ${ }^{\mathrm{e}}$ & $1.8 \mathrm{E}-10$ & $2.2 \mathrm{E}+10$ \\
\hline U-235 & $1.4 E+02$ & & & $5.2 \mathrm{E}-12$ & \\
\hline Pu-240 & $8.1 E+00$ & & no limit ${ }^{e}$ & $5.6 \mathrm{E}-10$ & $7.3 \mathrm{E}+09$ \\
\hline U-236 & $1.4 \mathrm{E}+02$ & & & $1.6 \mathrm{E}-10$ & \\
\hline Am-241 & $7.6 \mathrm{E}+00$ & & no limit ${ }^{e}$ & screened $^{\mathrm{f}}$ & $1.4 \mathrm{E}+03$ \\
\hline Np-237 & $8.9 E+00$ & & & $3.2 \mathrm{E}-03$ & \\
\hline
\end{tabular}


disposal units. The overall effect is that the longer time of assessment results in lower groundwater - based disposal limits for each disposal unit considered, as shown in Tables 5.4-5 through 5.4-10.

In addition to the parameters discussed above, the PA results pertinent to protection of the public and impacts on water resources are sensitive to the solubility assumed for radionuclides in the simulation domains, and to the rate of release of radionuclides from activated metals (i.e., in the naval reactor waste). Calculated groundwater concentrations are directly proportional to both of these factors. The uncertainty associated with the solubility limits applied is largely governed by the changes in geochemistry that may occur over time, as the vaults degrade. It is very difficult, if not impossible, to predict these changes and the effect they may have on solubility of $U$ and $\mathrm{Pu}$ with a quantifiable degree of certainty because of the multitude of competing geochemical processes involved. Therefore, quantification of uncertainty associated with the groundwater concentrations of $\mathrm{U}$ and $\mathrm{Pu}$ isotopes was not attempted in this analysis. Likewise, uncertainty associated with the release rate equation for corrosion of activated metals (Appendix C.1.2.6) was not evaluated. However, conservative assumptions were made regarding the fraction of metal that was the more-readily-corroding Inconel, to reduce the likelihood that results are underestimates of groundwater concentrations.

\subsection{ALARA Analysis}

As indicated in Section 2.5, one of the requirements of DOE Order 435.1 is that performance assessments shall include a demonstration that projected releases of radionuclides to the environment shall be maintained as low as reasonably achievable (ALARA)". The DOE interim guidance for performance assessment (DOE 1996), provides guidance on the application of the ALARA process to performance assessment.

Specifically, the interim guidance states: "Depending on the situation, the ALARA analysis could range from simple qualitative statements to rigorous quantitative analyses that consider individual and collective doses to members of the public. The rigor of the ALARA analysis should be commensurate with the magnitude of the calculated dose and the decisions to be made regarding the disposal facility."

DOE now requires that active and planned LLW disposal facilities complete a composite analysis in addition to a PA. The composite analysis estimates the cumulative impacts to a hypothetical future member of the public from the active or planned LLW disposal facility and other sources of radioactive material in the ground that may interact with the LLW disposal facility. SRS has recently completed the composite analysis for the E-Area LLWF and the Saltstone disposal facility (WSRC 1997b).

The SRS composite analysis estimates that the maximum dose to a hypothetical future member of the public at the mouth of Upper Three Runs, the closest point of public access (DOE 1998a), is 1.8 mrem per year. The calculated maximum collective dose to a hypothetical future population is 2.7 person-rem per year. This population dose includes sources draining to Fourmile Branch. The Upper Three Runs sources contribute about 60 percent of the total collective dose. The composite analysis concluded that an ALARA analysis was not warranted.

Table 5.5-1 presents a summary of results from the SRS composite analysis. The E-Area LLWF contributed less than 0.001 per cent to the flux of these radionuclides to the groundwater migrating to Upper Three Runs. Doses, both individual and collective, will be in direct proportion to radionuclide fluxes. Thus, the doses due to the LLWF operations will be on the order of $2 \times 10^{-5}$ mrem per year for a member of the public and $2 \times 10^{-5}$ person-rem per year for the future population. To aid in the ALARA process, DOE values collective dose at $\$ 1,000$ to $\$ 10,000$ per person-rem averted. If the collective dose from the LLWF were integrated over one thousand years and the maximum value per person-rem averted were applied, the value of reducing the dose to zero would be $\$ 200.00$. This clearly indicates that a more detailed ALARA analysis for the LLWF facility is not warranted. 
Table 5.5-1 Maximum Flux of Significant Radionuclides to the Water Table from Sources Draining to Upper Three Runs (WSRC 1997b, Table 4.4-5)

\begin{tabular}{|l|l|l|}
\hline Radionuclide & $\begin{array}{l}\text { Total Maximum Flux } \\
\text { from LLWF Sources, Ci/year }\end{array}$ & $\begin{array}{l}\text { Total Maximum Flux } \\
\text { from non-LLWF Sources, Ci/year }\end{array}$ \\
\hline${ }^{3} \mathrm{H}$ & $8.3 \mathrm{E}-1$ & $6.9 \mathrm{E}+4$ \\
\hline${ }^{14} \mathrm{C}$ & $4.1 \mathrm{E}-6$ & $1.4 \mathrm{E}+0$ \\
\hline${ }^{237} \mathrm{~Np}$ & $3.2 \mathrm{E}-9$ & $3.5 \mathrm{E}-2$ \\
\hline $\mathrm{U}$ (all isotopes) & $<\mathrm{E}-18$ & $7.4 \mathrm{E}-1$ \\
\hline
\end{tabular}


THIS PAGE INTENTIONALLY LEFT BLANK 


\section{SECTION 6}

INADVERTENT INTRUDER ANALYSIS 
THIS PAGE INTENTIONALLY LEFT BLANK

Rev. 1 


\section{INADVERTENT INTRUDER ANALYSIS}

As described in Sect. 2.5.3, disposal of low-level radioactive waste in the E-Area LLWF must meet a requirement to assess impacts on hypothetical individuals who are assumed to inadvertently intrude onto the disposal site. In particular, after assumed loss of active institutional control at 100 years after facility closure, the EDE to an intruder should not exceed 100 mrem per year for scenarios involving continuous exposure or $\mathbf{5 0 0} \mathrm{mrem}$ for scenarios involving a single acute exposure (DOE 1988). These dose limits apply to the sum of dose equivalents from all exposure pathways that are assumed to occur in a given exposure scenario for an inadvertent intruder.

The time period covered by the intruder analysis for this PA extends beyond 1,000 years after loss of institutional control. Some intruder scenarios cannot reasonably occur within the 1,000-year time period put forth as the compliance period for performance assessment in DOE Order 435.1 (Sect. 2.5), and ingrowth of radioactive daughters for some radionuclides may be more significant to dose beyond this time period. Therefore, analytical results for the first 10,000 years after assumed loss of active institutional control (and beyond for a few radionuclides) are used to evaluate performance of the E-Area disposal units with respect to inadvertent intruders (Sect. 7).

In this section, exposure scenarios considered in the E-Area LLWF PA for an inadvertent intruder are described. These scenarios are then compared to identify the dominant scenarios in terms of total exposure to radionuclides present in a disposal unit (Sect. 6.1). A screening analysis (Sect. 6.2) of the radionuclide inventory lists (Appendix A) for each type of disposal unit in E Area is then described, by which radionuclides of potential significance to estimated doses are identified. Analysis of dose to inadvertent intruders for the potentially significant scenarios and radionuclides is also described, and results of the dose calculations are presented (Sect. 6.3).

The focus in development of exposure scenarios for inadvertent intruders was on selecting reasonable events that may occur, giving consideration to regional customs and construction practices. An important assumption in all scenarios is that an intruder has no prior knowledge of the existence of a waste disposal facility at the site. Therefore, after active institutional control ceases, certain exposure scenarios are assumed to be precluded only by the physical state of the disposal facility, i.e., the integrity of the engineered barriers used in facility construction. Passive institutional controls, such as permanent marker systems at the disposal site and public records of prior land use, also could prevent inadvertent intrusion after active institutional control ceases, but the efficacy of passive institutional controls is not assumed in this analysis.

Intruder exposure scenarios described in Section 6.1 do not include consumption of groundwater and crop irrigation with groundwater because impacts associated with these exposure routes are evaluated separately in the water resource impacts analysis. Justification for this neglect is provided in Section 6.1.1 below. Pathways of exposure to radon and its short-lived progeny, and volatile forms of ${ }^{3} \mathrm{H}$ and ${ }^{14} \mathrm{C}$, are considered separately in the air pathway analysis.

\subsection{Exposure Scenarios for Inadvertent Intruders}

\subsubsection{Chronic Exposure Scenarios for Inadvertent Intruders}

Three distinct scenarios resulting in chronic exposure of inadvertent intruders are considered in the dose analysis for the E-Area LLWF. Two of these scenarios, which usually are referred to as the agriculture (or homesteader) and post-drilling scenarios, have often been applied in other intruder dose analyses for LLW disposal (NRC 1981; Oztunali and Roles 1986; Kennedy and Peloquin 1988; ORNL 1990). The third 
scenario considered in this analysis is referred to as the resident scenario. Assumptions made in defining the agriculture, resident, and post-drilling scenarios are discussed below.

\subsubsection{Agriculture Scenario}

The agriculture scenario assumes that an intruder comes onto the site after active institutional control ceases and establishes a permanent homestead, including on-site sources of water and foodstuffs. Waste in disposed units is assumed to be accessed when an intruder constructs a home directly on top of a disposal facility and the foundation of the home extends into the facility itself. All waste in the disposal facility at the time the foundation is dug is assumed to be physically indistinguishable from native soil.

In the agriculture scenario, some of the waste exhumed from the disposal facility is assumed to be mixed with native soil in the intruder's vegetable garden. The following exposure pathways involving exhumed waste or waste remaining in the exposed disposal facility on which the intruder's home is located then are assumed to occur:

- ingestion of vegetables grown in contaminated garden soil;

- direct ingestion of contaminated soil, primarily in conjunction with intakes of vegetables from the garden;

- external exposure to contaminated soil while working in the garden or residing in the home on top of the disposal facility;

- inhalation of radionuclides attached to soil particles that are suspended into air from contaminated soil while working in the garden or residing in the home; and

- inhalation of volatile radionuclides released into air from contaminated soil while working in the garden or residing in the home.

The agriculture scenario theoretically should also assume that the intruder's entire supply of water for domestic use is obtained from a well on the disposal site. The well would be assumed to be placed at the location beyond a $100-\mathrm{m}$ buffer zone around disposal units where the maximum concentrations of radionuclides in groundwater are projected to occur. Exposure pathways involving use of contaminated well water would be the same as those assumed in Sect. 4.2.1 for off-site members of the public who use contaminated groundwater or surface water for domestic purposes. Again, since rainfall normally is abundant at the SRS (see Sect. 3.1.2), irrigation of a vegetable garden is assumed to occur only occasionally during the summer and only in small amounts relative to the annual rainfall (Murphy 1990). Thus, pathways related to irrigation of a garden are considered negligible contributors to exposures. Irrigation of pasture grass ingested by dairy and beef cattle is neglected because extensive irrigation of agricultural land is not practiced near the SRS (U.S. Department of Commerce 1977; Baes and Sharp 1983). Justification for neglecting direct ingestion of well water at the disposal site in the agriculture scenario is given below.

The different exposure scenarios and exposure pathways for inadvertent intruders assumed for the E-Area LLWF are discussed in Section 6.1. The principal exposure scenarios of concern involve direct intrusion into disposal units, in order that limits on inventory and concentration of radionuclides in the waste may be established. Doses to inadvertent intruders resulting from use of contaminated groundwater obtained from a well on the disposal site are evaluated separately in the water resource impacts analysis and are not calculated for the intruder, in accordance with the guidance for DOE Order 435.1 (DOE 1996). Therefore, for purposes of demonstrating compliance with the dose limit for inadvertent intruders, only the exposure 
pathways involving direct intrusion into the disposal facility need to be considered, and the exposure pathways involving use of contaminated well water can be neglected since they are addressed in the allpathways and water resource impacts analyses (Section 4).

Potential exposures due to the release of radon from buried waste are accounted for in the separate radon flux analysis (Section 4.3).

Potential exposures due to volatile radionuclides are analyzed in the discussion of atmospheric pathways (Section 4.2), rather than in this intruder analysis. The reasons for this are:

1) The atmospheric analysis at the disposal site boundary includes no dispersion at the 100 meter distance, so the concentration of volatiles is no less at the 100 meter distance,

2) At the 100 meter distance the exposure is due to the entire disposal facility; at a location in the facility the hypothetical intruder is only exposed to releases from that portion of the facility that is upwind of his location,

3) The atmospheric pathway has a performance objective of $10 \mathrm{mrem} /$ year, which is ten times less than the performance measure of $100 \mathrm{mrem} / \mathrm{year}$ for an inadvertent intruder.

Direct intrusion into disposal units is assumed to be precluded for some disposal units for a period of time after assumed loss of active institutional control when the concrete roof on the vaults or other engineered barriers (e.g., non-degraded cementitious or grouted waste forms) maintain their structural and physical integrity. Intact engineered barriers and/or waste forms are assumed to preclude direct access to waste in the disposal facility by the types of equipment that normally would be used in digging a foundation for a home at the SRS.

\subsubsection{Resident Scenario}

As in the agriculture scenario described above, the resident scenario assumes that an intruder excavates a foundation for a home on top of a disposal facility. During excavation, however, the intruder may encounter an engineered barrier, such as the roof of a concrete vault, that cannot easily be penetrated by the types of excavation equipment normally used at the SRS. In these cases, the presence of intact engineered barriers or waste forms is assumed to preclude direct intrusion into the waste during excavation. Instead of abandoning the site, the intruder constructs a home directly on top of the intact barrier or waste form and, thus, establishes a permanent residence at that location.

From the definition of the resident scenario, the primary exposure pathway of concern is external exposure to photon-emitting radionuclides during the time the intruder resides in the home on the disposal site. The presence of intact barriers and/or waste forms would preclude any ingestion exposures and most inhalation exposures.

The resident scenario is assumed to occur at any time after loss of active institutional control over the disposal facility. However, even though the concentrations of most radionuclides in the disposal facility will decrease monotonically with time, due to radioactive decay and migration from the disposal facility, the dose in the resident scenario is not necessarily the highest at 100 years after facility closure. At 100 years after closure, the concrete roof on top of the LAW and IL vaults is assumed to be intact, thereby providing a substantial amount of shielding that greatly reduces the external dose from the waste. For the $\mathbb{L}$ vaults, the layer of uncontaminated grout on top of the waste provides a considerable amount of additional shielding. At some later time, however, the concrete roof is assumed to have lost its integrity and most of the layer of uncontaminated grout is assumed to have weathered to soil-equivalent material. These processes 
presumably take hundreds to thousands of years or more. Therefore, for long-lived radionuclides that are retained in the waste for long periods of time, the external dose in the resident scenario would be considerably higher long after active institutional control ceases, when excavation essentially to the depth of the waste could occur. For the trench disposal units (i.e., very low activity waste or slit, intimately-mixed cement-stabilized waste, and cement-stabilized encapsulated waste), the closure concept discussed in Section 3.2 ensures sufficient earthen material (i.e., a minimum of $3.1 \mathrm{~m}$ ) over the waste that the excavation assumed in the resident scenario (i.e., no more than $3 \mathrm{~m}$ ) will leave at least 100 centimeters of soil over the waste.

Thus, for the resident scenario, the maximum dose to an inadvertent intruder and the time at which the maximum dose occurs depend on 1) the half-lives and concentrations of the important photon-emitting radionuclides in the waste, 2) the time period over which the engineered barriers above the waste lose their integrity and can easily be excavated, and 3 ) the rate at which the important radionuclides migrate from the disposal facility. The maximum dose for this scenario can be estimated by considering two bounding cases: 1) intrusion at 100 years after disposal for all disposal units; and 2) intrusion at a much later time after disposal for units with engineered barriers that provide shielding for a period of time. The first bounding case takes into account radionuclides of both shorter and longer half-lives and any shielding provided by concrete roofs or other barriers between the waste and the roof, whereas the second bounding case applies to time periods when only long-lived radionuclides presumably are present, but the waste is assumed to be unshielded. In both cases, self-shielding provided by the waste and any encapsulating materials is taken into account in estimating external dose.

\subsubsection{Comparison of Agriculture and Resident Scenarios}

From the definition of the resident scenario, this scenario can be regarded as a variation of the agriculture scenario in which only one of the exposure pathways is potentially important; namely, external exposure while residing in the home located on top of the disposal facility. Therefore, since this exposure pathway is essentially the same in the two scenarios and the agriculture scenario includes other exposure pathways that are not relevant for the resident scenario, the agriculture scenario probably will be more important than the resident scenario. That is, the dose per unit concentration of radionuclides in disposed waste probably will be higher in the agriculture scenario than in the resident scenario. Thus, the agriculture scenario is expected to be more restrictive in regard to determining acceptable disposals.

However, a possibility exists that the resident scenario may result in higher doses than derived from the agriculture scenario if radionuclides are leached to a significant extent from the waste between the time the resident scenario occurs and the time the agriculture scenario can first occur. An example of this might be the case where the engineered barriers have degraded to soil-equivalent material, and can be excavated, but the waste form itself cannot yet be excavated. In this case, the external dose from unshielded waste could be greater than the total dose from all exposure pathways that would result at a later time when excavation into the waste is possible. This could particularly be the case for the $\mathrm{IL}$ vaults in which the waste is grouted, and thus may maintain its physical integrity past the time the overlying vault roof fails. Another possibility exists in which the doses from the resident scenario may exceed those from the agriculture scenario if shorter-lived radionuclides are important in the resident scenario at 100 years after disposal, when all engineered barriers are presumed to be intact, but have decayed significantly by the time the agricultural scenario may occur. Therefore, the resident scenario is considered in the intruder dose analysis for disposal units with engineered barriers that prevent excavation into the waste form (i.e., as required for the agriculture scenario) at the time the resident scenario may occur ( 100 years post-closure and beyond). 


\subsubsection{Post-Drilling Scenario}

The post-drilling scenario assumes that an intruder who resides permanently on the disposal site drills through a disposal unit in constructing a well for a domestic water supply. Following construction of the well, the contaminated material brought to the surface during drilling operations, which is assumed to be indistinguishable from native soil, is assumed to be mixed with native soil in the intruder's vegetable garden. The exposure pathways involving ingestion of contaminated vegetables, ingestion of contaminated soil, and external and inhalation exposures while working in the garden then are the same as the pathways described previously for the agriculture scenario. In the post-drilling scenario, however, external and inhalation exposures while residing in the home on the disposal site, which are important in the agriculture scenario, are considered insignificant. All drilling waste is assumed to be mixed with native soil in the garden, which is considered to be at a sufficient distance from the home that indoor exposures are minor relative to those in the garden.

As in the agriculture scenario, the post-drilling scenario assumes that the intruder's entire supply of water is obtained from the on-site well, and the exposure pathways from use of contaminated well water are the same as those described previously for the agriculture scenario. As described in Sect. 6.1.1.1, however, demonstration of compliance with the dose limit for inadvertent intruders for the post-drilling scenario can be based only on the exposure pathways involving direct intrusion into solid waste; i.e., the exposure pathways involving use of contaminated well water can be neglected.

In this analysis, as in the agriculture scenario, drilling through a disposal unit is assumed to be precluded during the time when the concrete vaults, steel containers, or cementitious waste forms maintain their integrity. For the $\mathbb{L}$ vaults, the naval reactor waste, the intimately-mixed cementitious waste forms, and the waste encapsulated in grout, the post-drilling scenario involving drilling through a disposal facility is assumed not to be credible until the same time as the agriculture scenario involving direct excavation into a disposal facility. The basis for this assumption is that the types of drill bits normally used in constructing wells in the soft sand and clay soils at the SRS could not easily penetrate an intact concrete vault or other grouted waste form or non-degraded heavy steel container. Therefore, in attempting to drill directly through a disposal facility, it seems reasonable to assume that an intruder would encounter considerable resistance and, instead of taking extraordinary measures to obtain a drill bit designed to penetrate through hard rock or heavy steel, would move the drilling operation to a different location away from the disposal facility.

For the LAW vaults, however, the post-drilling scenario conceivably could occur before the agricultural scenario. Because of the void space above the waste, the concrete roof could collapse but still consist primarily of large, intact pieces that would not be removed by normal excavation procedures. Thus, after collapse of the roof, drilling between intact sections of the roof could occur. For the slit trenches, the post drilling scenario could occur at the same time as the agriculture scenario, due to the lack of physical barriers to drilling through these units at any time.

\subsubsection{Comparison of Agriculture and Post-Drilling Scenarios}

Previous analyses of the agriculture and post-drilling scenarios (Oztunali and Roles 1986; Kennedy and Peloquin 1988; ORNL 1990) have shown that the dose to an intruder per unit concentration of radionuclides in excavated material should be considerably greater for the agriculture scenario than for the post-drilling scenario, provided the assumptions for the exposure pathways in the two scenarios are reasonably consistent. The principal reasons for the greater doses in the agriculture scenario are 1) the greater volume of waste exhumed during construction of a foundation for a home compared with the volume of waste exhumed during drilling of a well, which results in greater concentrations of radionuclides in contaminated soil in the intruder's vegetable garden, and 2) the doses from external and inhalation exposure while residing 
in a home on the disposal site, which contribute to the dose for the agriculture scenario but are not relevant for the post-drilling scenario.

However, if the post-drilling scenario could occur before the agriculture scenario (as postulated for the LAW vaults), then previous analyses have shown that the dose from the post-drilling scenario could exceed the dose from the agriculture scenario (ORNL 1990). Whether or not this is the case depends on the concentrations of the particular radionuclides in the waste and the assumed difference in time between the first credible occurrences of the post-drilling and agriculture scenarios. Therefore, the post-drilling scenario is included in the intruder dose analysis for the E-Area LLWF. As noted previously, this scenario could be particularly important for the LAW vaults if the roof should collapse long before the resultant rubble is degraded to a soil-like material.

\subsubsection{Acute Exposure Scenarios for Intruders}

Three distinct scenarios resulting in acute exposure of inadvertent intruders have commonly been applied to LLW disposal facilities. These scenarios usually are referred to as the construction, discovery, and drilling scenarios (NRC 1981; Oztunali and Roles 1986; Kennedy and Peloquin 1988). As noted previously, all acute exposure scenarios for inadvertent intruders are subject to a limit on EDE of $500 \mathrm{mrem}$. The following sections describe the three acute exposure scenarios and their potential importance in the intruder dose analysis for the E-Area Low Level Waste Disposal Facility.

\subsubsection{Construction Scenario}

The chronic agriculture scenario described in Sect. 6.1.1 is based on the assumption that an intruder builds a home on the disposal site, with the foundation extending into a disposal unit. The construction scenario considers exposures during the short period of time for digging a foundation and building a home.

During construction, the relevant exposure pathways are assumed to be inhalation of radionuclides suspended into air from an uncovered disposal unit and external exposure to photon-emitting radionuclides in the disposal unit. Ingestion exposure is assumed to be unimportant during normal work activities. The potential importance of the construction scenario arises primarily from the assumption that construction activities result in airborne concentrations of radionuclides that are substantially higher than those during normal activities while inhabiting the site, as in the agriculture scenario. The construction scenario also assumes external exposure to unshielded waste, whereas in the agriculture scenario shielding during indoor residence on the disposal site usually is taken into account.

From its definition, the construction scenario would occur at the same time as the agriculture scenario. Therefore, the dose analysis for the two scenarios would be based on the same concentrations of radionuclides. Previous calculations (Kennedy and Peloquin 1988) provide a direct comparison of doses for the two scenarios. For a few radionuclides, the dose per unit concentration could be slightly higher for the construction scenario but, for most radionuclides, the dose per unit concentration is expected to be much greater for the agriculture scenario. This result assumes a reasonable exposure time for the construction scenario and the use of a reasonably consistent set of assumptions for the exposure pathways in the two scenarios. Therefore, since the dose limit for the acute construction scenario is a factor of 5 higher than the dose limit for the chronic agriculture scenario, the agriculture scenario always will be more restrictive and the construction scenario generally can be neglected in demonstrating compliance of the E-Area LLWF with the performance measure for inadvertent intruder analysis. 


\subsubsection{Discovery Scenario}

As in the resident scenario described in Sect. 6.1.1, the discovery scenario assumes that an intruder attempts to dig into a disposal facility while excavating a foundation for a home on the disposal site, but encounters an intact concrete roof or other engineered barrier which cannot easily be penetrated by the types of excavating equipment that normally would be used at the SRS. However, in distinction from the resident scenario, the intruder soon decides to abandon digging at that location and moves elsewhere. Since intact engineered barriers are assumed not to be breached during excavation, the primary exposure pathway for this scenario is external exposure to photon-emitting radionuclides in the disposal facility during the time the intruder digs at the site and the barriers are uncovered. The presence of intact barriers is assumed to preclude any significant inhalation or ingestion exposures.

From its definition, the discovery scenario would occur at the same time as the resident scenario. Furthermore, the relevant exposure pathway, which is external exposure to photon-emitting radionuclides in the waste, is essentially the same in the discovery and resident scenarios. Other than the exposure time, the only difference is the shielding factor during indoor residence, which is relevant only for the resident scenario. Therefore, since the exposure time for the discovery scenario presumably would be no more than $100 \mathrm{~h}$ (ORNL 1990), which is considerably less than a reasonable exposure time for indoor residence in the resident scenario, and the dose limit for the discovery scenario is a factor of 5 greater than the dose limit for the resident scenario, the resident scenario always will be more restrictive and the discovery scenario generally can be neglected in demonstrating compliance of the E-Area LLWF with the performance measure for inadvertent intruder analysis.

\subsubsection{Drilling scenario}

The chronic post-drilling scenario described in Sect. 6.1.1 is based on the assumption that an intruder drills a well directly through a disposal unit. The acute drilling scenario considers exposures during the short period of time for drilling and construction of the well.

During well drilling and construction, the most important exposure pathway is assumed to be external exposure to uncovered drilling wastes confined to a pile near the well. Although some radionuclides in the drilling waste could be suspended into the air and inhaled during well drilling and construction, inhalation exposures are expected to be relatively unimportant due to such factors as the initial water content of the drilling wastes, the small volume of the waste produced, and the absence of direct mechanical disturbance of the waste pile. Ingestion exposure also is assumed to be unimportant during normal drilling activities. The potential importance of the drilling scenario arises primarily from the assumption that an intruder could be located near an unshielded waste pile for a substantial period of time.

From its definition, the drilling scenario would occur at the same time as the post-drilling scenario. Therefore, the dose analyses for the two scenarios would be based on the same concentrations of radionuclides. Previous calculations (Kennedy and Peloquin 1988) provide a direct comparison of doses for the two scenarios. For all radionuclides, the dose per unit concentration for the drilling scenario is expected to be at least an order of magnitude less than the dose per unit concentration for the post-drilling scenario, provided a reasonable exposure time for the drilling scenario and a reasonably consistent set of assumptions for the exposure pathways in the two scenarios are used. Therefore, the post-drilling scenario always will be more restrictive and the drilling scenario generally can be neglected in demonstrating compliance of the EArea LLWF with the performance measure for inadvertent intruder analysis. 


\subsubsection{Summary of Acute Exposure Scenarios}

In this section, three scenarios for acute exposure of inadvertent intruders were discussed, i.e., the construction, discovery, and drilling scenarios. However, an evaluation of these scenarios has shown that all three scenarios can be neglected for purposes of demonstrating compliance of the E-Area LLWF with the performance measure for inadvertent intruder analysis because the chronic agriculture, resident, and postdrilling scenarios will always be more restrictive.

\subsubsection{Summary of Exposure Scenarios for Inadvertent Intruders}

Several chronic and acute exposure scenarios for inadvertent intruders have been considered for use in the PA for the E-Area LLWF. However, on the basis of previous analyses and considerations of how these scenarios would apply to the E-Area LLWF, it is evident that only the following three chronic exposure scenarios need to be included in the PA:

- an agriculture scenario involving direct intrusion into disposal units at times after the engineered barriers above the waste have lost their structural and physical integrity and can be penetrated by the types of excavation procedures normally used at the SRS;

- a resident scenario involving permanent residence in a home located either on top of an intact concrete roof or other engineered barrier, which first could occur upon assumed loss of active institutional control at 100 years after facility closure, or on top of intact but essentially exposed waste at times after the engineered barriers have lost their integrity; and

- a post-drilling scenario involving exhumation of waste from a disposal unit at times after drilling through a disposal unit becomes credible.

Estimates of dose for all of these scenarios are considered in this PA. All acute exposure scenarios would be less restrictive in regard to demonstrating compliance with the performance measure for inadvertent intruder analysis and, thus, are not considered further in this analysis.

As described in Sect. 2.5.3, compliance with the performance measure for inadvertent intruder analysis is assumed to be required for 1,000 years after disposal. However, in cases where the maximum dose to an inadvertent intruder is projected to occur beyond 1,000 years after disposal, the calculations are carried out until the time the maximum dose occurs to provide additional information and perspective on the performance of disposal units. Consideration of potential doses beyond 1,000 years is particularly important for disposal of uranium, due to the very long time required for ingrowth of radiologically significant decay products.

A comparison of the relative importance of the chronic exposure scenarios for inadvertent intruders considered in this analysis requires a detailed analysis of each scenario based on the expected long-term performance of the engineered barriers in the different types of disposal units. Therefore, all three scenarios are evaluated in this analysis. An application of the intruder dose analysis of the different scenarios is the determination of minimal requirements for the performance of the engineered barriers for meeting performance objectives for inadvertent intruders.

\subsection{Screening of Radionuclides for Intruder Dose Analysis}

Many radionuclides decay significantly before an inadvertent intruder may come into contact with them according to the exposure scenarios described in Sect. 6.1. For these radionuclides, calculated allowable inventories greatly exceed any imaginable inventory in a disposal unit of the E-Area LLWF. Screening 
calculations were therefore carried out on a large suite of 730 radionuclides which may be encountered during disposal operations, in order to eliminate radionuclides that are negligible contributors to dose from further analysis. The list of 730 radionuclides were selected because they represent all radionuclides having published dose conversion factors (DOE 1999). A subset of these 730 radionuclides are listed in projected inventories for the E-Area LLWF disposal units. This section presents the results of a simple screening analysis for selecting the radionuclides of potential concern for the analysis of impacts on inadvertent intruders.

Screening was accomplished with spreadsheet calculations, described in detail in Cook (1998). The methodology described in NCRP Report 123 (NCRP 1996), applicable to disposal of radionuclides in the ground, was followed. This approach may be summarized as follows. The NCRP model assumes an intruder exhumes waste in a disposal unit ten years after burial. The model application by Cook allows for an additional $100 \mathrm{y}$ of institutional control. The only loss of radionuclides from the waste during this 110-year period of time is by radioactive decay; leaching is neglected. (Ingrowth of radiologicallysignificant daughters is not addressed in the screening model as implemented by Cook (1998); therefore, care was taken in interpreting the screening results to consider this potential before making a decision on each radionuclide.) Once exhumed, the waste is spread over $100 \mathrm{~m}^{2}$ of land to a depth of $0.15 \mathrm{~m}$. Thus, $15 \mathrm{~m}^{3}$ of waste is exhumed. Depletion of radionuclides from the spread waste as a result of leaching, erosion, or other factors are ignored. Exposure of an inadvertent intruder to radionuclides is assumed to occur as a result of external exposure to the ground surface which is essentially waste to a depth of $15 \mathrm{~cm}$, ingestion of waste and vegetation grown in the waste, and inhalation of resuspended contaminated soil. These pathways are similarly addressed in the agriculture scenario described in Sect. 6.1; however, the screening model assumes the intruder spends 25 percent of his time outdoors in the center of the region of undiluted waste. Application of the agriculture scenario more reasonably assumes the intruder spends 1 percent of his time in the garden, which consists of waste mixed with soil in a ratio of $2: 8$ (see Table C.316 in Appendix C). One-half of the intruder's annual intake of vegetables are assumed to be derived from the contaminated site.

The NCRP report (NCRP 1996) provides screening factors for the scenario described above, expressed in units of Sievert per Becquerel exhumed from the disposal unit. The fraction of the total activity in a unit which is exhumed is calculated by dividing the $15 \mathrm{~m}^{3}$ volume by the total volume of the unit. Disposal unit volumes are shown in Table 6.2-1. Doses to inadvertent intruders are calculated by multiplying the activity in the disposal unit by the screening factor, and correcting units to mrem/yr. The results are expressed as mrem/yr per $\mathrm{Ci}$ of each radionuclide disposed of in each unit (e.g., vault or trench). These doses are then multiplied by a factor of $10^{7}$. The factor of $10^{7}$ was selected because it represents the total number of curies, of all radionuclides combined, that has been disposed in LLW at SRS over 40 years of operation. The effect of this factor is to scale the estimated doses to a total disposal unit inventory that is greater than projected inventories, to provide a very conservative upper bound on dose. Radionuclides for which calculated doses are less that $1 / 100$ of the $100 \mathrm{mrem} / \mathrm{yr}$ limit for chronically-exposed inadvertent intruders (i.e., less than $1 \mathrm{mrem} / \mathrm{yr}$ ) are then considered to be screened from further consideration in this assessment.

A departure from the NCRP screening methodology occurred in how radioactive progeny were handled in the analysis. Instead of directly incorporating the daughter ingrowth into the spreadsheet calculations, each radionuclide in the inventory lists for each disposal unit was evaluated individually with respect to the potential for producing daughters of radiological significance. Radionuclides such as ${ }^{252} \mathrm{Cf}$ were retained for analysis because, although they are short-lived or are have low dose factors, they have radioactive daughters which are potentially radiologically-significant due to a longer half-life and/or higher dose factor. A table of radionuclides with significant long-lived daughters in NCRP Report 123 was consulted to select radionuclides for which further analysis was required, whether or not the parent radionuclide might be screened by the methodology described above. 
Table 6.2-1 Parameters Used in Screening Radionuclide Inventories for E-Area Low Level Waste Facility Disposal Units, and Lists of Radionuclides for Further Analysis.

\begin{tabular}{|c|c|c|}
\hline $\begin{array}{l}\text { Type of } \\
\text { Disposal Unit }\end{array}$ & $\begin{array}{l}\text { Volume of Waste } \\
\text { in Single Disposal } \\
\text { Unit (m) }\end{array}$ & $\begin{array}{l}\text { Radionuclides Identified as Potentially Significant Contributors } \\
\text { to Dose for Inadvertent Intruders }\end{array}$ \\
\hline LAW Vaults & 48,000 & $\begin{array}{l}{ }^{3} \mathrm{H},{ }^{14} \mathrm{C},{ }^{59} \mathrm{Ni},{ }^{60} \mathrm{Co},{ }^{63} \mathrm{Ni},{ }^{79} \mathrm{Se},{ }^{87} \mathrm{Rb},{ }^{90} \mathrm{Sr}+\mathrm{d},{ }^{93} \mathrm{Zr}+\mathrm{d},{ }^{94} \mathrm{Nb},{ }^{99} \mathrm{Tc}, \\
{ }^{107} \mathrm{Pd},{ }^{126} \mathrm{Sn}+\mathrm{d},{ }^{129} \mathrm{I},{ }^{135} \mathrm{Cs},{ }^{137} \mathrm{Cs}+\mathrm{d},{ }^{15} \mathrm{Sm},{ }^{152} \mathrm{Eu},{ }^{154} \mathrm{Eu},{ }^{232} \mathrm{Th}+\mathrm{d}, \\
{ }^{232} \mathrm{U}+\mathrm{d},{ }^{233} \mathrm{U}+\mathrm{d},{ }^{234} \mathrm{U}+\mathrm{d},{ }^{235} \mathrm{U}+\mathrm{d},{ }^{236}{ }^{2} \mathrm{U},{ }^{237} \mathrm{~Np},{ }^{238} \mathrm{U}+\mathrm{d},{ }^{238} \mathrm{Pu}+\mathrm{d}, \\
{ }^{239} \mathrm{Pu}+\mathrm{d},{ }^{240} \mathrm{Pu}+\mathrm{d},{ }^{241} \mathrm{Pu}+\mathrm{d},{ }^{242} \mathrm{Pu}+\mathrm{d},{ }^{244} \mathrm{Pu},{ }^{241} \mathrm{Am}+\mathrm{d},{ }^{243} \mathrm{Am}+\mathrm{d}, \\
{ }^{244} \mathrm{Cm}+\mathrm{d},{ }^{245} \mathrm{Cm}+\mathrm{d},{ }^{246} \mathrm{Cm},{ }^{247} \mathrm{Cm}+\mathrm{d},{ }^{248} \mathrm{Cm}+\mathrm{d},{ }^{249} \mathrm{Cf}+\mathrm{d},{ }^{250} \mathrm{Cf}+\mathrm{d}, \\
{ }^{251} \mathrm{Cf},{ }^{252} \mathrm{Cf}+\mathrm{d}\end{array}$ \\
\hline IL Vaults & 5700 & $\begin{array}{l}{ }^{3} \mathrm{H},{ }^{14} \mathrm{C},{ }^{59} \mathrm{Ni},{ }^{60} \mathrm{Co},{ }^{63} \mathrm{Ni},{ }^{79} \mathrm{Se},{ }^{90} \mathrm{Sr}+\mathrm{d},{ }^{93} \mathrm{Zr}+\mathrm{d},{ }^{99} \mathrm{Tc},{ }^{107} \mathrm{Pd},{ }^{126} \mathrm{Sn}+\mathrm{d}, \\
{ }^{129} \mathrm{I},{ }^{135} \mathrm{Cs},{ }^{137} \mathrm{Cs}+\mathrm{d},{ }^{154} \mathrm{Eu},{ }^{232} \mathrm{Th}+\mathrm{d},{ }^{232} \mathrm{U}+\mathrm{d},{ }^{233} \mathrm{U}+\mathrm{d},{ }^{234} \mathrm{U}+\mathrm{d}, \\
{ }^{235} \mathrm{U}+\mathrm{d},{ }^{236} \mathrm{U},{ }^{237} \mathrm{~Np},{ }^{238} \mathrm{U}+\mathrm{d},{ }^{238} \mathrm{Pu}+\mathrm{d},{ }^{239} \mathrm{Pu}+\mathrm{d},{ }^{240} \mathrm{Pu}+\mathrm{d},{ }^{241} \mathrm{Pu}+\mathrm{d}, \\
{ }^{242} \mathrm{Pu}+\mathrm{d},{ }^{244} \mathrm{Pu},{ }^{241} \mathrm{Am}+\mathrm{d},{ }^{242 \mathrm{~m}} \mathrm{Am}+\mathrm{d},{ }^{243} \mathrm{Am}+\mathrm{d},{ }^{244} \mathrm{Cm}+\mathrm{d},{ }^{245} \mathrm{Cm}+\mathrm{d}, \\
{ }^{246} \mathrm{Cm},{ }^{247} \mathrm{Cm}+\mathrm{d},{ }^{248} \mathrm{Cm}+\mathrm{d},{ }^{249} \mathrm{Cf}+\mathrm{d},{ }^{251} \mathrm{Cf},{ }^{252} \mathrm{Cf}+\mathrm{d}\end{array}$ \\
\hline Slit Trenches & 5760 & $\begin{array}{l}{ }^{3} \mathrm{H},{ }^{14} \mathrm{C},{ }^{59} \mathrm{Ni},{ }^{60} \mathrm{Co},{ }^{63} \mathrm{Ni},{ }^{79} \mathrm{Se},{ }^{87} \mathrm{Rb},{ }^{90} \mathrm{Sr}+\mathrm{d},{ }^{93} \mathrm{Zr}+\mathrm{d},{ }^{94} \mathrm{Nb},{ }^{99} \mathrm{Tc}, \\
{ }^{107} \mathrm{Pd},{ }^{133 \mathrm{~m}} \mathrm{Cd},{ }^{12 \mathrm{~m}} \mathrm{Sn},{ }^{126} \mathrm{Sn}+\mathrm{d},{ }^{129} \mathrm{I},{ }^{135} \mathrm{Cs},{ }^{137} \mathrm{Cs}+\mathrm{d},{ }^{151} \mathrm{Sm},{ }^{154} \mathrm{Eu}, \\
{ }^{228} \mathrm{Th},{ }^{232} \mathrm{Th}+\mathrm{d},{ }^{232} \mathrm{U}+\mathrm{d},{ }^{233} \mathrm{U}+\mathrm{d},{ }^{234} \mathrm{U}+\mathrm{d},{ }^{235} \mathrm{U}+\mathrm{d},{ }^{236} \mathrm{U},{ }^{237} \mathrm{~Np}, \\
{ }^{238} \mathrm{U}+\mathrm{d},{ }^{238} \mathrm{Pu}+\mathrm{d},{ }^{239} \mathrm{Pu}+\mathrm{d},{ }^{240} \mathrm{Pu}+\mathrm{d},{ }^{241} \mathrm{Pu}+\mathrm{d},{ }^{242} \mathrm{Pu}+\mathrm{d},{ }^{244} \mathrm{Pu}, \\
{ }^{241} \mathrm{Am}+\mathrm{d},{ }^{242 \mathrm{~m}} \mathrm{Am},{ }^{243} \mathrm{Am}+\mathrm{d},{ }^{242} \mathrm{Cm}+\mathrm{d},{ }^{243} \mathrm{Cm},{ }^{244} \mathrm{Cm}+\mathrm{d},{ }^{245} \mathrm{Cm}+\mathrm{d}, \\
{ }^{246} \mathrm{Cm},{ }^{247} \mathrm{Cm}+\mathrm{d},{ }^{248} \mathrm{Cm}+\mathrm{d},{ }^{249} \mathrm{Bk}+\mathrm{d},{ }^{249} \mathrm{Cf}+\mathrm{d},{ }^{250} \mathrm{Cf}+\mathrm{d},{ }^{251} \mathrm{Cf}, \\
{ }^{252} \mathrm{Cf}+\mathrm{d}\end{array}$ \\
\hline $\begin{array}{l}\text { Intimately- } \\
\text { mixed } \\
\text { Cement- } \\
\text { stabilized } \\
\text { Waste Units }^{\mathrm{a}}\end{array}$ & 5760 & $\begin{array}{l}{ }^{3} \mathrm{H},{ }^{14} \mathrm{C},{ }^{59} \mathrm{Ni},{ }^{60} \mathrm{Co},{ }^{63} \mathrm{Ni},{ }^{79} \mathrm{Se},{ }^{87} \mathrm{Rb},{ }^{90} \mathrm{Sr}+\mathrm{d},{ }^{93} \mathrm{Zr}+\mathrm{d},{ }^{94} \mathrm{Nb},{ }^{99} \mathrm{Tc}, \\
{ }^{107} \mathrm{Pd},{ }^{126} \mathrm{Sn}+\mathrm{d},{ }^{129} \mathrm{I},{ }^{135} \mathrm{Cs},{ }^{137} \mathrm{Cs}+\mathrm{d},{ }^{151} \mathrm{Sm},{ }^{152} \mathrm{Eu},{ }^{154} \mathrm{Eu},{ }^{232} \mathrm{Th}+\mathrm{d}, \\
{ }^{232} \mathrm{U}+\mathrm{d},{ }^{233} \mathrm{U}+\mathrm{d},{ }^{234} \mathrm{U}+\mathrm{d},{ }^{235} \mathrm{U}+\mathrm{d},{ }^{236}{ }^{237},{ }^{237} \mathrm{~Np},{ }^{238} \mathrm{U}+\mathrm{d},{ }^{238} \mathrm{Pu}+\mathrm{d}, \\
{ }^{239} \mathrm{Pu}+\mathrm{d},{ }^{240} \mathrm{Pu}+\mathrm{d},{ }^{241} \mathrm{Pu}+\mathrm{d},{ }^{242} \mathrm{Pu}+\mathrm{d},{ }^{244} \mathrm{Pu},{ }^{241} \mathrm{Am}+\mathrm{d},{ }^{243} \mathrm{Am}+\mathrm{d}, \\
{ }^{244} \mathrm{Cm}+\mathrm{d},{ }^{245} \mathrm{Cm}+\mathrm{d},{ }^{246} \mathrm{Cm},{ }^{247} \mathrm{Cm}+\mathrm{d},{ }^{248} \mathrm{Cm}+\mathrm{d},{ }^{249} \mathrm{Cf}+\mathrm{d},{ }^{250} \mathrm{Cf}+\mathrm{d}, \\
{ }^{251} \mathrm{Cf},{ }^{252} \mathrm{Cf}+\mathrm{d}\end{array}$ \\
\hline $\begin{array}{l}\text { Cement- } \\
\text { stabilized } \\
\text { Encapsulated } \\
\text { Waste Units } \\
\end{array}$ & 5760 & $\begin{array}{l}{ }^{3} \mathrm{H},{ }^{59} \mathrm{Ni},{ }^{60} \mathrm{Co},{ }^{63} \mathrm{Ni},{ }^{79} \mathrm{Se},{ }^{90} \mathrm{Sr}+\mathrm{d},{ }^{93} \mathrm{Zr}+\mathrm{d},{ }^{99} \mathrm{Tc},{ }^{107} \mathrm{Pd},{ }^{126} \mathrm{Sn}+\mathrm{d},{ }^{129} \mathrm{I}, \\
{ }^{135} \mathrm{Cs},{ }^{137} \mathrm{Cs}+\mathrm{d},{ }^{151} \mathrm{Sm},{ }^{154} \mathrm{Eu},{ }^{232} \mathrm{U}+\mathrm{d},{ }^{233} \mathrm{U}+\mathrm{d},{ }^{234} \mathrm{U}+\mathrm{d},{ }^{235} \mathrm{U}+\mathrm{d},{ }^{236} \mathrm{U}, \\
{ }^{238} \mathrm{U}+\mathrm{d},{ }^{238} \mathrm{Pu}+\mathrm{d},{ }^{239} \mathrm{Pu}+\mathrm{d},{ }^{240} \mathrm{Pu}+\mathrm{d},{ }^{242} \mathrm{Pu}+\mathrm{d}\end{array}$ \\
\hline $\begin{array}{l}\text { Naval Reactor } \\
\text { Components }\end{array}$ & 10000 & $\begin{array}{l}{ }^{3} \mathrm{H},{ }^{14} \mathrm{C},{ }^{59} \mathrm{Ni},{ }^{60} \mathrm{Co},{ }^{63} \mathrm{Ni},{ }^{79} \mathrm{Se},{ }^{90} \mathrm{Sr}+\mathrm{d},{ }^{93} \mathrm{Mo},{ }^{93} \mathrm{Zr}+\mathrm{d},{ }^{94} \mathrm{Nb},{ }^{99} \mathrm{Tc}, \\
{ }^{107} \mathrm{Pd},{ }^{16} \mathrm{Sn}+\mathrm{d},{ }^{129} \mathrm{I},{ }^{135} \mathrm{Cs},{ }^{137} \mathrm{Cs}+\mathrm{d},{ }^{151} \mathrm{Sm},{ }^{154} \mathrm{Eu},{ }^{232} \mathrm{Th}+\mathrm{d},{ }^{232} \mathrm{U}+\mathrm{d}, \\
{ }^{234} \mathrm{U}+\mathrm{d},{ }^{235} \mathrm{U}+\mathrm{d},{ }^{236} \mathrm{U},{ }^{237} \mathrm{~Np},{ }^{238} \mathrm{U}+\mathrm{d},{ }^{238} \mathrm{Pu}+\mathrm{d},{ }^{239} \mathrm{Pu}+\mathrm{d},{ }^{240} \mathrm{Pu}+\mathrm{d}, \\
{ }^{241} \mathrm{Pu}+\mathrm{d},{ }^{242} \mathrm{Pu}+\mathrm{d},{ }^{244} \mathrm{Pu},{ }^{241} \mathrm{Am}+\mathrm{d},{ }^{242 \mathrm{~m}} \mathrm{Am}+\mathrm{d},{ }^{243} \mathrm{Am}+\mathrm{d},{ }^{242} \mathrm{Cm}+\mathrm{d}, \\
{ }^{243} \mathrm{Cm},{ }^{244} \mathrm{Cm}+\mathrm{d},{ }^{245} \mathrm{Cm}+\mathrm{d},{ }^{246} \mathrm{Cm},{ }^{247} \mathrm{Cm}+\mathrm{d},{ }^{248} \mathrm{Cm}+\mathrm{d},{ }^{249} \mathrm{Bk}+\mathrm{d}, \\
{ }^{249} \mathrm{Cf}+\mathrm{d},{ }^{251} \mathrm{Cf}\end{array}$ \\
\hline
\end{tabular}

Starting list of radionuclides (i.e., before screening) assumed to be the same as that for the LAW vaults.

b Assumes waste from 100 naval casks buried in an area $43 \mathrm{~m} \times 43 \mathrm{~m} \times 5.4 \mathrm{~m}$ deep. 
The lists of radionuclides of potential significance with respect to inadvertent intruders, including those with potentially significant daughters noted by " $+d$ ", are given in Table 6.2-1 for each type of disposal unit in the $\mathrm{E}$ Area. This list is a subset of the inventory list for each unit provided in Appendix $\mathrm{A}$.

\subsection{Dose to Inadvertent Intruders}

Limits on disposal of radionuclides in waste intended for disposal in the E-Area LLWF are developed in this PA, and compared to projected inventories for each type of disposal unit. Estimated intruder-based limits on radionuclide inventories and concentrations in waste are developed in this section, which are based on the performance measure for inadvertent intruder analysis described in Sect. 2.5.3; i.e., a limit on EDE of 100 mrem per year for scenarios involving chronic exposure.

The different exposure scenarios and exposure pathways for inadvertent intruders assumed for the E-Area LLWF are discussed in Sect. 6.1. The principal exposure scenarios of concern involve direct intrusion into disposal units, in order that limits on inventory and concentration of radionuclides in the waste may be established. Doses to inadvertent intruders resulting from use of contaminated groundwater obtained from a well on the disposal site are evaluated separately, in the water resource impacts analysis, and are not calculated for the intruder, in accordance with the reasoning put forth in the Format and Content Guide for PAs (DOE 1996).

The discussion of possible exposure scenarios for inadvertent intruders in Sect. 6.1 shows that only three scenarios need be considered in the analysis for the E-Area LLWF. All of these scenarios involve chronic exposure and, thus, are subject to a limit on EDE from all exposure pathways of 100 mrem per year. These scenarios include 1) an agriculture scenario involving direct intrusion into disposal units at any time after the concrete vaults and any other engineered barriers above the waste have lost their structural and physical integrity and excavation into the waste becomes credible, 2) a resident scenario involving permanent residence in a home located immediately above an intact concrete roof or other engineered barrier at any time after loss of active institutional control, and 3) a post-drilling scenario involving exhumation of waste from a disposal unit at any time after drilling through a disposal unit becomes credible. The discussion in Sect. 6.1 shows that other scenarios involving chronic or acute exposure either are not credible for the EArea LLWF, would result in lower doses than the scenarios considered in the analysis, or are subject to a higher dose limit in the case of acute exposure scenarios (i.e., $500 \mathrm{mrem}$ ) and, thus, would be less restrictive than the chronic exposure scenarios considered in the analysis.

The models for estimating dose for the three chronic exposure scenarios for inadvertent intruders considered in this analysis are presented in Appendix C.3. The inputs to the model for each scenario are the maximum concentrations of radionuclides in the disposal facility at any time after the scenario is first assumed to be credible. The concentrations of radionuclides in disposal units over time are estimated using the initial concentrations at disposal corrected for radioactive decay. Depletion of radionuclide inventories in disposal units due to removal by infiltrating water also is considered in most cases, particularly for long-lived isotopes of uranium. Ingrowth of radiologically-significant decay products at times long after disposal is potentially important in the intruder dose analysis, and is accounted for in the analysis. The results of implementing models for the agriculture, resident, and post-drilling scenarios for a unit concentration in waste are summarized in Tables 6.3-1, 6.3-2, and 6.3-3, respectively. For each radionuclide and exposure scenario, the scenario dose conversion factor (SDCF) in the appropriate table gives the EDE in rem per year for a unit concentration in the disposal facility of $1 \mu \mathrm{Ci} / \mathrm{m}^{3}$. The calculation of radionuclide inventory and concentration limits in disposal facilities on the basis of an initial unit activity of each radionuclide in disposed waste is described below.

For an assumed exposure scenario and particular type of disposal unit, the EDE (rem/yr) to an inadvertent intruder from exposure to a given radionuclide can be expressed as 
Table 6.3-1 Annual EDEs Per Unit Concentration of Radionuclides in Disposal Units from All Exposure Pathways for Agriculture Scenario

\begin{tabular}{|c|c|c|c|}
\hline Radionuclide & $\begin{array}{c}\text { EDE } \\
\left(\mathrm{rem} / \mathrm{yr} \text { per } \mu \mathrm{Ci} / \mathrm{m}^{3}\right)\end{array}$ & Radionuclide & $\begin{array}{c}\text { EDE } \\
\left(\mathrm{rem} / \mathrm{yr} \text { per } \mu \mathrm{Ci} / \mathrm{m}^{3}\right)\end{array}$ \\
\hline $\mathrm{H}-3$ & $3.9 \mathrm{E}-06$ & $\mathrm{U}-235+\mathrm{d}$ & $1.7 \mathrm{E}-04$ \\
\hline C-14 & $1.5 \mathrm{E}-05$ & $\mathrm{~Pa}-231$ & $1.5 \mathrm{E}-04$ \\
\hline $\mathrm{Co}-60$ & $3.5 E-03$ & Ac- 227 & $3.0 \mathrm{E}-04$ \\
\hline Ni-59 & $6.8 \mathrm{E}-08$ & Th-227 & $1.2 \mathrm{E}-04$ \\
\hline $\mathrm{Ni}-63$ & $1.8 \mathrm{E}-07$ & $\mathrm{Ra}-223+\mathrm{d}$ & $2.7 \mathrm{E}-04$ \\
\hline $\mathrm{Se}-79$ & $1.2 \mathrm{E}-06$ & $\mathrm{U}-236$ & $1.0 \mathrm{E}-05$ \\
\hline $\mathrm{Rb}-87$ & $1.9 \mathrm{E}-06$ & $\mathrm{U}-238$ & $9.8 \mathrm{E}-06$ \\
\hline Sr-90 +d & $1.9 \mathrm{E}-04$ & Th-234 +d & $2.9 \mathrm{E}-05$ \\
\hline Mo-93 & $1.8 \mathrm{E}-06$ & U-234 & $1.1 \mathrm{E}+05$ \\
\hline $\mathrm{Zr}-93+\mathrm{d}$ & $6.4 \mathrm{E}-08$ & $\mathrm{~Np}-237+\mathrm{d}$ & 4.9E-04 \\
\hline $\mathrm{Nb}-94$ & $2.1 \mathrm{E}-03$ & Pu-238 & $3.5 \mathrm{E}-05$ \\
\hline Tc-99 & $1.1 \mathrm{E}-05$ & U-234 & $1.1 \mathrm{E}-05$ \\
\hline $\mathrm{Pd}-107$ & $3.2 \mathrm{E}-08$ & $\mathrm{Pu}-239$ & $3.9 \mathrm{E}-05$ \\
\hline $\mathrm{Cd}-113 \mathrm{~m}$ & $1.3 \mathrm{E}-04$ & U-235 & $1.6 \mathrm{E}-04$ \\
\hline $\mathrm{Sn}-121 \mathrm{~m}$ & 4.7E-07 & $\mathrm{Pu}-240$ & $3.9 \mathrm{E}-05$ \\
\hline $\mathrm{Sn}-126+d$ & $2.6 \mathrm{E}-03$ & U-236 & $1.0 \mathrm{E}-05$ \\
\hline $\mathrm{I}-129$ & $8.4 \mathrm{E}-05$ & $\mathrm{Pu}-241$ & 7.7E-07 \\
\hline Cs- 135 & $1.2 E-06$ & $A m-241$ & $5.5 \mathrm{E}-05$ \\
\hline Cs- $137+d$ & $7.7 \mathrm{E}-04$ & $\mathrm{~Np}-237+\mathrm{d}$ & $4.9 \mathrm{E}-04$ \\
\hline Sm-151 & $1.0 \mathrm{E}-08$ & $\mathrm{Pu}-242$ & $3.7 \mathrm{E}-05$ \\
\hline Eu-152 & $1.5 \mathrm{E}-03$ & U-238 & $9.8 \mathrm{E}-06$ \\
\hline Eu-154 & $1.7 \mathrm{E}-03$ & $\mathrm{Pu}-244+\mathrm{d}$ & $4.9 \mathrm{E}-04$ \\
\hline Th-228 & $1.3 \mathrm{E}-05$ & Am-241 & $5.5 \mathrm{E}-05$ \\
\hline Th- 230 & $1.1 \mathrm{E}-05$ & $\mathrm{~Np}-237+\mathrm{d}$ & $4.9 \mathrm{E}-04$ \\
\hline $\mathrm{Ra}-226+\mathrm{d}$ & $2.5 E-03$ & $A m-242 m+d$ & $5.6 \mathrm{E}-05$ \\
\hline $\mathrm{Pb}-210$ & $2.8 \mathrm{E}-04$ & Pu-238 & $3.5 \mathrm{E}-05$ \\
\hline Po-210 & $1.2 \mathrm{E}-05$ & U-234 & $1.1 \mathrm{E}-05$ \\
\hline Th-232 & $4.9 \mathrm{E}-05$ & $A m-243+d$ & $2.4 \mathrm{E}-04$ \\
\hline $\mathrm{Ra}-228+\mathrm{d}$ & $1.3 \mathrm{E}-03$ & Pu-239 & $3.9 \mathrm{E}-05$ \\
\hline Th-228 & 1.3E-05 & $\mathrm{Cm}-242$ & $1.1 \mathrm{E}-06$ \\
\hline $\mathrm{Ra}-224+\mathrm{d}$ & $2.2 \mathrm{E}-03$ & $\mathrm{Pu}-238$ & $3.5 \mathrm{E}-05$ \\
\hline$U-232$ & $5.5 E-05$ & U-234 & $1.1 \mathrm{E}-05$ \\
\hline Th-228 & $1.3 \mathrm{E}-05$ & $\mathrm{Cm}-243$ & $1.5 \mathrm{E}-04$ \\
\hline $\mathrm{Ra}-224+\mathrm{d}$ & $2.2 \mathrm{E}-03$ & $\mathrm{Cm}-244$ & $2.0 \mathrm{E}-05$ \\
\hline $\mathrm{U}-233$ & 1.1E-05 & $\mathrm{Pu}-240$ & $3.9 \mathrm{E}-0.5$ \\
\hline Th-229 & $1.4 \mathrm{E}-04$ & U-236 & $1.0 \mathrm{E}-05$ \\
\hline $\mathrm{Ra}-225+\mathrm{d}$ & $2.9 \mathrm{E}-04$ & $\mathrm{Cm}-245$ & 1.1E-04 \\
\hline $\mathrm{U}-234$ & $1.1 \mathrm{E}-05$ & $\mathrm{Pu}-241$ & $7.7 \mathrm{E}-07$ \\
\hline Th-230 & $1.1 \mathrm{E}-05$ & Am-241 & $5.5 \mathrm{E}-05$ \\
\hline $\mathrm{Ra}-226+d$ & $2.5 \mathrm{E}-03$ & Np-237 & 4.9E-04 \\
\hline $\mathrm{Pb}-210$ & $2.8 \mathrm{E}-04$ & $\mathrm{Cm}-246$ & $4.0 \mathrm{E}-05$ \\
\hline Po-210 & $1.2 \mathrm{E}-05$ & & \\
\hline
\end{tabular}


Table 6.3-1 Annual EDEs Per Unit Concentration of Radionuclides in Disposal Units from All Exposure Pathways for Agriculture Scenario

\begin{tabular}{cc}
\hline & EDE \\
Radionuclide & (rem/yr per $\mu \mathrm{Ci} / \mathrm{m}^{3}$ ) \\
\hline Cm-247 +d & $4.4 \mathrm{E}-04$ \\
$\mathrm{Am}-243$ & $7.7 \mathrm{E}-05$ \\
$\mathrm{~Np}-239$ & $1.7 \mathrm{E}-04$ \\
$\mathrm{Pu}-239$ & $3.9 \mathrm{E}-05$ \\
$\mathrm{Cm}-248$ & $1.4 \mathrm{E}-04$ \\
$\mathrm{Pu}-244+\mathrm{d}$ & $4.5 \mathrm{E}-04$ \\
$\mathrm{Bk}-249$ & $7.1 \mathrm{E}-08$ \\
$\mathrm{Cf}-249$ & $4.6 \mathrm{E}-04$ \\
$\mathrm{Cm}-245$ & $1.1 \mathrm{E}-04$ \\
& \\
\hline
\end{tabular}

\begin{tabular}{cc}
\hline Radionuclide & $\begin{array}{c}\mathrm{EDE} \\
\text { (rem/yr per } \mu \mathrm{Ci} / \mathrm{m}^{3} \text { ) }\end{array}$ \\
\hline $\mathrm{Cf}-249$ & $4.6 \mathrm{E}-04$ \\
$\mathrm{Cm}-245$ & $1.1 \mathrm{E}-04$ \\
$\mathrm{Pu}-241$ & $7.7 \mathrm{E}-07$ \\
$\mathrm{Am}-241$ & $5.5 \mathrm{E}-05$ \\
$\mathrm{~Np}-237$ & $4.9 \mathrm{E}-04$ \\
$\mathrm{Cf}-250$ & $1.7 \mathrm{E}-05$ \\
$\mathrm{Cm}-246$ & $4.0 \mathrm{E}-05$ \\
$\mathrm{Cf}-251$ & $1.6 \mathrm{E}-04$ \\
$\mathrm{Cf}-252$ & $8.9 \mathrm{E}-06$ \\
$\mathrm{Cm}-248$ & $1.4 \mathrm{E}-04$ \\
\end{tabular}

a Indented entries are decay products of parent radionuclide that are potentially radiologically-significant.

b The notation " $+\mathrm{d}$ " indicates that short-lived daughters were incorporated into the EDE. Dose from other daughters listed is calculated explicitly by adding EDE's. 
Table 6.3-2 Annual EDEs Per Unit Concentration of Radionuclides in Disposal Units for Resident Scenario

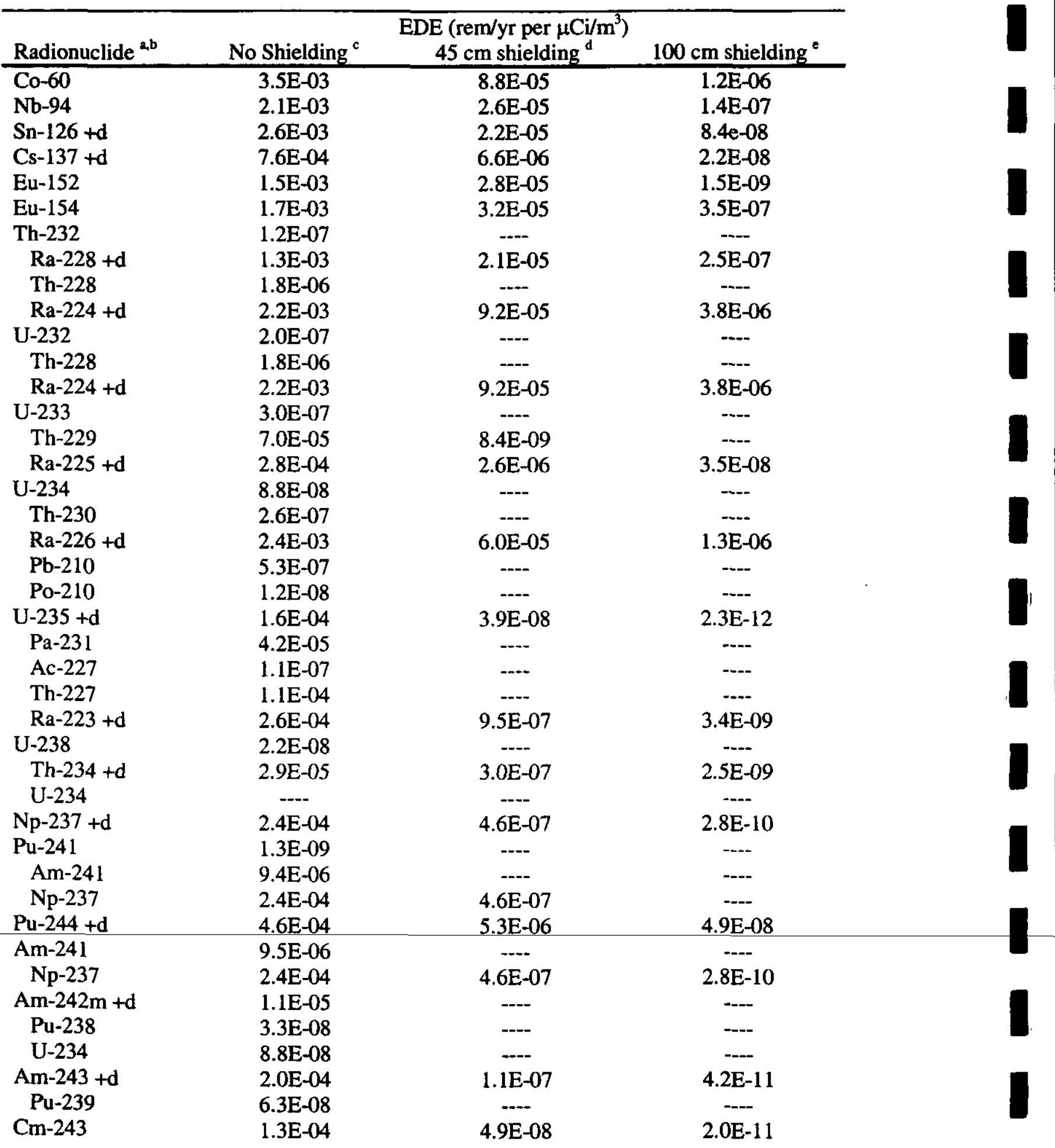


Table 6.3-2 Annual EDEs Per Unit Concentration of Radionuclides in Disposal Units for Resident Scenario

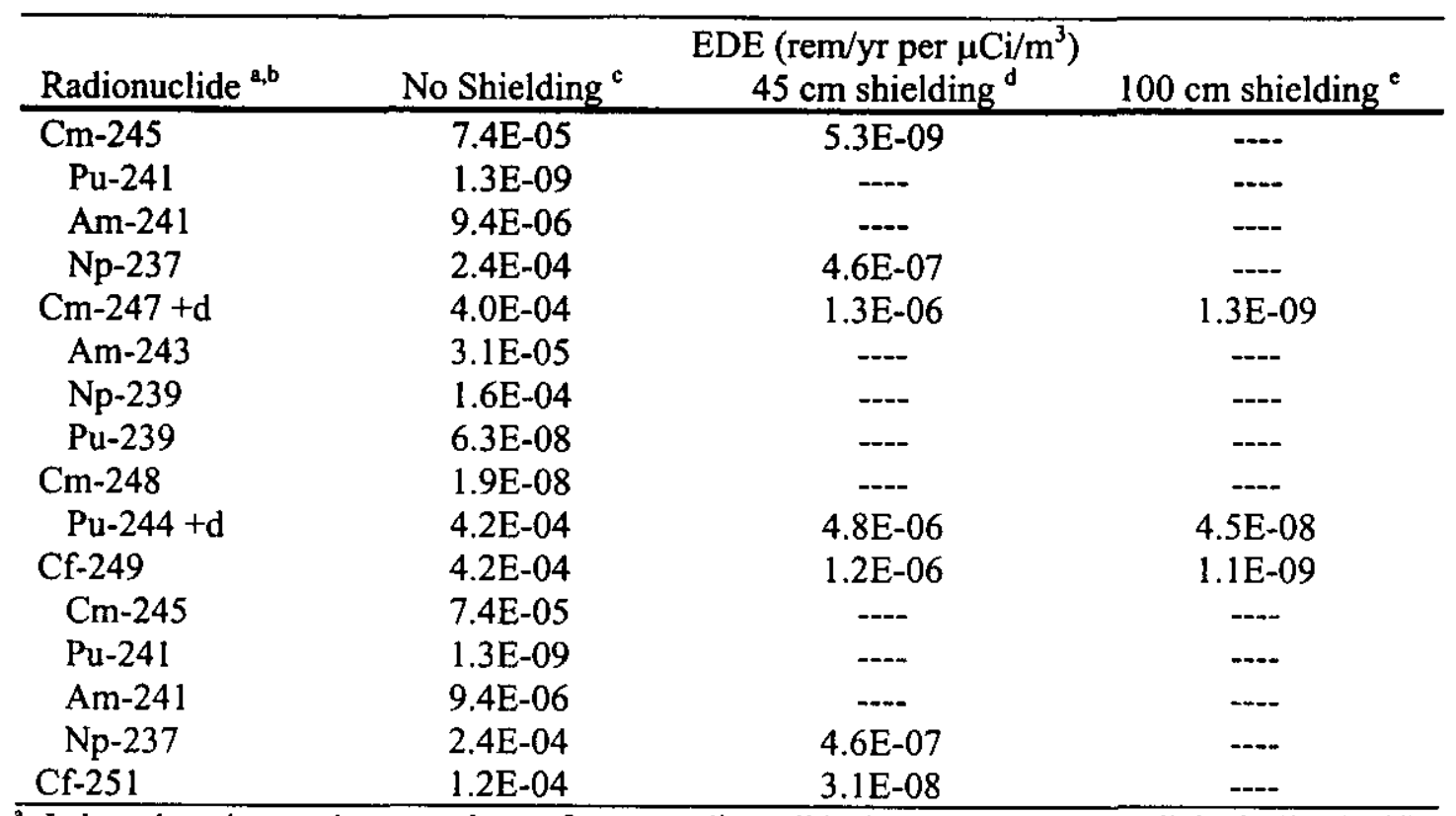

a Indented entries are decay products of parent radionuclide that are potentially radiologically-significant.

b The notation " $+d$ " indicates that short-lived daughters were incorporated into the EDE. Dose from other daughters listed is calculated explicitly by adding EDE's.

c Results apply to all disposal unit at times when engineered barriers which provide shielding above the waste are assumed to have lost they physical integrity.

'Results apply to LAW vaults at 100 years after facility closure, when the roofs of the vaults are assumed to be intact and residence on unshielded waste is not credible.

c Results apply to IL vaults at 100 years after facility closure, when the roofs of the vaults and uncontaminated grout layer over the waste are assumed to be intact and residence on unshielded waste is not credible. 
Table 6.3-3

Annual EDEs per Unit Concentration of Radionuclides in Exhumed Waste for Post-Drilling Scenario

\begin{tabular}{|c|c|}
\hline Radionuclide $^{a, b}$ & $\begin{array}{c}\text { EDE } \\
\left(\mathrm{rem} / \mathrm{yr} \text { per } \mu \mathrm{Ci} / \mathrm{m}^{3}\right)\end{array}$ \\
\hline $\mathrm{H}-3$ & $3.9 \mathrm{E}-07$ \\
\hline $\mathrm{C}-14$ & $1.5 \mathrm{E}-06$ \\
\hline $\mathrm{Co}-60$ & $1.8 \mathrm{E}-06$ \\
\hline $\mathrm{Ni}-59$ & $6.8 \mathrm{E}-09$ \\
\hline $\mathrm{Ni}-63$ & $1.8 \mathrm{E}-08$ \\
\hline Se-79 & $1.2 \mathrm{E}-07$ \\
\hline Rb-87 & $1.9 \mathrm{E}-07$ \\
\hline $\mathrm{Sr}-90+\mathrm{d}$ & $1.8 \mathrm{E}-05$ \\
\hline Mo-93 & $1.7 \mathrm{E}-07$ \\
\hline $\mathrm{Zr}-93+\mathrm{d}$ & $3.1 \mathrm{E}-09$ \\
\hline $\mathrm{Nb}-94$ & $1.1 \mathrm{E}-06$ \\
\hline Tc-99 & $1.1 \mathrm{E}-06$ \\
\hline Pd-107 & $3.1 \mathrm{E}-09$ \\
\hline $\mathrm{Cd}-113 \mathrm{~m}$ & $1.3 \mathrm{E}-05$ \\
\hline $\mathrm{Sn}-121 \mathrm{~m}$ & 5.3E-09 \\
\hline $\mathrm{Sn}-126+\mathrm{d}$ & $1.4 \mathrm{E}-06$ \\
\hline I- 129 & $8.1 \mathrm{E}-06$ \\
\hline Cs- 135 & $1.2 \mathrm{E}-07$ \\
\hline Cs- $137+d$ & $1.2 \mathrm{E}-06$ \\
\hline Sm-151 & $9.3 \mathrm{E}-10$ \\
\hline Eu-152 & $7.8 \mathrm{E}-07$ \\
\hline Eu-154 & $8.4 \mathrm{E}-07$ \\
\hline Th-232 & $1.7 E-06$ \\
\hline $\mathrm{Ra}-228+\mathrm{d}$ & $2.3 \mathrm{E}-06$ \\
\hline Th-228 & $2.6 \mathrm{E}-07$ \\
\hline $\mathrm{Ra}-224+\mathrm{d}$ & $1.7 \mathrm{E}-06$ \\
\hline $\mathrm{U}-232$ & $3.6 \mathrm{E}-06$ \\
\hline Th-228 & $2.6 \mathrm{E}-07$ \\
\hline $\mathrm{Ra}-224+\mathrm{d}$ & $1.7 \mathrm{E}-06$ \\
\hline U-233 & $7.5 \mathrm{E}-07$ \\
\hline Th-229 & $2.3 E-06$ \\
\hline $\mathrm{Ra}-225+\mathrm{d}$ & $6.4 \mathrm{E}-07$ \\
\hline $\mathrm{U}-234$ & $7.2 \mathrm{E}-07$ \\
\hline Th-230 & $3.4 \mathrm{E}-07$ \\
\hline $\mathrm{Ra}-226+\mathrm{d}$ & $2.7 \mathrm{E}-06$ \\
\hline $\mathrm{Pb}-210$ & $2.8 \mathrm{E}-05$ \\
\hline Po-210 & $1.2 \mathrm{E}-06$ \\
\hline$U-235+d$ & $7.9 \mathrm{E}-07$ \\
\hline $\mathrm{Pa}-231$ & $7.5 \mathrm{E}-06$ \\
\hline Ac- -227 & $1.1 \mathrm{E}-05$ \\
\hline Th-227 & $8.3 E-08$ \\
\hline $\mathrm{Ra}-223$ & $8.9 \mathrm{E}-07$ \\
\hline U-236 & $6.9 \mathrm{E}-07$ \\
\hline $\mathrm{U}-238$ & $6.4 \mathrm{E}-07$ \\
\hline Th-234 +d & $2.2 \mathrm{E}-08$ \\
\hline U-234 & $7.2 \mathrm{E}-07$ \\
\hline
\end{tabular}

\begin{tabular}{|c|c|}
\hline Radionuclide $^{a, b}$ & $\begin{array}{c}\text { EDE } \\
\left(\mathrm{rem} / \mathrm{yr} \text { per } \mu \mathrm{Ci} / \mathrm{m}^{3}\right)\end{array}$ \\
\hline $\mathrm{Np}-237+\mathrm{d}$ & 2.4E-05 \\
\hline Pu-238 & $2.2 \mathrm{E}-06$ \\
\hline $\mathrm{U}-234$ & $7.2 \mathrm{E}-07$ \\
\hline $\mathrm{Pu}-239$ & $2.4 \mathrm{E}-06$ \\
\hline U-235 & $7.8 \mathrm{E}-07$ \\
\hline $\mathrm{Pu}-240$ & $2.4 \mathrm{E}-06$ \\
\hline U-236 & $6.9 \mathrm{E}-07$ \\
\hline $\mathrm{Pu}-241$ & $4.9 E-08$ \\
\hline Am-241 & $3.1 \mathrm{E}-06$ \\
\hline Np-237 & $2.4 \mathrm{E}-05$ \\
\hline $\mathrm{Pu}-242$ & $2.3 \mathrm{E}-06$ \\
\hline U-238 & $6.4 \mathrm{E}-07$ \\
\hline $\mathrm{Pu}-244+\mathrm{d}$ & $2.5 \mathrm{E}-06$ \\
\hline Am-24l & $3.1 \mathrm{E}-06$ \\
\hline $\mathrm{Np}-237$ & $2.4 \mathrm{E}-05$ \\
\hline$A m-242 m+d$ & $2.9 \mathrm{E}-06$ \\
\hline $\mathrm{Pu}-238$ & $2.2 \mathrm{E}-06$ \\
\hline $\mathrm{U}-234$ & $7.2 \mathrm{E}-07$ \\
\hline$A m-243+d$ & $3.2 \mathrm{E}-06$ \\
\hline Pu-239 & $2.4 \mathrm{E}-06$ \\
\hline $\mathrm{Cm}-244$ & $1.3 \mathrm{E}-06$ \\
\hline Pu-240 & $2.4 \mathrm{E}-06$ \\
\hline U-236 & $6.9 \mathrm{E}-07$ \\
\hline $\mathrm{Cm}-245$ & $2.5 \mathrm{E}-06$ \\
\hline $\mathrm{Pu}-241$ & $4.9 \mathrm{E}-08$ \\
\hline Am-241 & $3.1 \mathrm{E}-06$ \\
\hline $\mathrm{Np}-237$ & $2.4 \mathrm{E}-05$ \\
\hline $\mathrm{Cm}-246$ & $2.5 \mathrm{E}-06$ \\
\hline $\mathrm{Cm}-247+\mathrm{d}$ & $2.5 \mathrm{E}-06$ \\
\hline $\mathrm{Am}-243$ & $3.1 E-06$ \\
\hline $\mathrm{Np}-239$ & $1.1 \mathrm{E}-07$ \\
\hline $\mathrm{Pu}-239$ & $2.4 \mathrm{E}-06$ \\
\hline $\mathrm{Cm}-248$ & $8.8 \mathrm{E}-06$ \\
\hline $\mathrm{Pu}-244+\mathrm{d}$ & $2.3 \mathrm{E}-06$ \\
\hline $\mathrm{Bk}-249$ & $3.4 \mathrm{E}-09$ \\
\hline Cf -249 & $2.8 \mathrm{E}-06$ \\
\hline $\mathrm{Cm}-245$ & $2.5 \mathrm{E}-06$ \\
\hline Cf-249 & $2.8 \mathrm{E}-06$ \\
\hline $\mathrm{Cm}-245$ & $2.5 \mathrm{E}-06$ \\
\hline $\mathrm{Pu}-241$ & $4.9 \mathrm{E}-08$ \\
\hline Am-241 & $3.1 \mathrm{E}-06$ \\
\hline $\mathrm{Np}-237$ & $2.4 \mathrm{E}-05$ \\
\hline Cf-250 & $1.0 \mathrm{E}-06$ \\
\hline $\mathrm{Cm}-246$ & $2.5 \mathrm{E}-06$ \\
\hline $\mathrm{Cf}-251$ & $2.6 \mathrm{E}-06$ \\
\hline Cf-252 & $5.2 \mathrm{E}-07$ \\
\hline $\mathrm{Cm}-248$ & $8.5 \mathrm{E}-06$ \\
\hline
\end{tabular}


a Indented entries are decay products of parent radionuclide that are potentially radiologically-significant.

b The notation " $+d$ " indicates that short-lived daughters were incorporated into the EDE. Dose from other daughters listed is calculated explicitly by adding EDE's 
where

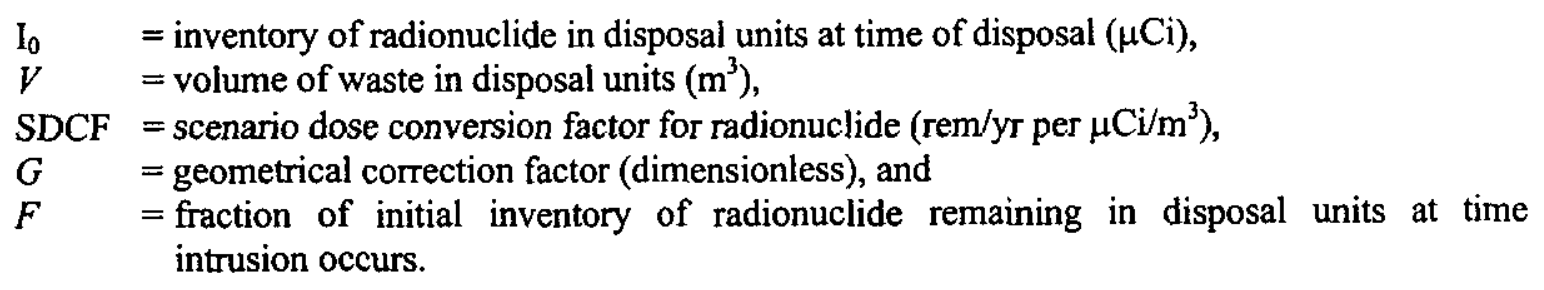

The correction factors $G$ and $F$ take into account the fact that the average radionuclide concentration encountered by an inadvertent intruder would be less than the initial average concentration in disposed waste and that the dose would be correspondingly reduced.

The geometrical correction factor, $G$, in Eq. 6.3-1 takes into account that a large-scale excavation into disposal units, as assumed in the agriculture and resident scenarios, would involve exposure to uncontaminated material between individual disposal units as well as disposed waste itself. This correction factor assumes, in essence, that excavation into disposal units would occur at random locations. Therefore, the geometrical correction factor is given by the fraction of the land area encompassed by the disposal units of a particular type that contains waste.

The values of the geometrical correction factor for the agriculture and resident scenarios assumed in this analysis for the different types of units are given in Table 6.3-4. These values were estimated in the following manner. An envelope was drawn around each grouping of each disposal unit type (Fig. 2.2-4 2.2-5), representing the total land area occupied by units and uncontaminated soil between each disposal unit in a grouping. Using known disposal unit dimensions and spacing, the correction factors were estimated by dividing the disposal unit areas in a grouping by the area of the corresponding envelope. The correction factors represent the fraction of land area occupied by the disposal units and the soil between these units that actually contains waste. For the post-drilling scenario, the geometrical correction factor is assumed to be unity for all disposal units, because an intruder is assumed to drill only through contaminated regions in each type of disposal unit. Any uncontaminated material above and below the waste that also would be exhumed by drilling is taken into account in estimating the SDCF for the post-drilling scenario in Table 6.3-3.

The parameter $F$ in Eq. 6.3-1 takes into account that, between the time of disposal and the time that a scenario for inadvertent intrusion is assumed to occur, the initial inventories of radionuclides in the disposal units would be reduced by radioactive decay and by mobilization and transport in water which infiltrates the disposal unit. This correction factor depends on the particular disposal unit as well as the radionuclide.

For any radionuclide in disposed waste, the parameter $F$ is a monotonically decreasing function of time after disposal. Therefore, if a radionuclide does not produce radiologically significant long-lived decay products, the dose to an inadvertent intruder for a given scenario will attain its maximum value at the time after disposal when the scenario first becomes credible. However, if a radionuclide produces radiologicallysignificant long-lived decay products (e.g. ${ }^{238} \mathrm{U}$, which produces ${ }^{226} \mathrm{Ra}$ ), the maximum dose from the parent radionuclide and its decay products could occur long after the scenario first becomes credible, depending on the rate of buildup of activity of the decay product relative to the rate of removal of the parent radionuclide from the disposal units. 
Table 6.3-4 Geometrical Reduction Factors $(G)$ Used in Dose Analyses for Inadvertent Intruders

\begin{tabular}{|l|c|}
\hline Disposal Units & Reduction Factor \\
\hline IL vaults & 0.4 \\
\hline LAW vaults & 0.8 \\
\hline Naval Reactor Waste & 0.3 \\
\hline $\begin{array}{l}\text { Trench units (slit, intimately- } \\
\text { mixed cement-stabilized, } \\
\text { encapsulated waste) }\end{array}$ & 0.6 \\
\hline
\end{tabular}

a See Eq. 6.1-1; reduction factors apply to agriculture and resident scenarios but not to post-drilling scenario.

For most radionuclides in the various disposal units, the value of the parameter $F$ as a function of time after disposal is obtained from calculations performed by the PORFLOW computer code. The fraction of the initial inventory remaining in disposal units at any time after disposal takes into account radioactive decay and removal from the disposal units by infiltrating water. For any radiologically-significant long-lived decay products, ingrowth is calculated explicitly by PORFLOW. Some radionuclides were not evaluated with the PORFLOW code, because they were not important to the water resource analysis (i.e., ${ }^{60} \mathrm{Co},{ }^{63} \mathrm{Ni}$, ${ }^{113 \mathrm{~m}} \mathrm{Cd},{ }^{121 \mathrm{~m}} \mathrm{Sn},{ }^{137} \mathrm{Cs},{ }^{151} \mathrm{Sm},{ }^{152} \mathrm{Eu},{ }^{154} \mathrm{Eu},{ }^{228} \mathrm{Th},{ }^{241} \mathrm{Am},{ }^{241} \mathrm{Pu},{ }^{242 \mathrm{~m}} \mathrm{Am},{ }^{242} \mathrm{Cm},{ }^{243} \mathrm{Cm},{ }^{244} \mathrm{Cm},{ }^{249} \mathrm{Bk},{ }^{250} \mathrm{Cf}$, ${ }^{251} \mathrm{Cf}$, and ${ }^{252} \mathrm{Cf}$ ). Only radioactive decay was considered in developing $\mathrm{F}$ factors for these radionuclides. Ingrowth of potentially significant radioactive daughters of these radionuclides for which PORFLOW simulations were not made was evaluated in the following manner. For radionuclides producing progeny with decay half-lives shorter or comparable to that of the parent (i.e., short-lived daughters of ${ }^{137} \mathrm{Cs}$ and ${ }^{242 \mathrm{~m}} \mathrm{Am}$ ), the daughter activities are assumed to be equivalent to that of the parent throughout the analysis. For radionuclides that are relatively short-lived and decay to longer-lived radioactive progeny (i.e., longlived daughters of ${ }^{241} \mathrm{Pu},{ }^{241} \mathrm{Am},{ }^{242 \mathrm{~m}} \mathrm{Am},{ }^{242} \mathrm{Cm},{ }^{244} \mathrm{Cm},{ }^{249} \mathrm{Bk},{ }^{250} \mathrm{Cf}$, and ${ }^{252} \mathrm{Cf}$ ), the fraction of daughters remaining in the waste was estimated by assuming that the shorter-lived parent decays completely to the daughter(s) in the disposal unit at time zero. This assumption neglects the loss of the parent through leaching and assumes instantaneous ingrowth of the daughter(s), thereby maximizing the value of the fraction remaining term for the daughters. The initial activity of the daughter, per $\mathrm{Ci}$ of original inventory of the parent, was calculated from:

$$
A_{D 0}=A_{P 0} \frac{\lambda_{d}}{\lambda_{p}}
$$

where

$A_{D 0} \quad=$ initial activity of the daughter, $\mathrm{Ci}$,

$A_{P 0}=$ initial activity of the parent, $(=1 \mathrm{Ci})$,

$\lambda_{\mathrm{d}}=$ radioactive decay constant $(0.693 /$ half-life $)$ of the daughter $\left(\mathrm{yr}^{-1}\right)$, and

$\lambda_{p} \quad=$ radioactive decay constant of the parent $\left(\mathrm{yr}^{-1}\right)$. 
To calculate the fraction of the daughter remaining at time $t$, an exponential decay term $\left(e^{-\lambda}{ }^{t}\right)$ was multiplied by the estimated initial activity of the daughter per $\mathrm{Ci}$ of the parent, $\mathrm{A}_{\mathrm{DO}}$. This produces an estimate of the activity $(\mathrm{Ci})$ of the daughter at time $\mathrm{t}$, per $\mathrm{Ci}$ of the parent radionuclide. In some cases, PORFLOW simulations of the remaining fraction of a radionuclide can be used in place of the exponential decay term (e.g., ${ }^{237} \mathrm{~Np}$ is present in the waste as a parent, and is simulated with PORFLOW, but is also a daughter of ${ }^{241} \mathrm{Pu}$ and $\left.{ }^{24} \mathrm{Am}\right)$. In these cases, the estimated initial activity of the daughter $\left(\mathrm{A}_{\mathrm{D}_{0}}\right)$ is multiplied by the fraction remaining of that radionuclide, as calculated by PORFLOW, to arrive at an estimate of the activity of the daughter at time $\mathrm{t}$, per $\mathrm{Ci}$ of the parent radionuclide.

Since the objective of the intruder dose analysis is to establish limits on inventories of radionuclides for disposal, Eq. 6.3-1 can be rearranged to give

$$
\mathrm{I}_{0}=(\mathrm{H} \times V) /(\mathrm{SDCF} \times G \times F) .
$$

Therefore, for a dose limit for inadvertent intruders of 100 mrem $(0.1 \mathrm{rem})$ per year and using a conversion factor for activity of $10^{-6} \mathrm{Ci} / \mu \mathrm{Ci}$, the inventory limit for a radionuclide in a particular type of disposal unit for a given exposure scenario is given by

$$
\mathrm{I}_{0}(\mathrm{Ci})=\left[10^{-7} \times V\left(\mathrm{~m}^{3}\right)\right] /\left[\mathrm{SDCF}\left(\mathrm{rem}-\mathrm{m}^{3} / \mu \mathrm{Ci}-\mathrm{y}\right) \times G \times F\right] .
$$

The volume $V$ depends only on the type of disposal unit, the SDCF depends only on the radionuclide and exposure scenario but not on the type of disposal unit, $G$ depends only on the type of disposal unit and exposure scenario, and $F$ depends on the time after disposal at which intrusion is assumed to occur and on the radionuclide and type of disposal unit.

Alternatively, the WAC could be expressed in terms of limits on average concentrations of radionuclides in disposed waste. From Eq. 6.3-4, the limit on average concentration of a radionuclide is given by

$$
\mathrm{C}_{0}\left(\mu \mathrm{Ci} / \mathrm{m}^{3}\right)=0.1 /\left[\operatorname{SDCF}\left(\mathrm{rem}-\mathrm{m}^{3} / \mu \mathrm{Ci}-\mathrm{y}\right) \times G \times F\right] \text {. }
$$

The models in Eqs. 6.3-4 and 6.3-5 for estimating limits on inventories or average concentrations of radionuclides in the different types of disposal units for the different exposure scenarios for inadvertent intruders are implemented in the following sections.

\subsubsection{Dose Analysis for Agriculture Scenario}

Application of the models in Eqs. 6.3-1 through 6.3-5 to the different disposal units in the E-Area LLWF produced the results of the dose analysis for intruder-agriculture, which are discussed in this section. The results provided exclude the contributions from radon, which are addressed separately in Sect. 5.2.

\subsubsection{Intermediate-Level Vaults}

Because of the design of the $\mathbb{L}$ vaults, the agriculture scenario involving direct excavation into the waste is not expected to become credible for a considerable period of time after disposal. Since the waste will be located well below the ground surface, a considerable amount of erosion will need to occur before the waste could be accessed by normal excavation procedures for a home. Then, the concrete roof and layer of uncontaminated grout above the waste are expected to preclude excavation into the waste for as long as they maintain their physical integrity. The assumed performance of the three barriers to excavation into waste is discussed below. 
The current closure concept for the $\mathrm{IL}$ vaults calls for an earthen cover above the concrete roof of thickness about $3 \mathrm{~m}$ (Sect. 3.2). From data provided in Sect. 3.1.4.1, the average erosion rate for cropland in the vicinity of the SRS is about $2 \mathrm{~kg} / \mathrm{m}^{2}-\mathrm{yr}$, or $1.4 \mathrm{~mm} / \mathrm{yr}$ assuming a reasonable average bulk density of cover soils of $1400 \mathrm{~kg} / \mathrm{m}^{3}$. This erosion rate probably is an upper-bound estimate for the earthen cover, because an estimated erosion rate for natural successional forests (see Sect. 3.1.4.1) is about $0.003 \mathrm{~mm} / \mathrm{yr}$. Excavation for a home normally is assumed to extend no more than about $3 \mathrm{~m}$ below the ground surface (NRC 1981; Oztunali and Roles 1986). The total thickness of the concrete roof and layer of uncontaminated grout above the waste in the IL vaults is expected to be about $1.7 \mathrm{~m}$ (see Sect. 3.2); therefore, at least $2.7 \mathrm{~m}$ of the earthen cover would need to erode before a significant thickness of the waste (about $1 \mathrm{~m}$ ) would be accessible during excavation, such that significant exposures according to the agriculture scenario could occur. Using the estimated erosion rates given above, the time required for $2.7 \mathrm{~m}$ of cover material to erode is estimated to be about 2,000 years and perhaps as long as 900,000 years. The very low erosion rate for natural successional forests is difficult to justify for such a long time period. However, the presence of a gravel layer about $0.9 \mathrm{~m}$ below the surface in the current closure concept undoubtedly would inhibit further erosion once the gravel layer is exposed. Therefore, erosion to a depth necessary to permit normal excavation into the waste presumably will not occur for at least several thousand years after disposal.

The models for degradation of the concrete roof are described in Sect. 4.1.3.1 and Appendix D. As indicated in Table 4.1-2, the roof above an $\mathbb{L}$ vault is expected to maintain its integrity for about 1,000 years after disposal, and collapse of the roof is expected to occur at about that time. If the roof were in the form of rubble after collapse, which probably represents a worst-case scenario, excavation through the collapsed roof could occur at that time.

After the concrete roof over an IL vault fails, the layer of uncontaminated grout above the waste presumably must weather almost entirely to soil-equivalent material before excavation into the waste would become credible. In order to estimate the weathering rate of grout, this material is assumed to resemble carbonate rock (e.g., limestone) in its weathering properties. Available data summarized by Ketelle and Huff (1984) indicate that the weathering rate of carbonate rock in regions near the SRS is in the range 35 to $100 \mathrm{~mm}$ per 1,000 years. For purposes of this analysis, a weathering rate for the layer of uncontaminated grout of 100 $\mathrm{mm}(0.1 \mathrm{~m})$ per 1,000 years is assumed. This value applies to the expected infiltration rate of water in native soil of $40 \mathrm{~cm} / \mathrm{yr}$ (see Appendix C.1.1) and, thus, applies at times after the concrete roof has failed at about 1,000 years after disposal. A weathering rate at the upper end of the range of reported values for carbonate rock is chosen, because grout should have a somewhat higher porosity than average carbonate rock and, thus, should be correspondingly more susceptible to weathering by infiltrating water.

The nominal thickness of the layer of uncontaminated grout above the waste in the $\mathrm{IL}$ vaults is $3 \mathrm{ft}(90 \mathrm{~cm})$. By assuming that essentially all of this grout layer must weather to soil-equivalent material in order for excavation into the waste to become credible, and using the estimated weathering rate given above, the time required for weathering of the grout at the normal infiltration rate of water is estimated to be about 9,000 years. This estimate shows that even in the absence of a concrete roof, the layer of uncontaminated grout above the waste should prevent excavation into the waste for many thousands of years after disposal.

The analysis described above assumes that excavation into the waste could occur as soon as the concrete roof has failed and the layer of uncontaminated grout above the waste has weathered to soil-equivalent material and the waste becomes accessible by excavation. This assumption probably is conservative because the space between waste packages in the IL vaults will be backfilled with grout, and the top layer (about $1 \mathrm{~m}$ ) of this grout presumably must weather to soil-equivalent material before significant excavation into the waste could occur. The weathering rate of this material presumably would be about the same as for the grout layer above the waste described above. Therefore, about 10,000 years presumably would be required for a 1-m thick layer of grouted waste to weather to soil-equivalent material. This time is in addition to the time required for weathering of the grout above the waste. 
In summary, the concrete roof above the vaults, the layer of uncontaminated grout above the waste, and the grouting of the waste itself also are expected to be effective barriers to excavation into the waste for many thousands of years after disposal. An analysis of the expected performance of the earthen cover above the IL vaults and the concrete roof and layers of grout in the vaults indicates that excavation into the waste probably is not credible for at least 20,000 years after disposal. The layer of gravel in the earthen cover, which will be placed about $3.5 \mathrm{~m}$ above the waste, presumably will be quite erosion-resistant, and a typical excavation to a depth of about $3 \mathrm{~m}$ below the ground surface would not access waste in the presence of the gravel layer. Even if the gravel layer were subject to the same erosion rate as native soil, the time required for a sufficient thickness of the cover to erode so that about $1 \mathrm{~m}$ of waste would be accessible by excavation should be at least several thousand years and could approach one million years if the current erosion rate for natural successional forests at the SRS is maintained.

From the analysis of the earthen cover and engineered barriers for the $\mathbb{I}$ vaults presented above, it is clear that the intruder-agriculture scenario is not credible for well beyond 1,000 years. Furthermore, only longlived radionuclides in the waste possibly could be of concern in an analysis of the agriculture scenario for inadvertent intruders. In this analysis, results are presented for two different times after disposal. The first is at 20,000 years after disposal, which is the earliest time that the engineered barriers are expected to have failed sufficiently to permit excavation into a layer of waste about $1-\mathrm{m}$ thick. The second time is far into the future (i.e., at 200,000 to $1,000,000$ years) when all barriers to excavation presumably have failed. Results at these far future times are presented only for ${ }^{233} \mathrm{U},{ }^{234} \mathrm{U},{ }^{235} \mathrm{U}$, and ${ }^{238} \mathrm{U}$, the purpose of the analysis being to capture possible exposures to radiologically-significant long-lived decay products which would reach their peak values only at very long times after disposal. A similar analysis was considered for ${ }^{237} \mathrm{~Np}$, but in this case removal of the parent radionuclide from the vaults by mobilization and transport in water is sufficiently rapid to more than compensate for the long-term buildup of ${ }^{233} \mathrm{U}$ and ${ }^{229} \mathrm{Th}$ decay products.

The results of the dose analysis for the agriculture scenario at the two times after disposal are given in Table 6.3-5. The results were calculated using Eqs. 6.3-4 and 6.3-5. The SDCFs for the long-lived radionuclides of concern are given in Table 6.3-1, the geometrical reduction factor for the IL vaults of 0.4 is obtained from Table 6.3-4, and the fraction of the initial inventory of radionuclides remaining in the vaults at the various times after disposal, which takes into account radioactive decay and mobilization and transport in water, was calculated either using the PORFLOW computer code, or assuming exponential radioactive decay alone, as described earlier. The results of the analysis are given in two forms, both of which are based on the dose limit for inadvertent intruders of 100 mrem per year. The first set of results is in the form of limits on average concentrations of radionuclides in the waste. The second set of results is in the form of limits on total activity of radionuclides in each vault.

The results in Table 6.3-5 may be interpreted as follows. For all radionuclides except the isotopes of uranium which produce long-lived decay products, the maximum dose would occur at the time after disposal at which the agriculture scenario first becomes credible, and the results at 20,000 years represent lower-bound estimates of limits on average concentrations and inventories of radionuclides in waste. For ${ }^{233} \mathrm{U},{ }^{234} \mathrm{U},{ }^{235} \mathrm{U}$, and ${ }^{238} \mathrm{U}$, the results at times far beyond 20,000 years represent worst-case estimates of concentration and inventory limits at times when the buildup of decay products has peaked.

\subsubsection{Low-Activity Waste Vaults}

Because of the presence of an earthen cover and concrete roof above the LAW vaults, the agriculture scenario involving direct excavation into the waste is not expected to become credible for a considerable period of time after disposal. However, these disposal units will not include a layer of uncontaminated grout above the waste, and the waste itself will not be grouted after disposal. 
Table 6.3-5 Intruder-Based Radionuclide Disposal Limits for IL Vaults Agriculture Scenario at 20,000 Years (and peak after 20,000 years for uranium decay products)

\begin{tabular}{|c|c|c|c|}
\hline Radionuclide $^{\mathbf{a b} b}$ & $\begin{array}{c}\text { Fraction } \\
\text { Remaining }^{\mathrm{c}, \mathrm{d}}\end{array}$ & $\begin{array}{c}\text { Concentration } \\
\text { Limit }^{\mathrm{e}} \\
\left(\mu \mathrm{Ci} / \mathrm{m}^{3}\right)\end{array}$ & $\begin{array}{c}\text { Inventory } \\
\text { Limit } \\
\text { (Ci/vault) }\end{array}$ \\
\hline $\mathrm{H}-3$ & $0.0 \mathrm{E}+00$ & $>1 \mathrm{E} 20$ & $>1 E 20$ \\
\hline$C-14$ & $0.0 \mathrm{E}+00$ & $>1 E 20$ & $>1 E 20$ \\
\hline Co- 60 & $0.0 \mathrm{E}+00^{\mathrm{g}}$ & $>1 \mathrm{E} 20$ & $>1 E 20$ \\
\hline $\mathrm{Ni}-59$ & $8.0 \mathrm{E}-21$ & $>1 \mathrm{E} 20$ & $>1 \mathrm{E} 20$ \\
\hline $\mathrm{Ni}-63$ & $7.4 \mathrm{E}-61^{\mathrm{g}}$ & $>1 \mathrm{E} 20$ & $>1 \mathrm{E} 20$ \\
\hline $\mathrm{Se}-79$ & $0.0 \mathrm{E}+00$ & $>1 \mathrm{E} 20$ & $>1 E 20$ \\
\hline $\mathrm{Sr}-90+\mathrm{d}$ & $0.0 \mathrm{E}+00$ & $>1 \mathrm{E} 20$ & $>1 E 20$ \\
\hline $\mathrm{Zr}-93+\mathrm{d}$ & $9.9 \mathrm{E}-01$ & $3.9 \mathrm{E}+06$ & $2.2 \mathrm{E}+04$ \\
\hline Tc-99 & $0.0 \mathrm{E}+00$ & $>1 \mathrm{E} 20$ & $>1 E 20$ \\
\hline$S n-126+d$ & $3.9 \mathrm{E}-01$ & $2.4 \mathrm{E}+02$ & $1.4 \mathrm{E}+00$ \\
\hline $\mathrm{I}-129$ & $0.0 \mathrm{E}+00$ & $>1 \mathrm{E} 20$ & $>1 E 20$ \\
\hline Cs-135 & $0.0 \mathrm{E}+00$ & $>1 \mathrm{E} 20$ & $>1 E 20$ \\
\hline Cs $-137+d$ & $3.1 \mathrm{E}-200^{\mathrm{g}}$ & $>1 \mathrm{E} 20$ & $>1 \mathrm{E} 20$ \\
\hline Eu-154 & $0.0 \mathrm{E}+00^{\mathrm{g}}$ & $>1 \mathrm{E} 20$ & $>1 \mathrm{E} 20$ \\
\hline Th-232 & $9.5 \mathrm{E}-01$ & $7.4 \mathrm{E}+01$ & $4.2 \mathrm{E}-01$ \\
\hline $\mathrm{Ra}-228+\mathrm{d}$ & $9.5 \bar{E}-01$ & & \\
\hline Th-228 & $9.4 \mathrm{E}-01$ & & \\
\hline $\mathrm{Ra}-224+\mathrm{d}$ & $9.5 \mathrm{E}-01$ & & \\
\hline $\mathrm{U}-232$ & $0.0 E+00$ & $>1 E 20$ & $>1 E 20$ \\
\hline Th-228 & $0.0 \mathrm{E}+00$ & & \\
\hline$R a-224+d$ & $0.0 E+00$ & & \\
\hline U-233 (20,000 years) & $9.2 \mathrm{E}-01$ & $7.1 \mathrm{E}+02$ & $4.0 \mathrm{E}+00$ \\
\hline Th-229 & $8.0 \mathrm{E}-01$ & & \\
\hline $\mathrm{Ra}-225+\mathrm{d}$ & $8.0 \mathrm{E}-01$ & & \\
\hline U-233 (34,000 years) & $8.6 \mathrm{E}-01$ & $6.6 \mathrm{E}+02$ & $3.8 \mathrm{E}+00$ \\
\hline Th-229 & $8.6 \mathrm{E}-01$ & & \\
\hline $\mathrm{Ra}-225+\mathrm{d}$ & $8.6 \mathrm{E}-01$ & & \\
\hline U-234 (20,000 years) & $9.6 \mathrm{E}-01$ & $1.9 \mathrm{E}+03$ & $1.1 E+01$ \\
\hline Th-230 & $1.6 \mathrm{E}-01$ & & \\
\hline $\mathrm{Ra}-226+\mathrm{d}$ & $4.4 \mathrm{E}-02$ & & \\
\hline $\mathrm{Pb}-210$ & $4.4 \mathrm{E}-02$ & & \\
\hline Po-210 & $4.4 \mathrm{E}-02$ & & \\
\hline U-234 ( 95,000 years) & $7.6 \mathrm{E}-01$ & $9.1 \mathrm{E}+02$ & $5.2 \mathrm{E}+00$ \\
\hline Th-230 & $4.0 \mathrm{E}-01$ & & \\
\hline $\mathrm{Ra}-226+\mathrm{d}$ & $9.5 \mathrm{E}-02$ & & \\
\hline $\mathrm{Pb}-210$ & $9.4 \mathrm{E}-02$ & & \\
\hline Po-210 & $9.4 \mathrm{E}-02$ & & \\
\hline $\mathrm{U}-235+\mathrm{d}(20,000$ years $)$ & $1.0 \mathrm{E}+00$ & $5.5 \mathrm{E}+02$ & $3.1 \mathrm{E}+00$ \\
\hline $\mathrm{Pa}-231$ & $3.4 \mathrm{E}-01$ & & \\
\hline Ac- 227 & $3.4 \mathrm{E}-0$ & & \\
\hline Th-227 & $3.4 \mathrm{E}-01$ & & \\
\hline Ra-223 & $3.4 \mathrm{E}-01$ & & \\
\hline
\end{tabular}


Table 6.3-5 Intruder-Based Radionuclide Disposal Limits for IL Vaults Agriculture Scenario at 20,000 Years (and peak after 20,000 years for uranium decay products)

\begin{tabular}{|c|c|c|c|}
\hline Radionuclide $^{a, b}$ & $\begin{array}{c}\text { Fraction } \\
\text { Remaining }^{\mathrm{c}, \mathrm{d}}\end{array}$ & $\begin{array}{c}\text { Concentration } \\
\text { Limit }^{e} \\
\left(\mu \mathrm{Ci} / \mathrm{m}^{3}\right)\end{array}$ & $\begin{array}{c}\text { Inventory } \\
\text { Limit }^{5} \\
\text { (Ci/vault) }\end{array}$ \\
\hline U-235 $+d(100,000$ years $)$ & $1.0 \mathrm{E}+00$ & $3.1 \mathrm{E}+02$ & $1.8 \mathrm{E}+00$ \\
\hline $\mathrm{Pa}-231$ & $7.5 \mathrm{E}-01$ & & \\
\hline Ac-227 & $7.5 \mathrm{E}-01$ & & \\
\hline Th-227 & $7.5 \mathrm{E}-01$ & & \\
\hline Ra-223 & $7.5 \mathrm{E}-01$ & & \\
\hline $\mathrm{U}-236$ & $1.0 \mathrm{E}+00$ & $2.4 \mathrm{E}+04$ & $1.4 \mathrm{E}+02$ \\
\hline U-238 $(20,000$ years $)$ & $1.0 \mathrm{E}+00$ & $6.4 \mathrm{E}+03$ & $3.6 \mathrm{E}+01$ \\
\hline Th-234 +d & $1.0 \mathrm{E}+00$ & & \\
\hline $\mathrm{U}-234$ & $2.8 \mathrm{E}-02$ & & \\
\hline U-238 ( 100,000 years $)$ & $1.0 \mathrm{E}+00$ & $6.0 \mathrm{E}+03$ & $3.4 \mathrm{E}+01$ \\
\hline Th-234 +d & $1.0 E+00$ & & \\
\hline U-234 & $2.5 \mathrm{E}-01$ & & \\
\hline $\mathrm{Np}-237+\mathrm{d}$ & $0.0 \mathrm{E}+00$ & $>1 E 20$ & $>1 \mathrm{E} 20$ \\
\hline Pu-238 & $0.0 \mathrm{E}+00$ & $6.8 \mathrm{E}+17$ & $3.9 E+15$ \\
\hline $\mathrm{U}-234$ & $3.4 \mathrm{E}-14$ & & \\
\hline Pu-239 & $6.9 E-01$ & $9.3 E+03$ & $5.3 \mathrm{E}+01$ \\
\hline $\mathrm{U}-235$ & $7.8 \mathrm{E}-06$ & & \\
\hline $\mathrm{Pu}-240$ & $2.5 \mathrm{E}-01$ & $2.6 \mathrm{E}+04$ & $1.5 E+02$ \\
\hline U-236 & $1.3 E-04$ & & \\
\hline $\mathrm{Pu}-241$ & $0.0 \mathrm{E}+00^{\mathrm{g}}$ & $1.2 \mathrm{E}+19$ & $6.7 \mathrm{E}+16$ \\
\hline Am-241 & $3.9 \mathrm{E}-16^{\mathrm{g}}$ & & \\
\hline $\mathrm{Np}-237+\mathrm{d}$ & $0.0 \mathrm{E}+00$ & & \\
\hline Pu-242 & $9.8 \mathrm{E}-01$ & $6.9 \mathrm{E}+03$ & $3.9 \mathrm{E}+01$ \\
\hline $\mathrm{U}-238$ & $1.5 \mathrm{E}-06$ & & \\
\hline $\mathrm{Pu}-244+\mathrm{d}$ & $1.0 \mathrm{E}+00$ & $5.1 E+02$ & $2.9 \mathrm{E}+00$ \\
\hline Am-241 & $1.2 \mathrm{E}-14^{\mathrm{g}}$ & $3.8 \mathrm{E}+17$ & $2.2 \mathrm{E}+15$ \\
\hline$N p-237+d$ & $0.0 \mathrm{E}+00$ & & \\
\hline$A m-242 m+d$ & $2.5 \mathrm{E}-40^{\mathrm{g}}$ & $3.9 \mathrm{E}+07$ & $2.2 \mathrm{E}+05$ \\
\hline $\mathrm{Pu}-238$ & $2.5 \mathrm{E}-40^{\mathrm{g}}$ & & \\
\hline U-234 & $5.9 \mathrm{E}-04$ & & \\
\hline$A m-243$ & $1.5 \mathrm{E}-01$ & $6.7 E+03$ & $3.8 \mathrm{E}+01$ \\
\hline Np-239 & $1.5 \mathrm{E}-01$ & & \\
\hline$P u-239$ & $6.0 \mathrm{E}-02$ & & \\
\hline $\mathrm{Cm}-244$ & $0.0 \mathrm{E}+00^{g}$ & $1.9 \mathrm{E}+07$ & $1.1 E+05$ \\
\hline Pu-240 & $3.4 \mathrm{E}-04$ & & \\
\hline U-236 & $5.3 E-06$ & & \\
\hline $\mathrm{Cm}-245$ & $1.9 \mathrm{E}-01$ & $7.4 \mathrm{E}+03$ & $4.2 \mathrm{E}+01$ \\
\hline $\mathrm{Pu}-241$ & $1.9 \mathrm{E}-01$ & & \\
\hline$A m-241$ & $2.0 \mathrm{E}-01$ & & \\
\hline $\mathrm{Np}-237+\mathrm{d}$ & $3.0 \mathrm{E}-03$ & & \\
\hline $\mathrm{Cm}-246$ & $5.4 \mathrm{E}-02$ & $1.1 \mathrm{E}+05$ & $6.6 \mathrm{E}+02$ \\
\hline
\end{tabular}


Table 6.3-5 Intruder-Based Radionuclide Disposal Limits for IL Vaults Agriculture Scenario at 20,000 Years (and peak after 20,000 years for uranium decay products)

\begin{tabular}{|c|c|c|c|}
\hline Radionuclide $^{\mathrm{a}, \mathrm{b}}$ & $\begin{array}{c}\text { Fraction } \\
\text { Remaining }\end{array}$ & $\begin{array}{c}\text { Concentration } \\
\text { Limit }^{e} \\
\left(\mu \mathrm{Ci} / \mathrm{m}^{3}\right)\end{array}$ & $\begin{array}{c}\text { Inventory } \\
\text { Limit }^{r} \\
\text { (Ci/vault) }\end{array}$ \\
\hline $\mathrm{Cm}-247+\mathrm{d}$ & $9.5 \mathrm{E}-01$ & $4.0 \mathrm{E}+02$ & $2.3 \mathrm{E}+00$ \\
\hline Am-243 & $8.1 \mathrm{E}-01$ & & \\
\hline $\mathrm{Np}-239$ & $8.1 \mathrm{E}-01$ & & \\
\hline Pu-239 & $1.8 \mathrm{E}-01$ & & \\
\hline $\mathrm{Cm}-248$ & $9.6 \mathrm{E}-01$ & $1.8 E+03$ & $1.0 \mathrm{E}+01$ \\
\hline Pu-244 & $4.2 \mathrm{E}-03$ & & \\
\hline Cf-249 & $6.5 \mathrm{E}-18$ & $1.7 \mathrm{E}+05$ & $9.9 E+02$ \\
\hline $\mathrm{Cm}-245$ & $8.0 \mathrm{E}-03$ & & \\
\hline $\mathrm{Pu}-241$ & $8.0 \mathrm{E}-03$ & & \\
\hline Am-241 & $8.4 \mathrm{E}-03$ & & \\
\hline $\mathrm{Np}-237+\mathrm{d}$ & $1.2 \mathrm{E}-04$ & & \\
\hline $\mathrm{Cf}-251$ & $4.5 \mathrm{E}-04$ & $3.5 E+06$ & $2.0 \mathrm{E}+04$ \\
\hline Cf- 252 & $0.0 \mathrm{E}+00$ & $2.4 E+08$ & $1.4 \mathrm{E}+06$ \\
\hline $\mathrm{Cm}-248$ & $7.5 \mathrm{E}-06$ & & \\
\hline \multicolumn{4}{|c|}{$\begin{array}{l}\text { Indented entries are decay products of parent radionuclide that are potentially } \\
\text { radiologically-significant. } \\
\text { The notation "+d" indicates that short-lived daughters were incorporated into the EDE. } \\
\text { Dose from other daughters listed is calculated explicitly. } \\
\text { Considers radioactive decay and leaching unless otherwise noted. } \\
\text { Fractions shown for radioactive daughters reflect fraction of initial activity of parent. } \\
\text { Limit on average concentration in disposed waste; obtained from Eq. } 6.3-5 \\
\text { Limit on inventory per vault; obtained from Eq. } 6.3-4 \text {, assuming a vault volume of } \\
5.7 \times 10^{3} \mathrm{~m}^{3} \text {. } \\
\text { Only radioactive decay accounted for. }\end{array}$} \\
\hline
\end{tabular}


As described previously in the dose analysis for the IL vaults, the erosion rate of the earthen cover should be no greater than $1.4 \mathrm{~mm} / \mathrm{yr}$ and could be as low as $0.003 \mathrm{~mm} / \mathrm{yr}$. For the LAW vaults, the earthen cover also is about $3 \mathrm{~m}$ thick, and the thickness of the concrete roof is about $40 \mathrm{~cm}$. Thus, for a layer of waste about 1 $\mathrm{m}$ thick to be accessible during excavation, about $1.4 \mathrm{~m}$ of the cover material would need to be removed by erosion. Based on the erosion rates given above, the time period required for this amount of erosion should be at least 1,000 years and could be as long as 500,000 years. These estimates do not take into account the presence of a gravel layer at about $0.9 \mathrm{~m}$ below the surface, which presumably would inhibit erosion once it is exposed.

The models for degradation of the concrete roof indicate that the roof above the LAW vauit should maintain its integrity for about 3,000 years after disposal, and collapse of the roof is expected to occur at about that time (Sect. 4.1.3.1). If the roof were in the form of rubble after collapse, then excavation through the collapsed roof could occur at that time.

The assumption that excavation through the concrete roof could occur immediately following collapse of the roof would be pessimistic if most of the roof were in large pieces. Excavation through the collapsed roof would become more likely after most of the roof has weathered to soil-equivalent material. As previously described with the IL vaults, the weathering rate of concrete is assumed to be about $0.1 \mathrm{~m}$ per 1,000 years. Therefore, since a collapsed roof presumably could weather from both top and bottom and the thickness of the roof is about $0.4 \mathrm{~m}$, the time required for essentially all of the concrete to weather to soil is expected to be about 2,000 years. Thus, taking into account that the roof is not expected to collapse for about 3,000 years, the estimated time at which excavation through the roof could occur is about 5,000 years after disposal.

From the analysis of the earthen cover and concrete roof for the LAW vaults presented above, it is clear that the intruder-agriculture scenario is not credible for well beyond 1,000 years after the vaults are closed. And again, only long-lived radionuclides in the waste possibly could be of concern in an analysis of the agriculture scenario for inadvertent intruders. In this analysis, results are presented for two different times after disposal. The first time is at 5,000 years after disposal, when the concrete roof presumably has weathered to soil-equivalent material and excavation into the waste could occur. This assumption is pessimistic because erosion of the cover material below the gravel layer again is presumed to have occurred. Results were also calculated for ${ }^{233} \mathrm{U},{ }^{234} \mathrm{U},{ }^{235} \mathrm{U}$, and ${ }^{238} \mathrm{U}$ at times beyond 5,000 years; however, buildup of radiologically significant decay products was found to peak before 5,000 years for these vaults. As with the IL vaults, similar long-term calculations were evaluated for ${ }^{237} \mathrm{~Np}$ and its long-lived decay products; however, rapid depletion of the ${ }^{237} \mathrm{~Np}$ from the LAW vaults once the vaults are assumed to begin to degrade (at 1,400 years) occurs due to mobilization and transport of this radionuclide in water, such that buildup of decay products ${ }^{233} \mathrm{U}$ and ${ }^{229} \mathrm{Th}$ in the vaults is insignificant at later times.

The results of the dose analysis for the agriculture scenario at the various times after disposal are given in Table 6.3-6. These results were obtained as described previously for the $\mathbb{L}$ vaults, except the geometrical reduction factor for the LAW vaults is 0.8 (see Table 6.3-4). For all radionuclides, the maximum dose would occur at the time after disposal at which the agriculture scenario first becomes credible, and the results at 5,000 years after disposal represent lower-bound estimates of limits on average concentrations and inventories of radionuclides in waste. 
Table 6.3-6 Intruder-Based Radionuclide Disposal Limits for LAW Vaults Agriculture Scenario at 5,000 Years

\begin{tabular}{|c|c|c|c|}
\hline Radionuclide ${ }^{2, b}$ & Fraction Remaining ${ }^{\text {c.d }}$ & $\begin{array}{c}\text { Concentration } \\
\text { Limit }^{e} \\
(\mu \mathrm{Ci} / \mathrm{m})\end{array}$ & $\begin{array}{c}\text { Inventory Limit } \\
\text { (Ci/vault) }\end{array}$ \\
\hline $\mathrm{H}-3$ & $0.00 \mathrm{E}+00$ & $>1 \mathrm{E} 20$ & $>1 \mathrm{E} 20$ \\
\hline C-14 & $2.69 \mathrm{E}-01$ & $3.1 E+04$ & $1.5 \mathrm{E}+03$ \\
\hline $\mathrm{Co}-60$ & $3.22 \mathrm{E}-286^{\mathrm{g}}$ & $>1 E 20$ & $>1 E 20$ \\
\hline $\mathrm{Ni}-59$ & $3.61 \mathrm{E}-02$ & $5.1 \mathrm{E}+07$ & $2.5 E+06$ \\
\hline $\mathrm{Ni}-63$ & $9.26 \mathrm{E}-16^{g}$ & $>1 E 20$ & $3.5 \mathrm{E}+19$ \\
\hline Se-79 & $1.47 \mathrm{E}-03$ & $7.0 \mathrm{E}+07$ & $3.3 \mathrm{E}+06$ \\
\hline Rb-87 & $2.13 \mathrm{E}-06$ & $3.1 E+10$ & $1.5 E+09$ \\
\hline Sr-90 +d & $0.00 \mathrm{E}+00$ & $>1 E 20$ & $>1 E 20$ \\
\hline $\mathrm{Zr}-93+\mathrm{d}$ & $7.72 \mathrm{E}-01$ & $2.5 \mathrm{E}+06$ & $1.2 \mathrm{E}+05$ \\
\hline $\mathrm{Nb}-94$ & $6.00 \mathrm{E}-03$ & $9.9 \mathrm{E}+03$ & $4.8 E+02$ \\
\hline Tc-99 & $0.00 \mathrm{E}+00$ & $>1 E 20$ & $>1 E 20$ \\
\hline Pd-107 & $6.43 \mathrm{E}-05$ & $6.1 E+10$ & $2.9 \mathrm{E}+09$ \\
\hline Sn-126+d & $1.48 \mathrm{E}-02$ & $3.2 \mathrm{E}+03$ & $1.6 \mathrm{E}+02$ \\
\hline$I-129$ & $0.00 \mathrm{E}+00$ & $>1 E 20$ & $>1 E 20$ \\
\hline Cs-135 & $7.33 \mathrm{E}-03$ & $1.4 \mathrm{E}+07$ & $6.7 \mathrm{E}+05$ \\
\hline Cs-137 +d & $1.32 \mathrm{E}-50$ & $>1 \mathrm{E} 20$ & $>1 E 20$ \\
\hline Sm-151 & $1.90 \mathrm{E}-17^{\mathrm{B}}$ & $>1 E 20$ & $>1 E 20$ \\
\hline $\mathrm{Eu}-152$ & $5.00 \mathrm{E}-113^{\mathrm{g}}$ & $>1 E 20$ & $>1 E 20$ \\
\hline $\mathrm{Eu}-154$ & $9.92 \mathrm{E}-172^{\mathrm{g}}$ & $>1 E 20$ & $>1 E 20$ \\
\hline Th-232 & 9.57E-01 & $9.9 \mathrm{E}+01$ & $4.8 E+00$ \\
\hline $\mathrm{Ra}-228+d$ & $3.86 \mathrm{E}-01$ & & \\
\hline Ac-228 & $3.86 \mathrm{E}-01$ & & \\
\hline Th-228 & $3.17 \mathrm{E}-01$ & & \\
\hline $\mathrm{Ra}-224+\mathrm{d}$ & $3.18 \mathrm{E}-01$ & & \\
\hline $\mathrm{U}-232$ & $6.68 \mathrm{E}-17$ & $4.0 \mathrm{E}+17$ & $1.9 E+16$ \\
\hline Th-228 & $1.41 \mathrm{E}-16$ & & \\
\hline Ra-224 +d & $1.41 \mathrm{E}-16$ & & \\
\hline $\mathrm{U}-233$ & $9.79 \mathrm{E}-01$ & $9.4 E+02$ & $4.5 E+01$ \\
\hline Th-229 & $2.87 \mathrm{E}-01$ & & \\
\hline Ra-225 +d & $2.86 \mathrm{E}-01$ & & \\
\hline $\mathrm{U}-234$ & $9.86 \mathrm{E}-01$ & $7.4 \mathrm{E}+03$ & $3.6 \mathrm{E}+02$ \\
\hline Th-230 & $3.50 \mathrm{E}-02$ & & \\
\hline $\mathrm{Ra}-226+d$ & $1.74 \mathrm{E}-03$ & & \\
\hline $\mathrm{Pb}-210$ & $4.67 \mathrm{E}-03$ & & \\
\hline Po-210 & $4.81 \mathrm{E}-03$ & & \\
\hline $\mathrm{U}-235+\mathrm{d}$ & $1.00 \mathrm{E}+00$ & $5.3 E+02$ & $2.6 \mathrm{E}+01$ \\
\hline $\mathrm{Pa}-231$ & $7.73 \mathrm{E}-02$ & & \\
\hline Ac-227 & $7.70 \mathrm{E}-02$ & & \\
\hline Th-227 & $7.70 \mathrm{E}-02$ & & \\
\hline Ra-223 & $7.69 \mathrm{E}-02$ & & \\
\hline $\mathrm{U}-236$ & $1.00 \mathrm{E}+00$ & $1.2 \mathrm{E}+04$ & $5.8 \mathrm{E}+02$ \\
\hline $\mathrm{U}-238$ & $1.00 \mathrm{E}+00$ & $2.7 \mathrm{E}+03$ & $1.3 E+02$ \\
\hline Th-234 +d & $1.00 \mathrm{E}+00$ & & \\
\hline U-234 & $5.97 \mathrm{E}-01$ & & \\
\hline
\end{tabular}


Table 6.3-6 Intruder-Based Radionuclide Disposal Limits for LAW Vaults Agriculture Scenario at 5,000 Years

\begin{tabular}{|c|c|c|c|}
\hline Radionuclide $^{a, b}$ & Fraction Remaining ${ }^{c, d}$ & $\begin{array}{l}\text { Concentration } \\
\text { Limit }^{e} \\
(\mu \mathrm{Ci} / \mathrm{m})\end{array}$ & $\begin{array}{l}\text { Inventory Limit } \\
\text { (Ci/vault) }\end{array}$ \\
\hline $\mathrm{Np}-237+\mathrm{d}$ & $5.06 \mathrm{E}-01$ & $5.0 \mathrm{E}+02$ & $2.4 \mathrm{E}+01$ \\
\hline Pu-238 & $7.10 \mathrm{E}-14$ & $3.2 \mathrm{E}+07$ & $1.5 E+06$ \\
\hline U-234 & $3.54 \mathrm{E}-04$ & & \\
\hline Pu-239 & 8.67E-01 & 3.7E+03 & $1.8 \mathrm{E}+02$ \\
\hline U-235 & $1.90 \mathrm{E}-04$ & & \\
\hline $\mathrm{Pu}-240$ & $5.92 \mathrm{E}-01$ & $5.4 \mathrm{E}+03$ & $2.6 \mathrm{E}+02$ \\
\hline U-236 & $4.33 \mathrm{E}-03$ & & \\
\hline Pu-241 & 3.15E- $105^{\mathrm{g}}$ & $5.5 \mathrm{E}+07$ & $2.6 \mathrm{E}+06$ \\
\hline Am-241 & $1.10 \mathrm{E}-05^{\mathrm{g}}$ & & \\
\hline $\mathrm{Np}-237+\mathrm{d}$ & $3.40 \mathrm{E}-06$ & & \\
\hline $\mathrm{Pu}-242$ & $9.92 \mathrm{E}-01$ & $3.4 \mathrm{E}+03$ & $1.6 \mathrm{E}+02$ \\
\hline U-238 & $3.28 \mathrm{E}-05$ & & \\
\hline $\mathrm{Pu}-244+\mathrm{d}$ & $1.00 \mathrm{E}+00$ & $2.5 \mathrm{E}+02$ & $1.2 \mathrm{E}+01$ \\
\hline $\mathrm{Am}-241$ & $3.30 \mathrm{E}-04^{\mathrm{g}}$ & $1.8 E+06$ & $8.8 E+04$ \\
\hline $\mathrm{Np}-237+\mathrm{d}$ & $1.02 \mathrm{E}-04$ & & \\
\hline Am-243 & $5.81 E-01$ & $7.9 \mathrm{E}+02$ & $3.8 E+01$ \\
\hline Np-239 & $5.83 \mathrm{E}-01$ & & \\
\hline$P u-239$ & $4.32 \mathrm{E}-01$ & & \\
\hline $\mathrm{Cm}-244$ & $8.06 \mathrm{E}-84^{\mathrm{g}}$ & $2.0 \mathrm{E}+06$ & $9.4 E+04$ \\
\hline $\mathrm{Pu}-240$ & $1.64 \mathrm{E}-03$ & & \\
\hline U-236 & $5.30 \mathrm{E}-06$ & & \\
\hline $\mathrm{Cm}-245$ & $6.43 \mathrm{E}-01$ & $8.2 \mathrm{E}+02$ & $3.9 E+01$ \\
\hline $\mathrm{Pu}-241$ & $1.57 \mathrm{E}+00$ & & \\
\hline Am-241 & $1.36 \mathrm{E}+00$ & & \\
\hline $\mathrm{Np}-237+d$ & $6.19 \mathrm{E}-03$ & & \\
\hline $\mathrm{Cm}-246$ & $4.63 \mathrm{E}-01$ & $6.7 \mathrm{E}+03$ & $3.2 \mathrm{E}+02$ \\
\hline $\begin{array}{c}\mathrm{Cm}-247+\mathrm{d} \\
\mathrm{Pu}-243\end{array}$ & $9.66 \mathrm{E}-01$ & $2.2 E+02$ & $1.1 E+01$ \\
\hline Am-243 & $5.18 \mathrm{E}-01$ & & \\
\hline Np-239 & $5.20 \mathrm{E}-01$ & & \\
\hline Pu-239 & $2.20 \mathrm{E}-01$ & & \\
\hline $\mathrm{Cm}-248$ & $9.57 \mathrm{E}-01$ & $9.2 \mathrm{E}+02$ & $4.4 \mathrm{E}+01$ \\
\hline Pu-244 & $3.52 \mathrm{E}-04$ & & \\
\hline Cf-249 & $4.40 \mathrm{E}-05$ & $1.9 E+04$ & $9.2 \mathrm{E}+02$ \\
\hline $\mathrm{Cm}-245$ & $2.76 E-02$ & & \\
\hline $\mathrm{Pu}-241$ & $6.74 E-02$ & & \\
\hline Am-241 & $5.83 \mathrm{E}-02$ & & \\
\hline $\mathrm{Np}-237+\mathrm{d}$ & $2.74 \mathrm{E}-04$ & & \\
\hline Cf -250 & $8.95 \mathrm{E}-116^{8}$ & $2.4 \mathrm{E}+06$ & $1.2 \mathrm{E}+05$ \\
\hline $\mathrm{Cm}-246$ & $1.27 \mathrm{E}-03$ & & \\
\hline Cf-251 & $2.13 \mathrm{E}-02^{\mathrm{B}}$ & $3.7 \mathrm{E}+04$ & $1.8 \mathrm{E}+03$ \\
\hline $\mathrm{Cf}-252$ & $0.00 \mathrm{E}+00^{\mathrm{g}}$ & $1.2 \mathrm{E}+08$ & $5.9 \mathrm{E}+06$ \\
\hline $\mathrm{Cm}-248$ & $7.45 \mathrm{E}-06$ & & \\
\hline
\end{tabular}


b The notation "+d" indicates that short-lived daughters were incorporated into the EDE. Dose from other daughters listed is calculated explicitly.

c Considers radioactive decay and leaching unless otherwise noted.

d Fractions shown for radioactive daughters reflect fraction of initial activity of parent.

e Limit on average concentration in disposed waste; obtained from Eq. 6.3-5

f Limit on inventory per vault; obtained from Eq. 6.3-4, assuming a vault volume of $4.8 \mathrm{E} 4 \mathrm{~m}^{3}$.

8 Only radioactive decay accounted for. 


\subsubsection{Slit Trenches}

The current closure concept for the slit trenches calls for an approximate 3-m thick earthen cover above the clean layer of soil in the trenches, similar to that overlying the vaults. Again, from Sect. 6.3.1.1, the average erosion rate for cropland in the vicinity of the SRS is about $1.4 \mathrm{~mm} / \mathrm{yr}$, which is probably an upper-bound estimate for the earthen cover, since an estimated erosion rate for natural successional forests is about 0.003 $\mathrm{mm} / \mathrm{yr}$. Since excavation for a home normally is assumed to extend no more than about $3 \mathrm{~m}$ below the ground surface (NRC 1981; Oztunali and Roles 1986), at least $1 \mathrm{~m}$ of the soil cover must be eroded before excavation into the slit trenches is credible. Using the estimated erosion rates given above, the time required for $1 \mathrm{~m}$ of cover material to erode is estimated to be about 700 years and perhaps as long as 300,000 years. Therefore, erosion to a depth necessary to permit normal excavation into the trenches presumably will not occur for at least 700 years after disposal, at which time the agriculture scenario is assumed to first become credible. The fact that the top $1 \mathrm{~m}$ of the trenches is to be filled with clean soil rather than waste is neglected in this analysis; it is assumed that the trenches are filled to the top with waste.

The results of the dose analysis for the agriculture scenario for the slit trenches are given in Table 6.3-7. The limits on concentrations and inventories of radionuclides are calculated using Eqs. 6.3-4 and 6.3-5. The SDCF for each radionuclide is obtained from Table 6.3-1, the geometrical reduction factor (G) for the slit trenches of 0.6 is obtained from Table $6.3-4$, and the fraction of the initial inventory of radionuclides remaining in the trenches at the time the agriculture scenario is assumed to occur was calculated by either using the PORFLOW code, or by accounting for radioactive decay alone. Ingrowth of potentiallysignificant radioactive daughters was addressed in both approaches to estimating the fraction remaining. Because the peak dose from longer-lived daughters may occur at times beyond the 700-year time at which the dose is initially evaluated, the limits are also evaluated at the time that ingrowth of these daughters peaks. For radionuclides for which daughter ingrowth is not explicitly modeled with PORFLOW ( ${ }^{241} \mathrm{Am}$, ${ }^{241} \mathrm{Pu},{ }^{242 \mathrm{Am}} \mathrm{Am},{ }^{242} \mathrm{Cm},{ }^{244} \mathrm{Cm},{ }^{249} \mathrm{Bk},{ }^{250} \mathrm{Cf},{ }^{252} \mathrm{Cf}$ ), the maximizing assumption that the long-lived daughters are produced instantaneously at time zero (ignoring leaching of the parent over time) allows consideration of daughter contributions to dose in developing dose limits. Limits are provided in Table 6.3-7 for the 700year time of occurrence of the agriculture scenario, and for the time at which the peak contribution from uranium daughters occurs (to consider maximum daughter ingrowth).

\subsubsection{Naval Reactor Waste}

The agriculture scenario involves direct excavation into disposal units at times after the engineered barriers above the waste have lost their structural and physical integrity and can be penetrated by normal excavation procedures at SRS. At some distant time in the future, it is conceivable that the carbon steel waste container will have degraded by corrosion and that the waste could be accessed by excavation, resulting in exposures of inadvertent intruders according to the agriculture scenario described in Sect 6.1.1.1.

On the basis of the design of the conceptual waste cask described in Sect. 3.3.5.4 and estimates of corrosion rates of carbon steel, excavation into the waste would not be a credible occurrence for a very long time after disposal. For excavation into the waste to occur, the top of the casks would need to be degraded by corrosion. Assuming the thickness of carbon steel on top of the disposal cask is $38 \mathrm{~cm}$ (Sect. 3.3.5.4), and using a corrosion rate of $4 \times 10^{-3} \mathrm{~cm} / \mathrm{yr}$ for carbon steel (Sullivan et al. 1988), the estimated time for complete corrosion of the carbon steel layer is about 9,500 years. The Naval Reactor components are constructed of highly corrosion-resistant Inconel and Zircaloy metals and hold the vast majority of radionuclide contaminants as activation products in the metal matrices. The Naval Reactor Inconel and Zircaloy waste forms are expected to maintain their structural and physical integrity for 30,000 years or more (Appendix C, Table C.1-7). Thus, unless the corrosion rates for Inconel or Zircaloy 
Table 6.3-7 Intruder-Based Radionuclide Disposal Limits for Slit Trenches - Agriculture Scenario at 700 Years (and peak for uranium decay products)

\begin{tabular}{|c|c|c|c|}
\hline Radionuclide & $\begin{array}{c}\text { Fraction } \\
\text { Remaining }\end{array}$ & $\begin{array}{c}\text { Concentration } \\
\text { Limit } \\
\left(\mu \mathrm{Ci} / \mathrm{m}^{3}\right)\end{array}$ & $\begin{array}{c}\text { Inventory } \\
\text { Limit } \\
\text { (Ci/5 trenches) }\end{array}$ \\
\hline $\mathrm{H}-3$ & $0.00 \mathrm{E}+00$ & $>1 \mathrm{E} 20$ & $>1 \mathrm{E} 20$ \\
\hline$C-14$ & $5.08 \mathrm{E}-16$ & $2.2 \mathrm{E}+19$ & $6.2 \mathrm{E}+17$ \\
\hline $\mathrm{Co}-60$ & $1.1 \mathrm{E}-40^{8}$ & $>1 E 20$ & $>1 \mathrm{E} 20$ \\
\hline $\mathrm{Ni}-59$ & $9.9 \mathrm{E}-01$ & $2.5 \mathrm{E}+06$ & $7.1 E+04$ \\
\hline $\mathrm{Ni}-63$ & $7.9 \mathrm{E}-03^{8}$ & $1.2 \mathrm{E}+08$ & $3.3 E+06$ \\
\hline Se-79 & $4.13 E-02$ & $3.3 E+06$ & $9.5 \mathrm{E}+04$ \\
\hline Rb-87 & $1.33 \mathrm{E}-02$ & $6.6 \mathrm{E}+06$ & $1.9 \mathrm{E}+05$ \\
\hline Sr-90 +d & $1.88 \mathrm{E}-09$ & $4.7 \mathrm{E}+11$ & $1.3 \mathrm{E}+10$ \\
\hline$Z r-93+d$ & $6.50 \mathrm{E}-01$ & $4.0 \mathrm{E}+06$ & $1.2 E+05$ \\
\hline Tc-99 & $0.00 \mathrm{E}+00$ & $>1 \mathrm{E} 20$ & $>1 \mathrm{E} 20$ \\
\hline Pd-107 & $2.69 \mathrm{E}-02$ & $2.0 \mathrm{E}+08$ & $5.6 \mathrm{E}+06$ \\
\hline Cd-113m & $3.7 \mathrm{E}-15^{\mathrm{g}}$ & $3.5 E+17$ & $1.0 \mathrm{E}+16$ \\
\hline $\mathrm{Sn}-121 \mathrm{~m}$ & $1.7 \mathrm{E}-03^{\mathrm{g}}$ & $2.1 E+08$ & $6.0 \mathrm{E}+06$ \\
\hline Sn-126+d & $3.25 \mathrm{E}-02$ & $2.0 \mathrm{E}+03$ & $5.6 \mathrm{E}+01$ \\
\hline $\mathrm{I}-129$ & $5.89 E-19$ & $>1 E 20$ & $9.8 \mathrm{E}+19$ \\
\hline Cs-135 & $3.57 \mathrm{E}-01$ & $3.8 \mathrm{E}+05$ & $1.1 \mathrm{E}+04$ \\
\hline Cs- $137+d$ & $1.0 \mathrm{E}-07^{\mathrm{g}}$ & $2.1 E+09$ & $6.0 \mathrm{E}+07$ \\
\hline Sm-151 & $4.6 \mathrm{E}-03^{\mathrm{g}}$ & $3.5 \mathrm{E}+09$ & $1.0 \mathrm{E}+08$ \\
\hline Eu-154 & $1.1 \mathrm{E}-24^{8}$ & $>1 \mathrm{E} 20$ & $>1 E 20$ \\
\hline Th-228 & $7.6 \mathrm{E}-111$ & $>1 \mathrm{E} 20$ & $>1 \mathrm{E} 20$ \\
\hline Th-232 & $9.38 \mathrm{E}-01$ & $5.0 \mathrm{E}+01$ & $1.4 \mathrm{E}+00$ \\
\hline $\mathrm{Ra}-228+\mathrm{d}$ & $9.32 \mathrm{E}-01$ & & \\
\hline Th-228 & $9.29 \mathrm{E}-01$ & & \\
\hline $\mathrm{Ra}-224+\mathrm{d}$ & $9.30 \mathrm{E}-01$ & & \\
\hline $\mathrm{U}-232$ & $1.62 \mathrm{E}-05$ & $4.7 \mathrm{E}+06$ & $1.3 \mathrm{E}+05$ \\
\hline Th-228 +d & $1.57 \mathrm{E}-05$ & & \\
\hline $\mathrm{Ra}-224$ & $1.57 \mathrm{E}-05$ & & \\
\hline U-233 & $1.22 \mathrm{E}-02$ & $3.4 \mathrm{E}+04$ & $9.8 \mathrm{E}+02$ \\
\hline Th-229 & $1.11 \mathrm{E}-02$ & & \\
\hline $\mathrm{Ra}-225+\mathrm{d}$ & $1.11 \mathrm{E}-02$ & & \\
\hline U-234 (700 years) & $1.22 \mathrm{E}-02$ & $2.4 \mathrm{E}+05$ & $7.0 \mathrm{E}+03$ \\
\hline Th-230 & $1.13 \mathrm{E}-03$ & & \\
\hline $\mathrm{Ra}-226+\mathrm{d}$ & $1.97 \mathrm{E}-04$ & & \\
\hline $\mathrm{Pb}-210$ & $1.79 \mathrm{E}-04$ & & \\
\hline Po-210 & $1.78 \mathrm{E}-04$ & & \\
\hline U-234 (1970 years) & $4.03 \mathrm{E}-03$ & $2.2 \mathrm{E}+05$ & $6.2 \mathrm{E}+03$ \\
\hline Th-230 & $1.10 \mathrm{E}-03$ & & \\
\hline $\mathrm{Ra}-226+\mathrm{d}$ & $2.60 \mathrm{E}-04$ & & \\
\hline $\mathrm{Pb}-210$ & $2.43 \mathrm{E}-04$ & & \\
\hline Po-210 & $2.42 \mathrm{E}-04$ & & \\
\hline
\end{tabular}


Table 6.3-7 Intruder-Based Radionuclide Disposal Limits for Slit Trenches - Agriculture Scenario at 700 Years (and peak for uranium decay products)

\begin{tabular}{|c|c|c|c|}
\hline Radionuclide & $\begin{array}{c}\text { Fraction } \\
\text { Remaining } \\
\end{array}$ & $\begin{array}{c}\text { Concentration } \\
\text { Limit } \\
\left(\mu \mathrm{Ci} / \mathrm{m}^{3}\right) \\
\end{array}$ & $\begin{array}{c}\text { Inventory } \\
\text { Limit } \\
\text { (Ci/5 trenches) } \\
\end{array}$ \\
\hline $\mathrm{U}-235+\mathrm{d}$ & $1.22 \mathrm{E}-02$ & $4.8 \mathrm{E}+04$ & $1.4 \mathrm{E}+03$ \\
\hline $\mathrm{Pa}-231$ & $1.68 \mathrm{E}-03$ & & \\
\hline Ac- 227 & $1.67 \mathrm{E}-03$ & & \\
\hline Th-227 & $1.67 \mathrm{E}-03$ & & \\
\hline $\mathrm{Ra}-223$ & $1.67 \mathrm{E}-03$ & & \\
\hline$U-236$ & $1.22 \mathrm{E}-02$ & $1.3 E+06$ & $3.8 \mathrm{E}+04$ \\
\hline $\mathrm{U}-238$ & $1.22 \mathrm{E}-02$ & $3.5 E+05$ & $1.0 \mathrm{E}+04$ \\
\hline Th-234 +d & $1.22 \mathrm{E}-02$ & & \\
\hline $\mathrm{U}-234$ & $2.42 \mathrm{E}-05$ & & \\
\hline $\mathrm{Np}-237+\mathrm{d}$ & $1.07 \mathrm{E}-07$ & $3.2 E+09$ & $9.1 E+07$ \\
\hline Pu-238 & $1.72 \mathrm{E}-04$ & $2.8 \mathrm{E}+07$ & $8.0 \mathrm{E}+05$ \\
\hline U-234 & $5.89 \mathrm{E}-06$ & & \\
\hline $\mathrm{Pu}-239$ & $4.00 \mathrm{E}-02$ & $1.1 \mathrm{E}+05$ & $3.1 \mathrm{E}+03$ \\
\hline U-235 & $1.57 \mathrm{E}-08$ & & \\
\hline $\mathrm{Pu}-240$ & $3.80 \mathrm{E}-02$ & $1.1 \mathrm{E}+05$ & $3.2 \mathrm{E}+03$ \\
\hline U-236 & $4.54 \mathrm{E}-07$ & & \\
\hline $\mathrm{Pu}-241$ & $2.3 \mathrm{E}-15^{\mathrm{g}}$ & $2.8 \mathrm{E}+05$ & $8.0 \mathrm{E}+03$ \\
\hline Am-241 & $1.1 \mathrm{E}-02^{\mathrm{g}}$ & & \\
\hline Np-237+d & $7.2 \mathrm{E}-13$ & & \\
\hline $\mathrm{Pu}-242$ & $4.08 E-02$ & $1.1 \mathrm{E}+05$ & $3.2 E+03$ \\
\hline U-238 & $2.50 \mathrm{E}-09$ & & \\
\hline $\mathrm{Pu}-244+d$ & $4.08 \mathrm{E}-02$ & $8.3 E+03$ & $2.4 \mathrm{E}+02$ \\
\hline Am-241 & $3.3 \mathrm{E}-01^{\mathrm{g}}$ & $9.3 E+03$ & $2.7 \mathrm{E}+02$ \\
\hline$N p-237+d$ & $2.2 \mathrm{E}-11$ & & \\
\hline$A m-242 m+d$ & 4. $1 \mathrm{E}-02^{\mathrm{g}}$ & $4.5 \mathrm{E}+04$ & $1.3 \mathrm{E}+03$ \\
\hline Pu-238 & $4.1 \mathrm{E}-02$ & & \\
\hline U-234 & $6.2 \mathrm{E}-04$ & & \\
\hline $\mathrm{Am}-243$ & $6.75 \mathrm{E}-01$ & $1.0 E+03$ & $2.9 \mathrm{E}+01$ \\
\hline Np-239 & $6.77 \mathrm{E}-01$ & & \\
\hline Pu-239 & $2.94 \mathrm{E}-03$ & & \\
\hline $\mathrm{Cm}-242$ & $0.0 \mathrm{E}+00^{\mathrm{g}}$ & $5.4 \mathrm{E}+09$ & $1.6 \mathrm{E}+08$ \\
\hline Pu-238 & $8.7 \mathrm{E}-07$ & & \\
\hline U-234 & $3.0 \mathrm{E}-08$ & & \\
\hline $\mathrm{Cm}-243$ & 4.1E- $-08^{\mathrm{B}}$ & $2.7 \mathrm{E}+10$ & $7.8 \mathrm{E}+08$ \\
\hline $\mathrm{Cm}-244$ & $2.3 \mathrm{E}-12^{\mathrm{g}}$ & $4.1 E+07$ & $1.2 \mathrm{E}+06$ \\
\hline $\mathrm{Pu}-240$ & $1.1 E-04$ & & \\
\hline U-236 & $1.3 \mathrm{E}-09$ & & \\
\hline $\mathrm{Cm}-245$ & $8.79 E-01$ & $1.3 E+03$ & $3.7 \mathrm{E}+01$ \\
\hline $\mathrm{Pu}-241$ & $7.40 \mathrm{E}-01$ & & \\
\hline$A m-241$ & $5.03 E-01$ & & \\
\hline $\mathrm{Np}-237+\mathrm{d}$ & $3.77 \mathrm{E}-06$ & & \\
\hline $\mathrm{Cm}-246$ & $8.39 \mathrm{E}-01$ & $4.9 E+03$ & $1.4 E+02$ \\
\hline
\end{tabular}


Table 6.3-7 Intruder-Based Radionuclide Disposal Limits for Slit Trenches - Agriculture Scenario at 700 Years (and peak for uranium decay products)

\begin{tabular}{|c|c|c|c|}
\hline Radionuclide & $\begin{array}{c}\text { Fraction } \\
\text { Remaining }\end{array}$ & $\begin{array}{c}\text { Concentration } \\
\text { Limit } \\
\left(\mu \mathrm{Ci} / \mathrm{m}^{3}\right)\end{array}$ & $\begin{array}{c}\text { Inventory } \\
\text { Limit } \\
\text { (Ci/5 trenches) } \\
\end{array}$ \\
\hline $\mathrm{Cm}-247+\mathrm{d}$ & $9.30 \mathrm{E}-01$ & $3.9 \mathrm{E}+02$ & $1.1 \mathrm{E}+01$ \\
\hline Am-243 & $5.80 \mathrm{E}-02$ & & \\
\hline Np-239 & $5.82 \mathrm{E}-02$ & & \\
\hline Pu-239 & $2.15 \mathrm{E}-04$ & & \\
\hline $\mathrm{Cm}-248$ & $9.29 \mathrm{E}-01$ & $1.3 \mathrm{E}+03$ & $3.6 \mathrm{E}+01$ \\
\hline $\mathrm{Pu}-244$ & $1.63 \mathrm{E}-06$ & & \\
\hline Bk-249 & $3.9 E-240^{g}$ & $9.6 \mathrm{E}+05$ & $2.8 \mathrm{E}+04$ \\
\hline Cf-249 & $3.6 \mathrm{E}-04^{8}$ & & \\
\hline $\mathrm{Cm}-245$ & $4.6 \mathrm{E}-05$ & & \\
\hline $\mathrm{Cf}-249$ & $1.45 \mathrm{E}-01^{\mathrm{g}}$ & $2.4 \mathrm{E}+03$ & $6.9 E+01$ \\
\hline $\mathrm{Cm}-245$ & $1.83 \mathrm{E}-02$ & & \\
\hline $\mathrm{Pu}-241$ & $1.43 E-02$ & & \\
\hline Am-241 & $6.83 \mathrm{E}-03$ & & \\
\hline $\mathrm{Np}-237+\mathrm{d}$ & $2.35 \mathrm{E}-08$ & & \\
\hline Cf-250 & $7.8 \mathrm{E}-17^{g}$ & $1.7 \mathrm{E}+06$ & $4.8 \mathrm{E}+04$ \\
\hline $\mathrm{Cm}-246$ & $2.5 \mathrm{E}-03$ & & \\
\hline $\mathrm{Cf}-251$ & $5.8 \mathrm{E}-01^{8}$ & $1.8 \mathrm{E}+03$ & $5.2 \mathrm{E}+01$ \\
\hline Cf-252 & $3.9 \mathrm{E}-81^{\mathrm{g}}$ & $1.5 \mathrm{E}+08$ & $4.5 \mathrm{E}+06$ \\
\hline \multicolumn{4}{|l|}{$\mathrm{Cm}-248$} \\
\hline \multicolumn{4}{|c|}{$\begin{array}{l}\text { Indented entries are decay products of parent radionuclide that are potentially } \\
\text { radiologically-significant. } \\
\text { - The notation "+d" indicates that short-lived daughters were incorporated into the EDE. } \\
\text { Dose from other daughters listed is calculated explicitly. } \\
\text { c Considers radioactive decay and leaching unless otherwise noted. } \\
\text { d Fractions shown for radioactive daughters reflect fraction of initial activity of parent. } \\
\text { e Limit on average concentration in disposed waste; obtained from Eq. } 6.3-5 \\
\mathrm{~g} \text { Limit on inventory per } 5 \text { trenches; obtained from Eq. } 6.3-4 \text {, assuming a volume of } 2.88 \mathrm{E} 4 \\
\mathrm{~m}^{3} \text { for } 5 \text { trenches. } \\
\mathrm{g} \text { Only radioactive decay accounted for. }\end{array}$} \\
\hline
\end{tabular}


have been underestimated by more than an order of magnitude, which does not appear likely, it seems reasonable to conclude that direct intrusion into the waste by excavation is not a credible occurrence for about the first 40,000 years after disposal which is well beyond the assumed time period for compliance with the performance measure for inadvertent intruder analysis (1000 years). Therefore, on the basis of the agriculture scenario, no limits on average concentrations or inventories of radionuclides in waste casks need to be imposed to provide acceptable impacts on hypothetical inadvertent intruders.

Simply for the purpose of providing a perspective on inventory limits based on the agriculture scenario, a dose analysis for this scenario at 10,000 years, about the time the carbon steel casks are expected to completely corrode, was performed for the radionuclides listed in Table 6.2-1 for Naval Reactor Components. Based on this analysis, limits on concentration and inventory were calculated (Eq. 6.3-4 and 6.3-5) for the naval reactor waste casks, and are presented in Table 6.3-8. The following assumptions were made for these calculations: 1) the total volume of a waste cask is $43 \mathrm{~m}^{3}(54-\mathrm{m}$ high, $3.2-\mathrm{m}$ in diameter; Fig. 3.3-1); 2) the SDCFs for the agriculture scenario from Table 6.3-1 are used; and 3) the waste casks will occupy about 40 percent of the total area of the disposal facility (Table 6.3-4).

The dose estimates for the agriculture scenario given above are conservative because they do not take into account the fact that most of the activity in the waste casks is present as activated metal. The metal waste form is unlikely to have corroded to a significant extent by 10,000 years, and thus both external exposure and internal exposure to the radionuclides present at this time is mitigated by the shielding provided by the metal and the retention of radionuclides in the metal.

\subsubsection{Intimately-Mixed Cement-Stabilized Waste Units}

The engineered barriers that may preclude excavation or drilling into the intimately-mixed cement-stabilized waste units for a time after loss of institutional control are the cementitious waste form and the soil cover over the trenches in which the waste form is present. This cement-based waste form meets the NRC Class B criteria for stability and therefore deters intrusion for 300 years after disposal. However, as was the case for the slit trenches, at least 700 years are necessary for sufficient erosion of the soil cover to allow excavation into the trenches of at least $1 \mathrm{~m}$. The earliest time that the agriculture scenario is credible for this waste form is therefore 700 years. This is considered the bounding case for radionuclides which do not produce long-lived daughters that may contribute significantly to dose. Despite the leaching of radionuclides that may occur from the waste form after 700 years, potentially-significant long-lived daughters of the radionuclides may grow into the waste form before the parent isotopes are effectively leached significantly from the waste form; thus, the potential contribution of these daughters to intruder dose is a factor in estimating concentration and inventory limits for this waste type. The time at which these daughter isotopes peak in the waste form was calculated either by using the PORFLOW code (Sect. 4.3.3), or by accounting for their ingrowth by considering radioactive decay alone. Because the peak dose from longer-lived daughters may occur at times beyond the 700 -year time at which the dose is initially evaluated, the limits are also evaluated at the time that ingrowth of these daughters peaks. For radionuclides with relatively longerlived daughters, for which daughter ingrowth is not explicitly modeled with PORFLOW $\left({ }^{241} \mathrm{Am},{ }^{24} \mathrm{Pu}\right.$, ${ }^{244} \mathrm{Cm}$, ${ }^{250} \mathrm{Cf}$, and ${ }^{252} \mathrm{Cf}$ ), the maximizing assumption that the long-lived daughters are produced instantaneously at time zero (ignoring leaching of the relatively short-lived parent over time) allows consideration of daughter contributions to dose in developing dose limits.

The results of the dose analysis of the intruder-agriculture scenario for the intimately-mixed cementstabilized waste form are presented in Table 6.3-9 for the 700-year time of occurrence of the agriculture scenario, and for the time at which the peak contribution from uranium daughters occurs (to consider maximum daughter ingrowth). The limits on concentrations and inventories of radionuclides in waste are 
Table 6.3-8 Intruder-Based Radionuclide Disposal Limits for Naval

Reactor Waste - Agriculture Scenario at 10,000 Years

\begin{tabular}{|c|c|c|c|}
\hline Radionuclide $^{a, b}$ & Fraction Remaining ${ }^{c, d}$ & $\begin{array}{c}\text { Concentration Limit } \\
\left(\mu \mathrm{Ci} / \mathrm{m}^{3}\right)\end{array}$ & $\begin{array}{c}\text { Inventory Limit }{ }^{\mathrm{f}} \\
(\mathrm{Ci} / \mathrm{pad})\end{array}$ \\
\hline $\mathrm{H}-3$ & $0.0 \mathrm{E}+00$ & $>1 E 20$ & $>1 \mathrm{E} 20$ \\
\hline C-14 & $1.5 \mathrm{E}-05$ & $1.4 \mathrm{E}+09$ & $1.4 \mathrm{E}+07$ \\
\hline $\mathrm{Co}-60$ & $0.0 \mathrm{E}+00^{\mathrm{g}}$ & $>1 E 20$ & $>1 E 20$ \\
\hline $\mathrm{Ni}-59$ & $4.8 \mathrm{E}-02$ & $1.0 \mathrm{E}+08$ & $1.0 \mathrm{E}+06$ \\
\hline $\mathrm{Ni}-63$ & $8.6 \mathrm{E}-31^{\mathrm{B}}$ & $>1 E 20$ & $>1 E 20$ \\
\hline $\mathrm{Se}-79$ & $8.2 \mathrm{E}-03$ & $3.3 E+07$ & $3.3 E+05$ \\
\hline $\mathrm{Sr}-90+\mathrm{d}$ & $0.0 \mathrm{E}+00$ & $>1 E 20$ & $>1 E 20$ \\
\hline Mo-93 & $7.7 \mathrm{E}-05$ & $2.4 \mathrm{E}+09$ & $2.4 \mathrm{E}+07$ \\
\hline $\mathrm{Zr}-93+\mathrm{d}$ & $1.0 \mathrm{E}-02$ & $5.1 \mathrm{E}+08$ & $5.1 E+06$ \\
\hline $\mathrm{Nb}-94$ & $5.6 \mathrm{E}-03$ & $2.8 \mathrm{E}+04$ & $2.8 \mathrm{E}+02$ \\
\hline Tc-99 & $0.0 \mathrm{E}+00$ & $>1 E 20$ & $>1 E 20$ \\
\hline Sn-126 +d & $4.0 \mathrm{E}-03$ & $3.2 E+04$ & $3.2 \mathrm{E}+02$ \\
\hline I-129 & $0.0 E+00$ & >1E20 & $>1 E 20$ \\
\hline Cs-135 & $1.9 \mathrm{E}-02$ & $1.4 \mathrm{E}+07$ & $1.4 \mathrm{E}+05$ \\
\hline Cs-137 +d & $1.8 \mathrm{E}-100^{8}$ & $>1 \mathrm{E} 20$ & $>1 \mathrm{E} 20$ \\
\hline $\mathrm{Sm}-151$ & $3.6 \mathrm{E}-34^{\mathrm{B}}$ & $>1 \mathrm{E} 20$ & $>1 E 20$ \\
\hline $\mathrm{Eu}-154$ & $0.0 \mathrm{E}+00^{\mathrm{g}}$ & $>1 E 20$ & $>1 E 20$ \\
\hline Th-232 & $1.2 \mathrm{E}-01$ & $5.7 \mathrm{E}+04$ & $5.7 E+02$ \\
\hline $\mathrm{Ra}-228+\mathrm{d}$ & $4.5 \mathrm{E}-11$ & & \\
\hline Th-228 & $1.5 \mathrm{E}-11$ & & \\
\hline $\mathrm{Ra}-224+\mathrm{d}$ & $7.8 \mathrm{E}-14$ & & \\
\hline U-232 & $0.0 \mathrm{E}+00$ & $>1 \mathrm{E} 20$ & $>1 \mathrm{E} 20$ \\
\hline Th-228 & $0.0 E+00$ & & \\
\hline $\mathrm{Ra}-224+\mathrm{d}$ & $0.0 \mathrm{E}+00$ & & \\
\hline U-234 & $2.7 \mathrm{E}-01$ & $1.1 E+05$ & $1.1 \mathrm{E}+03$ \\
\hline Th-230 & $1.9 \mathrm{E}-03$ & & \\
\hline $\mathrm{Ra}-226+\mathrm{d}$ & $2.0 \mathrm{E}-06$ & & \\
\hline $\mathrm{Pb}-210$ & $2.5 \mathrm{E}-08$ & & \\
\hline Po-210 & $4.2 \mathrm{E}-10$ & & \\
\hline $\mathrm{U}-235+\mathrm{d}$ & $2.8 \mathrm{E}-01$ & $7.1 E+03$ & $7.1 E+01$ \\
\hline $\mathrm{Pa}-231$ & $1.7 \mathrm{E}-07$ & & \\
\hline Ac-227 & $1.0 \mathrm{E}-10$ & & \\
\hline Th-227 & $2.4 \mathrm{E}-13$ & & \\
\hline Ra-223 & $1.5 \mathrm{E}-13$ & & \\
\hline $\mathrm{U}-236$ & $2.8 \mathrm{E}-01$ & $1.2 E+05$ & $1.2 \mathrm{E}+03$ \\
\hline $\mathrm{U}-238$ & $2.8 \mathrm{E}-01$ & $1.2 \mathrm{E}+05$ & $1.2 \mathrm{E}+03$ \\
\hline Th-234 & 4.1E-12 & & \\
\hline U-234 & $2.0 \mathrm{E}-07$ & & \\
\hline$N p-237+d$ & $2.9 \mathrm{E}-02$ & $2.3 E+04$ & $2.3 \mathrm{E}+02$ \\
\hline Pu-238 & $0.0 \mathrm{E}+00$ & $1.9 \mathrm{E}+10$ & $1.9 E+08$ \\
\hline U-234 & $1.6 \mathrm{E}-06$ & & \\
\hline Pu-239 & $2.0 \mathrm{E}-02$ & 2.7E+05 & 2.7E+03 \\
\hline U-235 & $2.9 \mathrm{E}-03$ & & \\
\hline
\end{tabular}

Rev. 1

January 31,2000 
Table 6.3-8 Intruder-Based Radionuclide Disposal Limits for Naval Reactor Waste - Agriculture Scenario at 10,000 Years

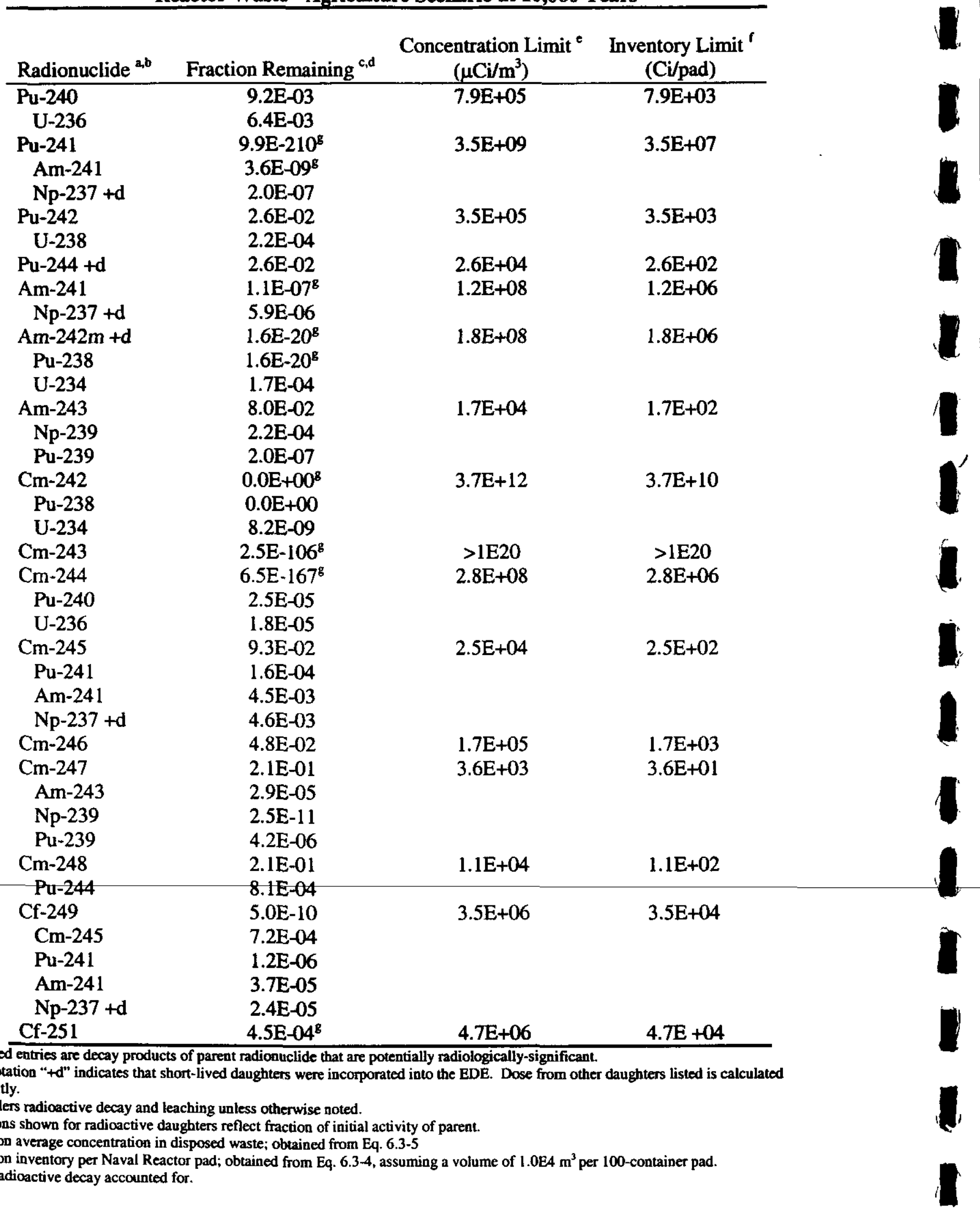


Table 6.3-9 Intruder-based Radionuclide Disposal Limits for Intimately-Mixed Cement-Stabilized Waste Trenches - Agriculture Scenario at 700 Years (and peak for uranium decay products)

\begin{tabular}{|c|c|c|c|}
\hline Radionuclide $^{\mathrm{a}, \mathrm{b}}$ & $\begin{array}{c}\text { Fraction } \\
\text { Remaining }\end{array}$ & $\begin{array}{c}\text { Concentration Limit } \\
\left(\mu \mathrm{Ci} / \mathrm{m}^{3}\right)\end{array}$ & $\begin{array}{l}\text { Inventory Limit }^{f} \\
\text { (Ci/5 trenches) }\end{array}$ \\
\hline $\mathrm{H}-3$ & $0.00 \mathrm{E}+00$ & $>1 E 20$ & $>1 \mathrm{E} 20$ \\
\hline$C-14$ & $9.14 \mathrm{E}-01$ & $1.2 \mathrm{E}+04$ & $3.5 \mathrm{E}+02$ \\
\hline Co-60 & $1.07 \mathrm{E}-40^{\mathrm{g}}$ & $>1 \mathrm{E} 20$ & $>1 \mathrm{E} 20$ \\
\hline $\mathrm{Ni}-59$ & $7.38 \mathrm{E}-01$ & $3.3 \mathrm{E}+06$ & $9.6 \mathrm{E}+04$ \\
\hline $\mathrm{Ni}-63$ & $7.86 \mathrm{E}-03^{\mathrm{g}}$ & $1.2 \mathrm{E}+08$ & $3.3 E+06$ \\
\hline Se-79 & $1.37 \mathrm{E}-06$ & $1.0 \mathrm{E}+11$ & $2.9 \mathrm{E}+09$ \\
\hline Rb-87 & $2.25 \mathrm{E}-02$ & $3.9 \mathrm{E}+06$ & $1.1 \mathrm{E}+05$ \\
\hline $\mathrm{Sr}-90+\mathrm{d}$ & $3.08 \mathrm{E}-21$ & $>1 \mathrm{E} 20$ & $>1 \mathrm{E} 20$ \\
\hline $\mathrm{Zr}-93+\mathrm{d}$ & $9.95 \mathrm{E}-01$ & $2.6 \mathrm{E}+06$ & $7.5 \mathrm{E}+04$ \\
\hline $\mathrm{Nb}-94$ & $9.26 \mathrm{E}-01$ & $8.5 E+01$ & $2.5 \mathrm{E}+00$ \\
\hline Tc-99 & $4.92 \mathrm{E}-27$ & $>1 \mathrm{E} 20$ & $>1 \mathrm{E} 20$ \\
\hline Pd- 107 & $7.42 \mathrm{E}-01$ & $7.1 \mathrm{E}+06$ & $2.0 \mathrm{E}+05$ \\
\hline $\mathrm{Sn}-126+\mathrm{d}$ & $9.69 \mathrm{E}-01$ & $6.6 \mathrm{E}+01$ & $1.9 \mathrm{E}+00$ \\
\hline I-129 & $0.00 \mathrm{E}+00$ & $>1 \mathrm{E} 20$ & $>1 \mathrm{E} 20$ \\
\hline Cs-135 & $2.25 \mathrm{E}-02$ & $6.0 \mathrm{E}+06$ & $1.7 \mathrm{E}+05$ \\
\hline $\mathrm{Cs}-137+\mathrm{d}$ & $1.04 \mathrm{E}-07^{\mathrm{g}}$ & $2.1 \mathrm{E}+09$ & $6.0 \mathrm{E}+07$ \\
\hline Șm-151 & $4.56 \mathrm{E}-03^{g}$ & $3.5 \mathrm{E}+09$ & $1.0 \mathrm{E}+08$ \\
\hline Eu- 152 & $1.90 \mathrm{E}-16^{\mathrm{g}}$ & $5.7 \mathrm{E}+17$ & $1.6 \mathrm{E}+16$ \\
\hline Eu-154 & $1.15 \mathrm{E}-24^{\mathrm{g}}$ & $>1 \mathrm{E} 20$ & $>1 \mathrm{E} 20$ \\
\hline Th-232 & $9.95 \mathrm{E}-01$ & $4.7 \mathrm{E}+01$ & $1.4 \mathrm{E}+00$ \\
\hline $\mathrm{Ra}-228+\mathrm{d}$ & $9.83 \mathrm{E}-01$ & & \\
\hline Th-228 & $9.80 \mathrm{E}-01$ & & \\
\hline $\mathrm{Ra}-224+\mathrm{d}$ & $9.81 \mathrm{E}-01$ & & \\
\hline U-232 & $1.19 \mathrm{E}-03$ & $6.0 \mathrm{E}+04$ & $1.7 \mathrm{E}+03$ \\
\hline Th-228 & $1.23 \mathrm{E}-03$ & & \\
\hline $\mathrm{Ra}-224+\mathrm{d}$ & $1.23 \mathrm{E}-03$ & & \\
\hline U-233 (700 years) & $9.97 \mathrm{E}-01$ & $4.4 E+03$ & $1.3 \mathrm{E}+02$ \\
\hline Th-229 & $6.25 \mathrm{E}-02$ & & \\
\hline $\mathrm{Ra}-225+\mathrm{d}$ & $6.23 \mathrm{E}-02$ & & \\
\hline U-233 ( 10,000 years $)$ & $9.60 \mathrm{E}-01$ & $6.7 E+02$ & $1.9 \mathrm{E}+01$ \\
\hline Th-229 & $5.55 \mathrm{E}-01$ & & \\
\hline $\mathrm{Ra}-225+\mathrm{d}$ & $5.54 \mathrm{E}-01$ & & \\
\hline U-234 (700 years) & $9.98 \mathrm{E}-01$ & $1.3 \mathrm{E}+04$ & $3.8 \mathrm{E}+02$ \\
\hline Th-230 & $6.25 \mathrm{E}-03$ & & \\
\hline $\mathrm{Ra}-226+d$ & $6.26 \mathrm{E}-04$ & & \\
\hline $\mathrm{Pb}-210$ & $5.81 \mathrm{E}-04$ & & \\
\hline Po-210 & $5.80 \mathrm{E}-04$ & & \\
\hline U-234 ( 10,000 years) & $9.72 \mathrm{E}-01$ & $3.8 \mathrm{E}+03$ & $1.1 \mathrm{E}+02$ \\
\hline Th-230 & $7.94 \mathrm{E}-02$ & & \\
\hline $\mathrm{Ra}-226+\mathrm{d}$ & $1.17 \mathrm{E}-02$ & & \\
\hline $\mathrm{Pb}-210$ & $1.17 \mathrm{E}-02$ & & \\
\hline Po-210 & $1.17 \mathrm{E}-02$ & & \\
\hline
\end{tabular}

Rev. 1 
Table 6.3-9 Intruder-based Radionuclide Disposal Limits for Intimately Mixed Cement-Stabilized Waste Trenches - Agriculture Scenario at 700 Years (and peak for uranium decay products)

\begin{tabular}{|c|c|c|c|}
\hline Radionuclide $^{\mathrm{a}, \mathrm{b}}$ & $\begin{array}{c}\text { Fraction } \\
\text { Remaining }^{\mathrm{c}, \mathrm{d}}\end{array}$ & $\begin{array}{c}\text { Concentration Limit } \\
\left(\mu \mathrm{Ci} / \mathrm{m}^{3}\right)\end{array}$ & $\begin{array}{l}\text { Inventory Limit }^{f} \\
\text { (Ci/S trenches) }\end{array}$ \\
\hline U-235 +d (700 years) & $1.00 \mathrm{E}+00$ & $9.2 \mathrm{E}+02$ & $2.6 \mathrm{E}+01$ \\
\hline $\mathrm{Pa}-231$ & $1.46 \mathrm{E}-02$ & & \\
\hline Ac-227 & $1.40 \mathrm{E}-02$ & & \\
\hline Th-227 & $1.40 \mathrm{E}-02$ & & \\
\hline $\mathrm{Ra}-223$ & $1.40 \mathrm{E}-02$ & & \\
\hline $\mathrm{U}-235+\mathrm{d}(10,000$ years $)$ & $1.00 E+00$ & $5.2 \mathrm{E}+02$ & $1.5 E+01$ \\
\hline $\mathrm{Pa}-231$ & $1.78 \mathrm{E}-01$ & & \\
\hline Ac- 227 & $1.78 \mathrm{E}-01$ & & \\
\hline Th-227 & $1.78 \mathrm{E}-01$ & & \\
\hline Ra-223 & $1.78 \mathrm{E}-01$ & & \\
\hline$U-236$ & $1.00 \mathrm{E}+00$ & $1.6 \mathrm{E}+04$ & $4.6 \mathrm{E}+02$ \\
\hline U-238 (700 years) & $1.00 \mathrm{E}+00$ & $4.3 E+03$ & $1.2 \mathrm{E}+02$ \\
\hline Th-234 +d & $1.00 \mathrm{E}+00$ & & \\
\hline U-234 & $1.13 \mathrm{E}-03$ & & \\
\hline U-238 ( 10,000 years $)$ & $1.00 \mathrm{E}+00$ & $4.3 E+03$ & $1.2 \mathrm{E}+02$ \\
\hline Th-234 +d & $1.00 \mathrm{E}+00$ & & \\
\hline U-234 & $2.71 \mathrm{E}-02$ & & \\
\hline $\mathrm{Np}-237+\mathrm{d}$ & $9.95 \mathrm{E}-01$ & $3.4 \mathrm{E}+02$ & $9.8 \mathrm{E}+00$ \\
\hline $\mathrm{Pu}-238$ & $4.74 \mathrm{E}-03$ & $1.0 \mathrm{E}+06$ & $2.9 E+04$ \\
\hline U-234 & $3.22 \mathrm{E}-05$ & & \\
\hline Pu-239 & $9.80 \mathrm{E}-01$ & $4.4 E+03$ & $1.3 \mathrm{E}+02$ \\
\hline $\mathrm{U}-235$ & $3.89 \mathrm{E}-07$ & & \\
\hline $\mathrm{Pu}-240$ & $9.29 \mathrm{E}-01$ & $4.6 \mathrm{E}+03$ & $1.3 E+02$ \\
\hline $\mathrm{U}-236$ & $1.12 \mathrm{E}-05$ & & \\
\hline $\mathrm{Pu}-24 \mathrm{l}$ & $2.34 \mathrm{E}-15^{\mathrm{g}}$ & $2.8 \mathrm{E}+05$ & $8.0 \mathrm{E}+03$ \\
\hline Am-241 & $1.08 \mathrm{E}-02^{\mathrm{g}}$ & & \\
\hline $\mathrm{Np}-237+\mathrm{d}$ & $6.70 \mathrm{E}-06$ & & \\
\hline $\mathrm{Pu}-242$ & $9.99 \mathrm{E}-01$ & $4.5 \mathrm{E}+03$ & $1.3 \mathrm{E}+02$ \\
\hline U-238 & $6.20 \mathrm{E}-08$ & & \\
\hline $\mathrm{Pu}-244+\mathrm{d}$ & $1.00 \mathrm{E}+00$ & $3.4 \mathrm{E}+02$ & $9.7 \mathrm{E}+00$ \\
\hline Am-241 & $3.25 \mathrm{E}-01^{\mathrm{g}}$ & $9.2 \mathrm{E}+03$ & $2.7 \mathrm{E}+02$ \\
\hline $\mathrm{Np}-237+\mathrm{d}$ & $2.01 E-04$ & & \\
\hline Am-243 & $9.32 \mathrm{E}-01$ & $7.4 \mathrm{E}+02$ & $2.1 E+01$ \\
\hline Np-239 & $6.20 \mathrm{E}-08$ & & \\
\hline Pu-239 & $1.13 \mathrm{E}-03$ & & \\
\hline $\mathrm{Cm}-244$ & $2.33 E-12^{8}$ & $1.7 E+06$ & $4.8 \mathrm{E}+04$ \\
\hline $\mathrm{Pu}-240$ & $2.57 \mathrm{E}-03$ & & \\
\hline U-236 & $3.10 \mathrm{E}-08$ & & \\
\hline $\mathrm{Cm}-245$ & $9.40 \mathrm{E}-01$ & $1.2 \mathrm{E}+03$ & $3.4 \mathrm{E}+01$ \\
\hline $\mathrm{Pu}-241$ & $9.41 \mathrm{E}-01$ & & \\
\hline Am-24i & $6.20 \mathrm{E}-01$ & & \\
\hline $\mathrm{Np}-237+\mathrm{d}$ & $8.13 E-05$ & & \\
\hline $\mathrm{Cm}-246$ & $8.97 \mathrm{E}-01$ & $4.6 \mathrm{E}+03$ & $1.3 \mathrm{E}+02$ \\
\hline
\end{tabular}


calculated using Eqs. 6.3-4 and 6.3-5. The SDCF for each radionuclide is obtained from Table 6.3-1, and the geometrical reduction factor $(G)$ for the trenches into which this waste form is placed $(0.6)$ is obtained from Table 6.3-4.

\subsubsection{Cement-Stabilized Encapsulated Waste Units}

The engineered barrier that may preclude excavation or drilling into the cement-stabilized encapsulated waste units for a time after loss of institutional control $0.3-\mathrm{m}$ (1-foot) thick grout encapsulating the waste forms. As with the intimately-mixed cement-stabilized waste form, this cement-based waste form meets the NRC Class B criteria for stability and therefore deters intrusion for 300 years after disposal. However, as was the case for the slit trenches, at least 700 years are necessary for sufficient erosion of the soil cover to allow excavation into the trenches of at least $1 \mathrm{~m}$. Therefore, the earliest time that the agriculture scenario is credible for this waste form is 700 years.

Again, potentially-significant long-lived daughters of the radionuclides may grow into the waste form before the parent isotopes are significantly leached from the waste form; thus, the potential contribution of these daughters to intruder dose is a factor in estimating concentration and inventory limits for this waste type. The time at which these daughter isotopes peak in the waste form was calculated either by using the PORFLOW code (Sect. 4.3.3), or by accounting for their ingrowth by considering radioactive decay alone. Because the peak dose from longer-lived uranium daughters may occur at times beyond the 700 -year time at which the dose is initially evaluated, the limits are also evaluated at the time that ingrowth of these daughters peaks. For radionuclides with relatively longer-lived daughters, for which daughter ingrowth is not explicitly modeled with PORFLOW ${ }^{241} \mathrm{Am}$ and $\left.{ }^{241} \mathrm{Pu}\right)$, the maximizing assumption that the long-lived daughters are produced instantaneously at time zero (ignoring leaching of the relatively short-lived parent over time) allows consideration of daughter contributions to dose in developing dose limits. Concentration and inventory limits are provided in Table 6.3-10 for the 700-year time of occurrence of the agriculture scenario and the time at which the peak fraction of potentially-significant long-lived daughters occurs.

\subsubsection{Dose Analysis for Resident Scenario}

Two bounding assumptions have been used in the dose analysis for the resident scenario for inadvertent intruders. In the first case, the intruder is assumed to reside in a home located immediately on top of an intact concrete roof or other engineered barrier above a disposal unit, and the scenario is assumed to be credible immediately following loss of active institutional control at 100 years after disposal. In the second case, the home is assumed to be located immediately on top of the waste in a disposal unit, but the scenario is assumed not to occur until the engineered barriers (e.g., concrete roof, cover material) above the waste have been eroded or have lost their integrity and can be penetrated during excavation.

In both bounding cases for the resident scenario, the intruder is assumed not to excavate into the waste itself while constructing a home on the disposal site. Thus, the only exposure pathway of concern for this scenario is external exposure to photon-emitting radionuclides in the waste while residing in the home. The only differences between the two bounding cases are the time at which the scenario is assumed to become credible, as described above, and the amount of shielding between the source region (i.e., the waste) and the receptor location.

The SDCFs obtained from the model for estimating dose to an inadvertent intruder for the resident scenario are summarized in Table 6.3-2. For all units, the geometrical reduction factors are listed in Table 6.3-4. The remainder of this section discusses application of the model represented by Eqs. 6.3-4 and 6.3-5 to the different disposal units in E Area. The resident scenario is potentially relevant for any disposal units whereby external exposure may occur following the 100-year institutional control period at a time before the 
Table 6.3-10 Intruder-Based Radionuclide Disposal Limits for Cement-Stabilized Encapsulated Waste Trenches - Agriculture Scenario at 700 Years (and peak for uranium decay products)

\begin{tabular}{|c|c|c|c|}
\hline Radionuclide $^{a, b}$ & Fraction Remaining ${ }^{c, d}$ & $\begin{array}{l}\text { Concentration Limit } \\
\qquad\left(\mu \mathrm{Ci} / \mathrm{m}^{3}\right)\end{array}$ & $\begin{array}{l}\text { Intruder Limit }{ }^{\mathrm{f}} \\
(\mathrm{Ci} / 5 \text { trenches })\end{array}$ \\
\hline $\mathrm{H}-3$ & $0.0 \mathrm{E}+00$ & $>1 \mathrm{E} 20$ & $>1 \mathrm{E} 20$ \\
\hline $\mathrm{Co}-60$ & $1.1 \mathrm{E}-40^{8}$ & $>1 \mathrm{E} 20$ & $>1 \mathrm{E} 20$ \\
\hline $\mathrm{Ni}-59$ & $7.6 \mathrm{E}-01$ & $3.2 \mathrm{E}+06$ & $9.3 E+04$ \\
\hline $\mathrm{Ni}-63$ & $7.9 \mathrm{E}-03^{\mathrm{g}}$ & $1.2 \mathrm{E}+08$ & $3.3 E+06$ \\
\hline $\mathrm{Se}-79$ & $2.0 \mathrm{E}-02$ & $7.0 \mathrm{E}+06$ & $2.0 E+05$ \\
\hline $\mathrm{Sr}-90+\mathrm{d}$ & $6.5 \mathrm{E}-28$ & $>1 \mathrm{E} 20$ & $>1 \mathrm{E} 20$ \\
\hline $\mathrm{Zr}-93+\mathrm{d}$ & $9.5 \mathrm{E}-01$ & $2.7 \mathrm{E}+06$ & $7.9 \mathrm{E}+04$ \\
\hline Tc-99 & $0.0 \mathrm{E}+00$ & $>1 \mathrm{E} 20$ & $>1 \mathrm{E} 20$ \\
\hline Pd-107 & $1.0 \mathrm{E}+00$ & $5.3 E+06$ & $1.5 \mathrm{E}+05$ \\
\hline $\mathrm{Sn}-126+d$ & $3.5 \mathrm{E}-0 \mathrm{I}$ & $1.8 \mathrm{E}+02$ & $5.2 \mathrm{E}+00$ \\
\hline I.129 & $0.0 \mathrm{E}+00$ & $>1 \mathrm{E} 20$ & $>1 \mathrm{E} 20$ \\
\hline Cs-135 & $2.2 \mathrm{E}-01$ & $6.2 \mathrm{E}+05$ & $1.8 \mathrm{E}+04$ \\
\hline $\mathrm{Cs}-137+\mathrm{d}$ & $1.0 \mathrm{E}-07^{\mathrm{g}}$ & $2.1 \mathrm{E}+09$ & $6.0 \mathrm{E}+07$ \\
\hline Sm-151 & $4.6 \mathrm{E}-03^{8}$ & $3.5 \mathrm{E}+09$ & $1.0 \mathrm{E}+08$ \\
\hline Eu-154 & $1.1 \mathrm{E}-24^{\mathrm{g}}$ & $>1 \mathrm{E} 20$ & $>1 \mathrm{E} 20$ \\
\hline $\mathrm{U}-232$ & $1.2 \mathrm{E}-03$ & $6.0 \mathrm{E}+04$ & $1.7 \mathrm{E}+03$ \\
\hline Th-228 & $1.2 \mathrm{E}-03$ & & \\
\hline $\mathrm{Ra}-224+\mathrm{d}$ & $1.2 \mathrm{E}-03$ & & \\
\hline U-233 (700 years) & $1.0 \mathrm{E}+00$ & $4.4 E+03$ & $1.3 \mathrm{E}+02$ \\
\hline Th-229 & $6.2 \mathrm{E}-02$ & & \\
\hline $\mathrm{Ra}-225$ & $6.2 \mathrm{E}-02$ & & \\
\hline U-233 (2,500 years $)$ & $9.9 \mathrm{E}-01$ & $1.4 \mathrm{E}+03$ & $4.1 E+01$ \\
\hline Th-229 & $2.1 \mathrm{E}-01$ & & \\
\hline $\mathrm{Ra}-225$ & $2.1 \mathrm{E}-01$ & & \\
\hline U-234 (700 years) & $1.0 \mathrm{E}+00$ & $1.5 \mathrm{E}+04$ & $4.2 \mathrm{E}+02$ \\
\hline Th-230 & $6.2 \mathrm{E}-03$ & & \\
\hline $\mathrm{Ra}-226+\mathrm{d}$ & $1.4 \mathrm{E}-04$ & & \\
\hline $\mathrm{Pb}-210$ & 1.3E-04 & & \\
\hline Po-210 & $1.3 \mathrm{E}-04$ & & \\
\hline U-234 ( 1,100 Years $)$ & $9.97 \mathrm{E}-01$ & $1.3 E+04$ & $3.9 E+02$ \\
\hline Th-230 & $2.94 \mathrm{E}-02$ & & \\
\hline $\mathrm{Ra}-226+d$ & $4.40 \mathrm{E}-04$ & & \\
\hline $\mathrm{Pb}-210$ & $4.0 \mathrm{E}-04$ & & \\
\hline Po-210 & 4.0E-04 & & \\
\hline $\mathrm{U}-235+\mathrm{d}(700$ years $)$ & $1.0 \mathrm{E}+00$ & $9.2 \mathrm{E}+02$ & $2.6 \mathrm{E}+01$ \\
\hline $\mathrm{Pa}-231$ & $1.4 \mathrm{E}-02$ & & \\
\hline Ac- 227 & $1.4 \mathrm{E}-02$ & & \\
\hline Th-227 & $1.4 \mathrm{E}-02$ & & \\
\hline $\mathrm{Ra}-223$ & $1.4 \mathrm{E}-02$ & & \\
\hline
\end{tabular}


agriculture scenario becomes credible. Once the agriculture scenario becomes credible, the resident exposure becomes irrelevant because the agriculture scenario includes the resident scenario. The resident scenario is relevant for all of the disposal unit types evaluated in this PA.

\subsubsection{Intermediate-Level Vaults}

As described previously, the $\mathbb{I}$ vaults will be constructed with a concrete roof of average thickness about 90 $\mathrm{cm}$ and a layer of uncontaminated grout above the waste of thickness about $90 \mathrm{~cm}$. Thus, the total thickness of the engineered barriers is about $1.8 \mathrm{~m}$, and this thickness of shielding would apply to the resident scenario for the II vaults at 100 years after disposal when all engineered barriers are assumed to be intact and impenetrable by normal excavation procedures.

As described in Appendix C.3.3, the $1.8 \mathrm{~m}$ thickness of shielding in the IL vaults is sufficient to reduce the external dose to very low levels for any conceivable concentrations of photon-emitting radionuclides in the waste. Therefore, in the dose analysis for the $\mathbb{L}$ vaults at 100 years after disposal, the conservative assumption is made that only the layer of uncontaminated grout above the waste is present to provide shielding. For purposes of this analysis, the thickness of the grout layer is assumed to be $100 \mathrm{~cm}$. This value is slightly greater than the planned thickness and is intended to take into account the somewhat greater shielding provided by any metal waste containers and waste forms in the IL vaults compared with the shielding provided by soil-equivalent material.

The results of the dose analysis for the resident scenario at 100 years after disposal are given in Table 6.311. The results are calculated in the same manner as those for the agriculture scenario using Eqs. 6.3-4 and 6.3-5, and the SDCFs are those for $100 \mathrm{~cm}$ of shielding in Table 6.3-2. The fraction remaining was calculated using PORFLOW for most radionuclides; for those not evaluated for the water resource impacts analysis, radioactive decay alone was evaluated (i.e., leaching was neglected during the 100 years prior to intrusion). The geometrical reduction factor of 0.4 was assumed (Table 6.3-4).

The results in Table 6.3-11 are expected to be quite pessimistic, and thus, the derived concentration and inventory limits are identified as worst-case conditions. As described above, the assumed thickness of shielding of $100 \mathrm{~cm}$ for these calculations greatly under-estimates the amount of shielding that would be provided by an intact concrete roof and the uncontaminated layer of grout above the waste. For the longlived isotopes of uranium, the calculated concentration limit is greater than the specific activity, indicating that no limit on these isotopes is necessary.

As described previously, the second bounding case for the resident scenario for the IL vaults is based on the assumption that the intruder's home is located immediately on top of exposed waste in a disposal unit, but that the excavation for the home does not penetrate into the waste itself, because the grouting at the depth of the top layer of waste is still intact. Therefore, this variation of the resident scenario could not reasonably occur until the concrete roof above the vaults has lost its integrity and the layer of uncontaminated grout above the waste has weathered to soil-equivalent material. An analysis described previously in presenting the results for the agriculture scenario indicates that the second bounding case for the resident scenario first could occur at about 10,000 years after disposal.

The results of the dose analysis for the resident scenario at 10,000 years after disposal are given in Table 6.3-12 and again are obtained using Eqs. 6.3-4 and 6.3-5. The SDCFs in this case are those for no shielding in Table 6.3-2. Only long-lived radionuclides, including long-lived decay products of the isotopes of uranium and neptunium, are of concern at this time. 
Table 6.3-11 Intruder-Based Radionuclide Disposal Limits for IL Vaults Resident Scenario at 100 Years

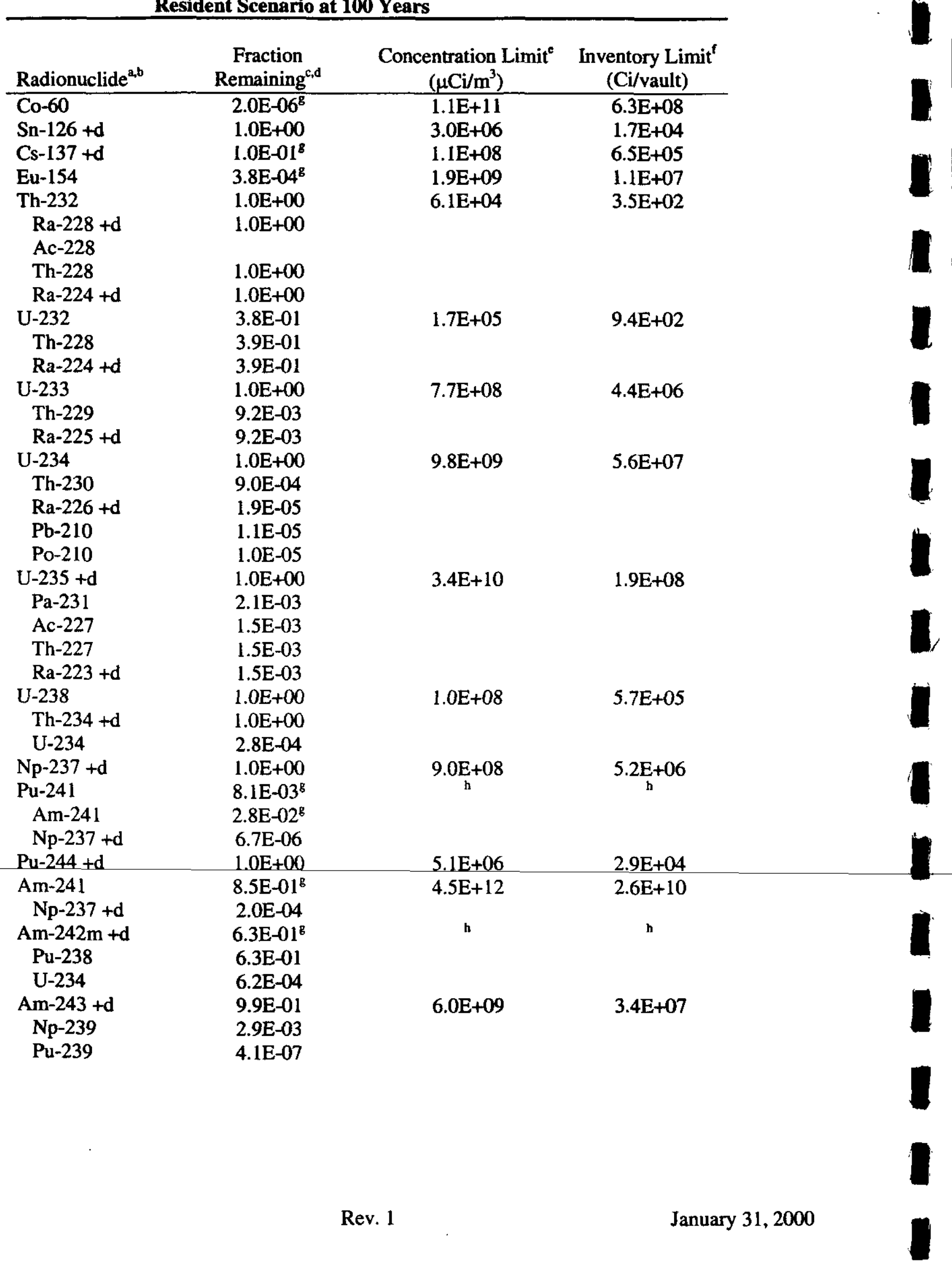


Table 6.3-11 Intruder-Based Radionuclide Disposal Limits for IL Vaults Resident Scenario at 100 Years

\begin{tabular}{|c|c|c|c|}
\hline Radionuclide $^{a, b}$ & $\begin{array}{c}\text { Fraction } \\
\text { Remaining }\end{array}$ & $\begin{array}{c}\text { Concentration Limit } \\
\left(\mu \mathrm{Ci} / \mathrm{m}^{3}\right)\end{array}$ & $\begin{array}{l}\text { Inventory Limit } \\
\text { (Ci/vault) }\end{array}$ \\
\hline $\mathrm{Cm}-245$ & $9.9 \mathrm{E}-01$ & $\mathrm{~h}$ & b \\
\hline Pu-24l & $9.8 \mathrm{E}-01$ & & \\
\hline Am-241 & $1.2 \mathrm{E}-01$ & & \\
\hline Np-237 +d & $1.7 \mathrm{E}-06$ & & \\
\hline $\mathrm{Cm}-247+\mathrm{d}$ & $1.0 \mathrm{E}+00$ & $2.0 \mathrm{E}+08$ & $1.1 \mathrm{E}+06$ \\
\hline Am-243 & $9.4 \mathrm{E}-03$ & & \\
\hline Np-239 & $9.4 \mathrm{E}-03$ & & \\
\hline Pu-239 & $1.4 \mathrm{E}-05$ & & \\
\hline $\mathrm{Cm}-248$ & $1.0 \mathrm{E}+00$ & 1.3E+09 & $7.6 \mathrm{E}+06$ \\
\hline Pu-244 & $4.2 \mathrm{E}-02$ & & \\
\hline Cf-249 & $8.2 \mathrm{E}-01$ & $2.9 E+08$ & $1.7 \mathrm{E}+06$ \\
\hline $\mathrm{Cm}-245$ & $7.4 \mathrm{E}-03$ & & \\
\hline $\mathrm{Pu}-241$ & $5.9 \mathrm{E}-03$ & & \\
\hline Am-241 & $3.9 \mathrm{E}-04$ & & \\
\hline$N p-237+d$ & $4.3 \mathrm{E}-09$ & & \\
\hline Cf- 251 & $9.3 \mathrm{E}-01^{\mathrm{g}}$ & b & h \\
\hline \multicolumn{4}{|c|}{$\begin{array}{l}\text { Indented entries are decay products of parent radionuclide that are potentially radiologically- } \\
\text { significant. } \\
\text { The notation " }+\mathrm{d} \text { " indicates that short-lived daughters were incorporated into the EDE. Dose } \\
\text { from other daughters listed is calculated explicitly. } \\
\text { Considers radioactive decay and leaching unless otherwise noted. } \\
\text { Fractions shown for radioactive daughters reflect fraction of initial activity of parent. } \\
\text { Limit on average concentration in disposed waste; obtained from Eq. } 6.3-5 \\
\text { Limit on inventory per vault; obtained from Eq. } 6.3-4 \text {, assuming a vault volume of } 5.7 \mathrm{E} 4 \mathrm{~m}^{3} \text {. } \\
\text { Only radioactive decay accounted for. } \\
\text { EDE negligible with the } 100 \mathrm{~cm} \text { shielding of intact vault. }\end{array}$} \\
\hline
\end{tabular}


Table 6.3-12 Intruder-Based Radionuclide Disposal Limits for IL Vaults Resident Scenario at 10,000 Years

\begin{tabular}{|c|c|c|c|}
\hline Radionuclide ${ }^{a b}$ & Fraction Remaining ${ }^{c, d}$ & $\begin{array}{c}\text { Concentration. Limit } \\
\left(\mu \mathrm{Ci} / \mathrm{m}^{3}\right)\end{array}$ & $\begin{array}{c}\text { Inventory Limit } \\
\text { (Ci/vault) }\end{array}$ \\
\hline $\mathrm{Co}-60$ & $0.0 \mathrm{E}+00^{8}$ & $>1 E 20$ & $>1 \mathrm{E} 20$ \\
\hline Sn-126+d & $7.4 \mathrm{E}-01$ & $1.3 \mathrm{E}+02$ & $7.5 \mathrm{E}-01$ \\
\hline Cs- $137+d$ & $1.8 \mathrm{E}-100^{\mathrm{g}}$ & $>1 E 20$ & $>1 E 20$ \\
\hline Eu-154 & $0.0 \mathrm{E}+00^{\mathrm{g}}$ & $>1 \mathrm{E} 20$ & $>1 \mathrm{E} 20$ \\
\hline Th-232 & $9.9 \mathrm{E}-01$ & $7.3 \mathrm{E}+01$ & $4.1 \mathrm{E}-01$ \\
\hline $\mathrm{Ra}-228+\mathrm{d}$ & $9.9 \mathrm{E}-01$ & & \\
\hline Th-228 & $9.9 \mathrm{E}-01$ & & \\
\hline $\mathrm{Ra}-224+\mathrm{d}$ & $9.9 \mathrm{E}-01$ & & \\
\hline $\mathrm{U}-232$ & $0.0 \mathrm{E}+00$ & $>1 E 20$ & $>1 E 20$ \\
\hline $\mathrm{Th}-228$ & $0.0 \mathrm{E}+00$ & & \\
\hline $\mathrm{Ra}-224+\mathrm{d}$ & $0.0 \mathrm{E}+00$ & & \\
\hline $\mathrm{U}-233$ & $9.6 \mathrm{E}-01$ & $1.2 \mathrm{E}+03$ & $7.0 \mathrm{E}+00$ \\
\hline Th-229 & $5.9 \mathrm{E}-01$ & & \\
\hline $\mathrm{Ra}-225+\mathrm{d}$ & $5.9 \mathrm{E}-01$ & & \\
\hline $\mathrm{U}-234$ & $9.7 \mathrm{E}-01$ & $4.3 E+03$ & $2.5 \mathrm{E}+01$ \\
\hline Th-230 & 8.5E-02 & & \\
\hline $\mathrm{Ra}-226+\mathrm{d}$ & $2.4 \mathrm{E}-02$ & & \\
\hline $\mathrm{Pb}-210$ & $2.4 \mathrm{E}-02$ & & \\
\hline Po-210 & $2.4 \mathrm{E}-02$ & & \\
\hline $\mathrm{U}-235+\mathrm{d}$ & $1.0 \mathrm{E}+00$ & $1.1 \mathrm{E}+03$ & $6.0 \mathrm{E}+00$ \\
\hline $\mathrm{Pa}-231$ & $1.9 \mathrm{E}-01$ & & \\
\hline Ac- 227 & $1.9 \mathrm{E}-01$ & & \\
\hline Th-227 & $1.9 \mathrm{E}-01$ & & \\
\hline $\mathrm{Ra}-223$ & $1.9 \mathrm{E}-01$ & & \\
\hline $\mathrm{U}-238$ & $1.0 \mathrm{E}+00$ & $8.6 \mathrm{E}+03$ & $4.9 \mathrm{E}+01$ \\
\hline Th-234 +d & $1.0 \mathrm{E}+00$ & & \\
\hline $\mathrm{U}-234$ & $2.5 \mathrm{E}-02$ & & \\
\hline $\mathrm{Np}-237+\mathrm{d}$ & $9.9 E-01$ & $1.0 \mathrm{E}+03$ & $6.0 \mathrm{E}+00$ \\
\hline $\mathrm{Pu}-241$ & $9.9 \mathrm{E}-210^{\mathrm{g}}$ & $1.6 \mathrm{E}+08$ & $8.9 \mathrm{E}+05$ \\
\hline Am-241 & $3.6 \mathrm{E}-09^{\mathrm{g}}$ & & \\
\hline $\mathrm{Np}-237+\mathrm{d}$ & $6.7 \mathrm{E}-06$ & & \\
\hline Pu-244 +d & $1.0 \mathrm{E}+00$ & $5.5 \mathrm{E}+02$ & $3.1 E+00$ \\
\hline Am-241 & $1.1 \mathrm{E}-07^{\mathrm{B}}$ & $5.2 E+06$ & $3.0 \mathrm{E}+04$ \\
\hline $\mathrm{Np}-237+\mathrm{d}$ & $2.0 \mathrm{E}-04$ & & \\
\hline$A m-242 m+d$ & $1.6 \mathrm{E}-20^{\mathrm{g}}$ & $4.7 E+09$ & $2.7 \mathrm{E}+07$ \\
\hline Pu-238 & $1.6 \mathrm{E}-20$ & & \\
\hline U-234 & $6.0 \mathrm{E}-04$ & & \\
\hline$A m-243+d$ & $3.9 \mathrm{E}-01$ & $3.3 E+03$ & $1.9 \mathrm{E}+01$ \\
\hline Np-239 & $1.4 \mathrm{E}-01$ & & \\
\hline Pu-239 & $2.1 \mathrm{E}-03$ & & \\
\hline $\mathrm{Cm}-245$ & $4.4 \mathrm{E}-01$ & $6.7 \mathrm{E}+03$ & $3.8 \mathrm{E}+01$ \\
\hline Pu-241 & $4.4 \mathrm{E}-01$ & & \\
\hline$A m-241$ & $4.6 \mathrm{E}-01$ & & \\
\hline $\mathrm{Np}-237+\mathrm{d}$ & $2.1 \mathrm{E}-03$ & & \\
\hline
\end{tabular}


Table 6.3-12 Intruder-Based Radionuclide Disposal Limits for IL Vaults Resident Scenario at 10,000 Years

\begin{tabular}{|c|c|c|c|}
\hline Radionuclide $^{\mathrm{a}, \mathrm{b}}$ & Fraction Remaining ${ }^{c, d}$ & $\begin{array}{c}\text { Concentration. Limit } \\
\left(\mu \mathrm{Ci} / \mathrm{m}^{3}\right)\end{array}$ & $\begin{array}{l}\text { Inventory Limit }{ }^{\mathrm{f}} \\
\text { (Ci/vault) }\end{array}$ \\
\hline $\mathrm{Cm}-247+\mathrm{d}$ & 9.9E-01 & $6.0 \mathrm{E}+02$ & $3.4 \mathrm{E}+00$ \\
\hline Am-243 & $6.1 \mathrm{E}-01$ & & \\
\hline Np-239 & $6.1 \mathrm{E}-01$ & & \\
\hline Pu-239 & $9.0 \mathrm{E}-02$ & & \\
\hline $\mathrm{Cm}-248$ & $9.8 \mathrm{E}-01$ & $1.4 \mathrm{E}+05$ & $8.1 E+02$ \\
\hline Pu-244 +d & $4.2 \mathrm{E}-03$ & & \\
\hline Cf-249 & $2.6 \mathrm{E}-09$ & $1.6 \mathrm{E}+05$ & $8.9 E+02$ \\
\hline $\mathrm{Cm}-245$ & $1.9 \mathrm{E}-02$ & & \\
\hline Pu-241 & $1.9 \mathrm{E}-02$ & & \\
\hline Am-241 & $2.0 \mathrm{E}-02$ & & \\
\hline$N p-237+d$ & $8.3 E-05$ & & \\
\hline Cf-251 & $4.5 \mathrm{E}-04^{\mathrm{g}}$ & $4.8 \mathrm{E}+06$ & 2.7E+04 \\
\hline \multicolumn{4}{|c|}{$\begin{array}{l}\text { Indented entries are decay products of parent radionuclide that are potentially radiologically- } \\
\text { significant. } \\
\text { The notation " }+\mathrm{d} \text { " indicates that short-lived daughters were incorporated into the EDE. Dose from } \\
\text { other daughters listed is calculated explicitly. } \\
\text { Considers radioactive decay and leaching unless otherwise noted. } \\
\text { Fractions shown for radioactive daughters reflect fraction of initial activity of parent. } \\
\text { Limit on average concentration in disposed waste; obtained from Eq. } 6.3-5 \\
\text { Limit on inventory per vault; obtained from Eq. } 6.3-4 \text {, assuming a vault volume of } 5.7 \mathrm{E} 4 \mathrm{~m}^{3} \text {. } \\
\text { Only radioactive decay accounted for. }\end{array}$} \\
\hline
\end{tabular}


The assumption that residence on top of exposed waste could occur at 10,000 years after disposal may also be pessimistic for the IL vaults. Even if the top layer of the earthen cover would erode to the level of the gravel layer by this time, which would occur only if the erosion rate was comparable to the value presently observed for agriculture lands at the SRS, but was considerably greater than the erosion rate for natural.forests at the site, the gravel layer presumably would be quite resistant to further erosion. Since the top of the gravel layer will lie about $3.5 \mathrm{~m}$ above the top layer of waste and an excavation for a home is assumed to extend no more than $3 \mathrm{~m}$ below the ground surface, an excavation at 10,000 years probably would not extend to the depth of waste, and the additional shielding provided by the remaining layer of uncontaminated material between the bottom of the excavation and the waste has not been taken into account in the dose analysis

In contrast to the dose analysis for the agriculture scenario, there is no need to perform a dose analysis for the resident scenario at times beyond the time at which residence on top of exposed waste first becomes credible. At later times, the top layer of waste presumably would begin to weather to soil-equivalent material and the agriculture scenario, which always results in a higher dose per unit concentration of radionuclides, then becomes the scenario of concern.

\subsubsection{Low-Activity Waste Vaults}

As described previously, the LAW vaults will be constructed with a concrete roof of average thickness about $50 \mathrm{~cm}$, but without a layer of uncontaminated grout above the waste. This thickness of shielding would apply to the resident scenario for the LAW vaults at 100 years after disposal when the concrete roof is assumed to be intact and impenetrable by normal excavation procedures.

As described in Appendix C.3-3, the nominal thickness of shielding provided by the concrete roof for the LAW vaults is assumed to be $45 \mathrm{~cm}$. This value is slightly less than the planned thickness of the roof and is intended to take into account the somewhat reduced shielding provided by the waste itself due to the presence of void spaces in these disposal units.

The results of the dose analysis for the resident scenario at 100 years after disposal are given in Table 6.3-13. The results are calculated using Eqs. 6.3-4 and 6.3-5, and the SDCFs are those for $45 \mathrm{~cm}$ of shielding in Table 6.3-2. As with the IL vaults, the fraction remaining was calculated using PORFLOW or by assuming radioactive decay alone; the geometrical reduction factor of 0.8 (Table 6.3.4) was used.

The assumption that the resident scenario could occur at 100 years after disposal probably is reasonable for the LAW vaults, because the thickness of the earthen cover above the vaults is approximately the same as the presumed maximum depth of an excavation in constructing a home. Therefore, significant erosion of the cover material would not be required in order for an excavation to uncover the roof of the vaults.

The second bounding case for the resident scenario, based on an assumption that the intruder's home is located immediately on top of exposed but impenetrable waste in a disposal unit is not relevant for the LAW vaults. This bounding case occurs only at a time when the concrete roof has failed and excavation to the depth of the waste could occur. As described previously, this time at which the concrete roof collapses is expected to be about 3,000 years after disposal for the LAW vaults. But another approximately 2,000 years is required for the large pieces of rubble to have degraded to a point that excavation through the failed roof is credible. By this time (i.e., 5,000 years), the waste forms and waste packages themselves presumably will have degraded to soil-equivalent material, because the waste in the LAW vaults will not be grouted. Therefore, at times after the concrete roof collapses, the agriculture scenario would become the scenario of concern and the resident scenario would no longer be relevant. 
Table 6.3-13 Intruder-Based Radionuclide Disposal Limits for LAW Vaults Resident Scenario at 100 Years

\begin{tabular}{|c|c|c|c|}
\hline Radionuclide $^{a, b}$ & $\begin{array}{c}\text { Fraction } \\
\text { Remaining }\end{array}$ & $\begin{array}{c}\text { Concentration Limit } \\
\left(\mu \mathrm{Ci} / \mathrm{m}^{\mathrm{e}}\right)\end{array}$ & $\begin{array}{c}\text { Inventory Limit } \\
\text { (Ci/vault) }\end{array}$ \\
\hline $\mathrm{Co}-60$ & $1.95 \mathrm{E}-06^{\mathrm{B}}$ & $7.3 \mathrm{E}+08$ & $3.5 \mathrm{E}+07$ \\
\hline $\mathrm{Nb}-94$ & $9.97 \mathrm{E}-01$ & $4.8 E+03$ & $2.3 E+02$ \\
\hline$S n-126+d$ & $9.99 \mathrm{E}-01$ & $5.7 \mathrm{E}+03$ & $2.8 \mathrm{E}+02$ \\
\hline $\mathrm{Cs}-137+d$ & $1.01 \mathrm{E}-01^{\mathrm{g}}$ & $1.9 E+05$ & $9.0 \mathrm{E}+03$ \\
\hline Eu-152 & $5.68 \mathrm{E}-03$ & $7.8 \mathrm{E}+05$ & $3.7 \mathrm{E}+04$ \\
\hline Eu-154 & $3.80 \mathrm{E}-04$ & $1.0 \mathrm{E}+07$ & $5.0 \mathrm{E}+05$ \\
\hline Th-232 & $1.00 \mathrm{E}+00$ & $1.1 \mathrm{E}+03$ & $5.3 \mathrm{E}+01$ \\
\hline $\mathrm{Ra}-228+\mathrm{d}$ & $9.99 \mathrm{E}-01$ & & \\
\hline Ac-228 & $9.99 \mathrm{E}-01$ & & \\
\hline Th-228 & $9.96 \mathrm{E}-01$ & & \\
\hline $\mathrm{Ra}-224+\mathrm{d}$ & $9.97 \mathrm{E}-01$ & & \\
\hline U-232 & $3.82 \mathrm{E}-01$ & $3.5 E+03$ & 1.7E+02 \\
\hline Th-228 & $3.92 \mathrm{E}-01$ & & \\
\hline $\mathrm{Ra}-224+\mathrm{d}$ & $3.93 \mathrm{E}-01$ & & \\
\hline U-233 & $1.00 \mathrm{E}+00$ & $5.3 E+06$ & $2.5 E+05$ \\
\hline Th-229 & $9.22 \mathrm{E}-03$ & & \\
\hline $\mathrm{Ra}-225+\mathrm{d}$ & $9.20 \mathrm{E}-03$ & & \\
\hline $\mathrm{U}-234$ & $1.00 \mathrm{E}+00$ & $1.1 E+08$ & $5.2 E+06$ \\
\hline Th-230 & $8.99 \mathrm{E}-04$ & & \\
\hline $\mathrm{Ra}-226+\mathrm{d}$ & $1.95 \mathrm{E}-05$ & & \\
\hline $\mathrm{Pb}-210$ & $1.10 \mathrm{E}-05$ & & \\
\hline Po-210 & $1.06 \mathrm{E}-05$ & & \\
\hline $\mathrm{U}-235+\mathrm{d}$ & $1.00 \mathrm{E}+00$ & $3.1 E+06$ & $1.5 \mathrm{E}+05$ \\
\hline Th-231 & & & \\
\hline $\mathrm{Pa}-231$ & $2.10 \mathrm{E}-03$ & & \\
\hline Ac- -227 & $1.48 \mathrm{E}-03$ & & \\
\hline Th-227 & $1.47 \mathrm{E}-03$ & & \\
\hline $\mathrm{Ra}-223$ & $1.47 \mathrm{E}-03$ & & \\
\hline $\mathrm{U}-238$ & $1.00 \mathrm{E}+00$ & $4.2 \mathrm{E}+05$ & $2.0 \mathrm{E}+04$ \\
\hline Th-234 +d & $1.00 \mathrm{E}+00$ & & \\
\hline U-234 & $2.83 \mathrm{E}-04$ & & \\
\hline $\mathrm{Np}-237+\mathrm{d}$ & $1.00 \mathrm{E}+00$ & $2.7 \mathrm{E}+05$ & $1.3 E+04$ \\
\hline Pu-241 & $8.13 E-03^{g}$ & & \\
\hline Am-241 & $2.84 \mathrm{E}-02^{\mathrm{g}}$ & & \\
\hline $\mathrm{Np}-237+\mathrm{d}$ & $6.73 E-06$ & & \\
\hline $\mathrm{Pu}-244+\mathrm{d}$ & $1.00 \mathrm{E}+00$ & $2.4 \mathrm{E}+04$ & $1.1 E+03$ \\
\hline Am-241 & $8.52 \mathrm{E}-01^{\mathrm{g}}$ & $1.4 E+09$ & $6.5 \mathrm{E}+07$ \\
\hline $\mathrm{Np}-237+\mathrm{d}$ & $2.02 \mathrm{E}-04$ & & \\
\hline$A m-243+d$ & $9.91 \mathrm{E}-01$ & $1.1 \mathrm{E}+06$ & $5.4 \mathrm{E}+04$ \\
\hline $\mathrm{Np}-239$ & $9.95 \mathrm{E}-01$ & & \\
\hline $\mathrm{Pu}-239$ & $2.85 \mathrm{E}-03$ & & \\
\hline
\end{tabular}


Table 6.3-13 Intruder-Based Radionuclide Disposal Limits for LAW Vaults Resident Scenario at 100 Years

\begin{tabular}{|c|c|c|c|}
\hline Radionuclide $^{\mathrm{a}, \mathrm{b}}$ & $\begin{array}{c}\text { Fraction } \\
\text { Remaining }\end{array}$ & $\begin{array}{l}\text { Concentration Limit } \\
\left(\mu \mathrm{Ci} / \mathrm{m}^{3}\right)\end{array}$ & $\begin{array}{l}\text { Inventory Limit } \\
\text { (Ci/vault) }\end{array}$ \\
\hline $\mathrm{Cm}-245$ & $9.92 \mathrm{E}-01$ & $2.4 \mathrm{E}+07$ & $1.2 \mathrm{E}+06$ \\
\hline Pu-241 & $9.85 \mathrm{E}-01$ & & \\
\hline Am-241 & $1.19 \mathrm{E}-01$ & & \\
\hline Np-237+d & $1.68 \mathrm{E}-06$ & & \\
\hline $\mathrm{Cm}-247+d$ & $1.00 \mathrm{E}+00$ & $9.8 E+04$ & 4.7E+03 \\
\hline Am-243 & $9.36 \mathrm{E}-03$ & & \\
\hline $\mathrm{Np}-239$ & $9.39 \mathrm{E}-03$ & & \\
\hline Pu-239 & $1.35 \mathrm{E}-05$ & & \\
\hline $\mathrm{Cm}-248$ & $1.00 \mathrm{E}+00$ & $3.0 E+10$ & $1.5 E+09$ \\
\hline Pu-244 & $8.55 \mathrm{E}-07$ & & \\
\hline Cf-249 & $8.20 \mathrm{E}-01^{\mathrm{g}}$ & $1.3 E+05$ & $6.2 \mathrm{E}+03$ \\
\hline $\mathrm{Cm}-245$ & $7.37 \mathrm{E}-03$ & & \\
\hline $\mathrm{Pu}-241$ & $5.94 \mathrm{E}-03$ & & \\
\hline Am-241 & $3.94 \mathrm{E}-04$ & & \\
\hline $\mathrm{Np}-237+\mathrm{d}$ & $9.61 \mathrm{E}-09$ & & \\
\hline Cf -251 & $9.26 \mathrm{E}-01^{\mathrm{g}}$ & $4.4 \mathrm{E}+06$ & $2.1 E+05$ \\
\hline \multicolumn{4}{|c|}{$\begin{array}{l}\text { Indented entries are decay products of parent radionuclide that are potentially } \\
\text { radiologically-significant. }\end{array}$} \\
\hline \multirow{3}{*}{\multicolumn{4}{|c|}{$\begin{array}{l}\text { The notation " }+d \text { " indicates that short-lived daughters were incorporated into the } \\
\text { EDE. Dose from other daughters listed is calculated explicitly. } \\
\text { Considers radioactive decay and leaching unless otherwise noted. }\end{array}$}} \\
\hline & & & \\
\hline & & & \\
\hline \multirow{2}{*}{\multicolumn{4}{|c|}{$\begin{array}{l}\text { Fractions shown for radioactive daughters reflect fraction of initial activity of parent. } \\
\text { Limit on average concentration in disposed waste; obtained from Eq. 6.3-5 }\end{array}$}} \\
\hline & & & \\
\hline \multicolumn{4}{|c|}{$\begin{array}{l}\text { Limit on inventory per vault; obtained from Eq. } 6.3-4 \text {, assuming a vault volume of } \\
4.8 \mathrm{E} 4 \mathrm{~m}^{3} \text {. }\end{array}$} \\
\hline $\begin{array}{l}\text { Only radioactiv } \\
\text { Onli }\end{array}$ & accounted for & & \\
\hline
\end{tabular}




\subsubsection{Slit Trenches}

No engineered barriers potentially shield the waste in the slit trenches once the soil cover is removed; therefore, only one bounding resident scenario applies to these units. In this bounding case, excavation through the 3-m cover is assumed to take place at the end of institutional control (at 100 years), and a house is assumed to be built directly on the trenches filled with waste. However, the clean soil covering waste in the trenches provides more than 100 centimeters of shielding material over the waste after the 3-m excavation. Inventory and concentration limits for the very-low-activity waste units (i.e., slit trenches) at 100 years were derived by application of the models represented by Eqs. 6.3-4 and 6.3-5. The fractions remaining in the slit trenches at 100 years were calculated using PORFLOW for most radionuclides. For those radionuclides that were not evaluated in the water resource impacts analysis, and thus not evaluated using PORFLOW, leaching was neglected and the fractions remaining were estimated by evaluating radioactive decay alone. The SDCFs were taken from Table $6.3-2$, assuming $100-\mathrm{cm}$ of shielding. The geometrical reduction factor of 0.6 (Table 6.3-4) was used. The results of this analysis are given in Table 6.3-14.

\subsubsection{Naval Reactor Waste}

The naval reactor components are encased in carbon steel or low-alloy steel waste disposal containers, or casks, which are closed by a gasket or a weld (Sect. 3.3.5.4). These casks are disposed in a "pad" at the E Area LLWF which is assumed to contain 100 casks. There is no standard disposal container due to the variety of components stored in the containers; therefore, precisely accounting for shielding afforded by the waste form or cask is not possible.

For the analysis of the resident scenario for the naval reactor waste, federal requirements for transportation of hazardous materials, specified in 49 CFR Part 173, were relied upon for estimating exposure to photon emissions from radionuclides projected to be present in the naval reactor waste to be disposed of at $\mathrm{E}$ Area. These regulations were useful in estimating an upper bound on the exposure rate at the surface of the casks, since the casks are transported to the SRS and therefore must conform to these requirements.

Before this analysis was conducted, the radionuclides of potential importance in the resident scenario were identified by calculating inventory limits for the 100 -cask pad containing naval reactor wastes, assuming no shielding existed for the naval reactor waste, and applying the models described in Eqs. 6.34 and 6.3-5, as well as the "no-shielding" SDCFs in Table 6.3-2. Comparison of these calculated limits with the projected inventory for the 100-cask pad from Appendix A indicated that the only radionuclides of potential concern to an intruder who lives on top of the waste pad at 100 years are ${ }^{60} \mathrm{Co}$ and ${ }^{94} \mathrm{Nb}$. Calculated inventory limits for all other radionuclides, assuming no shielding of any type at 100 years, were at least an order of magnitude less than the projected inventory limits for the naval reactor waste.

According to 49 CFR Part 173, the external dose rate at the surface of a waste cask may not exceed 0.2 $\mathrm{rem} / \mathrm{hr}(200 \mathrm{mrem} / \mathrm{hr})$. Measurements that have been done on selected naval reactor waste casks indicate that the external dose rate is less than $10 \mathrm{mrem} / \mathrm{hr}$. The following discussion will show that shielding provided by the waste casks and waste components must be significant to satisfy these requirements based on the projected inventories provided in Appendix A. 
Table 6.3-14 Intruder-Based Radionuclide Disposal Limits for Slit Trenches - Resident Scenario at 100 Years

\begin{tabular}{|c|c|c|c|}
\hline \multirow[b]{2}{*}{ Radionuclide $^{\mathrm{a}, \mathrm{b}}$} & \multicolumn{3}{|c|}{ Concentration } \\
\hline & $\begin{array}{c}\text { Fraction } \\
\text { Remaining }\end{array}$ & $\begin{array}{c}\text { Limit } \\
\left(\mu \mathrm{Ci} / \mathrm{m}^{3}\right)\end{array}$ & $\begin{array}{l}\text { Inventory Limit }{ }^{\mathrm{f}} \\
\text { (Ci/5 trenches) }\end{array}$ \\
\hline${ }^{60} \mathrm{Co}$ & $2.0 \mathrm{E}-06^{\mathrm{g}}$ & $7.4 \mathrm{E}+10$ & $2.1 \mathrm{E}+09$ \\
\hline${ }^{126} \mathrm{Sn}+\mathrm{d}$ & $1.0 \mathrm{E}+00$ & $2.0 \mathrm{E}+06$ & $5.7 \mathrm{E}+04$ \\
\hline${ }^{137} \mathrm{Cs}+\mathrm{d}$ & $1.0 \mathrm{E}-01^{\mathrm{g}}$ & $7.6 \mathrm{E}+07$ & $2.2 \mathrm{E}+06$ \\
\hline${ }^{154} \mathrm{Eu}$ & $3.8 \mathrm{E}-04^{\mathrm{g}}$ & $1.3 E+09$ & $3.6 \mathrm{E}+07$ \\
\hline${ }^{232} \mathrm{U}$ & $3.8 \mathrm{E}-01$ & $1.1 \mathrm{E}+05$ & $3.2 \mathrm{E}+03$ \\
\hline${ }^{228} \mathrm{Th}$ & $3.9 \mathrm{E}-01$ & & \\
\hline${ }^{224} \mathrm{Ra}+\mathrm{d}$ & $3.9 \mathrm{E}-01$ & & \\
\hline${ }^{233} \mathrm{U}$ & $1.0 \mathrm{E}+00$ & $5.2 E+08$ & $1.5 \mathrm{E}+07$ \\
\hline${ }^{229} \mathrm{Th}$ & $9.2 \mathrm{E}-03$ & & \\
\hline${ }^{225} \mathrm{Ra}+\mathrm{d}$ & $9.2 \mathrm{E}-03$ & & \\
\hline${ }^{234} U$ & $1.0 \mathrm{E}+00$ & $6.6 \mathrm{E}+09$ & $1.9 E+08$ \\
\hline${ }^{230} \mathrm{Th}$ & $9.0 \mathrm{E}-04$ & & \\
\hline${ }^{226} \mathrm{Ra}+\mathrm{d}$ & $1.9 \mathrm{E}-05$ & & \\
\hline${ }^{210} \mathrm{~Pb}$ & $1.1 \mathrm{E}-05$ & & \\
\hline${ }^{210} \mathrm{Po}$ & $1.0 \mathrm{E}-05$ & & \\
\hline${ }^{235} U+d$ & $1.0 \mathrm{E}+00$ & $2.3 \mathrm{E}+10$ & $6.5 E+08$ \\
\hline${ }^{231} \mathrm{~Pa}$ & $2.1 \mathrm{E}-03$ & & \\
\hline${ }^{227} \mathrm{Ac}$ & $1.5 \mathrm{E}-03$ & & \\
\hline${ }^{227} \mathrm{Th}$ & $1.5 \mathrm{E}-03$ & & \\
\hline${ }^{223} \mathrm{Ra}$ & $1.5 \mathrm{E}-03$ & & \\
\hline${ }^{238} \mathrm{U}$ & $1.0 \mathrm{E}+00$ & $6.7 \mathrm{E}+07$ & $1.9 \mathrm{E}+06$ \\
\hline${ }^{234} \mathrm{Th}+\mathrm{d}$ & $1.0 \mathrm{E}+00$ & & \\
\hline${ }^{234} \mathrm{U}$ & $2.8 \mathrm{E}-04$ & & \\
\hline $\begin{array}{l}\text { Indented entries a } \\
\text { radiologically sig }\end{array}$ & products of pa & dionuclide $t$ & potentially \\
\hline The notation " $+\mathrm{d}$ ' & tes that short-liv & ghters were & orated into the EDE. \\
\hline Dose from other & rs listed is calcul & xplicitly. & \\
\hline Considers radioao & cay and leaching & s otherwise $\mathrm{r}$ & \\
\hline Fractions shown $\mathrm{f}$ & active daughter & ct fraction of & I activity of parent. \\
\hline Limit on average & tration in dispose & te; obtained & Eq. $6.3-5$ \\
\hline $\begin{array}{l}\text { Limit on inventor } \\
28.800 \mathrm{~m}^{3} \text { for } 5\end{array}$ & trenches; obtain & n Eq. 6.3-4, & ing a volume of \\
\hline nly radioactive & nted & & \\
\hline
\end{tabular}


From Appendix A, the projected inventory of ${ }^{60} \mathrm{Co}$ in 100 waste casks is reported as $2.26 \times 10^{5} \mathrm{Ci}$, which is an average of $2.26 \times 10^{3} \mathrm{Ci}$ per cask. In reality, some casks may contain more than $2.26 \times 10^{3} \mathrm{Ci}$, and some may contain less. But all casks must conform to the exposure rate requirements of less than or equal to $0.2 \mathrm{rem} / \mathrm{hr}$ at the surface. If we assume, for simplicity, that the average activity is in the form of a point source at a distance of $1 \mathrm{~m}$ from the surface of the waste cask, then the external dose rate at the surface of the cask can be estimated from the known spectrum of photons emitted in the decay of ${ }^{60} \mathrm{Co}$ and the amount of shielding provided by the walls of the cask. At a distance of $1 \mathrm{~m}$ from a point source, the unshielded external dose rate in air per unit activity of ${ }^{60} \mathrm{Co}$ has been calculated from the decay data of Kocher (1981) as $1.4 \mathrm{rem} / \mathrm{h}$ per $\mathrm{Ci}$ (Unger and Trubey 1982). The minimum container closure weld thickness of the casks is 1.64 inches or $4 \mathrm{~cm}$ (Fig. 3.3-1), which was also proposed as a minimum container thickness (Dedrick, 1994). From Fig. 13 of NCRP (1976), a thickness of $4 \mathrm{~cm}$ of iron, which is a reasonable approximation for the shielding provided by carbon steel, reduces the external dose rate from ${ }^{60} \mathrm{Co}$ by a factor of 0.4 . Thus, the estimated dose rate for the simplified case considered here is $\left(2.26 \times 10^{3} \mathrm{Ci}\right) \times(1.4 \mathrm{rem} / \mathrm{h}$ per $\mathrm{Ci}) \times(0.4)=1266 \mathrm{rem} / \mathrm{h}$. This estimate far exceeds the $0.2 \mathrm{rem} / \mathrm{hr}$ acceptance criterion for the waste casks.

There are two possible explanations for the high estimate of external dose given above. The first is that the stated inventory of ${ }^{60} \mathrm{Co}$ in the waste is a highly conservative bounding inventory. If such a waste inventory were truly to be shipped, the disposal container, or the shipping/storage/disposal container package, must be made much thicker than the $4 \mathrm{~cm}$ thickness minimum. Indeed, to achieve $200 \mathrm{mrem} / \mathrm{h}$ at the container surface, a reduction factor of $1.58 \times 10^{-4}$ is needed, if credit is not taken for selfattenuation by the activation product matrix, or for a thicker container. The second explanation for the high estimated dose rate based on the projected inventory in Appendix A is that the Naval Reactor waste is mostly in the form of solid activated metals, and the shielding provided by the waste form matrix was not taken into account in the simple calculation given above. Per 10 CFR Part 61, NRC recommends using a reduction in dose by a factor of 10 for activated metals due to their inherent shielding properties. Taking credit for the activation waste form using this factor still does not achieve a credible dose rate, suggesting that self-attenuation and effective thickness of the containers are likely much greater than assumed for this calculation. Recent detailed shielding calculations were conducted by Rosenberger (1997) for the naval reactor waste casks. Assuming waste radionuclide inventories are uniformly distributed inside a $2.5 \mathrm{~m} \mathrm{x} 4.6 \mathrm{~m}(\mathrm{D} \mathrm{x} \mathrm{H})$ waste cask of $4 \mathrm{~cm}$ thickness, the results showed that the dose rate $30 \mathrm{~cm}$ from the top of the cask would be about $170 \mathrm{rem} / \mathrm{hr}$, or about $1 / 30$ th of that calculated by the simplified model above.

A simplified approach is used to obtain a conservative, upper-bound estimate of the external dose that could be received by an inadvertent intruder at 100 years after disposal, the presumed end of institutional control, which is the earliest time that exposures could occur. This approach is described below and will show that a container thickness sufficient to keep initial dose below $200 \mathrm{mrem} / \mathrm{h}$ at the container surface will be adequate for the residential intruder scenario at the end of institutional control.

Conservative, upper-bound estimates of external doses from ${ }^{60} \mathrm{Co}$ and ${ }^{94} \mathrm{Nb}$ at 100 years after disposal are obtained as follows. First, a conservative assumption is made that the external dose rate at the surface of a waste cask at the present time is $200 \mathrm{mrem} / \mathrm{h}$, which is the limit for any cask specified in 49 CFR Part 173. Next, it is assumed that all of the dose rate of $200 \mathrm{mrem} / \mathrm{h}$ is entirely due to ${ }^{60} \mathrm{Co}$ at the time of disposal, due to its relatively high projected inventory (Appendix A) and high energies and intensities of the emitted photons (Kocher 1981). This assumption also is conservative (i.e., the dose rate from ${ }^{60} \mathrm{Co}$ is overestimated), because a substantial fraction of the extemal dose at the present time is due to other photon-emitting radionuclides in the waste. 
If the dose rate from ${ }^{60} \mathrm{Co}$ at the present time is assumed to be $200 \mathrm{mrem} / \mathrm{h}$, the dose rate at 100 years after disposal would be reduced by a factor of $1.95 \times 10^{-6}$, based on the known half-life of 5.27 years. Thus, a conservative, upper-bound estimate of the external dose rate from ${ }^{60} \mathrm{Co}$ at 100 years after disposal would be $(200 \mathrm{mrem} / \mathrm{h}) \times\left(1.95 \times 10^{-6}\right)=3.9 \times 10^{-4} \mathrm{mrem} / \mathrm{h}$.

In order to estimate the contributions to external dose from ${ }^{94} \mathrm{Nb}$ at 100 years after disposal, we assume that the activities of ${ }^{60} \mathrm{Co}$ and ${ }^{94} \mathrm{Nb}$ in disposed waste are in the same proportions as the total activities of these radionuclides in all casks given in Appendix A. That is, the ratio of the activities of ${ }^{60} \mathrm{Co}$ and ${ }^{94} \mathrm{Nb}$ in casks are assumed to be $\left(2.26 \times 10^{5}\right):(10.8)$ at the time of disposal. Then, taking into account the decay of ${ }^{60} \mathrm{Co}$ after 100 years $\left({ }^{94} \mathrm{Nb}\right.$ experiences negligible decay over this time), the activity ratio at 100 years would be $(0.44):(10.8)$. It is then assumed that each radionuclide is a point source, in which case the dose rate per unit activity of each radionuclide calculated by Unger and Trubey (1982) can be used. The values in units of mrem $/ \mathrm{h}$ per $\mathrm{Ci}$ are 1,400 for ${ }^{60} \mathrm{Co}$ and 980 for ${ }^{94} \mathrm{Nb}$. We further assume that the only shielding between the source and receptor locations is the $4 \mathrm{~cm}$ minimum carbon steel container thickness and use the transmission curves for iron in Fig. 13 of NCRP (1976) to estimate the reduction in dose rate due to shielding. The latter assumption provides conservative overestimates of dose rate (i.e., underestimates of shielding) for ${ }^{94} \mathrm{Nb}$, because the actual amount of shielding will be greater than $4 \mathrm{~cm}$ and the transmission of photons from ${ }^{94} \mathrm{Nb}$ relative to the transmission of photons from ${ }^{60} \mathrm{Co}$ decreases as the amount of shielding increases. The transmission (shielding) factor for ${ }^{60} \mathrm{Co}$ for $4 \mathrm{~cm}$ of iron is obtained directly from Fig. 13 of NCRP (1976) as 0.4 , respectively, and the value for ${ }^{94} \mathrm{Nb}$ is estimated by interpolation, based on the known photon spectrum for this radionuclide, as 0.32 . With the information on dose rate per unit activity and transmission through $4 \mathrm{~cm}$ of iron given above, a conservative, upperbound estimate of the external dose rate from ${ }^{94} \mathrm{Nb}$ can be obtained from the previous upper-bound estimate of the dose rate from ${ }^{60} \mathrm{Co}$ of $3.9 \times 10^{-4} \mathrm{mrem} / \mathrm{h}$ as $\left(3.9 \times 10^{-4}\right) \times(10.8 / 0.44) \times(980 / 1,400) \times$ $(0.32 / 0.4)=5.36 \times 10^{-3} \mathrm{mrem} / \mathrm{h}$.

Thus, a conservative, upper-bound estimate of external dose rate next to a waste cask at 100 years after disposal of $5.75 \times 10^{-3} \mathrm{mrem} / \mathrm{h}$, which is due mostly to ${ }^{94} \mathrm{Nb}$. This estimate is conservative because (1) the dose rate from ${ }^{60} \mathrm{Co}$ alone is likely overestimated, based on the acceptance criterion on external dose rate for the waste casks of $200 \mathrm{mrem} / \mathrm{h}$ and measured dose rates for casks at the present time of less than $10 \mathrm{mrem} / \mathrm{h}$, and (2) the transmission of photons from ${ }^{94} \mathrm{Nb}$ through all shielding materials relative to the transmission for ${ }^{60} \mathrm{Co}$ has been overestimated. The analysis would provide an underestimate of the dose rate only if the activity of ${ }^{94} \mathrm{Nb}$ in the waste relative to the activity of ${ }^{60} \mathrm{Co}$ has been greatly underestimated.

The conservative, upper-bound estimate of external dose rate obtained above corresponds to a dose from continuous exposure of 50 mrem per year. If an inadvertent intruder were located next to an "average" waste cask continuously throughout the year, with no additional shielding assumed, the conservative, upper-bound estimate of the external dose rate indicates that the dose received from external exposure would be less than the dose limit of 100 mrem per year in the performance measure for inadvertent intruder analysis (DOE 1999). Thus, although the foregoing analysis is not intended to provide an accurate estimate of external dose at future times, the analysis clearly shows that the external dose to an inadvertent intruder due to exposure to intact waste casks at the end of institutional control should not be of concern in regard to meeting the performance objectives for disposal of the Naval Reactor wastes. External dose to an inadvertent intruder could be of concem only if the container thickness fails to provide adequate shielding at the start of institutional control or if the inventory of ${ }^{94} \mathrm{Nb}$ in the waste casks relative to the inventory of ${ }^{60} \mathrm{Co}$ were much larger than reported in Appendix A. 


\subsubsection{Intimately-Mixed Cement-Stabilized Waste Units}

No engineered barriers potentially shield the waste once the soil cover is removed from the intimatelymixed cement-stabilized waste units; therefore, only one bounding resident scenario applies to these units. In this bounding case, excavation through the 3-m cover is assumed to take place at the end of institutional control (at 100 years), and a house is assumed to be built directly on the trenches filled with the waste forms. However, the clean soil covering waste in the trenches provides more than 100 centimeters of shielding material over the waste. Inventory and concentration limits for the intimately-mixed cement-stabilized waste units at 100 years were derived by application of the models represented by Eqs. 6.3-4 and 6.3-5. The fractions remaining in this cementitious waste form at 100 years were calculated using PORFLOW for most radionuclides. For those radionuclides that were not evaluated in the water resource impacts analysis, and thus not evaluated using PORFLOW, leaching was neglected and the fractions remaining were estimated by evaluating radioactive decay alone. The SDCFs were taken from Table 6.3-2, assuming $100-\mathrm{cm}$ of shielding. The geometrical reduction factor of 0.6 (Table 6.3-4) was used. The results of this analysis are given in Table 6.3-15.

\subsubsection{Cement-Stabilized Encapsulated Waste Units}

Evaluation of the resident scenario is handled identically to that of the intimately-mixed cement-stabilized waste units; excavation through the 3-m cover is assumed to take place at the end of institutional control (at 100 years), and a house is assumed to be built directly on the trenches filled with the waste forms. However, the clean soil covering waste in the trenches provides more than 100 centimeters of shielding material over the waste. Although the waste in these units is encapsulated in a $0.3-\mathrm{m}$ "shell" of concrete initially, this shell is assumed to degrade completely by 300 years. Very little leaching occurs during the 300-year period that the shell is intact, and for most radionuclides emitting potentially-significant photons (except, for example, ${ }^{60} \mathrm{Co}$ and ${ }^{137} \mathrm{Cs}$ ), radioactive decay is minimal. Thus, the fraction remaining at 100 years is very similar to the fraction remaining at 300 years for most radionuclides. For those where there is a significant discrepancy (e.g., ${ }^{60} \mathrm{Co}$ and ${ }^{137} \mathrm{Cs}$ ), the 100-year fraction remaining leads to an overestimate of exposure, and thus leads to conservative estimates of inventory and concentration limits.

Inventory and concentration limits for the cement-stabilized encapsulated waste units at 100 years were derived by application of the models represented by Eqs. 6.3-4 and 6.3-5. The fractions remaining in this waste form at 100 years were calculated using PORFLOW for most radionuclides. For those radionuclides that were not evaluated in the water resource impacts analysis, and thus not evaluated using PORFLOW, leaching was neglected and the fractions remaining were estimated by evaluating radioactive decay alone. The SDCFs were taken from Table $6.3-2$, assuming $100-\mathrm{cm}$ of shielding. The geometrical reduction factor of 0.6 (Table 6.3-4) was used. The results of this analysis are given in Table 6.3-16.

\subsubsection{Dose Analysis for Post-Drilling Scenario}

The SDCFs obtained from the model for estimating dose to inadvertent intruders for the post-drilling scenario are summarized in Table 6.3-3. The remainder of this section discusses application of the SDCFs in Table 6.3-3 to the different disposal units in E Area. The model for estimating dose and limits on concentrations and inventories of radionuclides is given by Eqs. 6.3-4 and 6.3-5, except the geometrical correction factor $(G)$ is not relevant for the post-drilling scenario when drilling is assumed to occur through the waste, and thus is assigned a value of one. The post-drilling scenario is potentially relevant for any disposal units for which drilling into the waste may occur before the agriculture scenario becomes credible. In the IL vaults, the waste will be grouted, and drilling into the waste is not expected to be a credible occurrence until the grout essentially has weathered to soil-equivalent material, at which time the agriculture scenario becomes credible. Therefore, since the agriculture scenario always results in more restrictive. 
Table 6.3-16 Intruder-Based Radionuclide Disposal Limits for CementStabilized Encapsulated Waste - Resident Scenario at 100 Years

\begin{tabular}{|c|c|c|c|}
\hline \multirow[b]{2}{*}{ Radionuclide $a, b$} & \multicolumn{3}{|c|}{ Concentration } \\
\hline & $\begin{array}{c}\text { Fraction } \\
\text { Remaining }\end{array}$ & $\underset{\left(\mu \mathrm{Ci} / \mathrm{m}^{3}\right)}{\operatorname{Limit}}$ & $\begin{array}{l}\text { Inventory Limit }{ }^{\mathrm{f}} \\
(\mathrm{C} \mathrm{i} / 5 \text { trenches })\end{array}$ \\
\hline${ }^{60} \mathrm{Co}$ & $2.0 \mathrm{E}-06^{\mathrm{B}}$ & $7.4 \mathrm{E}+10$ & $2.1 \mathrm{E}+09$ \\
\hline${ }^{126} \mathrm{Sn}+\mathrm{d}$ & $1.0 \mathrm{E}+00$ & $2.0 \mathrm{E}+06$ & $5.7 E+04$ \\
\hline${ }^{137} \mathrm{Cs}+\mathrm{d}$ & $1.0 \mathrm{E}-01^{\mathrm{g}}$ & $7.6 \mathrm{E}+07$ & $2.2 \mathrm{E}+06$ \\
\hline${ }^{154} \mathrm{Eu}$ & $3.8 \mathrm{E}-04^{\mathrm{g}}$ & $1.3 \mathrm{E}+09$ & $3.6 \mathrm{E}+07$ \\
\hline${ }^{232} \mathrm{U}$ & $3.8 \mathrm{E}-01$ & $1.1 \mathrm{E}+05$ & $3.2 \mathrm{E}+03$ \\
\hline${ }^{228} \mathrm{Th}$ & $3.9 \mathrm{E}-01$ & & \\
\hline${ }^{224} \mathrm{Ra}+\mathrm{d}$ & $3.9 \mathrm{E}-01$ & & \\
\hline${ }^{233} \mathrm{U}$ & $1.0 \mathrm{E}+00$ & $5.2 E+08$ & $1.5 \mathrm{E}+07$ \\
\hline${ }^{229} \mathrm{Th}$ & $9.2 \mathrm{E}-03$ & & \\
\hline${ }^{225} \mathrm{Ra}+\mathrm{d}$ & $9.2 \mathrm{E}-03$ & & \\
\hline${ }^{234} \mathrm{U}$ & $1.0 \mathrm{E}+00$ & $6.6 \mathrm{E}+09$ & $1.9 E+08$ \\
\hline${ }^{230} \mathrm{Th}$ & $9.0 \mathrm{E}-04$ & & \\
\hline${ }^{226} \mathrm{Ra}+\mathrm{d}$ & $1.9 \mathrm{E}-05$ & & \\
\hline${ }^{210} \mathrm{~Pb}$ & $1.1 \mathrm{E}-05$ & & \\
\hline${ }^{210} \mathrm{Po}$ & $1.0 \mathrm{E}-05$ & & \\
\hline${ }^{235} \mathrm{U}+\mathrm{d}$ & $1.0 \mathrm{E}+00$ & $2.3 E+10$ & $6.5 E+08$ \\
\hline${ }^{2311} \mathrm{~Pa}$ & $2.1 \mathrm{E}-03$ & & \\
\hline${ }^{227} \mathrm{Ac}$ & $1.5 \mathrm{E}-03$ & & \\
\hline${ }^{227} \mathrm{Th}$ & $1.5 \mathrm{E}-03$ & & \\
\hline${ }^{223} \mathrm{Ra}$ & $1.5 E-03$ & & \\
\hline${ }^{238} \mathrm{U}$ & $1.0 \mathrm{E}+00$ & $6.7 \mathrm{E}+07$ & $1.9 \mathrm{E}+06$ \\
\hline${ }^{234} \mathrm{Th}+\mathrm{d}$ & $1.0 \mathrm{E}+00$ & & \\
\hline${ }^{234} \mathrm{U}$ & $2.8 \mathrm{E}-04$ & & \\
\hline $\begin{array}{l}\text { Indented entries } \\
\text { radiologically s }\end{array}$ & products of pare & onuclide th & potentially \\
\hline $\begin{array}{l}\text { The notation "+d } \\
\text { Dose from other }\end{array}$ & tes that short-live & hters were & orated into the EDE. \\
\hline Dose from other & rs listed is calcula & plicitly. & \\
\hline Considers radioa & cay and leaching & otherwise $\mathrm{r}$ & \\
\hline Fractions shown & bactive daughters & $t$ fraction of & activity of parent. \\
\hline Limit on average & tration in dispose & e; obtained & q. $6.3-5$ \\
\hline $\begin{array}{l}\text { Limit on invento } \\
28,800 \mathrm{~m}^{3} \text { for } 5 \mathrm{tt}\end{array}$ & trenches; obtaine & Eq. 6.3-4, & ing a volume of \\
\hline Only radioactive & counted for & & \\
\hline
\end{tabular}


disposal limits for radionuclides than the post-drilling scenario when the two scenarios are assumed to occur at the same time, the post-drilling scenario need not be considered further in the IL vaults. Likewise, for the naval reactor waste, the agriculture scenario and post-drilling scenario also become credible at the same time; at the time that failure of the casks occurs and the waste form has corroded. The post-drilling scenario is therefore only relevant to the LAW vaults, the slit trenches, the intimately-mixed cement-stabilized waste units, and the cement-stabilized encapsulated waste units

\subsubsection{Low-Activity Waste Vaults}

As described previously, the concrete roof on the LAW vaults is expected to remain intact for about 3,000 years. At the time the roof is expected to collapse, drilling through the disposal units is presumed to be a credible occurrence because, in contrast to the $\mathbb{I}$ vaults, the waste in the LAW vaults will not be grouted and any waste forms and waste packages presumably will be sufficiently degraded that drilling through the waste would not be precluded.

The results of the dose analysis for the post-drilling scenario at 3,000 years after disposal are given in Table 6.3-17. The SDCFs are obtained from Table 6.3-3, and the concentration and inventory limits are calculated from Eqs. 6.3-4 and 6.3-5. The post-drilling scenario need not be considered at times substantially beyond 3,000 years, because the more restrictive agriculture scenario is presumed to become credible by about 5,000 years. At 3,000 years after disposal, only long-lived radionuclides in the waste are of concern for the post-drilling scenario.

\subsubsection{Slit Trenches}

The waste disposed of in the slit trenches could be drilled into at the time institutional control is assumed to be lost; at 100 years. However, the agriculture scenario is not credible for 700 years due to the time required for erosion of $1 \mathrm{~m}$ of the soil cover, which is necessary before excavation into the trenches is credible. Therefore, drilling into the waste may occur before the agriculture scenario, and the post-drilling scenario is relevant.

The results of the dose analysis for the post-drilling scenario at 100 years after disposal are given in Table 6.3-18. The SDCFs are obtained from Table 6.3-3, and the concentration and inventory limits are calculated from Eqs. 6.3-4 and 6.3-5. Although ingrowth of radiologically-significant daughters may suggest evaluation of the post-drilling scenario at later times, it need not be considered at times substantially beyond 100 years because the more restrictive agriculture scenario is presumed to become credible by about 700 years and beyond, at which time the additional ingrowth of these daughters is evaluated

\subsubsection{Intimately-Mixed Cement-Stabilized Waste Units}

The cement waste form in the intimately-mixed cement-stabilized waste units is expected to remain intact for a minimum of 300 years. In this PA, it is assumed to degrade to soil-like material at that time. However, the agriculture scenario is not credible for 700 years due to the time required for erosion of $1 \mathrm{~m}$ of the soil cover, which is necessary before excavation into the waste units is credible. Therefore, drilling into the waste may occur before the agriculture scenario, and the post-drilling scenario is relevant.

The results of the dose analysis for the post-drilling scenario at 300 years after disposal are given in Table 6.3-19. The SDCFs are obtained from Table 6.3-3, and the concentration and inventory limits are calculated from Eqs. 6.3-4 and 6.3-5. Although ingrowth of radiologically-significant daughters may suggest evaluation of the post-drilling scenario at later times, it need not be considered at times substantially beyond 300 years, because the more restrictive agriculture scenario is presumed to become credible by about 700 years and beyond. 
Table 6.3-17 Intruder-Based Radionuclide Disposal Limits for LAW Vaults - Post-Drilling Scenario at 3,000 Years

\begin{tabular}{|c|c|c|c|}
\hline \multirow[b]{2}{*}{ Radionuclide ${ }^{a, b}$} & \multicolumn{3}{|c|}{ Concentration } \\
\hline & $\begin{array}{c}\text { Fraction } \\
\text { Remaining } \\
\end{array}$ & $\begin{array}{c}\text { Limit }^{e} \\
\left(\mu \mathrm{Ci} / \mathrm{m}^{3}\right)\end{array}$ & $\begin{array}{c}\text { Inventory Limit }{ }^{\mathrm{f}} \\
(\mathrm{Ci} / \text { vault })\end{array}$ \\
\hline $\mathrm{H}-3$ & $0.00 \mathrm{E}+00$ & $>1 \mathrm{E} 20$ & $>1 \mathrm{E} 20$ \\
\hline C-14 & $6.93 \mathrm{E}-01$ & $9.5 E+04$ & $4.6 \mathrm{E}+03$ \\
\hline Co-60 & $5.06 \mathrm{E}-172^{\mathrm{g}}$ & $>1 \mathrm{E} 20$ & $>1 \mathrm{E} 20$ \\
\hline $\mathrm{Ni}-59$ & $9.54 \mathrm{E}-01$ & $1.5 E+07$ & $7.4 \mathrm{E}+05$ \\
\hline $\mathrm{Ni}-63$ & $9.55 \mathrm{E}-10^{8}$ & $5.7 \mathrm{E}+15$ & $2.7 \mathrm{E}+14$ \\
\hline $\mathrm{Se}-79$ & $7.17 \mathrm{E}-01$ & $1.1 E+06$ & $5.5 E+04$ \\
\hline $\mathrm{Rb}-87$ & $3.24 \mathrm{E}-01$ & $1.6 \mathrm{E}+06$ & $7.9 \mathrm{E}+04$ \\
\hline Sr-90 +d & $4.57 \mathrm{E}-19$ & $>1 \mathrm{E} 20$ & $>1 \mathrm{E} 20$ \\
\hline Zr-93 +d & $9.99 E-01$ & $3.2 \mathrm{E}+07$ & $1.5 E+06$ \\
\hline $\mathrm{Nb}-94$ & $8.76 \mathrm{E}-01$ & $1.1 \mathrm{E}+05$ & $5.1 \mathrm{E}+03$ \\
\hline Tc-99 & $9.58 \mathrm{E}-01$ & $9.6 \mathrm{E}+04$ & $4.6 \mathrm{E}+03$ \\
\hline Pd-107 & $5.48 \mathrm{E}-01$ & $5.8 \mathrm{E}+07$ & $2.8 E+06$ \\
\hline Sn- $126+d$ & $9.55 \mathrm{E}-01$ & $7.4 E+04$ & $3.6 \mathrm{E}+03$ \\
\hline$I-129$ & $6.65 \mathrm{E}-09$ & $1.9 E+12$ & $9.0 \mathrm{E}+10$ \\
\hline Cs-135 & $8.79 \mathrm{E}-01$ & $9.3 E+05$ & $4.5 E+04$ \\
\hline Cs- $137+d$ & $1.18 \mathrm{E}-30^{g}$ & $>1 \mathrm{E} 20$ & $>1$ E20 \\
\hline $\mathrm{Sm}-151$ & $9.29 \mathrm{E}-11^{\mathrm{g}}$ & $1.2 E+18$ & $5.6 \mathrm{E}+16$ \\
\hline Eu-152 & $4.16 \mathrm{E}-68^{8}$ & $>1 E 20$ & $>1 \mathrm{E} 20$ \\
\hline Eu-154 & $2.50 \mathrm{E}-103^{8}$ & $>1 \mathrm{E} 20$ & $>1 E 20$ \\
\hline Th-232 & $1.00 \mathrm{E}+00$ & $1.7 E+04$ & $8.1 \mathrm{E}+02$ \\
\hline $\mathrm{Ra}-228+\mathrm{d}$ & $9.99 \mathrm{E}-01$ & & \\
\hline Th-228 & $9.96 \mathrm{E}-01$ & & \\
\hline $\mathrm{Ra}-224+\mathrm{d}$ & $9.97 \mathrm{E}-01$ & & \\
\hline $\mathrm{U}-232$ & 8.57E-10 & $1.7 \mathrm{E}+13$ & $8.1 E+11$ \\
\hline Th-228 & $1.46 \mathrm{E}-09$ & & \\
\hline $\mathrm{Ra}-224+\mathrm{d}$ & $1.47 \mathrm{E}-09$ & & \\
\hline U-233 & $9.88 \mathrm{E}-01$ & $7.0 \mathrm{E}+04$ & $3.4 \mathrm{E}+03$ \\
\hline Th-229 & $2.41 \mathrm{E}-01$ & & \\
\hline $\mathrm{Ra}-225$ & $2.40 \mathrm{E}-01$ & & \\
\hline U-234 & $9.92 \mathrm{E}-01$ & $9.9 \mathrm{E}+04$ & $4.8 \mathrm{E}+03$ \\
\hline Th-230 & $2.65 \mathrm{E}-02$ & & \\
\hline $\mathrm{Ra}-226+\mathrm{d}$ & $9.08 \mathrm{E}-03$ & & \\
\hline $\mathrm{Pb}-210$ & $8.96 \mathrm{E}-03$ & & \\
\hline Po-210 & $8.95 \mathrm{E}-03$ & & \\
\hline$U-235+d$ & $1.00 \mathrm{E}+00$ & $5.1 E+04$ & $2.4 E+03$ \\
\hline $\mathrm{Pa}-231$ & $6.13 \mathrm{E}-02$ & & \\
\hline Ac -227 & $6.09 \mathrm{E}-02$ & & \\
\hline Th-227 & $6.09 \mathrm{E}-02$ & & \\
\hline $\mathrm{Ra}-223$ & $6.09 \mathrm{E}-02$ & & \\
\hline U-236 & $1.00 \mathrm{E}+00$ & $1.4 \mathrm{E}+05$ & $7.0 \mathrm{E}+03$ \\
\hline $\mathrm{U}-238$ & $1.00 \mathrm{E}+00$ & $1.5 E+05$ & $7.2 \mathrm{E}+03$ \\
\hline Th-234 +d & $1.00 \mathrm{E}+00$ & & \\
\hline U-234 & $8.47 \mathrm{E}-03$ & & \\
\hline $\mathrm{Np}-237+\mathrm{d}$ & $9.99 \mathrm{E}-01$ & $4.2 E+03$ & $2.0 \mathrm{E}+02$ \\
\hline Pu-238 & $1.42 \mathrm{E}-08$ & $3.9 \mathrm{E}+08$ & $1.9 \mathrm{E}+07$ \\
\hline U-234 & $3.56 \mathrm{E}-04$ & & \\
\hline
\end{tabular}


Table 6.3-17 Intruder-Based Radionuclide Disposal Limits for LAW Vaults - Post-Drilling Scenario at 3,000 Years

\begin{tabular}{|c|c|c|c|}
\hline Radionuclide $^{\mathrm{a}, \mathrm{b}}$ & $\begin{array}{c}\text { Fraction } \\
\text { Remaining }\end{array}$ & $\begin{array}{c}\text { Concentration } \\
\text { Limit }^{e} \\
\left(\mu \mathrm{Ci} / \mathrm{m}^{3}\right)\end{array}$ & $\begin{array}{c}\text { Inventory Limit } \mathrm{f} \\
\text { (Ci/vault) }\end{array}$ \\
\hline Pu-239 & $9.19 \mathrm{E}-01$ & $4.5 \mathrm{E}+04$ & $2.2 \mathrm{E}+03$ \\
\hline U-235 & $2.84 \mathrm{E}-06$ & & \\
\hline $\mathrm{Pu}-240$ & $7.30 \mathrm{E}-01$ & $5.6 \mathrm{E}+04$ & $2.7 \mathrm{E}+03$ \\
\hline U-236 & $7.57 \mathrm{E}-05$ & & \\
\hline $\mathrm{Pu}-241$ & $1.99 \mathrm{E}-63^{\mathrm{g}}$ & $1.0 \mathrm{E}+08$ & $4.8 \mathrm{E}+06$ \\
\hline Am-241 & $2.71 \mathrm{E}-04^{\mathrm{g}}$ & & \\
\hline $\mathrm{Np}-237+\mathrm{d}$ & $6.72 \mathrm{E}-06$ & & \\
\hline $\mathrm{Pu}-242$ & $9.96 \mathrm{E}-01$ & $4.3 E+04$ & $2.1 \mathrm{E}+03$ \\
\hline U-238 & $4.65 \mathrm{E}-07$ & & \\
\hline $\mathrm{Pu}-244$ & $1.00 \mathrm{E}+00$ & $4.0 \mathrm{E}+04$ & $1.9 E+03$ \\
\hline Am-241 & $8.15 \mathrm{E}-03^{\mathrm{g}}$ & $3.3 E+06$ & $1.6 \mathrm{E}+05$ \\
\hline $\mathrm{Np}-237+\mathrm{d}$ & $2.02 \mathrm{E}-04$ & & \\
\hline Am-243 & $7.54 \mathrm{E}-01$ & $3.9 E+04$ & $1.9 \mathrm{E}+03$ \\
\hline Np-239 & $7.57 \mathrm{E}-01$ & & \\
\hline $\mathrm{Pu}-239$ & $7.17 \mathrm{E}-02$ & & \\
\hline $\mathrm{Cm}-244$ & $1.39 \mathrm{E}-50^{8}$ & $2.0 \mathrm{E}+07$ & $9.8 E+05$ \\
\hline $\mathrm{Pu}-240$ & $2.02 \mathrm{E}-03$ & & \\
\hline $\mathrm{U}-236$ & $5.30 \mathrm{E}-06$ & & \\
\hline $\mathrm{Cm}-245$ & $7.83 \mathrm{E}-01$ & $2.2 \mathrm{E}+04$ & $1.1 \mathrm{E}+03$ \\
\hline $\mathrm{Pu}-241$ & $7.84 \mathrm{E}-01$ & & \\
\hline Am-241 & $8.16 \mathrm{E}-01$ & & \\
\hline $\mathrm{Np}-237+\mathrm{d}$ & $6.94 \mathrm{E}-04$ & & \\
\hline $\mathrm{Cm}-246$ & $6.42 \mathrm{E}-01$ & $6.3 \mathrm{E}+04$ & $3.0 \mathrm{E}+03$ \\
\hline $\mathrm{Cm}-247+\mathrm{d}$ & $1.00 \mathrm{E}+00$ & $3.0 \mathrm{E}+04$ & $1.5 \mathrm{E}+03$ \\
\hline Am-243 & $2.46 \mathrm{E}-01$ & & \\
\hline Np-239 & $2.47 \mathrm{E}-01$ & & \\
\hline $\mathrm{Pu}-239$ & $1.08 \mathrm{E}-02$ & & \\
\hline $\mathrm{Cm}-248$ & $9.94 \mathrm{E}-01$ & $1.1 \mathrm{E}+04$ & $5.5 \mathrm{E}+02$ \\
\hline $\mathrm{Pu}-244$ & $2.56 \mathrm{E}-05$ & & \\
\hline Cf-249 & $2.69 \mathrm{E}-03$ & $5.0 \mathrm{E}+05$ & $2.4 \mathrm{E}+04$ \\
\hline $\mathrm{Cm}-245$ & $3.35 \mathrm{E}-02$ & & \\
\hline $\mathrm{Pu}-241$ & $3.36 \mathrm{E}-02$ & & \\
\hline $\mathrm{Am}-241$ & $3.40 \mathrm{E}-02$ & & \\
\hline $\mathrm{Np}-237+\mathrm{d}$ & $2.30 \mathrm{E}-05$ & & \\
\hline$C f-250$ & $9.36 \mathrm{E}-70^{\mathrm{g}}$ & $2.3 \mathrm{E}+07$ & $1.1 E+06$ \\
\hline $\mathrm{Cm}-246$ & $1.77 \mathrm{E}-03$ & & \\
\hline Cf-251 & $9.93 \mathrm{E}-02^{\mathrm{g}}$ & $3.9 \mathrm{E}+05$ & $1.9 E+04$ \\
\hline $\mathrm{Cf}-252$ & $0.00 \mathrm{E}+00^{\mathrm{g}}$ & $1.5 \mathrm{E}+09$ & $7.3 E+07$ \\
\hline $\mathrm{Cm}-248$ & $7.74 \mathrm{E}-06$ & & \\
\hline \multicolumn{4}{|c|}{$\begin{array}{l}\text { Indented entries are decay products of parent radionuclide that are potentially radiologically-significant. } \\
\text { The notation "+d" indicates that short-lived daughters were incorporated into the EDE. Dose from other } \\
\text { daughters listed is calculated explicitly. } \\
\text { Considers radioactive decay and leaching unless otherwise noted. } \\
\text { Fractions shown for radioactive daughters reflect fraction of initial activity of parent. } \\
\text { Limit on average concentration in disposed waste; obtained from Eq. } 6.3-5 \\
\text { Limit on inventory per vault; ; obtained from Eq. } 6.3-4 \text {, assuming a vault volume of } 4.8 E 4 \mathrm{~m}^{3} \text {. } \\
\text { Only radioactive decay accounted for. }\end{array}$} \\
\hline
\end{tabular}


Table 6.3-18 Intruder-Based Radionuclide Disposal Limits for Slit Trenches Post-Drilling Scenario at 100 Years

\begin{tabular}{|c|c|c|c|}
\hline Radionuclide $^{a, b}$ & Fraction Remaining ${ }^{c, d}$ & $\begin{array}{c}\text { Concentration Limit } \\
\left(\mu \mathrm{Ci} / \mathrm{m}^{3}\right)\end{array}$ & $\begin{array}{l}\text { Inventory Limit }{ }^{f} \\
\text { (Ci/5 trenches) }\end{array}$ \\
\hline $\mathrm{H}-3$ & $0.00 \mathrm{E}+00$ & $>1 E 20$ & $>1 \mathrm{E} 20$ \\
\hline C-14 & $8.91 \mathrm{E}-02$ & 3.7E+06 & $1.9 \mathrm{E}+04$ \\
\hline $\mathrm{Co}-60$ & $2.0 \mathrm{E}-06^{\mathrm{g}}$ & $1.4 \mathrm{E}+11$ & $7.3 \mathrm{E}+08$ \\
\hline $\mathrm{Ni}-59$ & $1.07 \mathrm{E}+00$ & $6.9 \mathrm{E}+07$ & $3.6 \mathrm{E}+05$ \\
\hline $\mathrm{Ni}-63$ & $5.0 \mathrm{E}-01^{\mathrm{g}}$ & $5.4 \mathrm{E}+07$ & $2.8 \mathrm{E}+05$ \\
\hline $\mathrm{Se}-79$ & $9.79 \mathrm{E}-01$ & $4.2 E+06$ & $2.2 \mathrm{E}+04$ \\
\hline Rb-87 & $9.48 \mathrm{E}-01$ & $2.8 \mathrm{E}+06$ & $1.5 \mathrm{E}+04$ \\
\hline Sr-90 +d & $6.63 \mathrm{E}-02$ & $4.1 E+05$ & $2.1 \mathrm{E}+03$ \\
\hline Zr-93 +d & $9.95 \mathrm{E}-01$ & $1.6 \mathrm{E}+08$ & $8.3 E+05$ \\
\hline Tc-99 & $3.25 \mathrm{E}-08$ & $1.4 E+13$ & $7.4 \mathrm{E}+10$ \\
\hline Pd-107 & $9.35 \mathrm{E}-01$ & $1.7 \mathrm{E}+08$ & $8.9 \mathrm{E}+05$ \\
\hline Cd-113m & $8.7 \mathrm{E}-03^{\mathrm{g}}$ & $4.6 E+06$ & $2.4 E+04$ \\
\hline $\mathrm{Sn}-121 \mathrm{~m}$ & $4.0 \mathrm{E}-01^{\mathrm{g}}$ & $2.4 \mathrm{E}+08$ & $1.2 \mathrm{E}+06$ \\
\hline $\mathrm{Sn}-126+\mathrm{d}$ & $9.77 \mathrm{E}-01$ & $3.6 \mathrm{E}+05$ & $1.9 \mathrm{E}+03$ \\
\hline I-129 & $7.28 \mathrm{E}-06$ & $8.5 E+09$ & $4.4 \mathrm{E}+07$ \\
\hline Cs-135 & $9.91 \mathrm{E}-01$ & $4.1 E+06$ & $2.1 \mathrm{E}+04$ \\
\hline Cs- $137+d$ & $1.0 \mathrm{E}-01^{8}$ & $4.0 \mathrm{E}+06$ & $2.1 \mathrm{E}+04$ \\
\hline Sm-151 & $4.6 \mathrm{E}-01^{\mathrm{B}}$ & $1.2 \mathrm{E}+09$ & $6.1 E+06$ \\
\hline Eu-154 & $3.8 \mathrm{E}-04^{\mathrm{B}}$ & $1.6 \mathrm{E}+09$ & $8.1 E+06$ \\
\hline Th-232 & $9.99 E-01$ & $8.4 \mathrm{E}+05$ & $4.4 \mathrm{E}+02$ \\
\hline $\mathrm{Ra}-228+\mathrm{d}$ & $9.98 \mathrm{E}-01$ & & \\
\hline Th-228 & $9.94 \mathrm{E}-01$ & & \\
\hline $\mathrm{Ra}-224+\mathrm{d}$ & $9.96 \mathrm{E}-01$ & & \\
\hline$U-232$ & $3.14 \mathrm{E}-01$ & $2.8 \mathrm{E}+05$ & $1.5 E+03$ \\
\hline Th-228 & $3.24 \mathrm{E}-01$ & & \\
\hline $\mathrm{Ra}-224+\mathrm{d}$ & $3.24 \mathrm{E}-01$ & & \\
\hline U-233 & $8.23 \mathrm{E}-01$ & $7.8 \mathrm{E}+05$ & $4,1 E+03$ \\
\hline Th-229 & $7.83 \mathrm{E}-03$ & & \\
\hline $\mathrm{Ra}-225+\mathrm{d}$ & $7.81 \mathrm{E}-03$ & & \\
\hline $\mathrm{U}-234$ & $8.23 \mathrm{E}-01$ & $8.4 \mathrm{E}+05$ & $4.4 \mathrm{E}+03$ \\
\hline Th-230 & $7.63 E-04$ & & \\
\hline $\mathrm{Ra}-226+\mathrm{d}$ & $1.64 \mathrm{E}-05$ & & \\
\hline $\mathrm{Pb}-210$ & $9.17 \mathrm{E}-06$ & & \\
\hline Po-210 & $9.04 \mathrm{E}-06$ & & \\
\hline$U-235+d$ & 8.23E-01 & $7.4 \mathrm{E}+05$ & $3.9 E+03$ \\
\hline $\mathrm{Pa}-231$ & $1.78 \mathrm{E}-03$ & & \\
\hline Ac-227 & $1.26 \mathrm{E}-03$ & & \\
\hline Th-227 & $1.26 \mathrm{E}-03$ & & \\
\hline Ra-223 & $1.26 \mathrm{E}-03$ & & \\
\hline U-236 & 8.23E-01 & $8.8 \mathrm{E}+05$ & $4.6 \mathrm{E}+03$ \\
\hline $\mathrm{U}-238$ & $8.23 \mathrm{E}-01$ & $9.2 E+05$ & $4.8 E+03$ \\
\hline Th-234 +d & $8.23 \mathrm{E}-01$ & & \\
\hline U-234 & $2.33 \mathrm{E}-04$ & & \\
\hline $\mathrm{Np}-237+\mathrm{d}$ & $5.28 \mathrm{E}-01$ & $4.0 \mathrm{E}+04$ & $2.1 \mathrm{E}+02$ \\
\hline
\end{tabular}


Table 6.3-18 Intruder-Based Radionuclide Disposal Limits for Slit Trenches Post-Drilling Scenario at 100 Years

\begin{tabular}{|c|c|c|c|}
\hline Radionuclide ${ }^{a, b}$ & Fraction Remaining ${ }^{c, d}$ & $\begin{array}{c}\text { Concentration Limit }{ }^{e} \\
\left(\mu \mathrm{Ci} / \mathrm{m}^{3}\right)\end{array}$ & $\begin{array}{c}\text { Inventory Limit }{ }^{\prime} \\
\text { (Ci/5 trenches) }\end{array}$ \\
\hline $\mathrm{Pu}-238$ & $4.49 \mathrm{E}-01$ & $5.2 \mathrm{E}+05$ & $2.75 \mathrm{E}+03$ \\
\hline U-234 & $1.87 \mathrm{E}-04$ & & \\
\hline Pu-239 & $9.86 \mathrm{E}-01$ & $2.1 \mathrm{E}+05$ & $1.1 \mathrm{E}+03$ \\
\hline $\mathrm{U}-235$ & $9.47 \mathrm{E}-08$ & & \\
\hline $\mathrm{Pu}-240$ & $9.79 E-01$ & $2.1 E+05$ & $1.1 E+03$ \\
\hline $\mathrm{U}-236$ & $2.81 \mathrm{E}-06$ & & \\
\hline $\mathrm{Pu}-241$ & $8.1 E-03^{g}$ & $5.7 \mathrm{E}+06$ & $3.0 \mathrm{E}+04$ \\
\hline Am-241 & $2.8 \mathrm{E}-02^{8}$ & & \\
\hline $\mathrm{Np}-237+\mathrm{d}$ & $3.6 \mathrm{E}-06$ & & \\
\hline $\mathrm{Pu}-242$ & $9.89 \mathrm{E}-01$ & $2.2 \mathrm{E}+05$ & $1.1 \mathrm{E}+03$ \\
\hline $\mathrm{U}-238$ & $1.49 \mathrm{E}-08$ & & \\
\hline $\mathrm{Pu}-244+\mathrm{d}$ & $9.89 \mathrm{E}-01$ & $2.0 \mathrm{E}+05$ & $1.1 \mathrm{E}+03$ \\
\hline Am-241 & $8.5 \mathrm{E}-01^{\mathrm{g}}$ & $1.9 \mathrm{E}+05$ & $9.9 \mathrm{E}+02$ \\
\hline$N p-237+d$ & $1.1 \mathrm{E}-04$ & & \\
\hline$A m-242 m+d$ & $6.3 \mathrm{E}-01^{\mathrm{g}}$ & $1.6 \mathrm{E}+05$ & $8.1 E+02$ \\
\hline $\mathrm{Pu}-238$ & $6.3 \mathrm{E}-01$ & & \\
\hline U-234 & $6.2 \mathrm{E}-04$ & & \\
\hline Am-243 & $1.12 \mathrm{E}+00$ & $1.4 E+05$ & $7.2 \mathrm{E}+02$ \\
\hline Np-239 & $1.13 E+00$ & & \\
\hline Pu-239 & $3.13 \mathrm{E}-03$ & & \\
\hline $\mathrm{Cm}-243$ & $8.8 \mathrm{E}-02^{\mathrm{g}}$ & $3.4 \mathrm{E}+06$ & $1.8 \mathrm{E}+04$ \\
\hline $\mathrm{Cm}-244$ & $2.2 \mathrm{E}-02^{\mathrm{g}}$ & $1.5 \mathrm{E}+07$ & $7.6 \mathrm{E}+04$ \\
\hline $\mathrm{Pu}-240$ & $2.7 \mathrm{E}-03$ & & \\
\hline U-236 & $7.8 \mathrm{E}-09$ & & \\
\hline $\mathrm{Cm}-245$ & $1.33 \mathrm{E}+00$ & $1.3 \mathrm{E}+05$ & $6.7 \mathrm{E}+02$ \\
\hline Pu-241 & $1.31 \mathrm{E}+00$ & & \\
\hline Am-241 & $1.49 \mathrm{E}-01$ & & \\
\hline $\mathrm{Np}-237+\mathrm{d}$ & $1.90 \mathrm{E}-06$ & & \\
\hline $\mathrm{Cm}-246$ & $1.32 \mathrm{E}+00$ & $1.5 \mathrm{E}+05$ & $7.9 E+02$ \\
\hline $\mathrm{Cm}-247+\mathrm{d}$ & $1.34 \mathrm{E}+00$ & $1.5 \mathrm{E}+05$ & $7.8 \mathrm{E}+02$ \\
\hline Am-243 & $1.21 \mathrm{E}-02$ & & \\
\hline Np-239 & $1.21 \mathrm{E}-02$ & & \\
\hline Pu-239 & $1.66 \mathrm{E}-05$ & & \\
\hline $\mathrm{Cm}-248$ & $1.34 \mathrm{E}+00$ & $4.2 \mathrm{E}+04$ & $-2.2 \mathrm{E}+02$ \\
\hline $\mathrm{Pu}-244$ & $1.07 \mathrm{E}-06$ & & \\
\hline Cf-249 & $8.16 \mathrm{E}-01$ & $2.2 \mathrm{E}+05$ & $1.1 E+03$ \\
\hline Cm-245 & $8.02 \mathrm{E}-03$ & & \\
\hline Pu-241 & $6.56 \mathrm{E}-03$ & & \\
\hline Am-241 & $4.51 \mathrm{E}-04$ & & \\
\hline $\mathrm{Np}-237+\mathrm{d}$ & $4.23 E-09$ & & \\
\hline Cf -250 & $5.0 \mathrm{E}-03^{\mathrm{g}}$ & $4.2 E+07$ & $2.2 \mathrm{E}+05$ \\
\hline $\mathrm{Cm}-246$ & $2.7 \mathrm{E}-03$ & & \\
\hline Cf-251 & $9.3 \mathrm{E}-01^{\mathrm{g}}$ & $2.1 \mathrm{E}+05$ & $1.1 \mathrm{E}+03$ \\
\hline $\mathrm{Cf}-252$ & $3.3 \mathrm{E}-12^{\mathrm{g}}$ & $7.5 E+09$ & $3.9 E+07$ \\
\hline $\mathrm{Cm}-248$ & $7.8 \mathrm{E}-06$ & & \\
\hline
\end{tabular}


- Indented entries are decay products of parent radionuclide that are potentially radiologically-significant.

- The notation "+d" indicates that short-lived daughters were incorporated into the EDE. Dose from other daughters listed is calculated explicitly.

c Considers radioactive decay and leaching unless otherwise noted.

"Fractions shown for radioactive daughters reflect fraction of initial activity of parent.

- Limit on average concentration in disposed waste; obtained from Eq. 6.3-5

Limit on inventory per 5 trenches; obtained from Eq. 6.3-4, assuming a volume of $2.88 \mathrm{E} 4 \mathrm{~m}^{3}$ for 5 trenches.

Only radioactive decay accounted for. 
Table 6.3-19 Intruder-Based Radionuclide Disposal Limits for Intimately Mixed Cement-Stabilized Waste - Post-Drilling Scenario at 300 Years

\begin{tabular}{|c|c|c|c|}
\hline Radionuclide $^{a, b}$ & Fraction Remaining ${ }^{c, d}$ & $\begin{array}{c}\text { Concentration Limit }{ }^{e} \\
\left(\mu \mathrm{Ci} / \mathrm{m}^{3}\right)\end{array}$ & $\begin{array}{l}\text { Inventory Limit } \\
\text { (Ci/5 trenches) }\end{array}$ \\
\hline H-3 & $4.36 \mathrm{E}-08$ & $5.9 \bar{E}+12$ & $1.7 \mathrm{E}+11$ \\
\hline C-14 & $9.64 E-01$ & $6.9 E+04$ & $2.0 E+03$ \\
\hline $\mathrm{Co}-60$ & $7.42 \mathrm{E}-18^{\mathrm{g}}$ & $>1 E 20$ & $>1 \mathrm{E} 20$ \\
\hline $\mathrm{Ni}-59$ & $9.97 \mathrm{E}-01$ & $1.5 E+07$ & $4.3 \mathrm{E}+05$ \\
\hline $\mathrm{Ni}-63$ & $1.25 \mathrm{E}-01^{\mathrm{g}}$ & $4.4 E+07$ & $1.3 E+06$ \\
\hline Se-79 & $9.55 \mathrm{E}-01$ & $8.6 \mathrm{E}+05$ & $2.5 E+04$ \\
\hline $\mathrm{Rb}-87$ & $1.00 \mathrm{E}-00$ & $5.3 E+05$ & $1.5 E+04$ \\
\hline $\mathrm{Sr}-90+\mathrm{d}$ & $6.95 \mathrm{E}-04$ & $7.8 \mathrm{E}+06$ & $2.2 E+05$ \\
\hline $\mathrm{Zr}-93+\mathrm{d}$ & $1.00 \mathrm{E}-00$ & $3.2 \mathrm{E}+07$ & $9.2 E+05$ \\
\hline $\mathrm{Nb}-94$ & $9.90 \mathrm{E}-01$ & $9.4 \mathrm{E}+04$ & $2.7 \mathrm{E}+03$ \\
\hline Tc-99 & $9.91 \mathrm{E}-01$ & $9.3 E+04$ & $2.7 E+03$ \\
\hline Pd-107 & $1.00 \mathrm{E}-00$ & $3.2 E+07$ & $9.2 \mathrm{E}+05$ \\
\hline$S n-126+d$ & $9.98 \mathrm{E}-01$ & $7.1 E+04$ & $2.0 \mathrm{E}+03$ \\
\hline I-129 & $9.96 \mathrm{E}-01$ & $1.2 \mathrm{E}+04$ & $3.6 \mathrm{E}+02$ \\
\hline Cs-135 & $9.99 \mathrm{E}-01$ & $8.2 E+05$ & $2.4 E+04$ \\
\hline Cs-137+d & $1.02 E-03^{g}$ & $7.9 \mathrm{E}+07$ & $2.3 E+06$ \\
\hline Sm-151 & $9.93 \mathrm{E}-02^{\mathrm{g}}$ & $1.1 E+09$ & $3.1 E+07$ \\
\hline Eu-152 & $1.83 \mathrm{E}-07^{\mathrm{g}}$ & $7.0 \mathrm{E}+11$ & $2.0 \mathrm{E}+10$ \\
\hline Eu-154 & $5.49 \mathrm{E}-11^{\mathrm{g}}$ & $2.2 \mathrm{E}+15$ & $6.2 \mathrm{E}+13$ \\
\hline Th-232 & $1.00 \mathrm{E}-00$ & $1.7 \mathrm{E}+04$ & $4.8 \mathrm{E}+02$ \\
\hline $\mathrm{Ra}-228+\mathrm{d}$ & $9.99 \mathrm{E}-01$ & & \\
\hline Th-228 & $9.96 \mathrm{E}-01$ & & \\
\hline $\mathrm{Ra}-224+\mathrm{d}$ & $9.97 \mathrm{E}-01$ & & \\
\hline $\mathrm{U}-232$ & $5.57 \mathrm{E}-02$ & $3.2 E+05$ & $9.2 \mathrm{E}+03$ \\
\hline Th-228 & $5.73 \mathrm{E}-02$ & & \\
\hline $\mathrm{Ra}-224+\mathrm{d}$ & $5.74 \mathrm{E}-02$ & & \\
\hline U-233 & $9.99 \mathrm{E}-01$ & $1.2 \mathrm{E}+05$ & $3.5 E+03$ \\
\hline Th-229 & $2.74 \mathrm{E}-02$ & & \\
\hline $\mathrm{Ra}-225+\mathrm{d}$ & $2.73 \mathrm{E}-02$ & & \\
\hline U-234 & $9.99 \mathrm{E}-01$ & $1.4 \mathrm{E}+05$ & $4.0 E+03$ \\
\hline Th-230 & $2.69 \mathrm{E}-03$ & & \\
\hline $\mathrm{Ra}-226+\mathrm{d}$ & $1.66 \mathrm{E}-04$ & & \\
\hline $\mathrm{Pb}-210$ & $1.35 \mathrm{E}-04$ & & \\
\hline Po- 210 & $1.34 \mathrm{E}-04$ & & \\
\hline$U-235$ & $1.00 E-00$ & $1.1 E+05$ & $3.2 E+03$ \\
\hline $\mathrm{Pa}-231$ & $6.30 \mathrm{E}-03$ & & \\
\hline Ac- 227 & $5.66 \mathrm{E}-03$ & & \\
\hline Th-227 & $5.66 \mathrm{E}-03$ & & \\
\hline Ra-223 & $5.66 \mathrm{E}-03$ & & \\
\hline U-236 & $1.00 \mathrm{E}-00$ & $1.4 \mathrm{E}+05$ & $4.2 E+03$ \\
\hline $\mathrm{U}-238$ & $1.00 \mathrm{E}-00$ & $1.5 \mathrm{E}+05$ & $4.4 E+03$ \\
\hline Th-234 +d & $1.00 \mathrm{E}-00$ & & \\
\hline U-234 & $8.50 \mathrm{E}-04$ & & \\
\hline $\mathrm{Np}-237+\mathrm{d}$ & $1.00 \mathrm{E}-00$ & $4.2 E+03$ & $1.2 \mathrm{E}+02$ \\
\hline
\end{tabular}


Table 6.3-19 Intruder-Based Radionuclide Disposal Limits for Intimately Mixed Cement-Stabilized Waste - Post-Drilling Scenario at 300 Years

\begin{tabular}{|c|c|c|c|}
\hline Radionuclide ${ }^{a, b}$ & Fraction Remaining ${ }^{c, d}$ & $\begin{array}{c}\text { Concentration Limit } \\
\left(\mu \mathrm{Ci} / \mathrm{m}^{3}\right)\end{array}$ & $\begin{array}{l}\text { Inventory Limit } \\
\text { (Ci/5 trenches) }\end{array}$ \\
\hline Pu-238 & $9.37 \mathrm{E}-02$ & $4.9 \mathrm{E}+05$ & $1.4 \mathrm{E}+04$ \\
\hline $\mathrm{U}-234$ & $3.25 \mathrm{E}-04$ & & \\
\hline $\mathrm{Pu}-239$ & $9.91 \mathrm{E}-01$ & 4.1E+04 & $1.2 \mathrm{E}+03$ \\
\hline $\mathrm{U}-235$ & 2.95E-07 & & \\
\hline Pu-240 & $9.69 \mathrm{E}-01$ & $4.2 E+04$ & $1.2 \mathrm{E}+03$ \\
\hline $\mathrm{U}-236$ & $8.69 \mathrm{E}-06$ & & \\
\hline $\mathrm{Pu}-241$ & $5.37 \mathrm{E}-07^{\mathrm{g}}$ & $1.6 \mathrm{E}+06$ & $4.5 \mathrm{E}+04$ \\
\hline Am-241 & $2.06 \mathrm{E}-02^{\mathrm{g}}$ & & \\
\hline $\mathrm{Np}-237+\mathrm{d}$ & $6.73 \mathrm{E}-06$ & & \\
\hline $\mathrm{Pu}-242$ & $9.99 \mathrm{E}-01$ & $4.3 E+04$ & $1.2 \mathrm{E}+03$ \\
\hline $\mathrm{U}-238$ & $4.66 \mathrm{E}-08$ & & \\
\hline $\mathrm{Pu}-244+\mathrm{d}$ & $1.00 \mathrm{E}-00$ & $4.0 \mathrm{E}+04$ & $1.2 \mathrm{E}+03$ \\
\hline Am-241 & $6.18 \mathrm{E}-01^{\mathrm{B}}$ & $5.2 \mathrm{E}+04$ & $1.5 \mathrm{E}+03$ \\
\hline Np-237 +d & $2.02 \mathrm{E}-04$ & & \\
\hline Am-243 & $9.72 \mathrm{E}-01$ & $3.2 E+04$ & $9.2 \mathrm{E}+02$ \\
\hline Np-239 & $4.66 \mathrm{E}-08$ & & \\
\hline Pu-239 & $8.50 \mathrm{E}-04$ & & \\
\hline $\mathrm{Cm}-244$ & $1.03 \mathrm{E}-05^{\mathrm{B}}$ & $1.5 \mathrm{E}+07$ & 4.4E+05 \\
\hline Pu-240 & $2.68 E-03$ & & \\
\hline $\mathrm{U}-236$ & $2.41 \mathrm{E}-08$ & & \\
\hline $\mathrm{Cm}-245$ & $9.76 \mathrm{E}-01$ & $2.8 E+04$ & $8.0 E+02$ \\
\hline Pu-241 & $9.77 \mathrm{E}-01$ & & \\
\hline Am-241 & $3.56 \mathrm{E}-01$ & & \\
\hline Np-237+d & $1.76 \mathrm{E}-05$ & & \\
\hline $\mathrm{Cm}-246$ & $9.57 \mathrm{E}-01$ & $4.2 E+04$ & $1.2 \mathrm{E}+03$ \\
\hline $\mathrm{Cm}-247$ & $1.00 \mathrm{E}-00$ & $3.9 \mathrm{E}+04$ & $1.1 E+03$ \\
\hline Am-243 & $2.78 \mathrm{E}-02$ & & \\
\hline $\mathrm{Np}-239$ & $2.79 \mathrm{E}-02$ & & \\
\hline $\mathrm{Pu}-239$ & $1.20 \mathrm{E}-04$ & & \\
\hline $\mathrm{Cm}-248$ & $9.99 \mathrm{E}-01$ & $1.1 E+04$ & $3.3 E+02$ \\
\hline Pu-244 & $2.57 \mathrm{E}-06$ & & \\
\hline Cf-249 & $5.52 \mathrm{E}-01$ & $6.3 E+04$ & $1.8 E+03$ \\
\hline $\mathrm{Cm}-245$ & $1.82 \mathrm{E}-02$ & & \\
\hline Pu-241 & $1.73 \mathrm{E}-02$ & & \\
\hline Am-241 & $3.66 \mathrm{E}-03$ & & \\
\hline $\mathrm{Np}-237+\mathrm{d}$ & $1.22 \mathrm{E}-07$ & & \\
\hline Cf -250 & $1.25 \mathrm{E}-07^{\mathrm{g}}$ & $1.5 \mathrm{E}+07$ & $4.4 \mathrm{E}+05$ \\
\hline $\mathrm{Cm}-246$ & $2.64 E-03$ & & \\
\hline Cf-251 & $7.94 \mathrm{E}-01^{\mathrm{g}}$ & $4.8 \mathrm{E}+04$ & $1.4 \mathrm{E}+03$ \\
\hline Cf-252 & $3.45 \mathrm{E}-35^{\mathrm{g}}$ & $1.5 \mathrm{E}+09$ & $4.3 E+07$ \\
\hline $\mathrm{Cm}-248$ & $7.78 \mathrm{E}-06$ & & \\
\hline
\end{tabular}




\subsubsection{Cement-Stabilized Encapsulated Waste Units}

Like the intimately-mixed cement-stabilized waste units, the grout encapsulating the waste in these units is expected to remain intact for a minimum of 300 years. At 300 years, it is assumed to degrade to soil-like material. The agriculture scenario is not credible for 700 years after closure of these units due to the time required for erosion of $1 \mathrm{~m}$ of the soil cover; thus, drilling into the waste may occur before the agriculture scenario, and the post-drilling scenario is relevant for these units.

The results of the dose analysis for the post-drilling scenario at 300 years after disposal are given in Table 6.3-20. The SDCFs are obtained from Table 6.3-3, and the concentration and inventory limits are calculated from Eqs. 6.3-4 and 6.3-5. Although ingrowth of radiologically-significant daughters may suggest a need to evaluate the post-drilling scenario at later times, it need not be considered at times substantially beyond 300 years, because the more restrictive agriculture scenario is presumed to become credible by about 700 years and beyond.

\subsection{Sensitivity and Uncertainty in Dose Models for Inadvertent Intruders}

The generalized model for estimating dose to an inadvertent intruder, as represented by Eq. 6.3-1, is based on estimates of annual doses per unit concentration of radionuclides in disposed waste, the so-called SDCFs for the agriculture, resident, and post-drilling scenarios summarized in Tables 6.3-1, 6.3-2, and 6.3-3, respectively. In this section, the sensitivity and uncertainty analyses of the models used to estimate the SDCFs for the different exposure scenarios for inadvertent intruders are discussed.

For each of the assumed exposure scenarios, the SDCFs for radionuclides are single values based on the models and parameter values presented in Appendix C.3. The parameter values adopted for use in models for the different exposure pathways usually were intended to represent reasonable average conditions that might be experienced, rather than maximum possible conditions that would yield the highest estimates of dose. This approach was used in selecting parameter values related to human activities, such as the annual consumption of foodstuffs, breathing rate, and exposure times, and parameter values describing transport of radionuclides through environmental pathways to man, such as the elemental plant-to-soil concentration ratios and atmospheric mass loading of activity suspended from surface soil.

The exposure pathways considered in the dose analyses for an inadvertent intruder for the different exposure scenarios include consumption of vegetables grown in contaminated garden soil, direct consumption of contaminated garden soil, external exposure while working in the garden or during indoor residence, and inhalation exposure while working in the garden or during indoor residence. In implementing the models for the various exposure pathways, data specific to the SRS generally were not available for such important parameters as the elemental plant-to-soil concentration ratios in vegetables grown in contaminated garden soil and the airborne concentration of suspended radionuclides in particulate form. Therefore, generic parameter values obtained from the literature were used in many of the exposure pathway models.

A list of parameters used in calculating SDCFs is provided in Table 6.4-1. The value assumed for each parameter, the exposure scenario to which each parameters is relevant, and comments pertinent to the choice of parameter value are given. In Table 6.4-2, the most significant radionuclides and pathways of exposure for the LAW vault and slit trench analyses are shown. The information provided in these two tables is utilized in the discussion below. 
Table 6.3-20 Intruder-Based Radionuclide Disposal Limits for

Cement-Stabilized Encapsulated Waste - Post-Drilling Scenario at 300 Years

\begin{tabular}{|c|c|c|c|}
\hline Radionuclide $^{2, b}$ & $\begin{array}{c}\text { Fraction } \\
\text { Remaining }\end{array}$ & $\begin{array}{c}\text { Concentration } \\
\text { Limit }^{e} \\
\left(\mu \mathrm{Ci} / \text { cu m }^{e}\right)\end{array}$ & $\begin{array}{l}\text { Inventory Limit } \\
\text { (Ci/5 trenches) }\end{array}$ \\
\hline $\mathrm{H}-3$ & $3.0 \mathrm{E}-09$ & $8.6 \mathrm{E}+13$ & $2.5 \mathrm{E}+12$ \\
\hline Co-60 & $7.4 \mathrm{E}-18^{\mathrm{g}}$ & $>1 E 20$ & $>1 \mathrm{E} 20$ \\
\hline $\mathrm{Ni}-59$ & $1.0 \mathrm{E}+00$ & $1.5 E+07$ & $4.3 E+05$ \\
\hline $\mathrm{Ni}-63$ & $1.3 \mathrm{E}-01^{\mathrm{g}}$ & $4.4 \mathrm{E}+07$ & $1.3 E+06$ \\
\hline $\mathrm{Se}-79$ & $1.0 \mathrm{E}+00$ & $8.2 E+05$ & $2.4 \mathrm{E}+04$ \\
\hline Sr-90 +d & $7.0 \mathrm{E}-04$ & $7.7 \mathrm{E}+06$ & $2.27 \mathrm{E}+05$ \\
\hline $\mathrm{Zr}-93+\mathrm{d}$ & $1.0 \mathrm{E}+00$ & $3.2 E+07$ & $9.2 \mathrm{E}+05$ \\
\hline Tc-99 & $1.0 \mathrm{E}+00$ & $9.2 E+04$ & $2.7 E+03$ \\
\hline Pd-107 & $1.0 \mathrm{E}+00$ & $3.2 E+07$ & $9.25 \mathrm{E}+05$ \\
\hline$S n-126+d$ & $1.0 \mathrm{E}+00$ & $7.1 \mathrm{E}+04$ & $2.0 \mathrm{E}+03$ \\
\hline $\mathrm{I}-129$ & $1.0 E+00$ & $1.2 E+04$ & $3.6 E+02$ \\
\hline Cs-135 & $1.0 \mathrm{E}+00$ & $8.24 \mathrm{E}+05$ & $2.4 E+04$ \\
\hline Cs $-137+d$ & $1.0 \mathrm{E}-03^{\mathrm{B}}$ & $7.9 \mathrm{E}+07$ & $2.3 E+06$ \\
\hline Sm-151 & $9.9 \mathrm{E}-02^{\mathrm{g}}$ & $1.1 \mathrm{E}+09$ & $3.1 \mathrm{E}+07$ \\
\hline Eu-154 & $5.5 \mathrm{E}-11^{\mathrm{g}}$ & $2.2 \mathrm{E}+15$ & $6.2 \mathrm{E}+13$ \\
\hline U-232 & $5.6 \mathrm{E}-02$ & $3.2 \mathrm{E}+05$ & $9.2 E+03$ \\
\hline Th-228 & $5.7 \mathrm{E}-02$ & & \\
\hline $\mathrm{Ra}-224+\mathrm{d}$ & $5.7 \mathrm{E}-02$ & & \\
\hline U-233 & $1.0 \mathrm{E}+00$ & $1.2 \mathrm{E}+05$ & $3.5 E+03$ \\
\hline Th-229 & $2.7 \mathrm{E}-02$ & & \\
\hline $\mathrm{Ra}-225$ & $2.7 \mathrm{E}-02$ & & \\
\hline U-234 & $1.0 \mathrm{E}+00$ & $1.4 \mathrm{E}+05$ & $4.0 \mathrm{E}+03$ \\
\hline Th-230 & $2.7 E-03$ & & \\
\hline $\mathrm{Ra}-226+\mathrm{d}$ & $1.7 \mathrm{E}-04$ & & \\
\hline $\mathrm{Pb}-210$ & $1.4 \mathrm{E}-04$ & & \\
\hline Po-210 & $1.3 \mathrm{E}-04$ & & \\
\hline $\mathrm{U}-235+\mathrm{d}$ & $1.0 \mathrm{E}+00$ & $1.1 \mathrm{E}+05$ & $3.2 \mathrm{E}+03$ \\
\hline $\mathrm{Pa}-231$ & $6.3 \mathrm{E}-03$ & & \\
\hline Ac- -227 & $5.7 \mathrm{E}-03$ & & \\
\hline Th-227 & $5.7 E-03$ & & \\
\hline Ra-223 & $5.7 \mathrm{E}-03$ & & \\
\hline $\mathrm{U}-236$ & $1.0 \mathrm{E}+00$ & $1.4 \mathrm{E}+05$ & 4.2E+03 \\
\hline U-238 & $1.0 \mathrm{E}+00$ & $1.5 \mathrm{E}+05$ & $4.4 \mathrm{E}+03$ \\
\hline $\mathrm{Th}-234+\mathrm{d}$ & $1.0 \mathrm{E}+00$ & & \\
\hline U-234 & $8.5 E-04$ & & \\
\hline $\mathrm{Pu}-238$ & $9.4 \mathrm{E}-02$ & $4.9 \mathrm{E}+05$ & $1.4 E+04$ \\
\hline U-234 & $3.3 \mathrm{E}-04$ & & \\
\hline Pu-239 & $9.9 \mathrm{E}-01$ & $4.1 E+04$ & $1.2 \mathrm{E}+03$ \\
\hline U-235 & $3.0 \mathrm{E}-07$ & & \\
\hline Pu-240 & $9.7 \mathrm{E}-01$ & $4.2 E+04$ & $1.2 \mathrm{E}+03$ \\
\hline U-236 & $8.7 \mathrm{E}-06$ & & \\
\hline
\end{tabular}


Table 6.3-20 Intruder-Based Radionuclide Disposal Limits for

Cement-Stabilized Encapsulated Waste - Post-Drilling Scenario at 300 Years

\begin{tabular}{|c|c|c|c|}
\hline Radionuclide $^{a, b}$ & $\begin{array}{c}\text { Fraction } \\
\text { Remaining c,d }\end{array}$ & $\begin{array}{c}\text { Concentration } \\
\text { Limit }{ }^{3} \\
(\mu \mathrm{Ci} / \text { cu m})\end{array}$ & $\begin{array}{l}\text { Inventory Limit }{ }^{\mathrm{f}} \\
\text { (Ci/5 trenches) }\end{array}$ \\
\hline $\mathrm{Pu}-241$ & $5.4 \mathrm{E}-07^{\mathrm{g}}$ & $1.6 \mathrm{E}+06$ & $4.5 \mathrm{E}+04$ \\
\hline Am-241 & $2.1 \mathrm{E}-02^{\mathrm{B}}$ & & \\
\hline Np-237 +d & $6.7 \mathrm{E}-06$ & & \\
\hline$N p-237+d$ & $6.7 \mathrm{E}-06$ & & \\
\hline $\mathrm{Pu}-242$ & $1.0 \mathrm{E}+00$ & $4.3 \mathrm{E}+04$ & $1.2 E+03$ \\
\hline U-238 & 4.7E-08 & & \\
\hline Am-241 & $6.2 \mathrm{E}-01^{\mathrm{B}}$ & $5.2 \mathrm{E}+04$ & $1.5 E+03$ \\
\hline $\mathrm{Np}-237+\mathrm{d}$ & $2.0 \mathrm{E}-04$ & & \\
\hline \multicolumn{4}{|c|}{$\begin{array}{l}\text { Indented entries are decay products of parent radionuclide that are potentially } \\
\text { radiologically-significant. } \\
\text { The notation "+d" indicates that short-lived daughters were incorporated into the EDE. } \\
\text { Dose from other daughters listed is calculated explicitly. } \\
\text { Considers radioactive decay and leaching unless otherwise noted. } \\
\text { Fractions shown for radioactive daughters reflect fraction of initial activity of parent. } \\
\text { Limit on average concentration in disposed waste; obtained from Eq. } 6.3-5 \\
\text { Limit on inventory per } 5 \text { trenches; obtained from Eq. } 6.3-4 \text {, assuming a volume of } \\
2.88 E 4 \mathrm{~m}^{3} \text { for } 5 \text { trenches. } \\
\text { Only radioactive decay accounted for. }\end{array}$} \\
\hline
\end{tabular}


Table 6.4-1 Parameters used in Calculating SDCFs for Intruder Dose Analyses, by Exposure Scenarios

\begin{tabular}{|c|c|c|c|}
\hline Parameter description & $\begin{array}{l}\text { Parameter } \\
\text { value }\end{array}$ & $\begin{array}{l}\text { Exposure } \\
\text { scenario }\end{array}$ & Comments \\
\hline Air intake (breathing rate) & $8,000 \mathrm{~m}^{3} / \mathrm{yr}$ & $\begin{array}{l}\text { Agriculture, } \\
\text { post-drilling }\end{array}$ & Standard value \\
\hline $\begin{array}{l}\text { Atmospheric mass loading of } \\
\text { contaminated surface soil - } \\
\text { working in garden }{ }^{\mathrm{a}} \\
\text { residing in home }\end{array}$ & $\begin{array}{l}10^{-7} \mathrm{~kg} / \mathrm{m}^{3} \\
10^{-8} \mathrm{~kg} / \mathrm{m}^{3}\end{array}$ & $\begin{array}{l}\text { Agriculture, } \\
\text { post-drilling }\end{array}$ & $\begin{array}{l}\text { Value based on site- } \\
\text { specific and nonurban U.S. } \\
\text { data }\end{array}$ \\
\hline Consumption of contaminated soil & $0.037 \mathrm{~kg} / \mathrm{yr}$ & $\begin{array}{l}\text { Agriculture, } \\
\text { post-drilling }\end{array}$ & $\begin{array}{l}\text { EPA value - may vary by at } \\
\text { least an order of magnitude }\end{array}$ \\
\hline $\begin{array}{l}\text { Consumption of contaminated } \\
\text { vegetables }\end{array}$ & $\begin{array}{l}90 \mathrm{~kg}(\mathrm{fresh} \\
\text { weight) per } \\
\text { year }\end{array}$ & $\begin{array}{l}\text { Agriculture, } \\
\text { post-drilling }\end{array}$ & $\begin{array}{l}\text { Site-specific and assumes } \\
1 / 2 \text { veg from garden }\end{array}$ \\
\hline Density of soil when waste is mixed in & $1,400 \mathrm{~kg} / \mathrm{m}^{3}$ & All & $\begin{array}{l}\text { Reasonable, and in } \\
\text { agreement with site- } \\
\text { specific values }\end{array}$ \\
\hline $\begin{array}{l}\text { Dilution factor for mixing of exhumed } \\
\text { waste with native soil in vegetable } \\
\text { garden }\end{array}$ & $\begin{array}{l}0.2^{b} \\
0.02^{c}\end{array}$ & $\begin{array}{l}\text { Agriculture, } \\
\text { post-drilling }\end{array}$ & $\begin{array}{l}\text { May vary by about } 1 \text { order } \\
\text { of magnitude; no data to } \\
\text { support, but consistent with } \\
\text { other intruder analyses }\end{array}$ \\
\hline $\begin{array}{l}\text { Exposure times - } \\
\text { working in garden } \\
\text { residing in home }\end{array}$ & $\begin{array}{l}1 \mathrm{percent} / \mathrm{yr} \\
50 \text { percent } / \mathrm{yr}\end{array}$ & All & $\begin{array}{l}\text { Reasonable, but could vary } \\
\text { for individuals }\end{array}$ \\
\hline Fraction remaining in waste & $\begin{array}{l}\text { Varies } \\
\text { according to } \\
\text { gw analysis }\end{array}$ & All & $\begin{array}{l}\text { May not be conservative } \\
\text { for intruders due to } \mathrm{K}_{\mathrm{d}} \\
\text { selection }\end{array}$ \\
\hline Plant-to-soil concentration factors & $\begin{array}{l}\text { Element- } \\
\text { specific }\end{array}$ & $\begin{array}{l}\text { Agriculture, } \\
\text { post-drilling }\end{array}$ & $\begin{array}{l}\text { May be uncertain by as } \\
\text { much as one-to-three orders } \\
\text { of magnitude }\end{array}$ \\
\hline $\begin{array}{l}\text { Shielding factor for external exposure } \\
\text { during indoor residence }\end{array}$ & 0.7 & $\begin{array}{l}\text { Agriculture, } \\
\text { resident }\end{array}$ & $\begin{array}{l}\text { May be uncertain by about } \\
\text { a factor of two }\end{array}$ \\
\hline $\begin{array}{l}\text { Thickness of engineered barriers - } \\
\text { LAW vaults } \\
\text { IL vaults }\end{array}$ & $\begin{array}{l}45 \mathrm{~cm} \\
100 \mathrm{~cm}\end{array}$ & Resident & $\begin{array}{l}\text { May be uncertain by } \\
\text { several } \mathrm{cm} \text {, but values are } \\
\text { underestimates }\end{array}$ \\
\hline
\end{tabular}

a Value of parameter applies to agriculture and post-drilling scenarios for inadvertent intruders.

b Value of parameter applies to agriculture scenario for inadvertent intruders.

c Value of parameter applies to post-drilling scenario for inadvertent intruders.

d Value of parameter applies to agriculture and resident scenarios for inadvertent intruders. 
Parameters listed in Table 6.4-1 that are the focus of the following discussion include: 1) atmospheric mass loading of contaminated surface soil; 2) consumption of contaminated soil; 3) exposure times for working in a garden and residing in a home; 4) fractions of initial radionuclide inventory remaining in the waste; and 5) plant-to-soil concentration factors. Other parameters listed in Table 6.4-1 are not a part of this discussion because they are either not considered as highly variable as the above-listed parameters (e.g., breathing rate of $8,000 \mathrm{~m}^{3} / \mathrm{yr}$; bulk density of soil or $1,400 \mathrm{~kg} / \mathrm{m}^{3}$; and shielding factor during indoor residence), and/or because their variability is not readily quantifiable. For parameters falling into this latter category (e.g., thicknesses of engineered barriers; annual consumption of $90 \mathrm{~kg}$ of home-grown vegetables; dilution factors for mixing exhumed or drilled waste into garden soil), conservative values were assumed that are likely to lead to overestimates of dose.

For all radionuclides and pathways, the fraction of radionuclide remaining in the waste at the time it is accessed by the intruder is important to the calculated inventory limit. In this PA, the fraction remaining is determined for many radionuclides in the analysis of leaching from the waste for water resource impacts. For some radionuclides, for which a leaching analysis was not done, it was assumed that only radioactive decay depletes the activity in the waste; a conservative assumption with respect to the intruder analysis. However, in the leaching analysis, sorption coefficients for radionuclides are chosen such that they tend to underestimate sorption, and thus overestimate ultimate groundwater concentration. For the intruder analysis, this is not a conservative approach. However, the following observation can be made. The radionuclides listed in Table 6.4-2, which are the more important radionuclides with respect to intruderbased inventory limits, tend to have high $\mathrm{K}_{d} \mathrm{~s}$. Thus, the estimated remaining fraction is highly dependent on their radioactive decay, which is a parameter that is well known. Although the possibility exists that sorption of a more mobile radionuclide is underestimated, the intruder models are not necessarily sensitive to this possibility due to the dominance of the highly-sorbing radionuclides.

For fission and activation products which do not emit significant intensities of high-energy photons (e.g., ${ }^{14} \mathrm{C},{ }^{90} \mathrm{Sr}$ and ${ }^{99} \mathrm{Tc}$ ), the vegetable pathway is the only significant contributor to the total dose for the agriculture and post-drilling scenarios, and the dose for this pathway is directly proportional to the plant-tosoil concentration ratio. Data available in the literature, which often were obtained under conditions that may not be representative of the SRS, indicate that this parameter could be uncertain by as much as one-tothree orders of magnitude depending upon the radionuclide ( $\mathrm{Ng}$ et al. 1982; Peterson 1983). From Table $6.4-2,{ }^{14} \mathrm{C}$ and ${ }^{90} \mathrm{Sr}$ are potentially significant contributors to intruder dose for the LAW vaults and slit trenches, respectively. Because the vegetable pathway is dominant in calculating dose, the intruder results for the LAW vaults are therefore sensitive to the value chosen for the plant-to-soil concentration ratio.

For actinide radioisotopes which do not emit significant intensities of high-energy photons (e.g., ${ }^{239} \mathrm{Pu}$ and ${ }^{241} \mathrm{Am}$ ), the soil ingestion and inhalation pathways are significant contributors to the total dose for the agriculture and post-drilling scenarios, unless radioactive daughters that emit high-energy photons grow in to significant levels. In the model for the soil ingestion pathway, the intake rate of contaminated soil is the only parameter that is subject to variability. There are few data on the distribution of intake rates that could be used to support an uncertainty analysis, but the intake rate presumably is uncertain by at least an order of magnitude. In the model for the inhalation pathway, the dose is proportional to the atmospheric mass loading of suspended activity from surface soil and exposure time in the garden. Generic data indicate that mass loading could be uncertain by two or three orders of magnitude (Anspaugh et al. 1975; Healy 1980). The assumed exposure time in a garden is probably uncertain by no more than a factor of three. 
Table 6.4-2 Radionuclides for Which Projected Inventories are Greater Than or Equal to $1 / 1,000^{\text {th }}$ of the Calculated Inventory Limits for the LAW Vaults and $1 / 100,000^{\text {th }}$ of the Calculated Inventory Limits for the Slit Trenches

\begin{tabular}{|c|c|c|c|c|}
\hline $\begin{array}{l}\text { Radionuclide } \\
\text { (disposal unit) }\end{array}$ & $\begin{array}{l}\text { Dominant } \\
\text { pathway for } \\
\text { exposure }\end{array}$ & $\begin{array}{c}\text { Projected } \\
\text { Inventory }(\mathrm{Ci})\end{array}$ & $\begin{array}{l}\text { Maximum calculated } \\
\text { inventory limit for any } \\
\text { scenario }(\mathrm{Ci})\end{array}$ & $\begin{array}{l}\text { Ratio of projected } \\
\text { inventory to } \\
\text { maximum inventory } \\
\text { limit }\end{array}$ \\
\hline \multicolumn{5}{|l|}{ LAW Vault: } \\
\hline$C-14$ & $\begin{array}{l}\text { ingestion of } \\
\text { vegetables }\end{array}$ & $1.5 \mathrm{E}-01$ & $1.5 \mathrm{E}+03$ & $1.0 \mathrm{E}-04$ \\
\hline Cs-137+d & external & $8.9 \mathrm{E}+01$ & $9.0 \mathrm{E}+03$ & $9.8 \mathrm{E}-03$ \\
\hline $\mathrm{Eu}-152$ & external & $6.2 E+00$ & $3.7 \mathrm{E}+04$ & $1.7 \mathrm{E}-04$ \\
\hline Th- $-232+d$ & external ${ }^{a}$ & $8.6 \mathrm{E}-03$ & $4.8 \mathrm{E}+00$ & $1.8 \mathrm{E}-03$ \\
\hline$U-233+d$ & external $^{a}$ & $9.8 \mathrm{E}-01$ & $4.5 \mathrm{E}+01$ & $2.2 \mathrm{E}-02$ \\
\hline $\mathrm{U}-234+\mathrm{d}$ & $\begin{array}{l}\text { ingestion of } \\
\text { vegetables; } \\
\text { inhalation; } \\
\text { external }^{\mathrm{a}}\end{array}$ & $6.6 \mathrm{E}-01$ & $3.6 \mathrm{E}+02$ & $1.9 \mathrm{E}-03$ \\
\hline $\mathrm{U}-235+\mathrm{d}$ & external & $1.4 \mathrm{E}-02$ & $2.6 \mathrm{E}+01$ & $5.4 \mathrm{E}-04$ \\
\hline$U-238+d$ & $\begin{array}{l}\text { ingestion of } \\
\text { vegetables; } \\
\text { inhalation; } \\
\text { external }\end{array}$ & $1.9 \mathrm{E}-01$ & $1.3 \mathrm{E}+02$ & $1.5 \mathrm{E}-03$ \\
\hline$N p-237+d$ & $\begin{array}{l}\text { ingestion of } \\
\text { vegetables; } \\
\text { external }\end{array}$ & $2.1 \mathrm{E}-02$ & $2.4 \mathrm{E}+01$ & $8.9 \mathrm{E}-04$ \\
\hline $\mathrm{Pu}-239+\mathrm{d}$ & $\begin{array}{l}\text { ingestion of } \\
\text { soil; inhalation }\end{array}$ & $1.9 \mathrm{E}+00$ & $1.8 \mathrm{E}+02$ & $1.1 \mathrm{E}-02$ \\
\hline$P u-240+d$ & $\begin{array}{l}\text { ingestion of } \\
\text { soil; inhalation }\end{array}$ & $6.8 \mathrm{E}-01$ & $2.6 \mathrm{E}+02$ & $2.6 \mathrm{E}-03$ \\
\hline \multicolumn{5}{|l|}{ Slit Trench: } \\
\hline $\mathrm{Sr}-90+\mathrm{d}$ & $\begin{array}{l}\text { ingestion of } \\
\text { vegetables }\end{array}$ & $1.2 \mathrm{E}-01$ & $2.1 \mathrm{E}+03$ & $5.7 \mathrm{E}-05$ \\
\hline$S n-126+d$ & external & 4.5E-04 & $1.9 \mathrm{E}+00$ & $2.4 \mathrm{E}-04$ \\
\hline Cs $-137+d$ & external & $8.8 \mathrm{E}-01$ & $6.3 \mathrm{E}+01$ & $1.4 \mathrm{E}-02$ \\
\hline Th- $232+d$ & external $^{a}$ & $5.9 \mathrm{E}-04$ & $1.4 \mathrm{E}+00$ & $4.2 \mathrm{E}-04$ \\
\hline$A m-241+d$ & $\begin{array}{l}\text { ingestion of } \\
\text { soil; inhalation }\end{array}$ & $2.2 \mathrm{E}-02$ & $2.7 \mathrm{E}+02$ & 8.1E-05 \\
\hline
\end{tabular}


The dose for the resident scenario is due entirely to external exposure; and, for radionuclides that emit significant intensities of high-energy photons (e.g., ${ }^{126} \mathrm{Sn}$ and ${ }^{137} \mathrm{Cs}$ ), this pathway is the only significant contributor to the total dose for the agriculture scenario and is an important contributor to the total dose for the post-drilling scenario. The dose from external exposure depends on the assumed exposure time and the amount of shielding between the source and receptor locations. Particularly in the resident scenario, estimates of external dose could be uncertain by an order of magnitude or more if the assumed thickness of shielding provided by engineered barriers is in error by only a few tens of $\mathrm{cm}$. As described in Appendix C.3, the assumed thicknesses of shielding for the types of disposal units constructed with engineered barriers probably result in overestimates of dose. External dose in the resident and agriculture scenarios also depends on the shielding factor for the walls of the home during indoor residence, and the duration of residence throughout a year. The shielding factor for the walls probably is uncertain by no more than a factor of two, as is the amount of time spent inside a home.

For some important parameters in the exposure pathway models, it is difficult to quantify the uncertainty even on the basis of generic data. An example of a parameter for which the uncertainty appears to be essentially unquantifiable is the assumed dilution factor for mixing of waste exhumed from disposal units with native soil in a vegetable garden. The dose from several exposure pathways in the agriculture scenario and from all exposure pathways in the post-drilling scenario is directly proportional to this dilution factor. An uncertainty analysis for this parameter could be based on estimated uncertainties in the volume of waste exhumed from disposal units, the fraction of exhumed waste that is mixed with soil in a vegetable garden, and the size of the garden. But, except for the assumed size of the garden, there are no data that could be used to support such an uncertainty analysis, essentially because the values are based primarily on assumptions presumed to be reasonable. The uncertainty in this dilution factor is probably an order of magnitude or more. However, it seems likely that the values chosen for use in this analysis tend to overestimate the average concentrations of radionuclides that would be found in contaminated soil in a vegetable garden. The dilution factor of 0.2 assumed in the agriculture scenario probably is conservative because exhumed waste presumably would not be fertile material and, thus, soil containing a significantly larger fraction of exhumed material would not support plant growth. The dilution factor of 0.02 assumed in the post-drilling scenario is based on reasonable assumptions for the volume of drilling waste and the size of the vegetable garden, and the assumption that all drilling waste is mixed with native soil in the garden clearly is conservative.

It is important to note that the most significant source of uncertainty in the estimates of the SDCFs for the different exposure scenarios probably is the definitions of the scenarios themselves, not withstanding any parameter uncertainties that could be quantified and regardless of whether or not the results would reasonably represent the variability in doses that could be experienced at the SRS. The dose analyses for inadvertent intruders are based on assumptions that the exposure scenarios will occur as postulated, but many of the explicit or implicit assumptions used in defining the scenarios are open to question and, furthermore, are likely to be conservative.

In defining exposure scenarios, it seems reasonable to assume that an inadvertent intruder will establish a homestead within the boundary of the disposal facility at some time after loss of active institutional controls. However, several of the assumptions used in developing the particular exposure scenarios used in this analysis are less certain and probably pessimistic. For example, all scenarios assume that individuals will have no knowledge of prior waste disposal activities at the site, but this assumption seems unreasonable for times soon after loss of active institutional controls. Furthermore, even if knowledge of the disposal facility were lost, all exposure scenarios assume that an inadvertent intruder will build a home or drill a well at the location of disposal units, rather than in uncontaminated areas, and that exhumed waste will be mixed with uncontaminated soil in a vegetable garden. Particularly at the SRS, it may also be pessimistic to assume that an intruder would excavate to depths well below the ground surface in constructing a home, because most homes near the site do not have a basement. 
By their very definitions, the exposure scenarios for inadvertent intruders assume conditions that probably tend to produce estimates of dose considerably greater than doses that reasonably could be received by most individuals who might come onto the disposal site. Therefore, it is not really the purpose of a dose analysis for inadvertent intruders to provide best estimates of dose that likely would be received and a quantification of uncertainties in these estimates. Rather, the primary purpose of the analysis is to establish WAC in the form of limits on average concentrations (total inventories) of radionuclides in waste. Furthermore, quantitative estimates of uncertainties in calculated doses (and, thus, in limits on average concentrations or inventories of radionuclides) based on parameter uncertainty analyses may not be meaningful, because the results are conditional on the occurrence of the assumed exposure scenarios. The most important factor in determining whether or not the WAC derived from dose analyses for inadvertent intruders are likely to be reasonable is the credibility of the assumed exposure scenarios, i.e., whether the assumed exposure scenarios reasonably could occur at a particular disposal facility, rather than any estimates of uncertainties in the results due to uncertainties in model parameters. 
THIS PAGE INTENTIONALLY LEFT BLANK 
SECTION 7

PERFORMANCE EVALUATION 
THIS PAGE INTENTIONALLY LEFT BLANK

Rev. 1 


\section{PERFORMANCE EVALUATION}

The purpose of this site-specific PA of the E-Area LLWF is to fulfill the DOE Order 435.1 requirement that such an assessment be prepared and maintained for any LLW disposal facility located at a DOE field site. The PA must provide reasonable assurance that the facility design and method of disposal will comply with the performance objectives of the Order, which are concerned with protection of public health and safety, limiting doses to members of the public and assessing impacts to hypothetical inadvertent intruders, and assessing impacts on water resouices. In this chapter of the PA, a comparison of the performance assessment results to the performance measures is provided and the utility of the results in developing operational limits is discussed. Ongoing or planned investigations that are needed in support of the PA process are also discussed.

\subsection{Comparison of Results to Performance Objectives}

The performance objectives and requirements of DOE Order 435.1 for LLW disposal are listed in Section 2.5. In essence, these objectives and requirements result in performance measures for members of the public and inadvertent intruders that are not to be exceeded through consideration of credible pathways.

For the assessment of impacts to water resources, it has been determined that compliance with current, not proposed, EPA standards is required because of the interpretation of CERCLA regulations by the State of South Carolina. However, if and when EPA changes those standards, the inventory limits presented in this report must be recalculated.

In order to evaluate the performance of the E-Area LLWF with respect to protection of the public from releases to water, soil, plants and animals and with respect to water resource impacts, groundwater concentrations were estimated, and compared with the more restrictive of either allowable groundwater concentrations based on a $25 \mathrm{mrem} / \mathrm{yr}$ dose (the performance objective for protection of off-site members of the public from radionuclides released to any media but the atmosphere) or MCLs (the performance measure for water resource impacts). Based on this comparison, inventory limits for the different types of disposal units planned for this facility were developed (Section 5.1). Inventory limits resulting from atmospheric releases of radionuclides were also evaluated (Section 5.2), based on a comparison of estimated doses with the EDE limit of $10 \mathrm{mrem} / \mathrm{yr}$ (Section 2.5). For inadvertent intruders, inventory limits were calculated and presented in Section 6, based on a comparison of estimated doses to intruders with the $100 \mathrm{mrem} / \mathrm{yr}$ limit on EDE for continuous exposure.

In this section, these calculated inventory limits are compared to the projected inventories for all of the disposal units, in order to evaluate whether the units will meet the performance measures from the standpoint of protection of the public, and assessing impacts on groundwater and hypothetical inadvertent intruders. The results of these comparisons are presented in Tables 7.1-1 through 7.1-6. The inventory limits in the second column of each of these tables lists the lowest limit calculated after consideration of all intruder scenarios, groundwater pathways, and air pathways for up to 10,000 years after closure of the facility. The limiting pathway is identified in the third column, which refers to the intruder scenario or groundwater or air pathway which provides this lowest limit for each radionuclide in a particular type of disposal unit. The fourth column lists the projected inventory of each radionuclide (from Appendix A) per vault, per naval reactor pad, or per number of trenches specified. Finally, the fifth column in these tables represents the value by which the performance of the disposal unit is evaluated in this PA; the ratio of the inventory limit (i.e., how much activity can be disposed of without violating requirements of the performance objectives) to the projected inventory. When the values in the fifth column are greater than one, disposal of the projected inventory is not expected to violate the requirements of the performance objectives. 
Table 7.1-1 Inventory Limits for LAW Vaults; Limiting Pathway; Comparison to Projected Inventory

\begin{tabular}{|c|c|c|c|c|}
\hline Radionuclide $^{\mathbf{a}}$ & $\begin{array}{l}\text { Inventory limit }{ }^{b} \\
\mathrm{Ci} / \text { vault }\end{array}$ & $\begin{array}{l}\text { Limiting } \\
\text { pathway }\end{array}$ & $\begin{array}{c}\text { Projected inventory } \\
\mathrm{Ci} / \text { vault }\end{array}$ & $\begin{array}{l}\text { Ratio of inventory limit } \\
\text { to projected inventory }\end{array}$ \\
\hline $\mathrm{H}-3$ & $6.4 \mathrm{E}+07$ & air & $5.5 \mathrm{E}+05$ & $1.1 \mathrm{E}+02$ \\
\hline C-14 & 2.7 & air & $1.5 \mathrm{E}-01$ & $1.8 \mathrm{E}+01$ \\
\hline Ni-59 & $1.1 \mathrm{E}+05$ & gw & 8.7E-02 & $1.2 \mathrm{E}+06$ \\
\hline Co-60 & $3.5 \mathrm{E}+07$ & resident & $8.6 \mathrm{E}+00$ & $4.1 \mathrm{E}+06$ \\
\hline $\mathrm{Ni}-63$ & $2.8 \mathrm{E}+14$ & post drilling & $6.5 E+00$ & $4.2 E+13$ \\
\hline $\mathrm{Se}-79$ & $1.0 \mathrm{E}+02$ & gw & $2.7 \mathrm{E}-02$ & $3.8 \mathrm{E}+03$ \\
\hline Rb-87 & $1.7 \mathrm{E}-01$ & gw & $0.0 \mathrm{E}+00$ & $\ldots$ \\
\hline $\mathrm{Sr}-90+\mathrm{d}$ & $4.6 E+18$ & gw & $6.2 \mathrm{E}+01$ & $7.5 \mathrm{E}+16$ \\
\hline $\mathrm{Zr}-93+\mathrm{d}$ & 4.1E+02 & gw & $9.2 \mathrm{E}-06$ & $4.5 \mathrm{E}+07$ \\
\hline $\mathrm{Nb}-94$ & $2.9 \mathrm{E}-01$ & gw & $9.6 \mathrm{E}-09$ & $3.0 \mathrm{E}+07$ \\
\hline Tc-99 & $5.3 E+00$ & gw & $3.3 E-02$ & $1.6 \mathrm{E}+02$ \\
\hline Pd-107 & $2.2 \mathrm{E}+01$ & gw & $3.2 \mathrm{E}-13$ & $6.9 E+13$ \\
\hline$S n-126+d$ & $7.3 \mathrm{E}+01$ & gw & $6.8 \mathrm{E}-04$ & $3.4 \mathrm{E}+04$ \\
\hline $\mathrm{I}-129$ & $6.1 \mathrm{E}-04$ & gw & $3.6 \mathrm{E}-05$ & $1.7 \mathrm{E}+01$ \\
\hline Cs-135 & $3.1 \mathrm{E}+00$ & gw & $1.4 \mathrm{E}-09$ & $2.2 \mathrm{E}+09$ \\
\hline Cs $-137+d$ & $9.0 \mathrm{E}+03$ & resident & $8.9 \mathrm{E}+01$ & $1.0 \mathrm{E}+02$ \\
\hline Sm-151 & $5.6 \mathrm{E}+16$ & post drilling & $1.4 \mathrm{E}-04$ & $>1 E 20$ \\
\hline $\mathrm{Eu}-152$ & $3.8 \mathrm{E}+04$ & resident & $6.2 E+00$ & $6.0 \mathrm{E}+03$ \\
\hline Eu-154 & $5.0 \mathrm{E}+05$ & resident & $4.1 E+00$ & $1.2 \mathrm{E}+05$ \\
\hline Th- $232+d$ & $4.8 \mathrm{E}+00$ & agriculture & $8.6 \mathrm{E}-03$ & $5.6 \mathrm{E}+02$ \\
\hline$U-232+d$ & $1.7 \mathrm{E}+02$ & resident & $1.6 \mathrm{E}-02$ & $1.0 \mathrm{E}+04$ \\
\hline $\mathrm{U}-233+\mathrm{d}$ & $4.5 E+01$ & agriculture & $9.8 \mathrm{E}-01$ & $4.6 \mathrm{E}+01$ \\
\hline $\mathrm{U}-234+\mathrm{d}$ & $1.2 \mathrm{E}+02$ & radon & $6.6 \mathrm{E}-01$ & $1.8 \mathrm{E}+02$ \\
\hline $\mathrm{U}-235+\mathrm{d}$ & $2.6 \mathrm{E}+01$ & agriculture & $1.4 \mathrm{E}-02$ & $1.8 \mathrm{E}+03$ \\
\hline $\mathrm{U}-236$ & $5.8 \mathrm{E}+02$ & agriculture & $2.4 \mathrm{E}-02$ & $2.4 \mathrm{E}+04$ \\
\hline $\mathrm{Np}-237+\mathrm{d}$ & $4.2 \mathrm{E}+00$ & gw & $2.1 \mathrm{E}-02$ & $2.0 \mathrm{E}+02$ \\
\hline $\mathrm{U}-238+\mathrm{d}$ & $1.3 E+02$ & agriculture & $1.9 \mathrm{E}-01$ & $6.7 E+02$ \\
\hline Pu-238 +d & $1.5 \mathrm{E}+06$ & agriculture & $5.2 \mathrm{E}+00$ & $2.9 E+05$ \\
\hline Pu-239+d & $1.8 \mathrm{E}+02$ & agriculture & $2.1 \mathrm{E}+00$ & $8.6 \mathrm{E}+01$ \\
\hline Pu-240 +d & $2.6 \mathrm{E}+02$ & agriculture & $6.8 \mathrm{E}-01$ & $3.8 \mathrm{E}+02$ \\
\hline$A m-241+d$ & $2.1 \mathrm{E}+04$ & gw & $5.3 E-01$ & $4.0 \mathrm{E}+04$ \\
\hline$P u-241+d$ & $6.3 E+05$ & gw & $3.0 \mathrm{E}+01$ & $2.1 \mathrm{E}+04$ \\
\hline $\mathrm{Pu}-242+\mathrm{d}$ & $1.6 \mathrm{E}+02$ & agriculture & $3.7 \mathrm{E}-04$ & $4.3 \mathrm{E}+05$ \\
\hline$A m-243+d$ & $2.4 \mathrm{E}+00$ & gw & $5.0 \mathrm{E}-05$ & $4.8 E+04$ \\
\hline $\mathrm{Pu}-244+\mathrm{d}$ & $1.2 E+01$ & agriculture & $2.4 \mathrm{E}-15$ & $4.9 E+15$ \\
\hline $\mathrm{Cm}-244+\mathrm{d}$ & $9.4 \mathrm{E}+04$ & agriculture & $4.4 \mathrm{E}-02$ & $2.1 \mathrm{E}+06$ \\
\hline $\mathrm{Cm}-245+\mathrm{d}$ & $3.6 \mathrm{E}+01$ & gw & $1.4 \mathrm{E}-09$ & $2.7 \mathrm{E}+10$ \\
\hline $\mathrm{Cm}-246$ & $3.2 \mathrm{E}+02$ & agriculture & $5.4 \mathrm{E}-10$ & $5.9 \mathrm{E}+11$ \\
\hline $\mathrm{Cm}-247+\mathrm{d}$ & $1.7 E+00$ & gw & $1.4 \mathrm{E}-12$ & $1.2 E+12$ \\
\hline $\mathrm{Cm}-248+\mathrm{d}$ & $4.4 \mathrm{E}+01$ & agriculture & $5.2 \mathrm{E}-15$ & $8.5 E+15$ \\
\hline C $-249+d$ & $8.5 E+02$ & gw & $1.2 \mathrm{E}-05$ & $7.0 \mathrm{E}+07$ \\
\hline $\mathrm{Cf}-250+\mathrm{d}$ & $1.2 E+05$ & agriculture & $1.6 \mathrm{E}-03$ & $7.4 \mathrm{E}+07$ \\
\hline $\mathrm{Cf}-251$ & $1.8 \mathrm{E}+03$ & agriculture & $3.2 \mathrm{E}-10$ & $5.6 \mathrm{E}+12$ \\
\hline Cf $-252+d$ & $5.9 E+06$ & agriculture & $1.4 \mathrm{E}-02$ & $4.4 E+08$ \\
\hline
\end{tabular}


b Inventory limit based on consideration of peak groundwater concentration outside $100-\mathrm{m}$ buffer zone around disposal units (Section 5) and inadvertent intruder doses (Section 6).

c Refers to intruder scenario, groundwater ingestion pathway ("gw"), or air pathway; whichever is more restrictive with respect to developing inventory limits.

d A ratio that is one or greater indicates the projected inventory is less than the estimated inventory limit and the performance objectives are met.

' Projected inventory is zero; therefore, assume performance objectives are met. 
Table 7.1-2 Inventory Limits for IL Vaults; Limiting Pathway; Comparison to Projected Inventory

\begin{tabular}{|c|c|c|c|c|}
\hline Radionuclide $^{a}$ & $\begin{array}{c}\text { Inventory limit }^{6} \\
\mathrm{Ci} / \text { vault }\end{array}$ & $\begin{array}{l}\text { Limiting } \\
\text { pathway }\end{array}$ & $\begin{array}{c}\text { Projected inventory } \\
\mathrm{Ci} / \text { vault }\end{array}$ & $\begin{array}{l}\text { Ratio of inventory limit } \\
\text { to projected inventory }\end{array}$ \\
\hline $\mathbf{H}-3$ & $5.5 \mathrm{E}+07$ & air & $4.32 \mathrm{E}+05$ & $1.2 \mathrm{E}+02$ \\
\hline$C-14$ & $2.7 \mathrm{E}+00$ & air & $3.52 \mathrm{E}-01$ & $7.7 \mathrm{E}+00$ \\
\hline $\mathrm{Ni}-59$ & $5.3 \mathrm{E}+02$ & gw & $9.10 \mathrm{E}-02$ & $5.8 \mathrm{E}+03$ \\
\hline Co-60 & $6.3 \mathrm{E}+08$ & resident & $1.69 \mathrm{E}+02$ & 3.7E+06 \\
\hline $\mathrm{Ni}-63$ & $\ldots$ & $\ldots$ & $8.60 \mathrm{E}+00$ & $\ldots e^{e}$ \\
\hline Se-79 & $2.8 \mathrm{E}+01$ & gw & $2.97 \mathrm{E}-04$ & $9.3 \mathrm{E}+04$ \\
\hline $\mathrm{Sr}-90+d$ & $1.3 E+10$ & gw & $3.69 \mathrm{E}+01$ & $5.0 \mathrm{E}+08$ \\
\hline$Z r-93+d$ & $1.0 \mathrm{E}+06^{6 \mathrm{f}}$ & gw & $1.22 \mathrm{E}-05$ & $8.4 E+10$ \\
\hline Tc-99 & $2.2 \mathrm{E}+01$ & gw & $9.97 \mathrm{E}-02$ & $2.2 \mathrm{E}+02$ \\
\hline$S n-126+d$ & $7.5 \mathrm{E}-01$ & resident & $1.88 \mathrm{E}-03$ & $4.0 \mathrm{E}+02$ \\
\hline $\mathrm{I}-129$ & $2.6 \mathrm{E}-04$ & gw & $2.51 \mathrm{E}-05$ & $1.0 \mathrm{E}+01$ \\
\hline Cs-135 & 1.1E+02 & gw & $0.00 \mathrm{E}+00$ & $\ldots{ }^{f}$ \\
\hline Cs $-137+d$ & $6.5 \mathrm{E}+05$ & resident & $2.30 \mathrm{E}+02$ & $2.8 \mathrm{E}+03$ \\
\hline Eu-154 & $1.1 \mathrm{E}+07$ & resident & $2.59 \mathrm{E}-01$ & 4.1E+07 \\
\hline Th-232+d & $4.2 \mathrm{E}-01$ & resident & $5.52 \mathrm{E}-05$ & $7.5 \mathrm{E}+03$ \\
\hline$U-232+d$ & $9.4 E+02$ & resident & $1.85 \mathrm{E}-06$ & $5.1 E+08$ \\
\hline $\mathrm{U}-233+\mathrm{d}$ & $7.0 \mathrm{E}+00$ & resident & $2.65 \mathrm{E}-01$ & $2.6 \mathrm{E}+01$ \\
\hline $\mathrm{U}-234+\mathrm{d}$ & $1.5 \mathrm{E}+01$ & radon & $3.22 \mathrm{E}-01$ & $4.7 \mathrm{E}+01$ \\
\hline $\mathrm{U}-235+\mathrm{d}$ & $6.0 \mathrm{E}+00$ & resident & $1.58 \mathrm{E}-02$ & $3.8 \mathrm{E}+02$ \\
\hline U-236 & $2.2 \mathrm{E}+12$ & gw & 4.17E-03 & $5.3 E+14$ \\
\hline $\mathrm{Np}-237+\mathrm{d}$ & $6.0 \mathrm{E}+00$ & resident & $9.16 \mathrm{E}-05$ & $6.6 \mathrm{E}+04$ \\
\hline $\mathrm{U}-238+\mathrm{d}$ & $4.9 \mathrm{E}+01$ & resident & $1.59 \mathrm{E}+00$ & $3.1 E+01$ \\
\hline $\mathrm{Pu}-238+\mathrm{d}$ & $2.2 \mathrm{E}+10$ & gw & $3.12 \mathrm{E}+00$ & $7.2 E+09$ \\
\hline Pu-239 +d & $4.3 \mathrm{E}+11$ & gw & $3.53 \mathrm{E}-01$ & 1.2E+12 \\
\hline Pu-240 +d & $1.9 \mathrm{E}+11$ & gw & $1.60 \mathrm{E}-02$ & $1.2 \mathrm{E}+13$ \\
\hline$A m-241+d$ & $3.0 \mathrm{E}+04$ & resident & $1.17 \mathrm{E}+00$ & $2.5 \mathrm{E}+04$ \\
\hline Pu-241 +d & $8.9 \mathrm{E}+05$ & resident & $1.15 \mathrm{E}+00$ & $7.7 \mathrm{E}+05$ \\
\hline Pu-242 +d & $5.8 \mathrm{E}+12$ & gw & $5.60 \mathrm{E}-03$ & $1.0 \mathrm{E}+15$ \\
\hline$A m-242 m+d$ & $2.7 \mathrm{E}+07$ & resident & $2.03 \mathrm{E}-05$ & 1. $3 E+12$ \\
\hline$A m-243+d$ & $1.9 \mathrm{E}+01$ & resident & $1.82 \mathrm{E}-07$ & $1.0 \mathrm{E}+08$ \\
\hline $\mathrm{Pu}-244+\mathrm{d}$ & $3.1 \mathrm{E}+00$ & resident & $2.73 \mathrm{E}-15$ & $1.1 E+15$ \\
\hline $\mathrm{Cm}-244+\mathrm{d}$ & $7.0 \mathrm{E}+13$ & gw & $2.35 E+00$ & $3.0 \mathrm{E}+13$ \\
\hline $\mathrm{Cm}-245+\mathrm{d}$ & $3.8 \mathrm{E}+01$ & resident & $1.52 \mathrm{E}-09$ & $2.5 \mathrm{E}+10$ \\
\hline $\mathrm{Cm}-246$ & $1.7 \mathrm{E}+17$ & gw & $6.08 \mathrm{E}-10$ & $>1 E 20$ \\
\hline $\mathrm{Cm}-247+\mathrm{d}$ & $3.4 \mathrm{E}+00$ & resident & $1.82 \mathrm{E}-15$ & $1.9 E+15$ \\
\hline $\mathrm{Cm}-248+\mathrm{d}$ & 8.1E+02 & resident & $5.76 \mathrm{E}-15$ & $1.4 \mathrm{E}+17$ \\
\hline Cf- $249+d$ & $8.9 \mathrm{E}+02$ & resident & $3.00 \mathrm{E}-14$ & $3.0 \mathrm{E}+16$ \\
\hline $\mathrm{Cf}-251$ & $2.7 E+04$ & resident & $1.21 \mathrm{E}-15$ & $2.2 E+19$ \\
\hline Cf $-252+d$ & $6.9 \mathrm{E}+10$ & gw & $0.00 \mathrm{E}+00$ & $---{ }^{f}$ \\
\hline
\end{tabular}

" " $+\mathrm{d}$ " indicates potentially-significant short- and long-lived daughters are accounted for in the limit

b Inventory limit based on consideration of peak groundwater concentration outside $100-\mathrm{m}$ buffer zone around disposal units (Section 5) and inadvertent intruder doses (Section 6)

c Refers to intruder scenario, groundwater ingestion pathway ("gw"), or air pathway; whichever is more restrictive with respect to developing inventory limits.

d A ratio that is one or greater indicates the projected inventory is less than the estimated inventory limit and the performance objectives are met. 
' Radionuclide only of potential concern for agriculture scenario, which is not credible in first 10,000 years after disposal.

Projected inventory is zero; therefore, assume performance objectives are met. 
Table 7.1-3 Inventory Limits for Slit Trenches; Limiting Pathway; Comparison to Projected Inventory

\begin{tabular}{|c|c|c|c|c|}
\hline Radionuclide $^{a}$ & $\begin{array}{l}\text { Inventory limit } \\
\mathrm{Ci} / 5 \text { trenches }\end{array}$ & $\begin{array}{l}\text { Limiting } \\
\text { pathway }{ }^{c}\end{array}$ & $\begin{array}{l}\text { Projected inventory } \\
\text { Ci/ } 5 \text { trenches }\end{array}$ & $\begin{array}{l}\text { Ratio of inventory limit } \\
\text { to projected inventory }\end{array}$ \\
\hline $\mathrm{H}-3$ & $6.3 \mathrm{E}+00$ & gw & $4.10 \mathrm{E}+00$ & $1.5 \mathrm{E}+00$ \\
\hline C-14 & $2.7 \mathrm{E}+00$ & air & $7.50 \mathrm{E}-03$ & $3.6 \mathrm{E}+02$ \\
\hline $\mathrm{Ni}-59$ & $3.7 \mathrm{E}+02$ & gw & $6.53 \mathrm{E}-03$ & $4.4 \mathrm{E}+04$ \\
\hline $\mathrm{Co}-60$ & $7.3 \mathrm{E}+08$ & post drilling & $5.95 \mathrm{E}-02$ & $1.2 \mathrm{E}+10$ \\
\hline $\mathrm{Ni}-63$ & $2.8 \mathrm{E}+05$ & post drilling & $1.77 \mathrm{E}-02$ & $1.6 \mathrm{E}+07$ \\
\hline $\mathrm{Se}-79$ & $1.1 \mathrm{E}+02$ & gw & $3.58 \mathrm{E}-05$ & 3.1E+06 \\
\hline Rb-87 & $3.1 \mathrm{E}-01$ & gw & $0.00 \mathrm{E}+00$ & --- ${ }^{e}$ \\
\hline $\mathrm{Sr}-90+\mathrm{d}$ & $5.7 \mathrm{E}+02$ & gw & $1.40 \mathrm{E}-01$ & 4. $1 E+03$ \\
\hline $\mathrm{Zr}-93+\mathrm{d}$ & $2.8 \mathrm{E}+01$ & gw & $0.00 \mathrm{E}+00$ & $--^{e}$ \\
\hline Tc-99 & $5.5 \mathrm{E}-01$ & gw & $2.43 \mathrm{E}-03$ & $2.2 \mathrm{E}+02$ \\
\hline Pd-107 & $4.1 \mathrm{E}+01$ & gw & $0.00 \mathrm{E}+00$ & - -.- $^{e}$ \\
\hline $\mathrm{Cd}-113 \mathrm{~m}$ & $2.4 \mathrm{E}+04$ & post drilling & $0.00 \mathrm{E}+00$ & $--^{e}$ \\
\hline $\mathrm{Sn}-121 \mathrm{~m}$ & $1.2 \mathrm{E}+06$ & post drilling & $0.00 \mathrm{E}+00$ & $\ldots$ \\
\hline$S n-126+d$ & $5.6 \mathrm{E}+01$ & agriculture & $4.50 \mathrm{E}-04$ & $1.2 \mathrm{E}+05$ \\
\hline $1-129$ & $5.2 \mathrm{E}-04$ & gw & $2.98 \mathrm{E}-07$ & $1.8 \mathrm{E}+03$ \\
\hline Cs-135 & $3.9 \mathrm{E}+02$ & gw & $8.78 \mathrm{E}-01$ & $3.2 \mathrm{E}+02$ \\
\hline Cs $-137+d$ & $2.1 E+04$ & post drilling & $8.78 \mathrm{E}-01$ & $2.4 \mathrm{E}+04$ \\
\hline $\mathrm{Sm}-151$ & $6.1 \mathrm{E}+06$ & post drilling & $0.00 \mathrm{E}+00$ & $--^{c}$ \\
\hline Eu-154 & $8.1 E+06$ & post drilling & 4.43E-04 & $1.8 \mathrm{E}+10$ \\
\hline Th-228 & $5.5 E+19$ & post drilling & $5.93 E-04$ & $>1 E 20$ \\
\hline Th-232+d & $1.3 E+00$ & agriculture & $5.93 \mathrm{E}-04$ & $2.2 \mathrm{E}+03$ \\
\hline$U-232+d$ & $1.4 \mathrm{E}+01$ & gw & $0.00 \mathrm{E}+00$ & $---^{e}$ \\
\hline$U-233+d$ & $2.4 \mathrm{E}+00$ & gw & $8.25 E-08$ & $2.9 \mathrm{E}+07$ \\
\hline $\mathrm{U}-234+\mathrm{d}$ & $8.5 \mathrm{E}+00$ & gw & $5.38 \mathrm{E}-03$ & $6.3 E+02$ \\
\hline $\mathrm{U}-235+\mathrm{d}$ & $4.9 \mathrm{E}+00$ & gw & $1.75 \mathrm{E}-04$ & $2.8 \mathrm{E}+04$ \\
\hline $\mathrm{U}-236$ & $9.6 \mathrm{E}-02$ & gw & $5.00 \mathrm{E}-04$ & $1.9 \mathrm{E}+02$ \\
\hline $\mathrm{Np}-237+\mathrm{d}$ & $4.8 \mathrm{E}-02$ & gw & $1.53 \mathrm{E}-05$ & $3.2 E+03$ \\
\hline $\mathrm{U}-238+\mathrm{d}$ & $2.4 \mathrm{E}-01$ & gw & $2.70 \mathrm{E}-03$ & $8.7 \mathrm{E}+01$ \\
\hline Pu-238 +d & $2.8 \mathrm{E}+02$ & gw & $5.05 \mathrm{E}-03$ & $5.6 \mathrm{E}+04$ \\
\hline$P u-239+d$ & $9.6 \mathrm{E}-01$ & gw & $1.37 \mathrm{E}-03$ & $6.8 \mathrm{E}+02$ \\
\hline Pu-240 +d & $1.2 \mathrm{E}+00$ & gw & $2.68 \mathrm{E}-04$ & $4.4 E+03$ \\
\hline$A m-241+d$ & $2.4 \mathrm{E}+02$ & gw & $2.19 \mathrm{E}-02$ & $1.1 E+04$ \\
\hline Pu-241 +d & $7.2 \mathrm{E}+03$ & gw & $1.45 \mathrm{E}-02$ & $4.9 \mathrm{E}+05$ \\
\hline Pu-242 +d & $1.7 \mathrm{E}-02$ & gw & $6.03 E-06$ & $2.8 \mathrm{E}+03$ \\
\hline$A m-242 m+d$ & $8.1 \mathrm{E}+02$ & post drilling & $0.00 \mathrm{E}+00$ & $--^{e}$ \\
\hline$A m-243+d$ & $9.0 \mathrm{E}-01$ & gw & $1.97 \mathrm{E}-06$ & $4.5 E+05$ \\
\hline $\mathrm{Pu}-244+\mathrm{d}$ & $1.8 \mathrm{E}-02$ & gw & $0.00 \mathrm{E}+00$ & $\ldots e^{e}$ \\
\hline $\mathrm{Cm}-242+\mathrm{d}$ & $1.8 E+05$ & gw & $0.00 \mathrm{E}+00$ & $\ldots-^{e}$ \\
\hline $\mathrm{Cm}-243$ & $1.8 \mathrm{E}+04$ & post drilling & $0.00 \mathrm{E}+00$ & $\ldots{ }^{e}$ \\
\hline $\mathrm{Cm}-244+\mathrm{d}$ & $4.3 E+02$ & gw & $3.58 \mathrm{E}-04$ & $1.2 E+06$ \\
\hline $\mathrm{Cm}-245+\mathrm{d}$ & $3.7 \mathrm{E}+01$ & agriculture & $0.00 \mathrm{E}+00$ & $-e^{e}$ \\
\hline $\mathrm{Cm}-246$ & $1.4 \mathrm{E}+02$ & agriculture & $0.00 \mathrm{E}+00$ & $---{ }^{e}$ \\
\hline $\mathrm{Cm}-247+\mathrm{d}$ & $7.1 \mathrm{E}-01$ & gw & $0.00 \mathrm{E}+00$ & $---^{e}$ \\
\hline $\mathrm{Cm}-248+d$ & $3.6 \mathrm{E}+01$ & agriculture & $0.00 \mathrm{E}+00$ & $--^{e}$ \\
\hline Bk-249 +d & $2.8 \mathrm{E}+04$ & agriculture & $0.00 \mathrm{E}+00$ & $--^{e}$ \\
\hline Cf $-249+d$ & $6.9 \mathrm{E}+01$ & agriculture & $0.00 \mathrm{E}+00$ & $\ldots e^{e}$ \\
\hline
\end{tabular}


Table 7.1-3 Inventory Limits for Slit Trenches; Limiting Pathway; Comparison to Projected Inventory

\begin{tabular}{llccl}
\hline Radionuclide $^{\mathrm{a}}$ & $\begin{array}{l}\text { Inventory limit } \\
\mathrm{Ci} / 5 \text { trenches }\end{array}$ & $\begin{array}{c}\text { Limiting } \\
\text { pathway }\end{array}$ & $\begin{array}{c}\text { Projected inventory } \\
\mathrm{Ci} / 5 \text { trenches }\end{array}$ & $\begin{array}{l}\text { Ratio of inventory limit } \\
\text { to projected inventory }\end{array}$ \\
\hline $\mathrm{Cf}-250+\mathrm{d}$ & $4.8 \mathrm{E}+04$ & agriculture & $0.00 \mathrm{E}+00$ & $\cdots$ \\
$\mathrm{Cf}-251$ & $5.2 \mathrm{E}+01$ & agriculture & $0.00 \mathrm{E}+00$ & $\ldots-\mathrm{-c}^{\mathrm{e}}$ \\
$\mathrm{Cf}-252+\mathrm{d}$ & $4.5 \mathrm{E}+06$ & agriculture & $0.00 \mathrm{E}+00$ & $\ldots-\mathrm{c}^{\mathrm{e}}$ \\
\hline
\end{tabular}

a " $+d$ " indicates potentially-significant short- and long-lived daughters are accounted for in the limit.

b Inventory limit based on consideration of peak groundwater concentration outside 100 -m buffer zone around disposal units (Section 5) and inadvertent intruder doses (Section 6).

c Refers to intruder scenario, groundwater ingestion pathway ("gw"), or air pathway; whichever is more restrictive with respect to developing inventory limits.

d A ratio that is one or greater indicates the projected inventory is less than the estimated inventory limit and the performance objectives are met.

e Projected inventory is zero; therefore, assume performance objectives are met. 
Table 7.1-4 Inventory Limits for Naval Reactor Pad Waste; Limiting Pathway; Comparison to Projected Inventory

\begin{tabular}{|c|c|c|c|c|}
\hline Radionuclide $^{\mathrm{a}}$ & $\begin{array}{c}\text { Inventory limit } \\
\mathrm{Ci}\end{array}$ & Limiting pathway $^{c}$ & $\begin{array}{c}\text { Projected } \\
\text { inventory } \\
\mathrm{Ci} / \text { pad } \\
\end{array}$ & $\begin{array}{l}\text { Ratio of inventory } \\
\text { limit to projected } \\
\text { inventory } \mathrm{d}\end{array}$ \\
\hline $\mathrm{H}-3$ & $3.2 \mathrm{E}+05$ & air & $1.1 \mathrm{E}+02$ & $2.9 \mathrm{E}+03$ \\
\hline C-14 & $2.8 E+03$ & gw & $2.3 E+02$ & $1.2 \mathrm{E}+01$ \\
\hline $\mathrm{Ni}-59$ & $1.7 \mathrm{E}+03$ & gw & $2.6 \mathrm{E}+03$ & $6.3 \mathrm{E}-01$ \\
\hline $\mathrm{Co}-60$ & $>1 \mathrm{E} 20^{\mathrm{e}}$ & agriculture & $2.3 E+05$ & $>1 \mathrm{E} 20^{\circ}$ \\
\hline $\mathrm{Ni}-63$ & $>1 \mathrm{E} 20^{\mathrm{e}}$ & agriculture & $3.0 \mathrm{E}+05$ & $>1 \mathrm{E} 20^{\circ}$ \\
\hline $\mathrm{Se}-79$ & $8.6 \mathrm{E}+01$ & gw & $3.5 \mathrm{E}-04$ & $2.5 \mathrm{E}+05$ \\
\hline Sr-90+d & $3.7 E+09$ & gw & $4.4 \mathrm{E}+00$ & $8.5 \mathrm{E}+08$ \\
\hline Mo-93 & $1.2 \mathrm{E}+02$ & gw & 4.1E-01 & $2.8 \mathrm{E}+02$ \\
\hline $\mathrm{Zr}-93+\mathrm{d}$ & $5.7 E+05$ & gw & $3.6 \mathrm{E}-05$ & $1.6 \mathrm{E}+10$ \\
\hline $\mathrm{Nb}-94$ & $2.5 \mathrm{E}+01$ & gw & $1.1 \mathrm{E}+01$ & $2.3 \mathrm{E}+00$ \\
\hline Tc-99 & $1.0 \mathrm{E}+02$ & gw & $2.4 \mathrm{E}-01$ & $4.3 E+02$ \\
\hline $\mathrm{Sn}-126+d$ & $3.5 \mathrm{E}+01$ & gw & $6.0 \mathrm{E}-06$ & $5.8 \mathrm{E}+06$ \\
\hline $\mathrm{I}-129$ & $5.0 \mathrm{E}-02$ & gw & $1.9 \mathrm{E}-06$ & $2.6 \mathrm{E}+04$ \\
\hline Cs- 135 & $4.0 \mathrm{E}+02$ & gw & $2.9 \mathrm{E}-05$ & $1.4 \mathrm{E}+07$ \\
\hline Cs- $137+d$ & $>1 \mathrm{E} 20^{\mathrm{e}}$ & agriculture & $4.3 E+00$ & $>1 E 20^{\circ}$ \\
\hline $\mathrm{Sm}-151$ & $>1 \mathrm{E} 20^{\mathrm{e}}$ & agriculture & $4.5 E-02$ & $>1 \mathrm{E} 20^{\circ}$ \\
\hline Eu-154 & $>1 \mathrm{E} 20^{e}$ & agriculture & $5.6 \mathrm{E}-02$ & $>1 \mathrm{E} 20^{\circ}$ \\
\hline Th- $232+d$ & $5.7 \mathrm{E}+02$ & agriculture & $1.3 \mathrm{E}-11$ & $4.5 E+13$ \\
\hline$U-232+d$ & $1.1 \mathrm{E}+08$ & gw & $2.0 \mathrm{E}-07$ & $5.5 E+14$ \\
\hline $\mathrm{U}-234+\mathrm{d}$ & $2.3 E+01$ & gw & $2.3 E-06$ & $9.9 E+06$ \\
\hline$U-235+d$ & $3.4 \mathrm{E}+01$ & gw & $1.7 \mathrm{E}-07$ & $2.0 \mathrm{E}+08$ \\
\hline U-236 & $3.4 \mathrm{E}+01$ & gw & $3.5 \mathrm{E}-06$ & $9.7 \mathrm{E}+06$ \\
\hline $\mathrm{Np}-237+\mathrm{d}$ & $8.9 \mathrm{E}-01$ & gw & $3.3 \mathrm{E}-06$ & $2.7 \mathrm{E}+05$ \\
\hline$U-238+d$ & $1.6 \mathrm{E}+00$ & gw & $1.9 E-05$ & $8.4 E+04$ \\
\hline $\mathrm{Pu}-238+\mathrm{d}$ & $1.5 E+06$ & gw & $2.2 \mathrm{E}-01$ & $6.7 \mathrm{E}+06$ \\
\hline $\mathrm{Pu}-239+\mathrm{d}$ & $7.9 \mathrm{E}+00$ & gw & $2.9 \mathrm{E}-01$ & $2.7 E+01$ \\
\hline $\mathrm{Pu}-240+\mathrm{d}$ & $1.7 \mathrm{E}+01$ & gw & $7.7 \mathrm{E}-02$ & $2.2 E+02$ \\
\hline Am-24l $+d$ & $4.4 E+03$ & gw & $1.4 \mathrm{E}-01$ & $3.1 E+04$ \\
\hline $\mathrm{Pu}-241+\mathrm{d}$ & $1.3 \mathrm{E}+05$ & gw & $2.0 \mathrm{E}+01$ & $6.7 \mathrm{E}+03$ \\
\hline $\mathrm{Pu}-242+\mathrm{d}$ & $6.1 E+00$ & gw & $3.4 \mathrm{E}-04$ & $1.8 E+04$ \\
\hline$A m-242 m+d$ & $1.8 \mathrm{E}+06$ & agriculture & $1.2 \mathrm{E}-06$ & $1.5 \mathrm{E}+12$ \\
\hline$A m-243+d$ & $1.7 \mathrm{E}+02$ & agriculture & $2.0 \mathrm{E}-03$ & $8.6 \mathrm{E}+04$ \\
\hline Pu-244 +d & $6.2 E+00$ & gw & $6.1 \mathrm{E}-15$ & $1.0 \mathrm{E}+15$ \\
\hline $\mathrm{Cm}-242+\mathrm{d}$ & $3.7 E+10$ & agriculture & $2.4 \mathrm{E}+00$ & $1.5 \mathrm{E}+10$ \\
\hline $\mathrm{Cm}-243$ & $>1 \mathrm{E} 20^{\mathrm{e}}$ & agriculture & $3.4 \mathrm{E}-07$ & $>1 \mathrm{E} 20^{\mathrm{e}}$ \\
\hline $\mathrm{Cm}-244+\mathrm{d}$ & $6.1 \mathrm{E}+03$ & $\mathrm{gw}$ & $1.6 \mathrm{E}-01$ & $3.9 \mathrm{E}+04$ \\
\hline $\mathrm{Cm}-245+\mathrm{d}$ & $3.3 E+00$ & gw & $8.4 \mathrm{E}-06$ & $3.9 \mathrm{E}+05$ \\
\hline $\mathrm{Cm}-246$ & $1.7 \mathrm{E}+03$ & agriculture & $3.2 \mathrm{E}-06$ & $5.2 \mathrm{E}+08$ \\
\hline $\mathrm{Cm}-247+\mathrm{d}$ & $3.6 \mathrm{E}+01$ & agriculture & $4.0 \mathrm{E}-15$ & $9.1 E+15$ \\
\hline $\mathrm{Cm}-248+\mathrm{d}$ & $4.9 \mathrm{E}+01$ & gw & $1.3 \mathrm{E}-14$ & $3.8 \mathrm{E}+15$ \\
\hline$C f-249+d$ & $1.1 \mathrm{E}+02$ & gw & $6.8 \mathrm{E}-14$ & $1.7 \mathrm{E}+15$ \\
\hline Cf- 251 & $4.7 E+04$ & agriculture & $2.7 \mathrm{E}-15$ & $1.8 \mathrm{E}+19$ \\
\hline
\end{tabular}


"Refers to intruder scenario, groundwater ingestion pathway ("gw"), or air pathway; whichever is more restrictive with respect to developing inventory limits.

d A ratio that is one or greater indicates the projected inventory is less than the estimated inventory limit and the performance objectives are met.

- Radionuclide (and daughters when present) decay to insignificant levels before exposure scenario is credible. 
Table 7.1-5 Inventory Limits for Intimately-Mixed Cement-Stabilized Waste Trenches; Limiting Pathway; Comparison to Projected Inventory

\begin{tabular}{|c|c|c|c|c|}
\hline Radionuclide $^{\mathrm{a}}$ & $\begin{array}{c}\text { Inventory limit } \\
\text { Ci/5 trenches }\end{array}$ & $\begin{array}{l}\text { Limiting } \\
\text { pathwayc }\end{array}$ & $\begin{array}{c}\text { Projected } \\
\text { inventory } \\
\text { Ci/5 trenches }\end{array}$ & $\begin{array}{l}\text { Ratio of inventory limit } \\
\text { to projected inventory }\end{array}$ \\
\hline $\mathrm{H}-3$ & $3.2 \mathrm{E}+05$ & air & $5.50 \mathrm{E}+05$ & $5.8 \mathrm{E}-01$ \\
\hline C-14 & $2.7 \mathrm{E}+00$ & air & $1.48 \mathrm{E}-01$ & $1.8 \mathrm{E}+01$ \\
\hline $\mathrm{Ni}-59$ & $4.7 \mathrm{E}+02$ & gw & $8.67 \mathrm{E}-02$ & $5.5 \mathrm{E}+03$ \\
\hline Co- 60 & $2.1 \mathrm{E}+09$ & resident & $8.55 E+00$ & $2.5 E+08$ \\
\hline $\mathrm{Ni}-63$ & $1.3 \mathrm{E}+06$ & post-drilling & $6.51 E+00$ & $2.0 \mathrm{E}+05$ \\
\hline Se-79 & $1.8 \mathrm{E}+01$ & gw & $2.66 \mathrm{E}-02$ & $6.7 \mathrm{E}+02$ \\
\hline $\mathrm{Rb}-87$ & $3.4 \mathrm{E}-01$ & gw & $0.00 \mathrm{E}+00$ & -..- \\
\hline Sr-90 +d & $2.6 \mathrm{E}+05$ & gw & $6.16 \mathrm{E}+01$ & $4.2 \mathrm{E}+03$ \\
\hline $\mathrm{Zr}-93$ & $1.7 \mathrm{E}+03$ & gw & $9.24 \mathrm{E}-06$ & $1.8 \mathrm{E}+08$ \\
\hline $\mathrm{Nb}-94$ & $2.1 \mathrm{E}+00$ & gw & $9.57 \mathrm{E}-09$ & $2.2 \mathrm{E}+08$ \\
\hline Tc-99 & $3.9 \mathrm{E}-01$ & gw & $3.30 \mathrm{E}-02$ & $1.2 \mathrm{E}+01$ \\
\hline Pd-107 & $9.9 \mathrm{E}+01$ & gw & $3.24 \mathrm{E}-13$ & $3.1 E+14$ \\
\hline Sn-126+d & $1.9 \mathrm{E}+00$ & agriculture & $6.81 E-04$ & $2.8 \mathrm{E}+03$ \\
\hline I- 129 & 4.1E-04 & gw & $3.57 \mathrm{E}-05$ & $1.1 \mathrm{E}+01$ \\
\hline Cs-135 & $2.0 \mathrm{E}+01$ & gw & $1.41 \mathrm{E}-09$ & $1.4 \mathrm{E}+10$ \\
\hline Cs- $137+d$ & $2.2 \mathrm{E}+06$ & resident & $8.87 E+01$ & $2.5 \mathrm{E}+04$ \\
\hline Sm-151 & $3.1 \mathrm{E}+07$ & post-drilling & $1.39 \mathrm{E}-04$ & $2.2 \mathrm{E}+11$ \\
\hline Eu-152 & $2.0 \mathrm{E}+10$ & post drilling & $6.21 E+00$ & $3.2 E+09$ \\
\hline Eu-154 & $3.6 \mathrm{E}+07$ & resident & $4.11 E+00$ & $8.8 E+06$ \\
\hline Th-232+d & $1.4 \mathrm{E}+00$ & agriculture & $8.58 \mathrm{E}-03$ & $1.6 \mathrm{E}+02$ \\
\hline $\mathrm{U}-232+\mathrm{d}$ & $1.7 E+03$ & agriculture & $1.63 \mathrm{E}-02$ & $1.0 \mathrm{E}+05$ \\
\hline $\mathrm{U}-233+\mathrm{d}$ & $1.3 E+02$ & agriculture & $9.84 \mathrm{E}-01$ & $1.3 E+02$ \\
\hline $\mathrm{U}-234+\mathrm{d}$ & $9.8 \mathrm{E}+00$ & radon & $6.60 \mathrm{E}-01$ & $1.5 E+01$ \\
\hline $\mathrm{U}-235+\mathrm{d}$ & $2.6 \mathrm{E}+01$ & agriculture & $1.38 \mathrm{E}-02$ & $1.1 \mathrm{E}+03$ \\
\hline $\mathrm{U}-236$ & $4.6 \mathrm{E}+02$ & agriculture & $2.38 \mathrm{E}-02$ & $1.9 E+04$ \\
\hline $\mathrm{Np}-237+d$ & $9.4 \mathrm{E}+00$ & $\mathrm{gw}$ & $2.14 \mathrm{E}-02$ & $4.4 \mathrm{E}+02$ \\
\hline $\mathrm{U}-238+\mathrm{d}$ & $1.2 \mathrm{E}+02$ & agriculture & $1.93 \mathrm{E}-01$ & $6.2 \mathrm{E}+02$ \\
\hline Pu-238 +d & $1.4 \mathrm{E}+04$ & post-drilling & $5.16 \mathrm{E}+00$ & $2.7 \mathrm{E}+03$ \\
\hline Pu-239 +d & $1.3 \mathrm{E}+02$ & agriculture & $2.10 \mathrm{E}+00$ & $6.2 \mathrm{E}+01$ \\
\hline Pu-240 +d & $1.3 E+02$ & agriculture & $6.78 \mathrm{E}-01$ & $1.9 E+02$ \\
\hline$A m-241+d$ & $2.7 \mathrm{E}+02$ & agriculture & $5.25 \mathrm{E}-01$ & $5.1 E+02$ \\
\hline Pu-241 +d & $8.0 \mathrm{E}+03$ & agriculture & $2.96 \mathrm{E}+01$ & $2.7 \mathrm{E}+02$ \\
\hline $\mathrm{Pu}-242+\mathrm{d}$ & $1.3 \mathrm{E}+02$ & agriculture & $3.69 \mathrm{E}-04$ & $3.5 E+05$ \\
\hline$A m-243+d$ & $2.1 E+01$ & agriculture & $4.95 E-05$ & $4.2 E+05$ \\
\hline Pu-244+d & $9.7 \mathrm{E}+00$ & agriculture & $2.44 E-15$ & $4.0 \mathrm{E}+15$ \\
\hline $\mathrm{Cm}-244+\mathrm{d}$ & $4.8 E+04$ & agriculture & $4.41 \mathrm{E}-02$ & $1.1 E+06$ \\
\hline $\mathrm{Cm}-245+\mathrm{d}$ & $3.4 \mathrm{E}+01$ & agriculture & $1.36 \mathrm{E}-09$ & $6.4 E+10$ \\
\hline $\mathrm{Cm}-246$ & $1.3 E+02$ & agriculture & $5.43 \mathrm{E}-10$ & $2.4 E+11$ \\
\hline $\mathrm{Cm}-247+d$ & $9.2 \mathrm{E}+00$ & gw & $1.42 \mathrm{E}-12$ & $6.5 E+12$ \\
\hline $\mathrm{Cm}-248+\mathrm{d}$ & $3.4 \mathrm{E}+01$ & agriculture & $5.16 \mathrm{E}-15$ & $6.6 \mathrm{E}+15$ \\
\hline Cf $-249+d$ & $4.0 \mathrm{E}+01$ & agriculture & $1.22 \mathrm{E}-05$ & $3.3 E+06$ \\
\hline Cf $-250+d$ & $4.8 \mathrm{E}+04$ & agriculture & $1.56 \mathrm{E}-03$ & $3.1 \mathrm{E}+07$ \\
\hline Cf-251 & $5.2 \mathrm{E}+01$ & agriculture & $3.24 \mathrm{E}-10$ & $1.6 \mathrm{E}+11$ \\
\hline
\end{tabular}


Table 7.1-5 Inventory Limits for Intimately-Mixed Cement-Stabilized Waste Trenches; Limiting Pathway; Comparison to Projected Inventory

\begin{tabular}{lcccc} 
Radionuclide $^{\text {a }}$ & $\begin{array}{c}\text { Inventory limit }^{b} \\
\mathrm{Ci} / 5 \text { trenches }\end{array}$ & $\begin{array}{c}\text { Limiting } \\
\text { pathway }\end{array}$ & $\begin{array}{c}\text { Projected } \\
\text { inventory } \\
\mathrm{Ci} / 5 \text { trenches }\end{array}$ & $\begin{array}{c}\text { Ratio of inventory limit } \\
\text { to projected inventory }\end{array}$ \\
\hline $\mathrm{Cf}-252+\mathrm{d}$ & $4.5 \mathrm{E}+06$ & agriculture & $1.35 \mathrm{E}-02$ & $3.3 \mathrm{E}+08$ \\
\hline
\end{tabular}

" $+\mathrm{d}$ " indicates potentially-significant short- and long-lived daughters are accounted for in the limit.

- Inventory limit based on consideration of peak groundwater concentration outside $100-\mathrm{m}$ buffer zone around disposal units (Section 5) and inadvertent intruder doses (Section 6).

c Refers to intruder scenario, groundwater ingestion pathway ("gw"), or air pathway; whichever is more restrictive with respect to developing inventory limits.

d A ratio that is one or greater indicates the projected inventory is less than the estimated inventory limit and the performance objectives are met.

c Projected inventory is zero; therefore, assume performance objectives are met 
Table 7.1-6 Inventory Limits for Cement-Stabilized Encapsulated Waste Trenches; Limiting Pathway; Comparison to Projected Inventory

\begin{tabular}{|c|c|c|c|c|}
\hline Radionuclide ${ }^{a}$ & $\begin{array}{l}\text { Inventory limit } \\
\text { Ci/ } 5 \text { trenches }\end{array}$ & $\begin{array}{l}\text { Limiting } \\
\text { pathway }{ }^{c}\end{array}$ & $\begin{array}{c}\text { Projected } \\
\text { inventory } \\
\text { Total Ci }\end{array}$ & $\begin{array}{l}\text { Ratio of inventory limit } \\
\text { to projected inventory }\end{array}$ \\
\hline $\mathrm{H}-3$ & $3.2 \mathrm{E}+05$ & air & $8.80 \mathrm{E}+01$ & $3.6 \mathrm{E}+03$ \\
\hline $\mathrm{Ni}-59$ & $4.4 \mathrm{E}+03$ & gw & $2.41 E+00$ & $1.8 \mathrm{E}+03$ \\
\hline $\mathrm{Co}-60$ & $2.1 \mathrm{E}+09$ & resident & $2.09 E+03$ & $1.0 \mathrm{E}+06$ \\
\hline $\mathrm{Ni}-63$ & $1.3 \mathrm{E}+06$ & post-drilling & $3.42 E+02$ & $3.8 E+03$ \\
\hline $\mathrm{Se}-79$ & $7.7 \mathrm{E}+01$ & gw & $6.56 \mathrm{E}-02$ & $1.2 \mathrm{E}+03$ \\
\hline Sr-90+d & $2.6 \mathrm{E}+05$ & gw & $1.13 E+04$ & $2.3 E+01$ \\
\hline $\mathrm{Zr}-93+\mathrm{d}$ & $1.6 \mathrm{E}+01$ & gw & $3.12 \mathrm{E}-01$ & $5.1 \mathrm{E}+01$ \\
\hline Tc-99 & $3.0 \mathrm{E}-01$ & gw & $2.35 E+00$ & $1.3 \mathrm{E}-01$ \\
\hline Pd-107 & $1.7 \mathrm{E}+01$ & gw & $1.81 \mathrm{E}-02$ & $9.3 E+02$ \\
\hline Sn-126+d & $5.2 \mathrm{E}+00$ & agriculture & $8.99 \mathrm{E}-02$ & $5.8 \mathrm{E}+01$ \\
\hline $1-129$ & $2.2 \mathrm{E}-04$ & gw & $6.11 \mathrm{E}-02$ & $3.6 \mathrm{E}-03$ \\
\hline Cs-135 & $2.0 \mathrm{E}+01$ & gw & $4.91 \mathrm{E}-02$ & $4.1 E+02$ \\
\hline Cs $-137+d$ & $2.2 \mathrm{E}+06$ & resident & $1.58 E+04$ & $1.4 E+02$ \\
\hline Sm-151 & $3.1 E+07$ & post-drilling & $1.97 \mathrm{E}+02$ & $1.6 \mathrm{E}+05$ \\
\hline Eu-154 & $3.6 \mathrm{E}+07$ & resident & $7.97 \mathrm{E}+02$ & $4.5 \mathrm{E}+04$ \\
\hline$U-232+d$ & $1.7 \mathrm{E}+03$ & agriculture & $4.98 \mathrm{E}-03$ & $3.4 \mathrm{E}+05$ \\
\hline $\mathrm{U}-233+\mathrm{d}$ & $6.6 \mathrm{E}+01$ & agriculture & $1.75 \mathrm{E}-03$ & $3.8 E+04$ \\
\hline $\mathrm{U}-234+\mathrm{d}$ & $9.8 \mathrm{E}+00$ & radon & $3.95 \mathrm{E}-01$ & $2.5 E+01$ \\
\hline$U-235+d$ & $2.6 E+01$ & agriculture & $2.82 \mathrm{E}-03$ & $9.2 E+03$ \\
\hline $\mathrm{U}-236$ & $4.6 \mathrm{E}+02$ & agriculture & $7.31 \mathrm{E}-02$ & $6.3 E+03$ \\
\hline $\mathrm{U}-238+\mathrm{d}$ & 1.2E+02 & agriculture & $2.33 \mathrm{E}-04$ & $5.2 \mathrm{E}+05$ \\
\hline $\mathrm{Pu}-238+\mathrm{d}$ & $1.4 E+04$ & post-drilling & $1.68 \mathrm{E}+00$ & $8.3 E+03$ \\
\hline$P u-239+d$ & $1.3 \mathrm{E}+02$ & agriculture & $1.63 \mathrm{E}-01$ & $8.0 \mathrm{E}+02$ \\
\hline $\mathrm{Pu}-240+\mathrm{d}$ & $1.3 E+02$ & agriculture & $3.80 \mathrm{E}-02$ & $3.4 E+03$ \\
\hline$A m-241+d$ & $2.7 \mathrm{E}+02$ & agriculture & $2.90 \mathrm{E}-02$ & $9.3 E+03$ \\
\hline $\mathrm{Pu}-241+\mathrm{d}$ & $8.0 \mathrm{E}+03$ & agriculture & $1.50 \mathrm{E}+00$ & $5.3 E+03$ \\
\hline $\mathrm{Pu}-242+\mathrm{d}$ & $1.3 \mathrm{E}+02$ & agriculture & $0.00 \mathrm{E}+00$ & - \\
\hline
\end{tabular}

a " $+\mathrm{d}$ " indicates potentially-significant short- and long-lived daughters are accounted for in the limit.

b Inventory limit based on consideration of peak groundwater concentration outside $100-\mathrm{m}$ buffer zone around disposal units (Section 5) and inadvertent intruder doses (Section 6).

c Refers to intruder scenario, groundwater ingestion pathway ("gw"), or air pathway; whichever is more restrictive with respect to developing inventory limits.

d A ratio that is one or greater indicates the projected inventory is less than the estimated inventory limit and the performance objectives are met.

c Projected inventory is zero; therefore, assume performance objectives are met. 
With a few exceptions, the calculated inventory limit is greater than the projected inventory for the EArea LLWF; thus, this facility can, for the most part, dispose of the forecasted waste receipts. For most radionuclides, the ratio is much greater than 100 . For the few radionuclides that show a projected inventory greater than the calculated limit $\left({ }^{3} \mathrm{H}\right.$ in the intimately-mixed cement-stabilized waste, ${ }^{99} \mathrm{Tc}$, and ${ }^{129} \mathrm{I}$, in the cement-stabilized encapsulated waste and ${ }^{59} \mathrm{Ni}$ in the Naval Reactor Pad), continued implementation of waste acceptance procedures (e.g., waste acceptance criteria, waste characterization, waste certification, computerized waste information and tracking system) will ensure that waste accepted for disposal will not exceed radionuclide inventory or concentration limits.

To ensure disposal capacity for the entire projected waste inventory, waste packages exceeding WAC for trench disposal could be disposed in one of the types of vault. With the exception of ${ }^{129}$ I, the intimatelymixed cement-stabilized and the cement-stabilized encapsulated waste exceeding the LAW vault limits can be accommodated in the IL vault. The ${ }^{129}$ I inventory projected for the cement-stabilized encapsulated waste exceeds the limit for the IL vault. Further investigation of this waste stream is needed to refine the projected ${ }^{129}$ I inventory. Additionally, the performance assessment analyses could be revised to remove conservatism so that all of the waste projected for trench or NR pad disposal can be accommodated.

\subsection{Impact of this PA Revision on the SRS Composite Analysis}

The composite analysis for the E-Area LLWF and the saltstone disposal facility was recently completed (WSRC 1997b). The composite analysis assessed the potential cumulative impacts to a hypothetical future member of the public from the E-Area LLWF and saltstone facilities and other sources of radioactive material in the ground that may interact with the LLW disposal facilities. The composite analysis did not include some of the disposal units or types of waste analyzed in this PA revision (e.g., disposal of contaminated equipment in trenches as CSEW). Therefore, this PA revision must consider whether addition of these waste types and disposal units to the E-Area LLWF will require additional assessment for the composite analysis.

The E-Area LLWF performance assessment and special analyses, including performance assessment revision, establishes radionuclide limits for each type of disposal unit to ensure that the performance objectives and assessment requirements of DOE 435.1 are not likely to be exceeded. The analyses are conducted for each type of disposal unit to determine limiting radionuclide concentrations or quantities, as appropriate, so that the most limiting performance objective (i.e., all pathways, air pathway, radon emission) or assessment requirement (i.e., water resource impacts, intruder impacts) will not be exceeded. In this PA, the new disposal units (e.g., trenches for CSEW) replaced projected LAW vaults analyzed previously. Thus, replacing a number of low-activity waste vaults with new disposal units will not cause any of the performance measures (Table 2-15) to be exceeded. As discussed in Section 5.4, the E-Area LLWF contributed less than 0.001 per cent to the flux of radionuclides migrating to the point of assessment (i.e., the mouth of Upper Three Runs creek). Thus, any increase in the flux of contaminants due to the new disposal units and waste types will not cause a significant increase in the composite analysis results.

\subsection{Use of Performance Assessment Results}

The inventory limits calculated in this analysis are implemented through a set of WAC and managed through the SRS's computerized Waste Information Tracking System (WITS). The operating limits for the E-Area LLWF, as documented in the SRS WAC Manual (WSRC 1997a), are derived from safety documentation and a PA. The WAC Manual is a compilation of the radionuclide limits from a SAR, cell criticality limits, $100 \mathrm{nCi} / \mathrm{g}$ transuranic concentration limit, NRC Class $\mathrm{C}$ limits, and vault performancebased inventory limits. Each of these limits is converted into a hypothetical container limit. For each 
radionuclide, the most restrictive limit is then implemented as a WAC container limit for the waste generators.

As packages are received for emplacement in the various vaults, their package contents will be entered into WITS. Before emplacement of each package, WITS will compare the package contents with the 100 $\mathrm{nCi} / \mathrm{g}$ transuranic limits and NRC Class $\mathrm{C}$ limits, and calculate the cell inventory (to ensure compliance with the cell criticality limits) and the total vault inventory (to ensure compliance with the PA-based limits). The SAR and PA-based limits are tracked as a sum-of-fractions of the individual radionuclide limits. For the PA-based limits, the total vault inventory for each radionuclide is divided by its corresponding limit. The sum of these fractions will be maintained less than one to ensure compliance with the limits. A similar procedure will be followed to ensure compliance with the SAR limits.

\subsection{Further Work}

The DOE, through DOE Order 435.1, requires that a maintenance program for performance assessments and composite analyses be implemented to provide greater confidence in the results of the analysis. In 1999, the Maintenance Program for the E-Area Vaults and Saltstone Performance Assessments, and the Composite Analysis (SWD-SWE-99-0040) was developed to confirm the continued adequacy of the PAs and CA, to increase confidence in the results of these assessments, and to authorize changes to the controls derived from them. The 5 elements of the PA/CA Maintenance Program (MAP) are 1) special analyses, 2) revisions, 3) reviews, 4) monitoring, and 5) tests and research. The two elements of monitoring and tests and research are discussed further in this section since these elements are necessary to improve understanding of specific mechanisms or assumptions used in the PA.

PA reviews began in FY98, CA reviews will begin in FY00; the reviews are conducted annually.

\subsubsection{Monitoring}

A monitoring program has been developed to validate the E-Area LLWF PA and is documented in the "E-Area Monitoring Program for the E-Area Low-Level Radioactive Waste Disposal Facility," (SWDSWE-98-0153). This program includes near-field monitoring which was recommended in the 1994 PA but was in the developmental stage at that time. A Vadose Zone Monitoring System (VZMS) has been developed to differentiate migration of radionuclides from the EADF and the existing groundwater contamination arising from past disposal practices. The E-Area Monitoring Program (EMOP) includes this first comprehensive state-of-the-art VZMS for verifying performance of a low-level radioactive waste disposal facility in the DOE complex. This system will monitor beneath shallow trenches and above-ground waste vaults (i.e., LAW and IL Vaults) within the E-Area LLWF. This program is being implemented in phases as discussed in the EMOP.

The VZMS in E Area meets the monitoring requirements established in DOE Order 435.1, and is providing data to validate the PA models and assumptions.

\subsubsection{Test and Research}

Various test and research activities to validate parameters or assumptions used in the PA are delineated in the MAP. The results of these activities are evaluated annually in the PA/CA annual reviews. As appropriate, based on results of the activities and other factors, planned test and research activities are revised to better reflect the needs of the SRS low-level waste disposal program. 


$$
\begin{array}{r}
1576549 \\
\text { WSRC-RP-94-0218 Reu.1 } \\
P+2
\end{array}
$$

SECTION 8

QUALITY ASSURANCE

RECORDS ADMINISTRATION

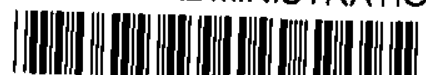

R0186509 
THIS PAGE INTENTIONALLY LEFT BLANK

Rev. 1 


\section{QUALITY ASSURANCE}

Quality assurance was addressed in this PA through development of Software Quality Assurance (QA) plans, adherence to the provisions of these plans, and careful documentation and discussion of critical assumptions made and parameters used in the analysis. Biweekly meetings were held throughout the period of time that technical decisions were being made, attended by experts in waste inventory, waste management, disposal unit design, and environmental assessment at Westinghouse Savannah River Company (WSRC). The purpose of these meetings were to develop, continuously update, and obtain concurrence on a list of critical assumptions and parameter values which were used in the PA. The meeting minutes and updated list of critical assumptions were documented and distributed to all interested parties for review.

Software QA plans were written by contributors to this PA for computer codes utilized in completing the analyses. These plans address the provisions of the American Society of Mechanical Engineers (ASME) Nuclear Quality Assurance (NQA)-2a, Part 2.7, Quality Assurance Requirements of Computer Software for Nuclear Facility Applications. The QA Plans were reviewed and approved by appropriate personnel at WSRC.

Copies of the Software QA Plans submitted are provided in Appendix F. A surveillance was conducted by WSRC QA personnel after work on the PA was underway, for the purpose of evaluating adherence to governing QA procedures described in the submitted QA plans and general project integration. The results of these surveillances are on file at WSRC. 
THIS PAGE INTENTIONALLY LEFT BLANK

Rev. 1 
SECTION 9

LIST OF PREPARERS 
THIS PAGE INTENTIONALLY LEFT BLANK

Rev. 1 


\section{LIST OF PREPARERS}

\section{BURNS, HEATHER HOLMES, WSRC/SWD, Principal Environmental Engineer}

\section{B.S. Chemical Engineering - Vanderbilt University}

Experience: Ms. Burns has served over 15 years with the SRS in various technical roles including lowlevel radioactive waste management, mixed waste research and development, incineration, and waste stabilization. She was responsible for the development of the Solid Waste Performance Assessment Maintenance Plan in response to the Defense National Facility Safety Board's 94-2 Recommendation. She also has been integrally involved in the development of the E-Area Monitoring Program, which has been designed to validate the PA results. She has worked for DuPont, Westinghouse, and now works for British Nuclear Fuels in the Solid Waste Department.

Contributions: PA background information (i.e., Chapter 2) and team member.

\section{BUTCHER, BYRON T., WSRC/SRTC, Civil, Environmental Engineer}

M.S. Environmental Engineering - University of Tennessee

B.S. Civil Engineering - University of Tennessee

Experience: Mr. Butcher is currently a manager of an applied R\&D group at the Savannah River Technology Center. This group, Waste Disposal and Environmental Development, is responsible for providing technology development and applications in support of SRS waste management, environmental restoration, and decontamination and decommissioning missions. Areas of support include geochemical and groundwater modeling; radiological performance assessments and low-level waste disposal technology; hazardous and radioactive waste treatability studies; development of grout-based wasteforms and barriers; and radioactive decontamination technologies. Previous assignments at SRS have included three years each as an environmental project manager in the Environmental Restoration Department and as a solid waste technology manager (and process engineer) in the Waste Management Technology Department.

Contributions: Performance Assessment project planning and management oversight.

\section{CARLTON, WILLIAM H., WSRC/SRTC, Health Physics}

Ph.D. Biophysics - Rutgers

M.S. Physics - Emory

B.S. Physics - Emory

Certified by the American Board of Health Physics

Experience: Dr. Carlton has 16 years of academic experience at Rutgers and the Medical College of Georgia. During his 17 years at the Savannah Rive Site, he has served as a manager in Health Physics and Waste Management Operations. The last six years have been spent in Environmental Dosimetry modeling the dose from atmospheric and aqueous releases of radioactivity

Contributions: Environmental dosimetry 


\section{COOK, JAMES R., WSRC/SRTC, Geology, Geochemistry}

M.S. Geochemistry - State University of New York at Binghamton

B.S. Geology - University of Arizona

Experience: Mr. Cook has 19 years of experience at the Savannah River Site, 17 of which have been in various aspects of low-level waste research. Research topics have included site selection, site characterization, site closure, and performance assessment. Mr. Cook served on the revision team for Chapter 3 of DOE Order 5820.2A and was a member of the Performance Assessment Task Team. He serves as the technical lead on the Performance Assessment team.

Contributions: WSRC Technical Leader Performance Assessment team, air pathway analysis.

\section{FLACH, GREGORY P., WSRC/SRTC, Numerical modeling and simulation}

Ph.D. Mechanical Engineering - North Carolina State University

M.M.E. Mechanical Engineering - North Carolina State University

B.S. Mechanical Engineering - University of Kentucky

Experience: Dr. Flach has 9 years of experience at the Savannah River Sitc focusing on numerical modeling and code development. Specific topics have included groundwater flow, solute contaminant transport, and multiphase, multicomponent reactor thermal-hydraulics. Recent efforts have involved groundwater flow modeling to optimize remediation strategies, future site characterization, and regulatory compliance boundary placement. Current research and development activities center on automating groundwater flow model development and calibration, and creating realistic heterogeneity in model hydraulic conductivity fields.

Contributions: Groundwater flow modeling.

\section{GOLDSTON, WELFORD T., WSRC/SWD, Senior Technical Advisor}

BS Chemical Engineering - University of South Carolina

MBA University of South Carolina

Experience: Mr.. Goldston has served over 20 years with SRS in various roles including technical, project management, and program management in chemical separations, high level radioactive waste management, DWPF, and low-level radioactive waste management. He has-spent-over-25-years-in-the chemical and nuclear industry in various engineering and management capacities. He has been integrally involved in the preparation of the Saltstone and E-area Vaults Radiological Performance Assessments and the startup of the Saltstone facilities. He has worked for the Dept. of Energy, Westinghouse, and is now assigned by Westinghouse to British Nuclear Fuels in the Solid Waste Dept. and is the Solid Waste Lead for the Composite Analysis. 


\section{HANE, RICHARD A., WSRC/SRTC, PHYSICS, Waste Disposal}

M.S. Nuclear Engineering - University of Missouri

M.S. Physics - University of Missouri

B.S. Physics - Southwest Missouri State University

Experience: Mr. Hane has 8 years of experience at the Savannah River Site, 6 of which have been in various aspects of radioactive waste research. Research topics have included waste characterization, transportation, packaging and disposal and impacts to performance assessments. Mr. Hane served on the revision team for WIPP requirements and was a contributor to the revision of DOE Order 5820.2A. He serves as a technical resource on the Composite Analysis advisory team.

Contributions: Intruder Sensitivity Analysis.

\section{LOWE, PAUL E., WSRC/SRTC, Quality Assurance}

BS Industrial Engineering - University of Akron Graduate Engineering studies - University of Michigan

Professional Engineer, certified auditor

Experience: Mr. Lowe has 9 years experience at SRTC which have been in various aspects of QA relating to waste isolation of High and Low level waste. He also served with Battelle Memorial Institute in site selection and characterization. Mr. Lowe has over 25 years experience in the Nuclear, Aerospace, and Commercial Industries in various engineering and management positions.

Contributions: SRTC Quality Assurance oversight, member of team

\section{MCDOWELL-BOYER, LAURA M., ALARA ENVIRONMENTAL ANALYSIS, INC., Environmental Engineering, Health Physics}

Ph.D. Civil/Environmental Engineering - University of California, Berkeley

M.S. Radiological Health Physics - Colorado State University

Experience: Dr. McDowell-Boyer has 12 years experience in radiological exposure assessment, has directed the development of a multi-media environmental transport model, studied mechanisms of subsurface contaminant migration via colloids, modeled groundwater flow and transport, and developed source terms for health risk assessments. Dr. McDowell-Boyer was the principal investigator from Oak Ridge National Laboratory on the Z-Area Performance Assessment, co-principal investigator on the EArea Performance Assessment, and is responsible for pathway and dose analysis and technical documentation of the majority of the Composite Analysis.

Contributions: Pathway and dose analysis; documentation of the Performance Assessment. 


\section{REYMERS, VANESSA J., Hydrogeologist}

\section{B.S. Hydrogeology - Northern Arizona University}

Experience: Ms. Reymers was working as an intern at Savannah River Site before entering graduate school to pursue a M.S. in Civil Engineering. As an undergraduate, she completed a senior thesis on the hydrological characterization of a perennial stream to provide data for an environmental restoration project.

Contributions: Assisted with Performance Assessment documentation.

\section{STEVENS, WILLIAM E., WSRC/SRTC, R \& D Management}

M.S. Chemical Engineering - University of Florida

B.S. Chemical Engineering - University of Delaware

Experience: Mr. Stevens has 21 years of industrial experience in chemical processing, waste management, and environmental restoration. His assignments include process engineering, development engineering, and management of process and project engineering groups, maintenance groups, and R \& D groups. For the past eight years, he has managed an R \& D organization that develops technology for support of environmental restoration and minimizing, recycling, treating, handling, and disposing of lowlevel radioactive, mixed, hazardous, and sanitary waste. The group has expertise in site closure, environmental transport, groundwater modeling, and decontamination. Mr. Stevens is a licensed Professional Engineer.

Contribution: Advisor to PA team.

\section{WHLHTE, ELMER L., WSRC/SRTC, Advisory Scientist}

BS Chemistry - University of Missouri

MS Inorganic Chemistry - Washington University

Experience: Mr. Wilhite has 28 years experience at the Savannah River Site. His assignments include environmental research, high-level and low-level waste research, supervision of environmental monitoring and analytical chemistry groups. Mr. Wilhite has served as a consultant to DOE Headquarters on-low-level waste-management-for-9-years. He-was the-chairman-of the-former DOE-Peer Review Panel and is the technical lead for DOE for the radiological assessments section of the response to the DNFSB recommendation 94-2. 


\section{YOUNG, KAREN E., RCS Corporation, Vice-President}

B.S. Environmental Resource Management - Pennsylvania State University

Experience: Ms. Young has over 8 years of experience as an environmental scientist with expertise in regulatory compliance. She is an expert in Resource Conservation and Recovery Act (RCRA) compliance and has assisted the Environmental Protection Agency (EPA) in developing RCRA regulations.

Contributions: Program integration and Regulatory Compliance

\section{YU, ANDREW D., ALARA ENVIRONMENTAL ANALYSIS, INC.}

B.S. Chemical Engineering - National Taiwan University

Ph.D. Chemical Engineering - University of Wisconsin

Experience: Dr. Yu has 22 years of experience in subsurface flow and transport modeling. He worked 12 years in simulating enhanced oil recovery processes in the oil industry and 9 years in groundwater modeling with Savannah River Technology Center. His current interests are in performance assessment, groundwater modeling and waste disposal technology.

Contributions: Performed subsurface flow and transport modeling. 
THIS PAGE INTENTIONALLY LEFT BLANK

Rev. 1 
SECTION 10

REFERENCES 
THIS PAGE INTENTIONALLY LEFT BLANK

Rev. 1 


\section{REFERENCES}

Aadland, R. K., J. A. Gellici, and P. A. Thayer. 1995. Hydrogeologic Framework of West-Central South Carolina, State of South Carolina, Department of Natural Resources, Water Resources Division, Report 5 , South Carolina.

Anspaugh, L. R., J. H. Shinn, P. L. Phelps, and N. C. Kennedy. 1975. Resuspension and Redistribution of Plutonium in Soils. Health Phys. 29:571.

Arnett, M. W., L.K. Karapatakis, and A. R. Mamatey. 1993. Savannah River Environmental Report for 1992, WSRC-TR-92-0075, Westinghouse Savannah River Company, Aiken, South Carolina.

Arnett, M. W. and A. R. Mamatey, 1996, Savannah River Environmental Report for 1995, WSRC-TR-960075, Westinghouse Savannah River Company, Aiken, South Carolina.

Arnett, M. W. and A. R. Mamatey, 1997, Savannah River Environmental Report for 1996, WSRC-TR-970171, Westinghouse Savannah River Company, Aiken, South Carolina.

ASME. 19. Quality Assurance Requirements of Computer Software for Nuclear Facility Applications. American Society of Mechanical Engineers Nuclear Quality Assurance (NQA)-2a, Part 2.7.

Baes, C. F. III, and R. D. Sharp. 1983. A Proposal for Estimation of Soil Leaching and Leaching Constants for Use in Assessment Models. J. Environ. Qual., 12:17.

Baes, C. F. III, R. D. Sharp, A. L. Sjoreen, and R. W. Shor. 1984. A Review and Analysis of Parameters for Assessing Transport of Environmentally Released Radionuclides through Agriculture. ORNL5786. Oak Ridge National Laboratory.

Bates, Robert L., 1969, Geology of the Industrial Rock and Minerals, Dover Pubications, New York, New York.

Bettis Atomic Power Laboratory. 1995a. DC-95-0273 Performance Assessment Information from Naval Reactors. Re: WAPD-SEA (RE) MD-23.

Bettis Atomic Power Laboratory. 1995b. DC-95-0273 Performance Assessment Information from Naval Reactors. Re: WAPD-SEA (RE) MD-144.

Bollinger, G. A., F. C. Davison, Jr., M. S. Sibol, and J. B. Birch. 1989. Magnitude Recurrence Relations for The Southeastern United States and its Subdivisions. Journal of Geophysical Research, 94(B3): 2857-2873.

Bradbury, M. H. and F. A. Sarott. 1995. Sorption Databases for the Cementitious Near-Field of a $L / I L W$ Repository for Performance Assessment, Paul Scherrer Institut, Villigen, March 1995.

Briese, L. A., and M. H. Smith. 1974. Seasonal Abundance and Movement of Nine Species of Small Mammals. J. Mammal., 55: 615-629.

Cook, J. R. 1991. Technical Basis for Non-Vault Disposal of Soil. WSRC-RP-91-58. Westinghouse Savannah River Company, Aiken, SC. 
Cook, J. R. and S. K. Salvo. 1993. Selection and Cultivation of Final Vegetative Cover for Closed Waste Sites at the Savannah River Site, SC. Proceeding of WM '93, Tucson AZ.

Cook J. R. and Wilhite, E. L. 1998. Radionuclide Screening and Preliminary Scoping Study for EAC Disposal of APT and TEF Wastes, WSRC-RP-98-00084, Westinghouse Savannah River Company, Aiken, SC.

CRC Press, Inc. 1981. CRC Handbook of Chemistry and Physics. Robert C. Weast and Melvin J. Astle, eds. Boca Raton, FL.

Cummins, C. L., D. K. Martin, and J. L. Todd. 1990. Savannah River Site Environmental Report. WSRC-IM-91-28, Volumes I and II. Westinghouse Savannah River Company, Savannah River Site, Aiken, SC.

Davenport, L. B. 1964. Structure of Two Peromyscus polionotus Populations in Old-Field Ecosystems at the AED Savannah River Plant. J. Mammal., 45:95-113.

Dennehy, K. F., D. C. Prowell, and P. B. McMahon. 1989. Reconnaissance Hydrological Investigation of the Defense Waste Processing Facility and Vicinity. E. I. du Pont de Nemours and Company Savannah River Laboratory, Aiken, SC.

Eckerman, K. F., A. B. Wohlbarst, and A. C. B. Richardson. 1988. Limiting Values of Radionuclide Intake and Air Concentration and Dose Conversion Factors for Inhalation, Submersion, and Ingestion. Federal Guidance Report No. 11. EPA-520/1-88-020. U. S. Environmental Protection Agency, Washington, D.C.

Fisher, D. L. 1994a. Ashcrete Product Report. WSRC-TR-94-00426. Westinghouse Savannah River Company. Aiken, SC.

Fisher, D. L. 1994b. Ashcrete Records. WSRC-TR-94-00135. Westinghouse Savannah River Company. Aiken, SC.

Fisher, D. L. 1995. CIF Blowdown Stabilization: Formula Development Report. WSRC-TR-95-001146. Westinghouse Savannah River Company. Aiken, SC.

Flach, G. P., L. L. Hamm, M. K. Harris, P. A. Thayer, J. S. Haselow, and A. D. Smits. 1997. Groundwater Flow and Tritium Migration from the SRS Old Burial Ground to Fourmile Branch (U). WSRC-TR-96-0037. Westinghouse Savannah River Company, Aiken, SC.

Freeze, R. A. and J. A. Cherry. 1979. Groundwater. Prentice-Hall, Inc., New Jersey.

General Engineering Laboratories 1995. Addendum to Permit Application for the Z-Area Saltstone Disposal Facility, Z-Area Closure Plan, Savannah River Site Aiken, SC, August 1995.

Golley, F. B., and J. B. Gentry. 1964. Bioenergetics of the Southern Harvester Ant, Pogonomyrmex badius. Ecol., 45:217-225.

Gruber, P. 1980. A Hydrologic Study of the Unsaturated Zone Adjacent to a Radioactive-Waste Disposal Site at the Savannah River Plant, Aiken, South Carolina. M.S. Thesis, University of Georgia, Athens, Georgia. 
Hamby, D. M. 1991. Land and Water Use Characteristics in the Vicinity of the Savannah River Site. WSRC-RP-91-17. Westinghouse Savannah River Company, Aiken, SC.

Hamby, D. M. 1994. MAXINE: An Improved Methodology for Estimating Maximum Individual Dose from Chronic Atmospheric Radioactive Releases. WSRC-TR-94-053. Westinghouse Savannah River Company, Aiken, SC.

Hamby, D. M. 1995. Verification of the MAXIGASP and POPGASP Computer Codes for Environmental Dose Assessment. WSRC-RP-94-522. Westinghouse Savannah River Company, Aiken, SC.

Hamby, D. M. and Bauer, L. 1993. The Vegetation to Air Concentration Ratio in a Specific Activity Atmospheric Tritium Model. Health Physics, 66(3).

Hayes, D. W. and W. L. Marter, 1991. Historical River Flow Rates for Dose Calculations. SRL-ETS910257. Westinghouse Savannah River Company, Savannah River Laboratory, Aiken, SC.

Healy, J. W. 1980. Review of Resuspension Models in Transuranic Elements in the Environment, p. 209. DOE/TIC-22800. Ed. by W. C. Hanson. U. S. Department of Energy, Washington, D. C.

Hoeffner, S. L. 1984. Additional Laboratory Studies on Radionuclide Sorption at the SRP Burial Ground. DPST-84-797. E. I. du Pont de Nemours and Company, Savannah River Laboratory, Aiken, $\mathrm{SC}$.

Hoeffner, S. L. 1985. Radionuclide Sorption on Savannah River Plant Burial Ground Soil: A Summary and Interpretation of Laboratory Data. DP-1702. E. I. du Pont de Nemours and Company, Savannah River Laboratory, Aiken, SC.

Horton, J. H. and E. L. Wilhite, 1978. Estimated Erosion Rate at the SRP Burial Ground. DP-1493. E. I. Du Pont de Nemours \& Co., Inc., Savannah River Laboratory, Aiken, SC.

ICRP. 1979. Limits for Intakes of Radionuclides by Workers. International Commission on Radiological Protection. Publication 30, Part 1. Ann. ICRP 2. No. 3/4. Pergamon Press, Oxford, U.K.

ICRP. 1959. Recommendation of the International Commission on Radiological Protection. International Commission on Radiological Protection. Publication No. 2. Pergamon Press, New York.

INTERA. 1986. Z-Area Site Assessment. INTERA Technologies, Inc., for E. I. du Pont de Nemours \& Co., Inc., Savannah Research Laboratory, Aiken, SC.

Kennedy, W. E., Jr., and R. A. Peloquin. 1988. Intruder Scenarios for Site-Specific Low-Level Waste Classification. DOE/LLW-71T. Idaho Operations Office, U. S. Department of Energy.

Ketelle, R. H, and D. D. Huff. 1984. Site Characterization of the West Chestnut Ridge Site. ORNL/TM9229. Oak Ridge National Laboratory, Oak Ridge, Tenn.

Kocher, D. C. 1981. Radioactive Decay Data Tables. Technical Information Center, U. S. Department of Energy, DOE/TIC-1 1026, Oak Ridge, TN. 
Looney, B. B., Grant, M. W., and King, C. M. 1987. Estimation of Geochemical Parameters for Assessing Subsurface Transport at the Savannah River Plant. Savannah River Laboratory Environmental Information Document. DPST-85-904. E. I. du Pont de Nemours and Company, Savannah River Laboratory, Aiken, SC, p. 13.

McIntyre, P. F. 1988. Sorption Properties of Carbon-14 on Savannah River Plant Soil. DPST-88-900. E. I. du Pont de Nemours and Company, Savannah River Laboratory, Aiken, SC.

Murphy, C. E., Jr. 1990. Lysimeter Study of Vegetative Uptake from Saltstone. WSRC-RP-90-421. Westinghouse-Savannah-River Company.

NCRP. 1996. Screening Models for Releases of Radionuclides to Atmosphere, Surface Water, and Ground, Vol. I and II, NCRP Report No. 123, National council on Radiation Protection and Measurements, Bethesda, MD.

NCRP. 1976. Structural Shielding Design and Evaluation for Medical Use of X Rays and Gamma Rays of Energies up to $10 \mathrm{MeV}$. NCRP Report No. 49. National Council on Radiation Protection and Measurements, Bethesda, MD.

NRC. 1981. Draft Environmental Impact Statement on IO CFR Part 61 "Licensing Requirements for Land Disposal of Radioactive Waste." NUREG-0782. U. S. Nuclear Regulatory Commission, Washington D. C.

NRC. 1977. Regulatory Guide 1.109. Calculation of Annual Doses to Man from Routine Releases of Reactor Effluents for the Purpose of Evaluating Compliance with 10 CFR Part 50, Appendix I. Nuclear Regulatory Commission, Washington D. C.

NRC. 1997. Draft Branch Technical Position on a Performance Assessment Methodology for Low-Level Radioactive Waste Disposal Facilities, NUREG-1573. Nuclear Regulatory Commission, Washington D. C.

Orebaugh, E. G., and R. M. Wallace. 1989. Quantification of Hazards Associated with the Decay Storage/Disposal of Tritium Crucibles (U). WSRC-RP-89-1226.

ORNL. 1990. Performance Assessment for Continuing and Future Operations at SWSA 6. Internal draft report. Oak Ridge National Laboratory, Oak Ridge, Tenn.

Oztunali, O. I., and G. W. Roles. 1986. Update of Part 61 Impacts Analysis Methodology. NUREG/CR4370. U.S. Nuclear Regulatory Commission and Envirosphere Company.

Ramsdell, J. V. and G. L. Andrews. 1986. Tornado Climatology of the Contiguous United States, NUREG/CR-4461, DNL-5697. Pacific Northwest Laboratory, Richland WA.

Rosenberger, K. H. 1997. Health Physics Technology Evaluation of Dose Rates Associated with Naval Reactor Waste Containers. ESH-HPT-97-0058. Westinghouse Savannah River Company, Aiken, SC.

SCDHEC. 1976. Air Pollution Control Regulations and Standards, South Carolina Code of Laws, Regulation 61-62, Columbia, SC. 
Serkiz, S. M. and Myers, J. L. 1996. Additional Information for E-Area Vault Performance Assessment, Appendix I, "Suspect Soil Performance Analysis"-Results of Modeling the Effects of Organic Matter on the Mobility of Radionuclides as it Relates to the Disposal of Wood Products in E-Area Slit Trenches, SRTC-WED-96-0195, April 24, 1996.

Sheppard, M. I., and D. H. Thibault. 1990. Default Soil Solid/Liquid Partition Coefficients, Kds, for Four Major Soil Types: A Compendium. Health Physics, 59:471-482.

Simpkins, A. A. 1998. Modeling of Releases from the New Burial Ground, E Area. SRT-EST-98-288. Westinghouse Savannah River Company, Aiken, SC.

Simpkins, A. A. and Carlton, W. H. 1998. Modeling of Releases from the New Burial Ground, E AreaMEI at 100 m. SRT-EST-98-333. Westinghouse Savannah River Company, Aiken, SC.

Siple, G. E. 1967. Geology and Ground Water of the Savannah River Plant and Vicinity, South Carolina. Geological Survey Water-Supply Paper 1984, U. S. Atomic Energy Commission.

Smith, M. H. 1971. Food as a Limiting Factor in the Population Ecology of Peromyscus polionotus (Wagner). Physiol. Zool., 40:31-39.

Stephenson, D. E. 1988. August 1988 Savannah River Plant Earthquake. DPST-88-841. E. I. du Pont de Nemours \& Company, Inc., Savannah River Laboratory, Aiken, SC.

Stephenson, D. E. 1993. Personal Communication 12/14/93.

Stephenson, D. E., P. Talwani, and J. Rawlins. 1985. Savannah River Plant Earthquake of June 1985. DPST-85-583. E. I. du Pont de Nemours \& Co., Inc., Savannah River Laboratory, Aiken, SC.

Smits, A. D., M. K. Harris, K. L. Hawkins, and G. P. Flach. 1997. Integrated Hydrologeological Analysis of the General Separations Area, Volume 1. WSRC-TR-96-0399, Savannah River Laboratory, Westinghouse Savannah River Company, Aiken, SC.

Ticknor, K. V., and Ruegger, B. 1989. A Guide to the NEA's Sorption Data Base. Version 2.0, 19 p.

Thompson, D.G. 1991. RE: Vault Closure Concepts for Saltstone Vaults. OPS-DZT-91-0002. Westinghouse Savannah River Company, Aiken, SC.

Unger, L. M., and D. K. Trubey. 1982. Specific Gamma-Ray Dose Constants for Nuclides Important to Dosimetry and Radiological Assessment. ORNL/TSIC-45/R1, Oak Ridge National Laboratory, Oak Ridge, TN.

URS/Blume, J. A. and Associates, Engineers. 1982. Update of Seismic Criteria for the Savannah River Plant. 1, Geotechnical, DPE-3699. E.I. du Pont de Nemours and Company, Savannah River Laboratory, Aiken, SC.

U. S. Department of Agriculture. 1985. Site Specific Cropland Erosion Inventory. Soil Conservation Service, Columbia, SC.

U. S. Department of Commerce. 1963. Maximum Permissible Body Burdens and Maximum Permissible Concentrations of Radionuclides in Air and Water for Occupational Exposure. National Bureau of Standards Handbook 69. NCRP Report No. 22. 
U. S. Department of Commerce. 1977. 1974 Census of Agriculture. Bureau of the Census, Agriculture Division.

U.S. DOE. 1987. Waste Management Activities for Groundwater Protection, Savannah River Plant, Aiken, SC. Final Environmental Impact Statement, DOE/EIS-0120, Vol. 1. U. S. Department of Energy, Savannah River Plant, Aiken, SC.

U.S. DOE. 1988. Internal Dose Conversion Factors for Calculation of Dose to the Public. DOE/EH0071. U. S. Department of Energy, Washington, D.C.

U.S. DOE. 1990. Radiation Protection of the Public and the Environment. U.S. Department of Energy. Washington, DC.

DOE 1995. Savannah River Site Waste Management Environmental Impact Statement, DOE/EIS-0217, July 1995.

U.S. DOE. 1996. Interim Format and Content Guide and Standard Review Plan for U.S. Department of Energy Low-Level Waste Disposal Facility Performance Assessments. October 1996. U.S. Department of Energy. Washington, DC.

U.S. DOE. 1997. Final Environmental Impact Statement, Shutdown of the River Water System at the Savannah River Site, DOE/EIS-0270D, Savannah River Operations Office, Aiken, SC.

U.S. DOE. 1998a. Savannah River Site Future Use Plan, March 1998.

U.S. DOE. 1998b. Construction \& Operation of a Tritium Extraction Facility at the Savannah River Site, U. S. Department of Energy, Aiken, SC.

U.S.DOE. 1999. Radioactive Waste Management, Order 435.1, U. S. Department of Energy.

U.S. EPA. 1991, 40 CFR Parts 141 and 142 - National Primary Drinking Water Regulations; Radionuclides; Proposed Rule. Federal Register, 56:33050.

USGS. 1997a. "Historical Streamflow Daily Values Data for Upper Three Runs Above Road C (Srs), Sc", USGS: Science for a Changing World, U. S. Geological Survey, http://water.usgs.gov /swr/SC/, USGS Station Number 02197310 (April 22, 1997).

USGS. 1997b. "Historical Streamflow Daily Values Data for Site No. 7 at Savannah River Site, Sc", USGS: Science for a Changing World, U. S. Geological Survey, http://water.usgs.gov /swr/SC/, USGS Station Number 02197342 (June 4, 1997).

USGS. 1997c. Savannah River Gauging data

USNRC. 1982. Final Environmental Impact Statement on 10 CFR Part 61 'Licensing Requirements for Land Disposal of Radioactive Waste. Washington DC.

USNRC. 1997. Calculation of Annual Doses to Man from Routine Release of Reactor Effluents for the Purpose of Evaluating Compliance with 10CFR Part 50, Appendix I. Washington DC.

Van Pelt, A. F. 1966. Activity and Density of Old-Field Ants of the Savannah River Plant, South Carolina. J. Elisha Mitchell Sci. Soc., 2:343-351. 
Walton, J. C., L. E. Plansky, and R. W. Smith. 1990. Models for Estimation of Service Life of Concrete Barriers in Low-Level Radioactive Waste Disposal. NUREG/CR-5542, EGG-2597. U.S. Nuclear Regulatory Commission, Washington, D.C.

Wike, L. D., R. W. Shipley, A. L. Bryan, Jr., J. A. Bowers, C. L. Cunningham, S. R. del Carmen, G. P. Friday, J. E. Irwin, J. J. Mayer, E. A. Nelson, M. H. Paller, V. A. Rogers, W. L. Specht, and E. Wilde, 1994, Savannah River Site Ecology Environmental Information Document, WSRC-RP-93496, Westinghouse Savannah River Company, Savannah River Site, Aiken, SC.

WSRC. 1992a. Safety Analysis 200 Area Replacement Tritium Facility. WSRC-SA-1-1. Savannah River Laboratory, Westinghouse Savannah River Company, Aiken, SC.

WSRC. 1992b. Radiological Performance Assessment for the Z-Area Saltstone Disposal Facility. WSRC-RP-92-1360. Savannah River Laboratory, Westinghouse Savannah River Company, Aiken, SC.

WSRC. 1996a. Safety Analysis Report Savannah River Site Solid Waste Management Facility (U), WSRCSA-22, Rev.0, December 1996.

WSRC. 1996b. Groundwater Protection Management Program, WSRC-TR-96-0193, August 1996.

WSRC. 1997a. WSRC 1S Savannah River Site Waste Acceptance Criteria Manual, Procedure WAC 3.17 Low Level Radioactive Waste Acceptance Criteria, Rev. 0, September 1997.

WSRC. 1997b. Westinghouse Savannah River Company, Composite Analysis E-Area Vaults and Saltstone Disposal Facilities, WSRC-RP-97-311, Rev. 0, September 1997.

Yu, A. D., C. A. Langton, and M. G. Serrato. 1993. Physical Properties Measurements Program. WSRC-93-894.

10 CFR Part 61. Code of Federal Regulations, Title 10, Energy, Part 61, "Licensing requirements for land disposal of radioactive waste."

40 CFR Part 61. Code of Federal Regulations, Title 40, Protection of Environment, Part 61, "National Emission Standards for Hazardous Air Pollutants."

40 CFR Part 141. Code of Federal Regulations, Title 40, Protection of Environment, Part 141, "National Primary Drinking Water Regulations."

40 CFR Part 300. Code of Federal Regulations, Title 40, Protection of Environment, Part 300, "National Oil and Hazardous Substances Pollution Contingency Plan."

49 CFR Part 173. Code of Federal Regulations, Title 49, Transportation, Part 173, "Shippers-general requirements for shipments and packagings." 
THIS PAGE INTENTIONALLY LEFT BLANK

Rev. 1 
APPENDIX A

PROJECTED INVENTORY FOR THE E-AREA LOW LEVEL WASTE FACILITY 
THIS PAGE INTENTIONALLY LEFT BLANK

Rev. 1 
Table A.1 Projected Inventory for LAW Vaults

\begin{tabular}{|c|c|c|c|}
\hline \multirow[b]{4}{*}{ Radionuclide } & LAW & 2004 LAW Inventory & 2014 LAW Inventory \\
\hline & Actual Inventory & Forecast - Vault 1 & Forecast - Vault 2 \\
\hline & As of $6 / 01 / 98$ & 10 Yr. Life & 10 Yr. Life \\
\hline & (Ci) & (Ci) & $(\mathrm{Ci})$ \\
\hline Other Alpha & $5.53 \mathrm{E}-02$ & $1.66 \mathrm{E}-01$ & $1.66 \mathrm{E}-01$ \\
\hline Ac-228 & $3.35 \mathrm{E}-03$ & $1.01 \mathrm{E}-02$ & $1.01 \mathrm{E}-02$ \\
\hline $\mathrm{Al}-26$ & $0.00 \mathrm{E}+00$ & $0.00 \mathrm{E}+00$ & $0.00 \mathrm{E}+00$ \\
\hline Am-241 & $1.75 \mathrm{E}-01$ & $5.25 \mathrm{E}-01$ & $5.25 \mathrm{E}-01$ \\
\hline Am-243 & $1.65 \mathrm{E}-05$ & $4.95 \mathrm{E}-05$ & 4.95E-05 \\
\hline Other B/G & $1.62 \mathrm{E}+00$ & $4.86 \mathrm{E}+00$ & $4.86 \mathrm{E}+00$ \\
\hline $\mathrm{Ba}-137 \mathrm{~m}$ & $1.42 \mathrm{E}+01$ & $4.27 \mathrm{E}+01$ & $4.27 \mathrm{E}+01$ \\
\hline $\mathrm{Bi}-210$ & $6.67 \mathrm{E}-05$ & $2.00 \mathrm{E}-04$ & $2.00 \mathrm{E}-04$ \\
\hline $\mathrm{Bi}-212$ & $8.25 \mathrm{E}-03$ & $2.48 \mathrm{E}-02$ & $2.48 \mathrm{E}-02$ \\
\hline $\mathrm{Bi}-214$ & $6.67 \mathrm{E}-05$ & $2.00 \mathrm{E}-04$ & $2.00 \mathrm{E}-04$ \\
\hline $\mathrm{C}-14$ & $4.93 \mathrm{E}-02$ & $1.48 \mathrm{E}-01$ & $1.48 \mathrm{E}-01$ \\
\hline $\mathrm{Cd}-109$ & $1.00 \mathrm{E}-05$ & $3.01 \mathrm{E}-05$ & $3.01 \mathrm{E}-05$ \\
\hline $\mathrm{Ce}-144$ & $6.73 \mathrm{E}-01$ & $2.02 \mathrm{E}+00$ & $2.02 \mathrm{E}+00$ \\
\hline Cf-249 & $4.06 \mathrm{E}-06$ & $1.22 \mathrm{E}-05$ & $1.22 \mathrm{E}-05$ \\
\hline Cf-250 & $5.19 \mathrm{E}-04$ & $1.56 \mathrm{E}-03$ & $1.56 \mathrm{E}-03$ \\
\hline Cf-251 & $1.08 \mathrm{E}-10$ & $3.24 \mathrm{E}-10$ & $3.24 \mathrm{E}-10$ \\
\hline Cf-252 & $4.49 \mathrm{E}-03$ & $1.35 \mathrm{E}-02$ & $1.35 \mathrm{E}-02$ \\
\hline $\mathrm{Cm}-244$ & $1.47 \mathrm{E}-02$ & $4.41 \mathrm{E}-02$ & $4.41 \mathrm{E}-02$ \\
\hline $\mathrm{Cm}-245$ & $4.54 \mathrm{E}-10$ & $1.36 \mathrm{E}-09$ & $1.36 \mathrm{E}-09$ \\
\hline $\mathrm{Cm}-246$ & $1.81 \mathrm{E}-10$ & $5.43 \mathrm{E}-10$ & $5.43 \mathrm{E}-10$ \\
\hline $\mathrm{Cm}-247$ & $4.73 \mathrm{E}-13$ & $1.42 \mathrm{E}-12$ & $1.42 \mathrm{E}-12$ \\
\hline $\mathrm{Cm}-248$ & $1.72 \mathrm{E}-15$ & $5.16 \mathrm{E}-15$ & $5.16 \mathrm{E}-15$ \\
\hline Co-57 & $8.12 \mathrm{E}-04$ & $2.44 \mathrm{E}-03$ & $2.44 \mathrm{E}-03$ \\
\hline Co-58 & $1.17 \mathrm{E}-01$ & $3.51 \mathrm{E}-01$ & $3.51 \mathrm{E}-01$ \\
\hline $\mathrm{Co}-60$ & $2.85 \mathrm{E}+00$ & $8.55 \mathrm{E}+00$ & $8.55 \mathrm{E}+00$ \\
\hline Cs-134 & $1.59 \mathrm{E}+00$ & $4.77 \mathrm{E}+00$ & $4.77 \mathrm{E}+00$ \\
\hline Cs-135 & $4.69 \mathrm{E}-10$ & $1.41 \mathrm{E}-09$ & $1.41 \mathrm{E}-09$ \\
\hline Cs-137 & $2.96 \mathrm{E}+01$ & $8.87 \mathrm{E}+01$ & $8.87 \mathrm{E}+01$ \\
\hline Eu-152 & $2.07 \mathrm{E}+00$ & $6.21 \mathrm{E}+00$ & $6.21 \mathrm{E}+00$ \\
\hline Eu-154 & $1.37 \mathrm{E}+00$ & $4.11 \mathrm{E}+00$ & $4.11 E+00$ \\
\hline Eu-155 & $5.10 \mathrm{E}-07$ & $1.53 \mathrm{E}-06$ & $1.53 \mathrm{E}-06$ \\
\hline $\mathrm{Fe}-55$ & $4.20 \mathrm{E}+00$ & $1.26 \mathrm{E}+01$ & $1.26 \mathrm{E}+01$ \\
\hline $\mathrm{Fe}-59$ & $3.60 \mathrm{E}-03$ & $1.08 \mathrm{E}-02$ & $1.08 \mathrm{E}-02$ \\
\hline $\mathrm{H}-3$ & $1.83 \mathrm{E}+05$ & $5.50 \mathrm{E}+05$ & $5.50 \mathrm{E}+05$ \\
\hline Hf- 181 & $1.41 \mathrm{E}-05$ & $4.23 \mathrm{E}-05$ & $4.23 \mathrm{E}-05$ \\
\hline $\mathrm{Hg}-203$ & $1.29 \mathrm{E}-05$ & $3.87 \mathrm{E}-05$ & $3.87 \mathrm{E}-05$ \\
\hline $\mathrm{I}-129$ & $1.19 \mathrm{E}-05$ & $3.57 \mathrm{E}-05$ & $3.57 \mathrm{E}-05$ \\
\hline $\mathrm{Kr}-85$ & $1.31 \mathrm{E}+00$ & $3.93 \mathrm{E}+00$ & $3.93 \mathrm{E}+00$ \\
\hline $\mathrm{Mn}-54$ & $7.11 \mathrm{E}-02$ & $2.13 \mathrm{E}-01$ & $2.13 \mathrm{E}-01$ \\
\hline $\mathrm{Nb}-93 \mathrm{~m}$ & $8.98 \mathrm{E}-04$ & $2.69 \mathrm{E}-03$ & $2.69 \mathrm{E}-03$ \\
\hline $\mathrm{Nb}-94$ & $3.19 \mathrm{E}-09$ & $9.57 \mathrm{E}-09$ & $9.57 \mathrm{E}-09$ \\
\hline $\mathrm{Nb}-95$ & $3.15 \mathrm{E}-03$ & $9.45 \mathrm{E}-03$ & $9.45 \mathrm{E}-03$ \\
\hline $\mathrm{Ni}-59$ & $2.89 \mathrm{E}-02$ & $8.67 \mathrm{E}-02$ & $8.67 \mathrm{E}-02$ \\
\hline $\mathrm{Ni}-63$ & $2.17 \mathrm{E}+00$ & $6.51 \mathrm{E}+00$ & $6.51 \mathrm{E}+00$ \\
\hline $\mathrm{Np}-237$ & $7.12 \mathrm{E}-03$ & $2.14 \mathrm{E}-02$ & $2.14 \mathrm{E}-02$ \\
\hline $\mathrm{Np}-239$ & $1.60 \mathrm{E}-08$ & $4.80 \mathrm{E}-08$ & $4.80 \mathrm{E}-08$ \\
\hline
\end{tabular}


Table A.1 Projected Inventory for LAW Vaults

\begin{tabular}{|c|c|c|c|}
\hline \multirow[b]{4}{*}{ Radionuclide } & LAW & 2004 LAW Inventory & 2014 LAW Inventory \\
\hline & Actual Inventory & Forecast - Vault 1 & Forecast - Vault 2 \\
\hline & As of $6 / 01 / 98$ & 10 Yr. Life & 10 Yr. Life \\
\hline & (Ci) & (Ci) & (Ci) \\
\hline $\mathrm{Pa}-234$ & $9.38 \mathrm{E}-04$ & $2.81 \mathrm{E}-03$ & $2.81 \mathrm{E}-03$ \\
\hline $\mathrm{Pa}-234 \mathrm{~m}$ & $5.68 \mathrm{E}-02$ & $1.70 \mathrm{E}-01$ & $1.70 \mathrm{E}-01$ \\
\hline $\mathrm{Pb}-210$ & $6.67 \mathrm{E}-05$ & $2.00 \mathrm{E}-04$ & $2.00 \mathrm{E}-04$ \\
\hline $\mathrm{Pb}-212$ & $8.24 \mathrm{E}-03$ & $2.47 \mathrm{E}-02$ & $2.47 \mathrm{E}-02$ \\
\hline $\mathrm{Pb}-214$ & $-6.67 \mathrm{E}-05$ & $2.00 \mathrm{E}-04$ & $-2.00 \mathrm{E}-04$ \\
\hline Pd-107 & $1.08 \mathrm{E}-13$ & $3.24 \mathrm{E}-13$ & $3.24 \mathrm{E}-13$ \\
\hline $\mathrm{Pm}-147$ & $5.35 \mathrm{E}+00$ & $1.61 \mathrm{E}+01$ & $1.61 \mathrm{E}+01$ \\
\hline Po-210 & $6.67 \mathrm{E}-05$ & $2.00 \mathrm{E}-04$ & $2.00 \mathrm{E}-04$ \\
\hline Po-212 & $1.75 \mathrm{E}-03$ & $5.25 \mathrm{E}-03$ & $5.25 \mathrm{E}-03$ \\
\hline Po-214 & $6.67 \mathrm{E}-05$ & $2.00 \mathrm{E}-04$ & $2.00 \mathrm{E}-04$ \\
\hline Po-216 & $8.23 \mathrm{E}-03$ & $2.47 \mathrm{E}-02$ & $2.47 \mathrm{E}-02$ \\
\hline $\mathrm{Po-218}$ & $6.67 \mathrm{E}-05$ & $2.00 \mathrm{E}-04$ & $2.00 \mathrm{E}-04$ \\
\hline Pr-144 & $6.62 \mathrm{E}-01$ & $1.99 \mathrm{E}+00$ & $1.99 \mathrm{E}+00$ \\
\hline Pr-144m & $3.48 \mathrm{E}-05$ & $1.04 \mathrm{E}-04$ & $1.04 \mathrm{E}-04$ \\
\hline $\mathrm{Pu}-238$ & $1.72 \mathrm{E}+00$ & $5.16 \mathrm{E}+00$ & $5.16 \mathrm{E}+00$ \\
\hline Pu-239 & $6.42 \mathrm{E} \sim 01$ & $1.93 \mathrm{E}+00$ & $1.93 \mathrm{E}+00$ \\
\hline $\mathrm{Pu}-240$ & $2.26 \mathrm{E}-01$ & $6.78 \mathrm{E}-01$ & $6.78 \mathrm{E}-01$ \\
\hline $\mathrm{Pu}-241$ & $9.88 \mathrm{E}+00$ & $2.96 \mathrm{E}+01$ & $2.96 \mathrm{E}+01$ \\
\hline $\mathrm{Pu}-242$ & $1.23 \mathrm{E}-04$ & $3.69 \mathrm{E}-04$ & $3.69 \mathrm{E}-04$ \\
\hline Pu-244 & $8.13 E-16$ & $2.44 \mathrm{E}-15$ & $2.44 \mathrm{E}-15$ \\
\hline $\mathrm{Ra}-224$ & $6.76 \mathrm{E}-03$ & $2.03 \mathrm{E}-02$ & $2.03 \mathrm{E}-02$ \\
\hline $\mathrm{Ra}-226$ & $6.70 \mathrm{E}-05$ & $2.01 \mathrm{E}-04$ & $2.01 \mathrm{E}-04$ \\
\hline $\mathrm{Ra}-228$ & $4.28 \mathrm{E}-03$ & $1.28 \mathrm{E}-02$ & $1.28 \mathrm{E}-02$ \\
\hline $\mathrm{Rb}-86$ & $4.65 \mathrm{E}-05$ & $1.40 \mathrm{E}-04$ & $1.40 \mathrm{E}-04$ \\
\hline $\mathrm{Rb}-87$ & $0.00 \mathrm{E}+00$ & $0.00 \mathrm{E}+00$ & $0.00 \mathrm{E}+00$ \\
\hline $\mathrm{Rh}-106$ & $4.69 \mathrm{E}-03$ & $1.41 \mathrm{E}-02$ & $1.41 \mathrm{E}-02$ \\
\hline $\mathrm{Rn}-220$ & $8.23 \mathrm{E}-03$ & $2.47 \mathrm{E}-02$ & $2.47 \mathrm{E}-02$ \\
\hline $\mathrm{Rn}-222$ & $6.67 \mathrm{E}-05$ & $2.00 \mathrm{E}-04$ & $2.00 \mathrm{E}-04$ \\
\hline Ru-106 & $3.21 \mathrm{E}-02$ & $9.63 \mathrm{E}-02$ & $9.63 \mathrm{E}-02$ \\
\hline $\mathrm{S}-35$ & $2.95 \mathrm{E}-03$ & $8.85 \mathrm{E}-03$ & $8.85 \mathrm{E}-03$ \\
\hline Sb-125 & $2.87 \mathrm{E}-02$ & $8.61 \mathrm{E}-02$ & $8.61 \mathrm{E}-02$ \\
\hline Se-79 & $8.85 \mathrm{E}-03$ & $2.66 \mathrm{E}-02$ & $2.66 \mathrm{E}-02$ \\
\hline Sm-151 & $4.64 \mathrm{E}-05$ & $1.39 \mathrm{E}-04$ & $1.39 \mathrm{E}-04$ \\
\hline Sn-126 & $2.27 \mathrm{E}-04$ & $6.81 \mathrm{E}-04$ & $6.81 \mathrm{E}-04$ \\
\hline Sr-85 & $5.13 \mathrm{E}-04$ & $1.54 \mathrm{E}-03$ & $1.54 \mathrm{E}-03$ \\
\hline Sr-90 & $1.89 \mathrm{E}+01$ & $5.67 \mathrm{E}+01$ & $5.67 \mathrm{E}+01$ \\
\hline Tc-93M & $2.60 \mathrm{E}-08$ & $7.80 \mathrm{E}-08$ & $7.80 \mathrm{E}-08$ \\
\hline Tc-99 & $1.10 \mathrm{E}-02$ & $3.30 \mathrm{E}-02$ & $3.30 \mathrm{E}-02$ \\
\hline Th-228 & $8.23 \mathrm{E}-03$ & $2.47 \mathrm{E}-02$ & $2.47 \mathrm{E}-02$ \\
\hline Th-230 & $2.58 \mathrm{E}-03$ & $7.74 \mathrm{E}-03$ & $7.74 \mathrm{E}-03$ \\
\hline Th-231 & $1.65 \mathrm{E}-03$ & $4.95 \mathrm{E}-03$ & $4.95 \mathrm{E}-03$ \\
\hline Th-232 & $2.86 \mathrm{E}-03$ & $8.58 \mathrm{E}-03$ & $8.58 \mathrm{E}-03$ \\
\hline Th-234 & $5.77 \mathrm{E}-02$ & $1.73 \mathrm{E}-0 \mathrm{I}$ & $1.73 \mathrm{E}-01$ \\
\hline Tl-208 & $9.85 \mathrm{E}-04$ & $2.96 \mathrm{E}-03$ & $2.96 \mathrm{E}-03$ \\
\hline $\mathrm{U}-232$ & $5.42 \mathrm{E}-03$ & $1.63 \mathrm{E}-02$ & $1.63 \mathrm{E}-02$ \\
\hline $\mathrm{U}-233$ & $3.28 \mathrm{E}-01$ & $9.84 \mathrm{E}-01$ & $9.84 \mathrm{E}-01$ \\
\hline U-234 & $2.20 \mathrm{E}-01$ & $6.60 \mathrm{E}-01$ & $6.60 \mathrm{E}-01$ \\
\hline
\end{tabular}


Table A.1 Projected Inventory for LAW Vaults

\begin{tabular}{|l|c|c|c|}
\hline \multirow{5}{*}{ Radionuclide } & LAW & 2004 LAW Inventory & 2014 LAW Inventory \\
\cline { 2 - 4 } & Actual Inventory & Forecast - Vault 1 & Forecast - Vault 2 \\
\cline { 2 - 4 } & As of 6/01/98 & 10 Yr. Life & 10 Yr. Life \\
\cline { 2 - 4 } & $(\mathrm{Ci})$ & $(\mathrm{Ci})$ & (Ci) \\
\hline $\mathrm{U}-235$ & $4.59 \mathrm{E}-03$ & $1.38 \mathrm{E}-02$ & $1.38 \mathrm{E}-02$ \\
\hline $\mathrm{U}-236$ & $7.94 \mathrm{E}-03$ & $2.38 \mathrm{E}-02$ & $2.38 \mathrm{E}-02$ \\
\hline $\mathrm{U}-238$ & $6.42 \mathrm{E}-02$ & $1.93 \mathrm{E}-01$ & $1.93 \mathrm{E}-01$ \\
\hline Y-90 & $1.67 \mathrm{E}+01$ & $5.01 \mathrm{E}+01$ & $5.01 \mathrm{E}+01$ \\
\hline Zn-65 & $1.03 \mathrm{E}-01$ & $3.09 \mathrm{E}-01$ & $3.09 \mathrm{E}-01$ \\
\hline Zr-93 & $3.08 \mathrm{E}-06$ & $9.24 \mathrm{E}-06$ & $9.24 \mathrm{E}-06$ \\
\hline Total & $1.84 \mathrm{E}+05$ & $5.51 \mathrm{E}+05$ & $5.51 \mathrm{E}+05$ \\
\hline
\end{tabular}


Table A.2 Projected Inventory for IL Vaults (ILNT = non-tritium; ILT = tritium)

\begin{tabular}{|c|c|c|c|}
\hline \multirow[b]{4}{*}{ Radionuclide } & ILV & 2004 ILNT Inventory & 2014 ILNT Inventory \\
\hline & Actual Inventory & Forecast - Vault 1 & Forecast - Vault 2 \\
\hline & As of $6 / 01 / 98$ & 10 Yr. Life & 10 Yr. Life \\
\hline & $(\mathrm{Ci})$ & (Ci) & (Ci) \\
\hline$\overline{\text { Other Alpha }}$ & $3.83 \mathrm{E}-03$ & $1.53 \mathrm{E}-02$ & $1.53 \mathrm{E}-02$ \\
\hline Other $\mathrm{B} / \mathrm{G}$ & $1.18 \mathrm{E}+00$ & $4.70 \mathrm{E}+00$ & $4.70 \mathrm{E}+00$ \\
\hline Al-26 & $0.00 \mathrm{E}+00$ & $0.00 \mathrm{E}+00$ & $0.00 \mathrm{E}+00$ \\
\hline Am-241 & $2.92 \mathrm{E}-01$ & $1.17 \mathrm{E}+00$ & $1.17 \mathrm{E}+00$ \\
\hline Am-242m & $5.08 \mathrm{E}-06$ & $2.03 \mathrm{E}-05$ & $2.03 \mathrm{E}-05$ \\
\hline $\mathrm{Am}-243$ & $4.56 \mathrm{E}-08$ & $1.82 \mathrm{E}-07$ & $1.82 \mathrm{E}-07$ \\
\hline $\mathrm{Ba}-137 \mathrm{~m}$ & $1.59 \mathrm{E}+01$ & $6.34 \mathrm{E}+01$ & $6.34 \mathrm{E}+01$ \\
\hline $\mathrm{Bi}-214$ & 7.67E-01 & $3.07 \mathrm{E}+00$ & $3.07 \mathrm{E}+00$ \\
\hline$C-14$ & $8.81 \mathrm{E}-02$ & $3.52 \mathrm{E}-01$ & $3.52 \mathrm{E}-01$ \\
\hline $\mathrm{Ce}-144$ & $5.65 \mathrm{E}-02$ & $2.26 \mathrm{E}-01$ & $2.26 \mathrm{E}-0 \mathrm{l}$ \\
\hline$\overline{C f-249}$ & $7.51 \mathrm{E}-15$ & $3.00 \mathrm{E}-14$ & $3.00 \mathrm{E}-14$ \\
\hline Cf-25I & $3.03 \mathrm{E}-16$ & $1.21 \mathrm{E}-15$ & $1.21 \mathrm{E}-15$ \\
\hline $\mathrm{Cf}-252$ & $0.00 \mathrm{E}+00$ & $0.00 \mathrm{E}+00$ & $0.00 \mathrm{E}+00$ \\
\hline $\mathrm{Cm}-244$ & $5.88 \mathrm{E}-01$ & $2.35 \mathrm{E}+00$ & $2.35 \mathrm{E}+00$ \\
\hline $\mathrm{Cm}-245$ & $3.79 \mathrm{E}-10$ & $1.52 \mathrm{E}-09$ & $1.52 \mathrm{E}-09$ \\
\hline $\mathrm{Cm}-246$ & $1.52 \mathrm{E}-10$ & $6.08 \mathrm{E}-10$ & $6.08 \mathrm{E}-10$ \\
\hline $\mathrm{Cm}-247$ & $4.56 \mathrm{E}-16$ & $1.82 \mathrm{E}-15$ & $1.82 \mathrm{E}-15$ \\
\hline $\mathrm{Cm}-248$ & $1.44 \mathrm{E}-15$ & $5.76 \mathrm{E}-15$ & $5.76 \mathrm{E}-15$ \\
\hline $\mathrm{Co}-58$ & $1.66 \mathrm{E}+00$ & $6.64 \mathrm{E}+00$ & $6.64 \mathrm{E}+00$ \\
\hline $\mathrm{Co}-60$ & $4.22 \mathrm{E}+01$ & $1.69 \mathrm{E}+02$ & $1.69 \mathrm{E}+02$ \\
\hline $\mathrm{Cs}-134$ & $1.72 \mathrm{E}-01$ & $6.88 \mathrm{E}-01$ & $6.88 \mathrm{E}-01$ \\
\hline Cs-135 & $0.00 \mathrm{E}+00$ & $0.00 \mathrm{E}+00$ & $0.00 \mathrm{E}+00$ \\
\hline Cs-137 & $5.76 \mathrm{E}+01$ & $2.30 \mathrm{E}+02$ & $2.30 \mathrm{E}+02$ \\
\hline Eu-154 & $6.47 \mathrm{E}-02$ & $2.59 \mathrm{E}-01$ & $2.59 \mathrm{E}-01$ \\
\hline $\mathrm{Fe}-55$ & $1.05 \mathrm{E}+01$ & $4.22 \mathrm{E}+01$ & $4.22 \mathrm{E}+01$ \\
\hline $\mathrm{H}-3$ & $1.09 \mathrm{E}+05$ & $4.32 \mathrm{E}+05$ & $4.32 \mathrm{E}+05$ \\
\hline I-129 & $6.27 \mathrm{E}-06$ & $2.51 \mathrm{E}-05$ & $2.51 \mathrm{E}-05$ \\
\hline $\mathrm{Kr}-85$ & $2.02 \mathrm{E}+01$ & $8.08 \mathrm{E}+01$ & $8.08 \mathrm{E}+01$ \\
\hline Mn-54 & $3.16 \mathrm{E}-01$ & $1.26 \mathrm{E}+00$ & $1.26 \mathrm{E}+00$ \\
\hline $\mathrm{Ni}-59$ & $2.28 \mathrm{E}-02$ & $9.10 \mathrm{E}-02$ & $9.10 \mathrm{E}-02$ \\
\hline $\mathrm{Ni}-63$ & $2.15 \mathrm{E}+00$ & $8.60 \mathrm{E}+00$ & $8.60 \mathrm{E}+00$ \\
\hline $\mathrm{Np}=237$ & $2.29 \mathrm{E}-0 \mathrm{~S}$ & $-9.16 \mathrm{E}-05$ & $-9.16 E-05$ \\
\hline $\mathrm{Pa}-234$ & $1.29 \mathrm{E}-01$ & $5.16 \mathrm{E}-01$ & $5.16 \mathrm{E}-01$ \\
\hline $\mathrm{Pa}-234 \mathrm{~m}$ & $2.67 \mathrm{E}-03$ & $1.07 \mathrm{E}-02$ & $1.07 \mathrm{E}-02$ \\
\hline $\mathrm{Pb}-210$ & $7.67 \mathrm{E}-01$ & $3.07 \mathrm{E}+00$ & $3.07 \mathrm{E}+00$ \\
\hline $\mathrm{Pb}-214$ & $7.67 \mathrm{E}-01$ & $3.07 \mathrm{E}+00$ & $3.07 \mathrm{E}+00$ \\
\hline Pm-147 & $1.55 \mathrm{E}+00$ & $6.20 \mathrm{E}+00$ & $6.20 \mathrm{E}+00$ \\
\hline Po-214 & $7.67 \mathrm{E}-01$ & $3.07 \mathrm{E}+00$ & $3.07 \mathrm{E}+00$ \\
\hline Po-218 & $7.67 \mathrm{E}-01$ & $3.07 \mathrm{E}+00$ & $3.07 \mathrm{E}+00$ \\
\hline Pu-238 & $7.80 \mathrm{E}-01$ & $3.12 \mathrm{E}+00$ & $3.12 \mathrm{E}+00$ \\
\hline $\mathrm{Pu}-239$ & $8.46 \mathrm{E}-02$ & $3.38 \mathrm{E}-01$ & $3.38 \mathrm{E}-01$ \\
\hline Pu-240 & 4.01E-03 & $1.60 \mathrm{E}-02$ & $1.60 \mathrm{E}-02$ \\
\hline $\mathrm{Pu}-241$ & $2.88 \mathrm{E}-01$ & $1.15 \mathrm{E}+00$ & $1.15 \mathrm{E}+00$ \\
\hline Pu-242 & $1.40 \mathrm{E}-03$ & $5.60 \mathrm{E}-03$ & $5.60 \mathrm{E}-03$ \\
\hline
\end{tabular}


Table A.2 Projected Inventory for IL Vaults (ILNT = non-tritium; ILT $=$ tritium)

\begin{tabular}{|c|c|c|c|}
\hline \multirow[b]{4}{*}{ Radionuclide } & ILV & 2004 ILNT Inventory & 2014 ILNT Inventory \\
\hline & Actual Inventory & Forecast - Vault 1 & Forecast - Vault 2 \\
\hline & As of $6 / 01 / 98$ & 10 Yr. Life & 10 Yr. Life \\
\hline & $(\mathrm{Ci})$ & $(\mathrm{Ci})$ & $(\mathrm{Ci})$ \\
\hline Pu-244 & $6.83 \mathrm{E}-16$ & $2.73 \mathrm{E}-15$ & $2.73 \mathrm{E}-15$ \\
\hline Ra-226 & $7.67 \mathrm{E}-01$ & $3.07 \mathrm{E}+00$ & $3.07 \mathrm{E}+00$ \\
\hline $\mathrm{Rn}-222$ & $7.67 \mathrm{E}-01$ & $3.07 \mathrm{E}+00$ & $3.07 \mathrm{E}+00$ \\
\hline $\mathrm{Ru}-106$ & $6.40 \mathrm{E}-02$ & $2.56 \mathrm{E}-01$ & $2.56 \mathrm{E}-01$ \\
\hline Sb-125 & $7.70 \mathrm{E}-02$ & $3.08 \mathrm{E}-01$ & $3.08 \mathrm{E}-01$ \\
\hline Se-79 & $7.42 \mathrm{E}-05$ & $2.97 \mathrm{E}-04$ & $2.97 \mathrm{E}-04$ \\
\hline Sn-126 & $4.70 \mathrm{E}-04$ & $1.88 \mathrm{E}-03$ & $1.88 \mathrm{E}-03$ \\
\hline $\mathrm{Sr}-90$ & $8.04 \mathrm{E}+00$ & $3.22 \mathrm{E}+01$ & $3.22 \mathrm{E}+01$ \\
\hline Tc-99 & $2.49 \mathrm{E}-02$ & $9.97 \mathrm{E}-02$ & $9.97 \mathrm{E}-02$ \\
\hline Th-231 & $2.27 \mathrm{E}-04$ & $9.08 \mathrm{E}-04$ & $9.08 \mathrm{E}-04$ \\
\hline Th-232 & $1.38 \mathrm{E}-05$ & $5.52 \mathrm{E}-05$ & $5.52 \mathrm{E}-05$ \\
\hline Th-234 & $1.32 \mathrm{E}-01$ & $5.27 \mathrm{E}-01$ & $5.27 \mathrm{E}-01$ \\
\hline $\mathrm{U}-232$ & $4.64 \mathrm{E}-07$ & $1.85 \mathrm{E}-06$ & $1.85 \mathrm{E}-06$ \\
\hline $\mathrm{U}-233$ & $6.62 \mathrm{E}-02$ & $2.65 \mathrm{E}-01$ & $2.65 \mathrm{E}-01$ \\
\hline $\mathrm{U}-234$ & $8.06 \mathrm{E}-02$ & $3.22 \mathrm{E}-01$ & $3.22 \mathrm{E}-01$ \\
\hline U-235 & $3.95 \mathrm{E}-03$ & $1.58 \mathrm{E}-02$ & $1.58 \mathrm{E}-02$ \\
\hline $\mathrm{U}-236$ & $1.04 \mathrm{E}-03$ & $4.17 \mathrm{E}-03$ & $4.17 \mathrm{E}-03$ \\
\hline $\mathrm{U}-238$ & $3.97 \mathrm{E}-01$ & $1.59 \mathrm{E}+00$ & $1.59 \mathrm{E}+00$ \\
\hline$Y-90$ & $3.45 \mathrm{E}+00$ & $1.38 \mathrm{E}+01$ & $1.38 \mathrm{E}+01$ \\
\hline $\mathrm{Zr}-93$ & $3.04 \mathrm{E}-06$ & $1.22 \mathrm{E}-05$ & $1.22 \mathrm{E}-05$ \\
\hline Total & $1.10 \mathrm{E}+05$ & $4.33 \mathrm{E}+05$ & $4.33 \mathrm{E}+05$ \\
\hline
\end{tabular}

\begin{tabular}{|l|l|l|l|}
\hline \multirow{5}{*}{ Radionuclide } & ILT & 2004 ILT Inventory & 2014 ILT Inventory \\
\cline { 2 - 4 } & Actual Inventory & Forecast - Vault 1 & Forecast - Vault 2 \\
\cline { 2 - 4 } & As of 6/01/98 & $10 \mathrm{Yr}$. Life & 10 Yr. Life \\
\cline { 2 - 4 } & $(\mathrm{Ci})$ & $(\mathrm{Ci})$ & $(\mathrm{Ci})$ \\
\hline $\mathrm{H}-3$ & $7.14 \mathrm{E}+04$ & $2.14 \mathrm{E}+05$ & $2.14 \mathrm{E}+05$ \\
\hline Total & $7.14 \mathrm{E}+04$ & $2.14 \mathrm{E}+05$ & $2.14 \mathrm{E}+05$ \\
\hline
\end{tabular}


Table A.3 Projected Inventory for Slit Trenches (5 trenches)

\begin{tabular}{|c|c|c|}
\hline \multirow[b]{4}{*}{ Radionuclide } & E Area Slit Trenches & 2014 E Area Slit Trenches \\
\hline & Actual Inventory & Forecast -1 st Set Of \\
\hline & As of $6 / 01 / 98$ & Trenches (20 Yr. Life) \\
\hline & (Ci) & $(\mathrm{Ci})$ \\
\hline Other Alpha & $3.44 \mathrm{E}-06$ & $8.60 \mathrm{E}-06$ \\
\hline Other B/G & $6.73 \mathrm{E}-03$ & $1.68 \mathrm{E}-02$ \\
\hline Ac-228 & 2.37E-04 & $5.93 \mathrm{E}-04$ \\
\hline $\mathrm{Al}-26$ & $0.00 \mathrm{E}+00$ & $0.00 \mathrm{E}+00$ \\
\hline Am-241 & $8.74 \mathrm{E}-03$ & $2.19 \mathrm{E}-02$ \\
\hline $\mathrm{Am}-242 \mathrm{~m}$ & $0.00 \mathrm{E}+00$ & $0.00 \mathrm{E}+00$ \\
\hline Am-243 & $7.88 \mathrm{E}-07$ & $1.97 \mathrm{E}-06$ \\
\hline $\mathrm{Ba}-137 \mathrm{~m}$ & $6.62 \mathrm{E}-04$ & $1.66 \mathrm{E}-03$ \\
\hline $\mathrm{Bi}-212$ & $2.37 \mathrm{E}-04$ & 5.93E-04 \\
\hline Bk-249 & $0.00 \mathrm{E}+00$ & $0.00 \mathrm{E}+00$ \\
\hline $\mathrm{C}-14$ & $3.00 \mathrm{E}-03$ & $7.50 \mathrm{E}-03$ \\
\hline $\mathrm{Cd}-113 \mathrm{~m}$ & $0.00 \mathrm{E}+00$ & $0.00 \mathrm{E}+00$ \\
\hline $\mathrm{Ce}-144$ & $2.33 \mathrm{E}-06$ & $5.83 \mathrm{E}-06$ \\
\hline Cf-249 & $0.00 \mathrm{E}+00$ & $0.00 \mathrm{E}+00$ \\
\hline $\mathrm{Cf}-250$ & $0.00 \mathrm{E}+00$ & $0.00 \mathrm{E}+00$ \\
\hline Cf-251 & $0.00 \mathrm{E}+00$ & $0.00 \mathrm{E}+00$ \\
\hline Cf-252 & $0.00 \mathrm{E}+00$ & $0.00 \mathrm{E}+00$ \\
\hline $\mathrm{Cm}-242$ & $0.00 \mathrm{E}+00$ & $0.00 \mathrm{E}+00$ \\
\hline $\mathrm{Cm}-243$ & $0.00 \mathrm{E}+00$ & $0.00 \mathrm{E}+00$ \\
\hline $\mathrm{Cm}-244$ & $1.54 \mathrm{E}-04$ & $3.85 \mathrm{E}-04$ \\
\hline $\mathrm{Cm}-245$ & $0.00 \mathrm{E}+00$ & $0.00 \mathrm{E}+00$ \\
\hline $\mathrm{Cm}-246$ & $0.00 \mathrm{E}+00$ & $0.00 \mathrm{E}+00$ \\
\hline $\mathrm{Cm}-247$ & $0.00 \mathrm{E}+00$ & $0.00 \mathrm{E}+00$ \\
\hline $\mathrm{Cm}-248$ & $0.00 \mathrm{E}+00$ & $0.00 \mathrm{E}+00$ \\
\hline $\mathrm{Co}-58$ & $3.22 \mathrm{E}-03$ & $8.05 \mathrm{E}-03$ \\
\hline $\mathrm{Co}-60$ & $2.38 \mathrm{E}-02$ & $5.95 \mathrm{E}-02$ \\
\hline Cs-135 & $0.00 \mathrm{E}+00$ & $0.00 \mathrm{E}+00$ \\
\hline Cs- 137 & $3.51 \mathrm{E}-01$ & $8.78 \mathrm{E}-01$ \\
\hline Eu-154 & $1.77 \mathrm{E}-04$ & $4.43 \mathrm{E}-04$ \\
\hline Eu-155 & $0.00 \mathrm{E}+00$ & $0.00 \mathrm{E}+00$ \\
\hline $\mathrm{Fe}-55$ & $8.06 \mathrm{E}-02$ & $2.02 \mathrm{E}-01$ \\
\hline $\mathrm{H}-3$ & $3.90 \mathrm{E}+00$ & $4.10 \mathrm{E}+00$ \\
\hline $\mathrm{I}=129$ & $1.19 \mathrm{E}-07$ & $2.98 \mathrm{E}-07$ \\
\hline $\mathrm{Nb}-93 \mathrm{~m}$ & $0.00 \mathrm{E}+00$ & $0.00 \mathrm{E}+00$ \\
\hline $\mathrm{Ni}-59$ & $2.61 \mathrm{E}-03$ & $6.53 \mathrm{E}-03$ \\
\hline $\mathrm{Ni}-63$ & $7.06 \mathrm{E}-03$ & $1.77 \mathrm{E}-02$ \\
\hline Np-237 & $6.10 \mathrm{E}-06$ & $1.53 \mathrm{E}-05$ \\
\hline $\mathrm{Pa}-231$ & $0.00 \mathrm{E}+00$ & $0.00 \mathrm{E}+00$ \\
\hline $\mathrm{Pa}-234 \mathrm{~m}$ & $7.85 \mathrm{E}-04$ & $1.96 \mathrm{E}-03$ \\
\hline $\mathrm{Pb}-210$ & $0.00 \mathrm{E}+00$ & $0.00 \mathrm{E}+00$ \\
\hline $\mathrm{Pb}+212$ & $3.46 \mathrm{E}-04$ & $8.65 \mathrm{E}-04$ \\
\hline Pd-107 & $0.00 \mathrm{E}+00$ & $0.00 \mathrm{E}+00$ \\
\hline $\mathrm{Pm}-147$ & $1.36 \mathrm{E}-05$ & $3.40 \mathrm{E}-05$ \\
\hline Po-212 & $1.52 \mathrm{E}-04$ & $3.80 \mathrm{E}-04$ \\
\hline Po-216 & $2.37 \mathrm{E}-04$ & $5.93 \mathrm{E}-04$ \\
\hline
\end{tabular}


Table A.3 Projected Inventory for Slit Trenches (5 trenches)

\begin{tabular}{|l|l|l|}
\hline \multirow{4}{*}{ Radionuclide } & E Area Slit Trenches & 2014 E Area Slit Trenches \\
\cline { 2 - 3 } & Actual Inventory & \multicolumn{1}{|c|}{ Forecast - 1st Set Of } \\
\cline { 2 - 3 } (1Ci) & Trenches (20 Yr. Life) \\
\hline Pr-144 & $2.30 \mathrm{E}-06$ & \\
\hline Pr-144m & $2.79 \mathrm{E}-08$ & $5.75 \mathrm{E}-06$ \\
\hline Pu-238 & $2.02 \mathrm{E}-03$ & $6.98 \mathrm{E}-08$ \\
\hline Pu-239 & $5.48 \mathrm{E}-04$ & $5.05 \mathrm{E}-03$ \\
\hline Pu-240 & $1.07 \mathrm{E}-04$ & $1.37 \mathrm{E}-03$ \\
\hline Pu-241 & $5.81 \mathrm{E}-03$ & $2.68 \mathrm{E}-04$ \\
\hline Pu-242 & $2.41 \mathrm{E}-06$ & $1.45 \mathrm{E}-02$ \\
\hline Pu-244 & $0.00 \mathrm{E}+00$ & $6.03 \mathrm{E}-06$ \\
\hline Ra-224 & $2.37 \mathrm{E}-04$ & $0.00 \mathrm{E}+00$ \\
\hline Ra-226 & $0.00 \mathrm{E}+00$ & $5.93 \mathrm{E}-04$ \\
\hline Ra-228 & $2.37 \mathrm{E}-04$ & $0.00 \mathrm{E}+00$ \\
\hline Rb-87 & $0.00 \mathrm{E}+00$ & $5.93 \mathrm{E}-04$ \\
\hline Rh-106 & $4.07 \mathrm{E}-06$ & $0.00 \mathrm{E}+00$ \\
\hline Rn-220 & $2.37 \mathrm{E}-04$ & $1.02 \mathrm{E}-05$ \\
\hline Ru-106 & $4.07 \mathrm{E}-06$ & $5.93 \mathrm{E}-04$ \\
\hline Sb-125 & $2.56 \mathrm{E}-03$ & $1.02 \mathrm{E}-05$ \\
\hline Se-79 & $1.43 \mathrm{E}-05$ & $6.40 \mathrm{E}-03$ \\
\hline Sm-151 & $0.00 \mathrm{E}+00$ & $3.58 \mathrm{E}-05$ \\
\hline Sn-121m & $0.00 \mathrm{E}+00$ & $0.00 \mathrm{E}+00$ \\
\hline Sn-126 & $1.80 \mathrm{E}-04$ & $0.00 \mathrm{E}+00$ \\
\hline Sr-90 & $4.91 \mathrm{E}-02$ & $4.50 \mathrm{E}-04$ \\
\hline Tc-99 & $9.70 \mathrm{E}-04$ & $1.23 \mathrm{E}-01$ \\
\hline Th-228 & $2.37 \mathrm{E}-04$ & $2.43 \mathrm{E}-03$ \\
\hline Th-229 & $0.00 \mathrm{E}+00$ & $5.93 \mathrm{E}-04$ \\
\hline Th-230 & $2.37 \mathrm{E}-04$ & $0.00 \mathrm{E}+00$ \\
\hline Th-232 & $2.37 \mathrm{E}-04$ & $5.93 \mathrm{E}-04$ \\
\hline Th-234 & $7.85 \mathrm{E}-04$ & $5.93 \mathrm{E}-04$ \\
\hline Tl-208 & $8.56 \mathrm{E}-05$ & $1.96 \mathrm{E}-03$ \\
\hline $\mathrm{U}-232$ & $0.00 \mathrm{E}+00$ & $2.14 \mathrm{E}-04$ \\
\hline $\mathrm{U}-233$ & $3.30 \mathrm{E}-08$ & $0.00 \mathrm{E}+00$ \\
\hline $\mathrm{U}-234$ & $2.15 \mathrm{E}-03$ & $8.25 \mathrm{E}-08$ \\
\hline $\mathrm{U}-235$ & $7.00 \mathrm{E}-05$ & $5.38 \mathrm{E}-03$ \\
\hline $\mathrm{U}-236$ & $2.00 \mathrm{E}-04$ & $1.75 \mathrm{E}-04$ \\
\hline $\mathrm{U}-238$ & $1.08 \mathrm{E}-03$ & $5.00 \mathrm{E}-04$ \\
\hline Y-90 & $4.15 \mathrm{E}-04$ & $2.70 \mathrm{E}-03$ \\
\hline $\mathrm{Zn}-65$ & $2.36 \mathrm{E}-03$ & $1.04 \mathrm{E}-03$ \\
\hline Zr-93 & $0.00 \mathrm{E}+00$ & $5.90 \mathrm{E}-03$ \\
\hline Total & $4.46 \mathrm{E}+00$ & $0.00 \mathrm{E}+00$ \\
\hline & & $5.50 \mathrm{E}+00$ \\
\hline
\end{tabular}


Table A.4 Projected Inventory for Naval Reactor Waste

\begin{tabular}{|c|c|}
\hline \multirow[b]{4}{*}{ Radionuclide } & 2014 NR Inventory \\
\hline & Forecast \\
\hline & 20 Yr. Life \\
\hline & $(\mathrm{Ci})$ \\
\hline Other Alpha & $2.44 \mathrm{E}+01$ \\
\hline Other $B / G$ & $7.84 E+04$ \\
\hline Am-241 & $1.43 \mathrm{E}-01$ \\
\hline Am-242m & $1.19 \mathrm{E}-06$ \\
\hline Am-243 & $1.98 \mathrm{E}-03$ \\
\hline $\mathrm{Ba}-137 \mathrm{~m}$ & $4.27 \mathrm{E}+00$ \\
\hline$C-14$ & $2.27 \mathrm{E}+02$ \\
\hline $\mathrm{Ce}-144$ & $4.05 \mathrm{E}+00$ \\
\hline Cf-249 & $6.78 \mathrm{E}-14$ \\
\hline Cf-251 & $2.68 \mathrm{E}-15$ \\
\hline $\mathrm{Cm}-242$ & $2.39 \mathrm{E}+00$ \\
\hline $\mathrm{Cm}-243$ & $3.38 \mathrm{E}-07$ \\
\hline $\mathrm{Cm}-244$ & $1.57 \mathrm{E}-01$ \\
\hline $\mathrm{Cm}-245$ & $8.43 \mathrm{E}-06$ \\
\hline $\mathrm{Cm}-246$ & $3.24 \mathrm{E}-06$ \\
\hline $\mathrm{Cm}-247$ & $3.95 \mathrm{E}-15$ \\
\hline $\mathrm{Cm}-248$ & $1.28 \mathrm{E}-14$ \\
\hline Co-58 & $3.39 \mathrm{E}+04$ \\
\hline $\mathrm{Co}-60$ & $2.26 \mathrm{E}+05$ \\
\hline Cr-51 & $1.04 \mathrm{E}-02$ \\
\hline Cs- 135 & $2.86 \mathrm{E}-05$ \\
\hline Cs-137 & $4.27 \mathrm{E}+00$ \\
\hline Eu-154 & $5.55 \mathrm{E}-02$ \\
\hline Eu-155 & $3.16 \mathrm{E}-02$ \\
\hline $\mathrm{Fe}-55$ & $2.04 \mathrm{E}+05$ \\
\hline $\mathrm{Fe}-59$ & $1.01 \mathrm{E}-01$ \\
\hline $\mathrm{H}-3$ & $1.11 \mathrm{E}+02$ \\
\hline Hf- 181 & $3.36 \mathrm{E}-02$ \\
\hline I-129 & $1.94 \mathrm{E}-06$ \\
\hline In-113m & $4.02 \mathrm{E}+03$ \\
\hline $\mathrm{Mn}-54$ & $1.13 E+03$ \\
\hline $\mathrm{Me}-93$ & $-4.08 \mathrm{E}-01$ \\
\hline $\mathrm{Nb}-93 \mathrm{~m}$ & $1.96 \mathrm{E}-0 \mathrm{I}$ \\
\hline $\mathrm{Nb}-94$ & $1.08 \mathrm{E}+01$ \\
\hline $\mathrm{Nb}-95$ & $2.12 \mathrm{E}+05$ \\
\hline $\mathrm{Nb}-95 \mathrm{~m}$ & $1.08 \mathrm{E}+03$ \\
\hline $\mathrm{Ni}-59$ & $2.62 \mathrm{E}+03$ \\
\hline $\mathrm{Ni}-63$ & $3.01 E+05$ \\
\hline $\mathrm{Np}-237$ & $3.31 \mathrm{E}-06$ \\
\hline Pm-147 & $2.45 \mathrm{E}+00$ \\
\hline Pu-238 & $2.21 \mathrm{E}-01$ \\
\hline Pu-239 & $2.91 \mathrm{E}-01$ \\
\hline $\mathrm{Pu}-240$ & $7.67 \mathrm{E}-02$ \\
\hline $\mathrm{Pu}-241$ & $1.98 \mathrm{E}+01$ \\
\hline
\end{tabular}

Table A.4 Projected Inventory for Naval Reactor Waste

\begin{tabular}{|l|l|}
\hline \multirow{2}{*}{} & \multicolumn{1}{|c|}{ Forecast } \\
\cline { 2 - 2 } & \multicolumn{1}{|c|}{20 Yr. Life } \\
\cline { 2 - 2 } & \multicolumn{1}{|c|}{ Ci) } \\
\hline Pu-242 & $3.36 \mathrm{E}-04$ \\
\hline Pu-244 & $6.07 \mathrm{E}-15$ \\
\hline Ru-106 & $3.45 \mathrm{E}-01$ \\
\hline Sb-125 & $9.27 \mathrm{E}+04$ \\
\hline Se-79 & $3.49 \mathrm{E}-04$ \\
\hline Sm-151 & $4.45 \mathrm{E}-02$ \\
\hline Sn-113 & $4.02 \mathrm{E}+03$ \\
\hline Sn-119m & $1.73 \mathrm{E}+05$ \\
\hline Sn-123 & $1.95 \mathrm{E}+03$ \\
\hline Sn-126 & $5.99 \mathrm{E}-06$ \\
\hline Sr-90 & $4.35 \mathrm{E}+00$ \\
\hline Ta-182 & $3.32 \mathrm{E}+04$ \\
\hline Tc-99 & $2.41 \mathrm{E}-01$ \\
\hline Te-125m & $2.10 \mathrm{E}+04$ \\
\hline Th-232 & $1.28 \mathrm{E}-11$ \\
\hline $\mathrm{U}-232$ & $1.97 \mathrm{E}-07$ \\
\hline U-234 & $2.28 \mathrm{E}-06$ \\
\hline $\mathrm{U}-235$ & $1.69 \mathrm{E}-07$ \\
\hline U-236 & $3.48 \mathrm{E}-06$ \\
\hline $\mathrm{U}-238$ & $1.92 \mathrm{E}-05$ \\
\hline Y-90 & $4.35 \mathrm{E}+00$ \\
\hline Zr-93 & $3.61 \mathrm{E}-05$ \\
\hline Zr-95 & $9.97 \mathrm{E}+04$ \\
\hline Total & $1.49 \mathrm{E}+06$ \\
\hline & \\
\hline
\end{tabular}


Table A.5 Projected Inventory for Intimately-mixed Cement-stabilized Waste

\begin{tabular}{|c|c|}
\hline \multirow[b]{3}{*}{ Radionuclide } & $\begin{array}{c}\text { Intimately-mixed } \\
\text { Cement Stablized } \\
\text { Waste } \\
\end{array}$ \\
\hline & 5 trenches \\
\hline & (Ci) \\
\hline Other Alpha & $1.66 \mathrm{E}-01$ \\
\hline Ac-228 & $1.01 \mathrm{E}-02$ \\
\hline $\mathrm{Al}-26$ & $0.00 \mathrm{E}+00$ \\
\hline Am-241 & $5.25 \mathrm{E}-01$ \\
\hline $\mathrm{Am}-243$ & $4.95 \mathrm{E}-05$ \\
\hline Other $\mathrm{B} / \mathrm{G}$ & $4.86 \mathrm{E}+00$ \\
\hline $\mathrm{Ba}-137 \mathrm{~m}$ & $4.27 \mathrm{E}+01$ \\
\hline $\mathrm{Bi}-210$ & $2.00 \mathrm{E}-04$ \\
\hline $\mathrm{Bi}-212$ & $2 . \dot{48 \mathrm{E}-02}$ \\
\hline $\mathrm{Bi}-214$ & $2.00 \mathrm{E}-04$ \\
\hline $\mathrm{C}-14$ & $1.48 \mathrm{E}-01$ \\
\hline Cd-109 & $3.01 \mathrm{E}-05$ \\
\hline $\mathrm{Ce}-144$ & $2.02 E+00$ \\
\hline $\mathrm{Cf}-249$ & $1.22 \mathrm{E}-05$ \\
\hline $\mathrm{Cf}-250$ & $1.56 \mathrm{E}-03$ \\
\hline $\mathrm{Cf}-251$ & $3.24 \mathrm{E}-10$ \\
\hline Cf -252 & $1.35 \mathrm{E}-02$ \\
\hline $\mathrm{Cm}-244$ & $4.41 \mathrm{E}-02$ \\
\hline $\mathrm{Cm}-245$ & $1.36 \mathrm{E}-09$ \\
\hline $\mathrm{Cm}-246$ & $5.43 E-10$ \\
\hline $\mathrm{Cm}-247$ & $1.42 \mathrm{E}-12$ \\
\hline $\mathrm{Cm}-248$ & $5.16 \mathrm{E}-15$ \\
\hline Co-57 & $2.44 \mathrm{E}-03$ \\
\hline $\mathrm{Co}-58$ & $3.51 \mathrm{E}-01$ \\
\hline Co-60 & $8.55 \mathrm{E}+00$ \\
\hline Cs-134 & $4.77 \mathrm{E}+00$ \\
\hline Cs-135 & 1.41E.09 \\
\hline Cs-137 & $8.87 \mathrm{E}+01$ \\
\hline Eu-152 & $6.21 \mathrm{E}+00$ \\
\hline Eu-154 & $4.11 \mathrm{E}+00$ \\
\hline Eu-155 & $1.53 \mathrm{E}-06$ \\
\hline $\mathrm{Fe}-55$ & $1.26 \mathrm{E}+01$ \\
\hline $\mathrm{Fe}-59$ & $1.08 \mathrm{E}-02$ \\
\hline $\mathrm{H}-3$ & $5.50 \mathrm{E}+05$ \\
\hline Hf- 181 & $4.23 \mathrm{E}-05$ \\
\hline Hg-203 & $3.87 \mathrm{E}-05$ \\
\hline $\mathrm{I}-129$ & $3.57 \mathrm{E}-05$ \\
\hline $\mathrm{Kr}-85$ & $3.93 \mathrm{E}+00$ \\
\hline $\mathrm{Mn}-54$ & $2.13 \mathrm{E}-01$ \\
\hline $\mathrm{Nb}-93 \mathrm{~m}$ & $2.69 \mathrm{E}-03$ \\
\hline $\mathrm{Nb}-94$ & $9.57 \mathrm{E}-09$ \\
\hline $\mathrm{Nb}-95$ & $9.45 \mathrm{E}-03$ \\
\hline
\end{tabular}

Table A.5 Projected Inventory for Intimately-mixed Cement-stabilized Waste

\begin{tabular}{|c|c|}
\hline & $\begin{array}{c}\text { Intimately-mixed } \\
\text { Cement Stablized } \\
\text { Waste }\end{array}$ \\
\hline & 5 trenches \\
\hline & (Ci) \\
\hline Ni-59 & $8.67 \mathrm{E}-02$ \\
\hline $\mathrm{Ni}-63$ & $6.51 \mathrm{E}+00$ \\
\hline Np-237 & $2.14 \mathrm{E}-02$ \\
\hline $\mathrm{Np}-239$ & $4.80 \mathrm{E}-08$ \\
\hline $\mathrm{Pa}-234$ & $2.81 \mathrm{E}-03$ \\
\hline $\mathrm{Pa}-234 \mathrm{~m}$ & $1.70 \mathrm{E}-01$ \\
\hline $\mathrm{Pb}-210$ & $2.00 \mathrm{E}-04$ \\
\hline $\mathrm{Pb}-212$ & $2.47 \mathrm{E}-02$ \\
\hline $\mathrm{Pb}-214$ & $2.00 \mathrm{E}-04$ \\
\hline Pd-107 & $3.24 \mathrm{E}-13$ \\
\hline Pm-147 & $1.61 \mathrm{E}+01$ \\
\hline Po-210. & $2.00 \mathrm{E}-04$ \\
\hline Po-212 & $5.25 \mathrm{E}-03$ \\
\hline Po-214 & $2.00 \mathrm{E}-04$ \\
\hline Po-216 & $2.47 \mathrm{E}-02$ \\
\hline Po-218 & $2.00 \mathrm{E}-04$ \\
\hline Pr-144 & $1.99 \mathrm{E}+00$ \\
\hline Pr-144m & $1.04 \mathrm{E}-04$ \\
\hline Pu-238 & $5.16 \mathrm{E}+00$ \\
\hline Pu-239 & $1.93 \mathrm{E}+00$ \\
\hline $\mathrm{Pu}-240$ & $6.78 \mathrm{E}-01$ \\
\hline $\mathrm{Pu}-241$ & $2.96 \mathrm{E}+01$ \\
\hline $\mathrm{Pu}-242$ & $3.69 \mathrm{E}-04$ \\
\hline $\mathrm{Pu}-244$ & $2.44 \mathrm{E}-15$ \\
\hline Ra-224 & $2.03 \mathrm{E}-02$ \\
\hline Ra-226 & $2.01 \mathrm{E}-04$ \\
\hline Ra-228 & $1.28 \mathrm{E}-02$ \\
\hline $\mathrm{Rb}-86$ & $1.40 \mathrm{E}-04$ \\
\hline $\mathrm{Rb}-87$ & $0.00 \mathrm{E}+00$ \\
\hline Rh-106 & $1.41 \mathrm{E}-02$ \\
\hline $\mathrm{Rn}-220$ & $2.47 \mathrm{E}-02$ \\
\hline $\mathrm{Rn}-222$ & $2.00 \mathrm{E}-04$ \\
\hline $\mathrm{Ru}-106$ & $9.63 \mathrm{E}-02$ \\
\hline S-35 & $8.85 \mathrm{E}-03$ \\
\hline Sb-125 & $8.61 \mathrm{E}-02$ \\
\hline Se-79 & $2.66 \mathrm{E}-02$ \\
\hline Sm-151 & $1.39 \mathrm{E}-04$ \\
\hline Sn-126 & $6.81 \mathrm{E}-04$ \\
\hline $\mathrm{Sr}-85$ & $1.54 \mathrm{E}-03$ \\
\hline $\mathrm{Sr}-90$ & $5.67 \mathrm{E}+01$ \\
\hline Tc-93m & $7.80 \mathrm{E}-08$ \\
\hline Tc-99 & $3.30 \mathrm{E}-02$ \\
\hline Th-228 & $2.47 \mathrm{E}-02$ \\
\hline
\end{tabular}


Table A.5 Projected Inventory for Intimately-mixed

Cement-stabilized

Waste

\begin{tabular}{|l|l|}
\hline \multirow{2}{*}{ Radionuclide } & $\begin{array}{c}\text { Intimately-mixed } \\
\text { Cement Stablized } \\
\text { Waste }\end{array}$ \\
\cline { 2 - 2 } & \multicolumn{1}{|c|}{ 5 trenches } \\
\cline { 2 - 2 } (Ci)
\end{tabular}


Table A.6 Projected Inventory for Cement-stabilized Encapsulated Waste

\begin{tabular}{|c|c|c|}
\hline \multirow[b]{3}{*}{ Radionuclide } & $\begin{array}{c}\text { Single Used } \\
\text { Equipment Storage } \\
\text { Area }^{a}\end{array}$ & $\begin{array}{c}\text { Combined Used Equipment } \\
\text { Storage Area with } 55 \% \\
\text { Reduction } \\
\end{array}$ \\
\hline & Actual Inventory & Actual Inventory \\
\hline & $(\mathrm{Ci})$ & (Ci) \\
\hline $\mathrm{Ag}-110$ & $3.39 \mathrm{E}-11$ & $2.98 \mathrm{E}-11$ \\
\hline $\mathrm{Ag}-110 \mathrm{~m}$ & $2.05 \mathrm{E}+00$ & $1.80 \mathrm{E}+00$ \\
\hline Am-241 & $1.54 \mathrm{E}-02$ & $1.36 \mathrm{E}-02$ \\
\hline $\mathrm{Ba}-137 \mathrm{~m}$ & $8.39 E+03$ & $7.38 \mathrm{E}+03$ \\
\hline $\mathrm{Ba}-140$ & $3.39 \mathrm{E}-11$ & $2.98 \mathrm{E}-11$ \\
\hline $\mathrm{Ce}-141$ & $3.39 \mathrm{E}-11$ & $2.98 \mathrm{E}-11$ \\
\hline $\mathrm{Ce}-144$ & $1.14 \mathrm{E}+03$ & $1.00 \mathrm{E}+03$ \\
\hline $\mathrm{Co}-60$ & $1.11 \mathrm{E}+03$ & $9.77 \mathrm{E}+02$ \\
\hline Cs-134 & $4.04 \mathrm{E}+03$ & $3.56 \mathrm{E}+03$ \\
\hline Cs-135 & $2.61 \mathrm{E}-02$ & $2.30 \mathrm{E}-02$ \\
\hline Cs-137 & $8.39 \mathrm{E}+03$ & $7.38 \mathrm{E}+03$ \\
\hline Eu-154 & $4.24 \mathrm{E}+02$ & $3.73 \mathrm{E}+02$ \\
\hline Eu-155 & $2.48 \mathrm{E}+02$ & $2.18 \mathrm{E}+02$ \\
\hline Eu-156 & $3.39 \mathrm{E}-11$ & $2.98 \mathrm{E}-11$ \\
\hline $\mathrm{Fe}-55$ & $1.83 E+02$ & $1.61 \mathrm{E}+02$ \\
\hline $\mathrm{H}-3$ & $4.68 \mathrm{E}+01$ & $4.12 \mathrm{E}+01$ \\
\hline I-129 & $3.25 \mathrm{E}-02$ & $2.86 \mathrm{E}-02$ \\
\hline $\mathrm{Kr}-85$ & $7.17 \mathrm{E}+02$ & $6.31 \mathrm{E}+02$ \\
\hline La-140 & $3.39 \mathrm{E}-11$ & $2.98 \mathrm{E}-11$ \\
\hline $\mathrm{Nb}-95$ & $1.45 \mathrm{E}-09$ & $1.28 \mathrm{E}-09$ \\
\hline $\mathrm{Nb}-95 \mathrm{~m}$ & $3.24 \mathrm{E}-04$ & $2.85 \mathrm{E}-04$ \\
\hline $\mathrm{Ni}-59$ & $1.28 \mathrm{E}+00$ & $1.13 \mathrm{E}+00$ \\
\hline $\mathrm{Ni}-63$ & $1.82 \mathrm{E}+02$ & $1.60 \mathrm{E}+02$ \\
\hline Pd-107 & $9.63 \mathrm{E}-03$ & $8.47 \mathrm{E}-03$ \\
\hline Pm-147 & $2.43 E+03$ & $2.24 \mathrm{E}+03$ \\
\hline $\mathrm{Pm}-148$ & $3.39 \mathrm{E}-11$ & $2.98 \mathrm{E}-11$ \\
\hline Pm-148m & $1.89 \mathrm{E}-10$ & $1.66 \mathrm{E}-10$ \\
\hline Pr-143 & $3.39 \mathrm{E}-11$ & $2.98 \mathrm{E}-11$ \\
\hline Pr-144 & $1.14 \mathrm{E}+03$ & $1.00 \mathrm{E}+03$ \\
\hline $\mathrm{Pu}-238$ & $8.93 \mathrm{E}-01$ & $7.86 \mathrm{E}-01$ \\
\hline $\mathrm{Pu}-239$ & $8.68 \mathrm{E}-02$ & $7.64 \mathrm{E}-02$ \\
\hline $\mathrm{Pu}-240$ & $2.02 \mathrm{E}-02$ & $1.78 \mathrm{E}-02$ \\
\hline $\mathrm{Pu}-241$ & $8.00 \mathrm{E}-01$ & $7.04 \mathrm{E}-01$ \\
\hline $\mathrm{Pu}-242$ & $0.00 \mathrm{E}+00$ & $0.00 \mathrm{E}+00$ \\
\hline Rh-106 & $1.52 \mathrm{E}+03$ & $1.34 \mathrm{E}+03$ \\
\hline $\mathrm{Ru}-103$ & $1.26 \mathrm{E}-08$ & $1.11 \mathrm{E}-08$ \\
\hline $\mathrm{Ru}-103 \mathrm{~m}$ & $1.26 \mathrm{E}-08$ & $1.11 \mathrm{E}-08$ \\
\hline $\mathrm{Ru}-106$ & $1.52 \mathrm{E}+03$ & $1.34 \mathrm{E}+03$ \\
\hline$S b-125$ & $2.23 \mathrm{E}+02$ & $1.96 \mathrm{E}+02$ \\
\hline Se-79 & $3.49 \mathrm{E}-02$ & $3.07 \mathrm{E}-02$ \\
\hline Sm-151 & $1.05 \mathrm{E}+02$ & $9.24 \mathrm{E}+01$ \\
\hline $\mathrm{Sn}-123$ & $4.02 \mathrm{E}-04$ & $3.54 \mathrm{E}-04$ \\
\hline Sn-126 & $4.78 \mathrm{E}-02$ & $4.21 \mathrm{E}-02$ \\
\hline Sr-89 & $9.64 \mathrm{E}-07$ & $8.48 \mathrm{E}-07$ \\
\hline
\end{tabular}


Table A.6 Projected Inventory for Cement-stabilized Encapsulated Waste

\begin{tabular}{|c|c|c|}
\hline \multirow[b]{3}{*}{ Radionuclide } & $\begin{array}{c}\text { Single Used } \\
\text { Equipment Storage } \\
\text { Area } \\
\end{array}$ & $\begin{array}{c}\text { Combined Used Equipment } \\
\begin{array}{c}\text { Storage Area with } 55 \% \\
\text { Reduction }\end{array} \\
\end{array}$ \\
\hline & Actual Inventory & Actual Inventory \\
\hline & $(\mathrm{Ci})$ & $(\mathrm{Ci})$ \\
\hline Sr-90 & $6.03 \mathrm{E}+03$ & $5.31 \mathrm{E}+03$ \\
\hline Tb-160 & $2.71 \mathrm{E}-06$ & $2.39 \mathrm{E}-06$ \\
\hline Tc-99 & $1.25 \mathrm{E}+00$ & $1.10 \mathrm{E}+00$ \\
\hline $\mathrm{Te}-125 \mathrm{~m}$ & $2.19 \mathrm{E}+02$ & $1.93 \mathrm{E}+02$ \\
\hline $\mathrm{Te}-127$ & $3.39 \mathrm{E}-11$ & $2.98 \mathrm{E}-11$ \\
\hline $\mathrm{Te}-127 \mathrm{~m}$ & $1.28 \mathrm{E}-02$ & $1.13 \mathrm{E}-02$ \\
\hline Te-129 & $3.39 \mathrm{E}-11$ & $2.98 \mathrm{E}-11$ \\
\hline $\mathrm{Te}-129 \mathrm{~m}$ & $3.39 \mathrm{E}-11$ & $2.98 \mathrm{E}-11$ \\
\hline $\mathrm{U}-232$ & $2.65 \mathrm{E}-03$ & $2.33 \mathrm{E}-03$ \\
\hline U-233 & $9.29 \mathrm{E}-04$ & $8.18 \mathrm{E}-04$ \\
\hline U-234 & $2.10 \mathrm{E}-01$ & $1.85 \mathrm{E}-01$ \\
\hline $\mathrm{U}-235$ & $1.50 \mathrm{E}-03$ & $1.32 \mathrm{E}-03$ \\
\hline $\mathrm{U}-236$ & $3.89 \mathrm{e}-02$ & $3.42 E-02$ \\
\hline U-238 & $1.24 \mathrm{E}-04$ & $1.09 \mathrm{E}-04$ \\
\hline Y-90 & $6.03 \mathrm{E}+03$ & $5.31 \mathrm{E}+03$ \\
\hline Y-91 & $1.98 \mathrm{E}-04$ & $1.74 \mathrm{E}-04$ \\
\hline Zr-93 & $1.66 \mathrm{E}-01$ & $1.46 \mathrm{E}-01$ \\
\hline $\mathrm{Zr}-95$ & $3.24 \mathrm{E}-04$ & $2.85 \mathrm{E}-04$ \\
\hline Total & $4.42 \mathrm{E}+04$ & $3.89 \mathrm{E}+04$ \\
\hline
\end{tabular}

a As per Calculation Number G-CLC-E-00013, Savannah River Site Internal Document. 
APPENDIX B

COMPUTER CODES 
THIS PAGE INTENTIONALLY LEFT BLANK 


\section{B.1 CODE SELECTION CRITERIA AND CONSIDERATIONS}

Listed below are criteria that were considered in selecting computer codes for use in the Performance Assessment (PA) of the E-Area Low Level Waste Facility (LLWF) at the Savannah River Site. The first list, which follows directly, consists of absolute requirements for any code ( $1 \mathrm{R}=\# 1$, Required); any code not meeting any one of these requirements was rejected.

1R. The theoretical framework of the selected computer code(s) should be based on appropriate fundamental principles of chemistry and physics (e.g., conservation of mass, momentum, and energy) and well established constitutive equations (e.g., Darcy's law, Fick's law, etc.).

2R. The selected code(s) should be verified (i.e., simulation results compared against known analytical solutions of the underlying equations) to demonstrate correctness of the source code. Such verification should be fully documented in a technical report.

3R. The selected code should be documented in a technical report and contain descriptions of: 1) model theory, governing equations and assumptions, 2) computational techniques and algorithms, and 3) example applications.

4R. All simulation codes(s) selected for use in the composite analysis must be maintained under a software QA and management program that assures that modifications and updates are traceable, auditable and documented, and that all production versions have been verified and validated.

This second list contains criteria describing attributes of computer codes that, though desirable, may not be presently attainable (1S = \#1, Suggested). Consideration was given to these criteria, and justification for using a code not meeting them is given in this appendix.

1S. The code(s) should allow site- and facility-specific applications; i.e., be capable of simulating the hydrologic, geologic and/or geochemical setting of the site, as well as specific design features of the facility over time.

2S. A contaminant transport code should be capable of: 1) tracking waste inventory over time, including radioactive daughter products, and 2) computing the contaminant fluxes at designated locations as a function of driving hydrologic processes and mass transport phenomena.

3S. The code(s) should be validated (e.g., simulation results compared with field data) for a system similar to that being modeled whenever possible. Benchmarking (i.e., code-to-code comparisons) is also useful in demonstrating code capabilities.

4S. The degree of complexity of the computer code(s) should be consistent with the quantity and quality of data, and the objectives of the computation. Screening calculations and sensitivity analyses should be used to simplify conceptual models, and ultimately direct code selection.

5S. Hardware requirements for the selected code should not be exotic (i.e., codes should run on readily accessible mainframe, mini, or personal computers (PC); convertibility is highly desirable).

6S. Consideration must be given to the ease of interfacing code output with other codes. For example, it is often desirable to use a groundwater code that simulates unsaturated and saturated flow, as well as mass transport, as coupling of output from each simulation type has already been accomplished. 
7S. Familiarity with the code(s) should also be a consideration in selection, in light of time constraints that may be imposed for completion of a composite analysis and the need to revise the code if problems arise.

\section{B.2 GEOCHEMICAL COMPUTER CODE}

The composition of pore fluids in the LAW vaults was estimated using the MINTEQ geochemical code.

\section{B.2.1 Code Description - MINTEQ}

Purpose and Scope: MINTEQ is a geochemical computer code used to predict and evaluate the equilibrium behavior of inorganic pollutants in a variety of geochemical environments. The code can model complex equilibrium relationships that exist among soluble species, insoluble solids, gases, and adsorbed species. The code can also be used to calculate the consequences of equilibrium mass transfer between aqueous and solid phases. However, the code does not have the capability to calculate reaction path models nor can it calculate reaction kinetics. MINTEQ is useful for calculating the source term concentrations and speciation of inorganic contaminants. In addition, MINTEQ contains algorithms that predict the sorption of contaminants on soils and sediments. The sorption algorithms include: activity $\mathbf{K}_{d}$, Langmuir isotherm, Freundlich isotherm, ion exchange, and surface complexation models. The code incorporates a Newton-Raphson iteration scheme to solve the set of mass-action and mass-balance expressions.

Development History: The MINTEQ code was originally developed at Pacific Northwest Laboratory (Felmy et al. 1984a) by combining the mathematical structure of the MINEQL and the geochemical attributes of the WATEQ geochemical codes. MINTEQ was developed to solve geochemical equilibria problems by applying fundamental principles of

thermodynamics. Changes to the code since its creation have been confined to improving ease of input and the flexibility of the output. Additional thermodynamic data has also been added to the database.

Code Attributes: The code is written in FORTRAN 77 programming language and includes several input data files containing data necessary for the operation of the code, such as: thermodynamic data, component identification numbers, ion charge and size, and formula weights.

Computer Requirements: Many applications of MINTEQ can be performed effectively and efficiently on a PC with a 286 central processor unit (cpu). More complex calculations will be more efficiently processed on

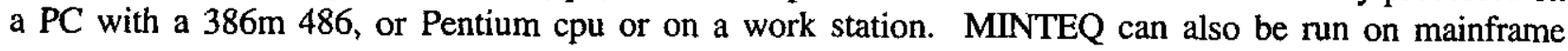
computer systems.

Restrictions: The MINTEQ code was developed by Pacific Northwest Laboratory for the U.S. NRC and the EPA; the code is public domain software. The code is documented in Felmy et al. (1984a), Brown and Allison (1987), and Peterson et al. (1987).

\section{B.2.2 Code Selection Basis}

General Critique: MINTEQ is one of several computer codes that has been developed to calculate equilibrium aqueous speciation and mineral mass transfer. Mechanistic adsorption models are included in the MINTEQ code, a major advantage over other geochemical codes such as EQ3/EQ6. The fundamental limitation of MINTEQ and other equilibrium based geochemical codes is that equilibrium conditions are often not obtained in low temperature systems. Furthermore, metastable conditions may persist for long periods of times in experimental systems, and experimentally observed concentrations may differ from those predicted by the code. 
Code Verification: MINTEQ calculates the equilibrium speciation for an aqueous composition. Verification can be performed by using the MINTEQ output and hand calculations to evaluate equilibrium. In addition, the MINTEQ code was verified during its development by comparison calculations against WATEQ4 (Felmy et al. 1984a, b)

Code Benchmarking: The code has been benchmarked using the river water test case of Nordstrom et. al. (1979; see Peterson et al. 1987). In addition, the code was benchmarked against WATEQ4 during development (Krupka and Morrey 1985).

Code Validation: The MINTEQ code has been partially validated for aqueous systems containing $\mathrm{Cu}(\mathrm{II})$, Pu, and U (Krupka and Morrey 1985).

\section{B.2.3 Theoretical Framework}

Governing Equation and Assumptions: The MINTEQ code calculates equilibrium speciation of aqueous phases. Speciation is defined as the chemical form of an element in an aqueous solution. The code solves mass balance expressions for each component ion (e.g., $\mathrm{Ca}^{2+}, \mathrm{HCO}_{3}{ }^{+}, \mathrm{Na}^{+}$, etc.) using mass action relationships and equilibrium constants relating each species (such as $\mathrm{CO}_{3}{ }^{2-}$, a species of the $\mathrm{HCO}_{3}{ }^{-}$ component) to MINTEQ components. Equilibrium constants for species are provided in the THERMO.DAT data base for calculations at a reference temperature of $25 \mathrm{EC}$ and infinite dilution. For temperatures that differ from 25EC, equilibrium constants are calculated either by using the Van't Hoff equation and enthalpies of reaction included in the data base or from analytical expressions relating equilibrium constants to temperature (Smith 1988). The concentration dependence of equilibrium constants is derived from individual ion activity coefficients calculated from the modified Debye-Huckel equation (Trusdell and Jones 1974), the Davies equation (Trusdell and Jones 1974), or the B-dot equation (Smith 1988).

Initial Conditions: The algorithm used in MINTEQ requires estimated starting values for the activities of component species. If these activity estimates are too far from the true values, the algorithm may fail to converge.

Numerical Techniques: MINTEQ uses a Newton-Raphson iteration method to simultaneously solve the non-linear mass balance equations.

\section{B.2.4 Code Inputs and Outputs}

Input Data Structure: To execute the MINTEQ computer code, an input data file is prepared for each problem. The data file consists of

- title or run identifier,

- analytical units and temperature,

- run-specific user options,

- component identification and concentrations, and

- component modifications (e.g., concentration of $\mathrm{H}^{+}$fixed by $\mathrm{pH}$ ). 
Output Options: The MINTEQ code outputs the following:

- Echo of the data file input

- progress of the Newton-Raphson iterations

- full speciation of the input water composition

- charge balance and ionic strength for the aqueous composition

- saturation state of the water with respect to minerals in the data base

The user can also specify that the thermodynamic data base be printed. Debugging printing options are supported.

\section{B.3 VARIABLY-SATURATED FLOW AND MASS TRANSPORT CODE}

\section{B.3.1 General Code Description}

Purpose and Scope. The PORFLOW computer code was selected to predict the isolation performance of the E-Area waste disposal units in the vadose zone, to predict transport of radionuclides released from the units to the underlying aquifer, and to predict contaminant transport in the aquifer. Specifically, flow of water through the overlying backfill and gravel-clay barrier into the disposal units was modeled, as well release of radionuclides from the waste form and migration through any engineered barriers and surrounding soils, and ultimately through underlying formations. The simulation results generated by the PORFLOW code were then post-processed to obtain predictions of

- fractions of radionuclides remaining in the waste zone over time,

- contaminant fluxes to the aquifer, and

- contaminant plume distributions in the aquifer's saturated zone.

These results are then used to characterize the isolation performance of the E-Area Low Level Waste Facility (LLWF).

Development History. The original version of the PORFLOW code (Runchal et al. 1985) was developed to analyze the isolation performance of deep geologic repositories. This early version was limited to saturated conditions and two-dimensional porous domains, and was extensively verified and benchmarked by Eyler and Budden (1984). The code was later extended to model variably saturated flow in three-dimensions and was therefore renamed PORFLO-3, Version 1.0 (Sagar and Runchal 1990). Version 1.0 of the threedimensional computer code was independently verified and benchmarked by Magnuson et al. (1990) against FEMWATER, FLASH, TRACR3D, and MAGNUM-2D for some applications. The code has been used in practical-applications-at-the-Hanford-Site-to-model-various-waste disposal-problems-(Smoot-and-Sagar-1990), at an experimental waste trench site in Las Cruces, NM to evaluate the solute transport simulation capabilities (Rockhold and Wurstner 1991), and at the INEL to model a large organic vapor plume (Baca et al. 1988).

A newer version of PORFLO-3 (Version 2.3) was recently developed which has a number of enhancements and new options. For example, one of the new features of Version 2.3 is the capability to model multiphase flow. The commercial version of PORFLO-3 which was used to model the performance of the E-Area disposal units in the vadose and saturated zones is PORFLOW, Version 3.0 (ACRI 1996). This later version has been verified and benchmarked to a greater degree than the previous one (ACRI 1994).

Code Attributes. The PORFLOW, Version 3.0, computer code is written in Fortran 77 programming language. Some of the unique attributes of this version are 
- alternate solver techniques (such as point successive over relaxation, Cholesky decomposition, Gauss elimination, and reduced system conjugate gradient) can be selected, providing user flexibility in solving difficult problems,

- multiple contaminants may be simulated in one run,

- solubility-limited release may be simulated, and

- ingrowth of radioactive daughters may be simulated, and assigned different decay and sorption properties.

The computer program is relatively portable and can be run on PCs, workstations and main-frame computers.

Computer Requirements. Practical applications of the PORFLOW code to realistic multidimensional flow and transport problems can be made on personal computers with 486 or Pentium processors. For the problem encountered in this assessment, at least 128K RAM was necessary.

Restrictions. Version 2.3 of PORFLO-3 was originally developed for the U.S. DOE and is therefore in the public domain. All versions of the PORFLO-3 code are copyright protected. Commercial versions of the code, PORFLOW, which include updates of the Version 2.3, are available from Analytic and Computational Research, Inc. (ACRI), Los Angeles, California.

\section{B.3.2 Code Selection Basis}

The code selection criteria put forth in Sect. B.1 of this appendix were used to select PORFLOW for use in the E-Area LLWF Radiological Performance Assessment (RPA). The procedure followed was to identify several codes meeting requirements $1 R-4 R$, and subsequently evaluate those codes in terms of the remaining eight desirable criteria (1S-8S).

For this RPA, the following alternatives for selecting a code for simulating mass transport were considered:

- use PORFLOW, which was utilized in the Performance Assessment for Z-Area and earlier work on the E-Area Performance Assessment,

- use the mass transport capabilities of the hydrologic code used for groundwater simulations (FACT), or

- select a new code.

PORFLOW has already been subjected to the code selection process described in Section B.1, as part of the Performance Assessment process, meeting all of the required and suggested criteria. Advantages of PORFLOW over the other two alternatives were that the user was familiar with the code, and has worked closely with the code author; PORFLOW allows simulations which consider radioactive daughter ingrowth and transport; and several contaminants may be simulated simultaneously. A recent enhancement of PORFLOW allows use of nonrectangular grids, such that flow fields from finite element codes that do not use rectangular grids can be meshed with a PORFLOW grid.

Code Verification and Benchmarking. Version 3.0 of the PORFLOW computer code has been verified by comparing the numerical solutions against known analytical solutions. The mass transport components has been verified against a number of analytical solutions for contaminant movement in steady-state flow fields. Code verification has been done using test cases that are documented in ACRI (1994). 
The PORFLOW code has been benchmarked by making code-to-code comparison for various flow simulations and one mass transport simulation. A number of hypothetical situations were postulated and were simulated with PORFLOW and other independent computer codes. The hypothetical test problems were formulated to be representative of typical waste sites with realistic hydrogeologic settings. The PORFLOW code has been benchmark tested against such codes as TRACR3D (Travis 1985), FEMWATER (Yeh and Ward 1979), SUTRA (Voss 1984), and FLASH (Baca and Magnuson 1992). Results of benchmark of Version 2.5 are documented in ACRI (1994). Version 3.0 has been benchmarked by using the same test cases.

Eode-Validation.--At-the present-time,-the PORFLOW code-has-not-been-validated-by-comparison to field data. However, benchmarking results indicate that PORFLOW compares favorably with other widely accepted codes; most of which are accepted because of their perceived ability to simulate real conditions.

\section{B.3.3 Theoretical Framework}

Governing Equations and Assumptions. The governing equations solved in the PORFLOW code are based on the conservation principles of continuum mechanics. These equations describe fluid flow and mass transport processes in a heterogeneous and anisotropic porous medium. The equations are well accepted mathematical representations and are found in such texts as Bear and Bachmat (1990), Freeze and Cherry (1979), and Huyakorn and Pinder (1983). The specific partial differential equation solved in PORFLOW for isothermal fluid flow around and through the E-Area waste disposal units is

$$
S_{e} \frac{\partial H}{\partial t}=\frac{\partial}{\partial x_{i}}\left[K_{i j}\left(\frac{\partial H}{\partial x_{j}}-\delta_{i 3}\right)\right]+m_{v}
$$

where

$\begin{array}{lll}S_{e} & = & \text { the fluid storage term (i.e., specific storage or moisture capacity term), } \\ H & = & \text { the total or hydraulic head, } \\ K_{i j} & = & \text { the hydraulic conductivity tensor, } \\ \delta_{i 3} & = & \text { the buoyancy vector, and } \\ m_{v} & = & \text { the fluid source or sink term, } \\ t & = & \text { time, and } \\ x_{i} & = & \text { distance in the ith direction. }\end{array}$

The quantity $H$ is defined by:

$$
H=h+z-z^{*}
$$

where
$h=$ pressure head,
$z=$ elevation head, and
$z^{*}=\quad$ reference datum. 
and the quantity $S_{e}$ is defined by:

where

$$
S_{e}=S\left(\alpha_{s}+\theta_{E} \alpha_{f}\right)+\theta_{E} \frac{\partial S}{\partial H}
$$

$$
\begin{array}{ll}
S & =\quad \text { the saturation level, } \\
\alpha_{s} \text { and } \alpha_{f} & =\quad \text { the solid and fluid compressibilities normalized by the specific } \\
& \text { weight of the fluid, and } \\
\Theta_{E} & =\quad \text { the effective porosity. }
\end{array}
$$

Some of the basic assumptions made in the above mathematical formulations are:

- fluid flow is laminar, slightly compressible, and single phase;

- fluid flow obeys Darcy's law for porous flow, where specific discharge is proportional to the hydraulic gradient;

- fluid viscosity is a function of temperature only;

- hydraulic properties of the porous continuum are volume averages; and

- osmotic effects are negligible.

In general, these assumptions are satisfied in the hydrogeologic environment of E-Area.

The specific partial differential equation solved in PORFLOW for contaminant transport from the E-Area disposal units is

$$
R_{D} \phi_{D}-\frac{\partial C}{\partial}+\frac{\partial}{\partial x_{i}}\left(V_{i} C\right)=\frac{\partial}{\partial x_{i}}\left[\Gamma_{i j}^{C} \frac{\partial C}{\partial x_{j}}\right]-\phi_{D} R_{D} \lambda C+S_{C}+\sum_{p} \phi_{D} R_{D}^{p} \sigma^{p} \lambda^{p} C
$$

where

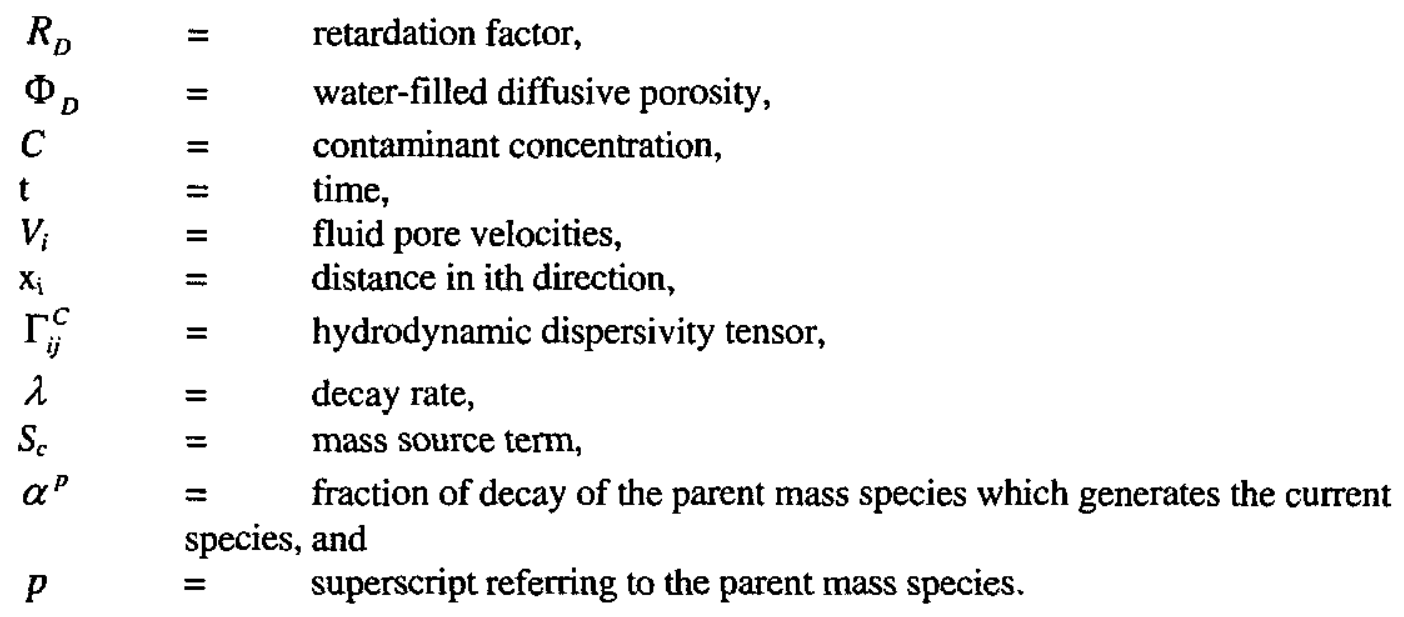

The last term in equation B.3.4 represents ingrowth of mass species. The quantity $R_{D}$ is defined by 


$$
R_{D}=\left[1+\frac{\left(1-\theta_{r}\right) \rho_{s} k_{d}}{\phi_{D}}\right]
$$

where

$$
\begin{array}{lll}
\theta_{\mathrm{\Gamma}} & = & \text { total porosity, } \\
p_{s} & = & \text { bulk density, } \\
k_{d} & = & \text { sorption coefficient, } \\
\Phi_{D}-- & = & \text { water } \text { filled diffusive-porosity,- }
\end{array}
$$

and the hydrodynamic dispersivity tensor, $\Gamma_{i j}^{C}$, is defined by

$$
\Gamma^{C}{ }_{i j}=\Phi_{D} \tau_{i j} D_{M}+\Phi_{E} D_{i j}
$$

where

$$
\begin{array}{ll}
\Phi_{E} & =\text { effective pore space saturated with water, } \\
\tau_{i j} & =\text { tortuosity tensor, } \\
D_{M} & =\text { molecular diffusion coefficient, and } \\
D_{i j} & =\text { mechanical dispersion tensor. }
\end{array}
$$

All other coefficients are as previously defined.

Some of the key assumptions that limit the applicability of the above formulation are as follows:

- contaminant concentrations are low enough that the fluid flow is independent of mass transport, i.e., concentrations do not affect the density or viscosity of the fluid;

- diffusion of the contaminants through the fluid obeys Fick's first law, where mass flux is proportional to the concentration gradient with the constant of proportionality being the diffusion coefficient;

- mechanical dispersion is described by Scheidegger's equation, (Scheidegger 1961);

- adsorption (and desorption) of contaminants onto the porous medium is an equilibrium process described by a linear isotherm.

The-model-formulation-is-applicable-to both-unsaturated-and-saturated flow-conditions.

Initial and Boundary Conditions. The PORFLOW code accommodates the specification of standard mathematical boundary conditions. These include: 1) Dirichlet, i.e., fixed head or concentration), 2) Neumann, i.e., specified flux, and 3) Robin, i.e., mixed, boundary conditions. Detailed information on boundary condition options is given in ACRI (1996).

Numerical Techniques. In the PORFLOW code, the governing equations for transport are solved using a method referred to as the Nodal Point Integration, a variation of the finite volume or integrated finite difference technique (ACRI 1996). In this method, the difference approximations to the governing equations are derived on a staggered grid system. The state variables are computed at the grid nodes whereas the fluxes are computed at the cell faces (located midway between adjacent grid nodes). Three discretization 
schemes, or basis functions to be integrated, are provided. The user may select which of the three schemes is to be used to maximize accuracy and stability.

The system of algebraic equations produced by the finite volume method are solved in the PORFLOW code using any one of five techniques

- Point successive over relaxation (Bear and Verruijt 1987),

- Alternating direction implicit (Peaceman and Rachford 1955),

- Cholesky decomposition (de Marsily 1986),

- Gauss elimination (Remson et al. 1971), or

- Reduced system conjugate gradient method (Hestenes and Stiefel 1952).

The nonlinearity of the governing equation for variably saturated flow is solved using a Picard iteration method.

\section{Code Inputs and Outputs}

Input Data Structure. Input data files for the PORFLOW code are relatively easy to prepare and check. The code uses a free-form input which allows the user to document the input data deck. The input file uses a keyword approach to define primary input data groups. For typical flow and transport simulations, the data groups consist of

- Title line and comments,

- Grid specification, i.e., number and size of grid nodes in each direction,

- Lists of grid node coordinates,

- Zone definitions that specify the grid locations of distinct strata,

- Material property specifications (i.e., porosity, density),

- Hydraulic property specifications (i.e., saturated hydraulic conductivity, moisture characteristic curve data or equations)

- Convergence and iteration parameters,

- Initial pressures and concentrations,

- Boundary values and/or fluxes,

- Mass transport properties including effective diffusion coefficients, dispersivities, $K_{d} s$, solubilities, half-lives,

- Source location and strength specifications, and

- Time step and output specifications.

Simulations of multidimensional flow and transport can be performed in either steady-state or time-dependent mode.

Output Options. Results from the PORFLOW simulation consist of total head, saturation, contaminant concentration, mass fluxes, Darcy velocities, and information related to mass balance considerations for each grid block in the computational grid. The user can select to print out any or all of the output variables. Each of these variables can be saved in archive files for subsequent post-processing to produce tabular or graphical output.

Documentation of Users Instructions. The PORFLOW, Version 3.0, is documented in ACRI (1996). This report describes the mathematical theory and numerical techniques of this version, serves as a user's manual, 
and provides detailed information on the code organization, selection of computational grids and time steps, input structure and key-word definitions.

\section{B.4 SATURATED FLOW CODE}

\section{B.4.1 General Code Description}

The FACT code, Version 1.0, (Hamm et al., 1996) was selected for use in simulating the flow of groundwater in saturated media beneath the GSA and in the surrounding subsurface. The FACT code utilizes meteorological data and hydrologic data in simulating the velocities and directions of -groundwater flow. These data are utilized as input to the contaminant transport code (Section B.3) for simulating contaminant transport.

Development History. FACT originated as a reduced version of the HydroGeoLogic, Inc. saturated flow code named SAFT3D, Version 1.3 (Huyakorn et al. 1991). The original FACT has been improved to include new boundary condition options, improved numerics, and a physically-based variably saturated model from VAM3DCG, Version 2.4 (Huyakorn et al. 1992).

Code Attributes. The FACT code, written in ANSI Standard FORTRAN 77, simulates flow and contaminant transport in an unconfined aquifer system whose soil moisture retention functions and relative permeability relationships do not exhibit hysteresis. Solution of the governing groundwater flow equation is approximated using the Bubnov-Galerkin finite element method, in conjunction with a symmetric Preconditioned Conjugate Gradient (ICCG) matrix solver. The code is designed specifically to handle complex multi-layer and/or heterogeneous aquifer systems, using highly efficient matrix generation and solutions techniques that allow application relatively large problem domains.

Computer Requirements. Because FACT is written in ANSI Standard FORTRAN 77, with some widelyaccepted extensions, it is designed to compile and run successfully on most standard micro, mini, and mainframe computer systems with at least 2 megabytes of core memory. Up to 1.4 megabytes of disk storage per 1000 nodes in the problem domain are required for array storage.

Restrictions. Presently, the FACT code remains under development, and thus has not been released for public use.

\section{B.4.2 Code Selection Basis}

The code selection criteria described in Sect. B.1 of this appendix were used to select FACT for use in the EArea Radiological Performance Assessment. The three alternatives considered were:

- use PORFLOW, a variably-saturated flow and transport code used in the Performance Assessments for Z-Area and E-Area,

- use FACT, which was recently documented (Hamm et al. 1996), and

- select a new code.

Both PORFLOW and FACT meet all of the required criteria listed in Section B.1, and meet most of the suggested criteria. Therefore, because of the in-house familiarity with PORFLOW and FACT, and the availability of technical support by code authors, the alternatives were narrowed to these two codes. The FACT code was ultimately selected for use in the E-Area RPA because of the prior work that had been completed in developing a saturated zone model of E-Area and surrounding regions. For reasons that are explained in Sect. B.3.2, PORFLOW was selected for the contaminant transport analysis, using the FACTgenerated flow field as input. 
Code Verification and Benchmarking. The capability of the FACT code to adequately simulated groundwater has been tested with ten documented test cases (Hamm et al. 1996). Simulation results from these test cases have been compared to analytical solutions, for the purpose of verification. Test results indicate a favorable comparison between analytical and numerical solutions by FACT. Benchmarking of the FACT code is planned, but has not been completed and documented at this time.

Code Validation. A partial validation of the flow portion of the FACT code is documented in Flach et al. (1996). In this test exercise, the FACT code was used to simulate groundwater in the vicinity of the Old Burial Grounds at SRS (within the boundaries of E-Area). The model devised was calibrated to the measured potentiometric surface of the water table aquifer (both upper and lower zones) and the Gordon aquifer. Simulated fluxes in streams compared reasonably to measured base flow in these streams. The simulated location of seepage faces compared well with the known location of seepage faces.

\section{B.4.3 Theoretical Framework}

Governing Equations and Assumptions. The governing equations for variably saturated flow that are solved by FACT are derived by combining a special form of Darcy's law (based on water phasic momentum balance) and the continuity equation for the water phase. The flow equation is

$$
\begin{array}{cl}
\text { where } & \nabla \cdot\left[\overline{\bar{K}} k_{r w} \nabla h\right]=\eta \frac{\partial h}{\partial t}-q \\
\overline{\bar{K}} & =\text { saturated hydraulic conductivity tensor, } \\
h^{\prime w} & =\text { relative permeability with respect to the water phase, } \\
\eta & =\text { hydraulic head, } \\
C & =C+S_{w} S_{s} \\
S_{w} & =\text { specific moisture capacity, } \\
S_{s} & =\text { specific storage of the reservoir formation, and } \\
q & =\text { water source or sink term. }
\end{array}
$$

This relative permeability term and the water saturation term depend on soil properties, and may be expressed as follows:

and

$$
k_{r w}=k_{r w}\left(S_{w}\right)
$$

$$
S_{w}=S_{w}(\psi)
$$

where $\psi$ is pressure head.

Some of the basic assumptions made in the above mathematical formulations are:

- Darcy's law is valid and hydraulic head gradients are the only significant driving force for fluid motion,

- The fluid is considered to be slightly compressible and homogeneous, 
- The soil or rock medium may be represented by a single continuum porous medium of spatially variable properties,

- the porosity and saturated hydraulic conductivity are constant with time, and

- gradients of fluid density, viscosity, and temperature do not affect the velocity distribution.

Initial and Boundary Conditions. Boundary conditions may be specified as steady-state or time-dependent, and may be in the form of hydraulic head (Dirichlet) or fluid flux (Neumann), as well as head-dependent fluxes (mixed). A more detailed discussion on options is provided in Hamm et al. (1996).

Numerical Technique. Equation B.4.1 is approximated numerically by FACT using the traditional BubnovGalerkin finite element method. In this procedure, an integral approximation of the flow equation is obtained for each element within the discretized flow region using the Galerkin weighted residual criterion. The system of algebraic equations produced when boundary conditions are incorporated is solved either using the Picard method or Newton-Raphson iterative technique. A more detailed description of the numerical solutions techniques employed by FACT is proved in Hamm et al. (1996).

\section{B.3.4 Code Inputs and Outputs}

Code Input. Input data for the saturated flow model in FACT include:

- system geometry (dimensions plus layering and other heterogeneity),

- porous media properties (hydraulic conductivities, specific storage, effective porosity), and

- initial boundary conditions (prescribed head and/or flux, recharge rate).

The FACT code uses unformatted FORTRAN READ statements, such that data may occupy multiple lines in the main input file. Data groups are delineated by required comment lines.

Output Options. Primary output from the flow model of FACT includes nodal values of hydraulic head and of Darcy velocity components at user-specified time intervals. The code can create additional output files intended for graphics post-processing.

Documentation of Users Instructions. The FACT code, Version 1.0, is documented in Hamm et al. (1996). This report describes the mathematical theory and numerical techniques of this version, serves as a user's guide, and provides detailed information on the code organization, selection of computational grids and time steps, and input structure. Test cases are also documented in this guide. 


\section{APPENDIX B REFERENCES}

ACRI. 1996. PORFLOW: A Model for Fluid Flow, Heat and Mass Transport in Multifluid, Multiphase Fractured or Porous Media, Users Manual, Version 3.0. Draft. Analytic and Computational Research, Inc., Los Angeles, Calif.

ACRI. 1994. PORFLOW Validation. Analytic and Computational Research, Inc., March 31, 1994.

Baca, R. G., J. C. Walton, and A. S. Rood. 1988. Organic Contaminant Release from a Mixed Waste Disposal Site: analysis of Vapor Transport through the Vadose zone and Site Remediation. Proceedings of Tenth Annual DOE Low-Level Waste Management Conference. Denver, CO.

Baca, R. G. and S. O. Magnuson. 1992. FLASH - Finite Element Computer Code for Variably Saturated Flow. EGG-GEO-10274. EG\&G Idaho, Inc., Idaho Falls, ID.

Bear, J., and A. Verruijt. 1987. Modeling Groundwater Flow and Pollution. D. Reidel Publishing Co., Boston, Mass.

Bear, J., and Y. Bachmat. 1990. Introduction to Modeling of Transport Phenomena in Porous Media. Kluwer Academic Publishers, Boston, Mass.

de Marsily, G. 1986. Quantitative Hydrogeology. Academic Press, Inc., New York, NY.

Eyler, L. L., and M. J. Budden. 1984. Verification and Benchmarking PORFLO: An Equivalent Porous Continuum Code for Repository Scale Analysis. PNL-5044. Pacific Northwest Laboratory, Richland, Wash.

Flach, G. P., L. L. Hamm, M. K. Harris, P. a. Thayer, J. S. Haselow, and A. D. Smits. 1996. Groundwater Flow and Tritium Migration from the SRS Old Burial Ground to Fourmile Branch $(U)$. WSRC-TR96-0037, Westinghouse Savannah River Company, Savannah River Site, Aiken, South Carolina.

Freeze, R. A. and J. A. Cherry. 1979. Groundwater. Prentice-Hall, Inc. Englewood Cliffs, NJ.

Hamm, L. L., S. E. Aleman, G. P. Flach, and W. F. Jones. 1986. FACT (Version 1.0): Subsurface Flow and Contaminant Transport Documentation and User's Guide $(U)$, WSRC-TR-95-0223, Savannah River Technology Center, Westinghouse Savannah River Company, Savannah River Site, May 15, 1986, Aiken, South Carolina.

Hestenes, M. R., and E. Stiefel. 1952. Methods of conjugate gradients for solving linear systems. NBS J. Res., 49:409-436.

Huyakorn, P. and S. Panday. 1992. VAM3DCG: Variably Saturated Analysis Model in Three-Dimensions with Preconditioned Conjugate Gradient Matrix Solvers, Documentation and User's Guide, Version 2.4, prepared for Westinghouse Hanford Company, Richmond, Washington.

Huyakorn, P., S. Panday, and T. Birdie. 1991. SAFT3D: Subsurface Analysis Finite Element Model for Flow and Transport in 3 Dimensions, Documentation and User's Guide, Version 1.3, prepared for Westinghouse Savannah River Company, Savannah River Technology Center, Aiken, South Carolina. 
Huyakom, P. S., and G. F. Pinder. 1983. Computational Methods in Subsurface Flow. Academic Press, Inc., New York, NY.

Magnuson, S. O., R. G. Baca, and A. J. Sondrup. 1990. Independent Verification and Benchmark Testing of the PORFLO-3 Computer Code, Version 1.0. EGG-BG-9175. EG\&G Idaho, Inc., ID.

Peaceman, D. W., and H. H. Rachford, Jr. 1955. The numerical solution of parabolic and elliptic differential equations. J. Soc. of Industrial and Applied Mathematics. 3:28-41.

Remson, I., G.-M. Hornberger,- and - R. F-Molz- - 1971. - Numerical Methods-in-Subsurface-Hydrology.-Wiley-Interscience, New York, NY.

Rockhold, M. L, and S. K. Wurstner. 1991. Simulation of Unsaturated Flow and Solute Transport at the Las Cruces Trench Site Using the PORFLO-3 Computer Code. PNL-7562. Pacific Northwest Laboratory, Richland, Wash.

Runchal, A. K., B. Sagar, R. G. Baca, and N. W. Kline. 1985. PORFLO - A Continuum Model for Fluid Flow, Heat Transfer, Mass Transport in Porous Media. RHO-BW-CR-150P. Rockwell Hanford Operations, Richland, Wash.

Sagar, B., and A. K. Runchal. 1990. PORFLO-3: A Mathematical Model for Fluid Flow, Heat and Mass Transport in Variably Saturated Geologic Media, Theory and Numerical Methods, Version 1.0. WHC-EP-0042. Westinghouse Hanford Operations, Richland, Wash.

Scheidegger, A. E. 1961. General Theory of Dispersion in Porous Media. J. Geophys. Res. 66(10):32733278.

Smoot, J. L., and B. Sagar. 1990. Three-dimensional Contaminant Plume Dynamics in the Vadose Zone: Simulation of the 241-T-106 Single-Shell Tank Leak at Hanford. PNL-7221. Pacific Northwest Laboratories, Richland, Wash.

Travis, B. 1985. TRACR3D: A Model of Flow and Transport in Porous Media. LA-9667-MS. Los Alamos National Laboratory, Los Alamos, NM.

Voss, C. I. 1984. A Finite-Element Simulation Model for Saturated-Unsaturated, Fluid-Density-Dependent Ground-Water Flow and Energy Transport or Chemically-Reactive Single-Species Solute Transport. U. S. Geological Survey, Reston, VA.

Yeh, G. T., and D. S. Ward. 1981. FEMWASTE: A Finte-Element Model of WASTE Transport Through Saturated-Unsaturated Porous Media. ORNL-5601. Oak Ridge National Laboratory, Oak Ridge, Tenn. 
APPENDIX C

SUPPORTING DETAILS OF MODELS AND ASSUMPTIONS 
THIS PAGE INTENTIONALLY LEFT BLANK 


\section{C.1 VADOSE ZONE MODELS}

Appendix C.1 provides details of models and assumptions that support the information provided in Sect. 4 of the main body of the revision of this Savannah River Site (SRS) E-Area Performance Assessment (PA).

\section{C.1.1 Infiltration}

For the analysis of flow around and through disposal units in E-Area, it is necessary to estimate the amount of precipitation that penetrates the ground surface and eventually percolates to the deeper soil layers (Sect. 4.3.3). The local infiltration rate is a measure of this penetrating water that is not lost from a defined region by evaporation, transpiration, or runoff.

An idealized cross section of the vadose, or unsaturated soil, zone representing the infiltration area is shown in Fig. C.1-1. Water infiltrates at the surface and either undergoes evapotranspiration (i.e., evaporation and/or transpiration) back through the surface and out of the domain or it infiltrates down to the underlying aquifer. The upper region in Fig. C.1-1, the dynamic zone, consists of the sediments near the surface where evaporation and transpiration have a dynamic role in reversing the downward movement of water due to gravity. The remaining region consists of the vadose zone. In the vadose zone, soil pores contain gases and water. Water is typically transported downward by gravity and capillarity.

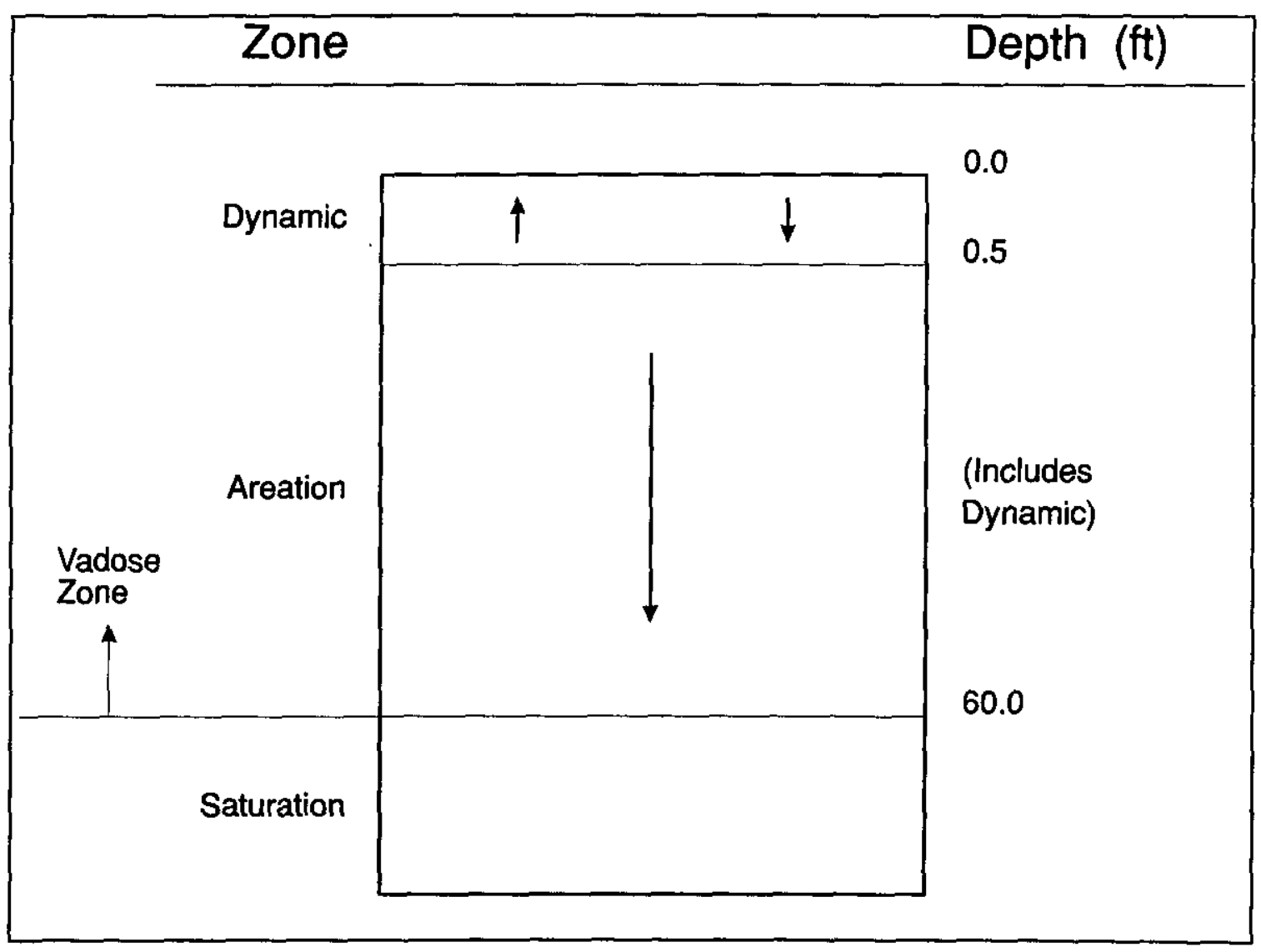

Figure C.1-1. Idealized cross-section of the SRS vadose zone. 


\section{C.1.1.1 Past Infiltration Studies}

Past studies of infiltration at or near the SRS offer estimates of average infiltration rates. Hubbard and Englehardt (1987) used the CREAMS computer code to calculate a water balance for the old SRS burial ground (643-G) for the period 1961-1986. The CREAMS code, developed by the U.S. EPA, considers daily rainfall records, site vegetation, climatic characteristics, and soil properties. Daily rainfall records from $F$ Separations Area were used in the simulation. Soils, vegetation, and climatic characteristics of the burial ground site were used for the hydrologic parameters in the model. The average annual infiltration rate was estimated to be $37 \mathrm{~cm}$ or about $1 / 3$ of annual average precipitation. Observed extremes for infiltration were $81 \mathrm{~cm}$ in 1964 and $10 \mathrm{~cm}$ in 1968 .

To estimate the net infiltration for time intervals corresponding to pumping of the Tank 24 lysimeter, INTERA Technologies (1986) estimated discrete event evaporation using these bases:

- maximum evaporation is limited to $80 \%$ of pan evaporation rates;

- if evaporation exceeds the precipitation by more than $10 \%$ of the pan rate, an infiltration deficit can remove water from the soil;

- the maximum infiltration deficit per month is assumed to be $20 \%$ of the pan rate; and

- the infiltration deficit accumulates until it is overcome by subsequent precipitation exceeding evaporation.

The algorithm developed from these bases was then used to estimate infiltration rates during discrete periods of precipitation. A yearly infiltration total for the period February 1984 through August 1985 was determined to be approximately $24 \mathrm{~cm}$.

Parizek and Root (1986) used a water balance method, where stream flow measurements were subtracted from annual precipitation to yield an estimated evaporation at $64 \%$ of the total annual precipitation. This estimate gives an average annual infiltration value of $45 \mathrm{~cm}$ for a grassland and intermittently forested portion of the SRS near the Low-Level Waste (LLW) burial site.

Dennehy and McMahon (1987) conducted a field study of water movement in the unsaturated zone at 4 grass-covered test trenches located at the LLW burial site. The study consisted of monitoring actual evapotranspiration, monitoring soil water, and water movement using field techniques and computer simulations. The results of the study relevant to net infiltration were:

- $43 \mathrm{~cm}$ of infiltration neglecting runoff occurred between June 1984 and July 1985 ;

- precipitation on trenches infiltrated the trench cap and moved vertically into the trench backfill; and

- infiltration mainly occurred during the winter and spring.

\section{C.1.1.2 Summary of Infiltration into the Vadose Zone}

Past estimates of infiltration at the SRS have ranged from 22 to $45 \mathrm{~cm} /$ year. Using the mean of the observed and predicted infiltration studies at the SRS results in an infiltration value of $37 \mathrm{~cm} /$ year. This mean infiltration value of $37 \mathrm{~cm} /$ year was rounded to one significant figure for the PA; i.e., $40 \mathrm{~cm} /$ year for the infiltration at E-Area. 


\section{C.1.2 Supporting Data for the Conceptual Vadose Zone Models}

\section{C.1.2.1 Hydraulic Data Used for LAW Vaults Conceptual Model}

In the conceptual model of the LAW vaults (Sect. 4.3.3), several types of porous materials are present in the vadose zone through which flow and transport are simulated. The model domain was illustrated in Fig. 4.3-1, showing these materials: top soil; gravel and clay of the infiltration barrier; backfill soil immediately in contact with the vaults; native soil into which the vault system is placed; concrete of the roof, floor, and walls of the vaults; and the waste and voids inside of the vault. Hydraulic properties of each of these porous media can be adequately described by the following hydraulic parameters: saturated hydraulic conductivity, effective porosity, and moisture characteristic curves. Moisture characteristic curves describe the nonlinear relationship between the matrix potential or pressure head, the moisture content, and the hydraulic conductivity.

Hydraulic parameters representing the concrete mix planned for use in the E-Area vaults, E-Area native soil, backfill, clay and gravel typically used at the SRS for closures are given in Table C.1-1. The parameters listed in the "Intact" column are largely based on laboratory measurements made by Core Labs on these materials in 1992 (Yu et al. 1993). The laboratory measurements consisted of several points on each curve for two or three samples of each type of material. Considerable interpolation was required to develop smooth curves for the tabulation of points required for the flow simulations. Samples of native soil were not submitted for Core Lab analysis; therefore, hydraulic parameters intermediate to those measured for top soil and backfill soil were assumed for this material. Capillary pressure curves for each material, developed from the Core Lab data, are shown in Fig. C.1-2. Relative permeability curves are shown in Fig. C.1-3.

Table C.1-1 Hydraulic Conductivity, Porosity, and Characteristics of Materials in LAW Vault Conceptual Model

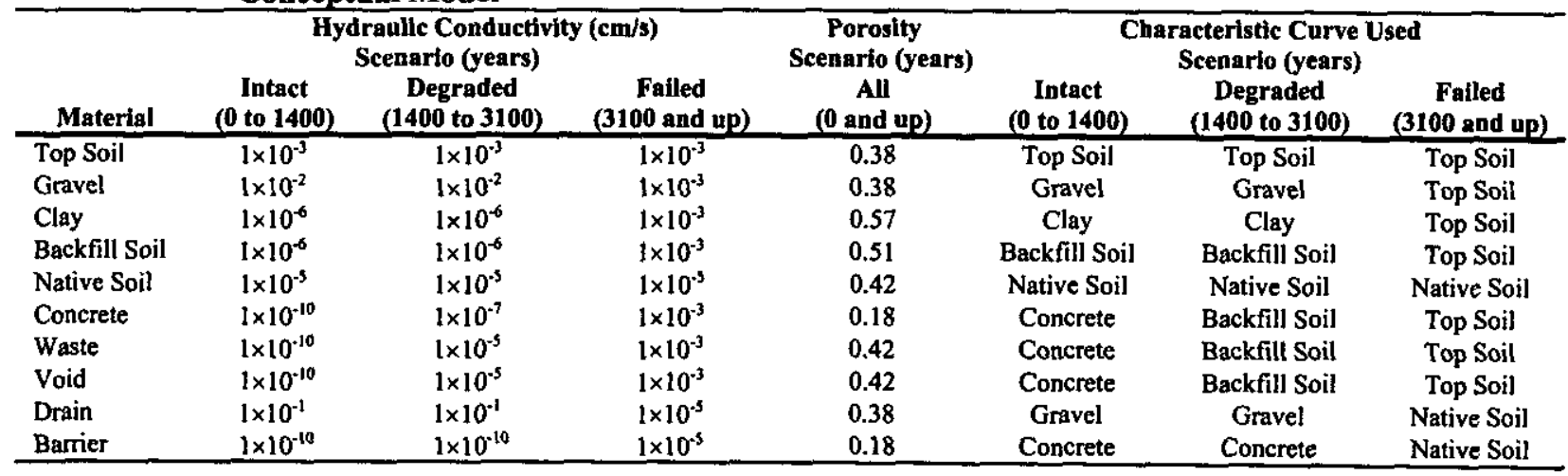

Laboratory moisture profiles, like those in Fig. C.1-2, may not be representative of field conditions because packing of columns tends to eliminate preferential flow paths that exist to varying degrees in natural environments. Drainage of water in the field may be faster in some vertical profiles of the soil than in laboratory columns. However, in a steady-state flow simulation with an intact closure cap, such as carried out in this assessment, water flux through the soil is dominated by the percolation rate through the cap. The saturation profiles used in these simulations have very little effect. When the closure cap and waste form degrade, the high permeabilities assumed for the degraded materials in the conceptual model results in most of the water traveling through the waste in the simulations of this scenario. Thus, the travel of radionuclides to the water table is a stronger function of the percolation rate for the intact case, and of the contrasting permeabilities between soil and the degraded materials for the degraded cases, than of the shape of the moisture profile. The low relative importance of the moisture profiles did not warrant the gathering of additional field data to further clarify the shape of these curves. 


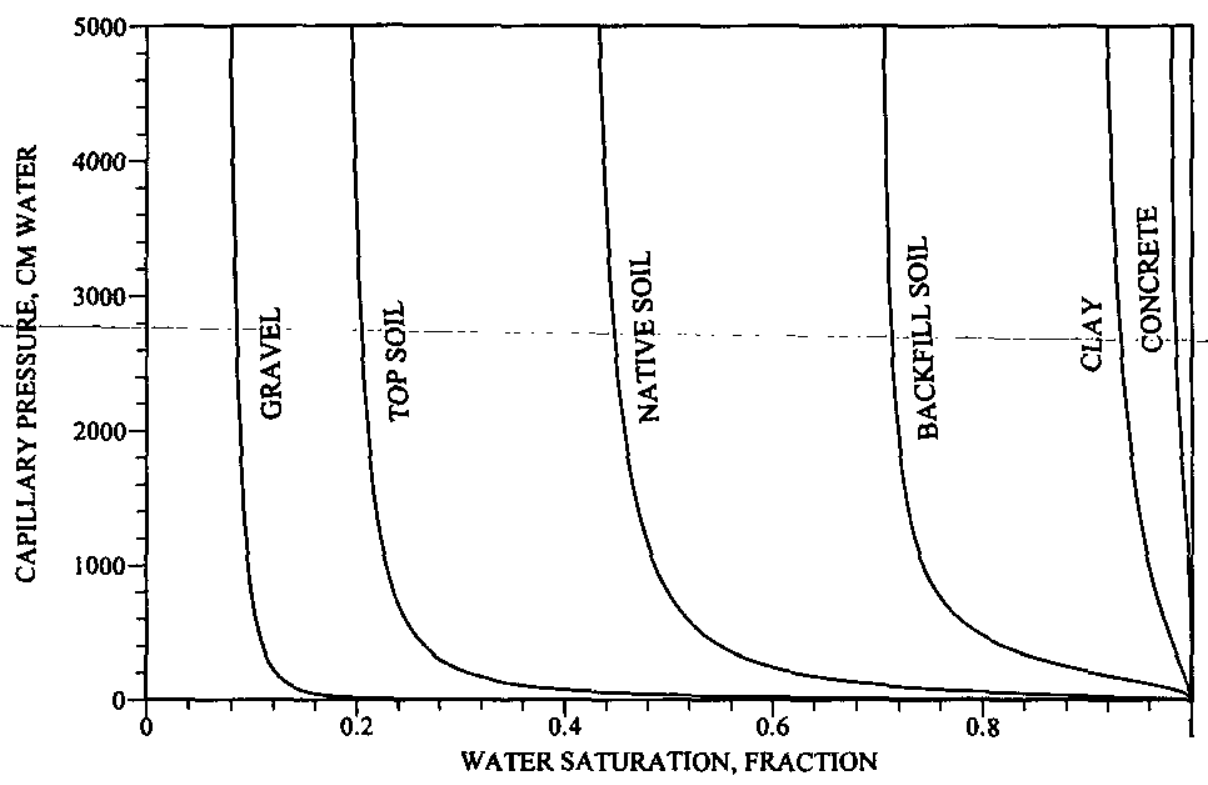

Figure C.1-2. Capillary Pressure curves for natural materials and cement-based wasteforms

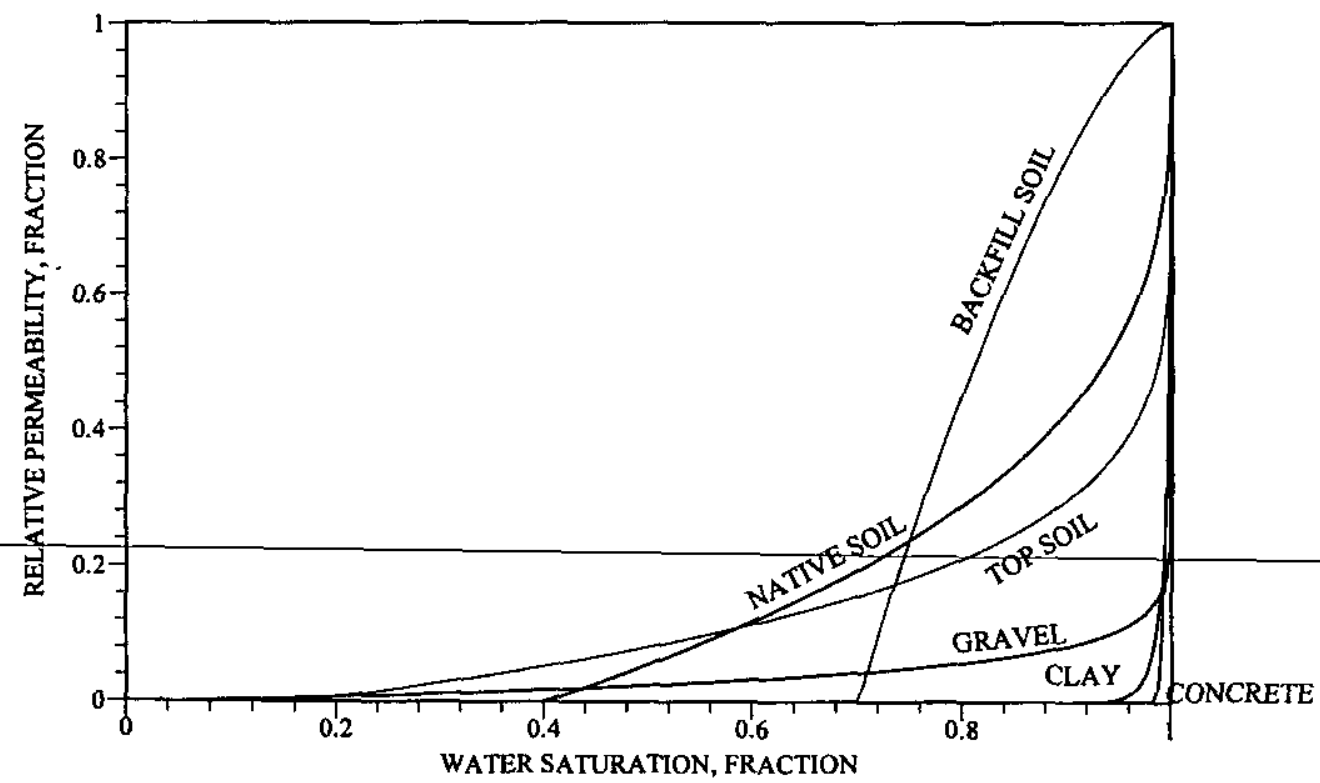

Figure C.1-3. Relative Permeability curves for natural materials and cement-based wasteforms 
Referring to Table C.1-1, it is apparent that other materials that were not addressed in the Core Lab measurements had to be characterized hydraulically, and that characterization of degraded and failed conditions of all materials was necessary. The hydraulic conductivity (permeability) of waste and voids are part of the LAW vault domain, and are treated as porous media by the simulation model PORFLOW. Assumptions made for each material in the conceptual model are described below.

\section{Top Soil}

The measured porosity of topsoil is 0.38 (Yu et al. 1993). The saturated conductivity of top soil was assigned a value of $10^{-5} \mathrm{~m} / \mathrm{s}$ for the intact, degraded, and failed conditions, based on Core Lab measurements. The characteristic curves (Fig. C.1-2 and C.1-3) used for these conditions were also based directly on Core Lab data. The material is likely to remain in a similar state throughout all conditions of the vaults; thus, the characteristic curves and hydraulic conductivity of topsoil are retained throughout all periods of the assessment.

\section{Gravel}

The measured porosity of gravel is 0.38 (Yu et al. 1993). The saturated conductivity of gravel was assigned a value of $10^{-4} \mathrm{~m} / \mathrm{s}$ for the intact condition. Core Lab measurements indicated a value of $10^{-3} \mathrm{~m} / \mathrm{s}$ for gravel. A more conservative value was chosen (i.e., corresponding to less efficient drainage) due to the likelihood that some infilling of less permeable material will occur even while the infiltration barrier is assumed to remain essentially intact. The characteristic curves (Fig. C.1-2 and C.1-3) used for gravel during the intact and degraded phases were based directly on Core Lab data. After roof failure, a saturated conductivity value of $10^{-5} \mathrm{~m} / \mathrm{s}$ is assumed, reflecting the likely loss of definition of this layer after collapse of the vault roof. After roof failure, the moisture retention characteristics of top soil are assumed for this zone.

\section{Clay}

The measured porosity of clay is 0.57 (Yu et al. 1993). The saturated conductivity of clay was assigned a value of $10^{-8} \mathrm{~m} / \mathrm{s}$ for the intact condition, which is about two orders of magnitude higher than Core Lab measurements. A more conservative value was chosen (i.e., greater leakage) because of the difficulty of achieving field conductivities for clay layers on the order of those measured in the laboratory. The characteristic curves used for this condition (Fig. C.1-2 and C.1-3) were also based directly on Core Lab data. At the time of vault cracking and until roof failure, a value of $10^{-8} \mathrm{~m} / \mathrm{s}$ is also assumed. After roof failure, the clay layer is assumed to have completely failed, the saturated conductivity is assumed to increase to that of the top soil in the failed condition, and the moisture retention characteristics of top soil are assumed to represent the zone of the model that was previously identified as clay. According to the characteristic curves, water entering top soil tends to drain more readily than from other materials represented in the conceptual models; thus, this assumption is conservative.

\section{Backfill Soil}

The measured porosity of backfill soil is 0.51 (Yu et al. 1993). The saturated conductivity of backfill soil was assigned a value of $10^{-8} \mathrm{~m} / \mathrm{s}$ for the intact and degraded conditions, which represents the upper end of values obtained in the Core Lab measurements. The characteristic curves used for these conditions (Fig. C.1-2 and C.1-3) are also based directly on Core Lab data. After roof failure, a value of $10^{-5} \mathrm{~m} / \mathrm{s}$ for the failed condition (after roof failure) is assumed. Again, this is a hypothetical number chosen to reflect the likely increase in permeability that may occur when roof failure causes a disturbance of the soils overlying the vault. The characteristic curve for top soil is assumed for all overlying materials during the failed condition. Although some of the backfill material does not overlie the vault, and thus may not increase in 
permeability after roof failure, for simplicity (to avoid redefining the conceptual model domain), all of the backfill was assumed to be more permeable, which is conservative from the standpoint of water resource impacts.

\section{Native Soil}

The measured porosity of native soil near E-Area is approximately 0.42 (Gruber 1980). The saturated vertical conductivity of native soil was assigned a value of $10^{-7} \mathrm{~m} / \mathrm{s}$ for all conditions of the vault. Samples of native soil, other than top soil, were not provided to Core Lab for measurement. Therefore, the saturated conductivity of native soil, and characteristic curvēs âssumed; were ${ }^{-}$selected intermediate to the values and curves for top soil $\left(10^{-5} \mathrm{~m} / \mathrm{s}\right)$ and for backfill $\left(10^{-8} \mathrm{~m} / \mathrm{s}\right)$. The saturated conductivity used is consistent with an estimate provided by Gruber (1980) for native soil in the vicinity of E-Area.

\section{Concrete Vault}

The measured porosity of concrete is 0.18 ( $\mathrm{Yu}$ et al. 1993). The saturated conductivity of concrete was assigned a value of $1 \times 10^{-12} \mathrm{~m} / \mathrm{s}$ for the intact condition, based on Core Lab measurements. The characteristic curves (Fig. C.1-2 and C.1-3) used for this condition are also based directly on Core Lab data.

At the time of vault cracking and until roof failure, a value of $10^{-9} \mathrm{~m} / \mathrm{s}$ is assumed, reflecting the likely increase in permeability that will occur as the vault degrades and cracks (Sect. 4.1.3). In Sect. 4.3.1 of Appendix D (Vault Degradation Study), equations are given for use in calculating an effective saturated hydraulic conductivity $\left(\mathrm{K}_{\mathrm{eff}}\right)$ for a clay/cracked concrete system. The same equation can be applied to the backfill/cracked concrete system, such that:

$$
K_{\text {eff }}=\zeta K_{\text {backfill }}
$$

Assuming a crack spacing of $1.5 \mathrm{~m}$, a crack width of $10^{-3} \mathrm{~m}$, and a backfill layer depth of $1 \mathrm{~m}$, a value for $\zeta$ is calculated, according to the equation in Appendix $\mathrm{D}$, to be approximately 0.1 . Therefore, with a $\mathrm{K}_{\text {backfill }}$ of $10^{-8} \mathrm{~m} / \mathrm{s}$, the saturated $\mathrm{K}_{\text {eff }}$ of the backfill/cracked concrete system is estimated to be $10^{-9} \mathrm{~m} / \mathrm{s}$. In the degraded condition, the characteristic curves for backfill are assumed to more adequately represent the water retention characteristics of this material. Most of the flow through the concrete will be through the cracks, which are not likely to exhibit the moisture retention characteristics of intact concrete. Backfill was chosen as a better representation of the drainage through the cracked material, largely because it directly contacts the roof, walls, and floors of the vaults.

After roof failure, the concrete roof is assumed to have completely failed, and the saturated conductivity of the resulting rubble mixed with overlying-soil, elay-and-gravel-is-assumed-to-increase-to-that-of-the-top-soil in the failed condition. The moisture retention characteristics of top soil are conservatively assumed for the zone of the model that was previously identified as the concrete roof after failure.

\section{Waste}

The hydrologic properties of waste have not been measured. The assumption that the waste resembles a porous material (porosity of 0.42 ) is conservative because this maximizes the surface area exposed to water, thereby maximizing the potential for leaching of radionuclides from the waste. During the period of time that the concrete vaults are considered to be intact, it is assumed that the hydraulic characteristics of waste are like those of concrete (saturated conductivity of $10^{-12} \mathrm{~m} / \mathrm{s}$ ), although the porosity remains closer to that of soil. This assumption was made to facilitate computations and because the hydraulic characteristics of the waste during the intact period are of little consequence; the vaults control the movement of water into the 
waste and out of the vaults during this period. Numerical computations are difficult to perform when adjacent materials have widely divergent conductivities,

Once the vaults are considered to be degraded (i.e. cracked), hydraulic properties of the waste are assumed to be like those of native soil (saturated conductivity of $10^{-7} \mathrm{~m} / \mathrm{s}$ ). Again, the less permeable concrete vaults control releases to the vadose zone during the degraded phase, such that hydrologic characteristics of the waste, as long as they represent a more permeable material than the vaults, are inconsequential during this phase. After roof failure, a saturated conductivity of $10^{-5} \mathrm{~m} / \mathrm{s}$ is assumed. This is a hypothetical number chosen to reflect the likely increase in permeability that may occur when roof failure creates a mixture of concrete rubble, gravel, clay, soil and waste. The characteristic curve for top soil is assumed during the failed condition.

\section{Void}

The hydrologic characterization of the void space was discussed in Sect. 4.3.3. During the intact phase, it is assumed that the void has the hydraulic characteristics of concrete to minimize the transport time of water entering the roof and contacting waste near the bottom of the vault, under steady-state conditions. Once cracks develop in the vaults, it is assumed that the void has the characteristics of the waste. As discussed previously for the waste zone, the less permeable concrete vaults control releases to the vadose zone during the degraded phase, such that hydrologic characteristics of the void, as long as they represent a more permeable material than the vaults, are inconsequential during this phase.

\section{C.1.2.2 Calculation of Void Volume for the LAW Vault Conceptual Model}

Waste containers placed in the LAW vaults are expected to corrode and lose their integrity much faster than the vaults. Therefore, it was assumed that upon placement of the waste, the boxes are completely corroded and compacted. The effective height of the waste zone and void fraction were estimated based on consideration of void space originally within the containers and in the vaults. The estimation assumed all waste is placed in B25 boxes, as this is the predominant container type destined for the LAW vaults. Other assumptions and methods used to calculate these values are given below.

\section{Assumptions:}

Each B25 container (1.2-m high outside) will have initially have a void space of $26 \%$ after waste treatment (i.e., supercompaction).

B25 boxes will be stacked four-high, leaving a 1.5-m (5-foot) head space in the vaults.

Each B25 box has a 7.6-cm (3") high tube steel support at the base (included in the outside dimensions), leaving a $7.6-\mathrm{cm}$ void in the vertical direction between boxes.

There are essentially no voids between adjacent boxes, horizontally, or between boxes and LAW vault walls.

The inner height of a LAW vault averages 6.4 meters ( 21 feet). 


\section{Calculation of Void Fraction:}

The effective height of waste in a B25 box, corresponding to $26 \%$ void:

Height of Waste in $B 25$ Boxes $=(1-0.26) \times(1.2 m-0.076 m)=0.83 m$

The effective height of waste in LAW vault, with B25 boxes stacked four-high, assuming boxes are corroded and provide no support:

Height of Waste in LAW Vault $=0.83 \mathrm{~m} \times 4=3.3 \mathrm{~m}$

The total void height within the vault is:

Total Void Depth $=6.4 m-3.3 m=3.1 \mathrm{~m}$.

Therefore, the void fraction within the vault is calculated from:

Void Fraction $=3.1 \mathrm{~m} / 6.4 \mathrm{~m}=0.48$

\section{C.1.2.3 Hydraulic Data Used in IL Vaults Conceptual Model}

In the conceptual model of the IL vaults (Sect. 4.3.3), several types of porous materials are present in the vadose zone through which flow and transport are simulated. The model domain was illustrated in Fig. 4.3-7, showing these materials: top soil; gravel and clay of the infiltration barrier; backfill soil immediately in contact with the vaults; native soil into which the vault system is placed; concrete of the roof, floor, and walls of the vaults; and the grouted waste inside of the vault.

Hydraulic properties of each of these porous media are identical to those described for the LAW vaults (Sect. C.1.2.1), with the exception of those for the degraded state of the waste form, and of those for several materials after roof failure. For the IL vaults, the waste form is grouted and void spaces are minimal; therefore, voids are ignored. During the period of time the concrete vaults are intact, the hydraulic characteristics of the IL waste are assumed to be most closely represented by characteristic curves used for the cement of the vaults, and a saturated conductivity of $10^{-12} \mathrm{~m} / \mathrm{s}$. Actually, the saturated conductivity of grout used in the IL waste may be higher than that used for the cement in the vaults $\left(10^{-12} \mathrm{~m} / \mathrm{s}\right)$, because the grout formulation does not have the level of design specification like of the vaults. However, while intact, the concrete vaults will control the rate of water entering and leaving the waste form.

When the vaults degrade, the saturated conductivity of the grouted waste form is assumed to increase to $10^{-9} \mathrm{~m} / \mathrm{s}$, and the characteristic curves for backfill are assumed to represent the material. These hydraulic parameters are reasonable for a grout that may be in a partial state of degradation due to cracking.

At roof failure (1050 years), the grouted waste form is assumed to have the hydraulic characteristics of native soil, yet retain the porosity of the original concrete. The failed waste form in the IL vaults is likely to be less permeable than the failed LAW waste form due to the absence of voids. Because of the support provided by the mass of concrete used in the grout around the IL waste form, roof failure is not expected to result in a "collapse" of the roof where a depression is formed; therefore, the failed state of the clay, backfill, and concrete vaults is assumed to more closely resemble the surrounding native soil, rather than the more permeable top soil as assumed for the LAW vault failed case. In Table C.1-2, the saturated hydraulic conductivity (permeability), porosity, and characteristic curve types are listed for each of the materials simulated in the IL vault conceptual model. 
Table C.1-2 Hydraulic Conductivity, Porosity, and Characteristics of Materials in IL Vault Conceptual Model

\begin{tabular}{|c|c|c|c|c|c|c|c|}
\hline \multirow[b]{2}{*}{ Material } & \multicolumn{3}{|c|}{$\begin{array}{l}\text { Hydraulic Conductivity }(\mathrm{cm} / \mathrm{s}) \\
\text { Scenarto (years) }\end{array}$} & \multirow{2}{*}{$\begin{array}{c}\text { Porosity } \\
\text { Scenario (years) } \\
\text { Al] } \\
\text { (0 and up) }\end{array}$} & \multicolumn{3}{|c|}{$\begin{array}{c}\text { Characteristic Curve Used } \\
\text { Scenario (years) }\end{array}$} \\
\hline & $\begin{array}{c}\text { Intact } \\
(0 \text { to } 575)\end{array}$ & $\begin{array}{l}\text { Degraded } \\
(575 \text { to } 1050)\end{array}$ & $\begin{array}{l}\text { Falled } \\
\text { (1050 and us) }\end{array}$ & & $\begin{array}{c}\text { Intact } \\
\text { (0 to } 575 \text { years })\end{array}$ & $\begin{array}{c}\text { Degraded } \\
(575 \text { to } 1050)\end{array}$ & $\begin{array}{c}\text { Falled } \\
\text { (1050 and up) }\end{array}$ \\
\hline Top Soil & $1 \times 10^{-3}$ & $1 \times 10^{-3}$ & $1 \times 10^{-3}$ & 0.38 & Top Soil & Top Soil & Top Soil \\
\hline Gravel & $1 \times 10^{-2}$ & $1 \times 10^{-2}$ & $1 \times 10^{-3}$ & 0.38 & Gravel & Gravel & Top Soil \\
\hline Clay & $1 \times 10^{-6}$ & $1 \times 10^{-6}$ & $1 \times 10^{-5}$ & 0.57 & Clay & Clay & Native Soil \\
\hline Backfill Soil & $1 \times 10^{-6}$ & $1 \times 10^{-6}$ & $1 \times 10^{-5}$ & 0.51 & Backfill Soil & Backfill Soil & Native Soil \\
\hline Native Soil & $1 \times 10^{-5}$ & $1 \times 10^{-5}$ & $1 \times 10^{5}$ & 0.42 & Native Soil & Native Soil & Native Soil \\
\hline Concrete & $1 \times 10^{-10}$ & $1 \times 10^{-7}$ & $1 \times 10^{-5}$ & 0.18 & Concrete & Backfill Soil & Native Soil \\
\hline Waste & $1 \times 10^{.10}$ & $1 \times 10^{-7}$ & $1 \times 10^{-5}$ & 0.18 & Concrete & Backfill Soil & Native Soil \\
\hline Drain & $1 \times 10^{-1}$ & $1 \times 10^{-1}$ & $1 \times 10^{-5}$ & 0.38 & Gravel & Gravel & Native Soil \\
\hline Barrier & $1 \times 10^{-10}$ & $1 \times 10^{-10}$ & $1 \times 10^{-5}$ & 0.18 & Concrete & Concrete & Native Soil \\
\hline
\end{tabular}

\section{C.1.2.4 Hydraulic Data Used in Slit Trench Conceptual Model}

In the conceptual model of the Slit and MWMF trenches (Sect. 4.3.3), fewer types of porous materials are present in the vadose zone than for the LAW and IL vault models. The model domain was illustrated in Fig. 4.3-9, showing these materials: top soil, gravel and clay of the infiltration barrier, backfill soil overlying and filling the top portion of the trench, native soil into which the trench is excavated, and waste in the trench. Hydraulic properties of each of these porous media are described in the same manner as for the conceptual model of the LAW vaults (Sect. C.1.2.1), with the exception of those for the clay and waste form. For the clay layer during the 100-year post closure period that this layer is assumed to be intact, a hydraulic conductivity of $10^{-9} \mathrm{~m} / \mathrm{s}$ is assumed. This is about an order of magnitude higher than Core Lab measurements for this material (Yu et al. 1993), but an order of magnitude lower than assumed for clay overlying the LAW and IL vaults. A less permeable clay was assumed for this case because the length of time this property is assumed to remain relevant for the trenches (100 years) is considerably less than the time period of relevance for the LAW ( 3100 years) and IL (1050 years) vaults.

For the trench waste form, which is partially composed of soil, the hydraulic characteristics of the waste are assumed to be most closely represented by those characteristics of the native soil while the infiltration barrier is intact. This assumption is made because the movement of water out of the trenches, and thus through the trenches, will be controlled by the hydraulic characteristics of the surrounding native soil. At the time of failure of the infiltration barrier, all materials, except native soil and the drain/barrier materials are assumed to become more pervious to water like the top soil material. This is a conservative assumption. In Table C.1-3, the saturated hydraulic conductivity (permeability), porosity, and characteristic curve types are listed for each of the materials simulated in the Slit/MWMF trench conceptual model.

\section{C.1.2.5 Hydraulic Data Used in Naval Reactor Conceptual Model}

The conceptual model of the Naval Reactor (NR) waste looks very much like that of the failed slit trenches. An intact phase for the NR components is not modeled, because there is no potential source of radionuclides to the vadose zone during this time (i.e., the first 750 years). When containment is breached at 750 years, the hydraulic properties of all materials, including waste components, are conservatively assumed to be like those of top soil; i.e., highly conductive to infiltrating water (see Sect. C.1.2.1). In Table C.1-4, the saturated hydraulic conductivity (permeability), porosity, and characteristic curve types are listed for each of the materials simulated in the NR component conceptual model. 
Table C.1-3 Hydraulic Conductivity, Porosity, and Characteristics of Materials in Conceptual Model for Slit Trenches

\begin{tabular}{|c|c|c|c|c|c|c|c|}
\hline \multirow[b]{2}{*}{ Material } & \multicolumn{3}{|c|}{$\begin{array}{c}\text { Hydraulic Conductivity (cm/s) } \\
\text { Scenario (years) }\end{array}$} & \multirow{2}{*}{$\begin{array}{l}\text { Porosity } \\
\text { Scenario (years) } \\
\text { All } \\
(0 \text { and up) }\end{array}$} & \multicolumn{3}{|c|}{$\begin{array}{c}\text { Characteristic Curve Used } \\
\text { Scenario (years) }\end{array}$} \\
\hline & $\begin{array}{c}\text { Intact } \\
(0 \text { to } 25)^{2}\end{array}$ & $\begin{array}{c}\text { Capped } \\
(25 \text { to } 125)^{b}\end{array}$ & $\begin{array}{c}\text { Falled } \\
(125 \text { and up })^{c}\end{array}$ & & $\begin{array}{c}\text { Intact } \\
(0 \text { to } 25)^{2}\end{array}$ & $\begin{array}{c}\text { Capped } \\
(25 \text { to } 125)^{b}\end{array}$ & $\begin{array}{c}\text { Failed } \\
(125 \text { and up })^{c}\end{array}$ \\
\hline Top Soil & NA & $1 \times 10^{-3}$ & $1 \times 10^{-3}$ & 0.38 & NA & Top Soil & Top Soil \\
\hline Gravel & NA & $1 \times 10^{-2}$ & $1 \times 10^{-3}$ & 0.38 & NA & Gravel & Top Soil \\
\hline Clay & NA & $1 \times 10^{-7}$ & $1 \times 10^{-3}$ & 0.57 & NA & Clay & Top Soil \\
\hline Backfill Soil & NA & $1 \times 10^{-6}$ & $1 \times 10^{-3}$ & 0.51 & NA & Backfill Soil & Top Soil \\
\hline Clean Backfill & $1 \times 10^{45}$ & $1 \times 10^{5-\cdots}$ & $-1 \times 10^{-3 \ldots}$ & -0.42 & _- Native Soil & -Native.Soil & _. Top.Soil \\
\hline Waste & $1 \times 10^{-5}$ & $1 \times 10^{-5}$ & $1 \times 10^{.3}$ & 0.42 & Native Soil & Native Soil & Top Soil \\
\hline Native Soil & $1 \times 10^{-5}$ & $1 \times 10^{-5}$ & $1 \times 10^{-5}$ & 0.42 & Native Soil & Native Soil & Native Soil \\
\hline Drain & NA & $1 \times 10^{-1}$ & $1 \times 10^{-5}$ & 0.38 & NA & Gravel & Native Soil \\
\hline Barrier & NA & $1 \times 10^{-10}$ & $1 \times 10^{-5}$ & 0.18 & NA & Concrete & Native Soil \\
\hline
\end{tabular}

It is assumed the trenches remain uncapped for 25 years.

b The cap is assumed to remain intact for 100 (starting at year 25).

C The cap is assumed to completely fail 100 years after capping.

Table C.1-4 Hydraulic Conductivity, Porosity, and Characteristics of Materials in Naval Reactor Components Conceptual Model

\begin{tabular}{|c|c|c|c|c|c|c|}
\hline \multirow[b]{2}{*}{ Material } & \multicolumn{3}{|c|}{$\begin{array}{l}\text { Hydraulic Conductivity }(\mathrm{cm} / \mathrm{s}) \\
\text { Scenario (years) }\end{array}$} & \multirow{2}{*}{$\begin{array}{c}\text { Porosity } \\
\text { Scenario (years) } \\
\text { All } \\
\text { (0 and up) }\end{array}$} & \multicolumn{2}{|c|}{$\begin{array}{l}\text { Characteristic Curve Used } \\
\text { Scenario (years) }\end{array}$} \\
\hline & $\begin{array}{c}\text { Intact" } \\
(0 \text { to } 750)\end{array}$ & Degraded & $\begin{array}{c}\text { Failled } \\
\text { (750 and up) }\end{array}$ & & $\begin{array}{c}\text { Intact } \\
\text { (0 to } 750)\end{array}$ & $\begin{array}{c}\text { Failed } \\
(750 \text { and up) }\end{array}$ \\
\hline Top Soil & & & $1 \times 10^{-3}$ & 0.38 & & Top Soil \\
\hline Gravel & & & $1 \times 10^{-3}$ & 0.38 & & Top Soil \\
\hline Clay & & & $1 \times 10^{-3}$ & 0.57 & & Top Soil \\
\hline Backfill Soil & & & $1 \times 10^{-3}$ & 0.51 & & Top Soil \\
\hline Waste & & & $1 \times 10^{-3}$ & 0.42 & & Top Soil \\
\hline Native Soil & & & $1 \times 10^{-5}$ & 0.42 & & Native Soil \\
\hline Drain & & & $1 \times 10^{-5}$ & 0.38 & & Native Soil \\
\hline Barrier & & & $1 \times 10^{-5}$ & 0.18 & & Native Soil \\
\hline
\end{tabular}

a Container for naval reactor components assumed to be water-tight (i.e., no entry or release of water) for 750 years.

\section{C.1.2.6 Corrosion and Contaminant Release Mechanisms for the Naval Reactor Component Waste}

As discussed in Sect. 4.1.3.1, a typical disposal container for the NR wastes is assumed to be intact for 750 years. When a container is breached, due to corrosion of welds sealing the container shut, the contents of the container are assumed to be available for leaching by infiltrating water. However, according to Bettis Atomic Power Laboratory, radionuclide contamination in a fraction of the NR component waste is in the form of activated metals; the remaining fraction being "corrosion product-contaminated". For two representative types of NR waste components (KAPL CB/TS units and KAPL Head units), Bettis provided radionuclide inventories (Bettis 1995a), and further characterized the inventories with respect to the quantity that "Activation" or "Crud" waste. Activation waste is intimately dispersed in the metal matrix, and is released only when the metal is corroded. Crud waste resides in a thin surface coating, and is assumed to be available for transport in the first year of container breach. In the KAPL CB/TS unit, about $8 \times 10^{4} \mathrm{Ci}$ were activation waste and $9.13 \mathrm{Ci}$ were crud waste. In the KAPL Head unit, $2.36 \times 10^{-2} \mathrm{Ci}$ were activation waste and $37.7 \mathrm{Ci}$ were crud waste. In this assessment, the release of radionuclides associated with the activation products is assumed to dominate that of the crud waste, which constitutes less than about $0.1 \%$ of the total activity in the NR waste taken as a whole. 
For radionuclides in the form of activation waste, release depends on the NR component materials which are activated, and their corrosion rates. Bettis data (Bettis 1995b) indicated that there are six contaminated NR component parts for one of their typical disposal containers (the KAPL CB/TS unit). Four components are made of Inconel and two are made of Zircaloy. The inventory fractions in the component parts for the two metals are shown in Table C.1-5.

Inventory fractions are based on a combination of analytical survey results and computer code-calculated ingrowth of activated products in the metal matrix of the waste component; thus, they represent the fraction of the radionuclide inventory of each component part in the type of metal specified. The peaking factor, $\alpha$, is defined as the ratio of peak flux at the surface to the average flux across the thickness of the metal component. It is used as a conservative correction factor, to account for the uneven radionuclide distribution across the thickness of the metal, in modeling release of activation products due to corrosion. Thus $\alpha$ has a minimum value of 1 and increases as the difference increases between the average flux and the peak flux at the surface. Using the peaking factor, $\alpha$, the effective component thickness can be calculated as,

$$
t_{\text {eff }}=t_{\text {actual }} / \alpha
$$

where $t_{\text {eff }}$ is the effective thickness and $t_{\text {actual }}$ is the actual thickness.

Because of the different constituents in Inconel and Zircaloy, the activation product distributions between these two alloys are also different. The distributions of some of the activation products in Inconel and Zircaloy are shown in Table C.1-6.

The corrosion rate for Inconel is conservatively estimated at $1.0 \times 10^{-5}$ inch/year and for Zircaloy at $1.0 \times 10^{-6} \mathrm{inch} / \mathrm{year}$. The corrosion rates are based on (Hanford 1993) and Bettis notification that Zircaloy corrosion rates in similar environments would be expected to be orders of magnitude below those identified for stainless steel and Inconel. It is assumed in this analysis that corrosion starts from both sides of a metal plate. Therefore, the effective corrosion rates for Inconel and Zircaloy are $2.0 \times 10^{-5}$ inch/year and $2.0 \times 10^{-6} \mathrm{inch} /$ year, respectively. The corrosion rates for the six NR component parts of the CB/TS unit are shown in Table C.1-7. The fraction of a component part corroded per year is the effective corrosion rate divided by the effective thickness. The inverse of fraction corroded is the time for the component to become completely corroded. For the six component parts shown in Table C.1-7, only component part 2 becomes completely corroded within 10,000 years, the simulation time period. For component part 2, the fraction corrosion rate $C_{f}$ was $2.11 \times 10^{-4}$ year $^{-1}$ from 750 to 5,500 years simulation time. Between 5,500 and 10,000 years, the corrosion rate is zero because component part 2 has already been completely corroded. For the other five component parts, the fractional corrosion rates shown in Table C.1-7 are used from 750 to 10,000 years.

The corrosion scenario described above, based on measured and estimated data for typical NR components, was applied to the NR analysis for this RPA. Activation inventories are assumed to be released according to:

$$
R=I_{A}\left(f_{I} \sum_{i=1}^{i=4} I_{f} C_{f}+f_{Z} \sum_{i=5}^{i=6} I_{f} C_{f}\right) e^{-t \ln 2 / t_{1 / 2}}
$$


Table C.1-5 Characteristics of the Naval Reactor Component Parts

\begin{tabular}{cccccc}
$\begin{array}{c}\text { Component } \\
\text { Part }\end{array}$ & Metal & $\begin{array}{c}\text { Inventory } \\
\text { fraction, } \mathrm{I}_{f}\end{array}$ & $\begin{array}{c}\text { Peaking } \\
\text { Factor, } \alpha\end{array}$ & $\begin{array}{c}\mathrm{t}_{\text {actual }} \\
{[\text { inch] }}\end{array}$ & $\begin{array}{c}\mathrm{t}_{\text {eff }} \\
\mathrm{t}_{\text {eff }}=\mathrm{t}_{\text {actual }} / \alpha \\
\text { [inch] }\end{array}$ \\
\hline 1 & Inconel & 0.6467 & 1.38 & 0.750 & 0.543 \\
2 & Inconel & 0.1617 & 1.00 & 0.095 & 0.095 \\
\hline 3 & Inconel & 0.1557 & -2.10 & 1.500 & 0.714 \\
4 & Inconel & 0.0359 & 3.10 & 2.250 & 0.726 \\
& Total & 1.0000 & & & \\
5 & Zircaloy & 0.4496 & 1.00 & 0.375 & 0.375 \\
6 & Zircaloy & 0.5504 & 1.00 & 0.150 & 0.150 \\
& Total & 1.0000 & & & \\
\hline
\end{tabular}

Table C.1-6 Distribution of Activation Products in Inconel and Zircaloy

\begin{tabular}{lcc}
\hline Radionuclides & $\begin{array}{c}\text { Inconel } \\
\text { fraction, } f_{\mathrm{I}}\end{array}$ & $\begin{array}{c}\text { Zircaloy } \\
\text { fraction, } f_{Z}\end{array}$ \\
\hline C-14 & 0.12 & 0.88 \\
Mo-93 & 0.95 & 0.05 \\
Nb-94 & 0.73 & 0.27 \\
Ni-59 & 0.83 & 0.17 \\
Pu-239 & 0.01 & 0.99 \\
Pu-240 & 0.00 & 1.00 \\
Tc-99 & 0.74 & 0.26 \\
Zr-93 & 0.00 & 1.00 \\
\hline
\end{tabular}

Table C.1-7 Corrosion Rates of the Naval Reactor Component Parts

\begin{tabular}{ccccc}
$\begin{array}{c}\text { Component } \\
\text { Part }\end{array}$ & Metal & $\begin{array}{c}\mathrm{t}_{\text {eff }} \\
\text { [inch] }\end{array}$ & $\begin{array}{c}\text { Fraction Corroded, } \mathrm{C}_{f}\left[\text { year }^{-1}\right] \\
\text { Time till 100\% corroded } \\
\text { [years] }\end{array}$ \\
\hline 1 & Inconel & 0.543 & $3.68 \mathrm{E}-05$ & $2.72 \mathrm{E}+04$ \\
2 & Inconel & 0.095 & $2.11 \mathrm{E}-04$ & $4.75 \mathrm{E}+03$ \\
3 & Inconel & 0.714 & $2.80 \mathrm{E}-05$ & $3.57 \mathrm{E}+04$ \\
4 & Inconel & 0.726 & $2.76 \mathrm{E}-05$ & $3.63 \mathrm{E}+04$ \\
5 & Zircaloy & 0.375 & $5.33 \mathrm{E}-06$ & $1.88 \mathrm{E}+05$ \\
6 & Zircaloy & 0.150 & $1.33 \mathrm{E}-05$ & $7.50 \mathrm{E}+04$ \\
\hline
\end{tabular}


where $\mathrm{R}$ is the contaminant release rate in $\mathrm{Ci} /$ year. In the PORFLOW model, contaminant release rate is represented by a time-dependent source term in the volumes of the containers. The symbols $I_{A}, f_{I}, I_{f}, C_{f}$, and $f_{Z}$ were defined in the previous tables. Component part index $i=1$ to 4 are for Inconel, $i=5,6$ are for Zircaloy. Time is $t$ and half-life for the radionuclide is $t_{1 / 2}$. The exponential term accounts for radioactive decay. Radionuclides in the projected inventory of the NR waste (Appendix A) for which fractional distribution between Inconel and Zircaloy $\left(f_{I}\right.$ and $f_{Z}$ ) are not provided in Table C.1-6, are assumed to be associated with Inconel only. This assumption provides a conservative (i.e., potential overestimate) of release of these radionuclides, because corrosion characteristics of Inconel are such that release rates are higher than for Zircaloy.

\section{C.1.2.7 Hydraulic Data Used in Intimately-mixed Cement-stabilized Waste Conceptual Model}

The conceptual model of the intimately-mixed cement-stabilized waste (Sect. 4.3.3) is similar to that of the slit trenches. An identical simulation grid is used for both models. Differences include hydraulic properties of the clay and waste form during the intact period, hydraulic properties of failed clay, backfill, and waste materials, and the time that failure is assumed to occur ( 300 years for the cement-stabilized waste). The model domain was illustrated in Fig. 4.3-5, showing these materials: top soil, gravel and clay of the infiltration barrier, backfill soil overlying and filling the top portion of the trench, native soil into which the trench is excavated, and waste in the trench.

Hydraulic properties of each of these porous media are described in the same manner as for the conceptual model of the IL vaults (Sect. C.1.2.1), for both intact and failed phases, with the exception of those for the waste form. For the intimately-mixed cement-stabilized waste form, the hydraulic characteristics of the waste are assumed to be most closely represented by characteristics of concrete. However, a saturated conductivity higher than that of the LAW and IL vault concrete was assumed, due to less rigid design criteria. The intact waste form is assumed to have a saturated hydraulic conductivity $0 f 10^{-10} \mathrm{~m} / \mathrm{s}$. At the time of failure of the waste form, all materials, except topsoil and gravel, are assumed to have properties similar to those of native soil. Topsoil and gravel are assumed to have the characteristics of topsoil when the waste form has failed. In Table C.1-8, the saturated hydraulic conductivity (permeability), porosity, and characteristic curve types are listed for each of the materials simulated in the intimately-mixed cementstabilized waste conceptual model.

\section{C.1.2.8 Hydraulic Data Used in Cement-stabilized Encapsulated Waste Conceptual Model}

The conceptual model of the cement-stabilized encapsulated waste (Sect. 4.3.3) is similar to that of the slit trenches. An identical simulation grid is used for both models. Differences in hydraulic properties of the waste form and clay during the intact phase exist and failure is assumed to occur at a different time (300 years). The model domain was illustrated in Fig. 4.3-5, showing these materials: top soil, gravel and clay of the infiltration barrier, backfill soil overlying and filling the top portion of the trench, native soil into which the trench is excavated, and waste in the trench.

Hydraulic properties of each of these porous media are described in the same manner as for the conceptual model of the LAW vaults (Sect. C.1.2.1), with the exception of those for the waste form. For the cementstabilized encapsulated waste form, the hydraulic characteristics of the waste are assumed to be most closely represented by characteristics of concrete. However, a saturated conductivity higher than that of the LAW and IL vault concrete was assumed, due to less rigid design criteria. The intact waste form (which includes the concrete cocoon and the inner waste components) is assumed to have a saturated hydraulic conductivity of $10^{-10} \mathrm{~m} / \mathrm{s}$. Voids within the waste are also assumed to have these properties while the concrete is intact, because the hydraulic characteristics of the materials inside the concrete cocoons are relatively unimportant when the concrete is controlling flow into and out of the waste. At the time of failure of the waste form, all materials, except native soil and the drain/barrier materials are assumed to become more pervious to water 
Table C.1-8 Hydraulic Conductivity, Porosity, and Characteristics of Materials in Intimately-mixed Cement-stabilized Waste Units Conceptual Model

\begin{tabular}{|c|c|c|c|c|c|c|c|}
\hline \multirow[b]{2}{*}{ Material } & \multicolumn{3}{|c|}{$\begin{array}{l}\text { Hydraulic Conductivity }(\mathrm{cm} / \mathrm{s}) \\
\text { Scenario (years) }\end{array}$} & $\begin{array}{c}\text { Porosity } \\
\text { Scenario (years) }\end{array}$ & \multicolumn{3}{|c|}{$\begin{array}{l}\text { Characteristic Curve Used } \\
\text { Scenario (years) }\end{array}$} \\
\hline & $\begin{array}{l}\text { Intact } \\
(0 \text { to } 300)\end{array}$ & Degraded & $\begin{array}{c}\text { Failed } \\
(300 \text { and up) }\end{array}$ & $\begin{array}{c}\text { All } \\
(0 \text { and up) }\end{array}$ & $\begin{array}{c}\text { Intact } \\
(0 \text { to } 300)\end{array}$ & Degraded & $\begin{array}{c}\text { Falled } \\
(300 \text { and up })\end{array}$ \\
\hline Top Soil & $1 \times 10^{-3}$ & & $1 \times 10^{-3}$ & 0.38 & Top Soil & & Top Soil \\
\hline Gravel & $1 \times 10^{-2}$ & & $1 \times 10^{-3}$ & 0.38 & Gravel & & Top Soil \\
\hline Clay & $1 \times 10^{-6}$ & & $1 \times 10^{-5}$ & 0.57 & Clay & & Native Soil \\
\hline Backfill Soil & $1 \times 10^{-6}$ & & $1 \times 10^{-5}$ & 0.51 & Backfill Soil & & Native Soil \\
\hline Native Soil ___ & $-1 \times 10^{-5}$ & $\ldots$ & $--1 \times 10^{-5}--$ & -0.42 & - Native-Soil & 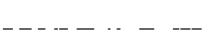 & Native.Soil. \\
\hline Clean Backfill & $1 \times 10^{-5}$ & & $1 \times 10^{-5}$ & 0.42 & Native Soil & & Native Soil \\
\hline Concrete Wasteform & $1 \times 10^{-8}$ & & $1 \times 10^{-5}$ & 0.18 & Concrete & & Native Soil \\
\hline Drain & $1 \times 10^{-1}$ & & $1 \times 10^{-5}$ & 0.38 & Gravel & & Native Soil \\
\hline Barrier & $1 \times 10^{.10}$ & & $1 \times 10^{-5}$ & 0.18 & Clay & & Native Soil \\
\hline
\end{tabular}

like the topsoil material. In Table C.1-9, the saturated hydraulic conductivity (permeability), porosity, and characteristic curve types are listed for each of the materials simulated in the cement-stabilized encapsulated waste conceptual model.

Table C.1-9 Hydraulic Conductivity, Porosity, and Characteristics of Materials in Cement-stabilized Encapsulated Waste Units Conceptual Model

\begin{tabular}{|c|c|c|c|c|c|c|c|}
\hline \multirow[b]{2}{*}{ Material } & \multicolumn{3}{|c|}{$\begin{array}{l}\text { Hydraulic Conductivity }(\mathrm{cm} / \mathrm{s}) \\
\text { Scenario (years) }\end{array}$} & \multirow{2}{*}{$\begin{array}{c}\text { Porosity } \\
\text { Scenario (years) } \\
\text { All } \\
\quad(0 \text { and up) }\end{array}$} & \multicolumn{3}{|c|}{$\begin{array}{l}\text { Characteristic Curve Used } \\
\text { Scenario (years) }\end{array}$} \\
\hline & $\begin{array}{c}\text { Intact } \\
(0 \text { to } 300)\end{array}$ & Degraded & $\begin{array}{c}\text { Failed } \\
\text { (300 and up) }\end{array}$ & & $\begin{array}{l}\text { Intact } \\
(0 \text { to } 300)\end{array}$ & Degraded & $\begin{array}{c}\text { Failed } \\
\text { (300 and up) }\end{array}$ \\
\hline Top Soil & $1 \times 10^{-3}$ & & $1 \times 10^{-3}$ & 0.38 & Top Soil & & Top Soil \\
\hline Gravel & $1 \times 10^{-2}$ & & $1 \times 10^{-3}$ & 0.38 & Gravel & & Top Soil \\
\hline Clay & $1 \times 10^{-6}$ & & $1 \times 10^{-3}$ & 0.57 & Clay & & Top Soil \\
\hline Backfill Soil & $1 \times 10^{-6}$ & & $1 \times 10^{-3}$ & 0.51 & Backfill Soil & & Top Soil \\
\hline Native Soil & $1 \times 10^{-5}$ & & $1 \times 10^{-5}$ & 0.42 & Native Soil & & Native Soil \\
\hline Concrete & $1 \times 10^{-8}$ & & $1 \times 10^{-3}$ & 0.18 & Concrete & & Top Soil \\
\hline Void & $1 \times 10^{-8}$ & & $1 \times 10^{-3}$ & 0.42 & Concrete & & Top Soil \\
\hline Waste & $1 \times 10^{-8}$ & & $1 \times 10^{-3}$ & 0.42 & Concrete & & Top Soil \\
\hline Drain & $1 \times 10^{-1}$ & & $1 \times 10^{-5}$ & 0.38 & Gravel & & Native Soil \\
\hline Barrier & $1 \times 10^{-10}$ & & $1 \times 10^{-5}$ & 0.18 & Concrete & & Native Soil \\
\hline
\end{tabular}

\section{C.2-SATURATEDZONE-MODEL}

\section{C.2.1 Analytical Model for Estimating Peak Groundwater Concentrations and Peak Times}

\section{C.2.1.1 Estimates for Cases with Peak Fluxes to the Water Table Occurring after 10,000 Years}

\section{Estimate of Peak Concentration at the 100-m Well}

The contaminant enters the source node at the peak flux rate to the water table Myr. Simultaneously, water enters the source node at the aquifer water influx rate to the source node Qyr. The concentration is

$$
\mathrm{C}(\mathrm{Ci} / \mathrm{cc})=\operatorname{Myr}(\mathrm{Ci} / \mathrm{yr}) / \text { Qyr }(\mathrm{cc} / \mathrm{yr}) \text {. }
$$


For ease of calculations, a duration of $T_{\text {enter }}$ is selected so that the volume of water entering the source node matches the volume of water that the source node contains. The source node contains a volume of water $V_{w}$ that is the product of the porosity $n$ and the total volume $V_{t}$ of the source node, i.e.,

$$
V_{w}(c c)=n(c c / c c) * V_{t}(c c)
$$

The duration $T_{\text {enter }}$ is calculated by dividing the source volume of water by the influx flow, i.e.,

$$
T_{\text {enter }}(y r)=V_{w}(c c) / Q y r(c c / y r)
$$

The mass of contaminant entering the source node during this duration is

$$
\mathrm{M}(\mathrm{Ci})=\mathrm{Myr}(\mathrm{Ci} / \mathrm{yr}) * \mathrm{~T}_{\text {enter }}(\mathrm{yr})
$$

The volume of water entering the source node during this duration is

$$
\mathrm{Q}(\mathrm{cc})=\mathrm{V}_{\mathrm{w}}(\mathrm{cc})=\mathrm{Qyr}(\mathrm{cc} / \mathrm{yr}) * \mathrm{~T}_{\mathrm{enter}}(\mathrm{yr})
$$

The mass $\mathrm{M}$ is distributed to the soil and to the water in the source node. However, because the goal of this calculation is to obtain a conservative estimate of the concentration in the source node, sorption of mass on soil in this node is neglected. This maximizes the quantity of mass available for transport to the point of compliance. Therefore, the mass in the water is $\mathrm{C}_{\mathrm{w}}{ }^{*} \mathrm{Q}$, where $\mathrm{C}_{\mathrm{w}}$ is the concentration in the water on a volumetric basis and $\mathrm{Q}$ is the volume of water in the source node. Therefore,

$$
\mathrm{C}_{\mathrm{w}}(\mathrm{Ci} / \mathrm{cc})=\mathrm{M}(\mathrm{Ci}) / \mathrm{Q}(\mathrm{cc}) \text {. }
$$

The contaminant decay is a function of the travel time to the well node and the rate of decay. The travel time to the well node is obtained by dividing the distance $\mathrm{D}$ by the speed of the contaminant $\bar{v}_{\mathrm{c}}$. The speed of the contaminant is the average linear water velocity $\mathrm{v}$ divided by the retardation factor. The average linear water velocity $\vec{v}$ is the Darcy velocity $v$ divided by the porosity. The Darcy velocity $v$ is the volumetric water outflux toward the well, Qout, divided by the cross-sectional area A. The above terms are expressed mathematically as follows:

$$
\begin{aligned}
& \mathrm{v}(\mathrm{cm} / \mathrm{yr})=\text { Qout }(\mathrm{cc} / \mathrm{yr}) / \mathrm{A}\left(\mathrm{cm}^{2}\right) \\
& \mathrm{v}(\mathrm{cm} / \mathrm{yr})=\mathrm{v}(\mathrm{cm} / \mathrm{yr}) / \mathrm{n}(\mathrm{cc} / \mathrm{cc})
\end{aligned}
$$

Combining the previous two equations yields

$$
\mathrm{v}(\mathrm{cm} / \mathrm{yr})=\text { Qout }(\mathrm{cc} / \mathrm{yr}) /\left[\mathrm{A}\left(\mathrm{cm}^{2}\right) * \mathrm{n}(\mathrm{cc} / \mathrm{cc})\right]
$$

The contaminant speed is

$$
\mathrm{v}_{\mathrm{c}}(\mathrm{cm} / \mathrm{yr})=\overline{\mathrm{v}}(\mathrm{cm} / \mathrm{yr}) / \mathrm{R}=\text { Qout }(\mathrm{cc} / \mathrm{yr}) /\left[\left(\mathrm{A}\left(\mathrm{cm}^{2}\right)^{*} \mathrm{n}(\mathrm{cc} / \mathrm{cc}) * \mathrm{R}\right]\right.
$$

The retardation factor is defined as

$$
\mathrm{R}=1+\left[\rho_{\mathrm{b}}(\mathrm{g} / \mathrm{cc}) * \mathrm{~K}_{\mathrm{d}}(\mathrm{cc} / \mathrm{g})\right] / \mathrm{n}(\mathrm{cc} / \mathrm{cc})
$$

where $K_{d}$ is the sorption coefficient for the aquifer matrix (Table 4.1-4). 
The travel time (the distance divided by the speed) is

$$
\mathrm{T}_{\text {travel }}(\mathrm{yr})=\mathrm{D}(\mathrm{cm}) / \overline{\mathrm{v}}_{\mathrm{c}}(\mathrm{cm} / \mathrm{yr}) \text {. }
$$

The rate of decay is $\lambda$. The decay factor is generated from the travel time and the rate of decay as follows:

$$
\text { Decay_fac }=e^{-[\lambda(1 / y r) * T \text { travel }(y r)]}
$$

Multiplying the decay factor by the undecayed peak concentration from Equation $10 \mathrm{~b}$ produces

$\mathrm{C}_{\mathrm{wd}}(\mathrm{Ci} / \mathrm{cc})=\mathrm{M}(\mathrm{Ci}) /\left[\mathrm{K}_{\mathrm{d}}(\mathrm{cc} / \mathrm{g}) * \rho_{\mathrm{b}}(\mathrm{g} / \mathrm{cc}) * \mathrm{~V}_{\mathrm{t}}(\mathrm{cc})+\mathrm{Q}(\mathrm{cc})\right] * \mathrm{e}^{-[\lambda(1 / \mathrm{yr}) * \text { Travel }(\mathrm{yr})]}$

\section{Estimate of Time of Peak Concentration at the 100-m Well}

The time of the peak concentration at the $100-\mathrm{m}$ well is determined by adding the travel time to the time of the peak contaminant flux at the water table. The time of peak concentration is

$$
\mathrm{T}_{\mathrm{pc}}(\mathrm{yr})=\mathrm{T}_{\mathrm{pf}}(\mathrm{yr})+\mathrm{T}_{\text {travel }}(\mathrm{yr})
$$

where $T_{p c}$ is the time of the peak concentration at the $100-\mathrm{m}$ well and $T_{p f}$ is the time of the peak flux at the water table.

\section{C.2.2 Technical Details of FACT Code Simulation of Saturated Flow}

\section{C.2.2.1 FACT Code Simulation Domain}

In Sect. 4.3.3.8, the model for simulating saturated flow under E-Area is discussed. Details of the 3-dimensional simulation domain are presented in this section.

The areal resolution of the model grid is $61 \mathrm{~m}(200 \mathrm{ft})$ on a side except in peripheral areas (Figure 4.3-1). There are 108 elements along the east-west axis, and 77 finite-elements along the north-south axis. The vertical resolution varies depending on hydrogeologic unit and terrain/hydrostratigraphic surface variations (Figure 4.3-2). Each hydrostratigraphic surface is defined by numerous "picks" ranging in number from approximately 70 to 375 depending on the surface. The "upper" aquifer zone of Upper Three Runs aquifer unit is represented with 9 finite-elements in the vertical including the vadose zone. The "lower" aquifer zone contains 5 finite-elements while the "tan clay" confining zone separating the aquifer zones is modeled with 2 vertical elements. The Gordon confining and aquifer units each contain 2 elements, for a total of 20 vertical elements from ground surface to the bottom of the Gordon aquifer. The 3D mesh size is therefore $108 \times 77 \times 20=166,320$ elements or $109 \times 78 \times 21=178,542$ nodes. The relatively fine vertical resolution of the model is designed to support subsequent contaminant transport analyses. 

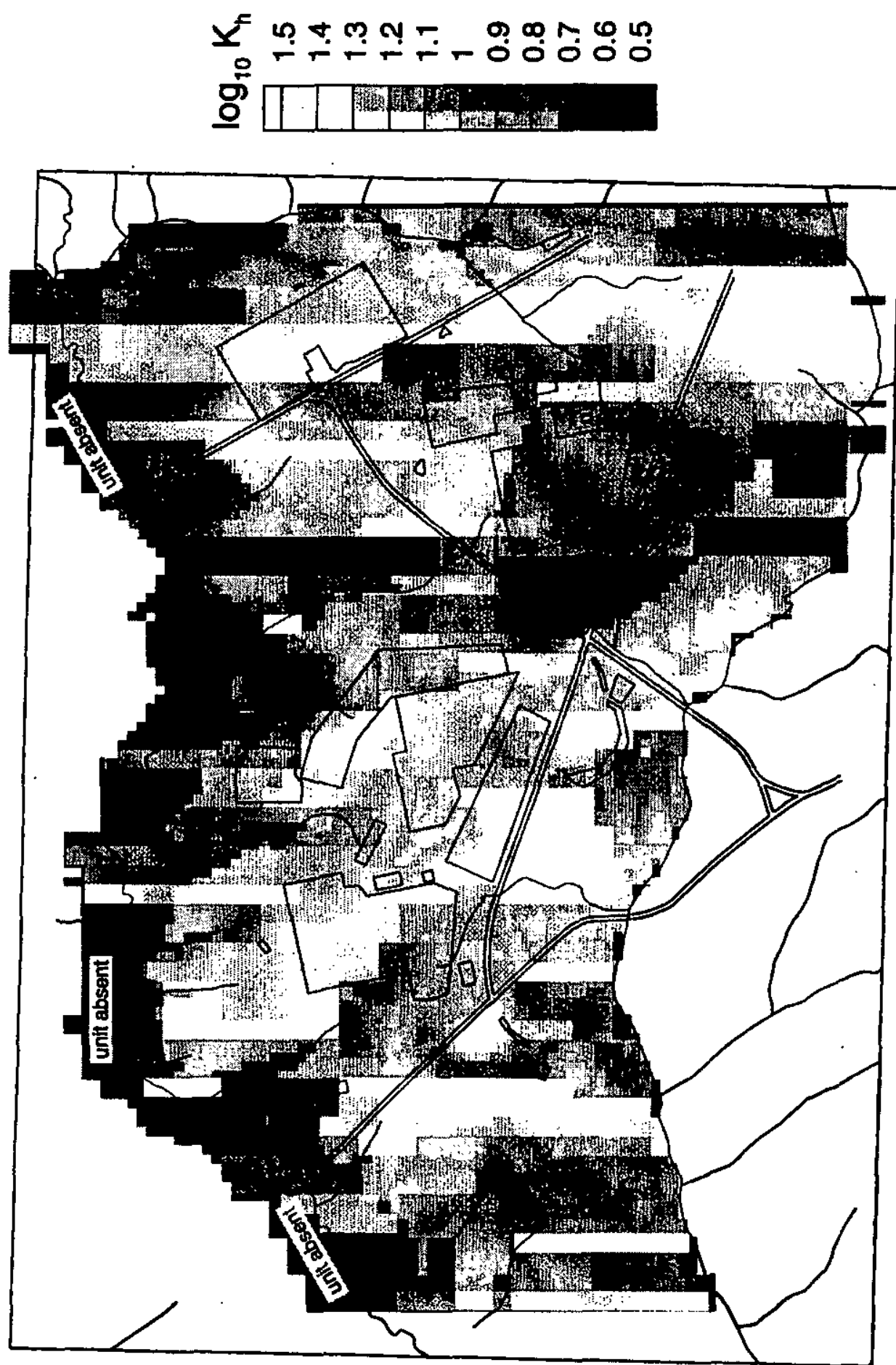

Figure C.2-1 Simulated horizontal conductivity in the UTR Aquifer Unit "Upper" zone (vertical average) 
Y م

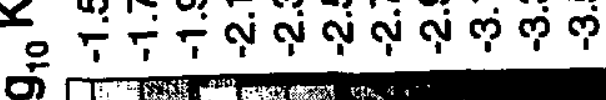

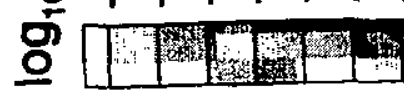

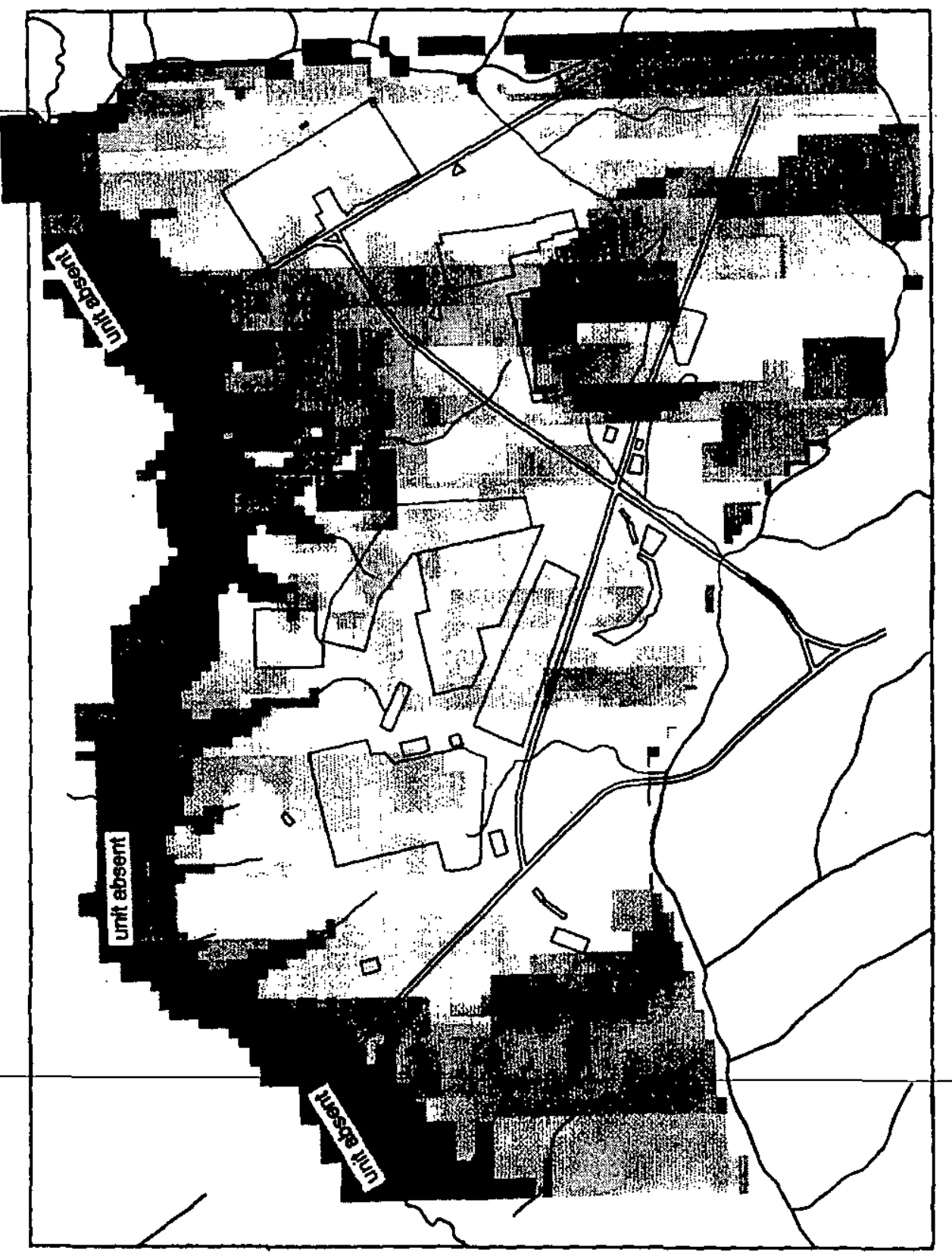

Figure C.2-2 Simulated vertical conductivity in the UTR Aquifer Unit

"Tan Clay" confining zone (vertical average) 

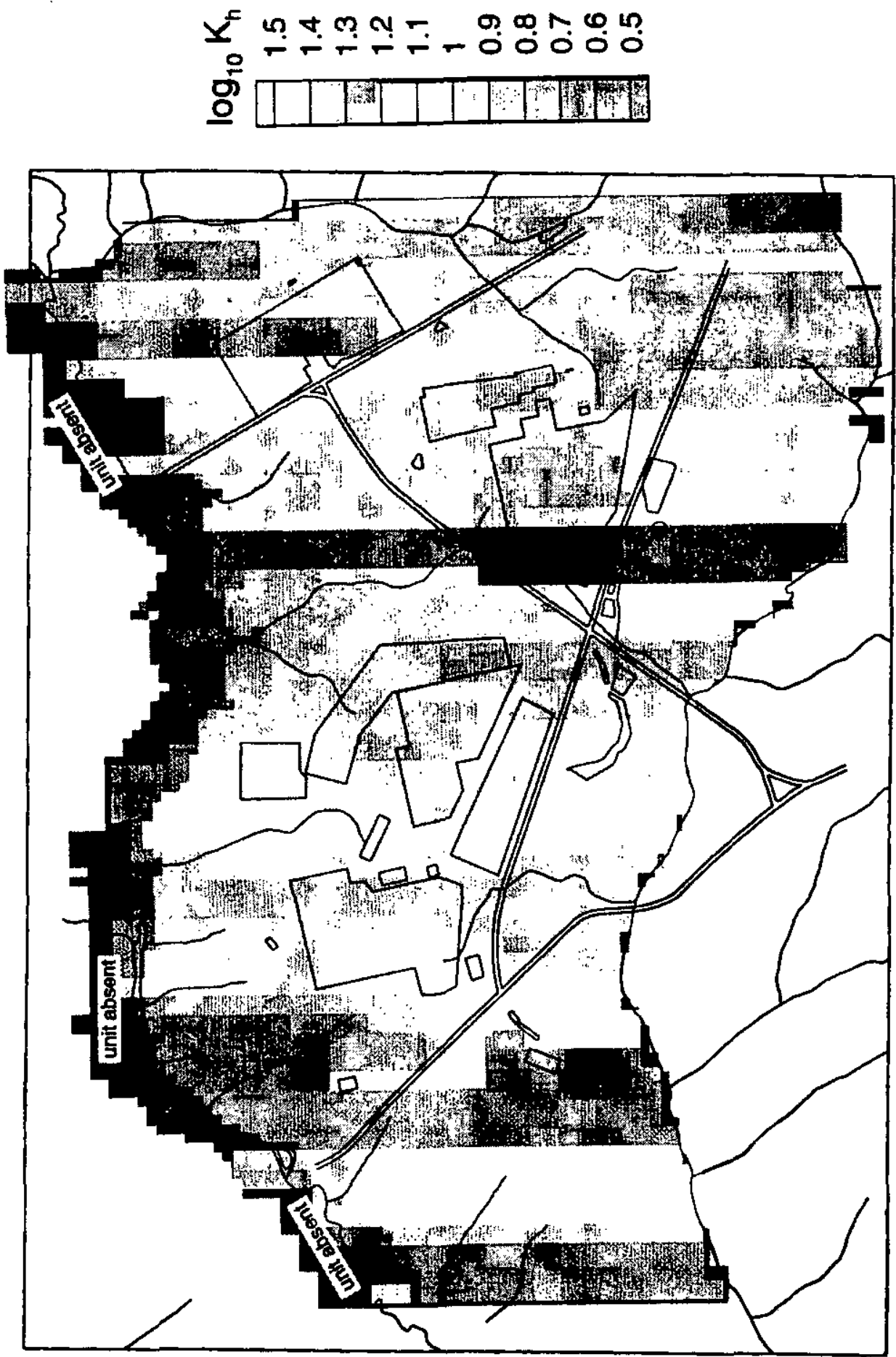

Figure C.2-3 Simulated horizontal conductivity in the UTR Aquifer Unit "Lower" zone (vertical average) 

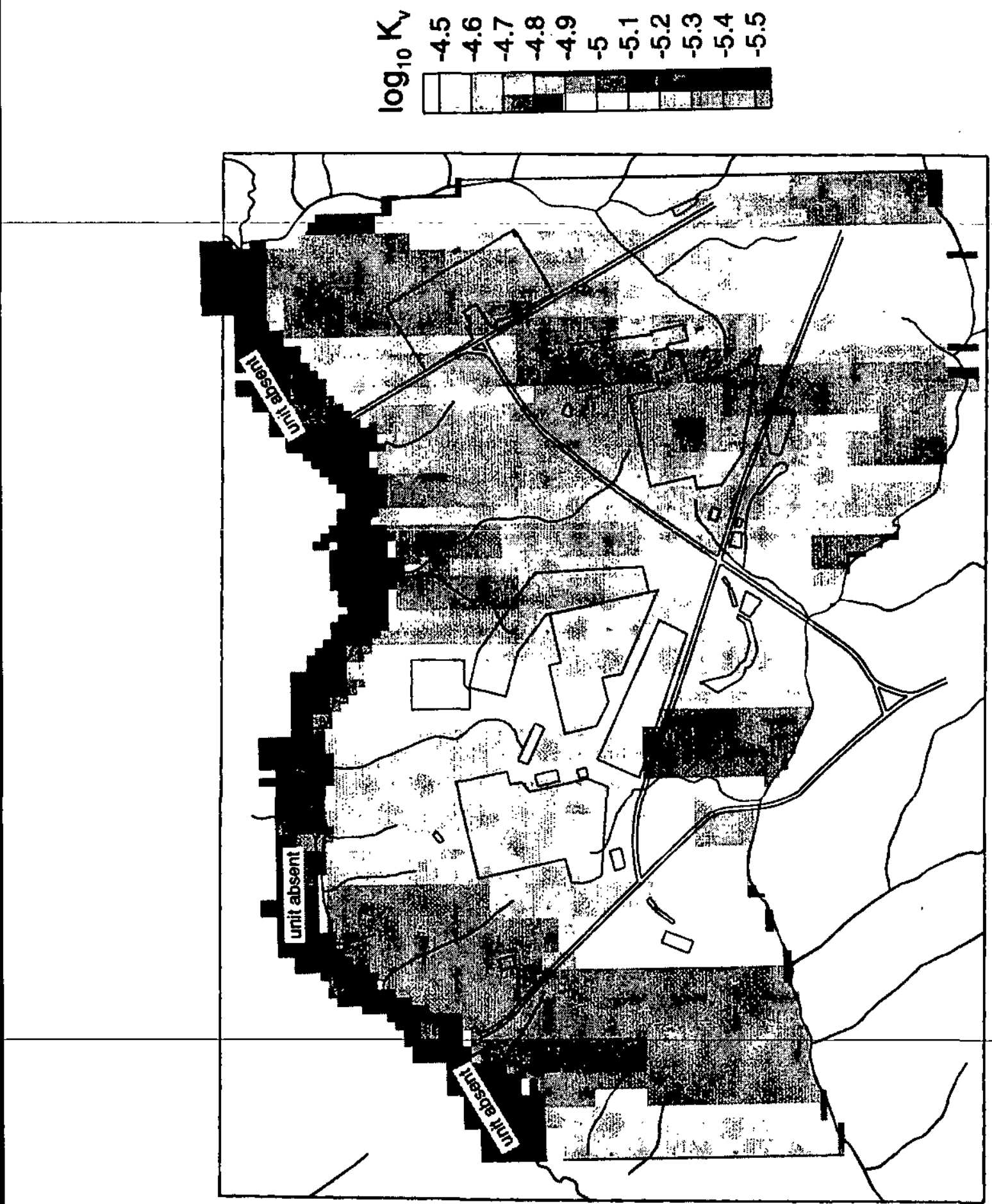

Figure C.2-4 Simulated vertical conductivity in the Gordon Confining Unit (vertical average) 

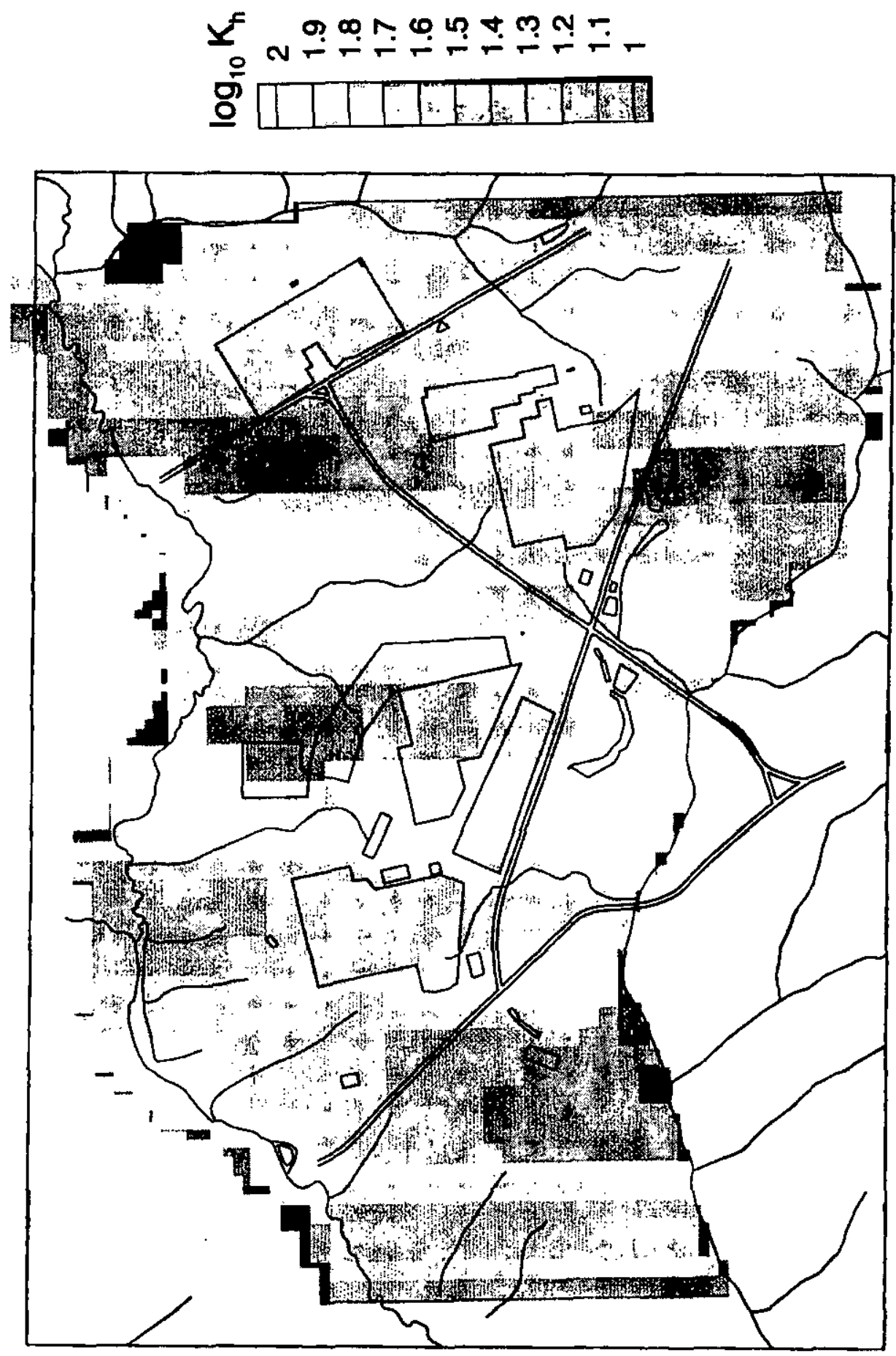

Figure C.2-5 Simulated horizontal conductivity in the Gordon Aquifer Unit (vertical average) 


\section{C.2.2.2 Hydraulic Conductivity in Saturated Flow Domain}

Hydraulic conductivity values in the model are based directly on a large characterization database comprised of approximately 100 pumping and 500 slug test data points, approximately 250 laboratory permeability measurements, and approximately 40,000 lithology data records. The conductivity field is heterogeneous within hydrogeologic units and reflects variations present in the characterization data (Figures C.2-1 through C.2-5). The average horizontal conductivities in the "upper" Upper Three Runs aquifer zone, "lower" UTR aquifer zone, and Gordon aquifer unit are $3.4 \times 10^{-5}, 3.3 \times 10^{-5}$, and $1.3 \times 10^{-4} \mathrm{~m} / \mathrm{s}$ $(9.6,9.3$, and $38 \mathrm{ft} / \mathrm{d})$, respectively. The average vertical conductivities for the "tan clay" confining zone and the Gordon confining unit are $2.2 \times 10^{-8}$ and $3.5 \times 10^{-11} \mathrm{~m} / \mathrm{s}\left(6.3 \times 10^{-3}\right.$ and $\left.1.0 \times 10^{-5} \mathrm{ft} / \mathrm{d}\right)$, respectively.

\section{C.2.2.3 Model Calibration}

Model calibration targets include hydraulic head and stream baseflow measurements. Tables C.2-1 through C.2-3 show observed and simulated head values in the "upper" and "lower" zones of the Upper Three Runs aquifer and the Gordon aquifer unit, respectively. The overall root-mean-square (r.m.s.) difference between simulated head and 667 time-averaged measurements is $1.01 \mathrm{~m}(3.30 \mathrm{ft})$. The r.m.s. residuals within the "upper", "lower", and Gordon aquifer zones/units are $0.79,1.5$, and $0.76 \mathrm{~m}(2.6,4.8$, and $2.5 \mathrm{ft}$ ), respectively; (Figures C.2-6 through C.2-8). Figures C.2-9 and C.2-10 illustrate the simulated vertically-averaged potentiometric surfaces for the aquifer zone containing the water table ("upper" and "lower" zones of the Upper Three Runs aquifer) and the Gordon aquifer unit, respectively. Measured head in the aquifer unit containing the water table is shown in Figure C.2-11, for comparison to Figure C.2-9. Measured head in the Gordon aquifer is shown in Figure C.2-12, for comparison to Figure C.2-10. These comparisons indicate that the GSA model reproduces the head gradients in the respective aquifer units fairly well, and thus should accurately simulate flow directions and rates in these units.

The estimated discharge rates to Upper Three Runs, Fourmile Branch, McQueen Branch, and Crouch Branch, based on baseflow measurements, within the model domain are $0.52,0.073,0.042$, and 0.051 $\mathrm{m}^{3} / \mathrm{s}$, respectively $\left(18.2,2.6,1.5\right.$, and $\left.1.8 \mathrm{ft}^{3} / \mathrm{s}\right)$. The simulated discharge rates are $0.41,0.10,0.13$, and $0.045 \mathrm{~m}^{3} / \mathrm{s}\left(14.5,3.6,4.7\right.$, and $\left.1.6 \mathrm{ft}^{3} / \mathrm{s}\right)$, indicating reasonable agreement with measured rates. Maps of simulated natural recharge and discharge and of man-made recharge are provided in Figures C.2-13 and C.2-14, respectively. Locations of predicted seepage faces are consistent with field observations (Figure C.2-15). Figures C.2-16 through C.2-18 illustrate simulated flow direction vertically-averaged over the entire thickness of the "upper" Upper Three Runs, "lower" Upper Three Runs, and Gordon aquifer zones/unit. For the "upper" and "lower" zones of the Upper Three Runs aquifer unit (Figures C.2-16 and C.2-17), the influence of Upper Three Runs and Fourmile Branch on flow directions is evident. A groundwater divide occurs in the vicinity of the Old Burial Grounds, representing the competing influence of the two creeks. For the Gordon aquifer, the overwhelming influence of the more deeplycutting Upper Three Runs (Section 3.1.5.2) is evident. Fourmile Branch does not incise this lower aquifer unit, and thus does not influence flow directions in this unit.

\section{C.3 INTRUDER MODELS}

This appendix describes models and data used to estimate effective dose equivalents (EDEs) per unit concentration of radionuclides in particular exposure media following disposal of LLW in the E-Area Low Level Waste Facility. The dose analysis considers two groups of exposed individuals:

- off-site individuals, i.e., members of the public who reside beyond the boundary of the disposal facility; and 
- inadvertent intruders, i.e., individuals who come onto the disposal site following loss of active institutional control.

Off-site individuals may be exposed to radionuclides released from the disposal facility at any time after disposal. During the period of active institutional control over the disposal site, which is assumed to last for 100 years after facility closure (U.S.DOE 435.1), off-site individuals are assumed to be restricted to locations beyond the present boundary of the SRS. However, after the period of active institutional control, off-site individuals could be located anywhere beyond the boundary of the buffer zone around the disposal facility, which is assumed to be no more than $100 \mathrm{~m}$ from the disposal units. Inadvertent intrusion onto the disposal site is assumed to be precluded by active institutional control until 100 years after facility closure. No credit is taken in this analysis for any passive institutional controls (e.g., marker systems at the disposal site, public records of land use) that could prevent inadvertent intrusion for some time after the period of active institutional control.

The Radiological Performance Assessment (RPA) for the E-Area LLWF assumes that releases of radionuclides to groundwater due to infiltration of precipitation through disposal units is the principal mechanism for transport of radionuclides to off-site locations. However, potential doses to off-site individuals resulting from airborne releases of volatile radionuclides were also considered (see Sect. 4.3.2). Potential doses to inadvertent intruders are estimated by assuming that certain scenarios for direct intrusion into disposal units occur.

The following sections discuss the exposure scenarios and exposure pathways assumed for off-site individuals and inadvertent intruders and the models and parameter values used in calculating annual EDEs to these groups of individuals for each exposure pathway. For exposures to contaminated groundwater, the results of the dose analysis are summarized in the form of annual EDEs per unit concentration of radionuclides in water. For exposures resulting from direct intrusion into disposal units, the results are summarized in the form of annual EDEs per unit concentration of radionuclides in solid waste at the time intrusion is assumed to occur.

\section{C.3.1 Radionuclides of Importance for Dose Analyses}

As indicated in Appendix A, waste in the E-Area LLWF potentially contains a large number of radionuclides. However, only a relatively few radionuclides are potentially important in the dose analyses for off-site individuals or inadvertent intruders. Most of the radionuclides either could occur only in very low concentrations or are sufficiently short-lived that they would decay to innocuous levels before off-site transport via the groundwater pathway or inadvertent intrusion onto the disposal site could occur.

The radionuclides which have been considered in the dose analyses for the E-Area LLWF, either for offsite individuals or for inadvertent intruders, are listed in Table C.3-1. These radionuclides were selected on the basis of conservative screening analyses for exposures of off-site individuals via the groundwater pathway and exposures of inadvertent intruders, as described in Sects. 4.1.3 and 6.2, respectively. The exposure scenarios which have been considered for each radionuclide are indicated in the table and are described in Sect. C.3.2. All other radionuclides listed in Appendix A can be neglected in the dose analyses for off-site individuals and inadvertent intruders, because their concentrations would be sufficiently low that they could not result in doses that exceed a very small fraction of the applicable limits for either group of individuals. 
Table C.2-1 Measured and Simulated Head Data in the "Upper" Zone of the Upper Three Runs Aquifer Unit

\begin{tabular}{|c|c|c|c|c|c|c|c|}
\hline Well ID & $\begin{array}{c}\text { Model x } \\
\text { (feet) }\end{array}$ & $\begin{array}{c}\text { Model y } \\
\text { (feet) }\end{array}$ & $\begin{array}{c}\text { Screen } \\
\text { bottom } \\
\text { (feet amsl) }\end{array}$ & $\begin{array}{l}\text { Screen top } \\
\text { (feet amsl) }\end{array}$ & $\begin{array}{c}\text { Measured } \\
\text { head } \\
\text { (feet amsl) }\end{array}$ & $\begin{array}{c}\text { Simulated } \\
\text { head } \\
\text { (feet amsl) }\end{array}$ & $\begin{array}{c}\text { Difference } \\
\text { (feet) }\end{array}$ \\
\hline BG 26 & 13846.42 & 8012.32 & 210.7 & 230.7 & 239.3 & 237.7 & -1.6 \\
\hline BG 27 & 13763.9 & 8401.98 & 234.4 & 254.4 & 240.9 & 237.4 & -3.5 \\
\hline $\mathrm{BG} 28$ & 13681.91 & $8 \overline{88.68}$ & 239.7 & 259.7 & 247.1 & 0 & $-247.1^{a}$ \\
\hline BG 29 & 13598.54 & 9179.49 & 231.6 & 251.6 & 245 & 235.7 & -9.3 \\
\hline BG 30 & 13514.9 & 9569.11 & 231.7 & 251.7 & 237.6 & 234.6 & -3 \\
\hline BG 31 & 13426.5 & 9959.05 & 223.3 & 243.3 & 233.7 & 233.4 & -0.3 \\
\hline BG 32 & 13343.14 & 10350.27 & 226.9 & 246.9 & 233.4 & 232 & -1.4 \\
\hline BG 33 & 13044.67 & 10419.74 & 221.2 & 241.2 & 232.9 & 231.9 & -1 \\
\hline BG 34 & 12632.37 & 10346.1 & 217.4 & 237.4 & 232.8 & 232 & -0.8 \\
\hline BG 35 & 12259.34 & 10268.55 & 228 & 248 & 232.9 & 231.9 & -1 \\
\hline BG 36 & 12103.11 & 10493.28 & 223.3 & 243.3 & 232.5 & 231.4 & -1.1 \\
\hline BG 37 & 11729.96 & 10472.55 & 227.8 & 247.8 & 232.8 & 231 & -1.8 \\
\hline BG 38 & 11338.78 & 10389.5 & 225.9 & 245.9 & 232.3 & 230.8 & -1.5 \\
\hline BG 39 & 10947.74 & 10306.28 & 226 & 246 & 231.7 & 230.9 & -0.8 \\
\hline BG 40 & 10556.14 & 10223.25 & 221.9 & 241.9 & 231.4 & 231.2 & -0.2 \\
\hline BG 41 & 10425.5 & 9961.57 & 221 & 241 & 230.8 & 231.5 & 0.7 \\
\hline BG 42 & 10508.83 & 9572.9 & 217.1 & 237.1 & 230.7 & 231.9 & 1.2 \\
\hline BG 43 & 10742.85 & 9289.05 & 222.9 & 242.9 & 230.5 & 232.6 & 2.1 \\
\hline BG 51 & 13660.18 & 7876.53 & 221.2 & 241.2 & 240.7 & 237.8 & -2.9 \\
\hline BG 52 & 10226.97 & 9238.59 & 223.8 & 243.8 & 229.3 & 231.7 & 2.4 \\
\hline BG 53 & 9735.08 & 9386.45 & 214.7 & 234.7 & 228 & 230.2 & 2.2 \\
\hline BG 54 & 9563.21 & 9023.39 & 215.2 & 235.2 & 228.6 & 229.5 & 0.9 \\
\hline BG 55 & 9393.65 & 8667.76 & 214.9 & 234.9 & 226.6 & 228 & 1.4 \\
\hline BG 56 & 9353.7 & 8333.35 & 210.9 & 230.9 & 225.1 & 226.7 & 1.6 \\
\hline BG 57 & 9727.26 & 8202.05 & 214.6 & 234.6 & 225.3 & 227.7 & 2.4 \\
\hline BG 58 & 10105.64 & 8068.29 & 218.2 & 238.2 & 226.8 & 228.9 & 2.1 \\
\hline BG 59 & 10485.14 & 7947.05 & 217.7 & 237.7 & 229.8 & 229.9 & 0.1 \\
\hline BG 60 & 10862.73 & 7815.58 & 215.5 & 235.5 & 230.8 & 231 & 0.2 \\
\hline BG 61 & 11426.71 & 7617.61 & 225 & 245 & 232.8 & 232.6 & -0.2 \\
\hline BG 62 & 11614.68 & 7551.44 & 222.5 & 242.5 & 233.4 & 233.2 & -0.2 \\
\hline BG 63 & 11991.99 & 7409.69 & 224.2 & 244.2 & 235.2 & 234.4 & -0.8 \\
\hline BG 64 & 12369.52 & 7278.01 & 227.3 & 247.3 & 238.1 & 235.1 & -3 \\
\hline BG 65 & 12745.34 & 7146.68 & 230.9 & 250.9 & 235.7 & 235.7 & 0 \\
\hline BG 66 & 12941.31 & 7438.19 & 231 & 251 & 235.2 & 236.9 & 1.7 \\
\hline BG 67 & 12960.04 & 7819.52 & 224.7 & 244.7 & 236.5 & 237.2 & 0.7 \\
\hline BG 98 & 11709.56 & 11278.93 & 212.5 & 242.5 & 224.5 & 224 & -0.5 \\
\hline BG 99 & 12837.14 & 10809.81 & 215.9 & 245.9 & 232.5 & 230.5 & -2 \\
\hline BG 100 & 13131.91 & 11803.82 & 203.3 & 233.3 & 224.8 & 217.5 & -7.3 \\
\hline BG 104 & 14260.71 & 11249.6 & 215.8 & 245.8 & 224.6 & 220.1 & -4.5 \\
\hline BG 107 & 14952.46 & 9111.5 & 208.3 & 228.3 & 235.2 & 232.3 & -2.9 \\
\hline BG 108 & 14754.09 & 8639.34 & 217.3 & 247.3 & 238.8 & 236.6 & -2.2 \\
\hline BG 109 & 14651.68 & 8150.56 & 228.4 & 258.4 & 240.2 & 238.7 & -1.5 \\
\hline BG 110 & 14429.22 & 7519.01 & 224.3 & 254.3 & 241.3 & 240.2 & -1.1 \\
\hline BG 124 & 11484 & 10879.4 & 214.8 & 234.8 & 231.8 & 227.4 & -4.4 \\
\hline
\end{tabular}


Table C.2-1 Measured and Simulated Head Data in the "Upper" Zone of the Upper Three Runs Aquifer Unit

\begin{tabular}{|c|c|c|c|c|c|c|c|}
\hline Well ID & $\begin{array}{l}\text { Model x } \\
\text { (feet) }\end{array}$ & $\begin{array}{c}\text { Model y } \\
\text { (feet) }\end{array}$ & $\begin{array}{c}\text { Screen } \\
\text { bottom } \\
\text { (feet amsl) }\end{array}$ & $\begin{array}{l}\text { Screen top } \\
\text { (feet amsl) }\end{array}$ & $\begin{array}{c}\text { Measured } \\
\text { head } \\
\text { (feet amsl) }\end{array}$ & $\begin{array}{c}\text { Simulated } \\
\text { head } \\
\text { (feet amsl) }\end{array}$ & $\begin{array}{c}\text { Difference } \\
(\text { feet })\end{array}$ \\
\hline BGO 1D & 13862.53 & 7790.32 & 225 & 245 & 238 & 238.1 & 0.1 \\
\hline $\mathrm{BGO} 2 \mathrm{D}$ & 13722.82 & 8593.83 & 218.9 & 238.9 & 238.4 & 236.9 & -1.5 \\
\hline BGO 3D & 13556.33 & 9374.68 & 227.6 & 247.6 & 235.6 & 235.1 & -0.5 \\
\hline BGO 4D & 13384.87 & 10154.88 & 220.6 & 240.6 & 232.1 & 232.7 & 0.6 \\
\hline BGO 5D & 13298.32 & 10471.2 & 219.3 & 239.3 & 231.1 & 231.2 & 0.1 \\
\hline $\mathrm{BGO} 6 \mathrm{D}$ & 12819.24 & 10379.38 & 217.2 & 237.2 & 231.5 & 232 & 0.5 \\
\hline BGO 7D & 12446.14 & 10307.44 & 220.2 & 240.2 & 233.1 & 232 & -1.1 \\
\hline BGO 8D & 12133.68 & 10337.43 & 220.6 & 240.6 & 233.4 & 231.7 & -1.7 \\
\hline BGO 10D & 11514.34 & 10426.92 & 230.5 & 250.5 & 231.9 & 230.8 & -1.1 \\
\hline BGO 10DR & 11556.56 & 10435.59 & 218.3 & 238.3 & 232.2 & 230.8 & -1.4 \\
\hline BGO $11 \mathrm{D}$ & 11143.33 & 10348.06 & 216.3 & 236.3 & 230.7 & 230.8 & 0.1 \\
\hline BGO 12D & 10732.29 & 10260.79 & 217.8 & 237.8 & 231.2 & 231 & -0.2 \\
\hline BGO 13D & 10349.71 & 10179.57 & 228.5 & 248.5 & 231.1 & 231.2 & 0.1 \\
\hline BGO 13DR & 10346.07 & 10198.63 & 210.3 & 220.3 & 231.4 & 231 & -0.4 \\
\hline BGO 14DR & 10400.68 & 9696.41 & 218.1 & 238.1 & 231.2 & 231.7 & 0.5 \\
\hline BGO 15D & 10541.34 & 9369.92 & 218.7 & 238.7 & 230.2 & 232.2 & 2 \\
\hline BGO 16D & 10923.02 & 9223.99 & 217.3 & 237.3 & 231.1 & 232.8 & 1.7 \\
\hline BGO 17D & 11147.57 & 9116.53 & 204 & 224 & 230.8 & 232.8 & 2 \\
\hline BGO 17DR & 11154.28 & 9122.45 & 216.9 & 236.9 & 232.2 & 233.2 & 1 \\
\hline BGO 18D & 11452.47 & 9181.75 & 219.6 & 239.6 & 232.1 & 233.5 & 1.4 \\
\hline BGO 19D & 11784.3 & 8996.69 & 196.8 & 216.8 & 231.1 & 232.7 & 1.6 \\
\hline BGO 20D & 11978.88 & 8641.59 & 216.3 & 236.3 & 234.5 & 235.4 & 0.9 \\
\hline BGO 21D & 12384.89 & 8448.07 & 217.7 & 237.7 & 235.2 & 236.3 & 1.1 \\
\hline BGO 22DR & 12782.92 & 8310.83 & 219.2 & 239.2 & 236.2 & 236.8 & 0.6 \\
\hline BGO 23D & 13126.36 & 8145.22 & 222 & 242 & 236.1 & 237.3 & 1.2 \\
\hline BGO 24D & 13472.4 & 7988.03 & 221 & 241 & 237.1 & 237.6 & 0.5 \\
\hline BGO 26D & 9683.76 & 9345.59 & 213.4 & 233.5 & 228.1 & 229.9 & 1.8 \\
\hline BGO 27D & 9449.78 & 8835.09 & 209.3 & 229.3 & 227.7 & 228.6 & 0.9 \\
\hline BGO 28D & 9300.74 & 8467.06 & 210.1 & 230.1 & 226.3 & 227 & 0.7 \\
\hline BGO 29D & 8899.31 & 8631.39 & 208.5 & 228.5 & 226.9 & 226.4 & -0.5 \\
\hline BGO 30D & 9374.53 & 8318.56 & 207.8 & 227.8 & 225.9 & 226.7 & 0.8 \\
\hline BGO $31 \mathrm{D}$ & 9751.63 & 8191.79 & 211.1 & 231.1 & 226.8 & 227.7 & 0.9 \\
\hline BGO 32D & 10204.9 & 8024.06 & 214.5 & 234.5 & 227.9 & 229 & 1.1 \\
\hline BGO 33D & 10694.08 & 7863.97 & 213.1 & 233.1 & 230.4 & 230.4 & 0 \\
\hline BGO 34D & 11122.7 & 7709.82 & 212.7 & 232.7 & 233.2 & 231.7 & -1.5 \\
\hline BGO 35D & 11645.04 & 7531.73 & 219.4 & 239.4 & 235.1 & 233.3 & -1.8 \\
\hline BGO 36D & 12011.43 & 7402.89 & 223.3 & 243.3 & 237.3 & 234.4 & -2.9 \\
\hline BGO 37D & 12459.99 & 7239.58 & 226.1 & 246.1 & 238.5 & 235.2 & -3.3 \\
\hline BGO 38D & 12752.38 & 7136.62 & 222.3 & 242.3 & 235.7 & 235.6 & -0.1 \\
\hline BGO 39D & 12967.06 & 7442.13 & 224.7 & 244.7 & 235.4 & 236.8 & 1.4 \\
\hline $\mathrm{BGO} 40 \mathrm{D}$ & 9315.84 & 9265.14 & 216.6 & 226.5 & 222.9 & 229.3 & 6.4 \\
\hline BGO 43D & 10687.53 & 10508.4 & 198.2 & 208.2 & 231.8 & 228.7 & -3.1 \\
\hline BGO 44D & 12384 & 10565.15 & 223.4 & 233.4 & 232.6 & 231.4 & -1.2 \\
\hline BGO 45D & 9320.45 & 8988.55 & 209.6 & 229.6 & 228.3 & 228.7 & 0.4 \\
\hline BGO 46D & 9329.06 & 8151.55 & 202.1 & 212.1 & 225.7 & 225.6 & -0.1 \\
\hline
\end{tabular}


Table C.2-1 Measured and Simulated Head Data in the "Upper" Zone of the Upper Three Runs Aquifer Unit

\begin{tabular}{|c|c|c|c|c|c|c|c|}
\hline Well ID & $\begin{array}{c}\text { Model } x \\
\text { (feet) }\end{array}$ & $\begin{array}{c}\text { Model y } \\
\text { (feet) }\end{array}$ & $\begin{array}{c}\text { Screen } \\
\text { bottom } \\
\text { (feet amsl) }\end{array}$ & $\begin{array}{l}\text { Screen top } \\
\text { (feet amsl) }\end{array}$ & $\begin{array}{c}\text { Measured } \\
\text { head } \\
\text { (feet amsl) }\end{array}$ & $\begin{array}{c}\text { Simulated } \\
\text { head } \\
\text { (feet amsl) }\end{array}$ & $\begin{array}{l}\text { Difference } \\
\text { (feet) }\end{array}$ \\
\hline BGO 47D & 9882.12 & 7968.44 & 203.4 & 213.4 & 226.7 & 226.7 & 0 \\
\hline BGO 48D & 10107.76 & 7859.67 & 202 & 212 & 227.1 & 227.2 & 0.1 \\
\hline BGO 49D & 11298.17 & 7443.17 & 218.5 & 238.5 & 234.9 & 231.6 & -3.3 \\
\hline$-\mathrm{BGO}-50 \mathrm{D}$ & -9092.1 & $8251-98$ & 208 & 228 & -225.6 & -225.4 & -0.2 \\
\hline $\mathrm{BGX} 1 \mathrm{D}$ & 13056.94 & 10759.31 & 214.7 & 234.7 & 229.8 & 230.5 & 0.7 \\
\hline BGX 9D & 13924.18 & 11072.97 & 212.4 & 232.4 & 226.8 & 224.8 & -2 \\
\hline$B G \times 10 D$ & 14318.75 & 10387.32 & 216.2 & 236.2 & 226 & 227.9 & 1.9 \\
\hline $\mathrm{BGX} 11 \mathrm{D}$ & 14322.18 & 9485.73 & 216.7 & 236.7 & 235.7 & 232.9 & -2.8 \\
\hline $\mathrm{BGX} 12 \mathrm{D}$ & 14598.05 & 8634.69 & 223.7 & 243.7 & 239.2 & 236.8 & -2.4 \\
\hline BRR 1D & 5096.27 & 9635.33 & 200.4 & 220.4 & 216.8 & 214.3 & -2.5 \\
\hline BRR 4D & 4624.12 & 9530.16 & 198.7 & 218.7 & 214.9 & 209.2 & -5.7 \\
\hline BRR 5D & 4550.2 & 9418.56 & 202.1 & 222.1 & 214.9 & 209.4 & -5.5 \\
\hline $\mathrm{F} \quad 10$ & 5414.98 & 7443.8 & 266.5 & 276.5 & 270.4 & 0 & $-270.4^{a}$ \\
\hline$F \quad 18 \mathrm{~A}$ & 5290.84 & 6410.31 & 194.4 & 204.4 & 203.8 & 204.6 & 0.8 \\
\hline FAC 3 & 9591.52 & 11258.51 & 224.8 & 254.8 & 229.1 & 226.8 & -2.3 \\
\hline FAC 5 & 9523.96 & 11184.86 & 214 & 234 & 224.9 & 225.1 & 0.2 \\
\hline FAC 5P & 9551.07 & 11410.83 & 225.7 & 235.7 & 229.7 & 226 & -3.7 \\
\hline FAC 6 & 9581.03 & 11369.46 & 216.2 & 236.2 & 220.8 & 223.8 & 3 \\
\hline FAC 7 & 9602.44 & 11368.28 & 215.7 & 235.7 & 223.2 & 223.6 & 0.4 \\
\hline FAC 8 & 9618.78 & 11338.53 & 216 & 236 & 227.2 & 223.8 & -3.4 \\
\hline FAL 1 & 8039.16 & 11028.33 & 207 & 238.5 & 218.9 & 224.7 & 5.8 \\
\hline FAL 2 & 8016.02 & 11142 & 206.6 & 238 & 217.1 & 224.2 & 7.1 \\
\hline $\mathrm{FC} \quad 1 \mathrm{D}$ & 7084.36 & 12432.91 & 217.2 & 222.2 & 223.6 & 0 & $-223.6^{\mathrm{a}}$ \\
\hline FCA $2 \mathrm{D}$ & 7961.45 & 11195.73 & 219 & 239 & 225.1 & 224.5 & -0.6 \\
\hline FCA 9D & 7915.61 & 11497.5 & 221.9 & 241.9 & 225.3 & 223.1 & -2.2 \\
\hline FCA $10 \mathrm{~A}$ & 7749.64 & 11503.01 & 221 & 241 & 225.3 & 222.8 & -2.5 \\
\hline FCA $10 D$ & 7906.32 & 11535.9 & 219.5 & 239.5 & 226.3 & 223 & -3.3 \\
\hline FCA $16 A$ & 7692.74 & 11755.8 & 215.1 & 235.1 & 225.2 & 221.4 & -3.8 \\
\hline FCA $16 D$ & 7840.35 & 11786.16 & 221.1 & 241.1 & 225 & 221.7 & -3.3 \\
\hline FCA 19D & 7970.24 & 11173.17 & 209.7 & 229.7 & 217.1 & 224.4 & 7.3 \\
\hline FCB 1 & 9396.41 & 10007.72 & 205.6 & 235.6 & 229.9 & 228.3 & -1.6 \\
\hline FCB 2 & 9600 & 9891.78 & 205.2 & 235.2 & 228.9 & 229.1 & 0.2 \\
\hline $\mathrm{FCB}-4$ & -9147.76 & -9898.63 & -204.5 & 234.5 & -227.9 & -227.7 & $=0.2$ \\
\hline $\mathrm{FCB} 5$ & 9371.04 & 9651.87 & 217.1 & 237.1 & 228.6 & 229.7 & 1.1 \\
\hline FCB 6 & 9313.7 & 9731.18 & 215.1 & 235.1 & 228.9 & 229.4 & 0.5 \\
\hline FCB 7 & 9463.53 & 10102.24 & 218.3 & 238.3 & 230.8 & 230.1 & -0.7 \\
\hline FET $1 \mathrm{D}$ & 7998.12 & 9025.74 & 206.9 & 226.9 & 223.6 & 225 & 1.4 \\
\hline FET 2D & 7711.29 & 8842.29 & 209.5 & 229.5 & 222.3 & 223.9 & 1.6 \\
\hline FET 3D & 7772.45 & 8768.6 & 203 & 223 & 222.3 & 223.7 & 1.4 \\
\hline FET 4D & 7893.41 & 8792.57 & 205.1 & 225.1 & 222.8 & 224.1 & 1.3 \\
\hline FSB OPD & 4959.48 & 6727.34 & 171.6 & 215.3 & 207.4 & 205.8 & -1.6 \\
\hline FSB 76 & 6133.77 & 8604.92 & 197 & 227 & 218.1 & 217.5 & -0.6 \\
\hline FSB 77 & 5683.29 & 7474.35 & 186.4 & 216.4 & 212.2 & 211.6 & -0.6 \\
\hline FSB 78 & 5222.84 & 7002.92 & 187.7 & 217.7 & 208.7 & 207.4 & -1.3 \\
\hline FSB 79 & 5427.28 & 5920.88 & 174.1 & 204.1 & 201.9 & 199.4 & -2.5 \\
\hline
\end{tabular}


Table C.2-1 Measured and Simulated Head Data in the "Upper" Zone of the Upper Three Runs Aquifer Unit

\begin{tabular}{|c|c|c|c|c|c|c|c|}
\hline Well ID & $\begin{array}{c}\text { Model x } \\
\text { (feet) }\end{array}$ & $\begin{array}{c}\text { Model y } \\
\text { (feet) }\end{array}$ & $\begin{array}{c}\text { Screen } \\
\text { bottom } \\
\text { (feet amsl) }\end{array}$ & $\begin{array}{l}\text { Screen top } \\
\text { (feet amsl) }\end{array}$ & $\begin{array}{c}\text { Measured } \\
\text { head } \\
\text { (feet amsl) }\end{array}$ & $\begin{array}{c}\text { Simulated } \\
\text { head } \\
\text { (feet amsl) }\end{array}$ & $\begin{array}{c}\text { Difference } \\
\text { (feet) }\end{array}$ \\
\hline FSB 87D & 4970.1 & 7789.87 & 187.4 & 216.8 & 213.6 & 211.2 & -2.4 \\
\hline FSB 88D & 6377.03 & 8125.21 & 202.1 & 222.1 & 216.1 & 216.7 & 0.6 \\
\hline FSB 89D & 6205.29 & 8013.57 & 201.9 & 221.9 & 215.5 & 215.9 & 0.4 \\
\hline FSB 90D & 6050.09 & 7805.35 & 205.1 & 225.1 & 215 & 214.6 & -0.4 \\
\hline FSB 91D & 5895.43 & 7599.39 & 200.9 & 220.9 & 213.7 & 213 & -0.7 \\
\hline FSB 92D & 5548.57 & 7360.25 & 201.7 & 221.7 & 211.9 & 210.5 & -1.4 \\
\hline FSB 93D & 5478.37 & 7184.52 & 197.9 & 217.9 & 210.8 & 209 & -1.8 \\
\hline FSB 94DR & 5199.23 & 7105.35 & 183.3 & 203.4 & 210.1 & 207.9 & -2.2 \\
\hline FSB 95D & 5026.06 & 7179.36 & 207.8 & 227.8 & 208.8 & 208.1 & -0.7 \\
\hline FSB 95DR & 5010.49 & 7190.57 & 187 & 207 & 210.3 & 208.1 & -2.2 \\
\hline FSB 97D & 4949.44 & 7379.2 & 196.9 & 216.9 & 210.7 & 209.1 & -1.6 \\
\hline FSB 98D & 5044.51 & 7586.5 & 200.3 & 220.3 & 212.4 & 210.6 & -1.8 \\
\hline FSB 99D & 5188.62 & 7944.07 & 198.1 & 218.1 & 211.9 & 212.9 & 1 \\
\hline FSB 104D & 4520.28 & 5934.71 & 190.4 & 210.4 & 204.2 & 200.8 & -3.4 \\
\hline FSB 105D & 4798.82 & 7403.82 & 203.7 & 223.7 & 208.3 & 209.2 & 0.9 \\
\hline FSB $105 D R$ & 4803.49 & 7418.92 & 188.5 & 208.6 & 211.1 & 209.1 & -2 \\
\hline FSB106D & 5803.34 & 6542.55 & 202.9 & 222.9 & 206.8 & 205.3 & -1.5 \\
\hline FSB 107D & 6100.51 & 7611.91 & 200.9 & 220.9 & 213.8 & 213.6 & -0.2 \\
\hline FSB108D & 5867.9 & 8670.17 & 203.8 & 223.8 & 217.6 & 217.2 & -0.4 \\
\hline FSB109D & 5312.65 & 8138.3 & 205.8 & 225.8 & 213.3 & 214.3 & 1 \\
\hline FSB 1 10D & 5318.9 & 6439.89 & 191.1 & 211.1 & 205.4 & 204.7 & -0.7 \\
\hline FSB $111 \mathrm{D}$ & 6415.84 & 7889.23 & 201.7 & 221.7 & 215 & 215.8 & 0.8 \\
\hline FSB $112 D$ & 3980.74 & 6186.53 & 188.9 & 208.9 & 206.2 & 201.7 & -4.5 \\
\hline FSB $113 D$ & 6262.8 & 6601.16 & 189.6 & 209.6 & 207.6 & 205.6 & -2 \\
\hline FSB 114D & 6929.24 & 7891.72 & 197.7 & 217.8 & 217.3 & 217.2 & -0.1 \\
\hline FSB $117 \mathrm{D}$ & 5682.11 & 6391.45 & 189.7 & 209.7 & 205.2 & 204.2 & -1 \\
\hline FSB 1 18D & 6323.89 & 7169.38 & 191.3 & 211.3 & 211.7 & 211.2 & -0.5 \\
\hline FSB119D & 5683.38 & 6932.84 & 193.1 & 213.1 & 208.4 & 207.9 & -0.5 \\
\hline FSB120D & 4076.41 & 7581.92 & 196.5 & 216.5 & 209.6 & 207.5 & -2.1 \\
\hline FSB $121 \mathrm{DR}$ & 3445.11 & 7021.62 & 191.3 & 211.3 & 207.4 & 203.6 & -3.8 \\
\hline FSB122C & 3479.6 & 5730.48 & 160 & 170 & 200 & 196.4 & -3.6 \\
\hline FSB 1 22D & 3489.55 & 5715.92 & 186.6 & 206.6 & 203.8 & 197.6 & -6.2 \\
\hline FSB123D & 6800.48 & 7132.46 & 194.1 & 214.1 & 212.3 & 212 & -0.3 \\
\hline FSL $1 \mathrm{D}$ & 7095.02 & 11796.01 & 208.5 & 228.6 & 224.4 & 218.8 & -5.6 \\
\hline FSL 2D & 6986.22 & 11336.75 & 208.7 & 228.8 & 224.9 & 221.2 & -3.7 \\
\hline FSL 3D & 6849.09 & 10416.84 & 205.9 & 226 & 223 & 222.6 & -0.4 \\
\hline FSL 4D & 6684.45 & 10062.06 & 204 & 224.1 & 217.2 & 222.1 & 4.9 \\
\hline FSL 5D & 6448.64 & 9598.19 & 203.5 & 223.7 & 220.8 & 220.5 & -0.3 \\
\hline FSL 6D & 6342.48 & 9254 & 202.1 & 222.1 & 220 & 219.1 & -0.9 \\
\hline FSL 7D & 6189.75 & 8807.18 & 199.5 & 219.6 & 219 & 217.9 & -1.1 \\
\hline FSL 8D & 6273.82 & 8545.85 & 202.7 & 222.8 & 218 & 217.6 & -0.4 \\
\hline FSL 9D & 6363.08 & 8272.12 & 201.4 & 221.5 & 216 & 217.2 & 1.2 \\
\hline FSS 1D & 8771.54 & 8261.85 & 209.9 & 229.9 & 223.7 & 224.5 & 0.8 \\
\hline FSS 2D & 882442 & 8115.54 & 204.4 & 224.4 & 223.1 & 223.9 & 0.8 \\
\hline FSS 3D & 8491.35 & 7898.55 & 205.8 & 225.8 & 220.8 & 221.8 & 1 \\
\hline
\end{tabular}


Table C.2-1 Measured and Simulated Head Data in the "Upper" Zone of the Upper Three Runs Aquifer Unit

\begin{tabular}{|c|c|c|c|c|c|c|c|}
\hline Well ID & $\begin{array}{l}\text { Model x } \\
\text { (feet) }\end{array}$ & $\begin{array}{l}\text { Model y } \\
\text { (feet) }\end{array}$ & $\begin{array}{c}\text { Screen } \\
\text { bottom } \\
\text { (feet amsl) }\end{array}$ & $\begin{array}{l}\text { Screen top } \\
\text { (feet amsl) }\end{array}$ & $\begin{array}{c}\text { Measured } \\
\text { head } \\
\text { (feet amsl) }\end{array}$ & $\begin{array}{c}\text { Simulated } \\
\text { head } \\
\text { (feet amsl) }\end{array}$ & $\begin{array}{l}\text { Difference } \\
\text { (feet) }\end{array}$ \\
\hline FSS 4D & 7714.11 & 8323.54 & 202.6 & 222.6 & 218.9 & 222 & 3.1 \\
\hline FTF 2 & 7730.52 & 10165.4 & 219.4 & 239.4 & 225 & 225.9 & 0.9 \\
\hline FTF 3 & 7721.82 & 10060.61 & 218.2 & 221.2 & 224 & 225.9 & 1.9 \\
\hline FTF 4 & $7766^{--}$ & $9965.31^{-}$ & 216.6 & 236.6 & 224.4 & $226^{--}$ & 1.6 \\
\hline FTF 5 & 7688.51 & 9849.36 & 215.3 & 235.3 & 224.8 & 225.6 & 0.8 \\
\hline FTF 6 & 7560.46 & 9940.53 & 216.9 & 236.9 & 224.3 & 225.3 & 1 \\
\hline FTF 7 & 7569.99 & 10028.95 & 222.1 & 226.1 & 223.6 & 225.4 & 1.8 \\
\hline FTF 8 & 7519.99 & 10120.86 & 219.6 & 239.6 & 226.7 & 225.2 & -1.5 \\
\hline FTF 9 & 7205.45 & 10203.88 & 216.4 & 236.4 & 224 & 224.2 & 0.2 \\
\hline FTF 10 & 7368.51 & 10088.46 & 215.1 & 235.1 & 224.2 & 224.7 & 0.5 \\
\hline FTF 11 & 7248.01 & 9904.07 & 215.8 & 235.8 & 224.8 & 224.2 & -0.6 \\
\hline FTF 12 & 7120.65 & 10020.85 & 215 & 235 & 226.7 & 223.8 & -2.9 \\
\hline FTF 13 & 7702.85 & 9445.72 & 216.1 & 236.1 & 225.6 & 225.2 & -0.4 \\
\hline FTF 15 & 7811.99 & 9565.23 & 197.5 & 227.5 & 225.1 & 225.6 & 0.5 \\
\hline FTF 16 & 7463.91 & 9518.43 & 203.8 & 233.8 & 223.3 & 224.5 & 1.2 \\
\hline FTF 17 & 7444.44 & 9630.23 & 200.6 & 230.6 & 223.1 & 224.6 & 1.5 \\
\hline FTF 18 & 7422.32 & 9711.2 & 202.3 & 232.3 & 223.4 & 224.6 & 1.2 \\
\hline FTF 19 & 7179.98 & 9847.08 & 198.3 & 228.3 & 222.5 & 223.4 & 0.9 \\
\hline FTF 20 & 7039.1 & 9690.27 & 198.3 & 228.3 & 221.9 & 222.9 & 1 \\
\hline FTF 21 & 7068.57 & 9544.92 & 198.7 & 228.7 & 223.2 & 222.9 & -0.3 \\
\hline FTF 22 & 7088.74 & 9431.23 & 212.6 & 242.6 & 221.8 & 223.2 & 1.4 \\
\hline FTF 23 & 7279.73 & 9329.21 & 201.2 & 231.2 & 222.3 & 223.6 & 1.3 \\
\hline FTF 24A & 7263.53 & 9984.97 & 212.7 & 232.7 & 221.9 & 224.3 & 2.4 \\
\hline FTF 25A & 7338.74 & 10053.91 & 212.8 & 232.8 & 223.3 & 224.5 & 1.2 \\
\hline FTF 26 & 7357.44 & 9998.18 & 206.3 & 226.3 & 223.3 & 224.5 & 1.2 \\
\hline FTF 27 & 7311.41 & 9965.09 & 213.5 & 243.5 & 223.4 & 224.4 & 1 \\
\hline H 6 & 13787.77 & 6007.01 & 225.2 & 235.2 & 231 & 233 & 2 \\
\hline H 7 & 13800.91 & 5948.56 & 224.9 & 234.9 & 229 & 232.3 & 3.3 \\
\hline H 8 & 13770.34 & 5600.81 & 218.4 & 228.4 & 227 & 227.8 & 0.8 \\
\hline H 9 & 13819.74 & 5567.55 & 207.4 & 217.4 & 226.8 & 227.5 & 0.7 \\
\hline H 10 & 13369.93 & 5507.31 & 222.5 & 232.5 & 227.3 & 227.5 & 0.2 \\
\hline H 11 & 13336.07 & 5457.89 & 212 & 222 & 227.7 & 226.6 & -1.1 \\
\hline H $18 \mathrm{~A}$ & 12951.07 & 5144.7 & 217.5 & 227.5 & 224.1 & 221.3 & -2.8 \\
\hline $\mathrm{H} 19$ & 12641.87 & 5175.69 & 219.6 & 221.1 & 223.8 & 220.2 & -3.6 \\
\hline HAA $1 \mathrm{D}$ & 18788.64 & 4871.94 & 261.8 & 281.8 & 276.2 & 276.1 & -0.1 \\
\hline HAA 2D & 16860.42 & 5572.65 & 260.3 & 280.4 & 276.4 & 272.1 & -4.3 \\
\hline HAA $3 D$ & 15689.74 & 5807.38 & 246.7 & 266.7 & 262.1 & 255.9 & -6.2 \\
\hline HAA 4D & 17220.16 & 6955.57 & 255.7 & 275.7 & 269.8 & 270.5 & 0.7 \\
\hline HAA 6D & 19349.23 & 6607.62 & 247.1 & 267.2 & 264.8 & 267.6 & 2.8 \\
\hline HAC 1 & 16766.61 & 6805.69 & 258.8 & 278.8 & 269.2 & 269.5 & 0.3 \\
\hline HAC 2 & 16709.13 & 6843.78 & 258.8 & 278.8 & 268.8 & 268.8 & 0 \\
\hline HAC 3 & 16664.65 & 6796.7 & 255 & 275 & 268.9 & 268.6 & -0.3 \\
\hline HAC 4 & 16734.89 & 6747.12 & 254.1 & 274.1 & 269.4 & 269.4 & 0 \\
\hline HAP 1 & 18906.71 & 6277.91 & 256.3 & 276.3 & 270.7 & 274 & 3.3 \\
\hline HAP 2 & 19043.13 & 6218.07 & 243.8 & 263.8 & 270.3 & 272.9 & 2.6 \\
\hline
\end{tabular}


Table C.2-1 Measured and Simulated Head Data in the "Upper" Zone of the Upper Three Runs Aquifer Unit

\begin{tabular}{|c|c|c|c|c|c|c|c|}
\hline Well ID & $\begin{array}{c}\text { Model x } \\
\text { (feet) }\end{array}$ & $\begin{array}{c}\text { Model y } \\
\text { (feet) }\end{array}$ & $\begin{array}{c}\text { Screen } \\
\text { bottom } \\
\text { (feet amsl) }\end{array}$ & $\begin{array}{l}\text { Screen top } \\
\text { (feet amsl) }\end{array}$ & $\begin{array}{c}\text { Measured } \\
\text { head } \\
\text { (feet amsl) }\end{array}$ & $\begin{array}{c}\text { Simulated } \\
\text { head } \\
\text { (feet amsl) }\end{array}$ & $\begin{array}{c}\text { Difference } \\
\text { (feet) }\end{array}$ \\
\hline $\mathrm{HC} \quad \mathrm{ID}$ & 17296.9 & 6483.92 & 206.5 & 211.5 & 268.9 & 272.1 & 3.2 \\
\hline $\mathrm{HC} \quad \mathrm{IE}$ & 17293.96 & 6483.29 & 251.5 & 256.5 & 275 & 273.7 & -1.3 \\
\hline $\mathrm{HC} \quad 2 \mathrm{E}$ & 17283.13 & 6519.84 & 205.7 & 210.7 & 269.5 & 271.8 & 2.3 \\
\hline $\mathrm{HC} \quad 2 \mathrm{~F}$ & 17283.96 & 6515.93 & 250.7 & 255.7 & 274.3 & 273.4 & -0.9 \\
\hline $\mathrm{HC} \quad 6 \mathrm{~B}$ & 17411.46 & 6921.29 & 210.2 & 215.2 & 268.9 & 269.5 & 0.6 \\
\hline $\mathrm{HC} \quad 11 \mathrm{C}$ & 16983.68 & 9229.19 & 190.8 & 195.8 & 236.6 & 236.5 & -0.1 \\
\hline HCA 1 & 18350.48 & 7500.89 & 253.7 & 273.7 & 269.2 & 261.4 & -7.8 \\
\hline HCA 2 & 18241.58 & 7216.23 & 242 & 273.4 & 270.2 & 266.4 & -3.8 \\
\hline $\mathrm{HCA} 3$ & 18323.16 & 7627.99 & 253.8 & 273.8 & 269 & 259.2 & -9.8 \\
\hline HCA 4 & 18187.59 & 7468.31 & 241.9 & 273.3 & 269.3 & 262.3 & -7 \\
\hline HCB 1 & 19372.87 & 6598.85 & 222.6 & 252.6 & 263.4 & 266.6 & 3.2 \\
\hline HCB 2 & 19280.47 & 6439.04 & 239.9 & 269.9 & 267.9 & 269.9 & 2 \\
\hline HCB 3 & 19439.5 & 6277.68 & 233.6 & 263.6 & 266.4 & 269.3 & 2.9 \\
\hline HCB 4 & 19540.92 & 6447.89 & 235.9 & 265.9 & 264.4 & 267 & 2.6 \\
\hline HET ID & 15962.7 & 6407.14 & 240.3 & 260.3 & 267.5 & 261.5 & -6 \\
\hline HET 2D & 15508.98 & 6369.69 & 239.7 & 259.7 & 258.3 & 255.6 & -2.7 \\
\hline HET 3D & 15506.45 & 6459.02 & 239.9 & 259.9 & 258.7 & 255.8 & -2.9 \\
\hline HET 4D & 15543.72 & 6553.02 & 239.5 & 259.6 & 259.1 & 256.6 & -2.5 \\
\hline HR3 11 & 15685.35 & 5790.5 & 200.4 & 230 & 259.4 & 253.7 & -5.7 \\
\hline HR3 13 & 15554.85 & 6014.87 & 205.1 & 234.8 & 258.5 & 253.4 & -5.1 \\
\hline HR8 11 & 14998.59 & 6199.56 & 207.9 & 237.6 & 245.9 & 244.6 & -1.3 \\
\hline HR8 12 & 14808.34 & 5989.82 & 206.3 & 235.9 & 239.4 & 239.1 & -0.3 \\
\hline HR8 13 & 14824.94 & 5767.92 & 201.7 & 231.4 & 237.7 & 237.9 & 0.2 \\
\hline HR8 14 & 15156.68 & 5707.37 & 202.3 & 231.9 & 244 & 243.8 & -0.2 \\
\hline HSB 65 & 13795.66 & 6434.49 & 212.4 & 242.4 & 232.7 & 236.3 & 3.6 \\
\hline HSB $65 \mathrm{C}$ & 13807.52 & 6451.32 & 207.8 & 218.6 & 232.7 & 236.3 & 3.6 \\
\hline HSB 66 & 12324.07 & 6125.37 & 198.1 & 228.1 & 225.4 & 229.2 & 3.8 \\
\hline HSB 67 & 13979.53 & 5532.41 & 200.7 & 223 & 223.8 & 225.2 & 1.4 \\
\hline HSB 68 & 12484.74 & 5238.19 & 213.3 & 241.8 & 221.9 & 220.3 & -1.6 \\
\hline HSB 69 & 12064.22 & 5168.13 & 199 & 229 & 219.5 & 216.7 & -2.8 \\
\hline HSB 70 & 11143.28 & 6056.06 & 205.7 & 235.7 & 224.5 & 223.4 & -1.1 \\
\hline HSB 71 & 10618.14 & 6219.44 & 204.8 & 234.8 & 224.1 & 222.9 & -1.2 \\
\hline HSB 83D & 14127.46 & 5689.7 & 198.7 & 228.7 & 224.8 & 228.5 & 3.7 \\
\hline HSB 84D & 11934.06 & 5178.29 & 199.5 & 219.5 & 218.9 & 215.8 & -3.1 \\
\hline HSB 85C & 14013.57 & 7888.26 & 214.2 & 224.2 & 238.9 & 238.1 & -0.8 \\
\hline HSB 86C & 11380.1 & 6027.47 & 189.4 & 199.4 & 223.8 & 223.4 & -0.4 \\
\hline HSB 86D & 11393.32 & 6022.51 & 206.6 & 236.6 & 223.7 & 223.9 & 0.2 \\
\hline HSB100D & 14225.73 & 6166.24 & 216.9 & 236.9 & 233.4 & 236.2 & 2.8 \\
\hline HSB101D & 14043.91 & 6049.59 & 216.1 & 236.1 & 230.7 & 234.1 & 3.4 \\
\hline HSB 102D & 13856.29 & 5963.6 & 216.3 & 236.3 & 228.2 & 232.6 & 4.4 \\
\hline HSB103D & 13855.93 & 5591.09 & 213.7 & 233.7 & 225.6 & 227.2 & 1.6 \\
\hline HSB 104D & 13666.68 & 5328.09 & 210.6 & 230.6 & 224.9 & 225.1 & 0.2 \\
\hline HSB 105D & 13455.02 & 5369.6 & 211.8 & 231.8 & 225.3 & 225.6 & 0.3 \\
\hline HSB106D & 13170.75 & 5588.27 & 210.7 & 230.7 & 225.9 & 228 & 2.1 \\
\hline HSB107D & 12949.72 & 5509.39 & 215.1 & 235.1 & 224.7 & 226.6 & 1.9 \\
\hline
\end{tabular}


Table C.2-1 Measured and Simulated Head Data in the "Upper" Zone of the Upper Three Runs Aquifer Unit

\begin{tabular}{|c|c|c|c|c|c|c|c|}
\hline Well ID & $\begin{array}{l}\text { Model x } \\
\text { (feet) }\end{array}$ & $\begin{array}{c}\text { Model y } \\
\text { (feet) }\end{array}$ & $\begin{array}{c}\text { Screen } \\
\text { bottom } \\
\text { (feet amsl) }\end{array}$ & $\begin{array}{l}\text { Screen top } \\
\text { (feet amsl) }\end{array}$ & $\begin{array}{c}\text { Measured } \\
\text { head } \\
\text { (feet amsl) }\end{array}$ & $\begin{array}{c}\text { Simulated } \\
\text { head } \\
\text { (feet amsl) }\end{array}$ & $\begin{array}{c}\text { Difference } \\
\text { (feet) }\end{array}$ \\
\hline HSB 108D & 12690.73 & 5445.55 & 212 & 232 & 223.6 & 224.4 & 0.8 \\
\hline HSB 109D & 12436.81 & 5389.12 & 213 & 233 & 222.9 & 222.2 & -0.7 \\
\hline HSB $110 \mathrm{D}$ & 12207.37 & 5442.18 & 211.4 & 231.4 & 222.2 & 221.7 & -0.5 \\
\hline $\mathrm{HSB}^{-11 \mathrm{D}^{-}}$ & 12004.33 & $5543.17^{-}$ & $-185: 7^{-}$ & ${ }^{--} 195.7$ & $222.1^{-}$ & 221.4 & $=0.7^{-}$ \\
\hline HSB $111 \mathrm{E}$ & 11995.82 & 5548.11 & 211.7 & 231.7 & 222.2 & 222 & -0.2 \\
\hline HSB $112 \mathrm{D}$ & 11870.88 & 5755.47 & 188.3 & 198.3 & 222.9 & 223.3 & 0.4 \\
\hline HSB $112 \mathrm{E}$ & 11861.43 & 5758.57 & 211.7 & 231.7 & 222.8 & 223.7 & 0.9 \\
\hline HSB I 13D & 11603.07 & 5842.79 & 216.2 & 236.2 & 222.9 & 223.4 & 0.5 \\
\hline HSBI 14D & 11509.02 & 5998.13 & 212.8 & 232.8 & 223.6 & 224.2 & 0.6 \\
\hline HSB $115 D$ & 11406.53 & 6168.65 & 213.9 & 233.9 & 224.3 & 225.2 & 0.9 \\
\hline HSB $116 \mathrm{D}$ & 11307.03 & 6388.57 & 214.5 & 234.5 & 226.3 & 227.1 & 0.8 \\
\hline HSB 125D & 14137.26 & 5558.98 & 199.4 & 219.4 & 221.1 & 225.5 & 4.4 \\
\hline HSB 126D & 12933.47 & 4418.98 & 190.5 & 200.5 & 204.9 & 206.5 & 1.6 \\
\hline HSB 127D & 12438.48 & 4912.35 & 197.8 & 217.8 & 218.2 & 213.5 & -4.7 \\
\hline HSBI29D & 10662.16 & 5166.79 & 185.2 & 205.2 & 208.3 & 209.6 & 1.3 \\
\hline HSB132C & 14341.77 & 5576.07 & 168.6 & 178.6 & 221.5 & 230.9 & 9.4 \\
\hline HSB132D & 14353.72 & 5575.65 & 206.5 & 226.5 & 221.1 & 227.8 & 6.7 \\
\hline HSB133D & 14551.55 & 6102.29 & 208.5 & 228.5 & 235 & 237.6 & 2.6 \\
\hline HSB134D & 13914.34 & 5224.42 & 205.8 & 223.2 & 222.1 & 223.5 & 1.4 \\
\hline HSB 135D & 12171.45 & 5037.36 & 199.9 & 219.9 & 218.3 & 215.8 & -2.5 \\
\hline HSB136D & 11467.81 & 5408.48 & 200.2 & 220.2 & 220.9 & 218.3 & -2.6 \\
\hline HSB 137D & 11150.05 & 5722.17 & 205.3 & 225.3 & 222.3 & 220.4 & -1.9 \\
\hline HSB138D & 10540.93 & 6493.69 & 208.1 & 228.1 & 224.1 & 224.1 & 0 \\
\hline HSB139D & 13039.66 & 4952.52 & 206.7 & 226.4 & 222.7 & 218.3 & -4.4 \\
\hline HSB 141D & 14776.48 & 5374.04 & 217.8 & 237.8 & 240.5 & 235.5 & -5 \\
\hline HSB 143D & 7985.6 & 6557.6 & 196.9 & 216.9 & 213.2 & 209.5 & -3.7 \\
\hline HSB 145D & 13410.48 & 4985.13 & 184.2 & 194.2 & 220.7 & 220.1 & -0.6 \\
\hline HSB 146D & 14261.98 & 4534.01 & 204 & 224.1 & 222 & 227.3 & 5.3 \\
\hline HSB147D & 10933.93 & 7259.84 & 215.2 & 235.2 & 232.2 & 229.5 & -2.7 \\
\hline HSB 149D & 12900.96 & 5133.23 & 207 & 227 & 222.3 & 220.7 & -1.6 \\
\hline HSB $150 D$ & 14203.16 & 5771.73 & 206.9 & 226.9 & 226.8 & 230.2 & 3.4 \\
\hline HSB $151 \mathrm{D}$ & 9367.37 & 6078.21 & 197.6 & 207.6 & 207.2 & 208.2 & 1 \\
\hline $\mathrm{HSB} 152 \mathrm{D}$ & -9900.75 & -5183.45 & 197 & 207 & 205.7 & 201.6 & -4.1 \\
\hline HSL ID & 14329.04 & 6296.36 & 219.8 & 239.8 & 234.8 & 237.6 & 2.8 \\
\hline HSL 2D & 14814.31 & 6410.96 & 225.2 & 245.3 & 241.2 & 241.6 & 0.4 \\
\hline HSL 3D & 15141.21 & 6542.5 & 233.7 & 253.8 & 249.8 & 248.9 & -0.9 \\
\hline HSL 4D & 15491.7 & 6823.72 & 245 & 265.1 & 261.3 & 255 & -6.3 \\
\hline HSL 5D & 15632.98 & 6964.67 & 247.8 & 267.7 & 265.5 & 256.3 & -9.2 \\
\hline HSL 6D & 15800.22 & 7099.9 & 243.9 & 264 & 259.2 & 257.3 & -1.9 \\
\hline HSL 7D & 15984.87 & 7154.18 & 242.3 & 262.4 & 259.1 & 258.3 & -0.8 \\
\hline HSL 8D & 16367.51 & 7249.52 & 248.4 & 268.4 & 260.3 & 260.8 & 0.5 \\
\hline HSS ID & 20903.98 & 3022.53 & 236.5 & 256.5 & 268.6 & 271.5 & 2.9 \\
\hline HSS 2D & 21064.76 & 2796.62 & 234.5 & 254.5 & 267.7 & 270.9 & 3.2 \\
\hline HSS 3D & 20802.58 & 3662.64 & 262.6 & 282.6 & 281.6 & 274.3 & -7.3 \\
\hline HTF 1 & 17492.73 & 6524.52 & 236.9 & 256.9 & 272.8 & 273.6 & 0.8 \\
\hline
\end{tabular}


Table C.2-1 Measured and Simulated Head Data in the "Upper" Zone of the Upper Three Runs Aquifer Unit

\begin{tabular}{|c|c|c|c|c|c|c|c|}
\hline Well ID & $\begin{array}{c}\text { Model x } \\
\text { (feet) }\end{array}$ & $\begin{array}{c}\text { Model y } \\
\text { (feet) }\end{array}$ & $\begin{array}{c}\text { Screen } \\
\text { bottom } \\
\text { (feet amsl) }\end{array}$ & $\begin{array}{l}\text { Screen top } \\
\text { (feet amsl) }\end{array}$ & $\begin{array}{c}\text { Measured } \\
\text { head } \\
\text { (feet amsl) }\end{array}$ & $\begin{array}{c}\text { Simulated } \\
\text { head } \\
\text { (feet amsl) }\end{array}$ & $\begin{array}{c}\text { Difference } \\
\text { (feet) }\end{array}$ \\
\hline HTF 2 & 17626.44 & 6414.92 & 237 & 257 & 274.1 & 274.6 & 0.5 \\
\hline HTF 4 & 17394.38 & 6386.04 & 235.2 & 255.2 & 274.2 & 273.9 & -0.3 \\
\hline HTF 5 & 17608.6 & 6186.22 & 264.3 & 284.3 & 277.1 & 277.6 & 0.5 \\
\hline HTF 6 & 17751.26 & 6082.61 & 263.6 & 283.6 & 275.9 & 278 & 2.1 \\
\hline HTF 7 & 17664.62 & 5932.32 & 263.5 & 283.5 & 275.9 & 278.2 & 2.3 \\
\hline HTF 8 & 17491.72 & 6038.69 & 263.6 & 283.6 & 273.7 & 277.5 & 3.8 \\
\hline HTF 9 & 17151.13 & 6356.83 & 245.8 & 265.8 & 273.5 & 273.7 & 0.2 \\
\hline HTF 10 & 17315.52 & 6256.83 & 245.2 & 265.2 & 273.2 & 274.8 & 1.6 \\
\hline HTF 11 & 17227.42 & 6113.37 & 238.9 & 258.9 & 273.9 & 273.9 & 0 \\
\hline HTF 12 & 17075.87 & 6205.89 & 242.9 & 262.9 & 273.4 & 273.3 & -0.1 \\
\hline HTF 13 & 16999.17 & 6533.09 & 262.6 & 282.6 & 274.2 & 273.5 & -0.7 \\
\hline HTF 14 & 16877.46 & 6509.26 & 261.9 & 281.9 & 273.5 & 272.5 & -1 \\
\hline HTF 15 & 16803.69 & 6332.05 & 260.7 & 280.7 & 273.5 & 272.5 & -1 \\
\hline HTF 16 & 17294.09 & 6896.34 & 248.3 & 268.3 & 269.7 & 270.9 & 1.2 \\
\hline HTF 17 & 16455.18 & 7178.08 & 238.4 & 258.4 & 262.5 & 261.9 & -0.6 \\
\hline HTF 18 & 16661.9 & 6375.32 & 251.7 & 271.7 & 271.5 & 270.3 & -1.2 \\
\hline HTF 19 & 16493.77 & 6473.2 & 245.7 & 265.7 & 269.1 & 267.7 & -1.4 \\
\hline HTF 20 & 16465.31 & 6641.77 & 251.9 & 271.9 & 267.9 & 267.5 & -0.4 \\
\hline HTF 21 & 16651.7 & 6604.61 & 242.6 & 262.6 & 269.5 & 268.6 & -0.9 \\
\hline HTF 22 & 18048.04 & 6252.43 & 251.4 & 271.4 & 275.4 & 276.4 & 1 \\
\hline HTF 23 & 18162.25 & 6276.4 & 256.8 & 276.8 & 274.8 & 276.5 & 1.7 \\
\hline HTF 24 & 18265.35 & 6297.8 & 257.8 & 277.8 & 274.2 & 276.2 & 2 \\
\hline HTF 25 & 18417.75 & 6188.81 & 252.5 & 272.5 & 274.6 & 276.1 & 1.5 \\
\hline HTF 26 & 18361.11 & 6040.18 & 255.5 & 275.5 & 275.4 & 277.5 & 2.1 \\
\hline HTF 27 & 18215.93 & 5975.79 & 259.1 & 279.1 & 276.1 & 278.5 & 2.4 \\
\hline HTF 28 & 18069.87 & 5967.44 & 251.9 & 271.9 & 275.9 & 277.9 & 2 \\
\hline HTF 29 & 17940.13 & 6093.01 & 259.9 & 289.9 & 275.6 & 277.9 & 2.3 \\
\hline HTF 31 & 18282.72 & 5672.14 & 246.7 & 266.7 & 275.7 & 278.5 & 2.8 \\
\hline HTF 32 & 18397.16 & 5833.05 & 251.1 & 271.1 & 274.7 & 278.3 & 3.6 \\
\hline HTF 34 & 17531.1 & 5918.35 & 251.7 & 271.7 & 275.8 & 276.7 & 0.9 \\
\hline MGA 36 & 12959.6 & 7768.21 & 234.2 & 254.2 & 237.3 & 237.4 & 0.1 \\
\hline MGC 9 & 10423.4 & 8730.02 & 217.3 & 237.3 & 229.6 & 231.8 & 2.2 \\
\hline $\mathrm{MGC} 11$ & 10604.81 & 8646.1 & 219.2 & 239.2 & 231.1 & 232.2 & 1.1 \\
\hline MGC 19 & 11329.13 & 8307.09 & 230.6 & 234.6 & 232.2 & 234 & 1.8 \\
\hline MGC 32 & 12510.33 & 7752.56 & 232 & 252 & 245.2 & 236.6 & -8.6 \\
\hline MGC 36 & 12880.95 & 7582.7 & 234.4 & 254.4 & 236.1 & 237.1 & 1 \\
\hline MGE 9 & 10337.4 & 8551.23 & 218.1 & 238.1 & 229.2 & 231.2 & 2 \\
\hline MGE 21 & 11424.5 & 8038.75 & 227.9 & 247.9 & 234.2 & 233.8 & -0.4 \\
\hline MGE 30 & 12252.53 & 7650.43 & 229.3 & 249.3 & 236.1 & 235.9 & -0.2 \\
\hline MGE 34 & 12615.31 & 7481.36 & 237.2 & 257.2 & 238.6 & 0 & $-238.6^{a}$ \\
\hline MGG 15 & 10798.89 & 8121.69 & 223.3 & 243.3 & 232.6 & 231.6 & -1 \\
\hline MGG 19 & 11165.16 & 7951.12 & 226 & 246 & 232.7 & 232.5 & -0.2 \\
\hline MGG 23 & 11526.03 & 7780.42 & 227.1 & 247.1 & 235.2 & 233.5 & -1.7 \\
\hline MGG 28 & 11985.06 & 7562.08 & 230.3 & 250.3 & 235.7 & 234.9 & -0.8 \\
\hline MGG 36 & 12719.53 & 7215.21 & 232.5 & 252.5 & 237.9 & 235.8 & -2.1 \\
\hline
\end{tabular}


Table C.2-1 Measured and Simulated Head Data in the "Upper" Zone of the Upper Three Runs Aquifer Unit

\begin{tabular}{|c|c|c|c|c|c|c|c|}
\hline Well ID & $\begin{array}{c}\text { Model } x \\
\text { (feet) }\end{array}$ & $\begin{array}{c}\text { Model y } \\
\text { (feet) }\end{array}$ & $\begin{array}{c}\text { Screen } \\
\text { bottom } \\
\text { (feet amsl) }\end{array}$ & $\begin{array}{l}\text { Screen top } \\
\text { (feet amsl) }\end{array}$ & $\begin{array}{c}\text { Measured } \\
\text { head } \\
\text { (feet amsl) }\end{array}$ & $\begin{array}{c}\text { Simulated } \\
\text { head } \\
\text { (feet amsl) }\end{array}$ & $\begin{array}{c}\text { Difference } \\
\text { (feet) }\end{array}$ \\
\hline NBG 1 & 7913.1 & 12212.5 & 200.9 & 232.3 & 224.4 & 217.1 & -7.3 \\
\hline NBG 2 & 8032.18 & 12032.73 & 203.6 & 233.6 & 224.8 & 219.3 & -5.5 \\
\hline NBG 3 & 8172.79 & 11898.84 & 202.1 & 233.5 & 217.6 & 221.1 & 3.5 \\
\hline P 27D & $19 \overline{6} \overline{6} \overline{6} . \overline{6}$ & 5590.06 & 199.5 & $219.5^{-}$ & 266.6 & $270.9^{-}$ & 4.3 \\
\hline SBG 2 & 19715.17 & 9885.23 & 205.9 & 235.9 & 237.7 & 238.4 & 0.7 \\
\hline SBG 3 & 20214.99 & 9101.73 & 206.6 & 236.6 & 237 & 238.3 & 1.3 \\
\hline SBG 5 & 19775.26 & 7483.34 & 199.4 & 219.4 & 249.3 & 249.3 & 0 \\
\hline SBG 6 & 18861.02 & 8711.09 & 208.1 & 238.1 & 244.3 & 245.6 & 1.3 \\
\hline SCA 2 & 19627.58 & 9130.94 & 215.9 & 245.9 & 242.2 & 241.7 & -0.5 \\
\hline SCA 3 & 19481.83 & 9211.09 & 220.3 & 240.3 & 241.4 & 242 & 0.6 \\
\hline SCA $3 A$ & 19480.65 & 9216.66 & 267.1 & 271.6 & 270.8 & 0 & $-270.8^{\mathrm{a}}$ \\
\hline SCA 4 & 19495.67 & 9108.93 & 220.4 & 240.4 & 241.7 & 242.4 & 0.7 \\
\hline SCA 4A & 19499.56 & 9108.43 & 265.3 & 272.8 & 268.8 & 0 & $-268.8^{a}$ \\
\hline SCA 5 & 19512.35 & 9354.16 & 223.7 & 243.7 & 241.4 & 241.5 & 0.1 \\
\hline SCA 6 & 19599.31 & 8977.3 & 221.3 & 241.1 & 242.1 & 242.5 & 0.4 \\
\hline SLP 1 & 19570.5 & 8206.67 & 228 & 248 & 245.2 & 246.4 & 1.2 \\
\hline SLP 2 & 19669.09 & 8130.5 & 217.7 & 237.7 & 244.7 & 245.9 & 1.2 \\
\hline YSC $1 D$ & 19865.99 & 13598.23 & 216.8 & 236.8 & 221.1 & 220.3 & -0.8 \\
\hline $\mathrm{Z} 2$ & 8169.39 & 7651 & 214 & 214.5 & 219.4 & 219.5 & 0.1 \\
\hline Z 3 & 6294.03 & 7560.01 & 206.6 & 207.1 & 212.6 & 213.7 & 1.1 \\
\hline $\mathrm{Z} 8$ & 6221.86 & 9133.69 & 213.6 & 214.1 & 219.3 & 218.5 & -0.8 \\
\hline Z 9 & 5002.69 & 9990.43 & 209.9 & 210.4 & 215 & 212.8 & -2.2 \\
\hline Z 9 & 5002.69 & 9990.43 & 207.5 & 227.5 & 215 & 212.8 & -2.2 \\
\hline $\mathrm{Z} \quad 12$ & 16954.73 & 5851.86 & 251.3 & 251.8 & 274.3 & 271.7 & -2.6 \\
\hline Z 13 & 17825.78 & 5614.68 & 256.6 & 257.1 & 276.1 & 277.8 & 1.7 \\
\hline ZBG 1 & 19926.85 & 11989.22 & 220 & 240.1 & 233.8 & 230.4 & -3.4 \\
\hline $\mathrm{ZBG} \quad \mathrm{lA}$ & 19940.34 & 11996.48 & 276 & 281 & 278.5 & 0 & $-278.5^{\mathrm{a}}$ \\
\hline ZDT 1 & 20494.85 & 7059.79 & 227 & 247 & 239.7 & 244.2 & 4.5 \\
\hline ZDT 2 & 20430.32 & 7099.34 & 225.1 & 245.1 & 241.2 & 244.9 & 3.7 \\
\hline ZW 4 & 10871.71 & 11171.89 & 229.2 & 239.7 & 232.3 & 0 & $-232.3^{a}$ \\
\hline ZW 5 & 9458.83 & 8929.12 & 221 & 231 & 227.4 & 228.9 & 1.5 \\
\hline ZW 6 & 6756.67 & 8762.27 & 216.7 & 227.2 & 220.3 & 219.9 & -0.4 \\
\hline ZW 7 & 15628.95 & 6797.48 & 254.5 & 264.8 & 265.8 & 258.8 & -7 \\
\hline ZW 8 & 19385.64 & 5961.58 & 254.1 & 264.1 & 270.9 & 271.7 & 0.8 \\
\hline ZW 9 & 16538.42 & 7807.55 & 242.4 & 252.4 & 252 & 252.8 & 0.8 \\
\hline $\mathrm{ZW} 10$ & 18492.49 & 8237.21 & 242.2 & 252.2 & 249.7 & 249.3 & -0.4 \\
\hline FPZ001A & 4103.01 & 5630.17 & 182 & 184.5 & 198 & 197.5 & -0.4 \\
\hline FPZ002A & 4174.47 & 5713.6 & 189.3 & 191.8 & 201.5 & 198.5 & -3 \\
\hline FPZ003A & 4501.13 & 5257.54 & 172.5 & 187.5 & 188.8 & 190.1 & 1.3 \\
\hline FPZ004A & 5098.46 & 5885.38 & 192 & 194.5 & 201.5 & 199.9 & -1.6 \\
\hline FPZ005A & 5087.85 & 5514.57 & 176.6 & 179.1 & 191.2 & 191 & -0.2 \\
\hline FPZ005B & 5087.85 & 5514.57 & 183.9 & 188.9 & 191.2 & 190.6 & -0.6 \\
\hline FPZ006A & 5213.24 & 5413.67 & 175.5 & 178 & 189.2 & 188.4 & -0.8 \\
\hline FPZ006B & 5213.24 & 5413.67 & 181.7 & 186.7 & 188.8 & 188.5 & -0.3 \\
\hline FPZ007A & 5615.96 & 5546.47 & 184.2 & 186.8 & 193 & 190.4 & -2.6 \\
\hline
\end{tabular}


Table C.2-1 Measured and Simulated Head Data in the "Upper" Zone of the Upper Three Runs Aquifer Unit

\begin{tabular}{cccccccc}
\hline Well ID & $\begin{array}{c}\text { Model x } \\
\text { (feet) }\end{array}$ & $\begin{array}{c}\text { Model y } \\
\text { (feet) }\end{array}$ & $\begin{array}{c}\text { Screen } \\
\text { bottom } \\
\text { (feet amsl) }\end{array}$ & $\begin{array}{c}\text { Screen top } \\
\text { (feet amsl) }\end{array}$ & $\begin{array}{c}\text { Measured } \\
\text { head } \\
\text { (feet amsl) }\end{array}$ & $\begin{array}{c}\text { Simulated } \\
\text { head } \\
\text { (feet amsl) }\end{array}$ & $\begin{array}{c}\text { Difference } \\
\text { (feet) }\end{array}$ \\
\hline FPZ007B & 5615.96 & 5546.47 & 189.1 & 194.1 & 194.2 & 190.4 & -3.8 \\
FPZ008A & 5971.51 & 5656.73 & 170.9 & 173.4 & 187.6 & 189.7 & 2 \\
FPZ008B & 5971.51 & 5656.73 & 176.9 & 184.4 & 187.6 & 190.3 & 2.8 \\
HPZ001A & 11334.72 & 4760.17 & 189.9 & 194.9 & 202.3 & 205.5 & 3.2 \\
HPZ002A & 11717.73 & 5241.62 & 207.2 & 212.2 & 218.4 & 215.7 & -2.7 \\
HPZ003A & 12014.77 & 4535.41 & 183.2 & 185.7 & 200.8 & 203.5 & 2.7 \\
HPZ003B & 12014.77 & 4535.41 & 193 & 198 & 200.7 & 202.7 & 2 \\
HPZ004A & 12240.9 & 4804.37 & 197 & 199.5 & 210.1 & 209.3 & -0.8 \\
HPZ005A & 12586.52 & 4715.43 & 204.3 & 206.8 & 212.6 & 210.9 & -1.7 \\
HPZ005B & 12586.52 & 4715.43 & 207.6 & 212.4 & 212.9 & 211 & -1.9 \\
HPZ006A & 12619.83 & 4300.74 & 192.7 & 197.7 & 201.8 & 202.4 & 0.6 \\
\hline
\end{tabular}

a Large negative residuals occur when the simulated head is below the well screen. In these cases, the FACT code does not compute head (denoted by a zero value in the simulated head column) and the computed residual becomes the negative of the measured head. These residual values are ignored in computing summary statistics (i.e., r.m.s. head). 
Table C.2-2 Measured and Simulated Head Data in the "Lower" Zone of the Upper Three Runs Aquifer Unit

\begin{tabular}{|c|c|c|c|c|c|c|c|}
\hline Well ID & $\begin{array}{c}\text { Model x } \\
\text { (feet) }\end{array}$ & $\begin{array}{c}\text { Model y } \\
\text { (feet) }\end{array}$ & $\begin{array}{c}\text { Screen } \\
\text { bottom } \\
\text { (feet amsl) }\end{array}$ & $\begin{array}{l}\text { Screen top } \\
\text { (feet amsl) }\end{array}$ & $\begin{array}{c}\text { Measured } \\
\text { head } \\
\text { (feet amsl) }\end{array}$ & $\begin{array}{c}\text { Simulated } \\
\text { head } \\
\text { (feet amsl) }\end{array}$ & $\begin{array}{c}\text { Difference } \\
\text { (feet) }\end{array}$ \\
\hline BG 92 & 10855.74 & 12550.9 & 197.2 & 227.2 & 208.8 & 208.7 & -0.1 \\
\hline BG 93 & 10991.82 & 13511.38 & 180.5 & 210.5 & 199 & 195.9 & -3.1 \\
\hline $\mathrm{BG}^{-94}$ & 11123.05 & 14496.6 & $152.8^{-}$ & 182.8 & $191^{--}$ & 177.4 & -13.6 \\
\hline BG 95 & 12183.95 & 13896.76 & 152.5 & 182.5 & 192.7 & 178.7 & -14 \\
\hline BG 96 & 12215.11 & 13224.96 & 177.2 & 207.2 & 197.6 & 193.9 & -3.7 \\
\hline BG 103 & 13952.13 & 12047.68 & 169.5 & 199.5 & 199.9 & 200.6 & 0.7 \\
\hline BG 115 & 12265.98 & 10997.77 & 198.9 & 218.9 & 215.8 & 220.5 & 4.7 \\
\hline BG 122 & 10909.45 & 12114.02 & 189.9 & 209.9 & 211.1 & 213.4 & 2.3 \\
\hline BGO $5 \mathrm{C}$ & 13307.93 & 10472.63 & 183.2 & 193.2 & 216.2 & 219.9 & 3.7 \\
\hline BGO $6 \mathrm{~B}$ & 12853.86 & 10454.11 & 139.7 & 149.7 & 219.2 & 221.3 & 2.1 \\
\hline $\mathrm{BGO} 6 \mathrm{C}$ & 12828.96 & 10381.25 & 158 & 168 & 220.2 & 222.1 & 1.9 \\
\hline BGO $8 \mathrm{C}$ & 12136.55 & 10328.23 & 174.3 & 184.3 & 224.6 & 224.5 & -0.1 \\
\hline BGO $10 \mathrm{~B}$ & 11426.87 & 10589.28 & 139 & 149 & 220.3 & 223.2 & 2.9 \\
\hline $\mathrm{BGO} 10 \mathrm{C}$ & 11524.59 & 10429.2 & 157.3 & 167.3 & 220.5 & 224.5 & 4 \\
\hline BGO 12C & 10742.07 & 10262.87 & 153.6 & 163.6 & 220.1 & 225 & 4.9 \\
\hline BGO 12CR & 10716.57 & 10258.27 & 144 & 154 & 221.8 & 224.9 & 3.1 \\
\hline BGO 14C & 10439.72 & 9751.33 & 192.1 & 202.1 & 221.2 & 226.7 & 5.5 \\
\hline BGO $14 \mathrm{CR}$ & 10397.03 & 9711.69 & 190.1 & 200.1 & 224.1 & 226.6 & 2.5 \\
\hline BGO 16B & 10901.77 & 9235.93 & 136 & 146 & 218.8 & 227.2 & 8.4 \\
\hline BGO 27C & 9443.46 & 8822.5 & 154.9 & 163.9 & 221 & 223.6 & 2.6 \\
\hline $\mathrm{BGO} 29 \mathrm{C}$ & 8902.07 & 8616.94 & 176.8 & 186.8 & 223.4 & 221.9 & -1.5 \\
\hline BGO $30 \mathrm{C}$ & 9388.74 & 8314.73 & 178.4 & 188.4 & 219.1 & 222.5 & 3.4 \\
\hline BGO 31C & 9728.2 & 8179.35 & 176.4 & 186.4 & 225.7 & 223.2 & -2.5 \\
\hline BGO 33C & 10678.1 & 7871.82 & 177.8 & 187.8 & 225.3 & 225.8 & 0.5 \\
\hline BGO 35C & 11632.83 & 7537.21 & 161.9 & 171.9 & 228.7 & 227.6 & -1.1 \\
\hline BGO 37C & 12445.05 & 7243.97 & 168.8 & 178.8 & 230.7 & 229.2 & -1.5 \\
\hline $\mathrm{BGO} 42 \mathrm{C}$ & 10122.25 & 9721.68 & 185.9 & 195.9 & 223.8 & 226 & 2.2 \\
\hline BGO 43CR & 10690.43 & 10487.03 & 178.4 & 188.4 & 225.8 & 224.6 & -1.2 \\
\hline $\mathrm{BGO} 44 \mathrm{~B}$ & 12341.49 & 10552.54 & 148.1 & 158.1 & 220.8 & 222.4 & 1.6 \\
\hline BGO 44C & 12369.58 & 10560.35 & 190.6 & 200.6 & 220.7 & 222.9 & 2.2 \\
\hline BGO 45B & 9301.84 & 8970.28 & 137 & 147 & 219.5 & 223.4 & 3.9 \\
\hline $\mathrm{BGO} 45 \mathrm{C}$ & 9316.44 & 8967.97 & 190.5 & 200.5 & 223.2 & 224.6 & 1.4 \\
\hline BGO 46B & 9357.73 & 8135.46 & 140.4 & 150.4 & 218.3 & 221 & 2.7 \\
\hline BGO 46C & 9345.07 & 8143.09 & 178 & 188 & 220.1 & 221.5 & 1.4 \\
\hline BGO 47C & 9889.83 & 7982.65 & 178.6 & 188.6 & 223.2 & 223.1 & -0.1 \\
\hline BGO 48C & 10108.34 & 7873.29 & 176.7 & 186.7 & 223.8 & 223.7 & -0.1 \\
\hline BGO 49C & 11304.47 & 7429.89 & 166 & 176 & 228.4 & 226.4 & -2 \\
\hline BGO 50C & 9078.37 & 8258.37 & 162.5 & 172.5 & 218.9 & 221 & 2.1 \\
\hline $\mathrm{BGX} \quad 1 \mathrm{C}$ & 13046.15 & 10767.75 & 176 & 186 & 216.2 & 218.7 & 2.5 \\
\hline BGX 2B & 12630.64 & 11071.39 & 137.2 & 147.2 & 213 & 215.6 & 2.6 \\
\hline BGX 2D & 12641.83 & 11062.53 & 181.1 & 191.1 & 215.7 & 217.7 & 2 \\
\hline BGX 3D & 12086.97 & 11337.78 & 201.6 & 221.6 & 215.3 & 219 & 3.7 \\
\hline BGX $4 \mathrm{C}$ & 11457.41 & 11520.07 & 170.7 & 180.7 & 215 & 217.1 & 2.1 \\
\hline BGX 5D & 11454.25 & 12046.72 & 195 & 215 & 209.4 & 213.6 & 4.2 \\
\hline
\end{tabular}


Table C.2-2 Measured and Simulated Head Data in the "Lower" Zone of the Upper Three Runs Aquifer Unit

\begin{tabular}{|c|c|c|c|c|c|c|c|}
\hline Well ID & $\begin{array}{c}\text { Model x } \\
\text { (feet) }\end{array}$ & $\begin{array}{c}\text { Model y } \\
\text { (feet) }\end{array}$ & $\begin{array}{c}\text { Screen } \\
\text { bottom } \\
\text { (feet amsl) }\end{array}$ & $\begin{array}{l}\text { Screen top } \\
\text { (feet amsl) }\end{array}$ & $\begin{array}{c}\text { Measured } \\
\text { head } \\
\text { (feet amsl) }\end{array}$ & $\begin{array}{c}\text { Simulated } \\
\text { head } \\
\text { (feet amsl) }\end{array}$ & $\begin{array}{c}\text { Difference } \\
\text { (feet) }\end{array}$ \\
\hline BGX 6D & 11595.53 & 12422.4 & 191 & 211 & 206.2 & 209.1 & 2.9 \\
\hline BGX 7D & 12447.46 & 12203.96 & 194.1 & 214.1 & 206 & 208.3 & 2.3 \\
\hline BGX 8DR & 13221.35 & 11591.78 & 183.1 & 203.1 & 205.7 & 210.5 & 4.8 \\
\hline BGX $12 \mathrm{C}$ & 14595.49 & 8651.53 & 174.1 & 184.1 & 235 & 230.4 & -4.6 \\
\hline FBP $1 \mathrm{~A}$ & 5260.36 & 11232.14 & 161.8 & 191.8 & 206.6 & 203.5 & -3.1 \\
\hline FBP 2A & 4555.55 & 11919.01 & 137.1 & 167.1 & 191.4 & 189.8 & -1.6 \\
\hline FBP $3 A$ & 4900.05 & 12122.59 & 141 & 171 & 194.2 & 191.3 & -2.9 \\
\hline FBP 4 & 5452.8 & 11709.58 & 165.2 & 195.2 & 212.3 & 201.5 & -10.8 \\
\hline FBP 5D & 5191.17 & 11524.95 & 192.6 & 212.6 & 205.5 & 201.7 & -3.8 \\
\hline FBP 6D & 4576.27 & 11884.05 & 178.3 & 198.3 & 195.5 & 191.6 & -3.9 \\
\hline FBP 7D & 4873.21 & 12082.94 & 183.2 & 203.2 & 194.7 & 192.6 & -2.1 \\
\hline FBP 8D & 5476.46 & 11685.78 & 172.8 & 192.8 & 207.4 & 201.9 & -5.5 \\
\hline FBP 9D & 5114.07 & 11888.16 & 177.9 & 197.9 & 200.6 & 197.1 & -3.5 \\
\hline FBP 10D & 4636.57 & 11546.01 & 180.8 & 200.8 & 201.2 & 195.8 & -5.4 \\
\hline FBP 11D & 4911.5 & 11368.9 & 192 & 212.1 & 203.4 & 200.5 & -2.9 \\
\hline FBP 12D & 5335.33 & 11288.25 & 182.1 & 202.1 & 208.5 & 204.2 & -4.3 \\
\hline FBP 13D & 4704.25 & 11988.96 & 172.7 & 192.7 & 195 & 191.8 & -3.2 \\
\hline $\mathrm{FC} \quad 1 \mathrm{~B}$ & 7088.16 & 12417.46 & 151.8 & 156.8 & 210.8 & 208 & -2.8 \\
\hline $\mathrm{FC} \quad 1 \mathrm{C}$ & 7086.65 & 12425.01 & 183.9 & 188.9 & 214 & 208.3 & -5.7 \\
\hline FC 3D & 11718.27 & 12436.53 & 165.9 & 170.9 & 206.4 & 208.1 & 1.7 \\
\hline $\mathrm{FC} \quad 3 \mathrm{E}$ & 11725.62 & 12438.51 & 185.7 & 190.7 & 205.3 & 208.3 & 3 \\
\hline $\mathrm{FC} \quad 3 \mathrm{~F}$ & 11733.09 & 12440.4 & 205.1 & 210.1 & 206.2 & 208.5 & 2.3 \\
\hline $\mathrm{FC} \quad 4 \mathrm{D}$ & 7328.02 & 15116.1 & 146.4 & 151.4 & 151 & 167 & 16 \\
\hline $\mathrm{FC} \quad 4 \mathrm{E}$ & 7331.13 & 15123.61 & 176.4 & 181.4 & 185.2 & 0 & $-185.2^{\mathrm{a}}$ \\
\hline FCB 3 & 9483.7 & 9609.56 & 195.3 & 225.3 & 221.7 & 226.9 & 5.2 \\
\hline FNB 1 & 8119.87 & 13126.56 & 177.2 & 207.2 & 210.8 & 205 & -5.8 \\
\hline FNB 2 & 8147.93 & 13429.82 & 180.8 & 210.8 & 206.8 & 200.6 & -6.2 \\
\hline FNB 3 & 7874.2 & 13484.92 & 182.1 & 212.1 & 209.1 & 199.7 & -9.4 \\
\hline FNB 4 & 7647.42 & 13290.21 & 179.6 & 209.6 & 213.6 & 201.6 & -12 \\
\hline FSB $76 C$ & 6147.28 & 8577.94 & 154.8 & 165.3 & 212.9 & 214 & 1.1 \\
\hline FSB 78C & 5226.46 & 7012.38 & 141.6 & 151.4 & 208 & 204.7 & -3.3 \\
\hline FSB $79 \mathrm{C}$ & 5457.17 & 5932.24 & 149.8 & 159.6 & 196.7 & 192.4 & -4.3 \\
\hline FSB $87 C$ & 4980.97 & 7797.9 & 148.8 & 159.3 & 208.8 & 206.8 & -2 \\
\hline FSB $88 C$ & 6368.72 & 8120.99 & 158.4 & 168.4 & 212.7 & 213 & 0.3 \\
\hline FSB $89 \mathrm{C}$ & 6213.46 & 8020.31 & 156.1 & 166.1 & 211.9 & 212 & 0.1 \\
\hline FSB 90C & 6056.57 & 7812.86 & 158.1 & 168.1 & 210.8 & 210.6 & -0.2 \\
\hline FSB 91C & 5900.99 & 7606.4 & 149.1 & 159.1 & 210.8 & 209 & -1.8 \\
\hline FSB 92C & 5553.29 & 7368.82 & 147.6 & 157.6 & 210.1 & 207.1 & -3 \\
\hline FSB 93C & 5482.31 & 7194.35 & 142 & 152 & 208.7 & 206 & -2.7 \\
\hline FSB 94C & 5215.98 & 7108.81 & 139.8 & 149.8 & 207.7 & 205 & -2.7 \\
\hline FSB 95C & 5034.89 & 7175.31 & 145.8 & 155.8 & 205.6 & 204.8 & -0.8 \\
\hline FSB 97C & 4946.58 & 7369.08 & 143.8 & 153.8 & 208.2 & 205.2 & -3 \\
\hline FSB 98C & 5047.37 & 7596.61 & 148.4 & 158.4 & 209.3 & 206.5 & -2.8 \\
\hline FSB 99C & $5184 . ! 2$ & 7934.94 & 157.2 & 167.2 & 209.7 & 208.3 & -1.4 \\
\hline FSB $102 C$ & 6123.86 & 5986.95 & 145.9 & 155.9 & 195.2 & 192.8 & -2.4 \\
\hline
\end{tabular}


Table C.2-2 Measured and Simulated Head Data in the "Lower" Zone of the Upper Three Runs Aquifer Unit

\begin{tabular}{|c|c|c|c|c|c|c|c|}
\hline Well ID & $\begin{array}{c}\text { Model x } \\
\text { (feet) }\end{array}$ & $\begin{array}{c}\text { Model y } \\
\text { (feet) }\end{array}$ & $\begin{array}{c}\begin{array}{c}\text { Screen } \\
\text { bottom } \\
\text { (feet amsl) }\end{array} \\
\end{array}$ & $\begin{array}{l}\text { Screen top } \\
\text { (feet amsl) }\end{array}$ & $\begin{array}{c}\text { Measured } \\
\text { head } \\
\text { (feet amsl) }\end{array}$ & $\begin{array}{c}\text { Simulated } \\
\text { head } \\
\text { (feet amsl) }\end{array}$ & $\begin{array}{c}\text { Difference } \\
\text { (feet) }\end{array}$ \\
\hline FSB105C & 4795.74 & 7392.84 & 141.5 & 151.5 & 207.6 & 204.7 & -2.9 \\
\hline FSB $106 C$ & 5818.13 & 6542.73 & 156 & 166 & 201.3 & 200.7 & -0.6 \\
\hline FSB 107C & 6107.21 & 7620.28 & 150.8 & 160.8 & 210 & 209.5 & -0.5 \\
\hline FSB $110 \mathrm{C}$ & 5328.25 & $6 \overline{4} 39.22$ & $1 \overline{3} \overline{7} . \overline{2}$ & 147.2 & 201 & 199.9 & -1.1 \\
\hline FSB $111 \mathrm{C}$ & 6425.93 & 7891.78 & 159 & 169 & 212.1 & 211.8 & -0.3 \\
\hline FSBI $12 \mathrm{C}$ & 3994.42 & 6193.33 & 129.1 & 139.1 & 202.1 & 194.4 & -7.7 \\
\hline FSB $113 \mathrm{C}$ & 6247.68 & 6603.98 & 154 & 164 & 202.6 & 200.5 & -2.1 \\
\hline FSB 114C & 6942.05 & 7904.57 & 158 & 168 & 213.7 & 213.2 & -0.5 \\
\hline FSB $120 \mathrm{C}$ & 4087.58 & 7564.97 & 150.7 & 160.7 & 206.4 & 201.4 & -5 \\
\hline FSB $121 \mathrm{C}$ & 3428.08 & 7021.88 & 148.4 & 158.4 & 204.6 & 197 & -7.6 \\
\hline FSB $123 \mathrm{C}$ & 6815.01 & 7139.64 & 155.3 & 165.3 & 210.6 & 207 & -3.6 \\
\hline HAA $1 B$ & 18771.25 & 4881.64 & 119.3 & 129.3 & 251.4 & 255.4 & 4 \\
\hline HAA $1 \mathrm{C}$ & 18779.34 & 4877.22 & 147.4 & 157.4 & 251.9 & 255.5 & 3.6 \\
\hline HAA $2 B$ & 16879.03 & 5566.39 & 127.2 & 137.2 & 252.9 & 251 & -1.9 \\
\hline HAA $2 \mathrm{C}$ & 16869.58 & 5569.49 & 171.9 & 181.9 & 254.1 & 251.2 & -2.9 \\
\hline HAA $3 B$ & 15706.07 & 5846.43 & 125.9 & 135.9 & 240.1 & 243.4 & 3.3 \\
\hline HAA $3 \mathrm{C}$ & 15698.7 & 5828.2 & 163.3 & 173.3 & 243.3 & 244 & 0.7 \\
\hline HAA 4B & 17239.71 & 6959.31 & 124.5 & 135 & 250 & 247.9 & -2.1 \\
\hline HAA $4 \mathrm{C}$ & 17229.88 & 6957.43 & 158.3 & 168.3 & 251.3 & 248 & -3.3 \\
\hline HAA $6 \mathrm{~B}$ & 19329.25 & 6603.48 & 131.3 & 141.4 & 235.4 & 248.2 & 12.8 \\
\hline HAA $6 \mathrm{C}$ & 19339.09 & 6605.77 & 161.1 & 171.1 & 235.6 & 248.2 & 12.6 \\
\hline $\mathrm{HC} \quad 2 \mathrm{C}$ & 17293.89 & 6522.13 & 135.7 & 140.7 & 253.7 & 250.2 & -3.5 \\
\hline $\mathrm{HC} \quad 2 \mathrm{D}$ & 17288.02 & 6520.88 & 178.2 & 183.2 & 255.8 & 250.5 & -5.3 \\
\hline $\mathrm{HC} \quad 4 \mathrm{~A}$ & 18834.31 & 6667.58 & 150 & 155 & 244.7 & 249.1 & 4.4 \\
\hline $\mathrm{HC} \quad 6 \mathrm{~A}$ & 17401.68 & 6919.21 & 156.2 & 161.2 & 252.2 & 248.4 & -3.8 \\
\hline $\mathrm{HC} \quad 8 \mathrm{C}$ & 14341.29 & 11722.28 & 187.3 & 192.3 & 197.5 & 203 & 5.5 \\
\hline $\mathrm{HC} \quad 10 \mathrm{~B}$ & 16192.68 & 10395.11 & 164.8 & 169.8 & 208.9 & 212.6 & 3.7 \\
\hline $\mathrm{HC} \quad 12 \mathrm{~B}$ & 14670.69 & 7398.79 & 177.3 & 182.3 & 240.8 & 236.5 & -4.3 \\
\hline HMD 1D & 11057.73 & 12299.5 & 199.7 & 219.7 & 209.9 & 211.4 & 1.5 \\
\hline HMD 2D & 11153.44 & 13274.82 & 190.8 & 210.8 & 201 & 199.3 & -1.7 \\
\hline $\mathrm{HMD} 3 \mathrm{D}$ & 11636.66 & 13288.48 & 187.7 & 207.7 & 200.5 & 197.5 & -3 \\
\hline HMD 4D & 12157.24 & 12971.49 & 188.9 & 208.9 & 199.9 & 198.7 & -1.2 \\
\hline HSB 65B & 13798.74 & 6455.59 & 123.3 & 133.3 & 224.4 & 231.5 & 7.1 \\
\hline HSB $68 B$ & 12466.77 & 5231.82 & 123.5 & 134.5 & 216.8 & 216 & -0.8 \\
\hline HSB $68 \mathrm{C}$ & 12457.87 & 5228.49 & 168.4 & 179.5 & 217.9 & 216.2 & -1.7 \\
\hline HSB 70C & 11143.52 & 6046.29 & 164.9 & 174.9 & 223.2 & 217.7 & -5.5 \\
\hline HSB $71 \mathrm{C}$ & 10622.32 & 6210.83 & 171.9 & 181.9 & 222.8 & 215.1 & -7.7 \\
\hline HSB 83B & 14118.42 & 5699.53 & 121.2 & 132.1 & 222.8 & 230.9 & 8.1 \\
\hline HSB $83 C$ & 14138.45 & 5701.03 & 160.2 & 171.2 & 224.7 & 231.1 & 6.4 \\
\hline HSB 84B & 11932.47 & 5197.78 & 121.8 & 132.9 & 210.8 & 213.1 & 2.3 \\
\hline HSB 84C & 11941.29 & 5193.32 & 170.9 & 181.8 & 213.8 & 213.3 & -0.5 \\
\hline HSB 85B & 14022.04 & 7876.77 & 133.2 & 143.2 & 233.7 & 233.6 & -0.1 \\
\hline HSB 86B & 11374.79 & 6015.4 & 113.8 & 124 & 221.7 & 217.9 & -3.8 \\
\hline HSB $100 \mathrm{C}$ & 14234.42 & 6171.56 & 153 & 163 & 226.7 & 233.5 & 6.8 \\
\hline $\mathrm{HSB} 101 \mathrm{C}$ & 14052.39 & 6055.89 & 166.3 & 176.3 & 225.4 & 232 & 6.6 \\
\hline
\end{tabular}


Table C.2-2 Measured and Simulated Head Data in the "Lower" Zone of the Upper Three Runs Aquifer Unit

\begin{tabular}{|c|c|c|c|c|c|c|c|}
\hline Well ID & $\begin{array}{l}\text { Model } x \\
\text { (feet) }\end{array}$ & $\begin{array}{l}\text { Model y } \\
\text { (feet) }\end{array}$ & $\begin{array}{c}\text { Screen } \\
\text { bottom } \\
\text { (feet amsl) }\end{array}$ & $\begin{array}{l}\text { Screen top } \\
\text { (feet amsl) }\end{array}$ & $\begin{array}{c}\text { Measured } \\
\text { head } \\
\text { (feet amsl) }\end{array}$ & $\begin{array}{c}\text { Simulated } \\
\text { head } \\
\text { (feet amsl) }\end{array}$ & $\begin{array}{c}\text { Difference } \\
\text { (feet) }\end{array}$ \\
\hline HSB $102 \mathrm{C}$ & 13860.85 & 5972.45 & 166.7 & 176.7 & 224.6 & 230.5 & 5.9 \\
\hline HSBl03C & 13862.55 & 5598.43 & 159.2 & 169.2 & 223.4 & 228.5 & 5.1 \\
\hline HSB104C & 13671.96 & 5335.96 & 163.5 & 173.5 & 220.7 & 225.3 & 4.6 \\
\hline HSB105C & 13462.84 & 5363.59 & 152.2 & 162.2 & 219.6 & 224.1 & 4.5 \\
\hline HSB $106 \mathrm{C}$ & 13178.73 & 5582.91 & 158.7 & 168.7 & 221.7 & 224 & 2.3 \\
\hline $\mathrm{HSB} 107 \mathrm{C}$ & 12968.69 & 5515.37 & 159.3 & 169.3 & 219.3 & 222.2 & 2.9 \\
\hline HSB $109 \mathrm{C}$ & 12446.86 & 5390.44 & 168.4 & 178.4 & 218.9 & 218.1 & -0.8 \\
\hline HSB110C & 12217.01 & 5438.2 & 171.4 & 181.4 & 219.2 & 217.5 & -1.7 \\
\hline $\mathrm{HSB} 111 \mathrm{C}$ & 12012.99 & 5538.06 & 140.7 & 150.7 & 220.4 & 217 & -3.4 \\
\hline $\mathrm{HSB} 112 \mathrm{C}$ & 11881.06 & 5752.31 & 140.6 & 150.6 & 221.7 & 218.2 & -3.5 \\
\hline HSB1 13C & 11597.26 & 5851.37 & 151.7 & 161.7 & 222.1 & 218.2 & -3.9 \\
\hline HSB 1 15C & 11411.74 & 6160.46 & 182.8 & 192.8 & 224.4 & 220.8 & -3.6 \\
\hline $\mathrm{HSB} 1 \mathrm{16C}$ & 11309.99 & 6378.97 & 180.5 & 190.5 & 225.3 & 221.7 & -3.6 \\
\hline $\mathrm{HSB} 117 \mathrm{C}$ & 10532.49 & 6063.02 & 165.1 & 175.1 & 221.8 & 212.8 & -9 \\
\hline $\mathrm{HSB} 125 \mathrm{C}$ & 14144.64 & 5566.07 & 145.6 & 155.6 & 223.3 & 230.5 & 7.2 \\
\hline $\mathrm{HSB} 127 \mathrm{C}$ & 12444.32 & 4904.6 & 148.4 & 158.4 & 210.2 & 212.2 & 2 \\
\hline HSB 129C & 10670.01 & 5161.61 & 147.8 & 157.8 & 205.6 & 205.4 & -0.2 \\
\hline HSB133C & 14558.13 & 6109.82 & 173.3 & 183.3 & 230.5 & 235.4 & 4.9 \\
\hline HSB 134C & 13909.34 & 5216.2 & 149.1 & 159.1 & 220.8 & 226.4 & 5.6 \\
\hline HSB135C & 12180.62 & 5032.67 & 147.3 & 157.3 & 206.6 & 212.4 & 5.8 \\
\hline HSB $136 \mathrm{C}$ & 11476.73 & 5404.55 & 160.5 & 170.5 & 217.4 & 213.1 & -4.3 \\
\hline HSB137C & 11155.93 & 5714.22 & 163.8 & 173.8 & 220.3 & 214.5 & -5.8 \\
\hline HSB139C & 13030.68 & 4947.14 & 148.5 & 158.5 & 214.4 & 216.4 & 2 \\
\hline $\mathrm{HSB} 141 \mathrm{C}$ & 14773.23 & 5385.92 & 154.7 & 164.7 & 228.9 & 235.2 & 6.3 \\
\hline HSB 142C & 8832.46 & 6088.42 & 161.6 & 171.6 & 198.2 & 199.5 & 1.3 \\
\hline HSB143C & 7987.62 & 6541.87 & 169.1 & 179.1 & 209.4 & 202.9 & -6.5 \\
\hline HSB $145 \mathrm{C}$ & 13422.99 & 4998.93 & 164.7 & 174.7 & 213.3 & 220.2 & 6.9 \\
\hline HSB146C & 14242.12 & 4531.73 & 152.3 & 162.3 & 209.9 & 225.9 & 16 \\
\hline HSB151C & 9356.1 & 6075.92 & 170.6 & 180.6 & 207.8 & 204.5 & -3.3 \\
\hline $\mathrm{HSB} 152 \mathrm{C}$ & 9885.63 & 5180.55 & 173.1 & 183.1 & 198.9 & 200.4 & 1.5 \\
\hline NBG 4 & 8427.66 & 11955.57 & 196.1 & 227.5 & 217 & 217.6 & 0.6 \\
\hline NBG 5 & 8609.72 & 11995.59 & 194.9 & 226.4 & 217.7 & 217 & -0.7 \\
\hline P $27 \mathrm{C}$ & 19669.65 & 5603.71 & 139.6 & 144.6 & 243.6 & 252.8 & 9.2 \\
\hline SBG 1 & 18540.45 & 9685.84 & 190.7 & 220.7 & 237.8 & 237.7 & -0.1 \\
\hline YSC $1 \mathrm{C}$ & 19859.25 & 13612.64 & 197.5 & 207.5 & 217.1 & 216.4 & -0.7 \\
\hline YSC 2D & 20100.53 & 13801.12 & 197.9 & 218 & 216.5 & 216.3 & -0.2 \\
\hline YSC $4 C$ & 20138.84 & 12520.4 & 195.9 & 205.9 & 227.4 & 224.5 & -2.9 \\
\hline ZBG 2 & 21860.39 & 11977.26 & 210.9 & 230.9 & 221.7 & 217.7 & -4 \\
\hline $\mathrm{ZW} \quad 2$ & 8120.06 & 13688.89 & 194.8 & 204.8 & 207.3 & 197.4 & -9.9 \\
\hline
\end{tabular}

a Large negative residuals occur when the simulated head is below the well screen. In these cases, the FACT code does not compute head (denoted by a zero value in the simulated head column) and the computed residual becomes the negative of the measured head. These residual values are ignored in computing summary statistics (i.e., r.m.s. head). 
Table C.2-3 Measured and Simulated Head Data in the Gordon Aquifer Unit

\begin{tabular}{|c|c|c|c|c|c|c|c|}
\hline Well ID & $\begin{array}{c}\text { Model } x \\
\text { (feet) }\end{array}$ & $\begin{array}{c}\text { Model y } \\
\text { (feet) }\end{array}$ & $\begin{array}{c}\text { Screen } \\
\text { bottom } \\
\text { (feet amsl) }\end{array}$ & $\begin{array}{l}\text { Screen top } \\
\text { (feet amsl) }\end{array}$ & $\begin{array}{c}\text { Measured } \\
\text { head } \\
\text { (feet amsl) }\end{array}$ & $\begin{array}{c}\text { Simulated } \\
\text { head } \\
\text { (feet amsl) }\end{array}$ & $\begin{array}{l}\text { Difference } \\
\text { (feet) }\end{array}$ \\
\hline BGO $8 \mathrm{~A}$ & 12138.28 & 10318.17 & 105.3 & 115.3 & 161 & 155.7 & -5.3 \\
\hline BGO $8 \mathrm{AR}$ & 12131.3 & 10347.15 & 94.6 & 104.6 & 161.1 & 155.6 & -5.5 \\
\hline BGO 9AA & 11812.71 & 10664.75 & 73.8 & 83.8 & 157.9 & 154.1 & -3.8 \\
\hline$B G O 14 \mathrm{~A}$ & 10437 & 9760.77 & 109.6 & 119.6 & 157.8 & 155.1 & $-2.7^{-}$ \\
\hline BGO 14AR & 10394.02 & 9725.36 & 96.8 & 106.8 & 158.9 & 155.2 & -3.7 \\
\hline BGO $16 \mathrm{~A}$ & 10914.13 & 9227.82 & 102.5 & 112.5 & 160.7 & 157.3 & -3.4 \\
\hline BGO I6AR & 10939.4 & 9219.09 & 103.7 & 113.7 & 161 & 157.4 & -3.6 \\
\hline BGO 18A & 11441.24 & 9179.26 & 99.5 & 109.5 & 161 & 158.3 & -2.7 \\
\hline BGO 25A & 10316.05 & 9511.17 & 104.1 & 114.1 & 160.6 & 155.7 & -4.9 \\
\hline BGO 26A & 9679.33 & 9361.62 & 81 & 91 & 160.1 & 155.2 & -4.9 \\
\hline BGO 29A & 8910.07 & 8600.45 & 102.5 & 112.5 & 159.5 & 156.2 & -3.3 \\
\hline BGO 41A & 9992.76 & 9760.4 & 103.3 & 113.3 & 158.2 & 154.5 & -3.7 \\
\hline BGO 43A & 10700.83 & 10516.03 & 105.9 & 115.9 & 159.4 & 153.2 & -6.2 \\
\hline BGO 43AA & 10714.74 & 10523.69 & 62.2 & 72.2 & 156.7 & 153.2 & -3.5 \\
\hline BGO 44A & 12327.38 & 10548.72 & 98 & 108 & 158.4 & 155.2 & -3.2 \\
\hline BGO 44AA & 12355.67 & 10556.57 & 61.2 & 71.3 & 158.5 & 155.2 & -3.3 \\
\hline BGO 45A & 9290.78 & 8957.4 & 116.9 & 126.9 & 160.7 & 155.8 & -4.9 \\
\hline $\mathrm{BGO} 47 \mathrm{~A}$ & 9875.68 & 7955.92 & 86.8 & 96.8 & 162.4 & 159.3 & -3.1 \\
\hline BGO 49A & 11310.3 & 7416.41 & 75.1 & 85.1 & 166.8 & 163.2 & -3.6 \\
\hline BGO 50A & 9059.3 & 8265.35 & 90.5 & 100.5 & 160 & 157.3 & -2.7 \\
\hline BGX IA & 13034.48 & 10777.43 & 114.1 & 124.1 & 159.1 & 155.4 & -3.7 \\
\hline$B G X \quad 4 A$ & 11471.98 & 11516.01 & 106.8 & 116.8 & 155.1 & 150.8 & -4.3 \\
\hline $\mathrm{FC} \quad 1 \mathrm{~A}$ & 7089.9 & 12409.76 & 96.7 & 101.7 & 143.5 & 142.1 & -1.4 \\
\hline $\mathrm{FC} \quad 3 \mathrm{~B}$ & 11700.81 & 12432.11 & 61.2 & 66.2 & 150.6 & 148.2 & -2.4 \\
\hline $\mathrm{FC} \quad 3 \mathrm{C}$ & 11709.65 & 12434.29 & 121 & 126 & 151.8 & 147.9 & -3.9 \\
\hline $\mathrm{FC} \quad 4 \mathrm{C}$ & 7324.74 & 15108.45 & 116.3 & 121.3 & 137.6 & 135.1 & -2.5 \\
\hline FSB 76A & 6138.53 & 8596.02 & 36.9 & 47.4 & 155 & 150.5 & -4.5 \\
\hline FSB 76B & 6142.85 & 8587.22 & 99.2 & 109.7 & 151.5 & 150.7 & -0.8 \\
\hline FSB 78A & 5232.08 & 6998.44 & 27 & 37.5 & 155.9 & 152.4 & -3.5 \\
\hline FSB 78B & 5236.24 & 7007.71 & 82.4 & 92.8 & 154.3 & 153.1 & -1.2 \\
\hline FSB 79A & 5436.67 & 5924.31 & 24 & 34.4 & 158 & 155.6 & -2.4 \\
\hline FSB 79B & 5445.73 & 5927.87 & 80.7 & 91.2 & 158 & 157.4 & -0.6 \\
\hline FSB 87A & 5000.84 & 7812.15 & 33.1 & 43.6 & 153.8 & 149.9 & -3.9 \\
\hline FSB 87B & 4991.16 & 7805.28 & 90 & 100.5 & 150.6 & 150.2 & -0.4 \\
\hline FSB 96A & 4820.7 & 7038.28 & 85.7 & 95.7 & 152.1 & 152.1 & 0 \\
\hline FSB 96AR & 4782.51 & 7063.6 & 79 & 89 & 153.3 & 151.9 & -1.4 \\
\hline FSB 97A & 4943.53 & 7359.85 & 85.8 & 95.8 & 152.1 & 151.4 & -0.7 \\
\hline FSB 98A & 5050.57 & 7606.08 & 84.7 & 94.7 & 150.4 & 150.9 & 0.5 \\
\hline FSB 98AR & 5040.9 & 7575.61 & 82.1 & 92.1 & 151.8 & 151 & -0.8 \\
\hline FSB 99A & 5180.13 & 7925.81 & 92.9 & 102.9 & 150.5 & 150.3 & -0.2 \\
\hline FSB $100 A$ & 5839.02 & 7921.51 & 95.8 & 105.8 & 151.3 & 151.8 & 0.5 \\
\hline FSB $101 \mathrm{~A}$ & 6028.45 & 8150.49 & 92.9 & 102.9 & 151.6 & 151.6 & 0 \\
\hline FSB $112 \mathrm{~A}$ & 4007.6 & 6200 & 81 & 91 & 153.5 & 153 & -0.5 \\
\hline FSB $113 \mathrm{~A}$ & 6230.52 & 6607.28 & 81 & 91.3 & 158.9 & 156.9 & -2 \\
\hline FSB114A & 6952.72 & 7915.93 & 95.2 & 105 & 155.6 & 154.3 & -1.3 \\
\hline
\end{tabular}


Table C.2-3 Measured and Simulated Head Data in the Gordon Aquifer Unit

\begin{tabular}{|c|c|c|c|c|c|c|c|}
\hline Well ID & $\begin{array}{c}\text { Model } x \\
(\text { feet })\end{array}$ & $\begin{array}{c}\text { Model y } \\
\text { (feet) }\end{array}$ & $\begin{array}{c}\text { Screen } \\
\text { bottom } \\
\text { (feet amsl) }\end{array}$ & $\begin{array}{l}\text { Screen top } \\
\text { (feet amsl) }\end{array}$ & $\begin{array}{c}\text { Measured } \\
\text { head } \\
\text { (feet amsl) }\end{array}$ & $\begin{array}{c}\text { Simulated } \\
\text { head } \\
\text { (feet amsl) }\end{array}$ & $\begin{array}{c}\begin{array}{c}\text { Difference } \\
\text { (feet) }\end{array} \\
\end{array}$ \\
\hline HAA $1 \mathrm{~A}$ & 18761.89 & 4886.7 & 94.9 & 104.9 & 180.8 & 181.6 & 0.8 \\
\hline HAA IAA & 18753.18 & 4891.6 & 13.6 & 23.6 & 180.7 & 180.8 & 0.1 \\
\hline HAA 2A & 16888.38 & 5563.26 & 107.3 & 117.3 & 176.6 & 177.1 & 0.5 \\
\hline HAA $3 \mathrm{~A}$ & 15714.13 & 5866.24 & 96.8 & 106.8 & 175.4 & 174.4 & -1 \\
\hline HAA $4 \mathrm{~A}$ & 17249.56 & 6961.51 & 105.4 & 115.3 & 174.4 & 174.5 & 0.1 \\
\hline HAA 6A & 19319.56 & 6601.93 & 95.6 & 105.6 & . 178.6 & 178.9 & 0.3 \\
\hline HAA $6 \mathrm{AA}$ & 19309.95 & 6600 & 25.8 & 35.8 & 178.3 & 178 & -0.3 \\
\hline $\mathrm{HC} \quad 1 \mathrm{~A}$ & 17295.03 & 6492.72 & 89.5 & 94.5 & 175.8 & 175.5 & -0.3 \\
\hline $\mathrm{HC} \quad 2 \mathrm{~A}$ & 17285.94 & 6530.66 & 72.2 & 77.2 & 175.8 & 175.2 & -0.6 \\
\hline $\mathrm{HC} \quad 2 \mathrm{~B}$ & 17297.59 & 6523.94 & 85.7 & 90.7 & 175 & 175.4 & 0.4 \\
\hline $\mathrm{HC} \quad 8 \mathrm{~B}$ & 14334.09 & 11723.92 & 132.5 & 137.5 & 155.5 & 154.1 & -1.4 \\
\hline $\mathrm{HC} 10 \mathrm{~A}$ & 16185.01 & 10399 & 114 & 117 & 163.3 & 163 & -0.3 \\
\hline HSB $65 \mathrm{~A}$ & 13797.37 & 6445.69 & 62.5 & 73.2 & 171.2 & 170.2 & -1 \\
\hline HSB 68A & 12476.26 & 5235.26 & 47.5 & 58 & 171.6 & 170.9 & -0.7 \\
\hline HSB 69A & 12053.92 & 5168.49 & 83.1 & 93.1 & 171.5 & 171.1 & -0.4 \\
\hline HSB 83A & 14127.51 & 5710.67 & 65.2 & 76 & 173 & 172.5 & -0.5 \\
\hline HSB 84A & 11942.58 & 5182.45 & 64.7 & 75.9 & 171.7 & 170.8 & -0.9 \\
\hline HSB 85A & 14011.82 & 7877.26 & 61.1 & 71.1 & 168.6 & 166.9 & -1.7 \\
\hline HSB 86A & 11383.35 & 6018.45 & 63.1 & 73.9 & 168.4 & 167.5 & -0.9 \\
\hline HSB $117 \mathrm{~A}$ & 10541.01 & 6057.57 & 84.8 & 94.8 & 166.5 & 166.1 & -0.4 \\
\hline HSB 1 18A & 11141.01 & 6147.07 & 91 & 101 & 167.4 & 166.8 & -0.6 \\
\hline HSB119A & 11378.24 & 6592.23 & 93.3 & 103.3 & 166.8 & 165.8 & -1 \\
\hline HSB120A & 11637.7 & 6966.96 & 91 & 101 & 166.1 & 165.1 & -1 \\
\hline $\mathrm{HSB} 121 \mathrm{~A}$ & 12859.37 & 5825.72 & 88.3 & 98.3 & 171.4 & 170.6 & -0.8 \\
\hline $\mathrm{HSB} 122 \mathrm{~A}$ & 13173.78 & 6067.47 & 85.4 & 95.4 & 171.2 & 170.5 & -0.7 \\
\hline HSB $123 \mathrm{~A}$ & 13544.2 & 6139.97 & 93.6 & 103.6 & 171.5 & 170.9 & -0.6 \\
\hline HSB $139 \mathrm{~A}$ & 13022.28 & 4942.9 & 87.6 & 97.6 & 173.3 & 173.1 & -0.2 \\
\hline HSB $141 \mathrm{~A}$ & 14768.25 & 5402.14 & 80.6 & 90.6 & 174.8 & 174.2 & -0.6 \\
\hline HSB I 44A & 11723.85 & 5448.69 & 78.6 & 88.6 & 171.3 & 169.8 & -1.5 \\
\hline HSB $146 \mathrm{~A}$ & 14221.92 & 4534.9 & 85.5 & 95.5 & 176 & 175.7 & -0.3 \\
\hline P 27B & 19662.2 & 5616.64 & 74.8 & 94.8 & 180.9 & 181.4 & 0.5 \\
\hline YSC $1 \mathrm{~A}$ & 19482.17 & 13382.92 & 76.8 & 136.9 & 163.1 & 160.5 & -2.6 \\
\hline YSC $2 \mathrm{~A}$ & 20072.45 & 13786.06 & 134.7 & 144.7 & 162.6 & 160.7 & -1.9 \\
\hline YSC $5 \mathrm{~A}$ & 21919.53 & 10073.35 & 116 & 121 & 180.9 & 178.4 & -2.5 \\
\hline
\end{tabular}




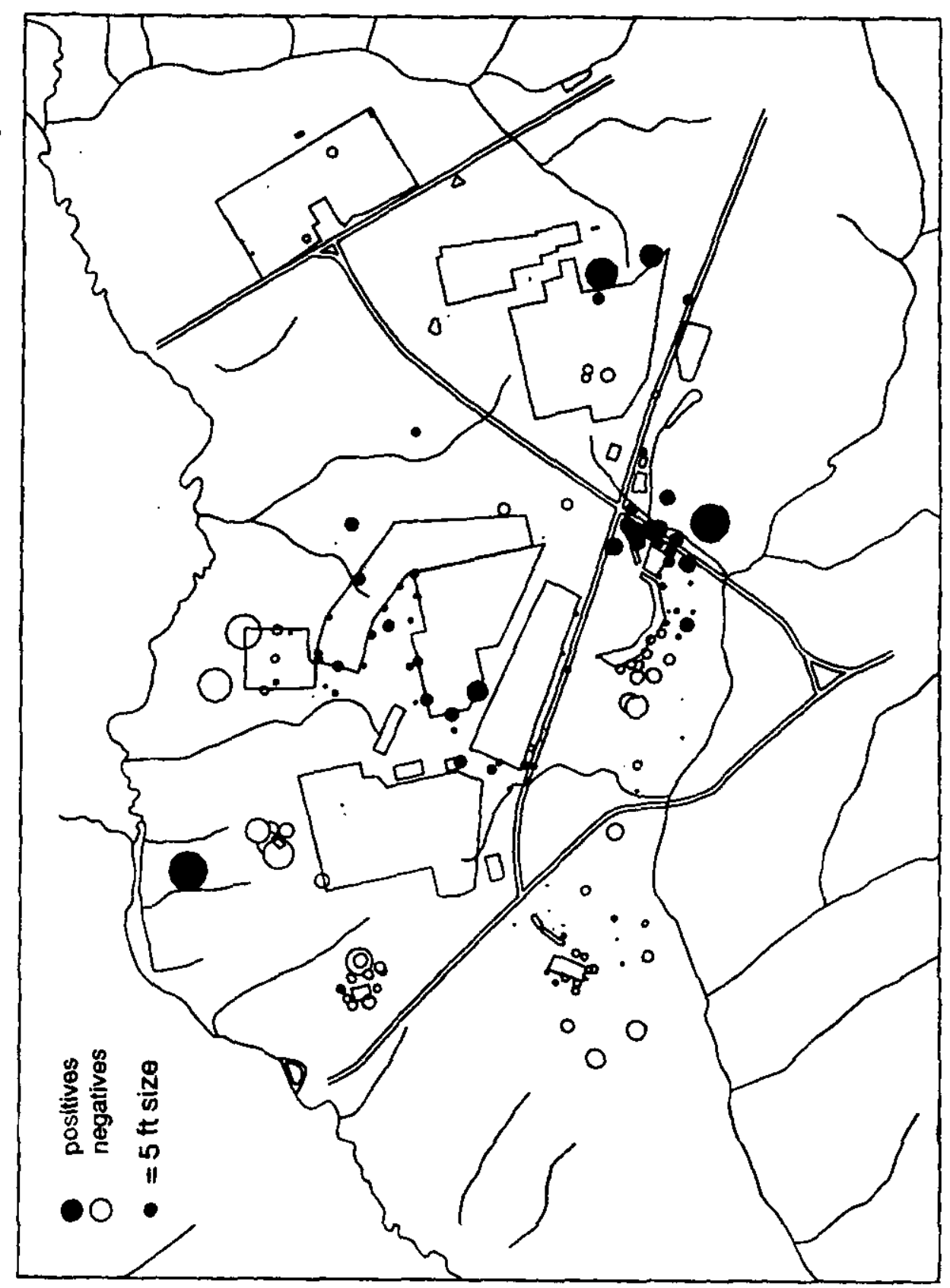

Figure C.2-7 Head residuals in the UTR Aquifer Unit, "Lower" zone 


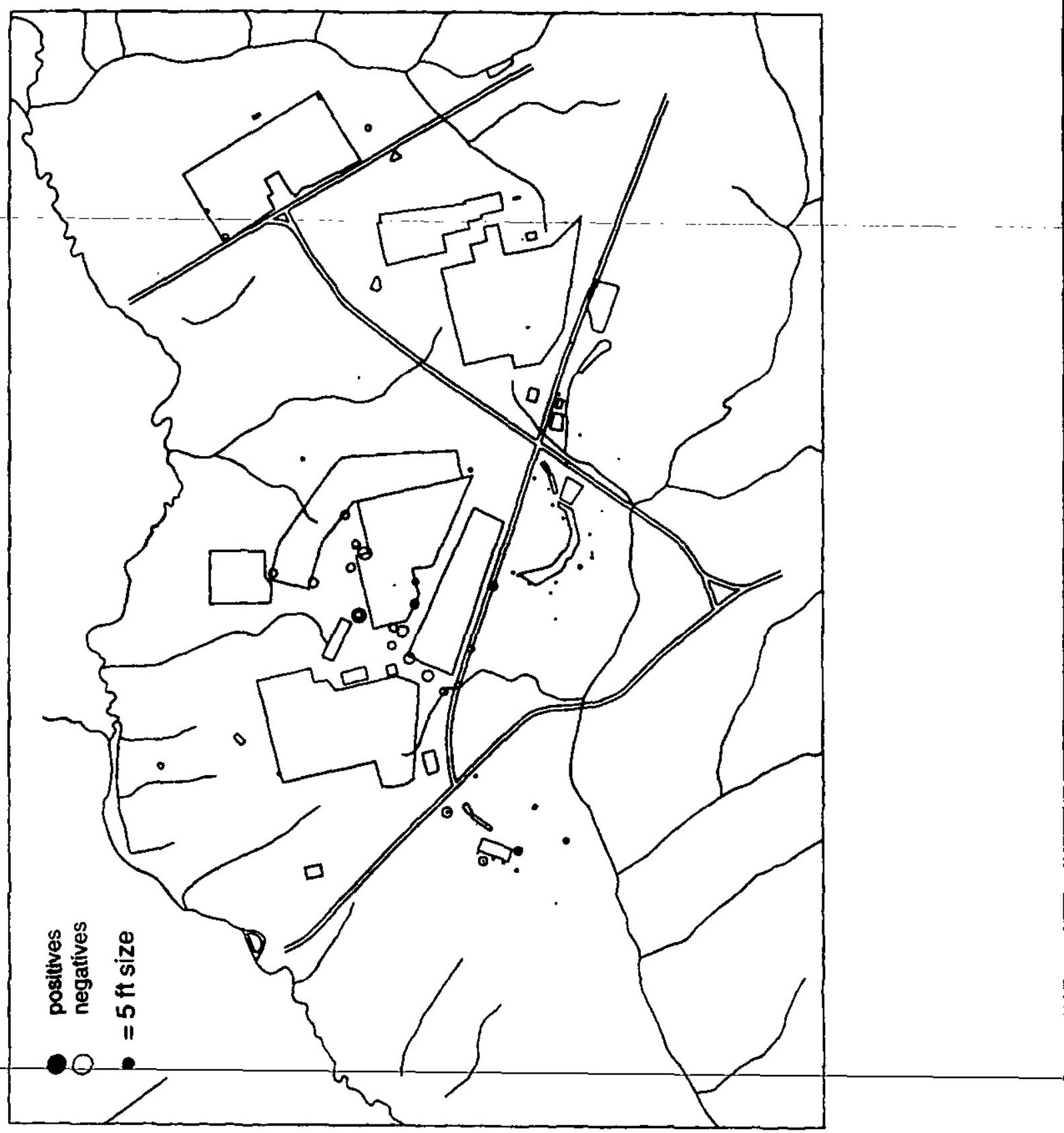

Figure C.2-8 Head residuals in the Gordon Aquifer Unit 


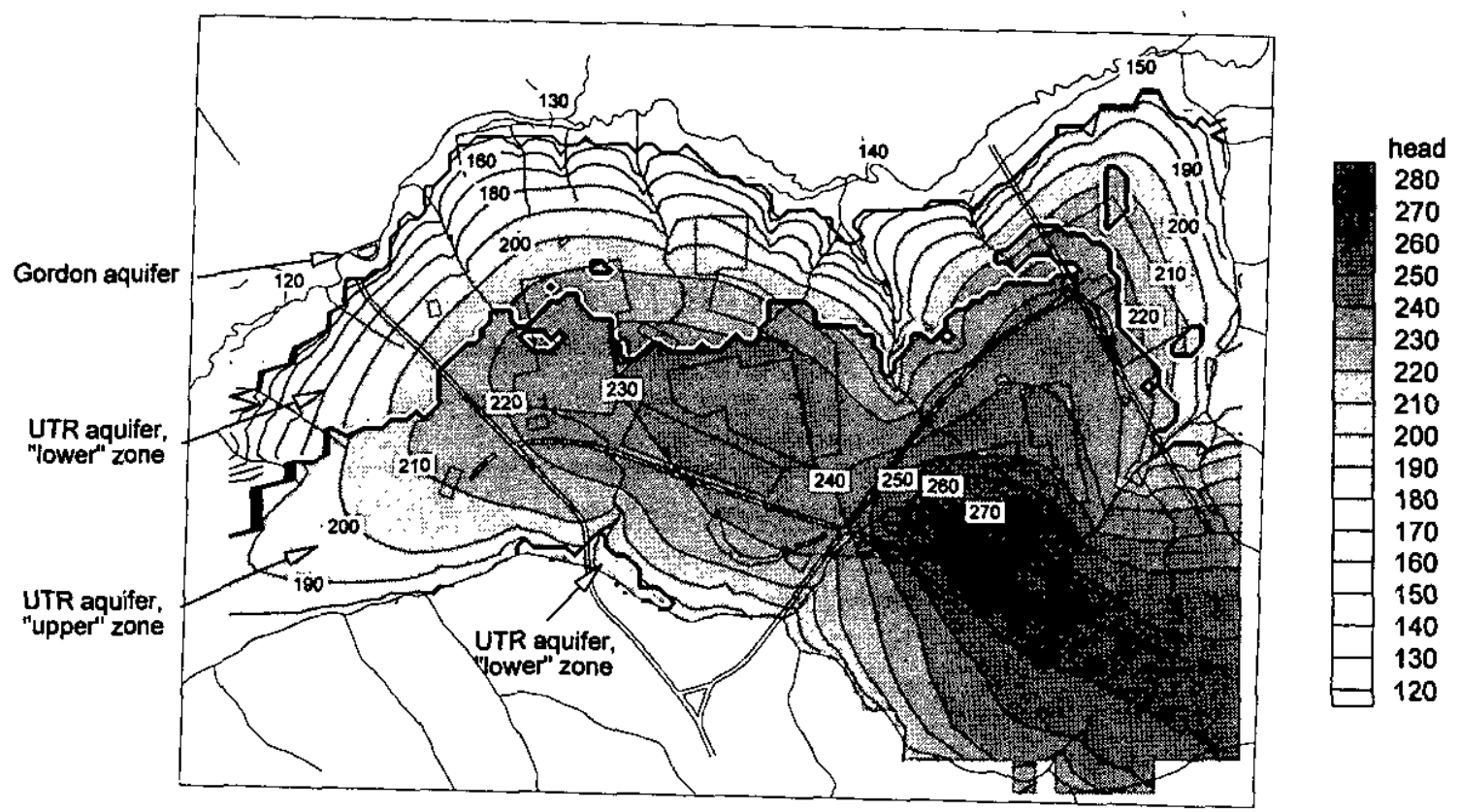

Figure C.2-9 Simulated hydraulic head in the aquifer zone containing the water table 


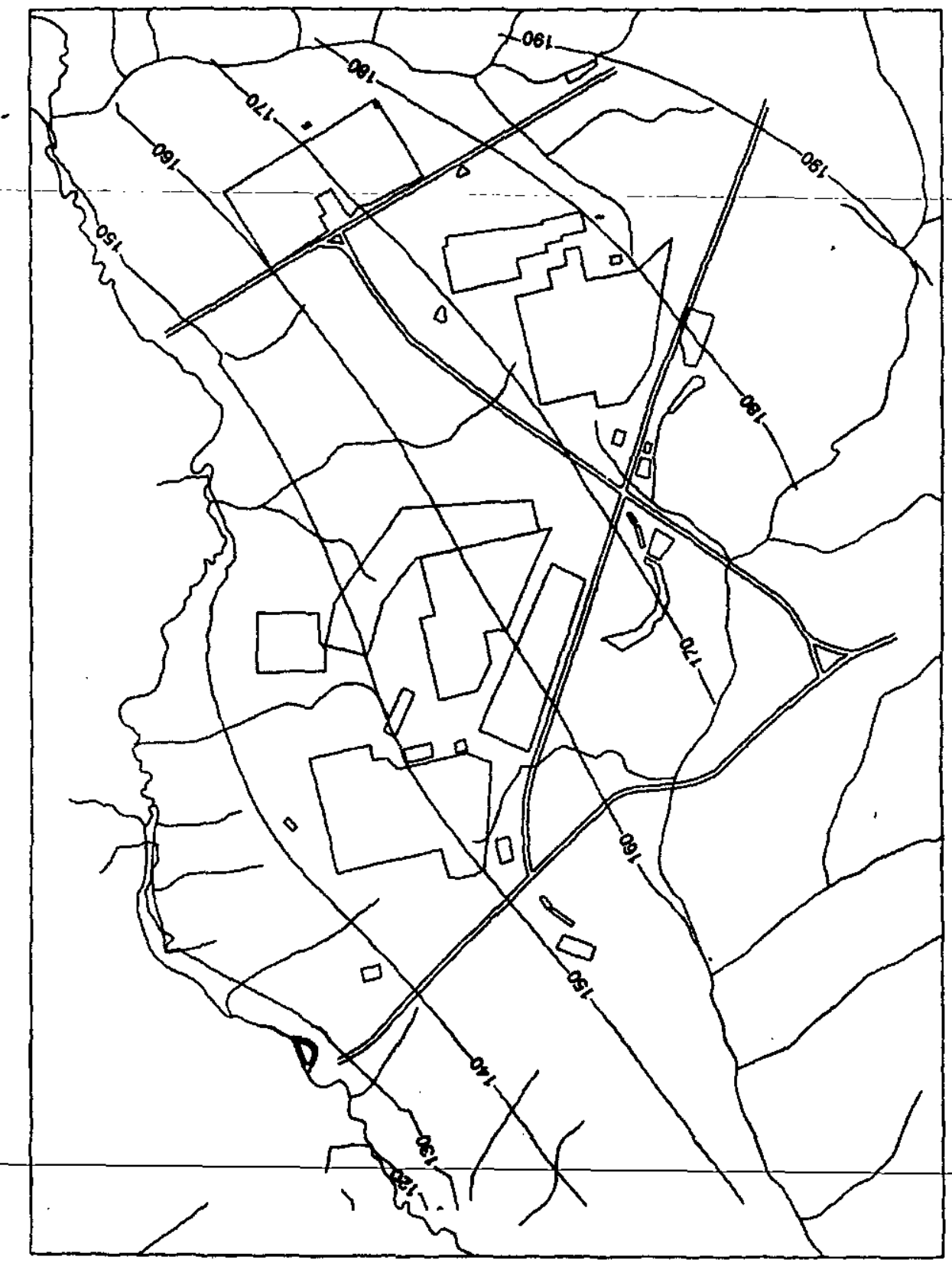

Figure C.2-10 Simulated hydraulic head in the Gordon Aquifer Unit 


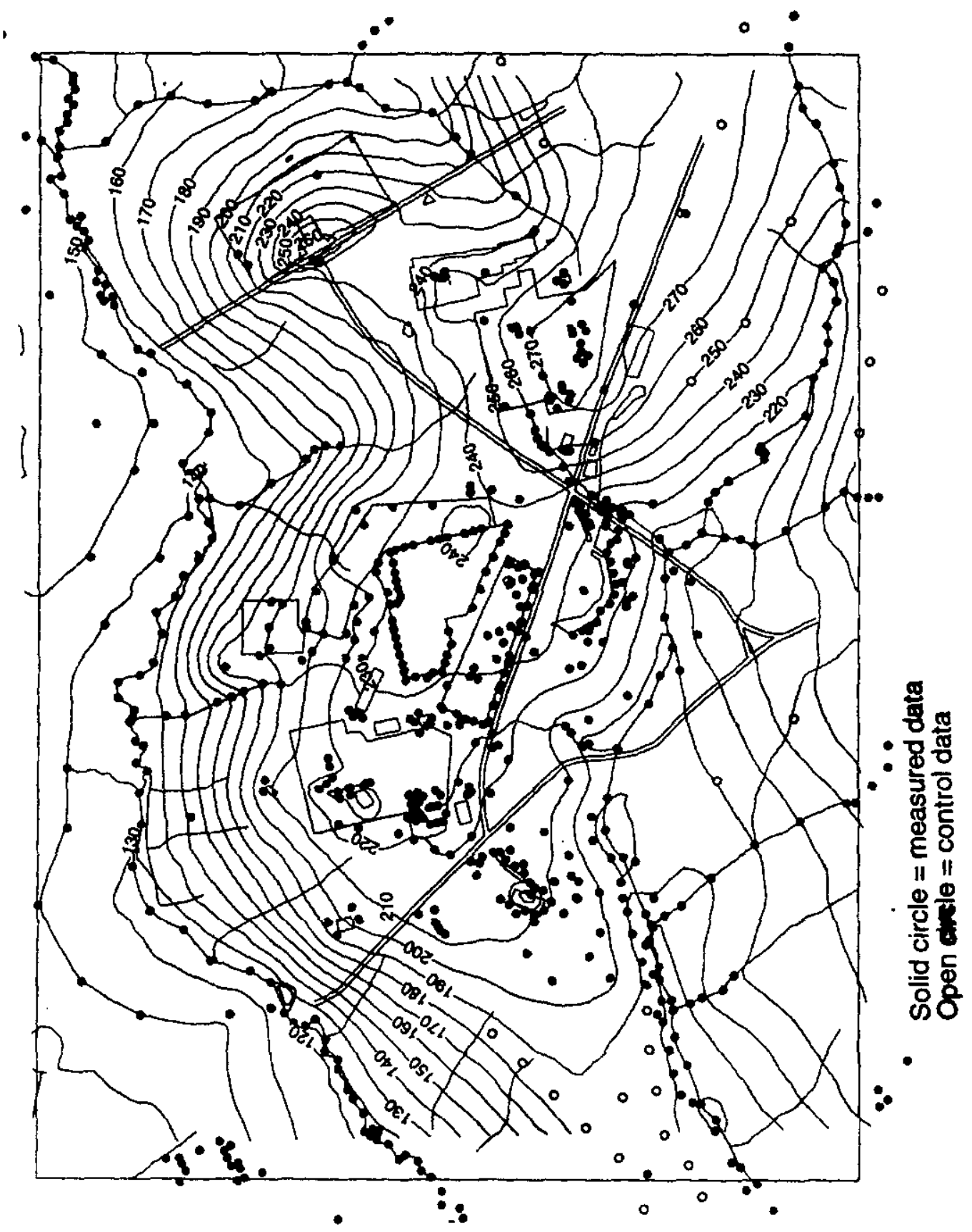

Figure C.2-11 Measured hydraulic head in the aquifer unit containing the water table 


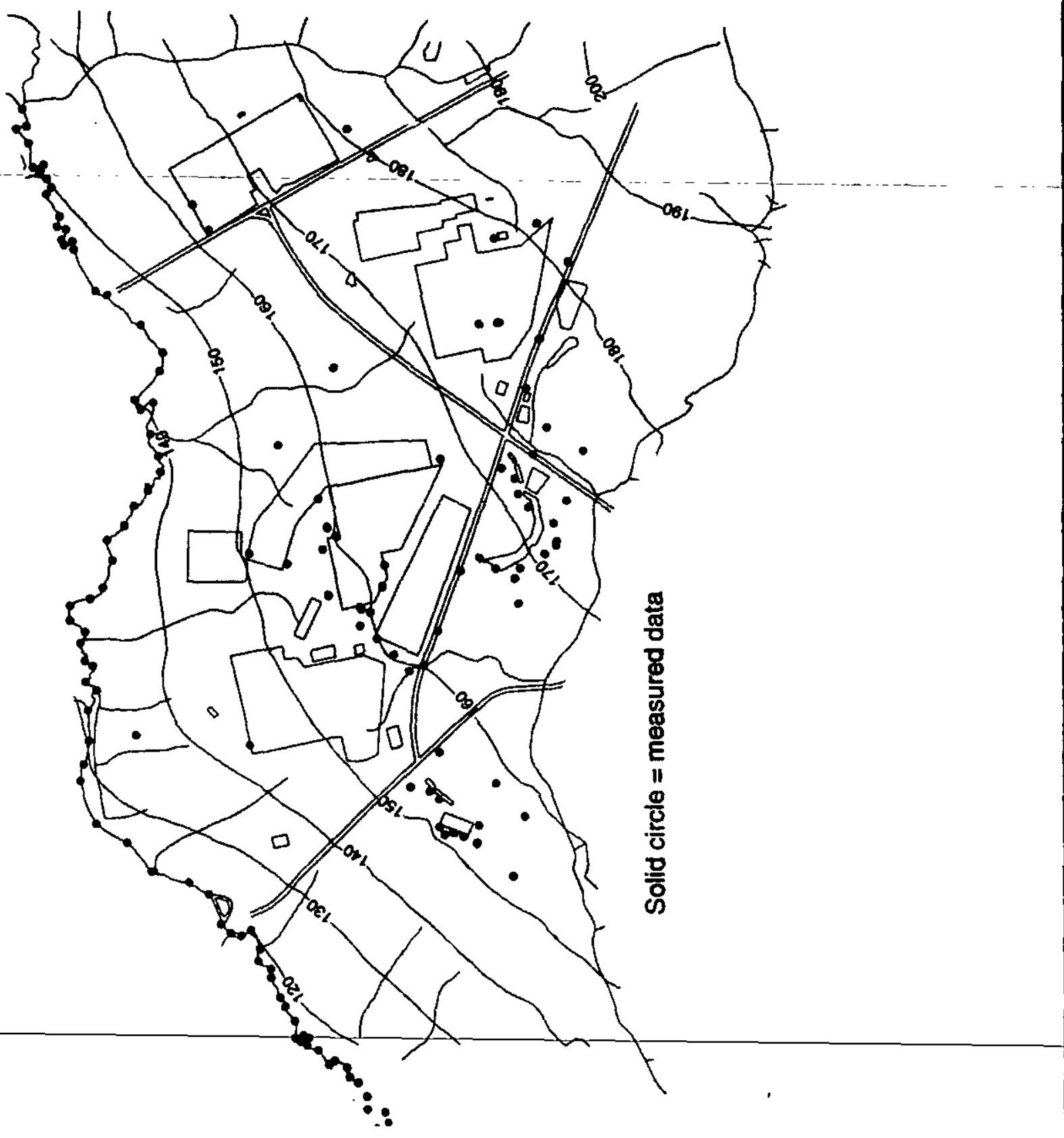

Figure C.2-12 Measured hydraulic head in the Gordon Aquifer Unit 


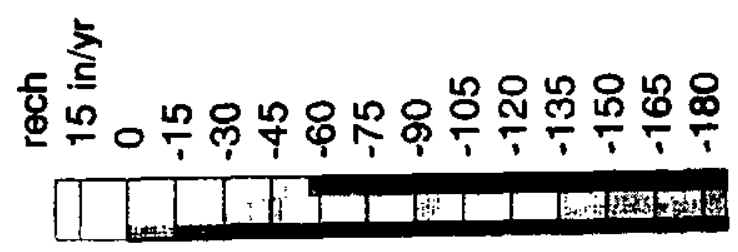

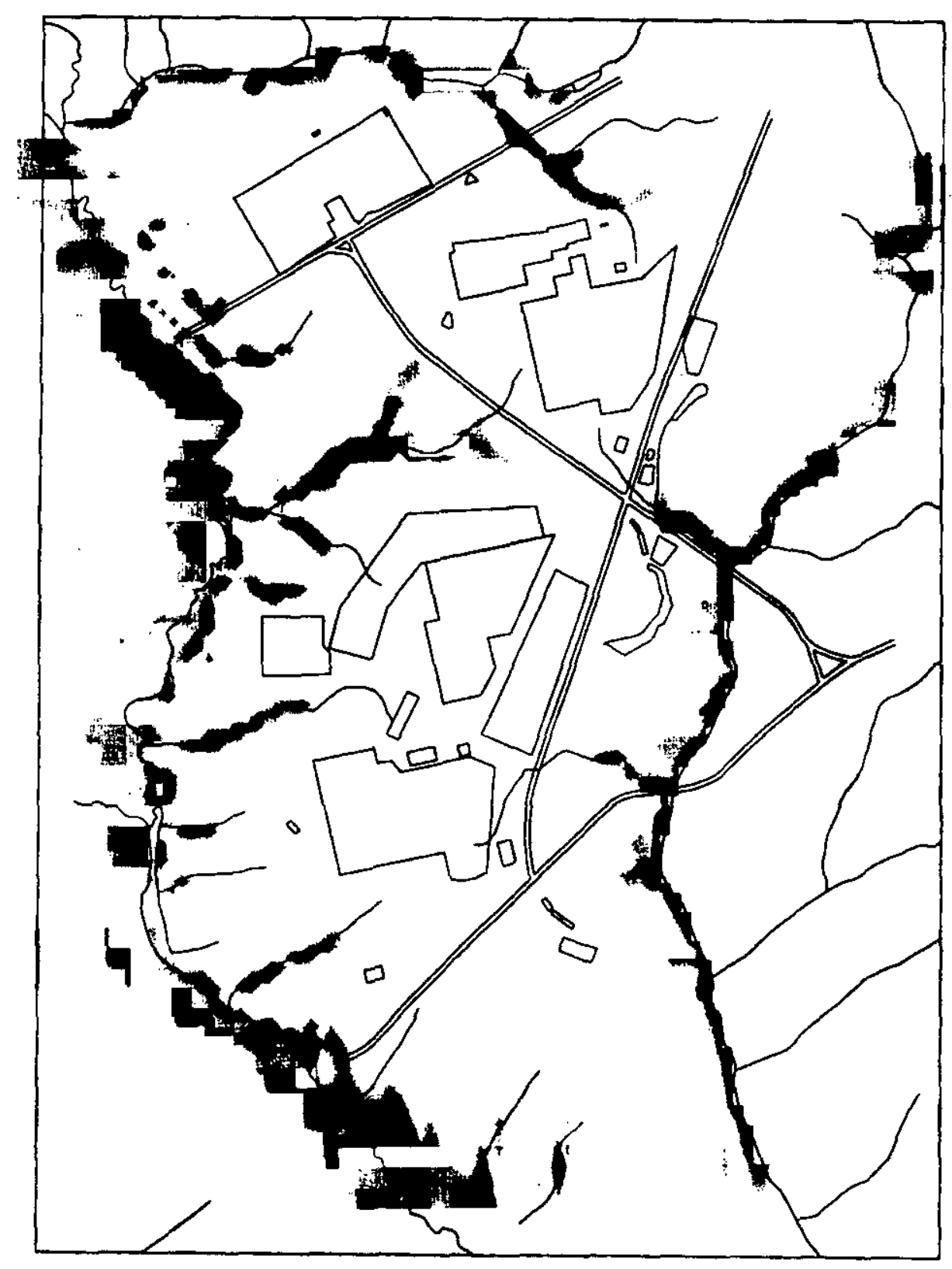

Figure C.2-13 Simulated Groundwater Discharge to Streams 
క.

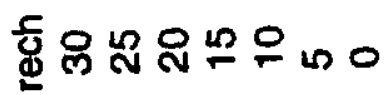
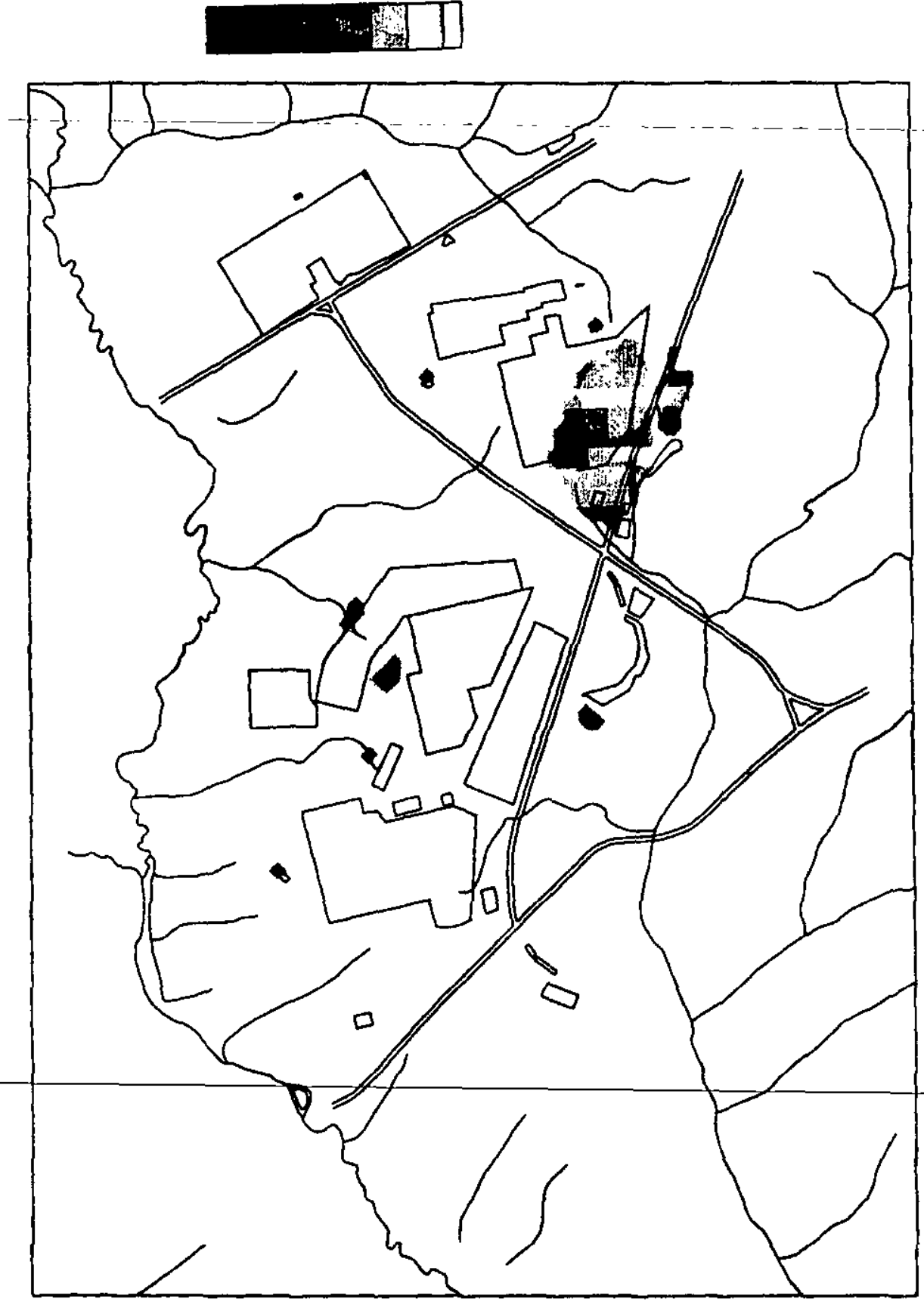

Figure C.2-14 Simulated groundwater recharge from artificial (man-made) sources 


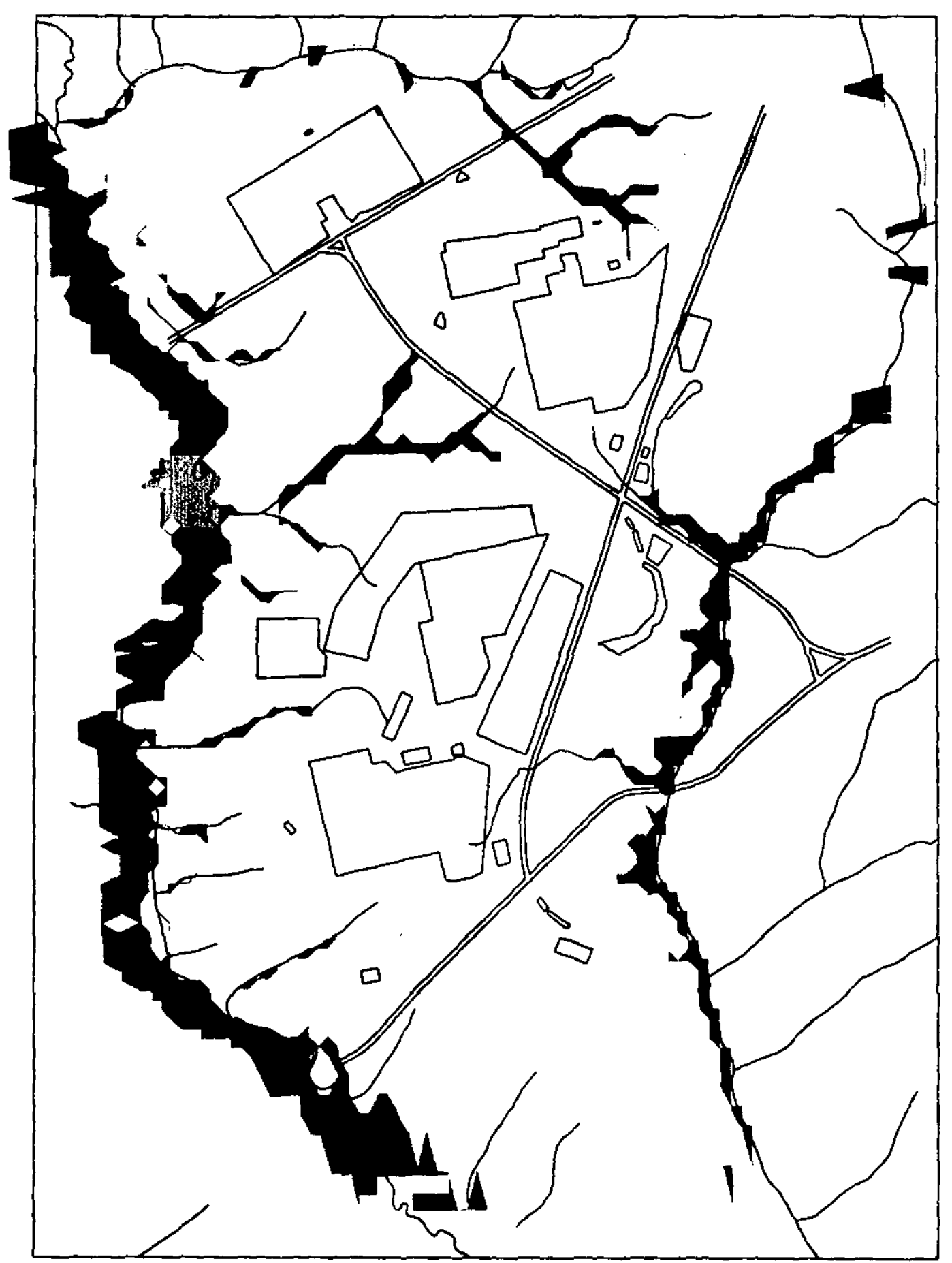

Figure C.2-15 Simulated seepage faces 


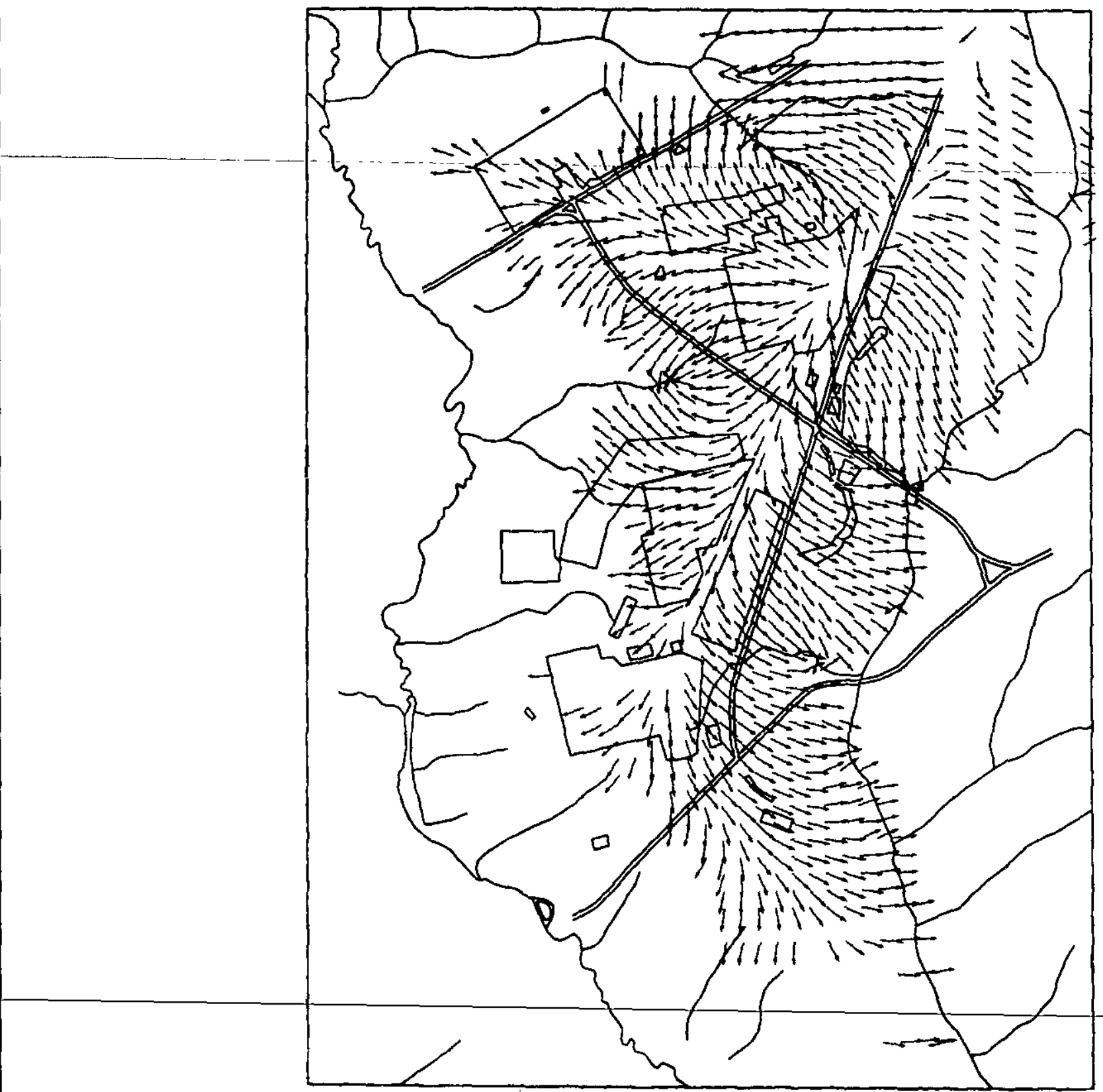

Figure C.2-16 Groundwater flow directions in the UTR Aquifer Unit, "Upper" zone 


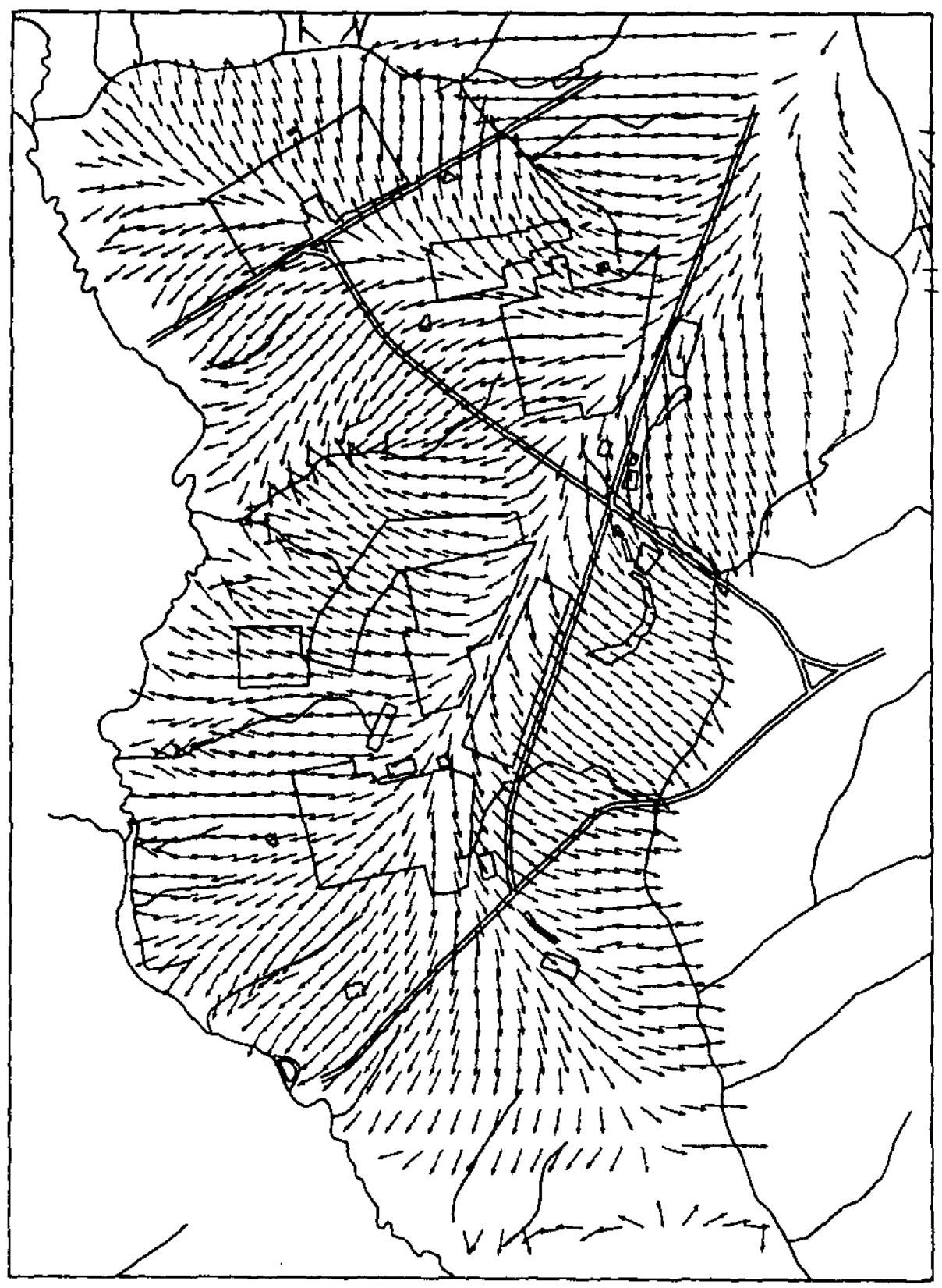

Figure C.2-17 Groundwater flow directions in the UTR Aquifer Unit, "Lower" zone 


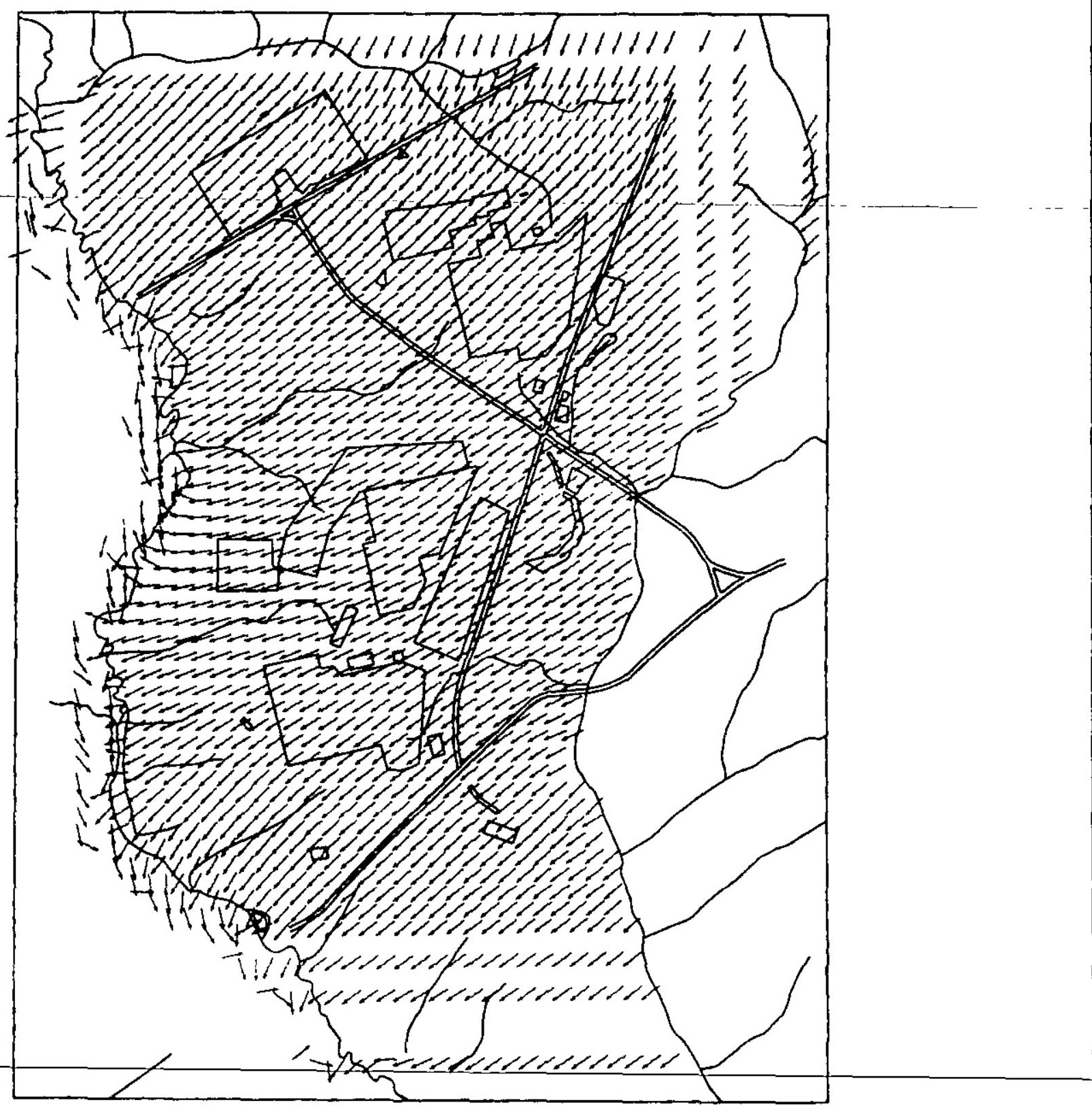

Figure C.2-18 Groundwater flow directions in the Gordon Aquifer Unit 
As indicated in Table C.3-1, some radionuclides included in the dose analyses decay to short-lived radionuclides that are potentially important for at least one exposure pathway. In all such cases, the doses from a parent radionuclide and its short-lived decay products are combined by assuming that the decay products are in secular equilibrium with the parent, and the activity concentrations of the decay products take into account the decay branching fractions given in Table C.3 1. Long-lived decay products that could be significant in the dose analyses (e.g., ${ }^{226} \mathrm{Ra},{ }^{229} \mathrm{Th},{ }^{230} \mathrm{Th}$, and ${ }^{231} \mathrm{~Pa}$ ) also are included in the table. However, these radionuclides are not assumed to be in secular equilibrium with their respective parent radionuclides, because buildup of the activity of decay products occurs over a very long time. Thus, in these cases, the activity of the long-lived decay products over time should be considered explicitly in the dose analyses, as is also the case when a radionuclide produces a longer-lived decay product.

\section{C.3.2 Assumed Exposure Scenarios and Exposure Pathways}

This section briefly describes the exposure scenarios and exposure pathways assumed in the dose analyses for off-site individuals and inadvertent intruders. A more detailed description of the assumed exposure scenarios, including the justification for neglecting other scenarios in the dose analyses, is given in Sect. 6.1. The model equations and parameter values for each exposure pathway then are presented in Sect. C. 3.4 .

\section{C.3.2.1 Exposure Scenarios and Pathways for Off-Site Individuals}

The RPA for the E-Area LLWF assumes that radionuclides are transported to off-site locations principally via the groundwater pathway. Off-site transport via atmospheric releases also was considered (see Sect. 4.3.2).

As described in Sect. 4.2, off-site individuals are assumed to use contaminated groundwater for domestic purposes, and the following exposure pathways involving use of contaminated water are assumed to occur: 1) direct ingestion of the contaminated drinking water; 2) ingestion of milk and meat from dairy and beef cattle that drink contaminated water; 3 ) ingestion of vegetables grown in garden soil irrigated with contaminated water; 4) direct ingestion of contaminated soil in conjunction with intakes of vegetables from the garden; 5) external exposure to contaminated soil while working in the garden; and 6) inhalation of radionuclides suspended into air from contaminated soil while working in the garden. Irrigation of pasture grass consumed by dairy and beef cattle is assumed to be unimportant, because irrigation of pasture is not widely practiced near the SRS. The relative importance of the different exposure pathways for off-site individuals is summarized below.

As described in Sect. 4.3.1, off-site releases of radionuclides via the groundwater pathway are assumed to be subject to two dose limits that are consistent with the performance objectives and PA requirements for LLW disposal (U.S.DOE 435.1): 1) a limit on EDE of 25 mrem per year from all exposure pathways and 2) a limit on EDE of 4 mrem per year from consumption of $2 \mathrm{~L} /$ day of drinking water from a contaminated source. The latter performance objective is used to limit concentrations of radionuclides in groundwater at locations beyond the $100-\mathrm{m}$ buffer zone around the disposal units.

In Sect. 4.3.1, an analysis was performed to compare the importance of the two performance measures for off-site releases of radionuclides listed above. The analysis showed that, at the SRS, the performance measure for analysis of groundwater impacts is expected to be more restrictive for any radionuclide than the performance objective for protection of off-site individuals from all exposure pathways. That is, if the lower dose limit for direct consumption of contaminated groundwater is met, then the higher dose limit for all exposure pathways also will be met without the need for further analysis of the pathways involving use of contaminated groundwater other than direct consumption of drinking water. 
Table C.3-1 Radionuclides considered in dose analyses for off site individuals or inadvertent intruders

\begin{tabular}{|c|c|c|c|}
\hline Radionuclide $^{\mathrm{a}}$ & Half-Life $^{6}$ & & Applicable scenarios ${ }^{\mathrm{c}}$ \\
\hline $\mathrm{H}-3$ & 12.28 & yr & $1,2,4$ \\
\hline $\mathrm{C}-14$ & 5730 & yr & $1,2,4$ \\
\hline Co-60 & $5.27 !$ & yr & $2,3,4$ \\
\hline $\mathrm{Ni}-59$ & $7.50 \mathrm{E}+04$ & yr & $1,2,4$ \\
\hline $\mathrm{Ni}-63$ & $1.00 \mathrm{E}+02$ & $\bar{y} \bar{x}$ & 2,4 \\
\hline Se-79 & $6.50 \mathrm{E}+04$ & yr & $1,2,4$ \\
\hline $\mathrm{Rb}-87$ & $4.73 E+10$ & yr & $1,2,4$ \\
\hline St -90 & 28.6 & $\mathrm{yr}$ & $1,2,4$ \\
\hline Y-90(1.0) & 64.1 & hr & \\
\hline Mo-93 & $3.50 \mathrm{E}+03$ & yr & $1,2,4$ \\
\hline Zr-93 & $1.53 \mathrm{E}+06$ & yr & $1,2,4$ \\
\hline $\mathrm{Nb}-93 \mathrm{~m}(1.0)$ & 14.6 & yr & \\
\hline $\mathrm{Nb}-94$ & $2.00 \mathrm{E}+04$ & yr & $1,2,3,4$ \\
\hline Tc-99 & $2.13 E+05$ & yr & $1,2,4$ \\
\hline Pd-107 & $6.50 \mathrm{E}+06$ & yr & $1,2,4$ \\
\hline Cd-113m & $1.46 \mathrm{E}+01$ & $\mathrm{yr}$ & 2,4 \\
\hline $\mathrm{Sn}-121 \mathrm{~m}$ & $7.60 \mathrm{E}+01$ & yr & 2,4 \\
\hline Sn-126 & $1.00 \mathrm{E}+05$ & $\mathrm{yr}$ & $1,2,3,4$ \\
\hline Sb-126m (1.0) & 19.0 & $\min$ & \\
\hline Sb-126 (0.14) & 12.4 & d & \\
\hline I- 129 & $1.57 \mathrm{E}+07$ & yr & $1,2,4$ \\
\hline Cs- 135 & $2.30 \mathrm{E}+06$ & yr & $1,2,4$ \\
\hline Cs-137 & 30.17 & yг & $2,3,4$ \\
\hline Ba- $137 \mathrm{~m}(0.946)$ & 2.552 & $\min$ & \\
\hline $\mathrm{Sm}-151$ & 90 & $\mathrm{yr}$ & 2,4 \\
\hline Eu-152 & 13.4 & $\mathrm{yr}$ & $2,3,4$ \\
\hline Eu-154 & 8.8 & yr & $2,3,4$ \\
\hline Th-228 & 1.9132 & yr & 2 \\
\hline Th-230 & $7.70 \mathrm{E}+04$ & $\mathrm{yr}$ & 1,2 \\
\hline $\mathrm{Ra}-226(1.0)$ & $1.60 \mathrm{E}+03$ & yr & \\
\hline $\mathrm{Pb}-214(1.0)$ & 26.8 & $\min$ & \\
\hline $\mathrm{Bi}-214(1.0)$ & 19.9 & $\min$ & \\
\hline $\mathrm{Pb}-210(1.0)$ & $2.23 \mathrm{E}+01$ & $\mathrm{yr}$ & \\
\hline Po-210 $(1.0)$ & 138 & d & \\
\hline Th-232 & $1.41 \mathrm{E}+10$ & yr & $1,2,3,4$ \\
\hline Ra-228 (1.0) & 5.75 & yr & \\
\hline Ac-228 (1.0) & 6.13 & $\mathrm{hr}$ & \\
\hline Th-228(1.0) & 1.9132 & yr & \\
\hline Ra-224 (1.0) & 3.62 & d & \\
\hline $\mathrm{Pb}-212(1.0)$ & 10.643 & $\mathrm{hr}$ & \\
\hline $\mathrm{Bi}-212(1.0)$ & 60.55 & $\min$ & \\
\hline Tl-208 (0.359) & 3.053 & $\min$ & \\
\hline U-232 & 72 & $\mathrm{yr}$ & $1,2,3,4$ \\
\hline Th-228 (1.0) & 1.9132 & yr & \\
\hline $\mathrm{Ra}-224(1.0)$ & 3.62 & d & \\
\hline $\mathrm{Pb}-212(1.0)$ & 10.643 & $\mathrm{hr}$ & \\
\hline
\end{tabular}


Table C.3-1 Radionuclides considered in dose analyses for off site individuals or inadvertent intruders

\begin{tabular}{|c|c|c|c|}
\hline Radionuclide $^{\mathbf{a}}$ & Half-Life $^{b}$ & & Applicable scenarios ${ }^{\mathrm{c}}$ \\
\hline $\mathrm{Bi}-212(1.0)$ & 60.55 & $\min$ & \\
\hline Tl-208 (.359) & 3.053 & $\min$ & \\
\hline U-233 & $1.60 E+05$ & yr & $1,2,3,4$ \\
\hline Th-229(1.0) & $7.34 \mathrm{E}+03$ & yr & \\
\hline $\mathrm{Ra}-225(1.0)$ & 14.8 & $\mathrm{~d}$ & \\
\hline Ac-225 (1.0) & 10.0 & d & \\
\hline Fr-221 (1.0) & 4.8 & $\min$ & \\
\hline $\mathrm{Bi}-213(1.0)$ & 45.65 & $\min$ & \\
\hline Tl-209 (0.02 16) & 2.20 & $\min$ & \\
\hline U-234 & $2.45 \mathrm{E}+05$ & yr & $1,2,3,4$ \\
\hline Th-230(1.0) & $7.70 \mathrm{E}+04$ & $\mathrm{yr}$ & \\
\hline $\mathrm{Ra}-226(1.0)$ & $1.60 \mathrm{E}+03$ & yт & \\
\hline $\mathrm{Pb}-214(1.0)$ & 26.8 & $\min$ & \\
\hline $\mathrm{Bi}-214(1.0)$ & 19.9 & $\min$ & \\
\hline $\mathrm{Pb}-210(1.0)$ & $2.23 E+01$ & $\mathrm{yr}$ & \\
\hline Po-210 (1.0) & 138 & d & \\
\hline $\mathrm{U}-235$ & $7.04 \mathrm{E}+08$ & $\mathrm{yr}$ & $1,2,3,4$ \\
\hline Th-23I (1.0) & 25.52 & $\mathrm{hr}$ & \\
\hline $\mathrm{Pa}-231(1.0)$ & $3.28 E+04$ & yr & \\
\hline$A c-227(1.0)$ & $2.18 \mathrm{E}+01$ & yr & \\
\hline Th-227 (0.986) & 18.718 & $\mathrm{~d}$ & \\
\hline $\mathrm{Ra}-223(1.0)$ & 11.434 & d & \\
\hline $\mathrm{Pb}-211(1.0)$ & 36.1 & $\min$ & \\
\hline $\mathrm{Bi}-211(1.0)$ & 2.13 & $\min$ & \\
\hline Tl-207 (0.99727) & 4.77 & $\min$ & \\
\hline U-236 & $2.34 \mathrm{E}+07$ & $\mathrm{yr}$ & $1,2,4$ \\
\hline $\mathrm{U}-238$ & $4.47 \mathrm{E}+09$ & $\mathrm{yr}$ & $1,2,3,4$ \\
\hline Th-234 (1.0) & 24.10 & d & \\
\hline $\mathrm{Pa}-234 \mathrm{~m}(1.0)$ & 1.17 & $\min$ & \\
\hline $\mathrm{Pa}-234(0.0016)$ & 6.70 & $\mathrm{hr}$ & \\
\hline $\mathrm{U}-234(1.0)$ & $2.45 \mathrm{E}+05$ & $\mathrm{yr}$ & \\
\hline $\mathrm{Np}-237$ & $2.14 \mathrm{E}+06$ & $\mathrm{yr}$ & $1,2,3,4$ \\
\hline $\mathrm{Pa}-233(1.0)$ & 27.0 & d & \\
\hline $\mathrm{Pu}-238$ & 87.75 & yr & $1,2,4$ \\
\hline U-234 (1.0) & $2.45 E+05$ & yr & \\
\hline $\mathrm{Pu}-239$ & 24131 & $\mathrm{yr}$ & $1,2,4$ \\
\hline U-235 (1.0) & $7.04 \mathrm{E}+08$ & $\mathrm{yr}$ & \\
\hline $\mathrm{Pu}-240$ & 6569 & $\mathrm{yr}$ & $1,2,4$ \\
\hline $\mathrm{U}-236(1.0)$ & $2.34 \mathrm{E}+07$ & $\mathrm{yr}$ & \\
\hline $\mathrm{Pu}-241$ & 14.4 & yr & $1,2,3,4$ \\
\hline Am-241 (1.0) & $4.32 \mathrm{E}+02$ & $\mathrm{yr}$ & \\
\hline $\mathrm{Np}-237(1.0)$ & $2.14 \mathrm{E}+06$ & $\mathrm{yr}$ & \\
\hline $\mathrm{Pa}-233(1.0)$ & 27.0 & d & \\
\hline $\mathrm{Pu}-242$ & $3.76 \mathrm{E}+05$ & yr & $1,2,4$ \\
\hline U-238 (1.0) & $4.47 \mathrm{E}+09$ & $\mathrm{yr}$ & \\
\hline Pu-244 & $8.26 \mathrm{E}+07$ & yr & $1,2,3,4$ \\
\hline $\mathrm{Np}-240 \mathrm{~m}(1.0)$ & 7.4 & $\min$ & \\
\hline
\end{tabular}


Table C.3-1 Radionuclides considered in dose analyses for off site individuals or inadvertent intruders

\begin{tabular}{|c|c|c|c|}
\hline Radionuclide ${ }^{\mathrm{a}}$ & Half-Life $^{b}$ & & Applicable scenarios \\
\hline Am-241 & 432.2 & $\mathrm{yr}$ & $1,2,3,4$ \\
\hline $\mathrm{Np}-237(1.0)$ & $2.14 \mathrm{E}+06$ & $\mathrm{yr}$ & \\
\hline $\mathrm{Pa}-233(1.0)$ & 27.0 & $d$ & \\
\hline Am-242m & $1.52 \mathrm{E}+02$ & $\mathrm{yr}$ & $1,2,3,4$ \\
\hline Am-242 (0.995) & 16.02 & $\mathrm{hr}$ & \\
\hline $\mathrm{Cm}-242(0.823)$ & $\cdots+\cdots 163.2$ & $\mathrm{~d}^{-}$ & \\
\hline $\mathrm{Pu}-238(1.0)$ & 87.75 & $\mathrm{yr}$ & \\
\hline $\mathrm{U}-234(1.0)$ & $2.45 \mathrm{E}+05$ & $\mathrm{yr}$ & \\
\hline Am-243 & $7.38 \mathrm{E}+03$ & yr & $1,2,3,4$ \\
\hline$N p-239(1.0)$ & 2.355 & d & \\
\hline Pu-239 (1.0) & $2.41 \mathrm{E}+04$ & yr & \\
\hline $\mathrm{Cm}-242$ & 163.2 & $\mathrm{~d}$ & 1,2 \\
\hline $\mathrm{Pu}-238(1.0)$ & 87.75 & $\mathrm{yr}$ & \\
\hline U-234 (1.0) & $2.45 \mathrm{E}+05$ & $\mathrm{yr}$ & \\
\hline $\mathrm{Cm}-243$ & $2.85 E+01$ & $\mathrm{yr}$ & $2,3,4$ \\
\hline $\mathrm{Cm}-244$ & 18.11 & $\mathrm{yr}$ & 2,4 \\
\hline $\mathrm{Pu}-240(1.0)$ & 6569 & yr & \\
\hline U-236 (1.0) & $2.34 \mathrm{E}+07$ & $\mathrm{yr}$ & \\
\hline $\mathrm{Cm}-245$ & $8.50 E+03$ & yr & $1,2,3,4$ \\
\hline $\mathrm{Pu}-241(1.0)$ & $1.44 \mathrm{E}+01$ & $\mathrm{yr}$ & \\
\hline Am-24I (1.0) & $4.32 E+02$ & yr & \\
\hline $\mathrm{Np}-237(1.0)$ & $2.14 \mathrm{E}+06$ & $\mathrm{yr}$ & \\
\hline $\mathrm{Pa}-233(1.0)$ & 27.0 & $\mathrm{~d}$ & \\
\hline $\mathrm{Cm}-246$ & $4.75 E+03$ & $\mathrm{yr}$ & $1,2,4$ \\
\hline $\mathrm{Cm}-247$ & $1.56 \mathrm{E}+07$ & $\mathrm{yr}$ & $1,2,3,4$ \\
\hline $\mathrm{Pu}-243(1.0)$ & 4.956 & $\mathrm{hr}$ & \\
\hline Am-243 (1.0) & $7.37 \mathrm{E}+03$ & $\mathrm{yr}$ & \\
\hline Np-239(1.0) & 2.355 & $\mathrm{~d}$ & \\
\hline $\mathrm{Pu}-239(1.0)$ & $2.41 E+04$ & $\mathrm{yr}$ & \\
\hline $\mathrm{Cm}-248$ & $3.39 E+05$ & $\mathrm{yr}$ & $1,2,3,4$ \\
\hline Pu-244 (0.917) & $8.10 \mathrm{E}+07$ & $\mathrm{yr}$ & \\
\hline Np-240m $(1.0)$ & 7.4 & $\min$ & \\
\hline$B k-249$ & 320 & d & 1,2 \\
\hline Cf-249(1.0) & 350.6 & $\mathrm{yr}$ & \\
\hline $\mathrm{Cm}-245(1.0)$ & $8.50 \mathrm{E}+03$ & $\mathrm{yr}$ & \\
\hline Cf-249 & 350.6 & $\mathrm{yr}$ & $1,2,3,4$ \\
\hline $\mathrm{Cm}-245(1.0)$ & $8.50 \mathrm{E}+03$ & $\mathrm{yr}$ & \\
\hline $\mathrm{Pu}-241(1.0)$ & 14.4 & yr & \\
\hline Am-241 (1.0) & 432 & $\mathrm{yr}$ & \\
\hline $\mathrm{Np}-237(1.0)$ & $2.14 \mathrm{E}+06$ & $\mathrm{yr}$ & \\
\hline $\mathrm{Pa}-233$ & 27.0 & $\mathrm{~d}$ & \\
\hline Cf -250 & 13.08 & $\mathrm{yr}$ & 2,4 \\
\hline Cm-246 (0.999) & $4.75 E+03$ & yr & \\
\hline Cf-251 & 900 & $\mathrm{yr}$ & $2,3,4$ \\
\hline $\mathrm{Cf}-252$ & 2.62 & $\mathrm{yr}$ & $1,2,4$ \\
\hline $\mathrm{Cm}-248(0.969)$ & $3.50 \mathrm{E}+05$ & $\mathrm{yr}$ & \\
\hline
\end{tabular}


Indented entries are decay products of parent radionuclide that are potentially radiologically-significant. With each decay product, branching fraction in decay of parent radionuclide is given in parentheses.

V Values from Kocher (1981).

c 1 = groundwater transport pathway, off-site individuals;

2 = agriculture scenario, inadvertent intruders;

$3=$ resident scenario, inadvertent intruders;

4 = post-drilling scenario, inadvertent intruders. 
Therefore, in the dose analysis for off-site individuals, only the following exposure pathway needs to be considered:

- direct ingestion of contaminated drinking water from a source of groundwater beyond the $100-\mathrm{m}$ buffer zone around disposal units.

This exposure pathway must be considered at any time after disposal. Therefore, for example, in the analysis of groundwater transport for ${ }^{234} \mathrm{U}$ in disposed waste, buildup of the long-lived decay products ${ }^{230} \mathrm{Th} /{ }^{226} \mathrm{Ra}$ must be taken into account in the analysis for the groundwater pathway.

\section{C.3.2.2 Exposure Scenarios and Pathways for Inadvertent Intruders}

In estimating doses to inadvertent intruders after the period of active institutional control (i.e., at any time beyond 100 years after closure of the disposal facility), it is assumed that such individuals could establish a permanent homestead on the site. Furthermore, it is assumed that an intruder has no a priori knowledge of waste disposal activities at the site. Inadvertent intruders are assumed to receive radiation exposures from use of contaminated groundwater obtained from a well on the disposal site and from direct intrusion into waste disposal units. Exposures of inadvertent intruders to volatile releases of ${ }^{3} \mathrm{H},{ }^{14} \mathrm{C}$, and radon are considered separately in Sect. 4.3.2.

For direct intrusion into disposal units after loss of active institutional control, exposures are assumed to occur according to one of three scenarios, which are called the agriculture, resident, and post-drilling scenarios. Other scenarios which were considered but shown to be less important are discussed in Sect. 6.1. The three scenarios considered in this analysis and their associated exposure pathways are described as follows.

In the agriculture scenario, an intruder is assumed to build a home directly on top of disposal units, and the foundation is assumed to extend into the units themselves. Radioactive wastes exhumed during excavation for the foundation are assumed to be indistinguishable from native soil, and some of the exhumed waste is assumed to be mixed with native soil in the intruder's vegetable garden. The following pathways involving exposure to radionuclides in solid waste then are assumed to occur:

- ingestion of vegetables grown in contaminated garden soil;

- direct ingestion of contaminated soil, primarily in conjunction with intakes of vegetables from the garden;

- external exposure to contaminated soil while working in the garden or residing in the home on top of the disposal units;

- inhalation of radionuclides attached to soil particles that are suspended into air from contaminated soil while working in the garden or residing in the home; and

- inhalation of volatile radionuclides released into air from contaminated soil while working in the garden or residing in the home.

Inhalation of the volatile radionuclides ${ }^{3} \mathrm{H},{ }^{14} \mathrm{C}$ and radon while working in the garden or residing in the home is considered separately in Sect. 4.3.2. 
In the resident scenario, an intruder also is assumed to excavate at the location of disposal units, but is assumed to encounter an intact engineered barrier (e.g., a reinforced concrete roof) used in constructing the disposal units which cannot readily be penetrated by the types of excavation equipment normally used near the SRS. Therefore, instead of excavating into the waste, the intruder is assumed to build a home immediately on top of the intact engineered barrier. Since waste in the disposal facility is not directly accessed during excavation, due to the assumed impenetrability of the engineered barriers, the only exposure pathway of concern for this scenario is external exposure to photon-emitting radionuclides in the waste while residing in the home.

In the post-drilling scenario, an intruder is assumed to access solid waste by drilling through a disposal unit, e.g., for the purpose of constructing a well for the intruder's domestic water supply. During drilling, a small volume of waste is brought to the surface, and all of the drilling waste is assumed to be mixed with native soil in the intruder's vegetable garden. The following pathways involving exposure to radionuclides in the solid waste then are assumed to occur:

- ingestion of vegetables grown in contaminated soil;

- direct ingestion of contaminated soil, primarily in conjunction with intakes of vegetables from the garden;

- external exposure to contaminated soil while working in the garden;

- inhalation of radionuclides attached to soil particles that are suspended into air from contaminated soil while working in the garden; and

- inhalation of volatile radionuclides released into air from contaminated soil while working in the garden.

As in the agriculture scenario, inhalation of the volatile radionuclides ${ }^{3} \mathrm{H},{ }^{14} \mathrm{C}$, and radon while working in the garden is considered in Sect. 4.3.2.

The pathways listed above for the post-drilling scenario correspond to some of the pathways for the agriculture scenario. However, in the post-drilling scenario, external and inhalation exposures while residing in the home are not relevant, because all drilling waste is assumed to be mixed with soil in the intruder's vegetable garden and the intruder's home is not located on top of disposal units.

\section{C.3.3 Dose Conversion Factors for Internal and External Exposure}

From the descriptions of the assumed exposure scenarios and pathways given in Sect. C.3.2, doses to offsite individuals and inadvertent intruders are assumed to result from ingestion, inhalation, and external exposure. This section presents the factors used in the dose analyses to convert intakes of radionuclides via ingestion and inhalation to intemal doses and to convert concentrations of radionuclides in the environment to external dose rates.

The internal DCFs for ingestion and inhalation of radionuclides are given in Table C.3-2. These factors give 50-year committed EDEs per unit activity intake. The entries for any short-lived decay products of a longer-lived radionuclide do not take into account the branching fraction in the decay of the parent radionuclide; i.e., the values for each decay product assume the same unit intake of activity (1 Ci). Dose conversion factors are listed for a short-lived decay product only if ingestion or inhalation of the decay product would contribute significantly to the dose from intakes of the parent radionuclide and the decay 
product in secular equilibrium. The internal DCFs in Table C.3-2 are those currently recommended for use by the U.S.DOE (1988) in assessing radiation doses to the public.

For some radionuclides, more than one DCF for ingestion or inhalation has been tabulated by the U.S.DOE (1988). Whenever ingestion DCFs are given for two GI-tract absorption fractions, the value corresponding to the higher absorption fraction is adopted in Table C.3-2, because radionuclides that are transported in water or through terrestrial food-chains should be in relatively soluble form and more easily absorbed in the GI tract. This choice does not always give the higher ingestion DCF, but the value corresponding to the lower GI-tract absorption fraction differs from the adopted value in such cases by less than $10 \%$. If inhalation DCFs are given for more than one-lung clearance-class,-the-clearance_class giving the highest value usually is adopted in Table C.3-2, because there is little information for most elements on the expected chemical forms and their solubilities in waste or soil and the choice of the highest inhalation DCF may result in conservative overestimates of inhalation doses. However, ${ }^{90} \mathrm{Sr}$ and ${ }^{99} \mathrm{Tc}$ are assumed to be Class $\mathrm{D}$ because their solubility in the environment is expected to be relatively high, and all isotopes of Th are assumed to be Class $Y$ because Th in the environment is expected to be highly insoluble.

Dose conversion factors for external exposure give dose-equivalent rates per unit concentration of radionuclides in the environment. These factors depend on the distribution of radionuclides in the source region, the amount of self-shielding provided by material in the source region, and the shielding provided by any uncontaminated material between the source regior, and the location of an exposed individual. Therefore, separate sets of DCFs are required for the assumed pathways involving external exposure to 1) activity in contaminated soil while working in the vegetable garden in the agriculture and post-drilling scenarios, 2) activity in exposed waste while residing in the home at the disposal site in the agriculture and resident scenarios, and 3) activity in waste shielded by intact engineered barriers while residing in the home at the disposal site in the resident scenario.

For external exposure to radionuclides in disposal units or in soil in the vegetable garden, the source region is assumed to be a uniformly contaminated slab of infinite lateral extent. Depending upon the particular exposure scenario and pathway, the slab is assumed to have either finite or infinite thickness, and the shielding provided by any uncontaminated material between the source and receptor locations is taken into account. The idealized distributions of radionuclides in the source region assumed in the dose analysis are reasonable, because radionuclides should be dispersed throughout the source regions and only about $1 \mathrm{~m}$ of soil-equivalent material between the source and receptor locations provides essentially complete shielding (Kocher and Sjoreen 1985).

In all calculations of external dose, an exposed individual is assumed to be located at a distance of $1 \mathrm{~m}$ above ground. In all cases, the shielding provided by $1 \mathrm{~m}$ of air is negligible compared with the shielding provided by the material in the source region itself or by the-thickness-of-any-uncentaminated-material (e.g., an intact concrete roof) between the source and receptor locations.

For external exposure while working in the vegetable garden, the source region is assumed to be a uniformly contaminated slab of soil with a thickness of $15 \mathrm{~cm}$, which is a typical depth of a plowed layer in a garden. The external dose-rate conversion factors for this case are given in Table C.3-3.

For external exposure while residing in the home in the agriculture scenario, the source region is assumed to be a slab of soil-equivalent material of essentially infinite thickness. This is a good approximation because sources more than $1 \mathrm{~m}$ below the surface would not contribute significantly to the dose (Kocher and Sjoreen 1985). No shielding is assumed between the source region and the receptor location other than that provided by the material in the source region itself. Shielding provided by the walls of the home 
Table C.3-2 Internal dose conversion factors (DCFs) for ingestion and inhalation of radionuclides

\begin{tabular}{|c|c|c|}
\hline Radionuclide $^{a}$ & $\begin{array}{c}\text { Ingestion } \mathrm{DCF}^{\mathrm{b}} \\
\mathrm{Rem} / \mathrm{uCi}\end{array}$ & $\begin{array}{c}\text { Inhalation } \mathrm{DCF}^{\mathrm{c}} \\
\text { Rem/uCi }\end{array}$ \\
\hline $\mathrm{H}-3$ & $6.3 \mathrm{E}-05$ & $6.3 \mathrm{E}-05$ \\
\hline C-14 & 2.1E-03 & $2.1 \mathrm{E}-03$ \\
\hline Co-60 & $2.6 \mathrm{E}-02$ & $1.5 \mathrm{E}-01$ \\
\hline $\mathrm{Ni}-59$ & $2.0 \mathrm{E}-04$ & $1.3 \mathrm{E}-03$ \\
\hline $\mathrm{Ni}-63$ & $5.4 \mathrm{E}-04$ & $3.0 \mathrm{E}-03$ \\
\hline $\mathrm{Se}-79$ & $8.3 E-03$ & $8.9 E-03$ \\
\hline $\mathrm{Rb}-87$ & $4.8 \mathrm{E}-03$ & $3.3 \mathrm{E}-03$ \\
\hline Sr-90 & 1.3E-01 & $2.3 \mathrm{E}-01^{\mathrm{d}}$ \\
\hline$Y-90$ & $1.0 \mathrm{E}-02$ & $8.2 \mathrm{E}-03$ \\
\hline Mo-93 & $1.3 \mathrm{E}-06$ & $2.8 \mathrm{E}-02$ \\
\hline $\mathrm{ZT}_{\mathrm{r}-93}$ & $1.6 \mathrm{E}-03$ & $3.2 \mathrm{E}-01$ \\
\hline $\mathrm{Nb}-93 \mathrm{~m}$ & $5.3 E-04$ & $2.8 \mathrm{E}-02$ \\
\hline $\mathrm{Nb}-94$ & $5.1 E-03$ & $3.3 \mathrm{E}-01$ \\
\hline Tc-99 & $1.3 \mathrm{E}-03$ & $8.4 \mathrm{E}-04^{\mathrm{d}}$ \\
\hline Pd-107 & $1.4 \mathrm{E}-04$ & $1.3 \mathrm{E}-02$ \\
\hline $\mathrm{Cd}-113 \mathrm{~m}$ & $1.5 \mathrm{E}-01$ & $1.6 \mathrm{E}+00$ \\
\hline $\mathrm{Sn}-121 \mathrm{~m}$ & $1.3 \mathrm{E}-03$ & $5.8 \mathrm{E}-03$ \\
\hline $\mathrm{Sn}-126$ & $1.7 \mathrm{E}-02$ & $8.6 \mathrm{E}-02$ \\
\hline $\mathrm{Sb}-126 \mathrm{~m}$ & $7.3 \mathrm{E}-05$ & $2.8 \mathrm{E}-05$ \\
\hline Sb-126 & $9.0 \mathrm{E}-03$ & $4.6 \mathrm{E}-03$ \\
\hline $1-129$ & $2.8 \mathrm{E}-01$ & $1.8 \mathrm{E}-01$ \\
\hline Cs -135 & $7.1 \mathrm{E}-03$ & $4.5 \mathrm{E}-03$ \\
\hline Cs-137 & $5.0 \mathrm{E}-02$ & $3.2 \mathrm{E}-02$ \\
\hline $\mathrm{Sm}-151$ & $3.4 \mathrm{E}-04$ & $2.9 \mathrm{E}-02$ \\
\hline Eu- 152 & $6.0 \mathrm{E}-03$ & $2.2 \mathrm{E}-01$ \\
\hline Eu-154 & $9.1 \mathrm{E}-03$ & $2.6 \mathrm{E}-01$ \\
\hline Th-228 & $3.8 \mathrm{E}-01$ & $3.1 \mathrm{E}+02^{\mathrm{e}}$ \\
\hline Th-230 & $5.3 \mathrm{E}-01$ & $2.6 \mathrm{E}+02^{\mathrm{e}}$ \\
\hline $\mathrm{Ra}-226$ & $1.1 E+00$ & $7.9 E+00$ \\
\hline $\mathrm{Pb}-214$ & $5.8 \mathrm{E}-04$ & $6.7 \mathrm{E}-03$ \\
\hline $\mathrm{Bi}-214$ & $2.4 \mathrm{E}-04$ & $6.3 \mathrm{E}-03$ \\
\hline $\mathrm{Pb}-210$ & $5.1 \mathrm{E}+00$ & $1.3 \mathrm{E}+01$ \\
\hline Po- 210 & $1.6 \mathrm{E}+00$ & $8.1 E+00$ \\
\hline Th-232 & $2.8 \mathrm{E}+00$ & $1.1 \mathrm{E}+03^{e}$ \\
\hline $\mathrm{Ra}-228$ & $1.2 \mathrm{E}+00$ & $4.2 \mathrm{E}+00$ \\
\hline Ac- 228 & $2.1 \mathrm{E}-03$ & $2.9 \mathrm{E}-01$ \\
\hline Th-228 & $3.8 \mathrm{E}-01$ & $3.1 \mathrm{E}+02^{\mathrm{e}}$ \\
\hline $\mathrm{Ra}-224$ & $3.3 \mathrm{E}-01$ & $2.9 E+00$ \\
\hline $\mathrm{Pb}-212$ & $4.1 \mathrm{E}-02$ & $1.6 \mathrm{E}-01$ \\
\hline $\mathrm{Bi}-212$ & $9.9 \mathrm{E}-04$ & $2.1 E-02$ \\
\hline $\mathrm{U}-232$ & $1.3 \mathrm{E}+00$ & $6.7 \mathrm{E}+02$ \\
\hline Th-228 & $3.8 \mathrm{E}-01$ & $3.1 \mathrm{E}+02^{\mathrm{c}}$ \\
\hline $\mathrm{Ra}-224$ & $3.3 \mathrm{E}-01$ & $2.9 \mathrm{E}+00$ \\
\hline $\mathrm{Pb}-212$ & $4.1 \mathrm{E}-02$ & $1.6 \mathrm{E}-01$ \\
\hline $\mathrm{Bi}-212$ & $9.9 \mathrm{E}-04$ & $2.1 \mathrm{E}-02$ \\
\hline
\end{tabular}


Table C.3-2 Internal dose conversion factors (DCFs) for ingestion and inhalation of radionuclides

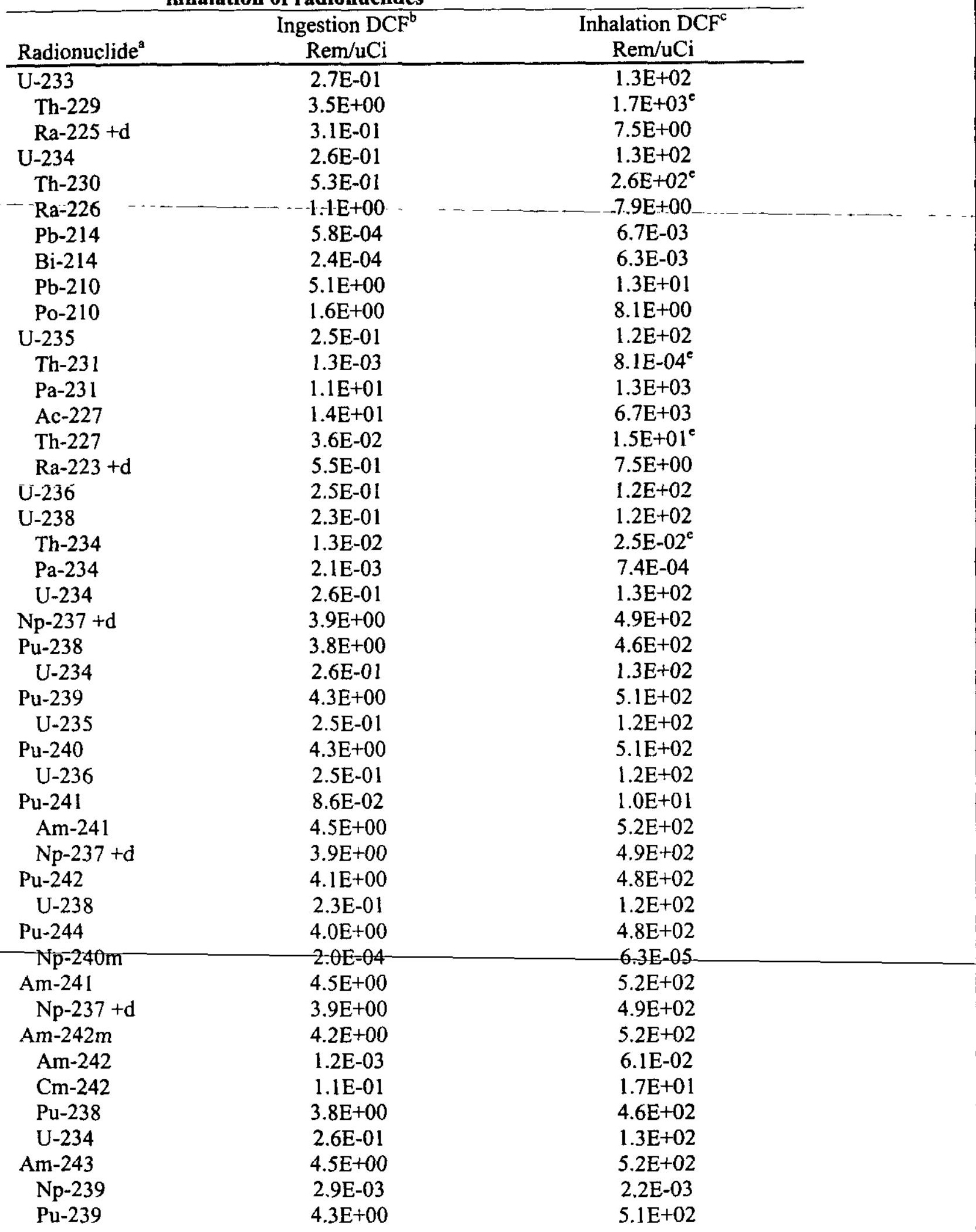


Table C.3-2 Internal dose conversion factors (DCFs) for ingestion and inhalation of radionuclides

\begin{tabular}{ccc}
\hline Radionuclide & $\begin{array}{c}\text { Ingestion DCF }^{\mathrm{b}} \\
\text { Rem/uCi }\end{array}$ & $\begin{array}{c}\text { Inhalation DCF } \\
\text { Rem/uCi }\end{array}$ \\
\hline $\mathrm{Cm}-242$ & $1.1 \mathrm{E}-01$ & $1.7 \mathrm{E}+01$ \\
$\mathrm{Pu}-238$ & $3.8 \mathrm{E}+00$ & $4.6 \mathrm{E}+02$ \\
$\mathrm{U}-234$ & $2.6 \mathrm{E}-01$ & $1.3 \mathrm{E}+02$ \\
$\mathrm{Cm}-243$ & $2.9 \mathrm{E}+00$ & $3.5 \mathrm{E}+02$ \\
$\mathrm{Cm}-244$ & $2.3 \mathrm{E}+00$ & $2.7 \mathrm{E}+02$ \\
$\mathrm{Pu}-240$ & $4.3 \mathrm{E}+00$ & $5.1 \mathrm{E}+02$ \\
$\mathrm{U}-236$ & $2.5 \mathrm{E}-01$ & $1.2 \mathrm{E}+02$ \\
$\mathrm{Cm}-245$ & $4.5 \mathrm{E}+00$ & $5.4 \mathrm{E}+02$ \\
$\mathrm{Pu}-241$ & $8.6 \mathrm{E}-02$ & $1.0 \mathrm{E}+01$ \\
$\mathrm{Am}-241$ & $4.5 \mathrm{E}+00$ & $5.2 \mathrm{E}+02$ \\
$\mathrm{~Np}-237+\mathrm{d}$ & $3.9 \mathrm{E}+00$ & $4.9 \mathrm{E}+02$ \\
$\mathrm{Cm}-246$ & $4.5 \mathrm{E}+00$ & $5.4 \mathrm{E}+02$ \\
$\mathrm{Cm}-247$ & $4.1 \mathrm{E}+00$ & $4.9 \mathrm{E}+02$ \\
Pu-243 & $3.3 \mathrm{E}-04$ & $1.5 \mathrm{E}-04$ \\
$\mathrm{Am}-243$ & $4.5 \mathrm{E}+00$ & $5.2 \mathrm{E}+02$ \\
$\mathrm{~Np}-239$ & $2.9 \mathrm{E}-03$ & $2.2 \mathrm{E}-03$ \\
$\mathrm{Pu}-239$ & $4.3 \mathrm{E}+00$ & $5.1 \mathrm{E}+02$ \\
$\mathrm{Cm}-248$ & $1.6 \mathrm{E}+01$ & $1.9 \mathrm{E}+03$ \\
$\mathrm{Pu}-244$ & $4.0 \mathrm{E}+00$ & $4.8 \mathrm{E}+02$ \\
$\mathrm{Bk}-249$ & $6.0 \mathrm{E}-03$ & $1.3 \mathrm{E}+00$ \\
$\mathrm{Cf}-249$ & $4.6 \mathrm{E}+00$ & $5.5 \mathrm{E}+02$ \\
$\mathrm{Cm}-245$ & $4.5 \mathrm{E}+00$ & $5.4 \mathrm{E}+02$ \\
$\mathrm{Cf}-249$ & $4.6 \mathrm{E}+00$ & $5.5 \mathrm{E}+02$ \\
$\mathrm{Cm}-245$ & $4.5 \mathrm{E}+00$ & $5.4 \mathrm{E}+02$ \\
Pu-241 & $8.6 \mathrm{E}-02$ & $1.0 \mathrm{E}+01$ \\
$\mathrm{Am}-241$ & $4.5 \mathrm{E}+00$ & $5.2 \mathrm{E}+02$ \\
$\mathrm{~Np}-237+\mathrm{d}$ & $3.9 \mathrm{E}+00$ & $4.9 \mathrm{E}+02$ \\
$\mathrm{Cf}-250$ & $1.9 \mathrm{E}+00$ & $2.2 \mathrm{E}+02$ \\
$\mathrm{Cm}-246$ & $4.5 \mathrm{E}+00$ & $5.4 \mathrm{E}+02$ \\
$\mathrm{Cf}-251$ & $4.6 \mathrm{E}+00$ & $5.6 \mathrm{E}+02$ \\
$\mathrm{Cf}-252$ & $9.4 \mathrm{E}-01$ & $1.3 \mathrm{E}+02$ \\
$\mathrm{Cm}-248$ & $1.6 \mathrm{E}+01$ & $1.9 \mathrm{E}+03$ \\
\hline
\end{tabular}

Indented entries are decay products of parent radionuclide that are potentially radiologicallysignificant; " $+d$ " indicates dose factor of short-lived daughter included in the dose factor provided.

b Fifty-year EDEs from USDOE 1988; when values are given for more than one GI-tract absorption fraction, value corresponding to higher absorption fraction is adopted.

c Fifty-year EDEs from USDOE 1988; when more than one DCF is given for different lung clearance classes, the clearance class giving the highest DCF is selected, except as noted.

d Assumed to be Class D because solubility in the environment is expected to be relatively high.

- Assumed to be Class $\mathrm{Y}$ because Th in the environment is expected to be highly insoluble. 
during indoor residence is taken into account in the dose analysis itself (see Eq. C.3-8). The external dose-rate conversion factors for this case are given in the column in Table C.3-4 labeled "No shielding".

For external exposure while residing in the home in the resident scenario, the source region also is assumed to be a slab of soil-equivalent material of infinite thickness. As described in Sect. 6.1, the maximum external dose in the resident scenario can be bounded by considering two limiting cases. The first involves exposure to both shorter- and longer-lived photon-emitting radionuclides and photonemitting daughters at the time active institutional control ceases at 100 years after facility closure when an intact concrete roof and any other engineered barriers on top of the waste may provide a considerable amount of shielding. The second case involves exposure ${ }^{-1}$ only to longer-lived photon-emitting radionuclides and photon-emitting daughters at a time long after disposal when the concrete roof and any other engineered barriers above the waste have lost their physical integrity and exposure to waste with no external shielding could occur.

As described in Sect. 3.2.2, the closure concept for the IL vaults includes a layer of uncontaminated grout about $3 \mathrm{ft}(90 \mathrm{~cm})$ thick on top of the waste and a concrete roof of variable thickness, the average thickness being about $3 \mathrm{ft}(90 \mathrm{~cm})$. The closure concept for the LAW vaults does not include a layer of uncontaminated grout on top of the waste, and the concrete roof is about $50 \mathrm{~cm}$ thick. Naval reactor waste is shielded by a minimum of $0.04-\mathrm{m}$ carbon steel at the closure weld of the containers, although in general, the containers are about 10 times (i.e., 0.4-m) the thickness of the material at the weld location. Equipment encapsulated in grout has a $0.3-\mathrm{m}$ (1-foot) thick layer of grout providing shielding. No difficult-to-penetrate barriers shield waste in the slit trenches or the intimately-mixed cement-stabilized waste trenches.

For the case of external exposure to waste shielded by engineered barriers at 100 years after disposal in the resident scenario, the total thickness of the concrete roof and layer of uncontaminated grout for the IL vaults thus is about $1.8 \mathrm{~m}$. The thickness of shielding for these vaults is sufficient to reduce the extemal dose from the waste to minuscule levels for any possible concentrations of photon-emitting radionuclides (Kocher and Sjoreen 1985). Therefore, in order to evaluate the need for the concrete roof in limiting external dose at 100 years after disposal for the resident scenario, the dose analysis for the IL vaults at this time is based on the assumption that only the layer of uncontaminated grout is present to provide shielding. The nominal thickness of the grout is assumed to be $100 \mathrm{~cm}$. This value is slightly higher than the planned thickness of the grout layer and is intended to take into account the somewhat greater shielding provided by the metal waste containers and waste forms in the IL vaults compared with the shielding provided by soil-equivalent material.

For the LAW vaults, the nominal thickness of the concrete roof at 100 years after disposal is assumed to be $45 \mathrm{~cm}$. This value is slightly less than the planned thickness of the concrete roof and is intended to take into account the somewhat reduced shielding provided by the waste itself, compared with soilequivalent material, due to the presence of void spaces in the vaults.

Thus, in Table C. $3-4$, the external dose-rate conversion factors for the resident scenario at 100 years after disposal are given in the column labeled " $45-\mathrm{cm}$ shielding" for the LAW vaults and the column labeled "100-cm shielding" for the IL vaults. Again, the assumed thickness of shielding for the IL vaults should provide considerable over-estimates of external dose, because the planned thickness of the concrete roof on top of the vaults is ignored.

External exposure to naval reactor waste is assumed to be reduced by the minimum $0.04-\mathrm{m}(4 \mathrm{~cm})$ carbon steel of the closure welds in the containers. A separate method for estimating maximum residential exposure for the naval reactor waste was developed, and is presented in Sect. 6.3. Therefore, no dose factors pertinent to this exposure scenario are presented in this appendix. 
Table C.3-3 External dose-rate conversion factors for radionuclides uniformly distributed in $15 \mathrm{~cm}$ of surface soil

\begin{tabular}{|c|c|c|c|}
\hline Radionuclide ${ }^{\mathrm{a}}$ & rem/yr per $\mathrm{uCi} / \mathrm{m}^{3 \mathrm{~b}}$ & Radionuclide $^{a}$ & $\mathrm{rem} / \mathrm{yr}$ per $\mathrm{uCi} / \mathrm{m}^{3 \mathrm{~b}}$ \\
\hline Co-60 & $8.5 \mathrm{E}-03$ & U-235 & $4.4 \mathrm{E}-04$ \\
\hline Sr-90 & $4.3 \mathrm{E}-07$ & Th-231 & $2.3 \mathrm{E}-05$ \\
\hline Y-90 & $1.4 \mathrm{E}-05$ & $\mathrm{~Pa}-231$ & $1.1 \mathrm{E}-04$ \\
\hline $\mathrm{Nb}-94$ & $5.3 \mathrm{E}-03$ & Ac- 227 & $3.1 \mathrm{E}-07$ \\
\hline $\mathrm{Sn}-121 \mathrm{~m}$ & 1.2E-06 & Th-227 & $3.1 \mathrm{E}-04$ \\
\hline Sn-126 & $9.2 \mathrm{E}-05$ & $\mathrm{Ra}-223+\mathrm{d}^{\mathrm{c}}$ & $6.9 \mathrm{E}-04$ \\
\hline $\mathrm{Sb}-126 \mathrm{~m}$ & $5.2 \mathrm{E}-03$ & U-236 & $1.3 \mathrm{E}-07$ \\
\hline Sb-126 & $9.5 \mathrm{E}-03$ & U-238 & $6.4 \mathrm{E}-08$ \\
\hline $\mathrm{I}-129$ & $8.1 \mathrm{E}-06$ & Th-234 & $1.5 \mathrm{E}-05$ \\
\hline Cs- 137 & $4.6 \mathrm{E}-07$ & $\mathrm{~Pa}-234 \mathrm{~m}$ & $4.9 \mathrm{E}-05$ \\
\hline $\mathrm{Ba}-137 \mathrm{~m}$ & $2.0 \mathrm{E}-03$ & $\mathrm{~Pa}-234$ & $6.3 \mathrm{E}-03$ \\
\hline Eu-152 & $3.8 \mathrm{E}-03$ & $\mathrm{~Np}-237$ & $4.9 \mathrm{E}-05$ \\
\hline Eu-154 & $4.1 \mathrm{E}-03$ & $\mathrm{~Pa}-233$ & $6.0 \mathrm{E}-04$ \\
\hline Th-228 & $4.9 E-06$ & $\mathrm{Pu}-239$ & $1.8 \mathrm{E}-07$ \\
\hline Th-230 & --- & $\mathrm{U}-235$ & $4.4 \mathrm{E}-04$ \\
\hline $\mathrm{Ra}-226$ & $1.9 \mathrm{E}-05$ & $\mathrm{Pu}-241$ & $3.7 \mathrm{E}-09$ \\
\hline $\mathrm{Pb}-214$ & $7.8 \mathrm{E}-04$ & Am-24l & $2.7 E-05$ \\
\hline $\mathrm{Bi}-214$ & $5.1 \mathrm{E}-03$ & $\mathrm{~Np}-237+\mathrm{d}^{\mathrm{d}}$ & $6.5 \mathrm{E}-04$ \\
\hline $\mathrm{Pb}-210$ & $1.5 \mathrm{E}-06$ & $\mathrm{Pu}-244$ & 4.7E-08 \\
\hline Po-210 & $2.9 \mathrm{E}-08$ & $\mathrm{~Np}-240 \mathrm{~m}$ & $1.1 E-03$ \\
\hline Th-232 & $3.2 \mathrm{E}-07$ & $A m-241$ & 2.7E-05 \\
\hline $\mathrm{Ra}-228$ & -..- & $\mathrm{Np}-237+\mathrm{d}^{\mathrm{d}}$ & $6.5 \mathrm{E}-04$ \\
\hline$A c-228$ & $3.2 \mathrm{E}-03$ & $\mathrm{Am}-242 \mathrm{~m}$ & $1.1 \mathrm{E}-06$ \\
\hline Th-228 & $4.9 \mathrm{E}-06$ & Am-242 & $3.1 \mathrm{E}-05$ \\
\hline $\mathrm{Ra}-224$ & $3.1 \mathrm{E}-05$ & $\mathrm{Cm}-242$ & --- \\
\hline $\mathrm{Pb}-212$ & 4.2E-04 & $\mathrm{Pu}-238$ & $9.4 \mathrm{E}-08$ \\
\hline $\mathrm{Bi}-212$ & $6.3 \mathrm{E}-04$ & U-234 & $2.5 \mathrm{E}-07$ \\
\hline $\mathrm{Tl}-208$ & $1.1 \mathrm{E}-02$ & Am-243 & $8.9 \mathrm{E}-05$ \\
\hline U-232 & $5.6 \mathrm{E}-07$ & Np-239 & $4.6 \mathrm{E}-04$ \\
\hline Th-228 & $4.9 \mathrm{E}-06$ & Pu-239 & $1.8 \mathrm{E}-07$ \\
\hline $\mathrm{Ra}-224$ & 3.1E-05 & $\mathrm{Cm}-243$ & $3.5 \mathrm{E}-04$ \\
\hline $\mathrm{Pb}-212$ & 4.2E-04 & $\mathrm{Cm}-245$ & $2.1 \mathrm{E}-04$ \\
\hline $\mathrm{Bi}-212$ & $6.3 \mathrm{E}-04$ & $\mathrm{Pu}-241$ & $3.7 \mathrm{E}-09$ \\
\hline Tl-208 & $1.1 \mathrm{E}-02$ & $\mathrm{Am}-241$ & $2.7 \mathrm{E}-05$ \\
\hline $\mathrm{U}-233$ & $8.4 \mathrm{E}-07$ & $\mathrm{~Np}-237+\mathrm{d}^{d}$ & $6.5 \mathrm{E}-04$ \\
\hline Th-229 & 2.0E-04 & $\mathrm{Cm}-247$ & $1.0 \mathrm{E}-03$ \\
\hline $\mathrm{Ra}-225$ & $6.9 \mathrm{E}-06$ & $\mathrm{Pu}-243$ & $4.9 \mathrm{E}-05$ \\
\hline Ac- 225 & $3.9 \mathrm{E}-05$ & $A m-243$ & $8.9 \mathrm{E}-05$ \\
\hline $\mathrm{Fr}-221$ & $9.2 \mathrm{E}-05$ & $\mathrm{~Np}-239$ & $4.6 \mathrm{E}-04$ \\
\hline $\mathrm{Bi}-213$ & $4.4 \mathrm{E}-04$ & $\mathrm{Pu}-239$ & $1.8 \mathrm{E}-07$ \\
\hline Tl-209 & $6.8 \mathrm{E}-03$ & $\mathrm{Cm}-248$ & $5.5 \mathrm{E}-08$ \\
\hline U-234 & $2.5 \mathrm{E}-07$ & $\mathrm{Pu}-244+\mathrm{d}^{\mathrm{e}}$ & $1.1 \mathrm{E}-03$ \\
\hline Th-230 & $7.5 \mathrm{E}-07$ & Bk-249 & $2.9 \mathrm{E}-09$ \\
\hline $\mathrm{Ra}-226$ & $1.9 \mathrm{E}-05$ & Cf-249 & $1.1 \mathrm{E}-03$ \\
\hline$P b-214$ & $7.8 \mathrm{E}-04$ & $\mathrm{Cm}-245$ & $2.1 \mathrm{E}-04$ \\
\hline $\mathrm{Bi}-214$ & $5.1 \mathrm{E}-03$ & & \\
\hline $\mathrm{Pb}-210$ & $1.5 \mathrm{E}-06$ & & \\
\hline Po-210 & $2.9 \mathrm{E}-08$ & & \\
\hline
\end{tabular}




\begin{tabular}{lc}
\hline Radionuclide $^{\mathrm{a}}$ & $\mathrm{rem} / \mathrm{yr}$ per uCi/m $\mathrm{m}^{3 \mathrm{~b}}$ \\
\hline $\mathrm{Cf}-249$ & $1.1 \mathrm{E}-03$ \\
$\mathrm{Cm}-245$ & $2.1 \mathrm{E}-04$ \\
$\mathrm{Pu}-241$ & $3.7 \mathrm{E}-09$ \\
$\mathrm{Am}-241$ & $2.7 \mathrm{E}-05$ \\
$\mathrm{~Np}-237+\mathrm{d}^{\mathrm{d}}$ & $6.5 \mathrm{E}-04$ \\
$\mathrm{Cf}-251$ & $3.2 \mathrm{E}-04$ \\
\hline
\end{tabular}

a Indented entries.are decay products of parent radionuclide that are potentially radiologically-significant.

${ }^{b}$ From Eckerman and Ryman (1993); EDE from external exposure per unit activity concentration in soil ${ }^{-}$ at distance of $1 \mathrm{~m}$ from source region.

c Includes contributions from $\mathrm{Pb}-211, \mathrm{Bi}-211$, and $\mathrm{Tl}-207$, assumed to be in secular equilibrium.

Includes contributions from $\mathrm{Pa}-233$, assumed to be in secular equilibrium.

c Includes contributions from $\mathrm{Np}-240 \mathrm{~m}$, assumed to be in secular equilibrium. 
Table C.3-4 External dose-rate conversion factors for radionuclides uniformly distributed in infinite thickness of soil-equivalent material

\begin{tabular}{|c|c|c|c|}
\hline Radionuclide $^{\mathrm{a}}$ & $\begin{array}{l}\text { Dose-rate factor } \\
\text { No shielding } \\
\text { Rem } / \text { yr per } \mu \mathrm{Ci} / \mathrm{m}^{3}\end{array}$ & $\begin{array}{l}\text { Dose-rate factor } \\
45 \mathrm{~cm} \text { shielding } \\
\text { Rem } / \mathrm{yr} \text { per } \mu \mathrm{Ci} / \mathrm{m}^{3}\end{array}$ & $\begin{array}{l}\text { Dose-rate factor }{ }^{\mathrm{c}} \\
100 \mathrm{~cm} \text { shielding } \\
\text { Rem } / \mathrm{yr} \text { per } \mu \mathrm{Ci} / \mathrm{m}^{3}\end{array}$ \\
\hline $\mathrm{Co}-60$ & $1.0 \mathrm{E}-02$ & $2.5 \mathrm{E}-04$ & $3.3 \mathrm{E}-06$ \\
\hline $\operatorname{Sr}-90$ & $4.4 \mathrm{E}-07$ & & \\
\hline Y-90 & $1.5 \mathrm{E}-05$ & & \\
\hline $\mathrm{Nb}-94$ & $6.0 \mathrm{E}-03$ & $7.4 \mathrm{E}-05$ & $4.0 \mathrm{E}-07$ \\
\hline $\mathrm{Sn}-121 \mathrm{~m}$ & $1.2 \mathrm{E}-06$ & & \\
\hline $\mathrm{Sn}-126$ & $9.2 \mathrm{E}-05$ & & \\
\hline $\mathrm{Sb}-126 \mathrm{~m}$ & $5.8 \mathrm{E}-03$ & 4.9E-05 & $1.8 \mathrm{E}-07$ \\
\hline $\mathrm{Sb}-126$ & $1.1 \mathrm{E}-02$ & $9.7 \mathrm{E}-05$ & 4.3E-07 \\
\hline I-129 & $8.1 \mathrm{E}-06$ & & \\
\hline Cs- 137 & $4.7 \mathrm{E}-07$ & & \\
\hline $\mathrm{Ba}-137 \mathrm{~m}$ & $2.3 \mathrm{E}-03$ & $2.0 \mathrm{E}-05$ & $6.6 \mathrm{E}-08$ \\
\hline Eu-152 & $4.4 \mathrm{E}-03$ & $8.1 \mathrm{E}-05$ & $9.9 \mathrm{E}-07$ \\
\hline $\mathrm{Eu}-154$ & $4.8 \mathrm{E}-03$ & $9.0 \mathrm{E}-05$ & $1.0 \mathrm{E}-06$ \\
\hline Th-228 & $5.0 \mathrm{E}-06$ & & \\
\hline \multicolumn{4}{|l|}{ Th-230 } \\
\hline Ra-226 & $2.0 \mathrm{E}-05$ & & \\
\hline $\mathrm{Pb}-214$ & $8.4 \mathrm{E}-04$ & & \\
\hline $\mathrm{Bi}-214$ & $6.1 \mathrm{E}-03$ & $1.7 \mathrm{E}-04$ & $3.8 \mathrm{E}-06$ \\
\hline $\mathrm{Pb}-210$ & $1.5 \mathrm{E}-06$ & & \\
\hline Po-210 & $3.3 \mathrm{E}-08$ & & \\
\hline Th-232 & $3.3 \mathrm{E}-07$ & & \\
\hline $\mathrm{Ra}-228$ & $0.0 \mathrm{E}+00$ & & \\
\hline Ac- 228 & $3.7 \mathrm{E}-03$ & $6.1 \mathrm{E}-05$ & $7.2 \mathrm{E}-07$ \\
\hline Th-228 & $5.0 \mathrm{E}-06$ & & \\
\hline $\mathrm{Ra}-224$ & $3.2 \mathrm{E}-05$ & & \\
\hline $\mathrm{Pb}-212$ & $4.4 \mathrm{E}-04$ & & \\
\hline $\mathrm{Bi}-212$ & $7.3 \mathrm{E}-04$ & $1.4 \mathrm{E}-05$ & $2.1 \mathrm{E}-07$ \\
\hline Tl-208 & $1.4 \mathrm{E}-02$ & $6.9 E-04$ & $3.0 \mathrm{E}-05$ \\
\hline $\mathrm{U}-232$ & $5.6 \mathrm{E}-07$ & & \\
\hline Th-228 & $5.0 \mathrm{E}-06$ & & \\
\hline $\mathrm{Ra}-224$ & $3.2 \mathrm{E}-05$ & & \\
\hline $\mathrm{Pb}-212$ & $4.4 \mathrm{E}-04$ & & \\
\hline $\mathrm{Bi}-212$ & 7.3E-04 & $1.4 \mathrm{E}-05$ & $2.1 \mathrm{E}-07$ \\
\hline $\mathrm{T} 1-208$ & $1.4 \mathrm{E}-02$ & $6.9 \mathrm{E}-04$ & $3.0 \mathrm{E}-05$ \\
\hline $\mathrm{U}-233$ & $8.7 \mathrm{E}-07$ & & \\
\hline Th-229 & $2.0 \mathrm{E}-04$ & $2.4 \mathrm{E}-08$ & \\
\hline $\mathrm{Ra}-225$ & $6.9 \mathrm{E}-06$ & & . \\
\hline Ac- 225 & $4.0 \mathrm{E}-05$ & $1.2 \mathrm{E}-08$ & \\
\hline Fr-221 & $9.6 \mathrm{E}-05$ & 4.1E-08 & \\
\hline $\mathrm{Bi}-213$ & $4.8 \mathrm{E}-04$ & $2.5 \mathrm{E}-06$ & 7.5E-09 \\
\hline Tl-203 & $8.1 \mathrm{E}-03$ & $2.2 \mathrm{E}-04$ & $4.3 \mathrm{E}-06$ \\
\hline
\end{tabular}


Table C.3-4 External dose-rate conversion factors for radionuclides uniformly distributed in infinite thickness of soil-equivalent material

\begin{tabular}{|c|c|c|c|}
\hline Radionuclide $^{\mathrm{a}}$ & $\begin{array}{l}\text { Dose-rate factor } \\
\text { No shielding } \\
\text { Rem } / \mathrm{yr} \text { per } \mu \mathrm{Ci} / \mathrm{m}^{3}\end{array}$ & $\begin{array}{l}\text { Dose-rate factor }{ }^{c} \\
45 \mathrm{~cm} \text { shielding } \\
\text { Rem } / \mathrm{yr} \text { per } \mu \mathrm{Ci} / \mathrm{m}^{3}\end{array}$ & $\begin{array}{l}\text { Dose-rate factor }{ }^{c} \\
100 \mathrm{~cm} \text { shielding } \\
\text { Rem } / \mathrm{yr} \text { per } \mu \mathrm{Ci} / \mathrm{m}^{3}\end{array}$ \\
\hline $\mathrm{U}-234$ & $2.5 \mathrm{E}-07$ & & \\
\hline Th-230 & $7.5 \mathrm{E}-07$ & & \\
\hline $\mathrm{Ra}=226$ & $2.0 \mathrm{E}-05$ & - - - - & \\
\hline $\mathrm{Pb}-214$ & $8.4 \mathrm{E}-04$ & & \\
\hline $\mathrm{Bi}-214$ & $6.1 \mathrm{E}-03$ & $1.7 \mathrm{E}-04$ & $3.8 \mathrm{E}-06$ \\
\hline $\mathrm{Pb}-210$ & $1.5 \mathrm{E}-06$ & & \\
\hline Po-210 & $3.3 E-08$ & & \\
\hline $\mathrm{U}-235$ & $4.3 \mathrm{E}-04$ & $1.1 \mathrm{E}-07$ & $6.5 \mathrm{E}-12$ \\
\hline Th-231 & $2.3 \mathrm{E}-05$ & & \\
\hline $\mathrm{Pa}-231$ & $1.2 \mathrm{E}-04$ & $1.6 \mathrm{E}-07$ & $8.0 \mathrm{E}-11$ \\
\hline Ac- 227 & $3.1 E-07$ & & \\
\hline Th-227 & $3.3 \mathrm{E}-04$ & $3.6 \mathrm{E}-07$ & $1.6 \mathrm{E}-10$ \\
\hline $\mathrm{Ra}-223+\mathrm{d}^{\mathrm{d}}$ & $7.4 \mathrm{E}-04$ & $2.7 \mathrm{E}-06$ & $9.8 E-09$ \\
\hline $\mathrm{U}-238$ & $6.4 \mathrm{E}-08$ & & \\
\hline Th-234 & $1.5 \mathrm{E}-05$ & & \\
\hline $\mathrm{Pa}-234 \mathrm{~m}$ & $5.6 \mathrm{E}-05$ & $6.8 \mathrm{E}-07$ & 5.2E-09 \\
\hline $\mathrm{Pa}-234$ & $7.2 \mathrm{E}-03$ & $1.1 \mathrm{E}-04$ & 1.2E-06 \\
\hline U-234 & $2.5 \mathrm{E}-07$ & & \\
\hline Np-237 & 4.9E-05 & & \\
\hline $\mathrm{Pa}-233$ & $6.4 \mathrm{E}-04$ & $1.3 \mathrm{E}-06$ & $7.9 \mathrm{E}-10$ \\
\hline $\mathrm{Pu}-241$ & 3.7E-09 & & \\
\hline Am-241 & $2.7 \mathrm{E}-05$ & $2.9 \mathrm{E}-13$ & \\
\hline $\mathrm{Np}-237+\mathrm{d}^{\mathrm{e}}$ & $6.5 \mathrm{E}-04$ & $1.3 \mathrm{E}-06$ & $7.9 \mathrm{E}-10$ \\
\hline $\mathrm{Pu}-244$ & 4.7E-08 & & \\
\hline $\mathrm{Np}-240 \mathrm{~m}$ & $1.3 \mathrm{E}-03$ & $1.5 \mathrm{E}-05$ & $1.4 \mathrm{E}-07$ \\
\hline Am-241 & $2.7 \mathrm{E}-05$ & $2.9 \mathrm{E}-13$ & \\
\hline$N p-237+d^{e}$ & $6.5 \mathrm{E}-04$ & $1.3 \mathrm{E}-06$ & $7.9 \mathrm{E}-10$ \\
\hline Am-242m & $1.1 \mathrm{E}-06$ & & \\
\hline Am-242 & $3.1 E-05$ & & \\
\hline $\mathrm{Cm}-242$ & & & \\
\hline $\mathrm{Pu}-238$ & $9.5 \mathrm{E}-08$ & & \\
\hline U-234 & $2.5 \mathrm{E}=07$ & & \\
\hline Am-243 & $8.9 \mathrm{E}-05$ & $2.5 \mathrm{E}-10$ & \\
\hline Np-239 & 4.7E-04 & $3.2 \mathrm{E}-07$ & $1.2 \mathrm{E}-10$ \\
\hline Pu-239 & $1.8 \mathrm{E}-07$ & & \\
\hline $\mathrm{Cm}-243$ & $3.6 \mathrm{E}-04$ & $1.4 \mathrm{E}-07$ & $5.8 \mathrm{E}-11$ \\
\hline $\mathrm{Cm}-245$ & 2.1E-04 & $1.5 \mathrm{E}-08$ & \\
\hline $\mathrm{Pu}-241$ & 3.7E-09 & & \\
\hline Am-241 & $2.7 \mathrm{E}-05$ & & \\
\hline $\mathrm{Np}-237+\mathrm{d}^{\mathrm{e}}$ & $6.5 E-04$ & 1.3E-06 & $7.9 \mathrm{E}-10$ \\
\hline
\end{tabular}


Table C.3-4 External dose-rate conversion factors for radionuclides uniformly distributed in infinite thickness of soil-equivalent material

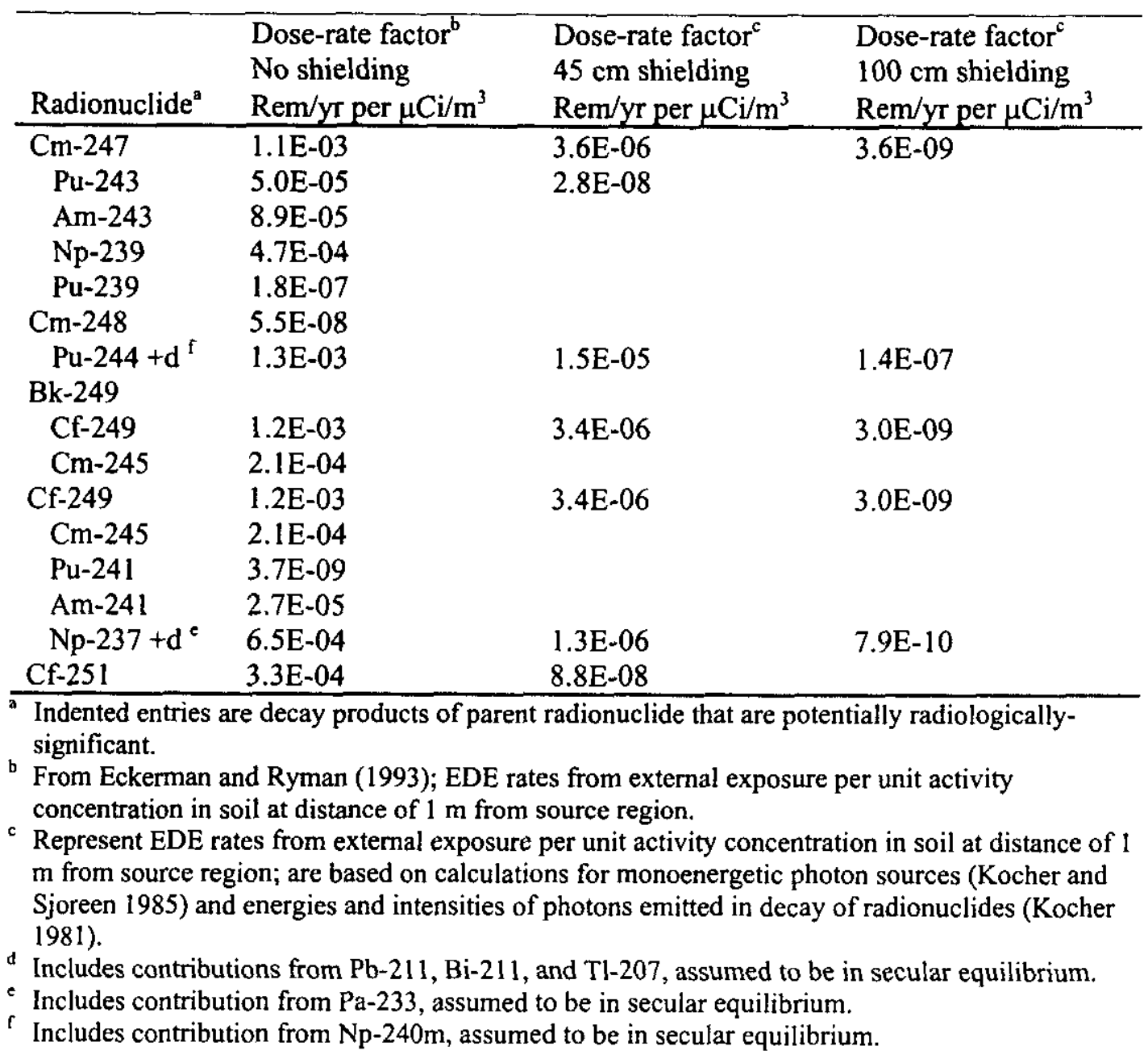


Residential exposure that may occur from waste encapsulated in grout and the intimately-mixed cementstabilized waste trenches at 100 years following institutional control was evaluated using the column in Table C.3-4 for "100-cm shielding". Since the scenario assumes that the excavation will not exceed 3-meters in depth, and the minimum about of soil equivalent material above the waste is 4.37 meters (i.e., $0.3 \mathrm{~m}$ of grout, $1.2 \mathrm{~m}$ of clean soil, and a minimum of $2.87 \mathrm{~m}$ of closure cap), at least 1.37 meters of soil equivalent material will shield the resident from the waste. Thus, the $100-\mathrm{cm}$ shielding column was conservatively applied. At 300 years, when degradation of the cement is assumed to occur for this type of disposal unit and thus the agriculture scenario may occur, exposure to unshielded waste is considered likely, and thus the dose factor for "No shielding" is appropriate.

For the slit trenches, residential exposure that may at 100 years following institutional control was evaluated using the column in Table C. $3-4$ for "100-cm shielding". Since the scenario assumes that the excavation will not exceed 3-meters in depth, and the minimum about of soil equivalent material above the waste is 4.07 meters (i.e., $1.2 \mathrm{~m}$ of clean soil, and a minimum of $2.87 \mathrm{~m}$ of closure cap), at least 1.07 meters of soil equivalent material will shield the resident from the waste. Thus, the $100-\mathrm{cm}$ shielding column was applied.

The external dose-rate conversion factors in Table C.3-3 and in the column labeled "No shielding" in Table C.3-4 were obtained from calculations of Eckerman and Ryman (1993). The external dose-rate conversion factors for the two thicknesses of shielding in Table C.3-4 were obtained from calculations of absorbed dose rates in air from monoenergetic photon sources in soil (Kocher and Sjoreen 1985), the spectrum of photons emitted in the decay of each radionuclide (Kocher 1981), and the assumption that absorbed doses in air can be converted to EDEs by multiplying by a factor of 0.8 . The entries for any short-lived decay products of a longer-lived radionuclide do not take into account the branching fraction in the decay of the parent radionuclide; i.e., the values for each decay product assume exposure to the same unit activity concentration $\left(1 \mu \mathrm{Ci} / \mathrm{m}^{3}\right)$.

On the basis of a direct comparison of results from Eckerman and Ryman (1993) and Kocher and Sjoreen (1985) for the case in Table C.3-4 of an infinitely thick source region with no shielding, the results from Kocher and Sjoreen for the two thicknesses of shielding in Table C.3-4 could be in error by as much as 25 to $30 \%$ in some cases. However, since the results from Kocher and Sjoreen appear to provide conservative overestimates of dose in almost all cases and the magnitude of the possible error is not large, these results reasonably can be used in this analysis. The calculations needed in this analysis for the different thicknesses of shielding between the source region and receptor location were not performed by Eckerman and Ryman.

\section{C.3.4 Models and Parameter Values for Exposure Pathways}

This section presents the models used to calculate-doses to-off-site-individuais and-inadvertent-intruders for the various exposure pathways considered in this analysis involving use of contaminated groundwater or direct intrusion into disposal units. In each case, the parameter values assumed in implementing the models also are presented. For each exposure pathway, the model results are presented in summary tables which give annual EDEs per unit concentration of radionuclides in water or in disposal units. For scenarios for direct intrusion into disposal units, the unit concentrations to which the dose estimates are normalized are the concentrations at the time exposures are assumed to occur, rather than the concentrations at the time of disposal.

\section{C.3.4.1 Exposure Pathways for Off-Site Individuals}

As discussed in Sect. 4.3.1 and C.3.2.1, direct consumption of drinking water from a source of contaminated groundwater is the only exposure pathway that needs to be considered in the dose analysis 
for off-site individuals, because the assumed limit on EDE of 4 mrem per year from the drinking water pathway only is expected to be more restrictive for any radionuclide than the limit on EDE of 25 mrem per year from all exposure pathways.

The annual EDE (rem/year) from direct ingestion of radionuclide $i$ in drinking water $(w)$ is given by

$$
H_{i w}=C_{i w} U_{w} D_{i}
$$

where

$\mathrm{C}_{\mathrm{iw}}=$ concentration of radionuclide $\mathrm{i}$ in drinking water $(\mu \mathrm{Ci} / \mathrm{L})$,

$\mathrm{U}_{\mathrm{w}}=$ annual consumption of drinking water (L/year), and

$D_{i} \quad=D C F$ for ingestion of radionuclide $\mathrm{i}(\mathrm{rem} / \mu \mathrm{Ci})$.

In implementing the model, a daily consumption of contaminated drinking water of 2 L, i.e., an annual consumption of $730 \mathrm{~L}$, is assumed.

Effective dose equivalents, per unit concentration $(\mu \mathrm{Ci} / \mathrm{L})$ of radionuclide in drinking water are listed in Table C.3-5. These EDEs are developed by applying the model described in Eq. C.3-1, using internal DCFs from Table C.3-2. The radionuclides listed in this table include those selected on the basis of a screening analysis for the groundwater pathway described in Sect. 4.1.3 and radioactive decay products that may occur in significant concentrations in groundwater at various times in the future.

\section{C.3.4.2 Exposure Pathways for Inadvertent Intruders}

As described in Sect. 6.1, exposures of inadvertent intruders resulting from direct intrusion into disposal units are assumed to occur according to the agriculture, resident, or post-drilling scenarios. This section presents the models and parameter values used to estimate doses to inadvertent intruders for each of these scenarios.

\section{Agriculture Scenario}

In the agriculture scenario, exposures of inadvertent intruders are assumed to occur after an intruder exhumes waste from disposal units while excavating to build a foundation for a home on top of the disposal facility and some of the exhumed waste is mixed with native soil in a vegetable garden. The exposure pathways assumed for this scenario then include: 1) ingestion of vegetables grown in contaminated garden soil; 2) direct ingestion of contaminated soil in conjunction with vegetable intakes; 3 ) external exposure to contaminated soil while working in the garden and residing in the home on top of the disposal units; and 4) inhalation of suspended activity in particulate form and inhalation of isotopes of radon and their short-lived decay products while working in the garden and residing in the home. The model for each exposure pathway is described below. The radionuclides included in the dose analysis for the agriculture scenario were selected on the basis of a screening analysis described in Sect. 6.2. Radioactive decay products that may occur in significant concentrations in disposal units at times far in the future also are included in the dose analysis. 
Vegetable Pathway. The annual EDE (rem/year) from ingestion of radionuclide $i$ in vegetables (v) is given by

$$
\mathrm{H}_{\mathrm{iv}}=\mathrm{C}_{\mathrm{iv}} \mathrm{U}_{\mathrm{v}} \mathrm{D}_{\mathrm{i}}
$$

where

$\mathrm{C}_{\mathrm{iv}}=$ concentration of radionuclide $\mathrm{i}$ in vegetables $(\mu \mathrm{Ci} / \mathrm{kg})$,

$\mathrm{U}_{\mathrm{v}} \quad \ldots$ annual consumption of vegetables ( $\mathrm{kg}$ fresh weight per year), and

$D_{i}=D C F$ for ingestion of radionuclide $\mathrm{i}(\mathrm{rem} / \mu \mathrm{Ci})$.

Radionuclides are assumed to be transferred to vegetables via root uptake from the contaminated garden soil, and the radionuclide concentrations in vegetables are given by

where

$$
\begin{aligned}
\mathrm{C}_{\mathrm{iv}} & =\mathrm{B}_{\mathrm{iv}} \mathrm{C}_{\mathrm{is}} / \rho_{\mathrm{s}} \\
& =\mathrm{B}_{\mathrm{iv}} \mathrm{f}_{\mathrm{s}} \mathrm{C}_{\mathrm{it}} / \rho_{\mathrm{s}}, \quad(\mathrm{C} .3-3)
\end{aligned}
$$

$\mathrm{B}_{\mathrm{iv}}=$ plant-to-soil concentration ratio for radionuclide $\mathrm{i}(\mu \mathrm{Ci} / \mathrm{kg}$ fresh weight in vegetation per $\mu \mathrm{Ci} / \mathrm{kg}$ dry weight in soil),

$\mathrm{C}_{\mathrm{is}}=$ concentration of radionuclide $\mathrm{i}$ in soil in vegetable garden $\left(\mu \mathrm{Ci} / \mathrm{m}^{3}\right)$,

$\rho_{\mathrm{s}}=$ bulk density of soil $\left(\mathrm{kg} / \mathrm{m}^{3}\right)$,

$\mathrm{C}_{\mathrm{it}}=$ concentration of radionuclide $\mathrm{i}$ in exhumed waste $\left(\mu \mathrm{Ci} / \mathrm{m}^{3}\right)$, and

$\mathrm{f}_{\mathrm{s}}=$ dilution factor for mixing of radionuclides in exhumed waste into soil in vegetable garden.

The assumed plant-to-soil concentration ratios in vegetables are given in Table C.3-6. Since site-specific data generally are lacking, the adopted values for all elements are based entirely on published evaluations and compilations which are generic in nature. The adopted values for almost all elements were obtained from the evaluation of published data by Baes et al. (1984). Although selection of these concentration ratios for use at the SRS clearly is judgmental, the use of data from a single source at least ensures some degree of consistency among the adopted values for the different elements.

Baes et al. (1984) give concentration ratios for vegetative portions of food crops, which would apply to leafy vegetables, and for nonvegetative (reproductive) portions, which would apply to nonleafy vegetables. The values for nonvegetative portions of food crops were adopted for use in this analysis, because consumption of nonleafy vegetables is expected to be considerably greater than consumption of leafy-vegetables (Baes-et-al._1984;-Hamby 1992). The reported concentration ratios on a dry-weight basis for nonleafy vegetation were converted to a fresh-weight basis by multiplying by a factor of 0.43 , which represents the average conversion factor for all types of nonleafy vegetables (Baes et al. 1984).

The other parameter values assumed in the model for the vegetable pathway are as follows: a dilution factor for mixing of radionuclides in exhumed waste into native soil in the vegetable garden of 0.2 (Napier et al. 1984), a bulk density of soil of $1,400 \mathrm{~kg} / \mathrm{m}^{3}$ (Baes and Sharp 1983), and an annual freshweight consumption of contaminated vegetables of $90 \mathrm{~kg}$. The assumed dilution factor for mixing of exhumed waste with native soil in a vegetable garden of 0.2 is based on a typical depth and area of an excavation for a home and the reasonable assumption that only a relatively small fraction of the soil in the vegetable garden could contain exhumed waste in order for the garden to be productive; this dilution factor is consistent with previous assumptions for the agriculture scenario (NRC 1981; Oztunali and Roles 1986). The assumed yearly consumption of vegetables of $90 \mathrm{~kg}$ is based on data obtained near the 
Table C.3-5 Annual EDEs from drinking water pathway per unit concentration of radionuclides in water

\begin{tabular}{|c|c|}
\hline Radionuclide ${ }^{a, b}$ & $\mathrm{EDE}, \mathrm{rem} / \mathrm{y}$ per $\mu \mathrm{Ci} / \mathrm{L}$ \\
\hline $\mathrm{H}-3$ & $4.6 \mathrm{E}-02$ \\
\hline $\mathrm{C}-14$ & $1.5 \mathrm{E}+00$ \\
\hline $\mathrm{Ni}-59$ & $1.5 \mathrm{E}-01$ \\
\hline Se-79 & $6.1 \mathrm{E}+00$ \\
\hline $\mathrm{Rb}-87$ & $3.5 \mathrm{E}+00$ \\
\hline Sr-90+d & $1.0 \mathrm{E}+02$ \\
\hline Mo-93 & $9.5 \mathrm{E}-01$ \\
\hline $\mathrm{Zr}-93+\mathrm{d}$ & $1.6 \mathrm{E}+00$ \\
\hline $\mathrm{Nb}-94$ & $3.7 \mathrm{E}+00$ \\
\hline Тc-99 & $9.5 \mathrm{E}-01$ \\
\hline Pd-107 & $1.0 \mathrm{E}-01$ \\
\hline $\mathrm{Sn}-126+\mathrm{d}$ & $1.3 \mathrm{E}+01$ \\
\hline I- 129 & $2.0 \mathrm{E}+02$ \\
\hline Cs-135 & $5.2 \mathrm{E}+00$ \\
\hline Th-230 & $3.9 E+02$ \\
\hline $\mathrm{Ra}-226+\mathrm{d}$ & $8.0 \mathrm{E}+02$ \\
\hline $\mathrm{Pb}-210$ & $3.7 \mathrm{E}+03$ \\
\hline Po- 210 & $1.2 \mathrm{E}+03$ \\
\hline $\mathrm{Th}-232$ & $2.0 \mathrm{E}+03$ \\
\hline $\mathrm{Ra}-228+\mathrm{d}$ & $8.8 \mathrm{E}+02$ \\
\hline Th-228 & $2.8 \mathrm{E}+02$ \\
\hline $\mathrm{Ra}-224+\mathrm{d}$ & $2.7 \mathrm{E}+02$ \\
\hline U-232 & $9.5 \mathrm{E}+02$ \\
\hline Th-228 & $2.8 \mathrm{E}+02$ \\
\hline $\mathrm{Ra}-224+\mathrm{d}$ & $2.7 \mathrm{E}+02$ \\
\hline$U-233$ & $2.0 \mathrm{E}+02$ \\
\hline Th-229 & $2.6 \mathrm{E}+03$ \\
\hline $\mathrm{Ra}-225+\mathrm{d}$ & $3.0 \mathrm{E}+02$ \\
\hline $\mathrm{U}-234$ & $1.9 \mathrm{E}+02$ \\
\hline Th-230 & $3.9 \mathrm{E}+02$ \\
\hline $\mathrm{Ra}-226+\mathrm{d}$ & $8.0 \mathrm{E}+02$ \\
\hline $\mathrm{Pb}-210$ & $3.7 \mathrm{E}+03$ \\
\hline Po-210 & $1.2 E+03$ \\
\hline $\mathrm{U}-235+\mathrm{d}$ & $1.8 \mathrm{E}+02$ \\
\hline $\mathrm{Pa}-231$ & $8.0 \mathrm{E}+03$ \\
\hline $\mathrm{Ac}-227$ & $1.0 \mathrm{E}+04$ \\
\hline Th-227 & $2.6 \mathrm{E}+01$ \\
\hline $\mathrm{Ra}-223+\mathrm{d}$ & $4.0 \mathrm{E}+02$ \\
\hline $\mathrm{U}-236$ & $1.8 \mathrm{E}+02$ \\
\hline $\mathrm{U}-238$ & $1.7 \mathrm{E}+02$ \\
\hline Th-234 +d & $9.5 \mathrm{E}+00$ \\
\hline U-234 & $1.9 \mathrm{E}+02$ \\
\hline $\mathrm{Np}-237+\mathrm{d}$ & $2.8 \mathrm{E}+03$ \\
\hline $\mathrm{Pu}-238$ & $2.8 \mathrm{E}+03$ \\
\hline U-234 & $1.9 E+02$ \\
\hline
\end{tabular}


Table C.3-5 Annual EDEs from drinking water pathway per unit concentration of radionuclides in water

\begin{tabular}{|c|c|}
\hline Radionuclide ${ }^{\mathrm{a}, \mathrm{b}}$ & $\mathrm{EDE}, \mathrm{rem} / \mathrm{y}$ per $\mu \mathrm{Ci} / \mathrm{L}$ \\
\hline Pu-239 & $3.1 \mathrm{E}+03$ \\
\hline U-235 & $1.8 \mathrm{E}+02$ \\
\hline Pu-240 & $3.1 E+03$ \\
\hline $\mathrm{U}-236$ & $1.8 \mathrm{E}+02$ \\
\hline Pu-241 & $6.3 \mathrm{E}+01$ \\
\hline Am-241 & $3.3 \mathrm{E}+03$ \\
\hline$-\mathrm{Np}-237+\mathrm{d}$ & $2-8 \mathrm{E}+03$ \\
\hline $\mathrm{Pu}-242$ & $3.0 \mathrm{E}+03$ \\
\hline $\mathrm{U}-238$ & $1.7 \mathrm{E}+02$ \\
\hline $\mathrm{Pu}-244+\mathrm{d}$ & $2.9 \mathrm{E}+03$ \\
\hline Am-241 & $3.3 \mathrm{E}+03$ \\
\hline $\mathrm{Np}-237+\mathrm{d}$ & $2.8 \mathrm{E}+03$ \\
\hline$A m-242 m+d$ & $3.1 E+03$ \\
\hline $\mathrm{Pu}-238$ & $2.8 \mathrm{E}+03$ \\
\hline U-234 & $1.9 \mathrm{E}+02$ \\
\hline $\mathrm{Am}-243+\mathrm{d}$ & $3.3 \mathrm{E}+03$ \\
\hline Pu-239 & $3.1 \mathrm{E}+03$ \\
\hline $\mathrm{Cm}-242$ & $8.0 \mathrm{E}+01$ \\
\hline $\mathrm{Pu}-238$ & $2.8 \mathrm{E}+03$ \\
\hline U-234 & $1.9 \mathrm{E}+02$ \\
\hline $\mathrm{Cm}-245$ & $3.3 E+03$ \\
\hline $\mathrm{Pu}-241$ & $6.3 \mathrm{E}+01$ \\
\hline Am-241 & $3.3 \mathrm{E}+03$ \\
\hline $\mathrm{Np}-237+\mathrm{d}$ & $2.8 \mathrm{E}+03$ \\
\hline $\mathrm{Cm}-246$ & $3.3 \mathrm{E}+03$ \\
\hline $\mathrm{Cm}-247+\mathrm{d}$ & $3.0 \mathrm{E}+03$ \\
\hline $\mathrm{Am}-243$ & $3.3 E+03$ \\
\hline $\mathrm{Np}-239$ & $2.1 \mathrm{E}+00$ \\
\hline $\mathrm{Pu}-239$ & $3.1 E+03$ \\
\hline $\mathrm{Cm}-248$ & $1.2 \mathrm{E}+04$ \\
\hline Pu-244 & $2.7 \mathrm{E}+03$ \\
\hline Bk-249 & $4.4 \mathrm{E}+00$ \\
\hline $\mathrm{Cf}-249$ & $3.4 \mathrm{E}+03$ \\
\hline $\mathrm{Cm}-245$ & $3.3 E+03$ \\
\hline Cf-249 & $3.4 \mathrm{E}+03$ \\
\hline$-\mathrm{Cm}=245$ & $-3.3 E+03$ \\
\hline $\mathrm{Pu}-241$ & $6.3 E+01$ \\
\hline $\mathrm{Am}-241$ & $3.3 \mathrm{E}+03$ \\
\hline $\mathrm{Np}-237+\mathrm{d}$ & $2.8 E+03$ \\
\hline $\mathrm{Cf}-252$ & $6.9 E+02$ \\
\hline $\mathrm{Cm}-248$ & $1.1 E+04$ \\
\hline
\end{tabular}

${ }^{\mathrm{a}}$ Indented entries are decay products of parent radionuclide that are potentially radiologicallysignificant.

"The notation " $+d$ " indicates that short-lived daughters were incorporated into the EDE. Dose from other daughters listed is calculated explicitly by adding EDE's. 
SRS (Hamby 1992), which indicate a total yearly consumption of all vegetables by an average adult of $180 \mathrm{~kg}$, and the assumption that half of an intruder's total intake of vegetables is obtained from the home garden. An assumption that an intruder's entire intake of all vegetables would be obtained from the home garden is regarded as unreasonably conservative.

Effective dose equivalents for the vegetable pathway are listed in Table C.3-7. The annual dose per unit concentration of a radionuclide in exhumed waste from a disposal unit at the time intrusion occurs is based on the model and parameter values described above and the ingestion DCFs given in Table C.3-2.

Soil Ingestion Pathway. The annual EDE (rem/year) from direct ingestion of radionuclide $\mathrm{i}$ in contaminated soil (s) is given by

$$
\mathrm{H}_{\mathrm{is}}=\mathrm{C}_{\mathrm{is}} \mathrm{U}_{\mathrm{s}} \mathrm{D}_{\mathrm{i}} \text {, }
$$

where

$\mathrm{C}_{\mathrm{is}}=$ concentration of radionuclide $\mathrm{i}$ in soil in vegetable garden $(\mu \mathrm{Ci} / \mathrm{kg})$,

$\mathrm{U}_{\mathrm{s}} \quad=$ annual consumption of contaminated soil $(\mathrm{kg} /$ year $)$, and

$\mathrm{D}_{\mathrm{i}} \quad=\mathrm{DCF}$ for ingestion of radionuclide $\mathrm{i}(\mathrm{rem} / \mu \mathrm{Ci})$.

Ingestion of contaminated soil is assumed to occur primarily as a result of incomplete washing of vegetables from the garden before consumption. Since the SRS is a humid site with extensive vegetation, ingestion of contaminated soil from sources other than the garden should be relatively unimportant for an average adult. Radionuclide concentrations in soil in the vegetable garden are given by

$$
\mathrm{C}_{\text {is }} \quad=\mathrm{f}_{\mathrm{s}} \mathrm{C}_{\mathrm{it}} / \rho_{\mathrm{s}} \text {, }
$$

where

$\mathrm{C}_{\mathrm{it}}=$ concentration of radionuclide $\mathrm{i}$ in exhumed waste $\left(\mu \mathrm{Ci} / \mathrm{m}^{3}\right)$,

$\mathrm{f}_{\mathrm{s}}=$ dilution factor for mixing of radionuclides in exhumed waste into soil in vegetable garden, and

$\rho_{\mathrm{s}} \quad=$ bulk density of soil $\left(\mathrm{kg} / \mathrm{m}^{3}\right)$.

A dilution factor for mixing of radionuclides in exhumed waste into native soil in the vegetable garden of 0.2 and a soil bulk density of $1,400 \mathrm{~kg} / \mathrm{m}^{3}$ are assumed, as in the model for the vegetable pathway. A daily consumption of contaminated soil from the vegetable garden of $0.1 \mathrm{~g}$, i.e., an annual consumption of $0.037 \mathrm{~kg}$, also is assumed (U.S.EPA 1989).

Effective dose equivalents for the soil ingestion pathway are listed in Table C.3-8. The annual dose per unit concentration of a radionuclide in exhumed waste from a disposal unit at the time intrusion occurs is based on the model and parameter values described above and the ingestion DCFs given in Table C.3-2. 
Table C.3-6 Elemental plant-to-soil concentration ratios in vegetables

\begin{tabular}{|c|c|c|c|}
\hline Element & $\mathrm{B}_{\mathrm{v}}^{\mathrm{a}, \mathrm{b}}$ & Element & $B_{v}{ }^{2, b}$ \\
\hline $\mathrm{Ac}$ & $1.5 \mathrm{E}-04$ & $\mathrm{~Pa}$ & $1.1 \mathrm{E}-04$ \\
\hline $\mathrm{Am}$ & $1.1 \mathrm{E}-04$ & $\mathrm{~Pb}$ & $3.9 \mathrm{E}-03$ \\
\hline $\mathrm{Ba}^{\mathrm{c}}$ & & Pd & $1.7 \mathrm{E}-02$ \\
\hline$B i^{c}$ & & Po & $1.7 \mathrm{E}-04$ \\
\hline $\mathrm{Bk}$ & $6.6 \mathrm{E}-06$ & $\mathrm{Pu}$ & $1.9 \mathrm{E}-05$ \\
\hline$C^{d}$ & $5.6 \mathrm{E}-01$ & $\mathrm{Ra}$ & $6.5 \mathrm{E}-04$ \\
\hline $\mathrm{Cd}$ & $6.5 \mathrm{E}-02$ & $\mathrm{Rb}$ & 3.0E-02 \\
\hline $\mathrm{Cf}^{e}$ & $6.6 \mathrm{E}-06$ & $\mathrm{Sb}$ & $1.3 \mathrm{E}-02$ \\
\hline $\mathrm{Cm}$ & $6.6 \mathrm{E}-06$ & $\mathrm{Se}$ & $1.1 \mathrm{E}-02$ \\
\hline $\mathrm{Co}$ & $3.0 \mathrm{E}-03$ & $\mathrm{Sm}$ & 1.7E-03 \\
\hline $\mathrm{Cs}$ & $1.3 \mathrm{E}-02$ & $\mathrm{Sn}$ & $2.6 \mathrm{E}-03$ \\
\hline $\mathrm{Eu}$ & $1.7 \mathrm{E}-03$ & $\mathrm{Sr}$ & $1.1 \mathrm{E}-01$ \\
\hline $\mathrm{H}^{\mathrm{f}}$ & $4.8 \mathrm{E}+00$ & $\mathrm{Tc}$ & $6.5 \mathrm{E}-01$ \\
\hline I & $2.2 \mathrm{E}-02$ & Th & 3.7E-05 \\
\hline $\mathrm{Mo}^{\mathrm{g}}$ & $1.0 \mathrm{E}-01$ & $\mathrm{Tl}^{\mathrm{c}}$ & \\
\hline $\mathrm{Ni}$ & $2.6 \mathrm{E}-02$ & $\mathrm{U}$ & $1.7 \mathrm{E}-03$ \\
\hline $\mathrm{Nb}$ & $2.2 \mathrm{E}-03$ & $Y^{c}$ & \\
\hline $\mathrm{Np}$ & 4.3E-03 & $\mathrm{Zr}$ & 2.2E-04 \\
\hline
\end{tabular}

$\mu \mathrm{Ci} / \mathrm{kg}$ fresh weight in vegetation per $\mu \mathrm{Ci} / \mathrm{kg}$ dry weight in soil.

b Except as noted, values are based on concentration ratios reported on basis of dry weight of vegetation given in Fig. 2.2 of Baes et al. (1984) multiplied by a factor of 0.43 to convert to fresh weight of vegetation (Baes et al. 1984).

c Short-lived daughter; is not taken up by plant roots independent of parent.

d Value based on measurement of Sheppard et al. (1991) for carbonate from in acidic soil with low organic matter content. Reported value for dry weight of vegetation is converted to fresh weight by multiplying by factor of 0.43 (Baes et al. 1984).

- Value is assumed to be same as value for $\mathrm{Cm}$.

f Value obtained from Table E-1 of NRC 1977.

8 From NCRP Report No. 123, Volume I (NCRP 1996). 
Table C.3-7 Annual EDEs from vegetable pathway per unit concentration of radionuclides in exhumed waste for agriculture scenario

\begin{tabular}{|c|c|}
\hline Radionuclide $^{a, b}$ & $\begin{array}{c}\text { EDE } \\
\left(\mathrm{rem} / \mathrm{y} \text { per } \mu \mathrm{Ci} / \mathrm{m}^{3}\right)\end{array}$ \\
\hline $\mathrm{H}-3$ & $3.9 \mathrm{E}-06$ \\
\hline C-14 & $1.5 E-05$ \\
\hline Co- 60 & 1.0E-06 \\
\hline $\mathrm{Ni}-59$ & $6.7 \mathrm{E}-08$ \\
\hline $\mathrm{Ni}-63$ & $1.8 \mathrm{E}-07$ \\
\hline Se-79 & $1.2 \mathrm{E}-06$ \\
\hline $\mathrm{Rb}-87$ & $1.9 \mathrm{E}-06$ \\
\hline Sr-90+d & $1.8 \mathrm{E}-04$ \\
\hline Mo-93 & $1.7 \mathrm{E}-06$ \\
\hline$Z r-93+d$ & $2.0 \mathrm{E}-08$ \\
\hline $\mathrm{Nb}-94$ & $1.4 \mathrm{E}-07$ \\
\hline Tc-99 & $1.1 \mathrm{E}-05$ \\
\hline Pd-107 & $3.1 \mathrm{E}-08$ \\
\hline $\mathrm{Cd}-113 \mathrm{~m}$ & $1.3 \mathrm{E}-04$ \\
\hline $\mathrm{Sn}-121 \mathrm{~m}$ & 4.3E-08 \\
\hline Sn- $126+d$ & $7.9 \mathrm{E}-07$ \\
\hline $\mathrm{I}-129$ & $7.9 \mathrm{E}-05$ \\
\hline Cs-135 & $1.2 \mathrm{E}-06$ \\
\hline $\mathrm{Cs}-137+\mathrm{d}$ & $8.4 \mathrm{E}-06$ \\
\hline Sm-151 & $7.4 \mathrm{E}-09$ \\
\hline Eu-152 & $1.3 \mathrm{E}-07$ \\
\hline Eu-154 & $2.0 \mathrm{E}-07$ \\
\hline Th-228 & $1.8 \mathrm{E}-07$ \\
\hline Th-230 & $2.5 \mathrm{E}-07$ \\
\hline $\mathrm{Ra}-226+\mathrm{d}$ & $9.2 \mathrm{E}-06$ \\
\hline $\mathrm{Pb}-210$ & $2.6 \mathrm{E}-04$ \\
\hline Po-210 & $3.5 \mathrm{E}-06$ \\
\hline Th-232 & $1.3 \mathrm{E}-06$ \\
\hline $\mathrm{Ra}-228+\mathrm{d}$ & $1.0 \mathrm{E}-05$ \\
\hline Th-228 & $1.8 \mathrm{E}-07$ \\
\hline $\mathrm{Ra}-224+\mathrm{d}$ & $4.8 \mathrm{E}-06$ \\
\hline $\mathrm{U}-232$ & $2.8 \mathrm{E}-05$ \\
\hline Th-228 & $1.8 \mathrm{E}-07$ \\
\hline $\mathrm{Ra}-224+\mathrm{d}$ & $4.8 \mathrm{E}-06$ \\
\hline $\mathrm{U}-233$ & $5.9 E-06$ \\
\hline Th-229 & $1.7 \mathrm{E}-06$ \\
\hline $\mathrm{Ra}-225+\mathrm{d}$ & $2.8 \mathrm{E}-06$ \\
\hline U-234 & $5.7 \mathrm{E}-06$ \\
\hline Th-230 & $2.5 \mathrm{E}-07$ \\
\hline $\mathrm{Ra}-226+d$ & $9.2 \mathrm{E}-06$ \\
\hline $\mathrm{Pb}-210$ & $2.6 \mathrm{E}-04$ \\
\hline Po-210 & $3.5 \mathrm{E}-06$ \\
\hline
\end{tabular}


Table C.3-7 Annual EDEs from vegetable pathway per unit concentration of radionuclides in exhumed waste for agriculture scenario

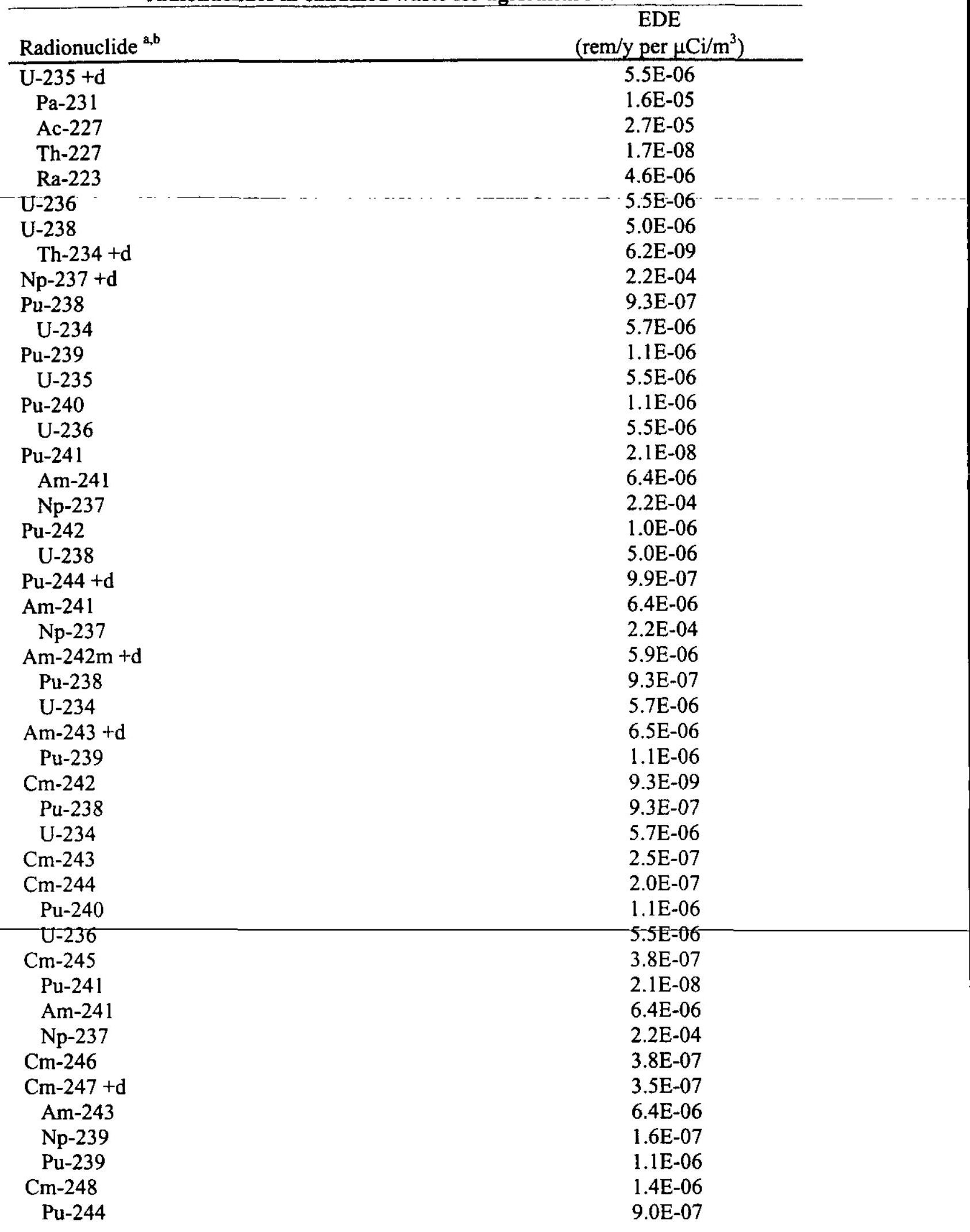


Table C.3-7 Annual EDEs from vegetable pathway per unit concentration of radionuclides in exhumed waste for agriculture scenario

\begin{tabular}{lc} 
Radionuclide a,b & $\begin{array}{c}\mathrm{EDE} \\
\left(\mathrm{rem} / \mathrm{y} \text { per } \mu \mathrm{Ci} / \mathrm{m}^{3}\right)\end{array}$ \\
\hline Bk-249 & $5.1 \mathrm{E}-10$ \\
$\mathrm{Cf}-249$ & $3.9 \mathrm{E}-07$ \\
$\mathrm{Cm}-245$ & $3.8 \mathrm{E}-07$ \\
$\mathrm{Cf}-249$ & $3.9 \mathrm{E}-07$ \\
$\mathrm{Cm}-245$ & $3.8 \mathrm{E}-07$ \\
$\mathrm{Pu}-241$ & $2.1 \mathrm{E}-08$ \\
$\mathrm{Am}-241$ & $6.4 \mathrm{E}-06$ \\
$\mathrm{~Np}-237$ & $2.2 \mathrm{E}-04$ \\
$\mathrm{Cf}-250$ & $1.6 \mathrm{E}-07$ \\
$\mathrm{Cm}-246$ & $3.8 \mathrm{E}-07$ \\
$\mathrm{Cf}-251$ & $3.9 \mathrm{E}-07$ \\
$\mathrm{Cf}-252$ & $8.0 \mathrm{E}-08$ \\
Cm-248 & $1.3 \mathrm{E}-06$ \\
\hline Indented entries are decay products of parent radionuclide that are potentially radiologically- \\
significant. \\
The notation "+d" indicates that short-lived daughters were incorporated into the EDE. Dose \\
from other daughters listed is calculated explicitly by adding EDE's.
\end{tabular}


External Exposure Pathways. For external exposure (e) to contaminated soil while working in the vegetable garden, the annual EDE (rem/year) from radionuclide $\mathrm{i}$ is given by

$$
\mathrm{H}_{\mathrm{ie}} \quad=\mathrm{C}_{\mathrm{is}} \mathrm{U}_{\mathrm{g}} \mathrm{D}_{\mathrm{is}}
$$

where

$\mathrm{C}_{\mathrm{is}}=$ concentration of radionuclide $\mathrm{i}$ in soil in vegetable garden $\left(\mu \mathrm{Ci} / \mathrm{m}^{3}\right)$,

$\mathrm{U}_{\mathrm{B}--}=$ fraction of the year during which external exposure to contaminated soil in vegetable garden occurs, and

$D_{\text {is }}=$ dose-rate conversion factor for external exposure to radionuclide $\mathrm{i}$ in garden soil (rem/y per $\mu \mathrm{Ci} / \mathrm{m}^{3}$ ).

As in the models for the vegetable and soil ingestion pathways, the radionuclide concentrations in soil in the vegetable garden are given by

where

$$
\mathrm{C}_{\text {is }}=\mathrm{f}_{\mathrm{s}} \mathrm{C}_{\mathrm{it}} \text {, }
$$

$\mathrm{C}_{\mathrm{it}}=$ concentration of radionuclide $\mathrm{i}$ in exhumed waste $\left(\mu \mathrm{Ci} / \mathrm{m}^{3}\right)$, and

$\mathrm{f}_{\mathrm{s}}=$ dilution factor for mixing of radionuclides in exhumed waste into soil in vegctable garden.

A dilution factor for mixing of radionuclides in exhumed waste into native soil in the vegetable garden of 0.2 is assumed, as in the models for the vegetable and soil ingestion pathways. The fraction of the year during which exposure while working in the garden occurs is assumed to be 0.01 (Oztunali et al. 1981); i.e., the assumed exposure time is about $100 \mathrm{~h} /$ year.

The model for estimating external dose while working in the garden is summarized in Table C.3-9. The annual dose per unit concentration of a radionuclide in exhumed waste from a disposal unit at the time intrusion occurs is based on the model and parameter values described above and the external dose-rate conversion factors given in Table C.3-3.

For external exposure during residence in a home on top of exposed disposal units, the annual EDE (rem/year) from radionuclide $\mathrm{i}$ is given by where

$$
\mathrm{H}_{\mathrm{ie}}=\mathrm{C}_{\mathrm{it}} \mathrm{U}_{\mathrm{h}} \mathrm{D}_{\mathrm{it}} \mathrm{S} \text {, }
$$

$\mathrm{C}_{\mathrm{it}}=$ concentration of radionuclide $\mathrm{i}$ in disposal unit $\left(\mu \mathrm{Ci} / \mathrm{m}^{3}\right)$,

$\mathrm{U}_{\mathrm{h}}=$ fraction of the year during which external exposure while residing in the home occurs,

$D_{i t}=$ dose-rate conversion factor for external exposure to radionuclide $i$ in disposal unit (rem/y per $\mu \mathrm{Ci} / \mathrm{m}^{3}$ ), and

$\mathrm{S}=$ shielding factor for radionuclides during indoor residence.

The shielding factor takes into account the reduction in external dose provided by the walls and floor of the home. 
Table C.3-8 Annual EDEs from soil ingestion pathway per unit concentration of radionuclides in exhumed waste for agriculture scenario

\begin{tabular}{|c|c|}
\hline Radionuclide $^{\mathrm{a}, \mathrm{b}}$ & $\begin{array}{c}\text { EDE } \\
\left(\mathrm{rem} / \mathrm{y} \text { per } \mu \mathrm{Ci} / \mathrm{m}^{3}\right)\end{array}$ \\
\hline $\mathrm{H}-3$ & $3.3 \mathrm{E}-10$ \\
\hline$C-14$ & $1.1 \mathrm{E}-08$ \\
\hline $\mathrm{Co}-60$ & $1.4 \mathrm{E}-07$ \\
\hline $\mathrm{Ni}-59$ & $1.1 \mathrm{E}-09$ \\
\hline Ni-63 & $2.9 \mathrm{E}-09$ \\
\hline Se-79 & $4.4 \mathrm{E}-08$ \\
\hline $\mathrm{Rb}-87$ & $2.5 \mathrm{E}-08$ \\
\hline $\mathrm{Sr}-90+\mathrm{d}$ & $7.4 \mathrm{E}-07$ \\
\hline Mo-93 & $6.9 \mathrm{E}-09$ \\
\hline $\mathrm{Zr}-93+\mathrm{d}$ & $1.1 \mathrm{E}-08$ \\
\hline $\mathrm{Nb}-94$ & $2.7 \mathrm{E}-08$ \\
\hline Tc-99 & $6.9 \mathrm{E}-09$ \\
\hline Pd-107 & $7.4 \mathrm{E}-10$ \\
\hline $\mathrm{Cd}-113 \mathrm{~m}$ & $7.9 \mathrm{E}-07$ \\
\hline $\mathrm{Sn}-121 \mathrm{~m}$ & $6.9 \mathrm{E}-09$ \\
\hline $\mathrm{Sn}-126+d$ & $9.7 \mathrm{E}-08$ \\
\hline $\mathrm{I}-129$ & $1.5 \mathrm{E}-06$ \\
\hline $\mathrm{Cs}-135$ & $3.8 \mathrm{E}-08$ \\
\hline Cs- $137+d$ & $2.6 \mathrm{E}-07$ \\
\hline $\mathrm{Sm}-151$ & $1.8 \mathrm{E}-09$ \\
\hline Eu-152 & $3.2 \mathrm{E}-08$ \\
\hline Eu-154 & $4.8 \mathrm{E}-08$ \\
\hline Th-228 & $2.0 \mathrm{E}-06$ \\
\hline Th-230 & $2.8 \mathrm{E}-06$ \\
\hline $\mathrm{Ra}-226+\mathrm{d}$ & $5.8 \mathrm{E}-06$ \\
\hline $\mathrm{Pb}-210$ & $2.7 \mathrm{E}-05$ \\
\hline Po-210 & $8.5 E-06$ \\
\hline Th-232 & $1.5 \mathrm{E}-05$ \\
\hline $\mathrm{Ra}-228+\mathrm{d}$ & $6.4 \mathrm{E}-06$ \\
\hline Th- 228 & $2.0 \mathrm{E}-06$ \\
\hline $\mathrm{Ra}-224+\mathrm{d}$ & $2.0 \mathrm{E}-06$ \\
\hline $\mathrm{U}-232$ & $6.9 E-06$ \\
\hline Th-228 & $2.0 \mathrm{E}-06$ \\
\hline $\mathrm{Ra}-224+\mathrm{d}$ & $2.0 \mathrm{E}-06$ \\
\hline $\mathrm{U}-233$ & $1.4 \mathrm{E}-06$ \\
\hline Th-229 & $1.9 \mathrm{E}-05$ \\
\hline $\mathrm{Ra}-225+\mathrm{d}$ & $2.1 \mathrm{E}-06$ \\
\hline U-234 & $1.4 \mathrm{E}-06$ \\
\hline Th-230 & $2.8 \mathrm{E}-06$ \\
\hline $\mathrm{Ra}-226+\mathrm{d}$ & $5.8 \mathrm{E}-06$ \\
\hline $\mathrm{Pb}-210$ & $2.7 \mathrm{E}-05$ \\
\hline Po-210 & $8.5 E-06$ \\
\hline
\end{tabular}


Table C.3-8 Annual EDEs from soil ingestion pathway per unit concentration of radionuclides in exhumed waste for agriculture scenario

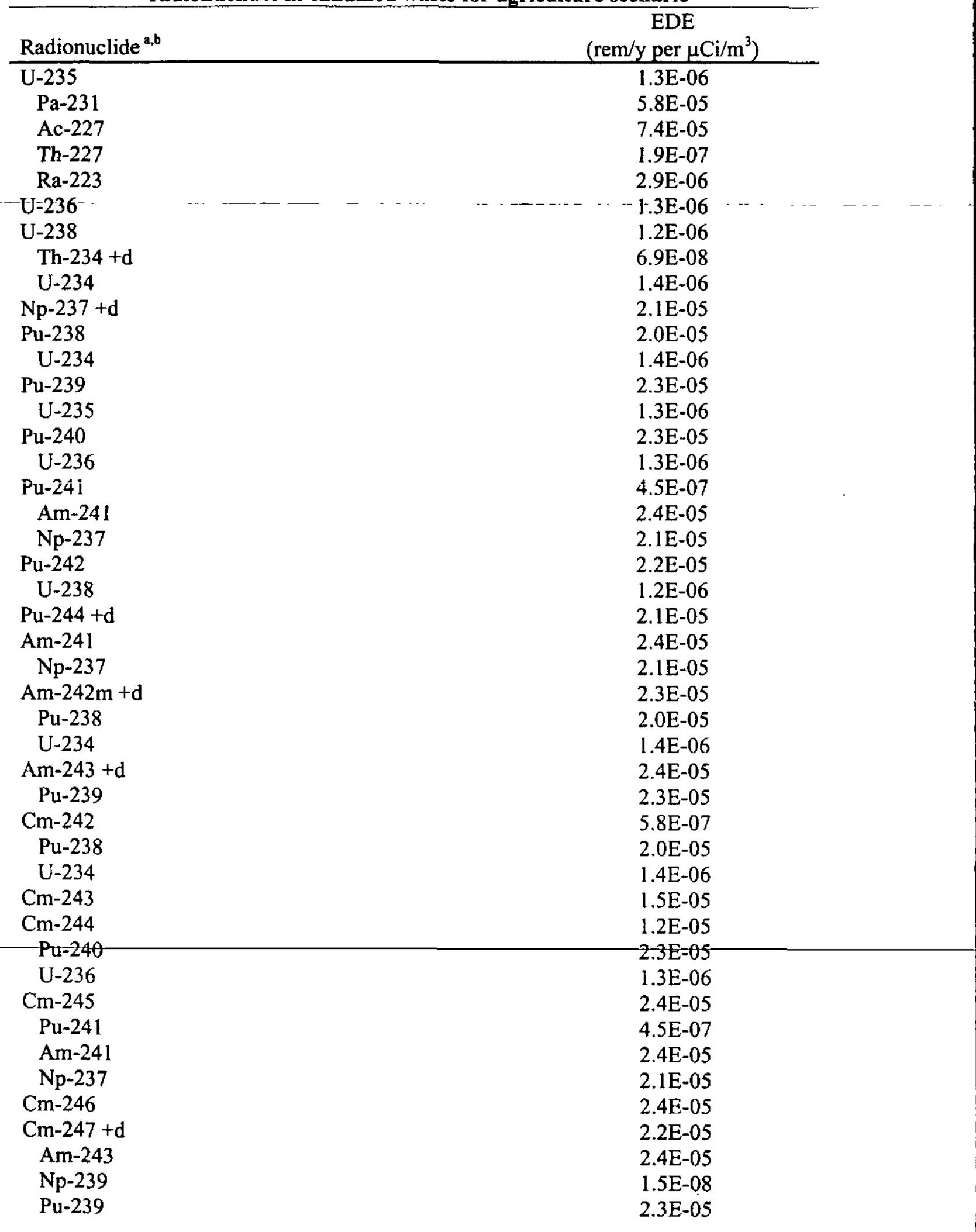


Table C.3-8 Annual EDEs from soil ingestion pathway per unit concentration of radionuclides in exhumed waste for agriculture scenario

\begin{tabular}{lc}
\hline Radionuclide a,b & $\begin{array}{c}\mathrm{EDE} \\
\left(\mathrm{rem} / \mathrm{y} \mathrm{per} \mu \mathrm{Ci} / \mathrm{m}^{3}\right)\end{array}$ \\
\hline $\mathrm{Cm}-248$ & $8.5 \mathrm{E}-05$ \\
Pu-244 & $1.9 \mathrm{E}-05$ \\
$\mathrm{Bk}-249$ & $3.2 \mathrm{E}-08$ \\
$\mathrm{Cf}-249$ & $2.4 \mathrm{E}-05$ \\
$\mathrm{Cm}-245$ & $2.4 \mathrm{E}-05$ \\
$\mathrm{Cf}-249$ & $2.4 \mathrm{E}-05$ \\
$\mathrm{Cm}-245$ & $2.4 \mathrm{E}-05$ \\
$\mathrm{Pu}-241$ & $4.5 \mathrm{E}-07$ \\
$\mathrm{Am}-241$ & $2.4 \mathrm{E}-05$ \\
$\mathrm{~Np}-237$ & $2.1 \mathrm{E}-05$ \\
$\mathrm{Cf}-250$ & $1.0 \mathrm{E}-05$ \\
$\mathrm{Cm}-246$ & $2.4 \mathrm{E}-05$ \\
$\mathrm{Cf}-251$ & $2.4 \mathrm{E}-05$ \\
$\mathrm{Cf}-252$ & $5.0 \mathrm{E}-06$ \\
$\mathrm{Cm}-248$ & $8.2 \mathrm{E}-05$ \\
\hline Indented entries are decay products of parent radionuclide that are potentially radiologically- \\
significant. \\
The notation “+d" indicates that short-lived daughters were incorporated into the EDE. Dose \\
from other daughters listed is calculated explicitly by adding EDE's.
\end{tabular}


Table C.3-9 Annual EDEs from external exposure in vegetable garden per unit concentration of radionuclides in exhumed waste for agriculture scenario

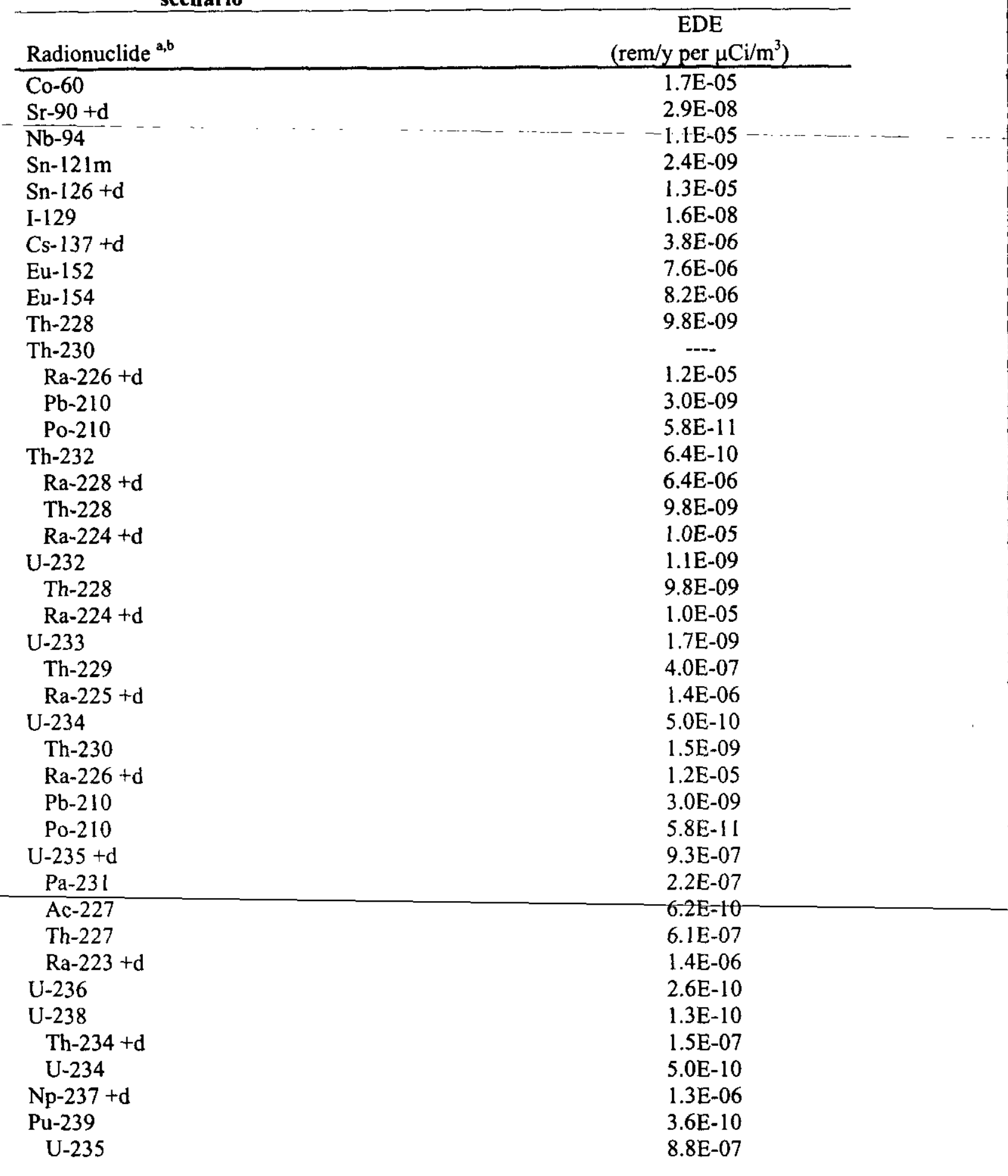


Table C.3-9 Annual EDEs from external exposure in vegetable garden per unit concentration of radionuclides in exhumed waste for agriculture scenario

\begin{tabular}{|c|c|}
\hline Radionuclide $^{\mathrm{a}, \mathrm{b}}$ & $\begin{array}{c}\text { EDE } \\
\left(\mathrm{rem} / \mathrm{y} \text { per } \mu \mathrm{Ci} / \mathrm{m}^{3}\right)\end{array}$ \\
\hline $\mathrm{Pu}-241$ & $7.4 \mathrm{E}-12$ \\
\hline Am-24I & $5.4 \mathrm{E}-08$ \\
\hline $\mathrm{Np}-237+d$ & $1.3 \mathrm{E}-06$ \\
\hline $\mathrm{Pu}-244+\mathrm{d}$ & $2.2 E-06$ \\
\hline Am-241 & $5.4 \mathrm{E}-08$ \\
\hline $\mathrm{Np}-237+\mathrm{d}$ & $1.3 \mathrm{E}-06$ \\
\hline$A m-242 m+d$ & $6.4 \mathrm{E}-08$ \\
\hline Pu-238 & $1.9 \mathrm{E}-10$ \\
\hline U-234 & $5.0 \mathrm{E}-10$ \\
\hline Am- $243+d$ & $1.1 \mathrm{E}-06$ \\
\hline Pu-239 & $3.6 \mathrm{E}-10$ \\
\hline $\mathrm{Cm}-243$ & $7.0 \mathrm{E}-07$ \\
\hline $\mathrm{Cm}-245$ & $4.2 \mathrm{E}-07$ \\
\hline $\mathrm{Pu}-241$ & $7.4 \mathrm{E}-12$ \\
\hline Am-241 & $5.4 \mathrm{E}-08$ \\
\hline $\mathrm{Np}-237+\mathrm{d}$ & $1.3 \mathrm{E}-06$ \\
\hline $\mathrm{Cm}-247+\mathrm{d}$ & $2.1 \mathrm{E}-06$ \\
\hline Am-243 & $1.8 \mathrm{E}-07$ \\
\hline Np-239 & $9.2 \mathrm{E}-07$ \\
\hline $\mathrm{Pu}-239$ & $3.6 \mathrm{E}-10$ \\
\hline $\mathrm{Cm}-248$ & $1.1 \mathrm{E}-10$ \\
\hline $\mathrm{Pu}-244+\mathrm{d}$ & $2.0 \mathrm{E}-06$ \\
\hline Bk-249 & $-\cdots$ \\
\hline $\mathrm{Cf}-249$ & $2.2 \mathrm{E}-06$ \\
\hline $\mathrm{Cm}-245$ & $4.2 \mathrm{E}-07$ \\
\hline Cf -249 & $2.2 \mathrm{E}-06$ \\
\hline $\mathrm{Cm}-245$ & $4.2 \mathrm{E}-07$ \\
\hline $\mathrm{Pu}-241$ & $7.4 \mathrm{E}-12$ \\
\hline Am-241 & $5.4 \mathrm{E}-08$ \\
\hline $\mathrm{Np}-237+\mathrm{d}$ & $1.3 \mathrm{E}-06$ \\
\hline $\mathrm{Cf}-251$ & $6.4 \mathrm{E}-07$ \\
\hline
\end{tabular}

Indented entries are decay products of parent radionuclide that are potentially radiologicallysignificant.

b The notation " $+d$ " indicates that short-lived daughters were incorporated into the EDE. Dose from other daughters listed is calculated explicitly by adding EDE's. 
Table C.3-10 Annual EDEs from external exposure in home per unit concentration of radionuclides in disposal units for agriculture scenario

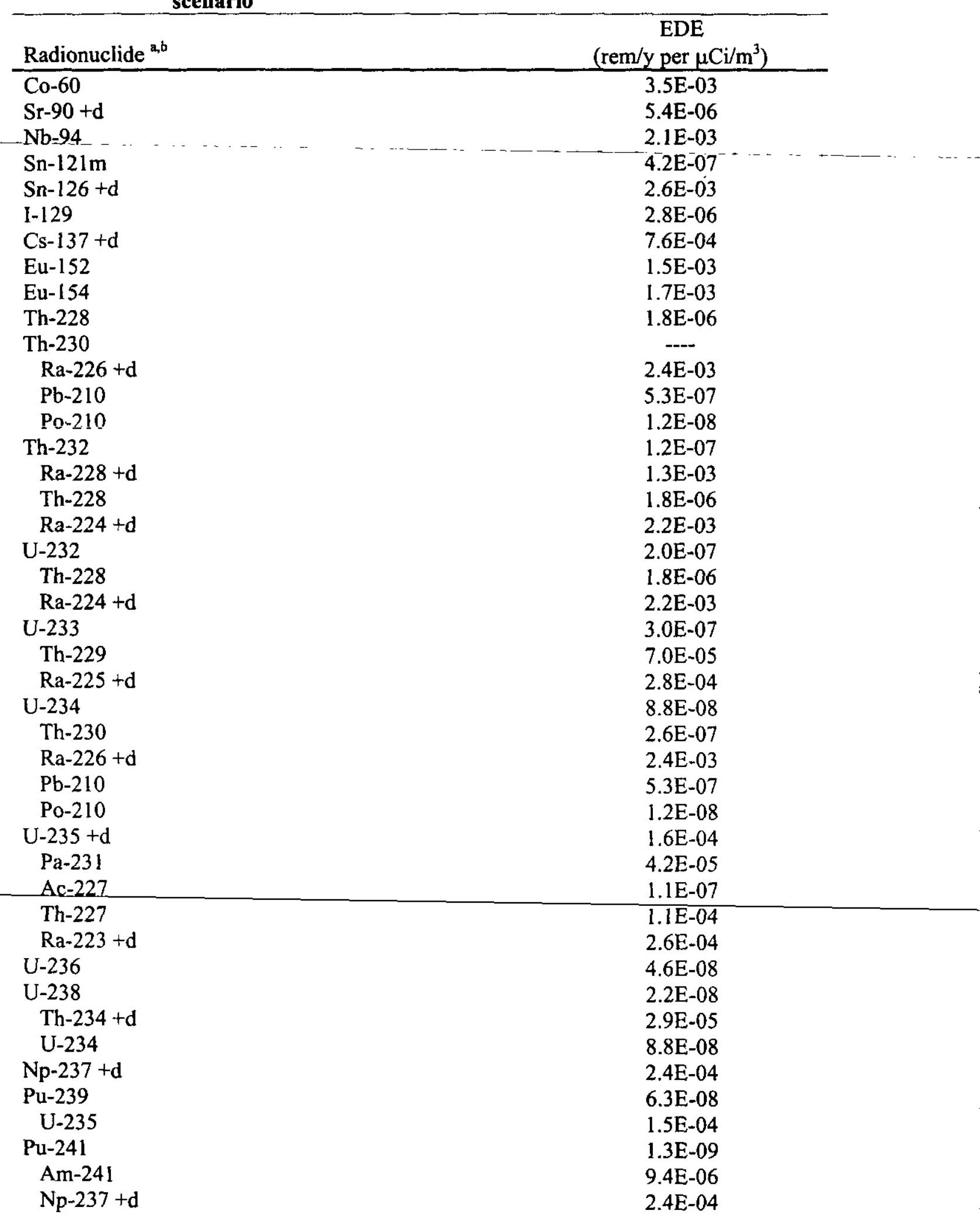


Table C.3-10 Annual EDEs from external exposure in home per unit concentration of radionuclides in disposal units for agriculture scenario

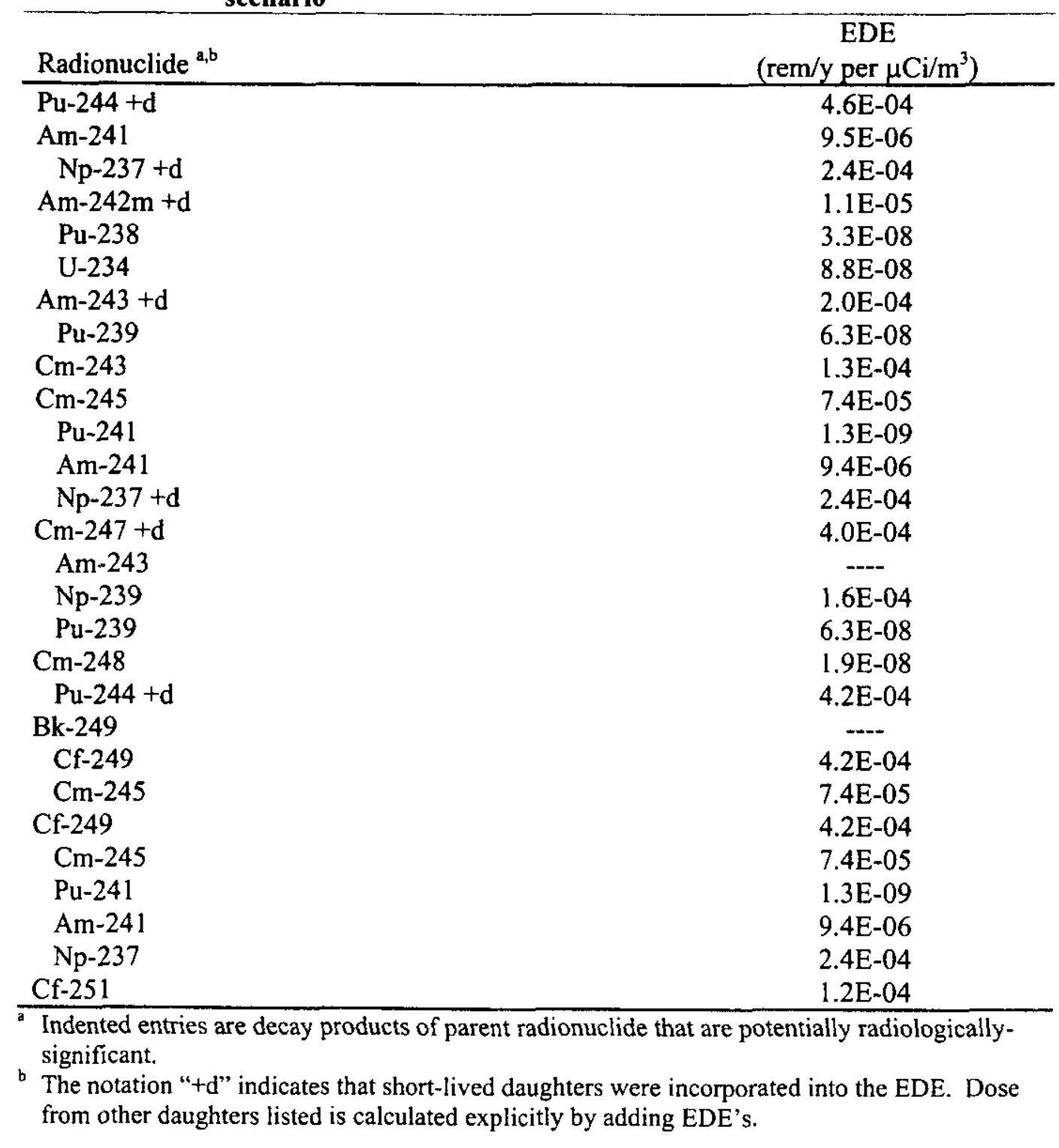


The fraction of the year during which exposure in the home is assumed to occur is 0.5 (Oztunali et al. 1981 ); i.e., the assumed exposure time is about $4,000 \mathrm{~h} /$ year. A shielding factor during indoor residence of 0.7 is assumed for all radionuclides (NRC 1977).

Effective dose equivalents for estimating external dose during indoor residence are listed in Table C.3-10. The annual dose per unit concentration of a radionuclide in a disposal unit at the time intrusion occurs is based on the model and parameter values described above and the external dose-rate conversion factors for sources uniformly distributed in an infinite thickness of soil-equivalent material given in the column in Table C.3-4 labeled "No shielding".

Inhalation Pathways. While working in the vegetable garden or residing in the home, the annual EDE (rem/year) from inhalation of radionuclide i suspended into air (a) in particulate form is given by

$$
\mathrm{H}_{\mathrm{ia}}=\mathrm{C}_{\mathrm{ia}} \mathrm{f}_{\mathrm{a}} \mathrm{U}_{\mathrm{a}} \mathrm{D}_{\mathrm{i}}
$$

where

$$
\begin{aligned}
& \mathrm{C}_{\mathrm{ia}}=\text { concentration of radionuclide } \mathrm{i} \text { in air }\left(\mu \mathrm{Ci} / \mathrm{m}^{3}\right), \\
& \mathrm{f}_{\mathrm{a}}=\text { fraction of the year during which inhalation exposure occurs, } \\
& \mathrm{U}_{\mathrm{a}} \quad=\text { annual air intake }\left(\mathrm{m}^{3} /\right. \text { year), and } \\
& \mathrm{D}_{\mathrm{i}} \quad=\mathrm{DCF} \text { for inhalation of radionuclide } \mathrm{i}(\mathrm{rem} / \mu \mathrm{Ci}) .
\end{aligned}
$$

Airborne concentrations of suspended radionuclides in particulate form are estimated using a massloading model (Anspaugh et al. 1975), which is based on observations of airborne concentrations of naturally occurring materials, such as uranium and thorium, relative to their concentrations in surface soils. In this model, airborne concentrations of suspended radionuclides in particulate form are given by

$$
\mathrm{C}_{\mathrm{ia}}=\mathrm{C}_{\mathrm{is}} \mathrm{L}_{\mathrm{a}} / \rho_{\mathrm{s}}
$$

where

$$
\begin{aligned}
& \mathrm{C}_{\mathrm{is}} \quad \text { = concentration of radionuclide } \mathrm{i} \text { in surface soil }\left(\mu \mathrm{Ci} / \mathrm{m}^{3}\right), \\
& \mathrm{L}_{\mathrm{a}} \quad=\text { atmospheric mass loading of surface soil }\left(\mathrm{kg} / \mathrm{m}^{3}\right), \text { and } \\
& \rho_{\mathrm{s}} \quad=\text { bulk density of soil }\left(\mathrm{kg} / \mathrm{m}^{3}\right) .
\end{aligned}
$$

For inhalation exposure while working in the vegetable garden, the concentration of radionuclide $\mathrm{i}$ in soil again is given by

$$
\mathrm{C}_{\mathrm{is}}=\mathrm{f}_{\mathrm{s}} \mathrm{C}_{\mathrm{it}}
$$

where

$$
\begin{aligned}
\mathrm{C}_{\mathrm{it}}= & \text { concentration of radionuclide } \mathrm{i} \text { in exhumed waste }\left(\mu \mathrm{Ci} / \mathrm{m}^{3}\right) \text {, and } \\
\mathrm{f}_{\mathrm{s}}= & \text { dilution factor for mixing of radionuclides in exhumed waste into soil in vegetable } \\
& \text { garden. }
\end{aligned}
$$

A dilution factor for mixing of radionuclides in exhumed waste into native soil in the garden of 0.2 , a soil bulk density of $1,400 \mathrm{~kg} / \mathrm{m}^{3}$, and a fraction of the year during which exposure while working in the garden occurs of 0.01 (about $100 \mathrm{~h}$ /year) again are assumed, and the annual air intake is assumed to be $8,000 \mathrm{~m}^{3}$ (NRC 1977). Finally, the atmospheric mass loading of contaminated soil while working in the garden is assumed to be $10^{-7} \mathrm{~kg} / \mathrm{m}^{3}$. 
The assumed atmospheric mass loading of contaminated soil while working in the vegetable garden of $10^{-7} \mathrm{~kg} / \mathrm{m}^{3}$ is a somewhat conservative approximation of the average background dust loading for nonurban locations in the U.S. of about $4 \times 10^{-8} \mathrm{~kg} / \mathrm{m}^{3}$ (Anspaugh et al. 1975) and, furthermore, is in good agreement with an average dust loading of $6 \times 10^{-8} \mathrm{~kg} / \mathrm{m}^{3}$ measured above two agricultural fields at the SRS (Shinn et al. 1982). The choice of an atmospheric mass loading for this exposure pathway is based on these data and the following considerations. Although some gardening activities (e.g., tilling and hoeing) presumably would increase atmospheric concentrations of suspended soil above background levels, it probably is unreasonable to assume that the average concentration during all gardening activities would be substantially above the average background level in the U.S. First, the average background level of suspended soil originating from the SRS should be substantially lower than the average level in the U.S. because of the high annual precipitation, extensive vegetation, and low average wind speed at the site. Second, at any location, airborne concentrations of suspended surface soil consist of material originating from a wide area, not just from the particular location where exposures occur. Finally, the model assumes that all suspended soil particles are respirable; but, particularly during more vigorous gardening activities that could result in above-average atmospheric mass loadings, some particles are likely to be too large to be respirable. Taking into account all of these factors, the choice of $10^{-7} \mathrm{~kg} / \mathrm{m}^{3}$ to represent the average mass loading during gardening activities at the SRS seems reasonable.

Effective dose equivalents for estimating inhalation dose while working in the vegetable garden are listed in Table C.3-11. The annual dose per unit concentration of a radionuclide in exhumed waste from a disposal unit at the time intrusion occurs is based on the model and parameter values described above and the inhalation DCFs given in Table C.3-2.

For inhalation exposure while residing in the home, the airborne concentration of radionuclide $\mathrm{i}$ is given by

$$
\mathrm{C}_{\mathrm{ia}}=\mathrm{C}_{\mathrm{it}} \mathrm{L}_{\mathrm{a}} / \rho_{\mathrm{s}}
$$

where

$$
\begin{aligned}
& \mathrm{C}_{\mathrm{it}}=\text { concentration of radionuclide } \mathrm{i} \text { in disposal unit }\left(\mu \mathrm{Ci} / \mathrm{m}^{3}\right), \\
& \mathrm{L}_{\mathrm{a}} \quad \text { atmospheric mass loading of surface soil }\left(\mathrm{kg} / \mathrm{m}^{3}\right) \text {, and } \\
& \rho_{\mathrm{s}} \quad=\text { bulk density of soil }\left(\mathrm{kg} / \mathrm{m}^{3}\right)
\end{aligned}
$$

In implementing the model, a fraction of the year during which exposure in the home occurs of 0.5 (i.e., about $4,000 \mathrm{~h} /$ year), a soil bulk density of $1,400 \mathrm{~kg} / \mathrm{m}^{3}$, and an annual air intake of $8,000 \mathrm{~m}^{3}$ again are assumed. The atmospheric mass loading of contaminated soil at the location of the home on top of the disposal facility is assumed to be $10^{-8} \mathrm{~kg} / \mathrm{m}^{3}$, which is approximately one-fourth of the average background dust loading in the U.S. (Anspaugh et al. 1975). On the basis of the previous discussion of the atmospheric mass loading while working in the vegetable garden, it seems unreasonable to assume that the atmospheric mass loading of largely undisturbed surface soil at the SRS would be as high as the average dust loading in the U.S. The assumption that the atmospheric mass loading of contaminated soil at the disposal site is about one-fourth of the average background level in the U.S. is intended to take into account the abundant precipitation, extensive vegetation, and low average wind speed at the site, compared with average conditions in the U.S., as well as the presence of uncontaminated soil suspended from other locations and the possibility that some suspended soil particles may not be respirable. In addition, the model for inhalation exposure indoors does not take into account the possibility that indoor concentrations of suspended soil particles may be somewhat less than the concentrations outdoors, due to such factors as filtering of air entering the home through windows and doorways and enhanced deposition on indoor surfaces. 
Table C.3-11 Annual EDEs from inhalation exposure in vegetable garden per unit concentration of radionuclides in exhumed waste for agriculture scenario

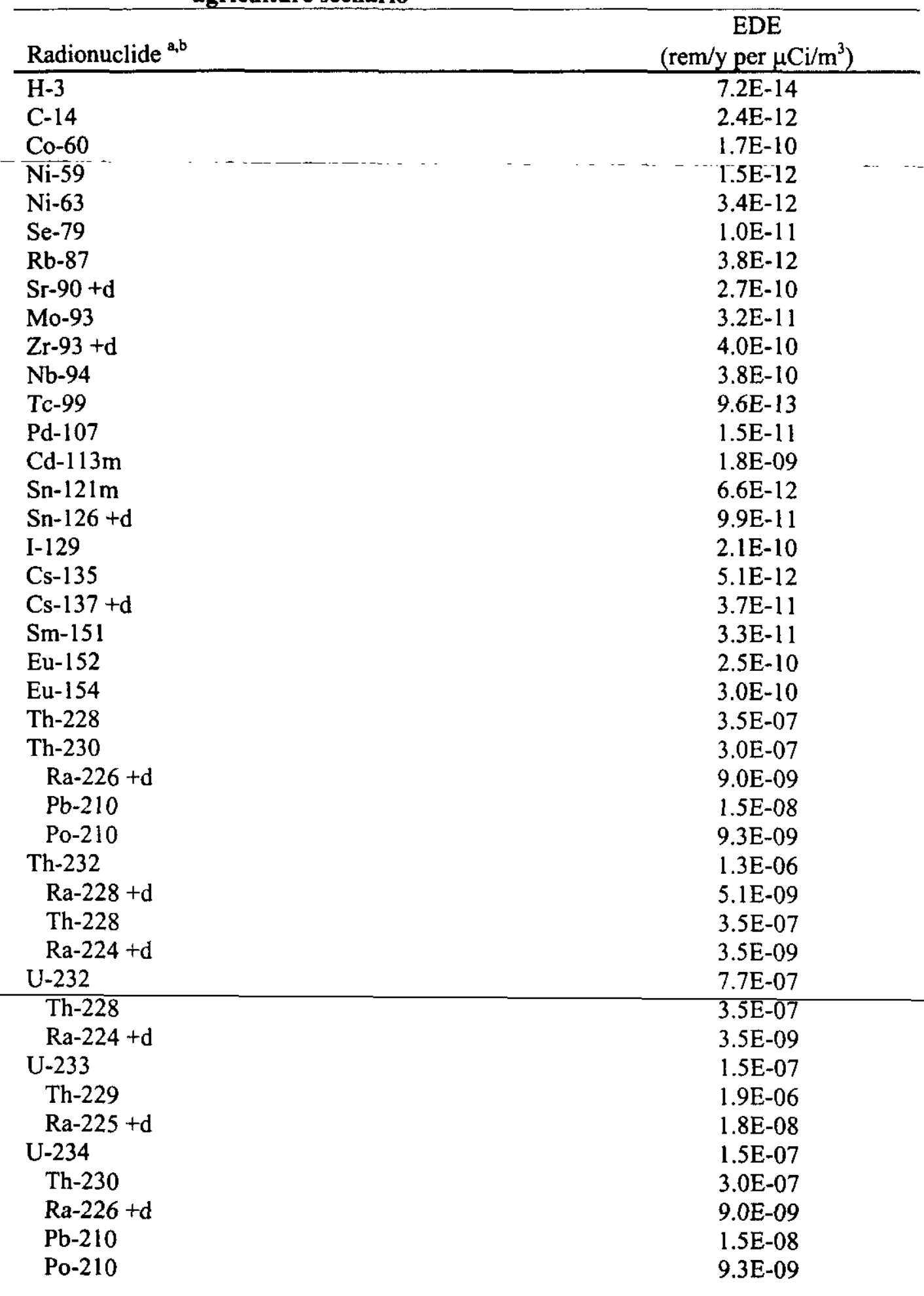


Table C.3-11 Annual EDEs from inhalation exposure in vegetable garden per unit concentration of radionuclides in exhumed waste for agriculture scenario

\begin{tabular}{|c|c|}
\hline Radionuclide ${ }^{a, b}$ & $\begin{array}{c}\text { EDE } \\
\left(\mathrm{rem} / \mathrm{y} \text { per } \mu \mathrm{Ci} / \mathrm{m}^{3}\right)\end{array}$ \\
\hline $\mathrm{U}-235+\mathrm{d}$ & $1.4 \mathrm{E}-07$ \\
\hline $\mathrm{Pa}-231$ & $1.5 \mathrm{E}-06$ \\
\hline Ac- 227 & 7.7E-06 \\
\hline Th-227 & $1.7 \mathrm{E}-08$ \\
\hline $\mathrm{Ra}-223$ & $8.6 \mathrm{E}-09$ \\
\hline U-236 & $1.4 \mathrm{E}-07$ \\
\hline $\mathrm{U}-238$ & $1.4 \mathrm{E}-07$ \\
\hline Th-234 +d & $2.9 \mathrm{E}-11$ \\
\hline $\mathrm{U}-234$ & $3.0 \mathrm{E}-07$ \\
\hline $\mathrm{Np}-237+\mathrm{d}$ & $5.6 \mathrm{E}-07$ \\
\hline Pu-238 & $5.3 \mathrm{E}-07$ \\
\hline U-234 & $1.5 \mathrm{E}-07$ \\
\hline Pu-239 & $5.8 \mathrm{E}-07$ \\
\hline $\mathrm{U}-235$ & $1.4 \mathrm{E}-07$ \\
\hline Pu-240 & $5.8 \mathrm{E}-07$ \\
\hline U-236 & $1.4 \mathrm{E}-07$ \\
\hline $\mathrm{Pu}-24 \mathrm{l}$ & 1. $1 \mathrm{E}-08$ \\
\hline Am-24l & $5.9 \mathrm{E}-07$ \\
\hline Np-237 & $5.6 \mathrm{E}-07$ \\
\hline $\mathrm{Pu}-242$ & $5.5 \mathrm{E}-07$ \\
\hline U-238 & $1.4 \mathrm{E}-07$ \\
\hline Pu-244 +d & $5.5 \mathrm{E}-07$ \\
\hline Am-241 & $5.9 \mathrm{E}-07$ \\
\hline Np-237 & $5.6 \mathrm{E}-07$ \\
\hline$A m-242 m+d$ & $6.1 \mathrm{E}-07$ \\
\hline $\mathrm{Pu}-238$ & $5.3 \mathrm{E}-07$ \\
\hline U-234 & $1.5 \mathrm{E}-07$ \\
\hline$A m-243+d$ & $5.9 \mathrm{E}-07$ \\
\hline Pu-239 & $5.8 \mathrm{E}-07$ \\
\hline $\mathrm{Cm}-242$ & $1.9 \mathrm{E}-08$ \\
\hline $\mathrm{Pu}-238$ & $5.3 \mathrm{E}-07$ \\
\hline $\mathrm{U}-234$ & $1.5 \mathrm{E}-07$ \\
\hline $\mathrm{Cm}-243$ & $4.0 \mathrm{E}-07$ \\
\hline $\mathrm{Cm}-244$ & $3.1 \mathrm{E}-07$ \\
\hline $\mathrm{Pu}-240$ & $5.8 \mathrm{E}-07$ \\
\hline U-236 & $1.4 \mathrm{E}-07$ \\
\hline $\mathrm{Cm}-245$ & $6.2 \mathrm{E}-07$ \\
\hline $\mathrm{Pu}-241$ & $1.1 \mathrm{E}-08$ \\
\hline $\mathrm{Am}-241$ & $5.9 \mathrm{E}-07$ \\
\hline$N p-237$ & $5.6 \mathrm{E}-07$ \\
\hline $\mathrm{Cm}-246$ & $6.2 \mathrm{E}-07$ \\
\hline $\mathrm{Cm}-247+\mathrm{d}$ & $5.6 \mathrm{E}-07$ \\
\hline $\mathrm{Am}-243$ & $5.9 \mathrm{E}-07$ \\
\hline $\mathrm{Np}-239$ & $2.5 \mathrm{E}-12$ \\
\hline Pu-239 & $5.8 \mathrm{E}-07$ \\
\hline
\end{tabular}


Table C.3-11 Annual EDEs from inhalation exposure in vegetable garden per unit concentration of radionuclides in exhumed waste for agriculture scenario

\begin{tabular}{lc}
\hline Radionuclide a,b & $\begin{array}{c}\text { EDE } \\
\left(\mathrm{rem} / \mathrm{y} \text { per } \mu \mathrm{Ci} / \mathrm{m}^{3}\right)\end{array}$ \\
\hline $\mathrm{Cm}-248$ & $2.2 \mathrm{E}-06$ \\
$\mathrm{Pu}-244$ & $5.0 \mathrm{E}-07$ \\
$\mathrm{Bk}-249$ & $1.5 \mathrm{E}-09$ \\
$\mathrm{Cf}-249$ & $6.3 \mathrm{E}-07$ \\
$\mathrm{Cm}-245^{-}$ & $6.2 \mathrm{E}-07-\cdots$ \\
$\mathrm{Cf}-249$ & $6.3 \mathrm{E}-07$ \\
$\mathrm{Cm}-245$ & $6.2 \mathrm{E}-07$ \\
$\mathrm{Pu}-241$ & $1.1 \mathrm{E}-08$ \\
$\mathrm{Am}-241$ & $5.9 \mathrm{E}-07$ \\
$\mathrm{~Np}-237$ & $5.6 \mathrm{E}-07$ \\
$\mathrm{Cf}-250$ & $2.5 \mathrm{E}-07$ \\
$\mathrm{Cm}-246$ & $6.2 \mathrm{E}-07$ \\
$\mathrm{Cf}-251$ & $6.4 \mathrm{E}-07$ \\
$\mathrm{Cf}-252$ & $1.5 \mathrm{E}-07$ \\
$\mathrm{Cm}-248$ & $2.1 \mathrm{E}-06$ \\
\hline
\end{tabular}

${ }^{a}$ Indented entries are decay products of parent radionuclide that are potentially radiologicallysignificant.

b The notation "+d" indicates that short-lived daughters were incorporated into the EDE. Dose from other daughters listed is calculated explicitly by adding EDE's. 
Table C.3-12 Annual EDEs from inhalation exposure in home per unit concentration of radionuclides in disposal units for agriculture scenario

\begin{tabular}{|c|c|}
\hline Radionuclide $^{\mathrm{a}, \mathrm{b}}$ & $\begin{array}{c}\text { EDE } \\
\left(\mathrm{rem} / \mathrm{y} \text { per } \mu \mathrm{Ci} / \mathrm{m}^{3}\right)\end{array}$ \\
\hline $\mathrm{H}-3$ & $1.8 \mathrm{E}-12$ \\
\hline C-14 & $6.0 \mathrm{E}-11$ \\
\hline Co-60 & 4.3E-09 \\
\hline $\mathrm{Ni}-59$ & $3.7 \mathrm{E}-11$ \\
\hline $\mathrm{Ni}-63$ & $8.6 \mathrm{E}-11$ \\
\hline Se-79 & $2.5 \mathrm{E}-10$ \\
\hline $\mathrm{Rb}-87$ & $9.4 \mathrm{E}-11$ \\
\hline Sr-90+d & $6.8 \mathrm{E}-09$ \\
\hline Mo-93 & $8.0 \mathrm{E}-10$ \\
\hline $\mathrm{Zr}-93+\mathrm{d}$ & $9.9 \mathrm{E}-09$ \\
\hline $\mathrm{Nb}-94$ & $9.4 \mathrm{E}-09$ \\
\hline Tc-99 & $2.4 \mathrm{E}-11$ \\
\hline Pd-107 & $3.7 \mathrm{E}-10$ \\
\hline $\mathrm{Cd}-113 \mathrm{~m}$ & $4.6 \mathrm{E}-08$ \\
\hline $\mathrm{Sn}-121 \mathrm{~m}$ & $1.7 \mathrm{E}-10$ \\
\hline $\mathrm{Sn}-126+d$ & $2.5 \mathrm{E}-09$ \\
\hline$I-129$ & $5.1 \mathrm{E}-09$ \\
\hline Cs-135 & $1.3 \mathrm{E}-10$ \\
\hline $\mathrm{Cs}-137+\mathrm{d}$ & $9.1 \mathrm{E}-10$ \\
\hline Sm-151 & $8.3 \mathrm{E}-10$ \\
\hline Eu-152 & $6.3 \mathrm{E}-09$ \\
\hline Eu-154 & $7.4 \mathrm{E}-09$ \\
\hline Th-228 & $8.9 \mathrm{E}-06$ \\
\hline Th-230 & $7.4 \mathrm{E}-06$ \\
\hline $\mathrm{Ra}-226+\mathrm{d}$ & $2.3 \mathrm{E}-07$ \\
\hline $\mathrm{Pb}-210$ & $3.7 \mathrm{E}-07$ \\
\hline Po-210 & $2.3 \mathrm{E}-07$ \\
\hline Th-232 & $3.1 \mathrm{E}-05$ \\
\hline $\mathrm{Ra}-228+\mathrm{d}$ & $1.3 \mathrm{E}-07$ \\
\hline Th-228 & $8.9 E-06$ \\
\hline $\mathrm{Ra}-224+\mathrm{d}$ & $8.8 \mathrm{E}-08$ \\
\hline U-232 & $1.9 \mathrm{E}-05$ \\
\hline Th-228 & $8.9 \mathrm{E}-06$ \\
\hline $\mathrm{Ra}-224+\mathrm{d}$ & $8.8 \mathrm{E}-08$ \\
\hline U-233 & 3.7E-06 \\
\hline Th-229 & $4.9 \mathrm{E}-05$ \\
\hline $\mathrm{Ra}-225+\mathrm{d}$ & $4.4 \mathrm{E}-07$ \\
\hline U-234 & $3.7 \mathrm{E}-06$ \\
\hline Th-230 & $7.4 \mathrm{E}-06$ \\
\hline $\mathrm{Ra}-226+\mathrm{d}$ & $2.3 \mathrm{E}-07$ \\
\hline $\mathrm{Pb}-210$ & 3.7E-07 \\
\hline Po-210 & $2.3 \mathrm{E}-07$ \\
\hline
\end{tabular}


Table C.3-12 Annual EDEs from inhalation exposure in home per unit concentration of radionuclides in disposal units for agriculture scenario

\begin{tabular}{|c|c|c|}
\hline Radionuclide $a, b$ & & $\begin{array}{c}\text { EDE } \\
\left(\mathrm{rem} / \mathrm{y} \text { per } \mu \mathrm{Ci} / \mathrm{m}^{3}\right)\end{array}$ \\
\hline $\mathrm{U}-235+\mathrm{d}$ & & $3.4 \mathrm{E}-06$ \\
\hline $\mathrm{Pa}-231$ & & $3.7 \mathrm{E}-05$ \\
\hline Ac- 227 & & $1.9 \mathrm{E}-04$ \\
\hline Th-227 & & 4.2E-07 \\
\hline $\mathrm{Ra}-223$ & $---\quad-\quad--\cdots \cdot-$ & $\cdots-\cdots$ \\
\hline $\mathrm{U}-236$ & & $3.4 \mathrm{E}-06$ \\
\hline U-238 & & $3.4 \mathrm{E}-06$ \\
\hline Th-234 +d & & $7.1 \mathrm{E}-10$ \\
\hline $\mathrm{U}-234$ & & $3.7 \mathrm{E}-06$ \\
\hline $\mathrm{Np}-237+\mathrm{d}$ & & $1.4 \mathrm{E}-05$ \\
\hline $\mathrm{Pu}-238$ & & $1.3 \mathrm{E}-05$ \\
\hline $\mathrm{U}-234$ & & $3.7 \mathrm{E}-06$ \\
\hline $\mathrm{Pu}-239$ & & $1.5 \mathrm{E}-05$ \\
\hline U-235 & & $3.4 \mathrm{E}-06$ \\
\hline $\mathrm{Pu}-240$ & & $1.5 \mathrm{E}-05$ \\
\hline $\mathrm{U}-236$ & & $3.4 \mathrm{E}-06$ \\
\hline $\mathrm{Pu}-241$ & & $2.9 \mathrm{E}-07$ \\
\hline Am-241 & & $1.5 \mathrm{E}-05$ \\
\hline Np-237 & & $1.4 \mathrm{E}-05$ \\
\hline $\mathrm{Pu}-242$ & & $1.4 \mathrm{E}-05$ \\
\hline $\mathrm{U}-238$ & & $3.4 \mathrm{E}-06$ \\
\hline Pu-244 +d & & $1.4 \mathrm{E}-05$ \\
\hline Am-241 & & $1.5 \mathrm{E}-05$ \\
\hline $\mathrm{Np}-237$ & & $1.4 \mathrm{E}-05$ \\
\hline$A m-242 m+d$ & & $1.5 \mathrm{E}-05$ \\
\hline $\mathrm{Pu}-238$ & & $1.3 \mathrm{E}-05$ \\
\hline U-234 & & 3.7E-06 \\
\hline$A m-243+d$ & & $1.5 \mathrm{E}-05$ \\
\hline Pu-239 & & $1.5 \mathrm{E}-05$ \\
\hline $\mathrm{Cm}-242$ & & $4.9 \mathrm{E}-07$ \\
\hline $\mathrm{Pu}-238$ & & $1.3 \mathrm{E}-05$ \\
\hline $\mathrm{U}-234$ & & $3.7 \mathrm{E}-06$ \\
\hline $\mathrm{Cm}-243$ & & $1.0 \mathrm{E}-05$ \\
\hline $\mathrm{Cm}-244$ & & $7.7 \mathrm{E}-06$ \\
\hline $\mathrm{Pu}-240$ & & $1.5 \mathrm{E}-05$ \\
\hline $\mathrm{U}-236$ & & $3.4 \mathrm{E}-06$ \\
\hline $\mathrm{Cm}-245$ & & $1.5 \mathrm{E}-05$ \\
\hline $\mathrm{Pu}-241$ & & $2.9 \mathrm{E}-07$ \\
\hline Am-241 & & $1.5 \mathrm{E}-05$ \\
\hline Np-237 & & $1.4 \mathrm{E}-05$ \\
\hline $\mathrm{Cm}-246$ & & $1.5 \mathrm{E}-05$ \\
\hline $\mathrm{Cm}-247+\mathrm{d}$ & & $1.4 \mathrm{E}-05$ \\
\hline $\mathrm{Am}-243$ & & $1.5 \mathrm{E}-05$ \\
\hline Np-239 & & $6.3 \mathrm{E}-11$ \\
\hline Pu-239 & & $1.5 \mathrm{E}-05$ \\
\hline
\end{tabular}


Table C.3-12 Annual EDEs from inhalation exposure in home per unit concentration of radionuclides in disposal units for agriculture scenario

\begin{tabular}{cc}
\hline Radionuclide $a, b$ & $\begin{array}{c}\mathrm{EDE} \\
\left.\text { (rem } / \mathrm{y} \text { per } \mu \mathrm{Ci} / \mathrm{m}^{3}\right)\end{array}$ \\
\hline Cm-248 & $5.4 \mathrm{E}-05$ \\
Pu-244 & $1.3 \mathrm{E}-05$ \\
Bk-249 & $3.7 \mathrm{E}-08$ \\
$\mathrm{Cf}-249$ & $1.6 \mathrm{E}-05$ \\
$\mathrm{Cm}-245$ & $1.5 \mathrm{E}-05$ \\
$\mathrm{Cf}-249$ & $1.6 \mathrm{E}-05$ \\
$\mathrm{Cm}-245$ & $1.5 \mathrm{E}-05$ \\
Pu-241 & $2.9 \mathrm{E}-07$ \\
$\mathrm{Am}-241$ & $1.5 \mathrm{E}-05$ \\
$\mathrm{~Np}-237$ & $1.4 \mathrm{E}-05$ \\
$\mathrm{Cf}-250$ & $6.3 \mathrm{E}-06$ \\
$\mathrm{Cm}-246$ & $1.5 \mathrm{E}-05$ \\
$\mathrm{Cf}-251$ & $1.6 \mathrm{E}-05$ \\
$\mathrm{Cf}-252$ & $3.7 \mathrm{E}-06$ \\
$\mathrm{Cm}-248$ & $5.3 \mathrm{E}-05$ \\
\hline
\end{tabular}

a Indented entries are decay products of parent radionuclide that are potentially radiologicallysignificant.

b The notation " $+\mathrm{d}$ " indicates that short-lived daughters were incorporated into the EDE. Dose from other daughters listed is calculated explicitly by adding EDE's. 
Effective dose equivalents for estimating inhalation dose during indoor residence are listed in Table C.3-12. The annual dose per unit concentration of a radionuclide in a disposal unit at the time intrusion occurs is based on the model and parameter values described above and the inhalation DCFs given in Table C.3-2.

All Pathways. For the agriculture scenario, the annual EDEs from all exposure pathways per unit concentration of radionuclides in disposal units at the time intrusion is assumed to occur are summarized in Table C.3-13. For each radionuclide the total dose is the sum of the doses from the vegetable, soil ingestion-external-exposure, and-inhalation pathways given in Tables C.3-7-through C.3-12.

Given the models and parameter values assumed in the dose analysis for the agriculture scenario, the most important exposure pathways depend on the particular radionuclide. For many of the fission and activation products, the vegetable pathway is by far the most important. However, for the photonemitting radionuclides ${ }^{60} \mathrm{Co},{ }^{126} \mathrm{Sn}$, and ${ }^{137} \mathrm{Cs}$, external exposure while residing in the home is the only important pathway. For ${ }^{151} \mathrm{Sm}$, the soil ingestion pathway is a minor contributor to the total dose. Finally, the inhalation pathways are never important for any fission and activation products. For ${ }^{226} \mathrm{Ra}$ and the actinide radionuclides, the vegetable and soil ingestion pathways and inhalation exposure while residing in the home usually are important contributors to the total dose, except the soil ingestion and inhalation pathways are of lesser importance when external exposure while residing in the home is a significant contributor to the total dose. For isotopes of $\mathrm{Th}$ and $\mathrm{Pu}$, which are assumed to have a low plant-to-soil concentration ratio, the soil ingestion pathway is more important than the vegetable pathway.

The models for the exposure pathways involving mixing of exhumed waste with native soil in a vegetable garden may be somewhat conservative for radionuclides that are highly mobile in surface soil, because the models assume that the concentration in soil during the first year after mixing is not reduced as a result of leaching and transport to deeper soil layers by infiltrating precipitation. Thus, for mobile radionuclides, the average concentration in surface soil during the first year after mixing, which is the appropriate concentration for calculating the maximum annual dose to an intruder, could be substantially less than the initial concentration after mixing, and the annual dose per unit concentration in exhumed waste could be correspondingly overestimated.

The radionuclides in Table C.3-13 for which leaching and transport from surface soil in a vegetable garden by infiltrating precipitation could reduce the annual dose per unit concentration in exhumed waste include ${ }^{3} \mathrm{H}$ and ${ }^{99} \mathrm{Tc}$. In each case, a leaching model, such as proposed by Baes and Sharp (1983) could be used to estimate the average concentration in surface soil during the first year after mixing of exhumed waste with native soil in the garden.

For ${ }^{3} \mathrm{H}$, which is expeeted to be removed-from the-soil root zone-(i.e., the-first- 30 em of surface-soil) at the same rate as infiltrating water, the leaching correction described above would reduce the annual dose per unit concentration in exhumed waste by about a factor of five. This correction is not applied to the dose estimate for ${ }^{3} \mathrm{H}$ in Table C.3-13, but it could be taken into account in the dose analysis if estimated doses from ${ }^{3} \mathrm{H}$ are a significant fraction of the performance measure for impacts on inadvertent intruders.

For ${ }^{99} \mathrm{Tc}$, the assumption of a small but non-zero distribution coefficient $\left(\mathrm{K}_{\mathrm{d}}\right)$ in surface soil, such as given in Sect. 4.1.3.1, would reduce the annual dose per unit concentration in exhumed waste by less than a factor of two. Thus, the leaching correction undoubtedly is considerably less than the uncertainty in the plant-to-soil concentration ratio $\left(\mathrm{B}_{\mathrm{v}}\right)$, which is the most important parameter in determining the dose from ${ }^{99} \mathrm{Tc}$ in the agriculture scenario. 
Table C.3-13 Annual EDEs per unit concentration of radionuclides in disposal units from all exposure pathways for agriculture scenario

\begin{tabular}{|c|c|}
\hline Radionuclide & $\begin{array}{c}\text { EDE } \\
\left(\mathrm{rem} / \mathrm{y} \text { per } \mu \mathrm{Ci} / \mathrm{m}^{3}\right)\end{array}$ \\
\hline $\mathrm{H}-3$ & $3.9 \mathrm{E}-06$ \\
\hline$C-14$ & $1.5 \mathrm{E}-05$ \\
\hline Co- 60 & $3.5 \mathrm{E}-03$ \\
\hline $\mathrm{Ni}-59$ & $6.8 \mathrm{E}-08$ \\
\hline $\mathrm{Ni}-63$ & $1.8 \mathrm{E}-07$ \\
\hline $\mathrm{Se}-79$ & $1.2 \mathrm{E}-06$ \\
\hline Rb-87 & $1.9 \mathrm{E}-06$ \\
\hline Sr-90+d & $1.9 \mathrm{E}-04$ \\
\hline Mo-93 & $1.8 \mathrm{E}-06$ \\
\hline$Z r-93+d$ & $6.4 \mathrm{E}-08$ \\
\hline $\mathrm{Nb}-94$ & $2.1 \mathrm{E}-03$ \\
\hline Tc-99 & $1.1 \mathrm{E}-05$ \\
\hline Pd-107 & $3.2 \mathrm{E}-08$ \\
\hline $\mathrm{Cd}-113 \mathrm{~m}$ & $1.3 \mathrm{E}-04$ \\
\hline $\mathrm{Sn}-121 \mathrm{~m}$ & 4.7E-07 \\
\hline $\mathrm{Sn}-126+d$ & $2.6 \mathrm{E}-03$ \\
\hline I-129 & $8.4 \mathrm{E}-05$ \\
\hline Cs-135 & 1.2E-06 \\
\hline Cs- $137+d$ & $7.7 \mathrm{E}-04$ \\
\hline Sm-151 & $1.0 \mathrm{E}-08$ \\
\hline Eu-152 & $1.5 \mathrm{E}-03$ \\
\hline Eu-154 & $1.7 \mathrm{E}-03$ \\
\hline Th-228 & $1.3 \mathrm{E}-05$ \\
\hline Th-230 & $1.1 \mathrm{E}-05$ \\
\hline $\mathrm{Ra}-226+\mathrm{d}$ & $2.5 \mathrm{E}-03$ \\
\hline $\mathrm{Pb}-210$ & $2.8 \mathrm{E}-04$ \\
\hline Po-210 & $1.2 \mathrm{E}-05$ \\
\hline Th-232 & $4.9 \mathrm{E}-05$ \\
\hline $\mathrm{Ra}-228+\mathrm{d}$ & $1.3 \mathrm{E}-03$ \\
\hline Th-228 & $1.3 \mathrm{E}-05$ \\
\hline $\mathrm{Ra}-224+\mathrm{d}$ & $2.2 \mathrm{E}-03$ \\
\hline $\mathrm{U}-232$ & $5.5 \mathrm{E}-05$ \\
\hline Th-228 & $1.3 \mathrm{E}-05$ \\
\hline $\mathrm{Ra}-224+\mathrm{d}$ & $2.2 \mathrm{E}-03$ \\
\hline $\mathrm{U}-233$ & $1.1 \mathrm{E}-05$ \\
\hline Th-229 & $1.4 \mathrm{E}-04$ \\
\hline $\mathrm{Ra}-225+\mathrm{d}$ & $2.9 \mathrm{E}-04$ \\
\hline $\mathrm{U}-234$ & $1.1 \mathrm{E}-05$ \\
\hline Th-230 & $1.1 \mathrm{E}-05$ \\
\hline $\mathrm{Ra}-226+\mathrm{d}$ & $2.5 \mathrm{E}-03$ \\
\hline $\mathrm{Pb}-210$ & $2.8 \mathrm{E}-04$ \\
\hline Po-210 & $1.2 \mathrm{E}-05$ \\
\hline
\end{tabular}


Table C.3-13 Annual EDEs per unit concentration of radionuclides in disposal units from all exposure pathways for agriculture scenario

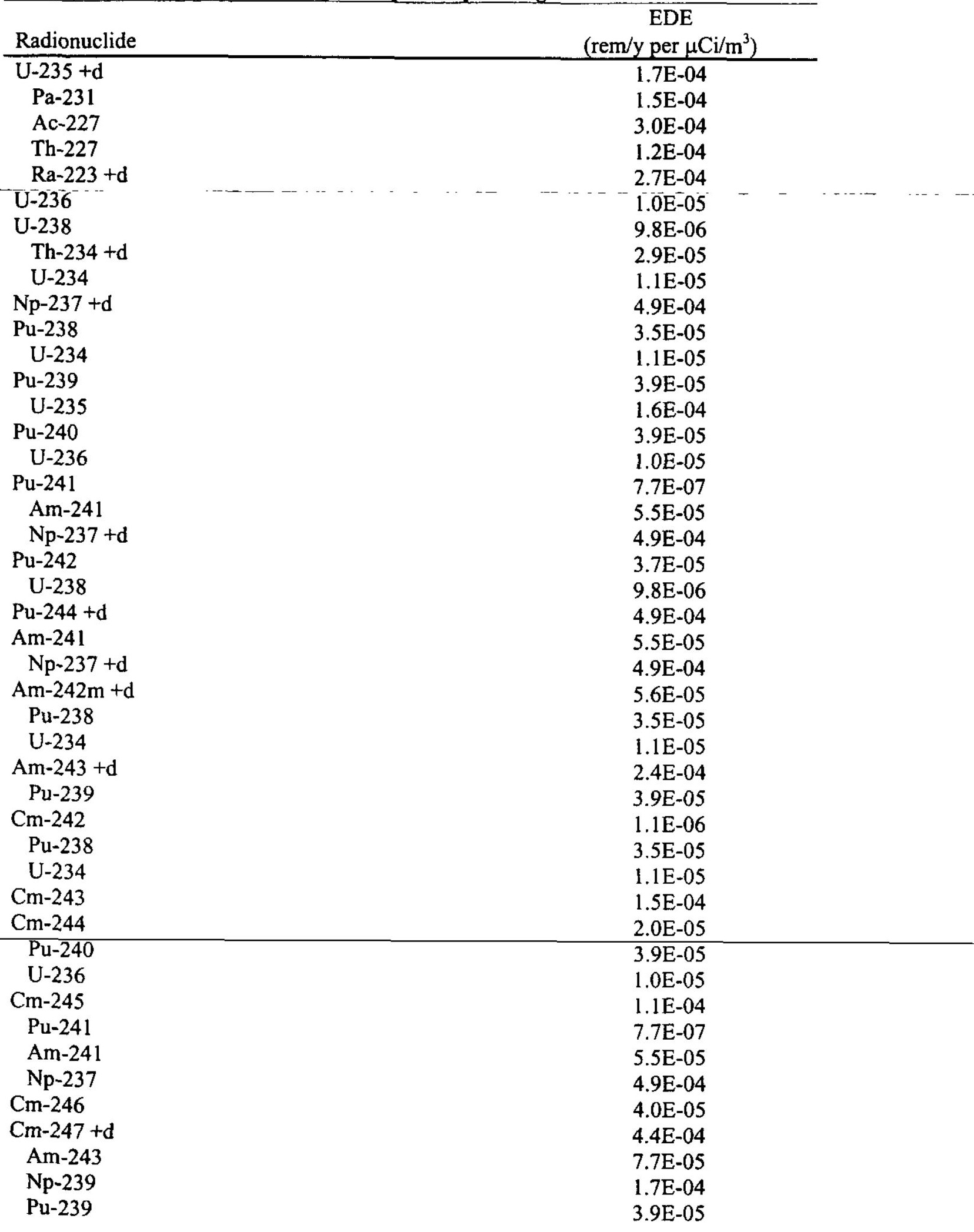


Table C.3-13 Annual EDEs per unit concentration of radionuclides in disposal units from all exposure pathways for agriculture scenario

\begin{tabular}{lc}
\hline Radionuclide & $\begin{array}{c}\mathrm{EDE} \\
\left(\mathrm{rem} / \mathrm{y} \text { per } \mu \mathrm{Ci} / \mathrm{m}^{3}\right)\end{array}$ \\
\hline $\mathrm{Cm}-248$ & $1.4 \mathrm{E}-04$ \\
$\mathrm{Pu}-244+\mathrm{d}$ & $4.5 \mathrm{E}-04$ \\
$\mathrm{Bk}-249$ & $7.1 \mathrm{E}-08$ \\
$\mathrm{Cf}-249$ & $4.6 \mathrm{E}-04$ \\
$\mathrm{Cm}-245$ & $1.1 \mathrm{E}-04$ \\
$\mathrm{Cf}-249$ & $4.6 \mathrm{E}-04$ \\
$\mathrm{Cm}-245$ & $1.1 \mathrm{E}-04$ \\
$\mathrm{Pu}-241$ & $7.7 \mathrm{E}-07$ \\
$\mathrm{Am}-241$ & $5.5 \mathrm{E}-05$ \\
$\mathrm{~Np}-237$ & $4.9 \mathrm{E}-04$ \\
$\mathrm{Cf}-250$ & $1.7 \mathrm{E}-05$ \\
$\mathrm{Cm}-246$ & $4.0 \mathrm{E}-05$ \\
$\mathrm{Cf}-251$ & $1.6 \mathrm{E}-04$ \\
$\mathrm{Cf}-252$ & $8.9 \mathrm{E}-06$ \\
$\mathrm{Cm}-248$ & $1.4 \mathrm{E}-04$ \\
\hline Indented entries are decay products of parent radionuclide that are potentially radiologically- \\
significant. \\
The notation "+d" indicates that short-lived daughters were incorporated into the EDE. Dose \\
from other daughters listed is calculated explicitly by adding EDE's.
\end{tabular}


Furthermore, there is evidence that the usual assumption of a low distribution coefficient for ${ }^{99} \mathrm{Tc}$ may overestimate considerably the removal rate from the soil root zone for a substantial fraction of the activity initially mixed into surface soil (Vandecasteele et al. 1989). Therefore, application of a leaching correction may not be valid in this case.

\section{Resident scenario}

In the resident scenario, exposures of inadvertent intruders are assumed to occur after an intruder encuunters an intact and impenetrable engineered barrier (e.g., a concrete roof) while excavating to build a-foundation-for a home at the-disposal-site. An-intruder then is-assumed-to-build-a-home immediately-on top of the intact engineered barrier and receives an external exposure while residing in the home. Ingestion and inhalation exposures are precluded when the waste is assumed to be inaccessible during excavation. The radionuclides included in the dose analysis for the resident scenario were selected on the basis of a screening analysis described in Sect. 6.2.

External dose during indoor residence for the resident scenario is estimated using the model given in Eq. (C.3-8). In implementing the model, the fraction of the year for indoor residence is assumed to be 0.5 and the shielding factor during indoor residence is assumed to be 0.7 , as in the agriculture scenario. The doserate conversion factor for each radionuclide is the external dose rate per unit concentration in disposal units taking into account the shielding provided by the material in the source region (i.e., the waste itself) and by an intact concrete roof and/or layer of uncontaminated grout or uncontaminated soil above the waste.

As described in Sect. 6.1, only two bounding cases need to be considered in evaluating potential doses for the resident scenario. The first is exposure to both shorter-lived and long-lived photon-emitting radionuclides at 100 years after disposal when engineered barriers shieiding exposure to waste in disposal units are assumed to be intact. The second case is exposure only to long-lived photon-emitting radionuclides in unshielded waste at a time long after disposal when engineered barriers initially present have lost their physical integrity and weathered to soil-equivalent material.

The EDEs for estimating external dose in the resident scenario are listed in Table C.3-14. In this table, the annual EDEs per unit concentration of radionuclides in the disposal units are given for the time intrusion occurs for different assumed thicknesses of shielding above the waste (see Sect. C.3.3). The results are obtained from the assumed exposure time and shielding factor during indoor residence and the external dose-rate conversion factors for the radionuclides of concern given in Table C.3-4. The results for $45-\mathrm{cm}$ and $100-\mathrm{cm}$ shielding apply to the bounding case of intact engineered barriers described above. The results for no shielding apply to the bounding case of no engineered barriers above the waste and are the same as the dose estimates during indoor residence for the agriculture scenario given in Table C.3-10.

In Table C.3-14, the calculations for "No shielding" apply to all disposal units, when impenetrable engineered barriers are either absent or have degraded. The calculations for $45-\mathrm{cm}$ shielding apply to physically intact (i.e., not crumbled) LAW vaults, and the calculations for $100-\mathrm{cm}$ shielding apply to physically intact IL vaults and to the trench disposal units. For the case of $45-\mathrm{cm}$ shielding, results are presented only for those radionuclides selected by the screening analysis for the LAW vaults (see Sect. 6.2). For 100 -cm shielding, no entry is given for some radionuclides, such as ${ }^{241} \mathrm{Am}$, because the dose per unit concentration is too low to be of concem for any possible concentrations of this radionuclide in waste. 
Table C.3-14 Annual EDEs per unit concentration of radionuclides in disposal units for resident scenario

\begin{tabular}{|c|c|c|c|}
\hline Radionuclide $^{a, b}$ & No Shielding ${ }^{c}$ & $\begin{array}{c}\mathrm{EDE}\left(\mathrm{rem} / \mathrm{y} \text { per } \mu \mathrm{Ci} / \mathrm{m}^{3}\right) \\
45 \mathrm{~cm} \text { shielding } \mathrm{d}\end{array}$ & $100 \mathrm{~cm}$ shielding ${ }^{c}$ \\
\hline Co-60 & $3.5 \mathrm{E}-03$ & $8.8 \mathrm{E}-05$ & $1.2 \mathrm{E}-06$ \\
\hline $\mathrm{Nb}-94$ & $2.1 \mathrm{E}-03$ & $2.6 \mathrm{E}-05$ & $1.4 \mathrm{E}-07$ \\
\hline Sn-126+d & $2.6 \mathrm{E}-03$ & $2.2 \mathrm{E}-05$ & $8.4 \mathrm{e}-08$ \\
\hline Cs- $137+d$ & $7.6 \mathrm{E}-04$ & $6.6 \mathrm{E}-06$ & $2.2 \mathrm{E}-08$ \\
\hline Eu-152 & $1.5 \mathrm{E}-03$ & $2.8 \mathrm{E}-05$ & $1.5 E-09$ \\
\hline Eu-154 & $1.7 \mathrm{E}-03$ & $3.2 \mathrm{E}-05$ & $3.5 \mathrm{E}-07$ \\
\hline Th-232 & $1.2 \mathrm{E}-07$ & --- & $-\cdots$ \\
\hline $\mathrm{Ra}-228+\mathrm{d}$ & $1.3 \mathrm{E}-03$ & $2.1 \mathrm{E}-05$ & $2.5 \mathrm{E}-07$ \\
\hline Th-228 & $1.8 \mathrm{E}-06$ & --- & --- \\
\hline $\mathrm{Ra}-224+\mathrm{d}$ & $2.2 \mathrm{E}-03$ & $9.2 \mathrm{E}-05$ & $3.8 \mathrm{E}-06$ \\
\hline $\mathrm{U}-232$ & $2.0 \mathrm{E}-07$ & --- & -.-- \\
\hline Th-228 & $1.8 \mathrm{E}-06$ & -.- & --- \\
\hline $\mathrm{Ra}-224+\mathrm{d}$ & $2.2 \mathrm{E}-03$ & $9.2 \mathrm{E}-05$ & $3.8 \mathrm{E}-06$ \\
\hline $\mathrm{U}-233$ & $3.0 \mathrm{E}-07$ & ---- & ---- \\
\hline Th-229 & $7.0 \mathrm{E}-05$ & $8.4 \mathrm{E}-09$ & ---- \\
\hline $\mathrm{Ra}-225+\mathrm{d}$ & $2.8 \mathrm{E}-04$ & $2.6 \mathrm{E}-06$ & $3.5 \mathrm{E}-08$ \\
\hline U-234 & $8.8 \mathrm{E}-08$ & --- & -..- \\
\hline Th-230 & $2.6 \mathrm{E}-07$ & ---- & $-\cdots$ \\
\hline $\mathrm{Ra}-226+\mathrm{d}$ & $2.4 \mathrm{E}-03$ & $6.0 \mathrm{E}-05$ & $1.3 \mathrm{E}-06$ \\
\hline $\mathrm{Pb}-210$ & $5.3 \mathrm{E}-07$ & ---- & --- \\
\hline Po-210 & $1.2 \mathrm{E}-08$ & ---- & ---- \\
\hline $\mathrm{U}-235+\mathrm{d}$ & $1.6 \mathrm{E}-04$ & $3.9 \mathrm{E}-08$ & $2.3 \mathrm{E}-12$ \\
\hline $\mathrm{Pa}-231$ & $4.2 \mathrm{E}-05$ & --- & -.-- \\
\hline Ac- 227 & $1.1 \mathrm{E}-07$ & $\cdots$ & --- \\
\hline Th-227 & $1.1 \mathrm{E}-04$ & --. & --- \\
\hline $\mathrm{Ra}-223+\mathrm{d}$ & $2.6 \mathrm{E}-04$ & $9.5 \mathrm{E}-07$ & $3.4 E-09$ \\
\hline $\mathrm{U}-238$ & $2.2 \mathrm{E}-08$ & -.-- & -- \\
\hline Th-234 +d & $2.9 \mathrm{E}-05$ & $3.0 \mathrm{E}-07$ & $2.5 \mathrm{E}-09$ \\
\hline U-234 & $8.8 \mathrm{E}-08$ & ---- & ---- \\
\hline $\mathrm{Np}-237+\mathrm{d}$ & $2.4 \mathrm{E}-04$ & $4.6 \mathrm{E}-07$ & $2.8 \mathrm{E}-10$ \\
\hline $\mathrm{Pu}-241$ & $1.3 \mathrm{E}-09$ & $-\cdots$ & -- \\
\hline Am-241 & $9.4 \mathrm{E}-06$ & --- & --- \\
\hline Np-237 & $2.4 \mathrm{E}-04$ & $4.6 \mathrm{E}-07$ & ---- \\
\hline $\mathrm{Pu}-244+\mathrm{d}$ & $4.6 \mathrm{E}-04$ & $5.3 \mathrm{E}-06$ & $4.9 \mathrm{E}-08$ \\
\hline Am-241 & $9.5 \mathrm{E}-06$ & --- & ---- \\
\hline Np-237 & $2.4 \mathrm{E}-04$ & $4.6 \mathrm{E}-07$ & --- \\
\hline$A m-242 m+d$ & $1.1 \mathrm{E}-05$ & ---- & $-\cdots$ \\
\hline $\mathrm{Pu}-238$ & $3.3 E-08$ & ---- & --- \\
\hline U-234 & $8.8 \mathrm{E}-08$ & ---- & --- \\
\hline$A m-243+d$ & $2.0 \mathrm{E}-04$ & $1.1 \mathrm{E}-07$ & $4.2 \mathrm{E}-11$ \\
\hline Pu-239 & $6.3 E-08$ & --- & -- \\
\hline $\mathrm{Cm}-243$ & $1.3 \mathrm{E}-04$ & 4.9E-08 & $2.0 \mathrm{E}-11$ \\
\hline
\end{tabular}


Table C.3-14 Annual EDEs per unit concentration of radionuclides in disposal units for resident scenario

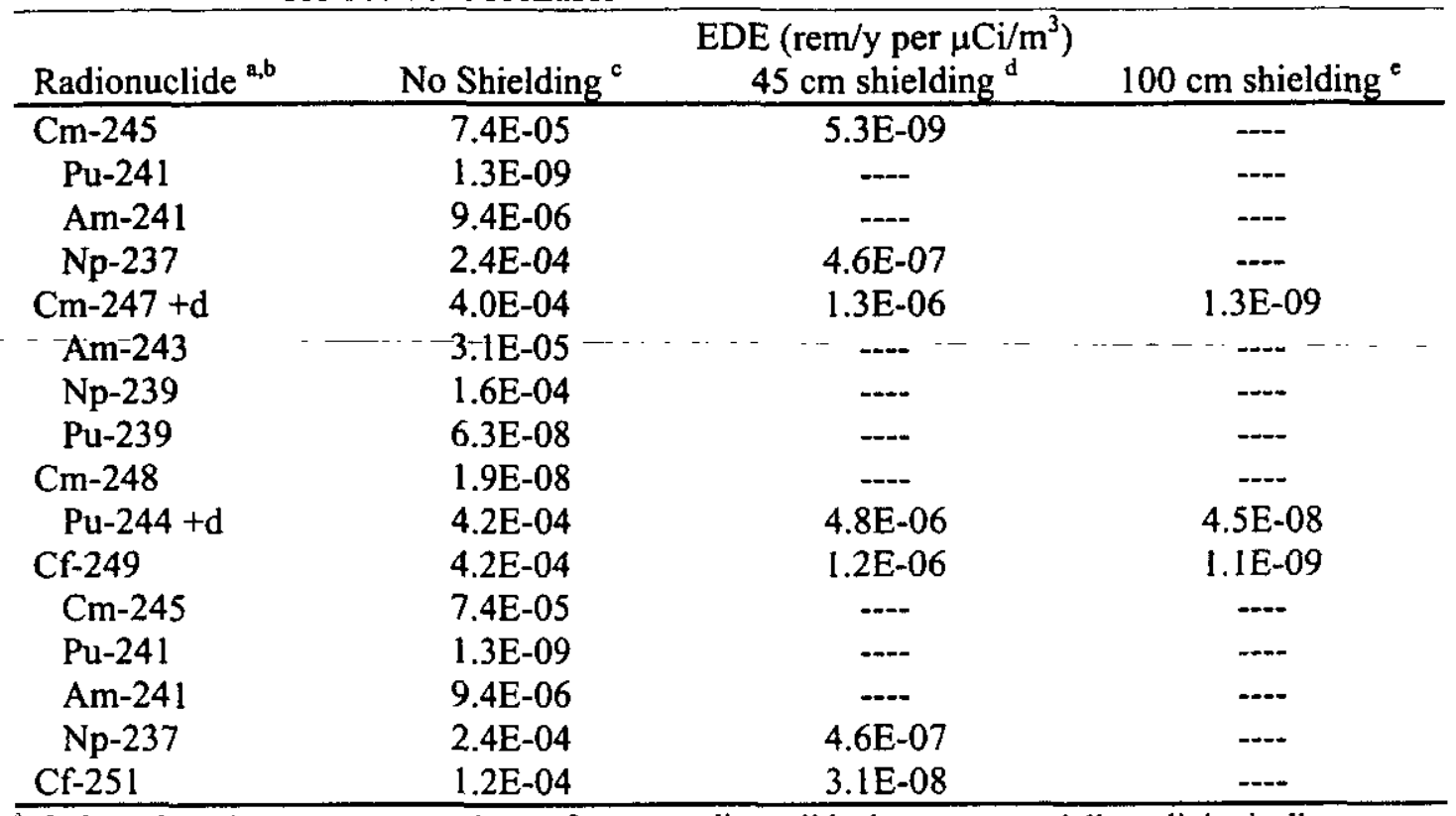

Indented entries are decay products of parent radionuclide that are potentially radiologicallysignificant.

b The notation " $+d$ " indicates that short-lived daughters were incorporated into the EDE. Dose from other daughters listed is calculated explicitly by adding EDE's.

c Results apply to all disposal unit at times when engineered barriers which provide shielding above the waste are assumed to have lost they physical integrity.

d Results apply to LAW vaults at 100 years after facility closure, when the roofs of the vaults are assumed to be intact and residence on unshielded waste is not credible.

c Results apply to IL vaults at 100 years after facility closure, when the roofs of the vaults and uncontaminated grout layer over the waste are assumed to be intact and residence on unshielded waste is not credible. 


\section{Post-drilling scenario}

In the post-drilling scenario, exposures of inadvertent intruders are assumed to occur after an intruder drills through a disposal unit, e.g., for the purpose of constructing a well for a domestic water supply. The entire amount of drilling waste is assumed to be mixed with native soil in a vegetable garden, and the exposure pathways assumed for this scenario then include: 1) ingestion of vegetables grown in contaminated garden soil; 2) direct ingestion of contaminated soil in conjunction with vegetable intakes; 3) external exposure to contaminated soil while working in the garden; and 4) inhalation of suspended activity in particulate form and inhalation of isotopes of radon and their short-lived decay products while working in the garden. The radionuclides included in the dose analysis for the post-drilling scenario were selected on the basis of the screening analysis described in Sect. 6.2.

The exposure pathways for the post-drilling scenario are the same as the corresponding pathways for the agriculture scenario described previously, but external and inhalation exposures during indoor residence do not occur in the post-drilling scenario since all of the exhumed waste is assumed to be mixed with native soil in the vegetable garden and the intruder's home is not located on top of exposed disposal units. Therefore, the models given by Eqs. (C.3-2) and (C.3-3) for the vegetable pathway, Eqs. (C.3-4) and (C.3-5) for the soil ingestion pathway, Eqs. (C.3-6) and (C.3-7) for external exposure while working in the garden, and Eqs. (C.3-9) through (C.3-11) for inhalation exposure to radionuclides in particulate form while working in the garden, as well as the natural analog model for estimating dose from exposure to radon while working in the garden, also apply to the post-drilling scenario.

In implementing the models for the different exposure pathways, most of the parameter values for the post-drilling scenario would be the same as the values assumed for the agriculture scenario. The one important exception is the dilution factor for mixing of radionuclides in exhumed waste with native soil in the vegetable garden, which is denoted by $f_{s}$. For all exposure pathways in the post-drilling scenario, the dose per unit concentration of a radionuclide in exhumed waste is directly proportional to this dilution factor.

In the post-drilling scenario, the volume of contaminated drilling waste is assumed to be $0.5 \mathrm{~m}^{3}$ (Kennedy et al. 1983), and this material is assumed to be mixed to a depth of $15 \mathrm{~cm}$ in a vegetable garden of area about $200 \mathrm{~m}^{2}$. The assumed area of the garden reasonably could provide half of the entire yearly intake of all vegetables by an intruder, which is the value assumed in this analysis. Therefore, the volume of soil in the garden into which the drilling waste is mixed is about $30 \mathrm{~m}^{3}$, and the resulting dilution factor is about 0.02 . The assumed dilution factor for the post-drilling scenario thus is a factor of ten less than the value 0.2 assumed for the agriculture scenario. Therefore, for any exposure pathway in the post-drilling scenario, the dose per unit concentration of a radionuclide in exhumed waste is a factor of ten less than the corresponding value for the same pathway in the agriculture scenario.

For the post-drilling scenario, the annual EDE from all exposure pathways per unit concentration of radionuclides in exhumed waste at the time intrusion occurs, as obtained from the models and parameter values described above, is summarized in Table C.3-15. The dose per unit concentration from the vegetable, soil ingestion, external exposure, and inhalation pathways again is one-tenth of the corresponding values for the agriculture scenario in Tables C.3-7 through C.3-9 and C.3-11, respectively.

Since all of the exposure pathways for the post-drilling scenario involve mixing of exhumed waste into surface soil in a vegetable garden, the leaching correction for ${ }^{3} \mathrm{H}$ discussed previously with the agriculture scenario also could be applied in this case. However, for the reasons previously discussed, a leaching correction will be applied in the dose analysis for the post-drilling scenario only if the dose from ${ }^{3} \mathrm{H}$ is expected to be significant. 
Table C.3-15 Annual EDEs per unit concentration of radionuclides in exhumed waste for post-drilling scenario

\begin{tabular}{|c|c|c|}
\hline Radionuclide $^{\mathrm{a}, \mathrm{b}}$ & & $\begin{array}{c}\text { EDE } \\
\left(\mathrm{rem} / \mathrm{y} \text { per } \mu \mathrm{Ci} / \mathrm{m}^{3}\right)\end{array}$ \\
\hline $\mathrm{H}-3$ & & $3.9 \mathrm{E}-07$ \\
\hline C-14 & & $1.5 \mathrm{E}-06$ \\
\hline $\mathrm{Co}-60$ & & $1.8 \mathrm{E}-06$ \\
\hline $\mathrm{Ni}-59$ & & $6.8 \mathrm{E}-09$ \\
\hline $\mathrm{Ni}=63^{-\cdots \cdots}$ & 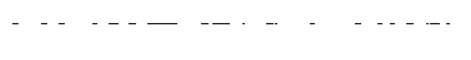 & $-1: 8 \mathrm{E}-08$ \\
\hline Se-79 & & $1.2 \mathrm{E}-07$ \\
\hline $\mathrm{Rb}-87$ & & $1.9 \mathrm{E}-07$ \\
\hline $\mathrm{Sr}-90+\mathrm{d}$ & & $1.8 \mathrm{E}-05$ \\
\hline Mo-93 & & 1.7E-07 \\
\hline $\mathrm{Zr}-93+\mathrm{d}$ & & 3.1E-09 \\
\hline $\mathrm{Nb}-94$ & & $1.1 \mathrm{E}-06$ \\
\hline Tc-99 & & $1.1 \mathrm{E}-06$ \\
\hline Pd-107 & & 3.1E-09 \\
\hline $\mathrm{Cd}-113 \mathrm{~m}$ & & $1.3 \mathrm{E}-05$ \\
\hline $\mathrm{Sn}-121 \mathrm{~m}$ & & $5.3 \mathrm{E}-09$ \\
\hline $\operatorname{Sn}-126+d$ & & $1.4 \mathrm{E}-06$ \\
\hline I-129 & & $8.1 \mathrm{E}-06$ \\
\hline Cs-135 & & $1.2 \mathrm{E}-07$ \\
\hline Cs $-137+d$ & & $1.2 \mathrm{E}-06$ \\
\hline Sm-151 & & $9.3 \mathrm{E}-10$ \\
\hline Eu-152 & & $7.8 \mathrm{E}-07$ \\
\hline $\mathrm{Eu}-154$ & & $8.4 \mathrm{E}-07$ \\
\hline Th-232 & & $1.7 \mathrm{E}-06$ \\
\hline $\mathrm{Ra}-228+d$ & & $2.3 \mathrm{E}-06$ \\
\hline Th-228 & & $2.6 \mathrm{E}-07$ \\
\hline $\mathrm{Ra}-224+\mathrm{d}$ & & $1.7 \mathrm{E}-06$ \\
\hline $\mathrm{U}-232$ & & $3.6 \mathrm{E}-06$ \\
\hline Th-228 & & $2.6 \mathrm{E}-07$ \\
\hline $\mathrm{Ra}-224+\mathrm{d}$ & & $1.7 \mathrm{E}-06$ \\
\hline $\mathrm{U}-233$ & & $7.5 \mathrm{E}-07$ \\
\hline Th-229 & & $2.3 \mathrm{E}-06$ \\
\hline $\mathrm{Ra}-225+\mathrm{d}$ & & $6.4 \mathrm{E}-07$ \\
\hline $\mathrm{U}-234$ & & $7.2 \mathrm{E}-07$ \\
\hline $\mathrm{Th}=230$ & & $-3.4 \mathrm{E}=07$ \\
\hline $\mathrm{Ra}-226+\mathrm{d}$ & & $2.7 \mathrm{E}-06$ \\
\hline $\mathrm{Pb}-210$ & & $2.8 \mathrm{E}-05$ \\
\hline Po-210 & & $1.2 \mathrm{E}-06$ \\
\hline $\mathrm{U}-235+\mathrm{d}$ & & $7.9 \mathrm{E}-07$ \\
\hline $\mathrm{Pa}-231$ & & $7.5 \mathrm{E}-06$ \\
\hline Ac- 227 & & $1.1 \mathrm{E}-05$ \\
\hline Th-227 & & $8.3 \mathrm{E}-08$ \\
\hline $\mathrm{Ra}-223$ & & 8.9E-07 \\
\hline U-236 & & $6.9 \mathrm{E}-07$ \\
\hline
\end{tabular}


Table C.3-15 Annual EDEs per unit concentration of radionuclides in exhumed waste for post-drilling scenario

\begin{tabular}{|c|c|}
\hline Radionuclide $\mathrm{a}^{\mathrm{a}, \mathrm{b}}$ & $\begin{array}{c}\mathrm{EDE} \\
\left(\mathrm{rem} / \mathrm{y} \text { per } \mu \mathrm{Ci} / \mathrm{m}^{3}\right)\end{array}$ \\
\hline $\mathrm{U}-238$ & $6.4 \mathrm{E}-07$ \\
\hline Th-234 +d & $2.2 \mathrm{E}-08$ \\
\hline U-234 & $7.2 \mathrm{E}-07$ \\
\hline $\mathrm{Np}-237+\mathrm{d}$ & $2.4 \mathrm{E}-05$ \\
\hline $\mathrm{Pu}-238$ & $2.2 \mathrm{E}-06$ \\
\hline U-234 & $7.2 \mathrm{E}-07$ \\
\hline Pu-239 & $2.4 \mathrm{E}-06$ \\
\hline U-235 & $7.8 \mathrm{E}-07$ \\
\hline $\mathrm{Pu}-240$ & $2.4 \mathrm{E}-06$ \\
\hline U-236 & $6.9 \mathrm{E}-07$ \\
\hline $\mathrm{Pu}-241$ & $4.9 \mathrm{E}-08$ \\
\hline Am-241 & $3.1 \mathrm{E}-06$ \\
\hline Np-237 & $2.4 \mathrm{E}-05$ \\
\hline $\mathrm{Pu}-242$ & $2.3 \mathrm{E}-06$ \\
\hline U-238 & $6.4 \mathrm{E}-07$ \\
\hline $\mathrm{Pu}-244+\mathrm{d}$ & $2.5 \mathrm{E}-06$ \\
\hline Am-24I & $3.1 \mathrm{E}-06$ \\
\hline Np-237 & $2.4 \mathrm{E}-05$ \\
\hline$A m-242 m+d$ & $2.9 \mathrm{E}-06$ \\
\hline $\mathrm{Pu}-238$ & $2.2 \mathrm{E}-06$ \\
\hline U-234 & $7.2 \mathrm{E}-07$ \\
\hline$A m-243+d$ & $3.2 \mathrm{E}-06$ \\
\hline Pu-239 & $2.4 \mathrm{E}-06$ \\
\hline $\mathrm{Cm}-243$ & $1.7 \mathrm{E}-06$ \\
\hline $\mathrm{Cm}-244$ & $1.3 \mathrm{E}-06$ \\
\hline $\mathrm{Pu}-240$ & $2.4 \mathrm{E}-06$ \\
\hline U-236 & $6.9 \mathrm{E}-07$ \\
\hline $\mathrm{Cm}-245$ & $2.5 \mathrm{E}-06$ \\
\hline $\mathrm{Pu}-24 \mathrm{l}$ & $4.9 \mathrm{E}-08$ \\
\hline Am-241 & $3.1 \mathrm{E}-06$ \\
\hline $\mathrm{Np}-237$ & $2.4 \mathrm{E}-05$ \\
\hline $\mathrm{Cm}-246$ & $2.5 \mathrm{E}-06$ \\
\hline $\mathrm{Cm}-247+\mathrm{d}$ & $2.5 \mathrm{E}-06$ \\
\hline $\mathrm{Am}-243$ & $3.1 \mathrm{E}-06$ \\
\hline Np-239 & $1.1 \mathrm{E}-07$ \\
\hline Pu-239 & $2.4 \mathrm{E}-06$ \\
\hline $\mathrm{Cm}-248$ & $8.8 \mathrm{E}-06$ \\
\hline $\mathrm{Pu}-244+\mathrm{d}$ & $2.3 \mathrm{E}-06$ \\
\hline $\mathrm{Bk}-249$ & $3.4 \mathrm{E}-09$ \\
\hline Cf-249 & $2.8 \mathrm{E}-06$ \\
\hline $\mathrm{Cm}-245$ & $2.5 \mathrm{E}-06$ \\
\hline Cf-249 & $2.8 \mathrm{E}-06$ \\
\hline $\mathrm{Cm}-245$ & $2.5 \mathrm{E}-06$ \\
\hline $\mathrm{Pu}-241$ & $4.9 \mathrm{E}-08$ \\
\hline Am-241 & $3.1 \mathrm{E}-06$ \\
\hline $\mathrm{Np}-237$ & $2.4 \mathrm{E}-05$ \\
\hline
\end{tabular}


Table C.3-15 Annual EDEs per unit concentration of radionuclides in exhumed waste for post-drilling scenario

\begin{tabular}{lc}
\hline Radionuclide $\mathrm{a,b}$ & $\mathrm{EDE}$ \\
Cf-250 & $\left(\mathrm{rem} / \mathrm{y}\right.$ per $\left.\mu \mathrm{Ci} / \mathrm{m}^{3}\right)$ \\
$\mathrm{Cm}-246$ & $1.0 \mathrm{E}-06$ \\
$\mathrm{Cf}-251$ & $2.5 \mathrm{E}-06$ \\
$\mathrm{Cf}-252$ & $2.6 \mathrm{E}-06$ \\
$\mathrm{Cm}-248$ & $5.2 \mathrm{E}-07$ \\
\hline
\end{tabular}

Indented entries are decay products of parent radionuclide that are potentially radiologicallysignificant.

b The notation " $+\mathrm{d}$ " indicates that short-lived daughters were incorporated into the EDE. Dose from other daughters listed is calculated explicitly by adding EDE's. 


\section{C.3.6 Summary}

This appendix has presented the models and data bases used in estimating annual EDEs to 1) off-site individuals resulting from exposure to radionuclides in contaminated ground-water and 2) inadvertent intruders resulting from direct intrusion into the E-Area LLWF. In each case, particular exposure scenarios and associated exposure pathways have been assumed. The scenarios and pathways chosen for analysis and the radionuclides selected for the dose analysis for each scenario were based on considerations discussed in Sect. 4.1.3, 4.2, 6.1, and 6.2. For each exposure pathway, simple models for estimating dose have been developed, and annual doses per unit concentration of radionuclides in groundwater or in disposal units have been estimated on the basis of assumed parameter values for the particular pathway models.

For each exposure scenario, the annual doses per unit concentration of a radionuclide for each exposure pathway have been combined to obtain the total dose per unit concentration from all pathways. The following tables give the total dose per unit concentration at the time intrusion occurs for the different exposure scenarios:

- Table C.3-5, exposure of off-site individuals to radionuclides in contaminated groundwater via the drinking water pathway;

- Table C.3-13, agriculture scenario for exposure of inadvertent intruders to radionuclides in disposal units;

- Table C.3-14, resident scenario for exposure of inadvertent intruders to photon-emitting radionuclides in disposal units; and

- Table C.3-15, post-drilling scenario for exposure of inadvertent intruders to radionuclides in disposal units.

The dose analyses for each exposure scenario and exposure pathway were based on certain model parameters, some of which are radionuclide- or element-specific and others of which are independent of radionuclide. The radionuclide- or element-specific parameter values are given in Tables C.3-2 through C.3-4 and C.3-6. The parameter values that are independent of radionuclide are summarized in Table C.3-16.

For the three scenarios involving direct intrusion into the E-Area disposal units, the radionuclide concentrations in the disposal units to which the annual doses obtained in this analysis are normalized are the concentrations at the time intrusion is assumed to occur, rather that the concentrations at the time of disposal. That is, the dose analysis for these scenarios presented in this appendix does not include any assumptions about the time after disposal at which intrusion occurs. In most cases, assumptions about the time intrusion occurs are applied when the results of the intruder dose analyses in this appendix are combined with projections of the concentrations of radionuclides remaining in the disposal units as a function of time after disposal. 
Table C.3-16. Summary of radionuclide-independent parameter values used in dose analyses for off-site individuals and inadvertent intruders

\begin{tabular}{|c|c|c|}
\hline Parameter description & Symbol & Parameter value \\
\hline Consumption of contaminated drinking water ${ }^{a}$ & $\mathrm{U}_{\mathrm{w}}$ & $730 \mathrm{~L} /$ year \\
\hline Consumption of contaminated vegetables ${ }^{b}$ & $\mathrm{U}_{\mathrm{v}}$ & $90 \mathrm{~kg}$ (fresh weight) per year \\
\hline 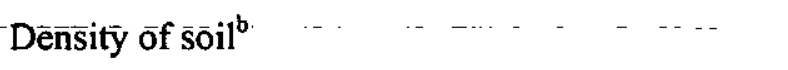 & $\rho_{s}$ & $1,400 \mathrm{~kg} / \mathrm{m}^{-3}$ \\
\hline $\begin{array}{l}\text { Dilution factor for mixing of exhumed waste with } \\
\text { native soil in vegetable garden }\end{array}$ & $\mathrm{f}_{\mathrm{s}}$ & $\begin{array}{l}0.2^{c} \\
0.02^{d}\end{array}$ \\
\hline Consumption of contaminated soil ${ }^{b}$ & $\mathrm{U}_{\mathrm{s}}$ & $0.037 \mathrm{~kg} /$ year \\
\hline $\begin{array}{l}\text { Exposure times - } \\
\text { working in garden } \\
\text { residing in home }^{\mathrm{e}}\end{array}$ & $\begin{array}{l}U_{g} \\
U_{h}\end{array}$ & $\begin{array}{l}1 \% \text { per year } \\
50 \% \text { per year }\end{array}$ \\
\hline $\begin{array}{l}\text { Shielding factor for external exposure during } \\
\text { indoor residence } \\
\text { c }\end{array}$ & $\mathrm{S}$ & 0.7 \\
\hline Air intake (breathing rate) ${ }^{\mathrm{b}}$ & $\mathrm{U}_{\mathrm{a}}$ & $8,000 \mathrm{~m}^{3} /$ year \\
\hline $\begin{array}{l}\text { Atmospheric mass loading of contaminated } \\
\text { surface soil - } \\
\text { working in garden } \\
\text { residing in home }\end{array}$ & $\mathrm{L}_{\mathrm{a}}$ & $\begin{array}{l}10^{-7} \mathrm{~kg} / \mathrm{m}^{3} \\
10^{-8} \mathrm{~kg} / \mathrm{m}^{3}\end{array}$ \\
\hline
\end{tabular}

Parameter applies to exposure of off-site individuals.

b Parameter applies to agriculture and post-drilling scenarios for inadvertent intruders.

c Parameter applies to agriculture scenario for inadvertent intruders.

d Parameter applies to post-drilling scenario for inadvertent intruders.

c Parameter applies to agriculture and resident scenarios for inadvertent intruders. 


\section{APPENDLX C REFERENCES}

Anspaugh, L. R., J. H. Shinn, P. L. Phelps, and N. C. Kennedy. 1975. Resuspension and Redistribution of Plutonium in Soils. Health Physics., 29:571.

Baes, C. F. III, and R. D. Sharp. 1983. A Proposal for Estimation of Soil Leaching Constants for Use in Assessment Models. Journal of Environmental Quality, 12:17.

Baes, C. F. III, R. D. Sharp, A. L. Sjoreen, and R. W. Shor. 1984. A Review and Analysis of Parameters for Assessing Transport of Environmentally Released Radionuclides Through Agriculture. ORNL-5786. Oak Ridge National Laboratory.

Dennehy, K. F., and P. B. McMahon. 1987. Water Movement in the Unsaturated Zone at a Low-Level Radioactive-Waste Burial Site Near Barnwell, South Carolina. U. S. Geological Survey Open-File Report 87-46, p.66.

Eckerman, K. F., and J. C. Ryman. 1993. External Exposure to Radionuclides in Air, Water, and Soil. Federal Guidance Report No. 12. EPA 402-R-93-081. Oak Ridge National Laboratory and U. S. Environmental Protection Agency.

Gruber, P. 1980. A hydrologic Study of the Unsaturated Zone Adjacent to a Radioactive Waste Disposal Site at the Savannah River Plant, Aiken, South Carolina. M.S. Thesis, University of Georgia, Athens, Georgia.

Hamby, D. M. 1992. Site-Specific Parameter Values for the Nuclear Regulatory Commission's Food Pathway Dose Model. Health Physics, 62:136.

Hubbard, J. E., and M. Engelhardt. 1987. Calculation of Groundwater Recharge at the Old SRP Burial Ground Using the CREAMS Model (1961-1986). July 31, 1987, Memorandum from J. E. Hubbard and M. Englehardt, Department of Earth Sciences, State University of New York, College at Brockport, N.Y.

INTERA. 1986. Validation of Unsaturated Flow Models Using Tank 24 Lysimeter Data. INTERA Technologies report H01203R005, INTERA Technologies, Inc., Austin, Texas.

Kennedy, W. E. Jr., B. A. Napier, and J. K. Soldat. 1983. Advanced Disposal Systems for Transuranic Waste: Preliminary Disposal Criteria for Plutonium-239 at Hanford. Nuclear Chemical Waste Management, 4:103.

Kocher, D. C. 1981. Radioactive Decay Data Tables. DOE/TIC-11026. U. S. Department of Energy.

Kocher, D. C., and A. L. Sjoreen. 1985. Dose-Rate Conversion Factors for External Exposure to Photon Emitters in Soil. Health Physics, 48:193.

Napier, B. A., R. A. Peloquin, W. E. Kennedy, Jr., and S. M. Neuder. 1984. Intruder Dose Pathway Analysis for the Onsite Disposal of Radioactive Waste: The ONSITE/MAXII Computer Program. NUREG/CR-3620, PNL-4054. Pacific Northwest Laboratory. 
NCRP. 1996. Screening Models for Releases of Radionuclides to Atmosphere, Surface Water, and Ground. NCRP Report No. 123 I, National Council on Radiation Protection and Measurements, Bethesda, MD.

NRC. 1977. Regulatory Guide 1.109. Calculation of Annual Doses to Man from Routine Releases of Reactor Effluents for the Purpose of Evaluating Compliance with 10 CFR Part 50, Appendix I. U. S. Nuclear Regulatory Commission, Washington, D.C.

NRC. 1981. Draft Environmental Impact Statement on 10 CFR Part 61 "Licensing Requirements for Land Disposal of Radioactive Waste". "NUREG-0945, Vol. "1. U. S. Nuclear Règulatory Commission, Washington, D.C.

Oztunali, O. I., G. C. Re, P. M. Moskowitz, E. D. Picazo, and C. J. Pitt. 1981. Data Base for Radioactive Waste Management. NUREG/CR-1759, Vol. 3. Dames and Moore, Inc.

Oztunali, O. I., and G. W. Roles. 1986. Update of Part 61 Impacts Analysis Methodology. NUREG/CR4370. U. S. Nuclear Regulatory Commission and Envirosphere Company.

Parizek, R. R., and R. W. Root. 1986. Development of a Ground-Water Velocity Model for the Radioactive Waste Management Facility, Savannah River Plant, South Carolina. College of Earth and Mineral Sciences, Pennsylvania State University, University Park, Penn.

Shinn, J. H., D. N. Homan, and D. D. Gay. 1982. Plutonium Aerosol Fluxes and Pulmonary Exposure Rates During Resuspension from Bare Soils Near a Chemical Separation Facility, p. 1131 in Precipitation Scavenging, Dry Deposition, and Resuspension. Vol. 2. Ed. by H. R. Pruppacher, R. G. Semonin, and W. G. N. Slinn, Elsevier Science Publishing Co., New York, N.Y.

U.S.DOE. 1988. Internal Dose Conversion Factors for Calculation of Dose to the Public. DOE/EH0071. U. S. Department of Energy.

U.S.DOE. 1999. Radioactive Waste Management, Order 435.1, U. S. Department of Energy.

U.S. EPA. 1989. Risk Assessment Guidance for Superfund. Volume I. Human Health Evaluation Manual (Part A). EPA/540/1-89/002. U. S. Environmental Protection Agency, Washington, D.C.

Vandecasteele, C. M., J. P. Dehut, S. Van Laer, D. Deprins, and C. Myttenaere. 1989. Long-Term Availability of Tc Deposited on Soil after Accidental Releases. Health Physics, 57:247.

Yu, A.D., C. A. Langton, and M. G. Serrato 1993. Physical Properties Measurement Program, WSRC-RP93-894, Savannah River Technology Center, Westinghouse Savannah River Company, Aiken, SC. 
APPENDIX D

\section{VAULT DEGRADATION STUDY}


THIS PAGE INTENTIONALLY LEFT BLANK 


\section{NOTE OF EXPLANATION FOR APPENDIX D}

Appendix D was prepared in 1993, at a time when two different types of IL vaults were planned: the ILNT vaults (intermediate-level non-tritium vaults), and the ILT vaults (intermediate-level tritium vaults).

The design for the ILNT vaults has since been adopted for IL vaults, and thus the results of the degradation assessment for that type of vault was used for the IL vaults. The results of the degradation assessment for the LAW vaults remains applicable, because the design has not changed. 
THIS PAGE INTENTIONALLY LEFT BLANK 


\title{
E-AREA VAULTS VAULT DEGRADATION STUDY
}

FINAL REPORT

\author{
Prepared For: \\ Westinghouse Savannah River Company \\ Aiken, SC 29803
}

Prepared By

Erich R. Brandstetter

Jim L. Lolcama

INTERA Inc.

501 Greene Street, Suite 200-D

Augusta, GA 30901

Tel.: (706)722-2356

Fax: (706)724-2583

September 30, 1993 


\section{EXECUTIVE SUMMARY}

The primary focus of this study was to determine the possible rates of roof and wall failure and the times to structural collapse of the roof and walls of three vault designs: the Intermediate Level Non-Tritium (ILNT), Intermediate Level Tritium (ILT) and Low Activity Waste (LAW) Vaults at the Department of Energy's Savannah River Site near Aiken, South Carolina. Failure was defined as a loss of ability to divert soil water around the vault. Collapse was defined as the total loss of structural integrity of the vault. Failure and eventual collapse of the three vault types results from concrete deterioration under stress, in the presence of corrosive soil water. Degradation rates for reinforced concrete-were utilized, and the resultant changes in properties (such as strength, thickness, cracking and hydraulic conductivity) were evaluated. Baseline times to failure and collapse of the walls and roof components were modeled, and sensitivity analyses were conducted to provide boundaries on these estimated times. Thus, the goal of the project was to provide a bounding analysis of the time to roof and wall failure and potential collapse, rather than an actual prediction of the time to failure and collapse. The overall approach was to develop an executive model which linked various pre-existing models of degradation of reinforced concrete and to integrate that model with structural engineering models which estimate stress in the structure, for the bounding analysis of failure and collapse.

Degradation processes considered were magnesium and sulfate attack, calcium leaching, carbonation, and rebar corrosion due to both oxygen diffusion to the rebar (including breakdown of the passivating layer that initially prevents corrosion of rebar) and due to the "hydrogen evolution" reaction. Existing empirical models for the individual degradation processes were combined into a single model to create an overall model of the degradation of reinforced concrete. The state of stress in the concrete and rebar was calculated and the roof components and walls fractured in order to eliminate excessive stress which cannot be borne by the degraded structure. Crack aperture and spacing were computed and used to estimate hydraulic conductivity.

For each type of vault, a sensitivity analysis was performed to bound the predictions. After an initial rough sensitivity analysis on a large number of factors, six factors were selected for detailed sensitivity analysis: rate of rebar corrosion due to the "hydrogen evolution" reaction, rebar diameter, depth of concrete cover over the rebar, size of AASHTO "bridge" beams used to support the vault roof in the LAW vault design, and depth of soil cover over the vaults, and concrete-strength.

The ILNT Vault design consists of 7 rectangular cells, each approximately $48.5^{\prime}$ long by $27^{\prime}$ wide by $29.75^{\prime}$ high. The $I \mathrm{LT}$ is a similar design, the main differences being that it consists of only 2 cells and utilizes a slightly thicker roof. The LAW vault consists of 4 cells, each approximately $145^{\prime} \times 53^{\prime} \times 26^{\prime}$. It utilizes a significantly different design in that AASHTO "bridge" beams are used to support the roof span. Baseline times to failure and collapse for the ILNT vault were 570 and 1,045 years, respectively. The thicker roof and two-cell design of the ILT vault result in longer times to failure and collapse for the ILT vault; 790 
and 1,300 years respectively. For the LAW vault, failure and collapse are predicted to occur in 1,420 and 3,100 years. The following table summarizes the baseline results for each vault type:

Summary of Baseline Results

\begin{tabular}{|c|c|c|c|}
\hline Vault & $\begin{array}{c}\text { Cracks Penetrate } \\
\text { Roof/Failure } \\
\text { (years) }\end{array}$ & $\begin{array}{c}\text { Cracks Penetrate Walls } \\
\text { (Mid-Height) } \\
\text { (years) }\end{array}$ & $\begin{array}{c}\text { Roof Collapse } \\
\text { (years) }\end{array}$ \\
\hline ILNT & 570 & 800 & 1,045 \\
\hline \hline ILT & 790 & 1,080 & 1,300 \\
\hline LAW & 1,420 & 2,235 & 3,100 \\
\hline
\end{tabular}

Sensitivity analysis indicated that the rate of rebar corrosion due to the hydrogen evolution reaction is the most critical and uncertain model parameter. Variation within the bounds of acceptable values reported in the literature can result in the times to failure and collapse varying hundreds to thousands of years. For example, for the ILNT vault, the time to failure varied from 285 years to 2,775 years, based on variation in the hydrogen evolution corrosion rate. Similarly, the time to collapse varied from 525 years to beyond the 3,000year duration of the simulation for the ILNT vault.

Variation in depth of concrete cover over rebar and in concrete strength within design constraints resulted in variation in times to failure and collapse of less than 100 years. Variation in depth of soil cover within design constraints resulted in variation in times to failure and collapse on the order of 100 to 400 years. Changing the rebar diameter has the potential to significantly impact the longevity of the vaults. For example, changing the bar designation by 1 (for example, from $\# 8$ to $\# 7$ or to $\# 9$ ) changes the time to failure and collapse on the order of 300 to 400 years. Changing the size of AASHTO beams has a similar impact on the time to collapse of the LAW vault. Utilizing a smaller beam, however, would result in cracks penetrating the vault (i.e., failure) immediately upon soil loading.

This study has combined pre-existing models for the degradation of reinforced concrete with proven structural engineering models to create a performance assessment code capable of predicting the time to failure (loss of ability to divert water) and collapse (loss of structural integrity) of buried concrete vaults. This code can also be used to estimate the impact of changes in design parameters on the longevity of reinforced concrete structures, and therefore has potential for application as a design aid tool for below-ground concrete storage facilities. The current mandate at DOE facilities to move in the direction of below-ground disposal in concrete-engineered structures makes this code a potentially important performance assessment tool. 


\section{TABLE OF CONTENTS}

EXECUTIVE SUMMARY $\ldots \ldots \ldots \ldots \ldots \ldots \ldots$ ii

LIST OF TABLES $\ldots \ldots \ldots \ldots \ldots \ldots \ldots \ldots \ldots \ldots \ldots \ldots \ldots \ldots$

LIST OF FIGURES $\ldots \ldots \ldots \ldots \ldots \ldots \ldots \ldots \ldots \ldots \ldots \ldots$ vii

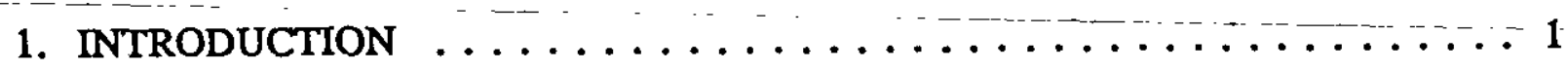

2. DESCRIPTION OF THE CLOSED IIT, ILNT AND LAW VAULTS $\ldots \ldots \ldots 3$

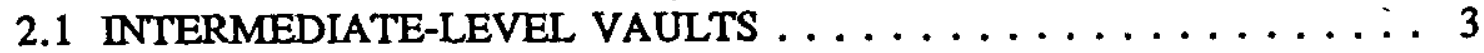

2.1 .1 ILNT Vaults $\ldots \ldots \ldots \ldots \ldots \ldots \ldots \ldots \ldots \ldots \ldots$

2.1 .2 ILT Vaults . . . . . . . . . . . . 3

2.2 LAW VAULT $\ldots \ldots \ldots \ldots \ldots \ldots \ldots \ldots \ldots \ldots \ldots \ldots \ldots$

2.3 VAULT CLOSURE $\ldots \ldots \ldots \ldots \ldots \ldots \ldots \ldots \ldots \ldots \ldots \ldots$

3. MODELS OF CHEMICAL DEGRADATION AND STRUCTURAL

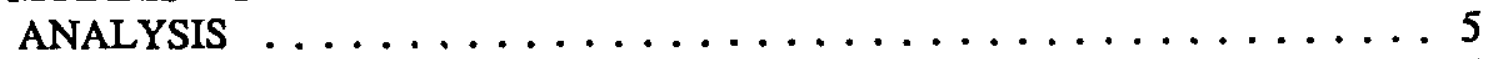

3.1 CHEMICAL ATTACK $\ldots \ldots \ldots \ldots \ldots \ldots \ldots \ldots \ldots$

3.1.1 Sulfate and Magnesium Attack ............. 5

3.1.2 Alkali and Calcium Hydroxide Leaching . . . . . . . 6

3.1 .3 Carbonation . . . . . . . . . . . . . 7

3.1 .4 Rebar corrosion . . . . . . . . . . . . 8

3.1 .5 Vault Interiors . . . . . . . . . . . . 10

3.2 STRUCTURAL/ENGINEERING ANALYSIS $\ldots \ldots \ldots \ldots \ldots 11$

3.2.1 Application to the $\Pi$ NT/ $/ \mathrm{LT}$ Vaults $\ldots \ldots \ldots \ldots \ldots \ldots 12$

3.2.2 Application to the LAW Vault $\ldots \ldots \ldots \ldots \ldots \ldots \ldots$

4. MODELING APPROACH $\ldots \ldots \ldots \ldots \ldots \ldots \ldots \ldots \ldots \ldots \ldots$

4.1 COMPUTER CODES . . . . . . . . . . . . . 16

4.2 LINKING BETWEEN DEGRADATION AND STRUCTURAL

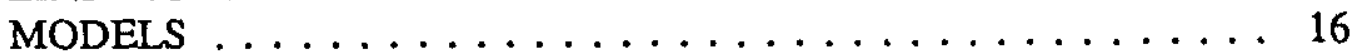

4.3 HYDRAULIC CONDUCTIVITY $\ldots \ldots \ldots \ldots \ldots \ldots \ldots \ldots$

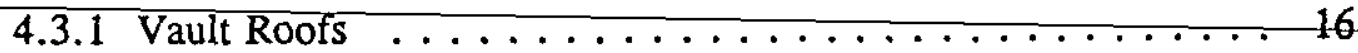

4.3 .2 Vault Walls . . . . . . . . . . . . . 18

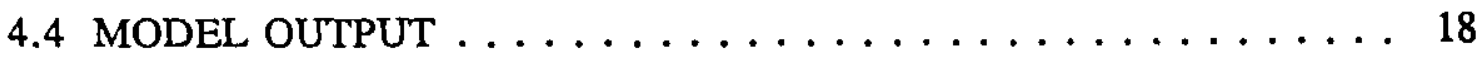

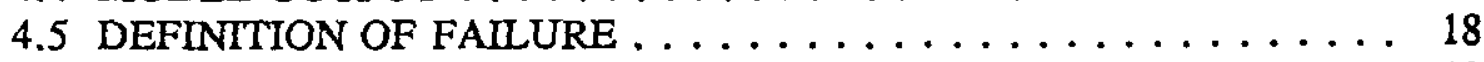

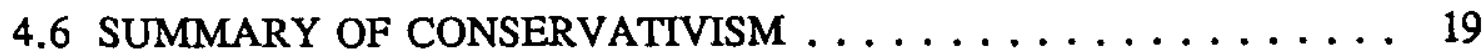

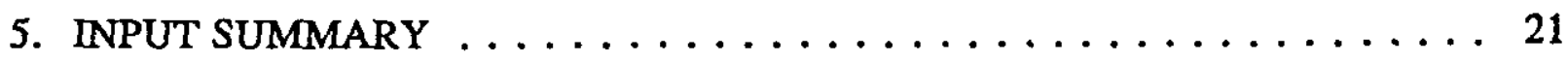

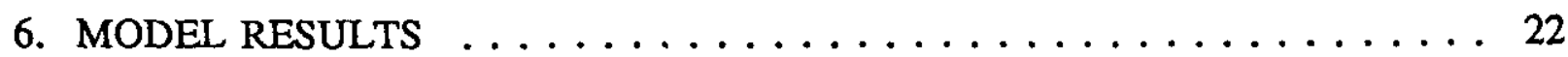




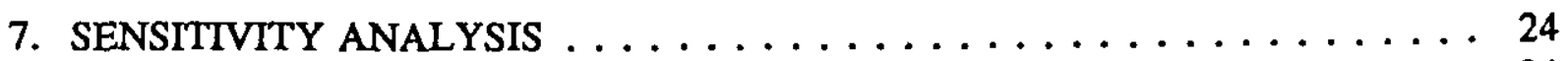

7.1 SELECTION OF PARAMETERS AND VALUES $\ldots \ldots \ldots \ldots 24$

7.2 OUTPUT SUMMARY $\ldots \ldots \ldots \ldots \ldots \ldots \ldots \ldots \ldots \ldots$

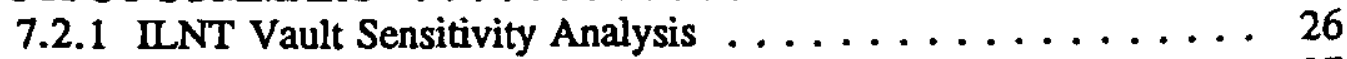

$7.2 .2 \mathrm{IIT}$ Vault Sensitivity Analysis . . . . . . . . . . 27

7.2.3 LAW Vault Sensitivity Analysis . . . . . . . . . 27

7.3 SUMMARY OF THE IMPACT OF DESIGN CHANGES . . . . . . 29

8. FUTURE RESEARCH AREAS $\ldots \ldots \ldots \ldots \ldots \ldots \ldots \ldots \ldots \ldots \ldots$

9. SUMMARY AND CONCLUSIONS $\ldots \ldots \ldots \ldots \ldots \ldots \ldots$

REFERENCES $\ldots \ldots \ldots \ldots \ldots \ldots \ldots \ldots \ldots \ldots \ldots \ldots \ldots \ldots \ldots \ldots \ldots \ldots$

ACRONYMS AND ABBREVIATIONS $\ldots \ldots \ldots \ldots \ldots \ldots$

APPENDIX: QUALITY ASSURANCE $\ldots \ldots \ldots \ldots \ldots \ldots \ldots$

A.1 IMPLEMENTATION OF THE PROJECT QUALITY ASSURANCE

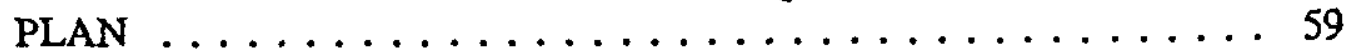

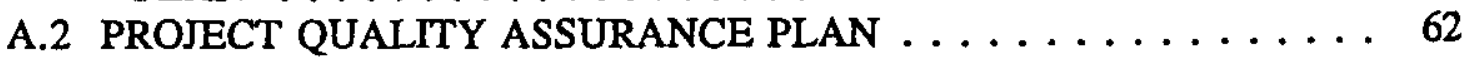




\section{LIST OF TABLES}

Page

Table 1. Summary of Output Parameters $\ldots \ldots \ldots \ldots \ldots \ldots \ldots \ldots \ldots \ldots \ldots \ldots$

Table 2. Structural Input for the IINT Vault $\ldots \ldots \ldots \ldots \ldots \ldots \ldots \ldots$

Table 3. Structural Input for the IIT Vault $\ldots \ldots \ldots \ldots \ldots \ldots \ldots \ldots$

Table 4. Structural Input for the LAW Vault . . . . . . . . . . . . 39

Table-5.-Design Drawings_Used . . ................... 40

Table 6. Summary of Degradation Modei Variables and Values . . . . . . . . 44

Table 7. Summary of Rebar Stress (ksi) in ILT Baseline Scenario . . . . . . . . . . 49

Table 8. Summary of Rebar Stress (ksi) in ILNT Baseline Scenario . . . . . . . 50

Table 9. Summary of Baseline Results . . . . . . . . . . . . 51

Table 10. Summary of ILNT Vault Sensitivity Analyses . . . . . . . . . 52

Table 11. Summary of ILT Vault Sensitivity Analyses . . . . . . . . . . 53

Table 12 . Summary of LAW Vault Sensitivity Analyses . . . . . . . . . 54

Table 13. Summary of Baseline Results Assuming High-pH Concrete . . . . . 55 


\section{LIST OF FIGURES}

Figure 1 Schematic of ILNT Vault

Figure 2 Schematic of ILT Vault

Figure 3 Schematic of LAW Vault

Figure 4 Portion of Vault Cross Section; Cracks Indicate Critical Stress Regions

Figure 5 LAW Vault Roof, Showing Cracking Due to Curvature Over Wall

Figure 6 Cross-Section of ILNT Vault Roof Showing Degradation at 400 Years

Figure 7 Effective Hydraulic Conductivity of Vault Roof; ILNT Vault Design

Figure 8 Effective Hydraulic Conductivity of Vault Roof; ILT Vault Design

Figure 9 Effective Hydraulic Conductivity of Vault Roof; LAW Design

Figure 10 ILNT Vault Time to Crack Penetration of Roof; Sensitivity to Hydrogen Evolution Corrosion Rate $(\mathrm{cm} / \mathrm{yr})$

Figure 11 ILNT Vault Time to Crack Penetration of Walls; Sensitivity to Hydrogen Evolution Corrosion Rate (cm/yr)

Figure 12 ILNT Vault Time to Roof Collapse; Sensitivity to Hydrogen Evolution Corrosion Rate $(\mathrm{cm} / \mathrm{yr})$

Figure 13 ILNT Vault Time to Crack Penetration of Roof; Sensitivity to Depth of Soil Cover

Figure 14 IINT Vault Time to Crack Penetration of Walls; Sensitivity to Depth of Soil Cover

Figure 15 ILNT Vault Time to Roof Collapse; Sensitivity to Depth of Soil Cover

Figure 16 ILNT Vault Time to Crack Penetration of Roof; Sensitivity to Rebar Size

Figure 17 ILNT Vault Time to Crack Penetration of Walls; Sensitivity to Rebar Size

Figure 18 ILNT Vault to Roof Collapse; Sensitivity to Rebar Size 


\section{LIST OF FIGURES (Continued)}

Figure 19 ILNT Vault Time to Crack Penetration of Roof; Sensitivity to Depth of Concrete Cover Over Rebar

Figure 20 ILNT Vault Time to Crack Penetration of Walls; Sensitivity to Depth of Concrete Cover Over Rebar

Figure-21 . ILNT-Vault Time to Roof Collapse; Sensitivity to Depth of Concrete Cover Over Rebar

Figure 22 ILNT Vault Time to Crack Penetration of Roof; Sensitivity to Concrete Strength

Figure 23 ILNT Vault Time to Crack Penetration of Roof; Sensitivity to Concrete Strength

Figure 24 ILNT Vault Time to Roof Collapse; Sensitivity to Concrete Strength

Figure 25 ILT Vault Time to Crack Penetration of Roof; Sensitivity to Hydrogen Evolution Corrosion Rate $(\mathrm{cm} / \mathrm{yr})$

Figure 26 ILT Vault Time to Crack Penetration of Walls; Sensitivity to Hydrogen Evolution Corrosion Rate $(\mathrm{cm} / \mathrm{yr})$

Figure 27 IIT Vault Time to Roof Collapse; Sensitivity to Hydrogen Evolution Corrosion Rate $(\mathrm{cm} / \mathrm{yr})$

Figure 28 ILT Vault Time to Crack Penetration of Roof; Sensitivity to Depth of Soil Cover

Figure 29 ILT Vault Time to Crack Penetration of Walls; Sensitivity to Depth of Soil Cover

Figure 30 IIT Vault Time to Roof Collapse; Sensitivity to Depth of Soil Cover

Figure 31 ILT Vault Time to Crack Penetration of Roof; Sensitivity to Rebar Size

Figure 32 ILT Vault Time to Crack Penetration of Walls; Sensitivity to Rebar Size

Figure 33 ILT Vault Time to Roof Collapse; Sensitivity to Rebar Size

Figure 34 ILT Vault Time to Crack Penetration of Roof; Sensitivity to Depth of Concrete Cover Over Rebar 
LIST OF FIGURES (continued)

Figure 35 ILT Vault Time to Crack Penetration of Walls; Sensitivity to Depth of Concrete Cover Over Rebar

Figure 36 ILT Vault Time to Roof Collapse; Sensitivity to Depth of Concrete Cover Over Rebar

Figure 37 ILT Vault Time to Crack Penetration of Roof; Sensitivity to Concrete Strength

Figure 38 IIT Vault Time to Crack Penetration of Walls; Sensitivity to Concrete Strength

Figure 39 ILT Vault Time to Roof Collapse; Sensitivity to Concrete Strength

Figure 40 LAW Vault Time to Crack Penetration of Roof; Sensitivity to Hydrogen Evolution Corrosion Rate $(\mathrm{cm} / \mathrm{yr})$

Figure 41 LAW Vauit Time to Crack Penetration of Walls; Sensitivity to Hydrogen Evolution Corrosion Rate $(\mathrm{cm} / \mathrm{yr})$

Figure 42 LAW Vault Time to Roof Collapse; Sensitivity to Hydrogen Evolution Corrosion Rate (H2rate; $\mathrm{cm} / \mathrm{yr}$ ) and Depth of Soil Cover

Figure 43 LAW Vault Time to Crack Penetration of Walls; Sensitivity to Depth of Soil Cover

Figure 44 LAW Vault Time to Crack Penetration of Roof; Sensitivity to Rebar Size

Figure 45 LAW Vault Time to Crack Penetration of Walls; Sensitivity to Rebar Size

Figure 46 LAW Vault Time to Roof Collapse; Sensitivity to Hydrogen Evolution Corrosion Rate (H2rate; $\mathrm{cm} / \mathrm{yr}$ ) and Beam Type

Figure 47 Cross-Section of Vault Roof Assuming Use of High-pH Concrete; Degradation at 50 Years

Figure 48 Cross-Section of Vault Roof Assuming Use of High-pH Concrete; Degradation at 400 Years 
THIS PAGE INTENTIONALLY LEFT BLANK 


\section{INTRODUCTION}

The E-Area Vaults (EAV), which are the focus of this study, are located at the Savannah River Site (SRS) in South Carolina. The EAV designs which will be discussed in this report are the Intermediate Level Non-Tritium (ILNT), Intermediate Level Tritium (ILT) and Low Activity Waste (LAW) Vaults. Westinghouse Savannah River Company (WSRC) operates this site and is currently developing a Radiological Performance Assessment (RPA) for the EAV. The vault degradation study is a supporting study for this RPA.

The EAV site is located on a 200-acre site immediately north of Building 643-7E at the SRS. The original SRS Solid Waste Disposal Facility (SWDF) and the added EAV site are centrally located between the two chemical separations areas near the center of the SRS, between Upper Three Runs Creek on the north and Four Mile Creek on the south. Of this 200 acre tract, only 100 acres have been developed at this time. The nearest site boundary to the SWDF is about seven miles to the west. The SWDF is in a relatively level highland region of the SRS at about $300 \mathrm{ft}$ above sea level.

The E-Area Vaults are reinforced concrete structures intended for below ground storage of low-activity and intermediate-level wastes. Each of the EAV designs are intended to house designated waste types. The LAW vaults, which are located at a separate facility from the IIT and ILNT vaults, are designed to receive and store low-activity waste radiating less than $200 \mathrm{mR} / \mathrm{hr}$ at $5 \mathrm{~cm}$ from an unshielded container and containing only incidental quantities of tritium. One section of the Intermediate Level facility is designated as the ILNT vault and receives waste radiating greater than $200 \mathrm{mR} / \mathrm{hr}$ at $5 \mathrm{~cm}$ in engineered metal containers. The remaining section is designated as the $\mathrm{ILT}$ vault and receives tritium-bearing waste contained in engineered metal containers or as overpacked tritium crucibles with most of the tritium removed. These two vault sections are adjacently located, share waste package handling equipment and are to be closed as one facility. The LAW vault facility will be closed separately. A third facility, also a part of the EAV Project, designated as the Long-Lived Waste Storage Building (LLWSB) has not been considered as part of this degradation study.

Closure of the vaults will be via below ground burial under about 8 feet of soil cover. The placement of the soil cover and soil backfill around the vaults will result in loading of the roof and walls of each unit. Chemical attack on the buried reinforced concrete will weaken the concrete, and the roof and walls of each vault type could be expected to fail and collapse over time. Failure is defined as a loss of ability to divert water around the vault. Degradation of concrete by sulfate attack can cause thinning, calcium hydroxide leaching results in weakening of the concrete, carbonation lowers the $\mathrm{pH}$ of the matrix-bound water, and oxic ("oxygen") and anoxic ("hydrogen evolution") rebar corrosion weakens the reinforced concrete mass. Failure of the vault would result in infiltrating ground water entering the interior of the vault rather than being diverted around its exterior. 
INTERA's approach to this performance assessment problem for the E-Area Vaults has been to construct a mathematical model which integrates structural loading calculations with chemical degradation calculations. The model runs on a PC-platform and utilizes, as subroutines, pre-existing empirical models for the chemical degradation calculations, and an American Concrete Institute code for the design of reinforced concrete structures to calculate the state of stress within the structure. Adopting this modeling approach facilitates sensitivity analyses on different design components of the vaults.

This report presents the chemical degradation mechanisms which have been modeled for degradation of the concrete of each of the vauil designs, describes the structural design model and the approach for integrating these models into one code, and finally, presents the results of the performance assessment calculations on the three vaults types for baseline (base case) and variant configurations of several of the design components. Further work which will likely be accomplished under a separate task will include evaluating the performance of the vault floors for the three vault designs, and extending the sensitivity analyses beyond six parameters. 


\section{DESCRIPTION OF THE CLOSED ILT, INT AND LAW VAULTS}

The EAV Project consists of three types of facilities to house four designated waste types and the necessary roadways to allow waste container delivery. This section describes in brief the three vault types.

\subsection{INTERMEDIATE-LEVEL VAULTS}

The intermediate-level vaults consist of two separate, subsurface reinforced concrete vault structures. The individual vaults are adjacently located, share a similar design, and are closed as a single unit. The vaults are identified as the Intermediate Level Tritium (ILT) Vault, and the Intermediate Level Non-tritium (ILNT) Vault.

\subsubsection{ILNT Vaults}

Each ILNT Vault consists of seven cells or subdivided sections within the vault structure (Figure 1) and provides a total of approximately $200,000 \mathrm{ft}^{3}$ of waste storage capacity. The vaults are subsurface concrete structures approximately $189 \mathrm{ft}$ long, $48.5 \mathrm{ft}$ wide, and 29.75 $\mathrm{ft}$ deep. Exterior end walls are $21 / 2 \mathrm{ft}$ thick, side walls are $2 \mathrm{ft}$ thick, and interior walls (between the cells) are $1 \frac{1 / 2}{\mathrm{ft}}$ thick. All walls are structurally mated to a base slab which is approximately $21 / 2 \mathrm{ft}$ thick and extends past the outside of the exterior walls approximately $2 \mathrm{ft}$. The base slab rests on two layers of crushed stone placed on the compacted subsurface. The crushed stone drains to a collection sump to prevent a positive water head against the vault exterior.

Concrete is reinforced with deformed steel bars. All concrete construction joints are located at defined control joints with no horizontal joints in any vertical wall. All concrete joints include a waterstop seal which is continuous around all corners and intersections. All exterior concrete surfaces exposed to soil are coated with a coal tar-based waterproofing.

\subsubsection{ILT Vaults}

Each ILT Vault consists of two cells or subdivided sections within the vault structure (Figure 2) and provides approximately $57,000 \mathrm{ft}^{3}$ of waste storage capacity. One cell will in most cases be fitted with a silo system to permit the disposal of tritium crucibles. The IIT Vaults are structurally very similar to the ILNT, with slight differences such as wall height and thickness of the (proposed) roof slab. The IIT Vaults are approximately 57 feet long, $48.5 \mathrm{ft}$ wide, and 28.5 feet deep. Wall arrangement, slab and slab base, and concrete are all identical for the two-cell configuration ILT vault and the seven-cell configuration IINT vault. 


\subsection{LAW VAULT}

Each LAW Vaults consists of either two or three major subdivisions, or modules. Each module provides approximately $566,500 \mathrm{ft}^{3}$ storage capacity and will accommodate more than 4,000 B-25 boxes. Figure 3 illustrates one module of a LAW Vault. Each module is approximately $214.5 \mathrm{ft}$ long and $145 \mathrm{ft}$ wide. Height of the vaults varies from approximately 26 to 27 feet. End, side, and interior walls of each module are all $2 \mathrm{ft}$ thick. All walls are structurally mated to a 30 -inch footer that is continuous under all cells in each module.

A reinforced concrete roof is supported by prestressed, concrete beams. The beams run between each wall the length of the vault. The end walls of each module have recessed beam seats to support a beam end, and the interior walls are equipped with bearing pads allowing beam ends to rest on the wall. The beams rest on elastomeric bearings which allow the bases of the beams to move towards each other as soil load and progressive deterioration of the structure causes the roof system to bend.

The slightly peaked roof is composed of $3^{1 / 2}$-inch thick, prestressed, concrete deck panels installed directly on the roof beams providing a base for a 16-inch, cast-in-place roof slab. The roof slab has 2-in. wide expansion joints between module walls. Each expansion joint has flashing installed to provide waterproofing. The roof slab is covered with a bonded-inplace layer of fiberboard insulation and a layer of waterproof membrane roofing.

\subsection{VAULT CLOSURE}

Final closure of the vaults consists of placing an earthen cover with an engineered clay cap over the entire 21-vault area. The final closure cap will consist of a 2-foot thick compacted clay layer, on top of which will be a clay geomembrane or clay/geotextile composite. This will be overlain with a 1-foot thick granular drainage layer. Above the drainage layer will be a geotextile filter fabric. The uppermost layer of the closure cap will be a 2-foot thick topsoil cover. The slope of each of these layers will be $3 \%$ over the ILNT and ILT Vaults, and $3 \%$ or $4.3 \%$ (depending on location) over the LAW Vaults. The total thickness of the soil layer will be between 8.5 and $9 \mathrm{ft}$. The "final closure cap" thus accounts for $5 \mathrm{ft}$ of this thickness. The remaining volume will utilize compacted fill material. In addition, in order to reduce the hydraulic conductivity of the layered soil/vault system, a clay layer will be placed immediately adjacent to the vault roofs. 


\section{MODELS OF CHEMICAL DEGRADATION AND STRUCTURAL ANALYSIS}

The selection of chemical degradation mechanisms for concrete was based on a process of eliminating mechanisms which demonstrated little or no effect under chemical conditions of the soil or concrete mix. The chemical degradation models which were included in the assessment were: $\mathrm{SO}_{4}$ and $\mathrm{Mg}$ attack, $\mathrm{Ca}(\mathrm{OH})_{2}$ leaching, carbonation, and rebar corrosion in oxic and anoxic conditions. Below we have presented the models for chemical degradation processes, some empirical and some analytic, and have provided a description of the attack mechanisms for which the models were derived. These mechanisms have been modeled independently. For example, thinning of the concrete surface will not result in an increased rate of reinforcing steel corrosion due to faster diffusion of oxygen through the decreased cover. In addition, the structural analysis modeling is described.

\subsection{CHEMICAL ATTACK}

\subsubsection{Sulfate and Magnesium Attack}

Sulfate and magnesium are naturally occurring elements at the Savannah River Site, input to the soil water from rainfall and weathering of rock minerals. Sulfate reacts with tricalcium aluminate $\left(\mathrm{C}_{3} \mathrm{~A}\right)$ to form calcium aluminum sulfates leading to expansion and cracking of the surface of the concrete (Walton et al., 1990). A related problem is the reaction of magnesium with the cement to form Brucite $\left[\mathrm{Mg}\left(\mathrm{OH}_{2}\right]\right.$. As the concrete cracks, its hydraulic conductivity increases, and water penetrates more easily into the interior, accelerating the deterioration of the concrete. Sulfate attack also results in a progressive loss of strength and mass due to deterioration in the cohesiveness of the cement hydration products. The reaction products have considerably greater volume than the reactants. This causes the expansion of the concrete which, in turn, results in cracking, spalling, and loss of strength. In addition, formation of gypsum causes a deterioration of the cement paste which results in a reduction in stiffness and strength, followed by more expansion, cracking, and loss of cohesiveness. Empirical studies indicate that the rate of attack by magnesium sulfate is twice that of sodium sulfate, and that the rate of attack is reduced by low water to cement ratio and by low $\mathrm{C}_{3} \mathrm{~A}$ content. The rate of surface loss due to sulfate attack was calculated according to:

$$
\mathrm{X}=0.55 \mathrm{C}_{\mathrm{z}}\left(\mathrm{C}_{\mathrm{Mg}}+\mathrm{C}_{\mathrm{SO}}\right) \mathrm{t}
$$

where:
$\mathrm{X}=$
distance of corrosion into concrete $(\mathrm{cm})$,
$\mathrm{C}_{\mathbf{2}}=$
$\mathrm{C}_{\mathrm{Mg}}=$
$\mathrm{C}_{3} \mathrm{~A}$ concentration in solid $\left(\mathrm{mole} / \mathrm{cm}^{3}\right)$, and
$\mathrm{C}_{\mathrm{so4}}=$
$\mathrm{Mg}$ concentration in solution (mole/ $\mathrm{cm}^{3}$ ),
$\mathrm{t}=$
$\mathrm{SO}_{4}$ concentration in solution $\left(\mathrm{mole} / \mathrm{cm}^{3}\right)$, and
time (s). 


\subsubsection{Alkali and Calcium Hydroxide Leaching}

When concrete is exposed to water, constituents in the concrete are leached. Alkalis are leached first, followed by calcium hydroxide. This process can be described in four stages:

1. Initially, the $\mathrm{pH}$ of standard concrete is approximately 13 due to the presence of alkali metal oxides and hydroxides. These alkali metals leach first.

2. - After the alkali metals are leached, the $\mathrm{pH}$ is controlled at 12.5 by solid calcium hydroxide. Free (not bound by C-S-H gel) calcium hydroxide is leached first.

3. Following loss of free calcium hydroxide, calcium hydroxide is leached at a slower rate from the C-S-H gel. The C-S-H gel dissolves incongruously, while the $\mathrm{pH}$ drops to 10.5 and the calcium to silicon ratio drops to 0.85 .

4. The $\mathrm{pH}$ is held to $\mathbf{1 0 . 5}$ by congruent dissolution of the $\mathrm{C}-\mathrm{S}-\mathrm{H}$ gel.

The loss of calcium results in a decrease in strength of approximately $1.5 \%$ for every $1 \%$ loss of total calcium content. The rate of calcium hydroxide leaching depends primarily on the flow of water through the concrete, but also on diffusion into the surrounding geology, and diffusion across a reaction zone in the concrete. Advective transport of leached calcium hydroxide from the concrete structure will dominate only under high rates of groundwater flow, and preferential flow of groundwater through the structure.

Atkinson and Hearne (1984) applied a shrinking core model to calcium hydroxide leaching. This model assumes that removal of calcium from the exterior of the concrete is rapid relative to movement of calcium through the concrete. Thus, leaching is controlled by conditions in the concrete and properties of the concrete, and so this process is referred to as "concrete-controlled leaching". As an alternative approach, Atkinson and Hearne also developed a leach model controlled by the surrounding geology ("geology-controlled leaching"). This model uses an equation for diffusion from a fixed concentration into a semi-infinite domain, with concentrations described by an error function (as in Crank, 1975), and allows for an analytic solution of the amount of calcium lost in a given amount of time. Both models predict that it will take over 1,000 years before calcium hydroxide leaching penetrates the upper $0.05 \mathrm{~cm}$ of the concrete. Both-analytic-models have been-added to the degradation model. The equations used to approximate concrete-controlled and geologycontrolled leaching, respectively, are:

$$
X_{c}=\left(2 D_{i} \frac{C_{i}-C_{g w}}{C_{i}} t\right)^{1 / 2}
$$

and 


$$
X_{0}=2 \phi \frac{C_{i}-C_{g m}}{C_{g}}\left(\frac{R_{d} D_{B} t}{\pi}\right)^{1 / 2},
$$

where,
$\mathrm{x}_{\mathrm{c}}=$
depth of leach penetration due to concrete-controlled leaching $(\mathrm{cm})$,
$\mathrm{X}_{\mathrm{o}}=$ depth of leach penetration due to geology-controlled leaching (cm),
$\mathrm{D}_{\mathrm{i}}=$ intrinsic diffusion coefficient of $\mathrm{Ca}^{++}$in concrete $\left(\mathrm{cm}^{2} / \mathrm{s}\right)$,
$\mathrm{C}_{\mathrm{i}}=$
$\mathrm{Ca}^{++}$concentration in concrete pore water $\left(\mathrm{mole} / \mathrm{cm}^{3}\right)$,
$\mathrm{C}_{\mathrm{sw}}=$
$\mathrm{Ca}^{++}$concentration in ground/soil water $\left(\mathrm{mole} / \mathrm{cm}^{3}\right)$,
$\mathrm{C}_{1}=$ bulk $\mathrm{Ca}^{++}$concentration in concrete solid $\left(\mathrm{mole} / \mathrm{cm}^{3}\right)$,
$\phi=$ porosity of soil (unitless),
$\mathrm{R}_{\mathrm{d}}=$ retardation coefficient (unitless), and
$\mathrm{D}_{\mathrm{B}}=$
effective dispersivity/diffusivity of $\mathrm{Ca}^{++}$in the surrounding geologic material $\left(\mathrm{cm}^{2} / \mathrm{s}\right)$.

A conservative estimate of the depth of leach penetration was obtained by summing $\mathrm{X}_{\mathrm{c}}$ and $\mathrm{X}_{\mathrm{O}}$.

\subsubsection{Carbonation}

Carbonation is the reaction of carbon dioxide with cement to form calcium carbonate according to the reaction,

$$
\mathrm{Ca}(\mathrm{OH})_{2}+\mathrm{H}_{2} \mathrm{O}+\mathrm{CO}_{2} \Rightarrow \mathrm{CaCO}_{3}+2 \mathrm{H}_{2} \mathrm{O} .
$$

Sources of carbon dioxide are atmospheric gases and soil gases. Carbonation occurs most aggressively when the concrete is less than fully saturated with water, allowing $\mathrm{CO}_{2}$ to diffuse through the air space in the concrete up to the reaction front within the concrete. At the reaction front, $\mathrm{CO}_{2}$ dissolves in pore water and combines with calcium to precipitate calcium carbonate. From Walton et al. (1990), the depth of carbonation is proportional to the square root of time as shown in the equation below. The rate of carbonation depends on the moisture content of the concrete and its relative humidity, and ultimately on the type of cement used in the concrete mix.

Carbonation does not render the concrete less durable. Some fully-carbonated Roman concretes has survived to modern times. Shrinkage of the concrete may occur with carbonation as will a drop in the $\mathrm{pH}$ of the pore water. Carbonation of hydrated Portlandcement pastes also results in reduced hydraulic conductivity and increased hardness 
(Verbeck, 1958). The pH shift can be from over 12 to about 8 . At this lower $\mathrm{pH}$, enhanced corrosion of steel reinforcing in the concrete may occur.

The rate of carbonation is dependent upon water saturation or relative humidity of the concrete. As relative humidity increases from 0 to $100 \%$, the rate of carbonation passes through a maximum. Since water is required in the carbonation reaction, partially saturated conditions promote the reaction of $\mathrm{CO}_{2}$ and $\mathrm{Ca}(\mathrm{OH})_{2}$ to form $\mathrm{CaCO}_{3}$, however increasing the water content above that required for this reaction to proceed will slow the diffusion rate of $\mathrm{CO}_{2}$ through the concrete and limit the carbonation reaction. Typical subsurface environments approach $100 \%$ relative humidity, resulting in a water saturated concrete matrix. Therefore slow rates of carbonation are commonly found. The following analytic expression was employed for estimating carbonation rate in the degradation model:

$$
X=\left(2 D_{i} \frac{C_{g W}}{C_{8}} t\right)^{1 / 2}
$$

where,

$\mathrm{X}=$ depth of penetration of carbonation $(\mathrm{cm})$

$\mathrm{D}_{i}=$ intrinsic diffusion coefficient of $\mathrm{Ca}^{++}$in concrete $\left(\mathrm{cm}^{2} / \mathrm{s}\right)$

$\mathrm{C}_{\mathrm{zw}}=$ total inorganic carbon in ground water or soil moisture $\left(\mathrm{mole} / \mathrm{cm}^{3}\right)$

$\mathrm{C}_{\mathrm{B}}=\mathrm{Ca}(\mathrm{OH})_{2}$ bulk concentration in concrete solid $\left(\mathrm{mole} / \mathrm{cm}^{3}\right)$ and

$\mathrm{t}=$ time (s)

Inherent in the use of this expression is the assumption that the concrete is water-saturated, and that the concrete is in direct contact with moisture containing a constant concentration of dissolved inorganic carbon.

\subsubsection{Rebar corrosion}

Corrosion of steel reinforcement results in a loss of strength due to loss of cross-sectional area of the rebar. In addition, a reinforced-concrete structure may suffer structural damage due to the loss of the bond between steel and concrete. Corrosion of the rebar produces a reaction product of greater volume than the rebar. Since the concrete surrounding the reinforcement prevents free expansion, this expansion exerts pressure on the concrete, and thus causes craeking-and potentially-spalling of the-concrete-structure, with consequent loss of strength. In the alkaline environment of standard concrete (low alkaline specialty concrete is used for the EAV construction), the rebar is protected from corrosion by the formation of a passivating layer around the rebar. This passivating layer, however, may be destroyed by the diffusion of chloride ions to the embedded steel (i.e., depassivation). Water to cement ratio and depth of concrete cover over the rebar are the most important factors in concrete construction that effect the time to depassivation. In the corrosion reaction, oxygen is electrochemically reduced and iron electrochemically oxidized, followed by conversion of the iron to iron oxides. The reaction rate is generally limited by diffusion of oxygen through 
the concrete to the rebar, with oxygen diffusion increasing over time as processes, such as calcium hydroxide leaching and sulfate attack, decrease the diffusion limiting concrete cover over the rebar.

Thus, the corrosion of reinforcing steel due to oxygen diffusion occurs in two steps. First, the passivating layer must be broken down before the onset of corrosion. The time to onset of corrosion was approximated by:

$$
t_{c}=\frac{129 X_{c}^{1.22}}{W C R * C 1^{0.12}}
$$

where,
$\mathrm{t}_{\mathrm{c}}=$
time to onset of corrosion (yr),
$\mathrm{X}_{\mathrm{c}}=$ thickness of concrete over rebar (inches),
$\mathrm{WCR}=$ water-cement ratio in concrete $(\mathrm{kg} / \mathrm{kg})$, and
$\mathrm{Cl}=$ chloride ion concentration in groundwater ( $\mathrm{ppm})$.

The reaction then proceeds, with a loss of reinforcing steel volume approximated by:

$$
\text { \% Rebar Remaining }=100\left(1-\frac{4 * 9.4\left(\frac{\mathrm{cm}^{3}}{\mathrm{~mole}_{\mathrm{e}}}\right) \mathrm{s}_{\mathrm{i}} \mathrm{C}_{\mathrm{i}}\left(\mathrm{t}-\mathrm{t}_{\mathrm{c}}\right)}{\pi \mathrm{d}^{2} \Delta \mathrm{X}}\right) \text {, }
$$

where,
$s=$
spacing between reinforcement bars $(\mathrm{cm})$,
$\mathrm{D}_{\mathrm{i}}=$ oxygen diffusion coefficient in concrete $\left(\mathrm{cm}^{2} / \mathrm{s}\right)$,
$\mathrm{C}_{\mathrm{zw}}=$ oxygen concentration in groundwater $\left(\mathrm{mole} / \mathrm{cm}^{3}\right)$,
$\mathrm{t}=$ time (s),
$d=$ diameter of rebar $(\mathrm{cm})$, and
$\Delta \mathrm{X}=$ depth of rebar below surface (in).

Another mechanism of reinforcing steel corrosion is via the hydrogen evolution reaction. In this mechanism, $\mathrm{H}^{+}$ion from the water molecule is used as the source of oxidant for corrosion. $\mathrm{H}_{2}$ is a by-product of this reaction. If we assume a low, constant rate of hydrogen evolution corrosion (i.e., a number from the low end of the literature range is adopted), then the relative volume of steel remaining is:

where, 


$$
\frac{V_{\mathrm{B}_{2}}}{V_{\mathrm{fmi}}}=\frac{2 a t-d^{2}}{d^{2}}
$$

$a=$ corrosion rate from hydrogen evolution reaction $(\mathrm{cm} / \mathrm{yr})$,

$t=$ time $(y r)$, and

$d=$ diameter of rebar $(\mathrm{cm})$.

$\mathrm{V}_{\mathrm{HR}}=\quad$ volume of steel after $\mathrm{H}_{2}$ corrosion

$V_{\text {inj }}=$ initial volume of steel

Literature review of hydrogen evolution corrosion rates indicated a $\mathrm{pH}$-dependance in the reaction rate. In the high $\mathrm{pH}$ range of typical concrete, the reaction rate is on the order of $1.5 \mathrm{E}-4$ to $1 \mathrm{E}-5 \mathrm{~cm} / \mathrm{yr}$. If the $\mathrm{pH}$ drops below approximately 9 , the reaction rate increases to values on the order of $1 E-3$ to $1 E-4 \mathrm{~cm} / \mathrm{yr}$.

A bounding analysis for corrosion will be utilized by combining the rates due to oxygenbased corrosion and hydrogen evolution corrosion.

\subsubsection{Vault Interiors}

The degradation mechanisms that were considered for the walls and roof in contact with site soil are: $\mathrm{Mg}+\mathrm{SO}_{4}$ attack, $\mathrm{Ca}(\mathrm{OH})_{2}$ leaching, concrete carbonation, and oxic and anoxic corrosion of the re-bar. Several of these mechanisms will not operate under the conditions anticipated inside the vaults or will occur so slowly that their net effect over the life of the vaults will be insignificant. Only anoxic ("hydrogen evolution") corrosion is anticipated as significant degradation process originating inside the vault, as discussed below.

Magnesium and sulfate attack requires a source of dissolved $\mathrm{Mg}$ and $\mathrm{SO}_{4}$ in contact with the concrete such as would be provided by a moist soil. There is no continuous source of $\mathrm{Mg}$ and $\mathrm{SO}_{4}$ in contact with the concrete in the vault interior, and therefore this mechanism is not anticipated to operate.

Two forms of calcium hydroxide leaching were considered: concrete controlled and geology controlled leaching. The concrete controlled leaching mechanism assumed a zeroconcentration boundary condition at the surface of the concrete, a condition which would require ground water to flow over the concrete surface and "sweep" the calcium away from the surface as it diffuses out of the concrete. Inside the vaults, during the period of performance prior to collapse, there is no recognizable mechanism to create this zeroconcentration boundary. As a result, a chemical diffusion gradient from the interior of the concrete towards the concrete surface will not be established and diffusion will not occur. 
Geology controlled leaching assumes that a concentration gradient can be established into the (soil) material adjacent to the concrete. This is physically impossible in the LAW vault because of the lack of in-filling material and in the case of the ILT and ILNT vaults, where cement grout will contact the walls, the calcium concentration in the grout porewater will be identical to that in the concrete at all times. These conditions prevent a concentration gradient from forming outwards away from the concrete.

Concrete carbonation occurs in the presence of dissolved carbonate and calcium in the porewater of the concrete. Leaching of calcium hydroxide provides a source of calcium and diffusion of carbonate ion from soil water in contact with the concrete provides a source of carbonate. The carbonate in the soil water is replenished from dissolution of $\mathrm{CO}_{2}$ gas from the soil air. Inside the $\mathrm{LAW}$ vault, the air space will contain $\mathrm{CO}_{2}$, although most likely at concentrations much less than in a biologically-active soil; differences of one to two orders of magnitude would be a reasonable estimate. Carbonation would most likely occur, however with only atmospheric levels of $\mathrm{CO}_{2}$ driving the reaction, the carbonation front would advance at a much slower rate than for the outer surfaces of the vaults. From the empirical relationship that INTERA has been using to describe carbonation, a slowing of the movement of the carbonation front by an order of magnitude would be possible.

Corrosion of the reinforcing bar in concrete under oxygenated conditions requires an initial depassivation of the steel surface. The mechanism that has been invoked in our modeling relies on diffusion of chloride to the passivating layer. Depassivation is followed by oxidation of the exposed steel. The interior of the vaults does not provide a source of chloride for the depassivation mechanism. Degradation modeling of the interior of the vaults should therefore not include oxic corrosion of rebar, unless the concrete mix is such that the $\mathrm{pH}$ of the concrete is below 9 .

Anoxic corrosion of rebar will occur in the presence of moisture in the concrete. Since water- saturated concrete has been assumed for the modeling of degradation, this mechanism would proceed at a rate approximately the same as for the exterior surfaces of the vault. Adjustments to the rate caused by a decrease in $\mathrm{pH}$ at the corroding surface following carbonation of the local concrete will not be required.

In summary, the dominant degradation mechanism for the interior surfaces of the vaults will likely be anoxic corrosion of re-bar. Carbonation is also likely to occur, however, the rate of advance of the carbonation front will be significantly less than for exterior surfaces. The effect of carbonation on anoxic corrosion will likely not be an important consideration.

\subsection{STRUCTURAL/ENGINEERING ANALYSIS}

The RCPC.DHelper models (Furlong, 1991) used as the basis for the structural analysis portion of this study are available commercially through the American Concrete Institute 
Software Sales Department. The programs have been in use for the past 4 years by approximately 300 engineering offices. The programs are intended to serve as a design aid in accordance with governing design documents, the principle one of which is the Building Code of the American Concrete Institute ACI 319-89. The Building Code is a strength design document with considerations for serviceability, but the major consideration for design is the limit strength of reinforced concrete members. Consequently, the computer design aids focus on decisions related to strength design instead of service load performance.

Strength design employs results from elastic analyses of frame response to the many different types and configurations of load that concrete structures support. An analytic routine known as the Portland Cement Association Two-Cycle Method is used for the interpretation of worst effects from pattern loading on beams. The analytic tools in RCPC.DHelper are just as appropriate for serviceability analyses as for strength design. The RCPC.DHelper programs apply required load factors and incorporate appropriate reliability factors in the logic required for design. These programs were modified to bypass load factors and reliability factors in order simply to use response to service load forces (load and reliability factors = 1) for estimates of service load stress in steel reinforcement and shear stress in concrete slabs. Steel stress was computed assuming that the concrete had cracked.

The program most appropriate for Vault Study is the Continuous Beam program in RCPC.DHelper. That program was prepared for design of floor beams in two-dimensional rigid frames. The Vault study involved two structures that consisted of roof slabs cast as rigid and monolithic with supporting walls. The structure represented by a unit width of wall and roof slab is a two-dimensional rigid frame. Distances between supports were adjusted such that the actual clear distances between faces of framing elements remained the same as those in the finished structure.

\subsubsection{Application to the ILNT/LT Vaults}

Because the ILNT and IIT vaults are virtually identical in their design, the same approach was used to analyze the two structures. The only changes required were changes in input parameters such as height of the structure and roof thickness. The structures were represented by a $1-\mathrm{ft}$ wide span of walls and roof in the direction of maximum stress. The direction of maximum stress in the short direction of each cell, or, for example, along the $189-\mathrm{ft}$ length of the ILNT vault. Hand calculations indicated that this approach is accurate to within approximately $3 \%$ of the full 2-way stab analysis (Furlong, 1993). Parameter values were selected to correspond to the respective height, thickness, amount of rebar, etc. in the walls and roof of each vault.

Stress in concrete and rebar was computed at the locations which experience the maximum stress. Maximum stress occurs over the walls, in the exterior face rebar, and at midspan, in the interior face rebar (Figure 4). After the stress in the rebar was calculated, the roof components and walls may fracture in order to eliminate excessive stress which cannot be borne by the degraded structure. When the stress in the rebar at a particular location 
exceeds $40 \mathrm{ksi}$, cracks are assumed to penetrate the concrete. The approach to the calculation of stress in rebar assumes that the concrete has cracked. Crack width and spacing were computed as functions of the distance between the neutral axis ${ }^{1}$ and the lower face of the concrete, the distance between the neutral axis and the center of the reinforcing steel, the diameter of the reinforcing steel, the concrete cover over the reinforcing steel, and the strain on the reinforcing steel.

When the stress in the rebar at a particular location reaches the yield strength of the rebar $(60 \mathrm{ksi})$, the rebar will yield. In most cells, yield strength is reached first at the midspan region. Excess moment is then transferred to other regions in the cell. In the case of the midspan region reaching yield strength first, excess moment is transferred to the regions over the walls. This, in turn, increases the stress levels in the rebar over the walls. When the rebar reaches its yield strength at all three locations, a "hinge" is created. This will allow the roof to sag, and it is presumed that structural integrity will be lost at this point. Therefore, the point in time at which this occurs has been defined as the time of collapse. This process can be summarized as follows:

1. Rebar at center of span reaches yield strength.

2. Excess moment (and corresponding stress) transferred to region over walls.

3. Rebar over walls reaches yield strength, resulting in severe cracking and collapse.

For cells 3, 4, and 5 of the IINT vault, the rebar reaches yield strength in the regions over the walls before reaching yield strength at midspan. In this case, the order is reversed:

1. Rebar over walls reaches yield strength.

2. Excess moment (and corresponding stress) transferred to midspan.

3. Rebar at midspan reaches yield strength, resulting in severe cracking and collapse.

\subsubsection{Application to the LAW Vault}

The 3" thick prestressed slabs in the LAW Vault roof design serve to hold the cast-in-place slab, and are therefore ignored in subsequent calculations. The soil and self weight (of the slab and the AASHTO beams) will cause the beams to move on the elastomeric bearings. As the beams move, the upper ends of the precast girders remain separated by a fixed distance at the slab atop the girders (Figure 5). Only the bases of the beams move toward each other, leaving at the end of each beam an angle of rotation each side of the supporting

'When a slab deforms under loading, part of the slab will be in compression and part of the slab will be in tension (e.g., at mid-span, the upper portion of the slab is in compression, and the lower portion in tension). The neutral axis is the location in the slab where compression changes to tension; it is therefore an axis of zero strain. 
wall. The angle of rotation remains essentially constant as long as the flexural stiffness of the girders remains constant under soil loading. Based upon the soil load and self load of the slab and beams, a curvature (in the roof, over the walls) of 0.35 radians/inch was calculated. This will result in a stress of $2.8 \mathrm{ksi}$ in the concrete, sufficient to crack the concrete. The curvature was then used to calculate the moment in the slab, and stresses in the cracked concrete and rebar. In the LAW Vault design, the stress level in the rebar increases relatively slowly as the structure degrades, and generally does not reach the 40-ksi limit. Therefore, the depth of the neutral axis was calculated in order to approximate the depth of crack penetration. As the structure degrades, the neutral axis, and therefore the cracks, penetrate further into the concrete. When the depth of the neutral axis moves to within 1 inch of the interior surface of the roof, cracks are assumed to penetrate the roof slab.

Due to the difference in roof design, the LAW Vault roof could not be analyzed in the same manner as the intermediate level vaults. The roof slab has only $5 \mathrm{ft}$ of unsupported span between the AASHTO beams. Preliminary calculations indicated that the 16-inch concrete slab can support soil loads across the slab even after significant degradation of the steel. Therefore, collapse of the vault will be determined by the ability of the AASHTO beams to support the structure. A moment arm calculation was used to calculate the moment at midspan of the beams after soil loading. This was then compared to the ultimate moment ${ }^{2}$ of the beams. Because the moment is approximately proportional to the steel area, the ratio of actual moment to ultimate moment is approximately equal to the amount of steel area that can be lost before collapse:

$$
A_{\text {ciit }}=A_{\text {init }} * \frac{M_{\text {pred }}}{M_{d}} \text {, }
$$

where:

$$
\begin{aligned}
& A_{\text {crix }}=\quad \text { critical steel area (the minimum area of steel in the AASHTO beams } \\
& \text { which is capable of supporting the soil load), } \\
& \left.A_{\text {init }}=\quad \text { initial steel area in the AASHTO beams ( } 7.01 \text { inch }^{2}\right) \text {, } \\
& \mathrm{M}_{\text {pred }}=\quad \text { predicted moment in beam after soil loading, and } \\
& \mathbf{M}_{\mathrm{u}}=\quad \text { ultimate moment in beam. }
\end{aligned}
$$

In the model, then, collapse occurs when the steel area in the beams is reduced to $A_{\text {crit }}$.

The NAWY models (Nawy, 1989) were used to calculate loss in prestress in the beams due to elasticity loss, creep, shrinkage and relaxation. The model predicted that $90 \%$ of the prestress loss occurs in the first 10 years after release, and was in agreement with the prestress loss calculations by Tindall Concrete Georgia, Inc. (hereafter referred to as

\footnotetext{
${ }^{2}$ The ultimate moment is the maximum moment that the system can support before collapse.
} 
"Tindall Concrete"). A value of $22 \%$ prestress loss was used as a conservative upper bound in the above calculations.

The LAW Vault walls were analyzed using the same RCPC-based code that was used for the intermediate level vaults. To do so, an equivalent roof slab was formulated for input into the code. After the roof slab of the LAW vault is cast, the system gains redundancy as a continuous, composite beam. The earth load was analyzed with the RCPC model using end span and wall models similar to that used for the intermediate level vaults. An equivalent roof slab width was computed to use a rectangular beam of 70-inch depth (the depth of the composite roof slab/AASHTO beam system) and produce the same moment as the composite slab and beam:

$$
b=\frac{886200 * 12}{70^{3}}-31 \text { in, }
$$

where:

$\mathrm{b}=$ equivalent slab width;

886200 = I value of composite slab and beam system (from Tindall, 1993).

In this manner the RCPC-based code can be used to analyze stresses in the LAW vault walls. 


\section{MODELING APPROACH}

\subsection{COMPUTER CODES}

The RCPC code (Furlong, 1991), as it is commercially available, is an interactive program; all input is typed in as the program runs, and output can be directed to the screen and/or a printer. In order to facilitate multiple model runs during the sensitivity analysis, and to maintain adequate Quality Assurance, the model was first modified to a file-based input/output system. In addition, minor modifications were added to compute stresses in rebar.

The NAWY models (Nawy, 1989) were used to evaluate prestress loss in the AASHTO beams and to confirm various calculations performed by Tindall Concrete. In addition to calculating time-dependent prestress loss, the NAWY models capabilities include service load analysis, strength analysis and design in flexure, shear reinforcement selection, and time dependent deflection of prestressed concrete beams.

\subsection{LINKING BETWEEN DEGRADATION AND STRUCTURAL MODELS}

The degradation model and structural model (modified RCPC) were combined, and a time loop was added so that the state of the structure through time could be modeled. The time loop was implemented as follows: First, the structural model is run at time zero on the (undegraded) structure. Next, the degradation model is run to determine the impact of degradation mechanisms on the physical state (thickness of concrete, diameter of reinforcing rebar, etc.) of the structure using a user-specified time step. After the degradation model is run, a temporary file is created that contains the modified concrete and reinforcing steel specifications. This file is then used as input for the next run of the structural model. Following the structural model run, the degradation model is run again, and the temporarily file is updated. This process of alternating between the structural and degradation models continues until the user-specified end of the simulation (e.g., 1,000 years). The state of the structure is printed at a user-specified time interval (e.g., 50 years).

\subsection{HYDRAULIC CONDUCTIVITY}

4.3.1 Vault Roofs

Walton (1993), presents a calculational method for Effective Hydraulic Conductivity $\left(K_{e f f}\right)$ of the vault roof. This method considers the adjacent porous media overlying the concrete roof. We have applied Walton's method in our $\mathbf{K}_{\text {eff }}$ determination. The closure design for each of the three vault designs considered in this report places a clay barrier over the roof to divert infiltration away from the roof. The infiltration flows laterally away from the vault through a granular drain layer which directly overlies the clay barrier. Only a very small amount of the infiltration will penetrate the intact clay barrier. During the period of 
performance in which the concrete contains no cracks or during which the cracks do not fully penetrate the roof, the infiltration which penetrates the clay barrier will drain off of the sloped roof. The limiting barrier to flow will be the reinforced concrete. With cracking of the roof under applied stresses, the clay barrier will limit the infiltration to the roof, and any infiltration passing through the clay will likely enter the vault through penetrating cracks. The clay barrier is assumed to stay intact until collapse of the vault structure.

$\mathrm{K}_{\text {off }}$ of the clay barrier and the concrete roof of the vault were derived using separate equations. The calculation of $K_{e f f}$ assumes steady, saturated flow through a set of equally spaced, paraliel fractures in the concrete. The following equations after Walton (1993) derive the $\mathrm{K}_{\mathrm{efr}}$ of the clay layer in the presence of fully penetrating cracks in the concrete.

$$
\begin{gathered}
\mathrm{K}_{\mathrm{eff}}=\zeta \mathrm{K}_{\mathrm{cly}}, \text { and } \\
\zeta=\left\{\frac{1}{2}+\frac{\tanh \left[\mathrm{a}+\mathrm{b} \ln \left(\frac{1}{x}\right)+c \ln (\mathrm{z})\right]}{2}\right\}^{\mathrm{d}},
\end{gathered}
$$

where

$$
\begin{array}{ll}
\mathrm{K}_{\mathrm{cimy}} & =\text { hydraulic conductivity of the clay layer }(\mathrm{m} / \mathrm{s}), \\
\psi & =1 / 2 \text { of crack width }(\mathrm{m}), \\
\mathrm{X} & =\mathrm{X} / \psi=\text { dimensionless crack spacing, } \\
\mathrm{Z} & =\mathrm{Z} / \psi=\text { dimensionless thickness of the clay layer, } \\
\mathrm{H} & =\text { depth of perched water on top of the vault }(\mathrm{m}), \\
\mathrm{X} & =1 / 2 \text { of the crack spacing }(\mathrm{m}), \\
\mathrm{Z} & =\text { thickness of the clay layer }(\mathrm{m}), \\
\mathrm{a} & =0.0477, \mathrm{~b}=0.606, \mathrm{c}=0.479, \text { and } \mathrm{d}=0.845 .
\end{array}
$$

The assumption of steady saturated flow through the clay layer can be demonstrated by calculating the depth of perched water above the clay layer in the granular drain. The analytic solutions for these equations are provided by McEnroe (1993). For the EAV geometry and hydraulic conductivity of the clay and granular drainage layer, a perched water table equal to the thickness of the granular drain was calculated, thereby verifying our assumptions.

The calculations of $\mathrm{K}_{\text {eff }}$ assume that the cracks are not infilled with porous material. Infilling of the cracks would result in much lower hydraulic conductivity of the clay/concrete layered system when the cracks have fully penetrated the concrete. 


\subsubsection{Vault Walls}

The model for the hydraulic conductivity of the vault roofs assumes that the soil adjacent to the roof will be saturated. This will generally not be the case for the vault walls. Similar models to estimate the hydraulic conductivity of a cracked vault/unsaturated soil system are not available at this time. Nevertheless, the hydraulic conductivity of the walls will be limited by the conductivity of the adjacent material. Therefore, the unsaturated hydraulic conductivity of the adjacent backfill material can be used as an upper bound for the hydraulic conductivity of the cracked wall/soil system (just as the saturated hydraulic conductivity of the adjacent clay was the limiting value for-the hydraulic-conductivity of the cracked roof/soil system). The unsaturated hydraulic conductivity of the backfill material (or any soil) is a function of its moisture content. The Idaho National Engineering Laboratory is in the process of conducting flow and transport modeling for the vaults. They utilizied a VanGenuchten approach to generate a moisture characteristic curve for the backfill material. This curve provides the relationship between moisture content and hydraulic conductivity. Model results indicate that the backfill will have a greater moisture content near the top of the vault, and therefore it will have a correspondingly greater hydraulic conductivity. For the intermediate level vaults, the unsaturated hydraulic conductivity of the backfill material adjacent to the walls was estimated as $7.5 \mathrm{E}-4 \mathrm{~cm} / \mathrm{s}$ near the top of the walls, $6.7 \mathrm{E}-4 \mathrm{~cm} / \mathrm{s}$ at mid-height of the walls, and $6.9 \mathrm{E}-4 \mathrm{~cm} / \mathrm{s}$ near the bottom of the walls. For the LAW Vault, the unsaturated hydraulic conductivity was estimated as $7 \mathrm{E}-4 \mathrm{~cm} / \mathrm{s}$ near the top of the walls, and $6.3 \mathrm{E}-4 \mathrm{~cm} / \mathrm{s}$ at mid-height and at the bottom of the walls. Thus, a value of $7.5 \mathrm{E}-$ $4 \mathrm{~cm} / \mathrm{s}$ can be taken as a worst-case assumption for the hydraulic conductivity of the vault walls.

\subsection{MODEL OUTPUT}

Model output can be divided into two broad classes; degradation output and structural output. Structural output for the LAW vault includes additional parameters specific to the calculation of stress and cracking in the roof slab due to curvature over the walls. Output parameters are summarized in Table 1. Output is directed to two files. One file contains a summary of all structural parameters at each print interval. In order to facilitate plotting and interpretation, the second file contains one line per print interval. Rebar stress in the first 4 spans (for example, the first wall and the first three cell roof spans) and all degradation parameters are sent to this file.

\subsection{DEFINITION OF FAILURE}

Failure of a vault can be defined in three ways:

- Loss of ability to resist penetration from drilling.

- Loss of ability to divert water around the vault. 
- Structural failure (collapse) of the vault.

Resistance to drill penetration is necessary to avoid accidental intrusion after the period of institutional control, for example, from a future resident attempting to put in a drinking water well. The geology in the vicinity of the vaults, to depths of approximately $200 \mathrm{ft}$, is made up of soft sediments only. Therefore, drill equipment is not outfitted for hard rock penetration. In the event that an attempt was made to drill over the vaults, the supervising geologist would almost certainly pull up and move over until a normal amount of resistance was encountered. Even in the event that the vault was highly degraded (for example, without rebar and with the consistency of limestone), the supervising geologist would again probably decide to pull up and move. This information on drilling equipment and procedures was obtained through a phone conversation with an experienced geologist in drilling oversight at the Savannah River Site (Asquith, 1993). Thus, drill penetration of the vaults is not expected to be of concern.

Intact concrete generally has a very low hydraulic conductivity; the E-Area Vaults concrete has a hydraulic conductivity of at most $10^{-12} \mathrm{~m} / \mathrm{s}$. Therefore, virtually all of the conductivity of the degraded structure will be through fractures. Calculations by INTERA indicate that, once fractures have penetrated the roof slab, the hydraulic conductivity will be very close to that of the clay overlying the vaults, or $10^{-9} \mathrm{~m} / \mathrm{s}$. Thus, loss of ability to divert water coincides with crack penetration of the roof.

The modeling approach to collapse of the vaults has been described previously. When a vault roof collapses, the engineered soil cap will also be compromised due to subsidence of the vault roof. This, in turn, will result in a very dramatic increase in hydraulic conductivity of the vault/soil cap system.

\subsection{SUMMARY OF CONSERVATIVISM}

This section summarizes the conservative assumptions made and approaches taken during the development and application of the performance assessment model. One of the assumptions having the greatest impact on model results was that the concrete was at a relatively low $\mathrm{pH}$ (at most 9.5). This results in more rapid degradation of the structure (basically due to more rapid rebar corrosion rates), and causes the estimated service life (i.e., time to crack penetration and collapse) to be several hundred years less than that of high-pH concrete. The sulfate attack rate is based upon empirical experiments using blocks of concrete. The equation was based on the observed attack rate at the location of greatest corrosion (at the corners of the blocks). Rebar corrosion will generally proceed via either anoxic or oxic corrosion. However, because it is not known at this time which mechanism will dominate at any given time, the rates were summed to estimate the rebar corrosion rate. This is clearly conservative because the sum will be greater than either rate individually. The soil cover was assumed to be of constant depth throughout the simulation. In reality, some erosion will take place in the 1,000 to 3,000-year period simulated, resulting in less load on the vaults and therefore lower stress levels and longer service life. In the structural model, 
a 1-way analysis was used. This examines the stress in a beam supported at each end (Figure 4). Because the roof is supported by four walls, a cross-section receives some support from adjacent walls as well as the walls at each end. Thus, estimated stress levels will be slightly (approximately $3 \%$ ) higher than those estimated by a 2 -way analysis. The structural analysis also assumed that there would be no interior support provided by the contents. Clearly, if the contents provided some support, there would be less deflection and therefore less stress in the concrete members. In examining the prestressed bridge beams in the LAW vault, a $22 \%$ loss in prestressing was assumed. This was estimated to be a maximum loss of prestress. Actual losses can be expected to be less, particularly in the first 5-10 years after release. Cracks were assumed to penetrate the IINT and ILT vault roofs and walls, and the LAW walls, when stress in rebar reached $40 \mathrm{ksi}$. This was estimated to be a conservative estimation of when crack depth would be sufficient to penetration the concrete members. For the LAW vault roof, crack depth was based upon a calculation of the depth of the neutral axis. To add conservatism to the estimation, cracks were assumed to penetrate when the depth of the neutral axis reached within 1 inch of the bottom of the roof slab. The approach for estimating the hydraulic conductivity of the cracked concrete assumed that cracks were evenly spaced across the entire surface of the concrete. In reality, the concrete can be expected to crack in fairly localized regions. This is particularly evident in the LAW vault roof, which is expected to crack only within a less than 2-foot wide region over the walls. This assumption is not expected to have a large impact on the calculated hydraulic conductivity, however, because a few cracks are sufficient to cause large changes in hydraulic conductivity. In contrast to the model assumptions, most of the input parameters for the baseline case utilized on average or typical values. For example, all chemical concentrations in groundwater were based on average values, reaction rates were based on the midpoint of the range of values found in the literature, and roof thickness and wall height used were the average (where variation existed). 


\section{INPUT SUMMARY}

Model input for the structural analyses are listed in Table 2 - Table 4 for the three vault types. Structural input essentially consisted of the dimensions of the vaults (wall height and thickness, roof span and thickness), the size and spacing of the rebar, the depth of cover over the rebar, the compressive strength of the concrete, and the yield strength of the rebar. The required information was obtained from the design drawings for the E-Area Vaults. A list of the drawings used is provided in Table 5.

Input required by the degradation portion of the model is listed in Table 6. Where available and applicable, ranges of values for the input parameters are presented. Input requirements include concentrations of corrosive components of the adjacent groundwater, concentrations of components in the concrete, and reaction rates.

A baseline run was defined to determine a best estimate of the times to crack penetration and failure of the three vault designs. In the baseline case, average values of environmental parameters were used (for example, sulfate concentration of the groundwater). Actual or proposed design parameters (such as rebar size or depth of soil cover) were used. Where design parameters were variable (such as roof thickness in the intermediate level vaults), average values were used.

Soil loading in the baseline case assumed a 9-foot depth of soil cover. A value of $1.7 \mathrm{~g} / \mathrm{cm}^{3}$ $\left(106 \mathrm{lb} / \mathrm{ft}^{3}\right)$ was used for the density of soil. In order to calculate the self-weight of the vault roofs, a concrete density of $2.34 \mathrm{~g} / \mathrm{cm}^{3}\left(146 \mathrm{lb} / \mathrm{ft}^{3}\right)$ was used. Lateral soil pressure on the walls was computed using a modified Rankine approach (Das, 1985). 


\section{MODEL RESULTS}

Figure 6 is a cross-section of the ILNT Vault after 400 years of simulated degradation. The sulfate attack mechanism has removed an average of $0.19 \mathrm{~cm}$ from the surface of the concrete, and the rebar radius has been reduced from $1.25 \mathrm{~cm}$ to $1.05 \mathrm{~cm}$, from a \#8 bar to a radius somewhat less than that of a \# 7 bar. Figures 7 through 9 present the effective hydraulic conductivity of the three vault designs. Prior to crack penetration, the hydraulic conductivity remains that of intact concrete, $10^{-12} \mathrm{~m} / \mathrm{s}$. When cracks penetrate the roof of the vault, the hydraulic conductivity of the (cracked) concrete increases to a conductivity near that of the surrounding clay, $10^{-9} \mathrm{~m} / \mathrm{s}$, followed by a gradual increase in hydraulic conductivity as crack apertures and the number of cracks increase, up to a theoretical maximum of $10^{-9} \mathrm{~m} / \mathrm{s}$.

Table 7 and Table 8 present summaries of the rebar stress for the baseline cases of the ILT and ILNT vaults, respectively. Each column in the tables represents a particular location in the vault. In this summary presentation, rebar stresses are tabulated at each time step for which an "event" occurs, with an event defined as crack penetration at some location in the vault, or collapse of a cell. Shading in the tables indicates that cracks have penetrated at that location. A box created with thick table lines indicates the time of roof collapse for each cell.

The ILT scenario is fairly straight-forward. Maximum rebar stress occurs at mid-span in the roof, due to the fact that there is twice as much rebar in the region over the walls as there is at mid-span. Rebar stress is slightly less over the interior wall than at midspan. Thus, crack penetration occurs first at mid-span in the roof (year 790), and soon thereafter over the interior wall (year 850). Rebar stress in the walls is much less than that in the roof, primarily because the lateral soil pressure on the walls is much less than the vertical soil pressure on the roof (lateral pressure is approximately one-third that of vertical). Thus, cracks do not penetrate the center region of the wall, or mid-height of the wall, until year 1,080. The rebar stress level in the roof rebar at mid-span and over the interior wall reaches its yield strength in years 1,125 and 1,150, respectively (not shown). As moment is transferred to the remaining rebar stress point at the exterior wall, this causes a rapid increase in rebar stress levels at this point, and cracks penetrate the roof over the exterior wall at year 1,225. The rapid increase in roof rebar stress over the exterior wall continues, and collapse of the roof occurs in year 1,300. With the loss of support from the roof, it is reasonable to assume that, although rebar stress in the walls near the roof and floor have not reached the levels indicative of crack penetration, the walls at this point will also fail and collapse.

Stress patterns in the ILNT Vault are similar to those in the ILT Vault, in that the rebar stress in the roof span of the exterior cells (cells 1 and 7 of Figure 1) over the exterior wall is much less than that over the interior wall of the same cell. In the first interior cell (cells 2 and 6), this effect is mediated somewhat, and in the remaining cells the rebar stress levels 
are equal over each wall for a given cell. The lower stress level over the exterior wall results in higher rebar stress levels at mid-span of the exterior cell. Thus, crack penetration occurs first at mid-span of the exterior cell (year 570), followed by the first interior wall (year 675). Next cracks penetrate over the remaining walls (year 750), followed soon thereafter by crack penetration at mid-span of the remaining cells (year 775). Cracks do not penetrate the roof over the exterior walls until year 1,000 . The first cells to collapse are the first interior cells (cells 2 and 6), in year 1,045, followed soon by the remaining interior cells in year 1,075. The exterior cells collapse in year 1,125. In the IINT vault, the walls are slightly higher than the IIT vault, so the stress levels are correspondingly greater, with the result that craciss penetrate at mid-height in year 800, and near the top of the vault in year 1,050. Stress levels at the bottom of the walls have not reached the levels indicative of crack penetration at the point at which the roof has collapsed in all cells (year 1,125).

Due to the different design and consequent different approach to the analysis, the same type of table cannot be generated to summarize the LAW vault progression through failure and collapse. While crack penetration in the walls is indicated in the same manner (i.e., rebar stress above $40 \mathrm{ksi}$ ) as in the intermediate level vaults, crack penetration in the roof is indicated by depth of the neutral axis. Collapse is indicated by the area of prestressed steel in the AASHTO beams dropping below a critical level. The scenario can be described as follows: Cracks penetrate the roof due to curvature over the walls in year 1,420. Next, cracks penetrate at the top, mid-height, and bottom of the walls in years 2,015, 2,235 and 2,300 , respectively. Finally, prestress steel loss is sufficient to cause collapse of the roof in year 3,110 . 


\section{SENSITIVITY ANALYSIS}

There are three classes of model input that could be considered in the sensitivity analysis. First, sensitivity analysis could be conducted for physical parameters, such as water chemistry or infiltration rates, which are represented by mean values, and are used in the models for the degradation of concrete. Second, sensitivity analysis could be performed for concrete degradation model parameters, such as reaction rates for any of the various degradation reactions. Finally, sensitivity analysis could be conducted on design parameters, such as depth of soil cover, thickness of roof slab, or diameter of rebar. All sensitivity analyses were conducted by varying a single parameter from the baseline case and leaving all other parameters unchanged. This section presents the rationale behind the selection of parameters to be included in the sensitivity analysis, and the results of the analysis.

\subsection{SELECTION OF PARAMETERS AND VALUES}

Calcium hydroxide is one of the primary buffers that contribute to the high $\mathrm{pH}$ of concrete. Based on an X-ray diffraction analysis of a sample of the E-Area Vault concrete, the concrete used for the E-Area Vaults contains no calcium hydroxide. This can be explained by a combination of two factors. First, the cement used in the concrete has a very low calcium hydroxide content. Second, the concrete is designed so that the calcium hydroxide will be removed via a reaction with slag in the concrete. Calculations by Chris Langton of the Savannah River Technology Center determined that the $\mathrm{pH}$ of the E-Area Vault concrete is approximately 8 , that it is at most around 9 to 9.5 , and that it may be as low as 7 . Because the E-Area Vault concrete has essentially no calcium hydroxide content and a relatively low $\mathrm{pH}$, the only degradation mechanisms that apply to the concrete are oxic and anoxic ("hydrogen evolution") corrosion of rebar, and sulfate attack. While varying the parameters relevant to the sulfate attack mechanism caused noticeable changes in the amount of surface loss due to sulfate attack, the impact on steel stress was minimal. The oxic corrosion rate has a slightly greater impact on steel stress, but the anoxic corrosion rate by far dominates the rebar corrosion. Thus, for low-pH concrete in the Savannah River Site environment, the only degradation process of interest in terms of the sensitivity analysis is hydrogen evolution corrosion of rebar. This process is modeled using only one parameter, the hydrogen evolution corrosion rate. Therefore, this parameter was selected for inclusion in the uncertainty analysis. Based on a literature review, the low-pH hydrogen evolution corrosion rate was varied between $1 \mathrm{E}-3$ and $1 \mathrm{E}-4 \mathrm{~cm} / \mathrm{yr}$, and the high-pH of hydrogen evolution corrosion between $1.5 \mathrm{E}-4$ and $1 \mathrm{E}-5 \mathrm{~cm} / \mathrm{yr}$. It is important to note that the low-pH assumption is generally conservative, in that most degradation mechanisms proceed at higher rates in the low-pH environment. The only exception is that, with calcium hydroxide leaching, there can be some decrease in concrete strength. Since the E-Area Vault concrete has no calcium hydroxide available for leaching, the concrete strength is assumed to remain constant throughout the simulation. 
A preliminary sensitivity analysis was performed to help determine parameters for which to conduct a detailed sensitivity analysis. Of the parameters included in the initial sensitivity analysis, hydrogen evolution corrosion rate (discussed above) and depth of concrete cover over rebar was selected for detailed analysis. Design constraints limited the range of allowable cover to between $1 \frac{1 / 2}{2}$ and 3 inch. In addition, thickness of vault roofs and numerous parameters related to degradation mechanisms were considered in the initial sensitivity analysis, but not selected for detailed analysis.

New parameters selected for detailed analysis were rebar diameter, size of AASHTO beams (LAW Vault only), concrete strength, and depth of soil cover over the vaults. Rebar diameter was varied approximately to the minimum and maximum allowable according to ACI 318. The limits varied between vaults and between walls and roofs depending on the values of the relevant design parameters. Standard AASHTO beam sizes were used in the sensitivity analysis. Because changing the size by only one increment is very significant both in cost and in strength of beam, only types III, IV, and V beams were analyzed for the sensitivity analysis. Finally, a minimum soil cover of $8 \mathrm{ft}$ is required to meet performance requirements. This was varied up to a maximum of $16 \mathrm{ft}$. For all parameters, intermediate values (i.e., between the extremes and the baseline) were selected as appropriate.

\subsection{OUTPUT SUMMARY}

In the sensitivity analysis, the first time of crack penetration of the roof and wall of the intermediate level vaults are reported, and, for the ILNT vault, the first cell to collapse. The first crack penetration occurs at mid-span of the exterior cell (for the ILT vault, the two cells are equivalent). The first cells to collapse in the ILNT vault are the first interior cells towards each end (cells 2 and 6). Collapse in a cell is indicated when the rebar reaches yield strength at mid-span and over the adjacent walls of that cell. In cells 2 and 6 , the first location at which the rebar reaches yield is at mid-span, followed by the wall towards the exterior end of the vault. Collapse, then, occurs when the rebar in the roof reaches yield strength at the remaining location, over the wall towards the interior of the vault. Thus, for the sensitivity analysis of the ILNT Vault, this is the location of interest. By observing the stress in the roof rebar at this location, the time to collapse can be determined. Similarly, for the ILT vault, the last location in the cells to reach yield strength in the rebar is over the exterior wall. Finally, crack penetration of the walls at mid-height was used to indicate crack penetration of walls.

For the LAW Vault, collapse is indicated by prestress steel in the AASHTO beams reaching a critical level. Therefore, observing changes in the area of prestress steel will provide the determination of time to collapse. Crack penetration of the roof is indicated by the neutral axis approaching to within 1 inch of the bottom of the roof slab. As in the case of the intermediate-level vaults, crack penetration at mid-height of the walls was selected to indicate crack penetration of the walls. 
Thus, for each vault, three critical output parameters have been selected on which to base the sensitivity analysis of the six input parameters. The output parameters can be used to determine the time to crack penetration of the roof, time to crack penetration of the walls, and collapse of the vaults. These pivotal times are summarized for the baseline case in Table 9.

Table 10 through Table 12 summarize the same pivotal times for each sensitivity run. For the LAW Vault, differences existed in some of the parameters between the different vault components, and these differences are indicated in the left-hand column of Table 12. For example, the AASHTO beams are made of a high-pH concrete: Therefore, they will be subject to the slower, high-pH rate of hydrogen evolution rebar corrosion. Furthermore, since they are on the interior of the vault, there are no corrosive processes available to lower the $\mathrm{pH}$ of the beam concrete and thereby increase the reaction rate. In addition, the rebar used in the roof and walls are different. In order to understand the dynamics of the vaults in greater detail, plots of steel stress vs. time are also presented for most of the sensitivity runs.

\subsubsection{ILNT Vault Sensitivity Analysis}

Pivotal times (time to crack penetration of the roof, time to crack penetration of the walls, and time to collapse) for the ILNT vault are summarized in Table 10.

All pivotal times are sensitive to hydrogen evolution corrosion rate (Figures 10,11 and 12). Varying the corrosion rate over a range of one order of magnitude changed the pivotal times by an order of magnitude as well. The change in pivotal times is very close to proportional to the ratio of the baseline corrosion rate divided by the new corrosion rate. Increasing the corrosion rate from 5E-4 to $1 \mathrm{E}-3$ changed the time to crack penetration (of the roof) from 570 years to 285 years, a decrease of 285 years, and decreasing the corrosion rate to $1 E-4$ increased the time to crack penetration to 2,775 years, an increase of over $280 \%$. Decreasing the corrosion rate to only $2.5 \mathrm{E}-4$ almost doubled the time to crack penetration of the roof.

Altering the depth of the soil has less impact on the pivotal times (Figures 13, 14 and 15). Decreasing the soil cover from $9 \mathrm{ft}$ to $8 \mathrm{ft}$ increases the pivotal times by approximately 50 to 100 years. Increasing the soil cover to $12 \mathrm{ft}$ decreases the pivotal times by approximately 200 years, and increasing to $16 \mathrm{ft}$ decreases the pivotal times by 300 to 400 years from the baseline values.

Changing the rebar size has the potential to create large changes in the pivotal times. Reducing the bar size to \#6 would result in cracks penetrating the roof immediately upon soil loading (Figure 16), and the wall after 175 years (Figure 17); collapse would occur in 425 years (Figure 18). Using a \#7 instead of the present \#8 would result in crack penetration of the roof after 250 years, and collapse after 735 years. Increasing the rebar size has 
similarly dramatic effects. Using \#9 rebar would increase the pivotal times to on the order of 1,000 years, and \#11 to on the order of 2,000 years.

Depth of concrete cover over the rebar has little impact on the longevity of low-pH vaults

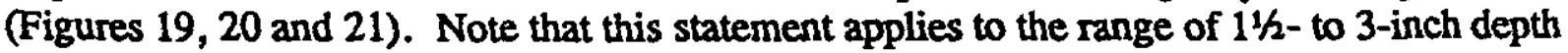
of concrete cover. Further decreasing the depth of cover further could have significant effects. Also, concrete cover over rebar can have very significant impacts if high-pH concrete is used; with increased cover reducing corrosion and thus extending the service life of the vault. Stress is slightly higher with greater depth of cover, and remains so throughout the simulation. Analysis of high-pH concrete (not shown) by INTERA demonstrated that depth of concrete cover over rebar can be very important. In high-pH concrete, several diffusion-limited processes become important. The result is that rebar with greater depth of cover degrades at significantly slower rates, and therefore, in the long term, experiences lower stress levels.

Concrete strength also has little impact on the longevity of the vault (Figures 22, 23, and 24). The reason for this is that concrete has very low tensile strength, and the rebar therefore provides the majority of the tensile strength in reinforced concrete. Thus, increasing the concrete strength decreases the stress levels in the rebar only slightly. Highstrength concrete provides other advantages, however, such as resistance to shear stress and reduced hydraulic conductivity.

\subsubsection{ILT Vault Sensitivity Analysis}

Pivotal times for the ILT Vault are summarized in Table 11. The results are qualitatively very similar to those of the ILNT vault, with quantitative differences caused by the slight differences in some of the design parameters. Again, changes in pivotal times are roughly proportional to changes in hydrogen evolution corrosion rates. At the lowest rate, cracks did not penetrate the IIT Vault prior to the end of the 3,000-year simulation (Figures 25, 26 and 27). At the minimum depth of soil cover, pivotal times decreased by approximately 50 years, and at the maximum, decreased by 300 to 400 years (Figures 28, 29 and 30). Due to the thicker roof in the IIT Vault, \#6 rebar did not result in crack penetration of the roof until year 155 (Figure 31). Otherwise (Figures 32 and 33), changing rebar size had similarly dramatic effects on the ILT Vault as was the case with the ILNT vault. Due to the overall more conservative design of the ILT Vault, depth of concrete cover over rebar (Figures 34, 35 and 36) and concrete strength (Figures 37, 38 and 39) had even less impact on the ILT vault than on the ILNT vault.

\subsubsection{LAW Vault Sensitivity Analysis}

Pivotal times for the LAW Vault sensitivity analysis are summarized in Table 12. Figure 40 shows the location of the neutral axis as a function of time for various rates of hydrogen evolution rebar corrosion. The depth is given in terms of the distance from the interior surface of the slab. This is done for two reasons. First, at the same time that the neutral 
axis is moving to lower positions in the slab, sulfate attack is removing surface material from the top of the slab. Therefore, indicating the depth of the neutral axis as a distance from the exterior could be misleading, and, at best, confusing. Second, cracks are assumed to penetrate the roof slab when the depth of the neutral axis reaches 1 inch. Thus, displaying the depth of the neutral axis in this manner provides a graphical interpretation of the time to crack penetration. In spite of the differences in design between the LAW and intermediate level vaults, and the resultant differences in the structural calculations, the changes in the time to crack penetration of the roof remain roughly proportional to the changes in the corrosion rate. Crack penetration of the LAW walls also maintains this proportionality (Figure 41).

Figure 42 shows the results of the sensitivity of time to roof collapse of the LAW vault for both hydrogen evolution corrosion rate and depth of soil. The curves represent the area of prestressed steel remaining for different hydrogen evolution corrosion rates, as a function of time. The horizontal lines indicate the area of prestressed steel required to support different depths of soil. The intersection of a curve with a line, then indicates the point in time at which collapse will occur for a given combination of corrosion rate and soil depth. To interpret the impact of hydrogen evolution corrosion rate, consider the horizontal line corresponding to the baseline soil depth $(9 \mathrm{ft})$, and disregard the other horizontal lines. This line indicates the rebar area necessary to support the weight of the vault and $9 \mathrm{ft}$ of soil. When a particular curve crosses that line, that point in time is the time of collapse for that hydrogen evolution rate and the baseline $(9 \mathrm{ft})$ depth of soil. These are the times that are presented under "Hydrogen Evolution Corrosion Rate" in Table 12. The proportionalities is maintained here as well, but not quite as close as in the other cases. At the highest corrosion rate, collapse is predicted at 1,600 years, and, at the lowest rate, the vault did not collapse prior to the end of the 10,000 -year simulation.

Because crack penetration of the roof is based upon a neutral axis calculation, and the depth of the neutral axis is not calculated as a function of loading, soil loading does not change the time to crack penetration of the roof. In reality, because increased soil loads will increase the stress level in the rebar, changing soil depth would be expected to have a small impact on the depth of cracks, and therefore on the time to crack penetration. It may appear from the graph of wall stress for different soil depths (Figure 43) that soil load has less impact on LAW walls than on the walls of the intermediate-level vaults. The absolute change, however, remains close to that of the intermediate level vaults: pivotal times are approximately 100 years greater than baseline times for the minimum depth of soil, and 200 to 300 years less for the maximum depth of soil. To examine the impact of soil depth on collapse of the vault, return to Figure 42 . This time, consider the baseline hydrogen evolution rate (8E-5) curve only, and neglect the other curves. When the baseline curve crosses the horizontal line for a particular soil depth, that indicates the time to collapse for that depth of soil. These are the values tabulated in Table 12 under "Depth of Soil Cover" (of course, other corrosion rate/soil depth combinations can also be interpreted from this graph). Depth of soil has a much more dramatic impact on time to LAW Vault collapse than on any other pivotal time (for the LAW Vault and the intermediate level vaults). At the 
minimum depth of soil, roof collapse increases by almost 200 years, and at the maximum, decreases by over 1,000 years.

Figure 44 shows the impact of changing rebar size on the time to crack penetration of the roof, using the same format as Figure 40 . Because the rebar in the roof slab is close to the ACI minimum, only one increment smaller (from \#6 to \#5) was used in the sensitivity analysis. Again, the effects are significant, decreasing the time to crack penetration by approximately 300 years. Nevertheless, this is still several hundred years greater than the time to crack penetration of the roof in the intermediate level vaults. Increasing the rebar size also has a significant impact on the time to crack penetration of the roof. Increasing to a \#8 bar increases the time to crack penetration by 600 years, and, to \#14, by approximately 2,400 years. Note that, in this case, the roof will collapse due to structural failure of the AASHTO beams before cracks penetrate the roof. Changes in crack penetration of the walls (Figure 45) are similarly dramatic, with a change of approximately 300 years for every unit increment in bar size. Because roof collapse is determined by the AASHTO beams, changing the bar size in the roof slab has no impact on time to collapse.

Increasing the size of the AASHTO beams from the current Type IV to Type V will have a relatively slight impact on the depth of cracks and therefore on the time to crack penetration. This is due to the neutral axis' lack of dependance on load factors and on the moment in the AASHTO beams. Due to the decreased stress levels in the roof slab rebar (not shown), some decrease in the time to crack penetration would be expected. Decreasing to Type III beams will result in increased stress levels in the roof slab rebar, caused by increased curvature over the walls. Stress levels will be sufficient to cause cracks to penetrate the roof slab (that is, greater than $40 \mathrm{ksi}$ ) immediately upon soil loading. Therefore, use of smaller beams is not recommended unless spacing between beams is decreased to compensate. Figure 46 illustrates the impact of using different sized AASHTO beams on the time to collapse, using the same format as Figure 42. The curves for various hydrogen evolution corrosion rates have been retained in order to maximize the amount of information available in the graph. In Figure 46, however, the horizontal lines represent the area of prestress steel required to maintain the structure for the different sizes of AASHTO beams. Using a larger beam results in a smaller requirement in terms of the area of prestress steel required. Using the baseline hydrogen evolution corrosion rate, changing the beam size changes the time to collapse by approximately 300 to 400 years.

\subsection{SUMMARY OF THE IMPACT OF DESIGN CHANGES}

Within the range of values selected $(3,000$ to $6,000 \mathrm{psi})$, concrete strength has little impact on the service life of the vaults, due to the fact that it is predominately the rebar that resists tensile stresses. It is important to note that concrete strength has other important contributions to the vaults, such as reducing permeability and resisting shear stress. Depth of concrete cover over rebar also had little impact on the service life of the vaults. There are two significant caveats to this statement, however. First, this statement applies to the range of $1 \frac{1}{2}-$ to 3 -inch depth of concrete cover. Further decreasing the depth of cover 
further could have significant effects. Second, concrete cover over rebar can have very significant impacts if high-pH concrete is used, with increased cover reducing corrosion and thus extending the service life of the vault.

Rebar size has notable impacts on the service life of the vaults. Increasing or decreasing the rebar by one increment (for example, from \#8 to \#9 or \#7) will increase or decrease, respectively, the service life of the vaults by from 200 to 300 years. Further increments in rebar size have similar effects. This is due to the increased cross-sectional area of the rebar. Thus, increasing or decreasing the rebar spacing would be expected to have impacts of the same type and magnitude.

The size of the AASHTO bridge beams that are used for the roof system in the LAW vaults has a significant influence on serviceability. In addition to the Type IV beams now used, smaller Type III and larger Type V beams were considered for this study. It was assumed that the spacing, amount of prestress steel, and amount of prestress applied were the same for each beam type. The nominal stiffness of beams is reflected by the I value. The ratio between Type III and Type IV beams is $125,390 / 260,741=0.48$. After the 16-inch slab is cast for composite action with the girders, the relative stiffness ratios will be higher, perhaps 0.6 to 0.7 . The curvature of the slab over supports will be 30 to $40 \%$ larger as the smaller girders rotate at supports more than the Type IV girders when soil is placed over the hardened slabs. Consequent cracking will result in larger and deeper cracks over supports, and probable crack penetration upon soil loading. The limit strength at midspan will be proportional to the overall depth from the top surface of the slab to the centroid of prestressed strands at midspan. As a consequence, roof collapse is predicted to occur approximately 400 years earlier if the smaller beams are used. The ratio between the nominal stiffness of Type V and Type IV beams is 521,100/260,741 $=2.0$. After the 16inch roof slab is added, the stiffness ratio will become 1.6 to 1.8 . With greater stiffness, the deeper girders will rotate at supports through smaller angles than will Type IV beams, and the curvature in the slabs will be smaller for slabs supported on deeper girders. Cracking from such smaller curvatures will be smaller and less deep than those for the slabs supported on Type IV beams, although the neutral axis calculation indicates the same depth of cracking. The time to collapse is extended by slightly over 300 years using the larger girders. In summary, the use of the smaller Type III beams is not recommended. Although some of the increased curvature could be compensated for by closer spacing of the beams, it is not likely that this will be practical, as the beam spacing is already relatively small. On the other hand, increasing the beam size will likely have only a slight impact on the time to crack penetration, and a relatively small impact on the time to collapse (increased from 3,110 years to 3,430 years, or by about $10 \%$ ). Thus, the present beam size seems to be appropriate. It may be possible to alter the beam spacing, however, and retain adequate service life. Larger beam spacing would result in greater curvature and thus decrease the time to crack penetration; and, of course, decrease the time to collapse. In addition, consideration would need to be given to whether the 16-inch roof span could support the larger distance between girders, particularly as the structure degrades. Nevertheless, it 
seems likely that beam spacing could be altered and the vaults still satisfy the performance criteria.

Finally, depth of soil cover has significant impacts on the service life of the vaults. Decreasing the soil cover from the assumed $9 \mathrm{ft}$ to the minimum of $8 \mathrm{ft}$ increased the service life of the vaults by 50 to 100 years. Increasing the soil cover to the maximum considered, $16 \mathrm{ft}$, decreased the service life by approximately 200 to 400 years. The notable exception to this is the time to collapse of the LAW Vault, which decreased by over 1,000 years when the soil cover was increased. 


\section{FUTURE RESEARCH AREAS}

This study was limited to the roof and walls of the IIT, ILNT and LAW vault types. If cracks penetrate the roof or walls of a vault before cracks penetrate the floor, there is the potential for infiltration water to enter and accumulate in the vault, resulting in leaching of the vault contents. When the floor does crack, toxic substances could then be released. Clearly, in order to accurately assess flow out of the vaults, it is necessary to estimate the time-to crack penetration of the vault-floors. This should be the first priority for additional work in this area.

This project has demonstrated the ability of the model to evaluate the impact of changes in design parameters on the longevity of reinforced concrete structures. A number of other design parameters were not considered in this study due to time and budget limitations. Additional sensitivity analyses could be conducted for structural parameters such as roof thickness, rebar spacing, AASHTO beam spacing, length, width and height of the vaults, and wall thickness, as well as degradation model inputs such as oxygen diffusion rate in the concrete, leach rate, carbonation rate, or time to depassivation of the rebar.

One issue that has not been addressed in this project is the potential for loss of bonding between the concrete and rebar as the rebar degrades. Corrosion products have greater volume than the rebar, and this can result in cracking or spalling of the concrete, or other mechanisms may result in loss of bonding.

If high-pH concrete is to be considered, sensitivity analysis should be conducted for other corrosion processes as well. Figures 47 and 48 demonstrate the importance of other processes in the corrosion of high-pH concrete. Figure 47 shows a worst-case degradation scenario at 50 years after burial. Sulfate attack has caused some surface loss. Oxic corrosion has caused the exterior face rebar to corrode at a slightly greater rate than the interior face rebar, which will remain passivated (and thus not subject to oxic corrosion) throughout the simulation. Leaching has resulted in a low-pH zone to a depth of $5.9 \mathrm{~cm}$ into the concrete. At 400 years (Figure 48), the low-pH zone has encompassed the exterior face rebar. This causes the hydrogen evolution corrosion reaction to proceed at an accelerated rate, resulting in significant corrosion of the exterior face rebar. The interior face rebar, still protected from oxic corrosion, corrodes much more slowly, at the high-pH rate of hydrogen evolution corrosion. In a low-pH concrete, both exterior and interior rebar corrode at the higher hydrogen evolution corrosion rate. Thus, the high-pH concrete has two basic differences in terms of its corrosion rates: First, there is a delay, both before the onset of oxic corrosion (minor impact) and before the high rate of hydrogen evolution corrosion (major impact). Second, the interior rebar corrodes only at the lower rate of hydrogen evolution corrosion throughout the simulation (major impact). Because of this, carbonation (which, in some scenarios, may be the mechanism for lowering $\mathrm{pH}$ ), leach penetration, and time to depassivation of the rebar all become important. Table 13 presents the results of a baseline analysis of baseline results for the different vault types, under the assumption that 
high-pH concrete is used. This can be compared to Table 9. LAW Vault results for highpH concrete are not presented because changes were made to the LAW approach such that the initial high-pH results are not directly comparable with the final low-pH results. With high-pH concrete, the time to crack penetration of the roof increases by approximately 600 years for both intermediate level vaults, and the time to collapse increases by approximately 800 years.

An issue that was beyond the scope of this project was the performance of the clay layer overlying the vault. It may be worthwhile to investigate whether cracks in the concrete can result in cracks in the clay. This would increase the hydraulic conductuctivity of the clay layer and therefore of the clay/roof system. Furthermore, the clay layer is assumed to maintain the same thickness and size over the long time frames of the simulation. The accuracy of this should be investigated, as well as the impact of changes in the clay layer on the performance of the vaults.

Other issues not addressed in this project include the long-term performance of waterstops and control joints, of waterproof coatings placed on the exterior of the vaults, and the longevity of the sealed shrinkage cracks.

Finally, the hydrogen evolution corrosion rate is a significant source of uncertainty in the model. Any work that could determine this rate with greater accuracy would decrease the uncertainty in the model predictions. 


\section{SUMMARY AND CONCLUSIONS}

This study has demonstrated a capability to estimate the degradation of the E-Area Vault structures and to utilize information on the degraded vaults to predict the times to failure (loss of ability to divert water) and collapse of the structures. The primary source of uncertainty in the model is the rate of rebar corrosion due to the anoxic hydrogen evolution reaction, which results in uncertainty of approximately one order of magnitude.

Degradation processes considered were magnesium and sulfate attack, calcium leaching, carbonation, and rebar corrosion due to both oxygen diffusion to the rebar (including breakdown of the passivating layer that initially prevents corrosion of rebar) and due to the "hydrogen evolution" reaction. Existing empirical models for the individual degradation processes were combined into a single model to create an overall model of the degradation of reinforced concrete. The degradation processes were used to predict the condition of the concrete, including its strength, thickness and hydraulic conductivity. The evaluation of structural response to loads and other influences (e.g., slow and steady degradation of reinforced concrete) is made on the basis of the equilibrium of forces and compatibility of deformation within the structure and in the surrounding media using the RCPC computer code as a foundation. In addition, the NAWY models were used to calculate loss in prestress in the beams due to elasticity loss, creep, shrinkage and relaxation. The state of stress in the concrete was calculated and the roof components and walls fractured in order to eliminate excessive stress which cannot be borne by the degraded structure. Crack width and spacing were also computed. By combining the degradation and structural models into a single performance assessment tool, sensitivity analysis can be conducted to determine the impact both of variation in important degradation processes and of changes in design parameters on the service life of the vaults.

Structural data for each vault type was based on a review of design drawings provided to INTERA by WSRC. Relevant environmental data (such as sulfate concentration in groundwater) were obtained through the Idaho National Engineering Laboratory (INEL). Corrosion rates were based upon an extensive literature review. All structural and degradation parameters were reviewed by WSRC and INEL. Structural analysis and calculations were reviewed by an expert structural engineer who specializes in the field of design of reinforced concrete structures.

For each type of vault, sensitivity analysis was performed to bound the predictions. After an initial rough sensitivity analysis on a large number of factors, six factors were selected for detailed sensitivity analysis: rate of rebar corrosion due to the "hydrogen evolution" reaction, rebar diameter, depth of concrete cover over the rebar, size of AASHTO "bridge" beams used to support the vault roof in the LAW vault design, and depth of soil cover over the vaults, and concrete strength. Output parameters for the sensitivity analysis were the time to first crack penetration of the vault roof, time to first crack penetration of the vault walls, and time to structural failure (collapse) of the vault roof. Times to crack penetration 
are important because the hydraulic conductivity increases by approximately 3 orders of magnitude (over that of intact concrete) upon crack penetration.

From the calculations in this study, we have concluded:

That concrete strength, and, for the low-pH concrete being used in the E-Area vaults, depth of concrete cover over the rebar, have little impact on the vault performance. Depth of soil cover can alter the service life of the vaults on the order of hundreds of years, and rebar size can alter the service life of the vaults on the order of hundreds to thousands of years. Changing the size of the AASHTO beams in the IAW Vaults will change the time to collapse of the vaults on the order of several hundred years. Using a smaller beam, however, is not recommended (unless beam spacing is decreased appropriately), as stress levels in the roof-slab-rebar over the walls will result in crack penetration of the roof upon soil loading.

Future work should include a similar analysis of cracking of the vault floors; in order to accurately assess flow out of the vaults, it is necessary to estimate the time to crack penetration of the vault floors. Sensitivity analyses beyond those conducted for this study could be conducted for structural parameters such as roof thickness, rebar spacing, AASHTO beam spacing, length, width and height of the vaults, and wall thickness, as well as degradation model inputs such as oxygen diffusion rate in the concrete, leach rate, carbonation rate, or time to depassivation of the rebar. In addition, if high-pH concrete is used, additional sensitivity analysis should be conducted on degradation mechanisms important in high-pH concrete. Mechanisms that may result in loss of bonding between rebar and concrete should be investigated and quantified. In addition, performance of the clay layer overlying the vault, of waterstops and control joints, of waterproof coatings placed on the exterior of the vaults, and the longevity of the sealed shrinkage cracks all could warrant further study. Finally, any work that could determine the anoxic (hydrogen evolution) corrosion rate in rebar with greater accuracy would decrease the uncertainty in the model predictions.

This project has demonstrated the ability of the code to estimate the impact of changes in design parameters on the longevity of reinforced concrete structures. The code therefore has potential for application as a design aid tool for below-ground concrete storage facilities. The current mandate at DOE facilities to move in the direction of below-ground disposal in concrete-engineered structures makes this code a potentially important performance assessment tool. 
Table 1. Summary of Output Parameters

\begin{tabular}{|c|c|}
\hline Parameter Description & Units \\
\hline \multicolumn{2}{|l|}{ Degradation Parameters } \\
\hline $\begin{array}{l}\text { rebar volume lost due to the oxygen-diffusion limited } \\
\text { reaction }\end{array}$ & $\%$ \\
\hline $\begin{array}{l}\text { \% of rebar volume lost due to the hydrogen evolution } \\
\text { reaction }\end{array}$ & $\underline{\%}$ \\
\hline $\begin{array}{l}\text { total loss of rebar at the exterior and interior face of the } \\
\text { slab }\end{array}$ & $\begin{array}{l}\text { \% volume loss } \\
\text { remaining diameter }(\mathrm{cm})\end{array}$ \\
\hline depth of $\mathrm{SO}_{4}$ penetration & $\mathrm{cm}$ \\
\hline $\begin{array}{l}\mathrm{Ca}(\mathrm{OH})_{2} \text { leach penetration via the concrete-controlled } \\
\text { assumption }\end{array}$ & $\mathrm{cm}$ \\
\hline $\begin{array}{l}\mathrm{Ca}(\mathrm{OH})_{2} \text { leach penetration via the geology-controlled } \\
\text { assumption }\end{array}$ & $\mathrm{cm}$ \\
\hline total leach $\mathrm{Ca}(\mathrm{OH})_{2}$ penetration & $\mathbf{c m}$ \\
\hline depth of carbonation penetration & $\mathrm{cm}$ \\
\hline fracture aperture & $\mathbf{m m}$ \\
\hline fracture spacing & $\mathbf{m}$ \\
\hline effective hydraulic conductivity & $\mathrm{m} / \mathrm{s}$ \\
\hline \multicolumn{2}{|l|}{ Structural Parameters } \\
\hline moments at critical stress regions & ft-kip \\
\hline shear at critical stress regions & kip \\
\hline concrete stresses at critical stress regions & psi \\
\hline rebar stress at critical stress regions & ksi \\
\hline concrete cracking stress & psi \\
\hline concrete shear limit stress & psi \\
\hline \multicolumn{2}{|c|}{ LAW Vault Curvature Parameters } \\
\hline curvature over walls & radians/in \\
\hline depth of neutral axis & inch and $\mathrm{cm}$ \\
\hline stress in rebar due to curvature & ksi \\
\hline
\end{tabular}


Table 2. Structural Input for the ILNT Vault

\begin{tabular}{|l|l|l|l||}
\hline Variable & "mean" & range & justification \\
\hline Spans & & & \\
\hline $\begin{array}{l}\text { Yoof center to first wall } \\
\text { center }\end{array}$ & $27 \mathrm{ft}$ & & \\
\hline inner wall center to center & $26.5 \mathrm{ft}$ & & \\
\hline roof thickness & 33 inches & $27-39$ inches & \\
\hline columns & & & \\
\hline outer wall thickness & 30 inches & & \\
\hline inner wall thickness & 18 inches & & \\
\hline misc & & & \\
\hline concrete cover over rebar & 2.375 inches & $1.5-3$ inches & $\begin{array}{l}2.375 \text { actual on blueprint, } \\
2-3 \text { accepted range; may } \\
\text { want to go to 4 }\end{array}$ \\
\hline exterior face bar area & 1.58 in & & \\
\hline interior face bar area & .79 in ${ }^{2}$ & & \\
\hline $\begin{array}{l}\text { concrete compressive } \\
\text { strength }\end{array}$ & 4750 psi & & $\begin{array}{l}\text { midpoint of minimum } \\
\text { spec (4,000) and } \\
\text { minimum test (5,500) }\end{array}$ \\
\hline rebar yield strength & $60 \mathrm{ksi}$ & & \\
\hline degradation & & & \\
\hline $\begin{array}{l}\text { maximum spacing } \\
\text { (outside, at stress points) }\end{array}$ & 12 inches & & \\
\hline rebar diameter & 1 inches \\
$2.5 \mathrm{~cm}$ & & & \\
\hline \hline
\end{tabular}

(1) based on $29^{\prime} 8^{\prime \prime}$ wall and $2^{\prime} 3^{\prime \prime}$ to $3^{\prime} 3^{\prime \prime}$ roof thickness 
Table 3. Structural Input for the ILT Vault

\begin{tabular}{|l|l|l|l||}
\hline Variable & baseline & range & justification \\
\hline Spans & & & \\
\hline roof center to first wall & $27 \mathrm{ft}$ & & \\
center & & & \\
\hline inner wall center to center & $\mathrm{N} . \mathrm{A}$. & & \\
\hline roof thickness & 48 inches & $42-54$ inches & \\
\hline columns & & & \\
\hline outer wall thickness & 30 inches & & \\
\hline inner wall thickness & 18 inches & & \\
\hline misc & & & \\
\hline concrete cover over rebar & 2.375 inches & $1.5-3$ inches & allowable range \\
\hline exterior face rebar area & 1.58 in ${ }^{2}$ & & \\
\hline interior face rebar area & .79 in ${ }^{2}$ & & \\
\hline $\begin{array}{l}\text { concrete compressive } \\
\text { strength }\end{array}$ & 4750 psi & & $\begin{array}{l}\text { midpoint of minimum } \\
\text { spec }(4,000) \text { and } \\
\text { minimum test }(5,500)\end{array}$ \\
\hline rebar yield strength & $60 \mathrm{ksi}$ & & \\
\hline degradation & & & \\
\hline $\begin{array}{l}\text { maximum spacing } \\
\text { (outside, at stress points) }\end{array}$ & 12 inches & & \\
\hline rebar diameter & 1 inches & & \\
\hline
\end{tabular}

(1) based on $28^{\prime} 6^{\prime \prime}$ wall and $3^{\prime} 6^{\prime \prime}$ to $4^{\prime} 6^{\prime \prime}$ roof thickness 
Table 4. Structural Input for the LAW Vault

\begin{tabular}{||l|l|l||}
\hline \hline \multicolumn{2}{|c|}{ Aariable } & \multicolumn{2}{l|}{ Value } & Source \\
\hline \hline \multicolumn{2}{|c|}{ AASHTO I-Beams } \\
\hline Length of I-beam & $52^{\prime}$ & Tindall \\
\hline Top flange width & $20^{\prime \prime}$ & Tindall \\
\hline Top flange depth & $11^{\prime \prime}$ & Tindall \\
\hline Bottom flange width & $26^{\prime \prime}$ & Tindall \\
\hline Bottom flange depth & $8^{\prime \prime}$ & Tindall \\
\hline Total depth & $54^{\prime \prime}$ & Tindall \\
\hline Web width & $8^{\prime \prime}$ & Tindall \\
\hline Concrete compressive strength at 28 days & $6,000 \mathrm{psi}$ & Tindall \\
\hline Concrete compressive strength at prestress & $5,000 \mathrm{psi}$ & Tindall \\
\hline Eccentricity at midspan & 17.13 & Tindall \\
\hline Eccentricity at support & 12 & Tindall \\
\hline Ultimate strength of prestress steel & 250,000 psi & Tindall \\
\hline Initial prestress & 202,500 psi & Tindall \\
\hline Yield strength of prestress steel & 240,000 psi & Tindall \\
\hline Young's modulus of prestress steel & $28,700,000$ & Tindall \\
\hline Area of prestress steel & 7.01 inch ${ }^{2}$ & Tindall \\
\hline Number of tendons & 42 & Tindall \\
\hline Thickness of roof panels & $3^{\prime \prime}$ & Design drawings \\
\hline Thickness of roof slab & $16^{\prime \prime}$ & Design drawings \\
\hline rebar area in roof slab & 0.88 in $/$ foot & Design drawings \\
\hline prestress loss & $22 \%$ & Tindall, confirmed by \\
& & NAWY10 \\
\hline
\end{tabular}


Table 5. Design Drawings Used

\begin{tabular}{|c|c|c|}
\hline Drawing Number & $\begin{array}{l}\text { Revision } \\
\text { Number }\end{array}$ & Title \\
\hline AA98143C-11-A-TC3 & & $\begin{array}{l}\text { AASHTO BEAMS AND ROOF PANELS (BY } \\
\text { TINDALL CONCRETE, INC.) }\end{array}$ \\
\hline SE5-6-2003303 & 2 & $\begin{array}{l}\text { BURIAL GROUND EXPANSION IIT } \\
\text { VAULT JOINTS LOCATIONS \& DETAIIS } \\
\text { (U) CONCRETE }\end{array}$ \\
\hline SE5-6-2003304 & 1 & $\begin{array}{l}\text { BURIAL GROUND EXPANSION ILT } \\
\text { VAULT BASE SLAB PLANS (U) } \\
\text { CONCRETE }\end{array}$ \\
\hline SE5-6-2003305 & 0 & $\begin{array}{l}\text { BURIAL GROUND EXPANSION ILT } \\
\text { VAULT WALLS REINFORCING } \\
\text { ELEVATIONS CONCRETE }\end{array}$ \\
\hline SE5-6-2003306 & 0 & $\begin{array}{l}\text { BURIAL GROUND EXPANSION ILT } \\
\text { VAULT WALLS SECTIONS \& DETAILS } \\
\text { CONCRETE }\end{array}$ \\
\hline SE5-6-2003307 & 0 & $\begin{array}{l}\text { BURIAL GROUND EXPANSION ILT } \\
\text { VAULT WALIS \& CRANE RUNWAY } \\
\text { PLAN AND SECTIONS CONCRETE }\end{array}$ \\
\hline SE5-6-2003308 & 2 & $\begin{array}{l}\text { BURIAL GROUND EXPANSION ILNT } \\
\text { VAULT JOINTS LOCATIONS \& DETAIIS } \\
\text { (U) CONCRETE }\end{array}$ \\
\hline SES-6-2003309 & 0 & $\begin{array}{l}\text { BURIAL GROUND EXPANSION ILNT } \\
\text { VAULT BASE SLAB PLANS CONCRETE }\end{array}$ \\
\hline SE5-6-2003310 & 1 & $\begin{array}{l}\text { BURIAL GROUND EXPANSION ILNT } \\
\text { VAULT WALLS REINF'G ELEVATIONS } \\
\text { (U) CONCRETE }\end{array}$ \\
\hline SE5-6-2003311 & 1 & $\begin{array}{l}\text { BURIAL GROUND EXPANSION ILNT } \\
\text { VAULT WALLS SECTIONS \& DETAILS } \\
\text { (U) CONCRETE }\end{array}$ \\
\hline SE5-6-2003315 & 0 & $\begin{array}{l}\text { BURIAL GROUND EXPANSION IIT } \\
\text { VAULT PERMANENT ROOF SLAB PLAN } \\
\& \text { SECTIONS (FUTURE) CONCRETE }\end{array}$ \\
\hline
\end{tabular}




\begin{tabular}{|c|c|c|}
\hline Drawing Number & $\begin{array}{l}\text { Revision } \\
\text { Number }\end{array}$ & Title \\
\hline SE5-6-2003317 & 0 & $\begin{array}{l}\text { BURIAL GROUND EXPANSION ILNT } \\
\text { VAULT PERMANENT ROOF SLAB PLAN } \\
\& \text { SECTIONS (FUTURE) CONCRETE }\end{array}$ \\
\hline SE5-6-2003318 & 2 & $\begin{array}{l}\text { BURIAL GROUND EXPANSION ILT \& } \\
\text { ILNT VAULTS GENERAL NOTES AND } \\
\text { LEGEND (U) CONCRETE }\end{array}$ \\
\hline SE5-6-2008800 & 1 & $\begin{array}{l}\text { BURIAL GROUND EXPANSION LAW } \\
\text { VAULT JOINTS LOCATIONS \& DETAILS } \\
\text { CONCRETE }\end{array}$ \\
\hline SE5-6-2008801 & 1 & $\begin{array}{l}\text { BURIAL GROUND EXPANSION LAW } \\
\text { VAULT GENERAL NOTES AND LEGEND } \\
\text { CONCRETE }\end{array}$ \\
\hline SE5-6-2008802 & 0 & $\begin{array}{l}\text { BURIAL GROUND EXPANSION LAW } \\
\text { VAULT FOUNDATION, SLAB \& ROOF } \\
\text { FRAMING KEY PLANS CONCRETE }\end{array}$ \\
\hline SE5-6-2008803 & 1 & $\begin{array}{l}\text { BURIAL GROUND EXPANSION LAW } \\
\text { VAULT FOUNDATION \& FLOOR SLAB } \\
\text { PLAN - MODULE } 1 \text { CONCRETE }\end{array}$ \\
\hline SE5-6-2008806 & 0 & $\begin{array}{l}\text { BURIAL GROUND EXPANSION LAW } \\
\text { VAULT ROOF FRAMING \& SLAB PLAN - } \\
\text { MODULE } 1 \text { CONCRETE }\end{array}$ \\
\hline SE5-6-2008809 & 0 & $\begin{array}{l}\text { BURIAL GROUND EXPANSION LAW } \\
\text { VAULT WALLS ELEVATIONS SHEET } 1 \\
\text { CONCRETE }\end{array}$ \\
\hline SE5-6-2008810 & 1 & $\begin{array}{l}\text { BURIAL GROUND EXTENSION LAW } \\
\text { VAULT WALLS ELEVATIONS SHEET } 2 \\
\text { CONCRETE }\end{array}$ \\
\hline SE5-6-2008811 & 0 & $\begin{array}{l}\text { BURIAL GROUND EXPANSION LAW } \\
\text { VAULT WALLS ELEVATIONS SHEET } 3 \\
\text { CONCRETE }\end{array}$ \\
\hline SE5-6-2008812 & 1 & $\begin{array}{l}\text { BURIAL GROUND EXPANSION LAW } \\
\text { VAULT WALIS SECTIONS \& DETAILS } \\
\text { SHEET } 1 \text { CONCRETE }\end{array}$ \\
\hline
\end{tabular}




\begin{tabular}{|c|c|c|}
\hline Drawing Number & $\begin{array}{l}\text { Revision } \\
\text { Number } \\
\end{array}$ & Title \\
\hline SE5-6-2008813 & 1 & $\begin{array}{l}\text { BURIAL GROUND EXPANSION LAW } \\
\text { VAULT WALLS SECTIONS \& DETAILS } \\
\text { SHEET } 2 \text { CONCRETE }\end{array}$ \\
\hline SE5-6-2008814 & 1 & $\begin{array}{l}\text { BURIAL GROUND EXPANSION LAW } \\
\text { VAULT WALLS SECTIONS \& DETAIIS } \\
\text { SHEET } 3 \text { (FUTURE) CONCRUTE }\end{array}$ \\
\hline SE5-6-2008815 & 1 & $\begin{array}{l}\text { BURIAL GROUND EXPANSION LAW } \\
\text { VAULT WALLS SECTIONS \& DETAIIS } \\
\text { SHEET } 4 \text { CONCRETE }\end{array}$ \\
\hline SE5-6-2008816 & 0 & $\begin{array}{l}\text { BURIAL GROUND EXPANSION LAW } \\
\text { VAULT ROOF FRAMING \& SLAB } \\
\text { SECTIONS \& DETAIIS CONCRETE } \\
\end{array}$ \\
\hline SE5-6-2008817 & 0 & $\begin{array}{l}\text { BURIAL GROUND EXPANSION LAW } \\
\text { VAULT PRESTRESSED ROOF BEAMS } \\
\text { SECTIONS \& DETAIIS CONCRETE } \\
\end{array}$ \\
\hline W2017824 & $\mathrm{C}$ & $\begin{array}{l}\text { BURIAL GROUND EXPANSION IIT, ILNT } \\
\text { \& LAW VAULTS CLOSURE CONCEPT } \\
\text { SITE PLAN CIVIL }\end{array}$ \\
\hline W2017825 & & $\begin{array}{l}\text { BURIAL GROUND EXPANSION ILT \& } \\
\text { ILNT VAULTS CLOSURE CONCEPT SITE } \\
\text { CROSS SECTIONS CIVIL }\end{array}$ \\
\hline W2017826 & B & $\begin{array}{l}\text { BURIAL GROUND EXPANSION LAW } \\
\text { VAULTS CLOSURE CONCEPT SITE } \\
\text { CROSS SECTIONS CIVIL }\end{array}$ \\
\hline W2017827 & & $\begin{array}{l}\text { BURIAL GROUND EXPANSION IIT \& } \\
\text { IINT VAULTS CLOSURE CONCEPT PLAN } \\
\text { AND SECTIONS CIVIL }\end{array}$ \\
\hline W2017828 & B & $\begin{array}{l}\text { BURIAL GROUND EXPANSION LAW } \\
\text { VAULTS CLOSURE CONCEPT PLAN \& } \\
\text { SELECTIONS CIVIL }\end{array}$ \\
\hline W2020320 & 1 & $\begin{array}{l}\text { BURIAL GROUND EXPANSION IIT } \\
\text { VAULT CRUCIBLE SILOS PLAN AND } \\
\text { SECTIONS CONCRETE }\end{array}$ \\
\hline
\end{tabular}




\begin{tabular}{|l|c|l|}
\hline Drawing Number & $\begin{array}{l}\text { Revision } \\
\text { Number }\end{array}$ & \multicolumn{1}{|c|}{ Title } \\
\hline W2020372 & B & $\begin{array}{l}\text { BURIAL GROUND EXPANSION LAW } \\
\text { VAULTS CONSTRUCTION STRATEGY } \\
\text { SITE CROSS SECTIONS CIVIL }\end{array}$ \\
\hline W2020422 & 1 & $\begin{array}{l}\text { BURIAL GROUND EXPANSION IIT } \\
\text { VAULT CRUCIBLE SILOS DETAIIS } \\
\text { CONCRETE }\end{array}$ \\
\hline
\end{tabular}




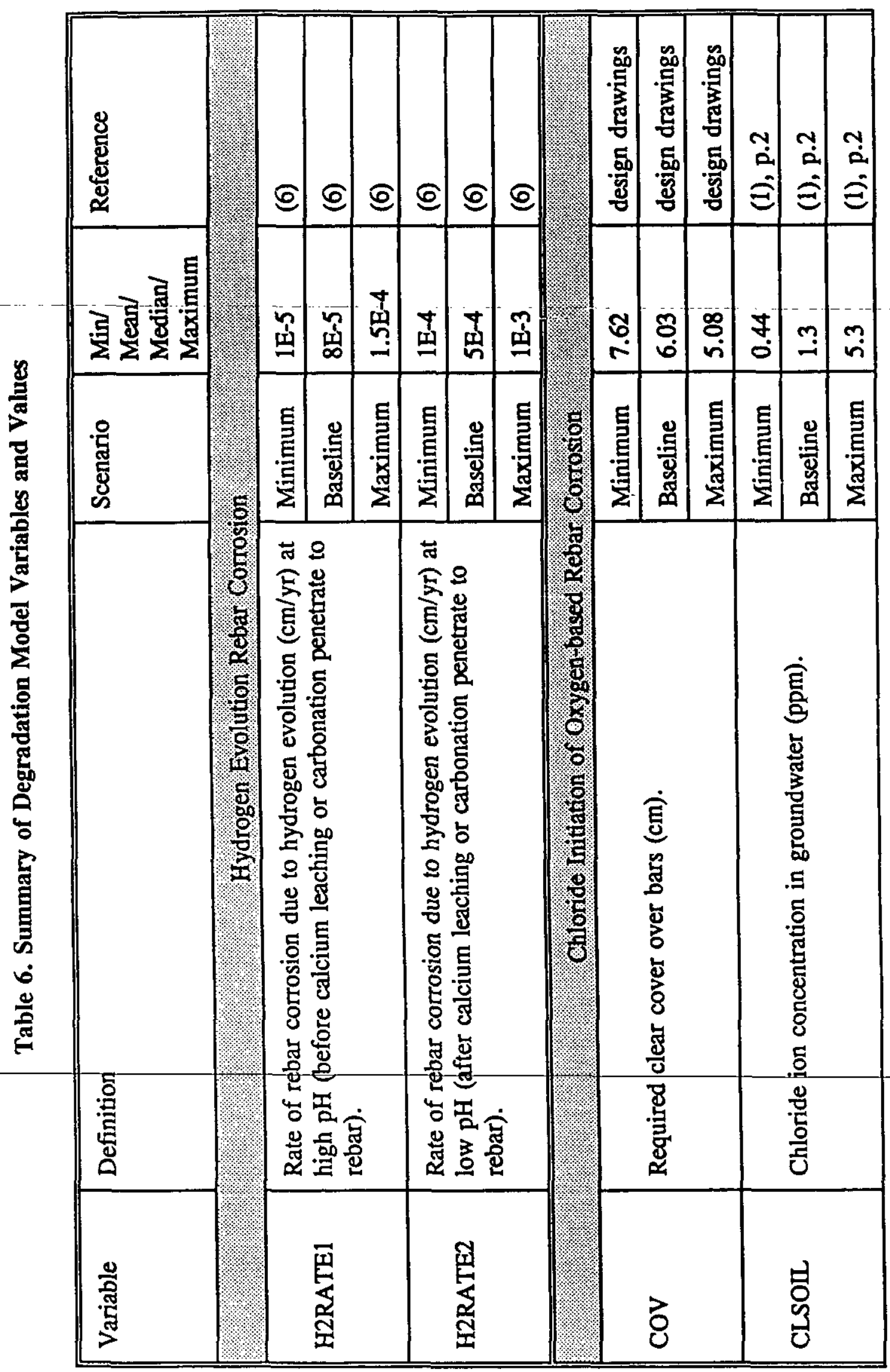




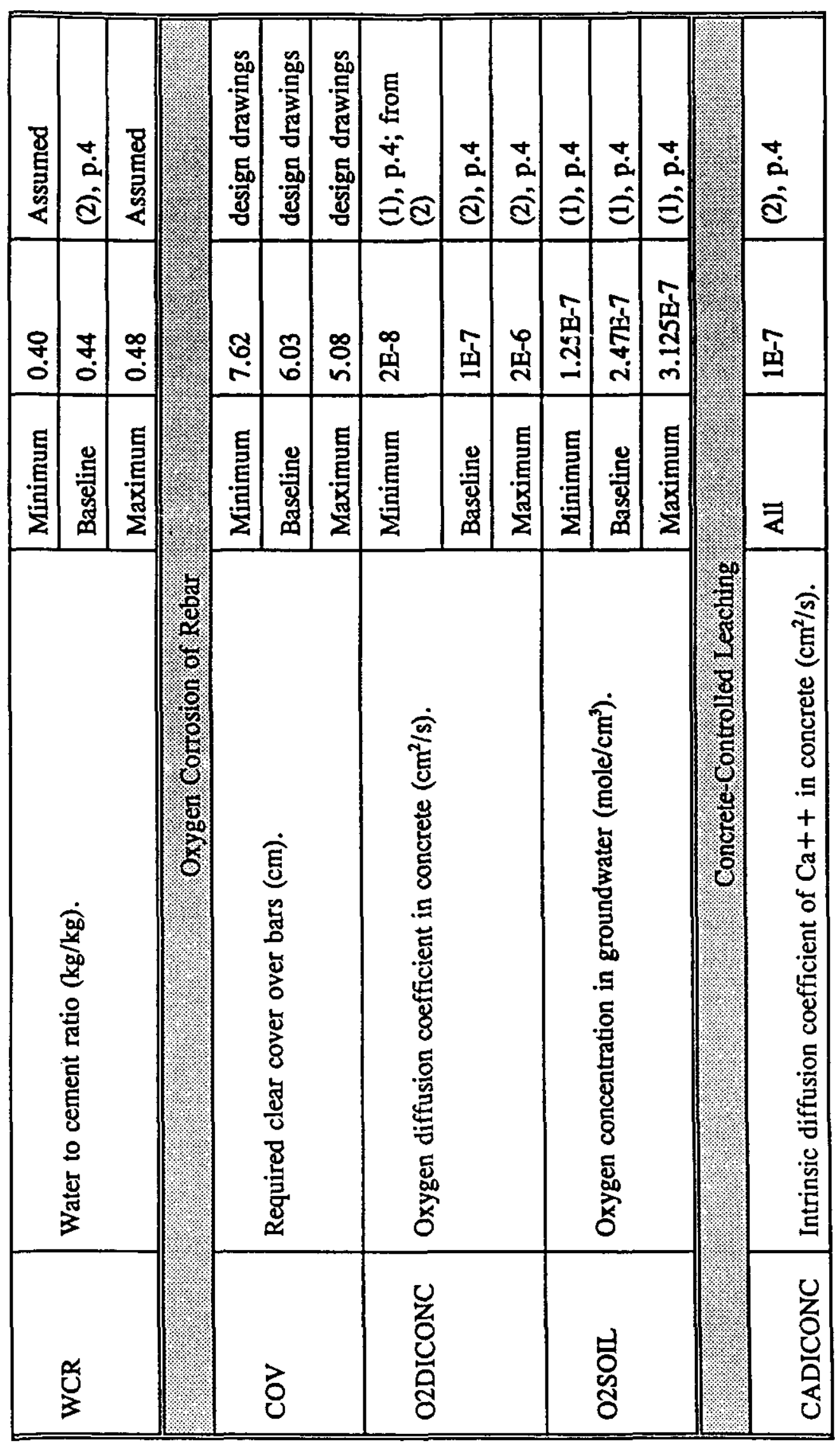




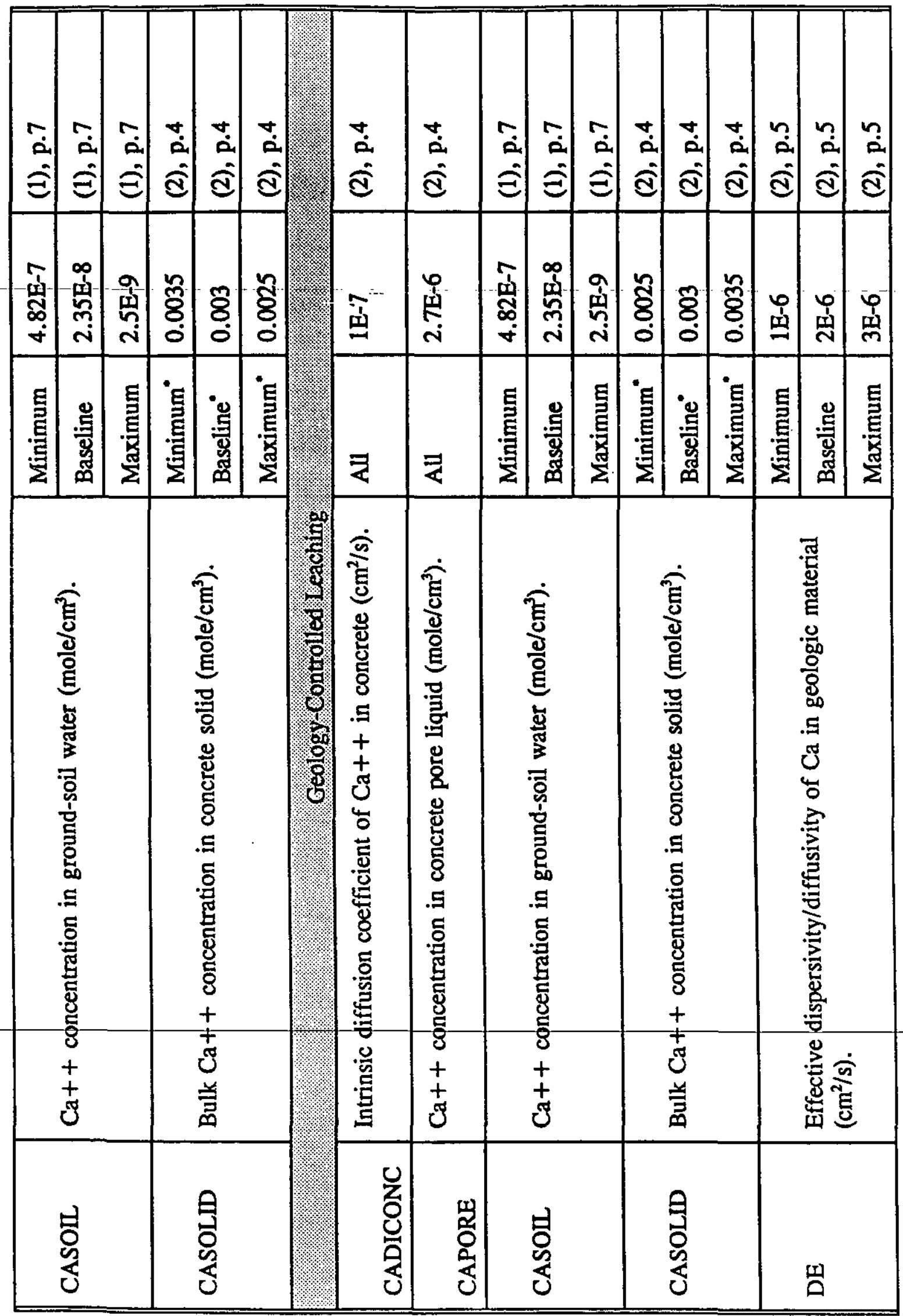




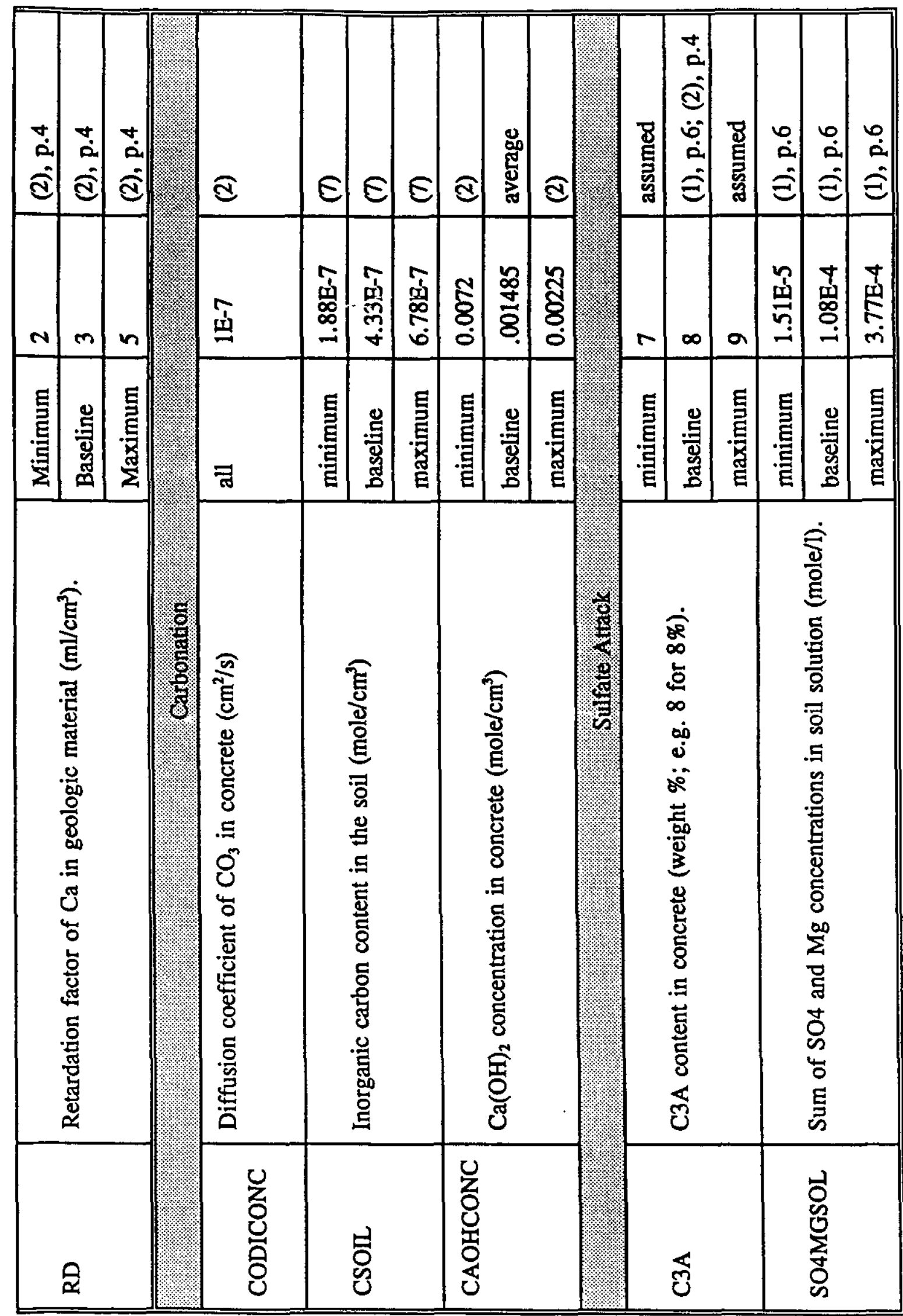




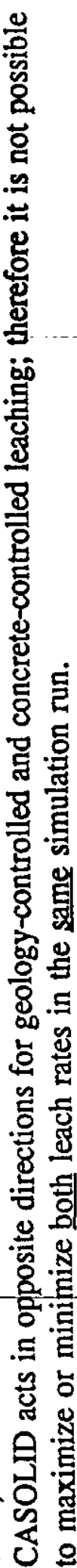

ชั

-

y

․ 8

궁

可

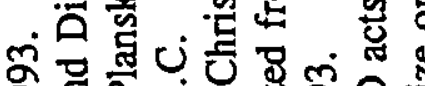

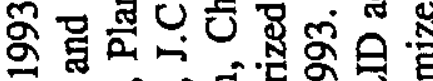

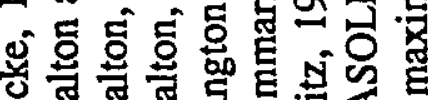

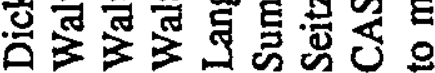

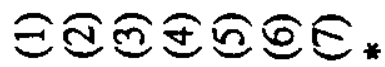




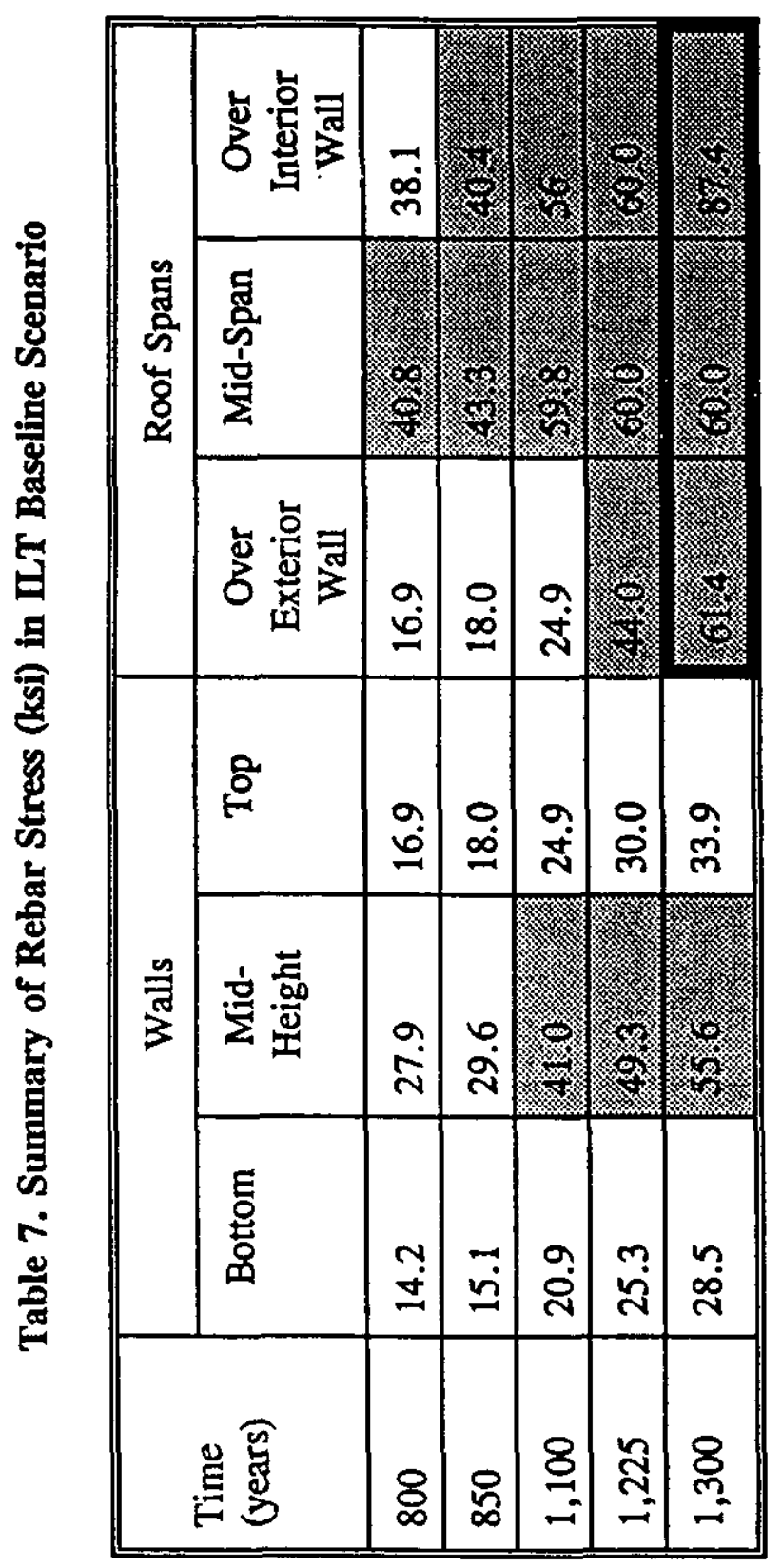




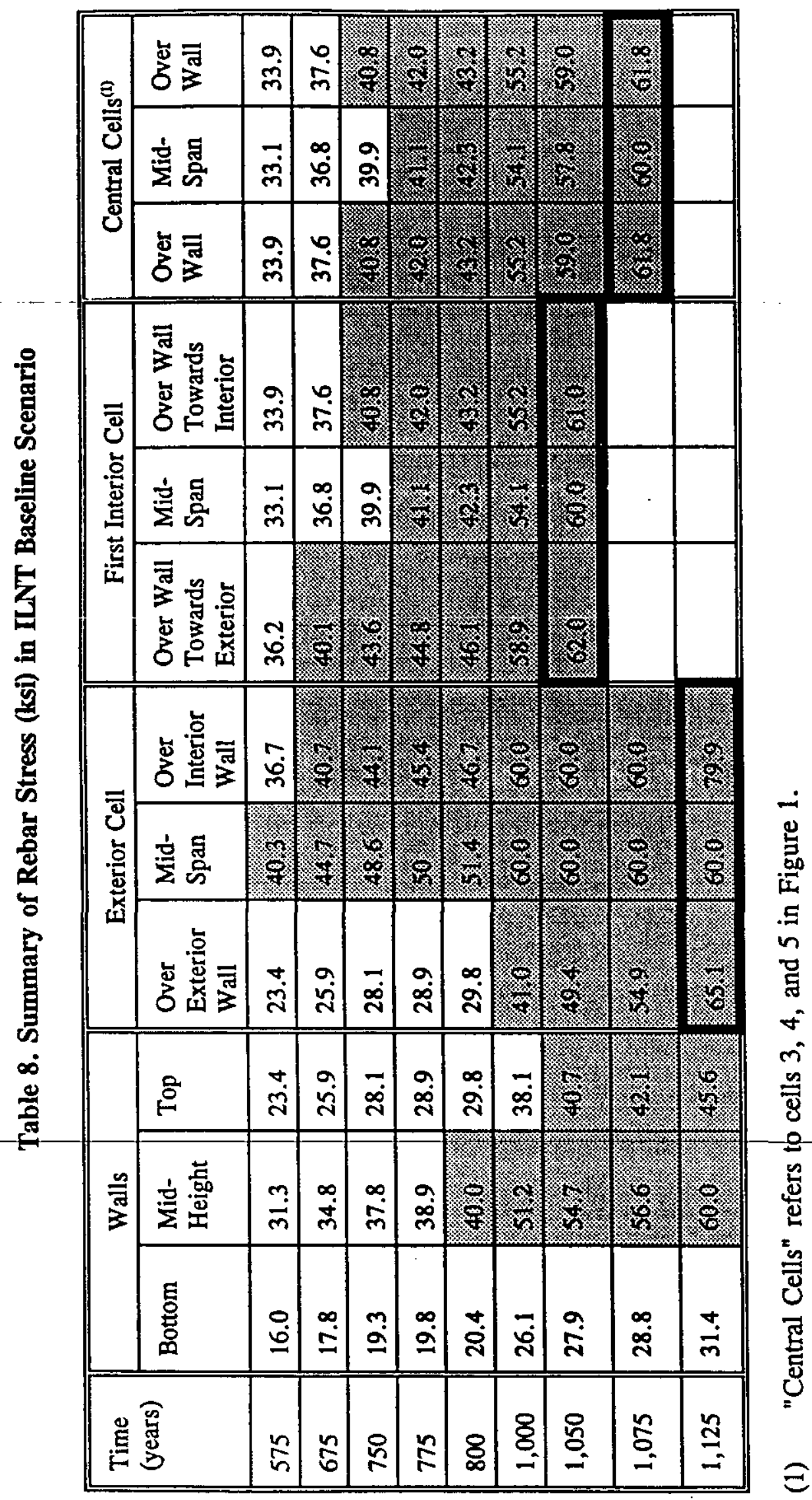


Table 9. Summary of Baseline Results

\begin{tabular}{||l|r|r|r|}
\hline Vault & $\begin{array}{c}\text { Cracks Penetrate Roof } \\
\text { (years) }\end{array}$ & $\begin{array}{c}\text { Cracks Penetrate Walls } \\
\text { (Mid-Height) } \\
\text { (years) }\end{array}$ & $\begin{array}{c}\text { Roof Collapse } \\
\text { (years) }\end{array}$ \\
\hline IINT & 570 & 800 & 1,045 \\
\hline \hline IIT & 790 & 1,080 & 1,300 \\
\hline LAW & 1,420 & 2,235 & 3,100 \\
\hline
\end{tabular}


Table 10. Summary of ILNT Vault Sensitivity Analyses

\begin{tabular}{|c|c|c|c|}
\hline Scenario & Cracks Penetrate Roof & $\begin{array}{c}\text { Cracks Penetrate Walls } \\
\text { (Mid-Height) }\end{array}$ & Roof Collapse \\
\hline Baseline & 570 & 800 & 1,045 \\
\hline \multicolumn{4}{|c|}{ Hydrogen Evolution Corrosion Rate (Baseline $=5 \mathrm{E}-4 \mathrm{~cm} / \mathrm{yr}$ ) } \\
\hline 1E-3 & 285 & 400 & 525 \\
\hline $7.5 \mathrm{E}-4$ & 380 & 535 & 700 \\
\hline $2.5 \mathrm{E}-4$ & 1,130 & 1,590 & 2,075 \\
\hline $1 \mathrm{E}-4$ & 2,775 & $3,000+$ & $3,000+$ \\
\hline \multicolumn{4}{|c|}{ Depth of Soil Cover (Baseline $=9$ feet) } \\
\hline 8 feet & 680 & 850 & 1,130 \\
\hline 12 feet & 400 & 590 & 925 \\
\hline 16 feet & 130 & 360 & 725 \\
\hline \multicolumn{4}{|c|}{ Rebar Size (Baseline $=\# 8$ ) } \\
\hline \#6 & 0 & 175 & 425 \\
\hline$\# 7$ & 250 & 485 & 735 \\
\hline$\# 9$ & 875 & 1,105 & 1,350 \\
\hline$\# 11$ & 1,785 & 1,965 & 2,150 \\
\hline$\# 18$ & $3,000+$ & $3,000+$ & $3,000+$ \\
\hline \multicolumn{4}{|c|}{ Depth of Concrete Cover Over Rebar (Baseline $=23 / \mathrm{s}^{\prime \prime}$ ) } \\
\hline $11 / 2^{n}$ & 600 & 825 & 1,060 \\
\hline -3"- & $-550^{-}$ & 780 & 1,030 \\
\hline \multicolumn{4}{|c|}{ Concrete Strength (Baseline $=4,750 \mathrm{psi}$ ) } \\
\hline $3,000 \mathrm{psi}$ & 570 & 800 & 1,040 \\
\hline $6,000 \mathrm{psi}$ & 570 & 800 & 1,045 \\
\hline
\end{tabular}

A " + " indicates that the event did not occur prior to the end of the simulation. 
Table 11. Summary of ILT Vault Sensitivity Analyses

\begin{tabular}{|c|c|c|c|}
\hline Scenario & Cracks Penetrate Roof & $\begin{array}{c}\text { Cracks Penetrate Walls } \\
\text { (Mid-Height) }\end{array}$ & Roof Collapse \\
\hline Baseline & 790 & 1,080 & 1,300 \\
\hline \multicolumn{4}{|c|}{ Hydrogen Evolution Corrosion Rate (Baseline $=5 \mathrm{E}-4 \mathrm{~cm} / \mathrm{yr}$ ) } \\
\hline 1E-3 & 395 & 535 & 655 \\
\hline $7.5 \mathrm{E}-4$ & 525 & 725 & 865 \\
\hline $2.5 \mathrm{E}-4$ & 1,560 & 2,155 & 2,565 \\
\hline $1 \mathrm{E}-4$ & $3,000+$ & $3,000+$ & $3,000+$ \\
\hline \multicolumn{4}{|c|}{ Depth of Soil Cover (Baseline $=9$ feet) } \\
\hline 8 feet & 850 & 1,140 & 1,340 \\
\hline 12 feet & 625 & 940 & 1,180 \\
\hline 16 feet & 415 & 735 & 1,035 \\
\hline \multicolumn{4}{|c|}{ Rebar Size (Baseline $=\# 8$ ) } \\
\hline$\# 6$ & 155 & 460 & 680 \\
\hline$\# 7$ & 470 & 770 & 985 \\
\hline$\# 9$ & 1,190 & 1,380 & 1,600 \\
\hline$\# 11$ & 1,950 & 2,185 & 2,340 \\
\hline$\# 18$ & $3,000+$ & $3,000+$ & $3,000+$ \\
\hline \multicolumn{4}{|c|}{ Depth of Concrete Cover Over Rebar (Baseline $=23 / 8 "$ ) } \\
\hline $1 \frac{1}{2 n}$ & 800 & 1,100 & 1,300 \\
\hline $3^{\prime \prime}$ & 775 & 1,075 & 1,290 \\
\hline \multicolumn{4}{|c|}{ Concrete Strength (Baseline $=4,750 \mathrm{psi}$ ) } \\
\hline 3,000 psi & 790 & 1,080 & 1,300 \\
\hline 6,000 psi & 790 & 1,080 & 1,300 \\
\hline
\end{tabular}

$A{ }^{~}+"$ indicates that the event did not occur prior to the end of the simulation. 
Table 12. Summary of LAW Vault Sensitivity Analyses

\begin{tabular}{|c|c|c|c|c|c|}
\hline \multirow[t]{2}{*}{ Scenario } & \multirow{2}{*}{$\begin{array}{c}\text { Cracks } \\
\text { Penetrate } \\
\text { Roof } \\
\end{array}$} & \multicolumn{3}{|c|}{ Cracks Penetrate Walls } & \multirow{2}{*}{$\begin{array}{c}\text { Roof } \\
\text { Collapse }\end{array}$} \\
\hline & & Top & Mid-Height & Bottom & \\
\hline Baseline & 1,420 & 2,015 & 2,235 & 2,300 & 3,110 \\
\hline $\begin{array}{l}\text { Beam/Roof \& } \\
\text { Walls }\end{array}$ & \multicolumn{5}{|c|}{$\begin{array}{l}\text { Hydrogen Evolution Corrosion Rate } \\
\text { (Baseline }=8 \mathrm{E}-5 / 5 \mathrm{E}-4 \mathrm{~cm} / \mathrm{yr} \text { ) }\end{array}$} \\
\hline $1.5 \mathrm{E}-4 / 1 \mathrm{E}-3$ & 710 & 1,010 & 1,150 & 1,150 & 1,600 \\
\hline $1.15 \mathrm{E}-4 / 7.5 \mathrm{E}-4$ & 950 & 1,350 & 1,550 & 1,550 & 2,100 \\
\hline $4.5 \mathrm{E}-5 / 2.5 \mathrm{E}-4$ & 2,820 & 4,000 & 4,480 & 4,550 & 5,400 \\
\hline $1 \mathrm{E}-5 / 1 \mathrm{E}-4$ & 6,900 & 9,750 & $10,000+$ & $10,000+$ & $10,000+$ \\
\hline \multicolumn{6}{|c|}{ Depth of Soil Cover (Baseline $=9$ feet) } \\
\hline 8 feet & 1,420 & 2,100 & 2,360 & 2,410 & 3,290 \\
\hline 12 feet & 1,420 & 1,900 & 2,185 & 2,235 & 2,610 \\
\hline 16 feet & 1,420 & 1,730 & 2,050 & 2,115 & 2,060 \\
\hline Walls/Roof Slab & \multicolumn{5}{|c|}{ Rebar Size (Baseline $=\# 10 / \# 6)$} \\
\hline$\# 7 / \# 5$ & 1,120 & 1,100 & 1,325 & 1,400 & 3,110 \\
\hline \#9/- & - & 1,700 & 1,940 & 2,000 & 3,110 \\
\hline$\# 14 / \# 8$ & 2,020 & $(3,150)$ & $(3,410)$ & $(3,450)$ & 3,110 \\
\hline$\# 18 / \# 14$ & $(3,800)$ & $(4,440)$ & $(4,710)$ & $(4,750)$ & 3,110 \\
\hline \multicolumn{6}{|c|}{ AASHTO Beam Size (Baseline = Type IV) } \\
\hline Type III & 0 & 2,015 & 2,235 & 2,300 & 2,700 \\
\hline Type V & 1,420 & 2,015 & 2,235 & 2,300 & 3,430 \\
\hline \multicolumn{6}{|c|}{ Depth of Concrete Cover Over Rebar (Baseline $=23 / 8$ ") } \\
\hline $11 / 2^{\prime \prime}$ & 1,420 & 2,015 & 2,250 & 2,300 & 3,110 \\
\hline $3 "$ & 1,415 & 2,015 & 2,250 & 2,300 & 3,110 \\
\hline \multicolumn{6}{|c|}{ Concrete Strength (Baseline $=4,750 \mathrm{psi}$ ) } \\
\hline $3,000 \mathrm{psi}$ & 1,420 & 2,015 & 2,235 & 2,300 & 3,110 \\
\hline $6,000 \mathrm{psi}$ & 1,420 & 2,015 & 2,235 & 2,300 & 3,110 \\
\hline
\end{tabular}

A " +" indicates that the event did not occur prior to the end of the simulation. Values in parentheses 0 indicate that roof collapse will occur prior to the indicated crack penetration. 
Table 13. Summary of Baseline Results Assuming High-pH Concrete

\begin{tabular}{|c|c|c|}
\hline Vault & $\begin{array}{c}\text { Cracks Penetrate Roof } \\
\text { (years) }\end{array}$ & $\begin{array}{c}\text { Roof collapse } \\
\text { (years) }\end{array}$ \\
\hline ILNT & 1,200 & 1,840 \\
\hline ILT & 1,375 & 2,225 \\
\hline LAW & \multicolumn{2}{|c|}{ Not Available } \\
\hline
\end{tabular}




\section{REFERENCES}

Asquith, S. 1993. Personal Communication. Conversation June 29, 1993 between Jim L. Lolcama of INTERA, Inc. and Shawn Asquith of Rust E and I.

Atkinson, A. and Hearne, J.A. 1984. "An Assessment of the Long-Term Durability of Concrete in Radioactive Waste Repositories". AERE-R11465, Harwell, UK.

Crank, J. 1975. The Mathematics of Diffusion. Oxford University Press, Oxford.

Das, B.M. 1985. Principles of Geotechnical Engineering. PWS Puvliahwea, Boston, MA. 571p.

Dicke, C. 1993. FAX of 3/29/93.

Furlong, R.W. 1991. Reinforced Concrete Personal Computer Design Handbook. Prince, Davidson, \& Wilson. Austin, TX. 77 pages.

Furlong, R.W. 1993. "Uniform Loading of Rectangular Flat Plates." Unpublished correspondence, June 3, 1993.

Grauer, P., Knecht, B., Kreiss, P. and Simpson, J.P. 1991. "Hydrogen Evolution from Corrosion of Iron and Steel in Intermediate Level Waste Repositories." Material Research Society Symposium Proceedings 212:295-302.

Hansson, C.M. 1985. "The Corrosion of Steel and Zirconium in Anaerobic Concrete." Material Research Society Symposium Proceedings 50:475-482.

Harrison, W.H. and Teychenne, D.C. 1981. Sulphate Resistance of Buried Concrete: Second Interim Report on Long Term Investigation at Northwick Park. Building Research Establishment, Her Majesty's Stationery Office, London.

Marine, I.W. 1976. Geochemistry of Groundwater at the Savannah River Plant. DP-1356. September, 1976. E. I. du Pont de Nemours and Company, Savannah River Laboratory, Aiken, SC.

Marsh, G.P. and Taylor, K.J. 1988. "An Assessment of Carbon Steel Containers for Radioactive Waste Disposal." Corrosion Science 28.3:289-320.

McEnroe, B.M. 1993. "Maximum Saturated Depth Over Landfill Liner." Journal of Environmental Engineering 119.2.

Morley, J. 1986. "Corrosion of Steel Foundation Caissons from the Old Redheugh Bridge in Newcastle upon Tyne." British Corrosion Journal 21.3:177-183. 
Nawy, E.G. 1989. Prestressed Concrete Computer Programs in BASIC. Prentice Hall. New Jersey.

Seitz, R.R. 1993. FAX of March 22, 1993.

Tindal Concrete. 1993. "Design Calculations for LAW Vault Expansion Modules Two and Three. Prepared for the United States Department of Energy, Savannah River Site. February 12, 1993, P.O. AA98143C, Project S-2890/4466, Job No. 52-106.

Walton, J.C. 1993. "E-Area Vault Effective Permeability and Reinforcement Corrosion". Unpublished correspondence, July 6, 1993.

Walton, J.C. 1993. "Degradation of Reinforced Concrete." Unpublished.

Walton, J.C. and Dicke, C. 1993. "E-Area Notebook for ILNT/ILT Vaults: Degradation Calculations, (4-13-93) latest mix design data." .

Walton, J.C., Plansky, L.E. and Smith, R.W. 1990. Models for Estimation of Service Life of Concrete Barriers in Low-Level Radioactive Waste Disposal. Idaho National Engineering Laboratory. NUREG/CR-5542, EGG-2597.

57 


\section{ACRONYMS AND ABBREVIATIONS}

ACI

$\mathrm{cm}$

$\mathrm{C}_{3} \mathrm{~A}$

American Concrete Institute

EAV

$\mathrm{ft}$

in centimeter

tri-calcium aluminate

E-Area Vaults

feet

inch

IINT intermediate-level non-tritium

IIT intermediate-level tritium

INEL

kip

Idaho National Engineering Laboratory

1,000 pounds

ksi

LAW

1,000 pounds per square inch

low-activity waste

LLWSB

Long-Lived Waste Storage Building

$\mathrm{m}$

meter

$\mathrm{mm}$

millimeter

ppm

parts per million

psi

$s$

pounds per square inch

second

SRS

WSRC

Savannah River Site

yr

Westinghouse Savannah River Company

year 


\section{APPENDIX: QUALITY ASSURANCE}

This Appendix is divided into three parts. First, the implementation of the Project Quality Assurance Plan is discussed. Next, the letter report describing INTERA's plan and procedures for software and technical reporting quality assurance for the E-Area Vaults Degradation Study is provided. Finally, forms used in maintaining Quality Assurance Control during the project are provided.

\section{A.1 IMPLEMENTATION OF THE PROJECT QUALITY ASSURANCE PLAN}

The RCPC.DHelper models (Furlong, 1991) used as the basis for the structural analysis portion of this study are available commercially through the American Concrete Institute Software Sales Department. The programs have been in use for the past 4 years by approximately 300 engineering offices.

The RCPC computer software for the analysis of reinforced concrete structures has formed the basis for this project. This software has been validated by the author. The software is divided into five main subroutines which do not interact, with each subroutine appropriate for a particular application. For the E-Area Vaults, the "Continuous Beams" program was utilized. This program was tested by using a sample data set available in the manual (Furlong, 1991), and comparing the computed results with results printed in the manual. All results were identical. Another program, NAWY10, was used to analyze the time-dependant loss of prestress in the AASHTO beams. In the same way, a sample data set available in the manual (Nawy, 1989) was used for testing the program. Computed results matched results printed in the manual.

There were four main revisions to the RCPC code:

1. Original program was designed for screen-based input and output. In order to facilitate the multiple runs necessary for the sensitivity analysis and calculation of stress levels through time, the program was modified to utilize file-based input and output.

2. Degradation subroutine was added.

3. A time loop was added to recursively calculate the vault condition through time.

4. For the LAW vault case, a section was added to compute the stress due to curvature and the depth of the neutral axis in the roof slab.

After the code was modified to utilize file-based input and output, an additional test was performed using the manual-supplied input and output. In addition, a data set was created appropriate for the E-Area Vaults. This data set was run in both the original model and in the modified model. Again, all results were identical. 
Next the degradation subroutine and time loop were added. Degradation model components included:

- Time to depassivation of rebar.

- Oxic corrosion of rebar.

- Anoxic ("hydrogen-evolution") corrosion of rebar.

- Sulfate attack.

- Calcium hydroxide leaching.

- Carbonation.

- Calculation of fracture aperture and spacing.

Testing of this modification consisted of two phases. First, results of the degradation model were compared to results obtained by modeling performed at INEL. There were extremely slight differences between INEL model results and INTERA results, easily attributed to rounding error. Next, testing was performed on the structural component of the code. The time zero results for the code were compared to the results obtained from the unmodified RCPC code. Because no degradation has taken place at time zero, these results should be, and were, the same. For the LAW vault modifications to calculate stress due to curvature in the roof, testing was performed by comparing model results to spreadsheet calculations.

All changes are documented in detail within the modified code, both at the point of modification and, in chronological order, at the top of the code.

Performance and Design Specifications were generated for the modifications to the RCPC.DHelper code, in order to incorporate concrete degradation, and were established as controlled documents (i.e., they were approved by the program manager and quality assurance manager and had a control date assigned). Performance and Design Specifications for RCPC.DHelper and NAWY10 were taken from the documentation for these codes and established as controlled documents. Performance Specifications for both acquired codes and modifications included the following components:

- a general description of RCPC.DHelper, NAWY10, and modifications to the RCPC.DHelper code, and the intended use of information expected from the codes, including relevant contract specifications.

- a description of physical and chemical phenomena accounted for and any important phenomena neglected.

- statement of relevant mathematical equations and derivations. 
- statement and rationalization of applicable assumptions, limitations and simplifications.

- a general description of the type of output information.

- a general description of the type of input information.

- references.

Design Specifications for both acquired codes and modifications included the following components:

- Description of numerical techniques used to solve governing equations.

- Statement of relevant discretized (or otherwise transformed for numerical solution) equations and derivations.

- Statement and rationalization of applicable assumptions and limitations.

- Description of the structure and organization of the computer programs, including logic flow.

- Description of program input and output.

- Description of code/system interfaces.

- Glossary of model variables.

RCPC.DHelper and NAWY10 software was baselined (i.e., entered into the Control File Index at our Austin, TX headquarters). Modifications to software were identified, documented, and tracked through the Control File Index. All data and results which were used in formal code testing and applications were baselined. The project report was baselined and subjected to internal (i.e., within INTERA) review before being submitted to WSRC. The review was documented in the form of required changes, recommended changes and other observations, in writing on a copy of the draft document. After changes were made in response to the internal review, the report was again baselined and submitted to WSRC with the subtitle "Draft Report." All comments in response to WSRC review were received verbally only. Therefore, INTERA prepared a memo summarizing the review comments and distributed copies to WSRC and to the Control File Index at INTERA headquarters. After response to WSRC comments was completed, the report was again baselined and submitted to WSRC as the final report for this Task \#7. 


\section{A.2 PROJECT QUAITTY ASSURANCE PLAN}

Mr. Shawn Reed

WSRC

Savannah River Technology Center

Solid Waste Engineering

\#742-7G

Aiken, SC 29802

May_20, 1993

Re: Quality Assurance Procedures for Software and Technical Reports_Under Contract \#AA20180P-Task Order 7

Dear Mr. Reed:

The following letter report describes INTERA's plan and procedures for software and technical reporting quality assurance for the E-Area Vaults Degradation Study. This letter report is intended to satisfy Paul Lowe's request at the May 10 status meeting for a summary QA plan for the structural analysis software currently being used on this project and report deliverables. Software for this project has been developed primarily outside of INTERA. The software is two structural analysis codes for concrete structures obtained from the University of Texas at Austin and Rutgers University. Through a co-operative effort between the code authors and INTERA-AUGUSTA the codes are currently being modified to allow, (1) input of concrete thickness and re-bar spacing, (2) the use of file handling for input and output rather than the interactive default mode, and (3) chemical degradation of the reinforced concrete.

The QA plan and procedures for computer software and report deliverables have been taken from INTERA's Project Quality Assurance Manual prepared for the Westinghouse Savannah River Company (Draft; December 20, 1990). This NQA-1 manual has been submitted for approval with WSRC, however this approval is pending. We anticipate a review of the manual prior to the end of the current fiscal year.

\section{PART_A_PROJECT QUALITY ASSURANCE PLAN}

Quality assurance calls for baselining software and supporting documentation through the assignment of Control Identification Numbers (CIN's) and entry into the project Control File Index (CFI). The QA plan requires, for codes developed outside of INTERA, review, verification, validation (when possible) and documentation of software modification activities. Changes to baselined software shall also be identified and tracked through the CFI and shall be subject to review, approval, verification and validation as appropriate. Changes to baselined software shall require documentation and this documentation shall be entered into the CFI. In addition, procedures for the revision of baselined software shall require 
identification of any baselines which might require changes as a result of the revision, and that users of affected software be notified of any revisions.

INTERA shall verify the suitability of previously developed computer codes by:

1. Reviewing previous applications of the code(s);

2. Performing a validation of the code(s) for the contract application by inputing data representative of the application;

3. Exercising the code(s) under expected use conditions; and

4. Evaluating the limitations of the code(s).

Results of the validation process shall be documented and entered into the project CFI. A summary report of the results shall be provided to the client.

The structural analysis code(s) adapted for this project are considered proprietary to the author, Dr. Richard Furlong, University of Texas at Austin and Dr. Edward Nawy, Rutgers University. The source code and documentation have been provided to INTERA for adaptation and use on this project without cost to WSRC.

\section{PART B PROJECT QUALITY ASSURANCE PROCEDURES}

\section{TITLE: QA Control File and Index}

The INTERA - AUGUSTA staff will be responsible for preparing and documenting records that will enter the QA Control File at our Corporate Headquarters in Austin. We will also be responsible for filing QA documents and documentation of client communications with the QA Administrator in Austin.

The INTERA - AUSTIN QA Administrator will be responsible for reviewing control documents, maintaining proper records storage, and maintaining the Control File Index.

\section{TITLE: Baselining and Revising Baselined Specifications}

Performance, Design, and Test Specifications shall be baselined for the major codes acquired and applied on this project. 
When revising a code, Performance, Design, and Test Specifications shall be developed, baselined, and established as controlled documents (i.e., be approved by the program manager and quality assurance manager and have a control date assigned).

An example of a QA Control Document which shall be completed for Specifications has been included as an attachment.

\section{THFE: Baselining and Revising Baselined Codes}

All structural analysis codes shall be documented following acquisition for the project and during modification and testing. The documentation of the unmodified code(s) shall include: Test Data, Test Results, Validation History (if any), Code Abstract and Users Manual. Modifications which are completed by INTERA-AUGUSTA to the codes to allow, (1) the use of file handling for input and output rather than the interactive default mode, and (2) chemical degradation of the reinforced concrete will be documented with brief performance specifications, design specifications, and a comparison of the code output with empirical results from INEL.

In addition, each code should be accompanied by the following documentation, as appropriate: Code Name and Version Number, Brief Description of Code, Original Source Code and Original Author(s), Brief History of Major Modifications, Proprietary Details, Disclaimer, Language and Level, Machine Where Operative, and References.

An example of a QA Control Document which shall be completed for Computer Codes has been included as an attachment.

\section{TITLE: Baselining and Revising Baselined Test, Application and Other Data}

All data which are to be used in formal (i.e., documented) code testing or in code applications shall be baselined. Data should be characterized in detail. The documentation should include, at a minimum, the following: source and method of acquisition, appropriateness for the intended model application, and derivation of input data (processed data) from raw data.

All test and application data baselines shall be written to diskette with copies furnished to the QA Administrator.

Baseline data shall be revised as necessary to correct problems or to improve/ensure quality. Revised baselines shall include justification for the revision.

An example of a QA Control Document which shall be completed for Test/Application/Other Data has been included as an attachment. 


\section{TTTLE: Baselining and Revising Baselined Test Results}

All output data from the code testing phase shall be baselined. Testing of the unmodified structural analysis codes shall be limited to execution of the test problem provided with the code on the PC with which the structural analysis is to be completed. A formal review by the project engineer of the Test Results shall be completed to ensure the accuracy of the installed code.

Testing of the code modifications concerning deterioration of the reinforced concrete shall be limited to accurate reproduction of empirical data provided by INEL. Formal testing shall be reviewed by person(s) not involved in the modification of the code(s). Test Results shall be analyzed for satisfaction of Test Specifications.

The Test Results, and the analyses thereof, must be documented and baselined. A print-out of the Test Results and the Test Data shall be filed with the QA Administrator when Results are baselined.

An example of a QA Control Document which shall be completed for Test/Application Results has been included as an attachment.

\section{TITLE: Baselining Application Results}

The results of all code applications to be transmitted outside of, or relied upon by, INTERA or which yield significant information about the code's capabilities or limitations, or about measured data, or about the system or process being modeled shall be baselined.

Where possible input data should be printed in conjunction with the corresponding Application Results output. A copy of the Application Results and Application Data shall be filed with the QA Administrator when results are baselined.

\section{TITLE: Baselining and Revising Baselined Technical Reports and Code Documentation}

All Reports which are considered deliverables shall be baselined before transmission outside of INTERA. Code Documentation shall be baselined for internal control. For proprietary reasons, these Baselines will not be allowed outside of INTERA.

Topical Reports and Letter Reports which are specified as contract deliverables shall undergo formal technical review. Baselined reports shall be revised as necessary to correct problems, improve quality, or expand scope. 
An example of a QA Control Document which shall be completed for Report/Code Documentation has been included as an attachment.

\section{TITLE: Technical Reviews}

Each Technical Report, Model Documentation Report, Letter Report, or other document containing technical information that is a project deliverable prepared to satisfy contract requirements shall be the subject of one of more technical reviews before being transmitted outside INTERA.

Documents and data shall be baselined before being submitted for technical review.

Reviews of reports and other documents should consider, as a minimum, the following items:

- Organization, clarity, and conciseness of the material presented;

- . Correctness of any assumptions that are made;

- $\quad$ Adequacy of the discussion of variables;

- Validity of the conclusions and recommendations;

- Adequacy of illustrations, graphs, tabular data, etc.; and

- Appropriate acknowledgement of contributions and referenced material.

Reviews shall be documented with written comments in the form of required changes, recommended changes, and other observations. The review shall also document the material being reviewed (title or description), the author of the material, date of the review, and persons performing the review.

Review comments must be stated in terms which will clearly convey the meaning of the comment to others knowledgeable on the subject.

Review comments may be in the form of annotations on the document being reviewed if the comment can be adequately recorded in this manner. When such annotation is inadequate or inappropriate, the comment(s) shall be recorded on separate sheets.

Each review comment shall be responded to and resolved and the response/resolution shall be documented. When review comments are recorded on the document being reviewed, responses may also be recorded on the document.

All review comments recorded on separate sheets shall be responded to either on the review sheets or on separate sheets.

Editorial recommendations may be acknowledged in summary fashion, e.g., "implemented where possible". 
When the technical reviewer is unable to accept the task manager's response to one or more required changes, the program manager shall be called upon to resolve the issue unless the program manager is involved in the disagreement, in which case one of the program manager's peers shall resolve the issue.

An example of a QA Control Document which shall be completed for Technical Reviews has been included as an attachment.

cc: Paul Lowe

Jim Cook

Keith Dykes 
$00 / 00 / 00$

QA CIN:

$\frac{L---1-|--|-|---|-\mid}{\text { YY } M M \text { D D }}$

Control Date (OAAA Only):

\begin{tabular}{|l|l|l|}
\hline-- & -- & - \\
\hline
\end{tabular}

\section{SPECIFICATION BASELINE}

$\square$ Original Baseline (Complete Section 1 only)

$\square$ Revision to Previous Baseline (Complete Sections 1 and 2)

Project Title:

Project Number:

Contract No.:

CFI Description:

\section{Section 1 - Baseline}

1. Code Name:

Code CIN:

2. Source (Check one and complete):

This $\square$ baseline $\square$ revision was developed by:

Signature/Printed Name.

This $\square$ baseline $\square$ revision was acquired from:

Printed Name/Organization

3. Specification Type (check one only):

$\square$ A. Peformance Specs.

$\square$ B. Design Specs.

$\square$ D. Test Spers.

4. Reference and Location of Specification (ff not attached):

5. Cross-Reference to other Specifications for this code: (where possible):

QA CIN

QA CIN
Control Date:

Control Date: 
QA CIN:

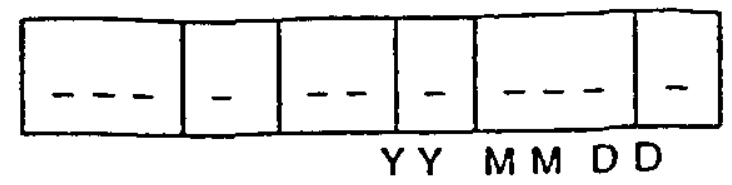

Control Date (OAAA Only):

\section{Section 2-Baseline Revision}

1. Reason for Revision:
a.
Response to Review
QA CIN:
Control Date:
b. $\square$ Problem Report/ QA CIN:
Control Date:
c. $\square$ Code Enhancement
d. $\square$ Other:

2. Description of Revision:

3. Baselines which may require revision as a result of this revision:

Recommended by: PM

Approved by: OAM
Date:
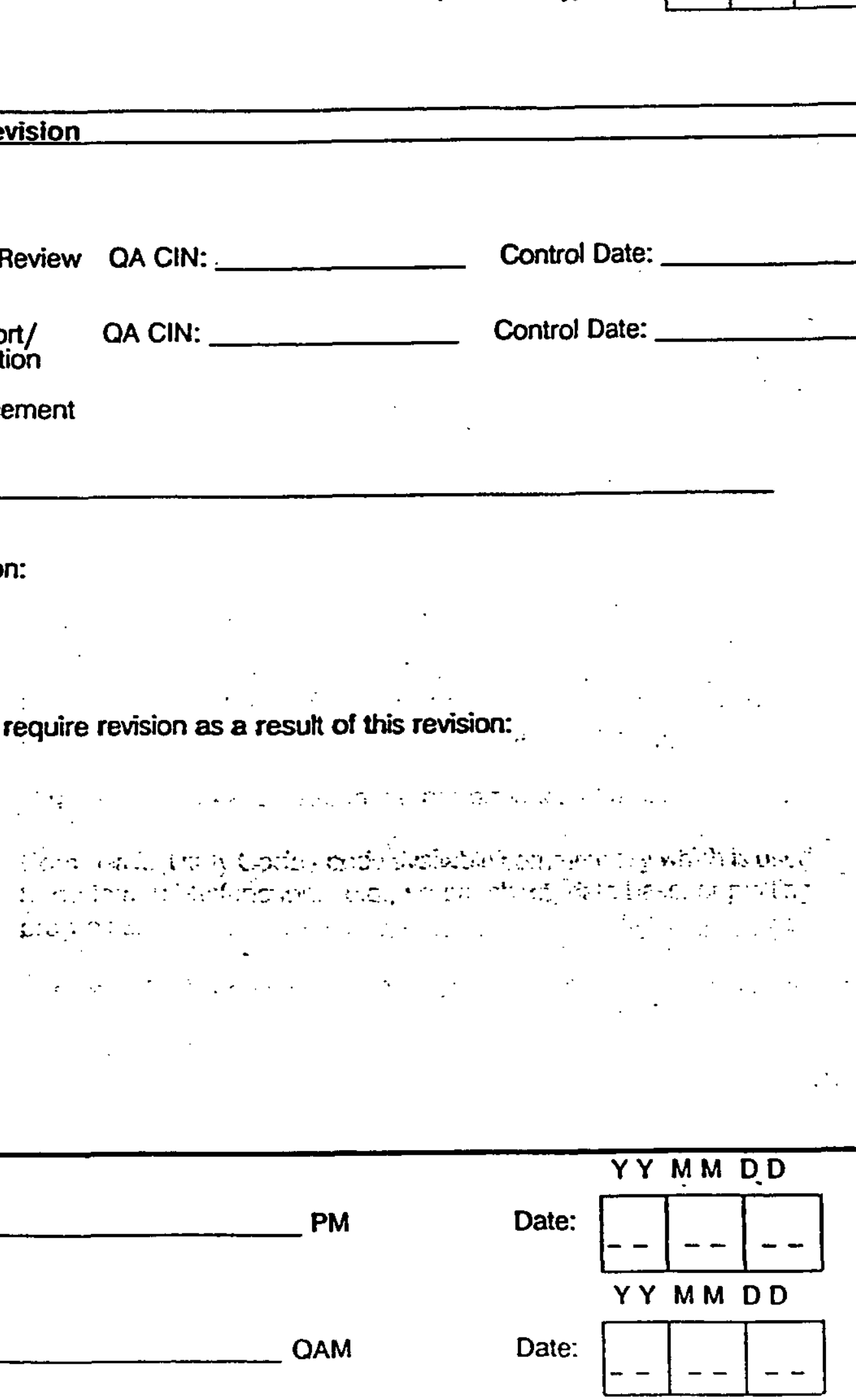
OA Control Document

$08 / 15 / 90$

QA CIN:

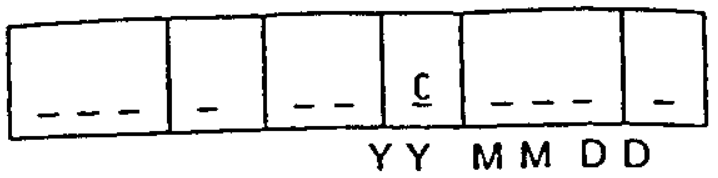

Control Date (OAAA Only):

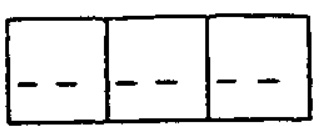

\section{CODE (C)}

$\square$ Original Baseline (Complete Section 1 only)

$\square$ Revision to Baseline (Complete Sections 1 and 2)

Project Name:

Project Number:

Contract No.:

CFI Description:

\section{Section 1: Code Baseline}

1. Code Name:

$\square$ Major Code $\square^{\text {Minor Code } \quad \square \text { Commercial Utility Code }}$

2. Source (check one and complete):
a. This
$\square$ baseline
revision was developed by:
Signature(s)/Printed Name
b. This $\square$ baseline revision was acquired from:

3. References:
a. $\square$ Performance Specs. QA CIN:
Control Date:
b. $\square^{\text {Design Specs. }}$
QA CIN:
Control Date:
c. $\square^{\text {Test Specs. }}$
QA CIN:
Control Date:
d.
Test Data
QA CIN:
Control Date:

e. $\square$ Test Results

OA CIN: Control Date:

5. Hardware:
a. $\square^{\mathrm{PC}}$
b. $\square$ Other (Specity):
c. Special Requirements:

6. Compiler/Linker Options:
a. $\square$ FORTRAN
a.
PASCAL
c. $\square$ Other (Specify):
d. Compiler \& Options: e. Linker \& Options: 
OA Control Document

$08 / 15 / 90$

OA CIN:

\begin{tabular}{|c|c|c|c|c|c|}
\hline-- & - & - & - & $\ldots$ & - \\
\hline
\end{tabular}

7. Code Storage:

a. $\square$ Tape Tape No:

Source File Title:

Executable File Title:

Format:

b. $\square$ Disk Disk No:

Source File Titte:

Executable File Title:

Format:

c. $\square$ Other (give details):

\section{Section 2: Code Revision}

1. Reason for Revision:
a. $\square$ Response to Review OA CIN:
Control Date:
b. $\square$ Problem Report/
QA CIN:
Control Date:
c. $\square$ Code Enhancement/Evolution
d. Other:

2. Description of Revision:

3. Baselines which may require changes as a result of this revision:

4. Revision approved by Code Custodian:

Date:

Signature

Recommended by:

PM

Date:

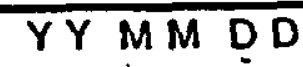

\begin{tabular}{|l|l|l|}
\hline-- & -- & - \\
\hline YY M M DD
\end{tabular}

Approved by:

OAM

Date: \begin{tabular}{|l|l|l|}
\hline-- & -- & -- \\
\hline
\end{tabular} 
QA Control Document

$08 / 15 / 90$

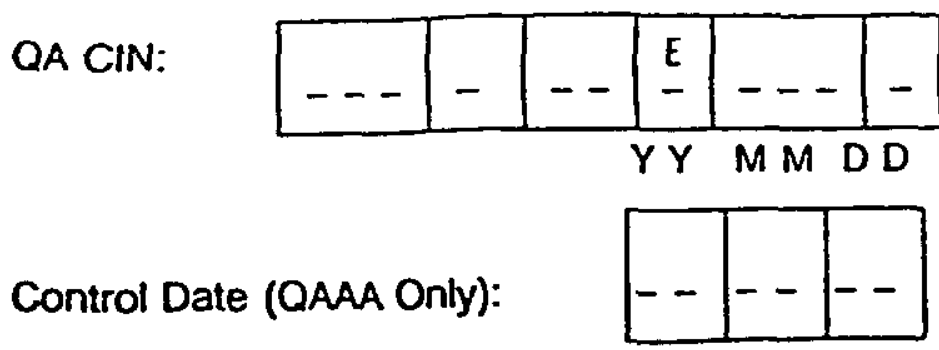

TEST/APPUCATION/OTHER DATA (E)

Original Baseline (Complete Section 1 only)

Revision to Previous Baseline (Complete Sections 1 and 2)

Project Title:

Project Number:

Jontract No.:

SFI Description:

Section 1 - Data Baseline

1. Data Type (check one):

a. $\square$ Test Data Code Name:

b. $\square$ Application Data $\mathrm{QA}$ CIN:

c. $\square$ Library Data

Control Date:

d. $\square$ Generic Data (describe):

2. Source of Data:

a. $\square$ Documented internally by:

Signature/Printed Name

Signature/Printed Name

References made to:

$\square$ Laboratory

$\square$ Field

$\square$ Model

$\square$ Literature

$\square$ Judgement

Reference(s) to source(s) (if not attached):

3. Data Storage

b. $\square$ Acquired From:
a. $\square$ Tape/Disk
i. Tape/Disk Number:
ii. File Names:
iii. Format:

b. $\square^{\text {Other: }}$ 
OA Control Document

$08 / 15 / 90$

QA CIN:

\begin{tabular}{|l|l|l|l|l|l|}
\hline-- & - & -- & - & -- & - \\
\hline
\end{tabular}

4. Data Documentation Description (if not attached):

Section 2: Data Revision

1. Reason for Revision

a.

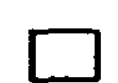
Response to Review

b.

Problem Report/

Corrective Action

c.

Other:
QA CIN:

QA CIN:

Control Date:

Control Date:

2. Description of Revision:

3. Baselines which may require changes as a result of this revision:

\begin{tabular}{|c|c|c|c|c|c|}
\hline \multirow[b]{2}{*}{ Recommended by: } & & \multicolumn{4}{|c|}{$Y Y M M D D$} \\
\hline & - PM & Date: & - - & $\ldots$ & - \\
\hline & & & $Y Y$ & $M M$ & D D \\
\hline Approved by: & OAM & Date: & - & -- & - - \\
\hline
\end{tabular}


QA CIN:

Project Name:

Project Number:

Contract No.:

CFI Description:

\section{Section 1: Test Results}

1. Code Name:

2. Code QA CIN:

3. Test Data QA CIN:

4. Library Data QA CIN: (if applicable)

5. Description of Test(s) (ff not attached):

6. Analysis and Interpretation of Results (if not attached):

7. Storage of Results:
a. $\square$ Tape/Disk
i. Tape/Disk Number:
ii. File Names:
iii. Format:

Control Date:

Control Date:

Control Date: 
OA Control Document

$08 / 15 / 90$

QA CIN:

\begin{tabular}{|l|l|l|l|l|l|}
\hline-- & - & - & - & $-\cdots$ & - \\
\hline
\end{tabular}

8. Test Performed by:

Signature/Printed Name

Date:

9. Results and Analysis Verified by:

Signature/Printed Name

Date:

\section{Section 2: Application Results}

1. Code Name:

2. Code QA CIN:

Control Date:

3. Test Data QA CIN:

Control Date:

4. Test Results QA CIN:

Control Date:

5. Application Data QA CIN:

Control Date:

6. Description of Application (if not attached):

7. Analysis and interpretation of results (ff not attached):

8. Storage of Results:

a. $\square$ Tape/Disk i Tape/Disk Number:

i. File Names:

iii. Format:

b. $\square$ Other:

9. Application Performed by:

Signature/Printed Name

Date:

10. If known, give references to documents where results will be presented:

Description

QA CIN (f known)

a.

b.

c.

Recommended by:

PM

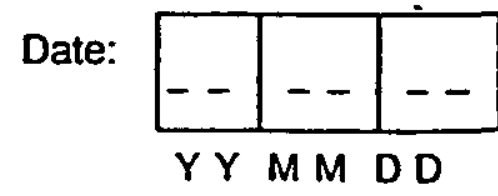

Approved by:

QAM

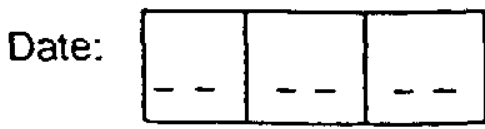


OA Control Document

$08 / 15 / 90$

QA CIN:

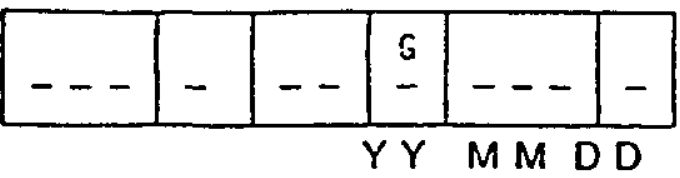

Control Date (QAAA Only):

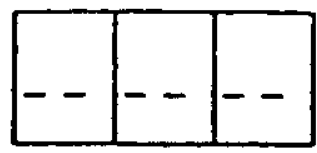

\section{REPORT/CODE DOCUMENTATION (G)}

Original Baseline (Complete Section 1 only)

Revision to Baseline (Complete Sections 1 and 2)

Project Name:

Project Number:

Contract No.:

CFI Description:

\section{Section 1: Baseline}

1. Report Type:
a. $\square$ Topical Report
b. $\square$ Letter Report
c. $\square$ Model Documentation: Code QA CIN:

Control Date:

2. Titie (or Subject):

3. This $\square^{\text {baseline }} \square^{\text {revision was developed by: }}$

Signature/Printed Name

Signature/Printed Name

Signature/Printed Name

4. This $\square$ baseline $\square$ revision was acquired from:

5. References:

Printed Name
a. $\square$ No reference to baselined data or results
b. $\square$ Reference is made to data/results with the following baseline QA CIN's: 
QA Control Document

$08 / 15 / 90$

OA CIN:

\begin{tabular}{|c|c|c|c|c|c|}
\hline-- & - & -- & - & $-\cdots$ & - \\
\hline
\end{tabular}

\section{Section 2: Baseline Revision}

1. Reason for Revision:

a. Response to Review QA CIN:

Control Date:

b. $\square$ Corrective Action

QA CIN:

Control Date:

c. $\square$ Other:

2. Description of Revision:

3. Baselines which may require changes as a result of this revision:

\begin{tabular}{|c|c|c|c|c|c|}
\hline \multirow[b]{2}{*}{ Recommended by: } & \multirow[b]{2}{*}{ PM } & & \multicolumn{3}{|c|}{ YY MM DD } \\
\hline & & Date: & - & -- & -- \\
\hline & \multicolumn{5}{|c|}{$Y Y M M D D$} \\
\hline Approved by: & QAM & Date: & -- & $\ldots$ & \\
\hline
\end{tabular}


QA Control Document

$08 / 15 / 90$

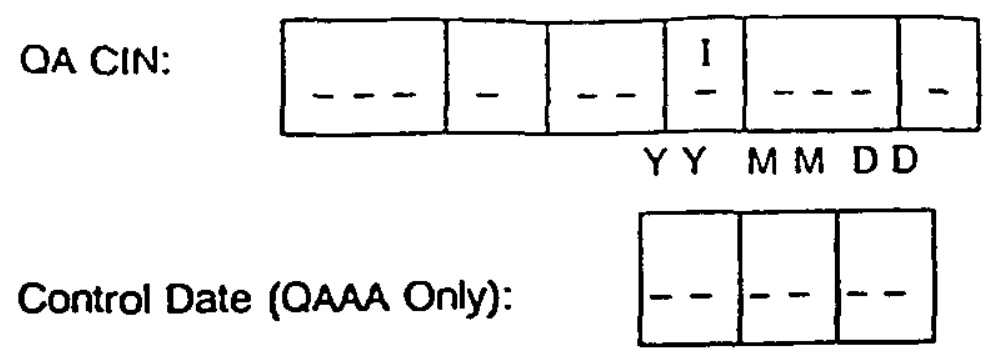

REVIEW (I)

Project Name:

Project Number:

Contract No.:

CFI Description:

1. Title or Description of Baseline Reviewed:

2. Author/Originator:

3. OA CIN of Baseline Reviewed: Control Date:

4. Location of Review Comments:

$\square$ On Document Review Form Reviewed by:

Printed Name/Signature

Date:

5. Brief Review Comments:

YYMM DD

Recommended by: PM

Date:

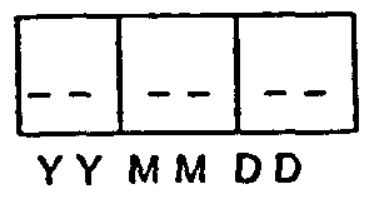

Approved by: QAM

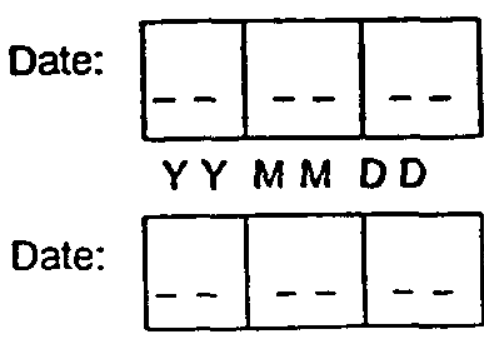




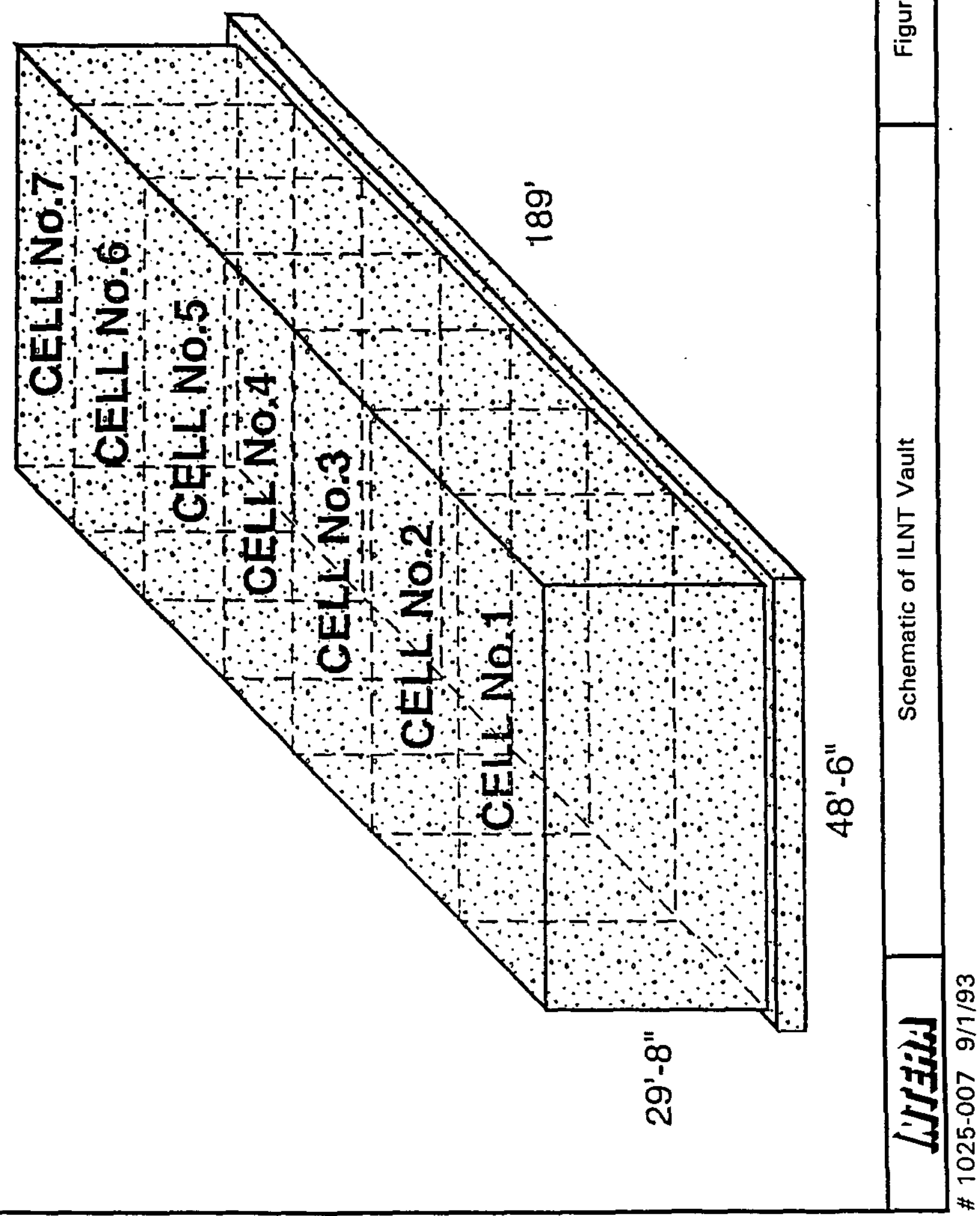




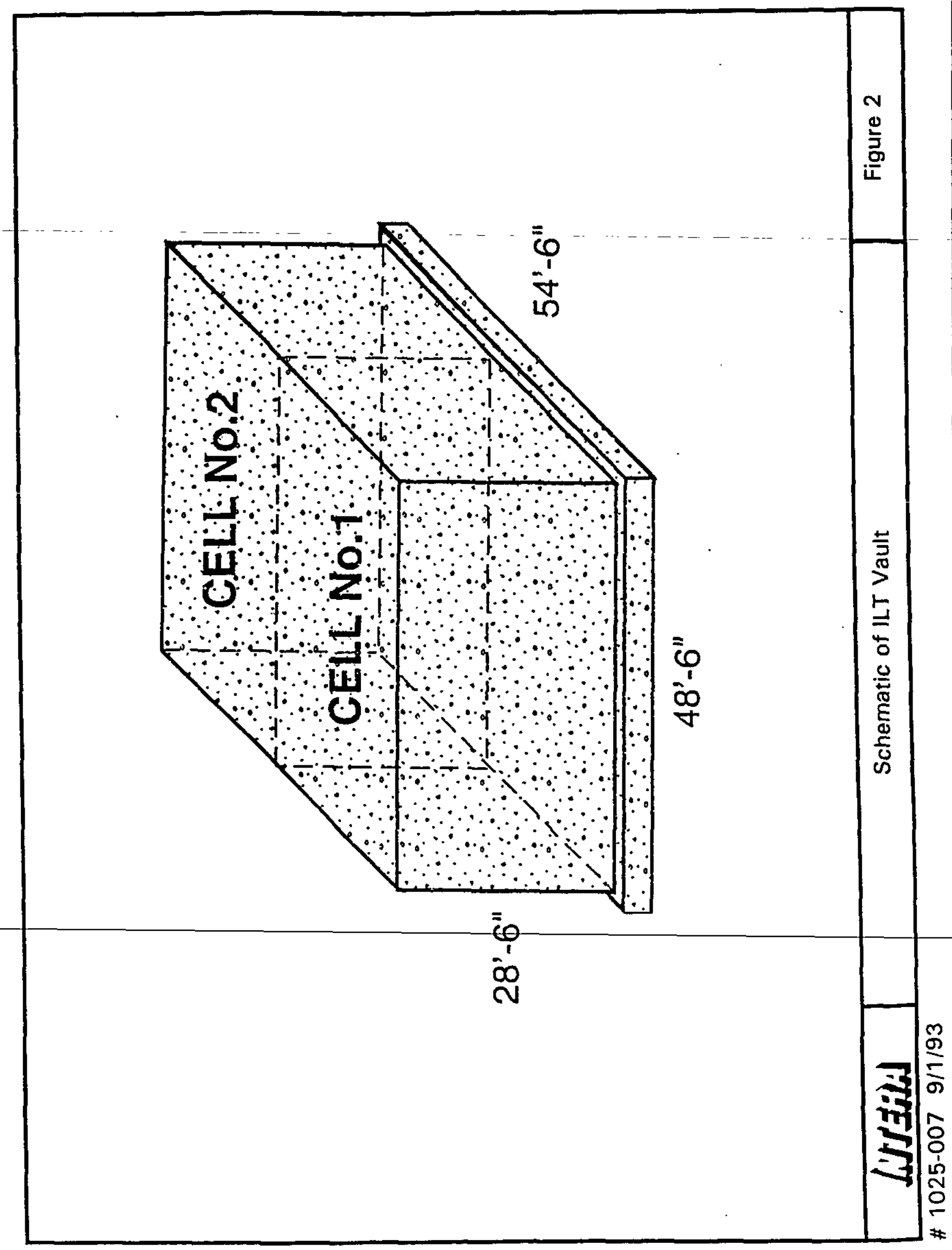




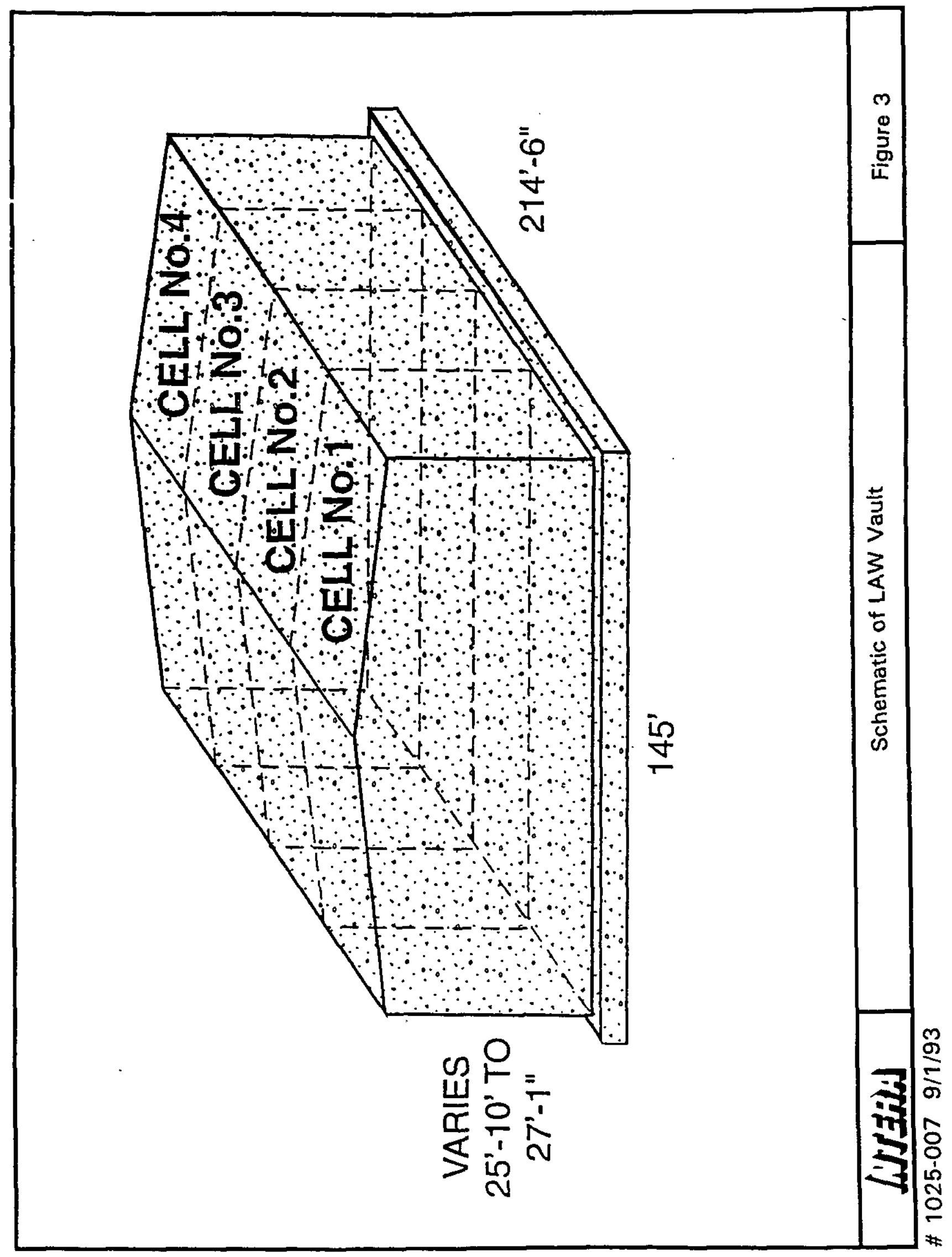




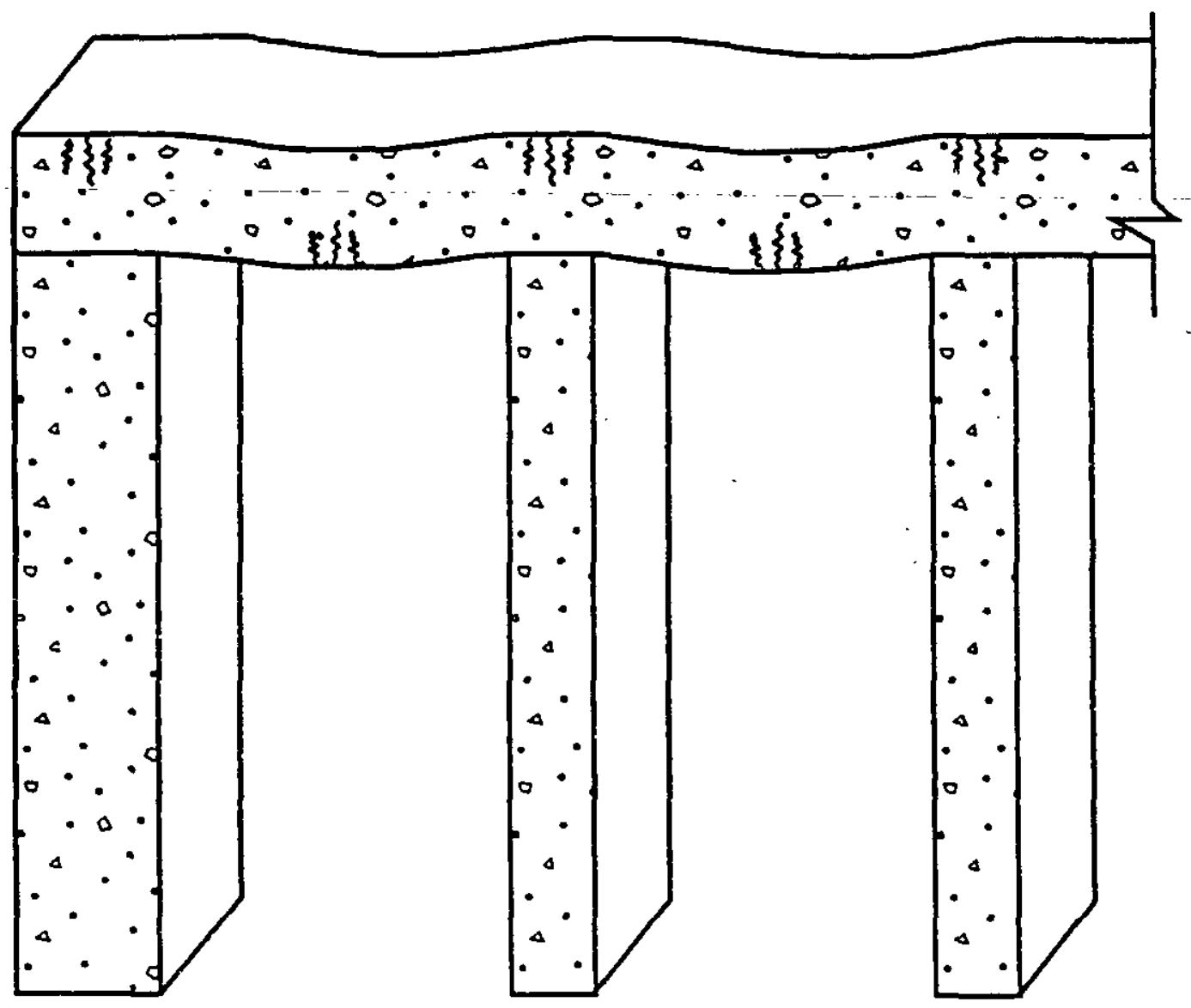

NOT TO SCALE

DEFLECTION HAS BEEN EXAGGERATED FOR EMPHASIS

\begin{tabular}{|l|c|}
\hline DATE: $9 / 7 / 93$ & $\begin{array}{c}\text { Portion of Vault Cross Section; } \\
\text { Cracks Indicate Critical Stress Regions }\end{array}$ \\
\hline REF: \#1025-007 &
\end{tabular}




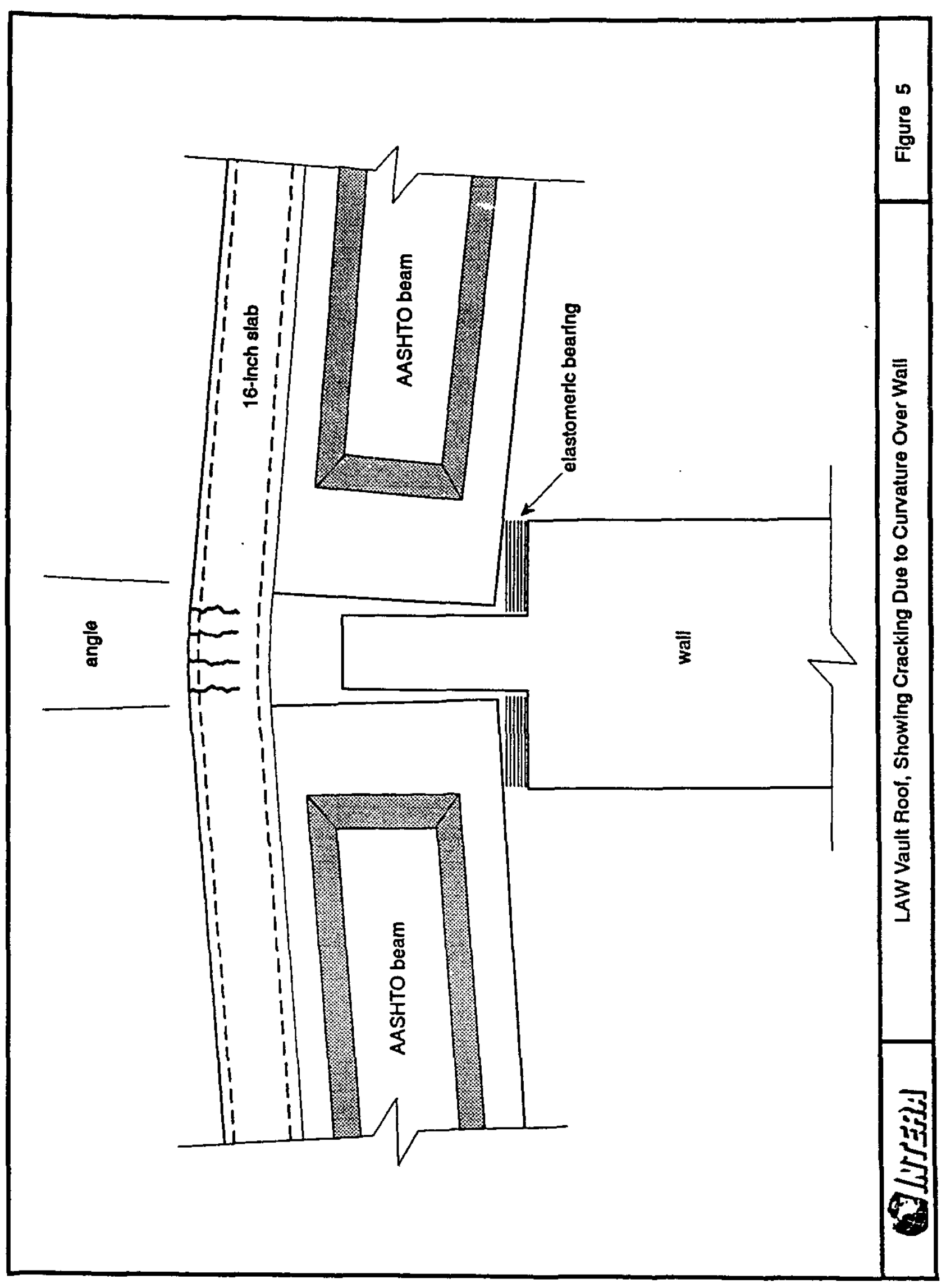




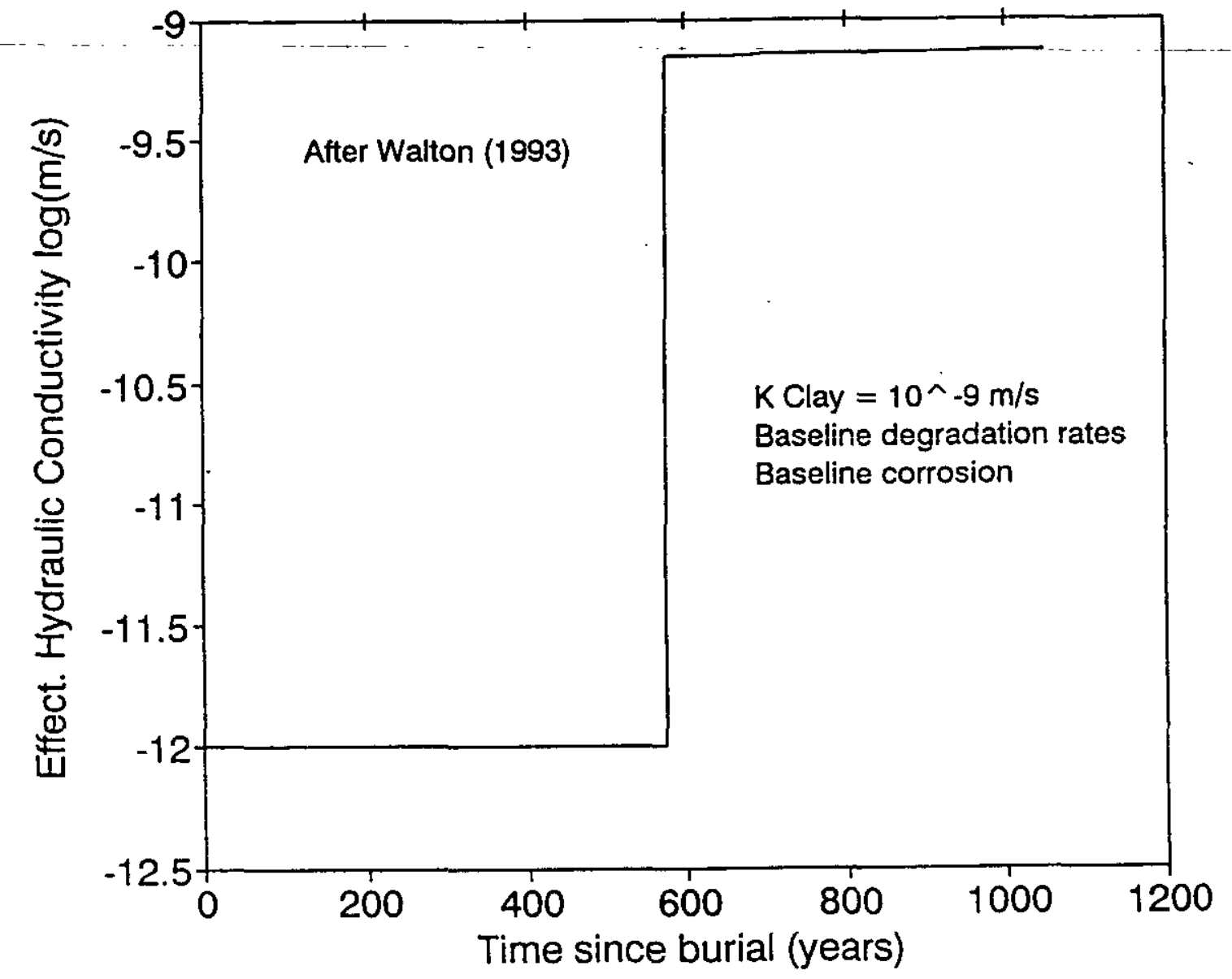

DATE: $9 / 7 / 93$

REF: \#1025-007

Effective Hydraulic Conductivity of Vault Roof; ILNT Vault Design 


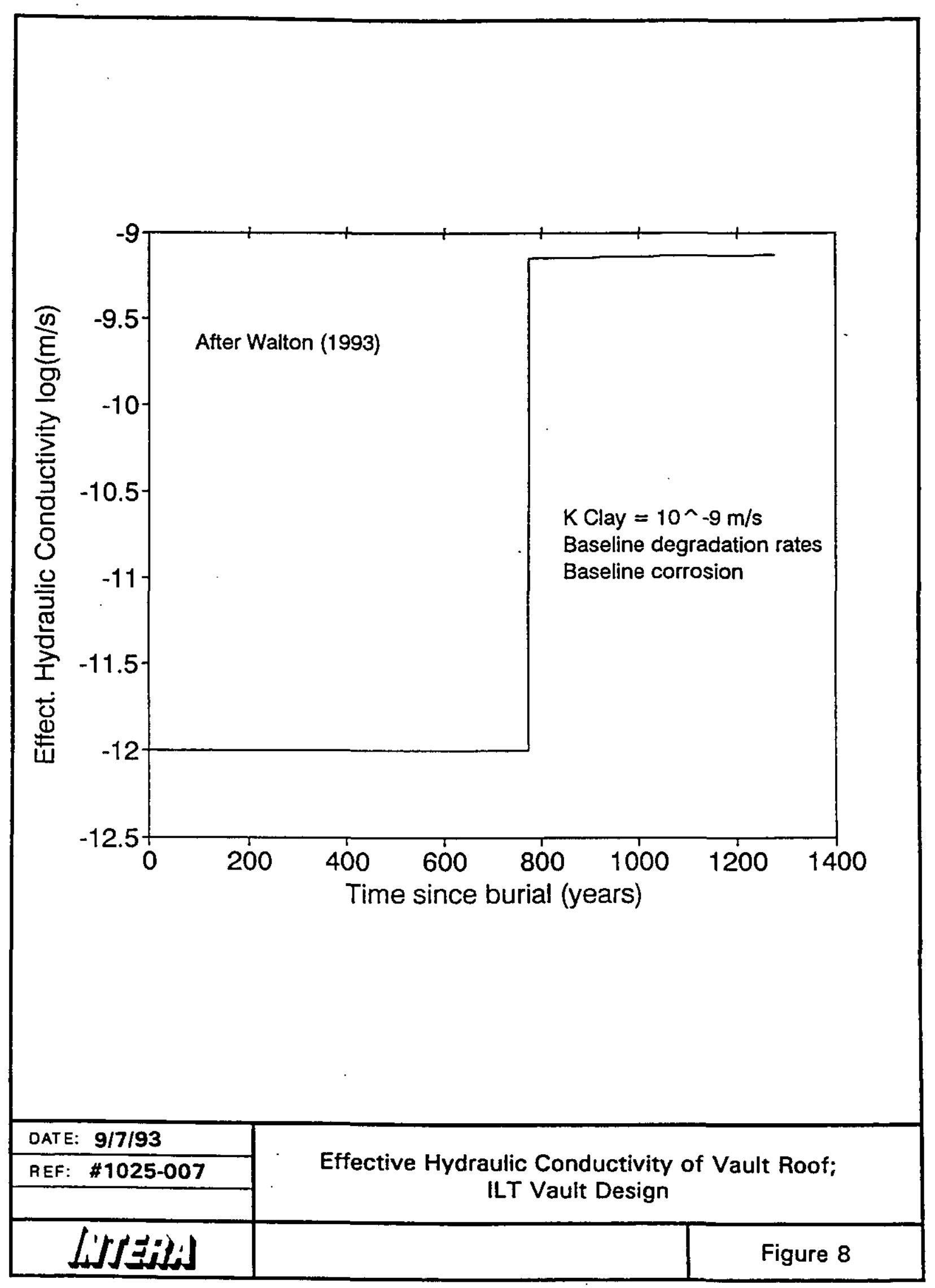




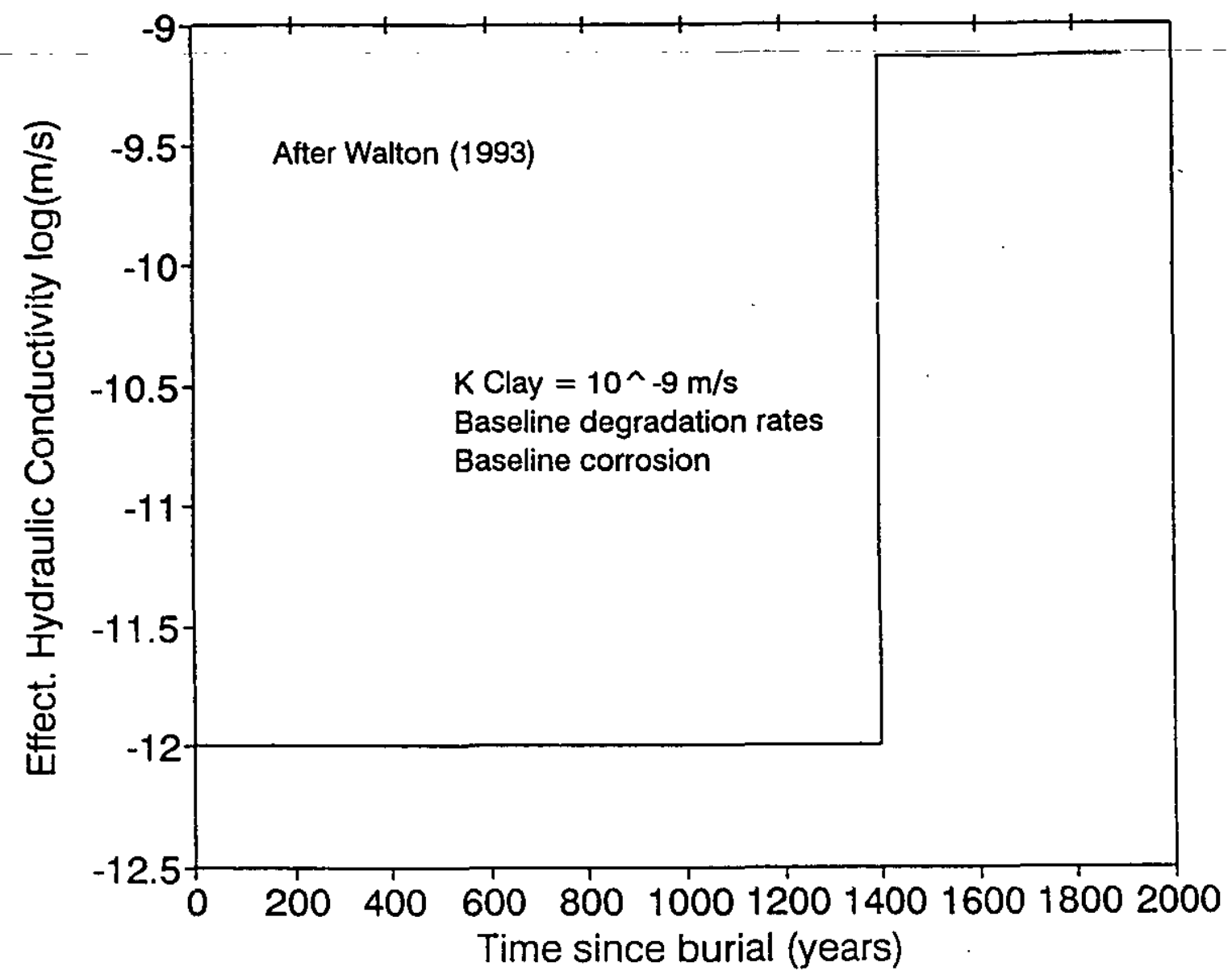

OATE: 9/7/93

REF: \#1025-007

Effective Hydraulic Conductivity of Vault Roof; LAW Vault Design 


\section{ORIGINAL CONCRETE ROOF SURFACE}

- - - - - - - - - - - - - -

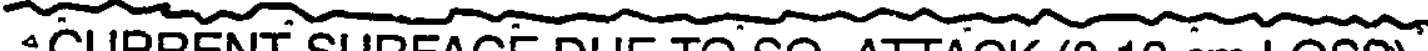
¿ CURRENT SURFACE DUE TO SO ATTACK $(0.19$ cm LOSS

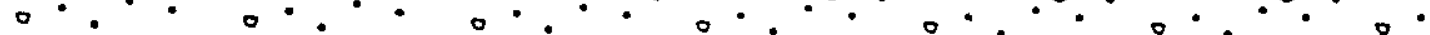

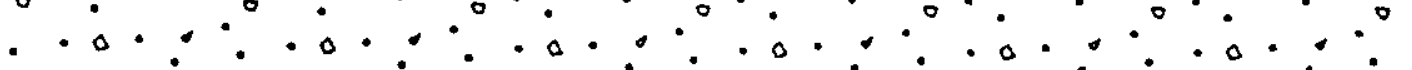

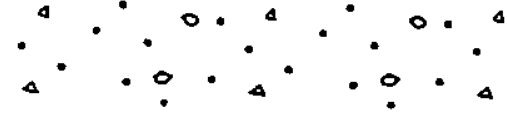$$
\text { - } . \circ . .0 \%
$$

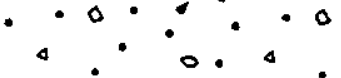$$
\text { CUGINAL REBAR RADIUS: } 1.25 \mathrm{~cm}
$$$$
\text { CUSRRENT REBBAR RADIUS: } 1.05 \mathrm{~cm}
$$

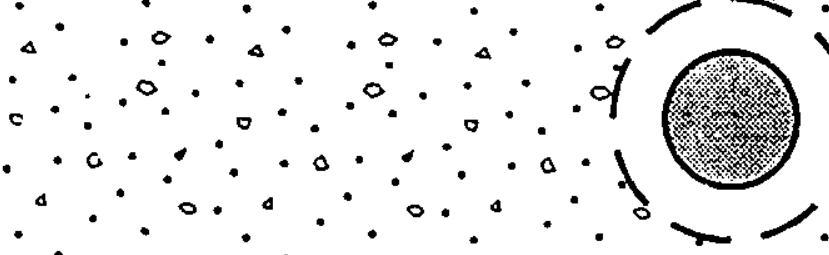<smiles>C1CCC1</smiles>
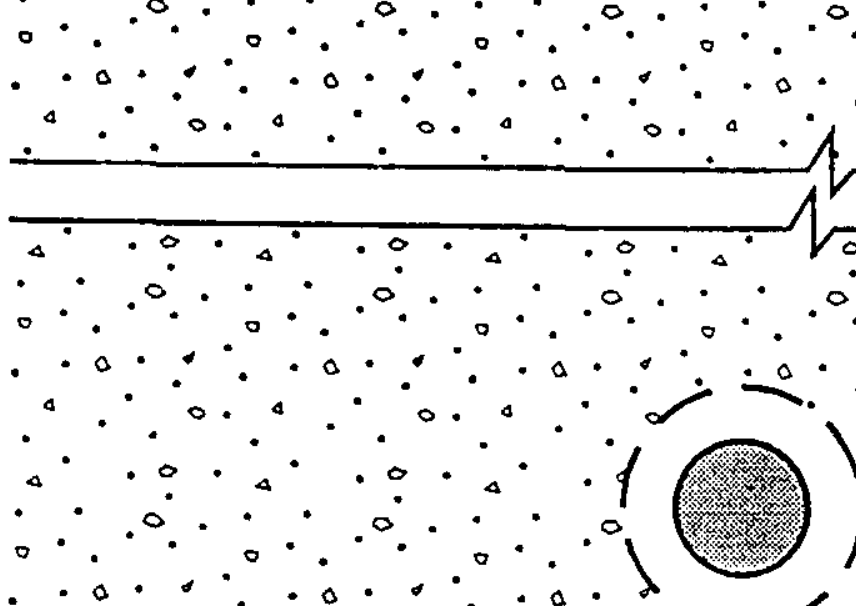

$\therefore \therefore$ ORIGINAL REBAR RADIUS: $1.25 \mathrm{~cm} . \therefore$. $\therefore \therefore$ CURRENT REBAR RADIUS: $1.05 \mathrm{~cm} \cdot .0^{\circ} \cdot$.

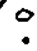

\section{VAULT INTERIOR}

\begin{tabular}{|c|c|c|}
\hline DATE: $9 / 7 / 93$ & \multicolumn{2}{|c|}{$\begin{array}{c}\text { Cross-Section of ILNT Vault Roof } \\
\text { Showing Degradation at 400 Years }\end{array}$} \\
\hline REF: \#1025-007 & & Figure 6 \\
\hline Lif/Jid] & & \\
\hline
\end{tabular}




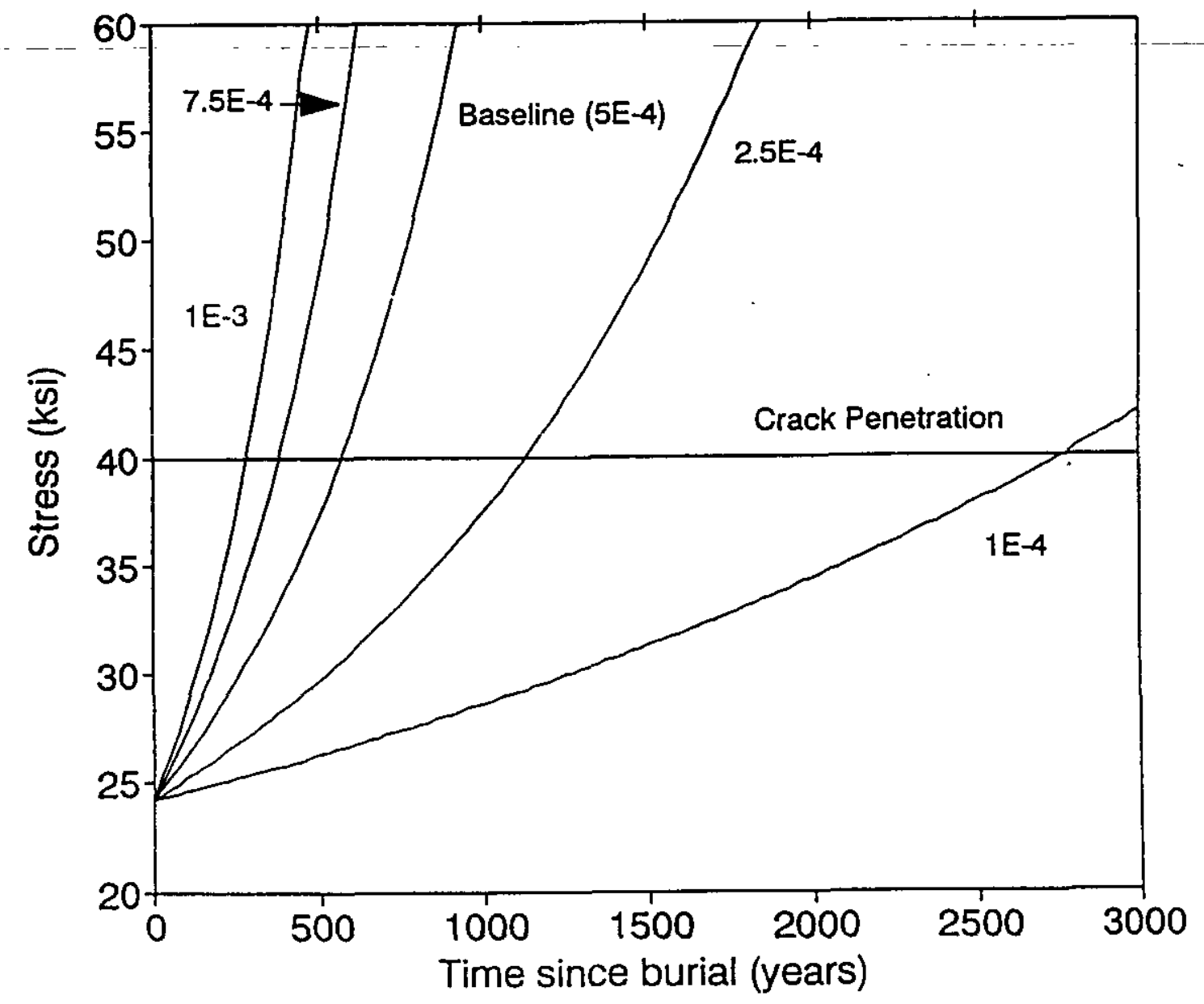

DATE: $9 / 7 / 93$

REF: \#1025-007
ILNT Vault Time to Crack Penetration of Roof; Sensitivity to Hydrogen Evolution Corrosion Rate $(\mathrm{cm} / \mathrm{yr})$ 


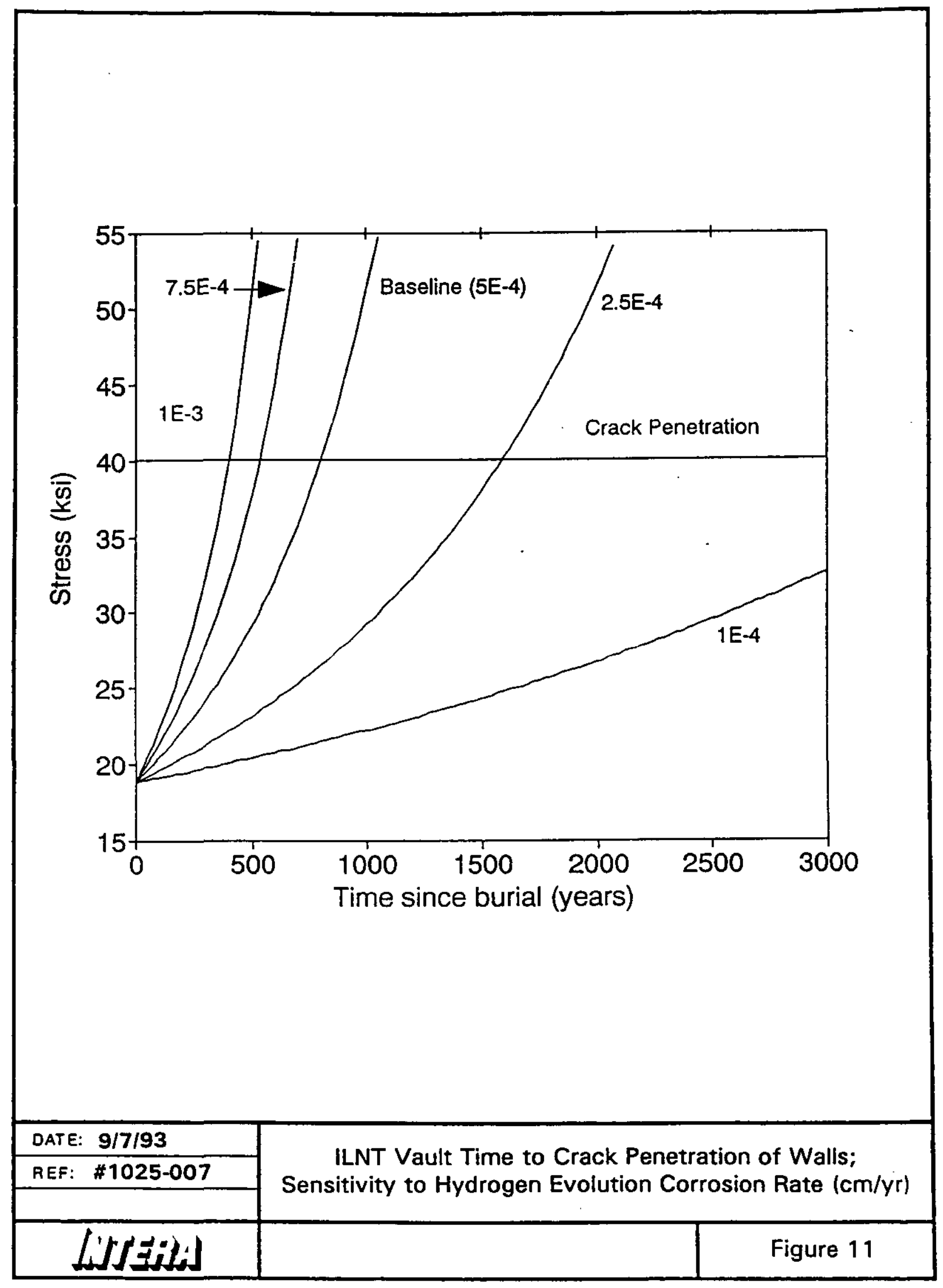




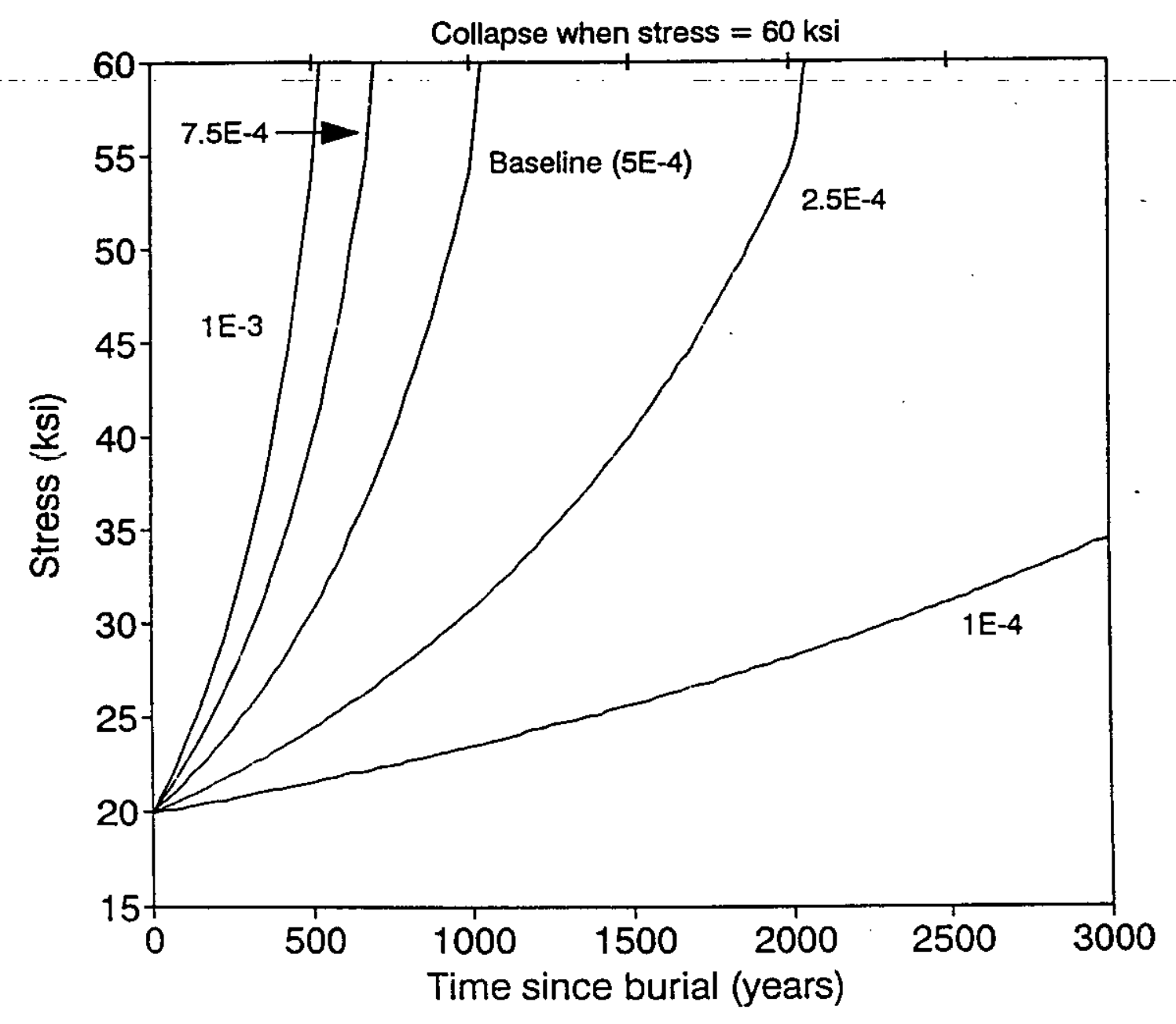

DATE: $9 / 7 / 93$

REF: \#1025-007
ILNT Vault Time to Roof Collapse;

Sensitivity to Hydrogen Evolution Corrosion Rate $(\mathrm{cm} / \mathrm{yr})$ 


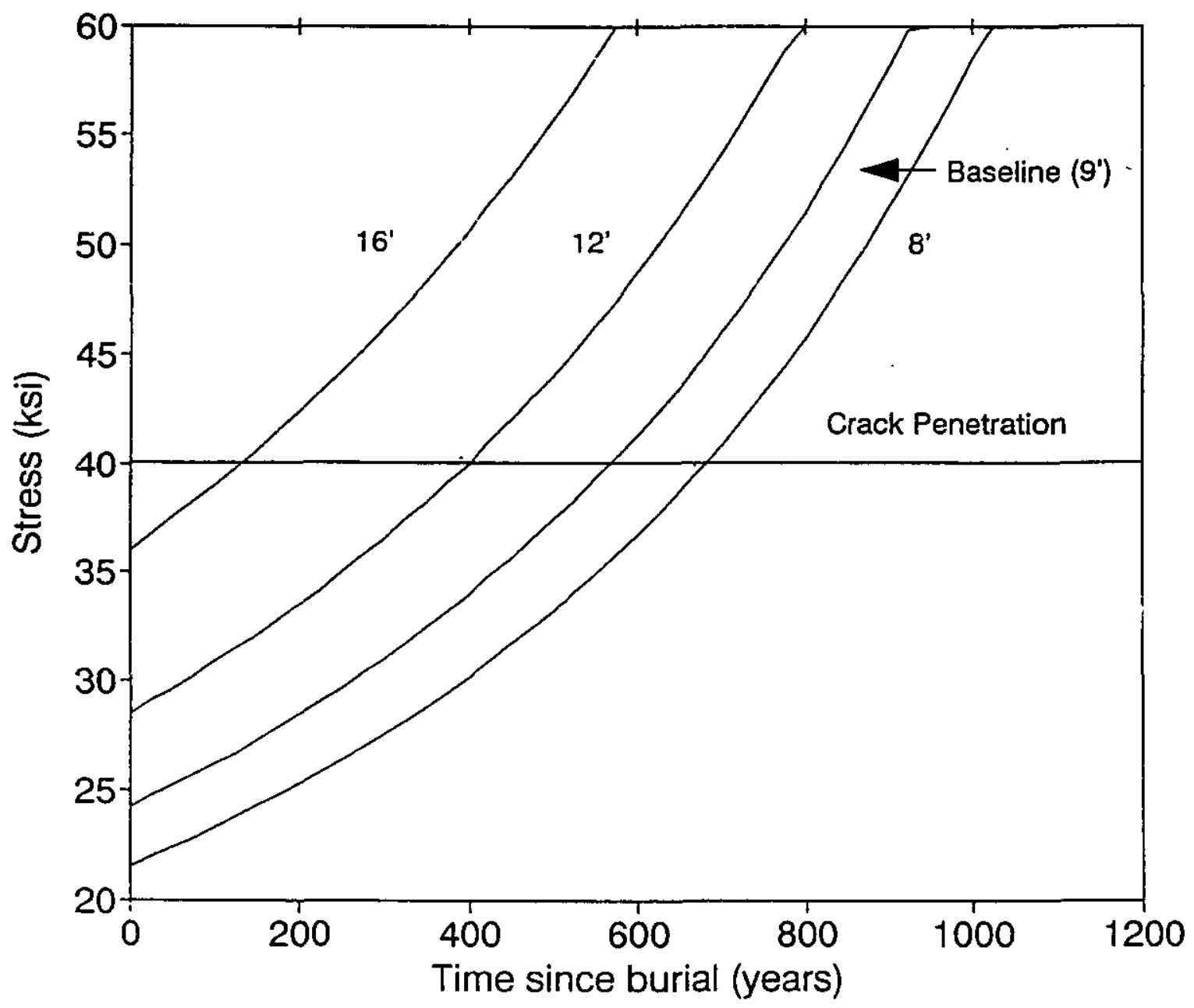

DATE: $9 / 7 / 93$

REF: \#1025-007

ILNT Vault Time to Crack Penetration of Roof; Sensitivity to Depth of Soil Cover 


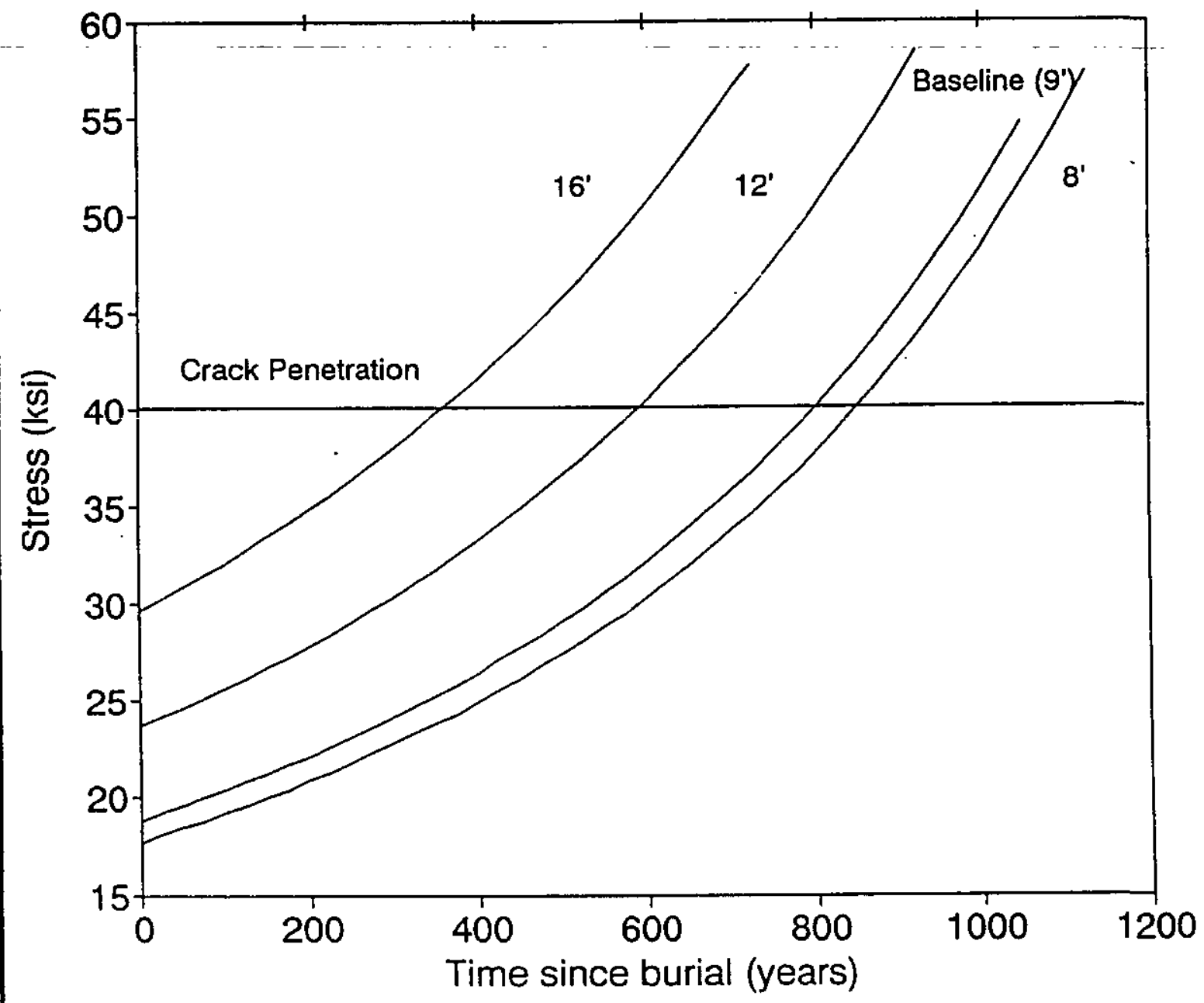

DATE: $9 / 7 / 93$

REF: \#1025-007
ILNT Vault Time to Crack Penetration of Walls; Sensitivity to Depth of Soil Cover 


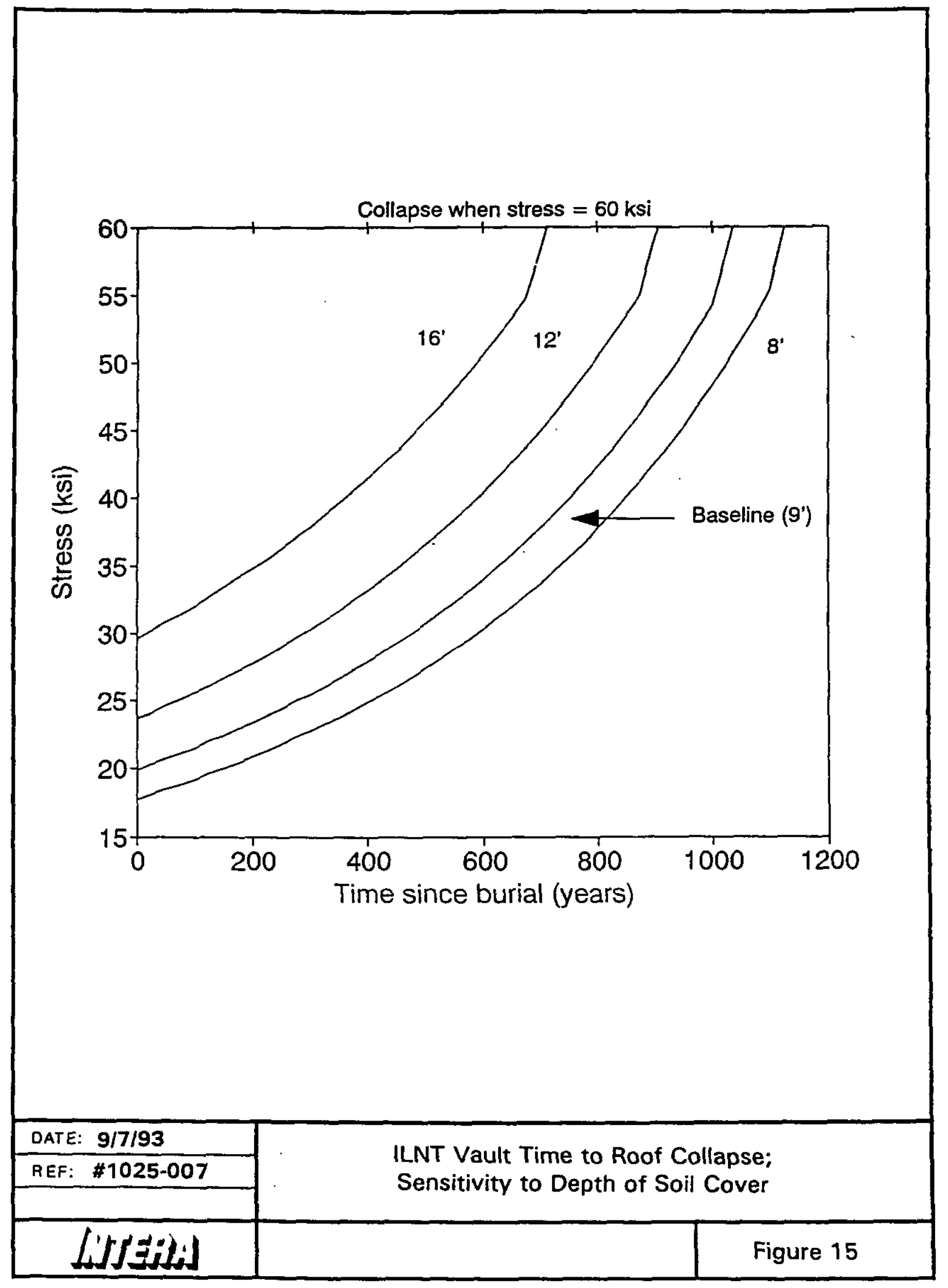




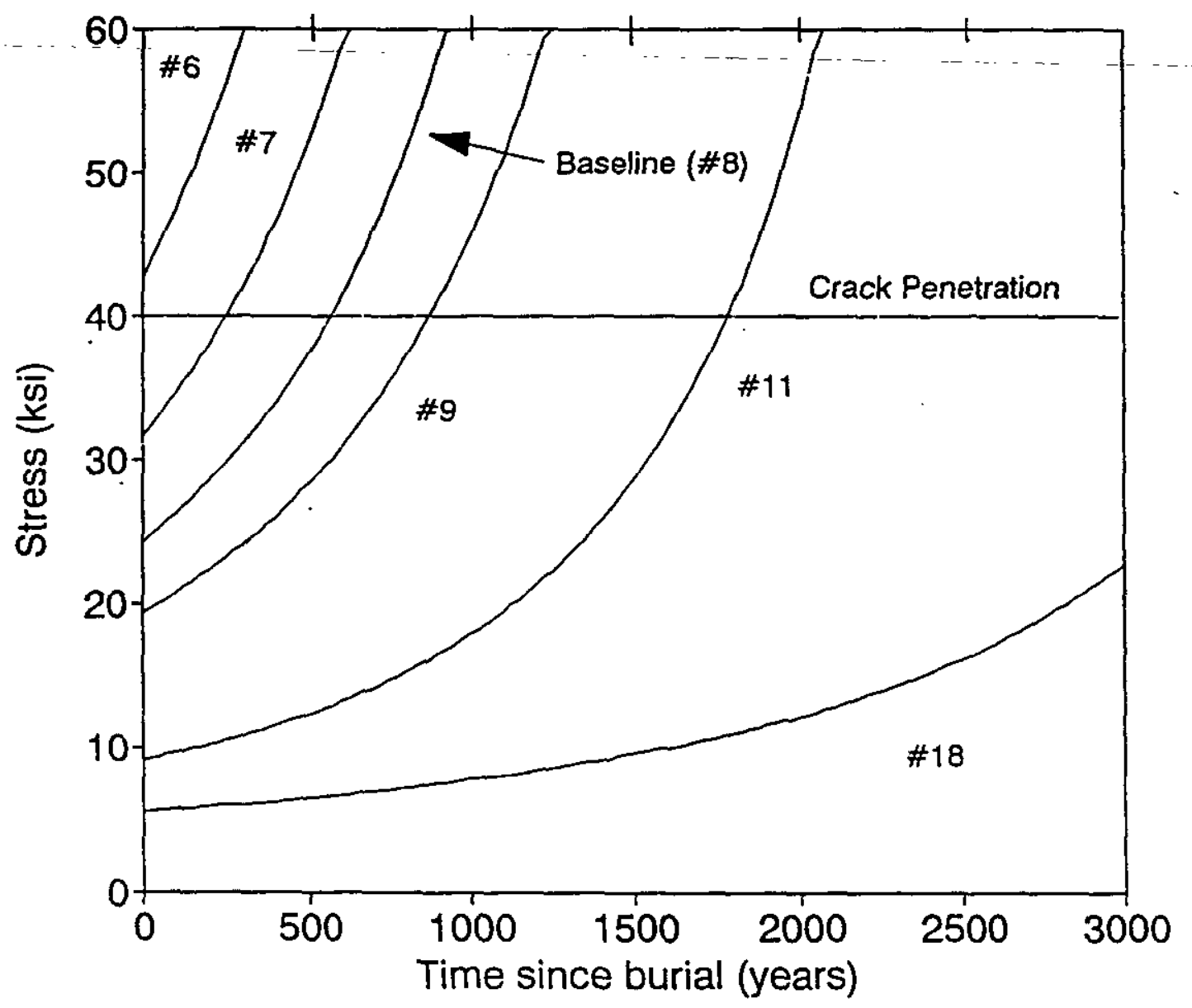

DATE: $9 / 7 / 93$

REF: \#1025-007

ILNT Vault Time to Crack Penetration of Roof; Sensitivity to Rebar Size 


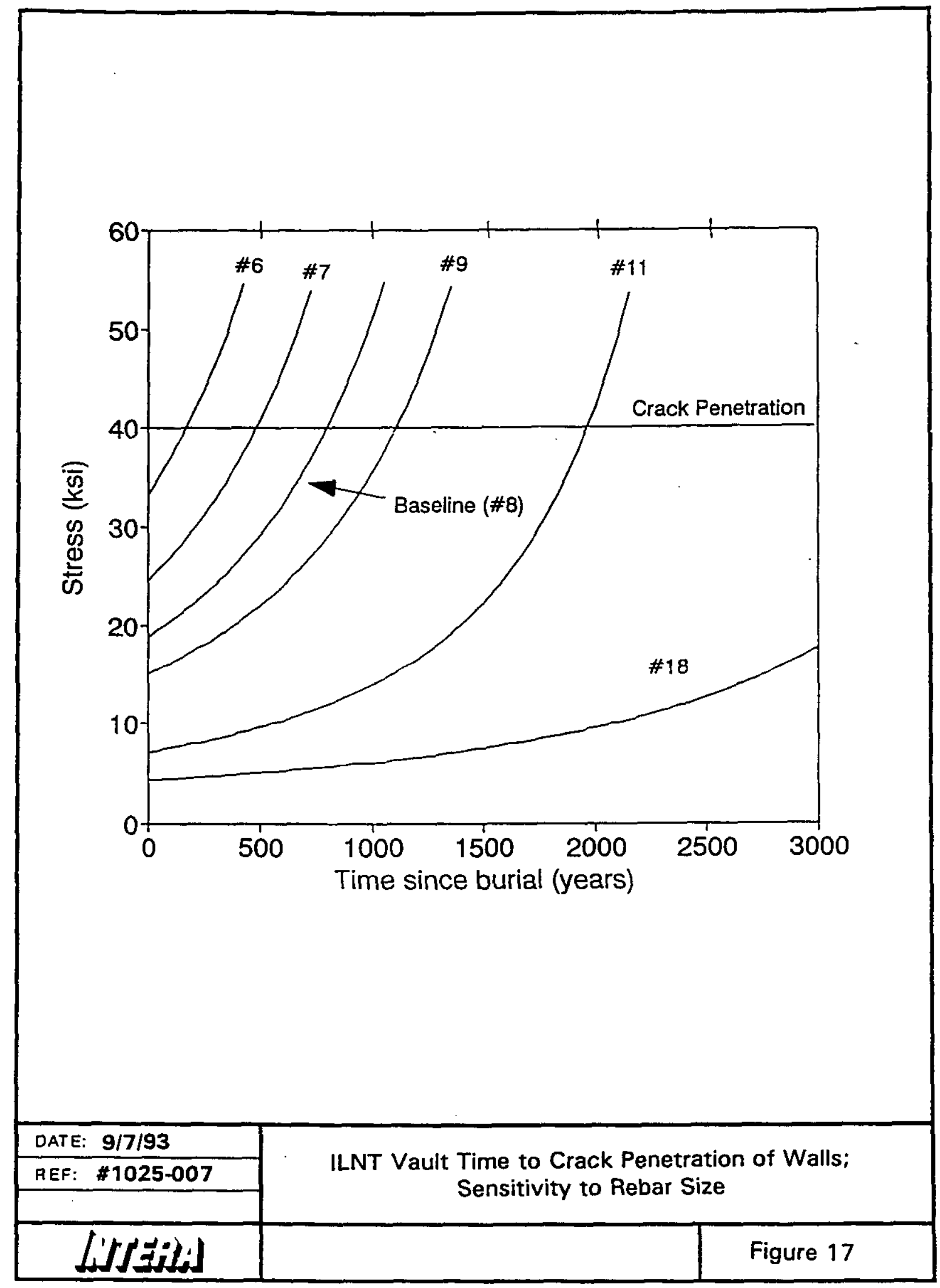




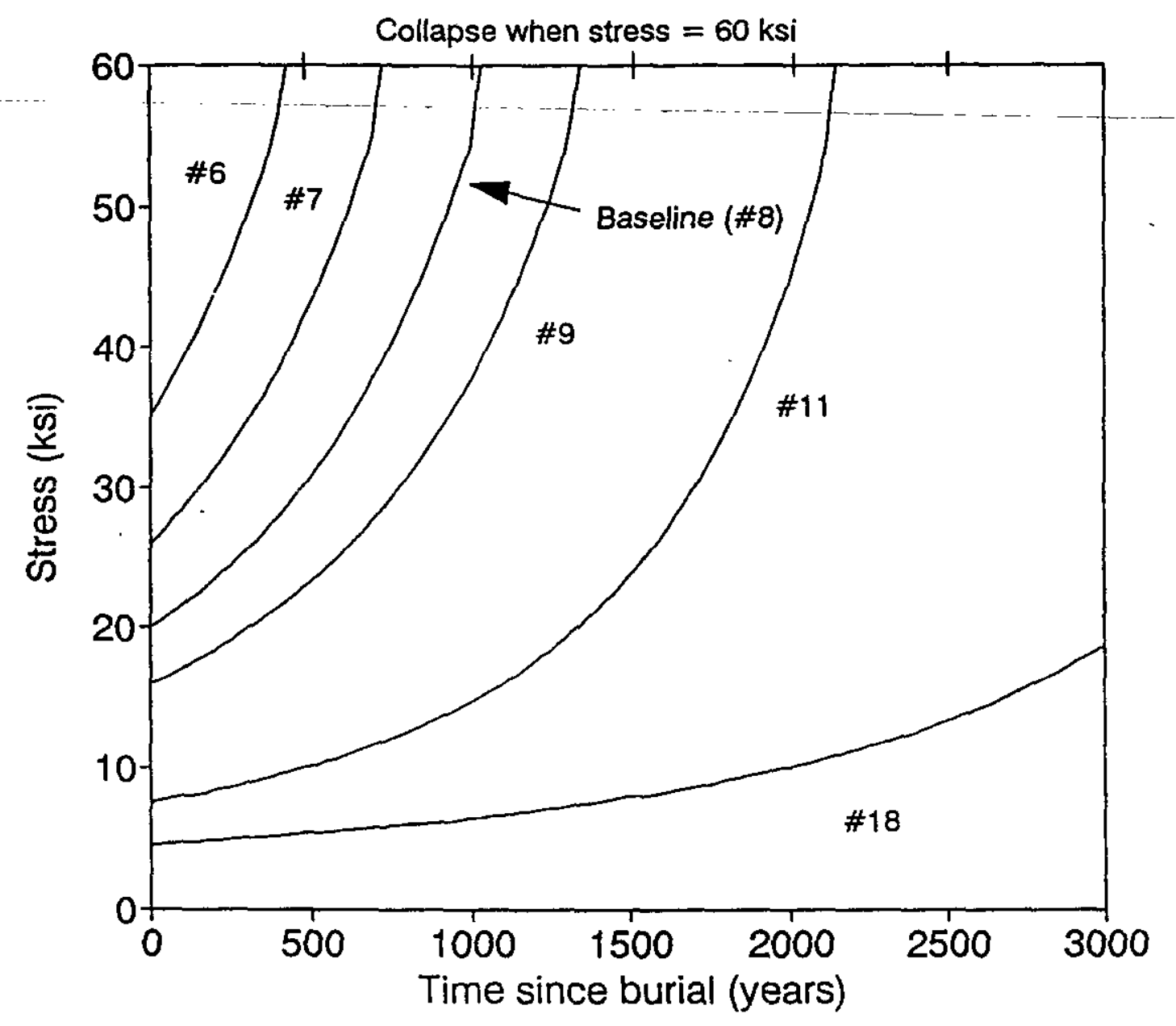

\begin{tabular}{|c|c|}
\hline DATE: $9 / 7 / 93$ & \multirow{2}{*}{$\begin{array}{l}\text { ILNT Vault Time to Roof Collapse; } \\
\text { Sensitivity to Rebar Size }\end{array}$} \\
\hline REF: \#1025-007 & \\
\hline L'rJİid & Figure 18 \\
\hline
\end{tabular}




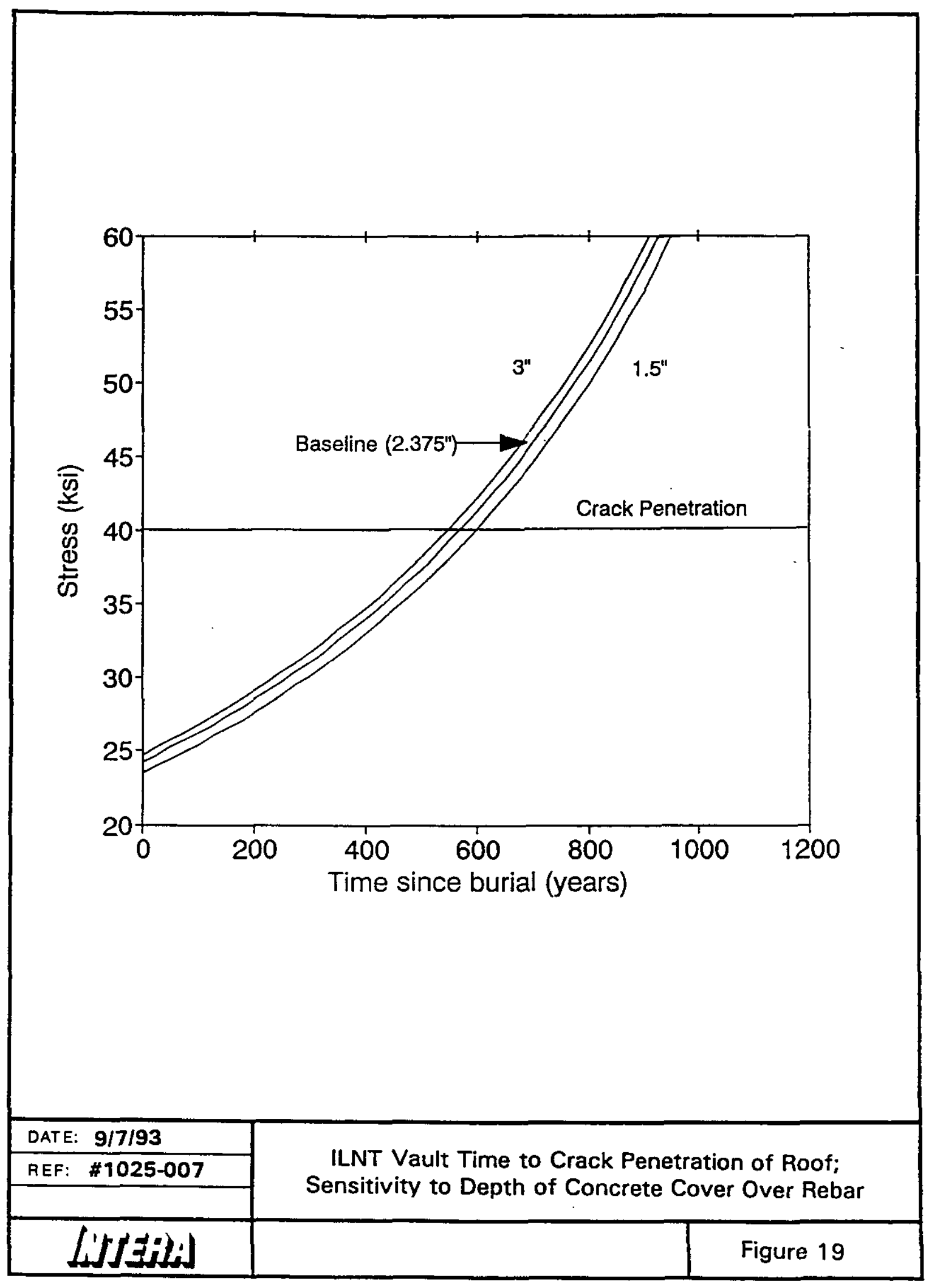




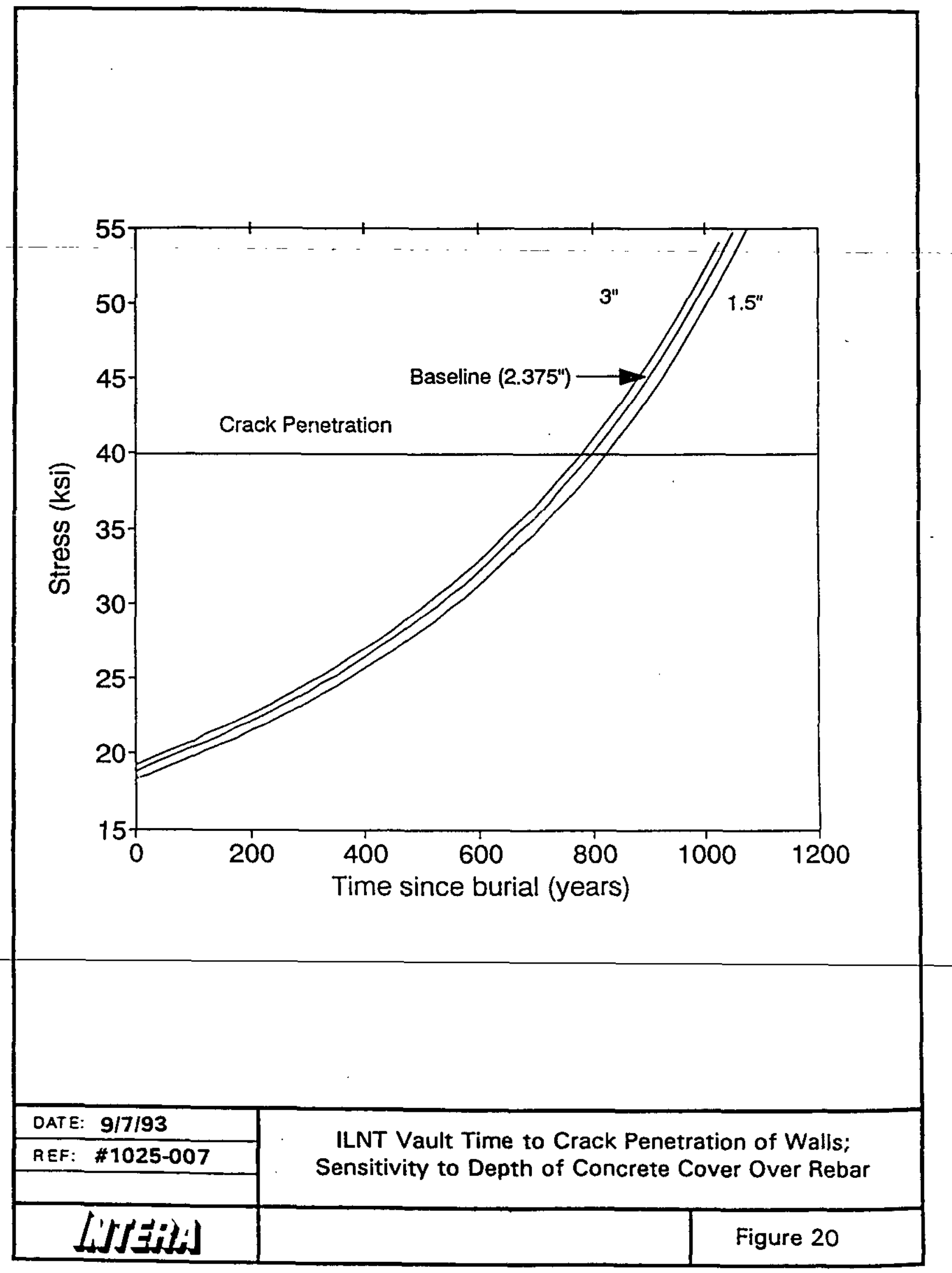




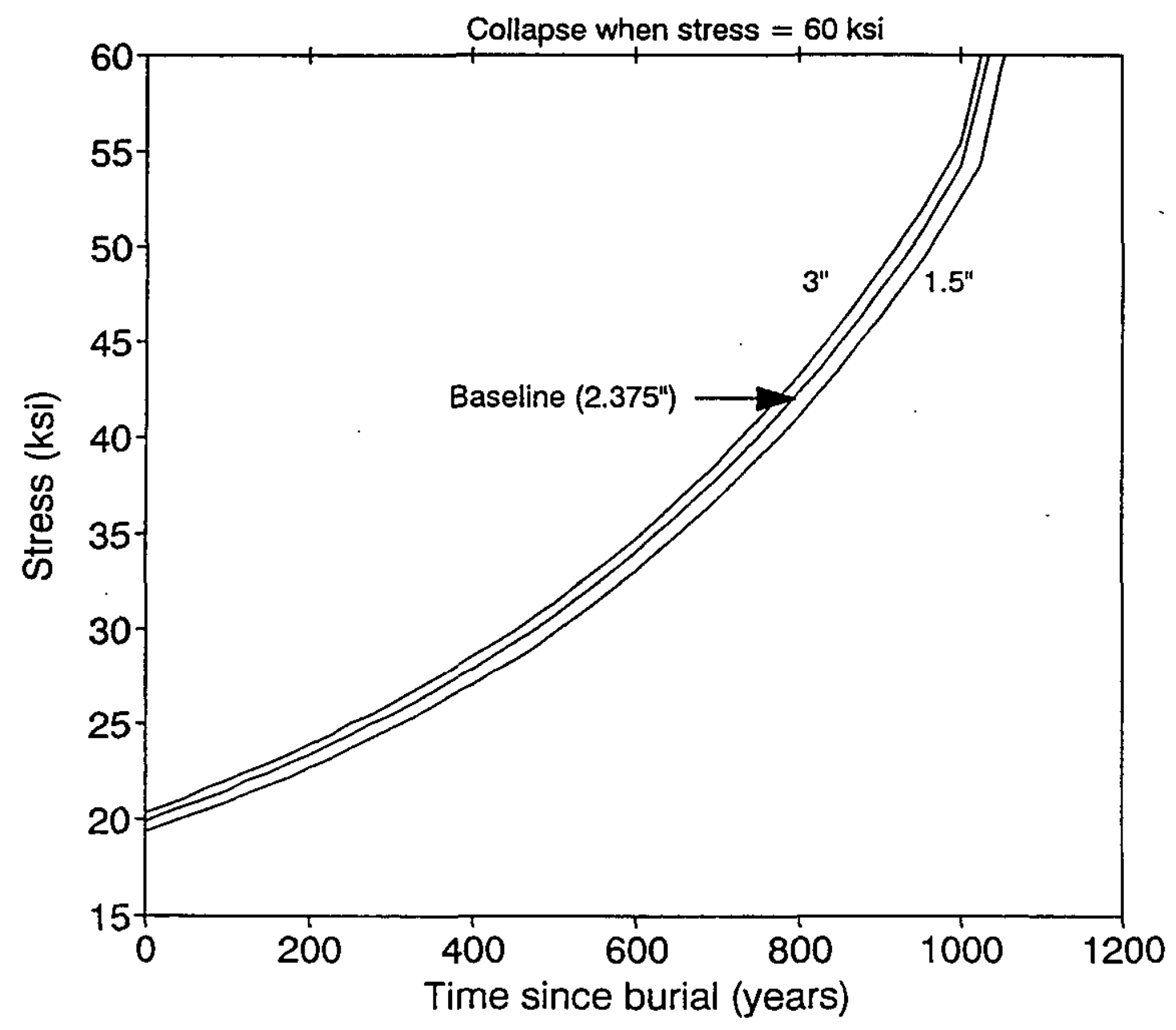

DATE: $9 / 7 / 93$

REF: \#1025-007

ILNT Vault Time to Roof Collapse;

Sensitivity to Depth of Concrete Cover Over Rebar

Figure 21 


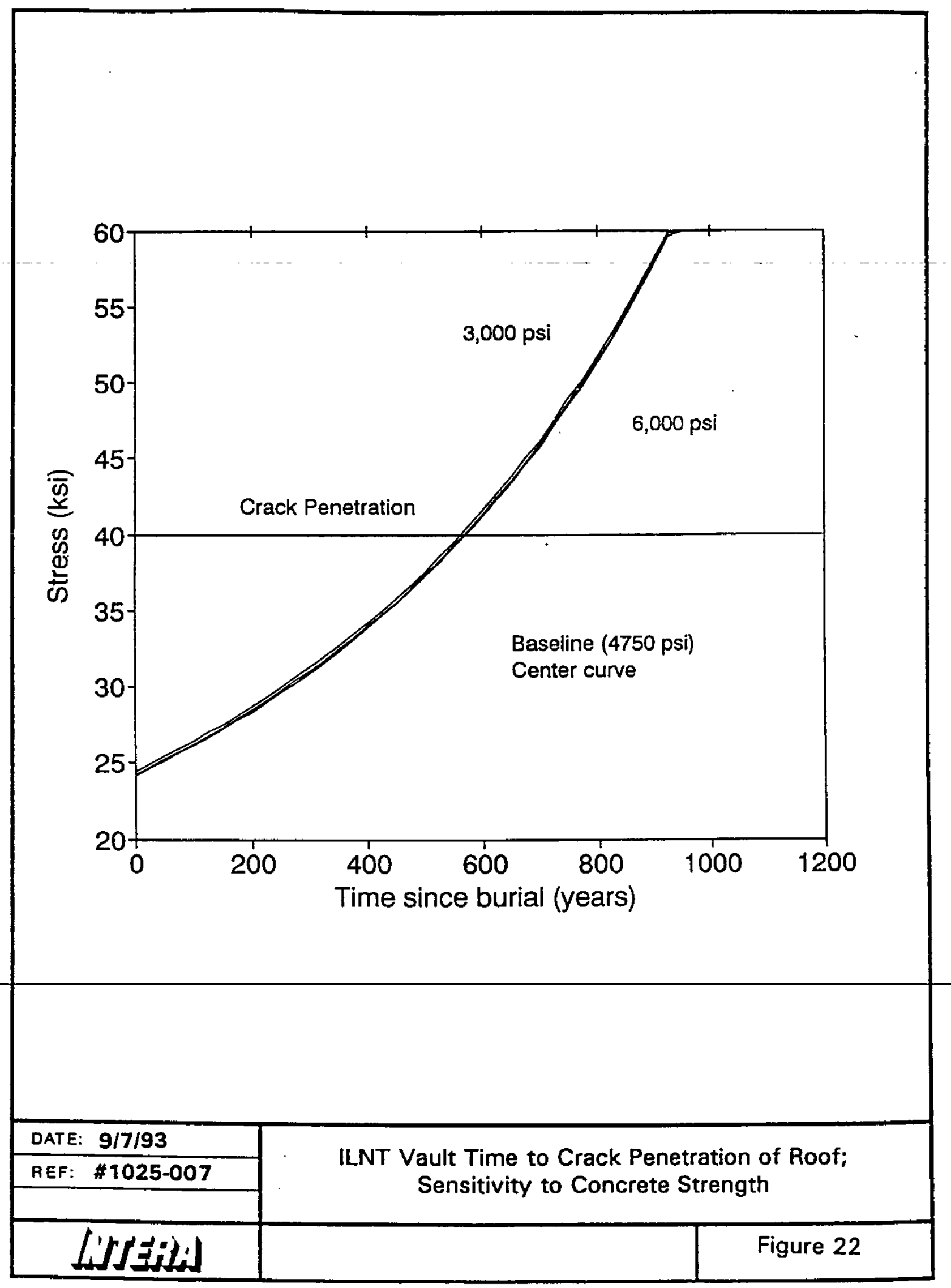




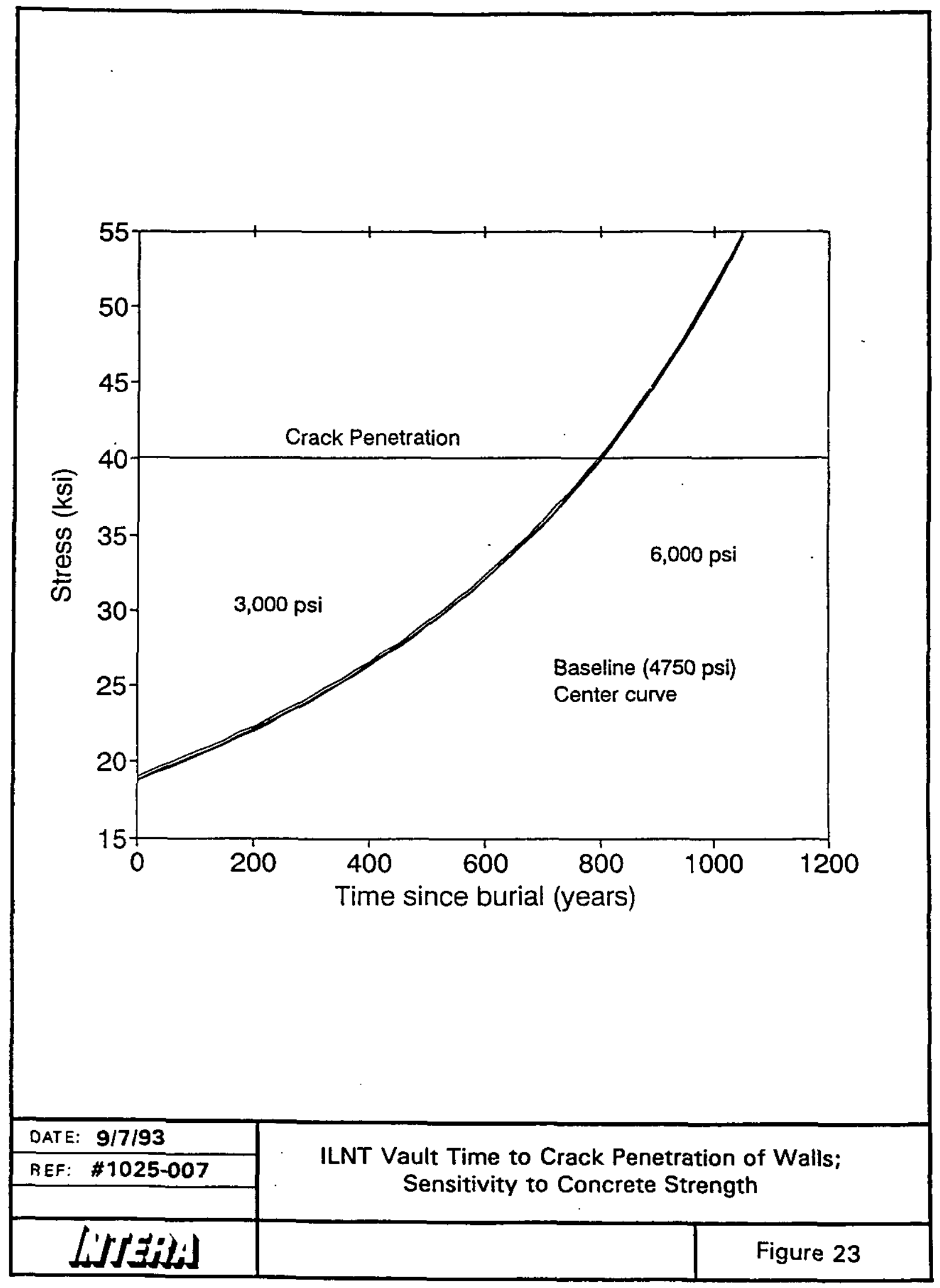




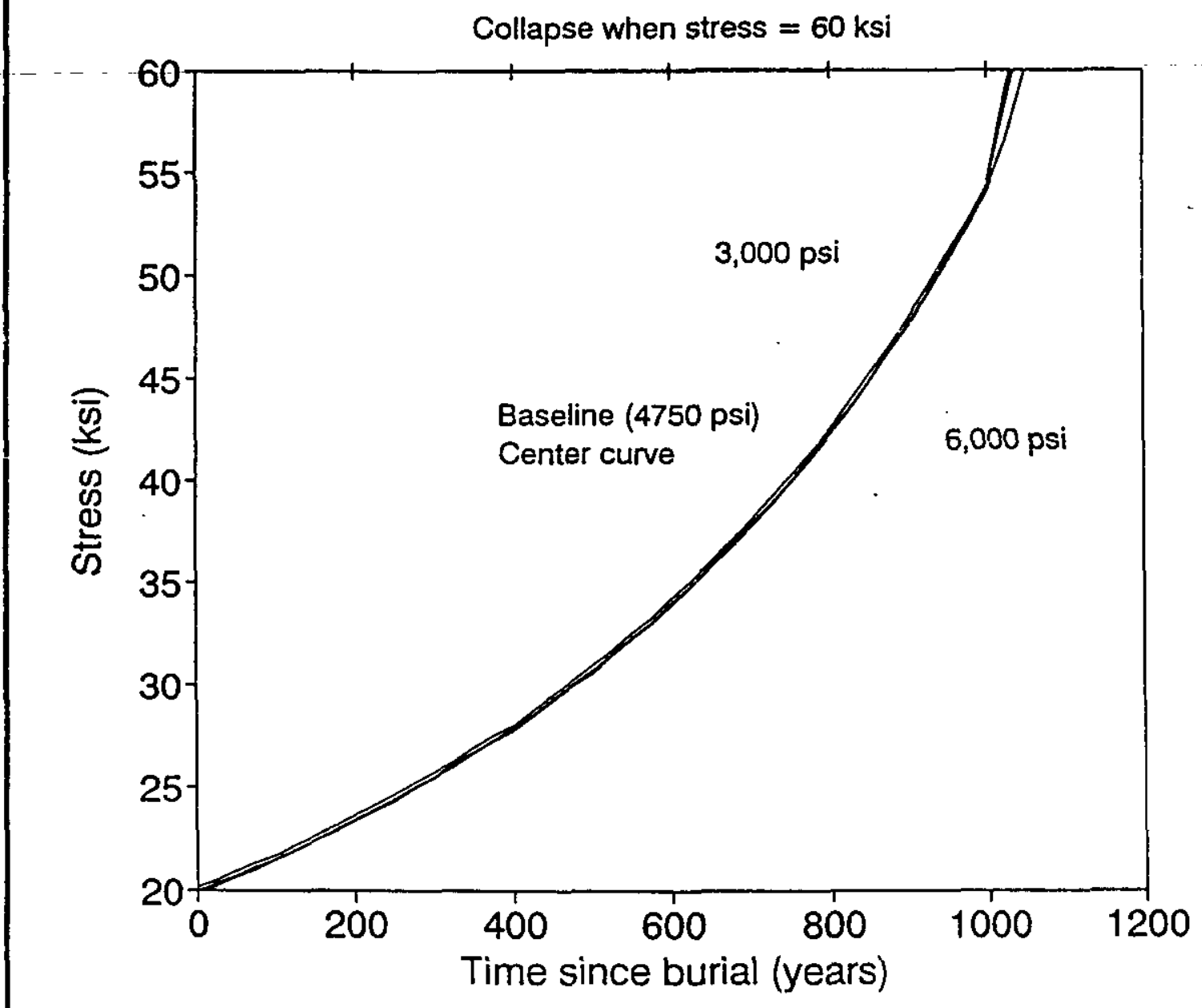

\begin{tabular}{|l|l|}
\hline DATE: $9 / 7 / 93$ & ILNT Vault Time to Roof Collapse; \\
REF: $\# 1025-007$ & Sensitivity to Concrete Strength
\end{tabular}




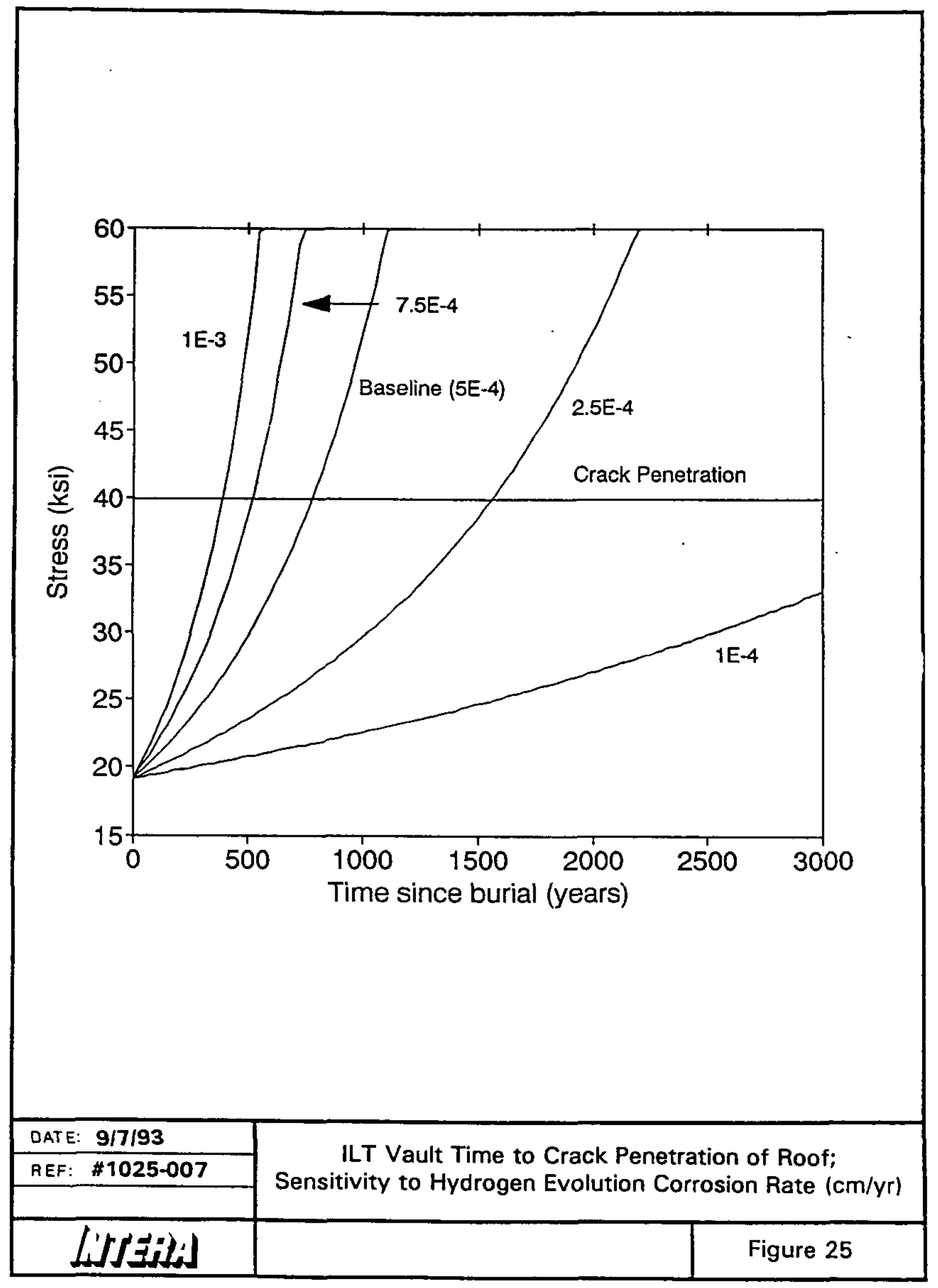




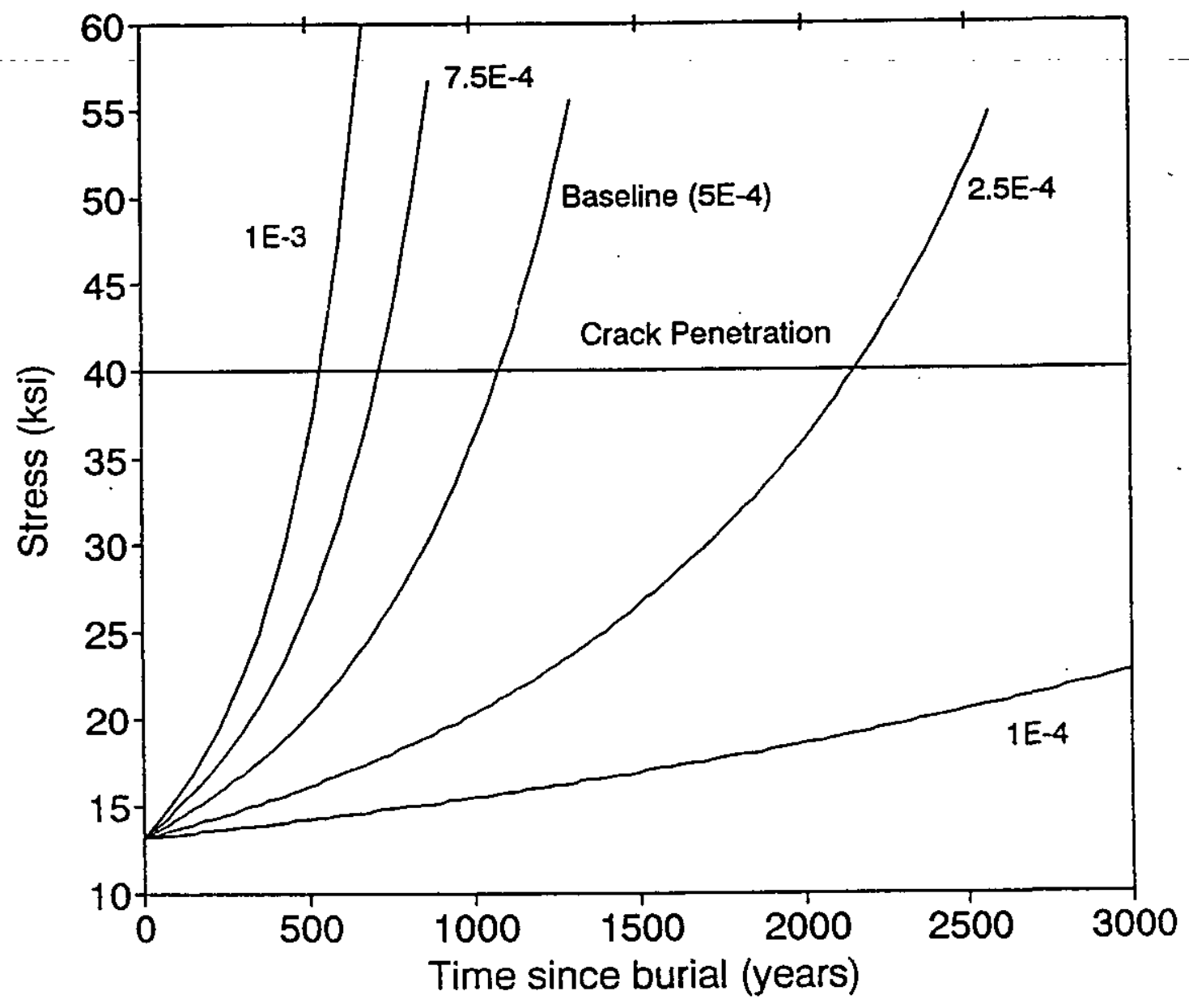

DATE: $9 / 7 / 93$

REF: \#1025-007
ILT Vault Time to Crack Penetration of Walls; Sensitivity to Hydrogen Evolution Corrosion Rate $(\mathrm{cm} / \mathrm{yr})$ 


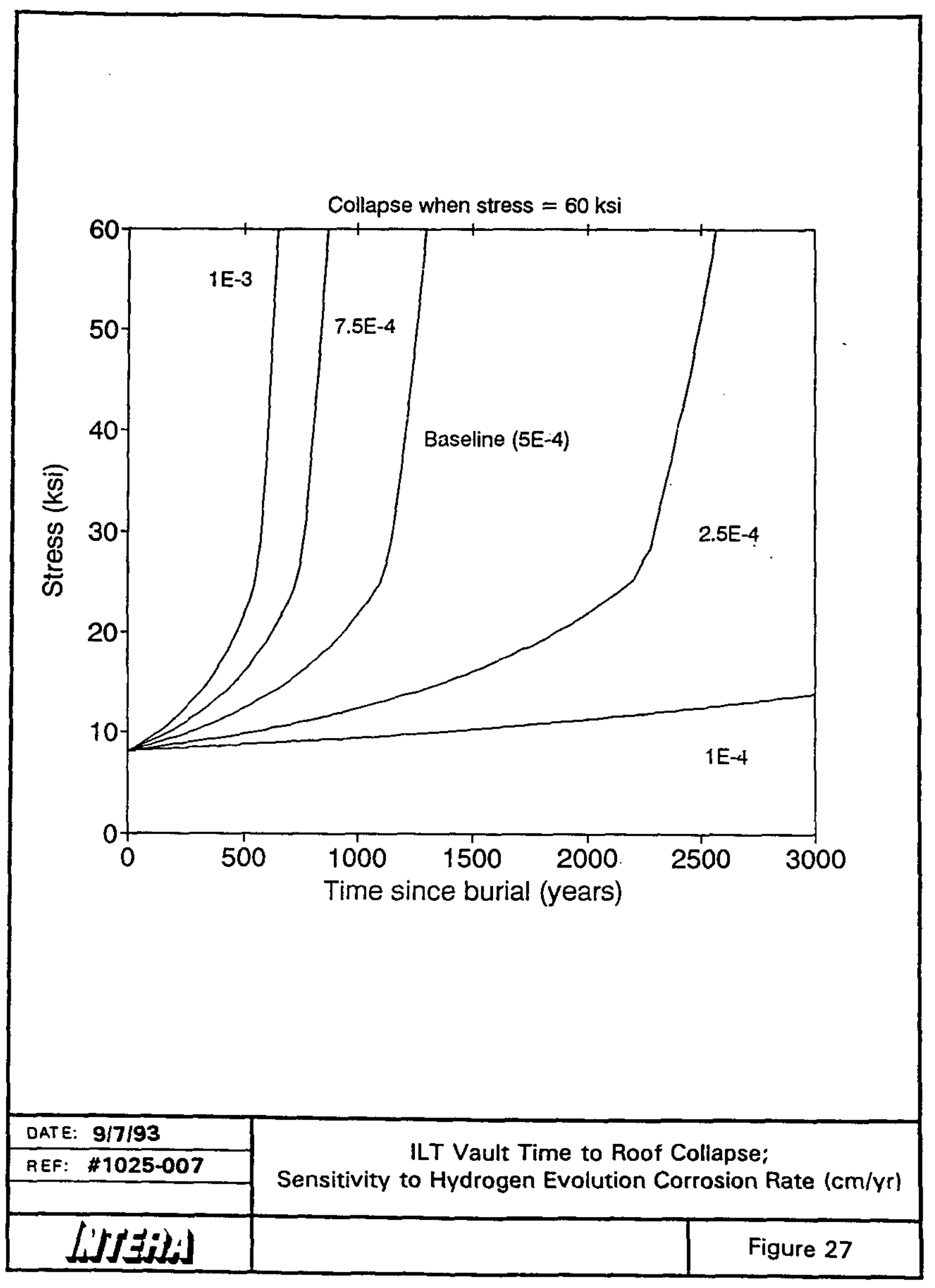




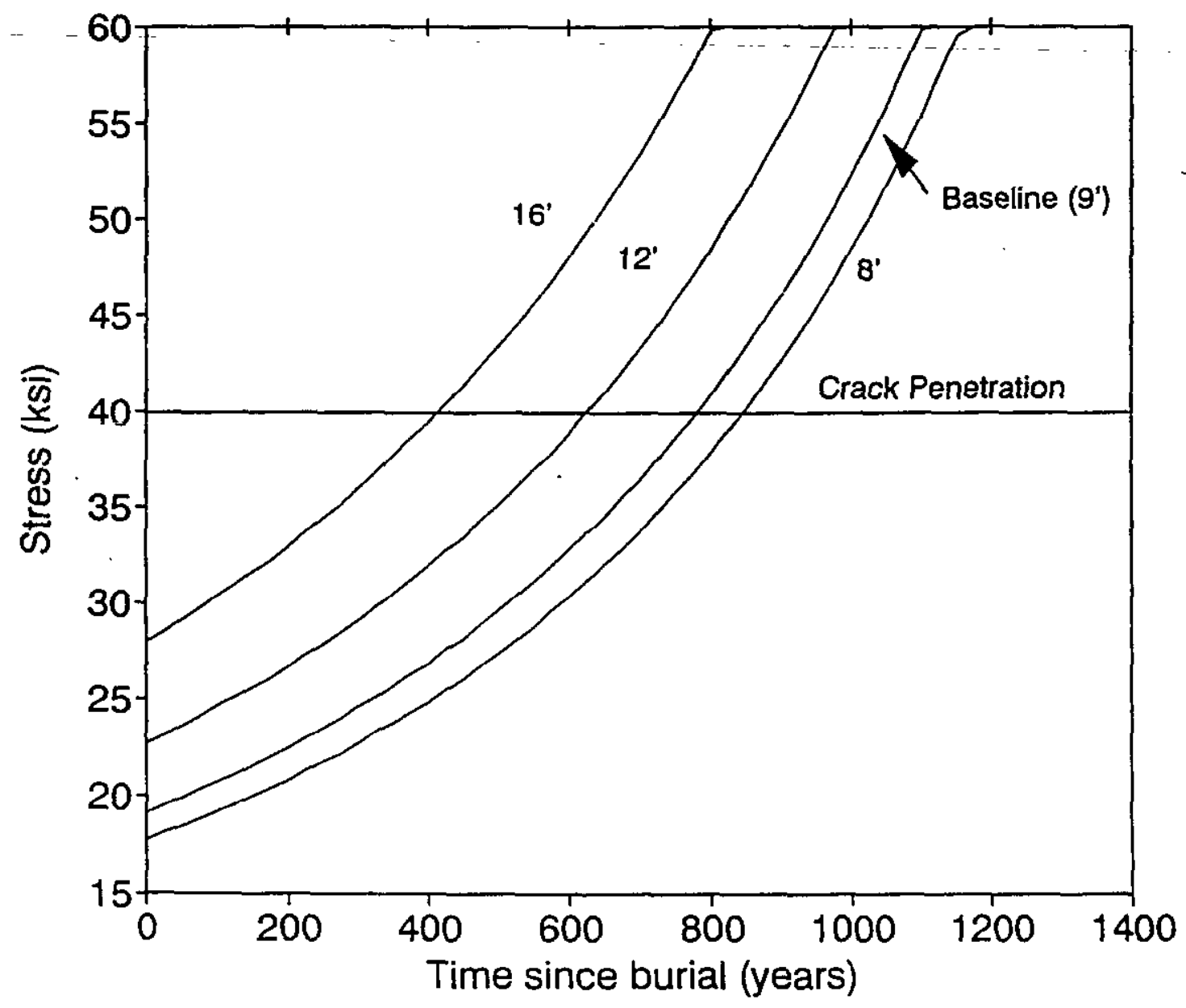

DATE: $9 / 7 / 93$

REF: \#1025-007

ILT Vault Time to Crack Penetration of Roof; Sensitivity to Depth of Soil Cover 


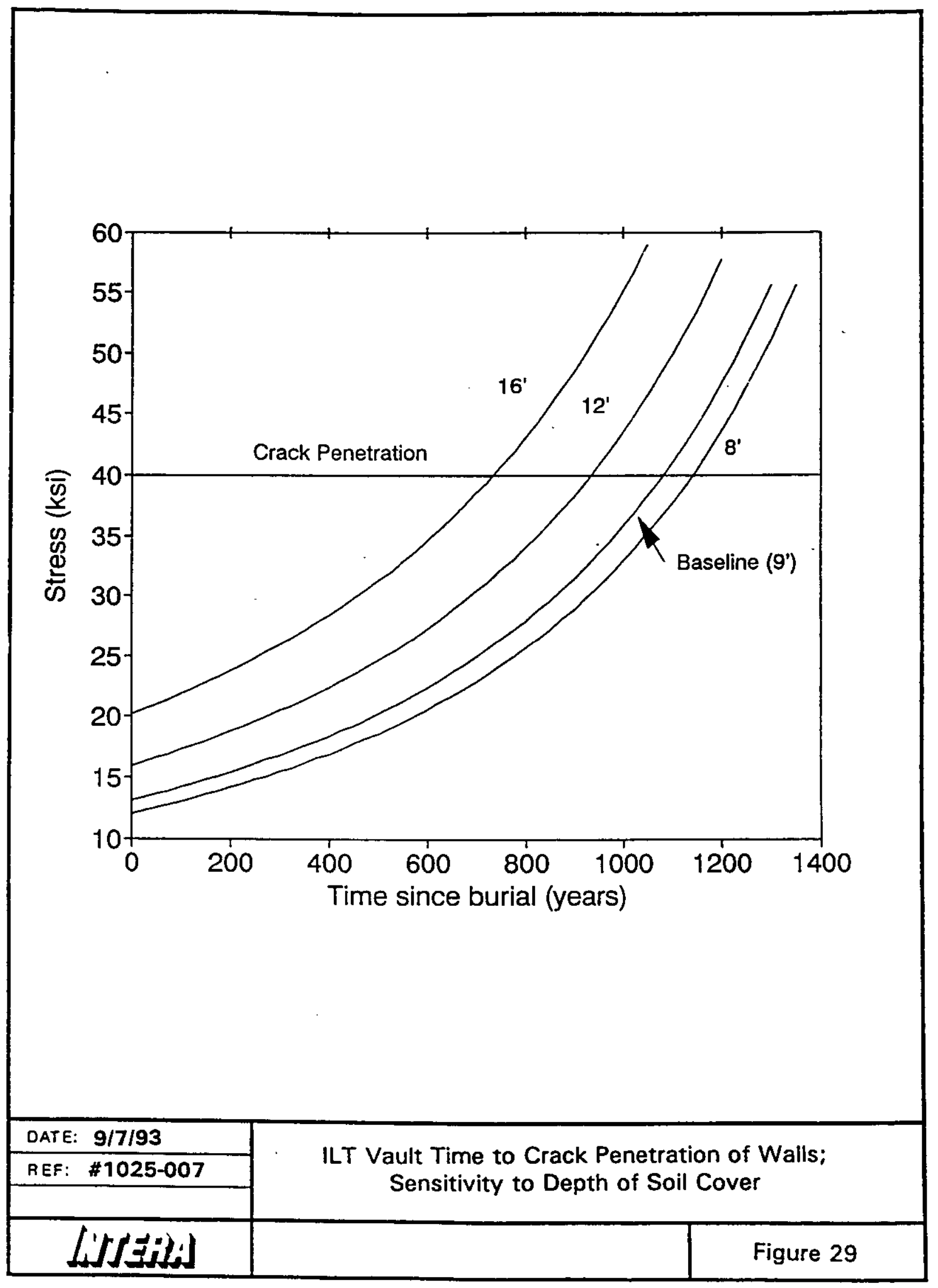




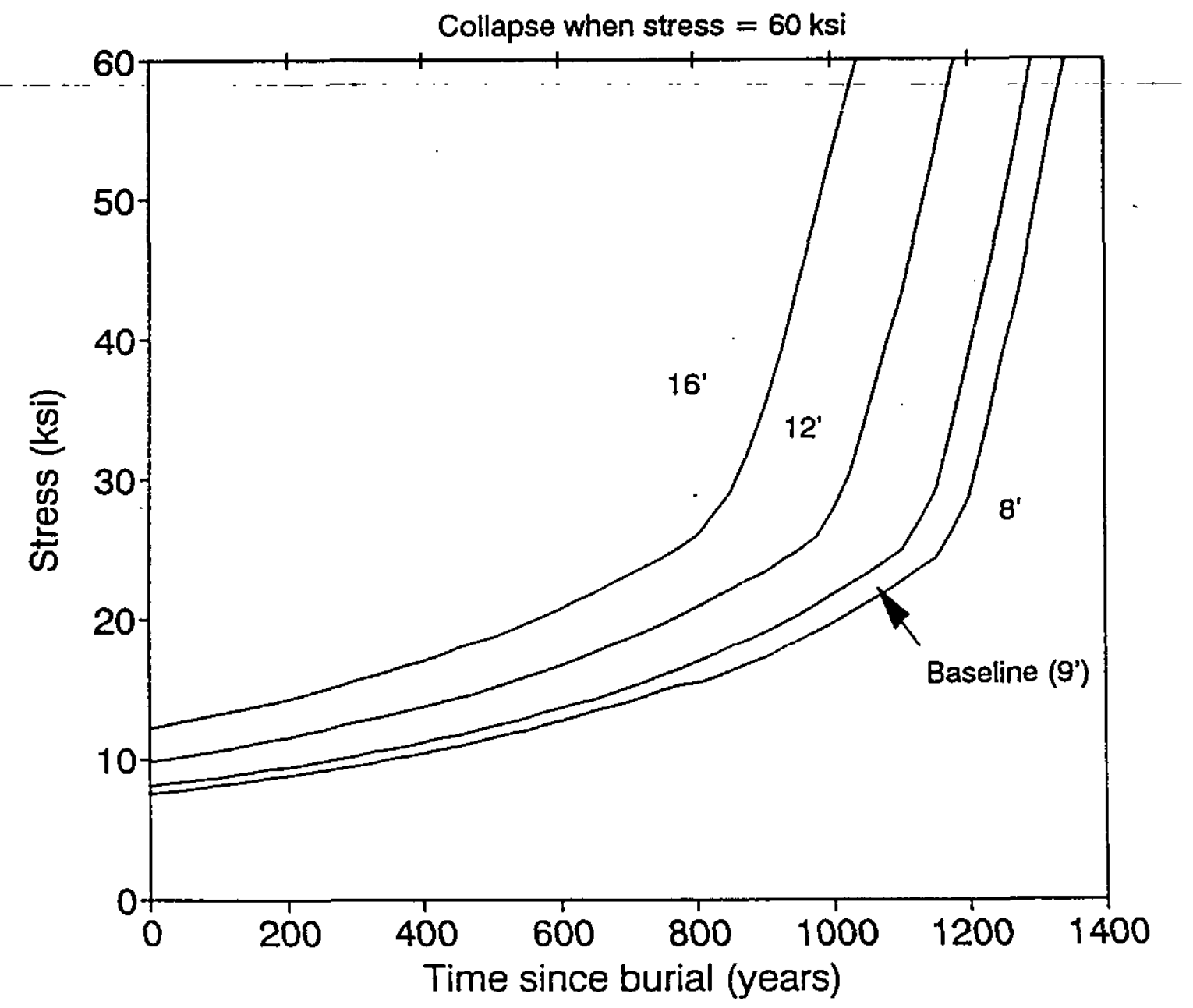

\begin{tabular}{|l|l|}
\hline OATE: $9 / 7 / 93$ & ILT Vault Time to Roof Collapse; \\
\hline REF: $\# 1025-007$ & Sensitivity to Depth of Soil Cover
\end{tabular}




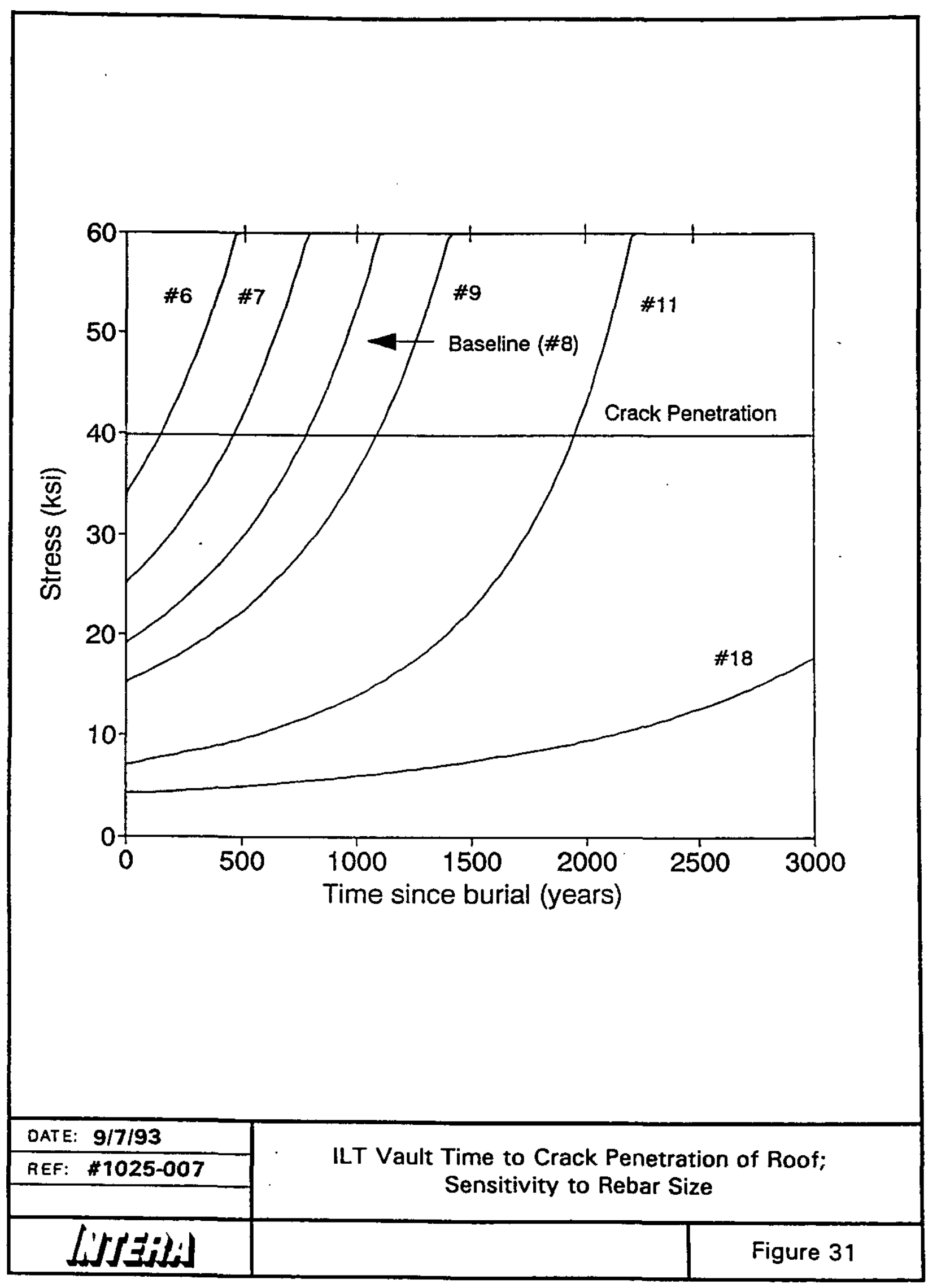




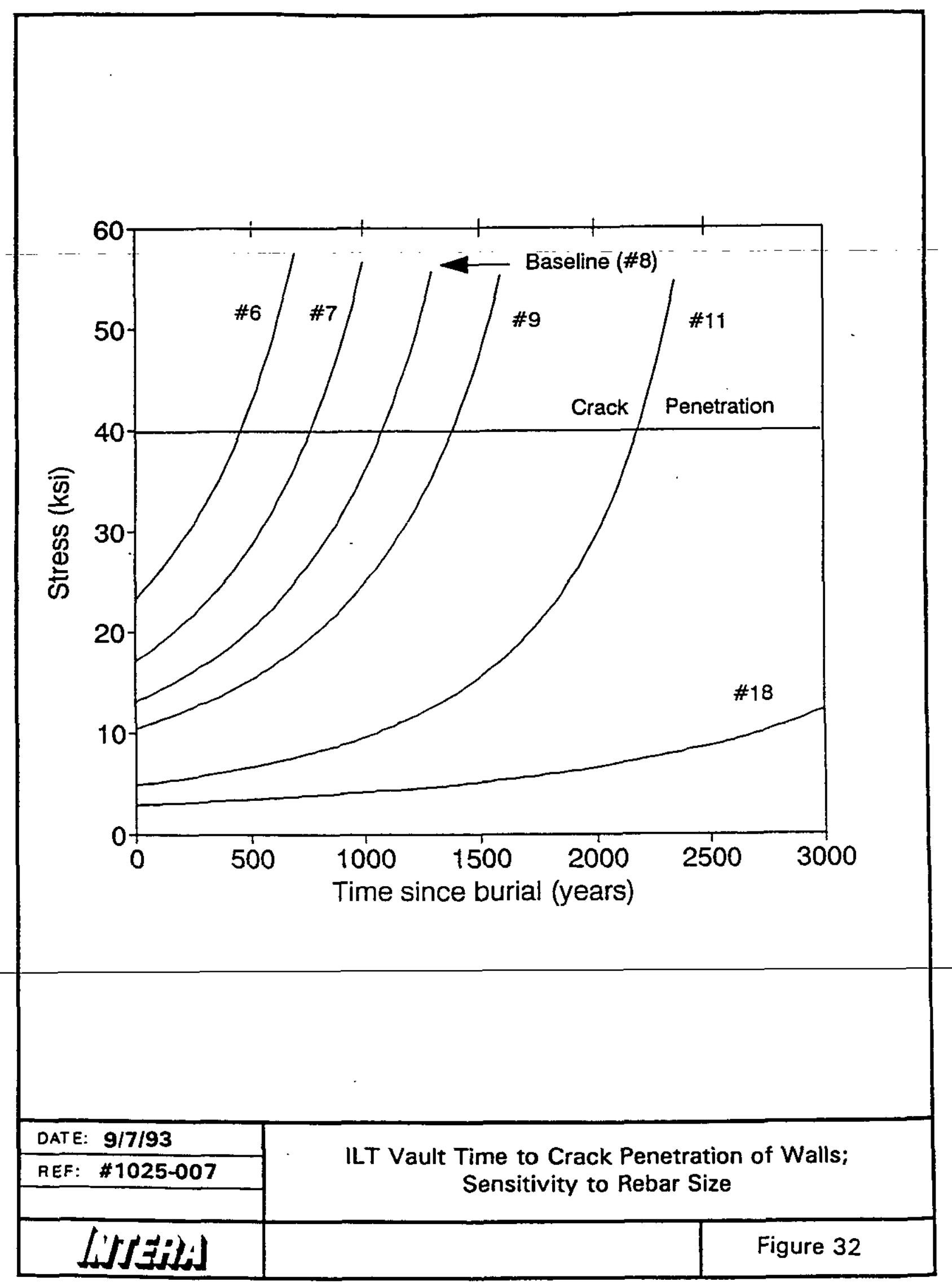




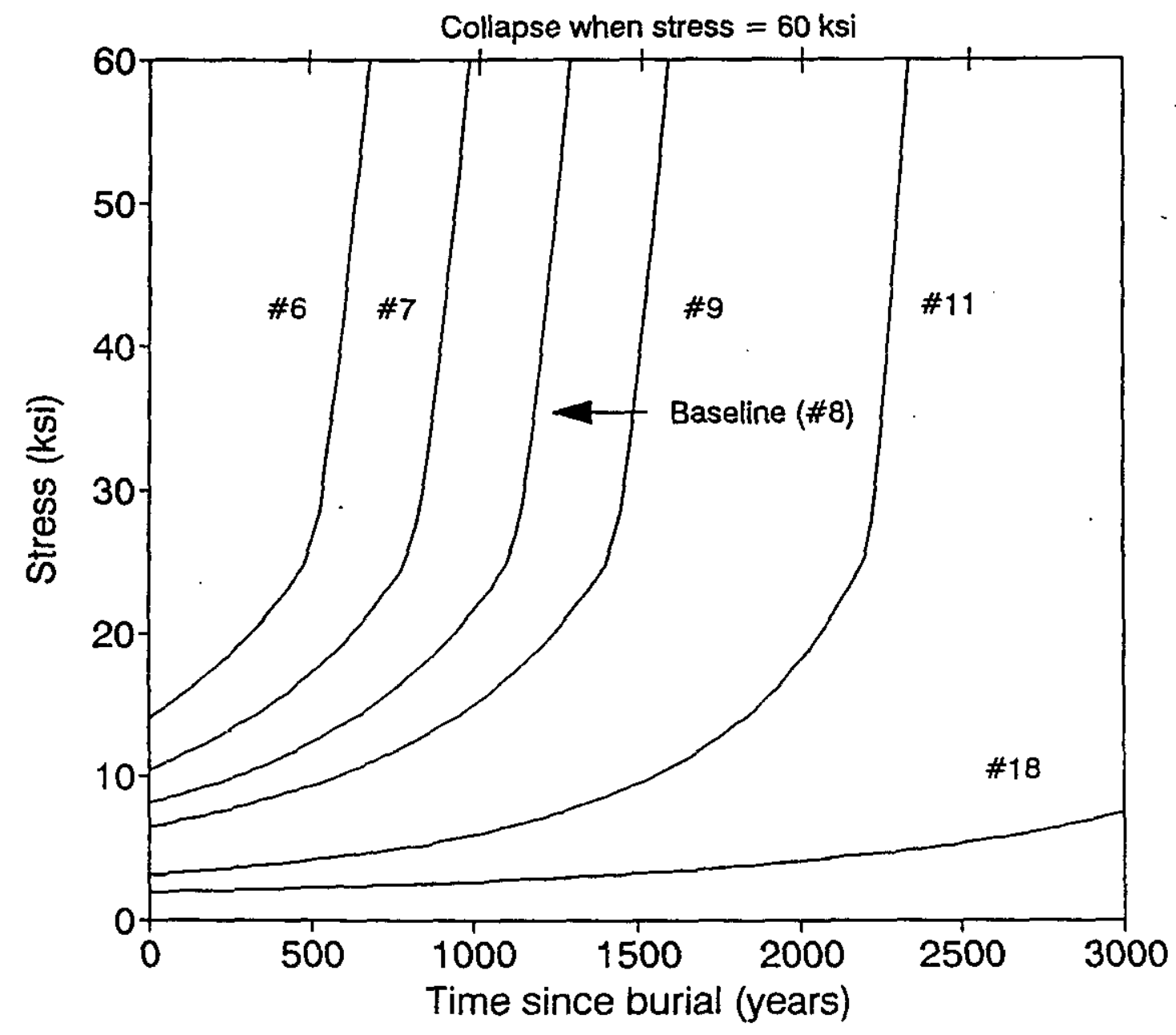

\begin{tabular}{|l|l|}
\hline DATE: $9 / 7 / 93$ & ILT Vault Time to Roof Collapse \\
REF: $\$ 1025-007$ & Sensitivity to Rebar Size
\end{tabular}




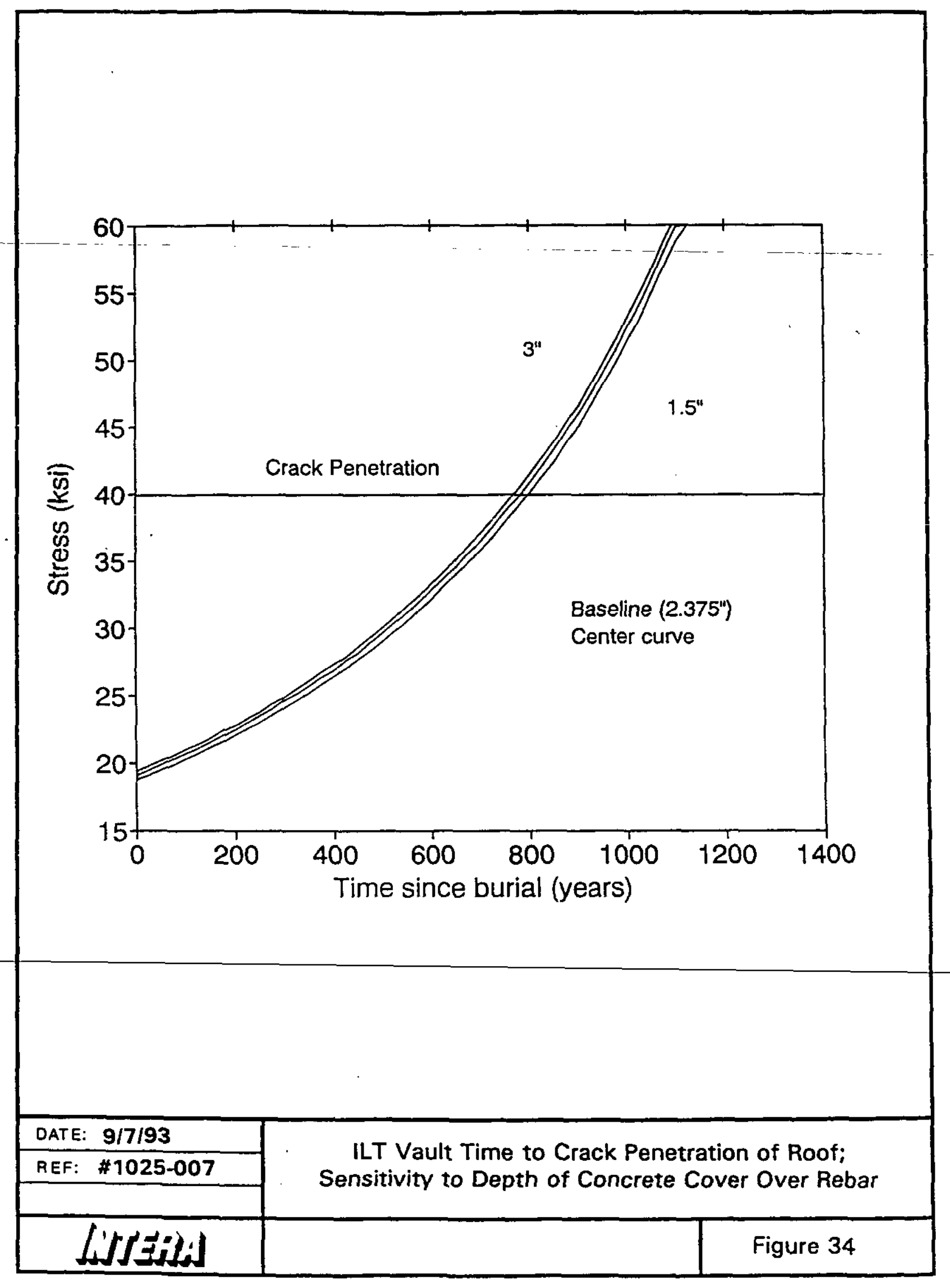




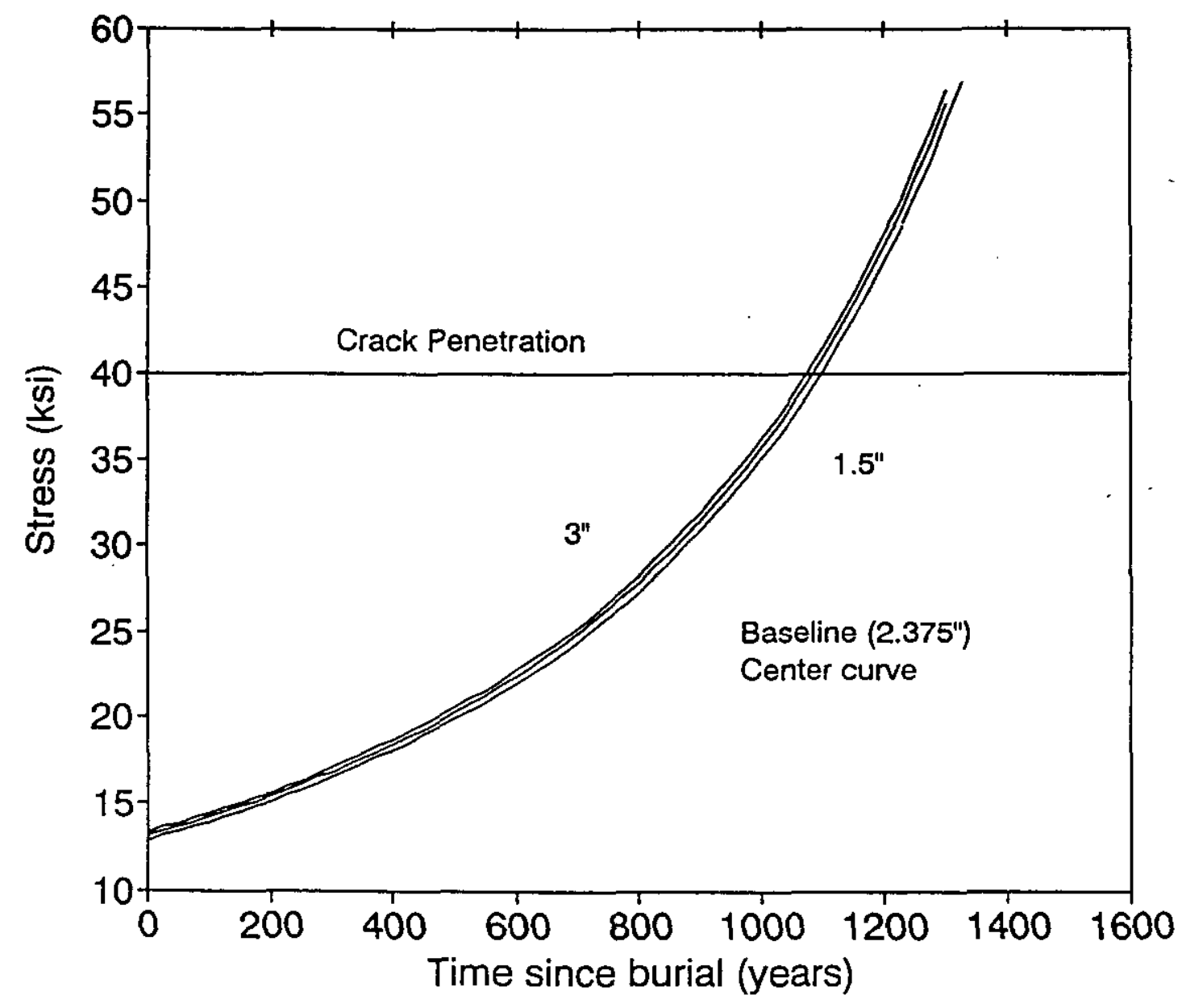

DATE: $9 / 7 / 93$

REF: \#1025-007

ILT Vault Time to Crack Penetration of Walls; Sensitivity to Depth of Concrete Cover over Rebar 


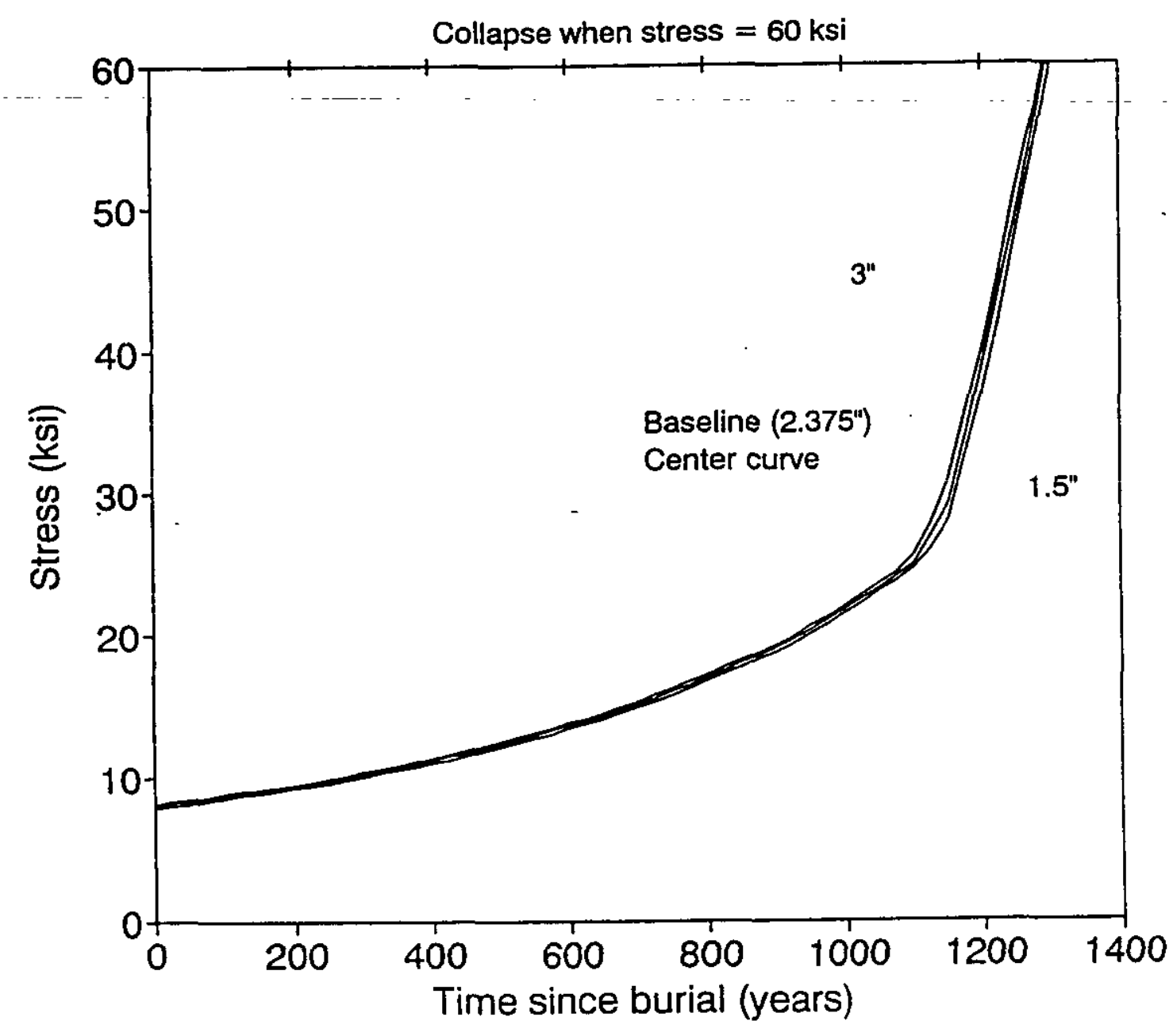

DATE: $9 / 7 / 93$

AEF: \#1025-007

ILT Vault Time to Roof Collapse;

Sensitivity to Depth of Concrete Cover Over Rebar

Figure 36 


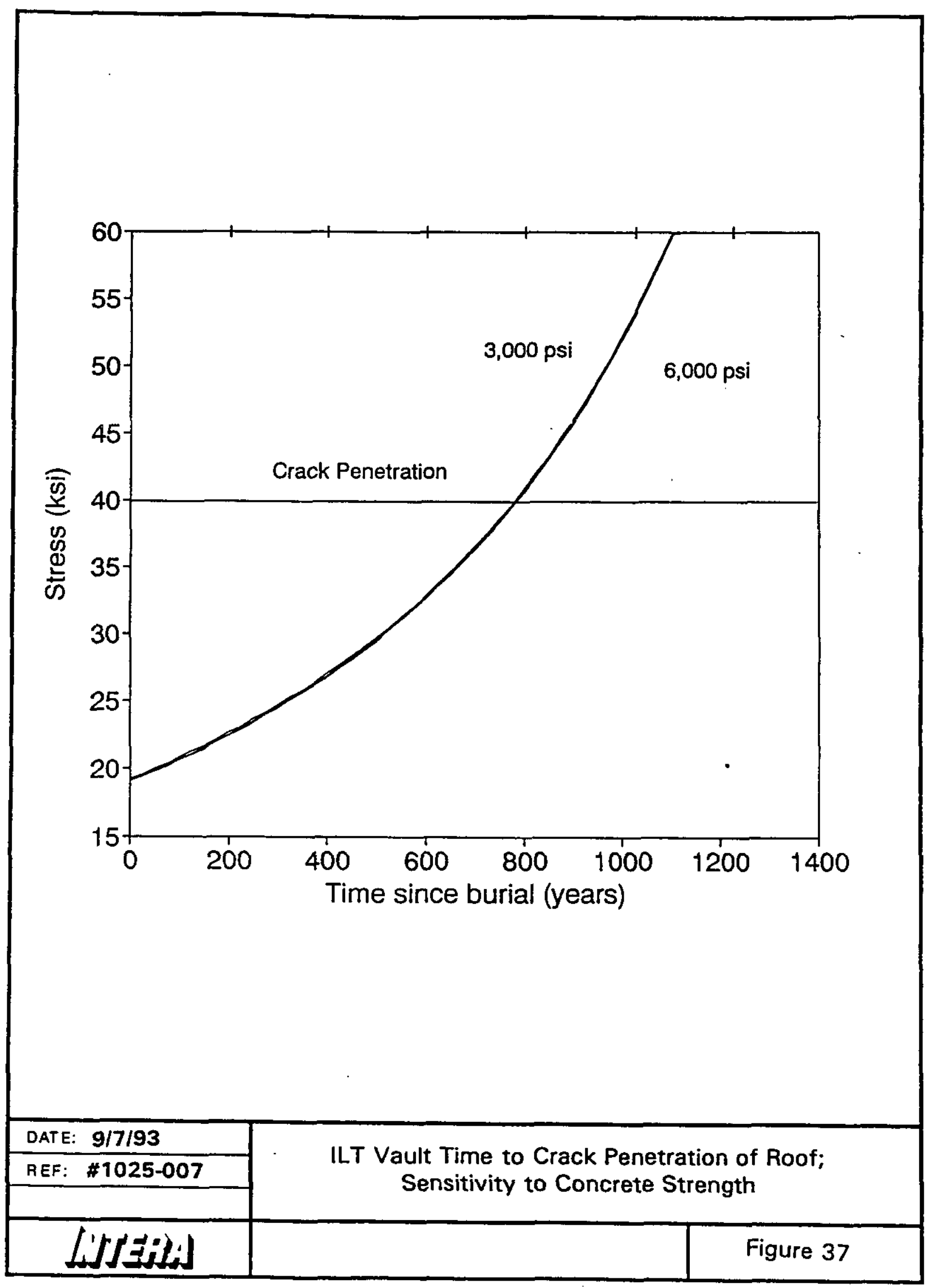




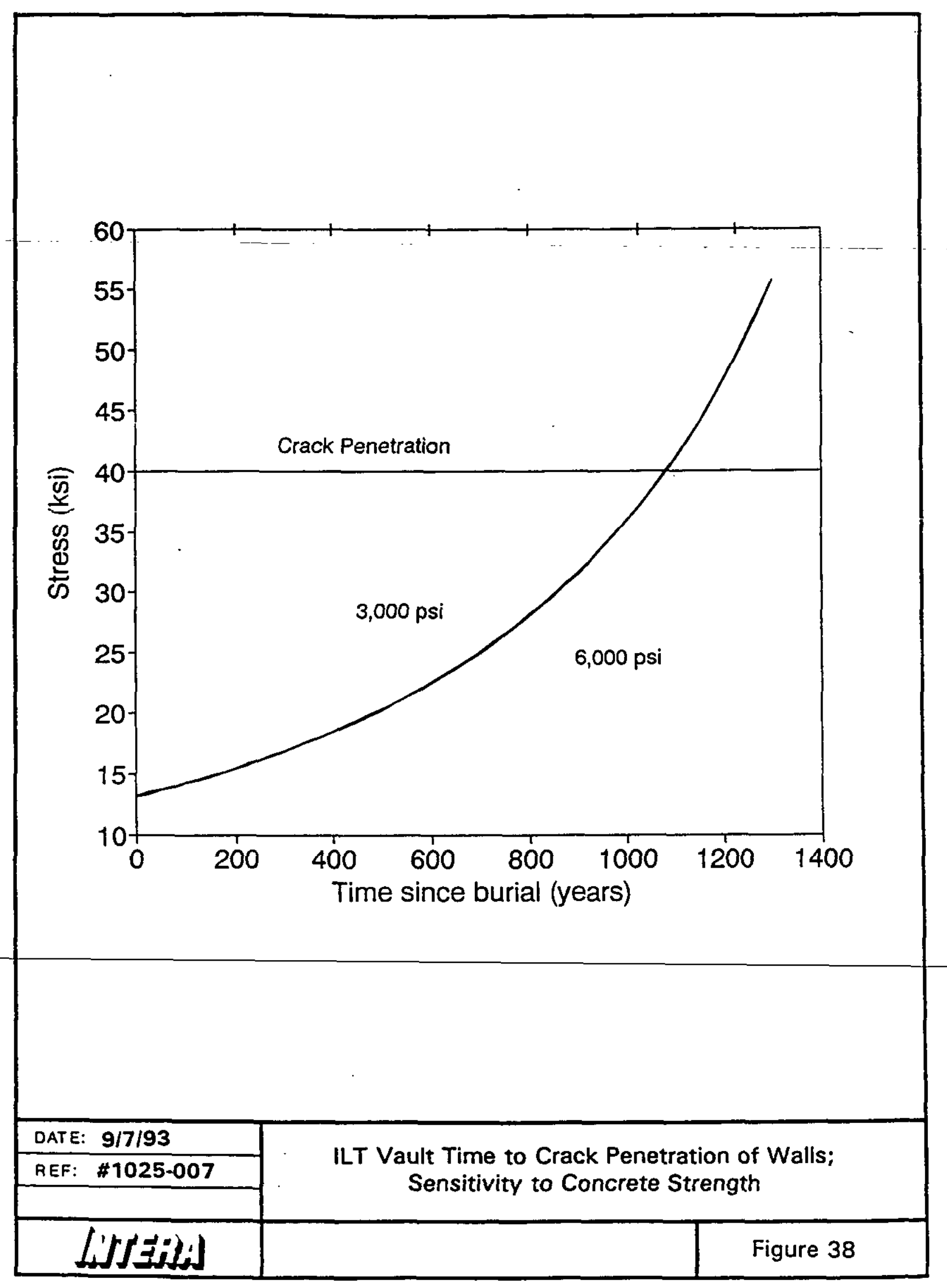




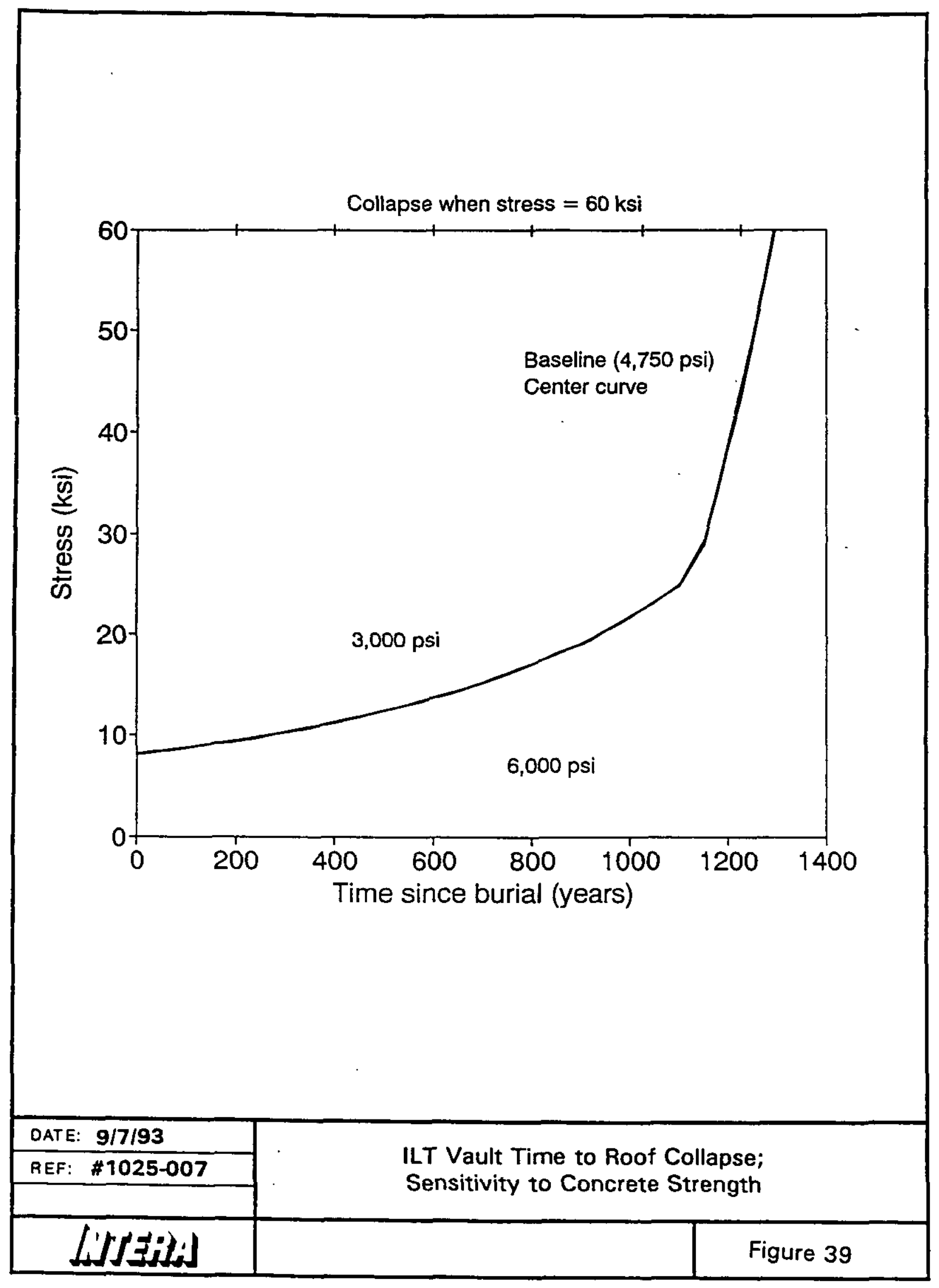




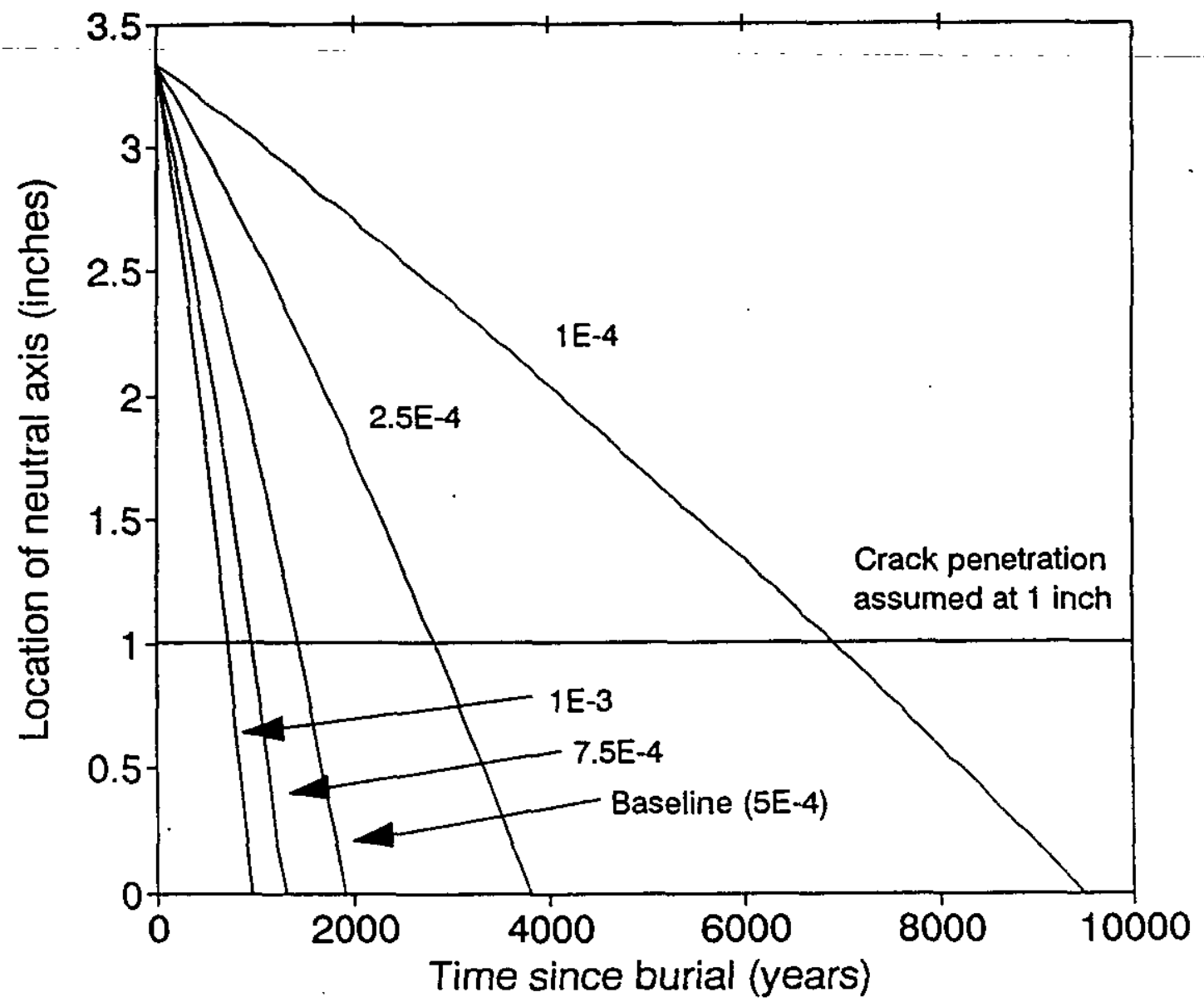

DATE: $9 / 7 / 93$

REF: \#1025-007

LAW Vault Time to Crack Penetration of Roof; Sensitivity to Hydrogen Evolution Corrosion Rate $(\mathrm{cm} / \mathrm{yr})$ 


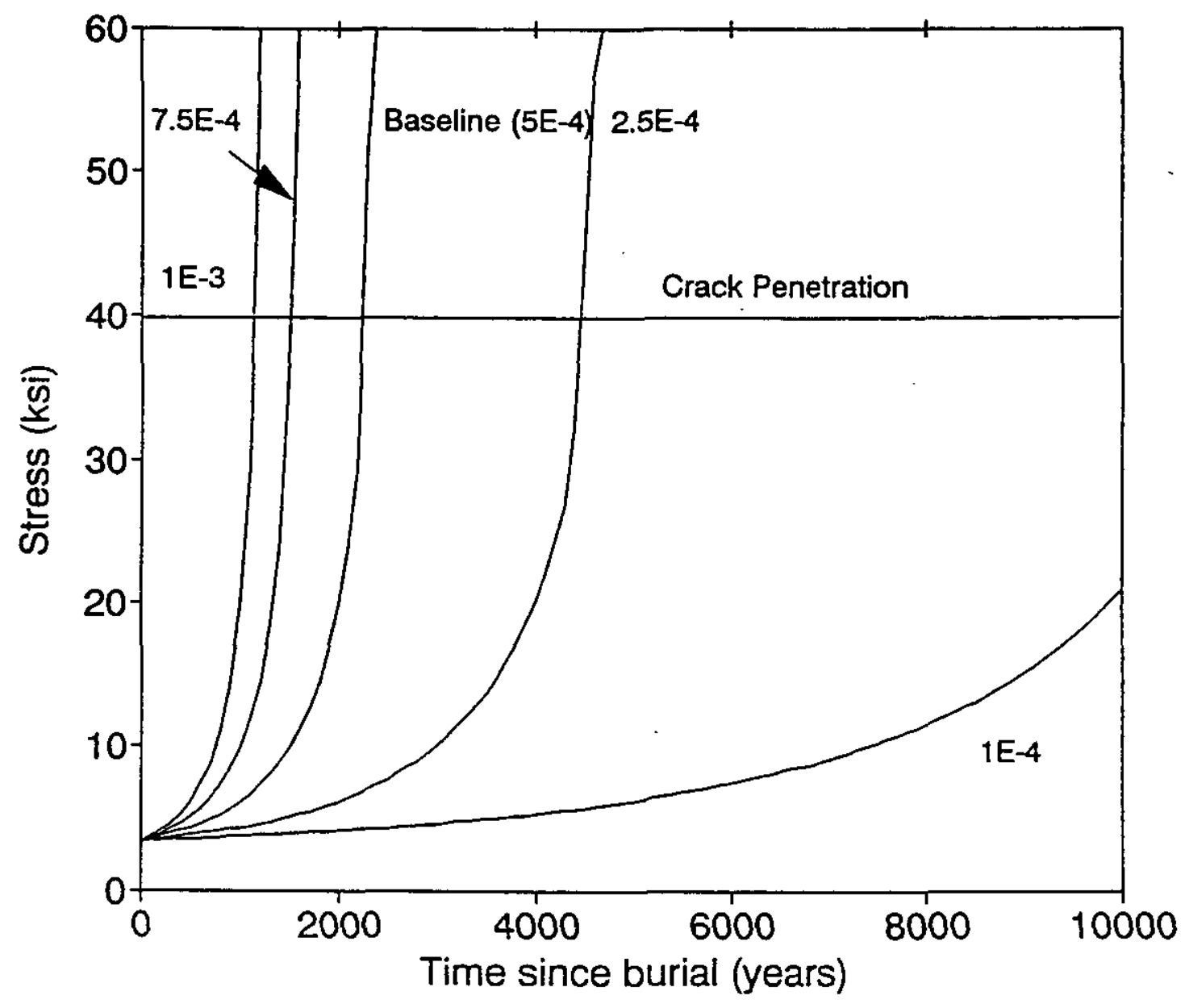

DATE: $9 / 7 / 93$

REF: \#1025-007

LAW Vault Time to Crack Penetration of Walls; Sensitivity to Hydrogen Evolution Corrosion Rate $(\mathrm{cm} / \mathrm{yr})$ 


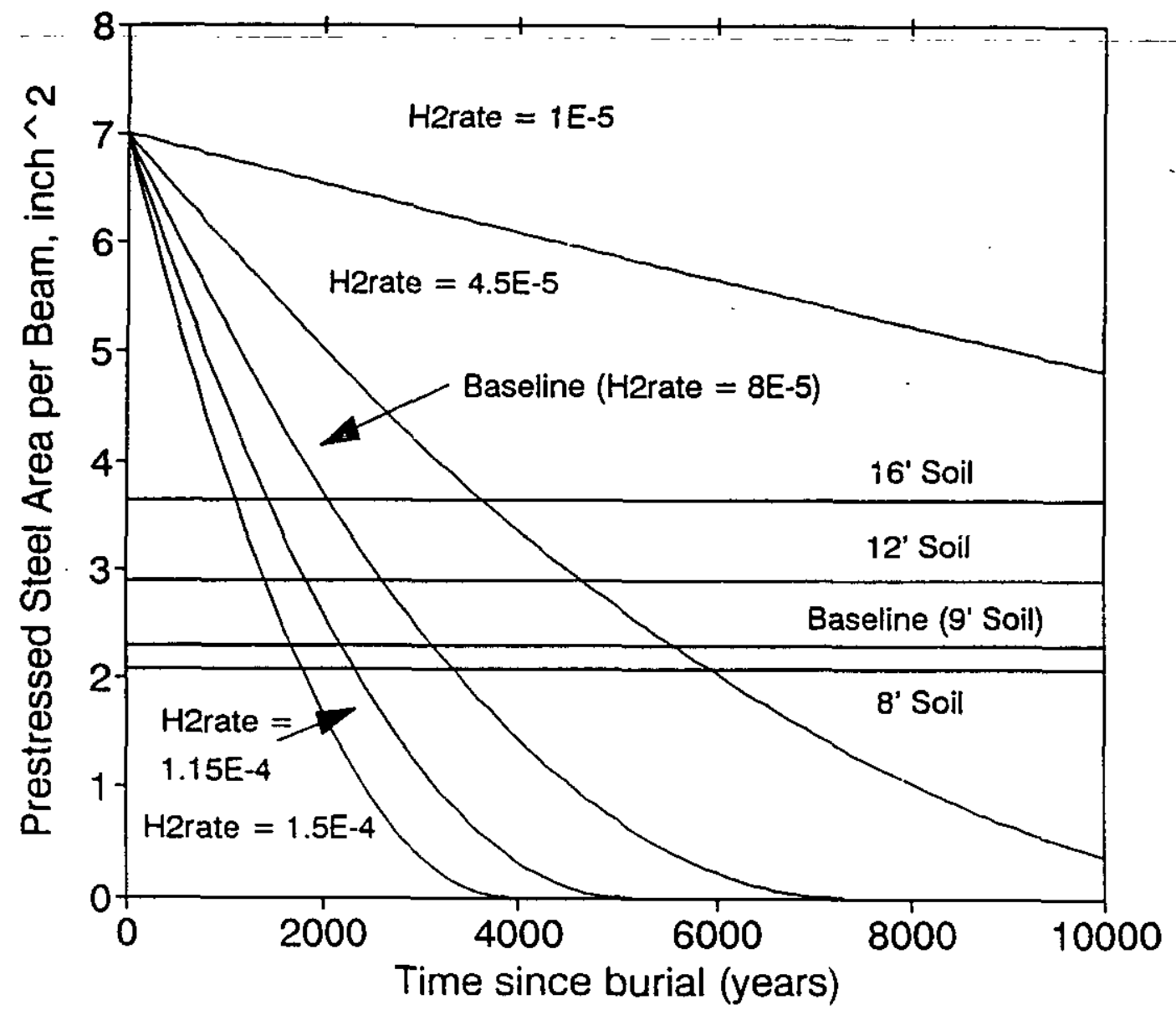

Horizontal lines indicate minimum prestressed steel area required for various depths of soil cover.

DATE: $9 / 7 / 93$

REF: \#1025-007

L'J'Jilid
LAW Vauit Time to Roof Collapse; Sensitivity to Hydrogen Evolution Corrosion Rate (H2rate; $\mathrm{cm} / \mathrm{yr}$ ) and Depth of Soil Cover 


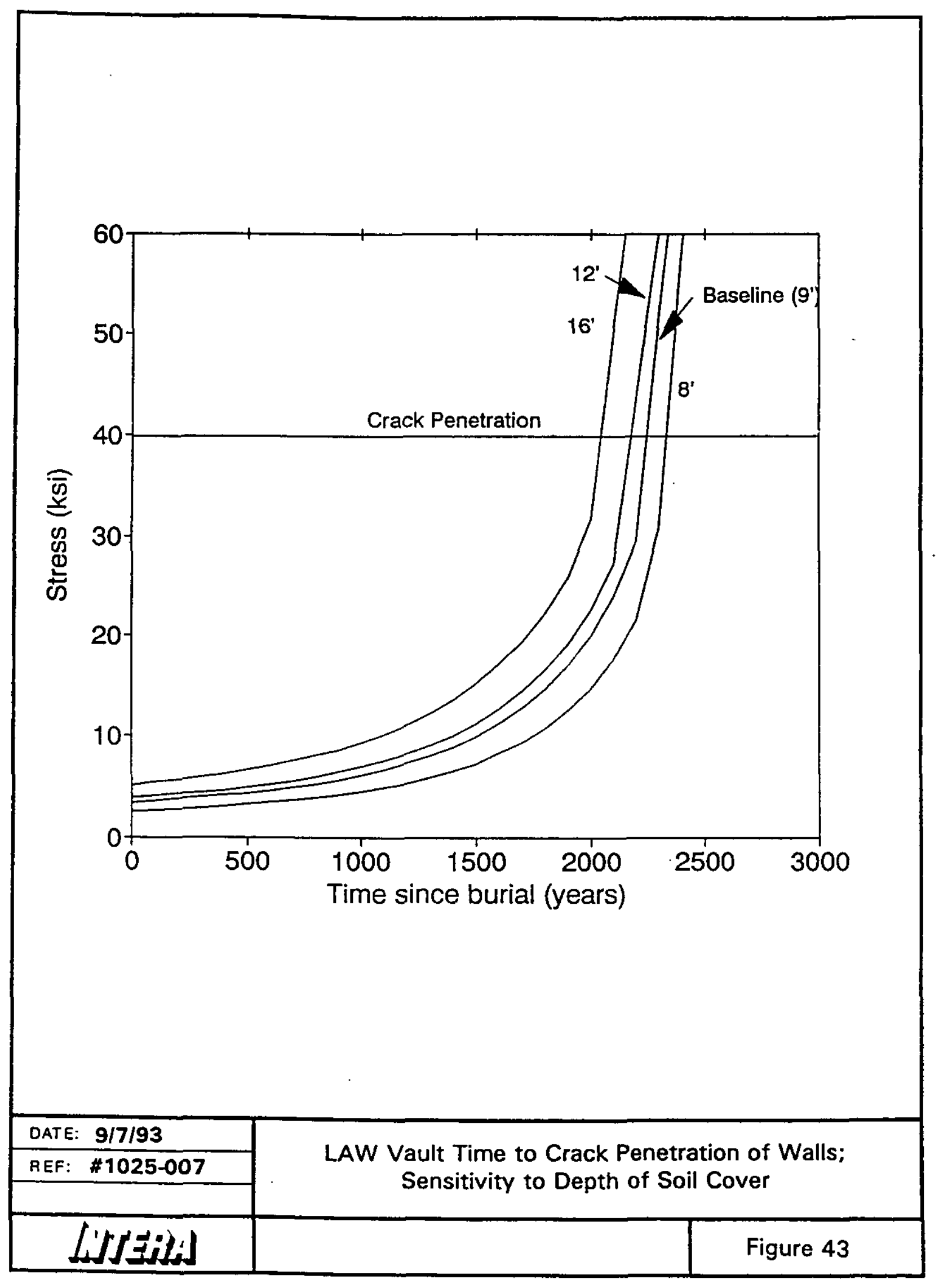




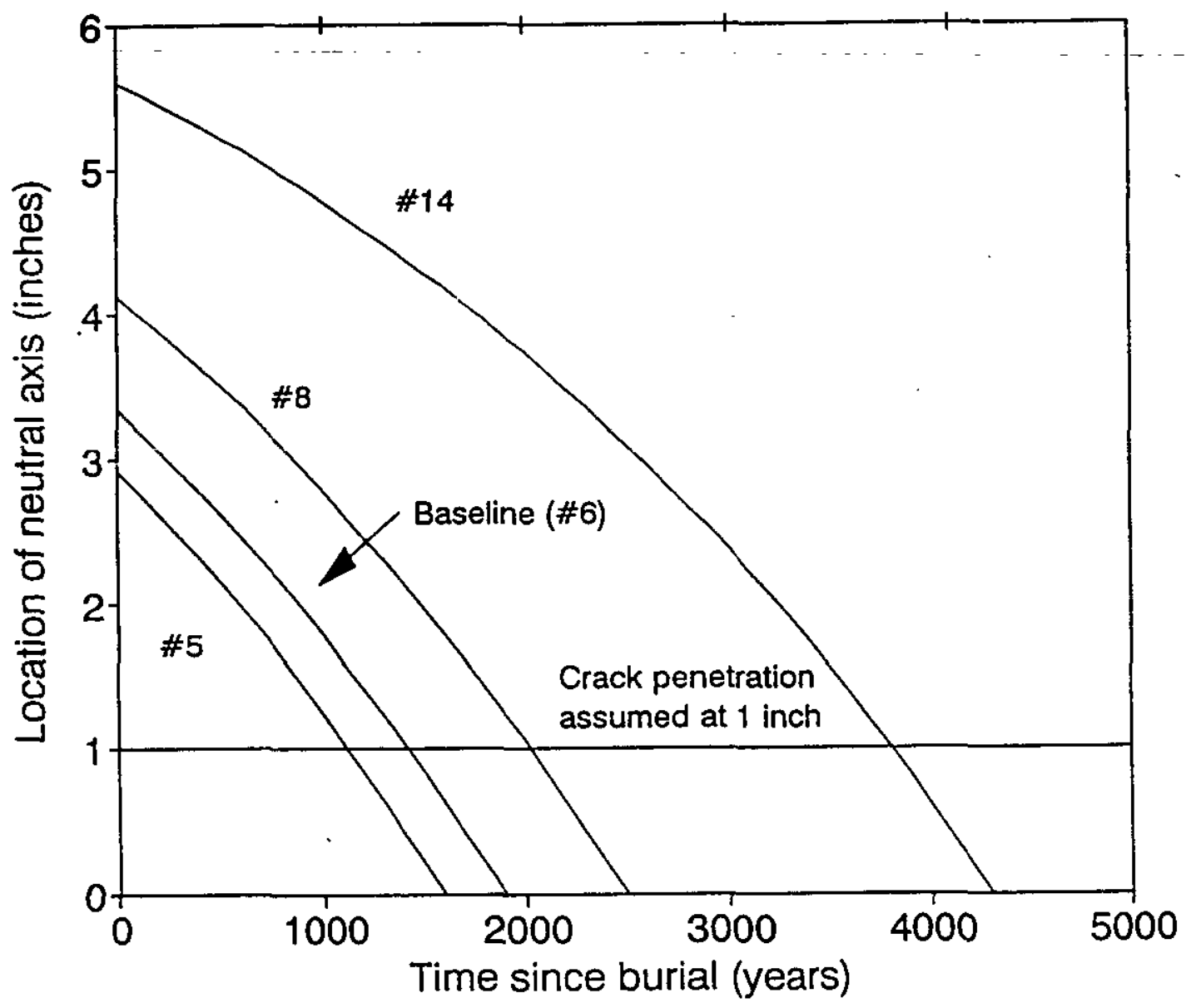

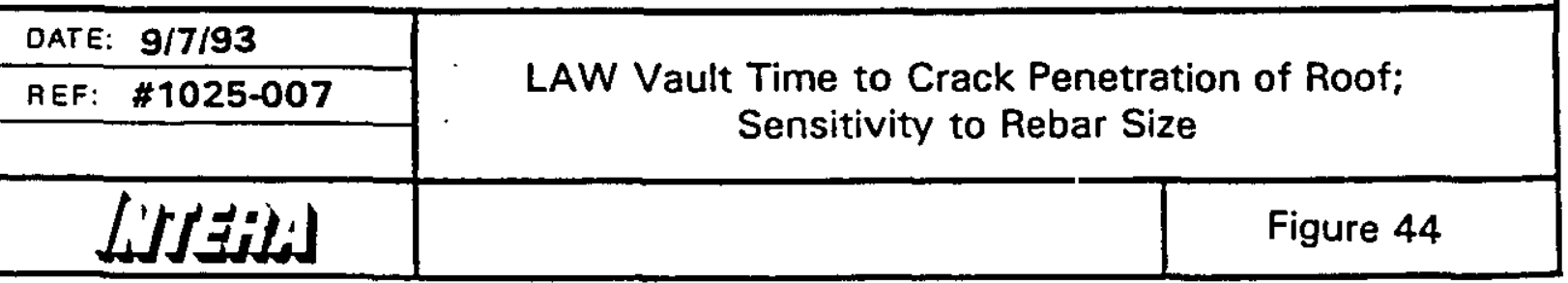




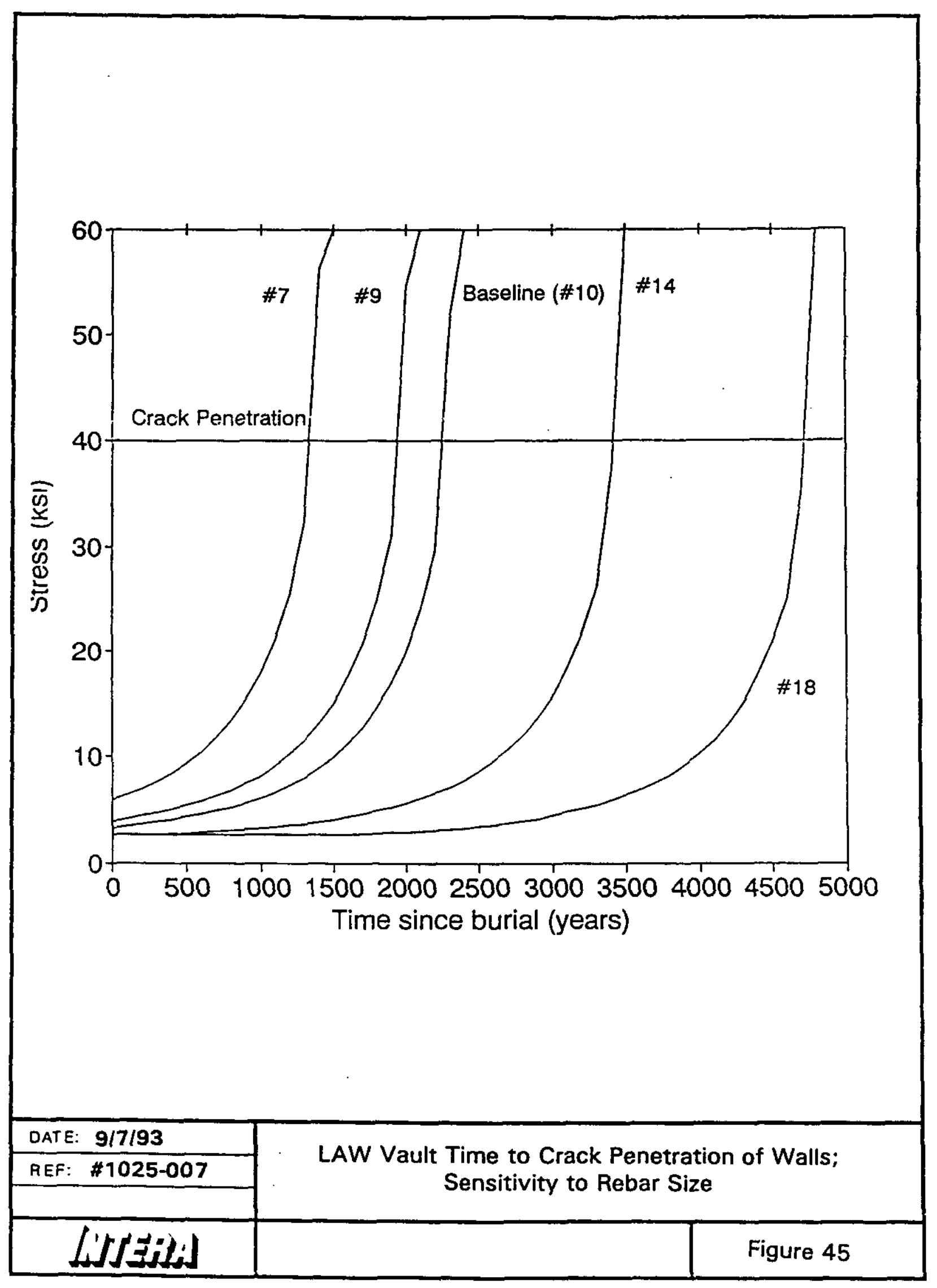




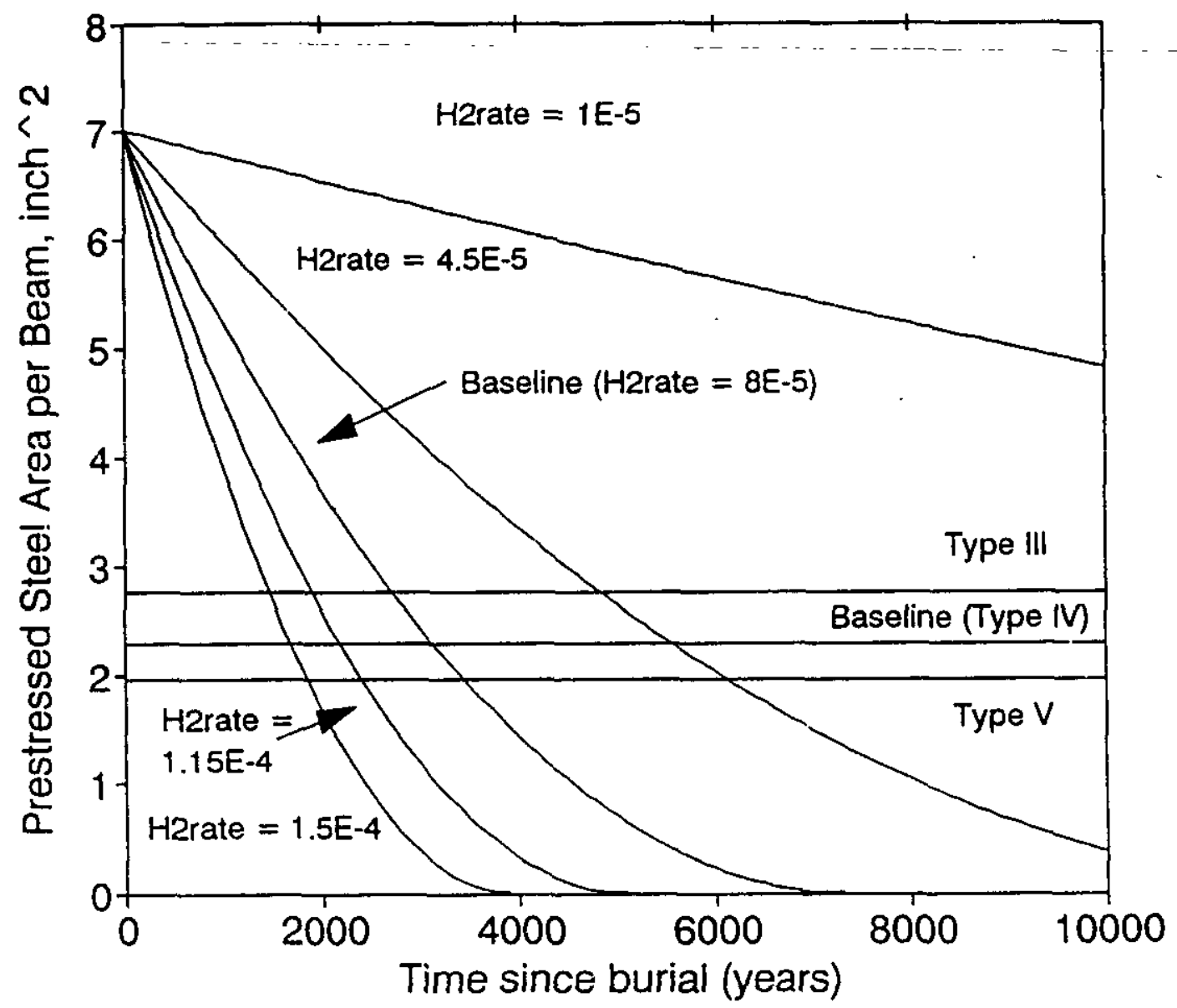

Horizontal lines indicate minimum prestressed steel area required for various sized AASHTO beams.

\begin{tabular}{|l|l|c|}
\hline DATE: $9 / 7 / 93$ & \multicolumn{2}{|c|}{$\begin{array}{c}\text { LAW Vault Time to Roof Collapse; } \\
\text { Sensitivity to Hydrogen Evolution Corrosion Rate } \\
\text { (H2rate; cm/yr) and Beam Type }\end{array}$} \\
\hline REF: \#1025-007 & \multicolumn{2}{|c|}{ Figure 46 } \\
\hline
\end{tabular}




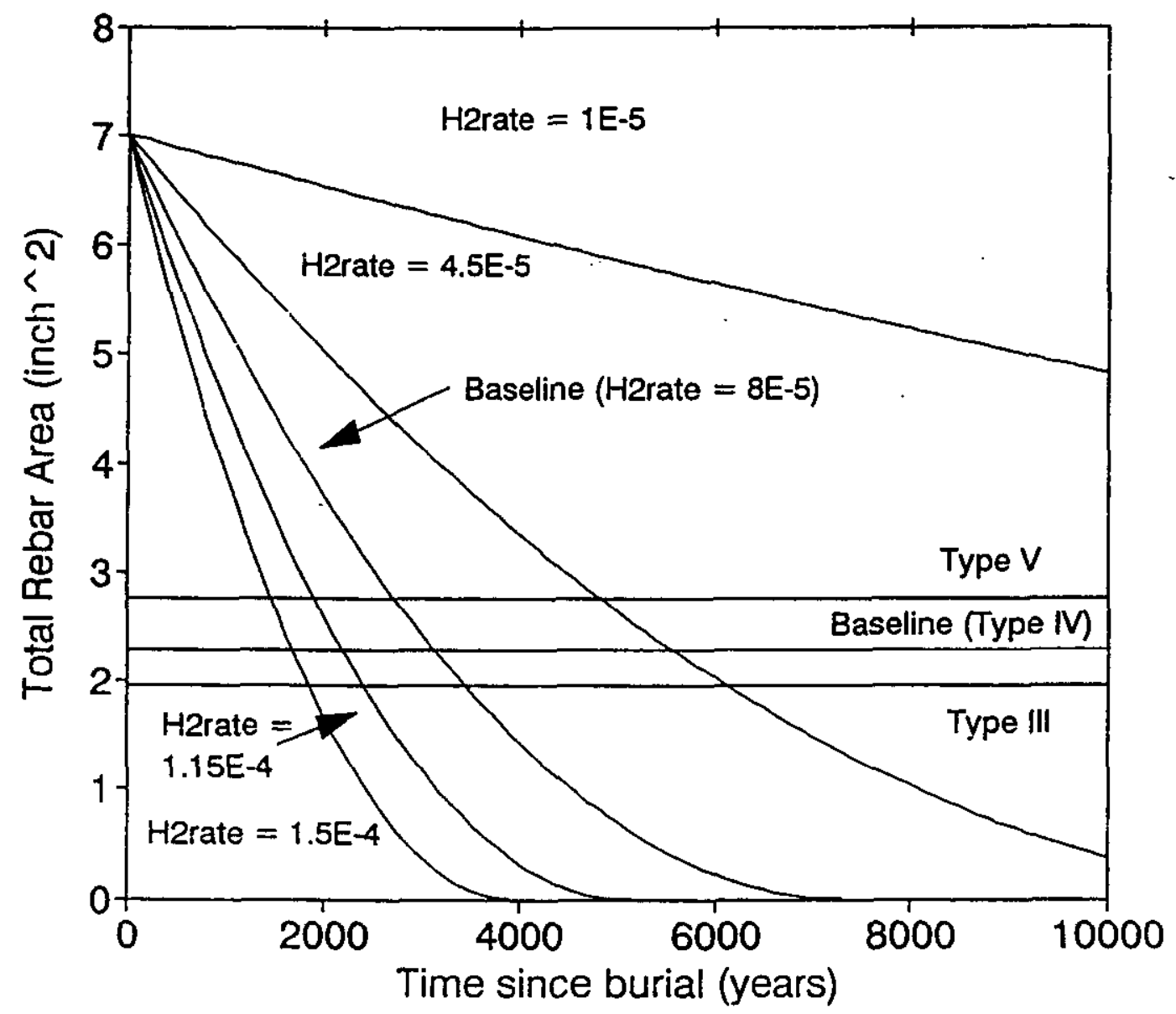

Horizontal lines indicate minimum prestressed steel area required for various sized AASHTO beams.

DATE: $9 / 7 / 93$

REF: \#1025-007
LAW Vault Time to Roof Collapse;

Sensitivity to Hydrogen Evolution Corrosion Rate (H2rate; $\mathrm{cm} / \mathrm{yr}$ ) and Beam Type 
ORIGINAL CONCRETE ROOF SURFACE

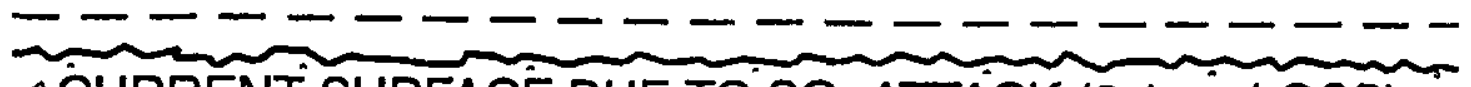
$\therefore$ CURRENT SURFACE DUE TO SO 4 ATTACK $(0.1 \mathrm{~cm}$ LOSS) Oم

THEORETICAL DEPTH OF CARBONATION $(0.9 \mathrm{~cm})$

$\therefore \therefore$ OHZONE $(=9.5)$

Nisis

๑LEACH PENETRATION: $5.9 \mathrm{~cm}$

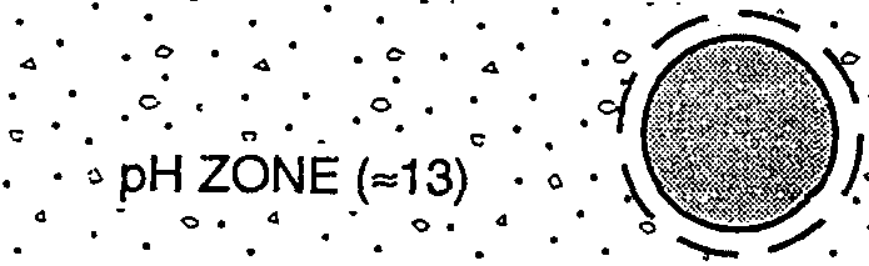

$\therefore \quad \therefore$ ORIGINAL REBAR RADIUS: $1.27 \mathrm{~cm}$

$\therefore \therefore$ CURRENT REBAR RADIUS: $1.25 \mathrm{~cm}$

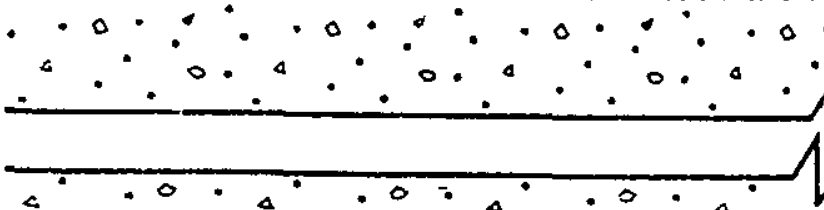

$\because \because \because 30$
PHZONE $(\approx 13)$

$\because$ pHZONE $(\approx 13)$

$\because \because \because . \because \therefore$.

$\therefore$ ORIGINAL REBAR RADIUS: $1.27 \mathrm{~cm}$

$\therefore \therefore$ MINIMAL REBAR LOSS $(0.006 \mathrm{~cm})$

VAULT INTERIOR

DATE: $9 / 7 / 93$

REF: \#1025-007

L'T'Jilid

Cross-Section of Vault Roof Assuming Use of High-pH Concrete; Degradation at 50 Years

Figure 47 


\section{ORIGINAL CONCRETE ROOF SURFACE}

- - - - - - - - - - - - - - - -

- CURRENT SURFACE DUETOSO ATTAK - CURRENT SURFACE DUE TO SO ATTACK $(0.7 \mathrm{~cm} \text { LOSS) })^{\star}$.

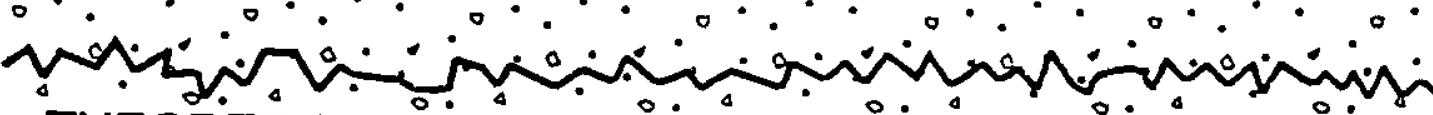
- THEOREETICAL DEPTH O̊F CARBONOATION $(2.60 \mathrm{~cm})$

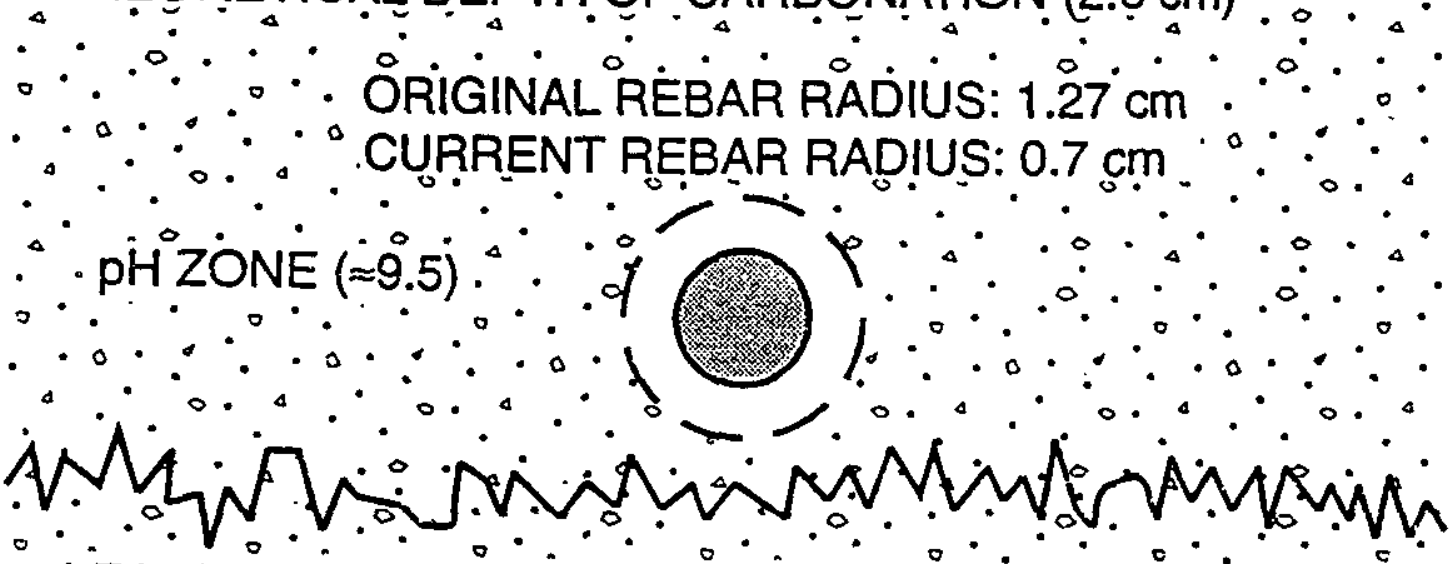
- LEACH PENETRATION: $16.7 \mathrm{~cm} \therefore$ PH ZONE $(\approx 13)$

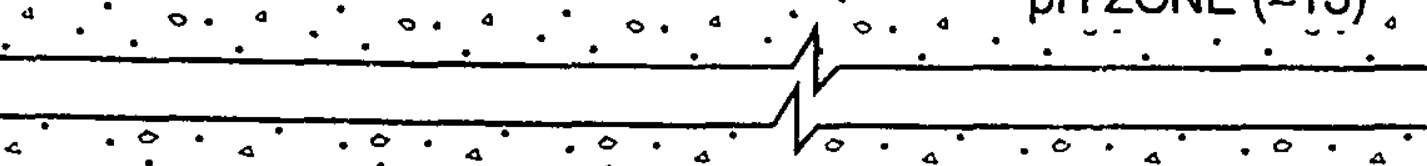

$\therefore$ PH ZONE $(\approx 13)$

\begin{tabular}{|c|c|}
\hline \multicolumn{2}{|c|}{ VAULT INTERIOR } \\
\hline DATE: $9 / 7 / 93$ & \multirow{2}{*}{$\begin{array}{l}\text { Cross-Section of Vault Roof Assuming Use of High-pH } \\
\text { Concrete; Degradation at } 400 \text { Years }\end{array}$} \\
\hline REF: \#1025-007 & \\
\hline L'JIJid & Figure 48 \\
\hline
\end{tabular}


THIS PAGE INTENTIONALLY LEFT BLANK 


$$
\begin{gathered}
\text { W.SRC-RP. } 94-0218 \text { Rev. } 117651 \\
\text { Pt. } 3
\end{gathered}
$$

RECORDS ADMINISTRATION<smiles>[GeH3]</smiles>

APPENDIX E

GEOCHEMICAL INTERACTIONS 
THIS PAGE INTENTIONALLY LEFT BLANK 


\section{E.1 INTRODUCTION}

Estimating the release of radionuclides from the E-Area Low Level Waste Facility is difficult because of the large variety of contaminated material that will be disposed of in the waste units. The discussion in this appendix focuses on geochemical considerations that may affect radionuclides contained in waste disposed in the LAW and IL vaults and in the intimately-mixed cement-stabilized waste and the cementstabilized encapsulated waste trenches.

Conceptually, radionuclides in waste contained in steel boxes (B-12 and B-25) or in activated metals disposed in the vaults as well as radionuclides in the intimately-mixed cement-stabilized waste and radionuclides in the cement-stabilized encapsulated waste will remain immobile until contacted by water that has leaked into the disposal units. Defensible estimation of water and contaminant movement these units and the effectiveness of boxes and activated metals in retarding waste release is not possible without development of a conservative simplified conceptual model. The key features of the conceptual model are summarized below.

Radionuclides in waste are immobile until contacted by water.

1) Water entering the disposal units will have a composition that can be represented as a mixture of concrete pore fluid and local groundwater equilibrated with soil levels of carbon dioxide gas.

2 Steel and activated metals present in the disposal units will result in the formation of corrosion products (i.e., hydrous $\mathrm{Fe}[\mathrm{III}]$ oxides) and lead to reducing conditions inside the units.

3) The entire radionuclide inventory is available to react with the reducing water inside the unit.

4) Aqueous radionuclide concentrations are controlled by sorption (represented with a $K_{d}$ or isotherm) onto corrosion products or grout with a solubility limited (oxide and hydroxide phases) upper concentration limit.

5) Contaminated water exiting the disposal units will interact with the concrete vault and/or grout and radionuclides will be chemically retarded by the vault wall and/or grout.

\section{E.2 RADIONUCLIDES CONSIDERED}

The radionuclides considered in detail for the LAW vaults are ${ }^{3} \mathrm{H},{ }^{14} \mathrm{C},{ }^{59} \mathrm{Ni},{ }^{79} \mathrm{Se},{ }^{87} \mathrm{Rb},{ }^{90} \mathrm{Sr},{ }^{93} \mathrm{Zr},{ }^{94} \mathrm{Nb}$, ${ }^{99} \mathrm{Tc},{ }^{107} \mathrm{Pd},{ }^{126} \mathrm{Sn},{ }^{129} \mathrm{I},{ }^{135} \mathrm{Cs},{ }^{232} \mathrm{Th},{ }^{232} \mathrm{U},{ }^{233} \mathrm{U},{ }^{234} \mathrm{U},{ }^{235} \mathrm{U},{ }^{236} \mathrm{U},{ }^{238} \mathrm{U},{ }^{237} \mathrm{~Np},{ }^{238} \mathrm{Pu},{ }^{239} \mathrm{Pu},{ }^{240} \mathrm{Pu},{ }^{241} \mathrm{Pu},{ }^{242} \mathrm{Pu}$, ${ }^{244} \mathrm{Pu},{ }^{241} \mathrm{Am},{ }^{243} \mathrm{Am},{ }^{244} \mathrm{Cm},{ }^{245} \mathrm{Cm},{ }^{246} \mathrm{Cm},{ }^{247} \mathrm{Cm},{ }^{248} \mathrm{Cm},{ }^{249} \mathrm{Cf}$, and ${ }^{252} \mathrm{Cf}$.

These radionuclides were selected for detailed numerical transport simulations based on the screening calculations discussed in Sect. 4.1.3. The anionic radioactive isotopes of $\mathrm{C}$, Tc, and $\mathrm{I}$, as well as tritium are weakly sorbed to corrosion products. If conditions in the vault are reducing enough, the anion $\mathrm{Tc}$ (VII) may be reduced to insoluble Tc(IV). Tritium release from tritium crucibles in the IL vaults was found to be limited by transport through the vault sufficiently that no leach rate calculations were required to reach adequate performance. Distribution coefficients for many of the remaining radionuclides were developed based on hydrous ferric oxide (HFO) adsorption. 


\section{E.3 VAULT WATER COMPOSITION}

Water compositions inside these disposal units will reflect the interaction of concrete pore water and vadose water. The composition of the water in the disposal units will be dominated by concrete interactions even under conditions of fracture flow through the vault or wasteform. The presence of $\mathrm{CO}_{2}$ gas in the soil and calcite present as a weathering product in the cement will buffer the $\mathrm{pH}$ of the disposal unit water to between 7 and 8 .

\section{E.4 RADIONUCLIDE SORPTION BEHAVIOR}

Wastes disposed of in the LAW vaults will be contained in steel boxes (B-12 and B-25). The basic assumption of the method used to derive distribution coefficients for the LAW vault waste form is that the corrosion of the boxes will result in the formation of HFO, (e.g., goethite) and that any water contaminated with radionuclides must pass over the corroded area of the box.

Distribution coefficients $\left(K_{d}\right)$ based on surface area of the adsorbent for the selected radionuclides were estimated by assuming that adsorption occurs exclusively on the corrosion products (HFO) of these boxes. The total potential concentration of HFO in the vault is $0.07 \mathrm{~g} / \mathrm{cm}^{3}$ [based on $9730 \mathrm{~B}-25$ at 350 lbs and $4330 \mathrm{~B}-12$ boxes at $300 \mathrm{lbs}$ in a $1,700,000 \mathrm{ft}^{3}$ vault (Harley 1990a,b)]. The surface area of goethite in the vault is predicted to be $32,000 \mathrm{~cm}^{2} / \mathrm{cm}^{3}$ based on a specific surface area of goethite of $450,000 \mathrm{~cm}^{2} / \mathrm{g}$ (Hsi and Langmuir 1985).

Numerous adsorption studies of metal and radionuclides onto hydrous metal oxides are reported in the literature (see Dzombak and Morel 1990). Specific studies for key radionuclides (summarized below) were used to estimate $K_{d}$ values at $\mathrm{pH} 8$ for the waste assuming $\mathrm{HFO}$ is the only reactive phase. Distribution coefficients for radionuclides that lack adsorption experiments were estimated using elemental analogs. The $K_{d}$ is calculated by relating the experimental data (i.e. fraction adsorbed and suspension concentration) to the waste in the vaults (i.e. surface area and bulk density of waste). This is accomplished by using the following equation.

$\mathrm{K}_{\mathrm{d}}=\mathrm{SAX} / \mathrm{rSA} \exp (1-X)$

where

SA is the specific surface area of the waste $\left(32,000 \mathrm{~cm}^{2} / \mathrm{cm}^{3}\right)$

$X$ is the fraction adsorbed

is the bulk density of the waste $\left(1.6 \mathrm{~g} / \mathrm{cm}^{3}\right)$

$\mathrm{SA}_{\text {exp }}$ is the concentration of solid in the adsorption experiment $\left(\mathrm{cm}^{2} / \mathrm{mL}\right)$

Estimated $K_{d}$ values for the LAW vaults are summarized below (Table E.4-1). 
Table E.4-1. Summary of distribution coefficients for selected radionuclides on goethite ( $\mathrm{pH}=\mathbf{8 . 0}$ )

\begin{tabular}{|c|c|c|}
\hline Radionuclide & Chemical Form & $\begin{array}{c}\begin{array}{c}\text { Distribution Coefficient } \\
(\mathrm{mL} / \mathrm{g})\end{array} \\
\end{array}$ \\
\hline $\mathrm{H}-3$ & HTO & 0 \\
\hline C-14 & $\mathrm{CO}_{3}{ }^{2-}$ & 0 \\
\hline Tc-99 & $\mathrm{TcO}_{4}^{-}$ & 0 \\
\hline $\mathrm{I}-129$ & $\mathrm{I}^{-}$ & 0 \\
\hline Cs-135 & $\mathrm{Cs}^{+}$ & \\
\hline Sr-90 & $\mathrm{Sr}^{2+}$ & 3 \\
\hline$Y-90$ & $\mathrm{Y}^{3+}$ & 3 \\
\hline $\mathrm{Sn}-126$ & $\mathrm{Sn}^{2+}$ & 55 \\
\hline $\mathrm{Ra}-226$ & $\mathrm{Ra}^{2+}$ & 60 \\
\hline Se-79 & $\mathrm{SeO}_{3}{ }^{2-}$ & 170 \\
\hline $\mathrm{Ni}-59$ & $\mathrm{Ni}^{2+}$ & 1200 \\
\hline Th-232 & $\mathrm{Th}^{4+}$ & 2200 \\
\hline $\mathrm{U}-234,235,236,238$ & $\mathrm{UO}_{2}{ }^{2+}$ & 6000 \\
\hline Np-237 & $\mathrm{NpO}_{2}^{+}$ & 750 \\
\hline $\mathrm{Pu}-238,239,240,241,242,244$ & $\mathrm{Pu}^{4+}$ & 2000 \\
\hline $\mathrm{Am}-241,243$ & $\mathrm{Am}^{3+}$ & 3700 \\
\hline $\mathrm{Cm}-244,245,246,247,248$ & $\mathrm{Cm}^{3+}$ & 3700 \\
\hline Bk-247, 249 & $\mathrm{Bk}^{3+}$ & 3700 \\
\hline $\mathrm{Cf}-249,251,252$ & $\mathrm{Cf}^{3+}$ & 3700 \\
\hline
\end{tabular}




\section{Plutonium}

Aqueous plutonium speciation is very complex because it may be simultaneously present in four oxidation states (III, IV, V, VI). The dominant oxidation states of plutonium in oxygenated waters are $\mathrm{Pu}(\mathrm{V})$ and $\mathrm{Pu}(\mathrm{VI})$ based on calculations and analyses (Nelson and Lovett 1978 and 1981; Nelson and Orlandini 1979; Bondietti and Trabalka 1980). Because of the large amount of reducing material, conditions inside these disposal units will not be oxidizing enough to support Pu(VI) species. The predominant oxidation states expected are $\mathrm{Pu}(\mathrm{V})$ and $\mathrm{Pu}(\mathrm{IV})$.

Plutonium adsorption on synthetic goethite as functions of $\mathrm{pH}$, ionic strength, carbonate alkalinity, and dissolved organic carbon was measured by Sanchez et al. (1985). The experiments consisted of a synthetic goethite suspension with a surface area of $285 \mathrm{~cm}^{2} / \mathrm{mL}$ in a borosilicate glass reaction vessel. Hydrogen activity was controlled using $\mathrm{HCl}$ or $\mathrm{NaOH}$. Adsorption of $\mathrm{Pu}(\mathrm{IV})$ is much stronger than $\mathrm{Pu}(\mathrm{V})$ on goethite because it is more strongly hydrolyzed. The adsorption edge for $\mathrm{Pu}(\mathrm{IV})$ occurs from pH 3 to 5 (Fig. E.4-1a) with relatively rapid kinetics (equilibrium reached in $1 \mathrm{~h}$ ). Pu(V) adsorption is much slower and equilibrium was not achieved after 20 days (Fig. E.4-1b). The Pu(V) adsorption edge changes with time from $\mathrm{pH} 7$ to $\mathrm{pH} 5$ over the 20 day period. Although $\mathrm{Pu}(\mathrm{V})$ is predicted to be stable based on thermodynamic calculations the slow shift of the adsorption edge toward that of Pu(IV) suggests that $\mathrm{Pu}(\mathrm{V})$ may be reduced to $\mathrm{Pu}(\mathrm{IV})$. The reduction may take place on the goethite surface after adsorption of the $\mathrm{Pu}(\mathrm{V})$ or $\mathrm{Pu}(\mathrm{V})$ may be reduced as it nears the goethite surface and the $\mathrm{Pu}(\mathrm{IV})$ state is adsorbed (Sanchez et al. 1985).

Adsorption of $\mathrm{Pu}(\mathrm{IV})$ or $\mathrm{Pu}(\mathrm{V})$ was not significantly affected by ionic strength in the range of 0.1 to $3 \mathrm{M}$ $\mathrm{NaNO}_{3}$ or $\mathrm{NaCl}$ (see Table E.4-2). A decrease in Pu adsorption on goethite occurs with increased carbonate alkalinity. However, this occurs at much higher alkalinity levels than will be found in these disposal units (Fig. E.4-2).

The data used to estimate $\mathrm{Pu}$ adsorption for these units is for a $\mathrm{pH}$ of 7 (negligible change from $\mathrm{pH} 7$ to 8) and a total $\mathrm{Pu}$ concentration of $10^{-11} \mathrm{M}$. At these conditions, $97.1 \%$ of the $\mathrm{Pu}$ is on the solid (Table D.4-2). This sorption fraction is consistent with a $\mathrm{K}_{d}$ of $2,000 \mathrm{~mL} / \mathrm{g}$ for expected bulk density and HFO content in the disposal units using Eq. 1.

\section{Uranium}

Uranium partitioning onto HFO under varying $\mathrm{pH}$, ionic strength, competing cation and complexing anions is described by Hsi and Langmuir (1985). The HFO used by Hsi and Langmuir were amorphous ferric oxyhydroxide, goethite, and hematite. Uranyl species were strongly adsorbed to all three of the iron oxides considered at $\mathrm{pHs}$ above 5 to 6 . The most adsorptive oxide considered was the amorphous ferric oxyhydroxide with natural hematite providing the least amount of adsorption. These differences in adsorption result from the difference in specific surface area of the polymorphs. We have calculated the adsorption of uranium in the waste based on goethite representing the steel corrosion products.

The surface area of the goethite suspension was $450 \mathrm{~cm}^{2} / \mathrm{mL} . \mathrm{HNO}_{3}$ and $\mathrm{NaOH}$ were used to maintain $\mathrm{pH}$ with a total uranyl concentration of $10^{-5} \mathrm{~m}$. Goethite removes over $99 \%$ of the $U$ from solution above pH 6 (Fig. E.4-3a). Uranyl adsorption was not affected by the presence of calcium and magnesium at total solution concentrations of $10^{-3} \mathrm{M}$. The disposal unit pore fluid concentrations of $\mathrm{Ca}^{2+}$ and $\mathrm{Mg}^{2+}$ are anticipated to be lower than this and there-fore should not result in reduced uranyl adsorption. 


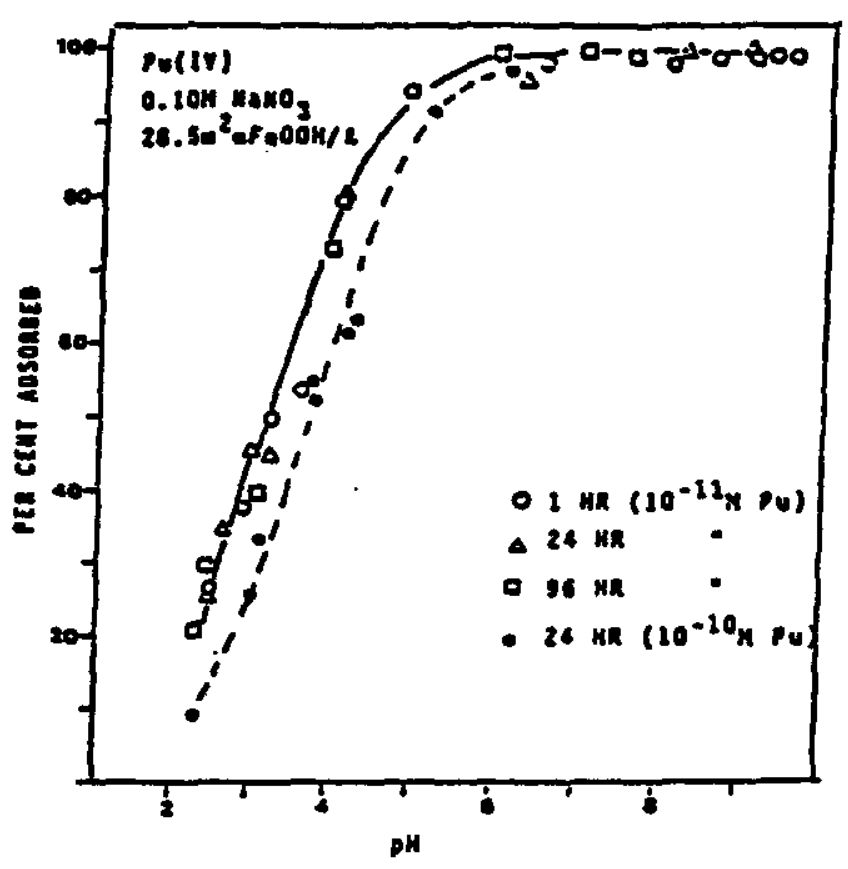

a)

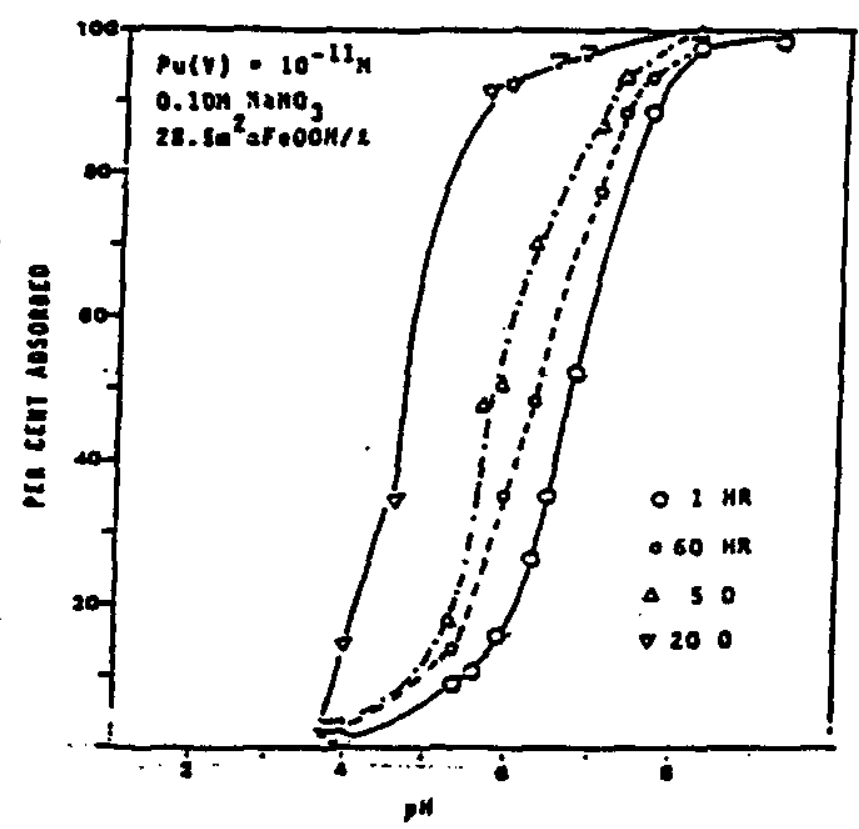

b)

Figure E.4-1 Adsorption of $\mathrm{Pu}$ on goethite as a function of $\mathrm{pH}$ at two plutonium concentrations (from Sanchez et al. 1985). a) Pu(IV), b) Pu(V). 
Table E.4-2. Adsorption of $\mathrm{Pu}(\mathrm{IV})$ on goethite as a function of ionic strength $(\mathrm{pH}=7.0$, Total $\mathrm{Pu}$ $=10^{-11} M$ ) from Sanchez et al. 1985

\begin{tabular}{cc}
$\begin{array}{c}\text { Electrolyte } \\
\text { Solution }\end{array}$ & $\begin{array}{c}\text { Percent Adsorbed } \\
\text { at Equilibrium }\end{array}$ \\
\hline $0.1 \mathrm{M} \mathrm{NaNO}_{3}$ & 97 \\
$0.5 \mathrm{M} \mathrm{NaNO}_{3}$ & 97 \\
$1.0 \mathrm{M} \mathrm{NaNO}_{3}$ & 98 \\
$3.0 \mathrm{M} \mathrm{NaNO}_{3}$ & 98 \\
$0.5 \mathrm{M} \mathrm{NaNO}_{3}$ & 98 \\
$3.0 \mathrm{M} \mathrm{NaNO}_{3}$ & 97 \\
$0.03 \mathrm{M} \mathrm{NaNO}_{3}$ & 97 \\
$0.15 \mathrm{M} \mathrm{NaNO}_{3}$ & 97 \\
$0.30 \mathrm{M} \mathrm{NaNO}_{3}$ & 95 \\
$\mathrm{Mean}^{2}$ & 97.1 \\
\hline
\end{tabular}

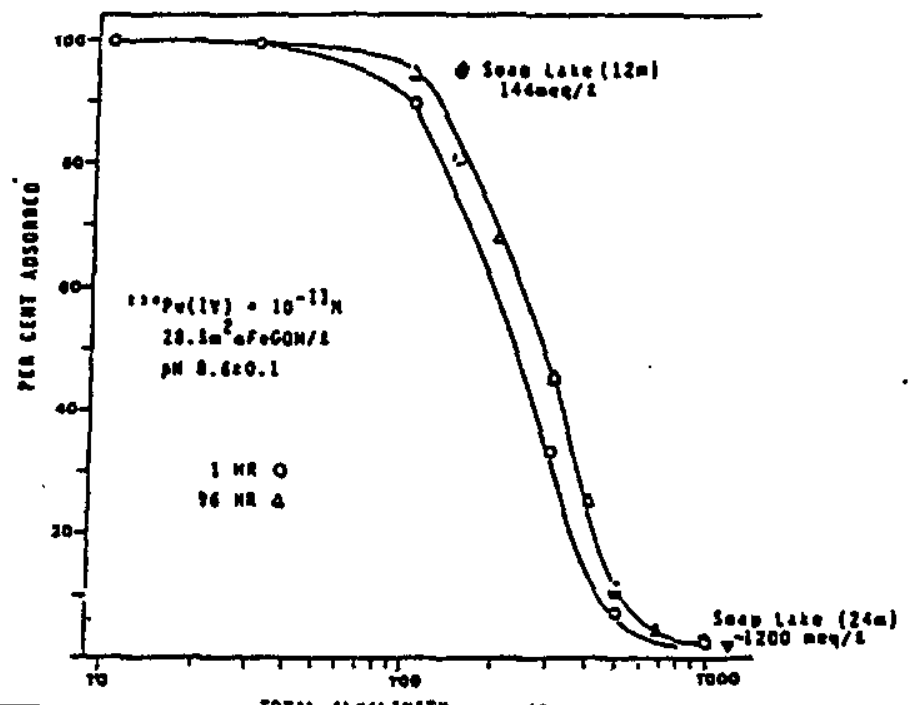

Figure E.4-2 The effect of carbonate alkalinity on the adsorption of $\mathrm{Pu}(\mathrm{IV})$ on goethite (from Sanchez et al. 1985). Alkalinity in the vault will be approximately $60 \mathrm{meq} / \mathrm{L}$.expected bulk density and HFO content in the vaults using Eq. 1. 


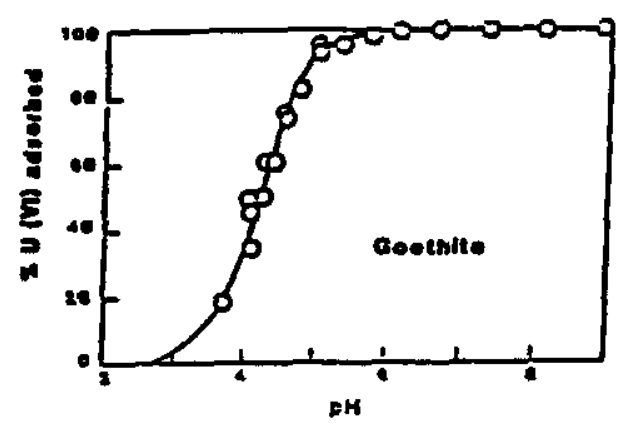

a)

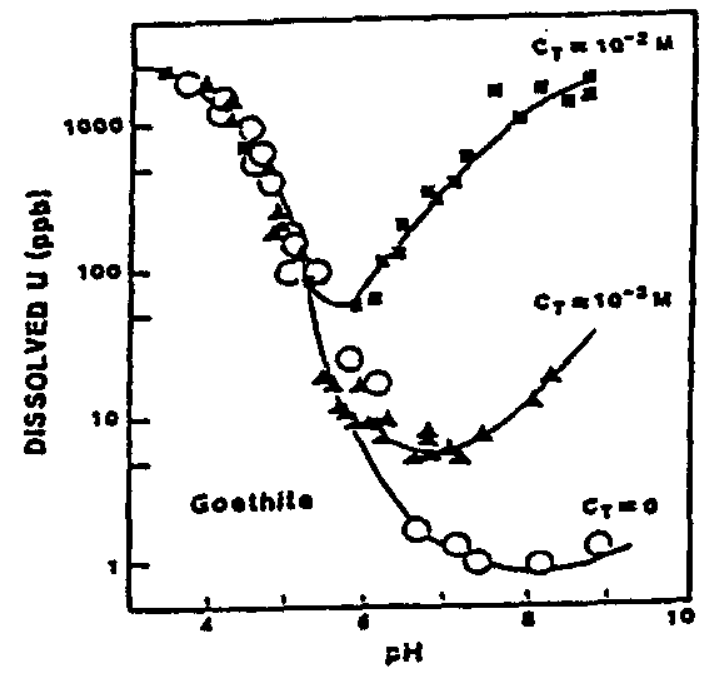

b)

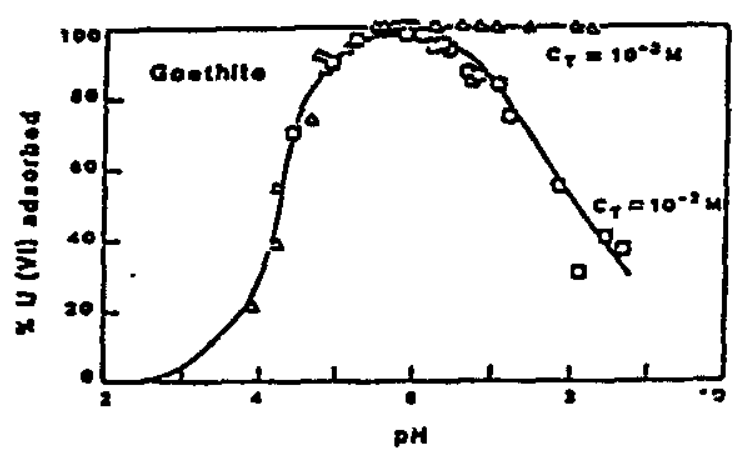

c)

Figure E.4-3 Adsorption of uranyl on a $1 \mathrm{~g} / \mathrm{L}$ goethite suspension as a function of $\mathrm{pH}$ in a $0.1 \mathrm{M}$ $\mathrm{NaNO}_{3}$ solution (from Hsi and Langmuir 1985). a) uranyl at $10^{-5} \mathrm{M}, \mathrm{b}$ ) dissolved uranium at $10^{-5} \mathrm{M}$ and varying total carbonate, c) effect of changes in total carbonate on the adsorption 
Total carbonate concentration influences the adsorption of uranium (VII) on goethite. Higher $\mathrm{CO}_{3}^{2-}$ content in solution results in increased uranyl carbonate complexation, predominantly $\mathrm{UO}_{2}\left(\mathrm{CO}_{3}\right)_{2}{ }^{2-}$ and $\mathrm{UO}_{2}\left(\mathrm{CO}_{3}\right)_{3}{ }^{4}$, and decreases adsorption of $\mathrm{UO}_{2}{ }^{2+}$ above $\mathrm{pH} 6$ (Fig. E.4-3b). The affect of total carbonate on the adsorption of $\mathrm{UO}_{2}{ }^{2+}$ is very evident in plots of soluble uranium versus $\mathrm{pH}$ with varying carbonate concentrations (Fig. E.4-3c). The dissolved uranium concentration at $\mathrm{pH} 7$ for a carbonate concentration of $10^{-3} \mathrm{M}$ was selected for use in the $\mathrm{K}_{\mathrm{d}}$ estimation because this carbonate concentration and $\mathrm{pH}$ match the expected pore fluid conditions. $A K_{d}$ for the $\mathrm{LAW}$ vault waste of $6000 \mathrm{~mL} / \mathrm{g}$ was calculated using Eq. 1.

\section{Strontium}

Adsorption of strontium onto hydrous ferric oxides has been studied by Kolarik (1961), Kinniburgh et al. (1975), and Kinniburgh et al. (1976). These experiments indicate that strontium ion adsorbs rapidly and is not significantly impacted by variations in the $\mathrm{Na}^{+}$concentration in the solution. These experiments also show that there is no selectivity for $\mathrm{Ca}^{2+}$ over $\mathrm{Sr}^{2+}$ (Kinniburgh et al. 1975). The adsorption edge for $\mathrm{Sr}^{2+}$ on the iron oxide (Kinniburgh et al. 1975) was between $\mathrm{pH} 6$ and 7.5.

Dzombak and Morel (1990) provide a summary of adsorption data for $\mathrm{Sr}^{2+}$ on HFO. The experiments used to determine the adsorption of strontium on HFO are from Kinniburgh et al. (1975) and Kolarik (1961). The HFO was prepared by the addition of $\mathrm{NaOH}$ to $\mathrm{Fe}\left(\mathrm{NO}_{3}\right)_{3}$ solution and the ionic strength of the solution was held at $1.0 \mathrm{~m} \mathrm{NaNO}_{3}$. The adsorption curves used to estimate strontium adsorption at pH 8 are shown in Fig. E.4-4a to $\mathrm{k}$ and the data are summarized in Table E.4-3. The total strontium in the experiments ranged from $10^{-2}$ to $10^{-7} \mathrm{M}$ and HFO surface area ranged from 10700 to 106620 $\mathrm{cm}^{2} / \mathrm{mL}$. An average $\mathrm{Sr}^{2+} \mathrm{K}_{\mathrm{d}}$ for LAW vault waste of $3 \mathrm{~mL} / \mathrm{g}$ was calculated from Eq. 1 .

\section{Nickel}

Dzombak and Morel (1990) provide a summary of adsorption data for $\mathrm{Ni}^{2+}$ on HFO. The experiment used to determine the adsorption curve for nickel on HFO is from Leckie et al. (1984). The HFO was prepared by the addition of $\mathrm{NaOH}$ to $\mathrm{Fe}\left(\mathrm{NO}_{3}\right)_{3}$ solution and the ionic strength of the solution was held at $0.1 \mathrm{M} \mathrm{NaNO}_{3}$. The adsorption edge is located between $\mathrm{pH} 6.5$ and 7.5 (Fig. E.4-5) for the experiment used to estimate nickel adsorption. The total nickel in the system is $10^{-7} \mathrm{M}$ and HFO surface area is 533 $\mathrm{cm}^{2} / \mathrm{mL}$. Approximately $97 \%$ of the nickel is adsorbed to the goethite surface at $\mathrm{pH} 8 . \mathrm{A} \mathrm{Ni}^{2+} \mathrm{K}_{\mathrm{d}}$ for LAW vault waste of $1200 \mathrm{~mL} / \mathrm{g}$ was calculated from Eq. 1 .

\section{Selenite}

Selenium geochemistry is strongly controlled by the geochemistry of iron (Howard 1977). In the pH range from 2 to 8 selenite $\left(\mathrm{SeO}_{3}{ }^{2-}\right)$ is strongly adsorbed and decreases from pH 8 to 11 . Dzombak and Morel (1990) provide a summary of adsorption data for $\mathrm{SeO}_{3}{ }^{2-}$ on HFO. The experiment used to determine the adsorption curve for selenite on HFO is from Plotnikov (1958). The HFO was prepared by the addition of $\mathrm{NH}_{4} \mathrm{OH}$ to $\mathrm{Fe}\left(\mathrm{NO}_{3}\right)_{3}$ solution and the ionic strength of the solution was held at $0.5 \mathrm{M}$ $\mathrm{NH}_{4} \mathrm{NO}_{3}$. The adsorption curve (Fig. E.4-6) was used to estimate selenite adsorption at pH 8. The total selenite in the system is $1.2710^{-5} \mathrm{M}$ and HFO surface area is $3806 \mathrm{~cm}^{2} / \mathrm{mL}$. At this $\mathrm{pH}, 97 \%$ of the selenite is adsorbed to the goethite surface. $\mathrm{A} \mathrm{Se}^{4+} \mathrm{K}_{\mathrm{d}}$ for $\mathrm{LAW}$ vault waste of $170 \mathrm{~mL} / \mathrm{g}$ was calculated from Eq. 1. 


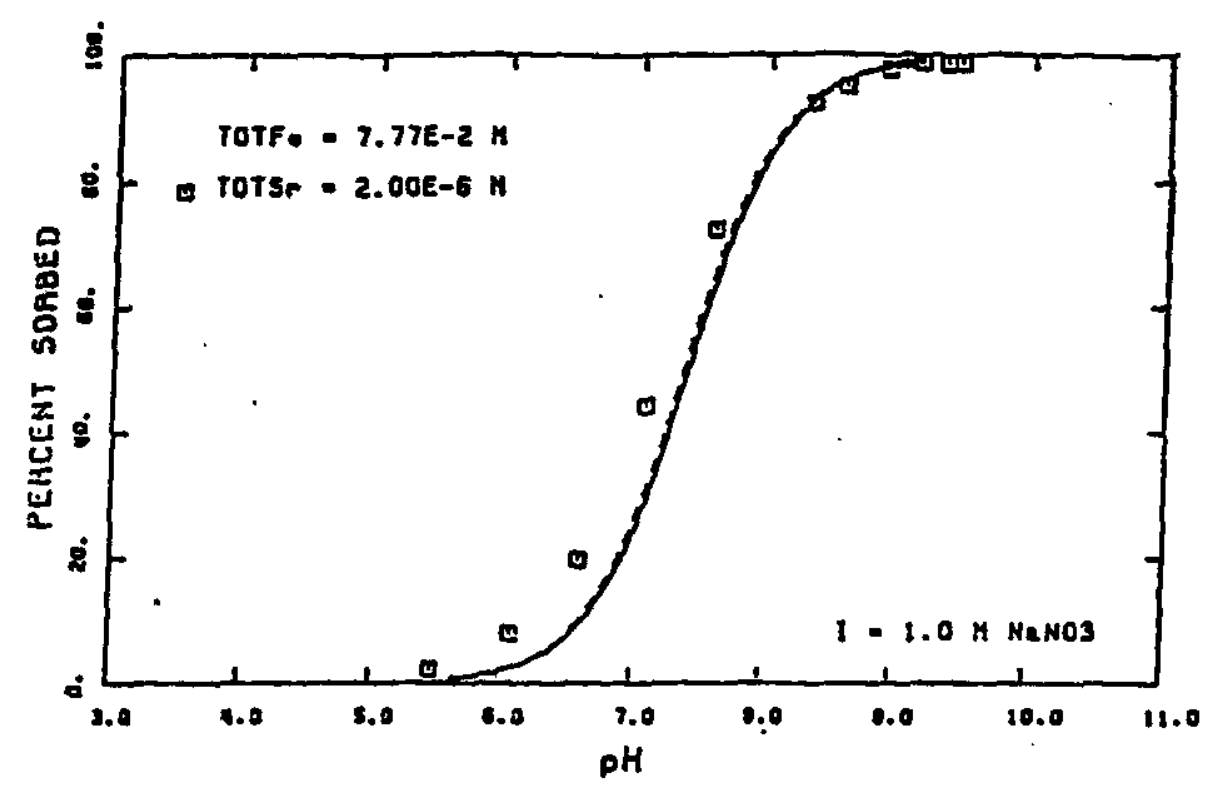

a)

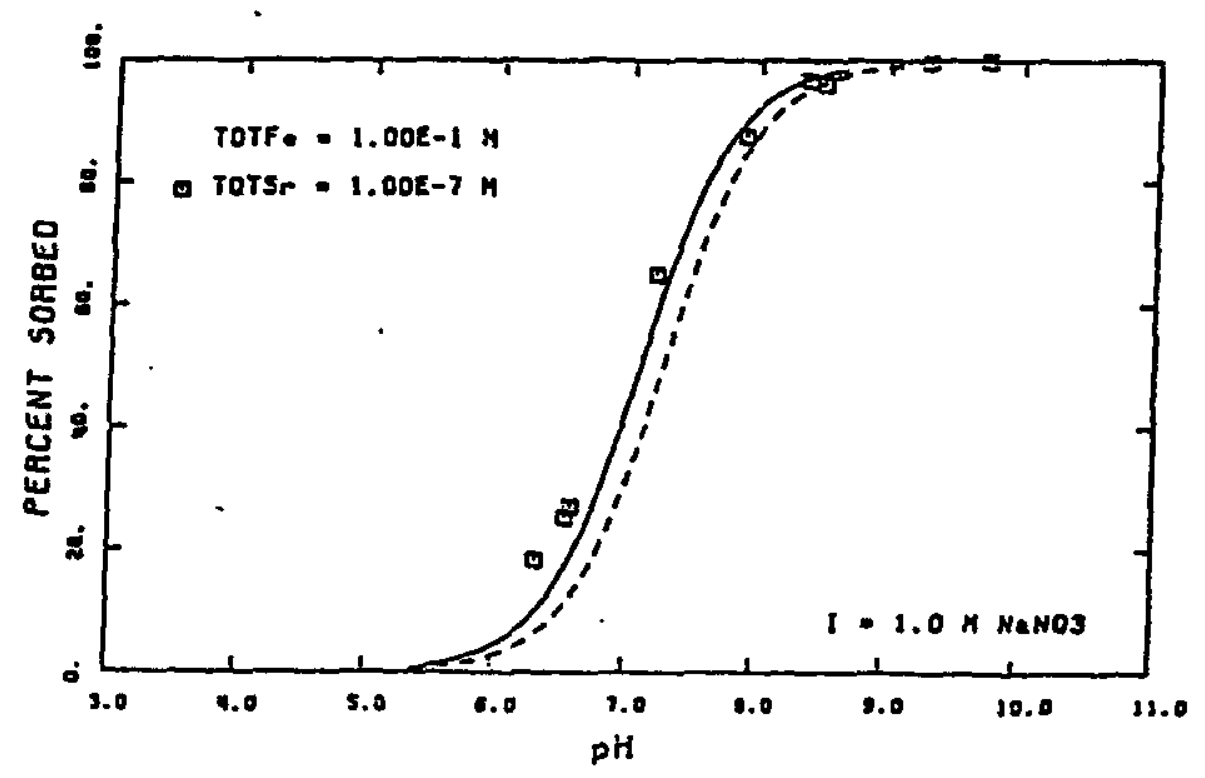

b)

Figure E.4-4 Adsorption of $\mathrm{Sr}^{2+}$ on goethite as a function of $\mathrm{pH}$ in a $1.0 \mathrm{M} \mathrm{NaNO}$ solution (from Dzombak and Morel 1990). a) $6.9 \mathrm{~g}$ goethite/L, b) $8.9 \mathrm{~g}$ goethite/L, c) $8.9 \mathrm{~g}$ goethite/L, d) $8.9 \mathrm{~g}$ goethite/L, e) $8.9 \mathrm{~g}$ goethite/L, f) $8.9 \mathrm{~g}$ goethite/L, g) $8.9 \mathrm{~g}$ goethite/L, h) $1.8 \mathrm{~g}$ goethite/L, i) 4.4 g goethite/L, j) 8.9 g goethite/L, k) $17.8 \mathrm{~g}$ goethite/L. 


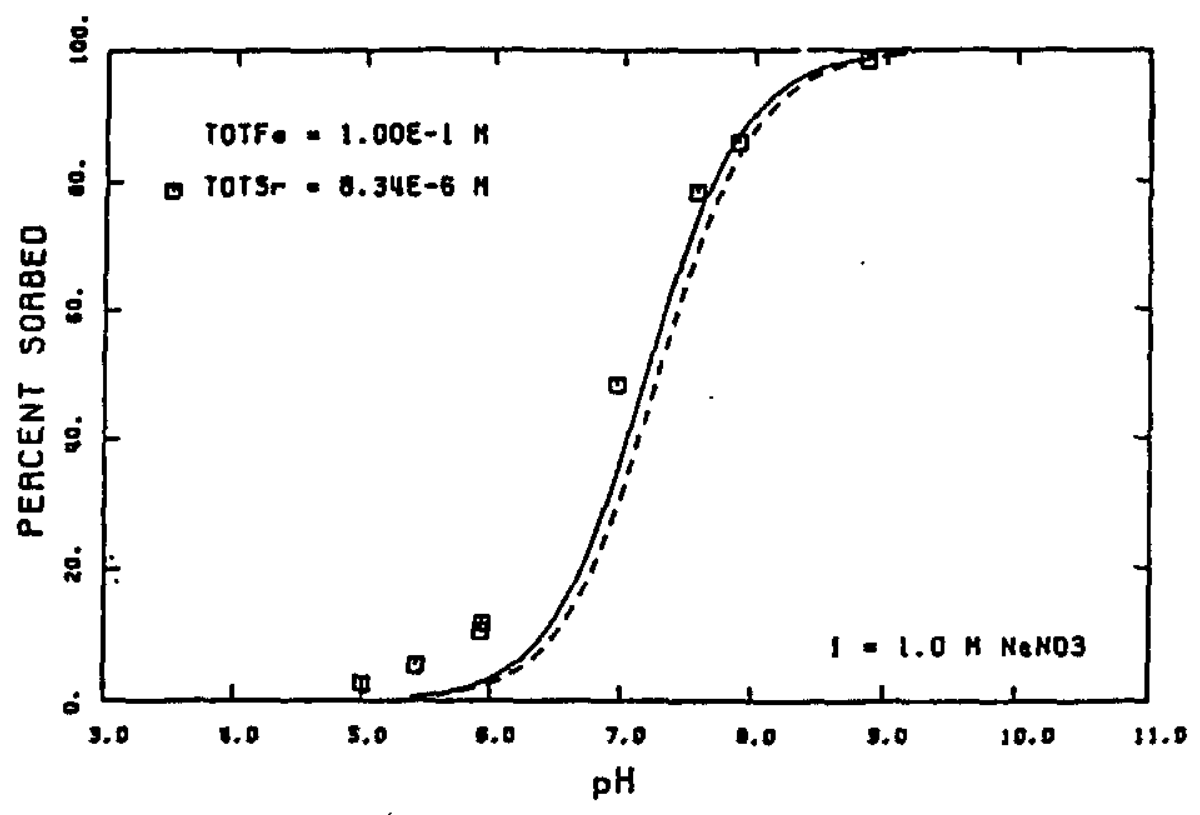

c)

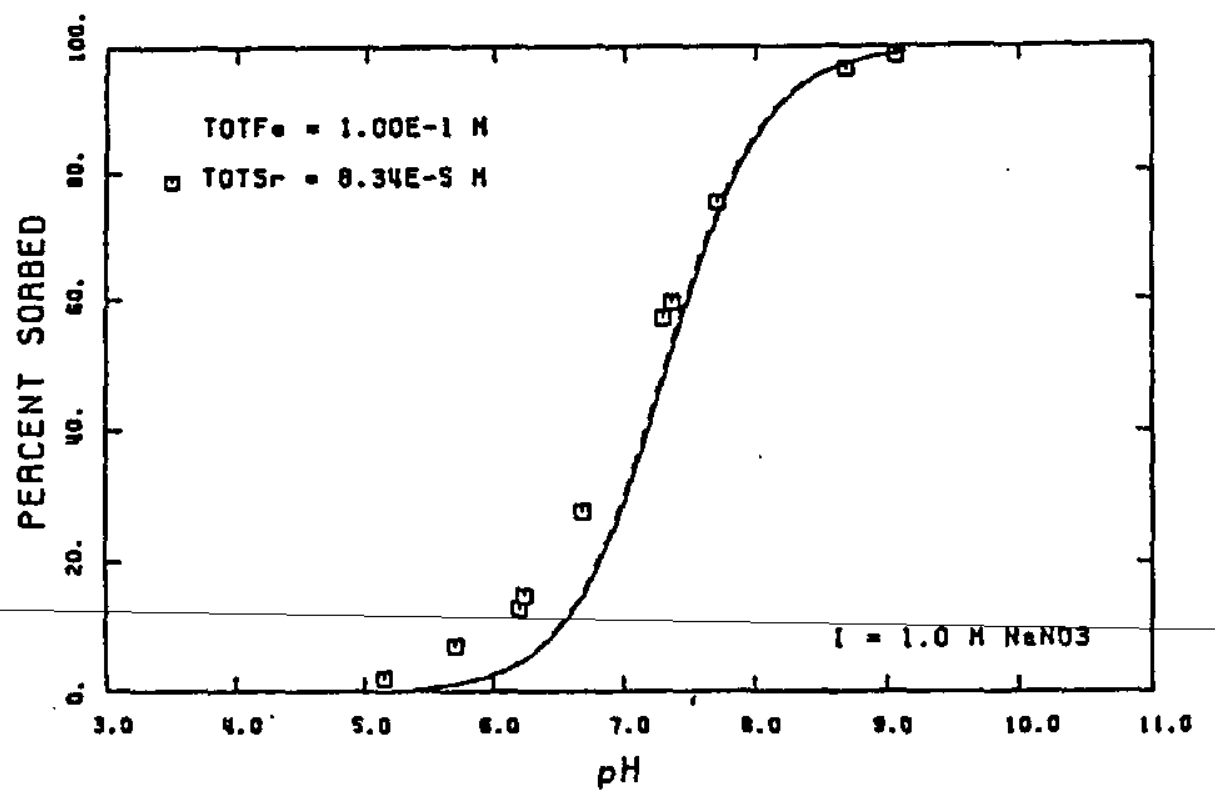

d)

Figure E.4-4. (continued). 


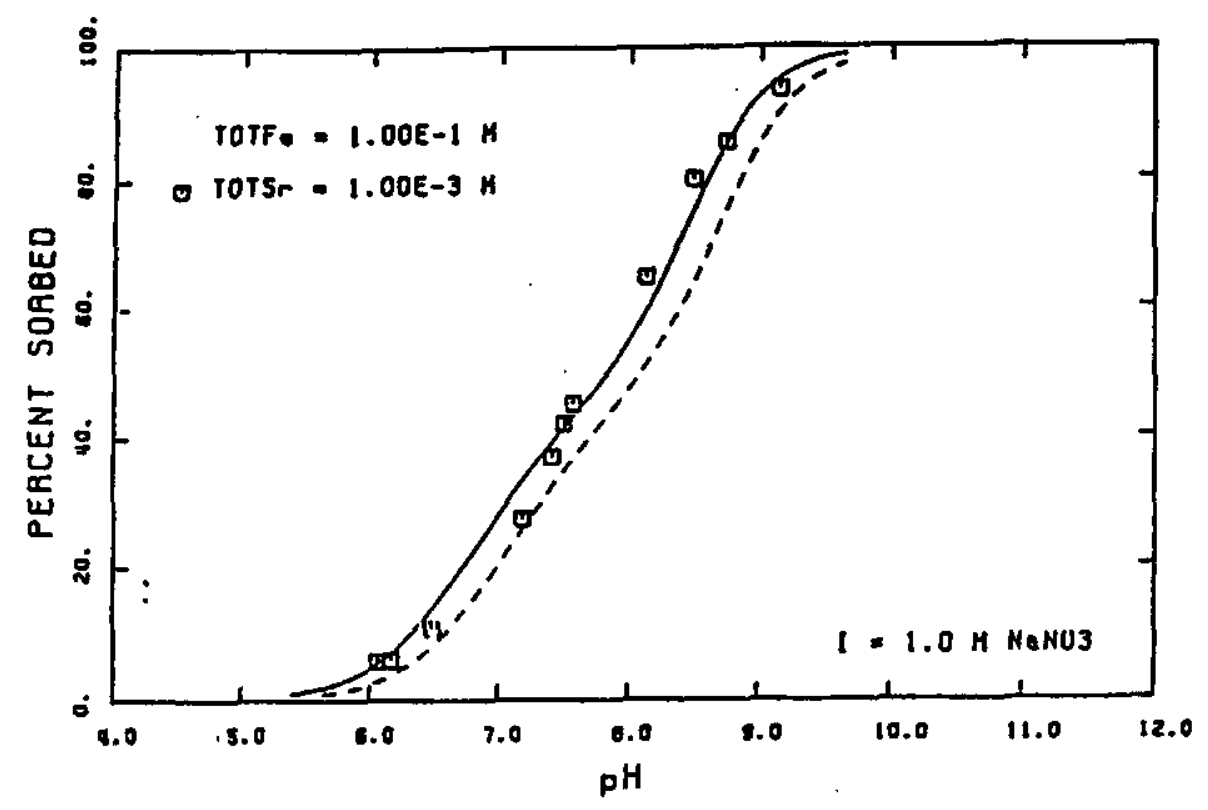

e)

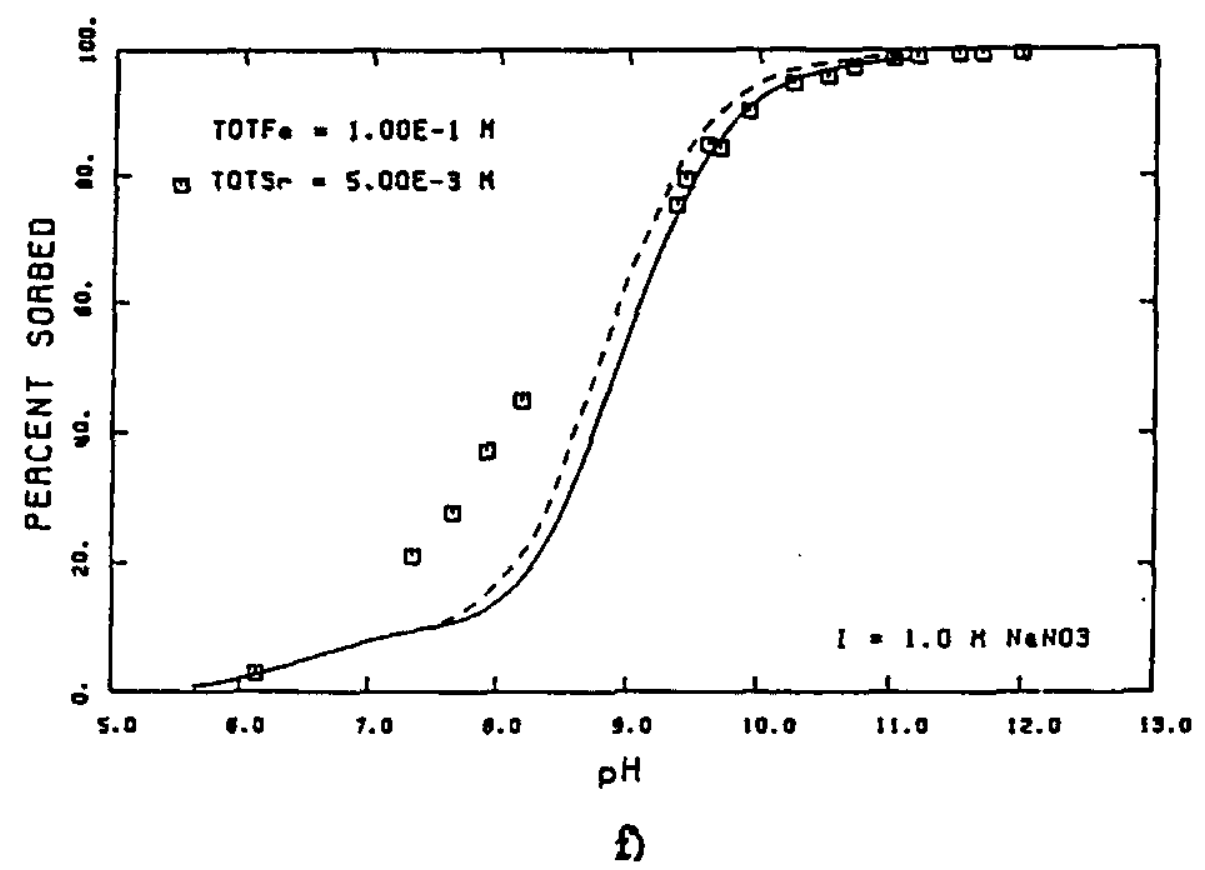

Figure E.4-4. (continued). 


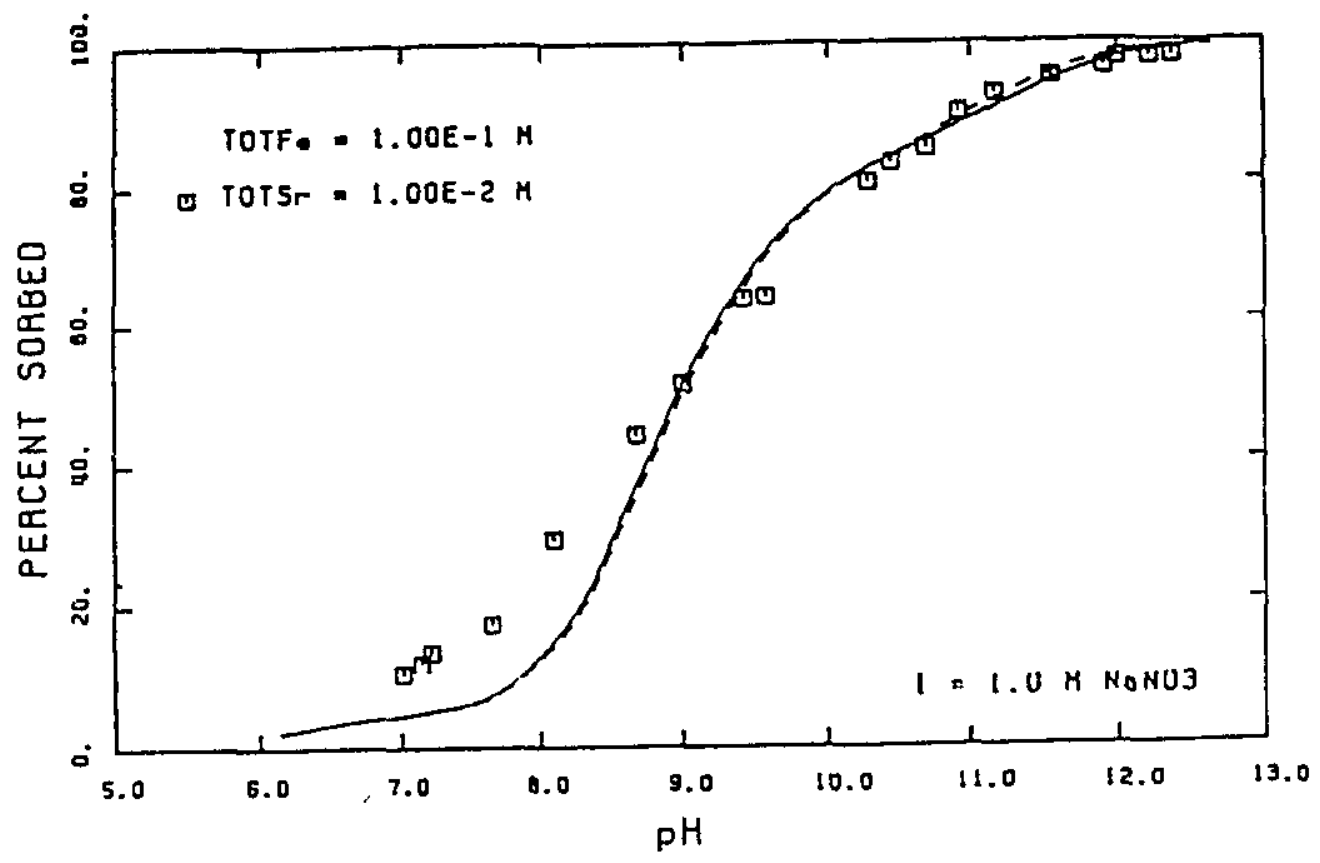

g)

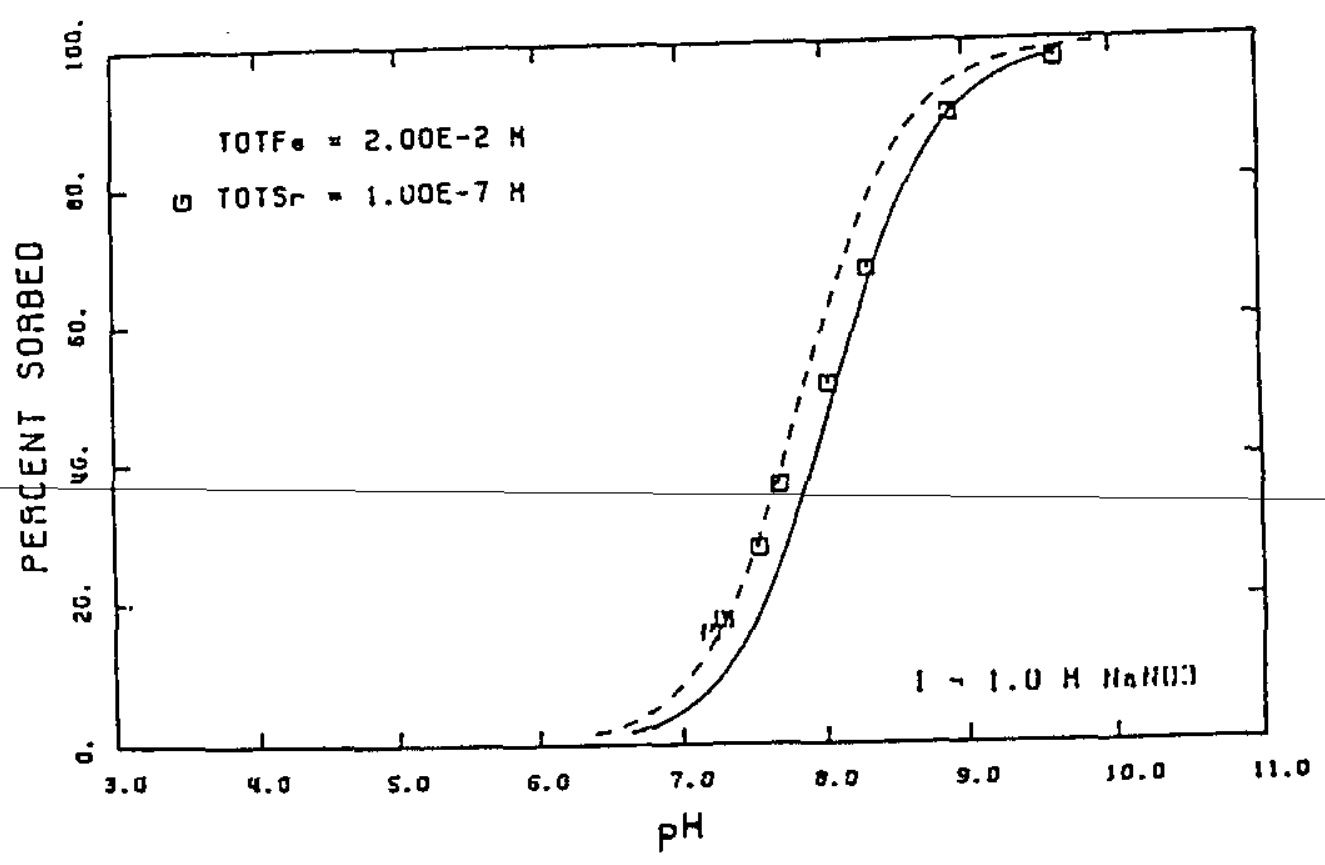

h)

Figure E.4-4. (continued). 


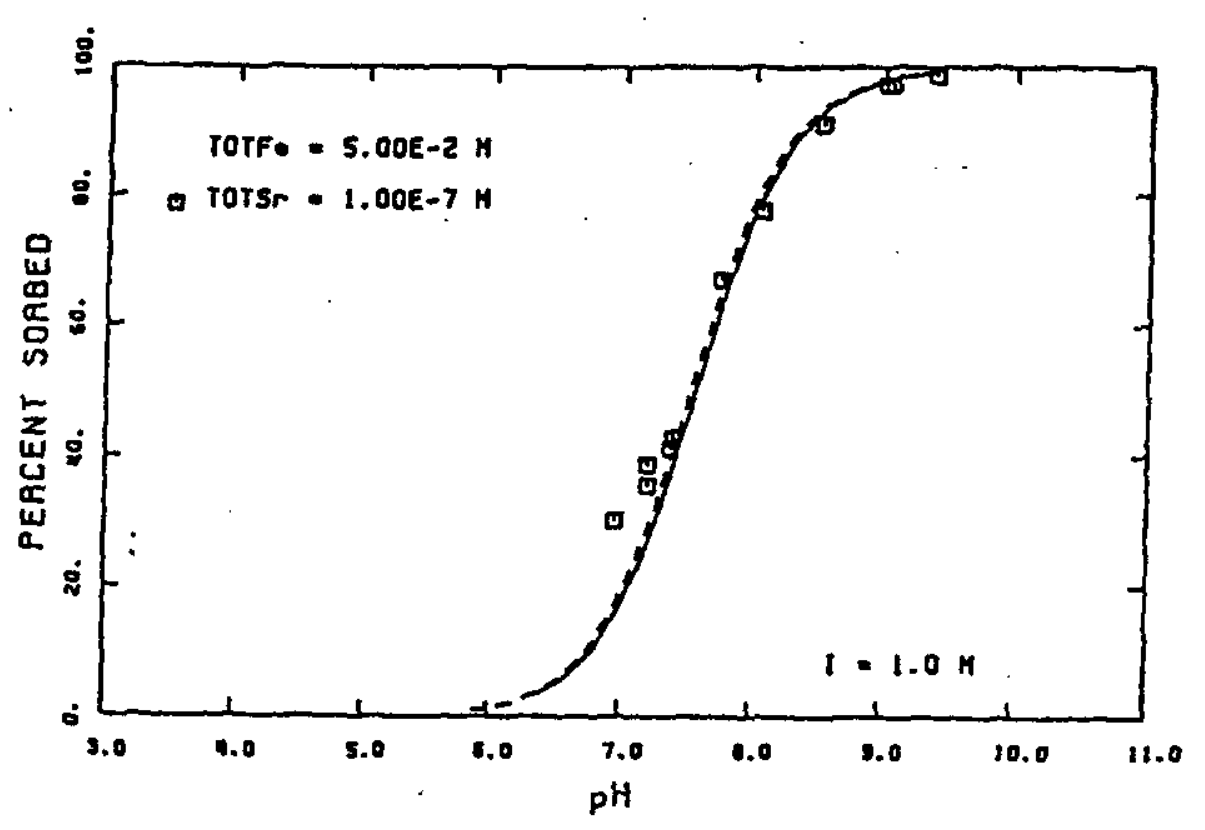

i)

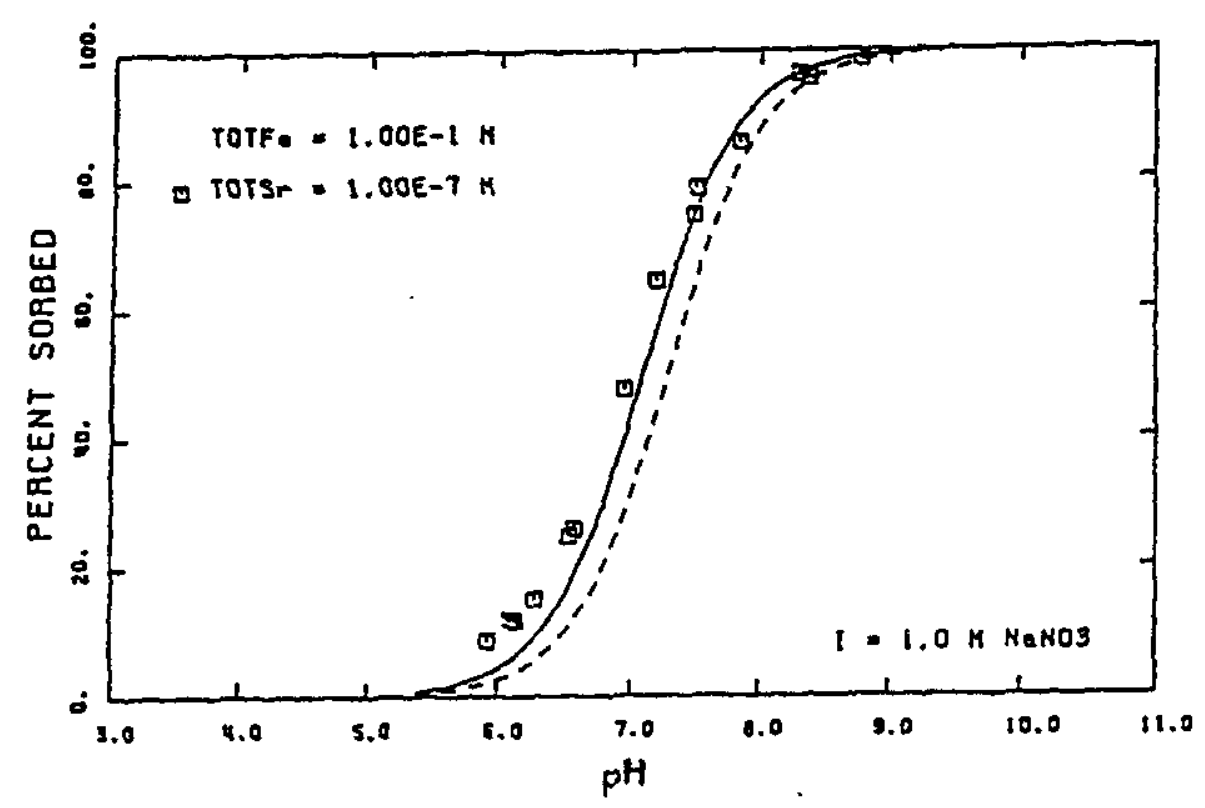

j)

Figure E.4-4. (continued). 


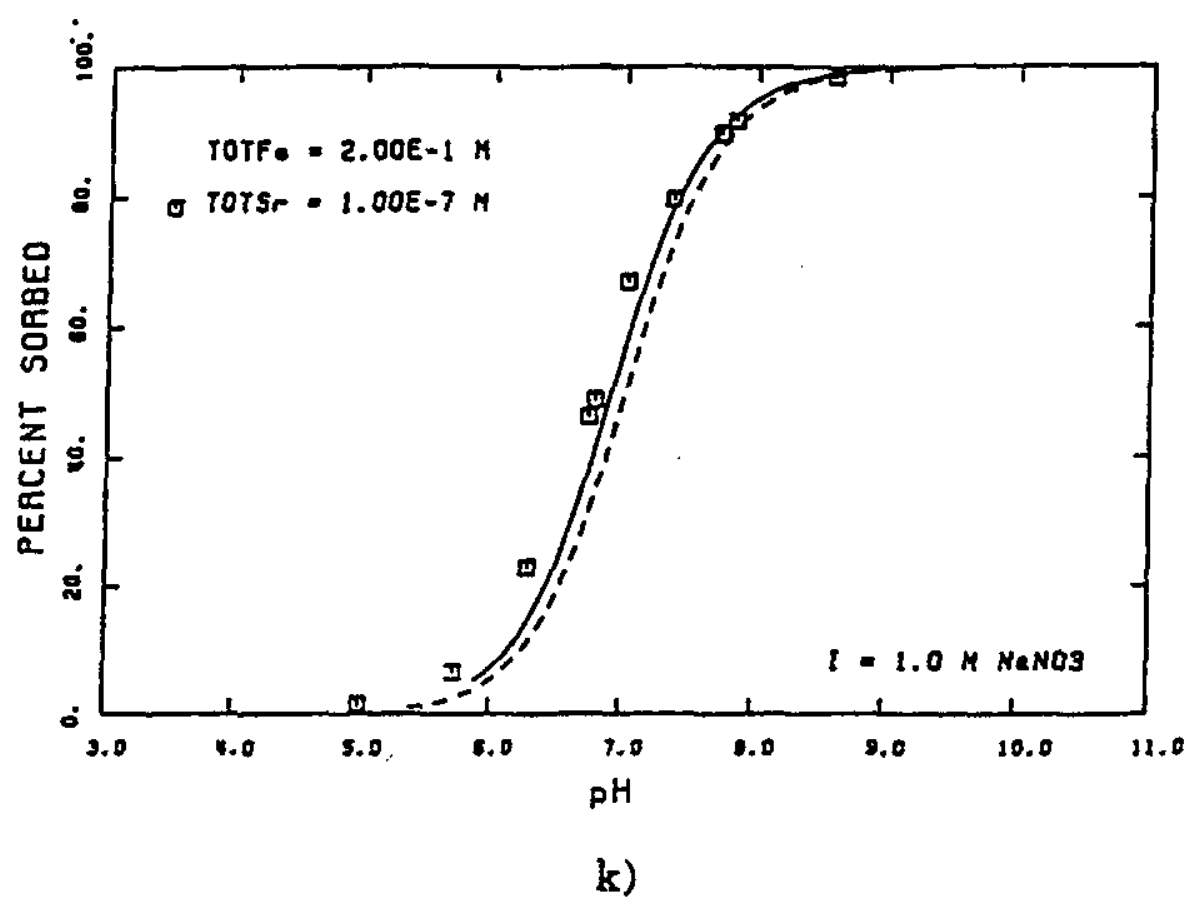

Figure E.4-4. (continued).

Table E.4-3. Adsorption data for strontium used to estimate $\mathbf{K}_{\mathbf{d}}$

\begin{tabular}{cccc}
$\begin{array}{c}\text { Total Sr } \\
(\mathrm{M})\end{array}$ & $\begin{array}{c}\text { Surface Area } \\
\left(\mathrm{cm}^{2} / \mathrm{mL}\right)\end{array}$ & Percent Adsorbed & $\begin{array}{c}\mathrm{K}_{\mathrm{d}} \\
(\mathrm{mL} / \mathrm{g})\end{array}$ \\
\hline & & & \\
$2.00 \times 10^{-6}$ & 41,420 & 87 & 3.2 \\
$1.00 \times 10^{-7}$ & 53,000 & 90 & 3.4 \\
$8.34 \times 10^{-6}$ & 53,000 & 90 & 3.4 \\
$8.34 \times 10^{-5}$ & 53,000 & 88 & 2.8 \\
$1.00 \times 10^{-3}$ & 53,000 & 58 & 0.5 \\
$5.00 \times 10^{-3}$ & 53,000 & 40 & 0.3 \\
$1.00 \times 10^{-2}$ & 53,000 & 30 & 0.2 \\
$1.00 \times 10^{-7}$ & 10,700 & 51 & 1.9 \\
$1.00 \times 10^{-7}$ & 26,700 & 80 & 3.0 \\
$1.00 \times 10^{-7}$ & 53,300 & 93 & 5.0 \\
$1.00 \times 10^{-7}$ & 106,620 & 95 & 3.6 \\
\hline
\end{tabular}




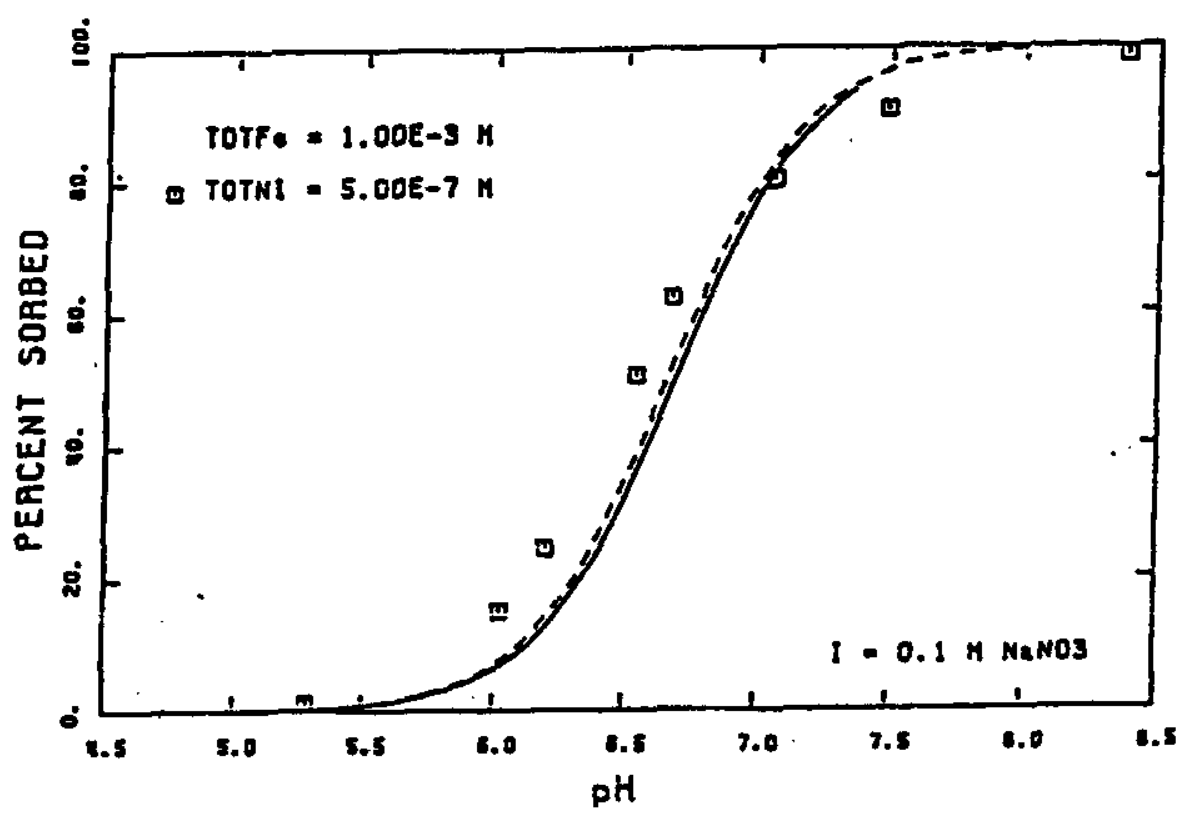

Figure E.4-5 Adsorption of nickel on goethite as a function of $\mathrm{pH}$ in a $0.1 \mathrm{M} \mathrm{NaNO}_{3}$ solution (from Dzombak and Morel 1990). 


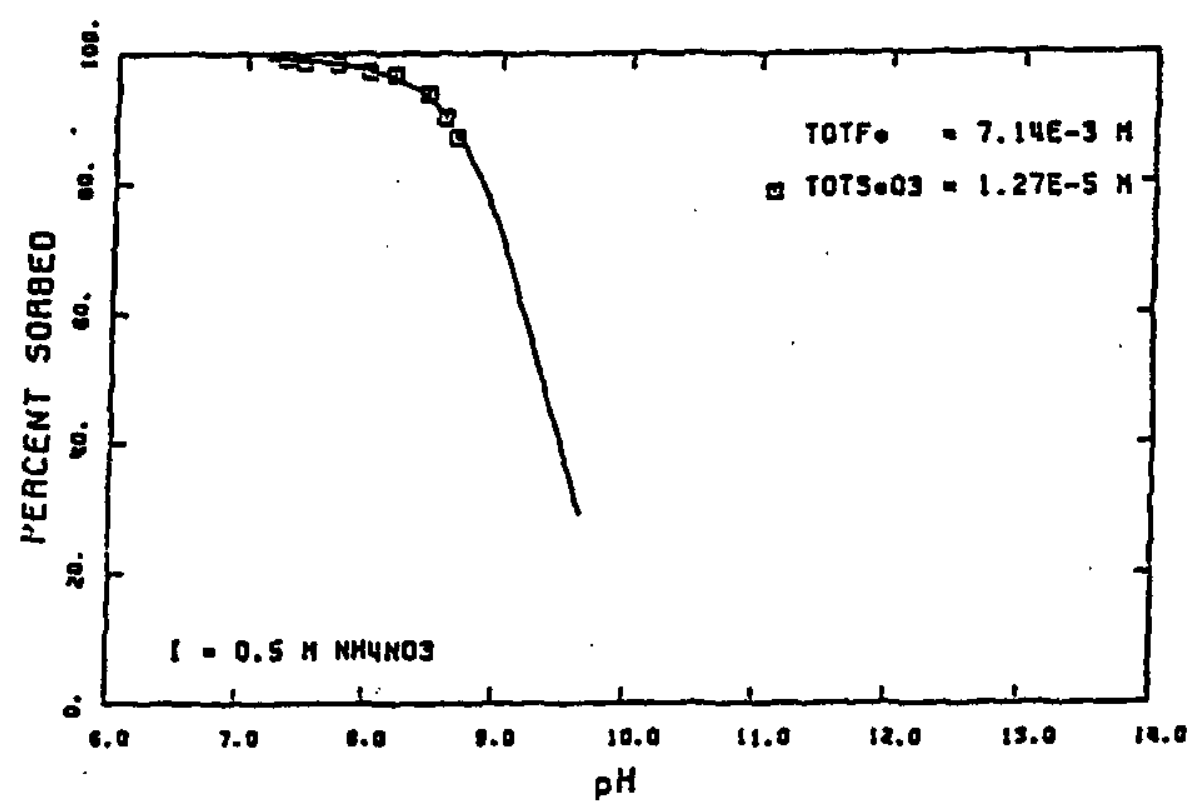

Figure E.4-6 Adsorption of selenite on goethite as a function of $\mathrm{pH}$ in a $0.5 \mathrm{M} \mathrm{NH} \mathrm{NO}_{3}$ solution (from Dzombak and Morel 1990). 


\section{Radium}

No information is available for radium adsorption on HFO. However, Dzombak and Morel (1990) provide a summary of adsorption data for barium ion on HFO. This barium data will be used as an analog for radium. The experiments used to determine the adsorption curves for barium on HFO are from Kurbatov (1949) and Duval and Kurbatov (1952). Kurbatov (1949) prepared HFO by the addition of $\mathrm{NH}_{4} \mathrm{OH}$ to $\mathrm{FeCl}_{3}$ solution at ionic strengths of $0.0038,0.033$, and $0.3 \mathrm{M} \mathrm{NH}_{4} \mathrm{Cl}$. Duval and Kurbatov (1952) prepared $\mathrm{HFO}$ by the addition of $\mathrm{NH}_{4} \mathrm{OH}$ to $\mathrm{FeCl}_{3}$ solution at an ionic strength of $0.0 .0087 \mathrm{~N}$ $\mathrm{NH}_{4} \mathrm{Cl}$. The adsorption curves (Fig. E.4-7a,b,c,d,e) were used to estimate barium adsorption at pH 8. The total barium, HFO surface areas, and percentage $\mathrm{Ba}^{2+}$ adsorbed at $\mathrm{pH} 8$ are shown in Table E.4-4. An average $\mathrm{Ba}^{2+} \mathrm{K}_{d}$ for $\mathrm{LAW}$ vault waste of $60 \mathrm{~mL} / \mathrm{g}$ was calculated for radium from $\mathrm{Eq} .1$.

Table E.4-4. Adsorption data for barium used to estimate radium $\mathbf{K}_{d}$

\begin{tabular}{cccc}
\hline $\begin{array}{c}\text { Total Ba } \\
(\mathrm{M})\end{array}$ & $\begin{array}{l}\text { Surface Area } \\
\left(\mathrm{cm}^{2} / \mathrm{mL}\right)\end{array}$ & Percent Adsorbed & $\begin{array}{c}\mathrm{K}_{\mathrm{d}} \\
(\mathrm{mL} / \mathrm{g})\end{array}$ \\
\hline & & & \\
$3.07 \times 10^{-10}$ & 330 & 46 & 52 \\
$3.02 \times 10^{-10}$ & 320 & 39 & 40 \\
$3.12 \times 10^{-8}$ & 70 & 23 & 85 \\
$3.12 \times 10^{-8}$ & 330 & 53 & 68 \\
$3.12 \times 10^{-8}$ & 1000 & 74 & 57 \\
\hline
\end{tabular}

\section{Thorium}

Hunter et al. (1988) conducted Th adsorption studies on goethite that show the characteristic adsorption edge of hydrolyzable metal ions on oxides. Adsorption was found to involve $\mathrm{Th}(\mathrm{OH})_{2}\left(^{2+}\right), \mathrm{Th}(\mathrm{OH})_{3}\left({ }^{+}\right)$, and $\mathrm{Th}(\mathrm{OH})_{4}$. Experiments were focused on determining the effects of the major ions $\mathrm{Mg}^{2+}, \mathrm{Ca}^{2+}$, and $\mathrm{SO}_{4}{ }^{2-}$ on the adsorption of $\mathrm{Th}$ on goethite as compared to adsorption in a $\mathrm{NaCl}$ electrolyte. Adsorbent and adsorbate concentrations were also varied to determine if these concentrations effect $\mathrm{Th}$ adsorption.

The HFO was prepared by the addition of $\mathrm{KOH}$ to $\mathrm{Fe}\left(\mathrm{NO}_{3}\right)_{3}$ solution and the ionic strength of the solution was held at $0.1 \mathrm{M} \mathrm{NaNO}_{3}$. The adsorption curve (Fig. E.4-8) was used to estimate thorium adsorption at $\mathrm{pH}$ 8. The total thorium in the system is $6.610^{-5} \mathrm{M}$ and HFO surface area is $80 \mathrm{~cm}^{2} / \mathrm{mL}$. At this pH, $90 \%$ of the thorium is adsorbed to the goethite surface. A Th $\mathrm{K}_{d}$ for LAW vault waste of $2200 \mathrm{~mL} / \mathrm{g}$ was calculated from Eq. 1.

\section{Neptunium}

Neptunium has been identified in the aqueous phase in the IV, V, and VI oxidation states with $\mathrm{Np}(\mathrm{V})$ being most common for waters in contact with atmospheric oxygen between pH 5 and 11 . Girvin et al. (1991) conducted $\mathrm{Np}(\mathrm{V})$ adsorption studies on synthetic iron oxyhydroxide. The HFO was prepared by the addition of $\mathrm{NaOH}$ to $\mathrm{Fe}\left(\mathrm{NO}_{3}\right)_{3}$ solution and the ionic strength of the solution was held at $0.1 \mathrm{M}$ $\mathrm{NaNO}_{3}$. The adsorption curve (Fig. E.4-9) was used to estimate neptunium adsorption at pH 8 . The total neptunium in the system is $4.710^{-12} \mathrm{M}$ and HFO surface area is $5330 \mathrm{~cm}^{2} / \mathrm{mL}$. At this $\mathrm{pH}, 99.5 \%$ of the $\mathrm{Np}$ is adsorbed to the goethite surface. A Np Kd for LAW vault waste of $750 \mathrm{~mL} / \mathrm{g}$ was calculated from Eq. 1. 


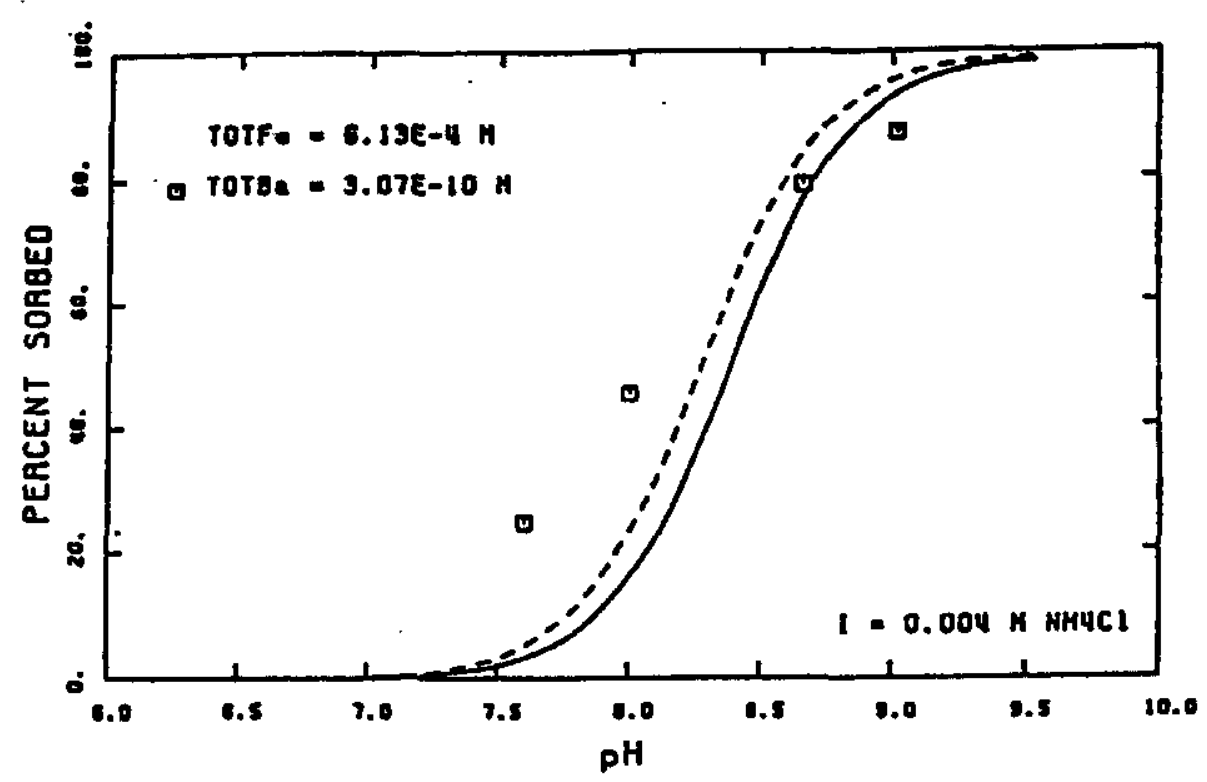

a).

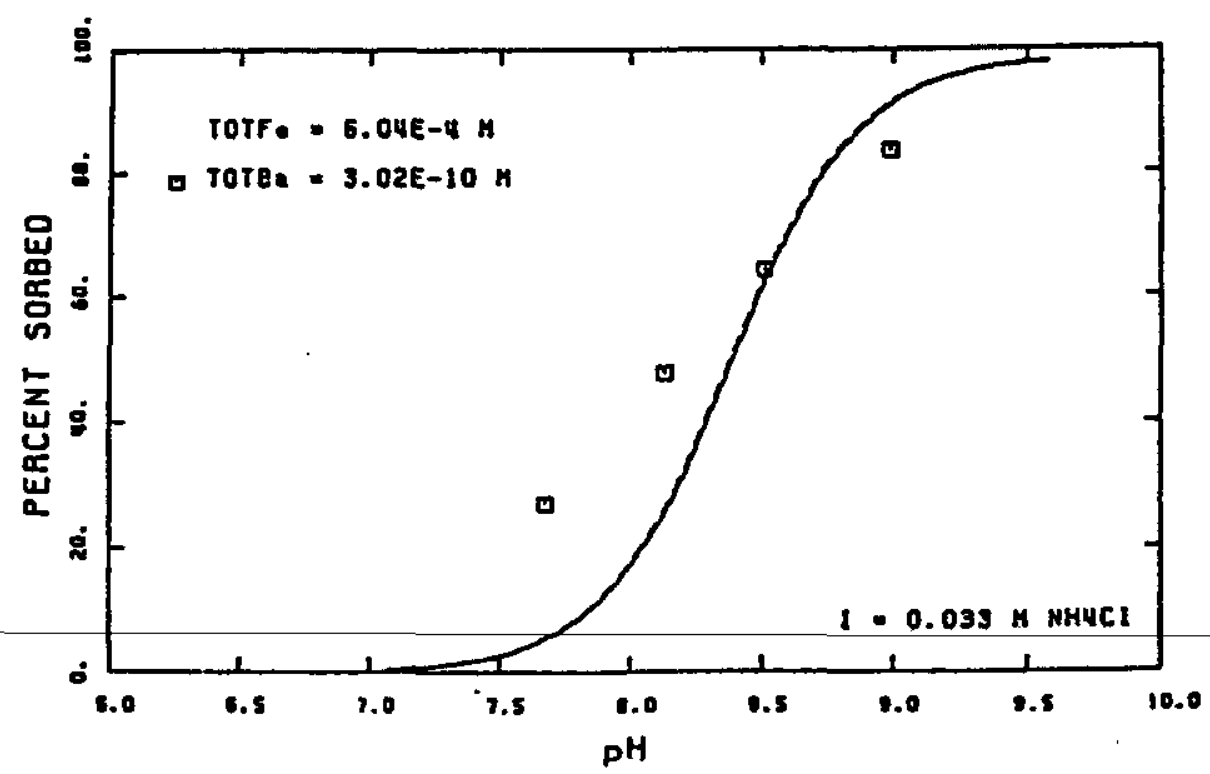

b)

Figure E.4-7 Adsorption of barium on goethite as a function of $\mathrm{pH}$ as an analog for radium (from Dzombak and Morel 1990). a) $0.05 \mathrm{~g}$ goethite/L, b) $0.05 \mathrm{~g}$ goethite/L, c) $0.01 \mathrm{~g}$ goethite/L, d) $0.06 \mathrm{~g}$ goethite/L, e) $0.2 \mathrm{~g}$ goethite/L. 


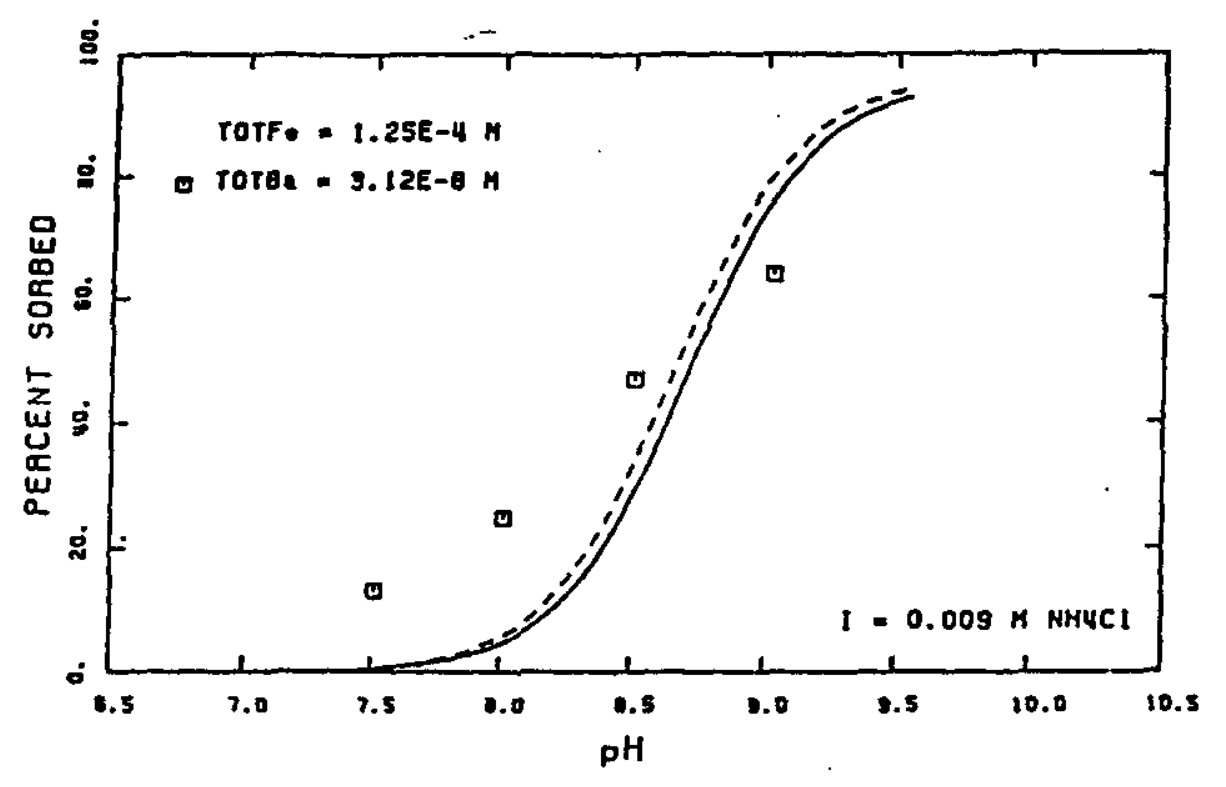

c)

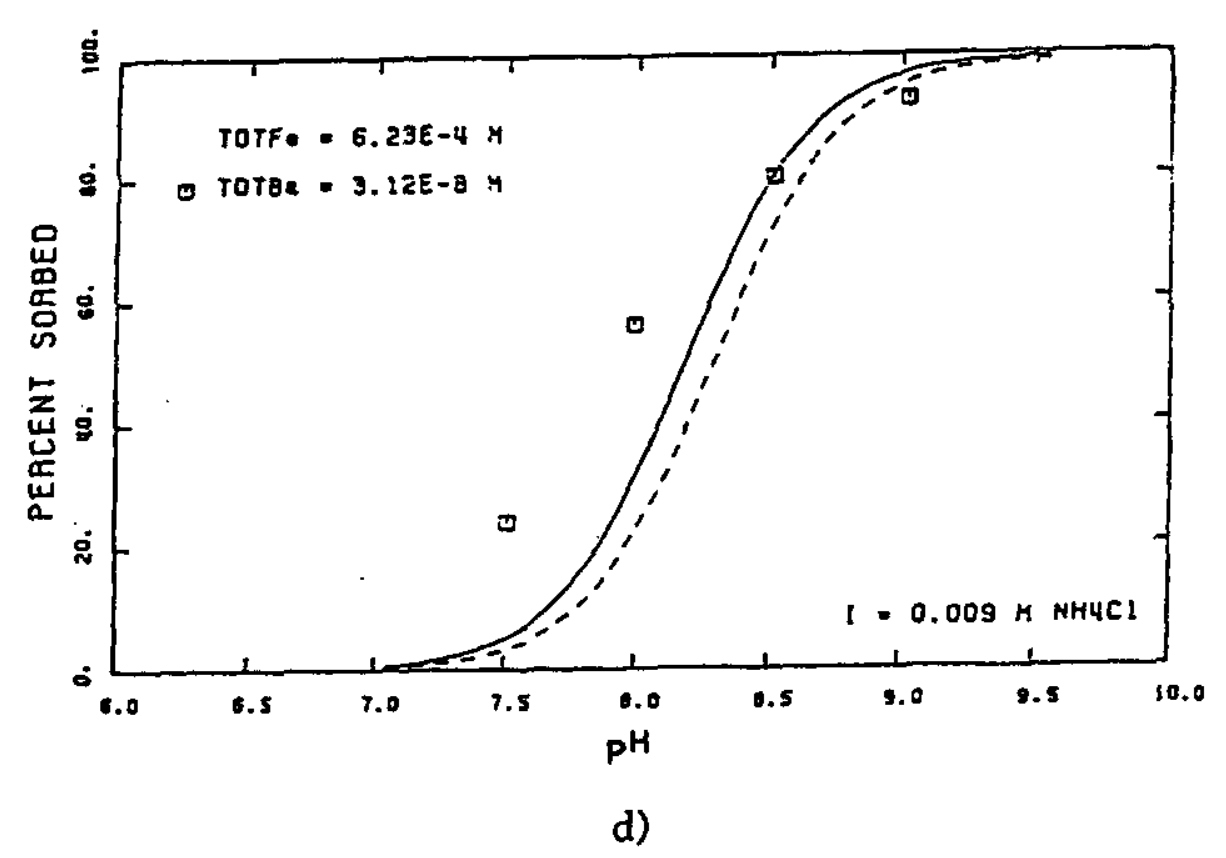

Figure E.4-7. (continued) 


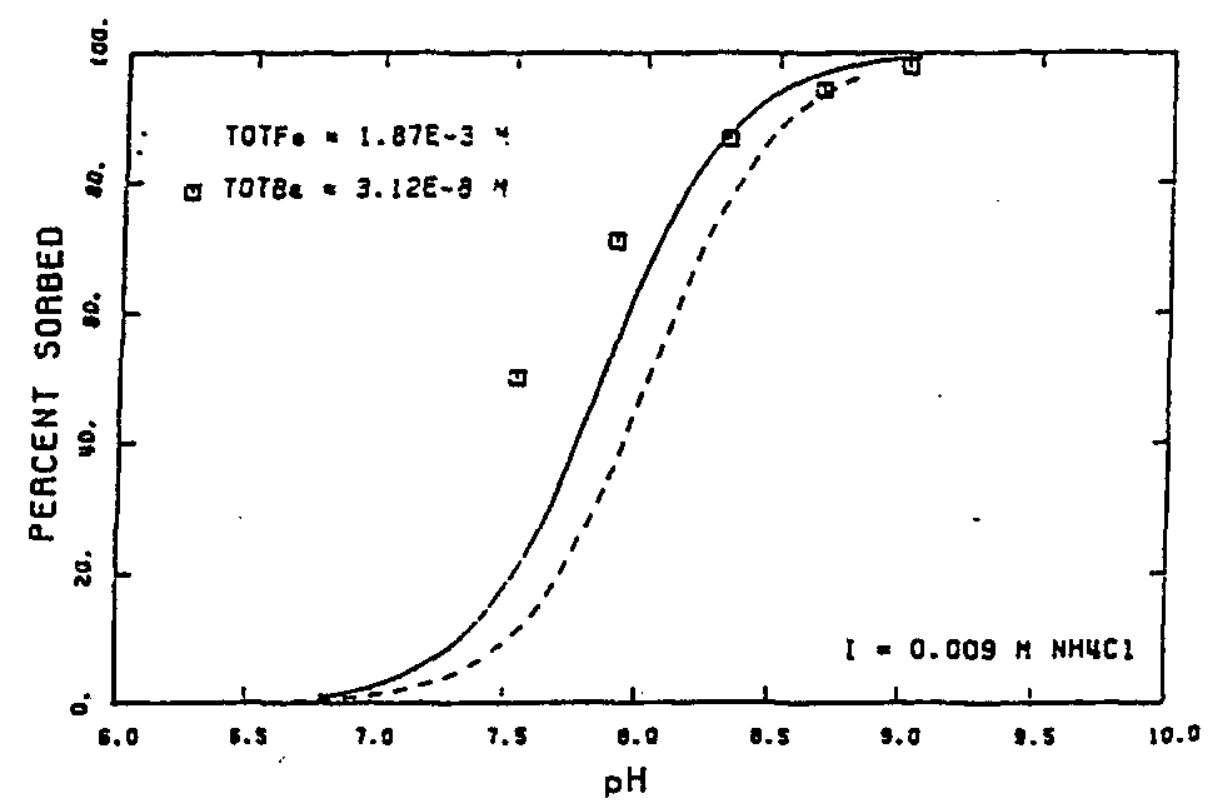

e)

Figure E.4-7. (continued) 


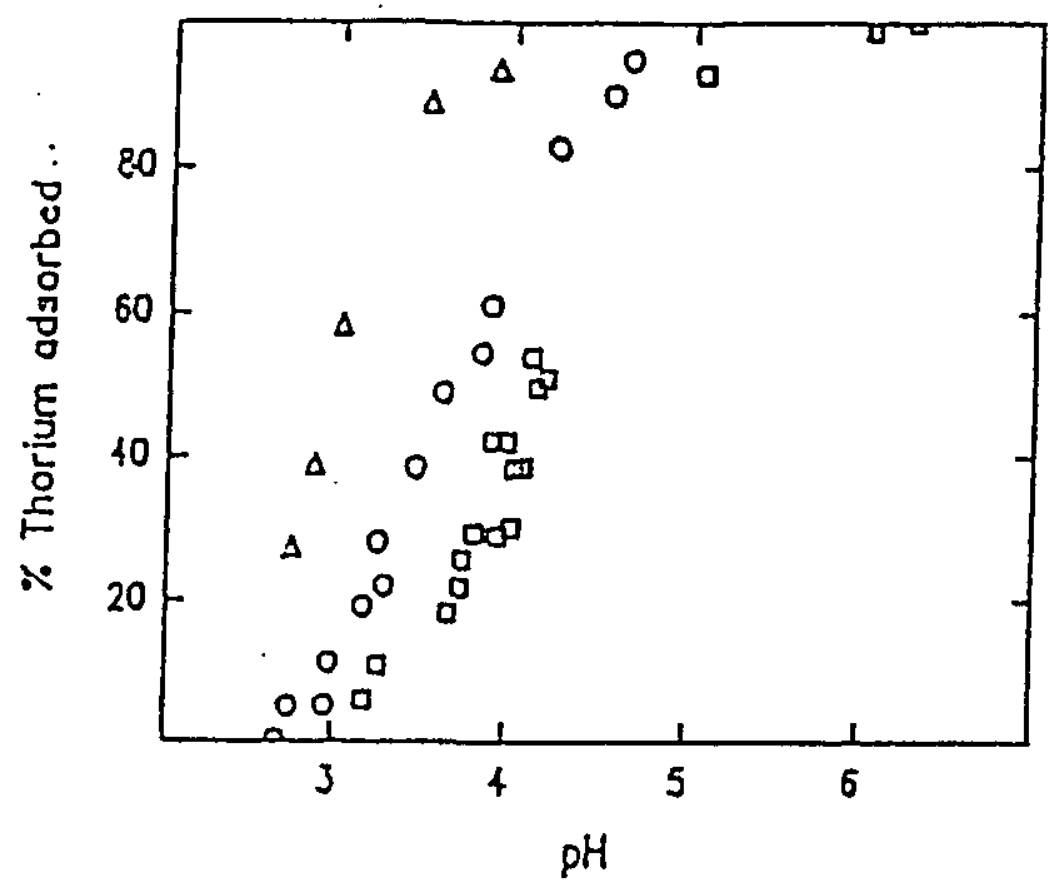

Figure E.4-8 Adsorption of thorium on goethite as function of $\mathrm{pH}$ in $0.422 \mathrm{~mol} / \mathrm{Kg} \mathrm{NaCl}$ eletrolyte at different thorium/oxide ratios (Hunter et al. 1988). Triangles: $9 \mathrm{micromol} / \mathrm{L} \mathrm{Th}, 8.6 \mathrm{~g} / \mathrm{L}$ goethite; Circles: 9 micromol/L Th, $0.54 \mathrm{~g} / \mathrm{L}$ Goethite: Squares: $45 \mathrm{micromol} / \mathrm{L}$ Th, $0.54 \mathrm{~g} / \mathrm{L}$ goethite 


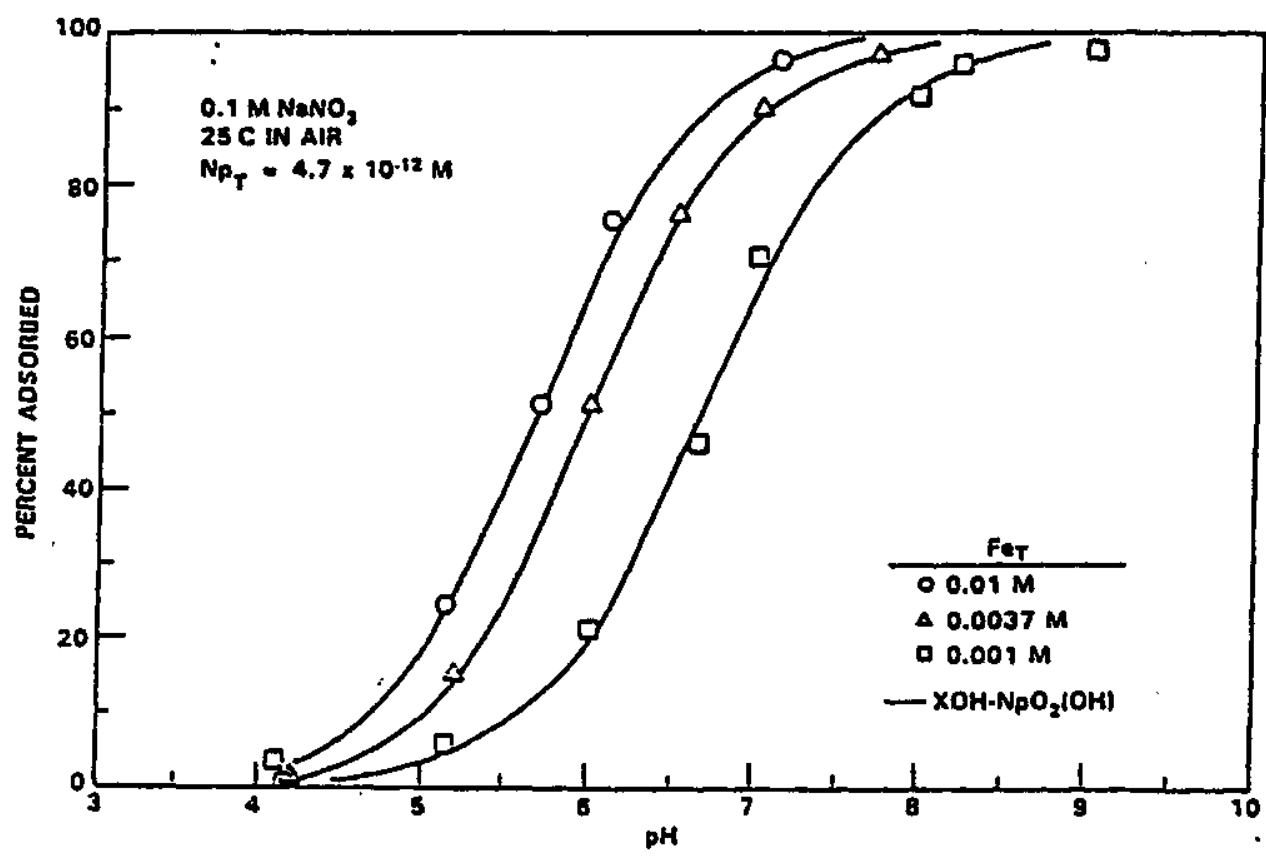

Figure E.4-9 Adsorption of neptunium on goethite as function of $\mathrm{pH}$ (Girvin et al. 1991). Triangles: $0.3 \mathrm{~g} / \mathrm{L}$ goethite; Circles: $0.9 \mathrm{~g} / \mathrm{L}$ goethite; Squares: $0.09 \mathrm{~g} / \mathrm{L}$ goethite. 
Tin

No tin adsorption data is available for iron oxides. However, Dzombak and Morel (1990) provide a summary of adsorption data for $\mathrm{Hg}$ on HFO. The $\mathrm{Hg}$ experimental data of Avotins (1975) was used to determine the analog adsorption curve for tin on $\mathrm{HFO}$. The HFO was prepared by the addition of $\mathrm{NaOH}$ to $\mathrm{Fe}\left(\mathrm{ClO}_{4}\right)_{3}$ solution and the ionic strength of the solution was held at $0.1 \mathrm{M} \mathrm{NaClO}$. The adsorption curves (Fig. E.4-10a,b) for mercury were used to estimate tin adsorption at $\mathrm{pH} 8$. The total $\mathrm{Hg}$ in the system is $3.4110^{-5} \mathrm{M}$ and HFO surface area is $300 \mathrm{~cm}^{2} / \mathrm{mL}$. At this $\mathrm{pH}, 97 \%$ of the mercury is adsorbed to the goethite surface. An average tin $\mathrm{K}_{d}$ for $\mathrm{LAW}$ vault waste of $55 \mathrm{~mL} / \mathrm{g}$ was calculated from Eq. 1 .

\section{Americium and Other Transplutonic Elements}

Americium in aqueous environments can be found in the III, IV, V, and VI oxidation states. Am (III) is the most predominant oxidation state. No americium adsorption data was available for $\mathrm{HFO}$ so $\mathrm{Cr}$ (III) adsorption data summarized by Dzombak and Morel (1990) was used as an analog for americium. The HFO was used by prepared by the addition of $\mathrm{NaOH}$ to $\mathrm{Fe}\left(\mathrm{NO}_{4}\right)_{3}$ solution and the ionic strength of the solution was held at $0.1 \mathrm{M} \mathrm{NaNO}_{3}$ (Leckie et al. 1980). The adsorption curve (Fig. E.4-11) was used to estimate Am adsorption at $\mathrm{pH}$ 8. The total $\mathrm{Cr}$ in the system is $5.0 \times 10^{-6} \mathrm{M}$ and HFO surface area is 530 $\mathrm{cm}^{2} / \mathrm{mL}$. At this $\mathrm{pH}, 99 \%$ of the chromium is adsorbed to the goethite surface. An americium $\mathrm{K}_{d}$ for LAW vault waste of $3700 \mathrm{~mL} / \mathrm{g}$ was calculated from Eq. 1. Due to chemical similarities of the transplutonic elements, this $\mathrm{K}_{\mathrm{d}}$ was also used for $\mathrm{Cm}(\mathrm{III}), \mathrm{Bk}(\mathrm{III})$, and $\mathrm{Cf}(\mathrm{III})$.

\section{E.5 RADIONUCLIDE SOLUBILITY LIMITS}

The release of radionuclides from the LAW and IL vaults and the intimately-mixed cement-stabilized waste and the cement-stabilized encapsulated waste trenches will depend on the aqueous chemistry, solubility, and sorption behavior of the relevant radionuclides. The chemical conditions in these units will be controlled by the dissolution of the soluble constituents of the cement and by the corrosion of the iron waste containers and activated metals (Ewart et al. 1992). Corrosion of the waste containers and infiltration of water through the units will cause slow changes in the chemical conditions. Work conducted by Ewart et al. (1992) has shown that the $\mathrm{pH}$ of concrete repositories will remain above 10.5 for extended periods of time and Sharland et al. (1986) have shown that the oxidation potential throughout the near field will become reducing approximately 100 years after saturation. Ewart et al. (1992) have shown that the carbonate concentration in the near-field groundwater remain at a constant level of about $10^{-4} \mathrm{M}$ to $10^{-5} \mathrm{M}$ by the relatively high calcium concentration. These conditions provide low solubilities for actinides and provide a valuable chemical component of the multi-barrier containment of the waste. This section discusses the solubility limits for plutonium and uranium in these units. Adsorption has been discussed in previous sections.

\section{Plutonium}

The tetravalent state of plutonium will predominate under the chemical conditions in the units. Solubility of plutonium was estimated assuming the controlling solid phase is amorphous $\mathrm{Pu}(\mathrm{OH})_{4}$ with the plutonium hydroxides (i.e. $\mathrm{Pu}(\mathrm{OH})^{3+}, \mathrm{Pu}(\mathrm{OH})_{2}{ }^{2+}, \mathrm{Pu}(\mathrm{OH})_{3}{ }^{+}$, and $\mathrm{Pu}(\mathrm{OH})_{4}$ ) comprising the soluble species. 


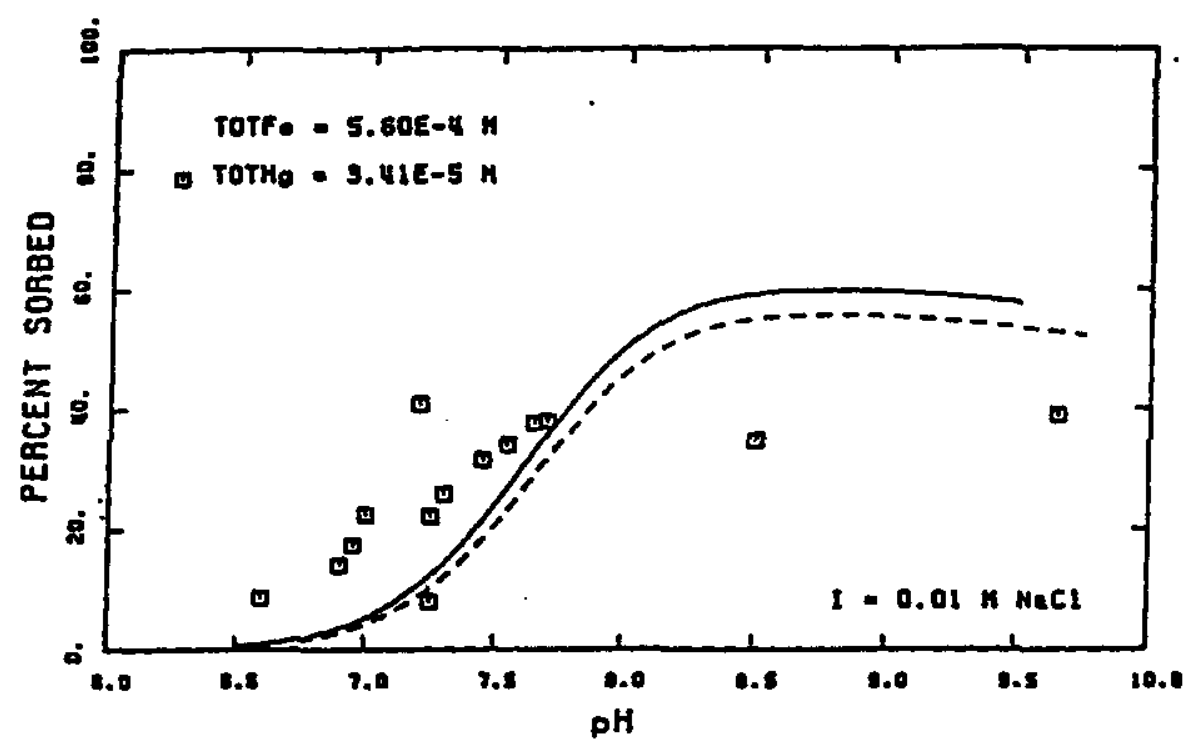

a)

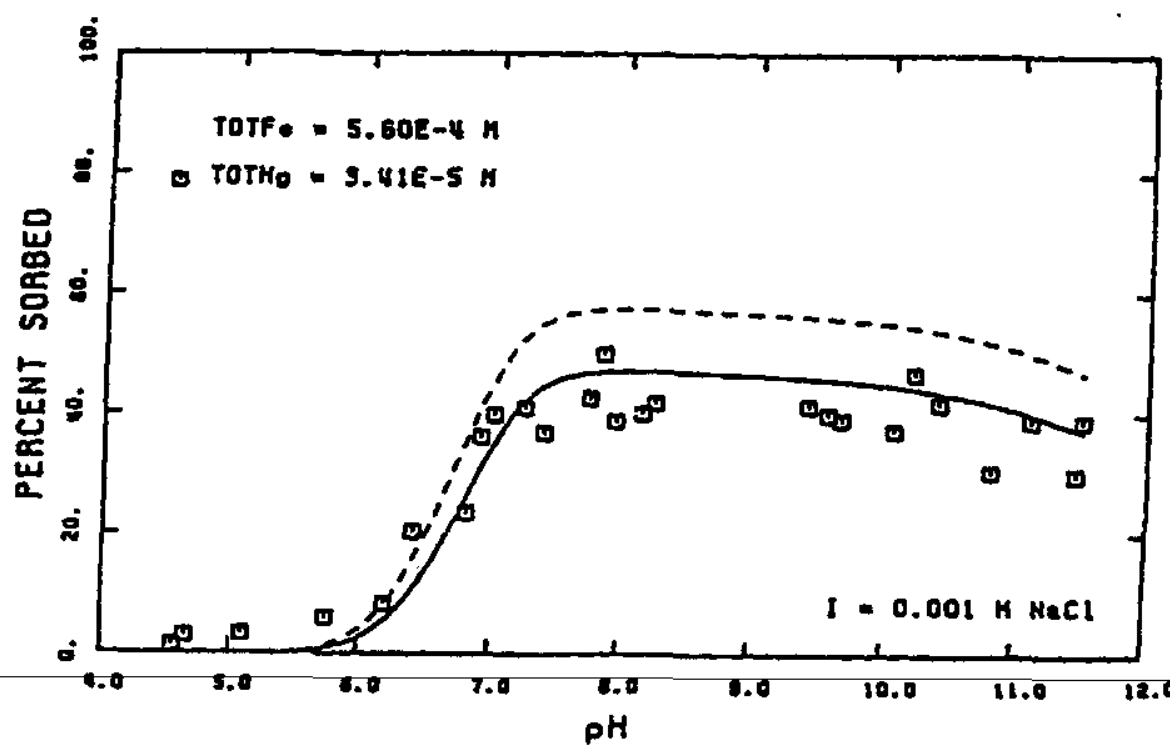

b)

Figure E.4-10 Adsorption of mercury on goethite as function of $\mathrm{pH}$ as an analog for tin (from Dzombak and Morel 1990). a) $0.05 \mathrm{~g} / \mathrm{L}$ goethite, b) $0.05 \mathrm{~g} / \mathrm{L}$ goethite. 


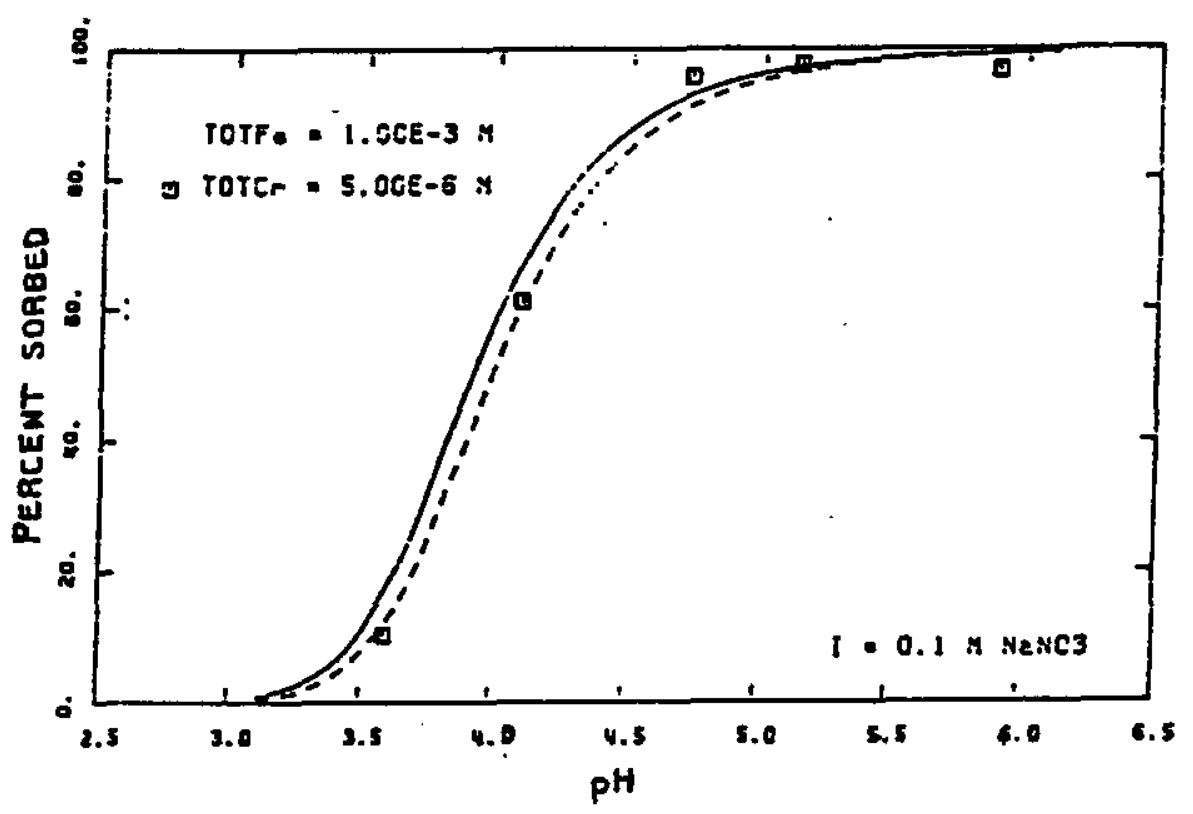

Figure E.4-11 Adsorption of chromium III on goethite as function of $\mathrm{pH}$ as an analog for americium (from Dzombak and Morel 1990). 
A large variance, up to 16 orders of magnitude, in the solubility product values has been shown in experimental or theoretical techniques. Kim and Kanellakopulos (1989) have redone the experiments in order to provide a more substantiated solubility product value. A solubility product of $\log \mathrm{K}_{\mathrm{sp}}=-\mathbf{5 7 . 8 5} \pm$ 0.05 for amorphous $\mathrm{Pu}(\mathrm{OH})_{4}$ was determined in a $1 \mathrm{M} \mathrm{HClO}_{4}$ solution (Kim and Kanellakopulos 1989). This is the lowest value ever measured for amorphous $\mathrm{Pu}(\mathrm{OH})_{4}$ because the experiment includes the spectroscopic speciation to measure only the $\mathrm{Pu}^{4+}$ concentration (Kim and Kanellakopulos 1989). The formation constants for $\mathrm{Pu}(\mathrm{OH})^{3+}, \mathrm{Pu}(\mathrm{OH})_{2}{ }^{2+}, \mathrm{Pu}(\mathrm{OH})_{3}{ }^{+}$, and $\mathrm{Pu}(\mathrm{OH})_{4} \mathrm{E}$ were taken from Ewart et al. (1992). The reactions and constants used in the model are listed below in Table E.5-1.

Solubility calculations based on these thermodynamic data show a solubility limit of approximately $4.4 \times 10^{-13} \mathrm{M}$ for Pu(IV) at $\mathrm{pH}$ greater than 7 . This value was used in the PORFLOW transport simulations. The solubility limit value does not change significantly above pH 7 (Fig. E.5-1). The solubility limit calculated here is lower than the average value reported by Ewart et al. (1992) of $7 \times 10^{-11}$ $\mathrm{M}$ at high $\mathrm{pH}$ because a lower solubility product was used. The $\mathrm{Pu}(\mathrm{OH})_{5}$ species was not considered in the solubility calculations. Experimental observations by Ewart et al. (1992) indicate that this should not impact the calculations because $\mathrm{Pu}(\mathrm{OH})_{5}{ }^{-}$does not form to a significant extent.

\section{Uranium}

Uranium may be present in more than one oxidation state under the conditions found in these units. The solubility of uranium for both tetravalent and hexavalent states has been studied. The dominant oxidation state in the high $\mathrm{pH}$ and reducing conditions in the vault will be U(IV). The controlling solid selected for the calculations is uraninite, crystalline $\mathrm{UO}_{2}$, which is stable under these conditions (Brookins 1988) and is also present in nature. The value used for solubility limited transport calculations were generated by Orebaugh (1993) and confirmed for higher $\mathrm{pH}$.

Orebaugh modeled uranium solubility using version 3.0 of ESP software from OLI Systems (OLI 1993). The calculations were based on the thermodynamic data provided with the software (based on Phillips et al., 1988). The oxidation state of the uranium was assumed to be reducing based on the presence of large amounts of iron in the units. The calculations were made for the major species U(IV) and U(VI) at concentrations of $10^{-6} \mathrm{M}$ for each oxidation state at pH's between 4 and 8 . Iron was present in equal amounts of $10^{-4} \mathrm{M}$ for $\mathrm{Fe}$ (II) and $\mathrm{Fe}$ (III) and the redox couple is described by the equation:

$\mathrm{UO}_{2}^{2+}+2 \mathrm{Fe}^{2+}+4 \mathrm{H}^{+}<=====>\mathrm{U}^{4+}+2 \mathrm{Fe}^{3+}+2 \mathrm{H}_{2} \mathrm{O}$

Above $\mathrm{pH} 7$ the solubility is controlled primarily by $\mathrm{U}(\mathrm{OH})_{4}$ in equilibrium with crystalline $\mathrm{UO}_{2}$. A total solubility for uranium of $3 \times 10^{-10} \mathrm{M}$ at $\mathrm{pH} 7$ was used to model the release of uranium from the units in PORFLOW (Fig. E.5-2).

Solubility calculations conducted for U(IV) using Mathematica with uraninite as the controlling solid phase gave a similar solubility to that calculated by Orebaugh (1993) for the pH range of 7 to 12 . Using the formation constants of Rai et al. (1990) and solubility product from Parks and Pohl (1988) a solubility of $3 \times 10^{-10} \mathrm{M}$ was calculated (Table E.5-2). 


\begin{tabular}{lllll}
$\mathrm{Pu}(\mathrm{OH})_{4}+4 \mathrm{H}^{+}$ & $=\mathrm{Pu}^{4+}$ & $+4 \mathrm{H}_{2} \mathrm{O}$ & -1.86 & Kim and Kanellakopulos 1989 \\
$\mathrm{Pu}^{4+}+\mathrm{H}_{2} \mathrm{O}$ & $==\mathrm{PuOH}^{3+}$ & $+\mathrm{H}^{+}$ & -0.9 & Ewart et al. 1992 \\
$\mathrm{Pu}^{4+}+2 \mathrm{H}_{2} \mathrm{O}$ & $==\mathrm{Pu}(\mathrm{OH})_{2}{ }^{2+}+2 \mathrm{H}^{+}$ & -2.2 & Ewart et al. 1992 \\
$\mathrm{Pu}^{4+}+3 \mathrm{H}_{2} \mathrm{O}$ & $=\mathrm{Pu}(\mathrm{OH})_{3}{ }^{+}$ & $+3 \mathrm{H}^{+}$ & -5.1 & Ewart et al. 1992 \\
$\mathrm{Pu}^{4+}+4 \mathrm{H}_{2} \mathrm{O}$ & $=\mathrm{=Pu}(\mathrm{OH})_{4} \mathrm{E}+4 \mathrm{H}^{+}$ & -10.54 & Ewart et al. 1992 \\
\hline
\end{tabular}

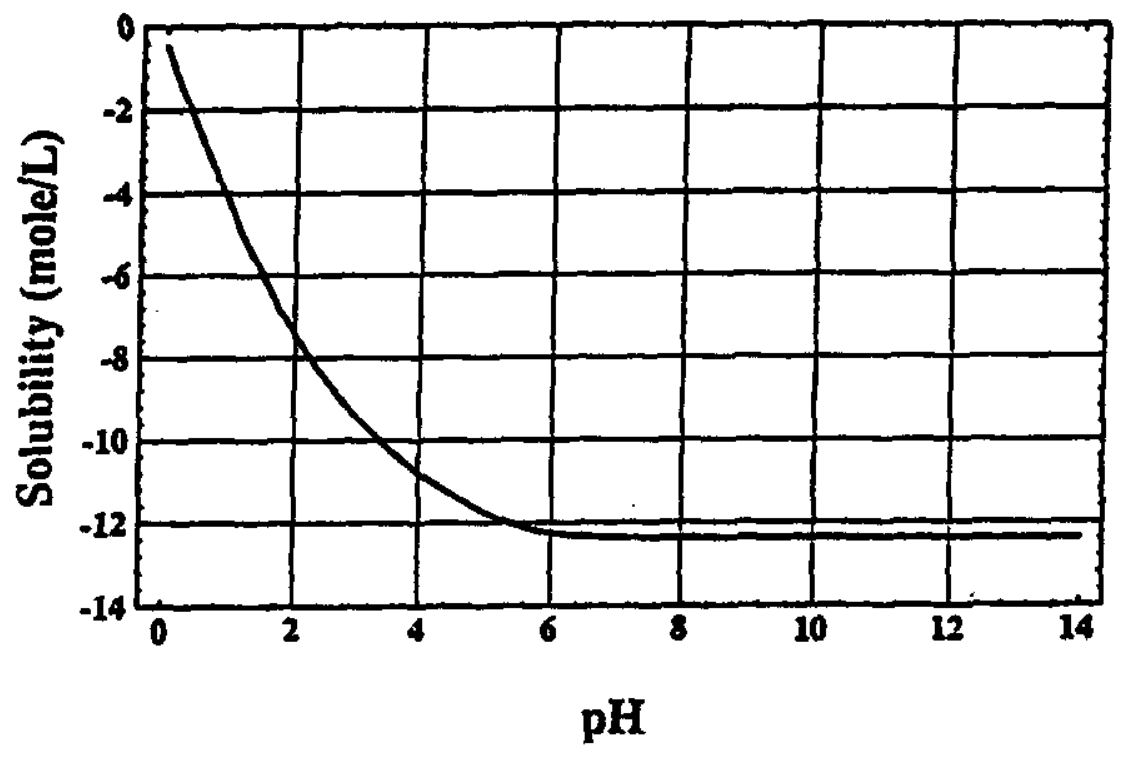

Figure E.5-1. Estimated Pu(IV) solubility under E-Area conditions 


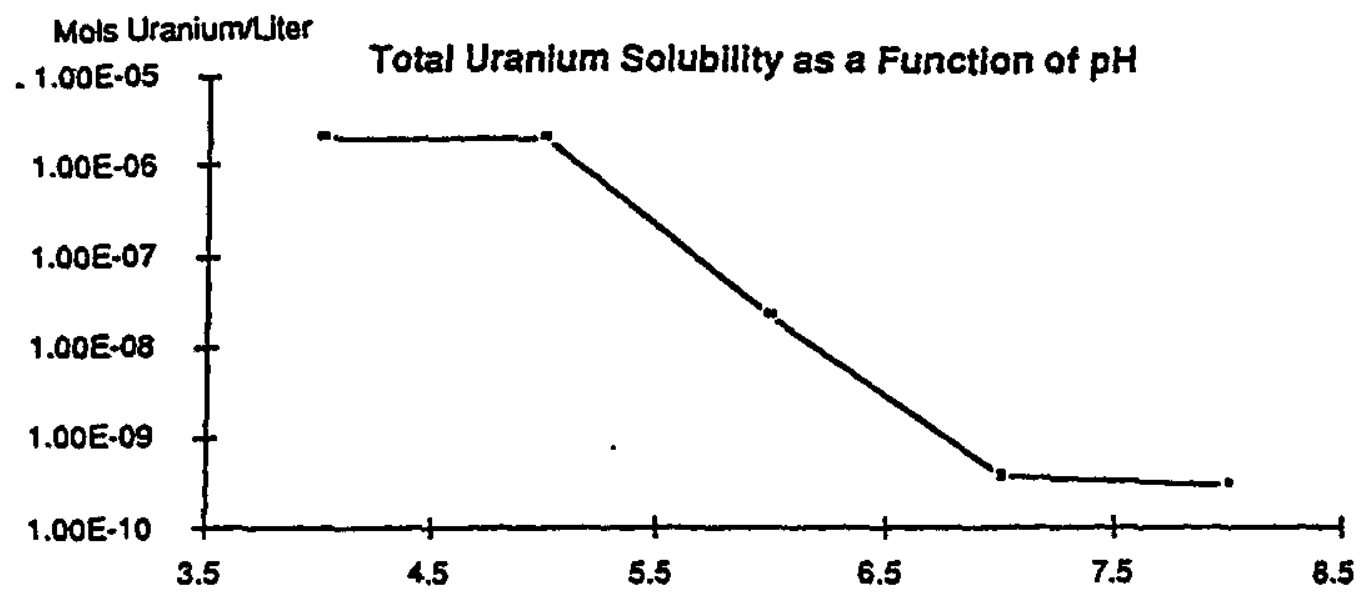

Figure E.5-2. Estimated total uranium solubility under E-Area conditions (Source: Orebaugh 1993).

Table E.5-2. Uranium reactions considered

Reactions

$\mathrm{UO}_{2}+4 \mathrm{H}^{+}==\mathrm{U}^{4+}+2\left(\mathrm{H}_{2} \mathrm{O}\right)$
$\mathrm{U}^{4+}+\mathrm{H}_{2} \mathrm{O}==\mathrm{UOH}^{3+}+\mathrm{H}^{+}$
$\mathrm{U}^{4+}+2 \mathrm{H}_{2} \mathrm{O}==\mathrm{U}(\mathrm{OH})_{2}{ }^{2+}+2 \mathrm{H}^{+}$
$\mathrm{U}^{4+}+3 \mathrm{H}_{2} \mathrm{O}==\mathrm{U}(\mathrm{OH})_{3}{ }^{+}+3 \mathrm{H}^{+}$
$\mathrm{U}^{4+}+4 \mathrm{H}_{2} \mathrm{O}==\mathrm{U}(\mathrm{OH})_{4} \mathrm{E}+4 \mathrm{H}^{+}$
$\mathrm{U}^{4+}+5 \mathrm{H}_{2} \mathrm{O}==\mathrm{U}(\mathrm{OH})_{4}+5 \mathrm{H}^{+}$ $\log \mathbf{K}$

2.5

$-0.5$

$-4.0$

$-8.0$

$-12.0$

$-26.0$
Reference

Parks and Pohl 1988

Rai et al. 1990

Rai et al. 1990

Rai et al. 1990

Rai et al. 1990

Rai et al. 1990 
The Orebaugh (1993) solubility calculations and Mathematica solubility calculations based on the thermodynamic data for U(IV) from Rai et al. (1990) and Parks and Pohl (1988) are in good agreement (Fig. E.5-3) above pH 7. Variation in the results below pH 7 is due to disregarding U(VI) in the Mathematica solubility calculation. This is not significant because the $\mathrm{pH}$ in these units should remain above pH 7 due to the high alkalinity of the concrete.

\section{D.6 SORPTION IN SOILS}

There has not been a need to generate $\mathrm{K}_{d}$ 's using iron oxide content of the soils. The $\mathrm{K}_{d}$ 's used in the PA are documented in tables within the text. 


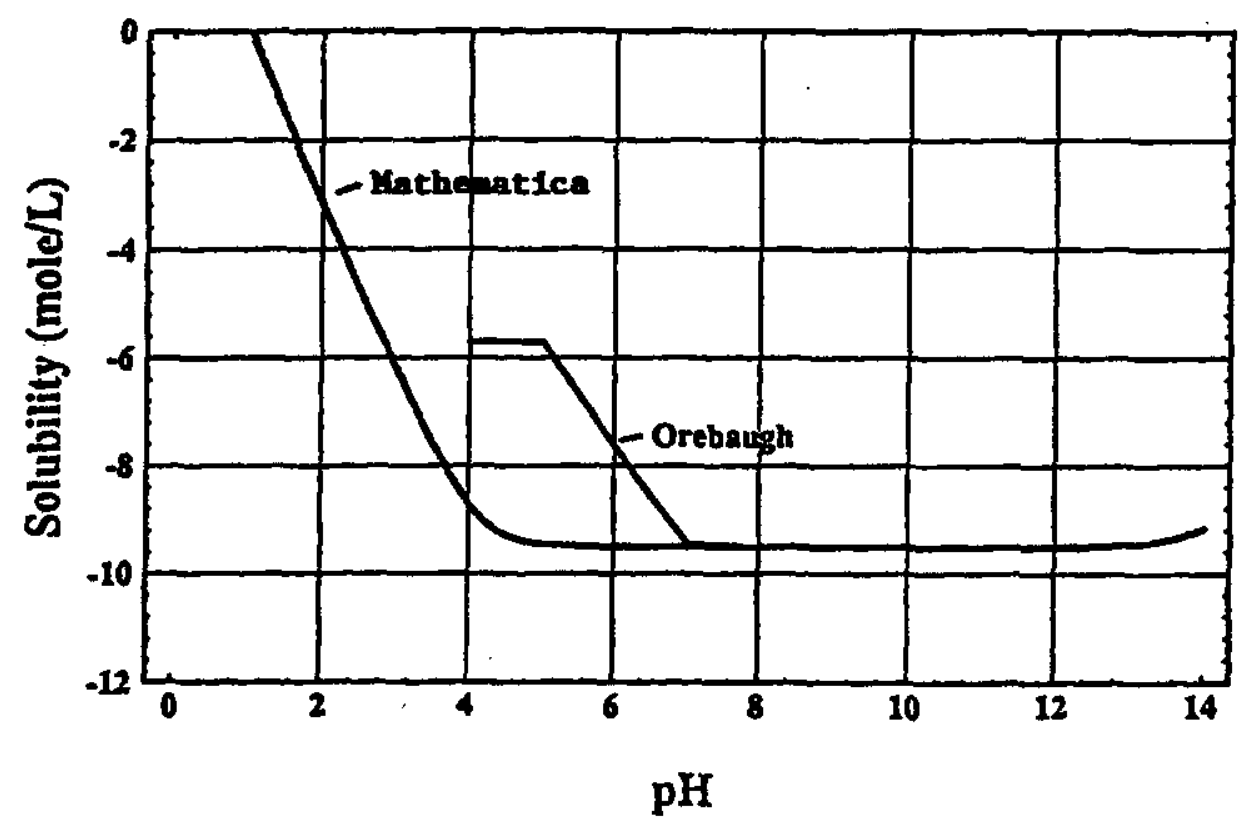

Fig.E.5-3. Comparison of uranium solubilities under E-Area conditions.

Rev. 1 


\section{APPENDIX E REFERENCES}

Avotins, P. V. 1975. Adsorption and Coprecipitation Studies of Mercury on Hydrous Iron Oxide.

Ph.D. thesis. Stanford University, Stanford, Calif.

Bondietti, E. A., and J. R. Trabalka. 1980. Evidence for Plutonium(V) in an Alkaline, Freshwater Pond. Radiochem. Radioanal. Letters, 42:169-176.

Brookins, D. G. 1988. Eh-pH Diagrams for Geochemistry. Springer-Verlag, New York. p. 176.

Duval, J. E., and M. H. Kurbatov. 1952. The Adsorption of Cobalt and Barium Ions by Hydrous Ferric Oxide at Equilibrium. J. Phys. Chem, 56(982-984).

Dzombak, D. A., and F. M. M. Morel. 1990. Surface Complexation Modeling: Hydrous Ferric Oxide. Wiley-Interscience Publication, John Wiley \& Sons, Inc.

Ewart, F. T., J. L. Smith-Briggs, H. P. Thomason, and S. J. Williams. 1992. The Solubility of Actinides in a Cementitious Near-Field Environment. Waste Management, 12:241-252.

Girvin, D. C., L. L. Ames, A. P. Schwab, and J. E. McGarrah. 1991. Neptunium Adsorption on Synthetic Amorphous Iron Oxyhydroxide. Journal of Colloid and Interface Science, 141:67-78.

Harley, J. P., Jr. 1990a. Specifications for Procurement of Low-Level Waste Burial Box. Procurement Specification No. S4-G-183.

Harley, J. P., Jr. 1990b. Specifications for Procurement of 45 ft3 Disposal/Storage Box. Procurement Specification No. S4-G-858.

Hingston, F. J., A. M. Posner, and J. P. Quirk. 1968. Adsorption of Selenite by Goethite. In Adsorption from Aqueous Solution, Advances in Chemistry Series, American Chemical Society, pp. 82-90.

Howard, J. H., III. 1977. Geochemistry of Selenium: Formation of Ferroselite and Selenium Behavior in the Vicinity of Oxidizing Sulfide and Uranium Deposits. Geochimica et Cosmochimica Acta, 41(1665-1678).

Hsi, C. K. D., and D. Langmuir. 1985. Adsorption of Uranyl onto Ferric Oxyhydroxides: Application of the Surface Complexation Site-Binding Model. Geochemica et Cosmochimica Acta, 49(1931-1941).

Hunter, K. A., D. J. Hawke, and L. K. Choo. 1988. Equilibrium Adsorption of Thorium by Metal Oxides in Marine Electrolytes. Geochimica et Cosmochimica Acta, 52(627-636).

Kim, J. I., and B. Kanellakopulos. 1989. Solubility Products of Plutonium(IV) Oxide and Hydroxide. Radiochimica Acta, 48:145-150.

Kinniburgh, D. G., J. K. Syers, and M. L. Jackson. 1975. Specific Adsorption of Trace Amounts of Calcium and Strontium by Hydrous Oxides of Iron and Aluminum. Soil Science Society of America Proceedings, 39(464-470). 
Kinniburgh, D. G., M. L. Jackson, and J. K. Syers. 1976. Adsorption of Alkaline Earth, Transition, and Heavy Metal Cations by Hydrous Oxide Gels of Iron and Aluminum. Soil Science Society of America Proceedings, 40(796-799).

Kolarik, Z. 1961. Sorption Radioaktiver Isotopen an Niederschlagen. VI. System Eisen(II)-Hydroxyd-Strontiumnitratlosung und die allgemeinen gesetzmassigkeiten der Sorption am Eisen(III)-Hydroxyd. Collection Czech. Chem. Commun., 27(938-949).

Kurbatov, M. H. 1949. Rate of Adsorption of Barium Ions in Extreme Dilution by Hydrous Ferric Oxide. Journal of American Chemical Society, 71(858-863).

Leckie, J. O., M. M. Benjamin, K. F. Hayes, G. Kaufman, and S. Altamann. 1980. Adsorption/Coprecipitation of Trace Elements from Water with Iron Oxyhydroxide. EPRI RP-910-1. Electric Power Research Institute, Palo Alto, CA.

Leckie, J. O., A. R. Appleton, N. B. Ball, K. F. Hayes, and B. D. Honeyman. 1984. Adsorptive Removal of Trace Elements from Fly-Ash Pond Effluents onto Iron Oxyhydroxide. EPRI RP-910-1. Electric Power Research Institute, Palo Alto, CA.

Nelson, D. M., and M. B. Lovett. 1978. Oxidation State of Plutonium in the Irish Sea. Nature, 236(599-601).

Nelson, D. M., and M. B. Lovett. 1981. Measurements of the Oxidation State and Concentration of Plutonium in Interstitial Waters of the Irish Sea. In Impacts of Radionuclide Releases into the Marine Environment, Proc., Symp., Otaniemi, June 30-July 4, 1975. IAEA, Vienna.

Nelson, D. M., and K. A. Orlandini. 1979. Identification of $\mathrm{Pu}(\mathrm{V})$ in Natural Waters. In Radiological and Environmental Research Division Annual Report, ANL-79-65, Part III, pp. 57-59.

OLI. 1993. ESP Version 3 Manual. OLI Systems, Inc., Morris Plains, NJ.

Orebaugh, E. G. 1993. Modeling Uranium Solubility in Aged Vault Disposal. WSRC-RP-93-1318. E. I. du Pont de Nemours and Company, Savannah River Laboratory, Aiken, SC.

Parks, G. A., and Pohl, D. C. 1988. Hydrothermal solubility of uraninite. Geochimica et Cosmochimica Acta, 52:863-875.

Phillips, S. L., Hale, F. V., Silvester, L. F., and Siegel, M. D. 1988. Thermodynamic Tables for Nuclear Waste Isolation. Aqueous Solution Database, NUREG/CR-4864, p. 138.

Plotnikov, V. I. 1958. Coprecipitation of Small Quantities of Selenium with Ferric Hydroxide. Russian Journal of Inorganic Chemicals, 3(8):1761-1766.

Rai, D., Felmy, A. R., and Ryan, J. L. 1990. Uranium(IV) Hydrolysis Constants and Solubility Product of UO2 xH2O(am). Inorganic Chemistry, 29:260-264.

Sanchez, A. L., J. W. Murray, and T. H. Sibley. 1985. The Adsorption of Plutonium IV and V on Goethite. Geochemica et Cosmochimica Acta, 49(2297-2307). 
Sharland, S. M., P. W. Tasker, and C. J. Tweed. 1986. The Evolution of Eh in the Pore Water of a Model Nuclear Waste Repository. UKAEA Report AERE-R12442. Harwell Laboratory, UK. 
THIS PAGE INTENTIONALLY LEFT BLANK

Rev. 1 
APPENDIX F

SOFTWARE QA PLAN 
THIS PAGE INTENTIONALLY LEFT BLANK

Rev. 1 


\section{CONTENTS}

Software QA Plan for PORFLOW Code

Certification Package for FACT Version 2.0

Software QA Plan for Environmental Dosimetry

(includes the MAXIGASP code used in the air pathway analysis) 
SOFTWARE QA PLAN FOR SOFTWARE CODES USED IN SAVANNAH RIVER SITE E-AREA PERFORMANCE ASSESSMENT REVISION

Prepared For:

RCS Corporation

Aiken, South Carolina 29803

Prepared By:

Alara Environmental Analysis, Inc.

Pleasanton, CA 94566

November 6, 1997 
ALARA ENVIRONMENTAL ANALYSIS, INC.

\section{SOFTWARE QUALITY ASSURANCE PLAN FOR ECLIPSE AND PORFLOW CODES USED IN E-AREA PERFORMANCE ASSESSMENT REVISION}

\subsection{PURPOSE}

This plan describes the steps taken by Alara Environmental Analysis, Inc. to implement software quality assurance (SQA) procedures, developed with consideration of the ASME NQA-2A (ASME NQA-2A-1990) requirements, as directed by Westinghouse Savannah River Company (WSRC), to the extent they can be applied to the acquired computer codes ECLIPSE (Intera Information Technologies Limited 1993) and PORFLOW (Runchal 1997).

\subsection{SCOPE}

The SQA plan applies to life-cycle phases of ECLIPSE and PORFLOW as they are used in conducting a revision of the performance assessment of the proposed E-Area low-level waste disposal facility at the Savannah River Site (SRS). These phases including installation, testing, operation and maintenance, and retirement of this preexisting custom software. Configuration control and quality control procedures are also included in the plan.

\subsection{TERMS/DEFINITIONS}

COMPUTER APPLICATIONS SPECIALIST (CAS)

The Computer Applications Specialist is the person employed by Alara Environmental Analysis, Inc., having overall technical responsibility for computer simulations used to prepare Revision 1.0 of the E-Area Performance Assessment.

\section{CONFIGURATION CONTROL}

Configuration control is the process of identifying and defining the configuration items in the ECLIPSE and PORFLOW software systems, controlling the release and change of these items throughout the systems' life cycle, and recording and reporting the status of configuration items and change requests.

\section{ECLIPSE}

ECLIPSE is a commercially-available computer code acquired by WSRC for use in simulating flow of water in the vadose zone around and through waste facilities. Simulation results will provide flow fields in the vadose zone, which will be used by PORFLOW to simulate mass transport in the vadose zone to the water table.

\section{PORFLOW}

PORFLOW is a commercially-available computer code acquired by WSRC for use in simulating mass transport in the vadose zone and saturated portion of the subsurface. Simulation results will provide fluxes to Upper Three Runs and groundwater concentrations of radionuclides originating from proposed low-level waste (LLW) disposal at E-Area. 
PRINCIPAL INVESTIGATOR (PI)

The PI is the individual responsible for coordinating tasks that are to be completed by Alara Environmental Analysis, Inc. for Revision 1.0 of the E-Area Performance Assessment.

QUALITY ASSURANCE (QA) COORDINATOR

The QA coordinator is the individual responsible for writing QA Plans and/or Procedures for Alara Environmental Analysis, Inc., and for ensuring implementation of the plans.

\section{SOFTWARE}

Software refers to computer programs, procedures, associated procedure manuals, computer source codes, and program disks.

\section{SOFTWARE VALIDATION}

Validation of software refers to the testing of the software with respect to the accuracy of decisions or assumptions incorporated into the software.

\section{SOFTWARE VERIFICATION}

Verification of software refers to the testing of the software with respect to accuracy of numerical algorithms.

\subsection{RESPONSIBLITIES FOR SQA}

\section{COMPUTER APPLICATIONS SPECIALIST}

The CAS for the E-Area Performance Assessment Revision is responsible for defining software needs. Upon acquisition, the CAS is responsible for overseeing that the software life cycle procedures are correctly implemented and for carrying out configuration control and quality control procedures. The CAS is also responsible for determining software compatibility with existing or acquired hardware, maintaining documentation of SQA procedures, and carrying out custodial requirements.

\section{PRINCIPAL INVESTIGATOR}

The PI is responsible for identifying the necessity for SQA plans and/or procedures.

\section{QA COORDINATOR}

The QA coordinator is responsible for writing plans and/or procedures for implementing SQA and reviewing implementation of SQA.

\subsection{SOFTWARE LIFE CYCLE}

\subsection{Software Installation}

Because ECLIPSE and PORFLOW are pre-existing software, installation must be preceded by testing to ensure the software is complete and free of viruses that may infect the computer system on which it is installed. Backup copies of the software will be made, and used for installation. The CAS will ensure that the original copies of the software shall be stored in a location safe from theft, loss, and environmental damage. Installation will take place in accordance with the installation instructions provided by the developer s of ECLIPSE and PORFLOW. 
Once installed, configuration control shall be initiated. The date of installation, version installed, and installation notes will be recorded in SQA Logbooks. These Logbooks (which will be maintained separately for each code) will contain the name and telephone number of the CAS responsible for ECLIPSE and PORFLOW and the name and contract number of the Performance Assessment project for which the software was acquired. Source code listings, software documentation, and user's manuals will be stored in a location accessible to designated users of the software and will not be removed without permission of the CAS.

\subsection{Software Testing}

Testing is required to confirm that ECLIPSE and PORFLOW satisfy the objectives and requirements of the simulations to be carried out for revision of the E-Area Performance Assessment. Verification testing, described in Section 5.2.1, is a demonstration of whether ECLIPSE and PORFLOW meet the requirements specified regarding function, performance, external interfaces, and attributes.

\subsubsection{Verification}

The capabilities of ECLIPSE and PORFLOW must be verified by comparing analytical solutions of the desired simulation equations for a defined problem to code output in order to evaluate the accuracy of numerical algorithms. Comparison of software simulation results with results from previously verified versions or codes (termed benchmarking) is acceptable.

\subsubsection{Validation or Benchmarking}

Complete validation of ECLIPSE and PORFLOW requires data that not only test the ability of the codes to predict contaminant transport under present conditions, but also test the predictability of results when perturbations are made to the vadose zone, groundwater system and similarly to the codes. These data are not presently available, nor will they be available for this revision of the E-Area Performance Assessment. However, benchmarking of ECLIPSE and PORFLOW results to results from software that has gained high acceptability by acknowledged experts has been carried out. These results are considered acceptable for validation of ECLIPSE and PORFLOW for the purposes of the E-Area Performance Assessment Revision 1.0.

\subsubsection{Documentation of Testing}

Results of efforts to reproduce verification tests of ECLIPSE and PORFLOW will be recorded in the SQA Logbooks that will be initiated when software is installed by the CAS (Sect. 5.1).

\subsection{Software Operation and Maintenance}

\subsubsection{Operation}

Operation of ECLIPSE and PORFLOW will be conducted by personnel approved by the CAS who, in the CAS's judgment, are appropriately trained. These individuals will have access to user's manuals and the SQA Logbooks. 
Operational tests will be performed whenever ECLIPSE and PORFLOW are installed on a different computer to be used in this project or when configurational changes are made to the software or hardware system. The results of these tests will be documented in the SQA Logbooks.

\subsubsection{Maintenance}

Maintenance to correct software errors or adapt to changes in software requirements or the operating environments will be made only with the CAS's approval and documented in the SQA Logbooks.

\subsection{Software Retirement}

Because ECLIPSE and PORFLOW will be licensed to WSRC, retirement of the codes will be the responsibility of WSRC, following transmittal of the installation software to WSRC upon completion of this project.

\subsection{CONFIGURATION CONTROL}

\subsection{Configuration Identification}

Configuration baselines will be defined for ECLIPSE and PORFLOW, described by input data sets including test cases, simulation results, and hardware as the tested and approved configuration. A labeling system will be implemented for each of these types of data files such that each file is uniquely identified and that configurations resulting from revisions of each file are uniquely identified.

\subsection{Configuration Change Control}

Changes to configuration items, including the ECLIPSE and PORFLOW codes, input data sets, simulation results, and hardware will be formally documented under the following guidelines.

\subsubsection{Changes to ECLIPSE and PORFLOW}

Changes to the baseline versions of ECLIPSE and PORFLOW must be approved by the CAS. Verification testing (as described in Sect. 5.2.1) will be performed to ensure that changes do not nullify the code testing results.

\subsubsection{Changes to/Creation of Data Sets and Simulation Results}

Changes to, or creation of new, data sets will be documented in a manner that uniquely identifies each set and corresponding simulation results set.

\subsubsection{Changes in Hardware Configuration}

Changes to hardware may affect the operation of ECLIPSE and PORFLOW. Therefore, such changes will be reflected in the archiving, or tracking, procedure and in the documentation. 


\subsection{Configuration Control Documentation}

Configuration control documentation will contain the information needed to manage the ECLIPSE and PORFLOW configurations and accompanying data sets, simulation results, and hardware requirements. This information will identify the approved configuration (via a well documented naming convention for software, data sets, and simulation results) and will be kept in the SQA Logbooks. These Logbooks will be easily decipherable with respect to reflecting modifications made to the various configurations.

\subsection{QUALITY CONTROL}

\subsection{Technical Review of Software}

The CAS will periodically review the approach and key assumptions, and evaluate input data sets to ensure that QA procedures have been applied and that proper documentation is generated throughout the life cycle of ECLIPSE and PORFLOW. When necessary, the CAS will call on others to review assumptions and input data to verify their appropriateness and accuracy.

\subsection{Sign-off and Approvals}

The sign-off and formal approvals on key assumptions and input data will be accomplished with cover letters transmitting the information being approved. Individuals whose approval is sought will be identified by either the CAS or WSRC and will include those with particular knowledge of the specific information from WSRC as well as appropriate managers.

\subsection{Quality Control Documentation}

Documentation of Quality Control procedures will be kept in the form of the signoff and approval cover letters that transmit information pertinent to these procedures. These signature forms and attached information will be kept in a separate notebook entitled Software Quality Control Notebook.

\subsection{PROBLEM REPORTING AND CORRECTIVE ACTION}

A formal procedure of software problems and corrective action reporting shall be established by the CAS for ECLIPSE and PORFLOW errors and failures. The reporting system will ensure that problems and corrective actions taken are promptly reported to affected organizations, such as WSRC. Problems and corrective actions will be reported in the form of letters to affected individuals and organizations, and will be described in the SQA Logbooks.

\subsection{RECORDS}

The following documents will be retained as records:

1) SQA Plan;

2) SQA Logbooks containing information on installation, software and 
hardware configuration, code testing results, and maintenance actions;

3) Documentation of ECLIPSE and PORFLOW, including the user's manual; and

4) SQC Notebook including documentation of approvals on input data and major assumptions made.

\subsection{REFERENCES}

ASME NQA-2A-1990. 1990. Part 2.7, Quality Assurance Requirements of Computer Software for Nuclear Facility Applications.

Intera Information Technologies Limited. 1993. ECLIPSE 100 Reference Manual, 94A Release, Oxfordshire, England.

Runchal, Akshai. 1997. PORFLOW: A Model For Fluid Flow, Heat and Mass Transport in Multifluid, Mulitphase Fractured or Porous Media: User's Manual Version 3. Analytic and Computational Research, Inc., Bel Air, Califomia.

Prepared and Approved by:

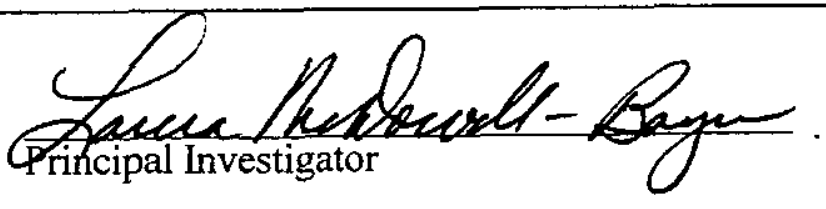

President, Alara Environmental Analysis. Inc. Title and Affiliation

Date: Yov. 7,1992 


\section{Certification Package for FACT Version 2.0 (U)}

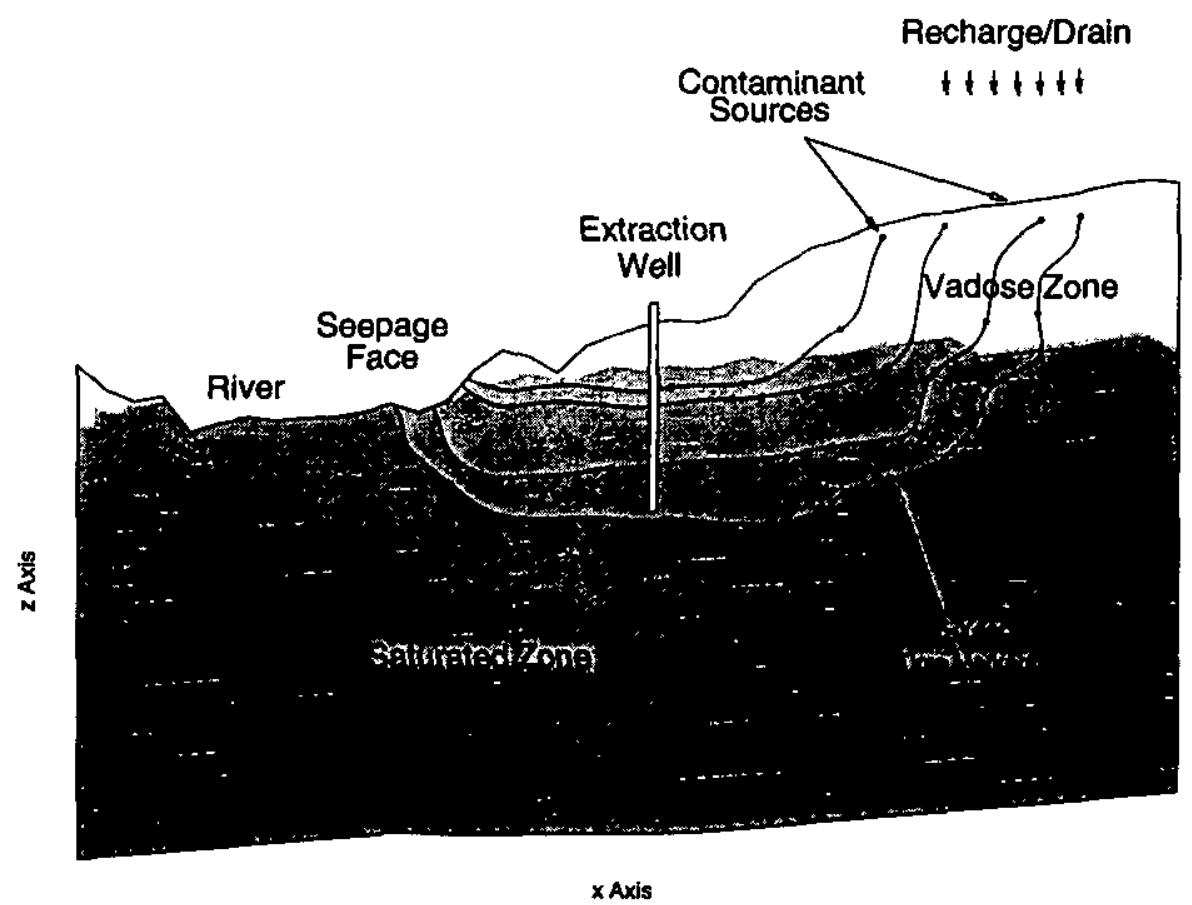

Westinghouse Savannah River Company

Savannah River Site

Aiken, SC 29808

Prepared for the U. S. Department of Energy under contract no. DE-AC09-96SR18500 


\section{Disclaimer}

This report was prepared as an account of work sponsored by agency of the United States Government. Neither the United States Government nor any agency thereof, nor any of their employees, makes any warranty, express or implied, or assumes any legal liability or responsibility for the accuracy, completeness, or usefulness of any information, apparatus, product, or process disclosed, or represents that its use would not infringe privately owned rights. Reference herein to any specific commercial product, process, or service by trade name, trademark, manufacturer, or otherwise does not necessarily constitute or imply its endorsement, recommendation, or favoring by the United States Government or any agency thereof. The views and opinions of authors expressed herein do not necessarily state or reflect those of the United States Government or any agency thereof. 
WSRC-TR-99-00422, Revision 0

Keywords: Groundwater

Fate and Transport

Finite Element Method

Retention:

Permanent

\section{Certification Package for FACT Version 2.0 (U)}

Sebastian E. Aleman

Publication Date: November 1999

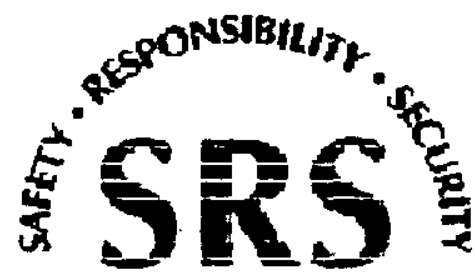

SAVANNAH RIVER SITE

Westinghouse Savannah River Company

Savannah River Site

Aiken, SC 29808 
DOCUMENT: $\quad$ WSRC-TR-99-00422, Revision 0

TITLE:

Certification Package for FACT Version 2.0 (U)

Authentication and Approvals:

Date:

Sebastian E. Aleman, CTF (ERTS/SRTC)

Date:

Gregory P. Flach, Technical Reviewer (ERTS/SRTC)

Date:

Elton T. Booth, CQF (QAD/SRTC)

Date:

Mary K. Harris, Manager, (ERTS/SRTC) 


\section{TABLE OF CONTENTS}

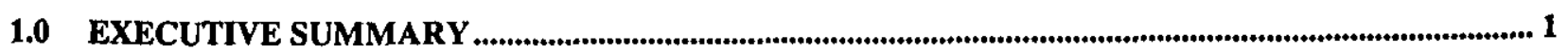

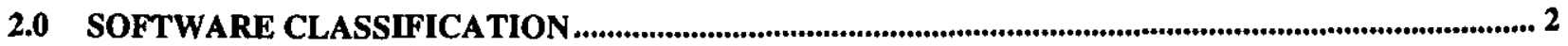

3.0 SOFTWARE QUALITY ASSURANCE PROCEDURES/PLANS ........................................................... 2

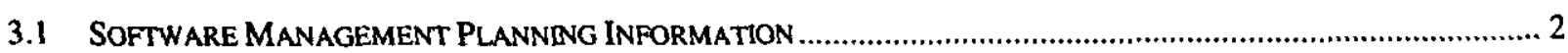

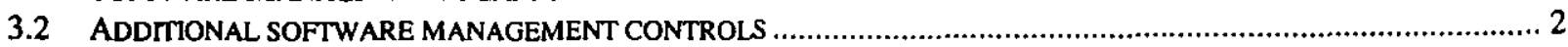

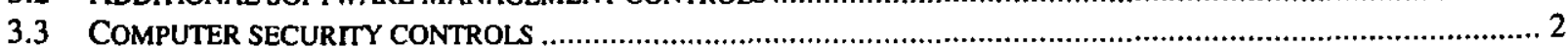

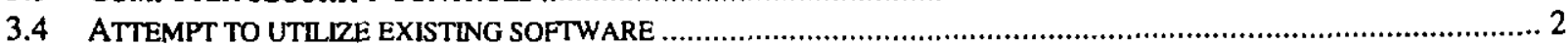

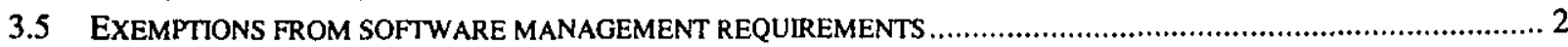

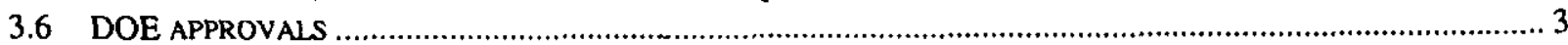

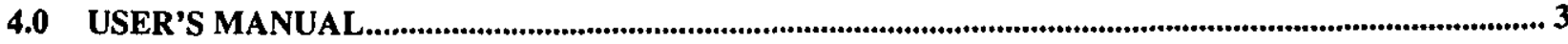

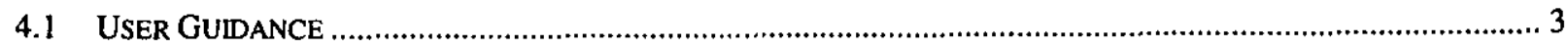

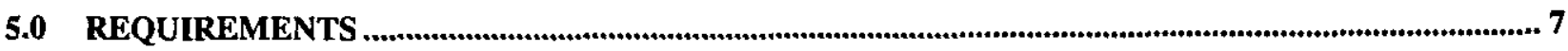

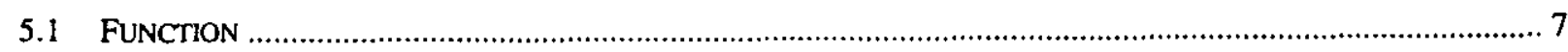

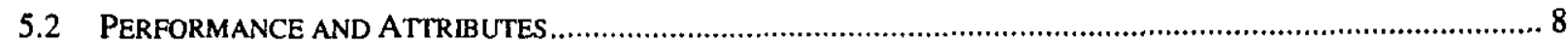

5.3 DESIGN CONSTRAINTS IMPOSED ON DESIGN AND IMPLEMENTATION ACTIVITIES ..................................... 9

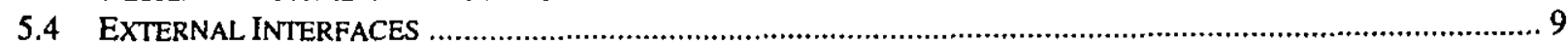

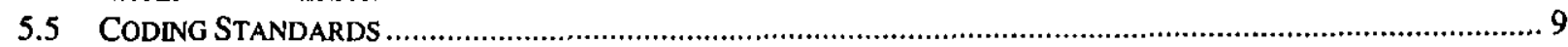

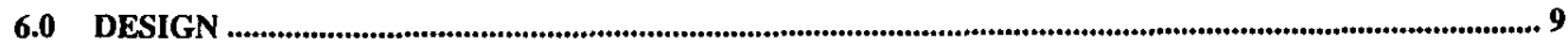

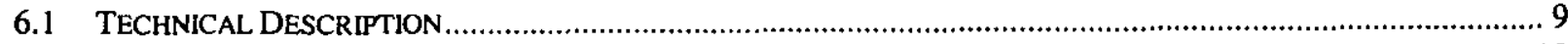

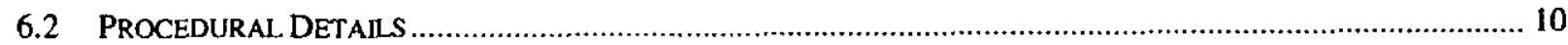

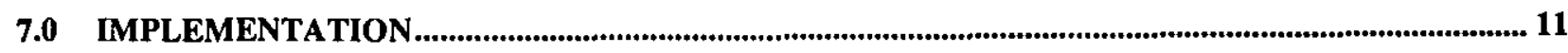

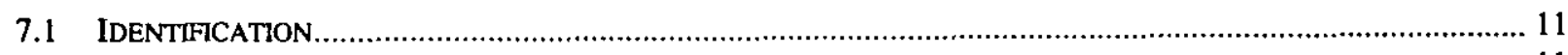

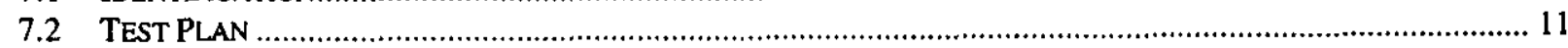

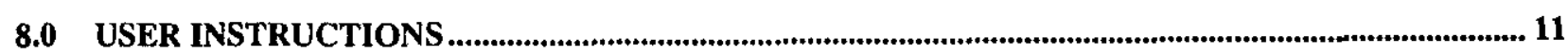

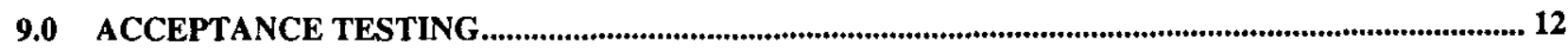

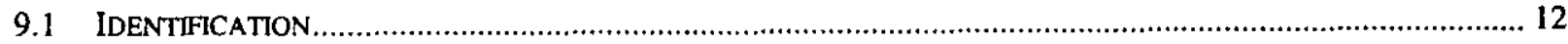

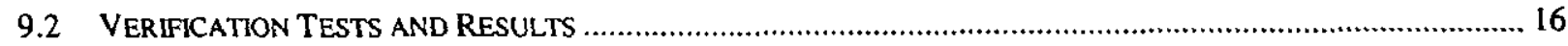

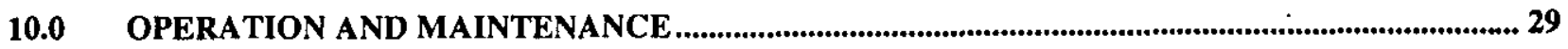

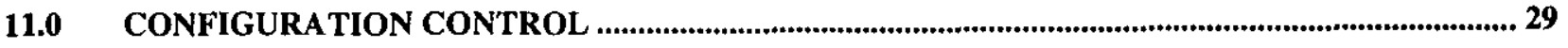

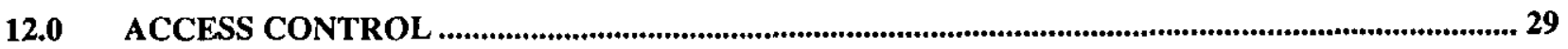

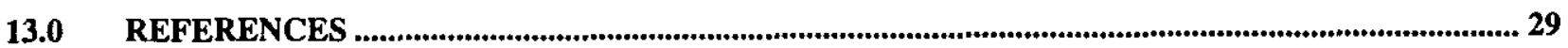

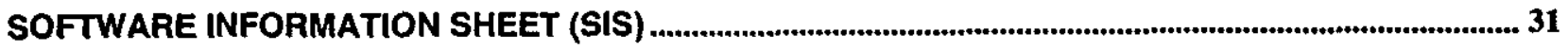

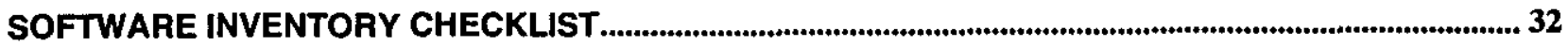


WSRC-TR-99-00422, Revision 0

\section{LIST OF TABLES}

Table 1 Individuals Identified in Certification Process. .. 1

Table 2 Summary of FACT Input and Output Files. 4

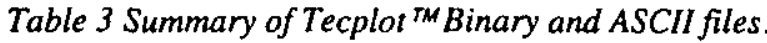
5 


\subsection{Executive Summary}

This report contains or references the necessary information for certification of the SRTC developed Flow And Contaminant Transport (FACT) code, Version 2.0. FACT solves the variably saturated formulation for subsurface flow and contaminant transport in a multdimensional porous media (fractured rock formations not handled). Even though FACT contains a general formulation, many unique features have been built into FACT to address the unique SRS environmental topographic and remedial alternatives typically encountered.

The purpose of this report is to document the implementation of the software management requirements and responsibilities provided in (1) Procedure QAP 20-1 Rev. 5 "Software Quality Assurance", Procedure L1 8.20 Rev. 0 and to also reference associated reports pertinent to the needs of the E7 manual. For more detailed information regarding FACT v2.0 see the documentation and user's guide (Hamm et. al., 1999b). This certification package is limited to the use of FACT v2.0 on the following computer platforms: (1) IRIX based Silicon Graphics machines running under IRIX 6.5 or later, and (2) Intel-based PC's running under the Windows $95^{\mathrm{TM}}$ or Windows $\mathrm{NT}^{\mathrm{TM}}$ Workstation 4.0 or later operating systems.

The following individuals have been identified for the purposes of completing the certification process:

Table 1 Individuals Identified in Certification Process

\begin{tabular}{|c|c|c|}
\hline Non & 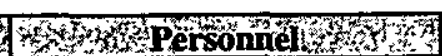 & for \\
\hline Customer(s) & Mary K. Harris & SRTC/ERTS \\
\hline Cognizant Technical Function (CTF) & Sebastian E. Aleman & SRTC/ERTS \\
\hline Tester & Sebastian E. Aleman & SRTC/ERTS \\
\hline Cognizant Quality Function (CQF) & Elton T. Booth & SRTC/QAD \\
\hline $\begin{array}{l}\text { Configuration Management System } \\
\text { (CMS) Custodian }\end{array}$ & Sebastian E. Aleman & SRTC/ERTS \\
\hline Techincal Reviewer (TR) & Gregory P. Flach & SRTC/ERTS \\
\hline Owner(s) & $\begin{array}{l}\text { Sebastian E. Aleman } \\
\text { L. Larry Hamm }\end{array}$ & $\begin{array}{l}\text { SRTC/ERTS } \\
\text { SRTC/EDS }\end{array}$ \\
\hline Owner(s) Manager & Mary K. Harris & SRTC/ERTS \\
\hline
\end{tabular}

Procedure QAP 20-1 Software Quality Assurance identifies the life cycle documentation requirements matrix for Level " $B$ " software development not part of SSCs with CLI numbers as

Software Classification

SQA Procedure/Plans

User's Manual

Requirements

Design

Implementation

User Instructions

Acceptance Test 
Operation and Maintenance

Configuration Control

Access Control

\subsection{Software Classification}

The majority of expected applications support fate and transport modeling to comply with environmental regulatory requirements/commitments (EPA, SCDHEC) Therefore, FACT v2.0 is assigned a software classification of Level "B" as defined in Procedure QAP 20-1, Rev.5.

\subsection{Software Quality Assurance Procedures/Plans}

Implementation of L1-8.20, Rev. 0 and QAP 20-1, Rev. 5 will be the basis for the SQA Procedures/Plans.

\subsection{Software Management Planning Information}

The FACT 2.0 software (Hamm et al., 1999b) is an upgrade of the existing FACT v1.1 code (Hamm et al., 1999a). This software is not expected to impact other DOE sites. However, the general capability of FACT is very appropriate for modeling groundwater flow and contaminant transport at most DOE facilities (for example, vadose modeling at the Hanford Site can be readily handled with FACT). The software is scientific/engineering software. Expected users will typically be from a variety of organizations (onsite and offsite).

\subsection{Additional software management controls}

Software management procedures applicable to this software upgrade project are 1B MRP 3.25 "Capture, Management and Release of Information and Software" and 1B MRP 3.60 "Software Inventory Management Control" (in addition to 1B MRP 3.62 "Software Management").

\subsection{Computer security controls}

The FACT $v 2.0$ software and applications are intended to be unclassified and nonsensitive. The code will be used on computer systems compliant with 7Q "WSRC Security Manual" and 10Q "Computer Security Manual (U)" for unclassified and nonsensitive applications. No other security controls have been identified.

\subsection{Attempt to utilize existing software}

FACT v2.0 is an upgrade to the existing FACT v1.1 software. Therefore, this project already utilizes existing software. Therefore, no search for existing software was performed.

\subsection{Exemptions from software management requirements}

Not applicable. 


\subsection{DOE approvals}

None required according to L1 8.20, Rev. 0 §5.1.6.

\subsection{User's Manual}

A User's Guide to FACT v2.0 can be found in the FACT v2.0 (Hamm et al., 1999b) code manual. No specific training is required beyond those instructions that are provided within that code manual.

\subsection{User Guidance}

The following is a very brief overview of input and output files typically encountered when a user of FACT performs groundwater modeling.

The above code manual contains the following topics (chapters and appendices):

- 1 Introduction

- 2 Governing Mathematical Models

- 3 Numerical Solution Techniques

- 4 Verification Tests and Results

- 5 Problem Definition and Simulation Procedure

- 6 Code Structure

- 7 Input and Output

- 8 References

- Appendix A Test Problem Listing

- Appendix B Flow Test Problem Input Files

- Appendix C Flow Test Problem Output Sample

- Appendix D Transport Test Problem Input Files

- Appendix E Transport Test Problem Output Sample

Chapter 7 of the code manual (Hamm et al., 1999b) describes the input and output file structures. All of the possible standard input and output files for a particular FACT run are listed in Table 1 below (also provided in Table 7.2 of the code manual). A super file input data structure exists where all necessary standard input and output files are pointed to within a "super file" that is unique for each FACT run. As pointed out in Table 1 certain data categories will always be required regardless of problem type. For input data categories the user has the option to place the input data either within the "main input" file or to locate it within a separate file. For each required (and separate data file) data category a filename must be supplied in either single or double quotes. The locations of these input and output files can exist within any directories containing proper permission (e.g., read for input and read/write for output). By default, filenames intended to be created or read from the current directory only require relative path names. Those filenames corresponding to files outside the current directory require complete path names. 
Upon completion of a FACT simulation, one or more output files will have been created. The number of such files is dependent on the FACT input parameters and whether it is a flow and/or transport simulation. Table 1 lists the possible standard output files that are generated. In addition to these standard output files, multiple graphical Tecplot ${ }^{\text {m }}$ Data Files are created in either binary or ASCII form (these files are compatible with both versions 7 and 7.5). Table 2 contains a listing of the possible Tecplot ${ }^{\mathrm{TM}}$ Data Files created (also provided in Table 7.3 of the code manual). The binary files are generated per a print frequency starting with the number 0000 and incrementing by the print frequency (e.g. by 10, tecn0000.plt, tecn0010.plt, tecn0020.plt, etc.). Each Tecplot ${ }^{\text {Th }}$ Data File created corresponds to a unique time step.

Table 2 Summary of FACT Input and Output Files

\begin{tabular}{|c|c|c|c|c|c|}
\hline File & Name & Unit & $\mathbf{1} / \mathbf{O}$ & Format & SY Comments \\
\hline super file & user-specified & 5 & input & $\begin{array}{c}\text { formatted } \\
\text { (ASCII) }\end{array}$ & $\begin{array}{c}\text { Required for } \\
\text { standard input }\end{array}$ \\
\hline main input & $\begin{array}{l}\text { user-specified in } \\
\text { super file }\end{array}$ & 10 & input & $\begin{array}{l}\text { formatted } \\
\text { (ASCII) }\end{array}$ & $\begin{array}{l}\text { Required always for } \\
\text { category MAIN }\end{array}$ \\
\hline geometry & $\begin{array}{l}\text { user-specified in } \\
\text { super file }\end{array}$ & 11 & input & $\begin{array}{l}\text { formatted } \\
\text { (ASCII) }\end{array}$ & $\begin{array}{c}\text { Required for } \\
\text { category GEOM }\end{array}$ \\
\hline material properties & $\begin{array}{l}\text { user-specified in } \\
\text { super file }\end{array}$ & 12 & input & $\begin{array}{l}\text { formatted } \\
\text { (ASCII) }\end{array}$ & $\begin{array}{c}\text { Required for } \\
\text { category MATL }\end{array}$ \\
\hline boundary conditions & $\begin{array}{l}\text { user-specified in } \\
\text { super file }\end{array}$ & 13 & input & $\begin{array}{l}\text { formatted } \\
\text { (ASCII) }\end{array}$ & $\begin{array}{l}\text { Required for } \\
\text { category BCFT }\end{array}$ \\
\hline spline data & $\begin{array}{l}\text { user-specified in } \\
\text { super file }\end{array}$ & 14 & input & $\begin{array}{l}\text { formatted } \\
\text { (ASCII) }\end{array}$ & $\begin{array}{l}\text { Required for } \\
\text { category SPLN }\end{array}$ \\
\hline printed output & $\begin{array}{l}\text { user-specified in } \\
\text { super file }\end{array}$ & 15 & output & $\begin{array}{l}\text { formatted } \\
\text { (ASCII) }\end{array}$ & $\begin{array}{l}\text { Created always for } \\
\text { category PRNT }\end{array}$ \\
\hline $\begin{array}{l}\text { initial condition } \\
\text { head }\end{array}$ & $\begin{array}{l}\text { user-specified in } \\
\text { super file }\end{array}$ & 20 & input & $\begin{array}{l}\text { binary } \\
\text { ASCII }\end{array}$ & $\begin{array}{l}\text { Required for } \\
\text { category ICHN }\end{array}$ \\
\hline $\begin{array}{l}\text { initial condition } \\
\text { concentration }\end{array}$ & $\begin{array}{c}\text { user-specified in } \\
\text { super file }\end{array}$ & 21 & input & $\begin{array}{l}\text { binary } \\
\text { ASCII }\end{array}$ & $\begin{array}{l}\text { Required for } \\
\text { category ICCN }\end{array}$ \\
\hline $\begin{array}{l}\text { initial condition } \\
\text { immobile } \\
\text { concentration }\end{array}$ & $\begin{array}{l}\text { user-specified in } \\
\text { super file }\end{array}$ & 22 & input & $\begin{array}{l}\text { binary } \\
\text { ASCII }\end{array}$ & $\begin{array}{l}\text { Required for } \\
\text { category ICCI }\end{array}$ \\
\hline $\begin{array}{c}\text { flow solution } \\
\text { elemental velocity }\end{array}$ & $\begin{array}{l}\text { user-specified in } \\
\text { super file }\end{array}$ & 23 & input & $\begin{array}{l}\text { binary } \\
\text { ASCII }\end{array}$ & $\begin{array}{c}\text { Required for } \\
\text { category FSVE }\end{array}$ \\
\hline $\begin{array}{c}\text { flow solution } \\
\text { water saturation }\end{array}$ & $\begin{array}{l}\text { user-specified in } \\
\text { super file }\end{array}$ & 24 & input & $\begin{array}{l}\text { binary } \\
\text { ASCII }\end{array}$ & $\begin{array}{c}\text { Required for } \\
\text { category FSWS }\end{array}$ \\
\hline $\begin{array}{l}\text { flow solution } \\
\text { nodal velocity }\end{array}$ & $\begin{array}{l}\text { user-specified in } \\
\text { super file }\end{array}$ & 25 & input & $\begin{array}{l}\text { binary } \\
\text { ASCII }\end{array}$ & $\begin{array}{c}\text { Required for } \\
\text { category FSVN }\end{array}$ \\
\hline flow solution & user-specified in & $\overline{26}$ & input & binary & Required for \\
\hline mass balance flow & super file & & & ASCII & category FSMB \\
\hline $\begin{array}{c}\text { flow solution } \\
\text { recharge/drain flow }\end{array}$ & $\begin{array}{l}\text { user-specified in } \\
\text { super file }\end{array}$ & 27 & input & $\begin{array}{l}\text { binary } \\
\text { ASCII }\end{array}$ & $\begin{array}{c}\text { Required for } \\
\text { category FSRD }\end{array}$ \\
\hline $\begin{array}{c}\begin{array}{c}\text { flow solution } \\
\text { water table }\end{array} \\
\end{array}$ & $\begin{array}{c}\text { user-specified in } \\
\text { super file }\end{array}$ & 28 & input & $\begin{array}{l}\text { binary } \\
\text { ASCII }\end{array}$ & $\begin{array}{c}\text { Required for } \\
\text { category FSWT }\end{array}$ \\
\hline $\begin{array}{c}\text { head } \\
\text { solution }\end{array}$ & $\begin{array}{l}\text { user-specified in } \\
\text { super file }\end{array}$ & 29 & output & $\begin{array}{l}\text { binary } \\
\text { ASCII }\end{array}$ & $\begin{array}{c}\text { Required for } \\
\text { category HEAD }\end{array}$ \\
\hline $\begin{array}{c}\text { concentration } \\
\text { solution }\end{array}$ & $\begin{array}{l}\text { user-specified in } \\
\text { super file }\end{array}$ & 30 & output & $\begin{array}{l}\text { binary } \\
\text { ASCII }\end{array}$ & $\begin{array}{l}\text { Required for } \\
\text { category CONC }\end{array}$ \\
\hline $\begin{array}{c}\text { immobile } \\
\text { concentration } \\
\text { solution }\end{array}$ & $\begin{array}{l}\text { user-specified in } \\
\text { super file }\end{array}$ & 31 & output & $\begin{array}{l}\text { binary } \\
\text { ASCII }\end{array}$ & $\begin{array}{l}\text { Required for } \\
\text { category CIMN }\end{array}$ \\
\hline $\begin{array}{c}\text { elemental velocity } \\
\text { solution }\end{array}$ & $\begin{array}{l}\text { user-specified in } \\
\text { super file }\end{array}$ & 32 & output & $\begin{array}{l}\text { binary } \\
\text { ASCII }\end{array}$ & $\begin{array}{c}\text { Required for } \\
\text { category VELE }\end{array}$ \\
\hline $\begin{array}{c}\text { water saturation } \\
\text { solution }\end{array}$ & $\begin{array}{c}\text { user-specified in } \\
\text { super file }\end{array}$ & 33 & output & $\begin{array}{l}\text { binary } \\
\text { ASCII }\end{array}$ & $\begin{array}{c}\text { Required for } \\
\text { category WSAT }\end{array}$ \\
\hline
\end{tabular}


Certification Package for FACT Version 2.0 (U)

Page:

\begin{tabular}{|c|c|c|c|c|c|}
\hline File & Name & Unit & I/O & Format & Comments $^{1}$ \\
\hline $\begin{array}{c}\text { nodal velocity } \\
\text { solution }\end{array}$ & $\begin{array}{c}\text { user-specified in } \\
\text { super file }\end{array}$ & 34 & output & $\begin{array}{c}\text { binary } \\
\text { ASCIl }\end{array}$ & $\begin{array}{c}\text { Required for } \\
\text { category VELN }\end{array}$ \\
\hline $\begin{array}{c}\text { mass balance } \\
\text { nodal flow }\end{array}$ & $\begin{array}{c}\text { user-specified in } \\
\text { super file }\end{array}$ & 35 & output & $\begin{array}{c}\text { binary } \\
\text { ASCIl }\end{array}$ & $\begin{array}{c}\text { Required for } \\
\text { category MASB }\end{array}$ \\
\hline $\begin{array}{c}\text { recharge/drain } \\
\text { flow }\end{array}$ & $\begin{array}{c}\text { user-specified in } \\
\text { super file }\end{array}$ & 36 & output & $\begin{array}{c}\text { binary } \\
\text { ASCII }\end{array}$ & $\begin{array}{c}\text { Required for } \\
\text { category RCDR }\end{array}$ \\
\hline $\begin{array}{c}\text { water table } \\
\text { elevations }\end{array}$ & $\begin{array}{c}\text { user-specified in } \\
\text { super file }\end{array}$ & 37 & output & $\begin{array}{c}\text { binary } \\
\text { ASCII }\end{array}$ & $\begin{array}{c}\text { Required for } \\
\text { category WTBL }\end{array}$ \\
\hline $\begin{array}{c}\text { steady-state } \\
\text { observation well } \\
\text { statistics }\end{array}$ & $\begin{array}{c}\text { user-specified in } \\
\text { super file }\end{array}$ & 38 & output & $\begin{array}{c}\text { formatted } \\
\text { (ASCII) }\end{array}$ & $\begin{array}{c}\text { Required for } \\
\text { category OBSW }\end{array}$ \\
\hline $\begin{array}{c}\text { summary of Tecplot } \\
\text { plot option time } \\
\text { steps and times }\end{array}$ & $\begin{array}{c}\text { user-specified in } \\
\text { super file }\end{array}$ & 39 & output & $\begin{array}{c}\text { formatted } \\
\text { (ASCII) }\end{array}$ & $\begin{array}{c}\text { Required for } \\
\text { category TECS }\end{array}$ \\
\hline
\end{tabular}

${ }^{1}$ Files associated with units 20-37 are binary by default with the standard 4 character category name. Appending the 2 characters "- $A$ " to the category name allows the file to be opened as formatted ASCII. For example, use "HEAD-A" to write out an ASCI head solution.

Table 3 Summary of Tecplot ${ }^{\mathrm{TM}}$ Binary and ASCII files

\begin{tabular}{|c|c|c|c|c|c|}
\hline File & Name & Unit & 1/O & Format & Comments \\
\hline nodal results & tecnxxxx.plt & - & output & C binary file & $\begin{array}{c}\text { Created if nplto }=0 \text {, } \\
1,2,6, \text { or } 9\end{array}$ \\
\hline elemental results & tecexxxx.plt & - & output & $\mathrm{C}$ binary file & $\begin{array}{c}\text { Created if nplto }=3 \\
\text { or } 4\end{array}$ \\
\hline water table results & tecwxxxx.plt & - & output & $\mathrm{C}$ binary file & $\begin{array}{c}\text { Created if nplto }=5 \\
\text { and iwatp=1 }\end{array}$ \\
\hline top boundary flows & tecqxxxx.plt & - & output & C binary file & $\begin{array}{c}\text { Created if nplto }=7 \\
\text { and imbal }=1\end{array}$ \\
\hline $\begin{array}{l}\text { observation well } \\
\text { group heads }\end{array}$ & obwfyyyy.plt & - & output & C binary file & $\begin{array}{l}\text { Created if kmod }=0 \\
\text { or } 2 \text { and iobswg }=1\end{array}$ \\
\hline $\begin{array}{l}\text { observation well } \\
\text { group } \\
\text { concentrations }\end{array}$ & obwtyyyy.plt & - & output & C binary file & $\begin{array}{c}\text { Created if } \mathrm{kmod}>0 \\
\text { and iobswg=1 }\end{array}$ \\
\hline $\begin{array}{c}\text { cell Peclet and } \\
\text { Courant numbers }\end{array}$ & pecoxxxx.plt & $\overrightarrow{-}$ & output & C binary file & Created if kmod>0 \\
\hline $\begin{array}{c}\text { total mass flow rate } \\
\text { of solute removed } \\
\text { from recharge/drain } \\
\text { by drainage }\end{array}$ & stmsrc.dat & 40 & output & $\begin{array}{l}\text { formatted } \\
\text { (ASCII) }\end{array}$ & $\begin{array}{c}\text { Created if kmod }>0 \\
\text { and nrch }=-1\end{array}$ \\
\hline $\begin{array}{c}\text { maximum } \\
\text { concentration }\end{array}$ & cmax.dat & 45 & output & $\begin{array}{l}\text { formatted } \\
\text { (ASCII) }\end{array}$ & Created if kmod $>0$ \\
\hline areal solute mass & sm.dat & 80 & output & $\begin{array}{l}\text { formatted } \\
\text { (ASCII) }\end{array}$ & $\begin{array}{c}\text { Created if kmod }>0 \\
\text { and nplto }=8\end{array}$ \\
\hline $\begin{array}{l}\text { total solute mass } \\
\text { within domain }\end{array}$ & tm.dat & 81 & output & $\begin{array}{l}\text { formatted } \\
\text { (ASCII) }\end{array}$ & $\begin{array}{c}\text { Created if kmod }>0 \\
\text { and nplto }=8\end{array}$ \\
\hline $\begin{array}{c}\text { nodal surface flux } \\
\text { due to } \\
\text { recharge/drain }\end{array}$ & sf.dat & 82 & output & $\begin{array}{l}\text { formatted } \\
\text { (ASCII) }\end{array}$ & $\begin{array}{c}\text { Created if kmod }>0 \\
\text { nrch }=-1 \text { and } \\
\text { nplto }=8\end{array}$ \\
\hline $\begin{array}{l}\text { vertically-averaged } \\
\text { concentration in } \\
\text { each aquifer unit }\end{array}$ & aquiferx.dat & $83-91$ & output & $\begin{array}{l}\text { formatted } \\
\text { (ASCII) }\end{array}$ & $\begin{array}{c}\text { Created if kmod }>0 \\
\text { and nplto }=8\end{array}$ \\
\hline
\end{tabular}


As stated above the FACT code provides a series of Tecplot ${ }^{\text {th }}$ binary and ASCII text files. Based upon which time shot is of interest (or multiple of time shots), the corresponding binary files (e.g., tecnxxxx.plt, tecexxxx.plt, tecwxxxx.plt, or tecqxxxx.plt) can be viewed directly. These binary files are already in Tecplot ${ }^{\text {Tu }}$ binary format. The user only has to select these files interactively while inside of Tecplot ${ }^{\text {tu }}$ itself.

The ASCII Tecplot ${ }^{\text {tw }}$ files can be either converted to binary form external to Tecplot ${ }^{\text {tw }}$ or internally. Externally, the conversion to binary is perform by redirecting standard input to the chosen ASCII Tecplot ${ }^{\mathrm{TH}}$ file (e.g., "filename.dat") and invoking Preplot ${ }^{\mathrm{TH}}$. Preplot ${ }^{\mathrm{Tm}}$ creates the binary file (e.g., named "filename.plt") that can be read directly into Tecplot". For user's guide information on the use of the commercial graphics tool Tecplot ${ }^{\mathrm{TM}}$ (and its supporting preprocessor Preplot ${ }^{\text {THW }}$ ) see (Amtec, 1998):

Two FACT v2.0 executables (fact90 and fact90.exe) are available.

An IRIX executable (fact90) that has the capability to run on the following computer platform:

Computer platform A:

Platform: $\quad$ SGI Indigo 2 (R 10000)

System: IRIX 6.5

Compilers: $\quad$ MIPSPro $7 \mathrm{f} 90$, MIPSPro $7 \mathrm{cc}$

Options: $\quad-n 32-O-O P T: O l i m i t=2500$ for FFLAGS; $-n 32-O$ for CFLAGS

is available. While a Win32 executable (fact90.exe) that has the capability to run on the following computer platform:

Computer platform B:

Platform: $\quad$ IBM Personal Computer 300PL (Pentium ${ }^{\circledR}$ II processor)

System: $\quad$ Microsoft Windows 95, 4.00.950a

Compilers: $\quad$ Digital $^{\mathrm{TM}}$ Visual Fortran 5.0, Microsoft $^{\circledR}$ Visual $^{\mathrm{C}}++5.0$

Options: Full Optimizations

Accuracy of results: See FACT v2.0 (Hamm et al., 1999b) code manual.

Error messages: See standard output files for printed messages. Limited, internal to FACT v2.0, error checking for input inconsistency and out of range values is provided.

Software version: $\quad$ FACT v2.0

User support: $\quad$ Sebastian E. Aleman (725-5226), L. Larry Hamm (725-2520) or Gregory P. Flach (725-5195)

Access controls: $\quad$ DCE Access Control Lists

Test requirements: The Software Test Plan shall have been executed for the current system software before each use. 


\subsection{Requirements}

Requirements of the FACT v2.0 code (Hamm et al., 1999b) are defined below. The starting point for the development of the FACT code was a previously existing code named SAFT3D that provided an initial algorithmic structure. The authors of SAFT3D (1991, developed with funding supnort from SRTC/WSRC) are employees of HydroGeoLogic, Inc.. The development of the FACT code was performed by employees of WSRC at SRS. During the FACT development period significant upgrades (e.g., dynamic allocation, input/output, graphics files, additional unique boundary condition features, and new algorithmic structure) have been made.

FACT is considered for QA purposes an existing code being brought under "Engineering Calculations" defined in procedure 2.31 of the E7 manual. The FACT code consists of groundwater flow and single solute transport solvers whose output results are converted to a form that is Tecplot ${ }^{\mathrm{TM}}$ compatible. Tecplot $^{\mathrm{TM}}$ (Amtec, 1998) is a commercially available interactive graphics tool outside the domain of this software management report.

\subsection{Function}

The functional requirements placed on FACT v2.0 are as follows:

1) Capability to simulate saturated-unsaturated transient groundwater flow and solute transport of a single species in three-dimensions using a variably-saturated approach. The transport formulation shall include mobile/immobile first-order mass transfer with equilibrium sorption, first-order reaction, and radioactive decay effects.

Acceptance criterion: Successful solution of one or more test problems which collectively involve all of the above stated attributes (in the judgement of the test report author(s) and independent technical reviewer).

2) Capability to model relatively arbitrary three-dimensional subsurface geometries with anisotropic, heterogeneous properties (invariant principle axes of conductivity tensor aligned with global coordinate axes).

Acceptance criterion: Successful solution of one or more test problems which collectively involve all of the above stated attributes (in the judgement of the test report author(s) and independent technical reviewer).

3) Capability to impose prescribed head, prescribed volumetric flow, recirculation wells, pumping/injection wells, head-dependent source beds, and groundwater recharge transient flow boundary conditions.

Acceptance criterion: Successful solution of one or more test problems which collectively involve all of the above stated attributes (in the judgement of the test report author(s) and independent technical reviewer). 
4) Capability to impose prescribed concentration, prescribed mass flow, recirculation wells, pumping/injection wells and groundwater recharge transient transport boundary conditions.

Acceptance criterion: Successful solution of one or more test problems which collectively involve all of the above stated attributes (in the judgement of the test report author(s) and independent technical reviewer).

5) Capability to simulate physically realistic soil characteristic curves.

Acceptance criterion: Successful solution of one or more test problems which collectively involve all of the above stated attributes (in the judgement of the test report author(s) and independent technical reviewer).

6) Capability to neglect capillary effects and physical relative permeability in the unsaturated zone as an efficient method of modeling saturated flow in an unconfined aquifer.

Acceptance criterion: Successful solution of one or more test problems which collectively involve all of the above stated attributes (in the judgement of the test report author(s) and independent technical reviewer).

7) Capability to write code results to output in a form which can readily be made usable by standard graphics software such as Tecplot.

Acceptance criterion: Documentation of test case results in graphical form using Tecplot or other graphics software.

\subsection{Performance and Attributes}

1) An IRLX based executable that has the capability to run on the following computer platform:

\section{Computer platform A:}

Platform: SGI Indigo 2 (R10000)

System: $\quad$ IRIX 6.5

Compilers: MIPSPro $7 \mathrm{f} 90$, MIPSPro $7 \mathrm{cc}$

Options: $\quad-n 32-O-O P T: O l i m i t=2500$ for FFLAGS; $-n 32-O$ for CFLAGS

Acceptance criterion: Successful installation testing.

2) Win 32 based executable that has the capability to run on the following computer platform:

Computer platform B:

Platform: $\quad$ IBM Personal Computer 300PL (Pentium ${ }^{\oplus}$ II processor)

System: $\quad$ Microsoft Windows 95, 4.00.950a

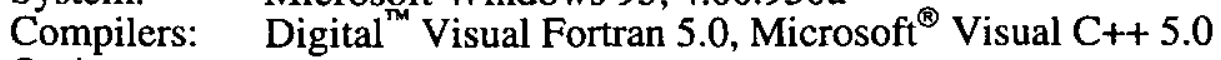

Options: Full Optimizations

Acceptance criterion: Successful installation testing. 


\subsection{Design Constraints Imposed on Design and Implementation Activities}

None.

\subsection{External Interfaces}

1) Capability for FACT v2.0 to write its results to cutput in a form (both ASCII and binary) that can readily be made usable by standard graphics software such as Tecplot version 7.5.

Acceptance criterion: Run the FACT $\mathrm{v} 2.0$ code on all problems that are presented/tabulated in the FACT v2.0 (Hamm et al., 1999b) code manual. Verify that the test case results generated in graphical form using Tecplot (versions 7.5) reproduce the published results in the FACT v 2.0 code manual.

\subsection{Coding Standards}

1) IRIX version: SGI Fortran $f 90$ and $C$ compilers compatible under the IRIX 6.5 or later operating system.

Acceptance criterion: Successful installation testing.

2) Win32 version: Digital ${ }^{\text {TM }}$ Visual Fortran 5.0 and Microsoft $^{\oplus}$ Visual $C++5.0$ compilers under the Microsoft Windows 95 operating system.

Acceptance criterion: Successful installation testing.

3) A modular code structure that minimizes the time and effort required to performed maintance and upgrades to its algorithms.

Acceptance criterion: Well commented subroutines having a uniform coding style.

4) A data storage scheme that is efficient with respect to grid sizing (i.e., problem size).

Acceptance criterion: Dynamic storage to minimize unused arrays appropriately.

\subsection{Design}

FACT v2.0 code manual (Hamm et al., 1999b) covers all of the necessary software design information for the FACT v2.0 code. Simple post-processing of FACT v2.0 results are performed with the Tecplot ${ }^{\mathrm{TM}}$ code (Amtec, 1998). FACT v2.0 writes its output in a form that is Tecplot $^{\mathrm{TM}}$ compatible. Tecplot $^{\mathrm{TM}}$ is a commercially available interactive graphics tool outside the domain of this software design report.

\subsection{Technical Description}

FACT v2.0 is a finite element based code designed to model subsurface Flow And Contaminant Transport. It was designed to perform transient three-dimensional calculations that simulate isothermal groundwater flow, moisture movement, and solute transport in variably saturated and fully saturated subsurface porous media. The code is designed specifically to handle complex multi-layer and/or heterogeneous aquifer systems in an efficient manner and accommodates a 
wide range of boundary conditions. Additionally, 1-D and 2-D (in Cartesian coordinates) problems are handled in FACT by simply limiting the number of elements in a particular direction(s) to one. The governing equations in FACT are formulated only in Cartesian coordinates. FACT v2.0 writes out both ASCII and binary files that are Tecplot ${ }^{\mathrm{TM}}$ compatible. Special features are available within FACT for handling the typical groundwater modeling needs for remediation efforts at the Savannah River Site.

\subsection{Procedural Details}

The overall structure (control and data flow) of FACT v2.0 can be found in Chapter 6 of the code manual (Hamm et al., 1999b). FACT v2.0 only provides graphical output files that are Tecplot ${ }^{\mathrm{TM}}$ compatible along with some standard line printer type of output.

Testing of the algorithms will be accomplished by running a variety of test case problems (both flow and transport) that attempt to span the range of modeling features provided within FACT v2.0. Analytical solutions to these problems will be compared for determining FACT's accuracy, mesh requirements, and optimum parameter settings. Specific test cases will also focus on specific portions of the program (e.g., steady-state soil column simulation to demonstrate that the water retention curve portion of FACT correctly simulates the vadose zone conditions under static conditions and that its algorithmic implementation within the code is verified).

The IRIX version of the FACT 2.0 code shall be compiled on the following computer hardware.

Computer platform A:

Platform: $\quad$ SGI Indigo 2 (R10000)

System: $\quad$ IRIX 6.5

Compilers: $\quad$ MIPSPro 7 f90, MIPSPro $7 \mathrm{cc}$

Options: $\quad-n 32-O-O P T: O l i m i t=2500$ for FFLAGS; $-n 32-O$ for CFLAGS

The executable generated will then be stored for later simulation tests to be performed on the same computer platform as specified above. All test runs will be performed on the above platform.

Similarly, the Win 32 version of the FACT v2.0 code shall be compiled on the following computer hardware.

Computer platform B:

Platform: $\quad$ IBM Personal Computer 300PL (Pentium ${ }^{\circledR}$ II processor)

System: $\quad$ Microsoft Windows 95, 4.00.950a

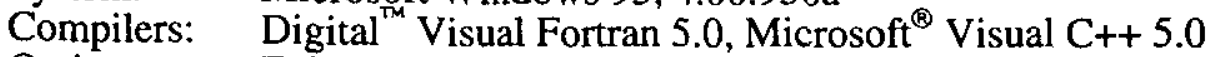

Options: Full Optimizations

The executable generated will then be stored for later simulation tests to be performed on the same computer platform as specified above. All test runs will be performed on the above platform. 


\subsection{Implementation}

The FACT v2.0 code is to be tested on several classical and field problems in the groundwater community. These problems are presented in the FACT v2.0 (Hamm et al., 1999b) code manual. These problems were also selected based on the fact that analytical solutions (or excellent approximations) exists that definitively establishes FACT's accuracy, capability and the resulting impact that mesh and control parameter settings have on accuracy.

\subsection{Identification}

Software: $\quad$ FACT v2.0

Hardware: SGI workstations (Indigo 2) under IRIX and

IBM 300PL personal computer under Windows ${ }^{\mathrm{TM}} 95$

Testing method from 6.0 Design section. Verification that generated output conforms to results tabulated in code manual.

\subsection{Test Plan}

Input decks consistent with those described in Appendix B ("Flow Test Problem Input Files") and Appendix D ("Transport Test Problem Input Files") of (Hamm et al., 1999b) will be generated. Each FACT test problem listed in Appendices B and D will be run and its output files stored for viewing. For each problem the graphics output files will be processed (if necessary) and viewed interactively within Tecplot ${ }^{\text {TM }}$ version 7.5. Key results for each problem are tabulated in sections 4.1, 4.2 or 4.3 of the FACT code manual (Hamm et al., 1999b). From the above executions (the standard output files from FACT v2.0 and the graphics output visually shown in Tecplot $^{\mathrm{TM}}$ ), selective hydraulic head and concentration solutions, along with certain mesh properties, will be cross verified with the tabulated values. The input decks, output files, source coding, and executables will all be stored under a protected CMS system. The official version of the above files will reside on the UNIX DFS system located in the directory:

\section{/dfs/project/codecms/FACT}

This test shall be performed for software design and implementation verification. Before use, the software shall have been tested under the current system and compiler software.

\subsection{User Instructions}

A general procedure for using FACT to simulate groundwater flow and solute transport in subsurface systems is outlined in Section 5 of the FACT code manual (Hamm et al., 1999b). The input and output files associated with the FACT code and their contents are described in Section 7 of the FACT code manual. Examples of typical input files can be seen in Appendices B and D of the FACT code manual. 


\subsection{Acceptance Testing}

The FACT v2.0 code was tested on several classical and field problems in the groundwater community. These problems are presented in the FACT v2.0 code manual (Hamm et al., 1999b). A listing of all the problems tested is summarized in Appendix A of this code manual. Appendix B contains the input files for each flow problem selected, while Appendix D contains the corresponding transport input files. The output results from FACT for the verification flow problem 4.1.1 is presented in Appendix C. The output results from FACT for the verification transport problem 4.2.1 is presented in Appendix E.

Chapter 4 of the FACT v2.0 code manual contains a description of the conceptual model, problem specification, boundary conditions, and a comparison between the FACT output results and analytical results. These comparisons are presented in graphical plots along with their corresponding numerical values given in tabular form.

\subsection{Identification}

The following platforms were employed in the software testing:

\section{Computer platform A:}

Platform: $\quad$ SGI Indigo 2 (R10000)

System: IRIX 6.5

Compilers: $\quad$ MIPSPro $7 \mathrm{f} 90$, MIPSPro $7 \mathrm{cc}$

Options: $\quad-n 32-O-O P T: O l i m i t=2500$ for FFLAGS; $-n 32-O$ for CFLAGS

\section{Computer platform B:}

Platform: $\quad$ IBM Personal Computer 300PL (Pentium ${ }^{\circledR}$ II processor)

System: $\quad$ Microsoft Windows $95,4.00 .950 \mathrm{a}$

Compilers: $\quad$ Digital $^{\mathrm{TM}}$ Visual Fortran 5.0, Microsoft ${ }^{\circledR}$ Visual $\mathrm{C}++5.0$

Options: Full Optimizations

Executables (fact90 and fact90.exe for FACT v2.0) were generated and used on each unique platform. The source files, input decks, batch files, output decks, and the executables have been placed into configuration management under DFS. The FACT v2.0 code was placed into software management under the classification of Level " $\mathrm{B}$ ".

The above UNIX and PC files are in the DFS system located in the directory:

\section{/dfs/project/codecms/FACT}

The basic directory structure and its contents for FACT v2.0 are as follows:

Full path name: /dfs/project/codecms/FACT/

README (file describing contents of this directory) sgi/

$\mathbf{v} 2.0 /$ (world read/execute permission)

bin/ 


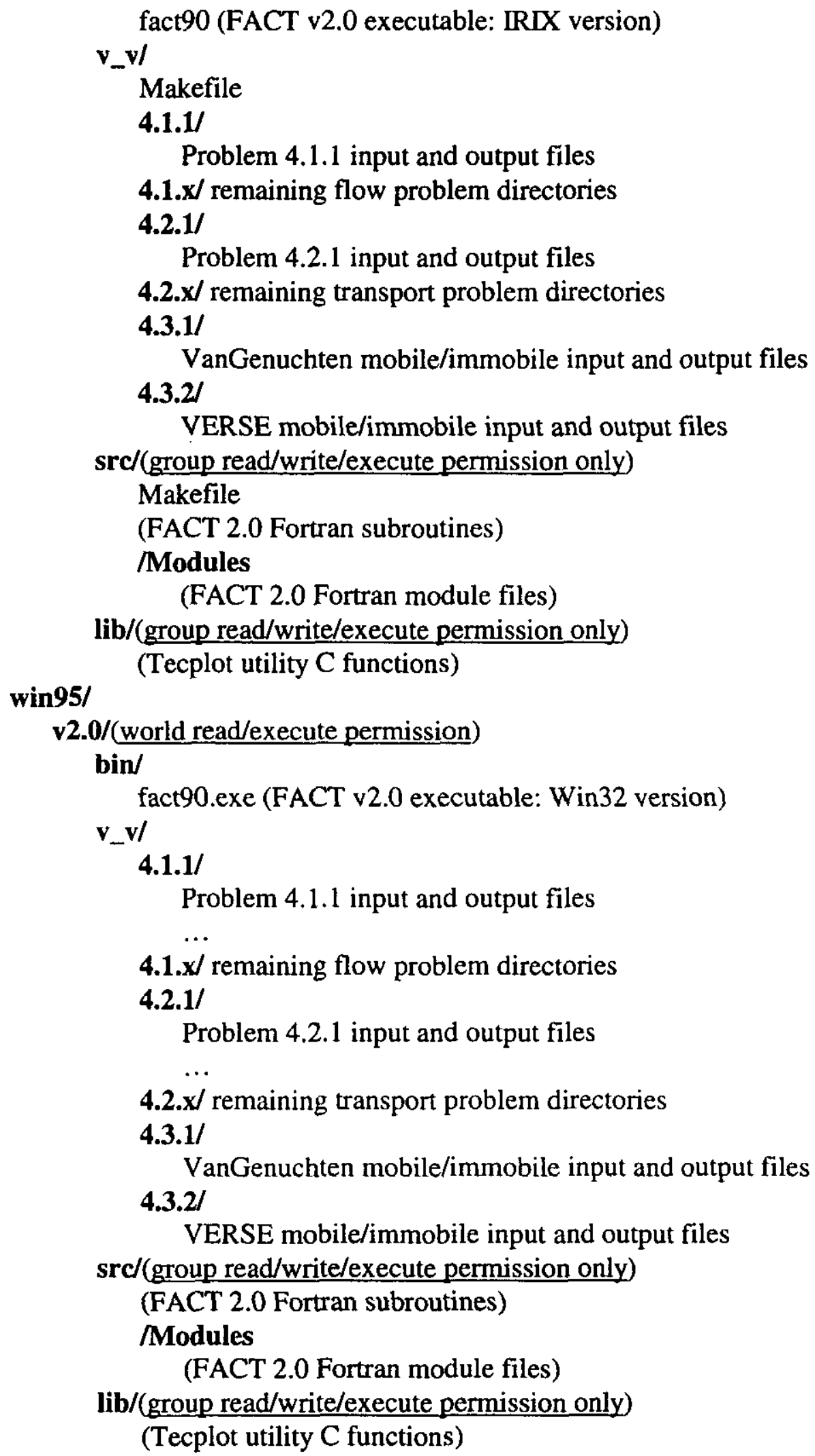

These directories contain: 
- The FACT v2.0 executables and V\&V test cases (i.e., the input, output, and batch files for each test problem) that are accessible to the world (read only permission). See the README file for instructions.

- All of the source files indicated above that are accessible only to a specified group (read only) and to its custodian (read/write/exe permissions).

The README file contains information for testing the software out on the target platform(s). If you or your group members are unable to access (read/execute only permission) this directory please contact the CMS custodian (Sebastian E. Aleman at 5-5227). The /src directories contain the source listings and access to these directories are restricted due to the copyright for this software. The current FACT v2.0 code is authorized for Level "B" use on SGI Indigo's running IRIX 6.5 or later and Intel-based PCs running under the operating systems Windows $95^{\mathrm{TM}}$ or Windows NTTM Workstation version 4.0 or later versions. The SGI IRIX executable contained in the above subdirectory should be used directly for controlled calculations and not copied over to other platforms and then executed. The Win32 executable must be copied to the user's PC to execute.

Individuals who plan to use FACT on their SGI's should run the test cases provided and compare their output to the output files provided.

Problem numbers presented below correspond to the actual problem numbers used in the FACT v2.0 (Hamm et al., 1999b) code manual. See Appendix A of the code manual for each problem numbers brief description, location within main body of report, and input filename nomenclature. 


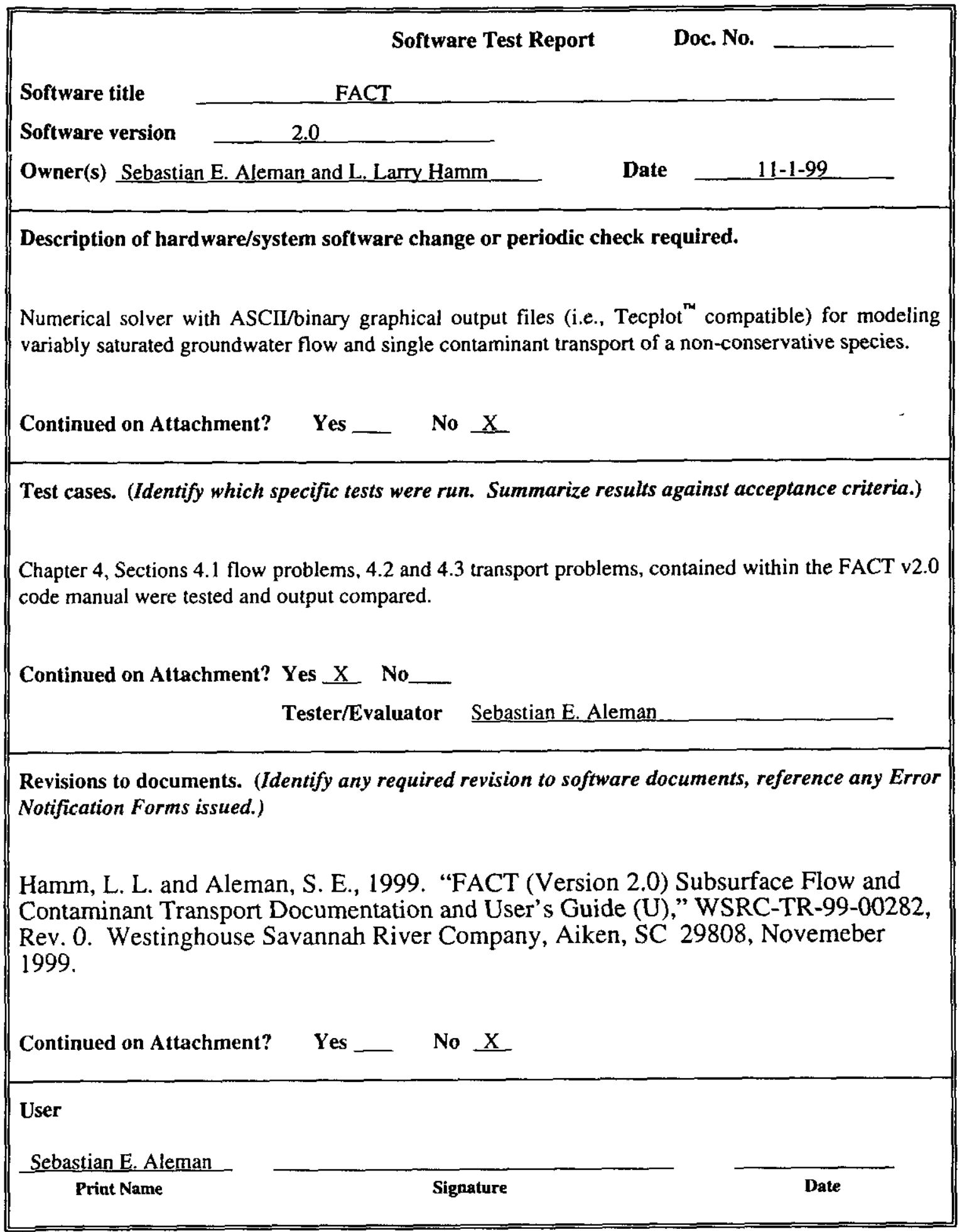




\subsection{Verification Tests and Results}

The following flow test cases are from Section 4.1 of the FACT v2.0 code manual:

\section{Problem 4.1.1 (problem 1)}

Description Steady-state, 1D flow in a confined aquifer with general head boundary condition.

Platforms: $\quad$ A and B

Input f_conf_gh.main

Output f_conf_gh.prnt

Comments No alterations to source or input decks necessary. Comparisons to results tabulated in Table 4.1.1.1 are in excellent agreement.

\section{Problem 4.1.1 (problem 2)}

Description Steady-state, 1D flow in a confined aquifer with river boundary condition.

Platforms: $\quad \mathrm{A}$ and $\mathrm{B}$

Input

f_conf_r.main

Output f_conf_r.prnt

Comments No alterations to source or input decks necessary. Comparisons to results tabulated in Table 4.1.1.2 are in excellent agreement.

\section{Problem 4.1.2 (problem 1)}

Description Steady-state, 1D flow in a unconfined aquifer with no recharge.

Platforms: $\quad \mathrm{A}$ and $\mathrm{B}$

Input f_unconf_nr.main

Output f_unconf_nr.prnt

Comments No alterations to source or input decks necessary. Comparisons to results tabulated in Table 4.1.2.1 are in excellent agreement.

\section{Problem 4.1.2 (problem 2)}

Description Steady-state, 1D flow in a unconfined aquifer with recharge.

Platforms: $\quad$ A and B

Input f_unconf_r.main

Output f_unconf_r.prnt

Comments No alterations to source or input decks necessary. Comparisons to results tabulated in Table 4.1.2.1 are in excellent agreement.

Problem 4.1.3

Description Steady-state, 2D flow through a heterogeneous aquifer system.

Platforms: $\quad A$ and $B$

Input

Output

f_heter.main

Comments No alterations to source or input decks necessary. Comparisons to results tabulated in Table 4.1.3.1 are in excellent agreement.

\section{Problem 4.1.4}

Description

Platforms:

Unconfined aquifer subject to a combined recharge/drain boundary condition.

Input

$A$ and $B$

Output

f_rechdrain.main

Comments

\section{f_rechdrain.prnt}

No alterations to source or input decks necessary. Comparisons to results tabulated in Table 4.1.4.1 are in excellent agreement. 


\section{Problem 4.1.5 (coarse full grid)}

Description Transient, 1D flow to a well in a confined aquifer with full mesh, coarse discretization.

Platforms: $\quad A$ and $B$

Input f_theis_fc.main

Output f_theis_fc.prnt

Comments No alterations to source or inpu ciecks necessary. Comparisons to results tabulated in Table 4.1.5.1 are in excellent agreement.

\section{Problem 4.1.5 (coarse quadrant grid)}

Description Transient, 1D flow to a well in a confined aquifer with quadrant mesh, coarse discretization.

Platforms: $\quad A$ and $B$

Input f_theis_qc.main

Output f_theis_qc.prnt

Comments No alterations to source or input decks necessary. Comparisons to results tabulated in Table 4.1.5.1 are in excellent agreement.

Problem 4.1.5 (fine quadrant grid)

Description Transient, 1D flow to a well in a confined aquifer with quadrant mesh, fine discretization.

Platforms: $\quad A$ and $B$

Input f_theis_qf.main

Output f_theis_qf.prnt

Comments No alterations to source or input decks necessary. Comparisons to results tabulated in Table 4.1.5.1 are in excellent agreement.

\section{Problem 4.1.6 (coarse full grid)}

Description Transient, ID flow to a well in an anisotropic confined aquifer with full mesh, coarse discretization.

Platforms: $\quad A$ and $B$

Input f_aniso_fc.main

Output f_aniso_fc.prnt

Comments No alterations to source or input decks necessary. Comparisons to results tabulated in Tables 4.1.6.1, 4.1.6.2, and 4.1.6.3 are in excellent agreement.

Problem 4.1.6 (coarse quadrant grid)

Description Transient, 1D flow to a well in an anisotropic confined aquifer with quadrant mesh, coarse discretization.

Platforms: $\quad \mathrm{A}$ and $\mathrm{B}$

Input f_aniso_qc.main

Output f_aniso_qc.prnt

Comments No alterations to source or input decks necessary. Comparisons to results tabulated in Tables 4.1.6.1, 4.1.6.2, and 4.1.6.3 are in excellent agreement.

Problem 4.1.6 (fine quadrant grid)

Description Transient, 1D flow to a well in an anisotropic confined aquifer with quadrant mesh, fine discretization.

Platforms: $\quad A$ and $B$

Input f_aniso_qf.main

Output f_aniso_qf.prnt 
Comments No alterations to source or input decks necessary. Comparisons to results tabulated in Tables 4.1.6.1, 4.1.6.2, and 4.1.6.3 are in excellent agreement.

\section{Problem 4.1.7 (coarse grid)}

Description Transient, 1D flow to a well in a leaky confined aquifer with coarse mesh.

Platforms: $\quad A$ and $B$

Input

$\begin{array}{ll}\text { Output } & \text { f_leaky_c.prnt } \\ \text { Comments } & \text { No alterations to source or input decks necessary. Comparisons to results }\end{array}$

f_leaky_c.main tabulated in Table 4.1.7.1 are in excellent agreement.

\section{Problem 4.1.7 (fine grid)}

Description Transient, ID flow to a well in a leaky confined aquifer with fine mesh.

Platforms: $\quad A$ and $B$

Input f_leaky_f.main

Output f_leaky_f.prnt

Comments No alterations to source or input decks necessary. Comparisons to results tabulated in Table 4.1.7.1 are in excellent agreement.

\section{Problem 4.1.8 (transient run)}

Description Transient, 2D flow to a well in an unconfined aquifer.

Platforms: $\quad$ A and B

Input f_neumann_t.main

Output f_neumann_t.prnt

Comments No alterations to source or input decks necessary. Comparisons to results tabulated in Table 4.1.8.3 are in excellent agreement.

\section{Problem 4.1.9}

Description

Platforms:

Transient, 2D flow in an unconfined aquifer.

Input

Output

Comments

$\mathrm{A}$ and $\mathrm{B}$

f_trandrain.main

f_trandrain.prnt

No alterations to source or input decks necessary. Comparisons to results tabulated in Table 4.1.9.1 are in excellent agreement.

Problem 4.1.10.(water retention curve; coarse grid)

Description Unsaturated vertical soil column reproduction of water retention curve.

Platforms: $\quad$ A and B

Input f_unsat_wrc-10.main

Output f_unsat_wrc-10.prnt

Comments No alterations to source or input decks necessary. Comparisons to results tabulated in Table 4.1.10.1 are in excellent agreement.

Problem 4.1.10.(water retention curve; fine grid)

Description Unsaturated vertical soil column reproduction of water retention curve.

Platforms: $\quad A$ and $B$

Input f_unsat_wrc-250.main

Output f_unsat_wrc-250.prnt

Comments No alterations to source or input decks necessary. Comparisons to results tabulated in Table 4.1.10.1 are in excellent agreement.

\section{Problem 4.1.10.(constant saturation)}


Description Unsaturated vertical soil under conditions of steady-state flow at constant saturation.

Platforms: $\quad A$ and $B$

Input $\quad f_{-}$unsat_cs.main

Output f_unsat_cs.prnt

Comments No alterations to source or input decks necessary. Comparisons to results tabulated in Table 4.1.10.1 are in excellent agreement.

The following solute transport test cases are from Section 4.2 of the FACT v2.0 code manual:

\section{Problem 4.2.1 (Basecase)}

Description 1-D saturated solute transport in a uniform flow field under basecase conditions.

Platforms: $\quad A$ and $B$

Input t_ld_basecase.main

Output t_ld_basecase.prnt

Comments No alterations to source or input decks necessary. Comparisons to results tabulated in Table 4.2.1.3 are in excellent agreement.

\section{Problem 4.2.1 (case a)}

Description 1-D saturated solute transport in a uniform flow field under retardation conditions.

Platforms: $\quad \mathrm{A}$ and $\mathrm{B}$

Input t_ld_case_a.main

Output t_ld_case_a.prnt

Comments No alterations to source or input decks necessary. Comparisons to results tabulated in Table 4.2.1.4 are in excellent agreement.

\section{Problem 4.2.1 (case b)}

Description - 1-D saturated solute transport in a uniform flow field under radioactive decay conditions.

Platforms: $\quad A$ and $B$

Input t_ld_case_b.main

Output t_ld_case_b.prnt

Comments No alterations to source or input decks necessary. Comparisons to results tabulated in Table 4.2.1.5 are in excellent agreement.

Problem 4.2.1 (case c)

Description 1-D saturated solute transport in a uniform flow field under retardation and radioactive decay conditions.

Platforms: $\quad \mathrm{A}$ and $\mathrm{B}$

Input t_ld_case_c.main

Output t_ld_case_c.prnt

Comments No alterations to source or input decks necessary. Comparisons to results tabulated in Table 4.2.1.6 are in excellent agreement.

\section{Problem 4.2.1 (case d)}

Description 1-D saturated solute transport in a uniform flow field under element size of $\Delta x=20 \mathrm{~m}$ conditions.

Platforms: $\quad \mathrm{A}$ and $\mathrm{B}$

Input t_ld_case_d.main

Output t_1d_case_d.prnt 
Comments No alterations to source or input decks necessary. Comparisons to results tabulated in Table 4.2.1.7 are in excellent agreement.

Problem 4.2.1 (case e)

Description 1-D saturated solute transport in a uniform flow field under element size of $\Delta \mathrm{x}=40 \mathrm{~m}$ conditions.

Platforms: $\quad A$ and $B$

Input

Output t_ld_case_e.main

t_1d_case_e.prnt

Comments No alterations to source or input decks necessary. Comparisons to results tabulated in Table 4.2.1.7 are in excellent agreement.

Problem 4.2.1 (case f)

Description 1-D saturated solute transport in a uniform flow field under element size of

Platforms: $\quad A \mathrm{x}=80$

Input t_1d_case_f.main

Output t_ld_case_f.prnt

Comments No alterations to source or input decks necessary. Comparisons to results tabulated in Table 4.2.1.7 are in excellent agreement.

Problem 4.2.1 (case g)

Description 1-D saturated solute transport in a uniform flow field under time step size of $\Delta \mathrm{t}=5 \mathrm{~d}$ conditions.

Platforms: $\quad \mathrm{A}$ and $\mathrm{B}$

Input t_1d_case_g.main

Output t_ld_case_g.prnt

Comments No alterations to source or input decks necessary. Comparisons to results tabulated in Table 4.2.1.8 are in excellent agreement.

Problem 4.2.1 (case h)

Description 1-D saturated solute transport in a uniform flow field under time step size of $\Delta t=10 \mathrm{~d}$ conditions.

Platforms: $\quad \mathrm{A}$ and $\mathrm{B}$

Input t_Id_case_h.main

Output t_ld_case_h.prnt

Comments No alterations to source or input decks necessary. Comparisons to results tabulated in Table 4.2.1.8 are in excellent agreement.

Problem 4.2.1 (case i)

Description 1-D saturated solute transport in a uniform flow field under time step size of $\Delta t=25 d$ conditions.

Platforms: $\quad A$ and $B$

Input t_ld_case_i.main

Output t_1d_case_i.prnt

Comments No alterations to source or input decks necessary. Comparisons to results tabulated in Table 4.2.1.8 are in excellent agreement.

Problem 4.2.1 (case j)

Description 1-D saturated solute transport in a uniform flow field under upstream spatial weighting conditions.

Platforms: $\quad \mathrm{A}$ and $\mathrm{B}$

Input t_1d_case_j.main 
Output t_ld_case_j.prnt

Comments No alterations to source or input decks necessary. Comparisons to results tabulated in Table 4.2.1.9 are in excellent agreement.

\section{Problem 4.2.1 (case $\mathrm{k}$ )}

Description 1-D saturated solute transport in a, uniform flow field under temporal Platforms: $\quad A$ and $B$

Input t_ld_case_k.main

Output t_ld_case_k.prnt

Comments No alterations to source or input decks necessary. Comparisons to results tabulated in Table 4.2.1.10 are in excellent agreement.

\section{Problem 4.2.1 (case I)}

Description 1-D saturated solute transport in a uniform flow field under upstream spatial

Platforms: $\quad A$ and $B$

Input t_ld_case_l.main

Output t_ld_case_l.prnt

Comments No alterations to source or input decks necessary. Comparisons to results tabulated in Table 4.2.1.11 are in excellent agreement.

\section{Problem 4.2.1 (case m)}

Description 1-D saturated solute transport in a uniform flow field under longitudinal dispersivity $\left(\alpha_{1}=0.01\right)$ conditions.

Platforms: $\quad \mathrm{A}$ and $\mathrm{B}$

Input

Output

t_ld_case_m.main

t_ld_case_m.prnt

Comments No alterations to source or input decks necessary. Comparisons to results tabulated in Table 4.2.1.12 are in excellent agreement.

\section{Problem 4.2.1 (case $n$ )}

Description 1-D saturated solute transport in a uniform flow field under longitudinal dispersivity $\left(\alpha_{1}=0.01\right)$ and upstream spatial weighting $(\omega=1.0)$ conditions.

Platforms: $\quad A$ and $B$

Input

Output t__ld_case_n.main

t_ld_case_n.prnt

Comments

No alterations to source or input decks necessary. Comparisons to results tabulated in Table 4.2.1.13 are in excellent agreement.

Problem 4.2.1 (case o)

Description 1-D saturated solute transport in a uniform flow field under longitudinal dispersivity $\left(\alpha_{L}=0.01\right)$ and upstream spatial weighting $(\omega=0.27)$ conditions.

Platforms: $\quad$ A and B

Input

Output t_ld_case_o.main

t_ld_case_o.prnt

Comments

No alterations to source or input decks necessary. Comparisons to results tabulated in Table 4.2.1.14 are in excellent agreement.

\section{Problem 4.2.2 (basecase parallel grid)}

Description 2-D saturated solute transport in a uniform flow field under basecase parallel grid conditions. 

Platforms:
$A$ and $B$
Input
Output
t_2d_parallel.main
Comments
t_2d_parallel.pmt
No alterations to source or input decks necessary. Comparisons to results tabulated in Tables 4.2.2.3, 4.2.2.4, and 4.2.2.5 are in excellent agreement.

\section{Problem 4.2.2 (basecase diagonal grid)}

Description 2-D saturated solute transport in a uniform flow field under basecase diagonal

Platforms: $\quad \mathrm{A}$ and $\mathrm{B}$

Input t_2d_diagonal.main

Output t_2d_diagonal.prnt

Comments No alterations to source or input decks necessary. Comparisons to results tabulated in Tables 4.2.2.3, 4.2.2.4, and 4.2.2.5 are in excellent agreement.

\section{Problem 4.2.2 (case a)}

Description 2-D saturated solute transport in a uniform flow field under upstream spatial weighting (parallel grid) conditions.

Platforms: $\quad \mathrm{A}$ and $\mathrm{B}$

Input t_2d_case_a.main

Output t_2d_case_a.prnt

Comments No alterations to source or input decks necessary. Comparisons to results tabulated in Table 4.2.2.6 are in excellent agreement.

Problem 4.2.2 (case b)

Description 2-D saturated solute transport in a uniform flow field under upstream spatial weighting (diagonal grid) conditions.

Platforms: $\quad A$ and $B$

Input t_2d_case_b.main

Output t_2d_case_b.prnt

Comments No alterations to source or input decks necessary. Comparisons to results tabulated in Table 4.2.2.6 are in excellent agreement.

\section{Problem 4.2.2 (case c)}

Description 2-D saturated solute transport in a uniform flow field under retardation (parallel grid) conditions.

Platforms: $\quad A$ and $B$

Input t_2d_case_c.main

Output t_2d_case_c.prnt

Comments No alterations to source or input decks necessary. Comparisons to results tabulated in Table 4.2.2.7 are in excellent agreement.

Problem 4.2.2 (case d)

Description 2-D saturated solute transport in a uniform flow field under radioactive decay

(parallel grid) conditions.

Platforms: $\quad \mathrm{A}$ and $\mathrm{B}$

Input t_2d_case_d.main

Output t_2d_case_d.prnt

Comments No alterations to source or input decks necessary. Comparisons to results tabulated in Table 4.2.2.7 are in excellent agreement. 


\section{Problem 4.2.3 (parallel grid)}

Description 3-D saturated solute transport in a uniform flow field under basecase (parallel

Platforms: $\quad$ A and B

Input

Output

$$
A \text { and } B
$$

Comments

$$
\text { t_3d_parallel.main }
$$

No alterations to source or input decks necessary. Comparisons to results tabulated in Table 4.2.3.2 are in excellent agreement.

The following solute transport test cases are from Section 4.3 of the FACT v2.0 code manual:

Problem 4.3.1 $(\phi=0.35)$

Description 1-D saturated solute transport in a uniform flow field with first-order mobile/immobile mass transfer. Calculated effluent curves as influenced by the fraction of mobile liquid, $\phi$

Platforms: $\quad A$ and $B$

Input

Output

Comments

$$
\text { phi-0.35.main }
$$

phi-0.35.prnt,obwt0001.plt

No alterations to source or input decks necessary. Comparisons to results presented in Section 4.3.1 are in excellent agreement.

Problem 4.3.1 $(\phi=0.50)$

Description 1-D saturated solute transport in a uniform flow field with first-order mobile/immobile mass transfer. Calculated effluent curves as influenced by the fraction of mobile liquid, $\phi$

Platforms: $\quad A$ and B

Input phi-0.50.main

Output phi-0.50. prnt,obwt0001.pit

Comments No alterations to source or input decks necessary. Comparisons to results presented in Section 4.3.1 are in excellent agreement.

Problem 4.3.1 $(\phi=0.65)$

Description 1-D saturated solute transport in a uniform flow field with first-order mobile/immobile mass transfer. Calculated effluent curves as influenced by the fraction of mobile liquid, $\phi$

Platforms: $\quad \mathrm{A}$ and $\mathrm{B}$

Input phi-0.65.main

Output phi-0.65. prnt,obwt0001.plt

Comments No alterations to source or input decks necessary. Comparisons to results presented in Section 4.3.1 are in excellent agreement.

Problem 4.3.1 $(\phi=0.85)$

Description 1-D saturated solute transport in a uniform flow field with first-order mobile/immobile mass transfer. Calculated effluent curves as influenced by

Platforms: $\quad A$ and $B$

Input

Output phi-0.85.main

Comments phi-0.85. prnt,obwt0001.plt No alterations to source or input decks necessary. Comparisons to results presented in Section 4.3.1 are in excellent agreement. 
Problem 4.3.1 $(\phi=0.999)$

Description 1-D saturated solute transport in a uniform flow field with first-order mobile/immobile mass transfer. Calculated effluent curves as influenced by the fraction of mobile liquid, $\phi$

Platforms: $\quad$ A and B

Input phi-0.999.main

Output

Comments phi-0.999.prnt, obwt0001.plt

No alterations to source or input decks necessary. Comparisons to results presented in Section 4.3.1 are in excellent agreement.

Problem 4.3.1 $(f=0.25)$

Description 1-D saturated solute transport in a uniform flow field with first-order mobile/immobile mass transfer. Calculated effluent curves as influenced by the fraction of adsorption sites in the dynamic region, $\mathrm{f}$

Platforms: $\quad$ A and B

Input f-0.25.main

Output f-0.25. prnt,obwt0001.plt

Comments No alterations to source or input decks necessary. Comparisons to results presented in Section 4.3.1 are in excellent agreement.

Problem 4.3.1 ( $f=0.40)$

Description 1-D saturated solute transport in a uniform flow field with first-order mobile/immobile mass transfer. Calculated effluent curves as influenced by the fraction of adsorption sites in the dynamic region, $\mathrm{f}$

Platforms: $\quad A$ and B

Input f-0.40.main

Output f-0.40. prnt,obwt0001.plt

Comments No alterations to source or input decks necessary. Comparisons to results presented in Section 4.3.1 are in excellent agreement.

Problem 4.3.1 $(f=0.55)$

Description 1-D saturated solute transport in a uniform flow field with first-order mobile/immobile mass transfer. Calculated effluent curves as influenced by the fraction of adsorption sites in the dynamic region, $f$

Platforms: $\quad$ A and B

Input $\mathrm{f}-0.55$. main

Output f-0.55. prnt,obwt0001.plt

Comments No alterations to source or input decks necessary. Comparisons to results presented in Section 4.3.1 are in excellent agreement.

Problem 4.3.1 $(f=0.70)$

Description 1-D saturated solute transport in a uniform flow field with first-order mobile/immobile mass transfer. Calculated effluent curves as influenced by the fraction of adsorption sites in the dynamic region, $\mathrm{f}$

Platforms: $\quad A$ and $B$

Input

Output

Comments f-0.70.main

f-0.70.prnt, obwt0001.plt

No alterations to source or input decks necessary. Comparisons to results presented in Section 4.3.1 are in excellent agreement. 


\section{Problem 4.3.1 $(\alpha=0.0)$}

Description 1-D saturated solute transport in a uniform flow field with first-order mobile/immobile mass transfer. Calculated effluent curves as influenced by

Platforms: $\quad A$ and $B$

Input

Output

A and B

Comments

$$
\text { alpha-0.0.prnt, obwt0001.plt }
$$

No alterations to source or input decks necessary. Comparisons to results presented in Section 4.3.1 are in excellent agreement.

Problem 4.3.1 $(\alpha=0.05)$

Description 1-D saturated solute transport in a uniform flow field with first-order mobile/immobile mass transfer. Calculated effluent curves as influenced by the mass transfer coefficient, $\alpha$

Platforms: $\quad A$ and $B$

Input alpha-0.05.main

Output alpha-0.05.prnt, obwt0001.plt

Comments No alterations to source or input decks necessary. Comparisons to results presented in Section 4.3.1 are in excellent agreement.

Problem 4.3.1 $(\alpha=0.15)$

Description 1-D saturated solute transport in a uniform flow field with first-order mobile/immobile mass transfer. Calculated effluent curves as influenced by the mass transfer coefficient, $\alpha$

Platforms: $\quad \mathrm{A}$ and $\mathrm{B}$

Input alpha-0.15.main

Output alpha-0.15.prnt, obwt0001.plt

Comments No alterations to source or input decks necessary. Comparisons to results presented in Section 4.3.1 are in excellent agreement.

Problem 4.3.1 $(\alpha=0.50)$

Description 1-D saturated solute transport in a uniform flow field with first-order mobile/immobile mass transfer. Calculated effluent curves as influenced by the mass transfer coefficient, $\alpha$

Platforms: $\quad \mathrm{A}$ and $\mathrm{B}$

Input alpha-0.50.main

Output alpha-0.50.prnt, obwt0001.plt

Comments No alterations to source or input decks necessary. Comparisons to results presented in Section 4.3.1 are in excellent agreement.

Problem 4.3.1 $(\alpha=2.0)$

Description 1-D saturated solute transport in a uniform flow field with first-order mobile/immobile mass transfer. Calculated effluent curves as influenced by

Platforms: $\quad \mathrm{A}$ and $\mathrm{B}$

Input

Output alpha-2.0.main

alpha-2.0.prnt, obwt0001.plt

Comments No alterations to source or input decks necessary. Comparisons to results presented in Section 4.3.1 are in excellent agreement. 
Problem 4.3.1 $(\alpha=\infty)$

Description 1-D saturated solute transport in a uniform flow field with first-order mobile/immobile mass transfer. Calculated effluent curves as influenced by

Platforms: $\quad \mathrm{A}$ and $\mathrm{B}$

Input alpha-inf.main

Output alpha-inf.prnt, obwt0001.plt

Comments No alterations to source or input decks necessary. Comparisons to results presented in Section 4.3.1 are in excellent agreement.

Problem 4.3.1 $(\mathrm{D}=0)$

Description 1-D saturated solute transport in a uniform flow field with first-order mobile/immobile mass transfer. Calculated effluent curves as influenced by

Platforms: $\quad \mathrm{A}$ and $\mathrm{B}$

Input d-0.main

Output d-0.prnt, obwt0001.plt

Comments No alterations to source or input decks necessary. Comparisons to results presented in Section 4.3.1 are in excellent agreement.

Problem 4.3.1 (D = 5)

Description 1-D saturated solute transport in a uniform flow field with first-order mobile/immobile mass transfer. Calculated effluent curves as influenced by the dispersion coefficient, D

Platforms: $\quad A$ and $B$

Input d-5.main

Output d-5.prnt, obwt0001.plt

Comments No alterations to source or input decks necessary. Comparisons to results presented in Section 4.3.1 are in excellent agreement.

Problem 4.3.1 $(\mathrm{D}=30)$

Description 1-D saturated solute transport in a uniform flow field with first-order mobile/immobile mass transfer. Calculated effluent curves as influenced by

Platforms: $\quad$ A and $B$

Input d-30.main

Output d-30.prnt, obwt0001.plt

Comments No alterations to source or input decks necessary. Comparisons to results presented in Section 4.3.1 are in excellent agreement.

Problem 4.3.1 $(\mathrm{D}=50)$

Description 1-D saturated solute transport in a uniform flow field with first-order mobile/immobile mass transfer. Calculated effluent curves as influenced by the dispersion coefficient, D

Platforms: $\quad$ A and B

Input d-50.main

Output d-50.prnt, obwt0001.plt

Comments No alterations to source or input decks necessary. Comparisons to results presented in Section 4.3.1 are in excellent agreement. 
Problem 4.3.1 (D = 100)

Description 1-D saturated solute transport in a uniform flow field with first-order mobile/immobile mass transfer. Calculated effluent curves as influenced by the dispersion coefficient, $\mathrm{D}$

Platforms: $\quad \mathrm{A}$ and $\mathrm{B}$

Input d-100.main

Output d-100.prnt, obwt0001.plt

Comments No alterations to source or input decks necessary. Comparisons to results presented in Section 4.3.1 are in excellent agreement.

Problem 4.3.1 $(K=0.0)$

Description 1-D saturated solute transport in a uniform flow field with first-order mobile/immobile mass transfer. Calculated effluent curves as influenced by

Platforms: $\quad \mathrm{A}$ and $\mathrm{B}$

Input $\quad \mathrm{k}-0.0$.main

Output k-0.0.prnt, obwt0001.plt

Comments No alterations to source or input decks necessary. Comparisons to results presented in Section 4.3.1 are in excellent agreement.

Problem 4.3.1 $(\mathrm{K}=\mathbf{0 . 2 5})$

Description 1-D saturated solute transport in a uniform flow field with first-order mobile/immobile mass transfer. Calculated effluent curves as influenced by the distribution coefficient, $\mathrm{K}$

Platforms: $\quad A$ and B

Input $\quad \mathrm{k}-0.25$.main

Output k-0.25.prnt, obwt0001.plt

Comments No alterations to source or input decks necessary. Comparisons to results presented in Section 4.3.1 are in excellent agreement.

Problem 4.3.1 $(\mathrm{K}=0.50)$

Description 1-D saturated solute transport in a uniform flow field with first-order mobile/immobile mass transfer. Calculated effluent curves as influenced by the distribution coefficient, $\mathrm{K}$

Platforms: $\quad A$ and $B$

Input $\quad \mathrm{k}-0.50$ main

Output k-0.50.prnt, obwt0001.plt

Comments No alterations to source or input decks necessary. Comparisons to results presented in Section 4.3.1 are in excellent agreement.

Problem 4.3.1 $(K=0.75)$

Description 1-D saturated solute transport in a uniform flow field with first-order mobile/immobile mass transfer. Calculated effluent curves as influenced by the distribution coefficient, $\mathrm{K}$

Platforms: $\quad A$ and $B$

Input $\quad \mathrm{k}$-0.75.main

Output k-0.75.prnt, obwt0001.plt

Comments No alterations to source or input decks necessary. Comparisons to results presented in Section 4.3.1 are in excellent agreement. 
Problem 4.3.1 (K = 1.0)

Description 1-D saturated solute transport in a uniform flow field with first-order mobile/immobile mass transfer. Calculated effluent curves as influenced by the distribution coefficient, $\mathrm{K}$

Platforms: $\quad A$ and $B$

Input $\quad \mathrm{k}$-1.0.main

Output k-1.0.prnt, obwt0001.plt

Comments No alterations to source or input decks necessary. Comparisons to results presented in Section 4.3.1 are in excellent agreement.

Problem 4.3.1 $(K=2.0)$

Description 1-D saturated solute transport in a uniform flow field with first-order mobile/immobile mass transfer. Calculated effluent curves as influenced by

Platforms: $\quad \mathrm{A}$ and $\mathrm{B}$

Input

Output

k-2.0.main

Comments

k-2.0.prnt, obwt0001.plt

No alterations to source or input decks necessary. Comparisons to results presented in Section 4.3.1 are in excellent agreement.

Problem 4.3.2 $(\mathrm{kf}=0.0, \alpha=0.0)$

Description 1-D saturated solute transport in a uniform flow field with first-order mobile/immobile mass transfer (VERSE-LC Case_4a comparison). Calculated effluent curves and column profiles as influenced by the surface mass transfer coefficient, kf-VERSE-LC, $\alpha$-FACT

Platforms: $\quad \mathrm{A}$ and $\mathrm{B}$

Input $\quad \mathrm{kf}-0.0$.main

Output kf-0.0.prnt, obwt0001.plt

Comments No alterations to source or input decks necessary. Comparisons to results presented in Section 4.3.2 are in excellent agreement.

Problem 4.3.2 $(\mathrm{kf}=0.00001, \alpha=0.0021)$

Description 1-D saturated solute transport in a uniform flow field with first-order mobile/immobile mass transfer (VERSE-LC Case_4a comparison). Calculated effluent curves and column profiles as influenced by the surface

Platforms: mass transfer coefficient, $\mathrm{kf}$-VERSE-LC, $\alpha$-FACT

Input $\mathrm{A}$ and $\mathrm{B}$

Output $\mathrm{kf}-0.00001$.main

Comments kf-0.00001.pmt, obwt0001.plt

No alterations to source or input decks necessary. Comparisons to results presented in Section 4.3.2 are in excellent agreement.

Problem 4.3.2 $(\mathrm{kf}=0.0001, \alpha=0.021)$

Description 1-D saturated solute transport in a uniform flow field with first-order mobile/immobile mass transfer (VERSE-LC Case_4a comparison). Calculated effluent curves and column profiles as influenced by the surface mass transfer coefficient, $k$ f-VERSE-LC, $\alpha$-FACT

Platforms: $\quad \mathrm{A}$ and $\mathrm{B}$

Input kf-0.0001.main

Output kf-0.0001.prnt, obwt0001.plt

Comments No alterations to source or input decks necessary. Comparisons to results presented in Section 4.3.2 are in excellent agreement. 
Problem 4.3.2 $(\mathrm{kf}=0.001, \alpha=0.21)$

Description 1-D saturated solute transport in a uniform flow field with first-order mobile/immobile mass transfer (VERSE-LC Case_4a comparison). Calculated effluent curves and column profiles as influenced by the surface

Platforms: mass transfer coefficient, kf-VERSE-LC, $\alpha$-FACT

Input $\mathrm{A}$ and $\mathrm{B}$

Output kf-0.001.main

Comments kf-0.001.prnt, obwt0001.plt No alterations to source or input decks necessary. Comparisons to results presented in Section 4.3.2 are in excellent agreement.

Problem 4.3.2 $(\mathrm{kf}=3.0, \alpha=630)$

Description 1-D saturated solute transport in a uniform flow field with first-order mobile/immobile mass transfer (VERSE-LC Case_4a comparison). Calculated effluent curves and column profiles as influenced by the surface

Platforms: mass transfer coefficient, $k f$-VERSE-LC, $\alpha$-FACT

Input $\mathrm{A}$ and $\mathrm{B}$

Output kf-3.0.main

Comments kf-3.0.prnt, obwt0001.plt No alterations to source or input decks necessary. Comparisons to results presented in Section 4.3.2 are in excellent agreement.

\subsection{Operation and Maintenance}

Section 5.5 "Operate and Maintain Software" of procedure L1-8.20, Rev. 0 implements this requirement.

\subsection{Configuration Control}

Section 5.3 "Establish a Configuration" of procedure L1-8.20, Rev. 0 implements this requirement

\subsection{Access Control}

The DCE/DFS access control lists are use to permit authorized and prevent unauthorized access to the FACT $\mathrm{v} 2.0$ source code, executables and verification/validation test cases. This system complies with applicable site automated data processing requirements specified in WSRC $10 \mathrm{Q}$.

\subsection{References}

Amtec Engineering, Inc., 1998. Tecplot ${ }^{\circledR}$ Version 7.5. Amtec Engineering, Inc., Bellevue, WA.

Hamm, L. L., Aleman, S. E., Flach, G. P., and Jones, W. F., 1999a. "FACT (Version 1.1)

Subsurface Flow and Contaminant Transport Documentation and User's Guide (U)," WSRC-TR95-0223, Rev. 1. Westinghouse Savannah River Company, Aiken, SC 29808, April 1999. 
Hamm, L. L. and Aleman, S. E., 1999b. "FACT (Version 2.0) Subsurface Flow and

Contaminant Transport Documentation and User's Guide (U)," WSRC-TR-99-00282, Rev. 0.

Westinghouse Savannah River Company, Aiken, SC 29808, November 1999.

Huyakorn, P. S., Panday, S. and Birdie, T., 1991. "SAFT3D, Subsurface Analysis Finite Element Model for Flow and Transport in 3 Dimensions, Version 1.3, Documentation and User's Guide," HydroGeoLogic, Inc., 1165 Herndon Parkway, Suite 900, Herndon, Va. 22070, May 1991.

Manual 1Q, WSRC Quality Assurance Manual, QAP 20-1, Rev. 5, “Software Quality Assurance", August 12, 1999.

Savannah River Technology Center Procedures Manual L1, 8-20, Rev. 0, "Software Management Quality Assurance (U)", August 10, 1994.

WSRC E7 Conduct of Engineering and Technical Support, Procedure 2.31-Engineering Calculations (U), Rev. 3, June 19, 1998. 
Sottware name FACT

\section{SIS Revision}

Number 4

Date 11/5/99

Descrintion SIS revised to reflect update of FACT from version 1.1 to 2.0

\section{Designation of Responsibilities}

CTF Sebastian E. Aleman

Customer Mary K. Harris

Software Management Documentation (optional)

Document and revision

Description

WSRC-TR-99-00422

Contains management reqds. for $L 1$ manual

\section{Configuration Identification}

Configuration revision/version identifier 2.0

CQF verification of functional classification (signature) ${ }^{1}$

QA procedure/plan $L 18.20$

Configuration items:

Name and revision or version

WSRC-TR-99-00422

FACT (Version 2.0): Subsurface Flow and Contaminant Transport

Documentation and User's Guide (U), WSRC-TR-99-00282, Rev, 0 ,

1999 (L. L. Hamm and S. E. Aleman)

WSRC-TR-99-00422

WSRC-TR-99-00422

WSRC-TR-99-00422

WSRC-TR-99-00422

FACT v2.0 source code

WSRC-TR-99-00422

\section{Configuration Status}

Configuration status ${ }^{3}$ Operational

Description and status of open change requests or NCRs, if any

\section{Description ${ }^{2}$}

P

$D, I, U, V \& V, C$

\begin{tabular}{l}
$D$ \\
\hline$U$ \\
\hline$V \& V, T$ \\
\hline$C$ \\
\hline$\& V, T$ \\
\hline
\end{tabular}

For "operational" status:

Software Quality Assurance completion ${ }^{4}$

CTF signature 1

Date

Acceptance for operational use

Customer signature ${ }^{1}$

Date

\section{User(s) List}

L. L. Hamm

G.P. Flach

S. E. Aleman

\section{G. Jackson}

- R. A. Hiergesell

\footnotetext{
'Signature on a previous SIS which is still applicable may be referenced.

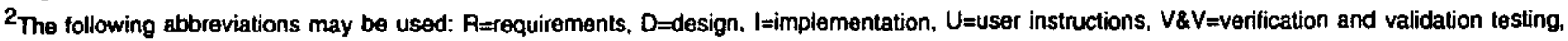
$T=$ installation testing, $\mathrm{C}=$ code, $\mathrm{O}=$ other.

3 Choices are "developmenthesting", "operational" or "retired".

${ }^{4} \mathrm{CTF}$ verification that all $\mathrm{QA}$ requitements for operational use have been met.
} 


\section{SOFTWARE INVENTORY CHECKLIST}

\section{REGISTRATION}

Software Task Title: Subsurface Flow and Contaminant Transport Code

Software Identifier: FACT v2.0

(1) CTF (dev/mtn) organization: SRTC/ERTS

$\begin{array}{ll}\text { (2) CTF: Sebastian E. Aleman } & \text { (3) phone no.: } 5-5226\end{array}$

CTF (resp org) manager: Mary K. Harris

\section{IDENTIFICATION}

(15) Customer contact: Mary K. Harris

(Attach listing for multiple customers.)

phone no.: $\underline{5-4184}$

$\left(6^{*}\right)$ Release /version number (operating/purchased): Version 2.0 NA

Acquisition: new existing $\underline{x}$

purchased

(7) Acquisition source: NA

(9) Application status: in production $\underline{\underline{x}}$ under development

(10) Classification: Classified __ Unclassified $\underline{x}$

(11*) Functional classification: Level "B"

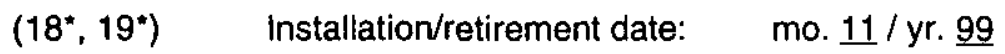

\section{ACCOUNTING}

(5) System/package name: Subsurface Flow and Contaminant Transport Code

(4*) System acronym: FACT

NA

(8) Briefly describe software function.

FACT is a finite element based code designed to model subsurface Flow And Contaminant Transport. It was designed to perform transient three-dimensional calculations that simulate groundwater flow, moisture movement, and solute transport in variably saturated and fully saturated subsurface porous media.

(12) Platform (hardware): SGI workstation and IBM PC

(13) Software package /database /language: FORTRAN 77, FORTRAN 90, C

(14) Operating system: IRIX 6.5 or later, Windows 95 . Windows NT Workstation 4.0 or later

\section{COMPLETION}

CTF: Date:

CTF manager: Date: 
Retention: Lifetime

\section{SOFTWARE QUALITY ASSURANCE PLAN FOR ENVIRONMENTAL DOSIMETRY}

A. A. Simpkins

Issued: November 1994 
Approvals

A. A. Simpkins, CTF
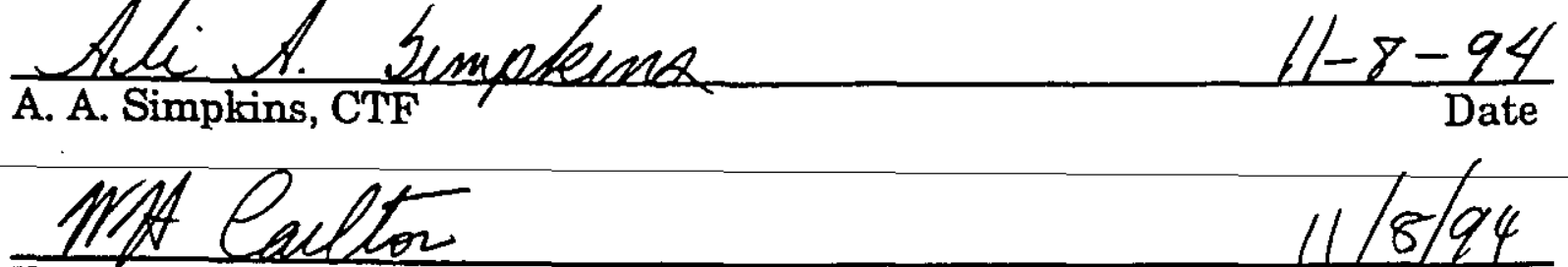

W. H. Carlton, Technical Lead, EDG

Pox Son

A. L. Boni, Manger, ETS

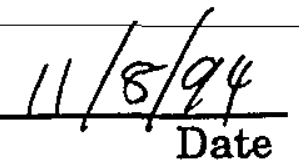

$11-8-94$

Date 
WESTINGHOUSE SAVANNAH RIVER COMPANY

WSRC-RP-94-1159

ABSTRACT

A software quality assurance plan has been developed for application with codes owned by the Environmental Dosimetry Group. The plan contains the specific requirements for the operation and maintenance of the codes as specified in Manual L1 Procedure 8.20 concerning Software Management and Quality Assurance. All portions of this procedure which are not addressed will be complied with directly. 


\section{TABLE OF CONTENTS}

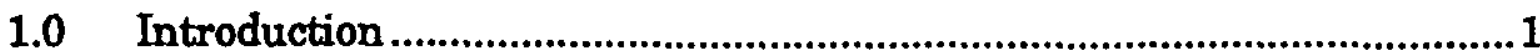

2.0 Configuration Planning Phase .............................................................1

3.0 Configuration Establishment Phase ........................................................1

4.0 Operation and Maintenance Phase ...........................................................3

5.0 Requirements for Existing EDG Software.................................................

5.1 AXAIR89Q ....................................................................................

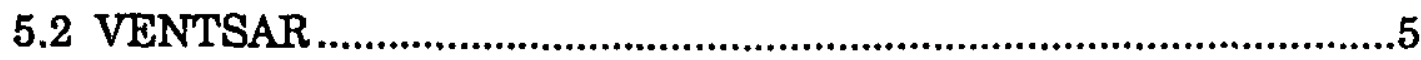

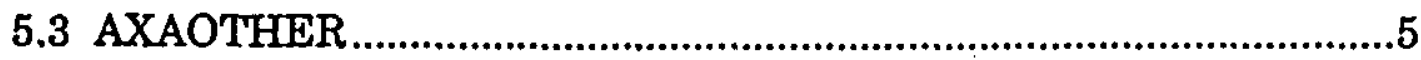

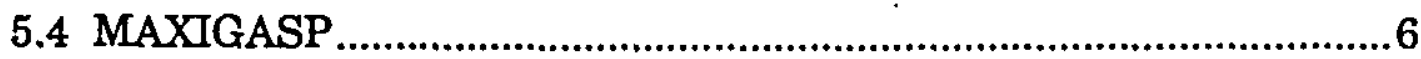

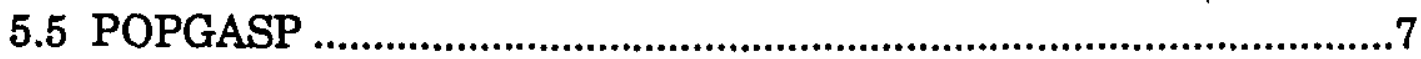

5.6 CAP88

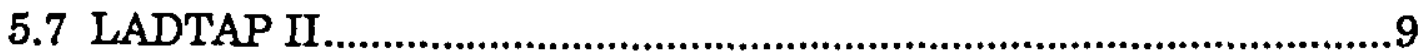

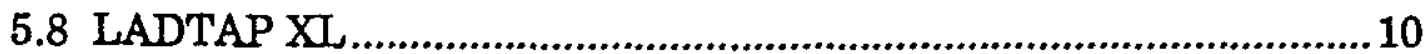

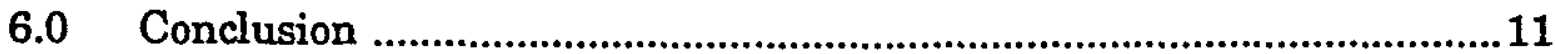

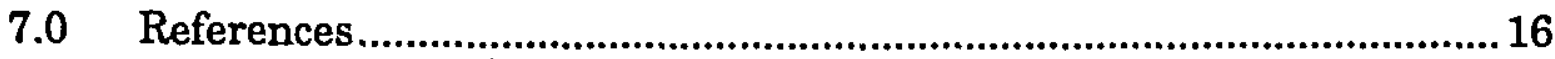

\section{LIST OF FIGURES}

Figure 1. Procedure Flowchart...................................................................12

Figure 2. Configuration Planning Stage .........................................................13

Figure 3. Configuration Establishment Stage ............................................. 14

Figure 4. Operations and Maintenance Phase ................................................15 


\section{TERMS AND DEINTIUONS}

The following terms are listed to ensure understanding. These definitions are taken from Manual L1 Procedure 8.20 unless noted.

Code - one or more computer programs or part of a computer program.

Computer Program - a combination of computer instructions and data definitions that enable computer hardware to perform computational or control functions.

Configuration management - the process of identifying and defining the hardware/software items in a system, controlling the release and change of these items throughout the system life cycle, and recording and reporting the status of configuration items and change requests.

CP - Critical Protection - the functional classification that applies to those structures, systems, and components necessary for the protection of the health and safety of the co-located worker from both non-radiological toxic material and from radiological hazards (Manual E7, 2.25).

CQF - cognizant quality function - person/organization responsible for reviewing and approving SQA plans and verifying software has been functionally classified.

CTF - cognizant technical function - primary point of contact for the organization responsible for ensuring applicable software management and quality assurance controls are implemented. Designated by management and responsible for software technical adequacy during acquisition, development and or maintenance activities.

Customer - the primary point of contact for the user community.

GS - General Services - the functional classification assigned to all structures, systems, and components not required to provide NS, CP, or PS function. All SRS structures, systems, and components are as a minimum, classified as GS to assure that proper design, operations and maintenance requirements are assigned to provide for the health and safety of the facility worker and to assure compliance with other Site requirements (Manual E7, 2.25).

Independent technical review - a documented, traceable review performed by qualified personnel who are independent of those who performed the work. Technical reviews are indepth, critical reviews, analysis, and evaluation of software, documentation, or data that require verification for applicability, correctness, adequacy, and completeness.

IRM - Information Resource Management 


\section{NCR - Non Conformance Report}

NS - Nuclear Safety - the functional classification that applies to those structures, systems, and components necessary for the protection of the health and safety of the public from both non-radiological toxic material and from radiological hazards (Manual E7, 2.25).

PS - Production Support - the functional classification that applies to those structures, systems, and components necessary to. support continued operation of a Nuclear Production Facility, including selected environmental monitor and Emergency Plan communications devices (Manual E7, 2.25).

Software - computer programs, procedures, rules and associated documentation and data pertaining to the operation of a computer system.

SIS - Software Information Sheet - base document containing software data upon which $Q A$ requirements are described or subsequent documentation identified.

Software validation - the test and evaluation of the completed software to ensure compliance with software requirements.

Software verification - the process of determining whether or not the product of a given phase of the software development cycle fulfills the requirements imposed by the previous phase.

Test case - a specific set of test data and associated procedures developed for a particular objective, such as to exercise a particular program path or to verify compliance with a specified requirement.

Testing - the process of exercising or evaluating a system or system component by manual or automated means, to verify that it satisfies specified requirements or to identify differences between expected and actual results. 


\title{
SOFTWARE QUALITY ASSURANCE PLAN FOR ENVIRONMENTAL DOSIMETRY
}

\author{
A. A. Simpkins \\ Westinghouse Savannah River Company \\ Savannah River Site \\ Aiken, SC 29808
}

\subsection{INTRODUCTION}

This plan lists the requirements for completing the quality assurance activities to be performed over the life cycle of software managed by the Environmental Dosimetry Group (EDG). This plan follows procedures specified in Manual L1 Procedure 8.20 concerning Software Management and Quality Assurance. The life cycle of software is outlined in Figure 1. Each of the phases will be addressed in detail for generic use with any EDG code and then specific information will be provided on each of the eight codes currently owned by EDG.

The Cognizant Technical Function (CTF) of the code is responsible for ensuring that the procedures are followed. Items which are not addressed in this document must follow the guidelines specified in Manual L1 Procedure 8.20. Portions of this document are expected to be revised over time. Please refer to the CTF for the current version.

\subsection{CONFIGURATION PLANNING PHASE}

The configuration planning phase is designed for use with the purchase of or decision to develop software. This stage is simplified in Figure 2. EDG does not acquire software on a regular basis. For compliance with this procedure refer directly to Manual L.1 Procedure 20.1 Section 5.1. No exceptions to this procedure will be made unless approval has been obtained from the Cognizant Quality Function (CQF) and the customer.

\subsection{CONFIGURATION ESTABLISHMENT PHASE}

The configuration establishment phase governs the use of the codes once they are in existence regardless of whether developed in-house or purchased or whether pre-existing. This phase is simplified in Figure 3. This document is designed to satisfy all of the items listed in Figure 3 for each of the codes owned by EDG as well as set up a generic procedure to be used for newly acquired codes. 
For each of the codes the following items must be completed:

1. Identify the functional classification of the software (GS,PS,CP, or NS See Terms and Definitions).

2. Fill out a Software Information Sheet. (See Attachment 1 for an example.)

3. Define the requirements of the code. This includes requirements for functionality, performance, design constraints, attributes, and external interfaces. An item is a requirement only if its achievement can be verified and validated, and it is traceable throughout the remaining stages of the software life cycle. This report will serve to describe the requirements for all of the codes owned by EDG. The following must be defined for every code owned by EDG:

- Function - the functions the software is to perform, including its interactions with data.

- Performance - the time-related issues of software operation, such as speed, recovery time, response time, etc.

- Design Constraints - elements that restrict design options.

- Attributes - non-time-related issues of software operation such as portability, acceptance criteria, maintainability, security, etc.

- External Interfaces - interactions with people, hardware, and other software.

4. Assemble V\&V testing documentation. Must have independent technical review.

5. Establish a User's Manual. Must have independent technical review.

6. Obtain customer acceptance. This is noted by signature on the SIS form.

Since many of the codes owned by EDG are used by a wide range of customers on site representing different departments and even divisions, it is not feasible to have one customer contact external to EDG. For this reason the customer of our codes is assumed to be the Level 3 Manger of Environmental Technology, A. L. Boni. Departments that use the codes frequently will be provided with a copy of the Software Quality Assurance Plan for reference and all users will be notified of any changes or problems within a code. 
The Software Information Sheet addressed in Item 2 is a key form that addresses all of the required documentation. This form alone conveys to the customer all of the required documentation in a traceable manner. All users should have access to this form.

\subsection{OPERATIONS AND MAINTENANCE PHASE}

The operations and maintenance phase is depicted in Figure 3. This figure is self explanatory and will be applied directly. For the box near the bottom labeled "perform successful installation testing" this will entail either execution of the test cases or development of new set of test cases based on the new requirements of the code. Test cases have already been set up for each of the Environmental Dosimetry Codes and are performed every six months or when a code change is made.

\subsection{REQUIREMENTS FOR EXISTING EDG SOFTWARE}

As part of the configuration establishment phase, the requirements for each of the codes will be discussed. This plan addresses the following codes: AXAIR89Q, VENTSAR, AXAOTHER, MAXIGASP, POPGASP, CAP88, LADTAP II, and LADTAP XL. A completed SIS is in Attachment 1 along with all previous revisions of SIS. Refer to the SIS for a complete list of the up-to-date references for aid in code execution. Software Inventory Checklists have been completed for each of the codes and forwarded to IRM. Copies of these Software Inventory Checklists are shown in Attachment 2.

\subsection{AXAIR89Q}

\subsubsection{Function}

AXAIR89Q is a site-specific code used to predict doses following radioactive atmospheric releases of short duration. AXAIR89Q strictly follows the guidance in USNRC Regulatory Guide 1.145 (USNRC, 1982). Dose modeling provided by AXAIR89Q is primarily used for Safety Analysis Reports. Given minimal input to characterize a release, the AXAIR89Q code estimates the doses via inhalation and plume shine radiation pathways to the onsite population, the offsite population within 50 miles, onsite individuals at userselected locations and the offsite maximum individual. The doses evaluated are those that would be exceeded only $0.5 \%$ of the time based on worst-case, worst-sector meteorological probability analysis. The doses are provided by radionuclide, body organ, and pathway.

AXAIR89Q provides automatic selection or generation of the following: dose conversion factors, inhalation and gamma exposure parameters, onsite and offsite population distributions, meteorological parameters, relative terrain elevations, and minimum boundary distance in each compass sector. 
Ingrowth of daughter radionuclides from released parent decay during plume transport may be considered at the user's discretion. Different methodologies can be used in the determination of external dose via gamma radiation using one of the following assumptions:

- nonuniform plume upper-bound approximation,

- rigorous nonuniform plume approximation, or

- semi-infinite uniform plume.

Results can be presented as a summary or as full output with doses reported by pathway and nuclide. The user may choose the summary, full output, or both. Several of the input datasets are echoed as part of the output. These include: terrain data file, meteorological joint frequency distribution, and onsite and offsite population databases.

\subsubsection{Performance}

AXAIR89Q will perform approximately 50,000 calculations of downwind air concentration and dose. CPU time should be on the order of 5 to 10 minutes on the IBM unclassified mainframe depending on the number of nuclides entered. CPU time will be longer if a large number of isotopes is selected. The code is set to limit the CPU time to 10 minutes in order to avoid incorrect input resulting in misused CPU time.

\subsubsection{Design Constraints}

Coding is accomplished using FORTRAN 77 (or equivalent), executable through IBM JCL.

\subsubsection{Attributes}

The computer code AXAIR89Q has been compiled and link-edited, and is ready for execution on the IBM unclassified mainframe with the JCL cards and user input template specified in a controlled dataset. FORTRAN and load modules are maintained in a write-protected file, accessible by only the CTF.

\subsubsection{External Interfaces}

Users are expected to have a base knowledge of atmospheric dispersion and dosimetry prior to executing the code. AXAIR89Q requires minimal input with defaults for a majority of the parameters. The User's Manual offers a guide to the beginner as well as advanced user. Training courses are offered as needed. Any questions concerning the code or the models it employs should be referred to the CTF if unable to be answered by reference to the User's Manual or the Verification report. 


\subsection{VENTSAR}

\subsubsection{Function}

The VENTSAR code was developed for estimating pollutant concentrations on or near buildings. The building may be modeled as a simple rectangular structure or a structure that contains a penthouse on the roof. The release point may be either upwind or on top of the structure. The user also has the option of allowing for plume rise from either thermal buoyancy or momentum or both. Concentrations are predicted at downwind distances at userspecified increments.

\subsubsection{Performance}

VENTSAR operates on the IBM 3090. An input template is accessed to obtain user information. CPU time for VENTSAR is typically less than one minute. Results are presented in a tabular form.

\subsubsection{Design Constraints}

Coding of software is accomplished using FORTRAN 77, executable through IBM JCL.

\subsubsection{Attributes}

VENTSAR has been compiled and link-edited, and is ready for execution on the IBM unclassified mainframe. FORTRAN and load modules are maintained in a write-protected file, accessible only by the CTF.

\subsubsection{External Interfaces}

The user is expected to have general knowledge of atmospheric dispersion and building wake effects prior to executing the code. Assistance for execution of the code can be found in the Environmental Dose Assessment Manual (Hamby, 1991) or by contacting the CTF.

\subsection{AXAOTHER}

\subsubsection{Function}

AXAOTHER is used to predict doses during a postulated tornado or periods of high-velocity straight winds. With known dispersion factors, the AXAOTHER code can be used to calculate radiological consequences including maximum dose to an offsite individual and doses to onsite and offsite populations. The exposure pathways considered in the AXAOTHER code include inhalation of radionuclides and immersion in the plume. 
AXAOTHER allows for automatic selection or generation of dose conversion factors, and inhalation and gamma exposure parameters. Inhalation and gamma-shine doses to the maximum individual at a user specified location and the populations within 50 miles are determined. External dose via gamma radiation using a semi-infinite uniform plume model is also determined.

\subsubsection{Performance}

AXAOTHER operates on the IBM 3090 in a compiled and linked version of FORTRAN. CPU time is on the order of a few seconds.

\subsubsection{Design Constraints}

Coding of software is accomplished using FORTRAN 77, executable through IBM JCL.

\subsubsection{Attributes}

AXAOTHER has been compiled and link-edited, and is ready for execution on the IBM unclassified mainframe. FORTRAN and load modules are maintained in a write-protected file, accessible only by the CTF.

\subsubsection{External Interfaces}

The user is expected to have general knowledge of atmospheric dispersion prior to executing the code. Assistance for execution of the code can be found in the Environmental Dose Assessment Manual (Hamby, 1991) or by contacting the CTF.

\subsection{MAXIGASP}

\subsubsection{Function}

MAXIGASP is used to estimate dose to the maximally exposed offsite individual resulting from a chronic atmospheric release and follows the methodologies discussed in USNRC Regulatory Guides 1.109 and 1.111 (USNRC 1977a and 1977b). The MAXIGASP code calculates annual average air and ground deposition concentrations per unit release at the site boundary in 16 compass sectors. No credit is taken for plume rise induced by momentum or thermal effects. The average air and ground concentrations and the user-specified source term are then used to estimate radiation doses from atmospheric exposure pathways. The main outputs from the MAXIGASP code are the doses at the location of the maximum exposed individual dose along the SRS boundary. The maximally exposed individual is assumed to reside continuously at the location of highest potential exposure. MAXIGASP allows for automatic selection of dose factors, meteorological data, terrain data, etc. 


\subsubsection{Performance}

MAXIGASP operates on the IBM unclassified mainframe in a compiled and linked version of FORTRAN. CPU time is typically less than one minute.

\subsubsection{Design Constraints}

Coding of software is accomplished using FORTRAN 77, executable through IBM JCL.

\subsubsection{Attributes}

MAXIGASP has been compiled and link-edited, and is ready for execution on the IBM unclassified mainframe. FORTRAN and load modules are maintained in a write-protected file, accessible only by the CTF.

\subsubsection{External Interfaces}

The user is expected to have general knowledge of the models discussed in USNRC Regulatory Guides 1.109 and 1.111 (USNRC, 1977a\&b) prior to executing the code. Assistance for execution of the code can be found in the Environmental Dose Assessment Manual (Hamby, 1991) or by contacting the CTF.

\subsection{POPGASP}

\subsubsection{Function}

POPGASP is used to estimate 50-mile offsite population dose resulting from a chronic atmospheric release and follows the methodologies discussed in USNRC Regulatory Guides 1.109 and 1.111 (USNRC 1977a and 1977b). The POPGASP code calculates annual average air and ground deposition concentrations per unit release for each of 16 compass sectors within an 80kilometer radius of the release location. No credit is taken for plume rise induced by momentum or thermal effects. The main output from the POPGASP code is the dose to the population residing within 80 kilometers of the release location.

POPGASP allows for automatic selection of dose factors, meteorological frequency distributions, agricultural data, terrain data, population distribution, etc. POPGASP predicts the dose to the 80 kilometer population from inhalation, ingestion, and external pathways.

\subsubsection{Performance}

POPGASP operates on the IBM 3090 in a compiled and linked version of FORTRAN. CPU time is typically less than one minute. 


\subsubsection{Design Constraints}

Coding of software is accomplished using FORTRAN 77, executable through IBM JCL.

\subsubsection{Attributes}

POPGASP has been compiled and link-edited, and is ready for execution on the IBM unclassified mainframe. FORTRAN and load modules are maintained in a write-protected file, accessible only by the CTF.

\subsubsection{External Interfaces}

The user is expected to have general knowledge of the models discussed in USNRC Regulatory Guides 1.109 and 1.111 (USNRC 1977a and 1977b). prior to executing the code. Assistance for execution of the code can be found in the Environmental Dose Assessment Manual (Hamby, 1991) or by contacting the CTF.

\subsection{CAP88}

\subsubsection{Function}

CAP88 estimates health impacts from the inhalation, ingestion, air immersion and ground surface irradiation pathways, and tabulates results for maximally exposed individuals and regional populations. CAP88 uses a modified Gaussian plume equation to estimate the average dispersion of radionuclides released from up to six sources at the same release location with different release heights. Assessments are done for a circular grid within a radius of 80 kilometers. The use of CAP88 is required when assessing health impacts for NESHAPS application.

CAP88 has automatic selection or generation of one or more of the following: dose conversion factors, inhalation, ingestion, and gamma exposure parameters, onsite and offsite population distributions, agricultural parameters, and meteorological joint frequency data. Determination of inhalation, ingestion, and gamma-shine dose to the maximum individual at a user specified location and the population within 50 miles.

\subsubsection{Performance}

CAP88 software can handle a maximum of 36 nuclides released from up to six stack heights. The EPA program has been installed on the IBM 3090 and can estimate either individual or population doses with CPU time on the order of seconds. 


\subsubsection{Design Constraints}

Coding of software is accomplished using FORTRAN 77, executable through IBM JCL.

\subsubsection{Attributes}

CAP88 has been compiled and link-edited, and is ready for execution on the IBM unclassified mainframe. FORTRAN and load modules are maintained in a write-protected file, accessible only by the CTF.

\subsubsection{External Interfaces}

The user is expected to have general knowledge of atmospheric dispersion and the assessment of health effects for NESHAPS applications. Assistance for execution of the code can be found in the Environmental Dose Assessment Manual (Hamby, 1991) or by contacting the CTF.

\subsection{LADTAP II}

\subsubsection{Function}

The LADTAP II code is designed to evaluate radiological dose due to the release of radioactive material from the Savannah River Site (SRS) during normal operation via liquid effluent pathways. The code implements the models described in the USNRC Regulatory Guide 1.109 (USNRC, 1977b) for liquid radioactive releases. Up to 200 nuclides may be included in the release source term. Available options include the complete mixing, partial mixing, or the plug-flow model. These models are described in the USNRC Regulatory Guide 1.113 (USNRC 1977c). LADTAP II calculates the radiation exposure to man from potable water, aquatic foods, and also the dose to biota. Doses are calculated for both individuals and offsite populations, and are summarized for each pathway by age group and organ.

Doses are determined for the following receptors and locations:

- The SRS maximum individual

- Beaufort-Jasper

- maximum individual

- average individual

- population

- Port Wentworth

- maximum individual

- average individual

- population

- Biota

- Downstream consumers of fresh and salt water fish and invertebrates. 


\subsubsection{Performance}

LADTAP II performs up to 200 calculations of downstream doses in less than 5 CPU seconds on the IBM 3090.

\subsubsection{Design Constraints}

Coding of software is accomplished using FORTRAN 77, executable through IBM JCL.

\subsubsection{Attributes}

LADTAP II has been compiled and link-edited, and is ready for execution on the IBM unclassified mainframe. FORTRAN and load modules are maintained in a write-protected file, accessible only by the CTF.

\subsubsection{External Interfaces}

The user is expected to have a general knowledge of the models discussed in USNRC Regulatory Guides 1.109 and 1.113 prior to executing the code.

\subsection{LADTAP XL}

\subsubsection{Function}

LADTAP XL is an EXCEL Spreadsheet version of LADTAP II. The LADTAP $\mathrm{XI}$ code is designed to evaluate doses due to the release of radioactive material from the Savannah River Site (SRS) during normal operation via liquid effluent pathways. The code implements the models described in the USNRC Regulatory Guide 1.109 (USNRC, 1977b) for liquid radioactivity releases. LADTAP XI calculates the radiation exposure to man from potable water, aquatic foods, and swimming and boating. Doses are calculated for both individuals and offsite populations, and are summarized for each pathway by age group and organ.

Usage and population parameters specific to the SRS vicinity are automatically selected. Doses are determined for the following receptors and locations:

- The SRS maximum individual

- Beaufort-Jasper

- maximum individual

- average individual

- population

- $\quad$ Port Wentworth

- maximum individual

- average individual

- population 


\subsubsection{Performance}

LADTAP XL performs calculations of downstream doses instantaneously through changes in the input portion of the spreadsheet.

\subsubsection{Design Constraints}

LADTAP XL has been programmed using a Microsoft EXCEL spreadsheet.

\subsubsection{Attributes}

LADTAP XL has been locked to avoid changes by the user. Only the input may be changed.

\subsubsection{External Interfaces}

The user is expected to have a general knowledge of the models discussed in USNRC Regulatory Guide 1.109 prior to executing the code. Use is limited to EDG personnel.

\subsection{CONCLUSION}

This document allows EDG to be compliant with certain aspects of SRTC's Software Management and Quality Assurance Procedure. All portions of the procedure not specifically addressed in this document are complied with directly without the need of supporting documentation. This document shall be updated by EDG as needed to reflect changes in procedures or changes in the use of EDG software. 
Figure 1. PROCEDURE FLOWCHART

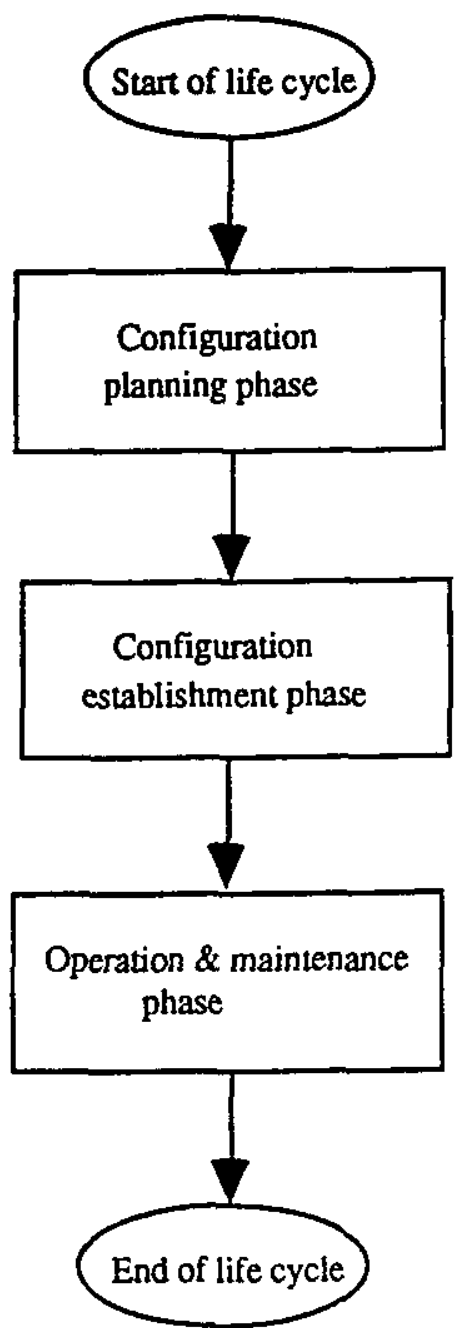




\section{Figure 2. CONFIGURATION PLANNING PHASE}

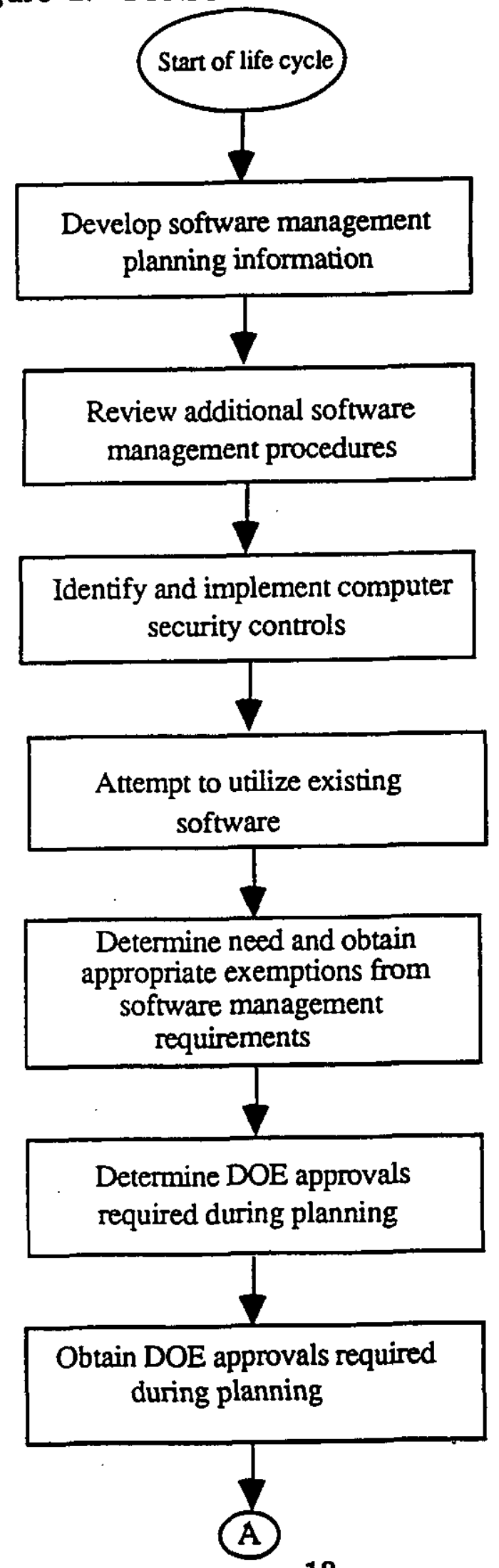


Figure 3. CONFIGURATION ESTABLISHMENT PHASE

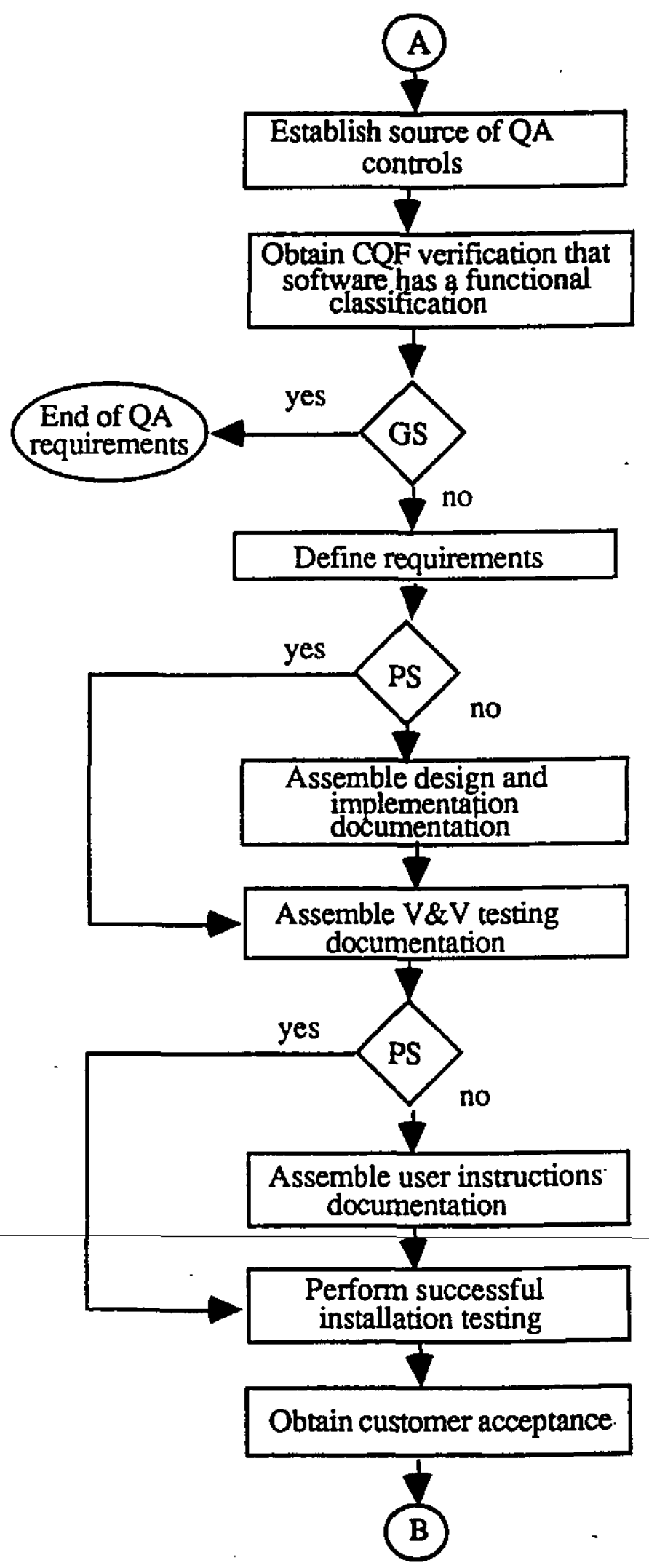


Figure 4. OPERATION \& MAINTENANCE PHASE

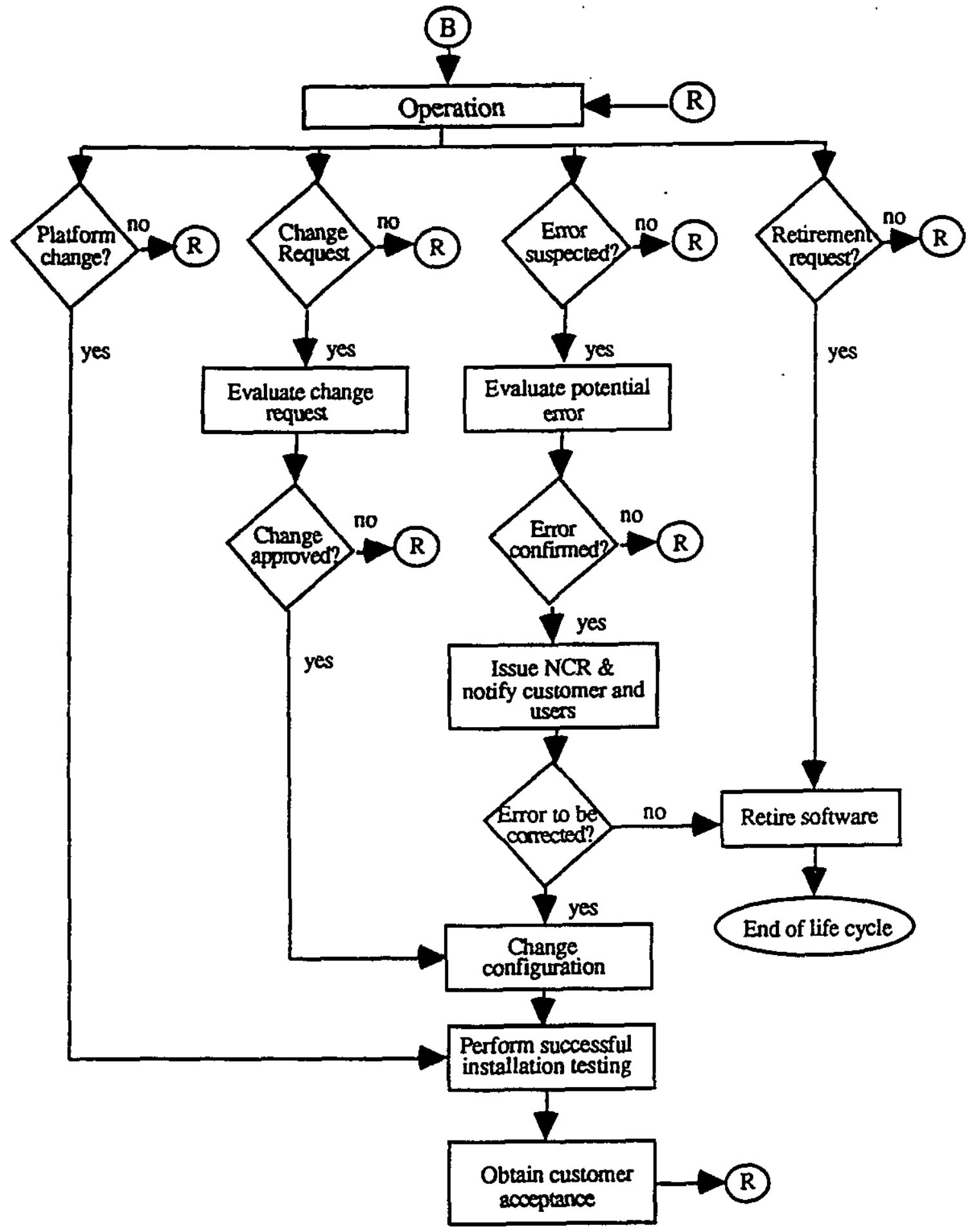




\subsection{REFERENCES}

Hamby 1991. Hamby, D.M., Environmental Dose Assessment Manual(U), WSRC-IM-91-1, Westinghouse Savannah River Company, Aiken, SC, 1991.

USNRC 1977a.U.S. Nuclear Regulatory Commission, "Regulatory Guide 1.111: Methods for Estimating Atmospheric Transport and Dispersion of Gaseous Effluents in Routine Releases from Light-Water-Cooled Reactors.", Rev. 1, Washington, DC, July, 1977.

USNRC 1977b.U.S. Nuclear Regulatory Commission, "Regulatory Guide 1.109: Calculation of Annual Doses to Man from Routine Releases of Reactor Effluents for the Purpose of Evaluating Compliance with 10 CFR 20, Appendix I", Rev. 1, Washington, DC, 1977.

USNRC 1977c. U.S. Nuclear Regulatory Commission, "Regulatory Guide 1.113: Estimating Aquatic Dispersion of Effluents from Accidental and Routine Reactor Releases for the Purpose of Implementing Appendix I", Rev. 1, Washington, DC, 1977.

USNRC 1982 US Nuclear Regulatory Commission, "Regulatory Guide 1.145: Atmospheric Dispersion Models for Potential Accidental Consequence Assessments at Nuclear Power Plants", Rev. 1, Washington, DC, November, 1982. 
Attachment 1. Software Information Sheets 
THIS PAGE INTENTIONALLY LEFT BLANK 


\section{SOFTWARE INFORMATION SHEET (SIS)}

Page 1 of 2

Software name AXAIR890

SIS Revision

Number 0

Date $10-30-94$

Designation of Responslbillties

CTF Ali A. Simpkins

Customer A. L. Boni

Software Management Documentation (optional)

Document and revision

Description

NA-Pre-Existing Software

Conflguration Identification

Configuration revlsion /version identifler Version 1.2

Functlonal classification

NS

CQF verification of functional classification (signature) ${ }^{1}$

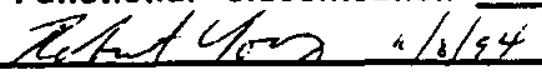

QA Procedure Plan WSRC-RP-94-1159

Conflguration Items:

Name and revision or version

Soltware OA Plan, WSRC-RP-94-1159.

Verification Report, WSRC-RP-90-1222

User's Guide, WSRC-RP-94-313

Conflguration Status

Conflguration Status

Operational

Description and status of open change request or NCRs if any none

For "active-operational" status:

Software Quality Assurapce completion ${ }^{4}$

CTF signature ${ }^{1}$

Acceptance for operational to:

Customer signature ${ }^{1}$

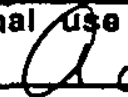

Description $^{2}$

Defines Requirements

Describes all existing modules

Contains user instructions

User(s) List

A. A. Simpkins

J. G. Black

W.H. Cartion

Soe Attached

Signature on a previous SIS which is still aplicable may be referenced.

2 The following abbreviations may be used: R=requirements, D-design, I=implementation, U=user

instructions, $V \& V=v e r i f i c a t i o n$ and validation testing, $C=c o d e, O=0$ ther.

"Choices are "development/testing" or "retired".

4 CTF verification that all QA requirements for operational use have been met. 
G. T. Geiger Stanley Chow

Kathy Marshall

Victor Serrano

D. P. Eisele

Fred Ramirez

Jeff McKinney

Ted A. Long

David K. Allison

Tinh H. Tran

R. L. Garret

Gregory R. Swenson

Jeffrey A. Tacca

Lance Christiansen

Terri L. Slaven

Raphael Lopez

D. P. Kearnaghan

C.C. Fields

G. A. Bevirt

J. M. Pareizs

J. C. Huang

J. D. Townsend

Pauline Hang

Ingle $\mathrm{K}$. Paik

J. K. Norkus

D. F. Gehr

F. D. Benton

J. R. Taylor

J. W. Ray

E. P. Hope

Steve Rabin

S. T. Gough

K. R. O'Kula

P. B. Gerrard

S. P. Tinnes

M. W. Geeting

Dave Thoman

Lisa Stringfield

H. A. Ford

Liz DelGenio

LeRoy Geoff

J. M. East

K. S. Beard 
Software name MAXIGASP

S1S Rovision

Number 0

Date $10-30-94$

Designatlon of Responsiblittles

CTF Ali A. Simpkins

Customer A. L. Boni

Software Management Documentation (optlonal)

Document and revision

Description

NA - Pre-Existing Software

Configuration Identification

Conflguration revision /version identifler Version 1.2

Functional classiflcation

NS

CQF verification of functional classification (signature) ${ }^{1}$

QA Procodure Plan WSRC-RP-94-1159
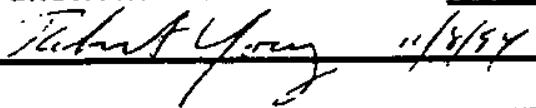

Configuration items:

Name and revision or version

Software QA Plan, WSRC-RP-94-1159

Verification Report. WSRC-RP-91-320

Verification Report, WSAC-RP-92-418

Verification Report, WSRC-RP.94-522

\section{Description ${ }^{2}$}

Defines Requirements

Describes all existino modules in X00000

Describes all existing modules in GASPAB

Describes $X O O D O O$ and GASPAR connections

Conflguration Status

Conflguration Status ${ }^{3}$

Operational

Description and status of open change request or NCRs If any none

For "active-operational" status:

Software Quality Assujance completion"

CTF signature ${ }^{1}$

Acceptance for operationg yse

Customer signature ${ }^{1}$

User(8) Llst

A.A. Simpkins

J.G. Black

W.H.Cartion
Date $\frac{11-7-94}{\mu-8-94}$

'Signature on a previous SIS which is still aplicable may be referenced.

2 The following abbreviations may be used: $R=$ requirements, D-design, I=implementation, $U=$ user instructions, $V \& V=$ verification and validation testing, $C=c o d e, O=0$ ther.

"Choices are "development/testing" or "retired".

- CTF verification that all QA requirements for operational use have been met. 
Software name POPGASP

SIS Revision

Number 0

Date $10-30-94$

Designation of Responsibllitles

CTF Ali A. Simpkins

Customer A. L. Boni

Software Management Documentation (optional)

Document and revision

Description

NA - Pre-Existina Software

Configuration Identification

Configuration revision /version Identifler Version 1.2 Functional classification

CQF verification of functional classification (signature) ${ }^{1}$

QA Procedure Plan WSRC-RP-94-1159

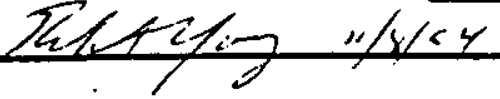

Conflguration Items:

Name and revision or verslon

Software OA Plan, WSRC-RP-94-1159

Verification Report, WSRC-AP-91-320

Verification Report, WSRC-RP-92-418

Verification Report, WSRC-RP-94-522

Description ${ }^{2}$

Defines Requirements

Describes all existing modules in XOODOO

Describes all existing modules in GASPAR

Describes $X O Q D O O$ and GASPAR connections

Conflguration Status

Conflguration Status ${ }^{3}$

Operational

Description and status of open change request or NCRs if any none

For "active-operational" status:

Sottware Quallty Assurgnce completion"

CTF signature'

Acceptance for operatloner use

Customer stgnature'

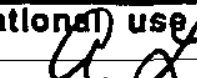

User(s) Llst

A.A. Simpkins

J.G. Black

W. H. Cartion
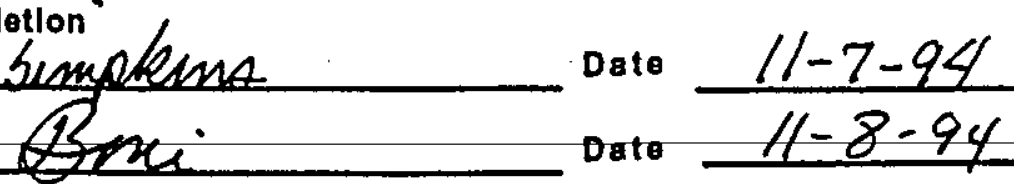

1

Signature on a previous SIS which is still aplicable may be referenced.

2 The following abbreviations may be used: $R=$ requirements, D-design, I=implementation, U=user

instructions, $V \& V=$ verification and validation testing, $C=c o d e, O=0$ ther.

"Choices are "development/testing" or "retired".

CTF verification that all QA requirements for operational use have been met. 
Software name VENTSAR

\title{
SIS Revision
}

Number 0

Date $10-30-94$

Designation of Responsiblittles

CTF Ali A. Simpkins

Customer A. L. Boni

Software Management Documentation (optlonal)

Document and rovision

Description

NA - Pre-Existing Software

Conflguration Identification

Conflguration revision iversion Identifler Version 1.2 CQF verification of functional classification (signature) ${ }^{1}$

QA Procedure Plan WSRC-RP-94-1159

Functional classification

NS

Conflguration Items:

Name and revision or version

Software QA Plan, WSRC-RP-94-1159

Environmental Dose Assessment Manual, WSRC-IM-91-1

Methodology Report, DP-1668

\author{
Description ${ }^{2}$ \\ Defines Requirements \\ Code Description \\ Describes models used
}

Configuration Status

Conflguration Status ${ }^{3}$ Operational

Description and status of open change request or NCRs if any none

For "active-operational" status:

Software Quality Assurance completlon" CTF signature ${ }^{\prime}$ A. A. Acceptance for operatlonal yse Customer signature'

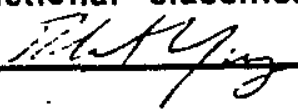

\section{User(s) Llst}

A. A. Simpkins

J.G. Black

W.H.Cartion

Signature on a previous SIS which is still aplicable may be referenced.

2 The following abbreviations may be used: $R=$ requirements, D-design, I=implementation, U=user instructions, $V \& V=v e r i f i c a t i o n$ and validation testing, $C=c o d e, O=o$ ther.

"Choices are "development/testing" or "retired".

- CTF verification that all $Q A$ requirements for operational use have been met. 
Software name CAP88

Sis Rovision

Number 0

Date $10-30-94$

Designation of Responsibilities

CTF Ali A. Simpkins

Customer A.L.Boni

Software Management Documentation (optlonal)

Document and revision

Description

NA-Pre-Existing Software

Configuration Identification

Configuration revision /version Identifier Version 1.2

CQF verification of functional classification (signature) ${ }^{t}$

Functionat classification

NS

OA Procoduro Plan

Configuration Items:

Name and revision or version

Description $^{2}$

Software QA Plan, WSRC-RP-94-1159

CAP88 User's Manual, CCC-452

Defines Requirements

Describes modules and ingut instructions

Configuration Status

Conflguration Status ${ }^{3}$ Operational

Descriptlon and status of open change request or NCRs if any none

For "active-operational" status:

Software Quality Assugance completion"

CTF signature ${ }^{1}$

Acceptance for operatlonal use

Customer signature'

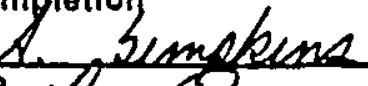

Date

$11-7-94$

User(8) Llst

Date

$11-8-94$

A.A. Simpkins

J.G. Black

W. H. Cartion

Signature on a previous SIS which is still aplicable may be referenced.

2 The following abbreviations may be used: R=requirements, D-design, I=implementation, U=user

instructions, $V \& V=$ verification and validation testing, $C=$ code, $O=0$ ther.

"Choices are "development/testing" or "retired".

- CTF verification that all QA requirements for operational use have been met. 
Software name AXAOTHER

SIS Rovision

Number 0

Date 10-30-94

Designation of Responslbilities

CTF Ali A. Simpkins

Software Management Documentation (optional)

Document and revision

NA-Pre-Exisung Software
Customer A. L. Boni

Description

\section{Conflguration Identification}

Configuration revision /version Identifier Version 1.2 CQF verification of functional classification (signature) ${ }^{2}$

QA Procedure Plan

Functional classiflcation

NS

Conflguration Items:

Name and reviston or version

Software QA Plan, WSRC-RP-94-1159

Methodologr Report. DPST-85-505

Environmental Dose Assessment Manual, WSRC-IM-91-1

Description

Defines Requirements

Describes methodology

User Instructions

Conflguration Status.

Configuration Status ${ }^{3}$

Operational

Description and status of open change request or NCRs if any none

For "active-operational" status:

Software Quality Assurange completion CTF signature ${ }^{\prime}$ Als $A$.

Acceptance for operational use Customer signature ${ }^{1}$
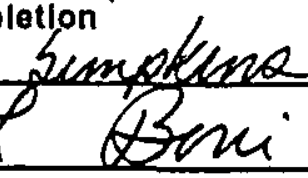

Q⿻n一𠃋 Date $\frac{11-7-94}{11-8-94}$

User(8) List

A.A. Simpkins

J.G. Black

W.H. Cartion

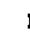

Signature on a previous SIS which is still aplicable may be referenced.

2 The following abbreviations may be used: $R=$ requirements, $D$-design, I=implementation, $U=u s e r$ instructions, $V \& V=v e r i f i c a t i o n$ and validation testing, $C=c o d e, O=0$ ther.

"Choices are "development/testing" or "retired".

"CTF verification that all QA requirements for operational use have been met. 
Software name LADTAP XL

SIS Rovision

Number 0

Date $10-30-94$

Designation of Responsiblittles

CTF Ali A. Simpkins

Customer A. L. Boni

Software Management Documentation (optlonal)

Document and rovision

Description

NA - Pre-Existing Snftware

Configuration Identiflcation

Conflguration revision /version identifier Version 1.2 Functional classification

CQF verification of functional classification (signature) ${ }^{1}$

QA Procedure Plan

Configuration Items:

Name and revision or version

Sottware QA Plan, WSRC-RP-94.1159

Verification Report. WSRC-RP-91-143

Description ${ }^{2}$

Defines Requirements

Describes all existing modules

Configuration Status

Conflguration Status

Operational

Description and status of open change request or NCAs If any none

For "active-operational" status:

Software Quallty Assurance completion"

CTF signature'

Acceptance for operational /usp

Custemer otgnatura 1

User(s) List

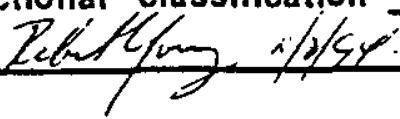

A.A. Simpkins

J.G. Black

W.H.Cartion

Signature on a previous SIS which is still aplicable may be referenced.

2 The following abbreviations may be used: $R=$ requirements, D-design, I=implementation, U=user instructions, V\&V=verification and validation testing, $C=c o d e, O=0$ ther.

'Choices are "development/testing" or "retired".

- CTF verification that all QA requirements for. operational use have been met. 
Software name LADTAP II

sis Revision

Number 0

Date 10-30-94

Designation of Responsibilities

CTF Ali A. Simpkins

Customer A.L. Boni

Software Management Documentation (optional)

Document and revision

Description

NA-Pre-Existing Sotiware

Conflguration Idenification

Conflguration revision /version Identifler Version 1.2

Functional, classification

CQF verification of functional classification (signature) ${ }^{1}$

QA Procedure Plan

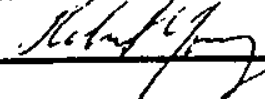

NS

Conflguration Items:

Name and revlsion or version

Description

Sottware OA Plan. WSRC-RP-94-1159

LADTAP |l Description, CCC-362

Defines Requirements

Describes all existing modules

Conflguration Status

Conflguration Status ${ }^{3}$ Operational

Description and status of open change request or NCRs if any none

For "active-operationai" status:

Software Quallty Assurgnce completion ${ }^{4}$

CTF signature?

Acceptance for operational/uje Customer sigriature'

User(8) List

A. A. Simpkins

J.G. Black

W. H. Cartion

Signature on a previous SIS which is still aplicable may be referenced.

2 The following abbreviations may be used: $R=$ requirements, D-design, I=implementation, U=user

instructions, V\&V=verification and validation testing, $C=c o d e, O=0$ ther.

"Choices are "development/testing" or "retired".

- CTF verification that all QA requirements for. operational use have been met. 
THIS PAGE INTENTIONALLY LEFT BLANK 
Attachment 2. Software Inventory Checklist 


\section{REGISTRATION}

Software Task Title: AXAIR89Q

Software Identlfler: AXAIRB9Q

CTF (dov/mtn) organization: WMET

CTF: Ali A. Simpkins

phone no: $5-9643$

CTF (resp org) manager. A. L. Boni

\section{IDENTIFICATION}

Customer contact: A. L. Boni

phone no. $5-2628$

(attach listing for multiple customers.)

Release/version number (operating/purchased): Version 1.2 NA

Acquisition: Onew Oexisting Opurchased

Acquisition source:

NA $X$

Application Status: $O$ In production Ounder development

Classification: Oclassifled O Unclassified

Functional classification:

ONS OCP OPS OGS

Installation/retirement date: Mo 2 yr 82

\section{ACCOUNTING}

System/package name: AXAIR89Q

System acronym: AXAIR89Q

NA

Brlefly describe software function

AXAIR89Q predicts maximum individual and population doses following hypothetical atmospheric releases that occur over a short period of time.

Platform (hardware) IBM 3090

Software package/database/language: Fortran

Operating system: IBM JCL

COMPLETLON,

CTF:
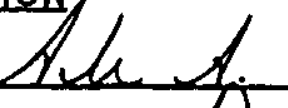

iematines

Date: $11-8-94$

CTF MANAGER: 


\section{REGISTRATION}

Software Task TItle: MAXIGASP

Software Identifler: MAXIGASP

CTF (dev/mtn) organlzatlon: WMET

CTF: Ali A. Simpkins

phone no: 5-9643

CTF (resp org) manager. A. L. Boni

\section{IDENTIFICATION}

Customer contact: A.L. Boni phone no. 5-2628

(attach listing for multiple customers.)

Release/version number (operating/purchased): Original NA

Acquisition: Onew Oexisting Opurchased

Acquisition source:

NA $X$

Application Status: $O$ in production $O$ under development

Classiffcation: OClassified O Unclassifled

Functional classiflcation: ONS OCP OPS OGS

Installation/retirement date: Mo 11 yr 81

\section{ACCOUNTING}

System/package name: MAXIGASP

System acronym: MAXIGASP NA

Briefly describe software function

MAXIGASP predicts doses to the maximally exposed offsite individual following annual releases of radioactive materials from locations on the Savannah River Site.

Platform (hardware) IBM 3090

Software package/database/language: Fortran

Operating system: IBM JCL

COMPLETION

ctr: shes semptems

CTF MANAGER:

13 \& $40 \mathrm{x}$

Date: $/ 1-8-94$

Date: $11-8-94$ 


\section{SOFTWARE INVENTORY CHECKLIST}

\section{REGISTRATION}

Software Task Title: POPGASP

Software Identifler: POPGASP

CTF (dev/mtn) organlzatlon: WMET

CTF: Ali A. Simpkins

phone no: $5-9643$

CTF (resp org) manager. A. L. Boni

\section{IDENTIFICATION}

Customer contact: A. L. Boni

(attach listing for multiple customers.)

phone no. $5-2628$

Release/version number (operating/purchased): Original NA

Acquisition: Onew Oexisting Opurchased

Acquisition source:

NA $X$

Application status: $O$ in production $O$ under development

Classiflcation: $O$ Classifled $O$ Unclassifled

Functional classification: ONS OCP OPS OGS

Installation/retirement date: Mo 2 yr 82

\section{ACCOUNTING}

System/package name: POPGASP

System acronym: POPGASP

NA

Briefly describe software function

POPGASP predicts doses to the offsite population within 50 miles of SRS following annual releases of radioactive materials.

Platform (hardware) IBM 3090

Software package/database/language: Fortran

Operating system: IBM JCL

COMPLETION

CTF:

CTF MANAGER:

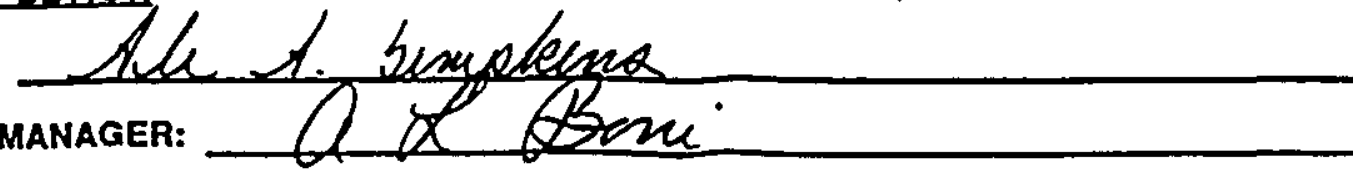

Date: $11-8-94$

Dato: $11-8-94$ 


\section{REGISTRATION}

Software Task Title: VENTSAR

Software Identlfler: VENTSAR

CTF (dev/mtn) organlzatlon: WMET

CTF: Ali A. Simpkins

phone no: $5-9643$

CTF (resp org) manager. A. L. Boni

\section{IDENTIFICATION}

Customer contact: A. L. Boni

phone no. $5-2628$

(attach Ilsting for mult|ple customers.)

Release/verslon number (operating/purchased): Original

NA

Acquisition: Onew Oexisting Opurchased

Acquisition source:

NA $X$

Application Status: $O$ in production $O$ under development

Classiflcation: OClassified O Unclassifled

Functional classiflcation: ONS OCP OPS OGS

Instaltation/retirement date: Mo 11 yr 83

\section{ACCOUNTING}

System/package name: VENTSAR

System acronym: VENTSAR

NA

Briefly describe software function

VENTSAR predicts dowmwind concentrations of radioactive or chemical releases with building wake effects and plume rise options.

Platform (hardware) IBM 3090

Software package/database/language: Fortran

Operating system: IBM JCL

COMPLETION

CTF:

CTF MANAGER:

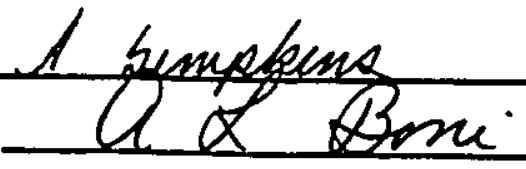

Date: $11-8-94$

Date: 


\section{BEGISTRATION}

Software Task Titte: CAP88

Software Identifler: CAP88

CTF (dov/mtn) organlzation: WMET

CTF: Ali A. Simpkins

phone no: 5-9643

CTF (resp org) manager. A. L. Boni

\section{IDENTIEICATION}

Customer contact: A. L. Boni

phone no. $5-2628$

(attach listing for multiple customers.)

Release/version number (operatıng/purchased): Original

NA

Acquisition: Onew Oexisting Opurchased

Acquisition source:

NA $X$

Application Status: $O$ in production Ounder development

Classiflcation: OClassifled O Unclassifled

Functional classification: ONS OCP OPS OGS

Installation/retirement date: Mo __ yr 89

\section{ACCOUNTING}

System/package name: CAP88

System acronym: CAP88

NA

Brlefly describe software function

CAP88 estimates health impacts from the inhalation, ingestion, air immersion and ground surface irradiation pathways, and tabulates results for maximally exposed individuals and regional populations.

Platform (hardware) IBM 3090

Software package/database/language: Fortran

Operating system: IBM JCL

COMPLETION

CTF:<smiles>CC1CCCC(C)C1</smiles>

CTF MANAGER:

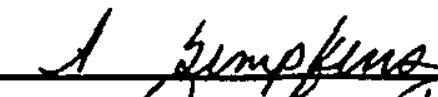

Date:

Date:

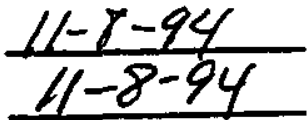


THIS PAGE INTENTIONALLY LEFT BLANK 


\section{APPENDIX G}

RESULTS OF FLOW AND TRANSPORT MODELING 
THIS PAGE INTENTIONALLY LEFT BLANK 


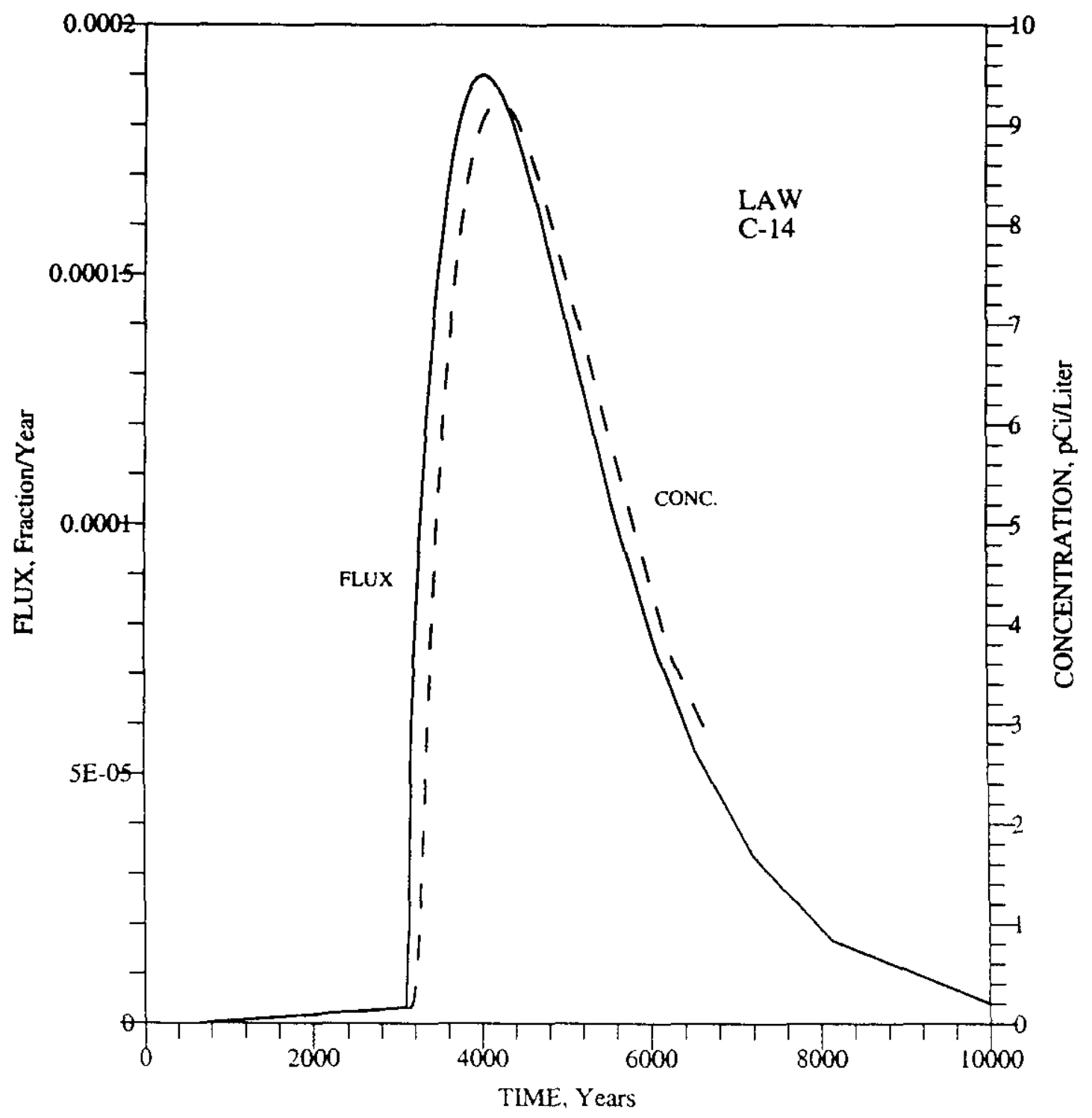

Figure G-1. PORFLOW estimated C-14 fractional release (Ci/year/Ci inventory) to the water table and normalized concentration (pCillter/Ci inventory) at the 100-meter well for the Low Activity Waste Vaults (LAW). 


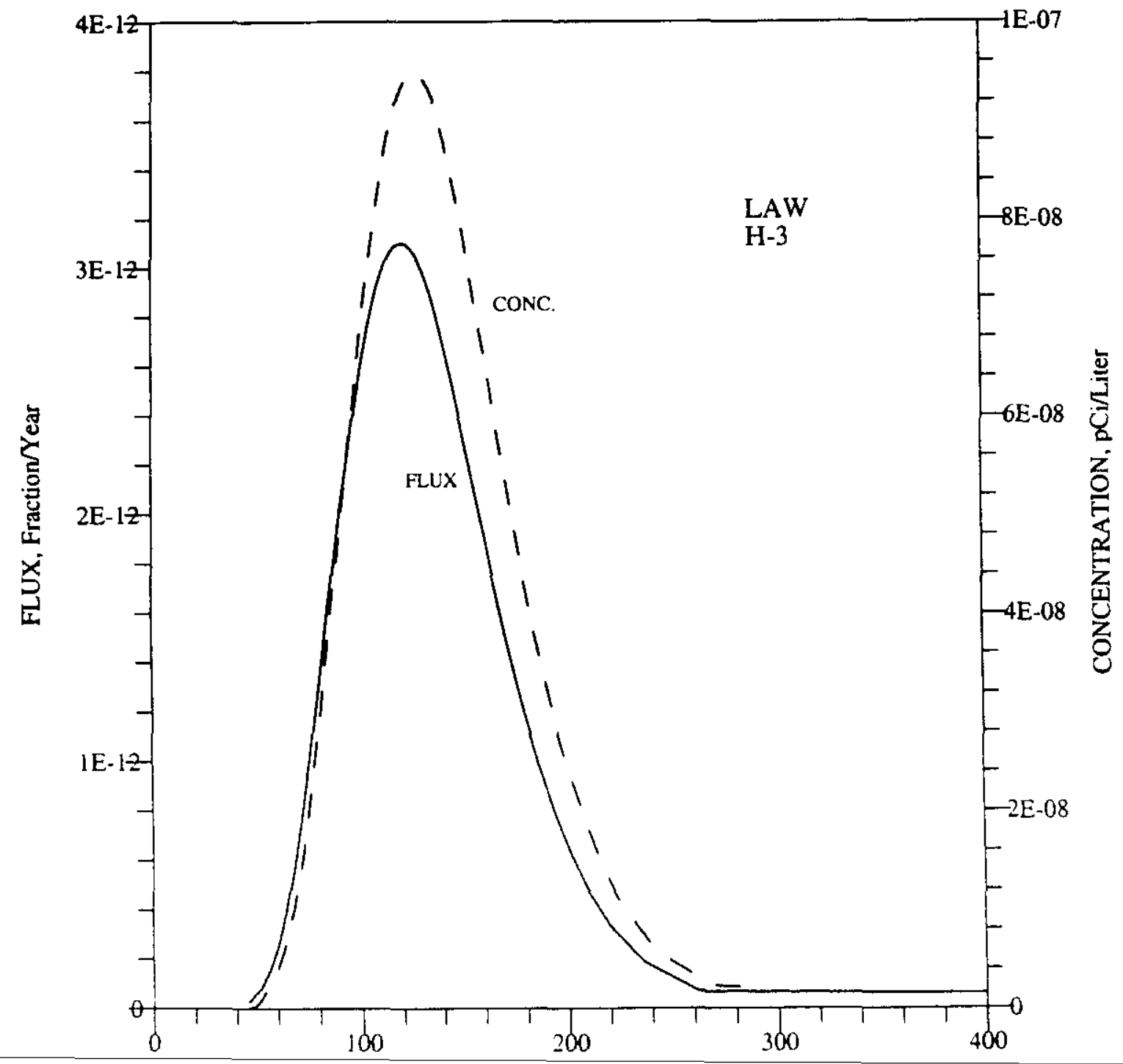

TIME, Years

Figure G-2. PORFLOW estimated $\mathrm{H}-3$ fractional release ( $\mathrm{Ci} /$ year/Ci inventory) to the water table and normalized concentration ( $\mathrm{pCi} / \mathrm{liter} / \mathrm{Ci}$ inventory) at the 100 -meter well for the Low Activity Waste Vaults (LAW). 


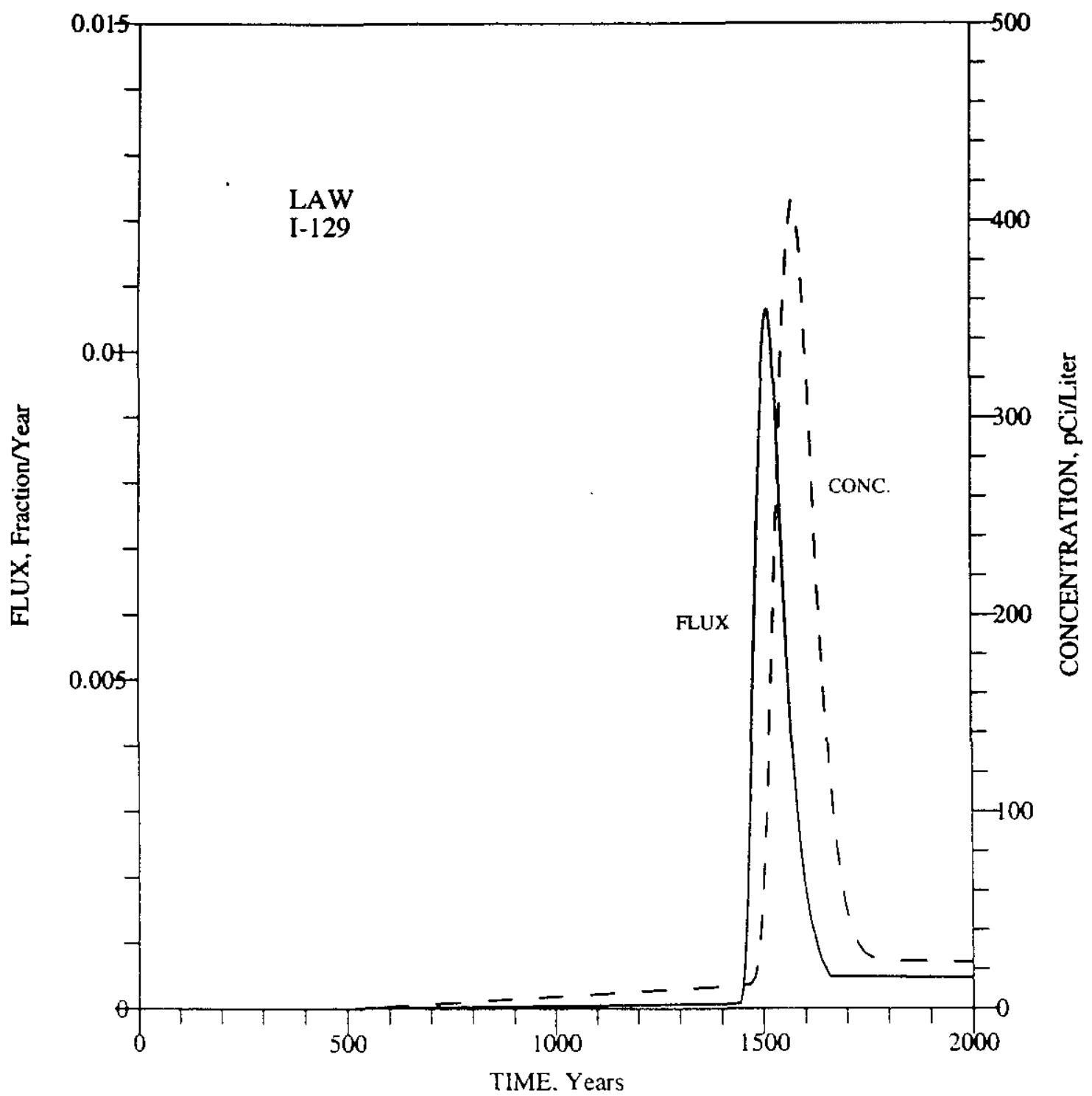

Figure G-3. PORFLOW estimated I-129 fractional release (Ci/year/Ci inventory) to the water table and normalized concentration $(\mathrm{pCi} /$ liter/ $\mathrm{Ci}$ inventory) at the 100 -meter well for the Low Activity Waste Vaults (LAW). 


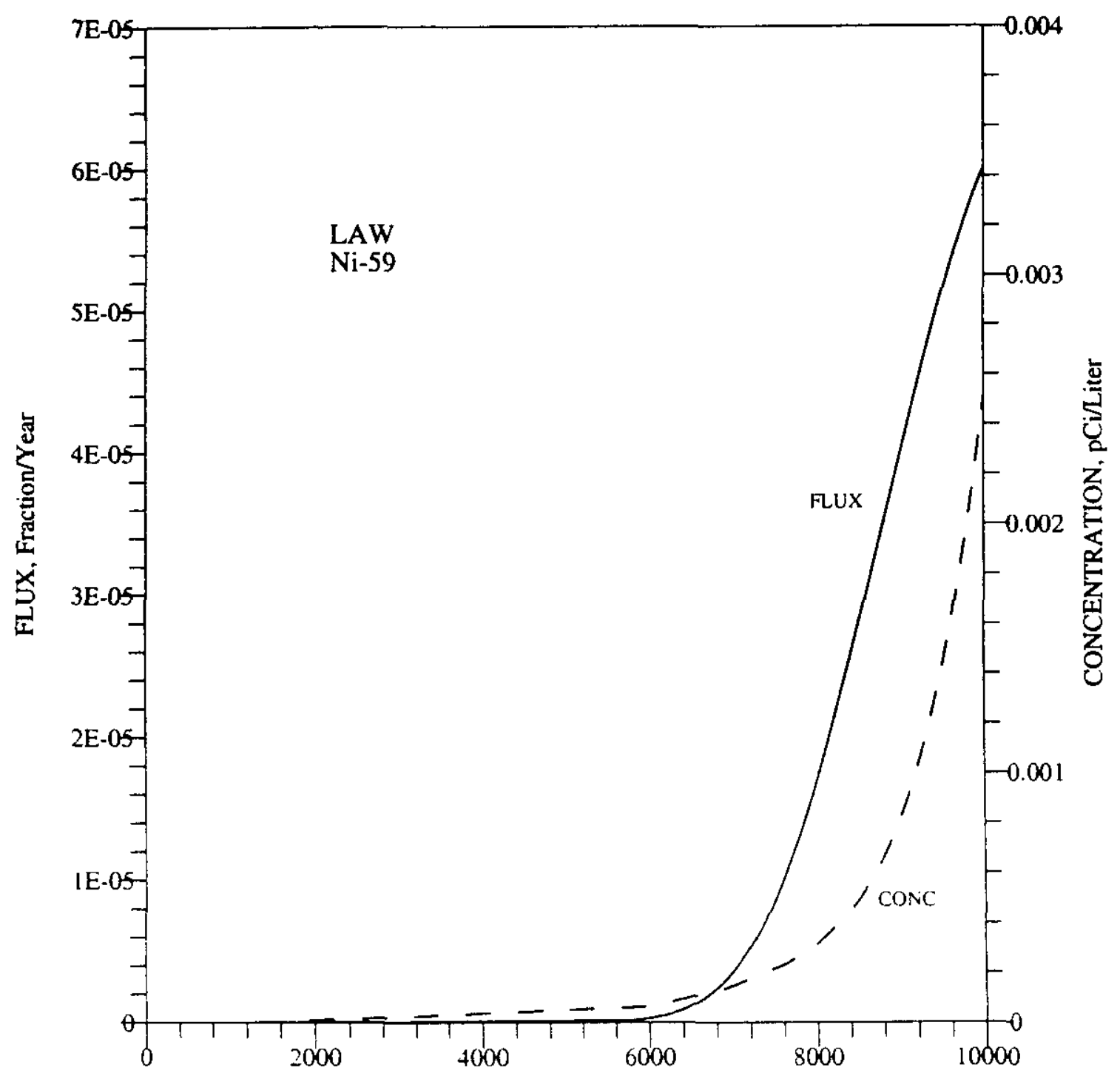

TIME. Years

Figure G-4. PORFLOW estimated Ni-59 fractional release (Ci/year/Ci inventory) to the water table and normalized concentration ( $\mathrm{pCi} /$ iter/ $\mathrm{Ci}$ inventory) at the 100-meter well for the Low Activity Waste Vaults (LAW). 


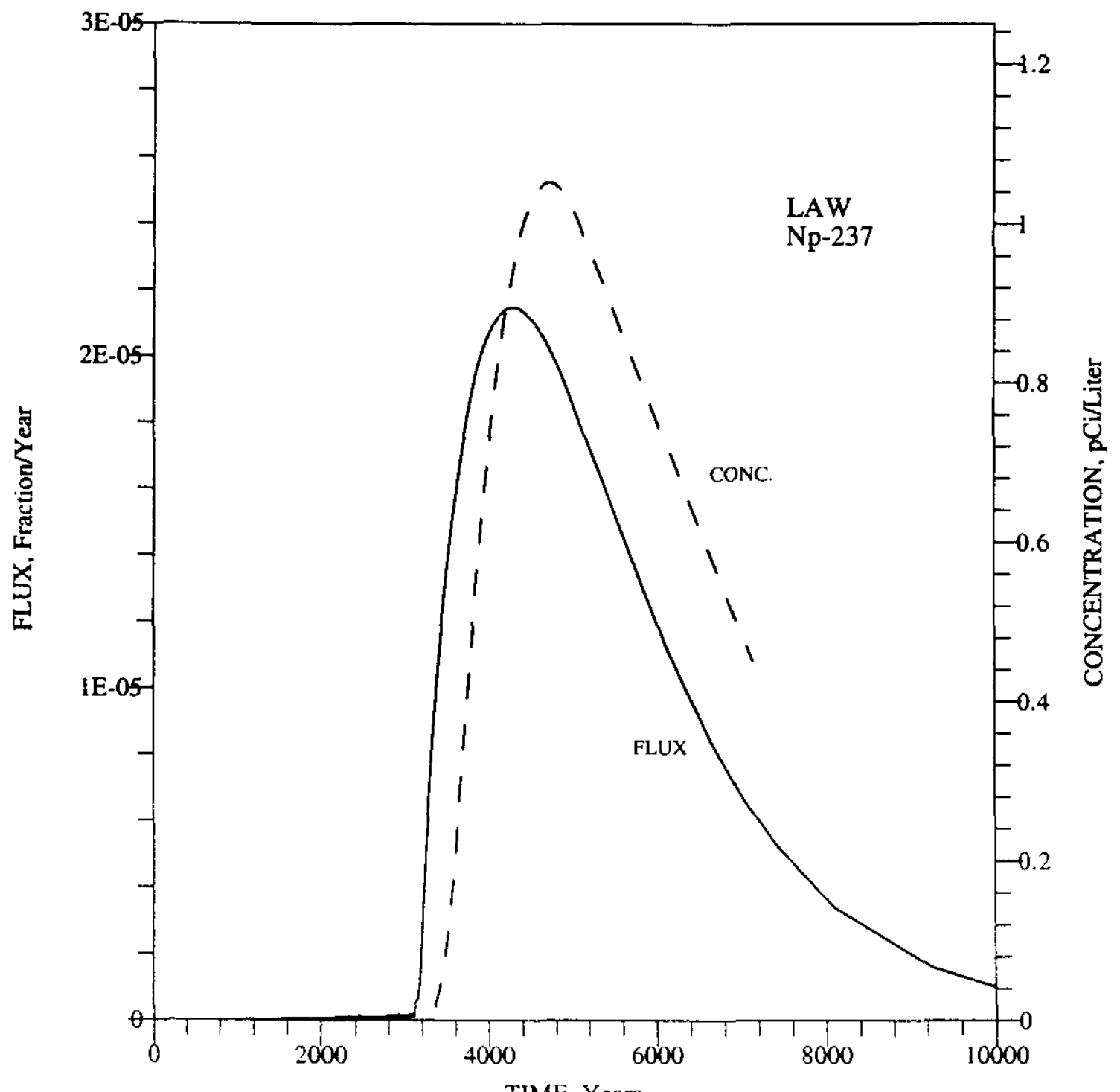

TIME, Years

Figure G-5. PORFLOW estimated Np-237 fractional release ( $\mathrm{Ci}$ /year/Ci inventory) to the water table and normalized concentration ( $\mathrm{pCi} /$ liter/ $\mathrm{Ci}$ inventory) at the 100 -meter well for the Low Activity Waste Vaults (LAW). 


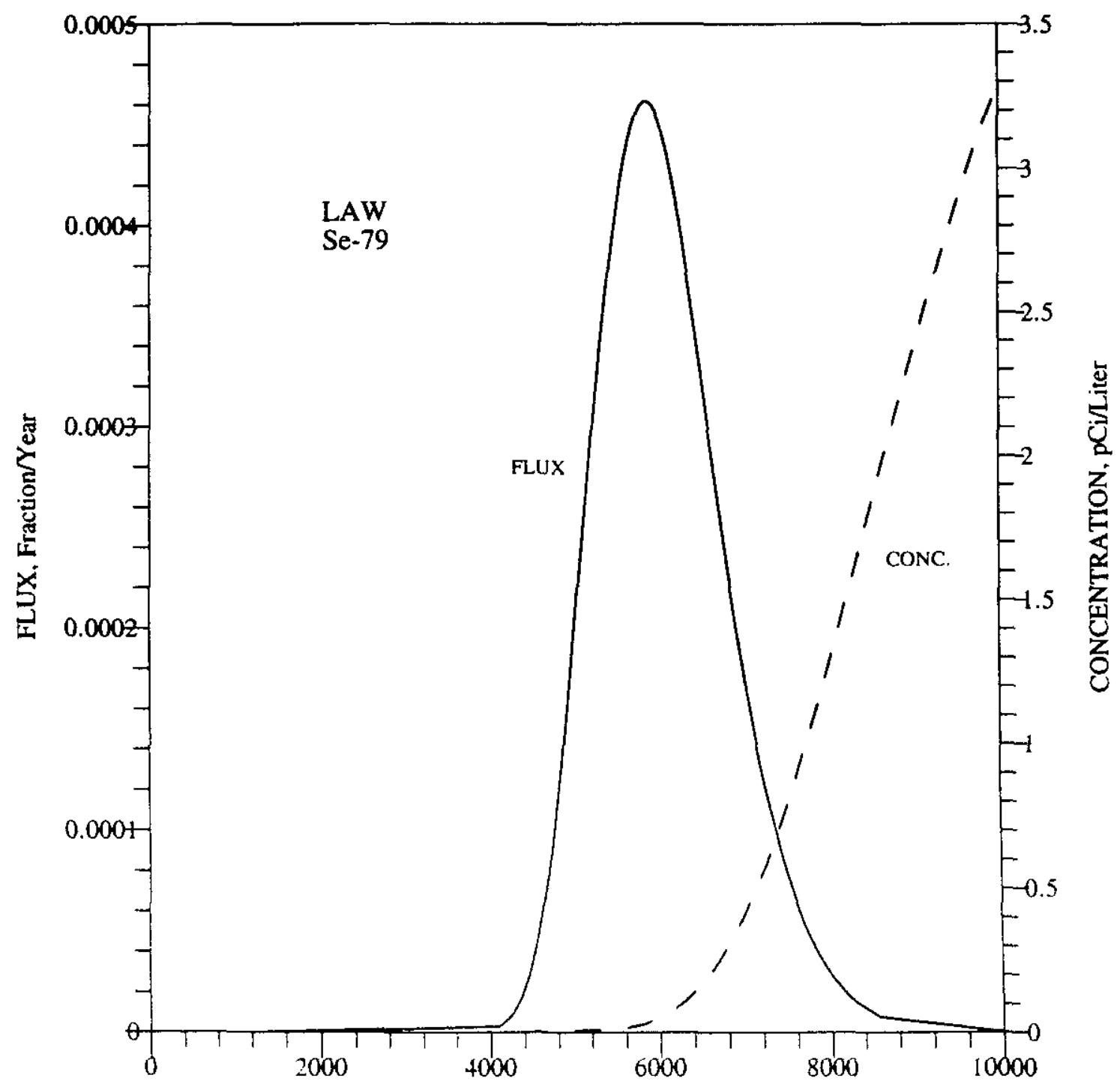

TIME. Years

Figure G-6. PORFLOW estimated Se-79 fractional release (Ci/year/Ci inventory) to the water table and normalized concentration ( $\mathrm{pCi} / \mathrm{liter} / \mathrm{Ci}$ inventory) at the 100 -meter well for the Low Activity Waste Vaults (LAW). 


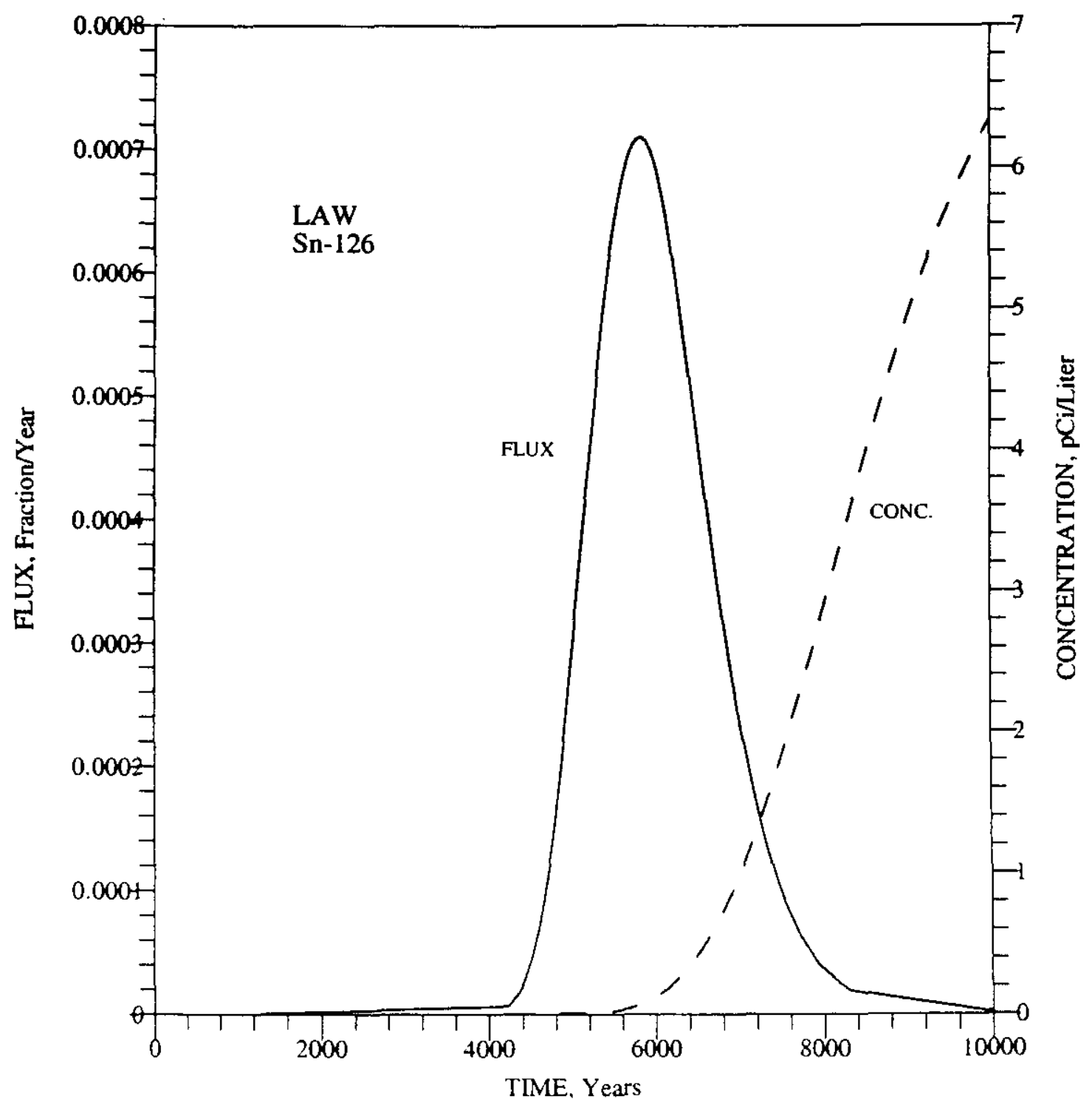

Figure G-7. PORFLOW estimated $\mathrm{Sn}-126$ fractional release $(\mathrm{Ci} /$ year/Ci inventory) to the water table and normalized concentration ( $\mathrm{pCi} / \mathrm{iter} / \mathrm{Ci}$ inventory) at the 100 -meter well for the Low Activity Waste Vaults (LAW). 


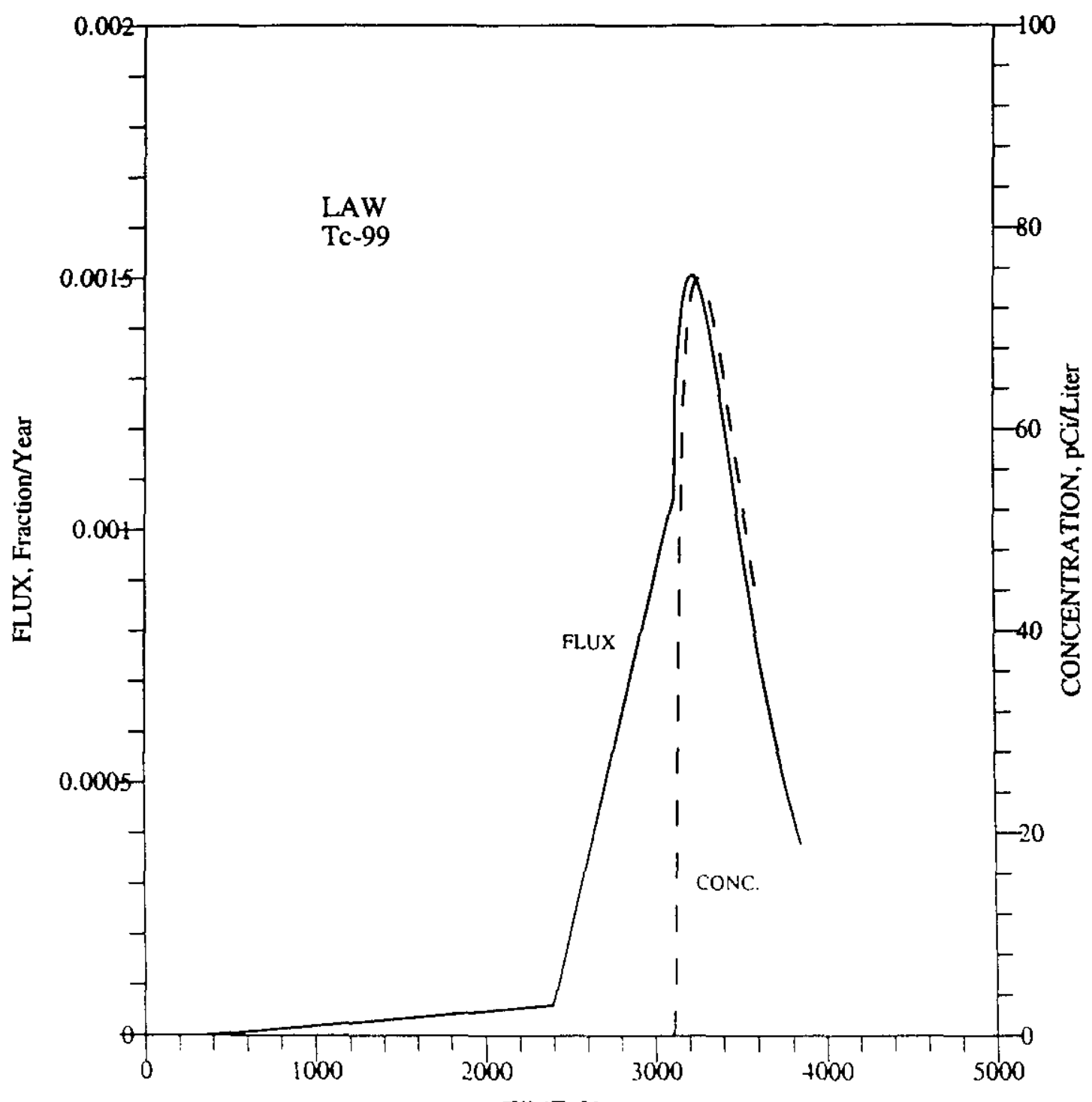

TIME. Years

Figure G-8. PORFLOW estimated Tc-99 fractional release $(\mathrm{Ci} /$ year/Ci inventory) to the water table and normalized concentration ( $\mathrm{pCi} / \mathrm{liter} / \mathrm{Ci}$ inventory) at the 100 -meter well for the Low Activity Waste Vaults (LAW). 


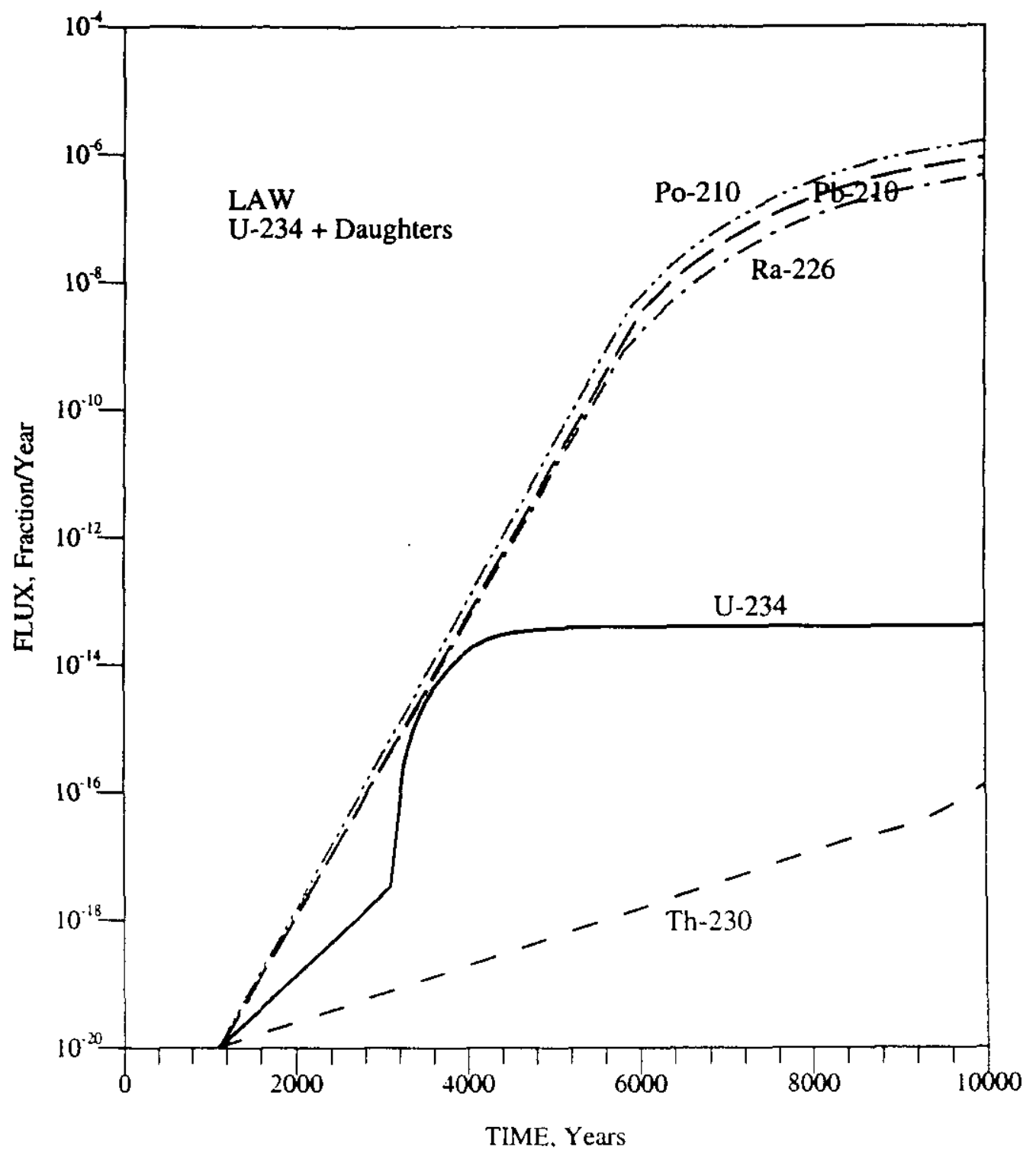

Figure G-9. PORFLOW estimated U-234 + Daughters fractional release (Ci/year/Ci inventory) to the water table for the Low Activity Waste Vaults (LAW). 


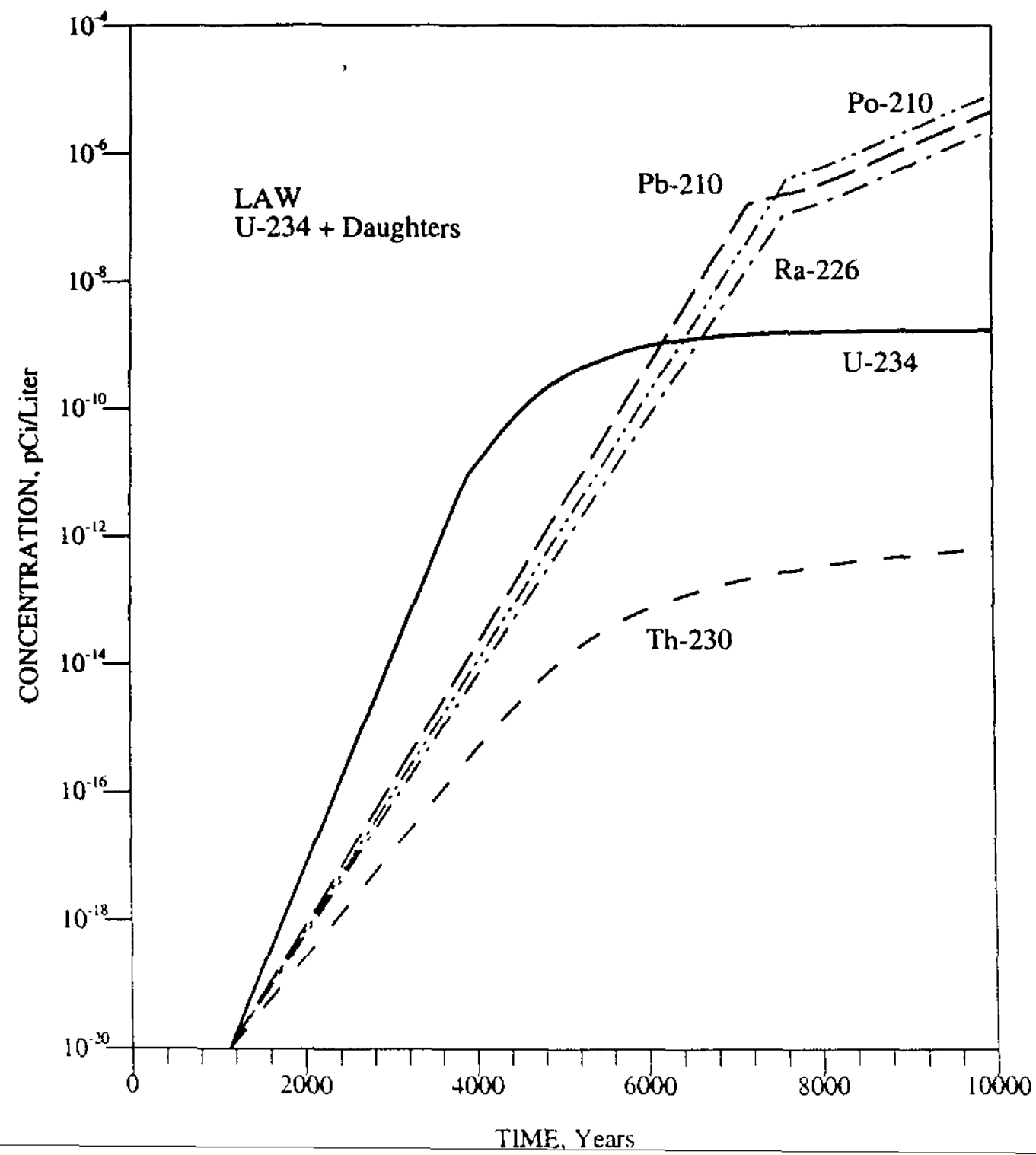

Figure G-10. PORFLOW estimated U-234 + Daughters normalized concentration (pCi/liter/Ci inventory) at the 100-meter well for the Low Activity Waste Vaults (LAW). 


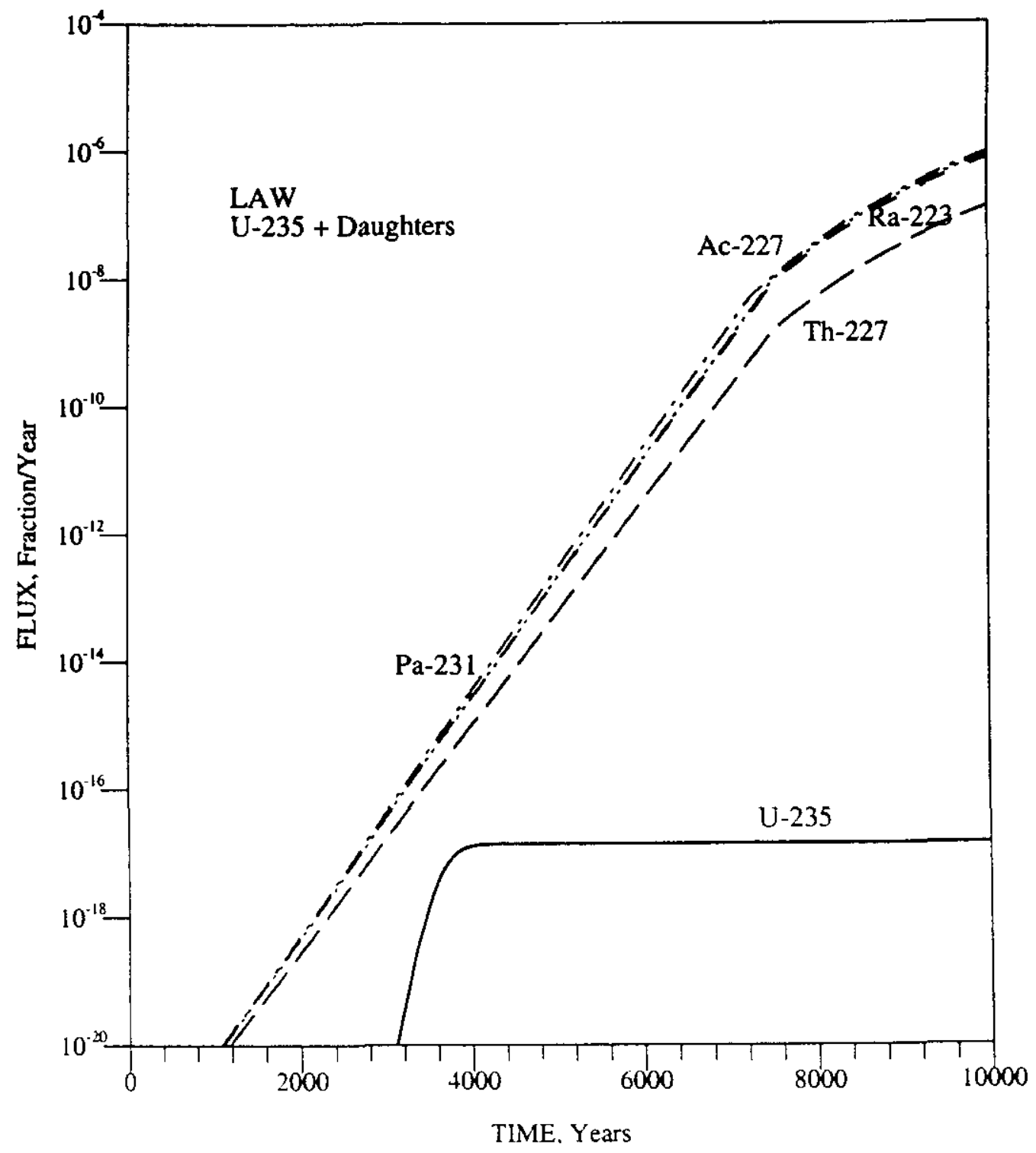

Figure G-11. PORFLOW estimated U-235 + Daughters fractional release (Ci/year/Ci inventory) to the water table for the Low Activity Waste Vaults (LAW). 


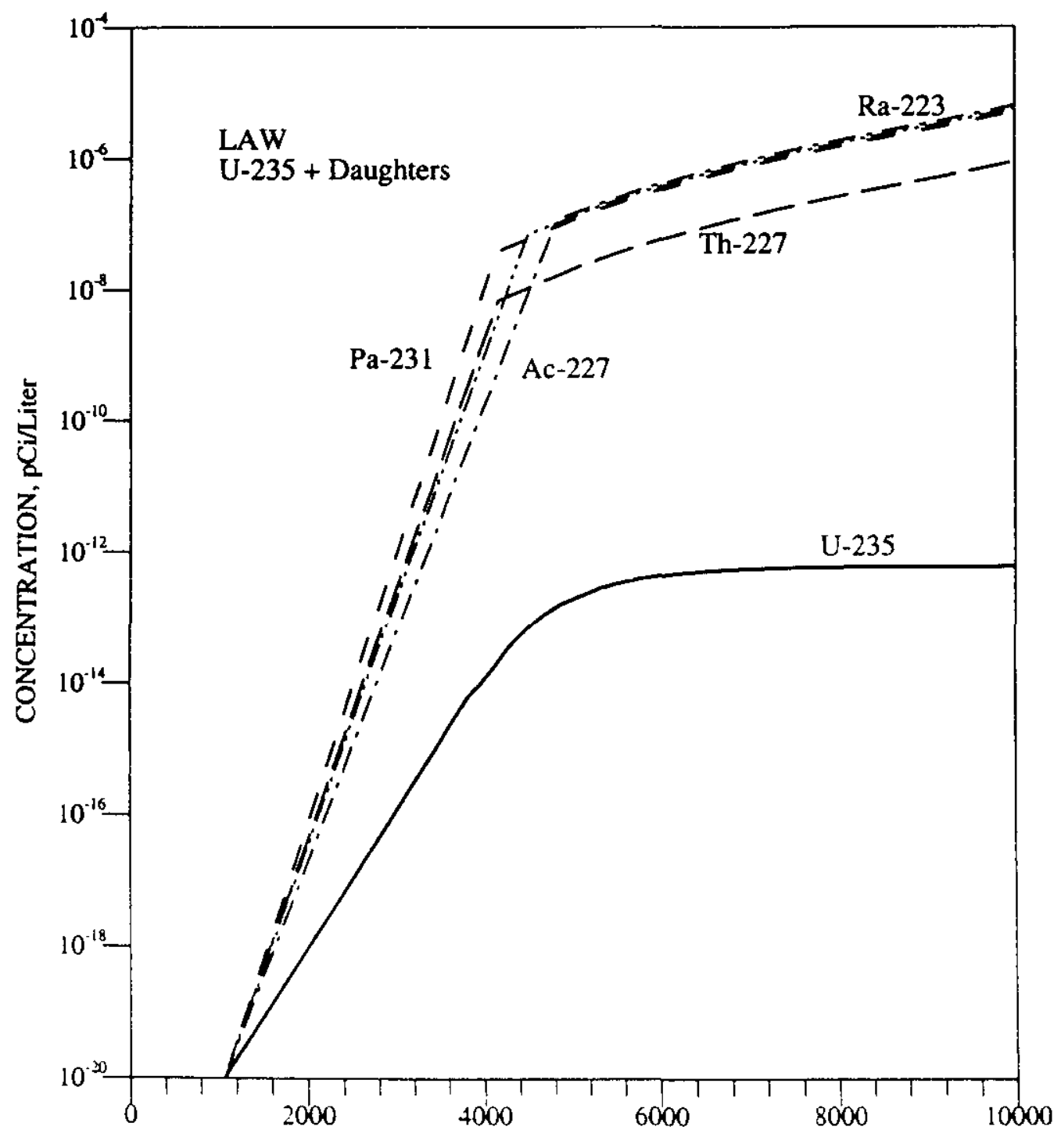

TIME, Years

Figure G-12. PORFLOW estimated U-235 + Daughters normalized concentration (pCi/liter/Ci inventory) at the 100-meter well for the Low Activity Waste Vaults (LAW). 


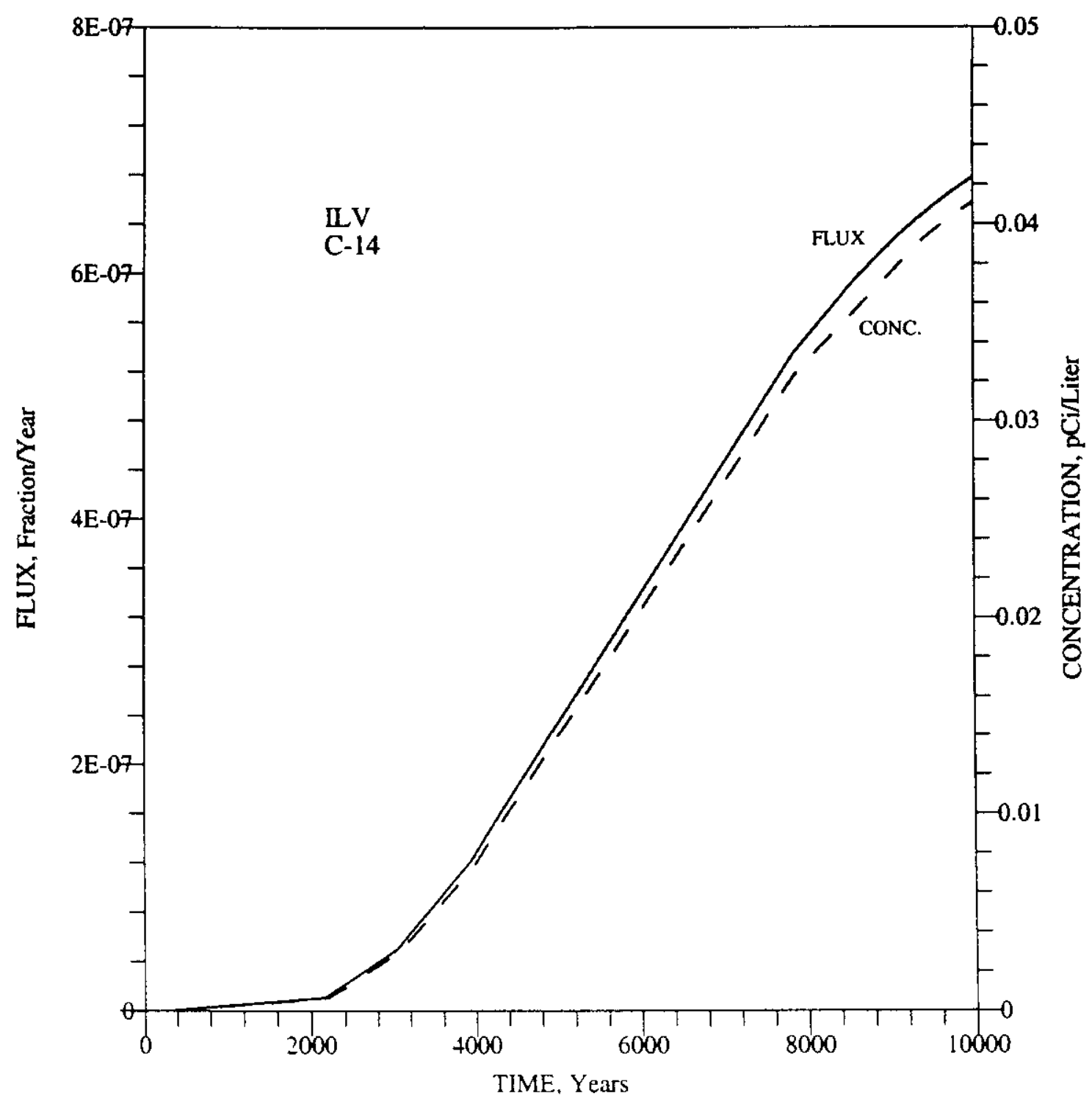

Figure G-13. PORFLOW estimated C-14 fractional release (Ci/year/Ci inventory) to the water table and normalized concentration ( $\mathrm{pCi} / \mathrm{liter} / \mathrm{Ci}$ inventory) at the 100 -meter well for the Intermediate Level Vaults (ILV). 


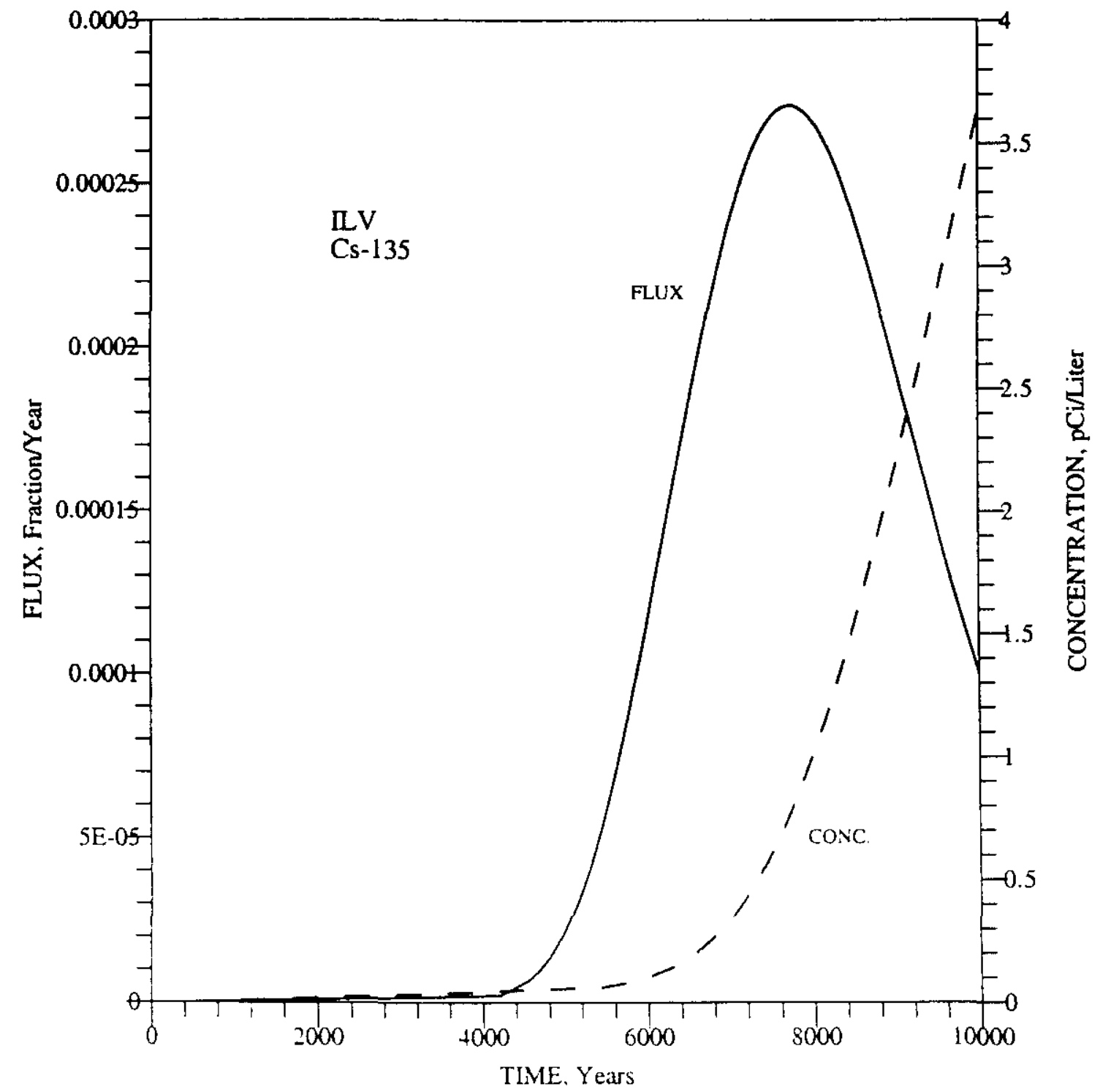

Figure G-14. PORFLOW estimated Cs-135 fractional release (Ci/year/Ci inventory) to the water table and normalized concentration ( $\mathrm{pCi} /$ liter/Ci inventory) at the 100 -meter well for the Intermediate Level Vaults (ILV). 


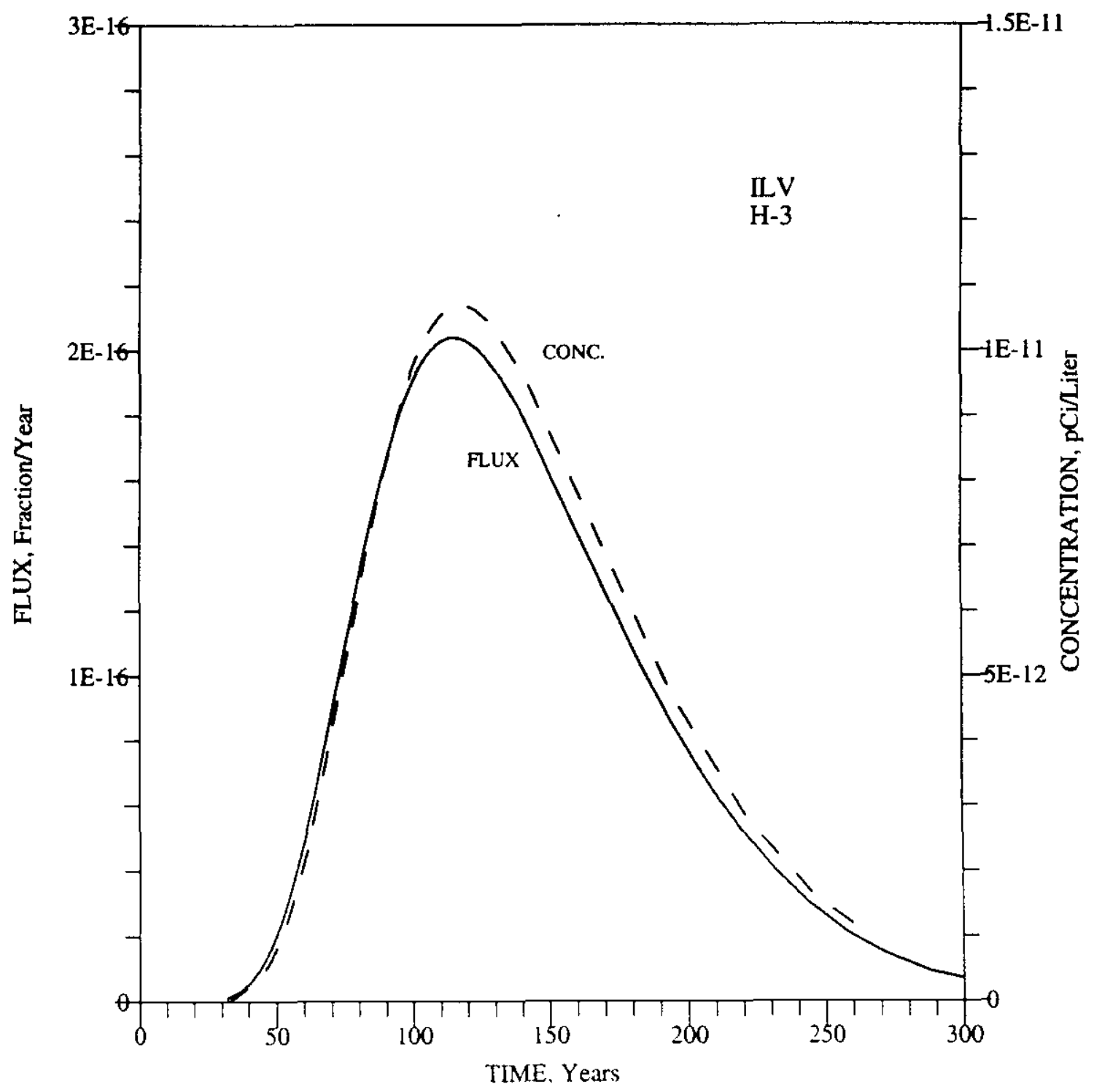

Figure G-15. PORFLOW estimated $\mathrm{H}-3$ fractional release $(\mathrm{Ci} /$ year/Ci inventory) to the water table and normalized concentration ( $\mathrm{pCi} /$ liter/ $\mathrm{Ci}$ inventory) at the 100 -meter well for the Intermediate Level Vaults (ILV). 


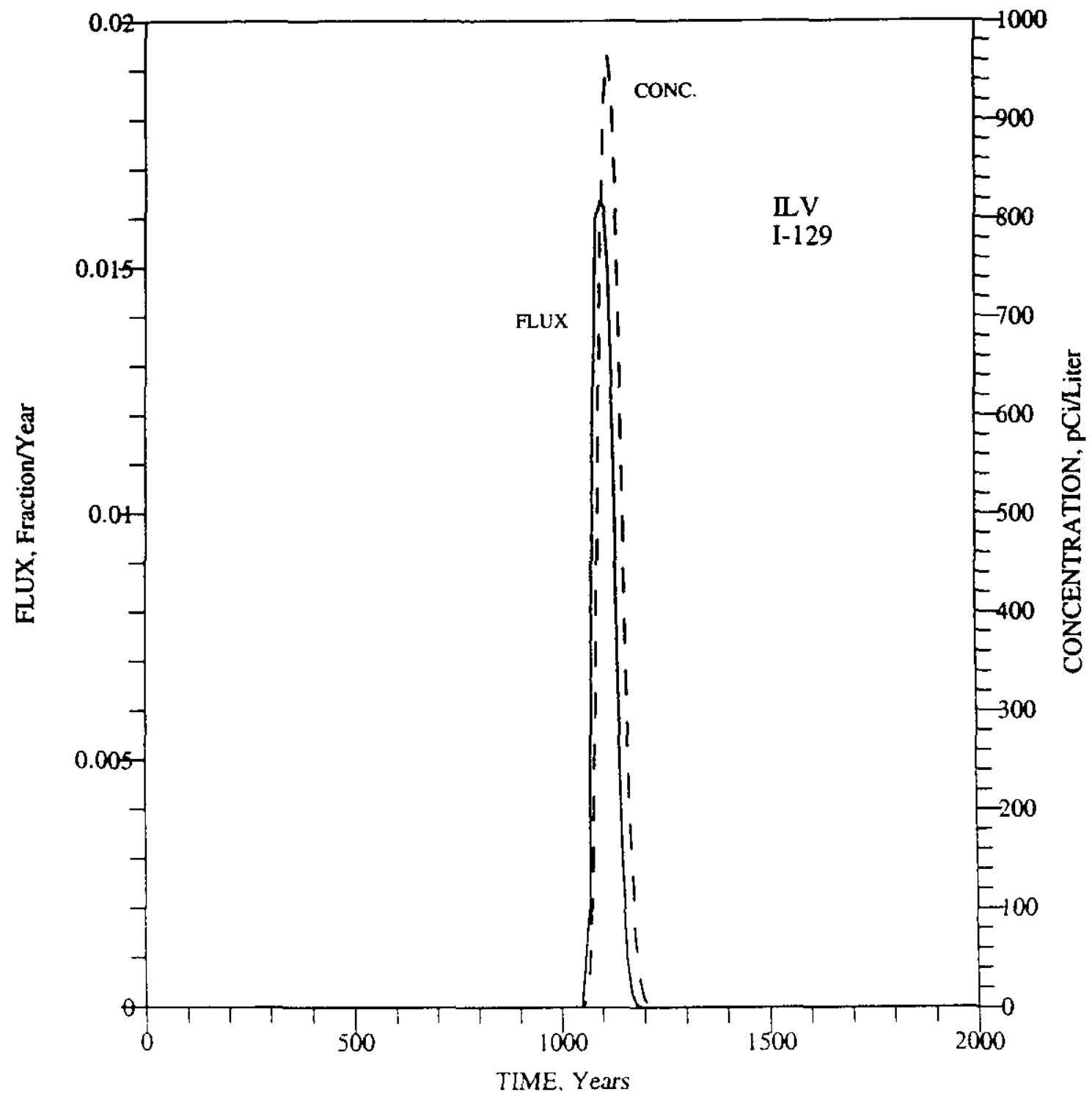

Figure G-16. PORFLOW estimated $\mathrm{I}-129$ fractional release $(\mathrm{Ci} /$ year/Ci inventory) to the water table and normalized concentration ( $\mathrm{pCi} /$ iter/ $\mathrm{Ci}$ inventory) at the 100 -meter well for the Intermediate Level Vaults (ILV). 


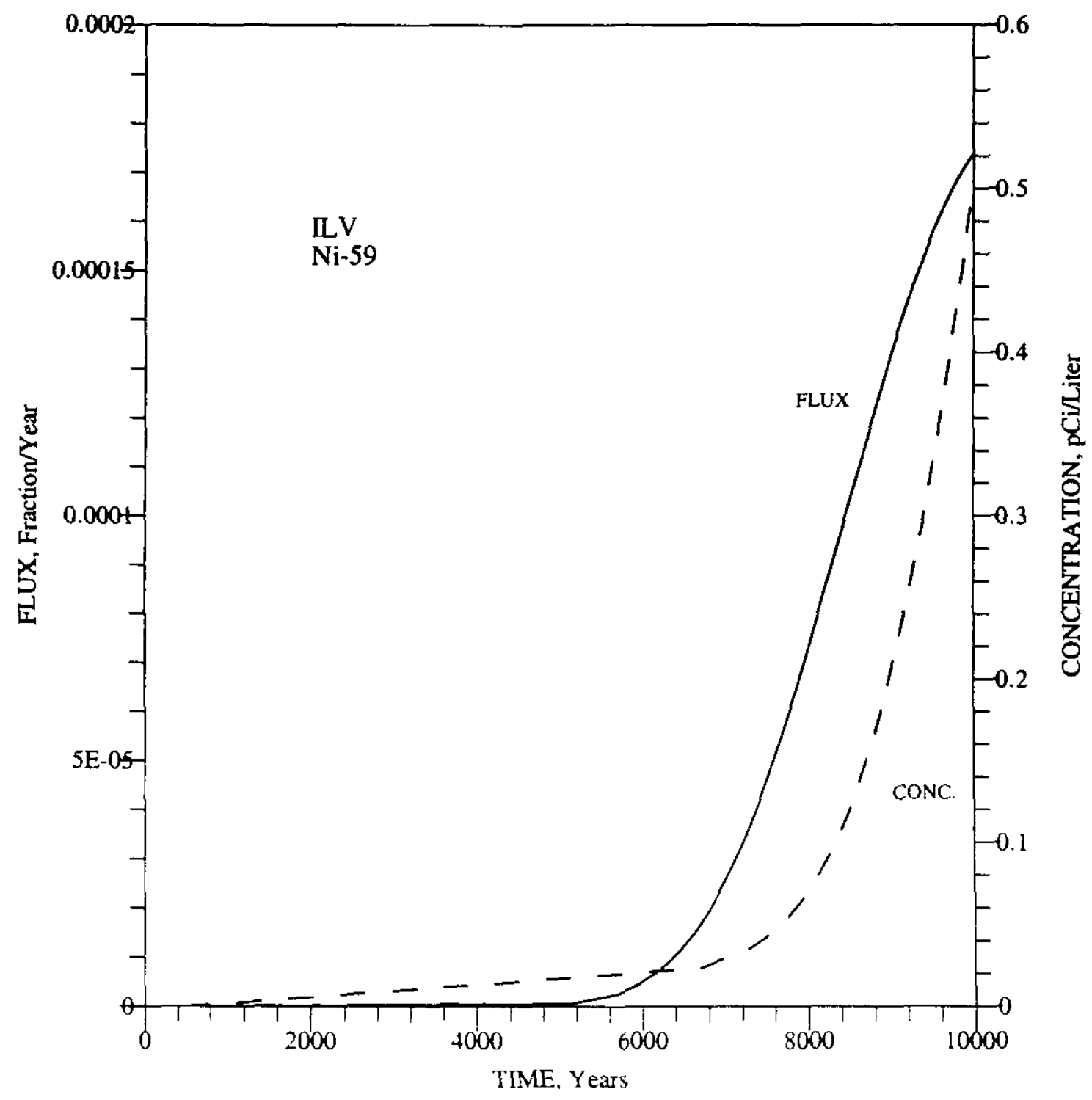

Figure G-17. PORFLOW estimated Ni-59 fractional release ( $\mathrm{Ci} /$ year/Ci inventory) to the water table and normalized concentration ( $\mathrm{pCi} / \mathrm{liter} / \mathrm{Ci}$ inventory) at the 100 -meter well for the Intermediate Level Vaults (ILV). 


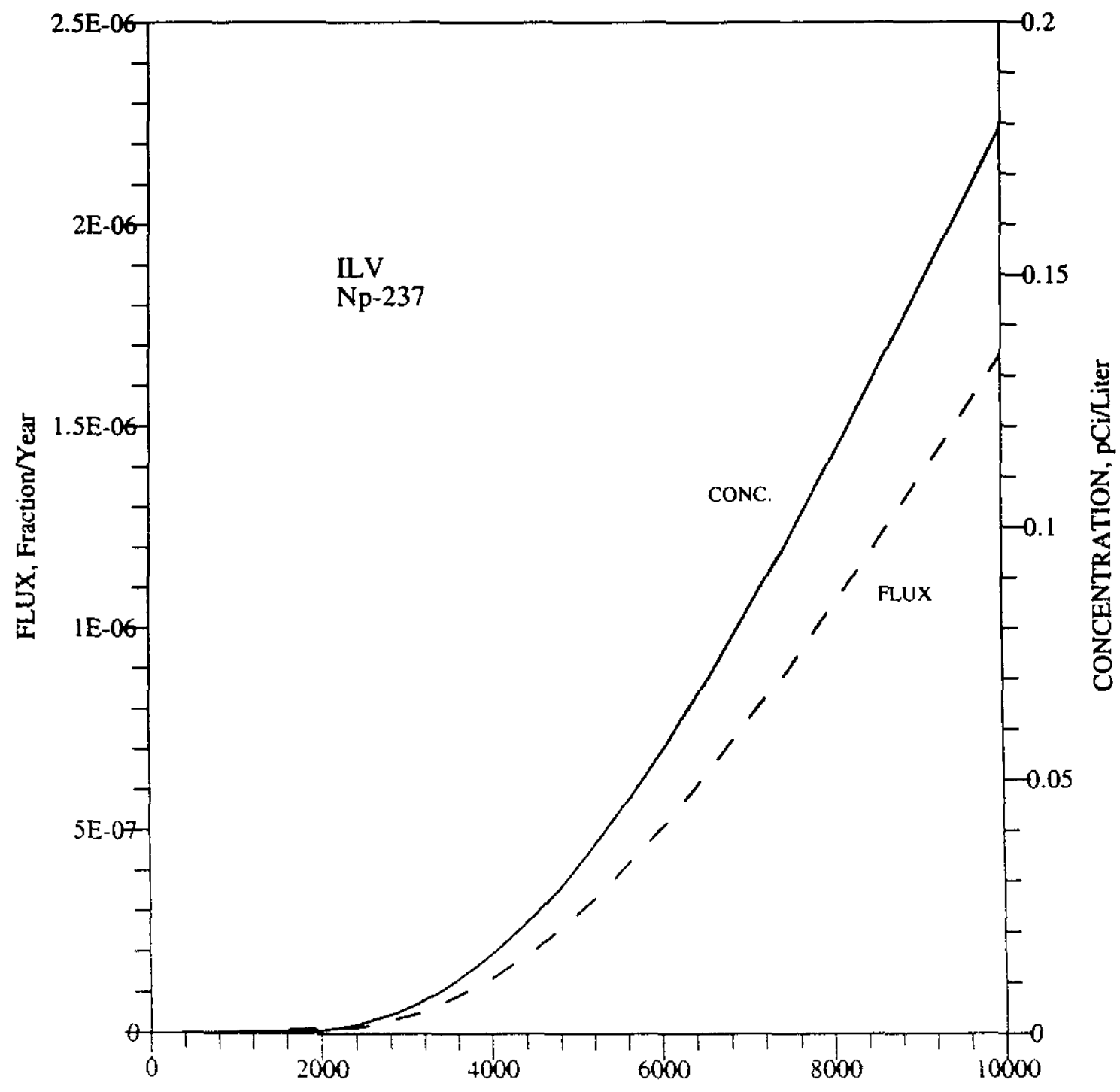

TIME. Years

Figure G-18. PORFLOW estimated Np-237 fractional release $(\mathrm{Ci} /$ year/Ci inventory) to the water table and normalized concentration ( $\mathrm{pCi} /$ iter/ $\mathrm{Ci}$ inventory) at the 100 -meter well for the Intermediate Level Vauits (ILV). 


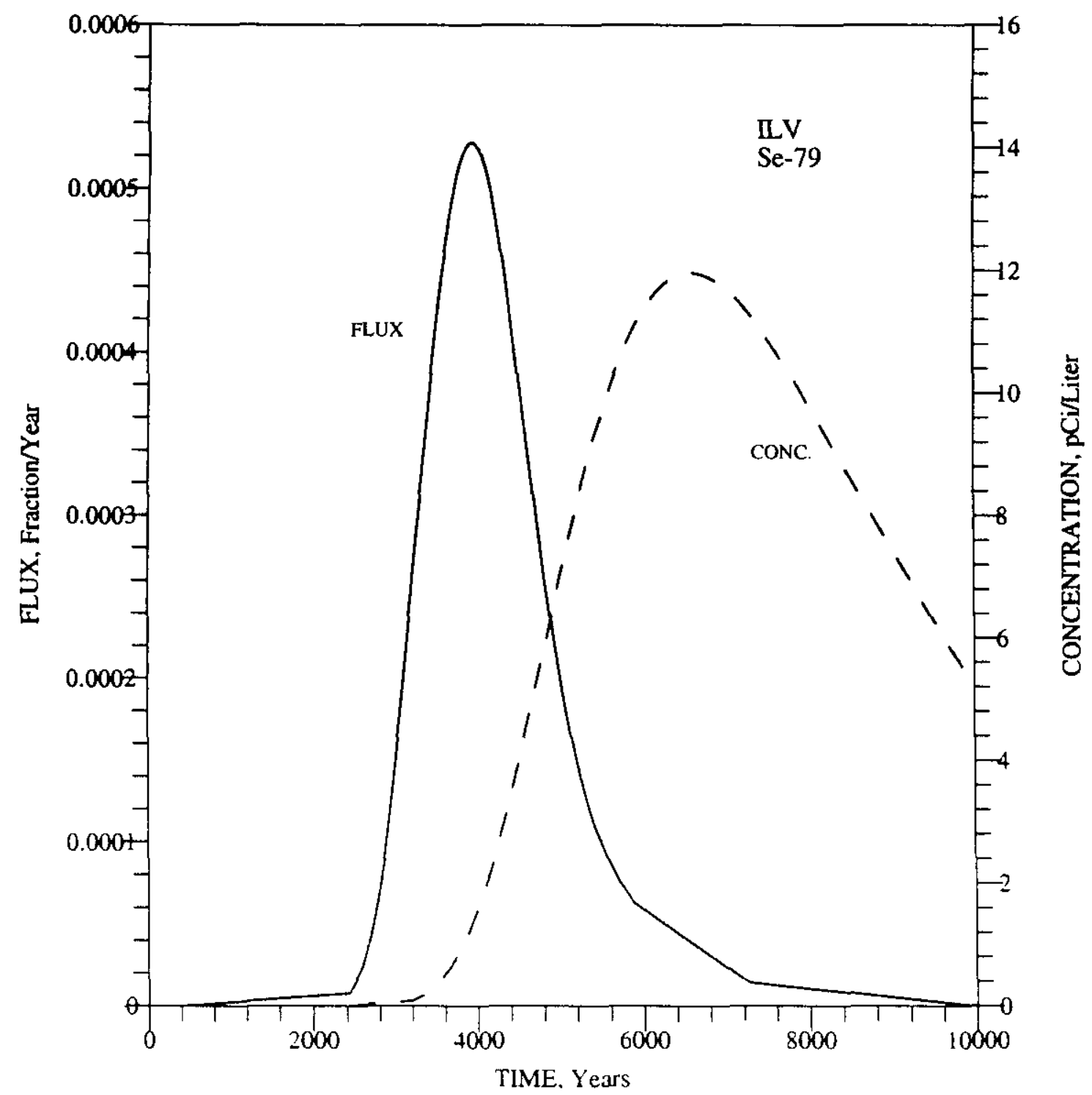

Figure G-19. PORFLOW estimated Se-79 fractional release (Ci/year/Ci inventory) to the water table and normalized concentration ( $\mathrm{pCi}$ /iter/ $\mathrm{Ci}$ inventory) at the 100 -meter well for the Intermediate Level Vaults (ILV). 


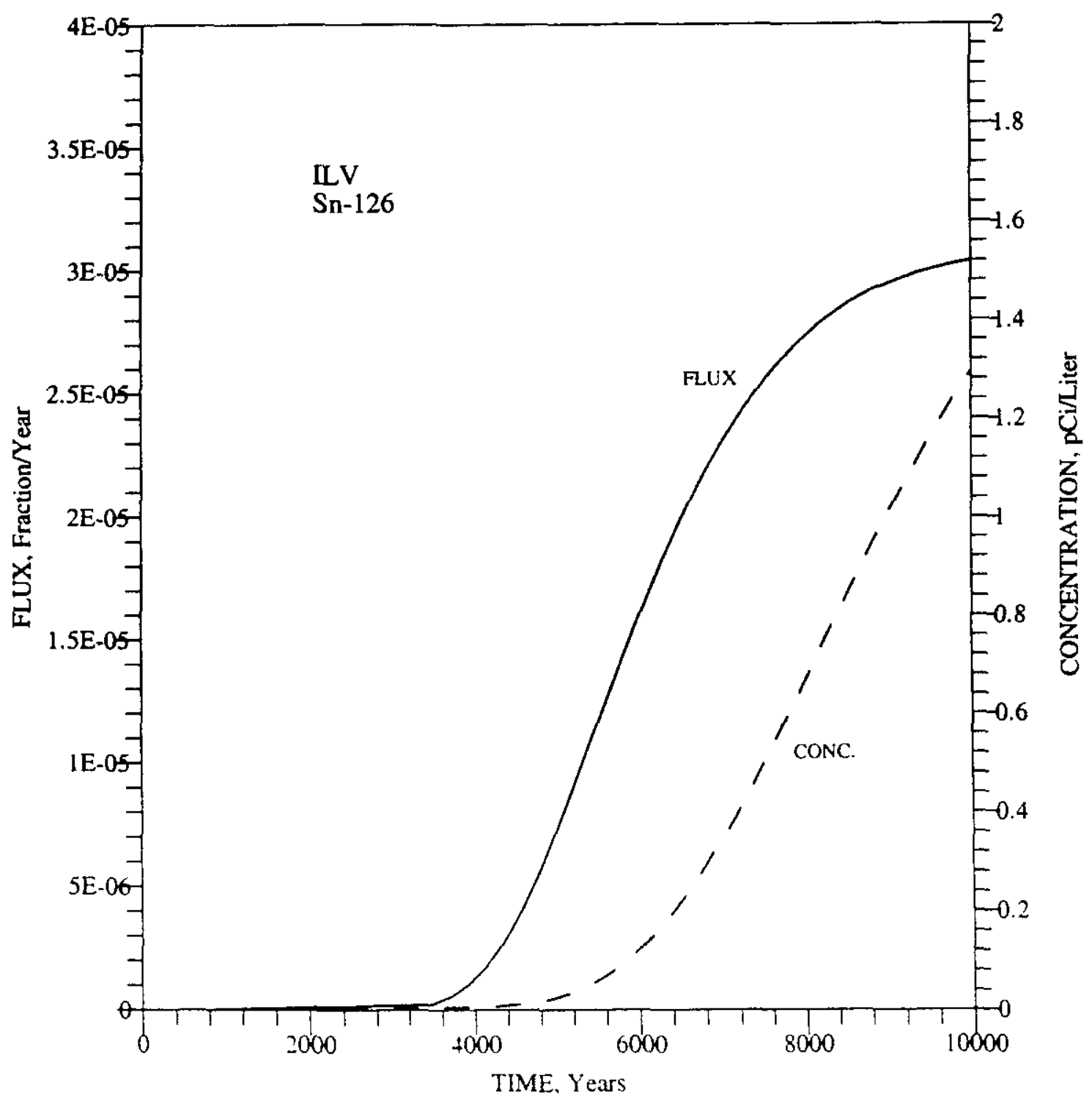

Figure G-20. PORFLOW estimated Sn-126 fractional release ( $\mathrm{Ci} /$ year/Ci inventory) to the water table and normalized concentration $(\mathrm{pCi} / \mathrm{liter} / \mathrm{Ci}$ inventory) at the 100 -meter well for the Intermediate Level Vaults (ILV). 


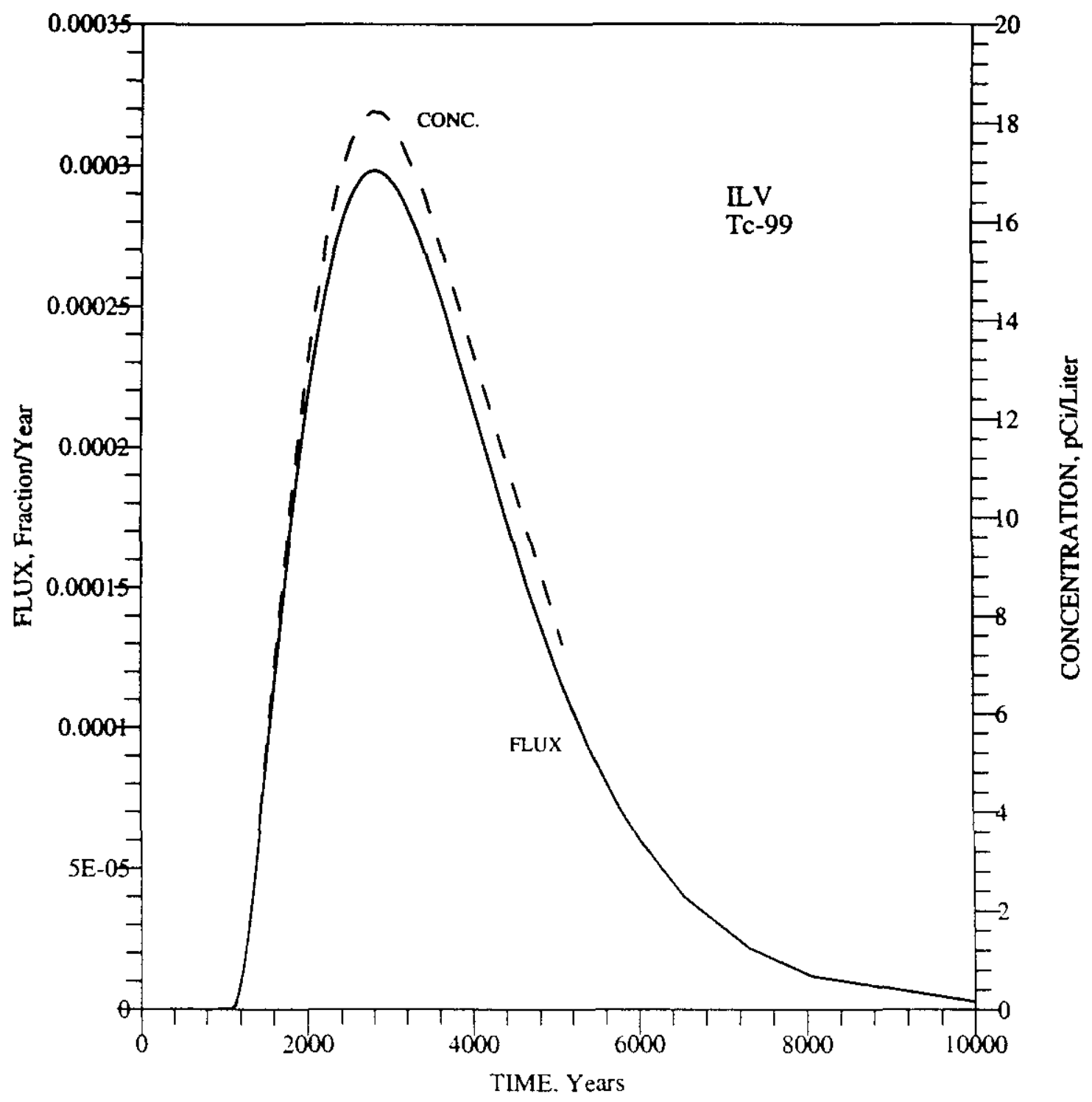

Figure G-21. PORFLOW estimated Tc-99 fractional release (Ci/year/Ci inventory) to the water table and normalized concentration ( $\mathrm{pCi} / \mathrm{liter} / \mathrm{Ci}$ inventory) at the 100 -meter well for the Intermediate Level Vaults (ILV). 


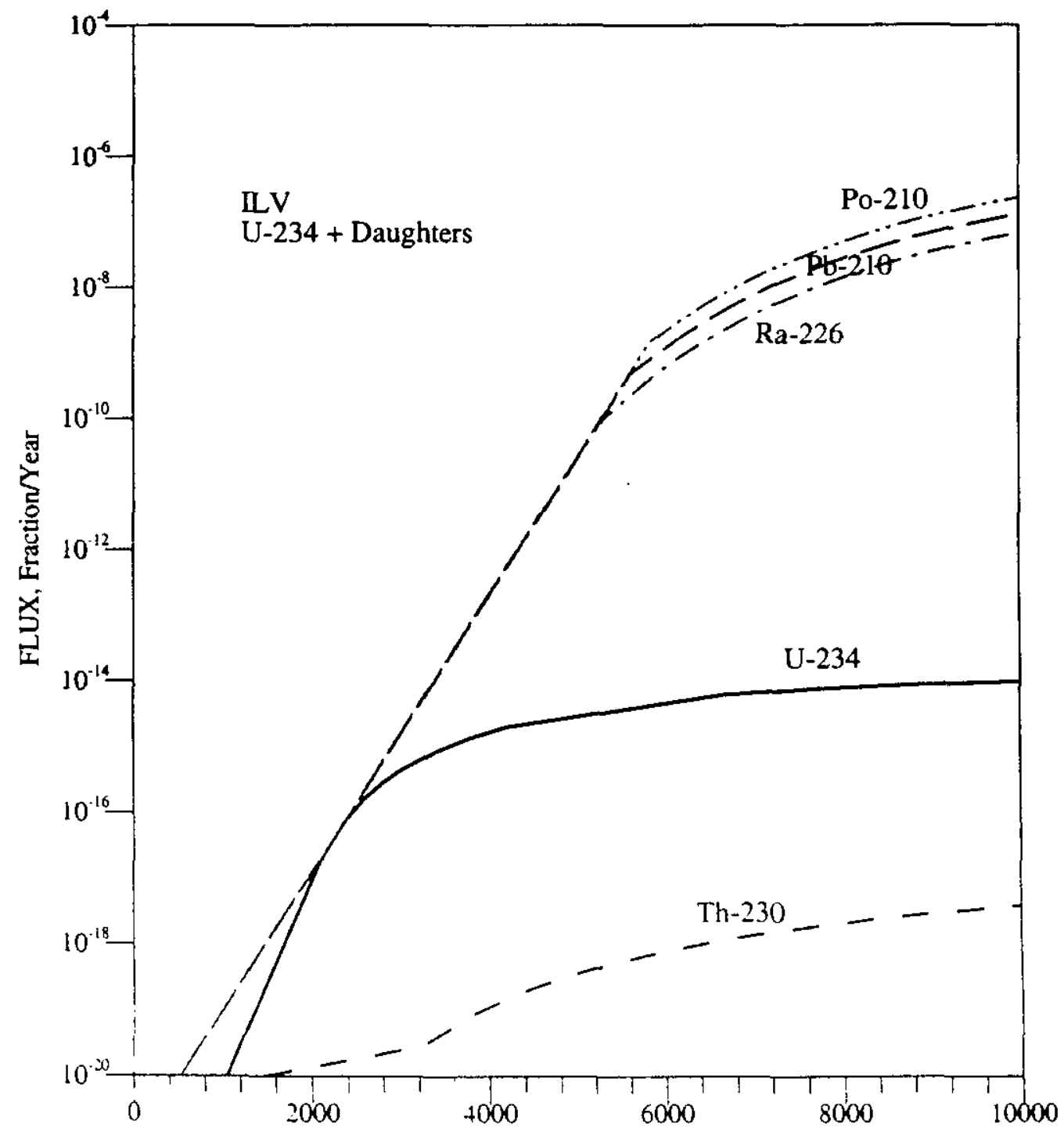

TIME. Years

Figure G-22. PORFLOW estimated U-234 + Daughters fractional release (Ci/year/Ci inventory) to the water table for the Intermediate Level Vaults (ILV). 


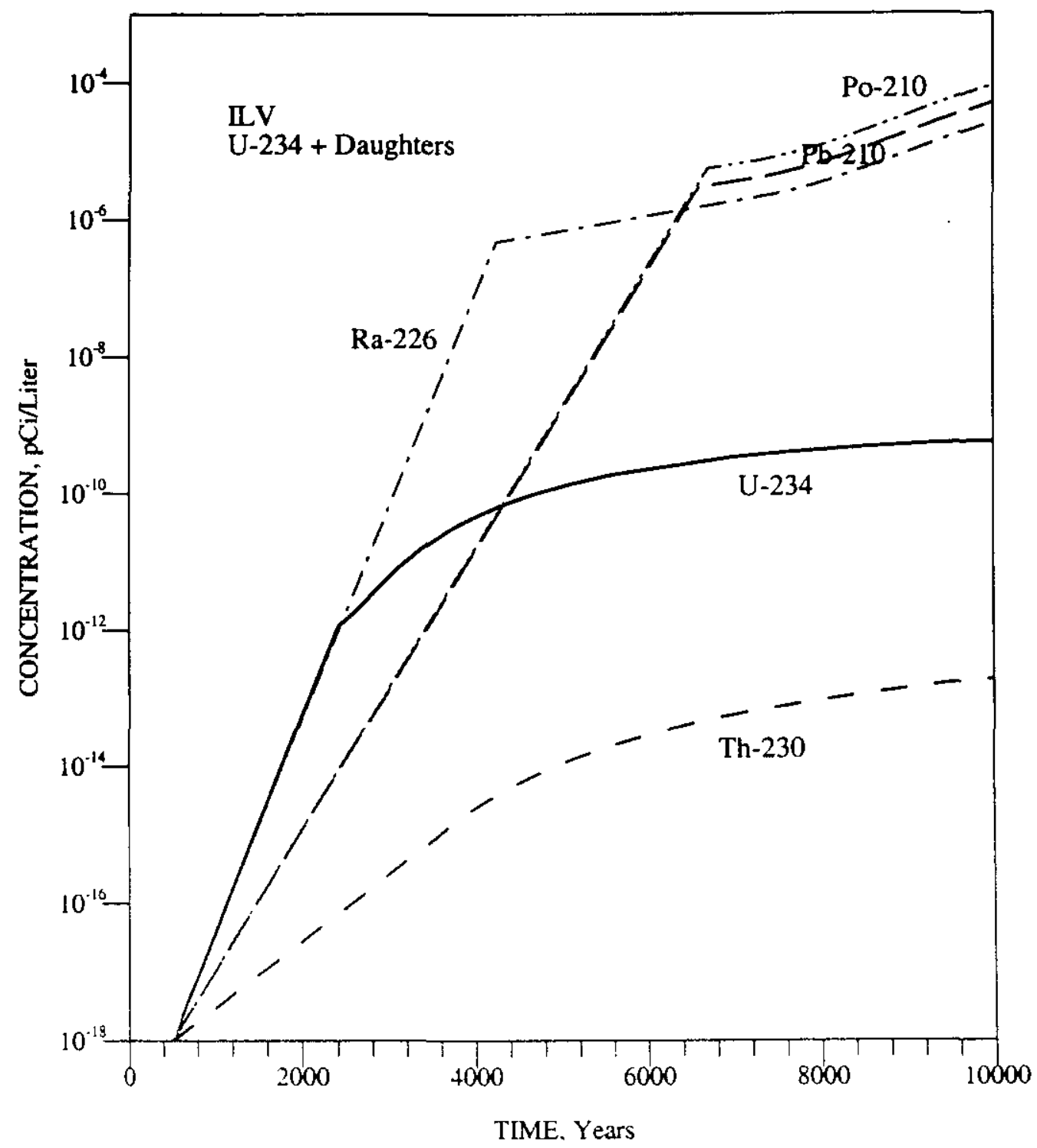

Figure G-23. PORFLOW estimated U-234 normalized concentration (pCi/liter/Ci inventory) at the 100-meter well for the Intermediate Level Vaults (ILV). 


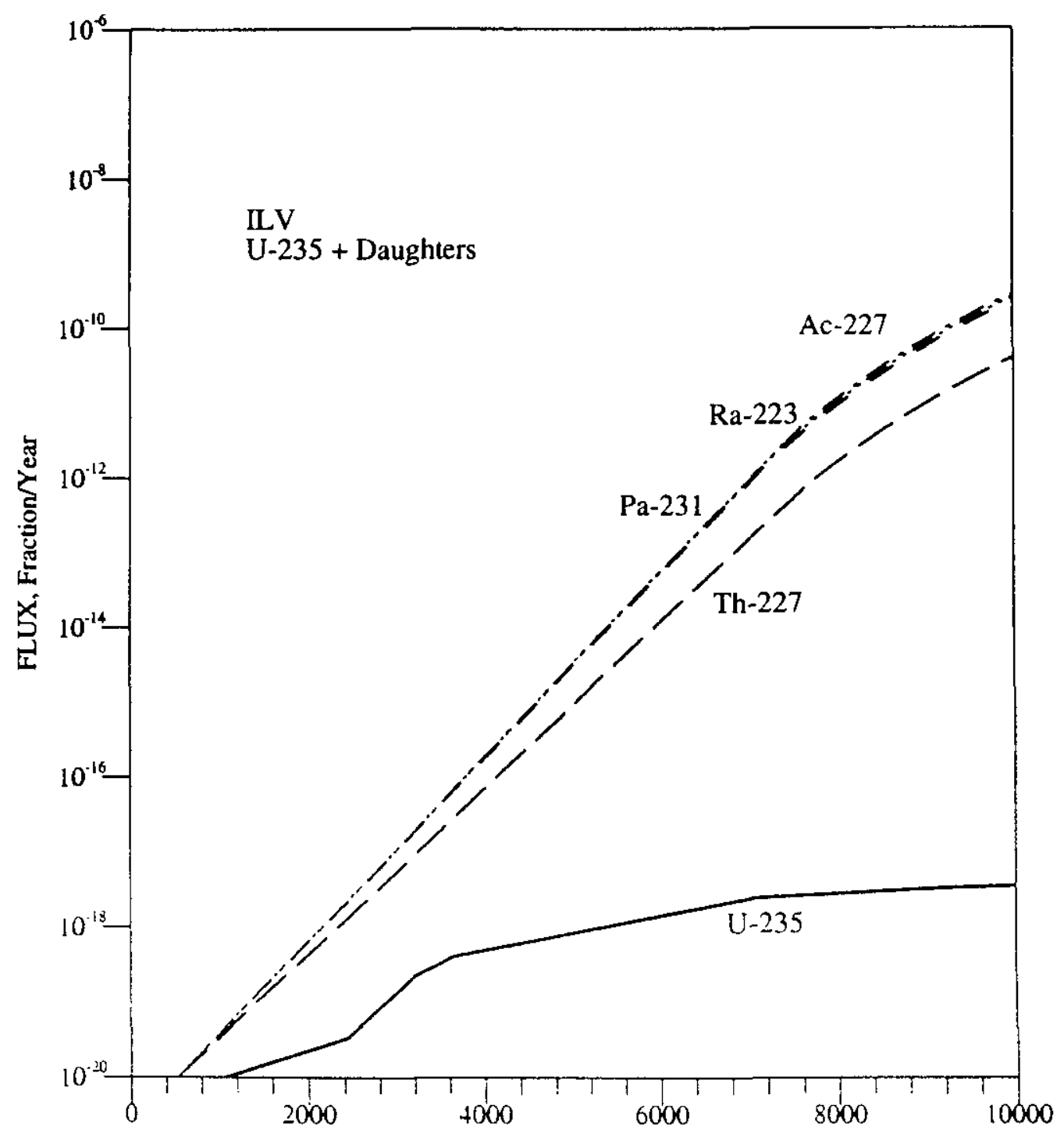

TIME. Years

Figure G-24. PORFLOW estimated U-235 + Daughters fractional release (Ci/year/Ci inventory) to the water table for the Intermediate Level Vaults (ILV). 


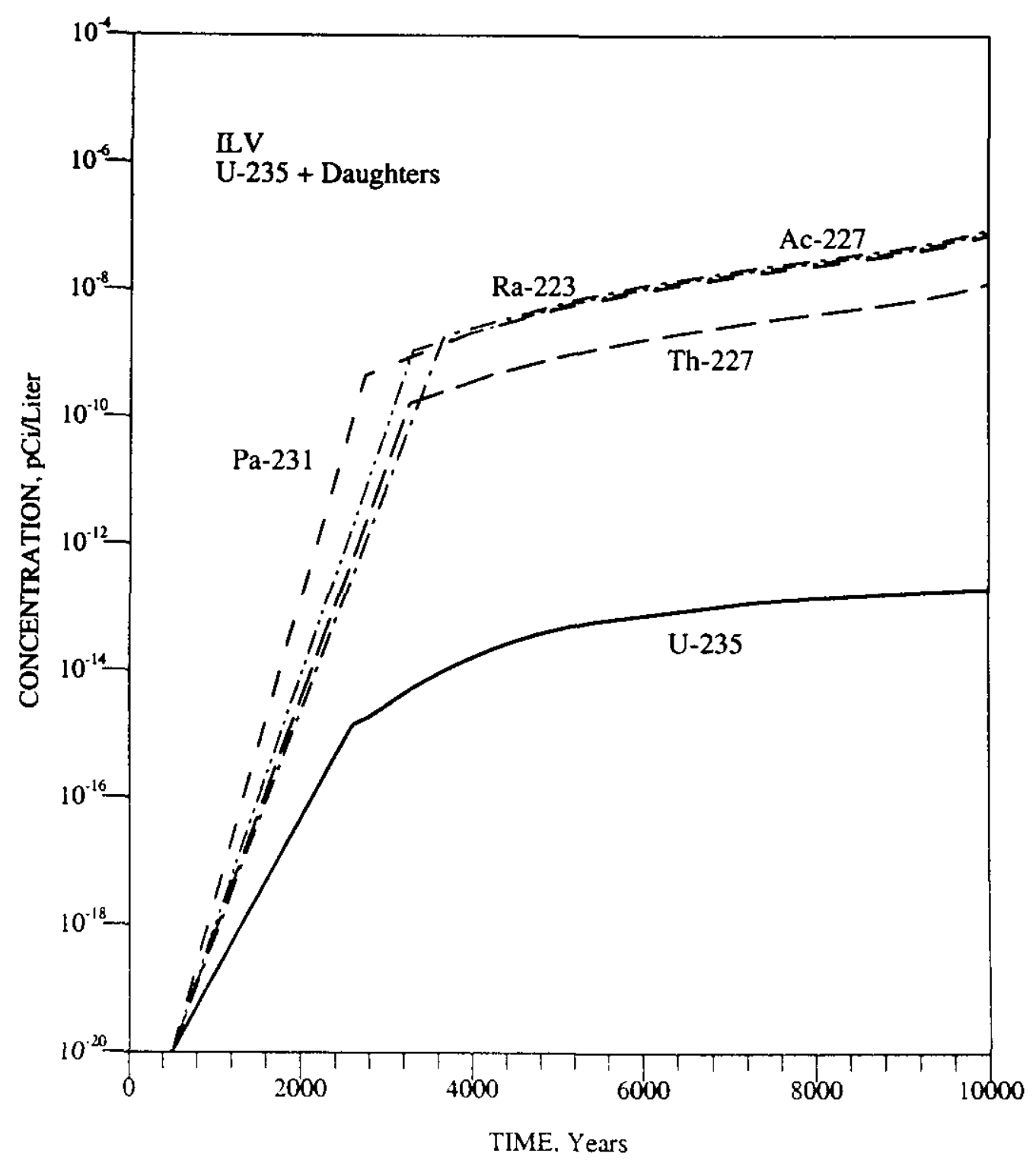

Figure G-25. PORFLOW estimated U-235 normalized concentration (pCi/liter/Ci inventory) at the 100-meter well for the Intermediate Level Vaults (ILV). 


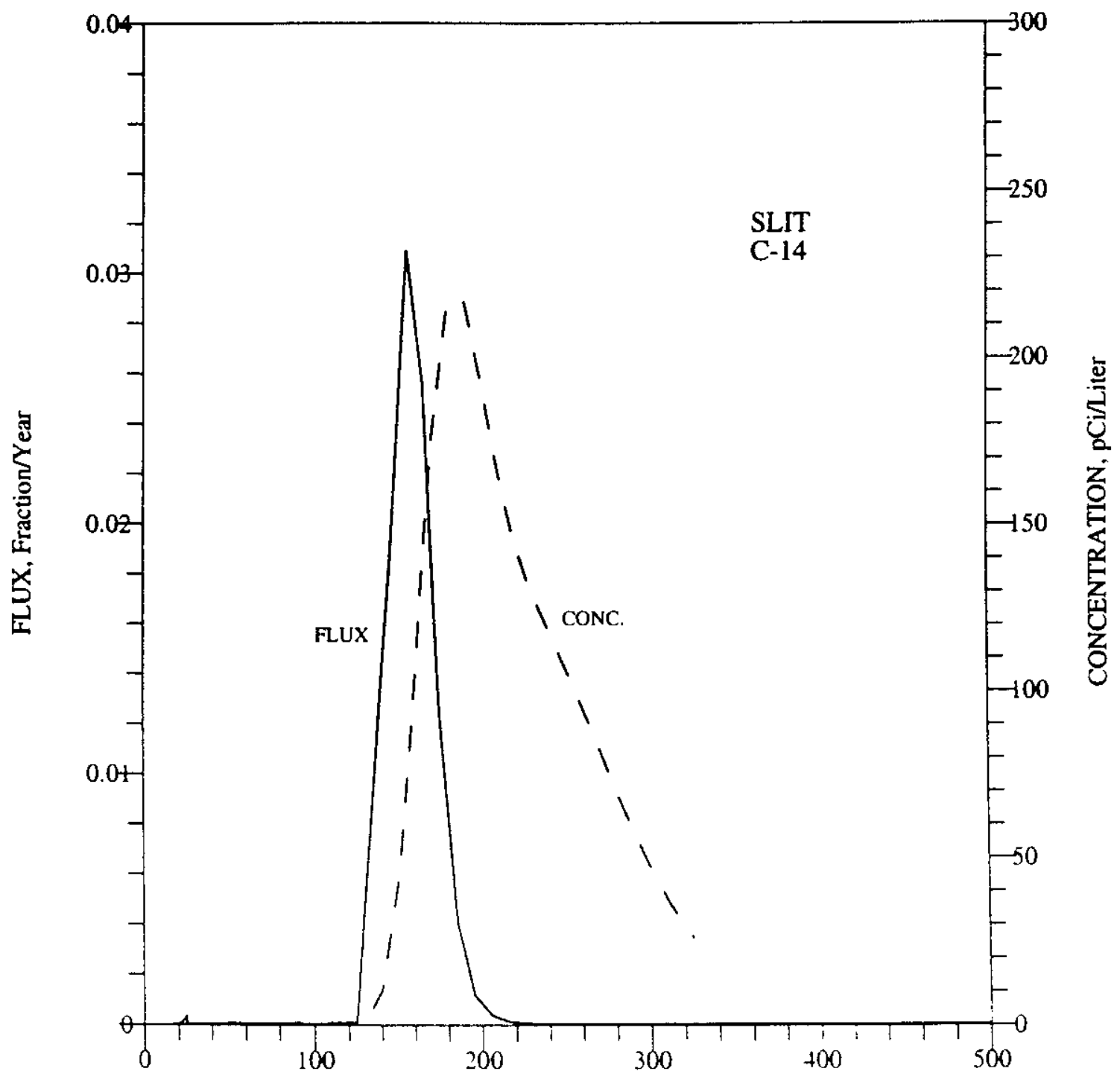

THME, Years

Figure G-26. PORFLOW estimated C-14 fractional release (Ci/year/Ci inventory) to the water table and normalized concentration ( $\mathrm{pCi} / \mathrm{liter} / \mathrm{Ci}$ inventory) at the 100 -meter well for the Slit Trenches (SLIT). 


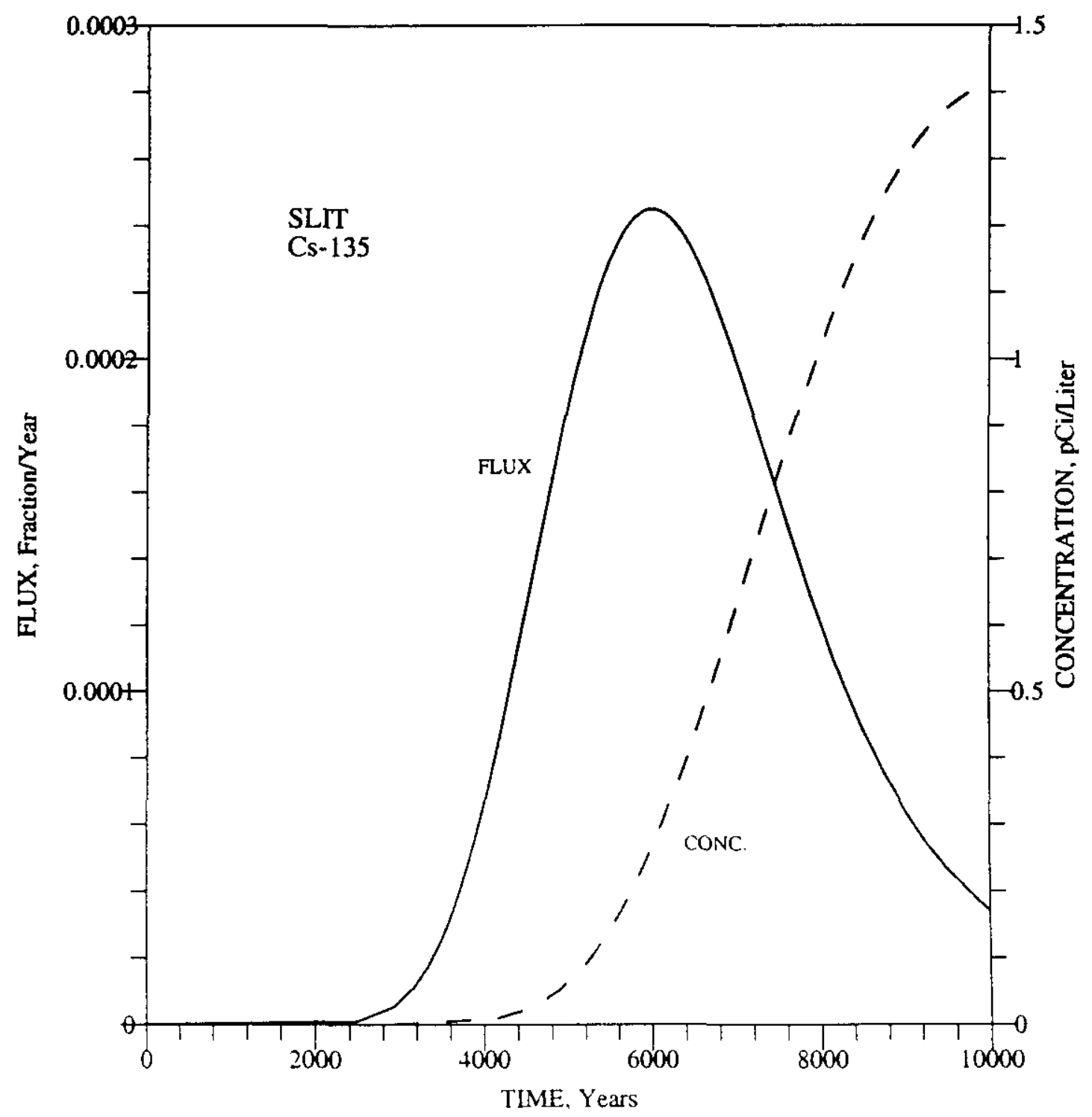

Figure G-27. PORFLOW estimated Cs-135 fractional release (Ci/year/Ci inventory) to the water table and normalized concentration ( $\mathrm{pCi} / \mathrm{liter} / \mathrm{Ci}$ inventory) at the 100 -meter well for the Slit Trenches (SLIT). 


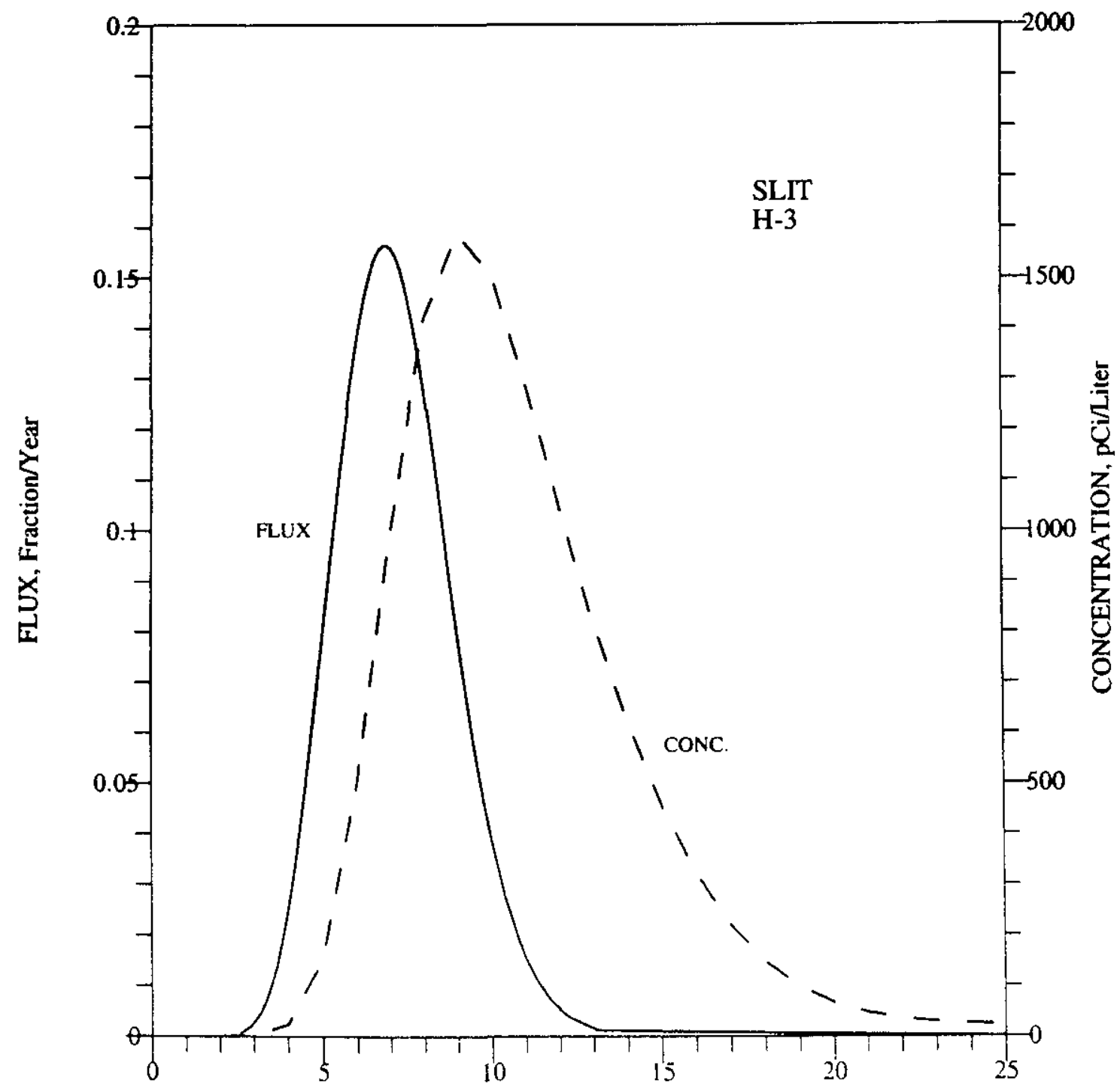

TIME. Years

Figure G-28. PORFLOW estimated $\mathrm{H} \cdot 3$ fractional release $(\mathrm{Ci} / \mathrm{year} / \mathrm{Ci}$ inventory) to the water table and normalized concentration ( $\mathrm{pCi} /$ iter/ $\mathrm{Ci}$ inventory) at the 100 -meter well for the Slit Trenches (SLIT). 


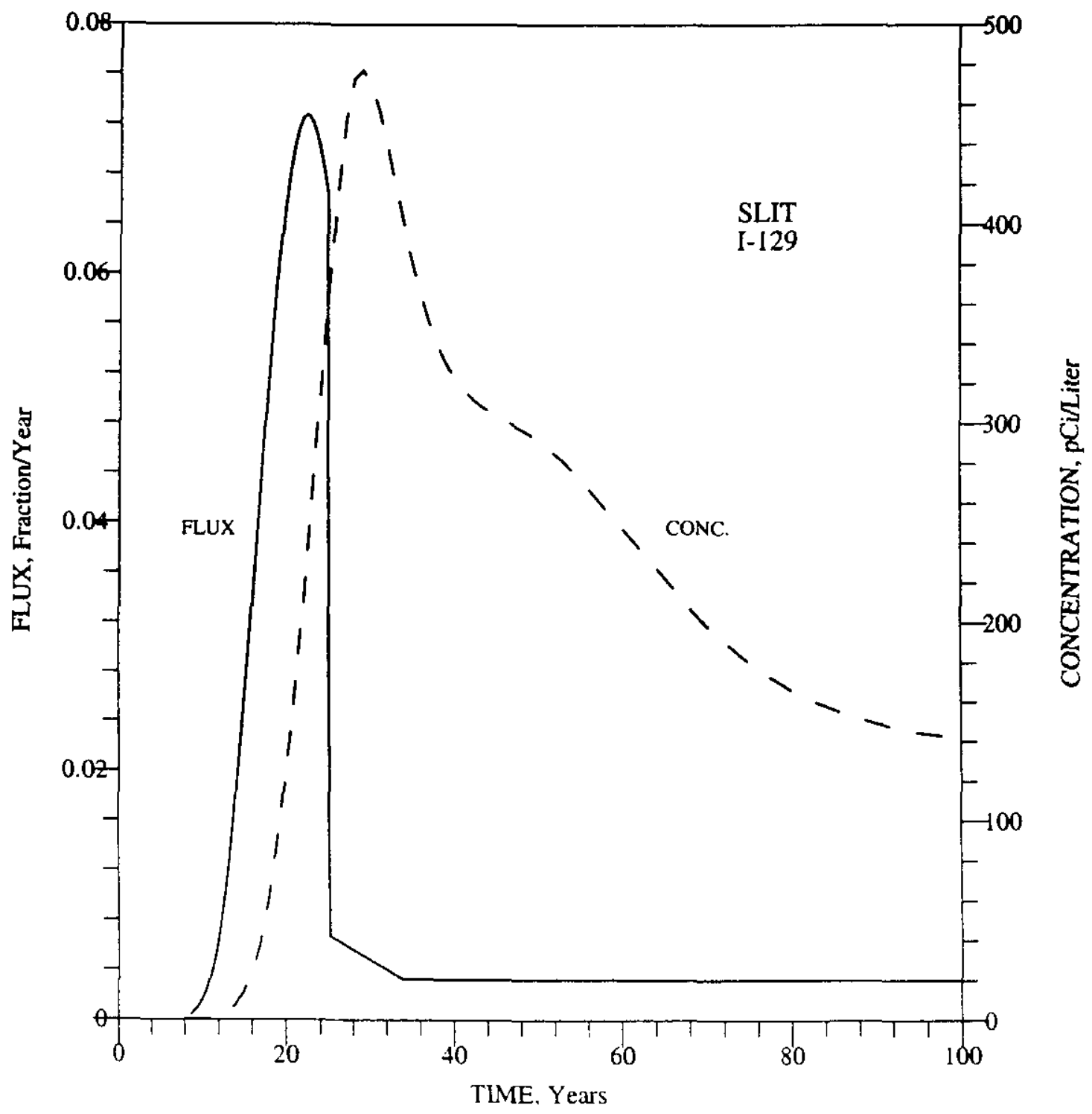

Figure G-29. PORFLOW estimated I-129 fractional release (Ci/year/Ci inventory) to the water table and normalized concentration ( $\mathrm{pCi} / \mathrm{liter} / \mathrm{Ci}$ inventory) at the 100 -meter well for the Slit Trenches (SLIT). 


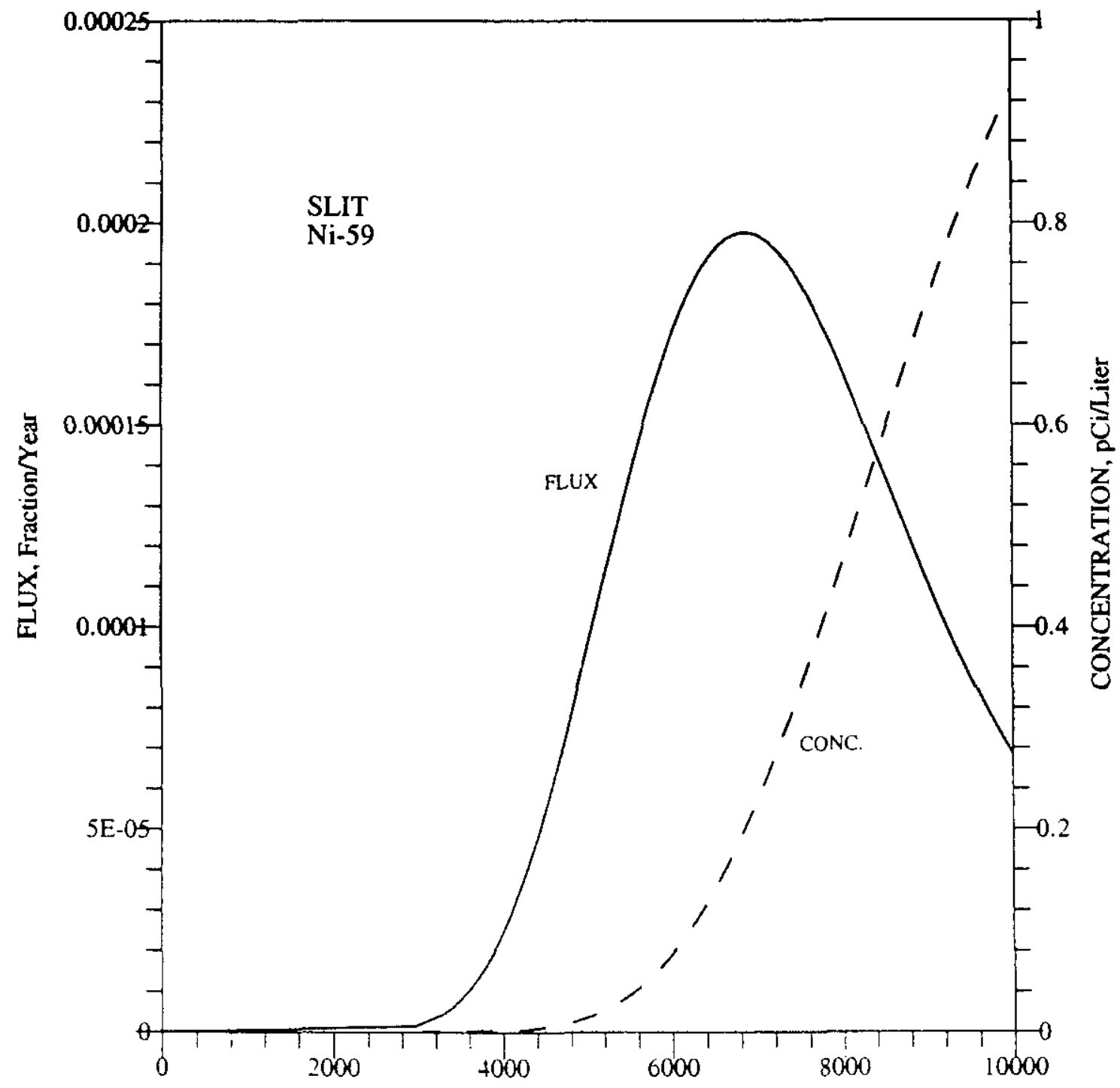

TIME, Years

Figure G-30. PORFLOW estimated Ni-59 fractional release ( $\mathrm{Ci} /$ year/Ci inventory) to the water table and normalized concentration ( $\mathrm{pCi} / \mathrm{liter} / \mathrm{Ci}$ inventory) at the 100 -meter well for the Slit Trenches (SLIT). 


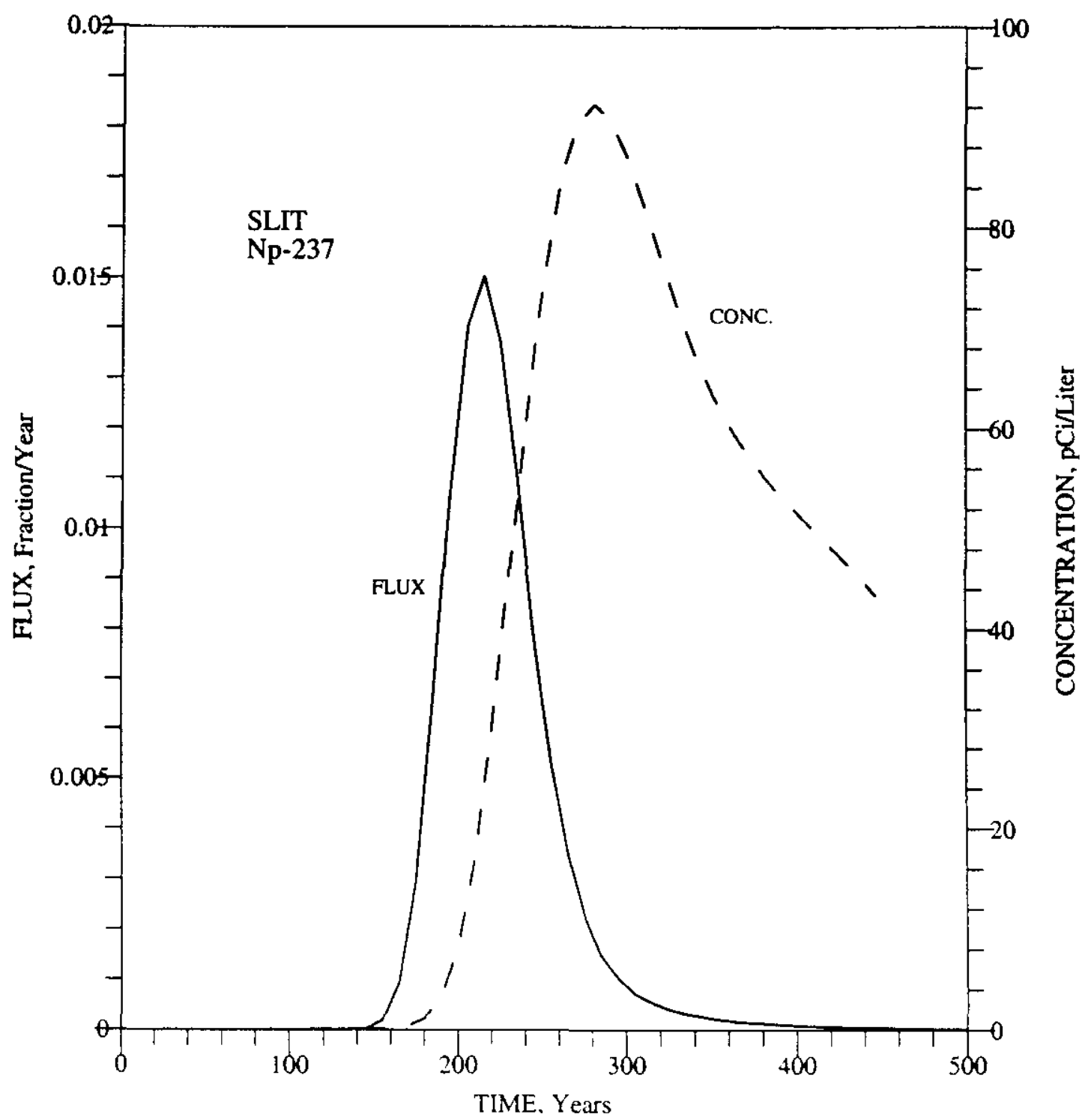

Figure G-31. PORFLOW estimated Np-237 fractional release $(\mathrm{Ci} /$ year/Ci inventory) to the water table and normalized concentration ( $\mathrm{pCi} / \mathrm{liter} / \mathrm{Ci}$ inventory) at the 100 -meter well for the Slit Trenches (SLIT). 


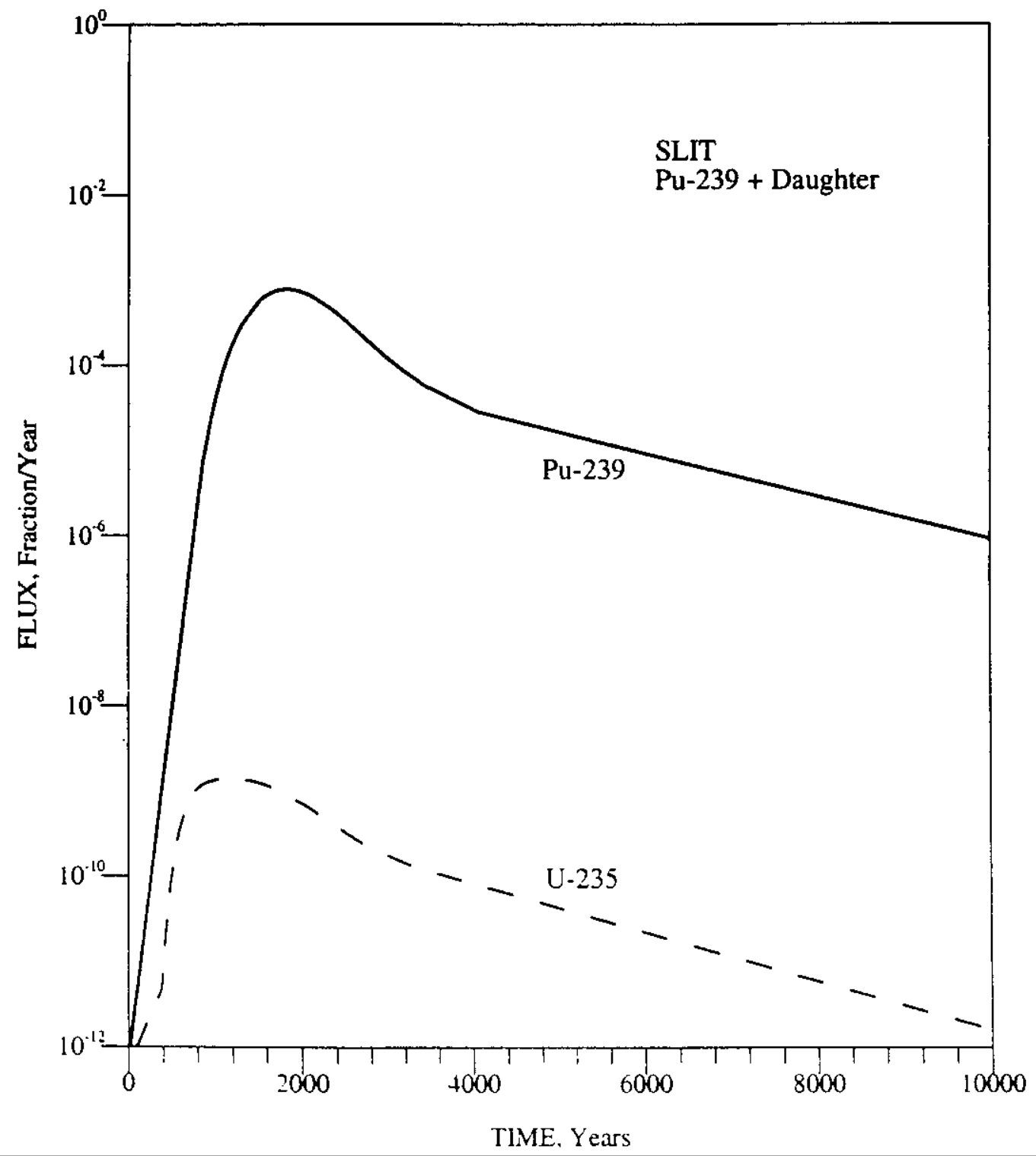

Figure G-32. PORFLOW estimated Pu-239 + Daughter fractional release (Ci/year/Ci inventory) to the water table for the Slit Trenches (SLIT). 


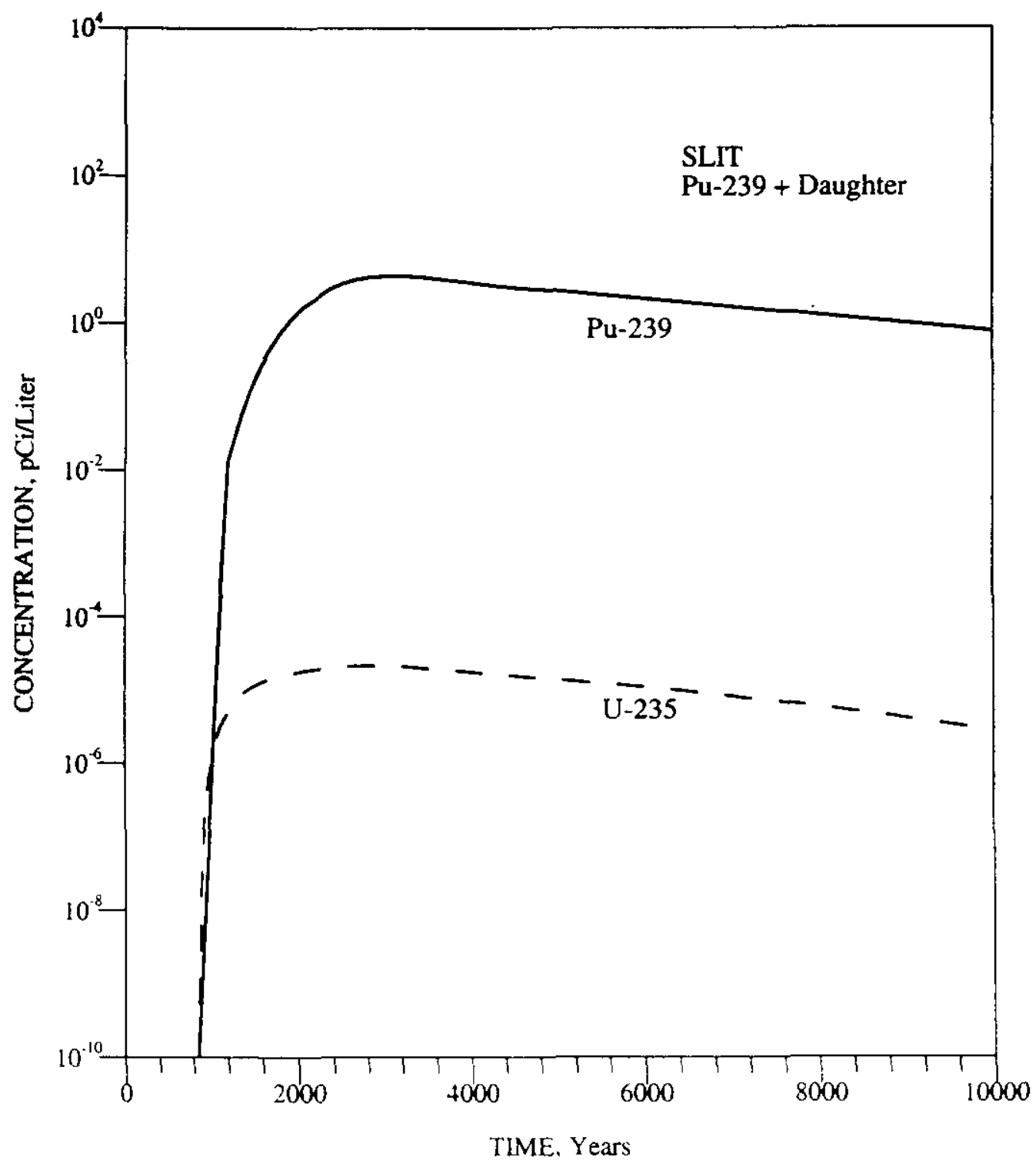

Figure G-33. PORFLOW estimated Pu-239 + Daughter normalized concentration ( $\mathrm{pCi} / \mathrm{iter} / \mathrm{Ci}$ inventory) at the 100-meter well for the Slit Trenches (SLIT). 


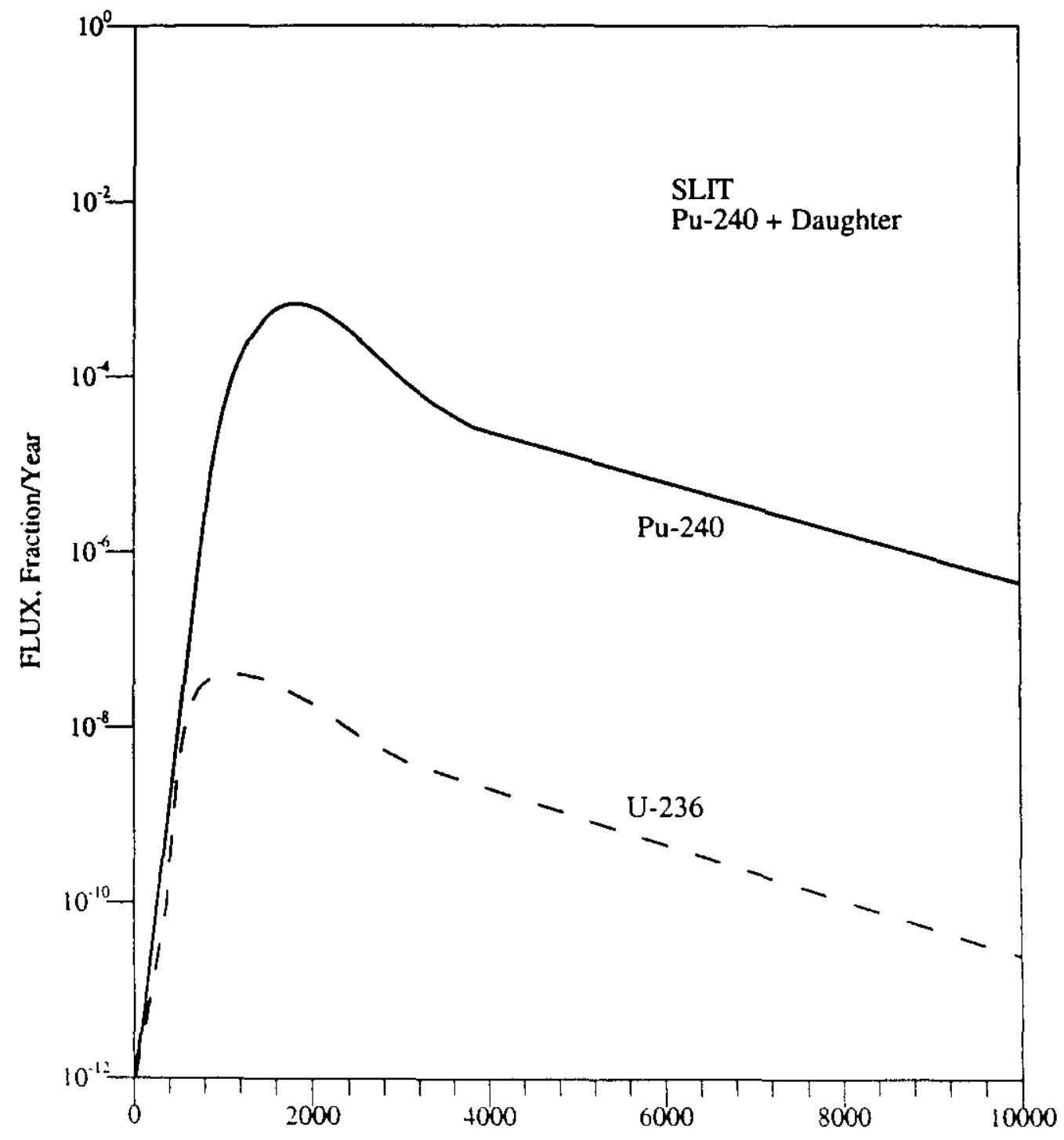

TIME. Years

Figure G-34. PORFLOW estimated Pu-240 + Daughter fractional release (Ci/year/Ci inventory) to the water table for the Slit Trenches (SLIT). 


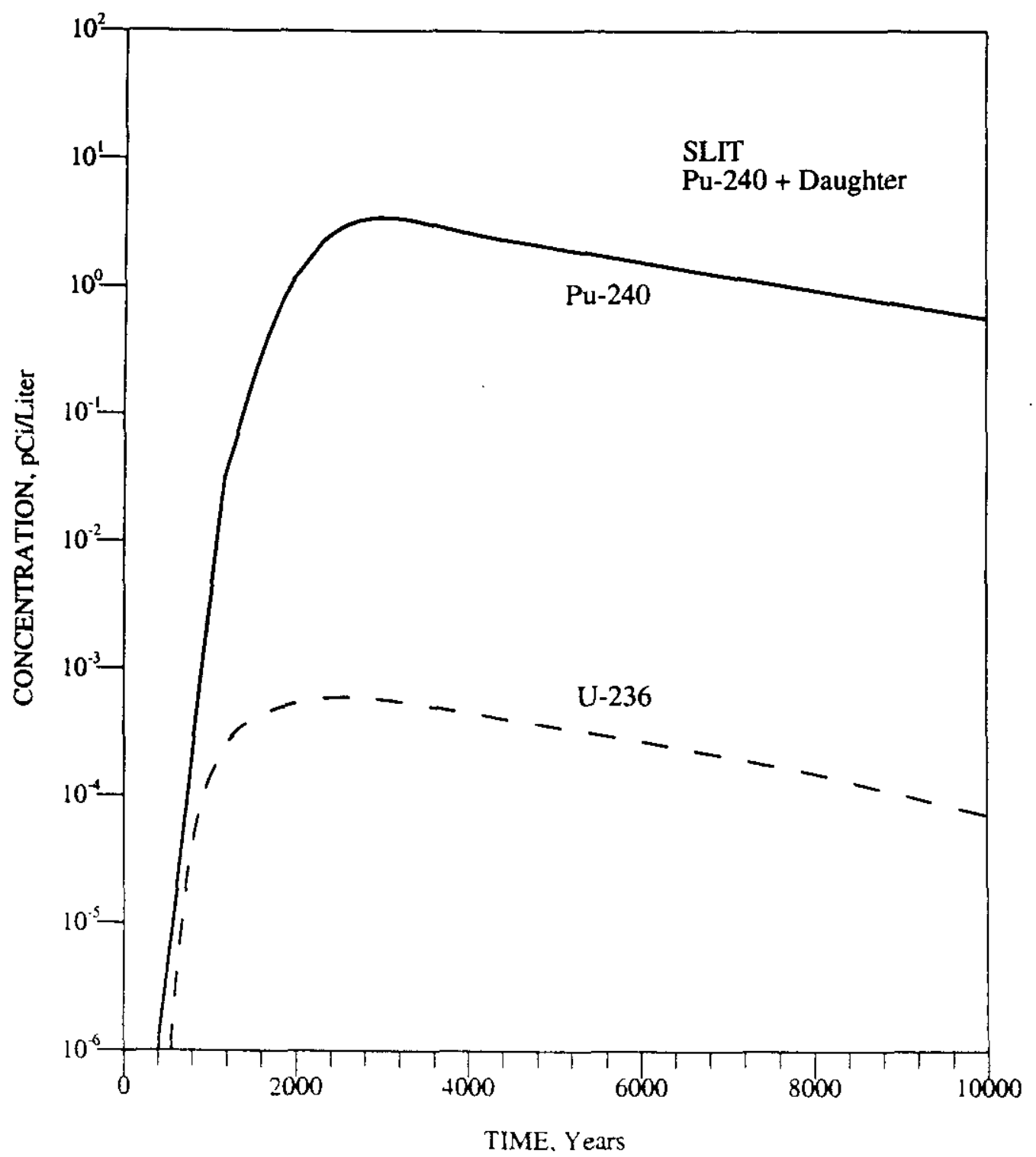

Figure G-35. PORFLOW estimated Pu-240 + Daughter normalized concentration (pCi/liter/Ci inventory) at the 100-meter well for the Slit Trenches (SLIT). 


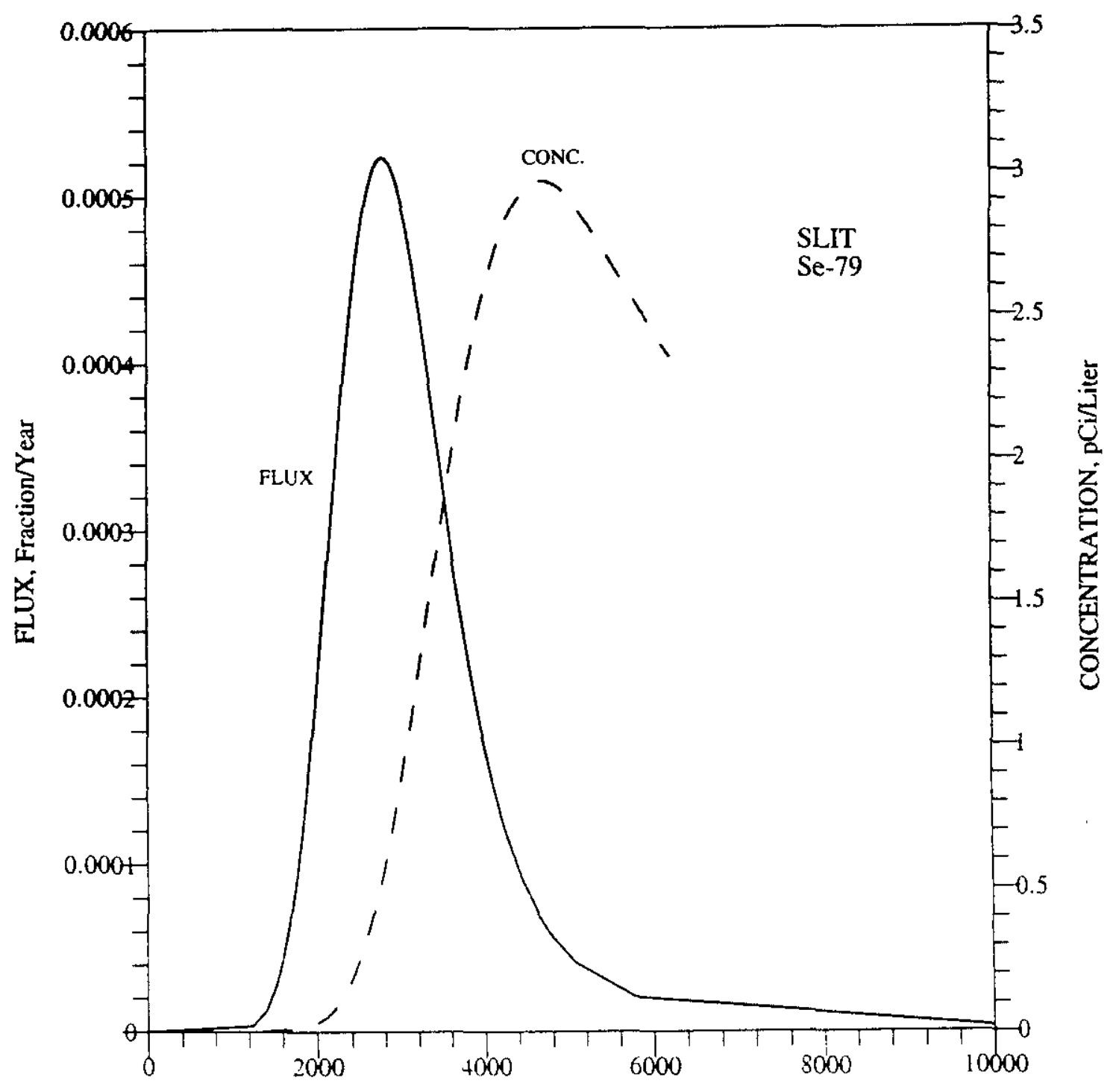

TIME, Years

Figure G-36. PORFLOW estimated Se-79 fractional release (Ci/year/Ci inventory) to the water table and normalized concentration ( $\mathrm{pCi} / \mathrm{liter} / \mathrm{Ci}$ inventory) at the 100 -meter well for the Slit Trenches (SLIT). 


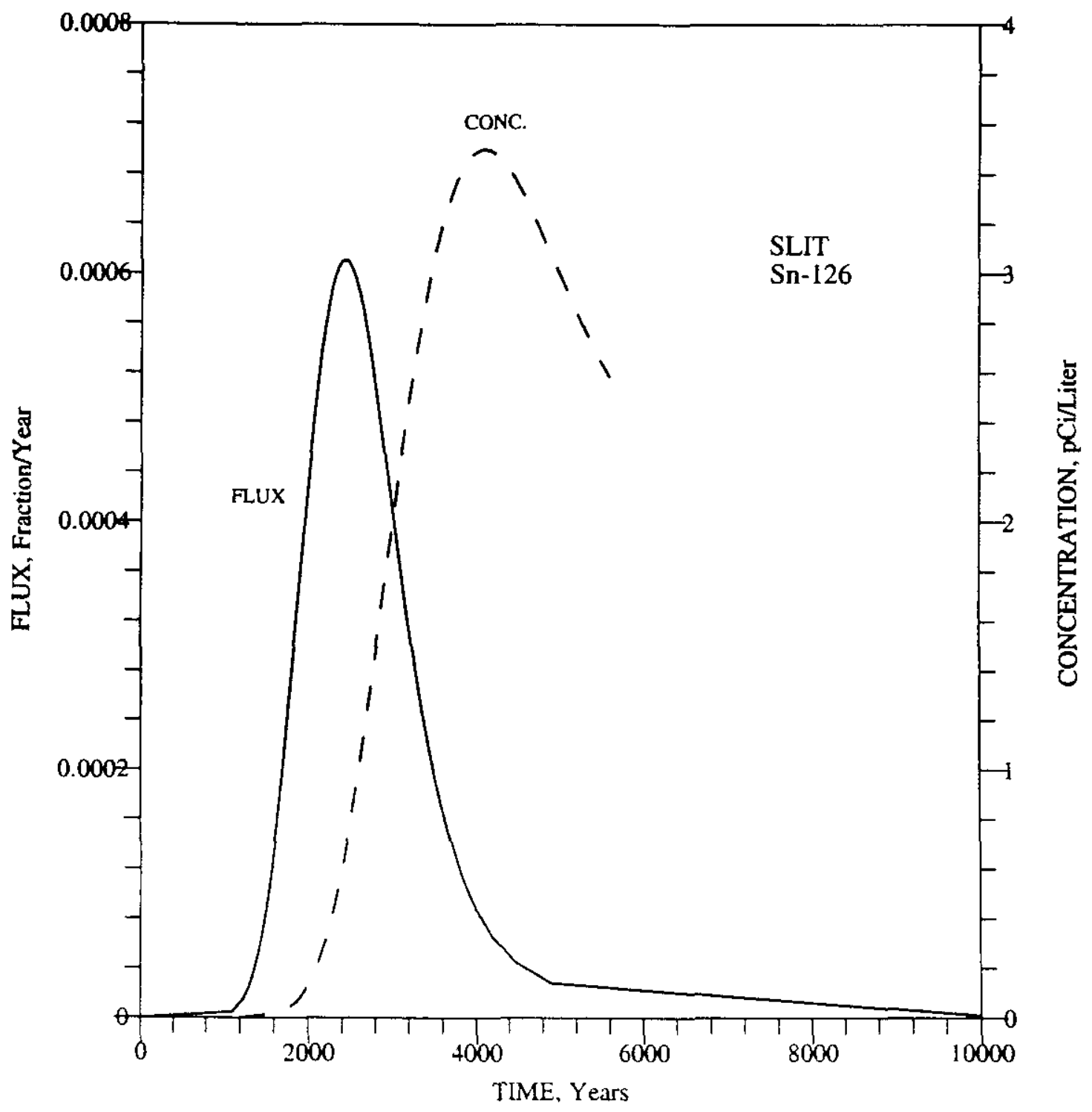

Figure G-37. PORFLOW estimated Sn-126 fractional release (Ci/year/Ci inventory) to the water table and normalized concentration ( $\mathrm{pCi} / \mathrm{liter} / \mathrm{Ci}$ inventory) at the 100 -meter well for the Slit Trenches (SLIT). 


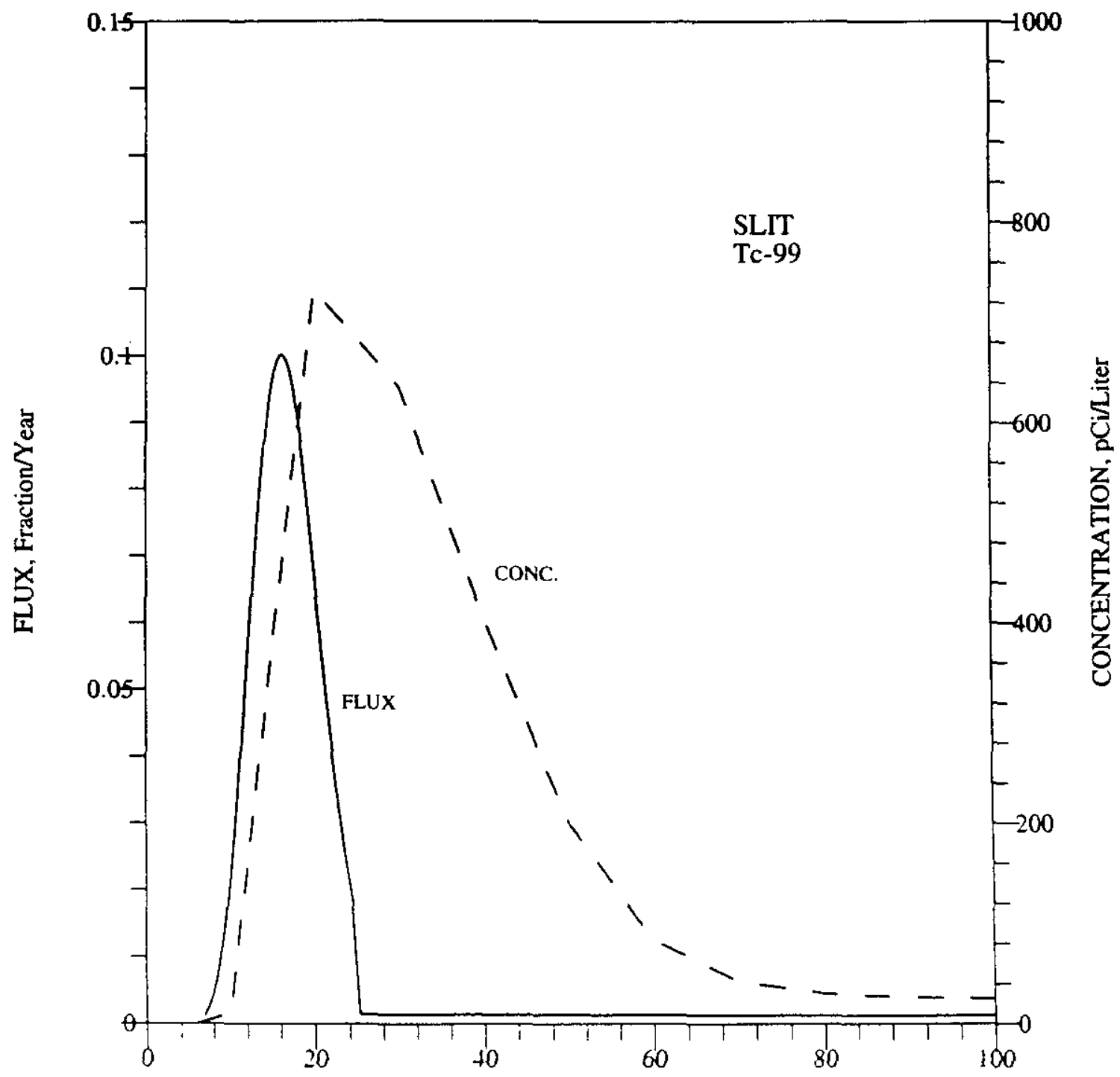

TIME, Y'ears

Figure G-38. PORFLOW estimated Tc-99 fractional release ( $\mathrm{Ci}$ /year/Ci inventory) to the water table and normalized concentration ( $\mathrm{pCi}$ liter/Ci inventory) at the 100-meter well for the Slit Trenches (SLIT). 


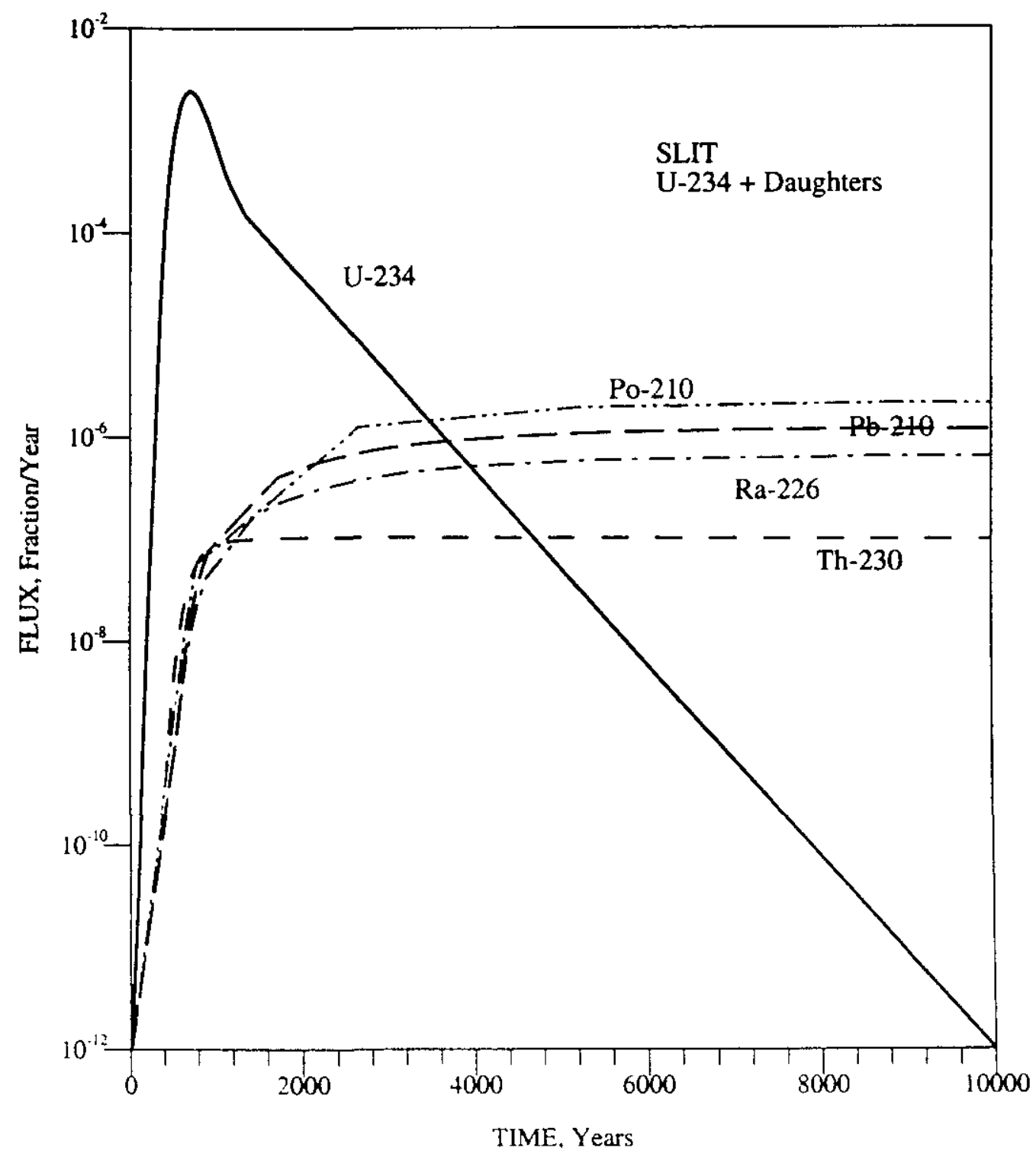

Figure G-39. PORFLOW estimated U-234 + Daughters fractional release (Ci/year/Ci inventory) to the water table for the Slit Trenches (SLIT). 


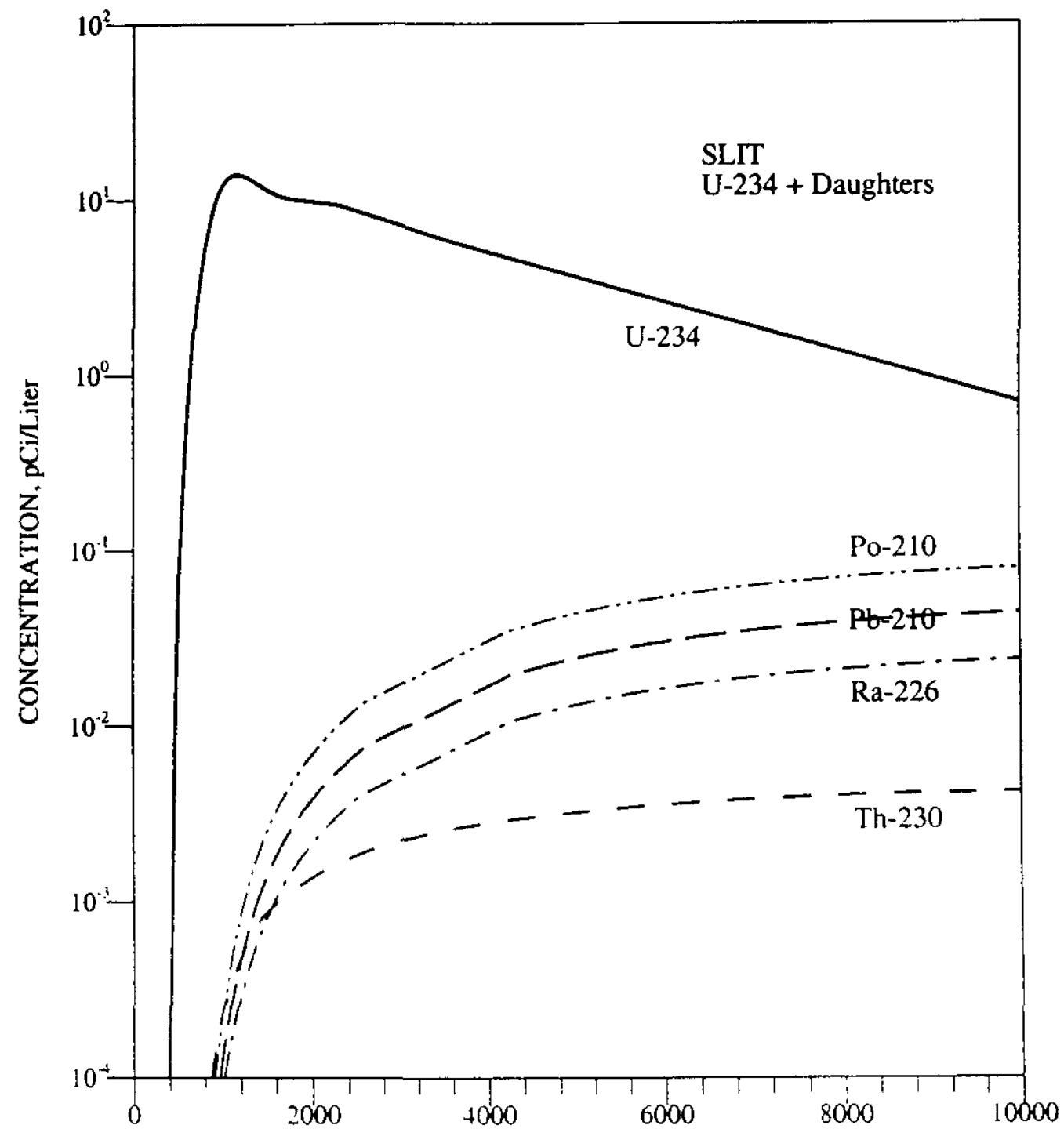

TIME, Years

Figure G-40. PORFLOW estimated U-234 + Daughters normalized concentration ( $\mathrm{pCi} / \mathrm{liter} / \mathrm{Ci}$ inventory) at the 100-meter well for the Slit Trenches (SLIT). 


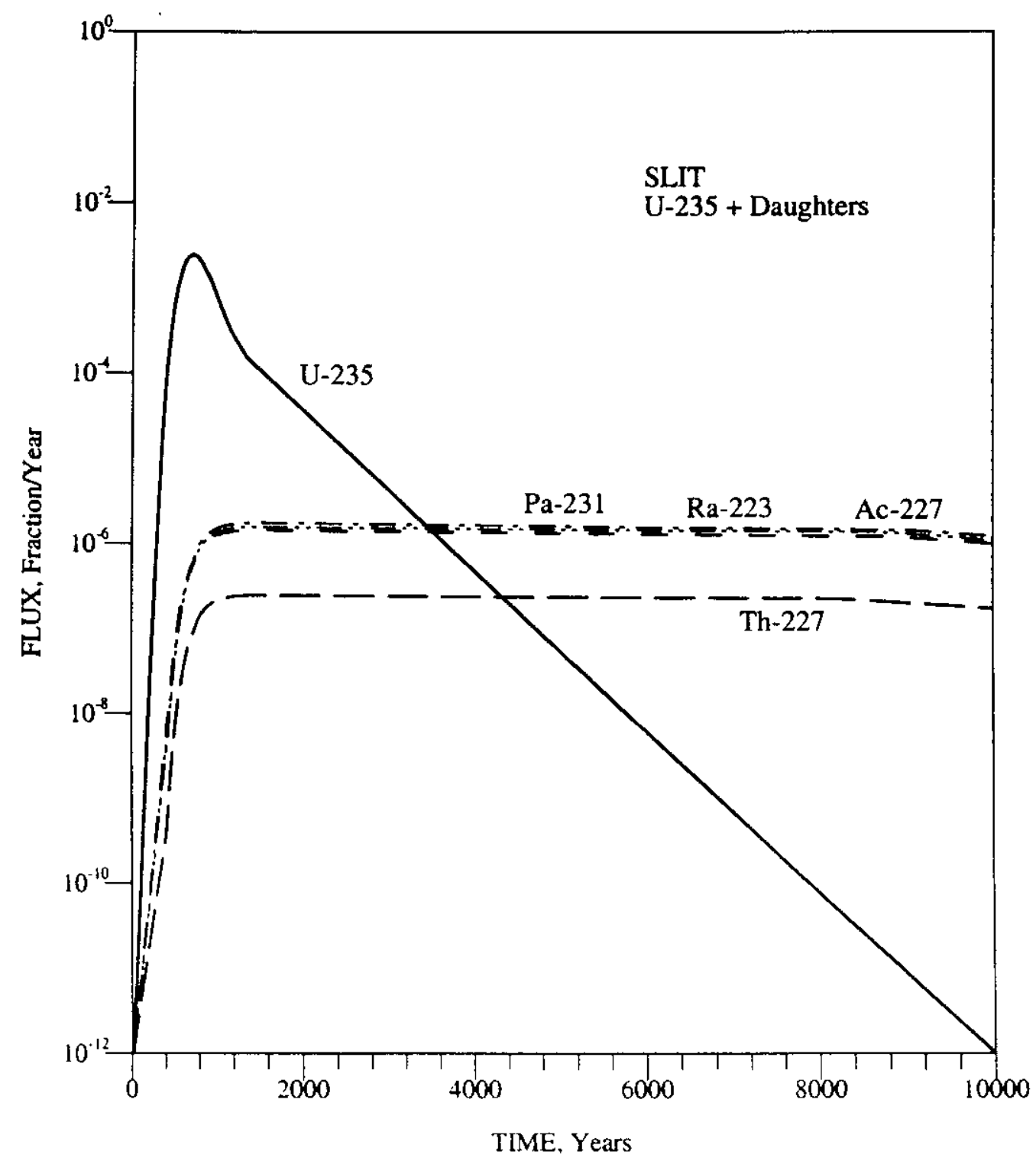

Figure G-41. PORFLOW estimated U-235 + Daughters fractional release ( $\mathrm{Ci} /$ year/Ci inventory) to the water table for the Slit Trenches (SLIT). 


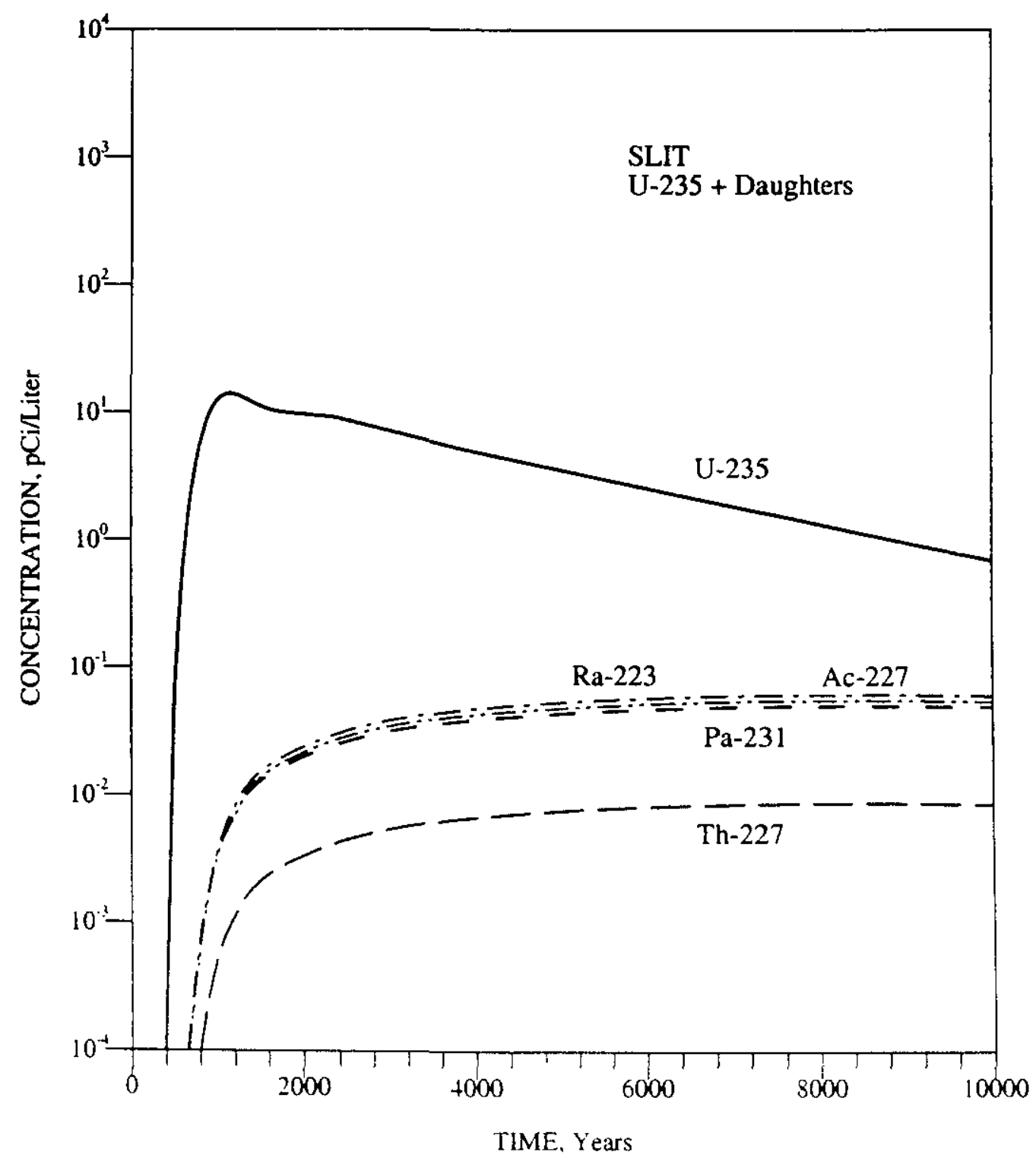

Figure G-42. PORFLOW estimated U-235 + Daughters normalized concentration (pCi/liter/Ci inventory) at the 100-meter well for the Slit Trenches (SLIT). 


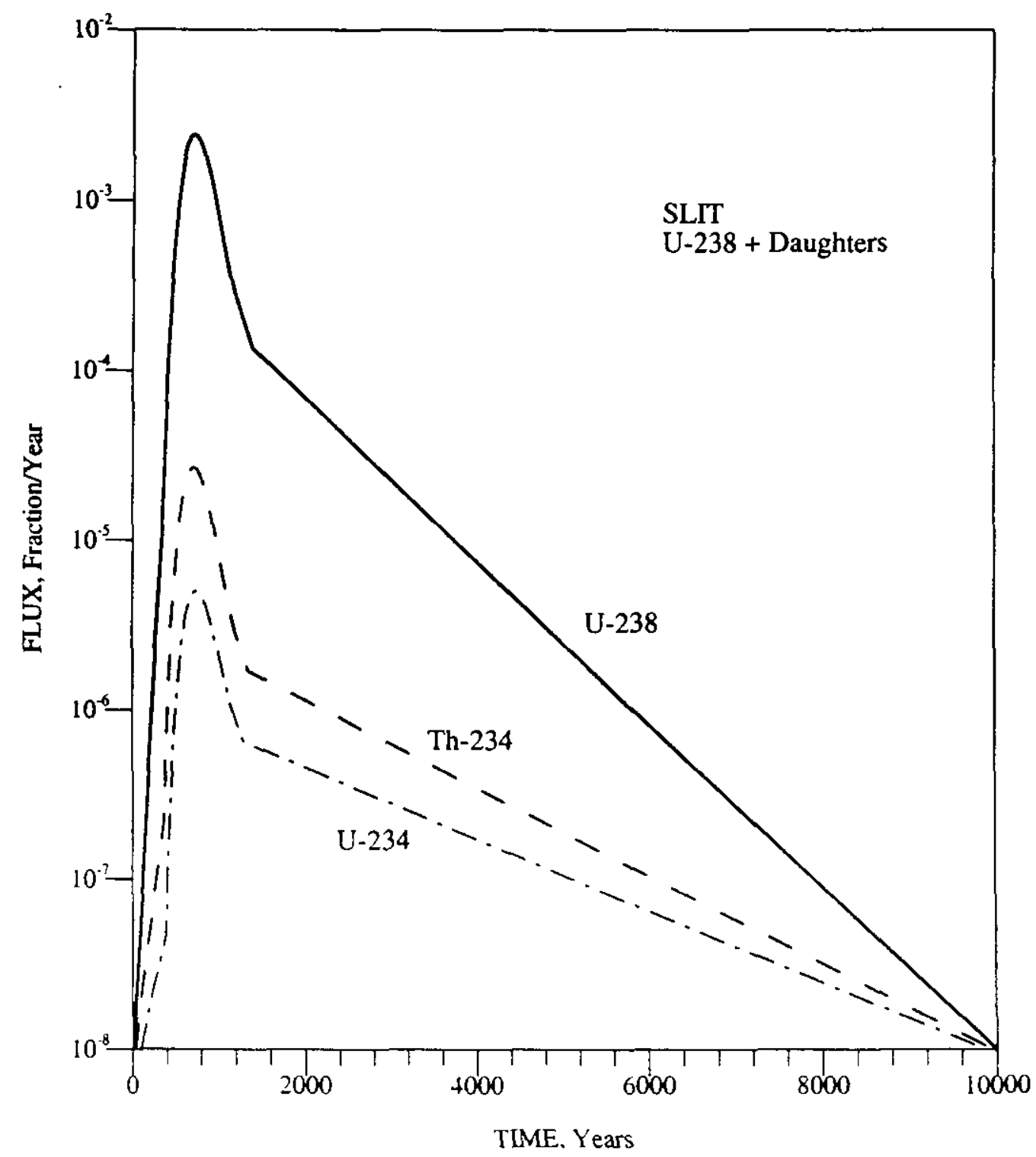

Figure G-43. PORFLOW estimated U-238 + Daughters fractional release (Ci/year/Ci inventory) to the water table for the Slit Trenches (SLIT). 


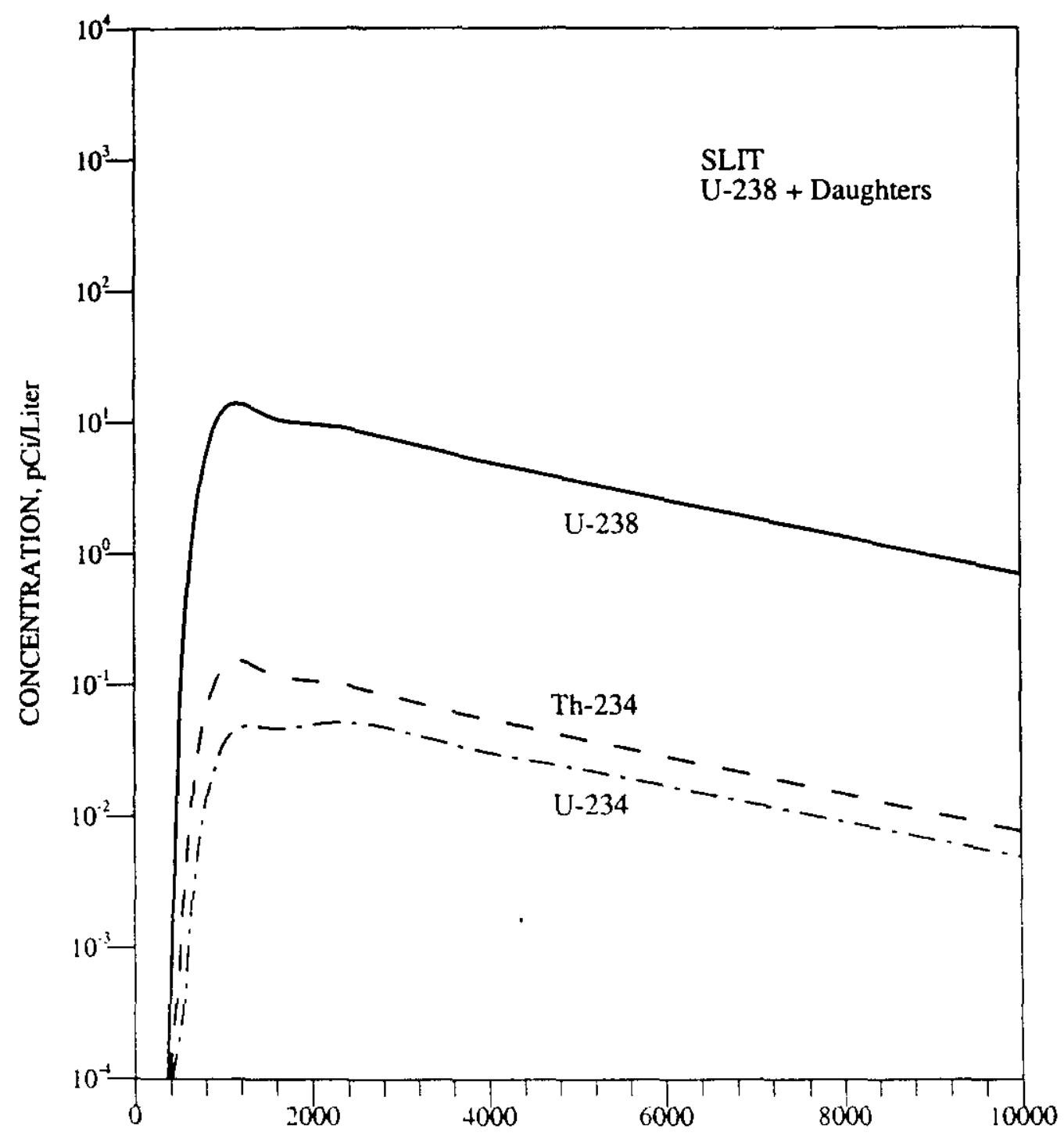

TIME, Years

Figure G-44. PORFLOW estimated U-238 + Daughters normalized concentration (pCi/liter/Ci inventory) at the 100-meter well for the Slit Trenches (SLIT). 


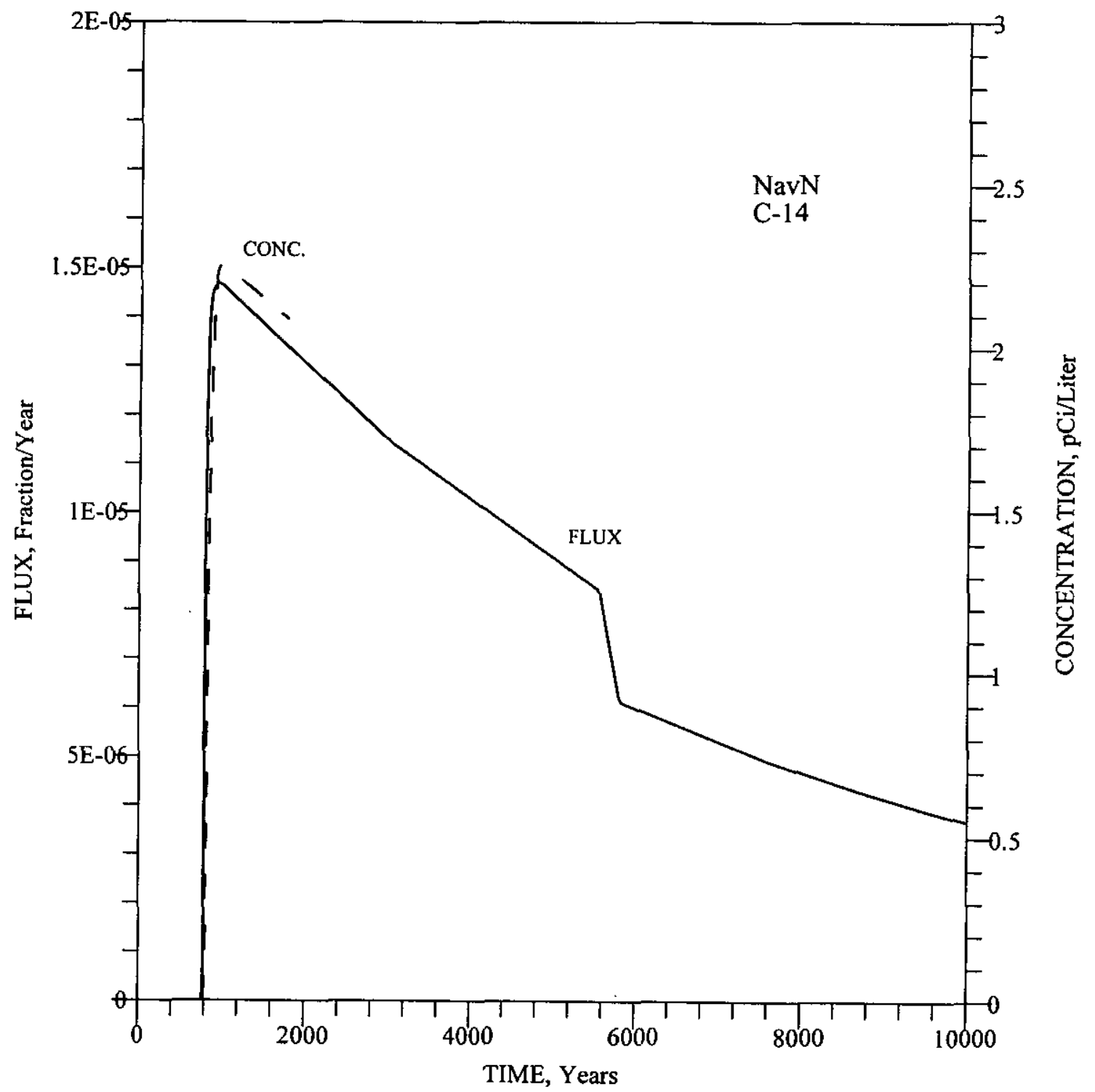

Figure G-45. PORFLOW estimated C-14 fractional release (Ci/year/Ci inventory) to the water table and normalized concentration ( $\mathrm{pCi} /$ liter/Ci inventory) at the 100-meter well for the Naval Reactor Waste Pad (NavN). 


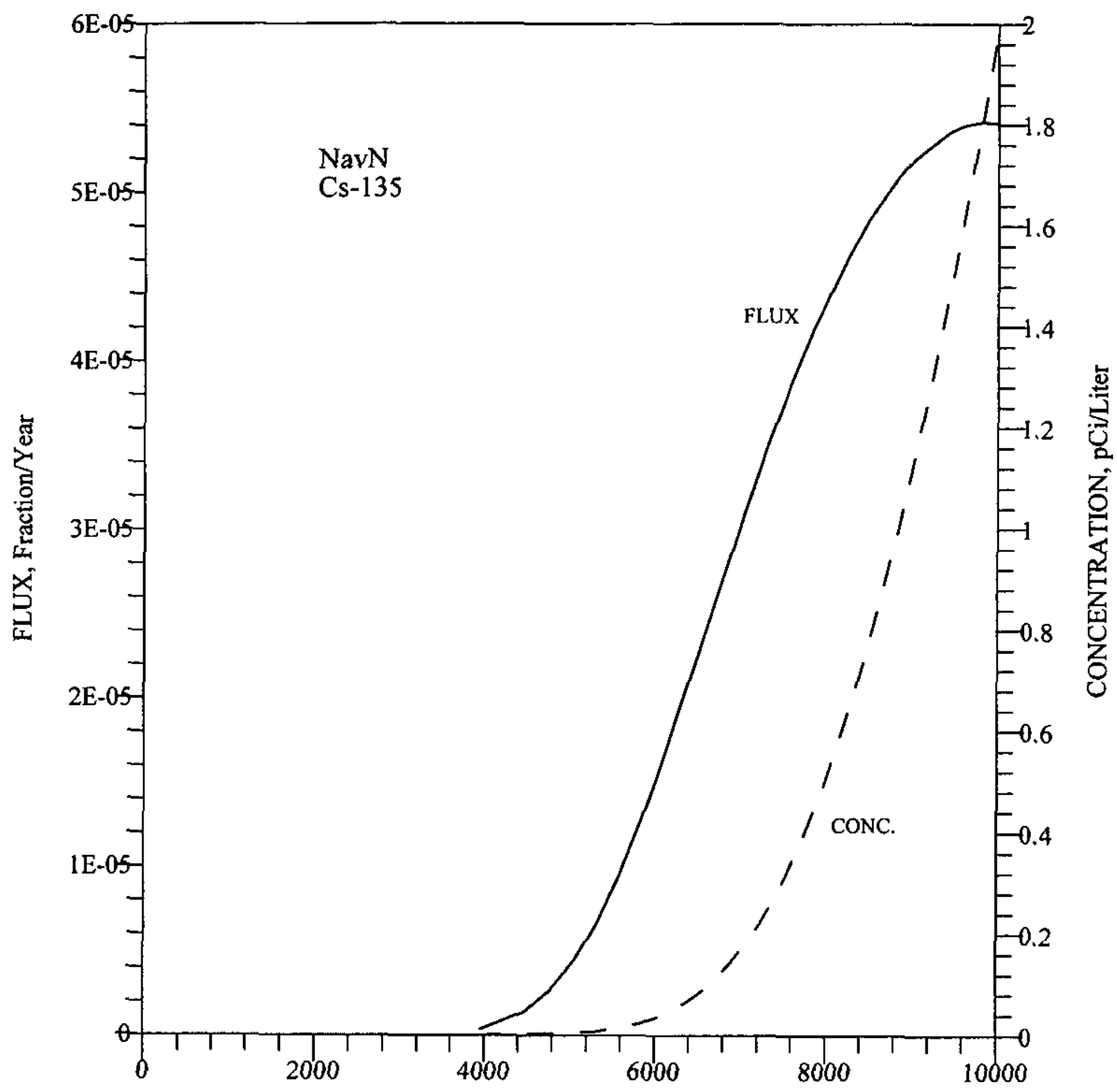

TIME, Years

Figure G-46. PORFLOW estimated Cs-135 fractional release ( $\mathrm{Ci} /$ year/Ci inventory) to the water table and normalized concentration ( $\mathrm{pCi} /$ liter/Ci inventory) at the 100 -meter well for the Naval Reactor Waste Pad (NavN). 


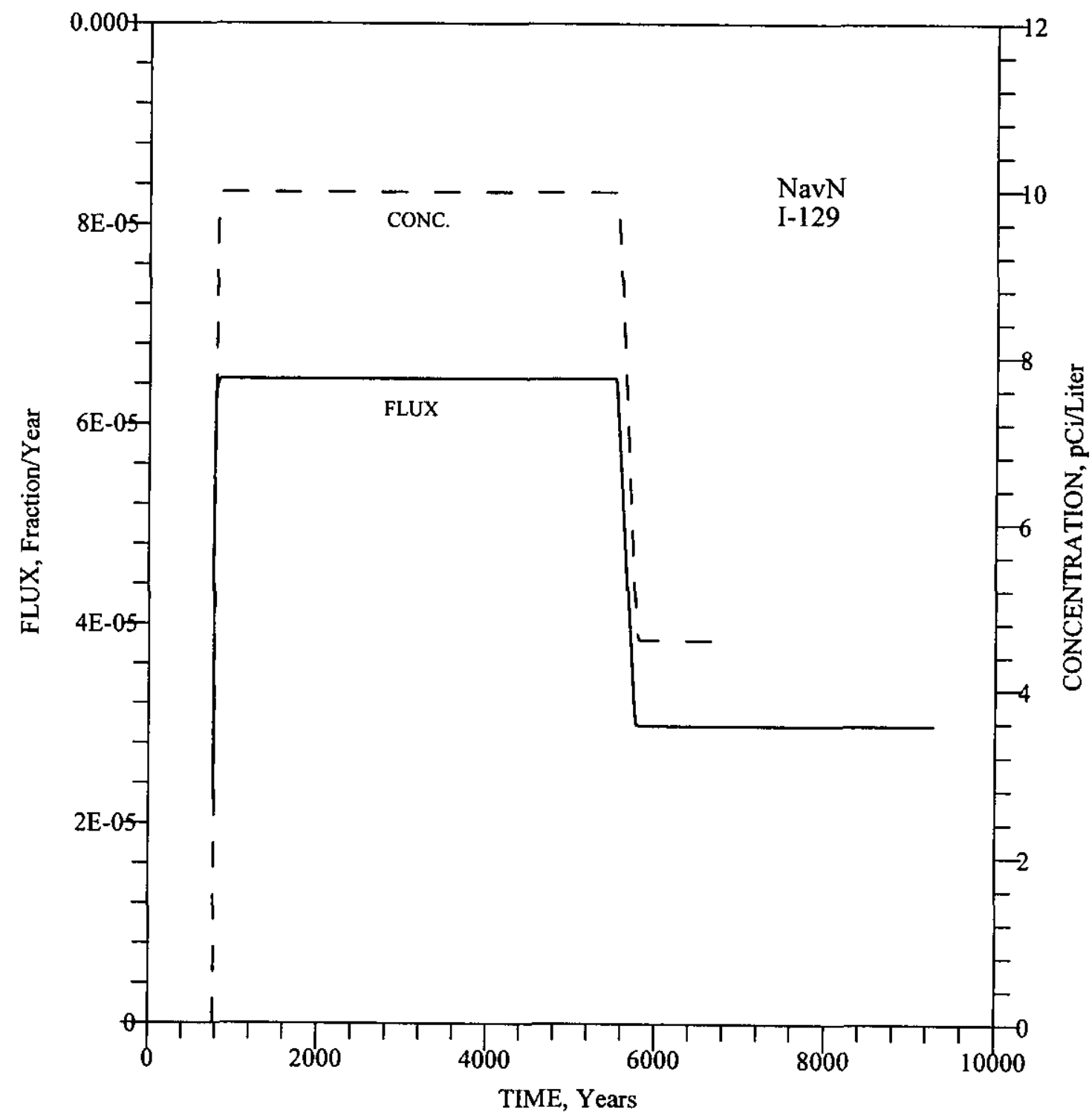

Figure G-47. PORFLOW estimated I-129 fractional release (Ci/year/Ci inventory) to the water table and normalized concentration ( $\mathrm{pCi} / \mathrm{liter} / \mathrm{Ci}$ inventory) at the 100-meter well for the Naval Reactor Waste Pad (NavN). 


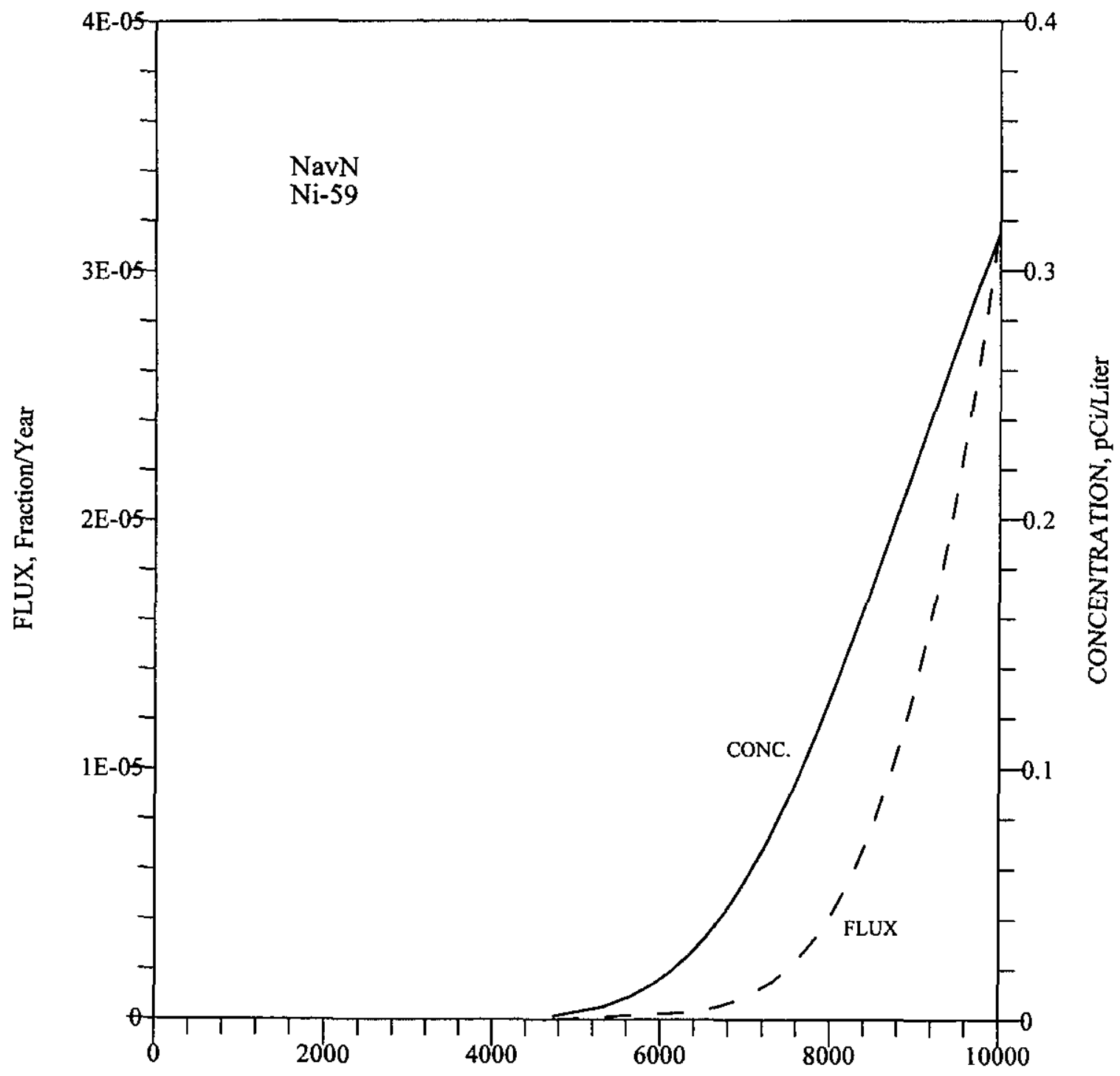

TIME, Years

Figure G-48. PORFLOW estimated $\mathrm{Ni}-59$ fractional release (Ci/year/Ci inventory) to the water table and normalized concentration ( $\mathrm{pCi} /$ liter/ $\mathrm{Ci}$ inventory) at the 100 -meter well for the Naval Reactor Waste Pad (NavN). 


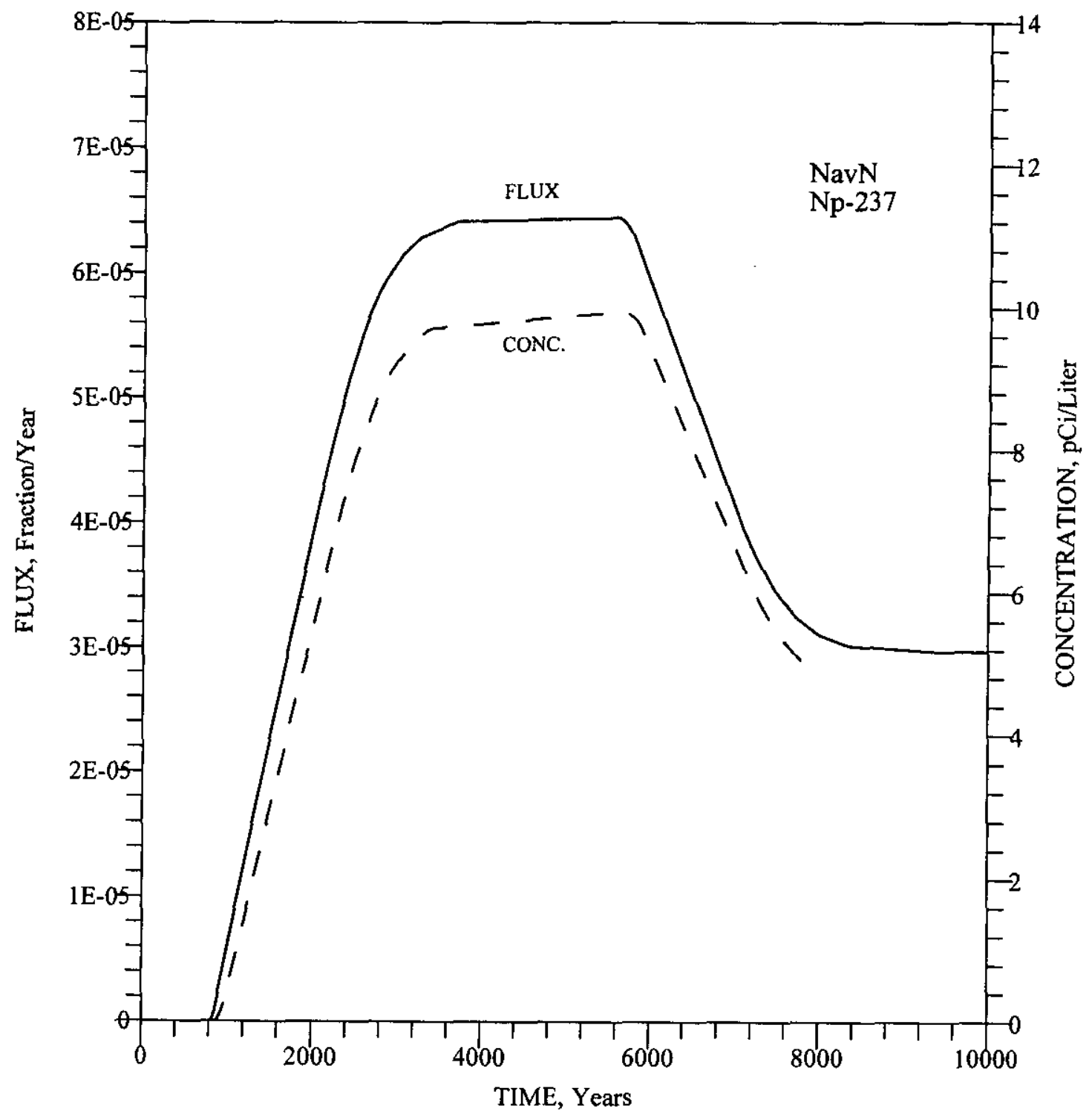

Figure G-49. PORFLOW estimated Np-237 fractional release ( $\mathrm{Ci} /$ year/Ci inventory) to the water table and normalized concentration ( $\mathrm{pCi} /$ liter/Ci inventory) at the 100-meter well for the Naval Reactor Waste Pad (NavN). 


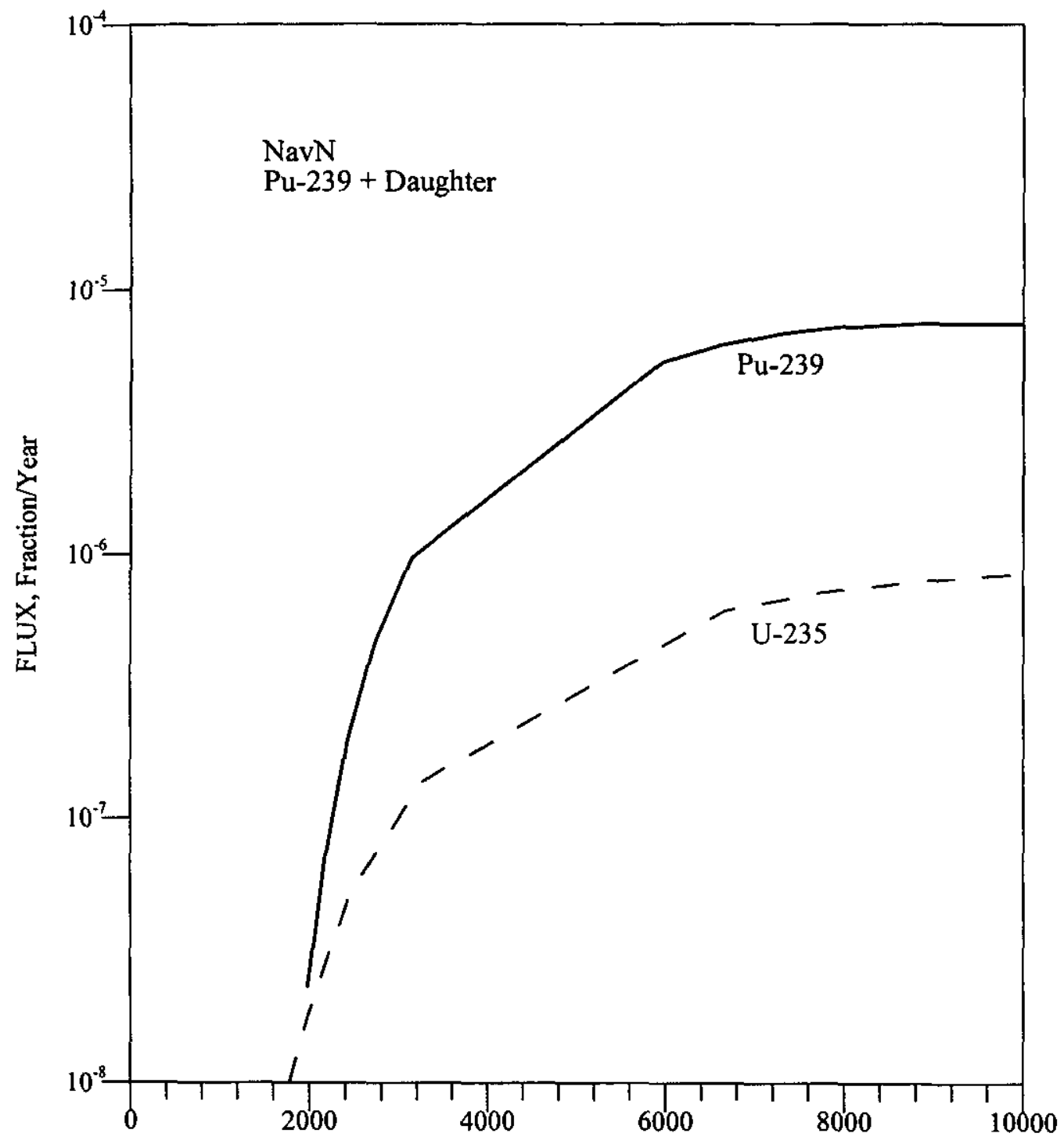

TIME, Years

Figure G-50. PORFLOW estimated Pu-239 + Daughter fractional release (Ci/year/Ci inventory) to the water table for the Naval Reactor Waste Pad (NavN). 


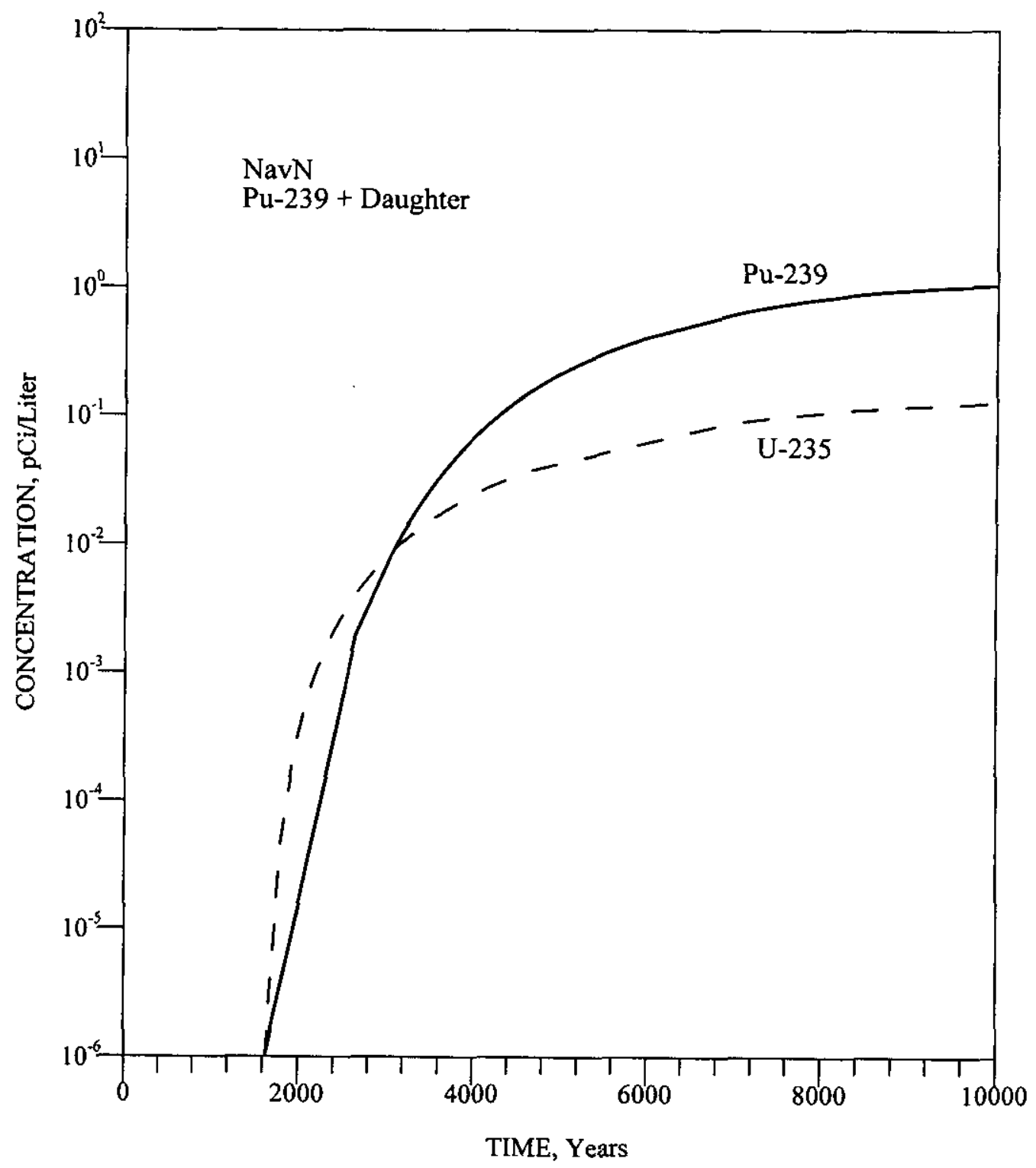

Figure G-51. PORFLOW estimated Pu-239 + Daughter normalized concentration (pCi/liter/Ci inventory) at the 100-meter well for the Naval Reactor Waste Pad (NavN). 


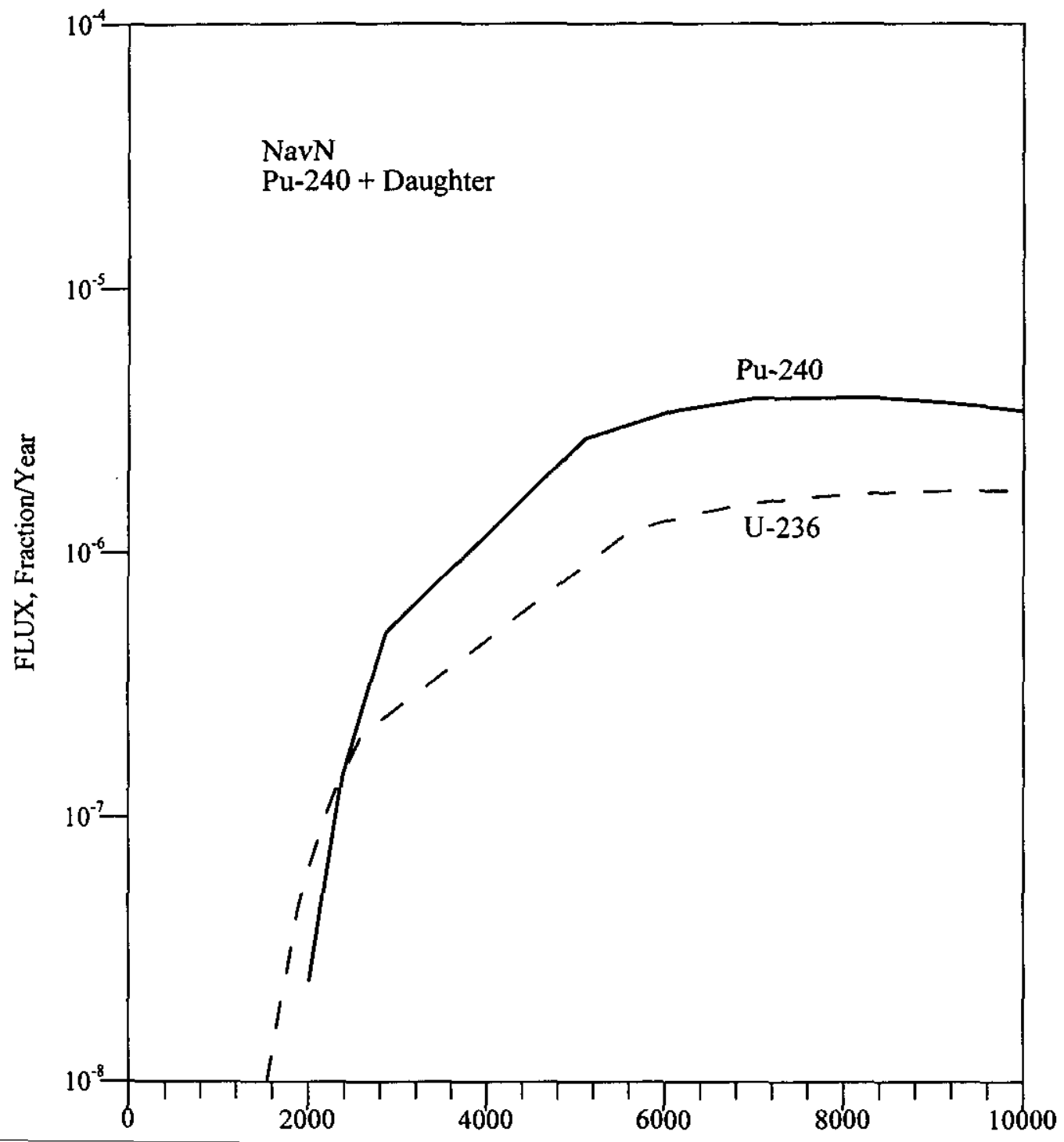

TIME, Years

Figure G-52. PORFLOW estimated Pu-240 + Daughter fractional release (Ci/year/Ci inventory) to the water table for the Naval Reactor Waste Pad (NavN). 


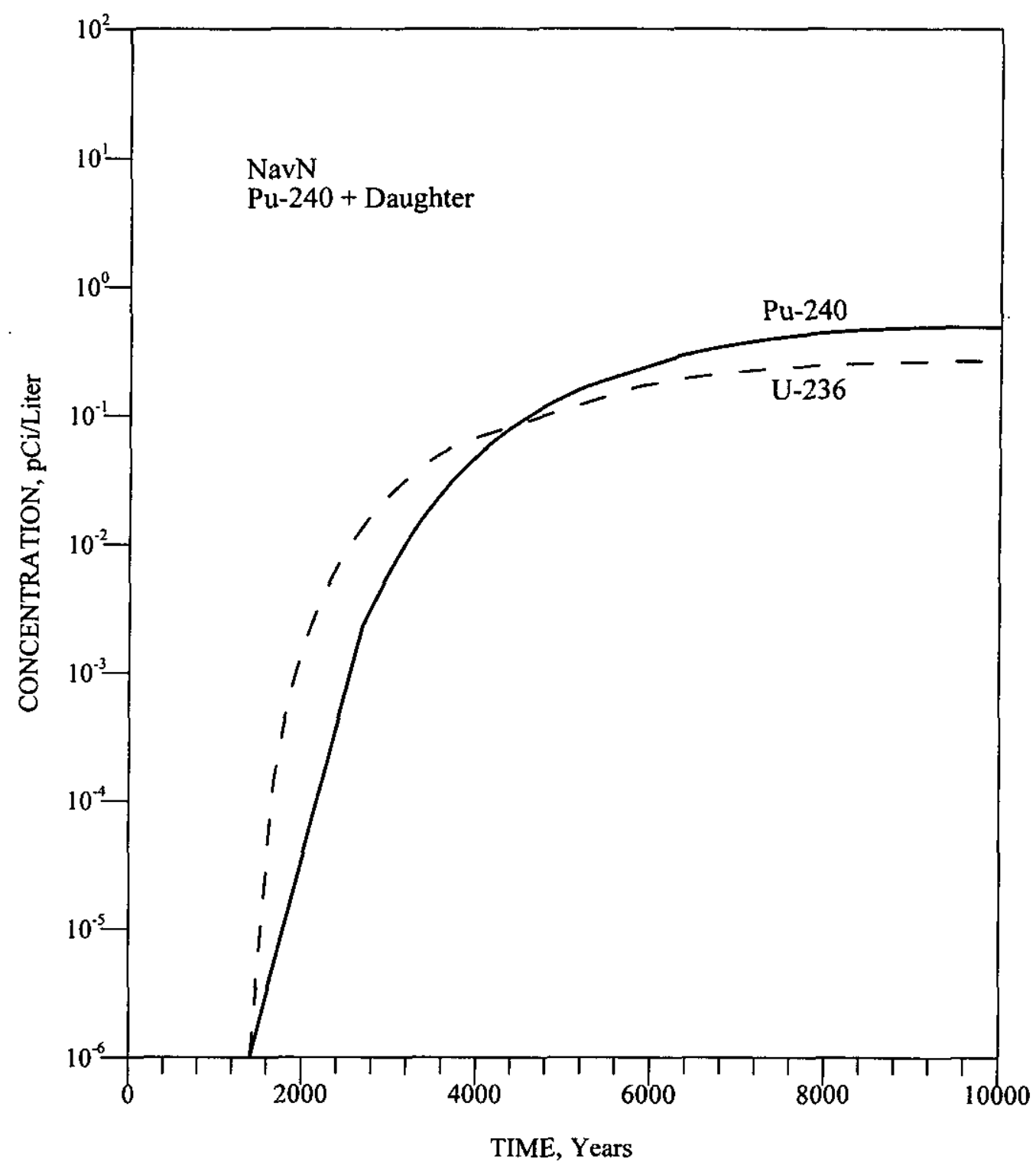

Figure G-53. PORFLOW estimated Pu-240 + Daughter normalized concentration (pCi/liter/Ci inventory) at the 100-meter well for the Naval Reactor Waste Pad (NavN). 


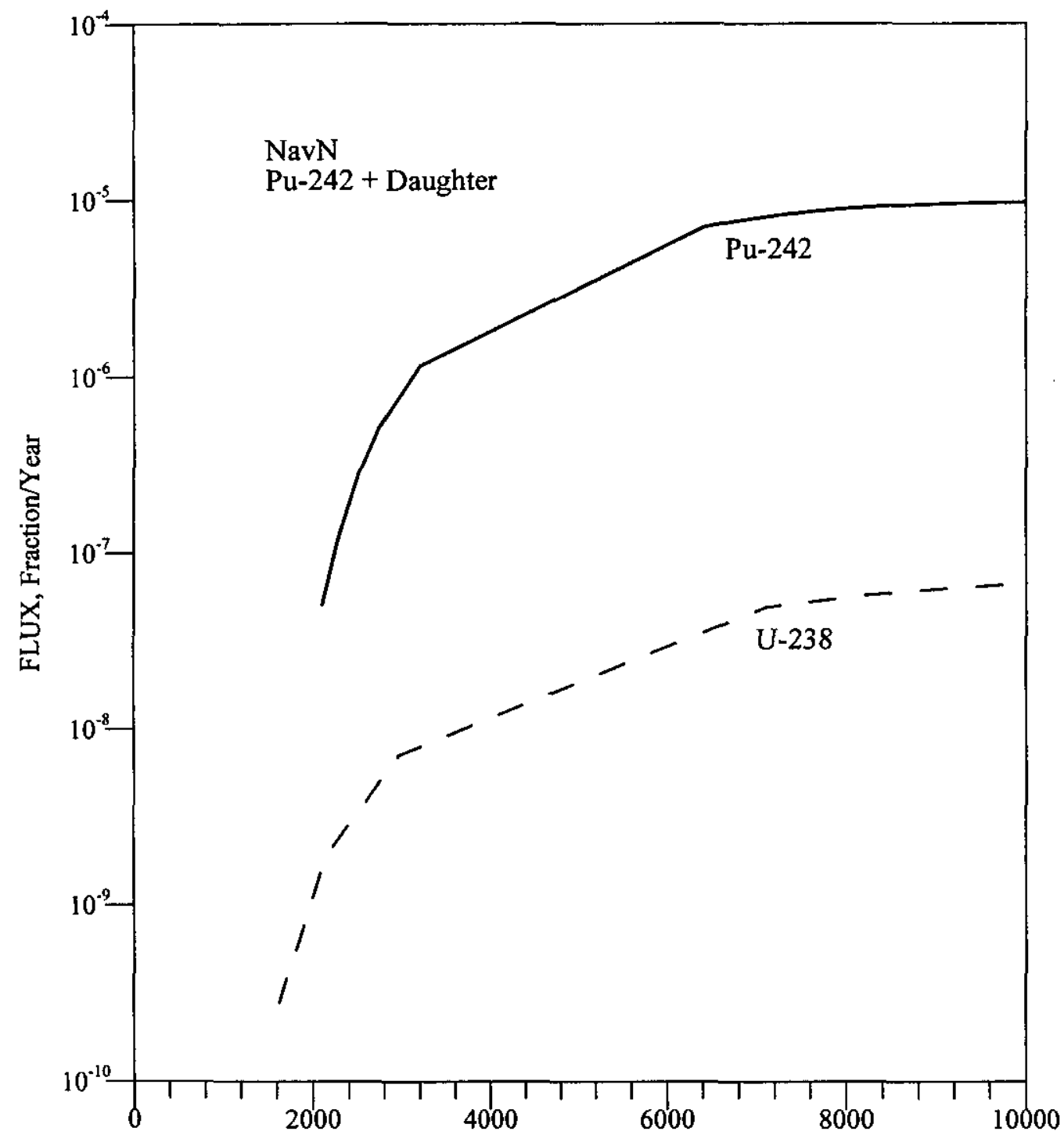

TIME, Years

Figure G-54. PORFLOW estimated Pu-242 + Daughter fractional release (Ci/year/Ci inventory) to the water table for the Naval Reactor Waste Pad (NavN). 


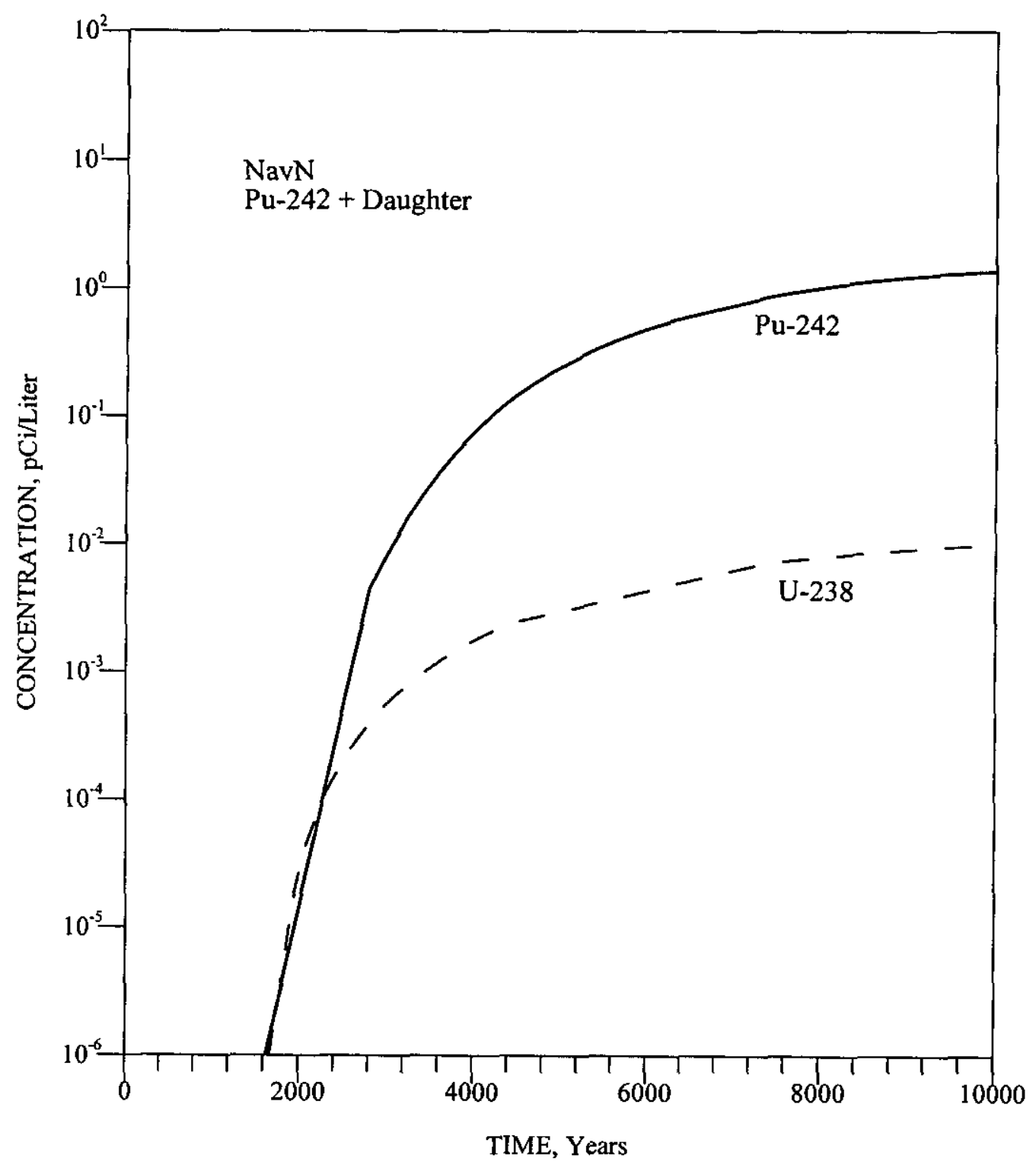

Figure G-55. PORFLOW estimated Pu-242 + Daughter normalized concentration (pCi/liter/Ci inventory) at the 100-meter well for the Naval Reactor Waste Pad (NavN). 


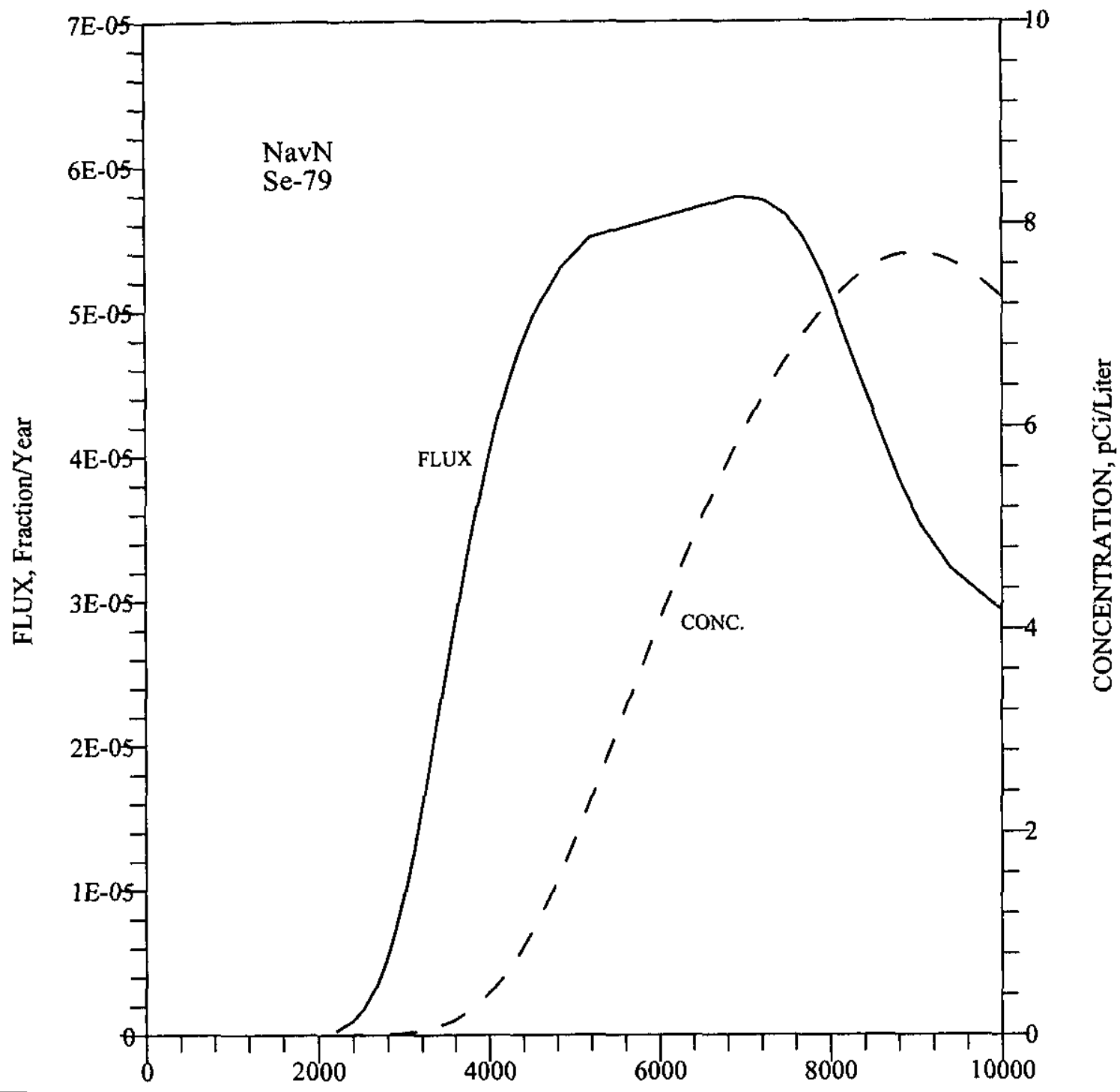

TIME, Years

Figure G-56. PORFLOW estimated Se-79 fractional release (Ci/year/Ci inventory) to the water table and normalized concentration ( $\mathrm{pCi} / \mathrm{liter} / \mathrm{Ci}$ inventory) at the 100-meter well for the Naval Reactor Waste Pad (NavN). 


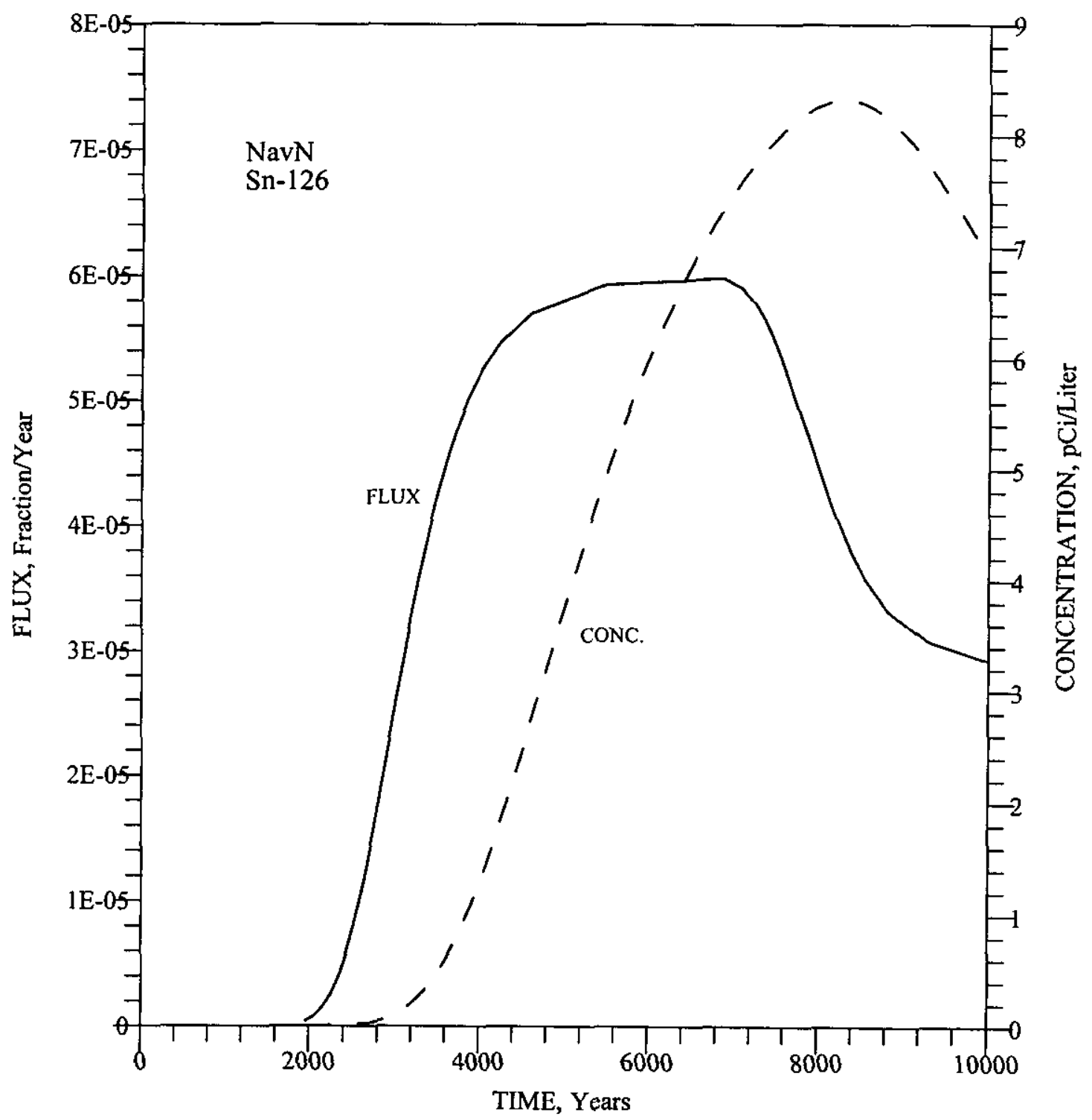

Figure G-57. PORFLOW estimated Sn-126 fractional release ( $\mathrm{Ci} /$ year/Ci inventory) to the water table and normalized concentration ( $\mathrm{pCi} /$ liter/Ci inventory) at the 100 -meter well for the Naval Reactor Waste Pad (NavN). 


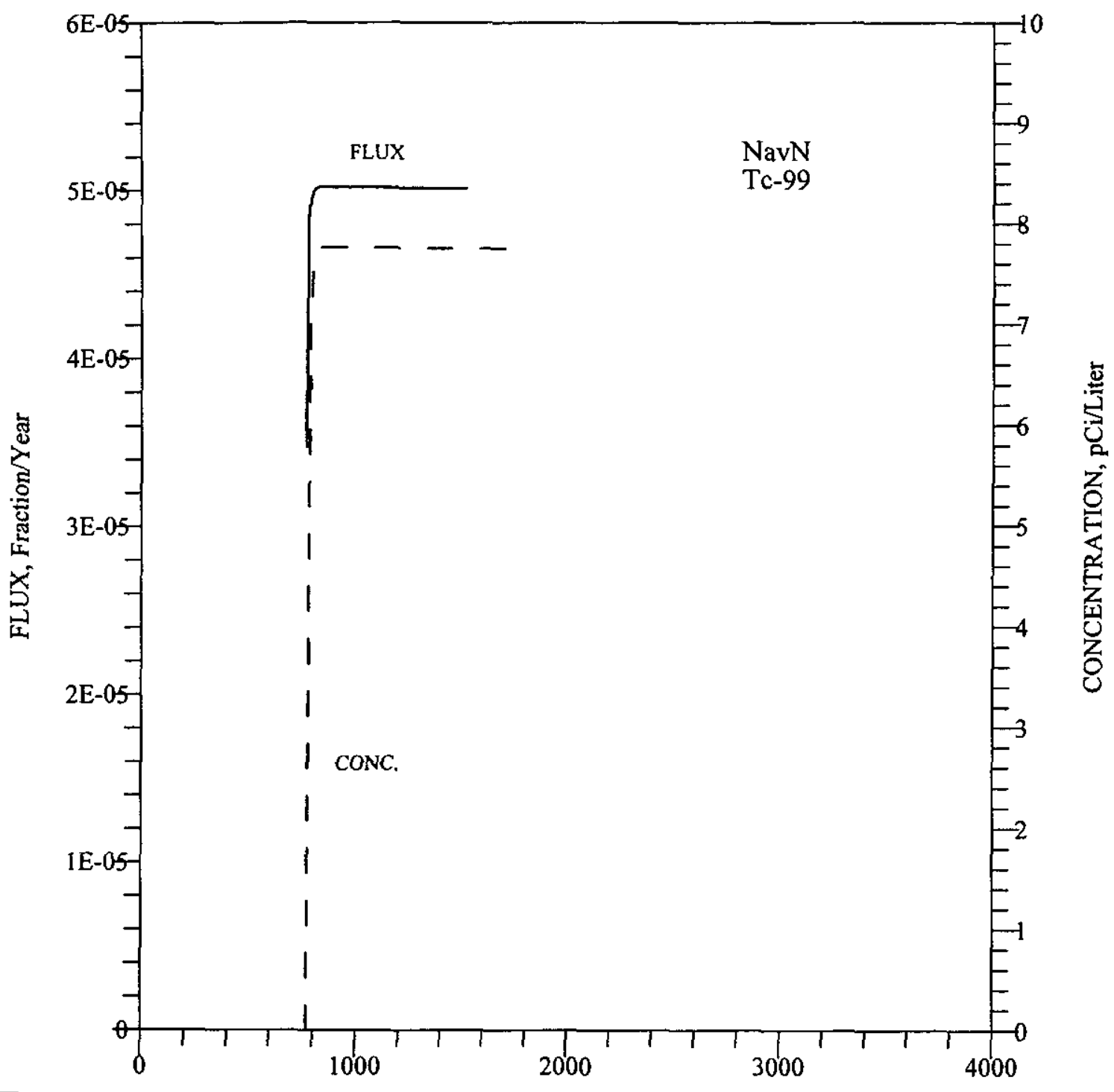

TIME, Years

Figure G-58. PORFLOW estimated Tc-99 fractional release (Ci/year/Ci inventory) to the water table and normalized concentration ( $\mathrm{pCi} /$ /iter/Ci inventory) at the 100-meter well for the Naval Reactor Waste Pad (NavN). 


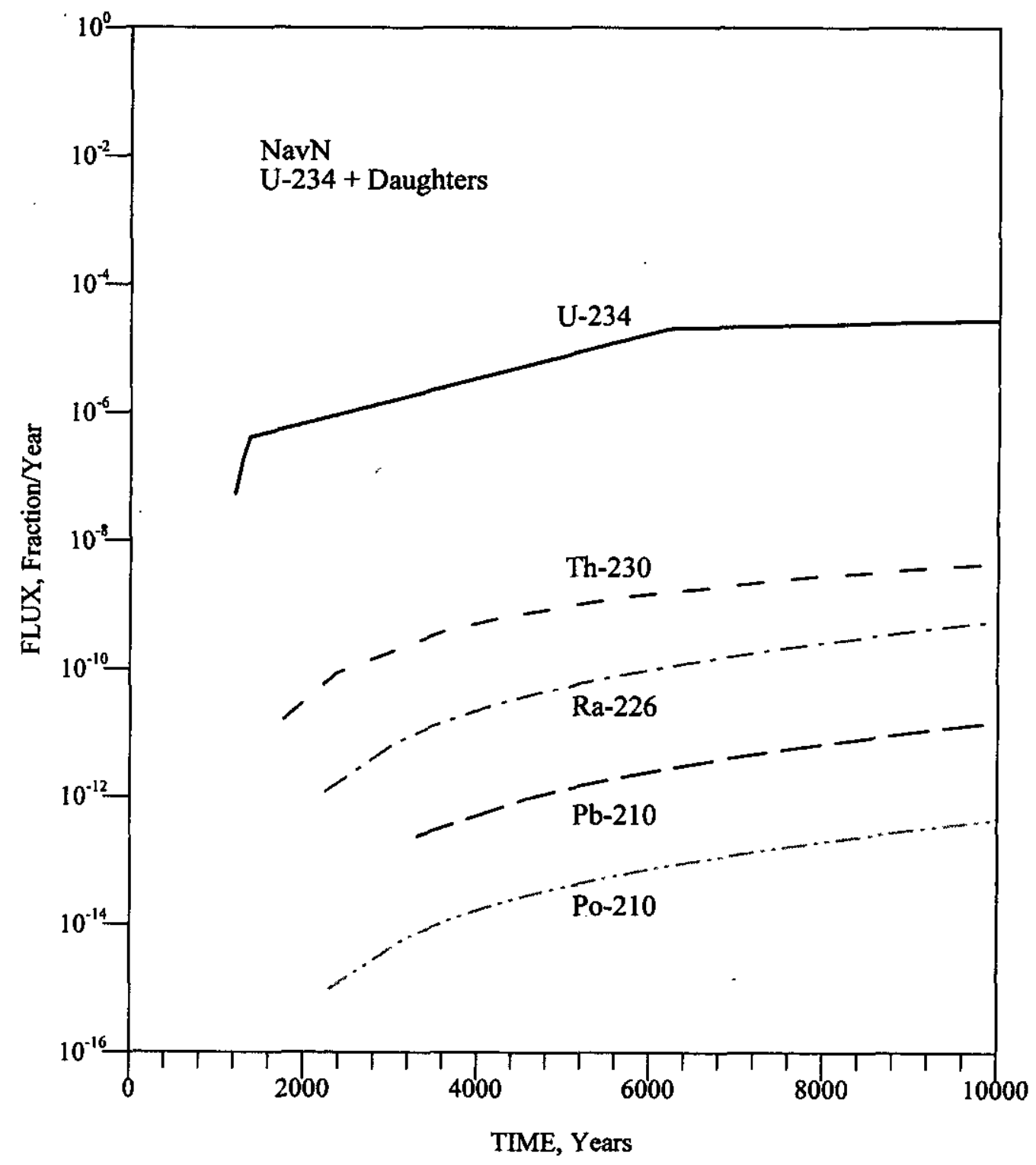

Figure G-59. PORFLOW estimated U-234 + Daughters fractional release (Ci/year/Ci inventory) to the water table for the Naval Reactor Waste Pad (NavN). 


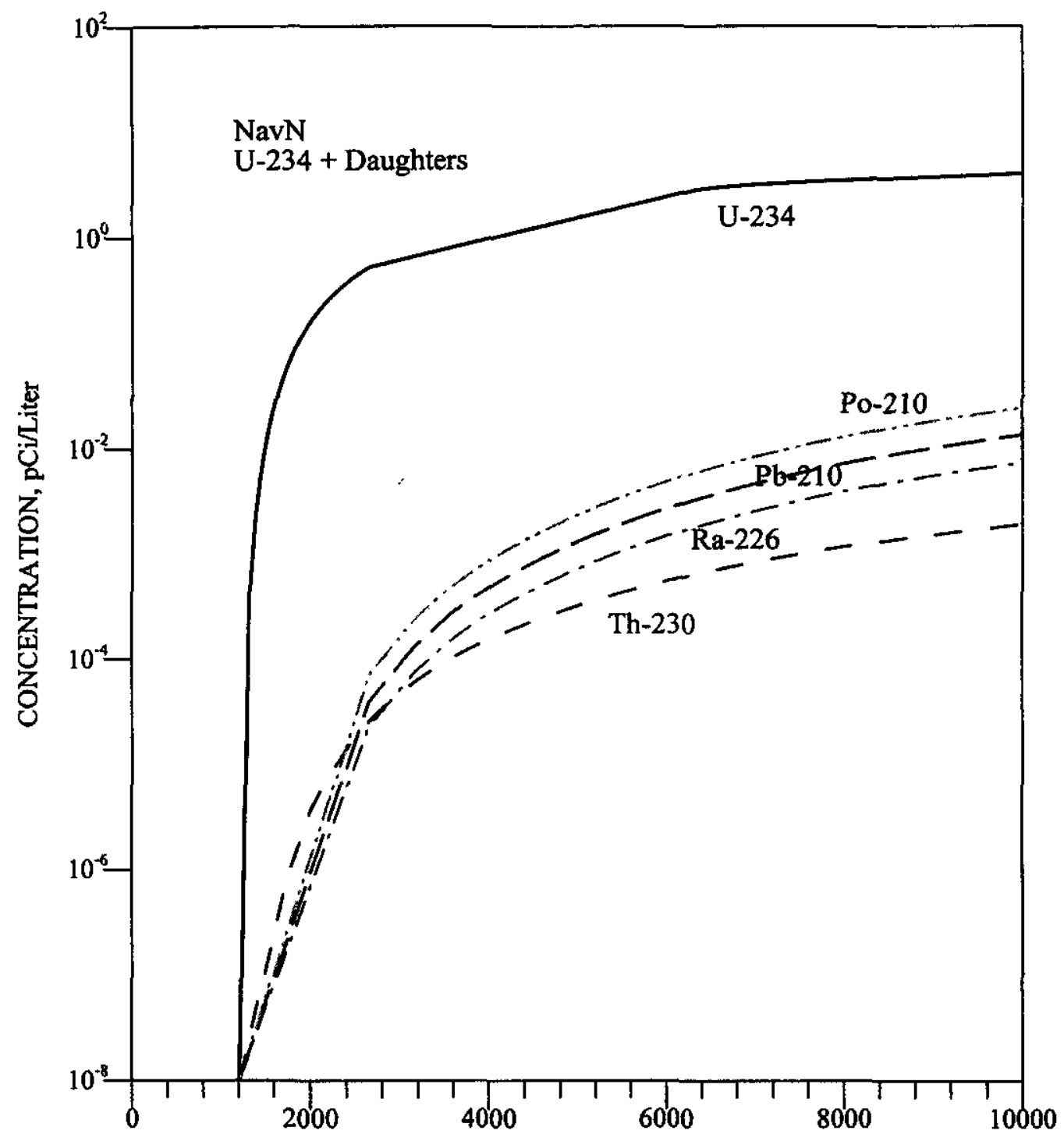

TIME, Years

Figure G-60. PORFLOW estimated U-234 + Daughters normalized concentration (pCi/liter/Ci inventory) at the 100-meter well for the Naval Reactor Waste Pad (NavN). 


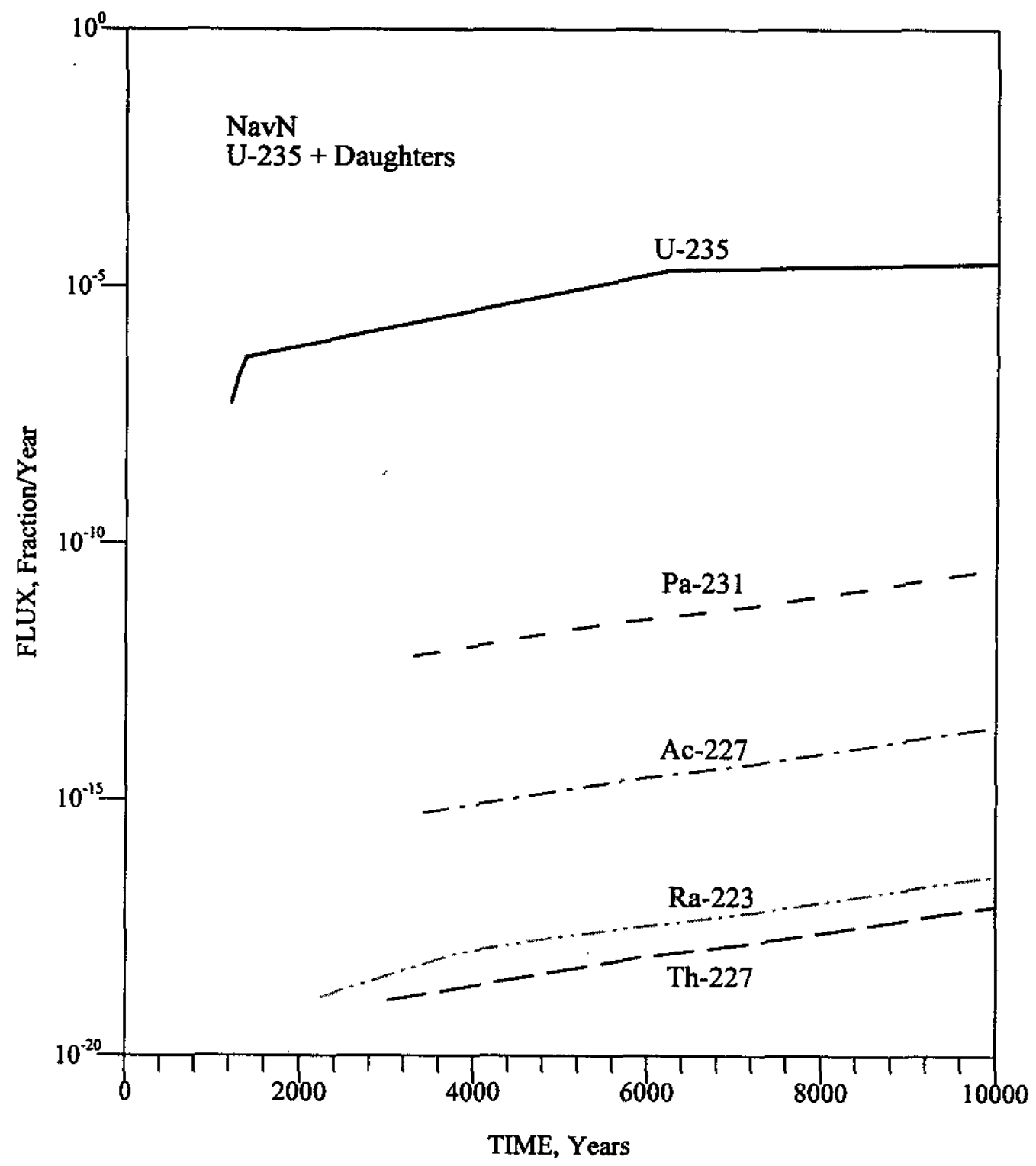

Figure G-61. PORFLOW estimated U-235 + Daughters fractional release (Ci/year/Ci inventory) to the water table for the Naval Reactor Waste Pad (NavN). 


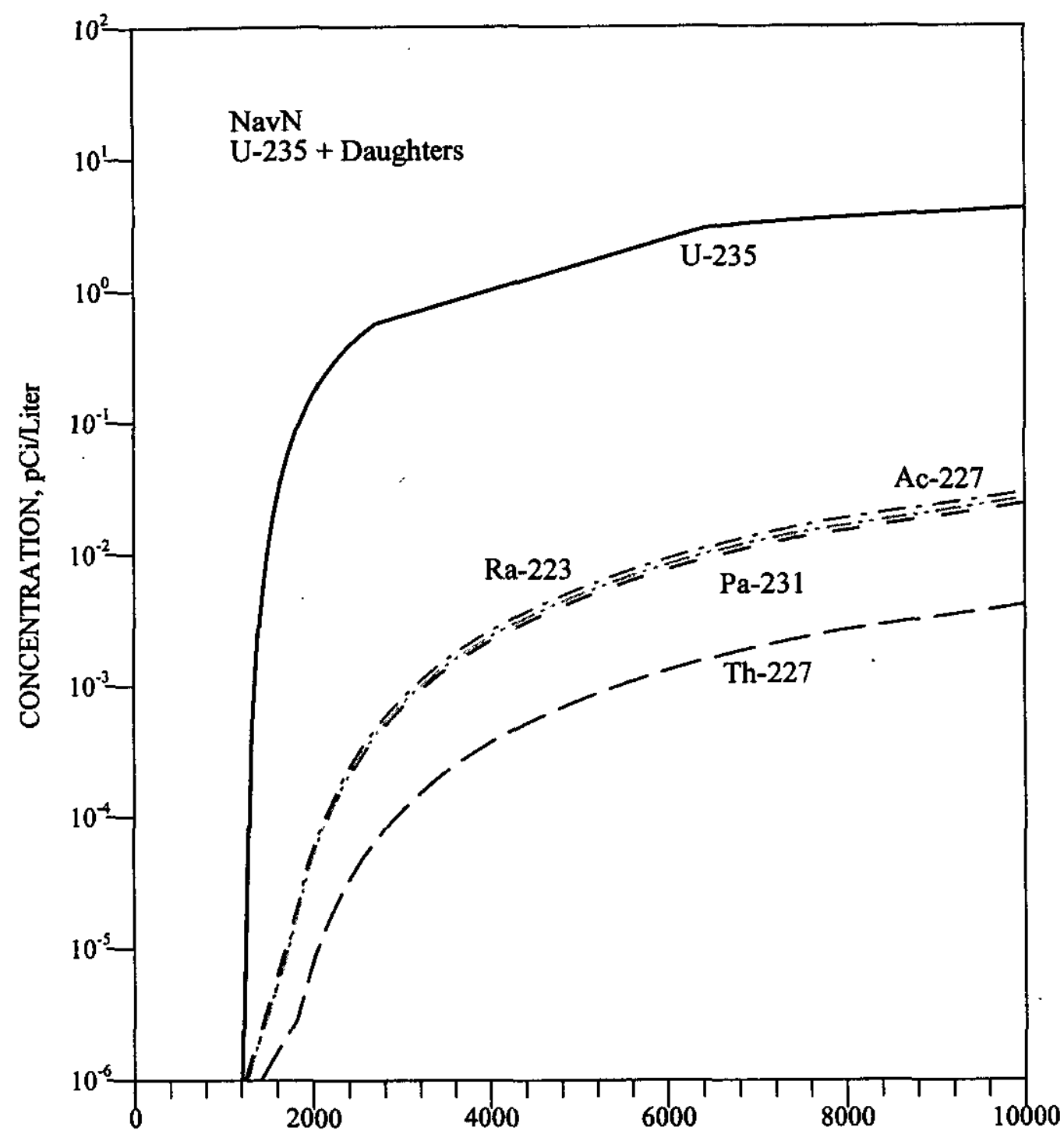

TIME, Years

Figure G-62. PORFLOW estimated U-235 + Daughters normalized concentration (pCi/liter/Ci inventory) at the 100-meter well for the Naval Reactor Waste Pad (NavN). 


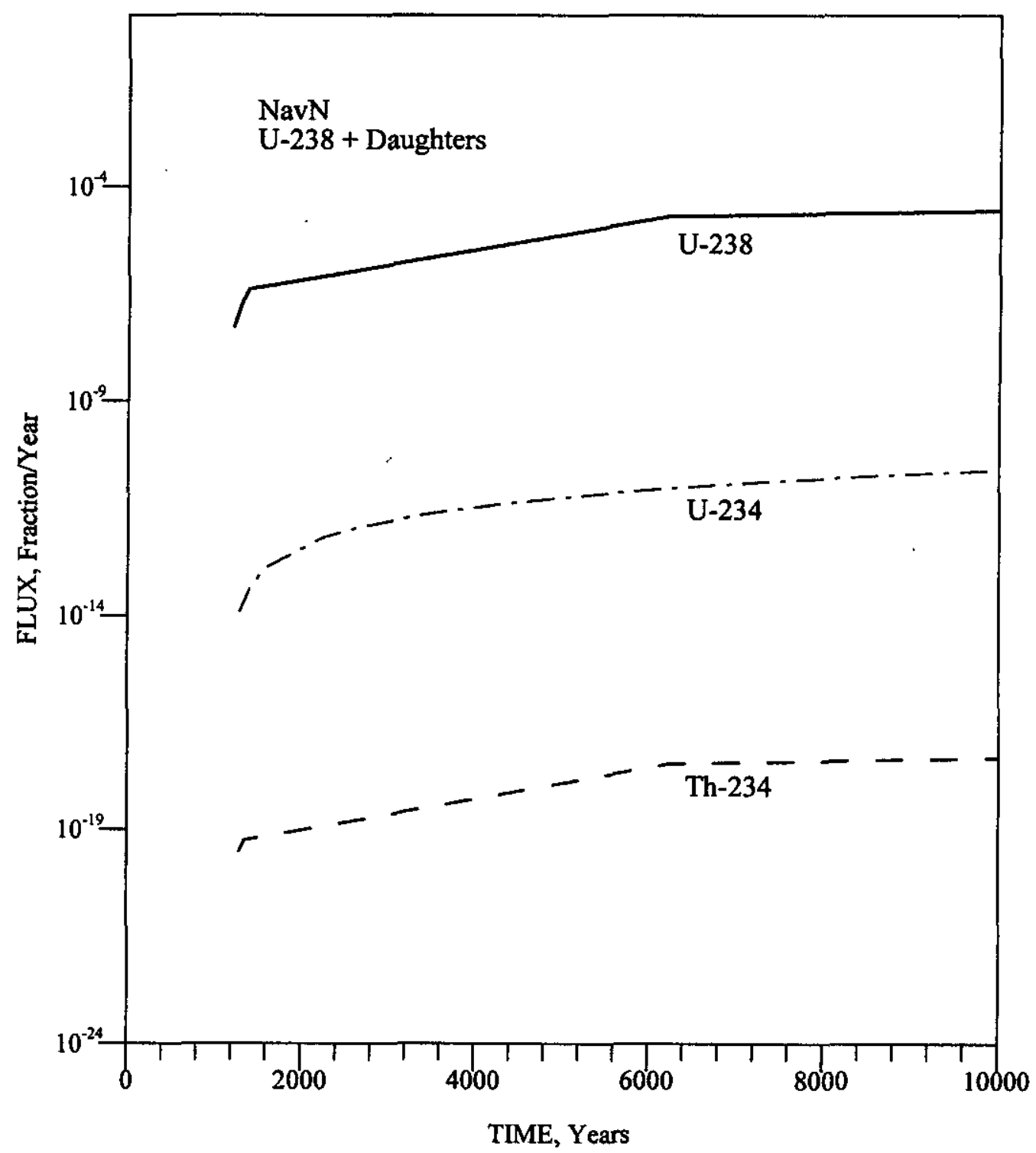

Figure G-63. PORFLOW estimated U-238 + Daughters fractional release (Ci/year/Ci inventory) to the water table for the Naval Reactor Waste Pad (NavN). 


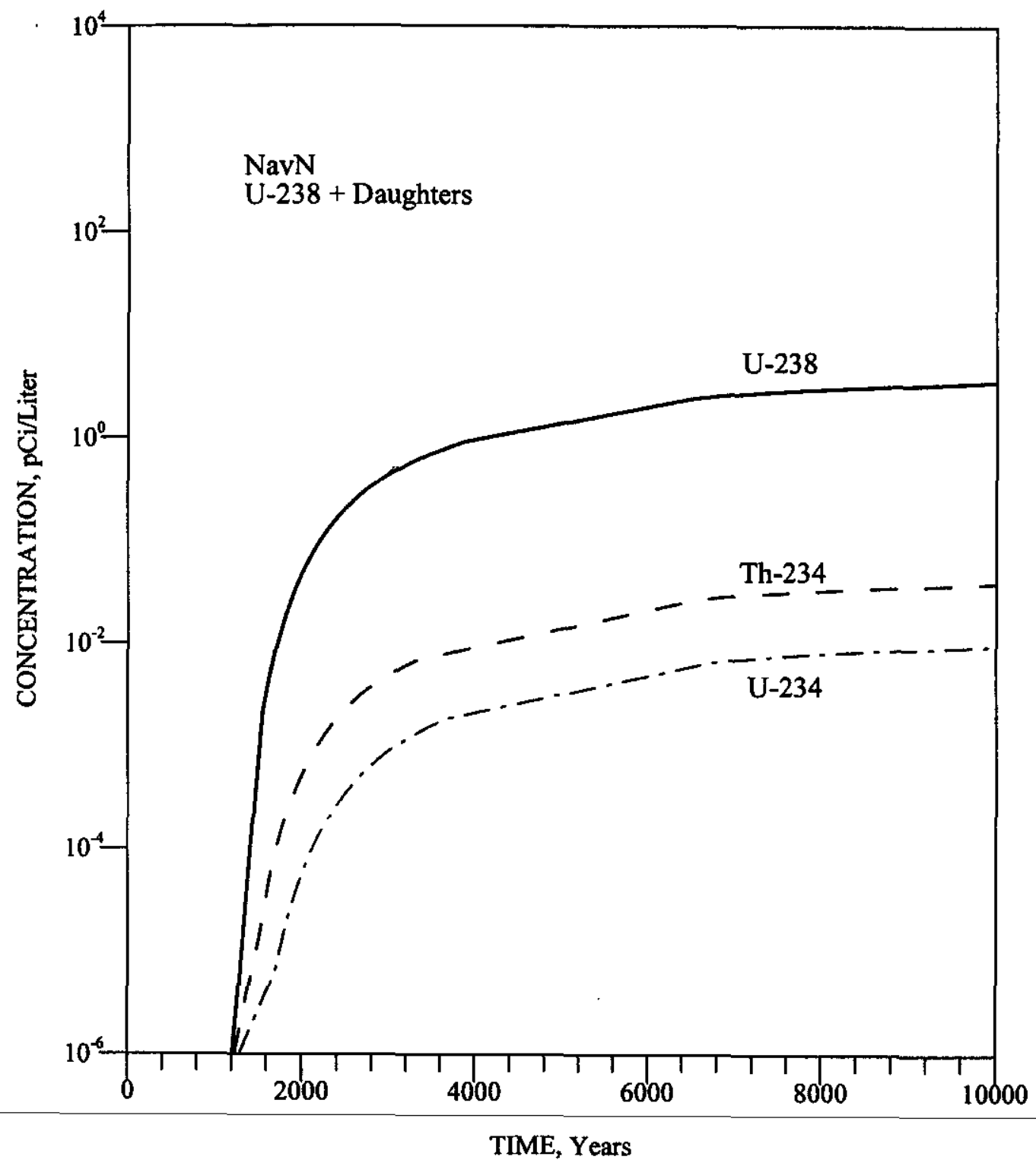

Figure G-64. PORFLOW estimated U-238 + Daughters normalized concentration (pCi/liter/Ci inventory) at the 100-meter well for the Naval Reactor Waste Pad (NavN). 


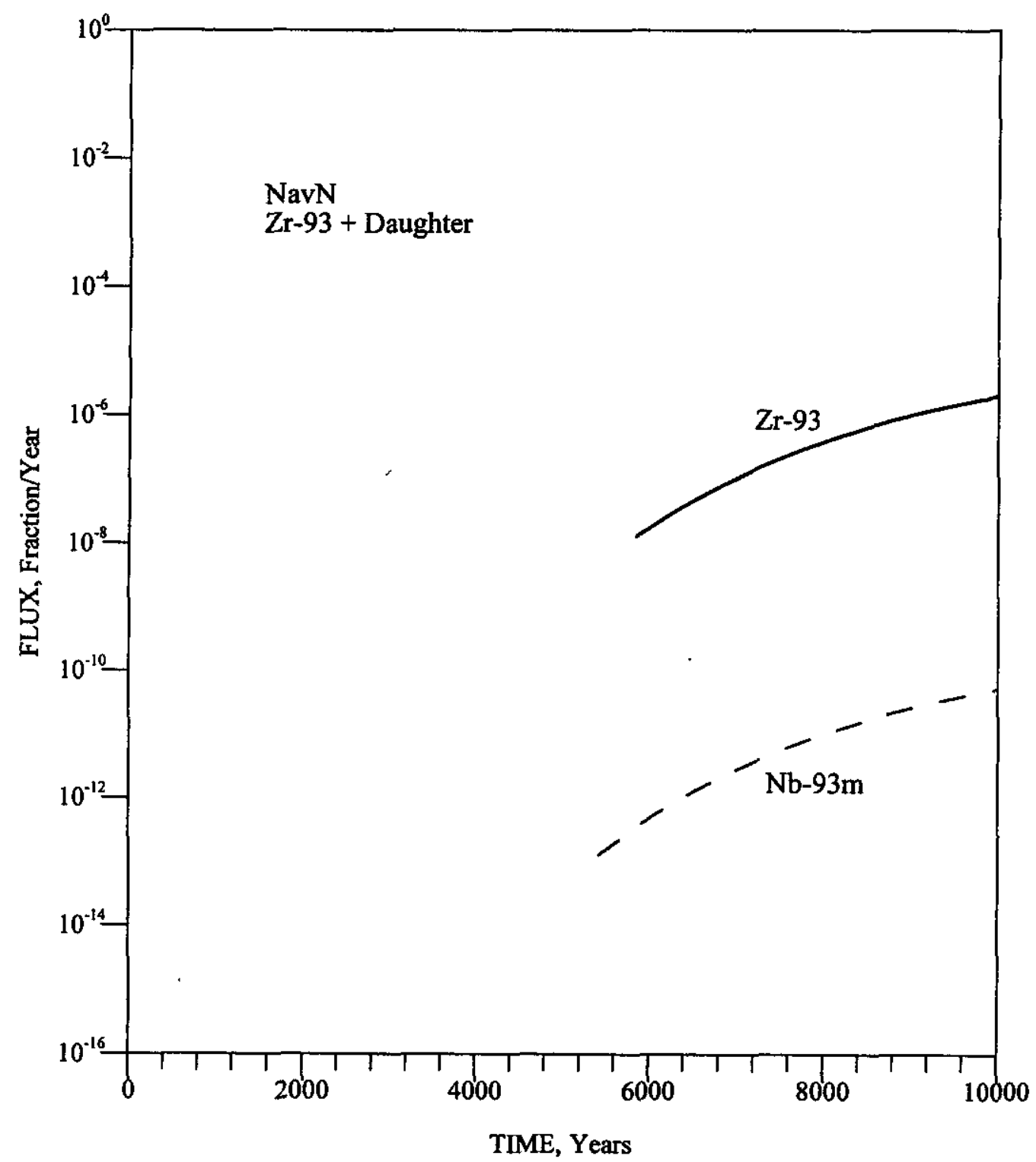

Figure G-65. PORFLOW estimated Zr-93 + Daughter fractional release (Ci/year/Ci inventory) to the water table for the Naval Reactor Waste Pad (NavN). 


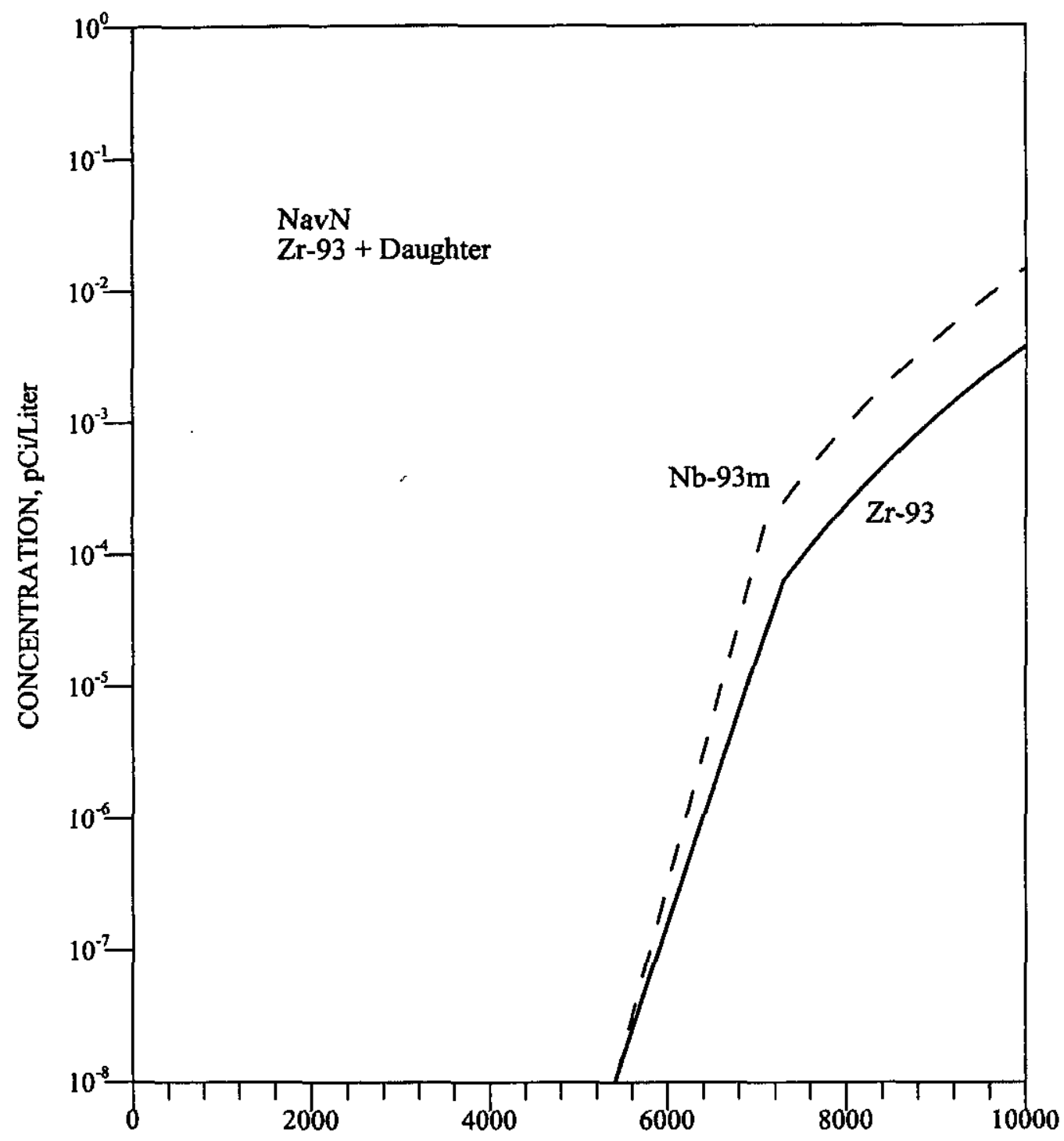

TIME, Years

Figure G-66. PORFLOW estimated Zr-93 + Daughter normalized concentration (pCi/liter/Ci inventory) at the 100-meter well for the Naval Reactor Waste Pad (NavN). 


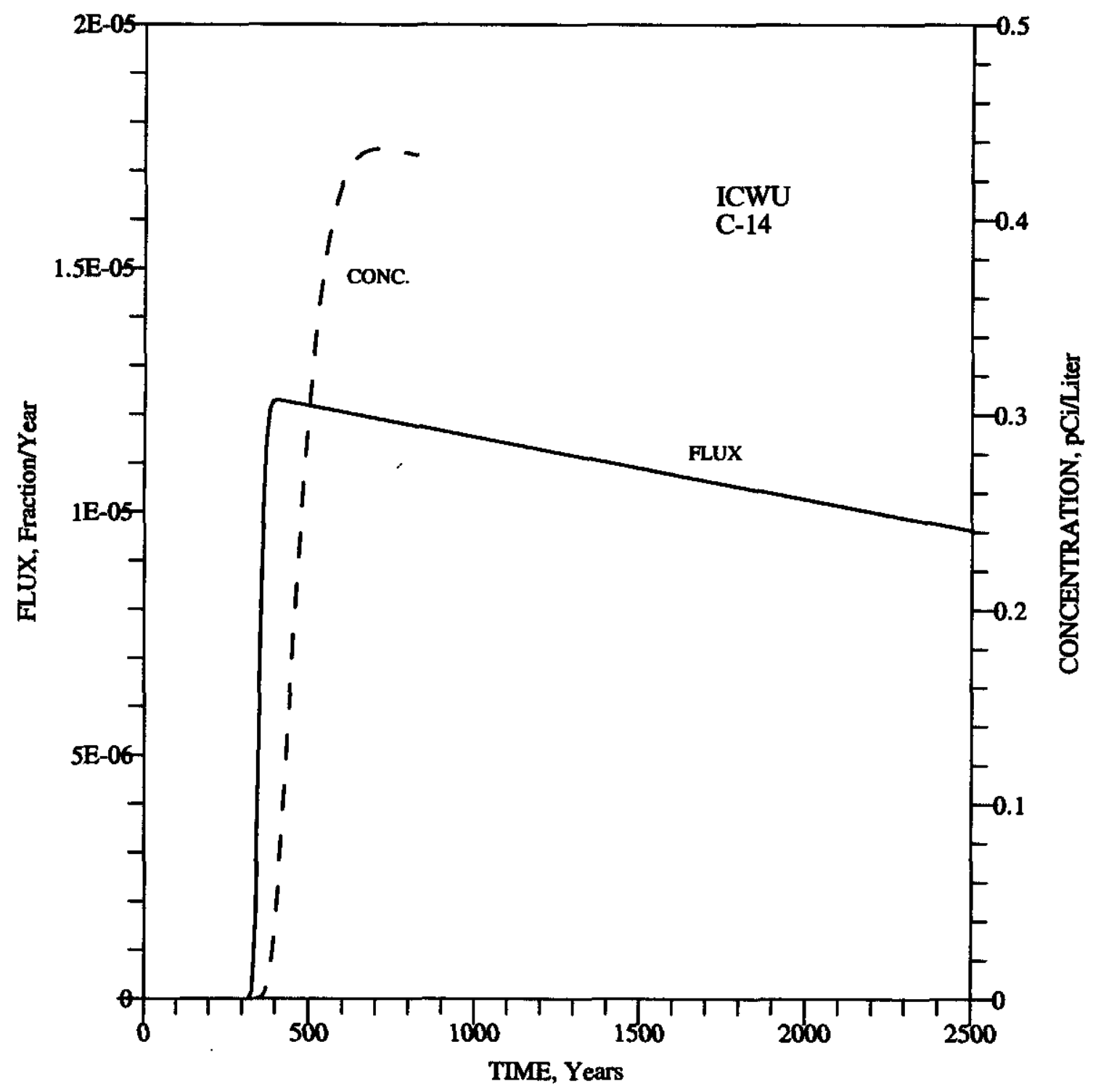

Figure G-67. PORFLOW estimated C-14 fractional release (Ci/year/Ci inventory) to the water table and normalized concentration ( $\mathrm{pCi} / \mathrm{iter} / \mathrm{C}$ inventory) at the 100-meter well for the Intimately-mixed Cement-stabilized Waste Units (ICWU). 


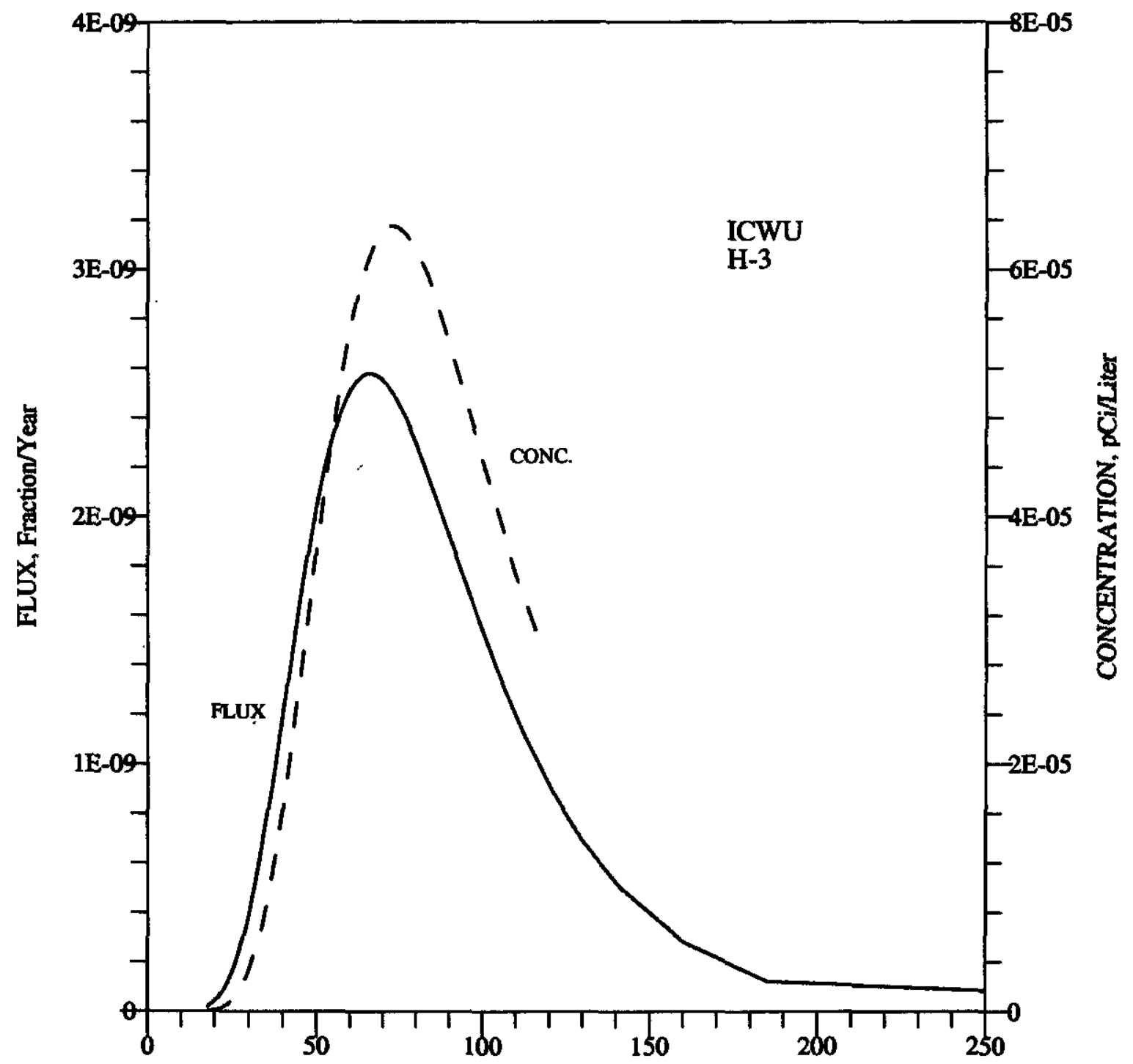

TIME, Years

Figure G-68. PORFLOW estimated H-3 fractional release (Ci/year/Ci inventory) to the water table and normalized concentration ( $\mathrm{pCi} / \mathrm{iter} / \mathrm{Ci}$ inventory) at the 100-meter well for the Intimately-mixed Cement-stabilized Waste Units (ICWU). 


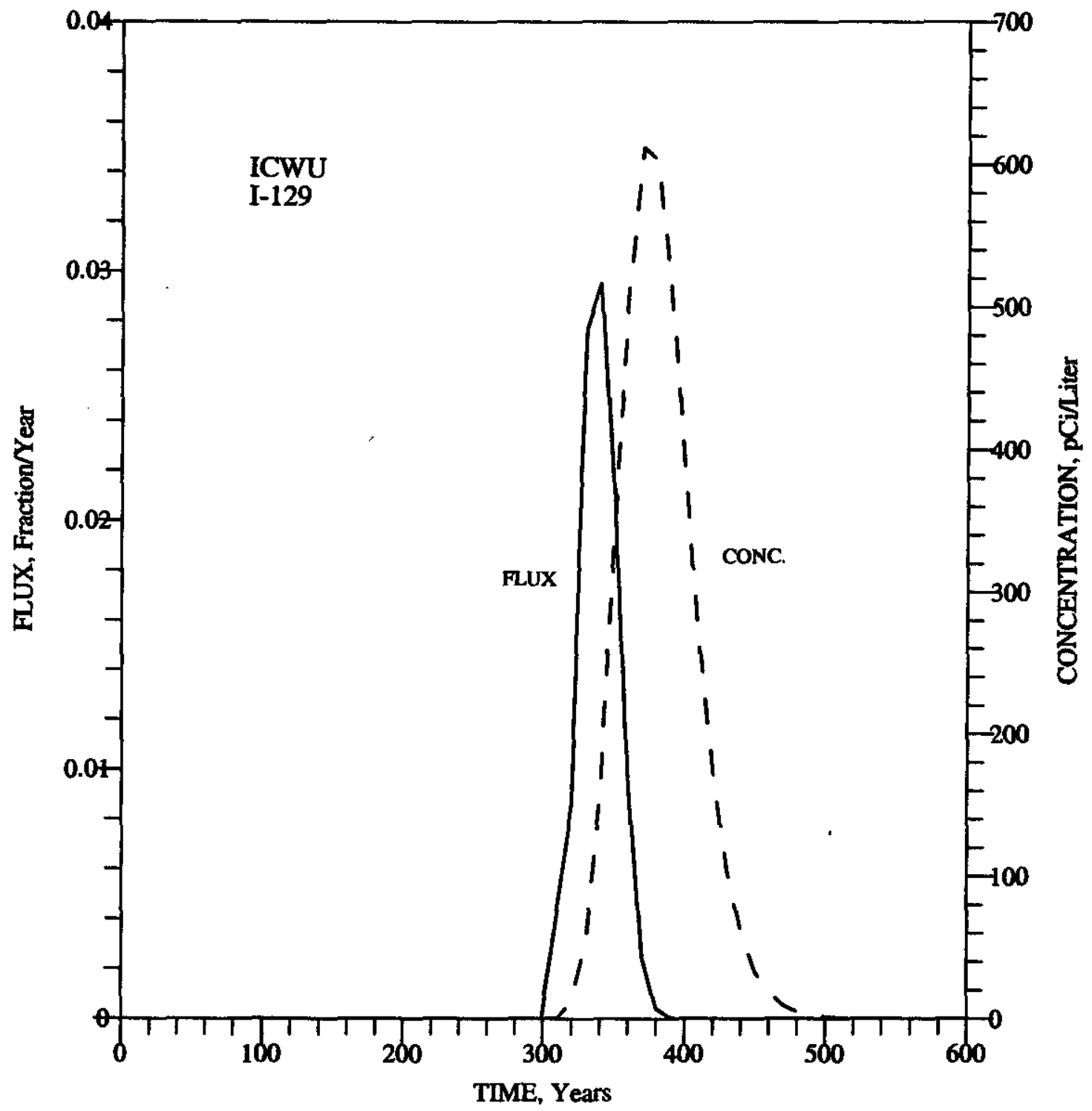

Figure G-69. PORFLOW estimated I-129 fractional release (Ci/year/Ci inventory) to the water table and normalized concentration ( $\mathrm{pCi} /$ iter/ $\mathrm{C}$ inventory) at the 100 -meter well for the Intimately-mixed Cement-stabilized Waste Units (ICWU). 


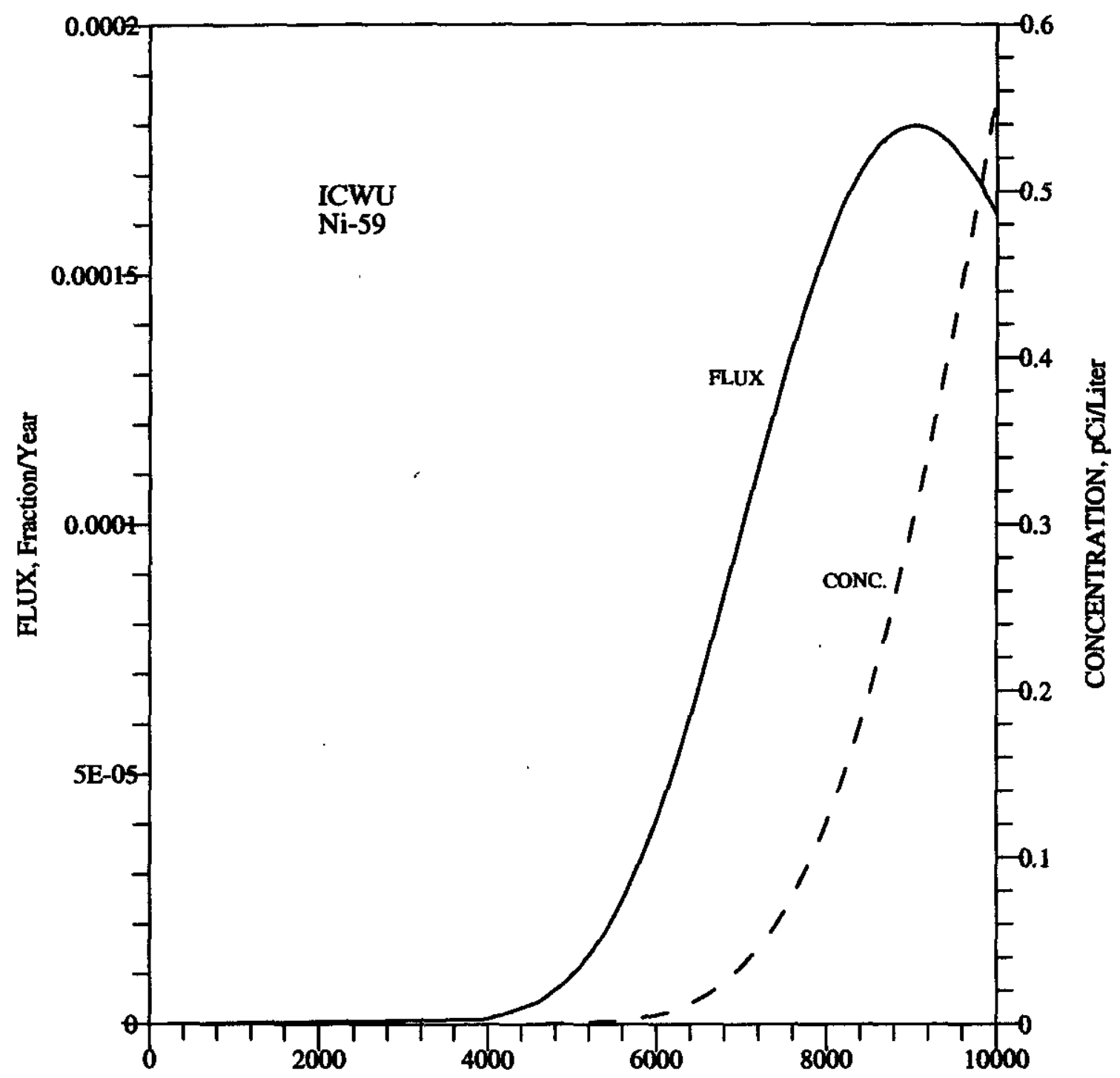

TIME, Years

Figure G-70. PORFLOW estimated Ni-59 fractional release (Ci/year/Ci inventory) to the water table and normalized concentration ( $\mathrm{pCM} / \mathrm{iter} / \mathrm{C}$ inventory) at the 100 -meter well for the Intimately-mixed Cement-stabilized Waste Units (ICWU). 


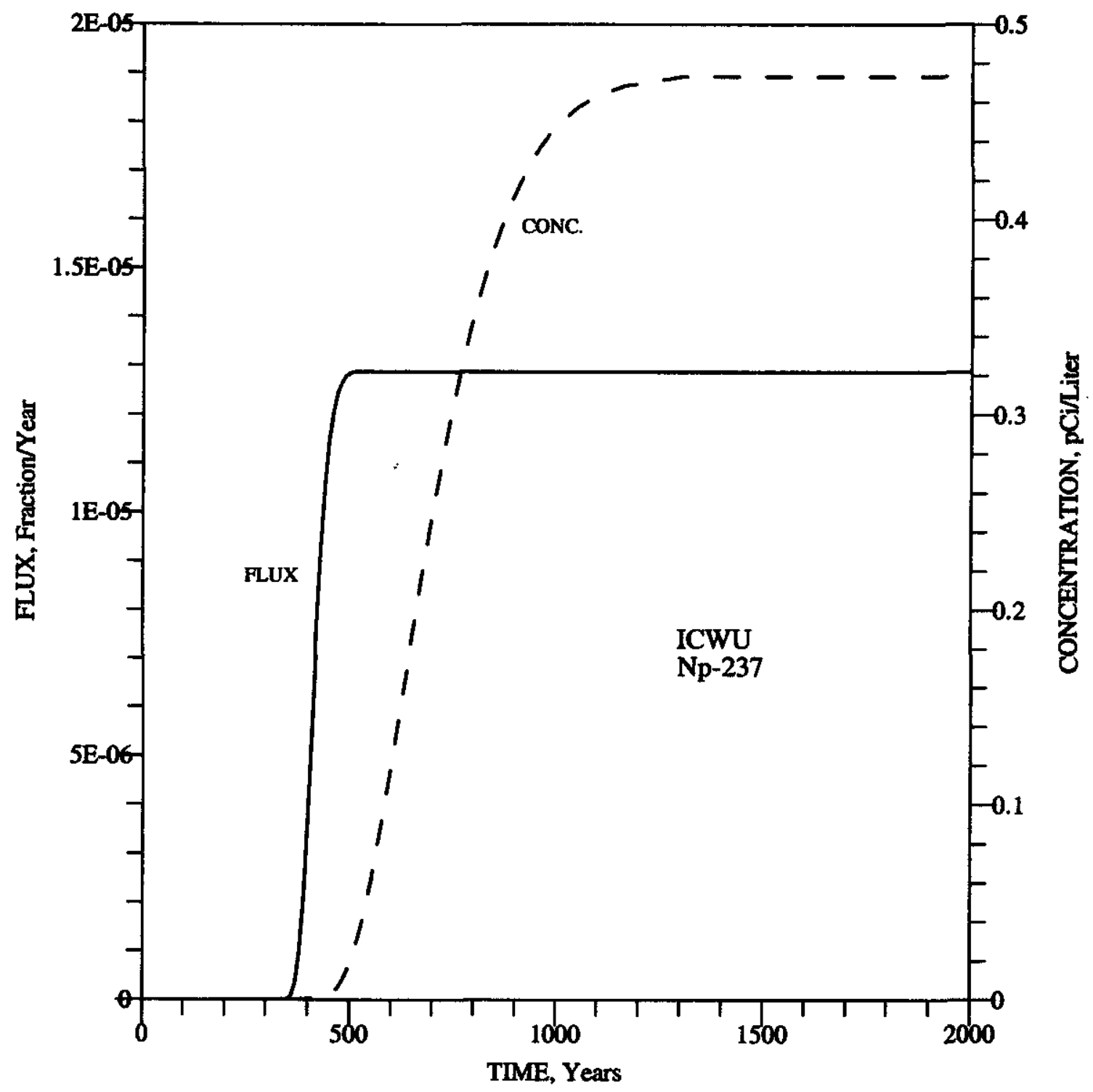

Figure G-71. PORFLOW estimated Np-237 fractional release (Ci/year/Ci inventory) to the water table and normalized concentration (pCi/iter/Ci inventory) at the 100 -meter well for the Intimately-mixed Cement-stabilized Waste Units (ICWU). 


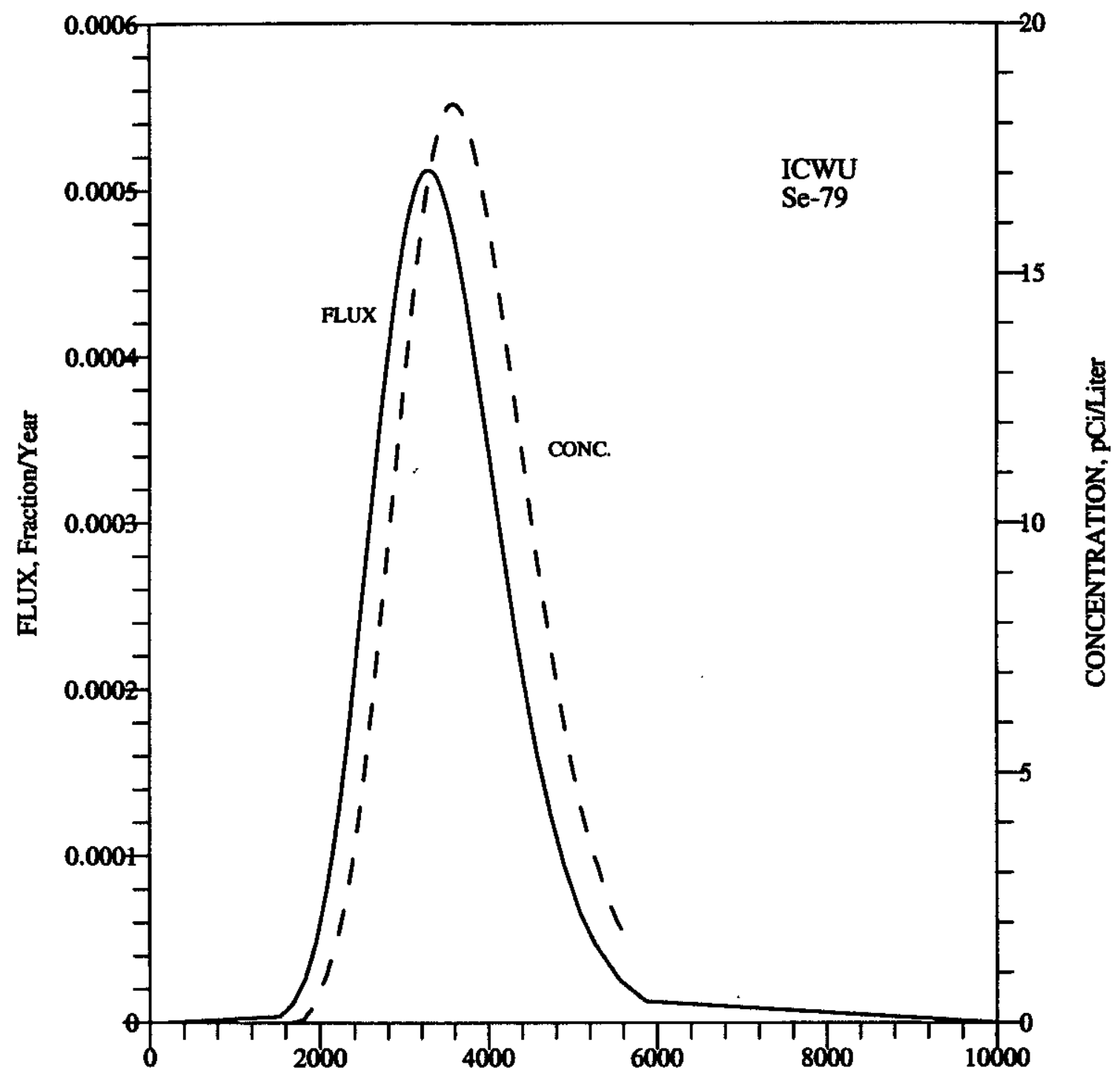

TIME, Years

Figure G-72. PORFLOW estimated Se-79 fractional release (Ci/year/Ci inventory) to the water table and normalized concentration ( $\mathrm{pCl} / \mathrm{iter} / \mathrm{C}$ inventory) at the 100-meter well for the Intimately-mixed Cement-stabilized Waste Units (ICWU). 


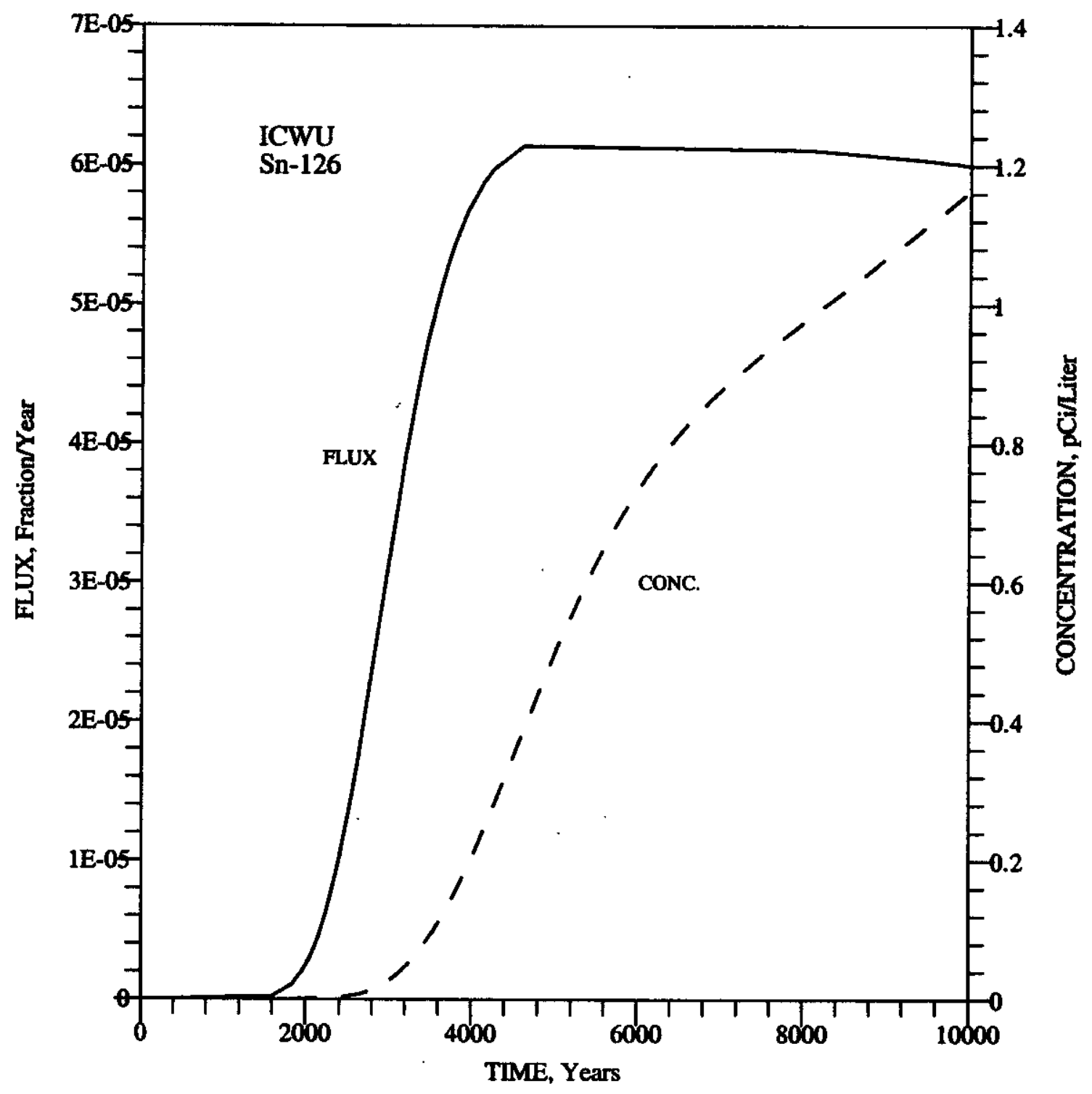

Figure G-73. PORFLOW estimated Sn-126 fractional release (Ci/year/Ci inventory) to the water table and normalized concentration (pCi/liter/ $\mathrm{C}$ inventory) at the 100-meter well for the Intimately-mixed Cement-stabilized Waste Units (ICWU). 


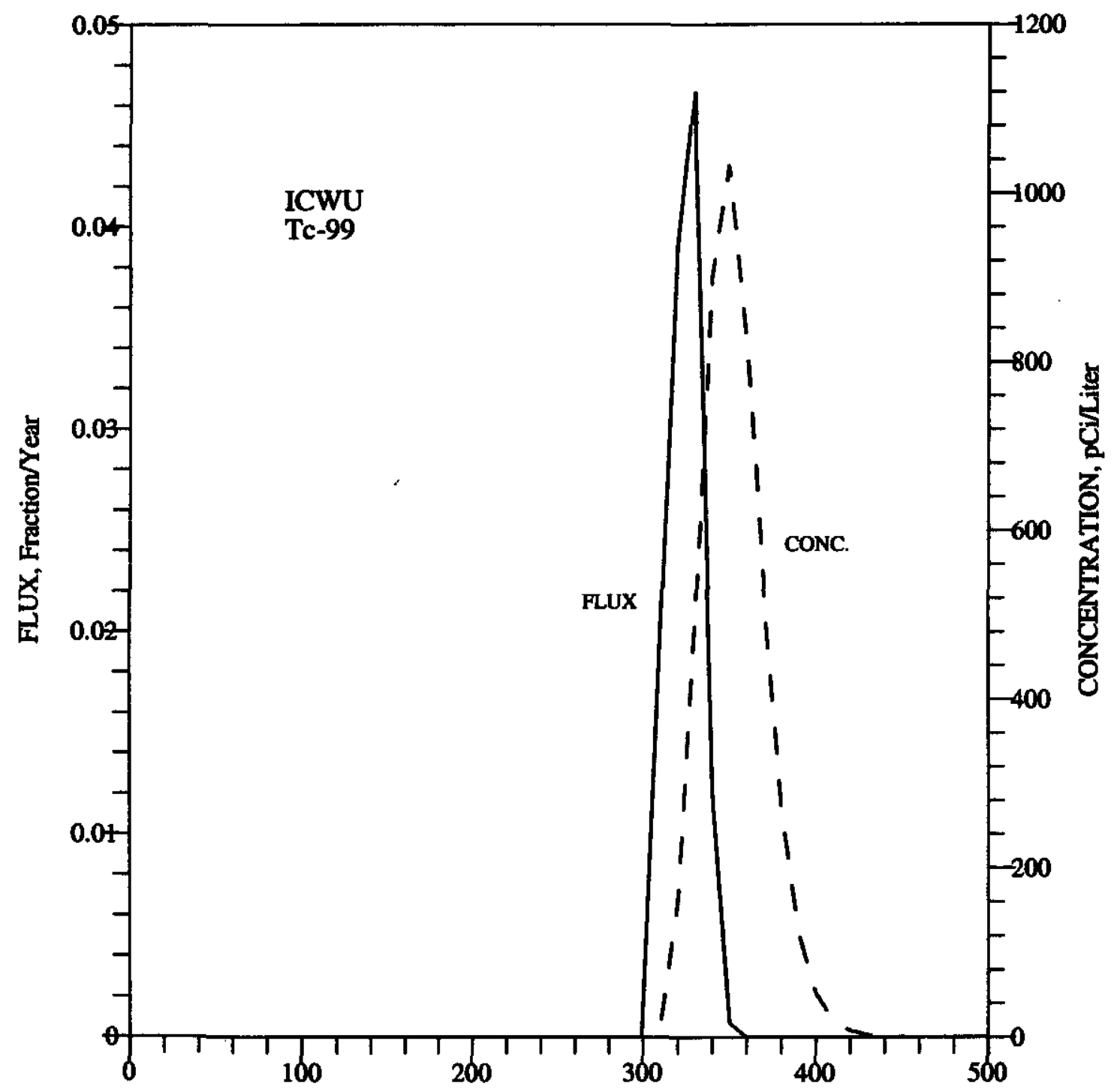

TIME, Years

Figure G-74. PORFLOW estimated Tc-99 fractional release (Ci/year/Ci inventory) to the water table and normalized concentration (pCi/iter/ $\mathrm{Ci}$ inventory) at the 100-meter well for the Intimately-mixed Cement-stabilized Waste Units (ICWU). 


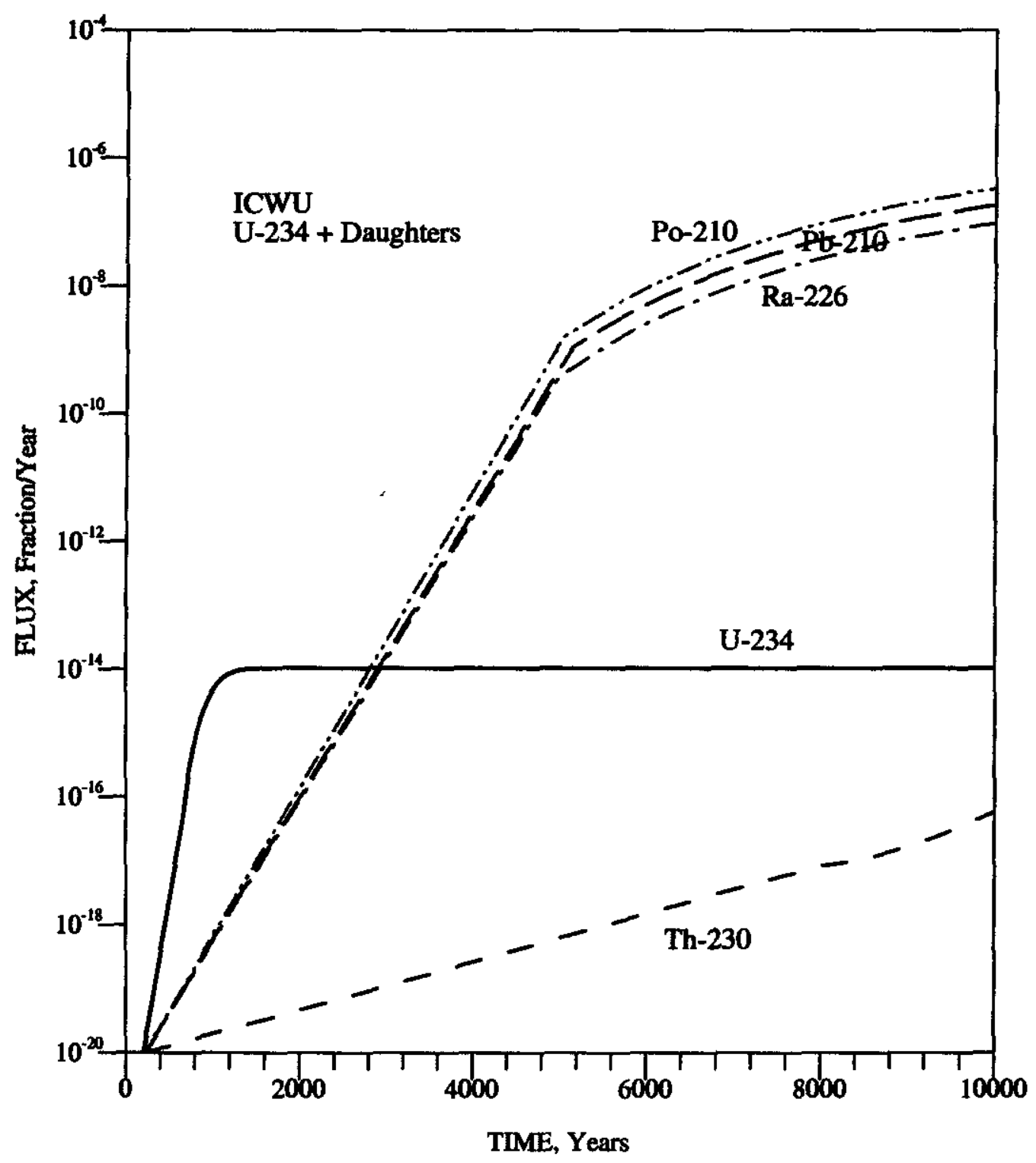

Figure G-75. PORFLOW estimated U-234 + Daughters fractional release (Ci/year/Ci inventory) to the water table for the Intimately-mixed Cement-stabilized Waste Units (ICWU). 


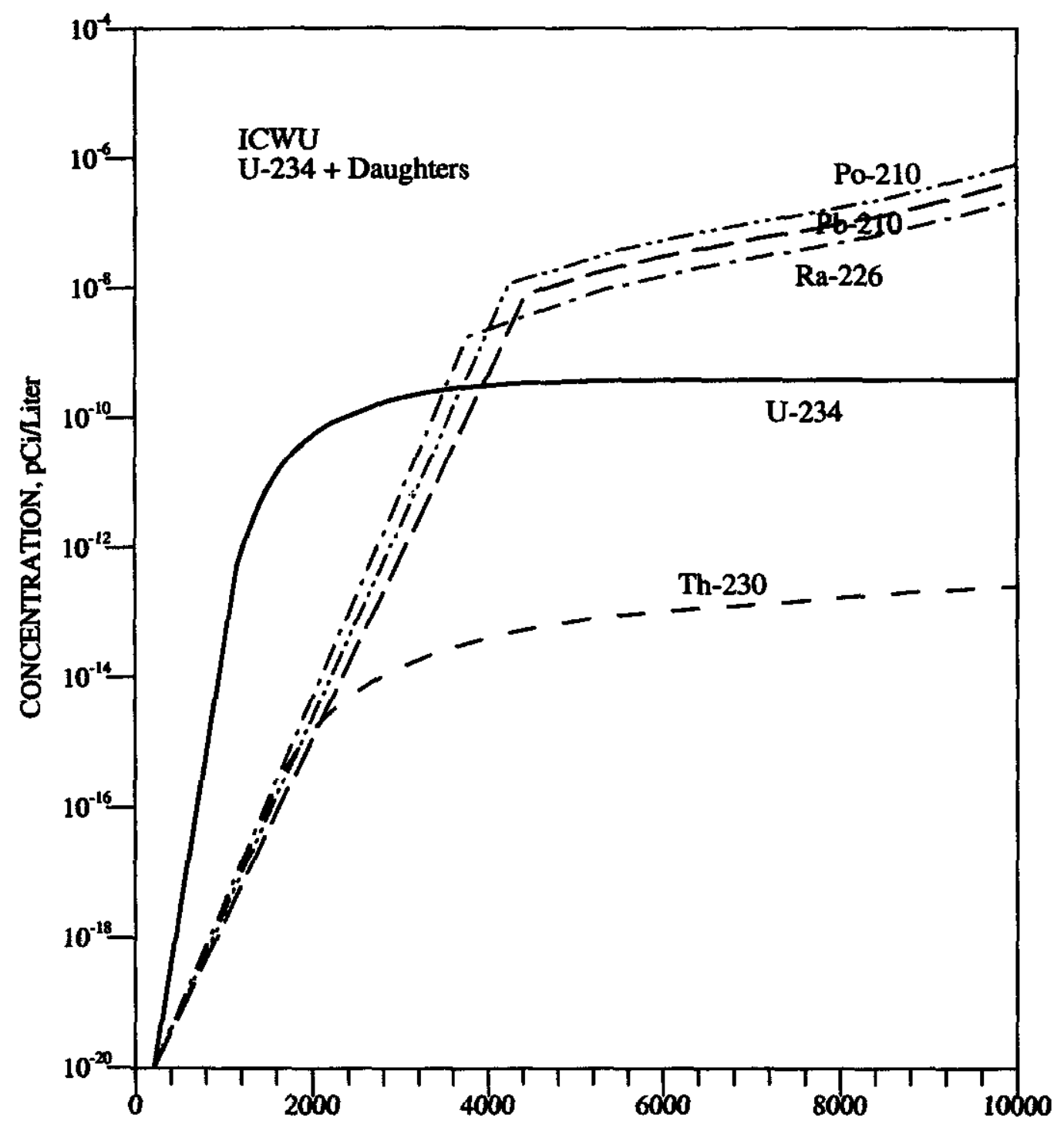

TIME, Years

Figure G-76. PORFLOW estimated U-234 + Daughters normalized concentration (pCi/iter/Ci inventory) at the 100-meter well for the Intimately-mixed Cement-stabilized Waste Units (ICWU). 


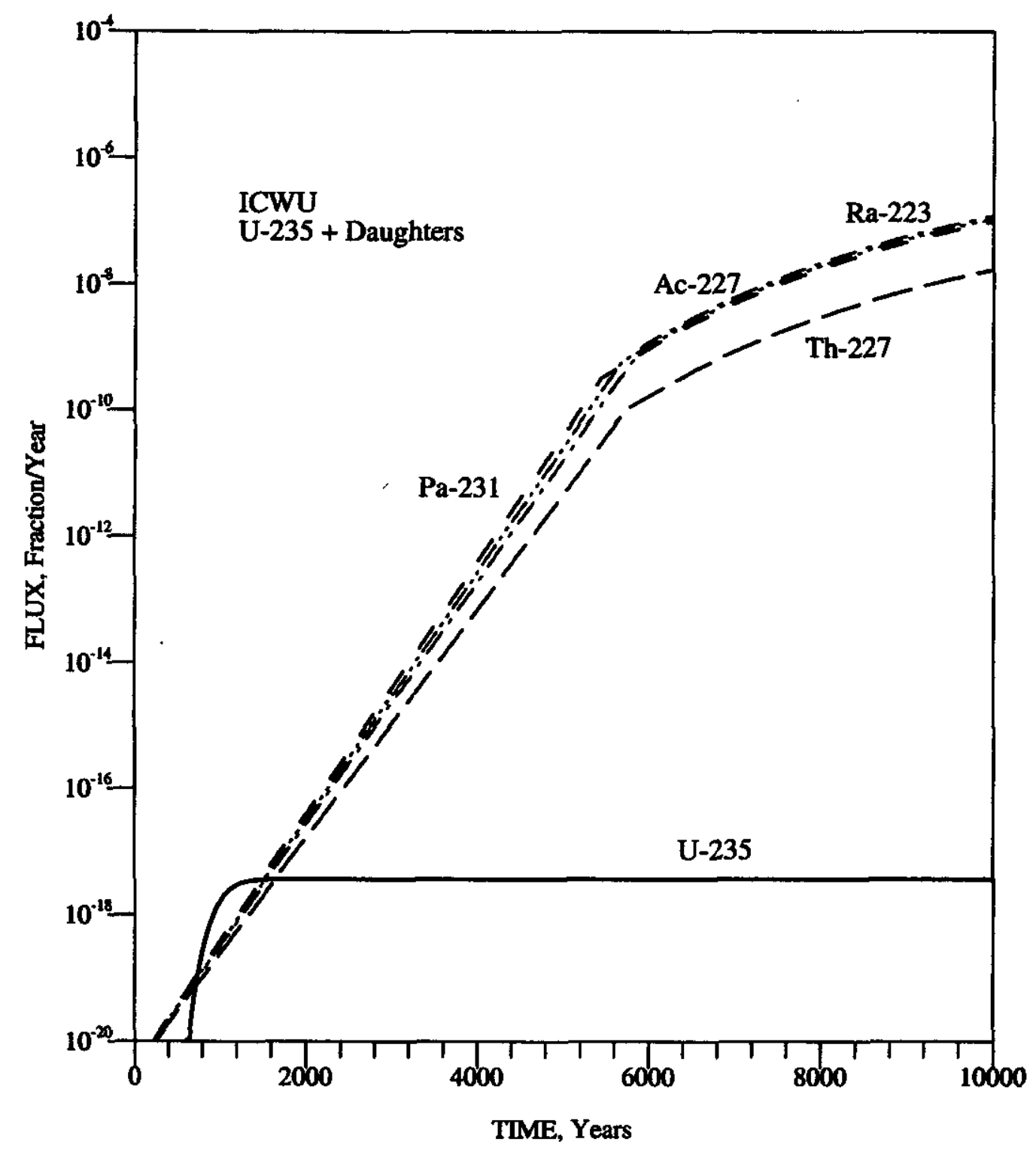

Figure G-77. PORFLOW estimated U-235 + Daughters fractional release (Ci/year/Ci inventory) to the water table for the Intimately-mixed Cement-stabilized Waste Units (ICWU). 


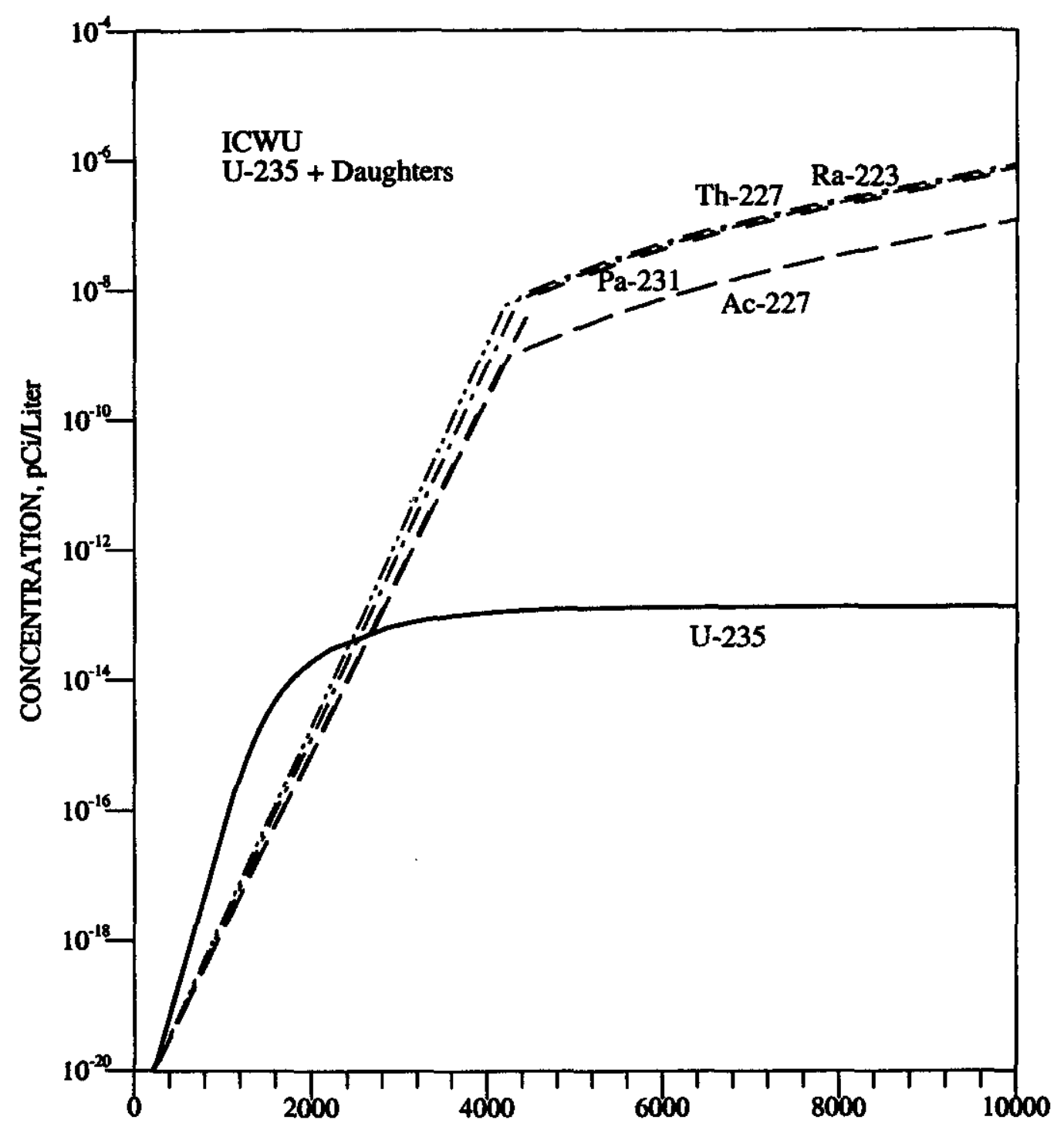

TIME, Years

Figure G-78. PORFLOW estimated U-235 + Daughters normalized concentration (pCi/iter/Ci inventory) at the 100-meter well for the Intimately-mixed Cement-stabilized Waste Units (ICWU). 


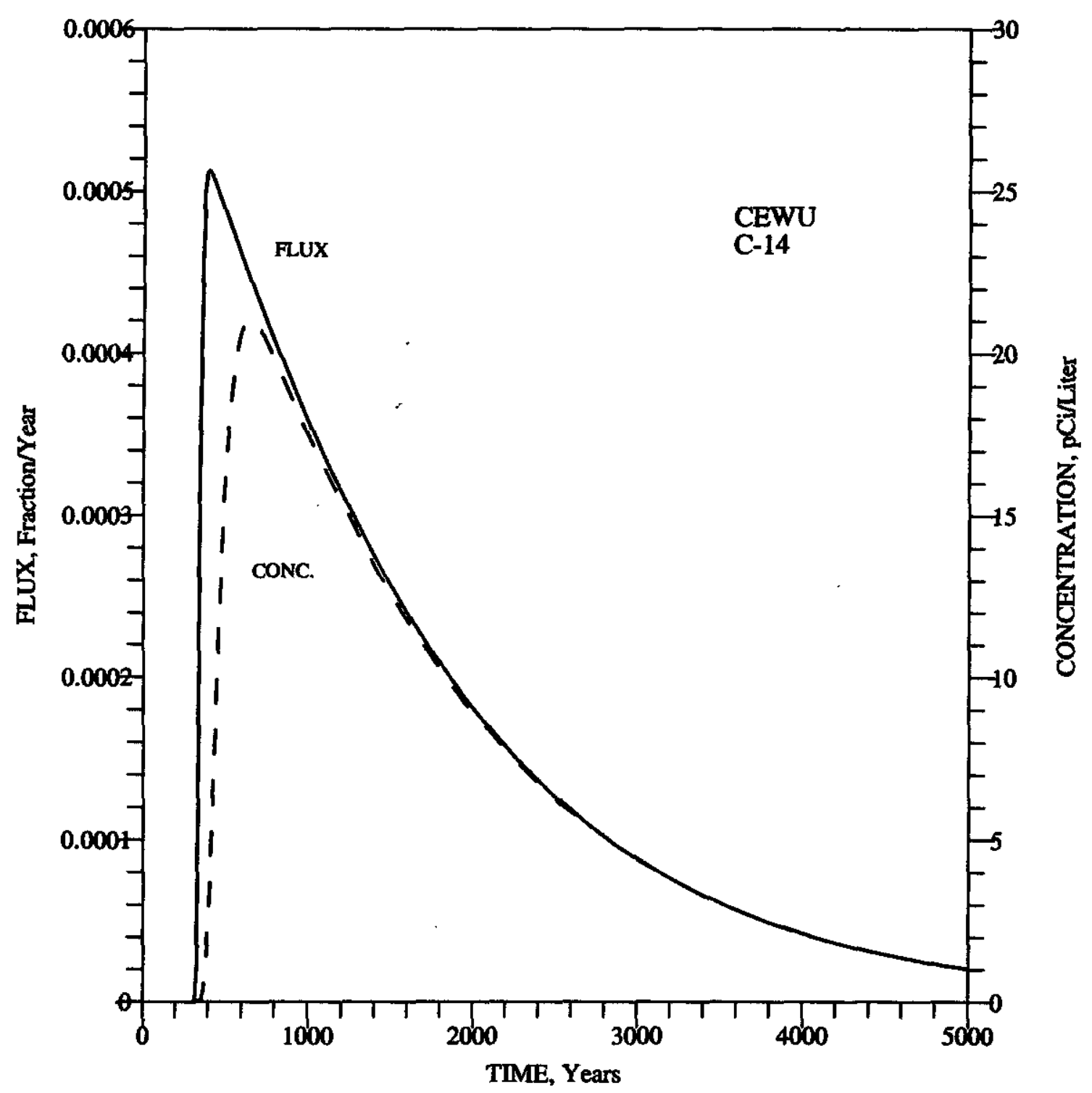

Figure G-79. PORFLOW estimated C-14 fractional release (Ci/year/Ci inventory) to the water table and normalized concentration ( $\mathrm{pCi} / \mathrm{iter} / \mathrm{Ci}$ inventory) at the 100-meter well for the Cement-stabilized Encapsulated Waste Units (CEWU). 


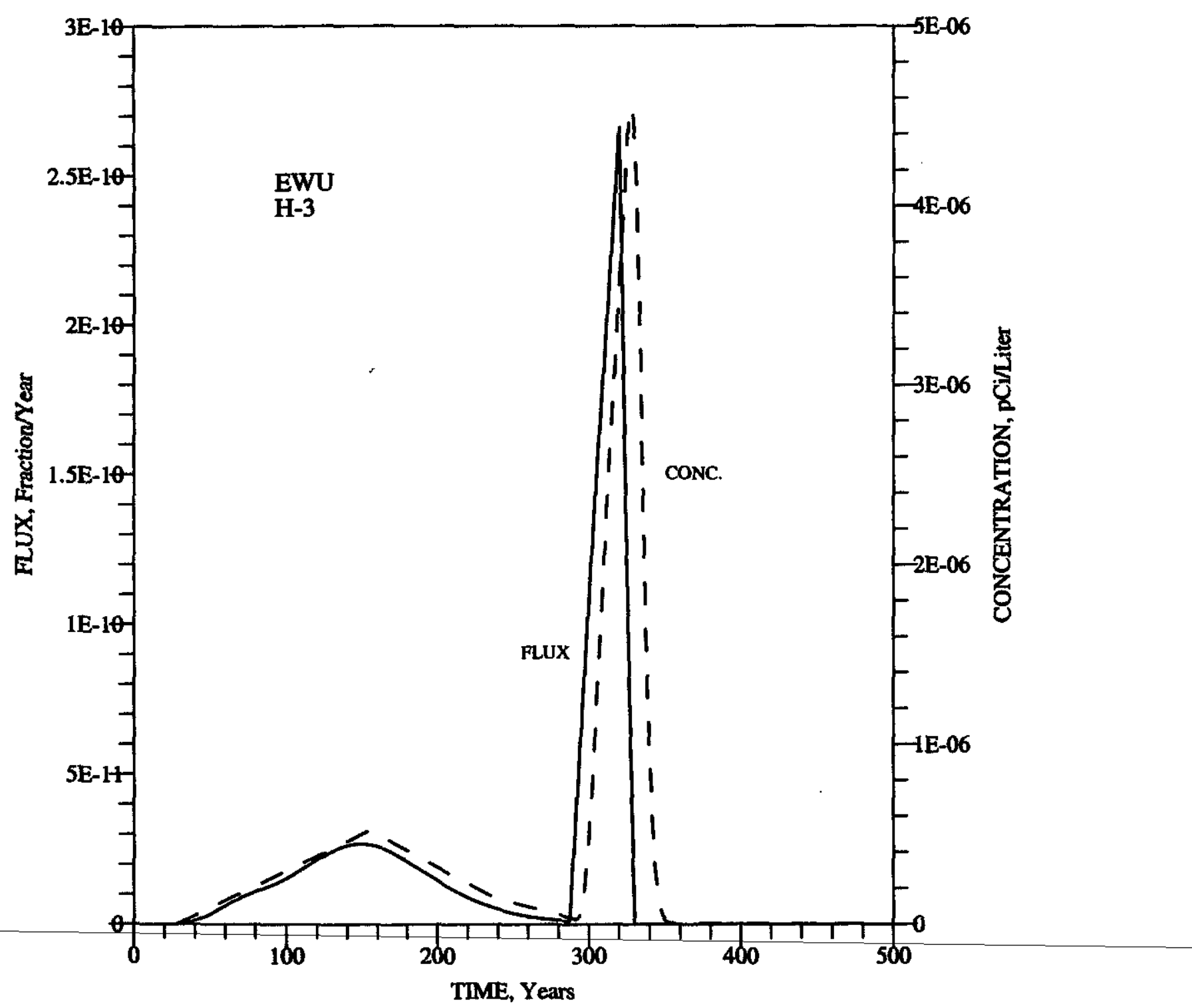

Figure G-80. PORFLOW estimated H-3 fractional release (CI/year/Ci inventory) to the water table and normalized concentration ( $\mathrm{pCi} /$ iter/Ci inventory) at the 100-meter well for the Cement-stabilized Encapsulated Waste Units (CEWU). 


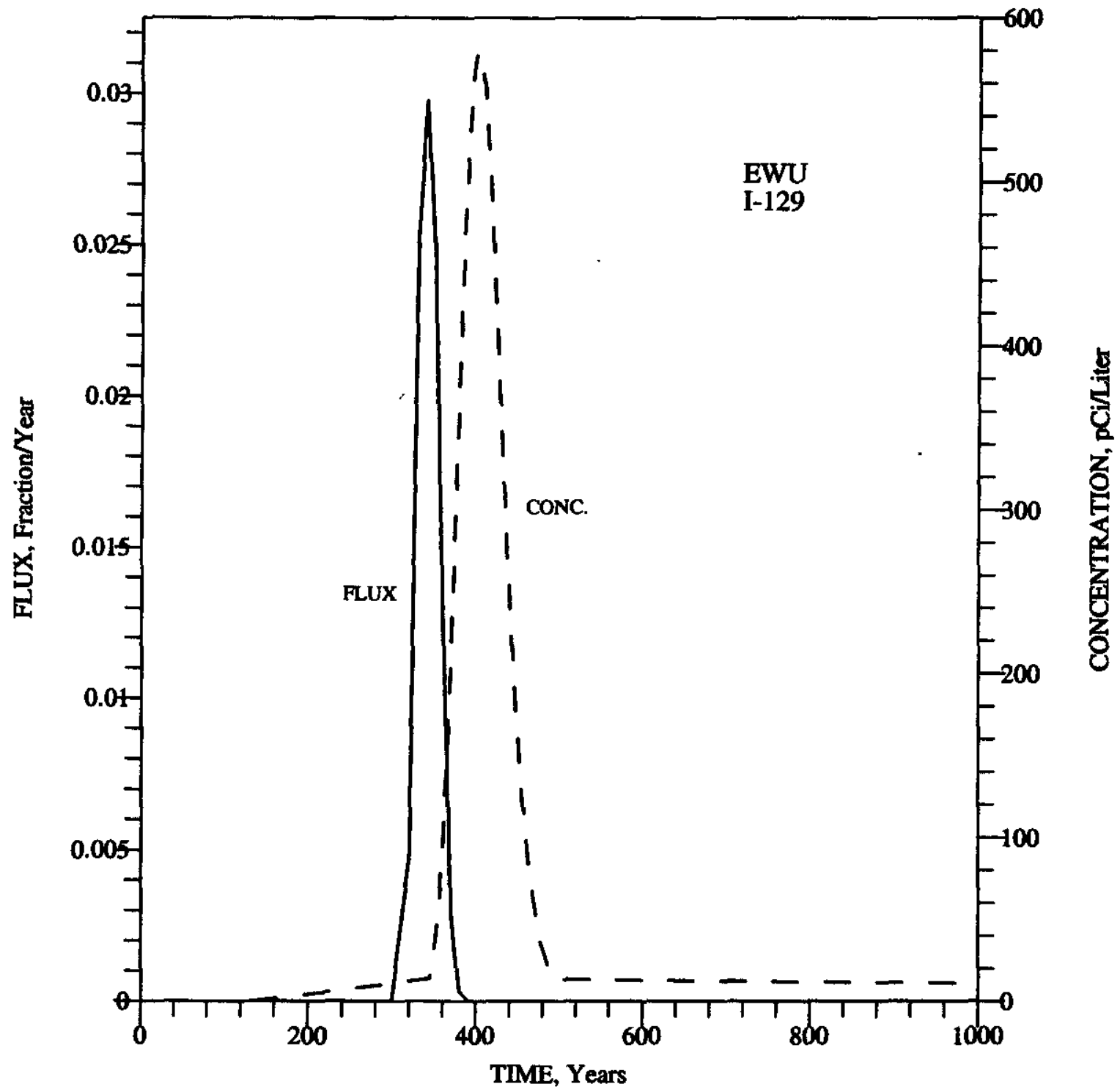

Figure G-81. PORFLOW estimated I-129 fractional release (Ci/year/Ci inventory) to the water table and normalized concentration (pCi/liter/Ci inventory) at the 100-meter well for the Cement-stabilized Encapsulated Waste Units (CEWU). 


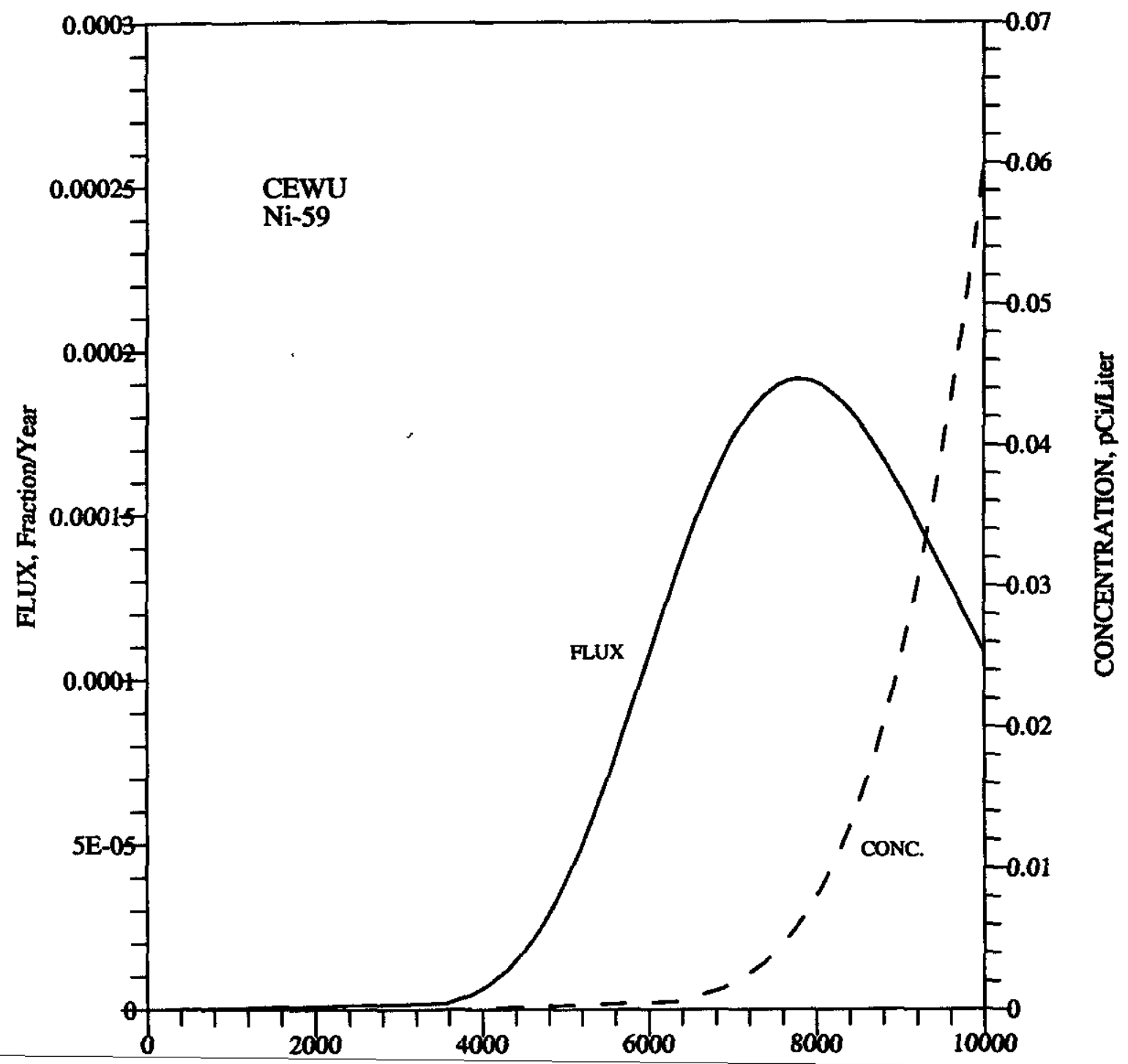

TIME, Years

Figure G-82. PORFLOW estimated Ni-59 fractional release (Ci/year/Ci inventory) to the water table and normalized concentration (pCi/liter/Ci inventory) at the 100-meter well for the Cement-stabilized Encapsulated Waste Units (CEWU). 


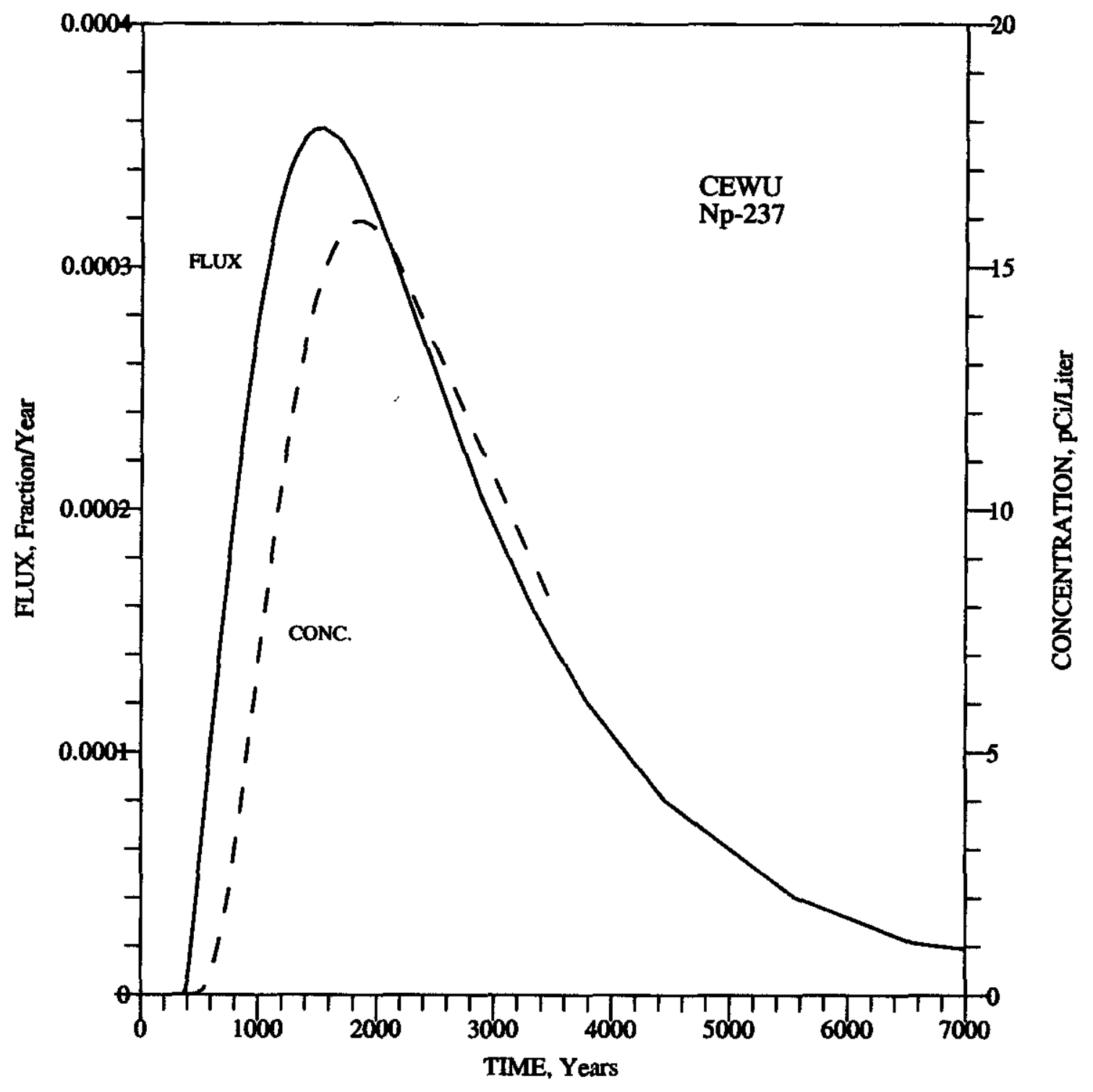

Figure G-83. PORFLOW estimated Np-237 fractional release (Ci/year/Ci inventory) to the water table and normalized concentration (pCi/liter/Ci inventory) at the 100-meter well for the Cement-stabilized Encapsulated Waste Units (CEWU). 


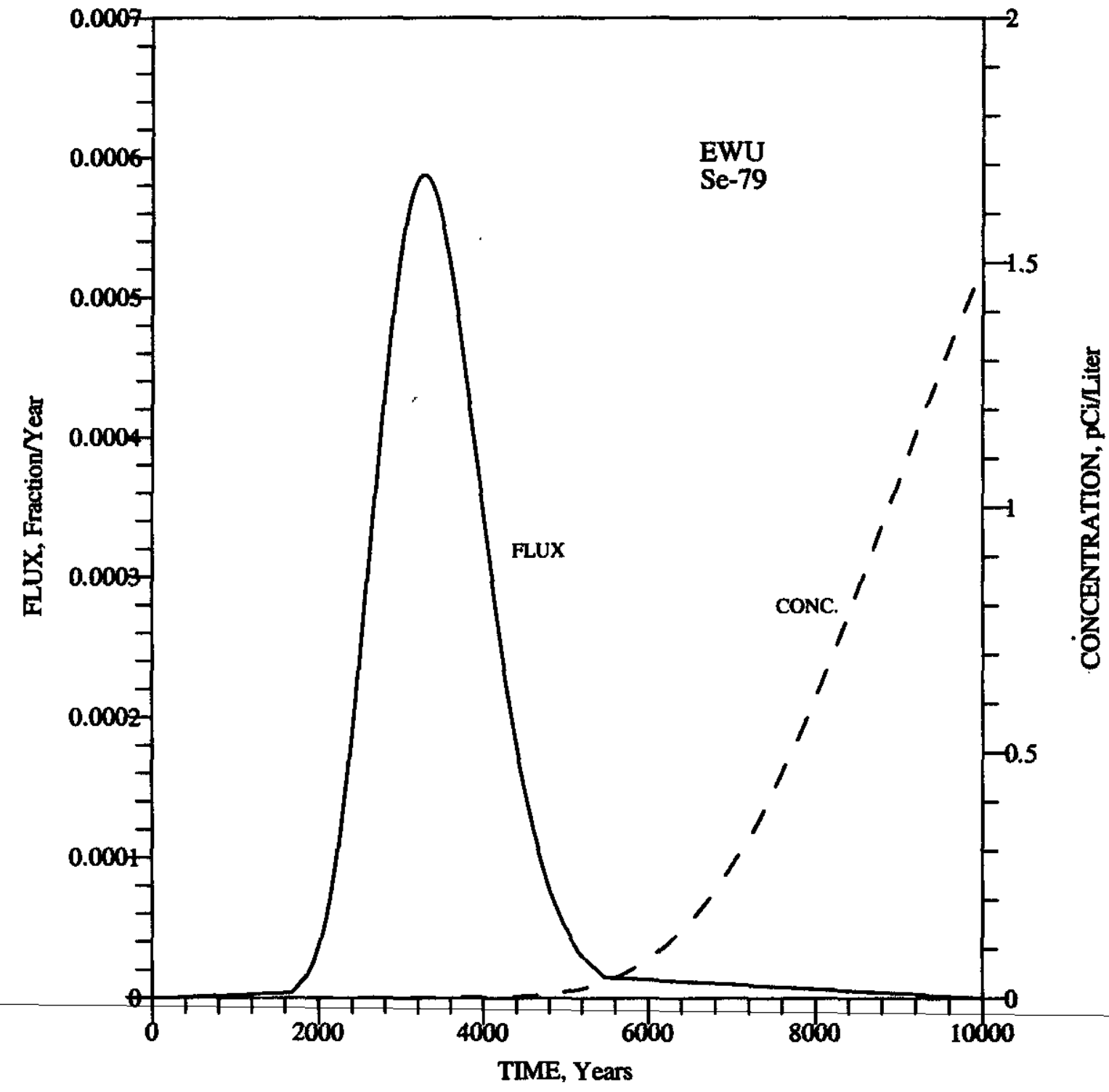

Figure G-84. PORFLOW estimated Se-79 fractional release (Ci/year/Ci inventory) to the water table and normalized concentration ( $\mathrm{PCi} / \mathrm{iter} / \mathrm{Ci}$ inventory) at the 100-meter well for the Cement-stabilized Encapsulated Waste Units (CEWU). 


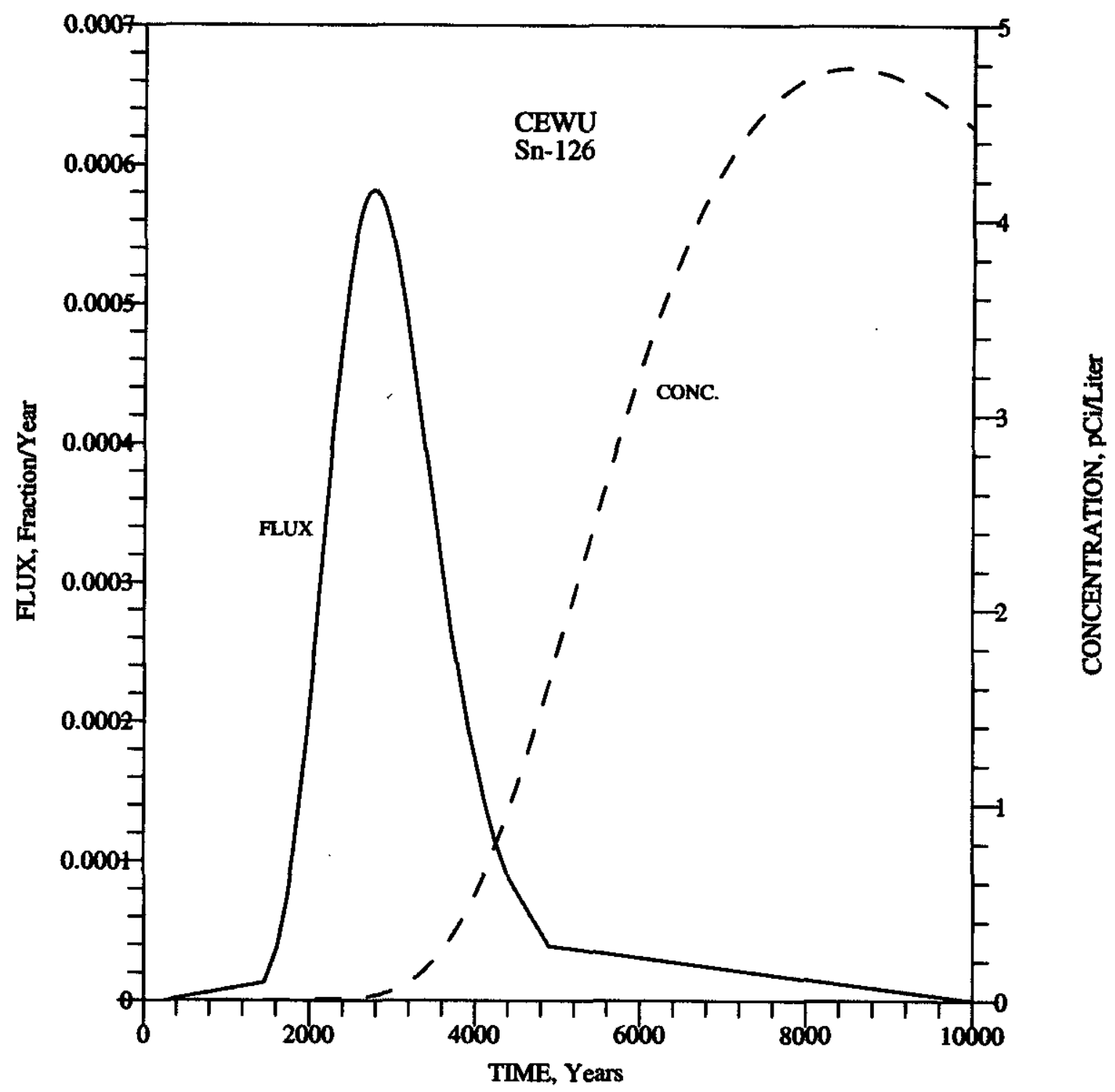

Figure G-85. PORFLOW estimated Sn-126 fractional release (Ci/year/Ci inventory) to the water table and normalized concentration (pCititer/Ci inventory) at the 100-meter well for the Cement-stabilized Encapsulated Waste Units (CEWU). 


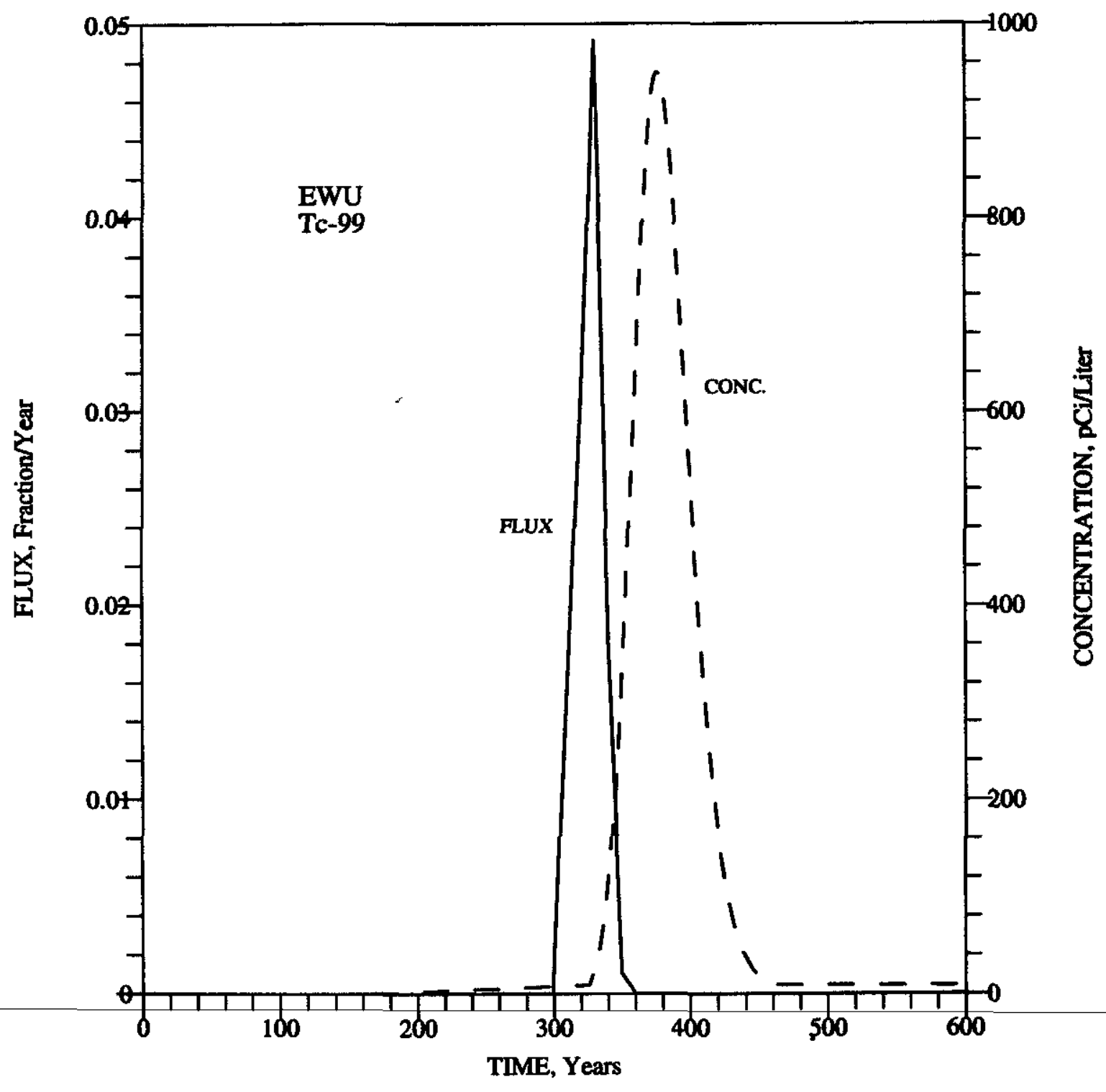

Figure G-86. PORFLOW estimated Tc-99 fractional release (Ci/year/Ci inventory) to the water table and normalized concentration ( $\mathrm{pCi} / \mathrm{iter} / \mathrm{C}$ inventory) at the 100-meter well for the Cement-stabilized Encapsulated Waste Units (CEWU). 


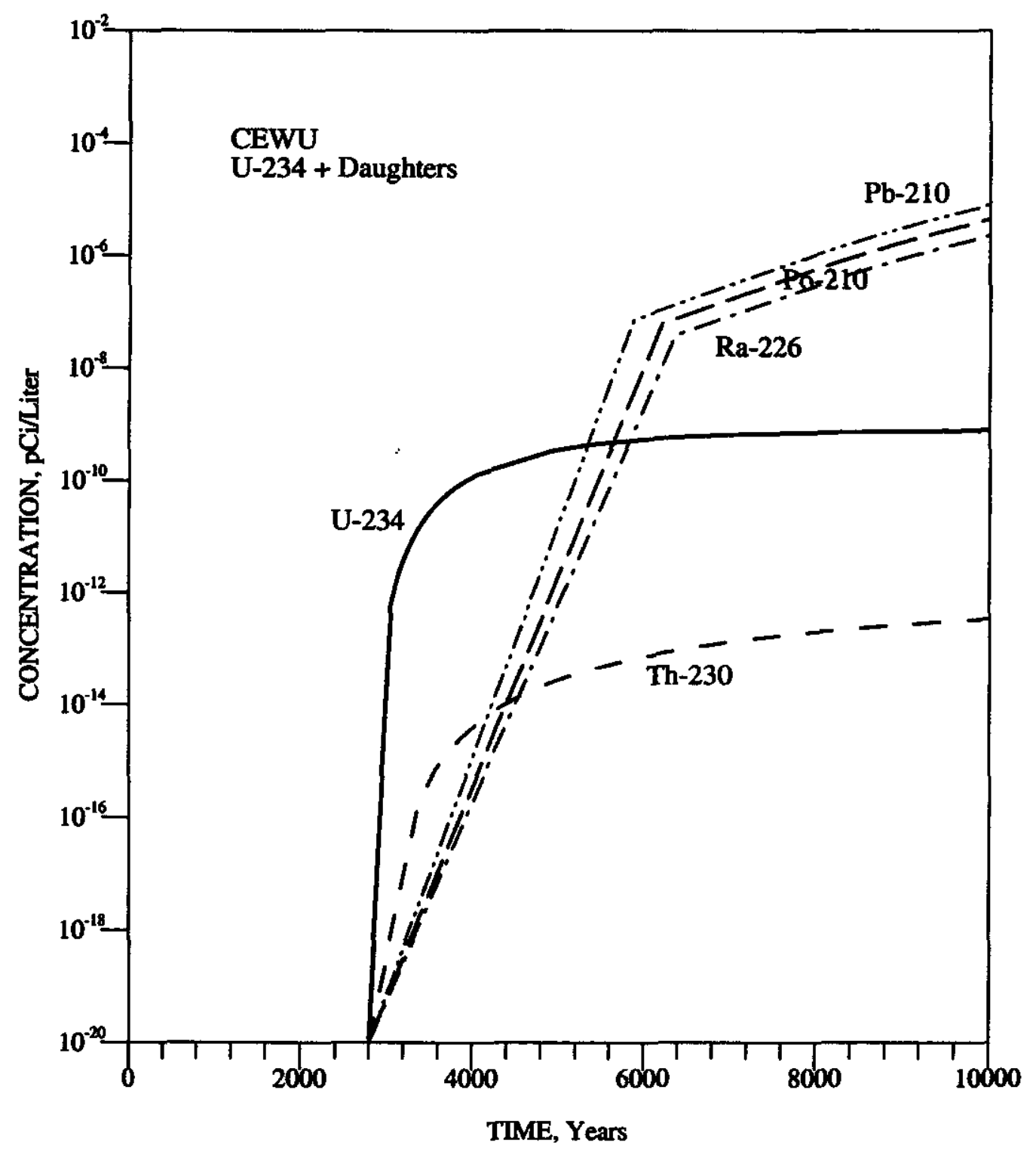

Figure G-87. PORFLOW estimated U-234 + Daughters normalized concentration (pCi/iter/Ci inventory) at the 100-meter well for the Cement-stabilized Encapsulated Waste Units (CEWU). 


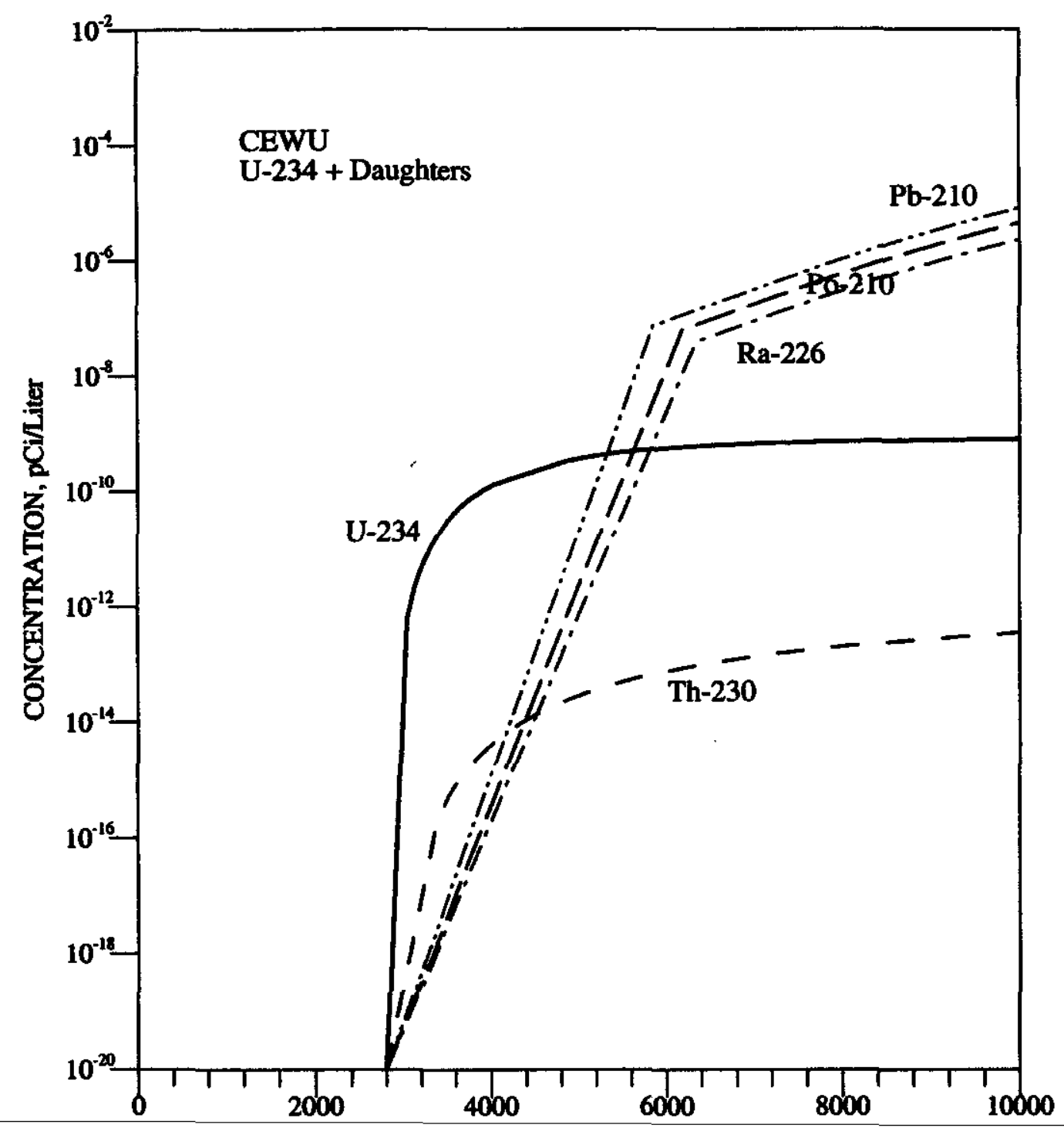

TIME, Years

Figure G-88. PORFLOW estimated U-234 + Daughters normalized concentration (pCi/liter/Ci inventory) at the 100-meter well for the Cement-stabilized Encapsulated Waste Units (CEWU). 


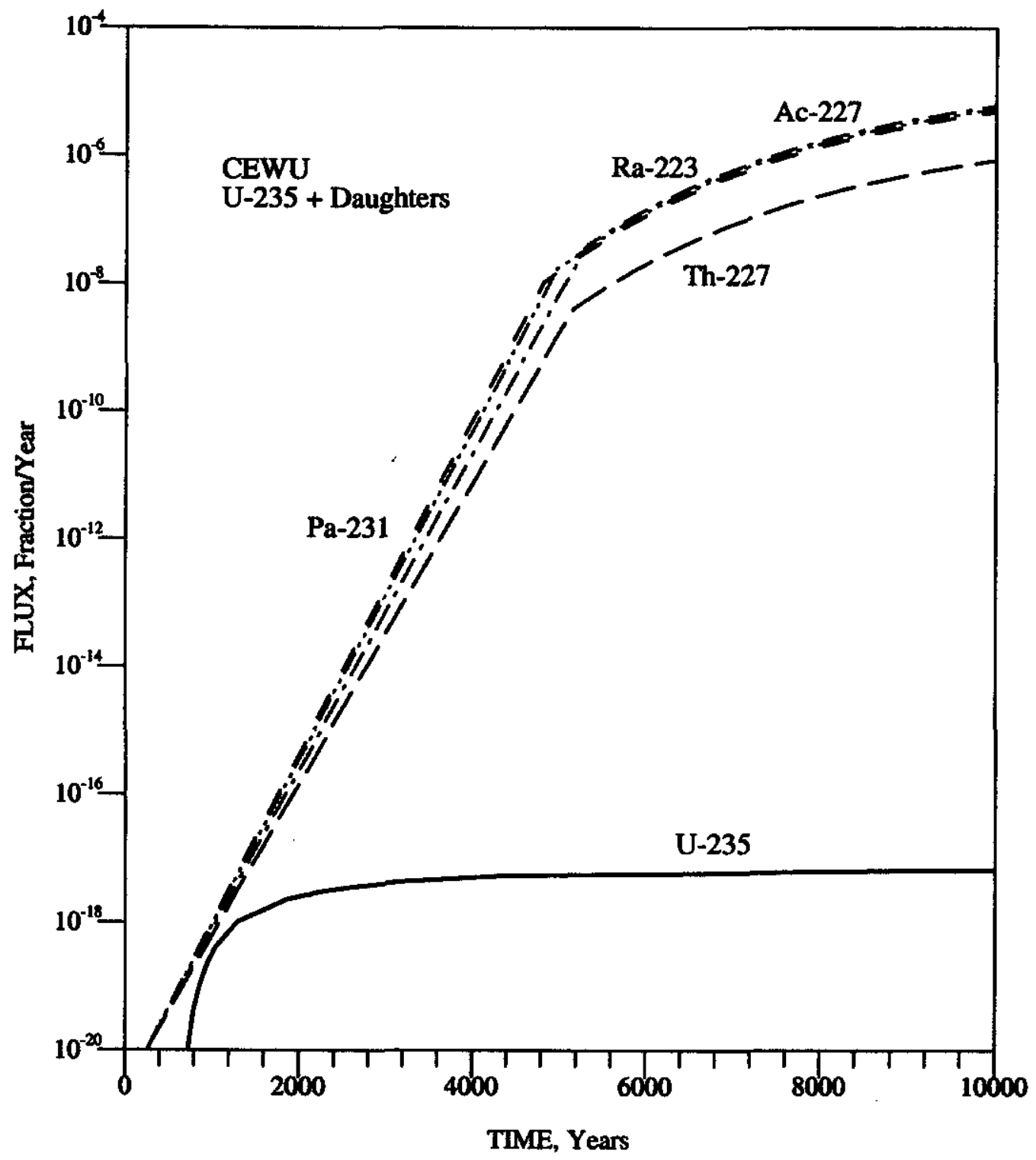

Figure G-89. PORFLOW estimated U-235 + Daughters fractional release (Ci/year/Ci inventory) to the water table for the Cement-stabilized Encapsulated Waste Units (CEWU). 


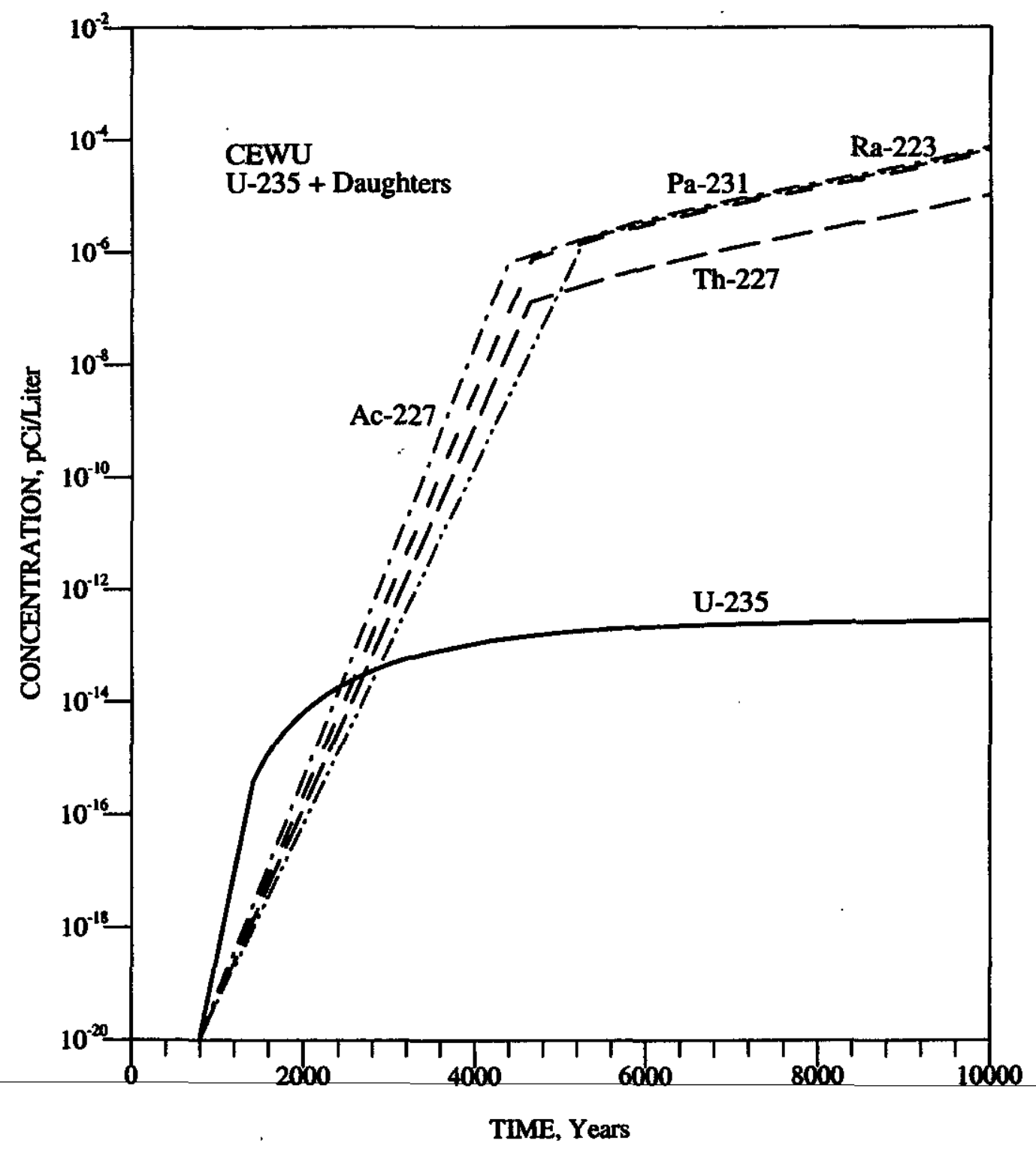

Figure G-90. PORFLOW estimated U-235 + Daughters normalized concentration (pCi/liter/Ci inventory) at the 100-meter well for the Cement-stabilized Encapsulated Waste Units (CEWU). 


\section{APPENDIX H}

\section{SENSITIVITY/UNCERTAINTY ANALYSIS}

FOR GROUNDWATER 


\section{H.1 INTRODUCTION}

The sensitivity and uncertainty of the PORFLOW simulations of the IL vault system were evaluated in terms of the movement of ${ }^{99} \mathrm{Tc}$ from the vault area through the vadose zone and in groundwater. The movement of contaminated water through the system is principally governed by: 1) infiltration; 2) hydraulic properties of the waste form, vaults, and soil; 3) depth to the water table; and 4) retention of contaminants by various materials in the waste, vaults and soil. Sensitivity and uncertainty of PORFLOW simulations of vault-contained low-level radioactive waste were evaluated in the Z-Area Radiological Performance Assessment (WSRC 1992) with respect to variable infiltration rates and hydraulic and diffusive properties of the waste form, vaults, and soil. The results indicated a low sensitivity to infiltration rate, due to the flux-controlling nature of the low-conductivity concrete materials, and a high sensitivity to hydraulic conductivity. This study focuses on the sensitivity and uncertainty in model results with respect to the parameter representing retention of contaminants in the waste form, concrete, and soil, which is the solid/liquid partition coefficient, or $\mathrm{K}_{\mathrm{d}}$.

Since a radionuclide will move through each of the three media (i.e., waste form, concrete vault, and soil) differently according to its $\mathrm{K}_{\mathrm{d}}$ in each material, three $\mathrm{K}_{\mathrm{d}} \mathrm{s}$, and appropriate probability distributions, were specified for ${ }^{99} \mathrm{Tc}$. In addition to the $\mathrm{K}_{\mathrm{d}} \mathrm{s}$, the time to cracking and time to collapse of the vaults roof were specified. The time-to-roof collapse was the sum of the time-to-roof cracking and the time between roof cracking and roof collapse, both of which were varied.

The $\mathrm{K}_{\mathrm{d}}$ and time parameters together resulted in five factors being specified for the PORFLOW simulations in this analysis. Since there is considerable uncertainty associated with these five factors, they are considered to be random variables and distributions were specified for each factor. Based on the available literature, the $\mathrm{K}_{\mathrm{d}} \mathrm{s}$ are assumed to be observations from log-normal distributions. The bounds of the $\mathrm{K}_{\mathrm{d}}$ distributions were estimated from available literature. The times associated with roof cracking and time between cracking and roof collapse are assumed to be distributed uniformly. The bounds of the time-to-failure distributions were estimated by assuming the baseline values in Appendix D are approximately the midpoint of the ranges, and by considering the sensitivity data provided in Table 10 of that appendix.

The distributions and their limits for the five factors were entered into a Latin Hypercube Sample (LHS) generation program (Iman and Shortencarier 1984), which creates a sample based on the principles of LHS Theory. Table H.1-1 provides the factor information needed for the sample generation routine. 
Table H.1-1. Factor specification for Latin Hypercube Sample generation

\begin{tabular}{|c|c|c|c|}
\hline Factor & Distribution & Lower Limit & Upper Limit \\
\hline $\begin{array}{c}\mathrm{K}_{\mathrm{d}}{ }^{99} \mathrm{Tc} \\
\text { waste form }\end{array}$ & $\begin{array}{c}\log \\
\text { normal }\end{array}$ & 1.0 & 6.2 \\
\hline $\begin{array}{c}\mathrm{K}_{\mathrm{d}}{ }^{99} \mathrm{Tc} \\
\text { concrete }\end{array}$ & $\begin{array}{c}\log \\
\text { normal }\end{array}$ & 70 & 7000 \\
\hline $\begin{array}{c}\mathrm{K}_{\mathrm{d}}{ }^{99} \mathrm{Tc} \\
\text { soil }\end{array}$ & $\begin{array}{c}\log \\
\text { normal }\end{array}$ & 0.01 & 0.4 \\
\hline $\begin{array}{c}\text { Time to roof } \\
\text { cracking }\end{array}$ & uniform & 150 years & 950 years \\
\hline $\begin{array}{c}\text { Time between } \\
\text { roof cracking and } \\
\text { collapse }\end{array}$ & uniform & 175 years & 775 years \\
\hline
\end{tabular}

\section{H.2 PRELIMINARY SAMPLE}

Initially a data file containing the necessary information for a pre-sample of ten LHS runs was set up and electronically transferred to the PORFLOW program. These runs were given in terms of five parameters, three $\mathrm{K}_{\mathrm{d}} \mathrm{s}$ and the two vault failure times. The general purpose of these initial ten runs was the identification of sampling and analysis problems.

These results were analyzed using linear regression analysis. An examination of the data indicated the possibility of several linear trends in terms of $\log$ responses versus the logs of the $\mathrm{K}_{\mathrm{d}}$ or the $\log$ response versus the time factors. So the data analysis was directed towards the log-transform of the response data.

The data vector consisted of three responses; the maximum groundwater concentration of ${ }^{99} \mathrm{Tc}$ observed, the number of years after vault disposal that the maximum occurred, and the location of the sampling point where the maximum was observed. Since the analysis of the initial ten runs did not raise the possibility of any real data problems, the study proceeded with the 100 runs.

\section{H.3 SENSITIVITY ANALYSIS}

The analysis of the full 100 runs involved the consideration of a full five factor multiple regression model with all interaction terms and quadratic effects. The form of this multiple regression model was the following:

\section{Multiple Regression Model}

Log(Response $)=A 0+A 1 * X 1+A 2 * X 2+A 3 * X 3+A 4 * X 4+A 5 * X 5+A 12 * X 1 * X 2+A 13 * X 1 * X 3+$ $A 14 * X 1 * X 4+A 15 * X 1 * X 5+A 23 * X 2 * X 3+A 24 * X 2 * X 4+A 25 * X 2 * X 5+A 34 * X 3 * X 4+$ $A 35 * X 3 * X 5+A 45 * X 4 * X 5+A 11 * X 1 * X 1+A 22 * X 2 * X 2+A 33 * X 3 * X 3+A 44 * X 4 * X 4+$ A55*X5*X5 + error. 
The definitions of these factors are given in Table H.3-1. An inspection of the data showed that 85 of the $100{ }^{99} \mathrm{Tc}$ results occurred at the same node within the simulation domain. Thus, the location of the response was not included as a variable in the analysis.

Table H.3-1. Variable definitions for multiple regression model

\begin{tabular}{cc}
\hline Variable & Definition \\
\hline $\mathrm{X} 1$ & $\log \left(\mathrm{K}_{\mathrm{d}}\right.$ Waste Form $)$ \\
$\mathrm{X} 2$ & $\log \left(\mathrm{K}_{\mathrm{d}}\right.$ Concrete $)$ \\
$\mathrm{X} 3$ & Log $\left(\mathrm{K}_{\mathrm{d}}\right.$ Soil) \\
$\mathrm{X} 4$ & Time to Roof Cracking \\
$\mathrm{X} 5$ & Time Between Roof Cracking and Roof Collapse \\
\hline
\end{tabular}

The selection of the important factor combinations was done in terms of the amount of variation that a group of factors would explain. These groups of factor combinations were selected by the use of a statistical procedure called step-wise regression. This procedure selects factor combinations in groups of one, two, three, etc., that explain the largest portion of the existing variation in the data. The intent was to obtain the smallest set of factor combinations that would explain the most variation. The set of factor combinations was allowed to increase only if the additional factor combination showed a real increase in the amount of variation explained by the linear model.

For example, for the $\log \left(\max \mathrm{GW}{ }^{99} \mathrm{Tc}\right)$ response, the linear model involving only the term $\mathrm{X} 2{ }^{*} \mathrm{X} 2$ explains about $96 \%$ of the total variation in the data; the addition of any other factor combinations did not make any real increase in the amount of variation explained by the model. Thus one can say that the peak groundwater concentration of ${ }^{99} \mathrm{Tc}$ is most sensitive to $\mathrm{X} 2$, or the $\mathrm{K}_{\mathrm{d}}$ in concrete, of the parameters considered.

The factor combinations that have the most influence on the log responses are given in Table H.3-2.

Table H.3-2. Important variable combinations

\begin{tabular}{|c|c|c|}
\hline Response & $\begin{array}{c}\text { Important Variable } \\
\text { Combinations }\end{array}$ & $\begin{array}{c}\text { Percent of Variation } \\
\text { Explained by Important } \\
\text { Variables }\end{array}$ \\
\hline Max GW ${ }^{99}$ Tc & $\mathrm{X} 2^{*} \mathrm{X} 2$ & $96 \%$ \\
\hline Years to Max GW ${ }^{99} \mathrm{Tc}$ & $\mathrm{X} 4 \mathrm{X} 2^{*} \mathrm{X} 2$ & $96 \%$ \\
\hline
\end{tabular}

\section{H.4 UNCERTAINTY ANALYSIS}

The amount of variability present in the simulated response data has been illustrated in two ways. The widths of the $95 \%$ confidence intervals for the means of the response distributions, Table H.4-1, and the width of the tolerance intervals for the response distributions. The tolerance intervals were computed in terms of $95 \%$ coverage of the response distributions, with $95 \%$ confidence, as shown in Table H.4-2. In both cases the intervals were based on the entire sample of 100 simulations. While the limits for the means are relatively tight, the limits for distributions are rather broad.

The plots of the response against the simulation variables, which are given in Sect. H.7, indicate that the variation in the ${ }^{99} \mathrm{Tc}$ groundwater results was dominated by the magnitude of the concrete $\mathrm{K}_{\mathrm{d}}(\mathrm{X} 2)$ values. 
The dominance for the maximum groundwater concentration is total, while the time to occurrence of the maximum is also influenced by a small positive trend

Table H.4-1. Confidence intervals for mean

\begin{tabular}{|c|c|c|}
\hline \multirow{2}{*}{ Response } & \multicolumn{2}{|c|}{ 95\% Confidence Limits } \\
& & \\
\cline { 2 - 3 } & Lower & Upper \\
\hline \hline Max GW ${ }^{99}$ Tc & 0.035 & 0.046 \\
\hline Years to Max GW ${ }^{99}$ Tc & 1897 & 2254 \\
\hline
\end{tabular}

Table H.4-2. Tolerance limits on response distribution

\begin{tabular}{|c|c|c|}
\hline \multirow{2}{*}{ Response } & \multicolumn{2}{|c|}{$\begin{array}{c}\text { 95\% Confidence that 95\% of Distribution } \\
\text { Covered by Interval }\end{array}$} \\
& & \multicolumn{2}{|c|}{} \\
\cline { 2 - 3 } & Lower Limit & Upper Limit \\
\hline Max GW ${ }^{99}$ Tc & 0.008 & 0.192 \\
\hline Years to Max GW ${ }^{99} \mathrm{Tc}$ & 783 & 5460 \\
\hline
\end{tabular}

associated with the time to cracking of the roof (X4). The variation present in the ${ }^{99} \mathrm{Tc}$ concentrations are also illustrated by the estimated cumulative distribution functions (plus $95 \%$ confidence limits) of the concentrations (Sect. H.6).

\section{H.5 SUMMARY}

In general one can say that the ${ }^{99} \mathrm{Tc}$ responses are dominated by the concrete $\mathrm{K}_{\mathrm{d}}$, with some additional influence of the time-to-roof cracking. The $K_{d} s$ for waste form and soil, along with the time between roof cracking and collapse do not seem to have any real effect on these responses. 
H.6 RESPONSE PLOTS AND CUMULATIVE PROBABILITY DISTRIBUTION 


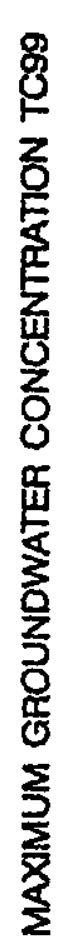

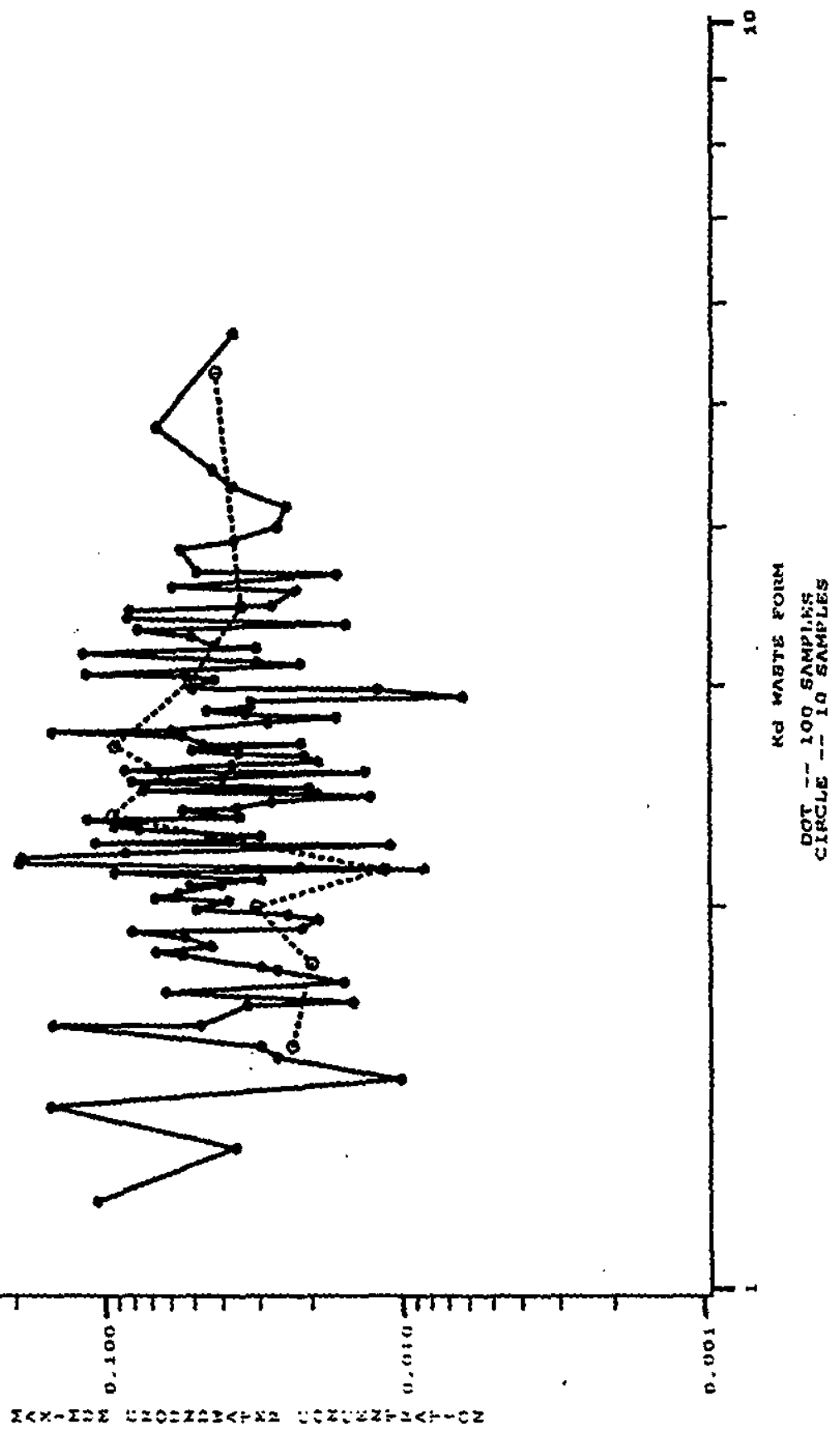

Rev. 1 
是
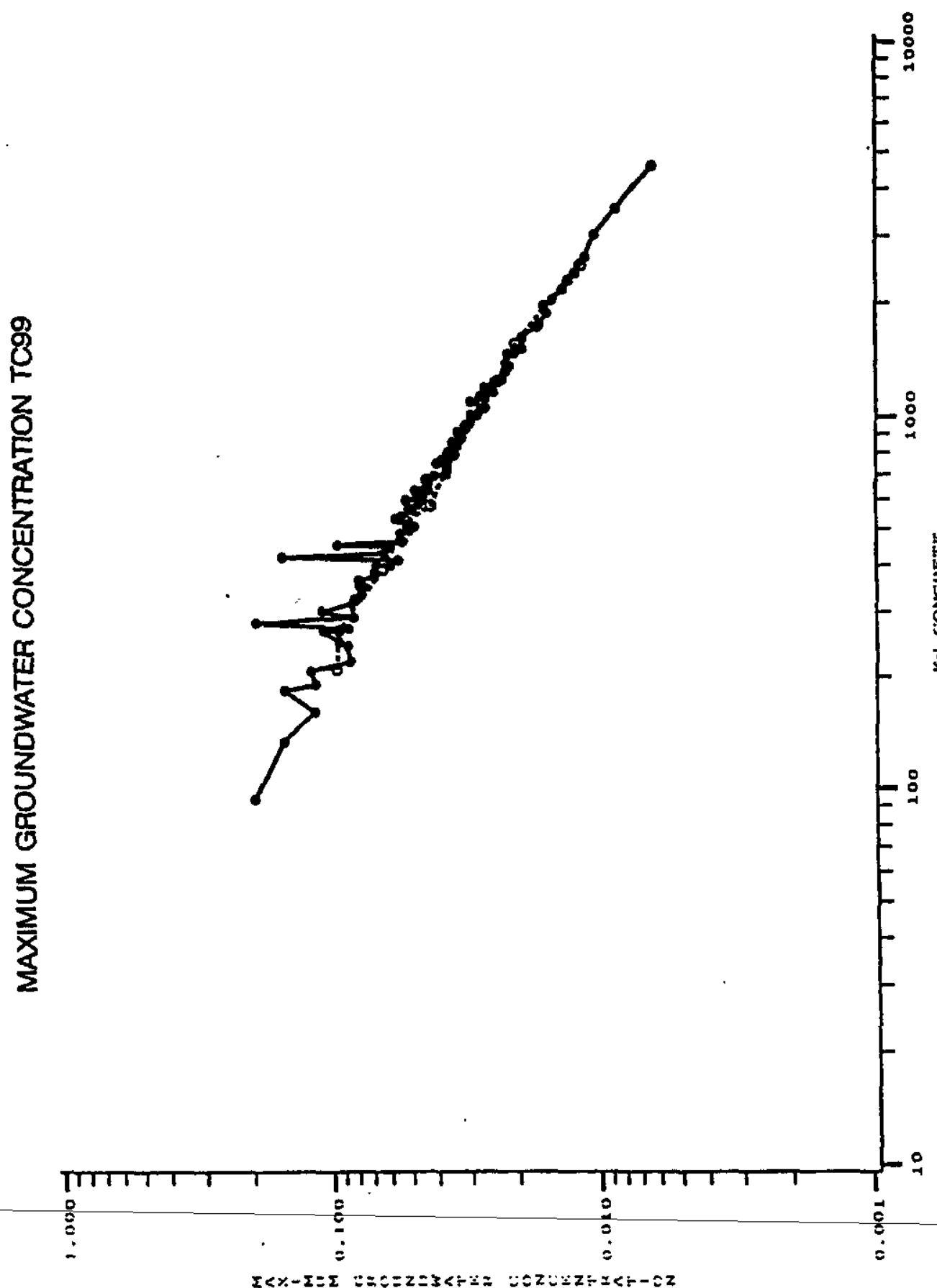


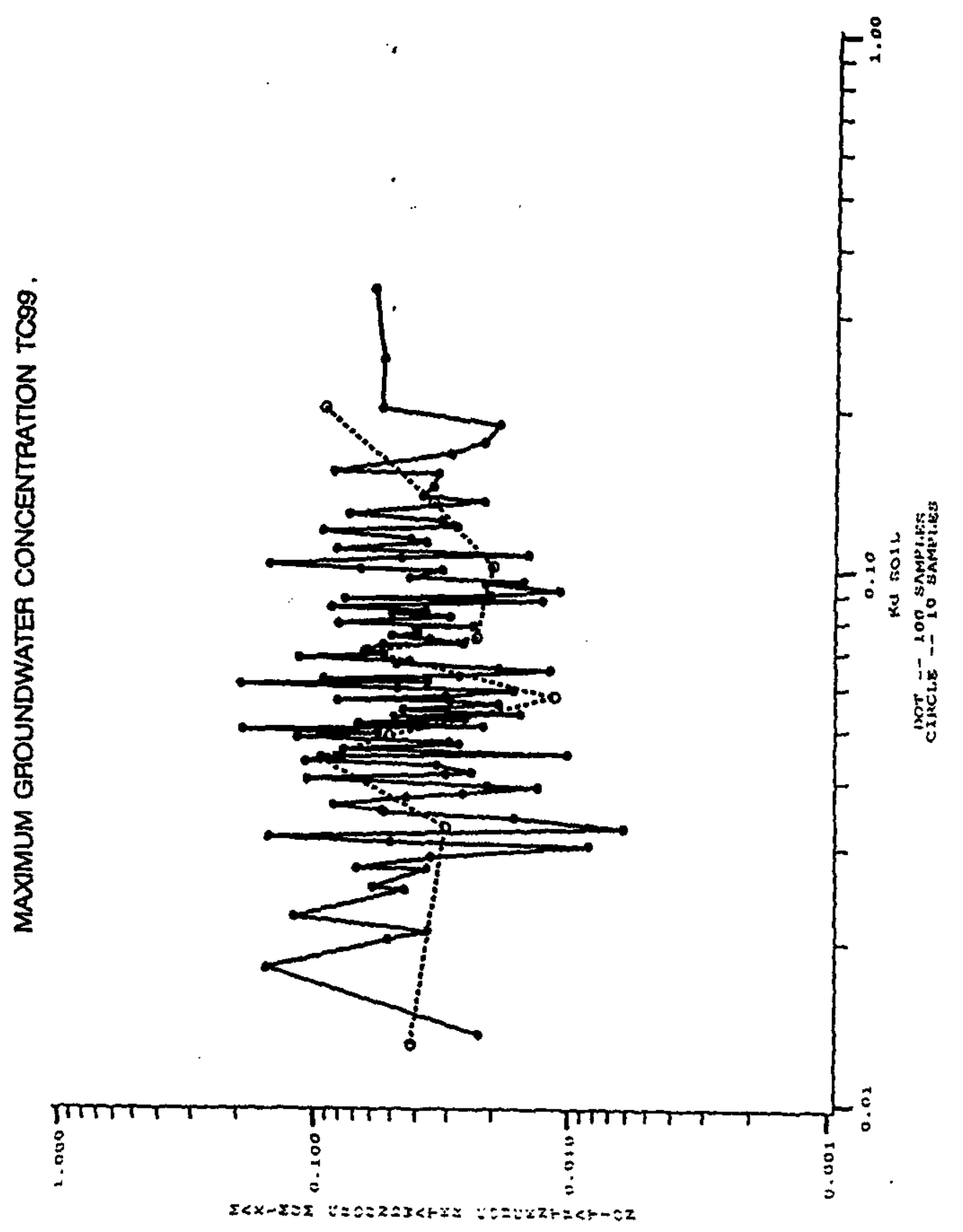

Rev. 1 


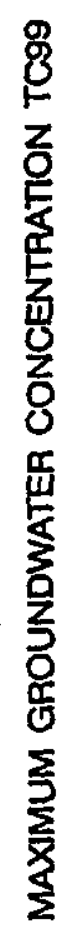
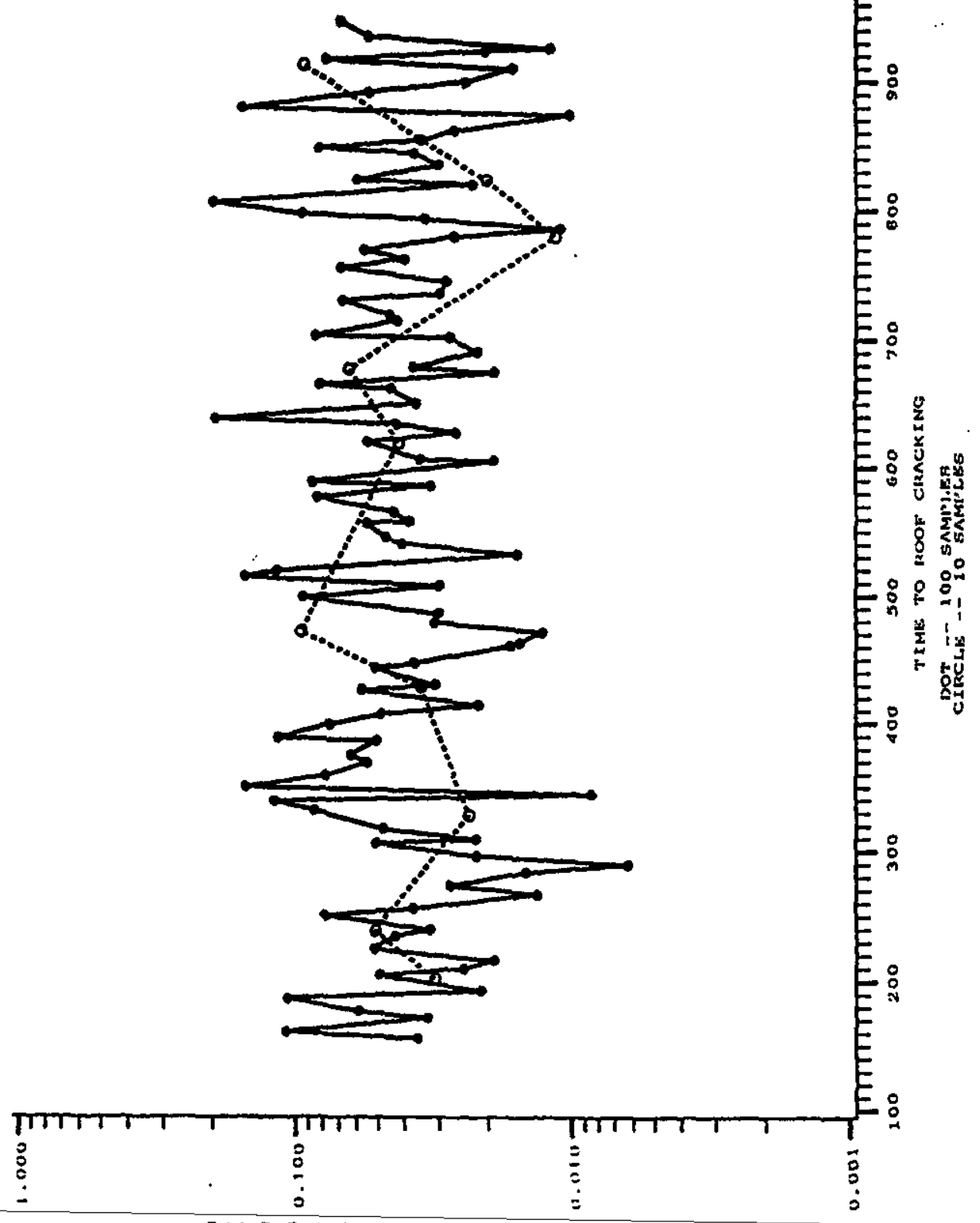

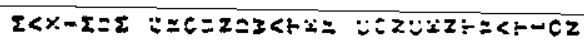




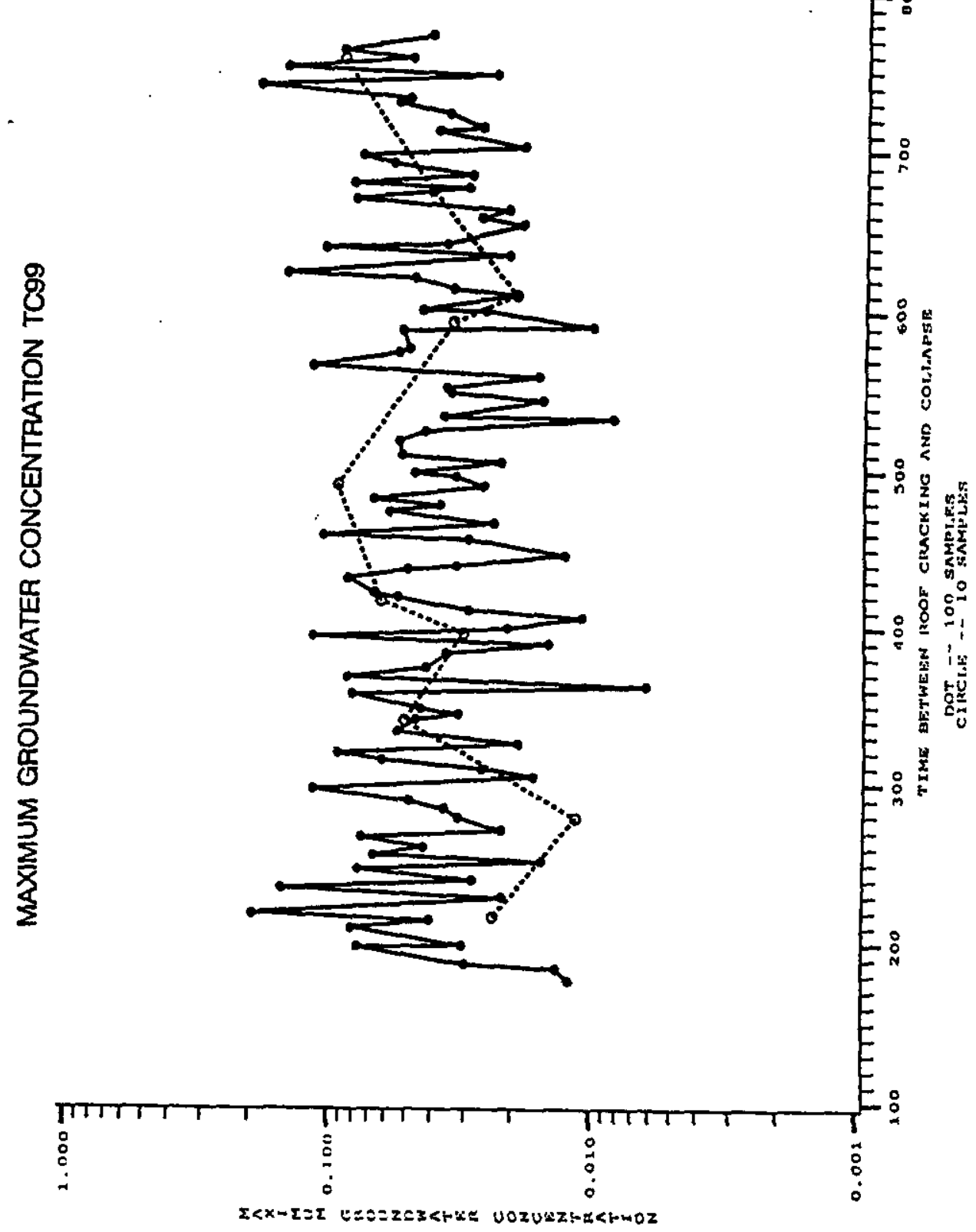

Rev. 1

January 31,2000 


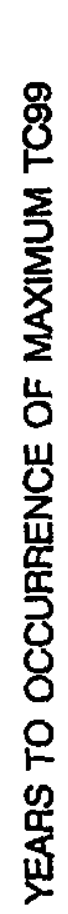

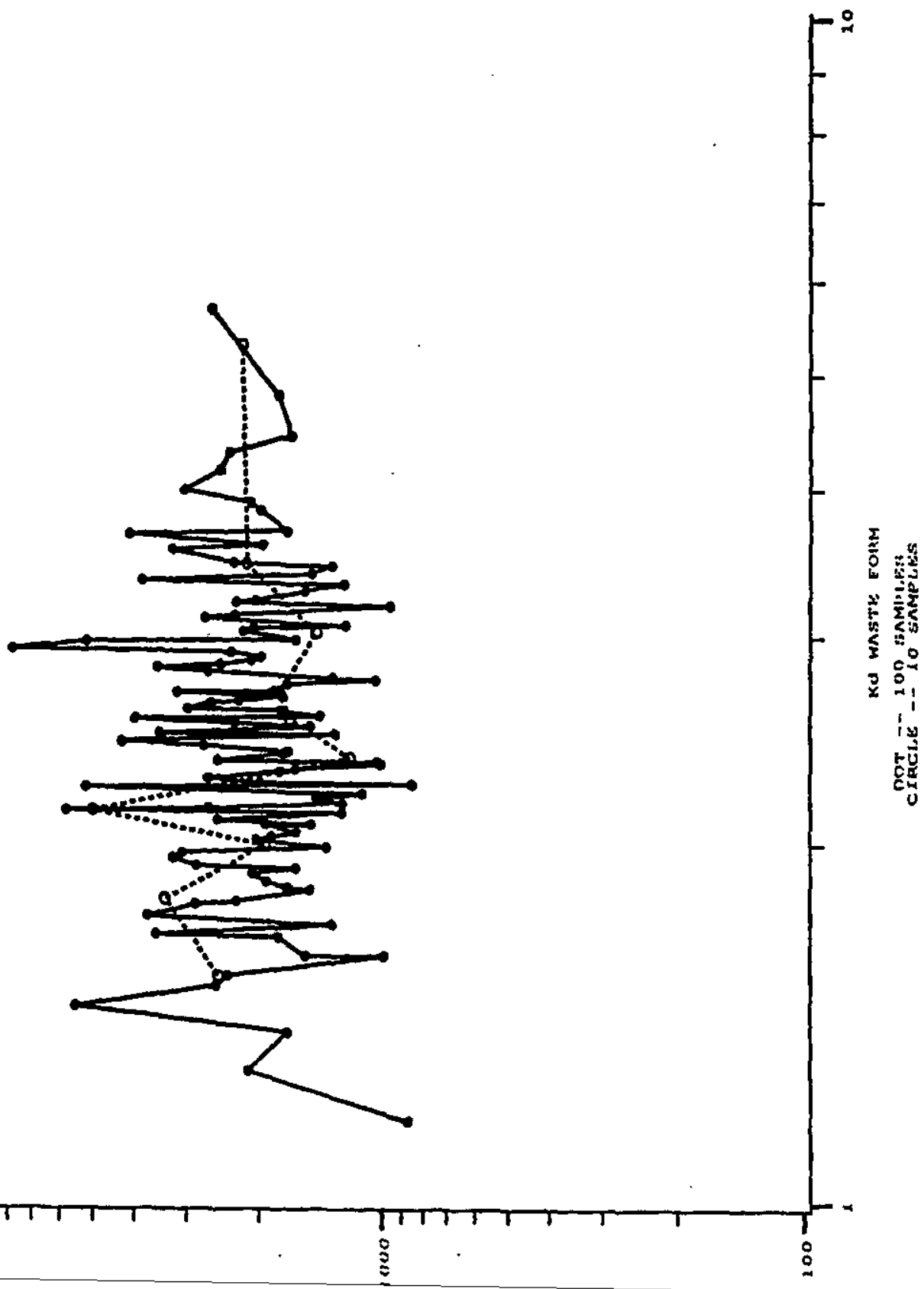

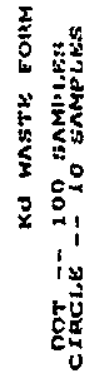

W 


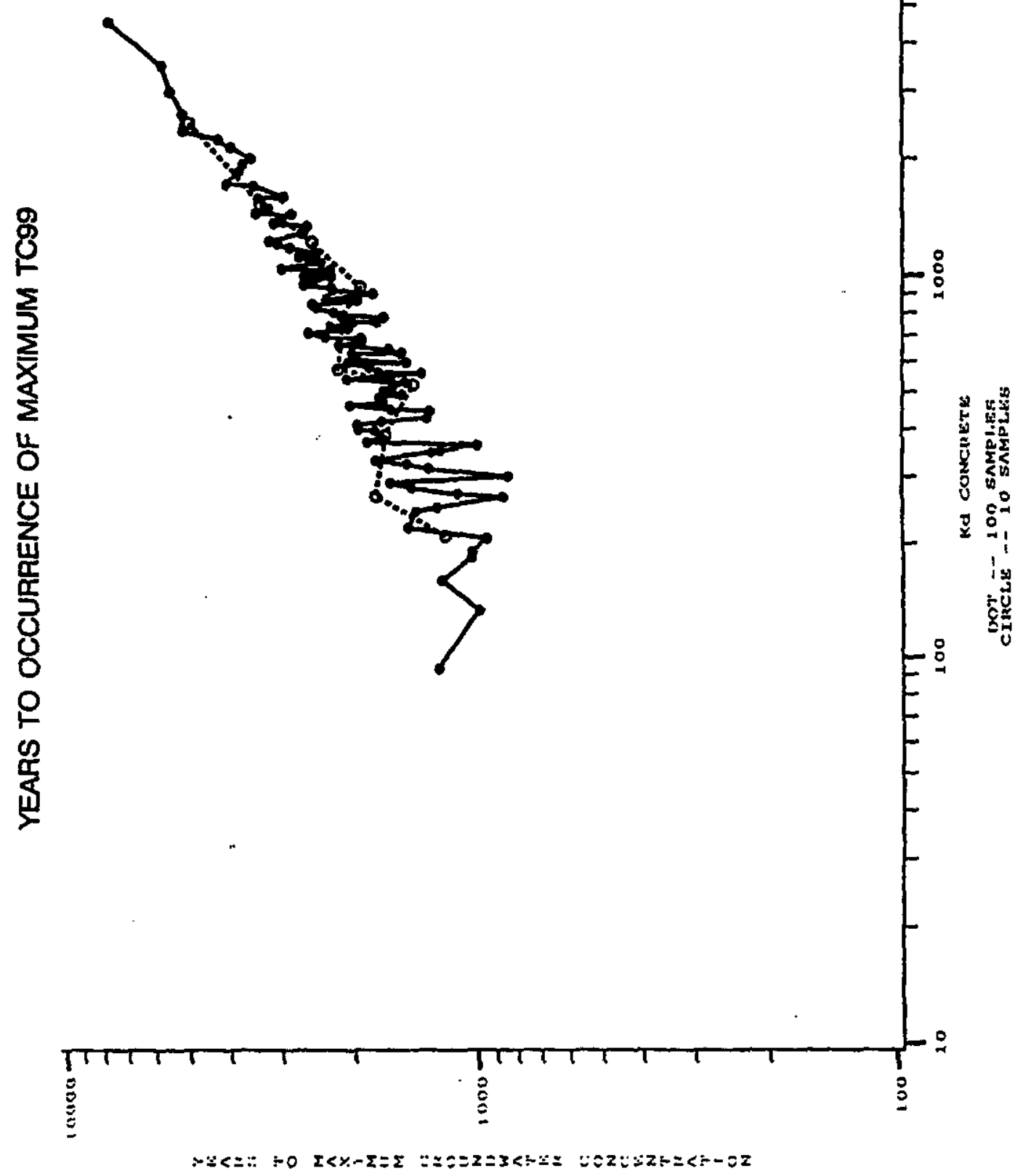

Rev. 1 


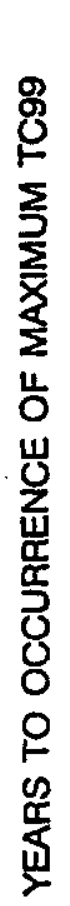
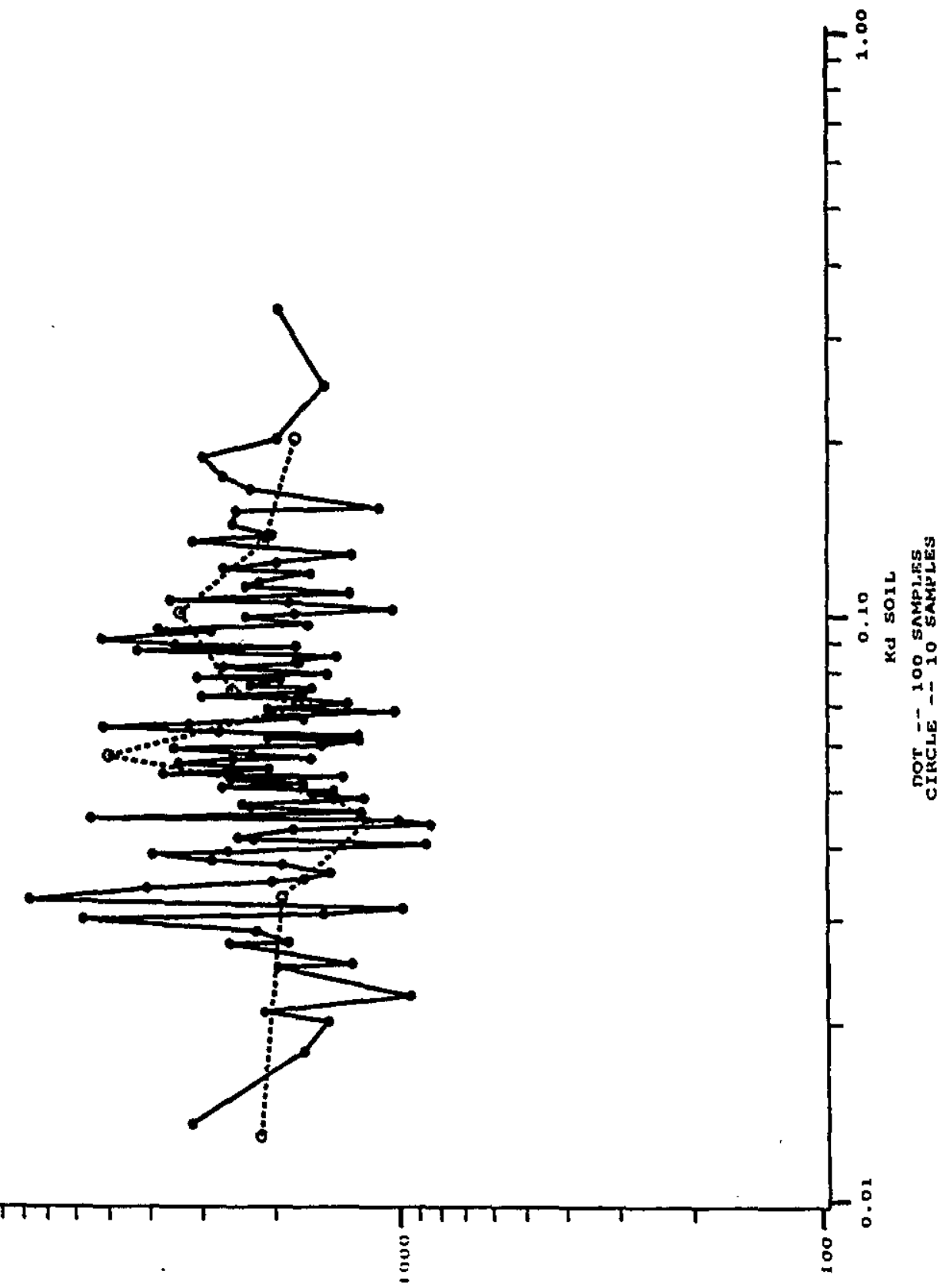

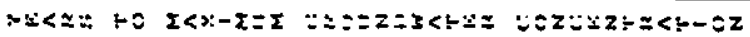




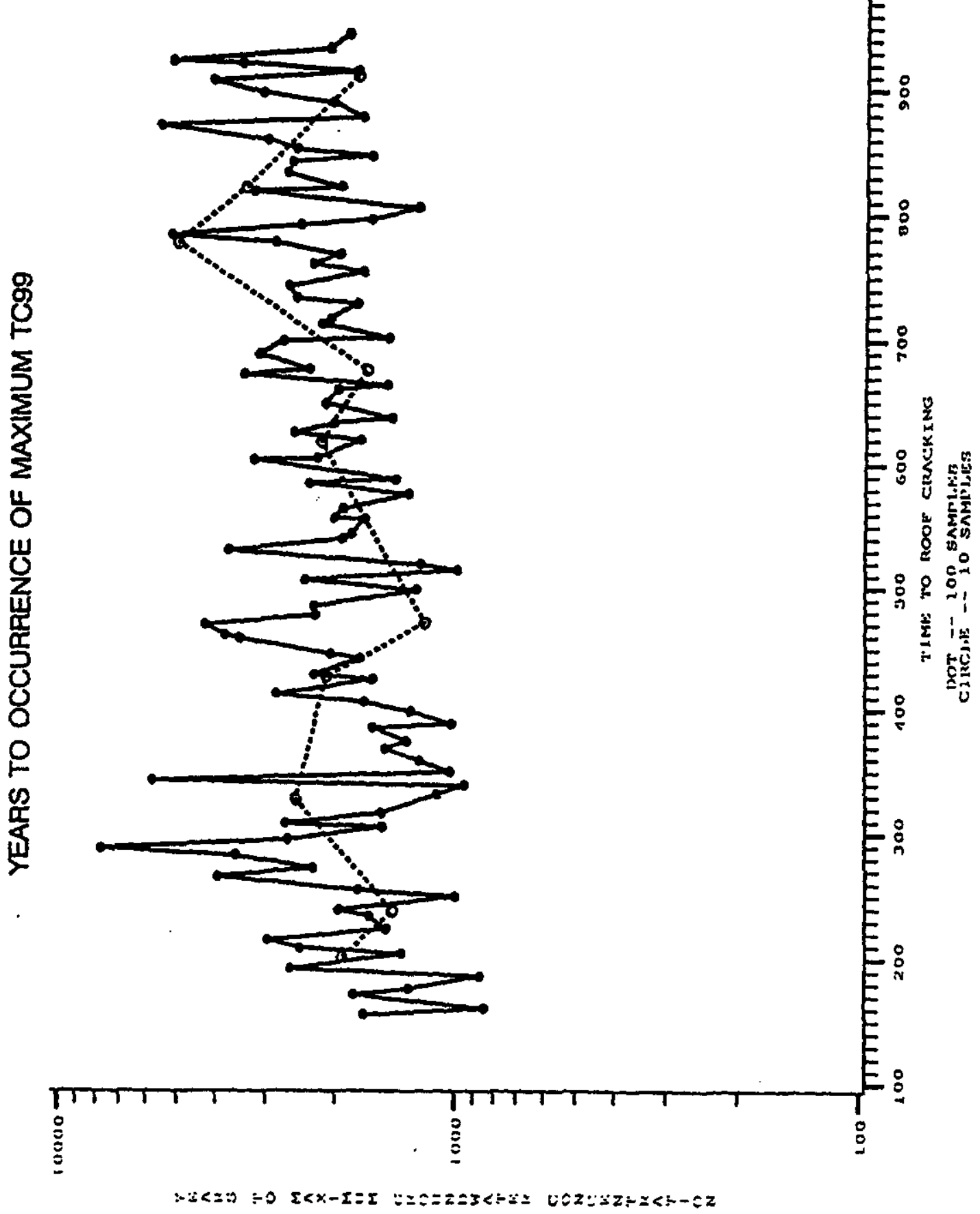




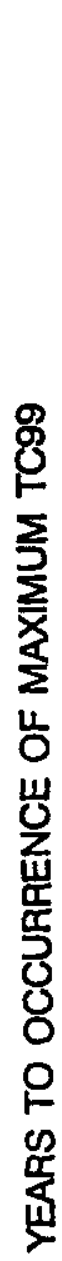
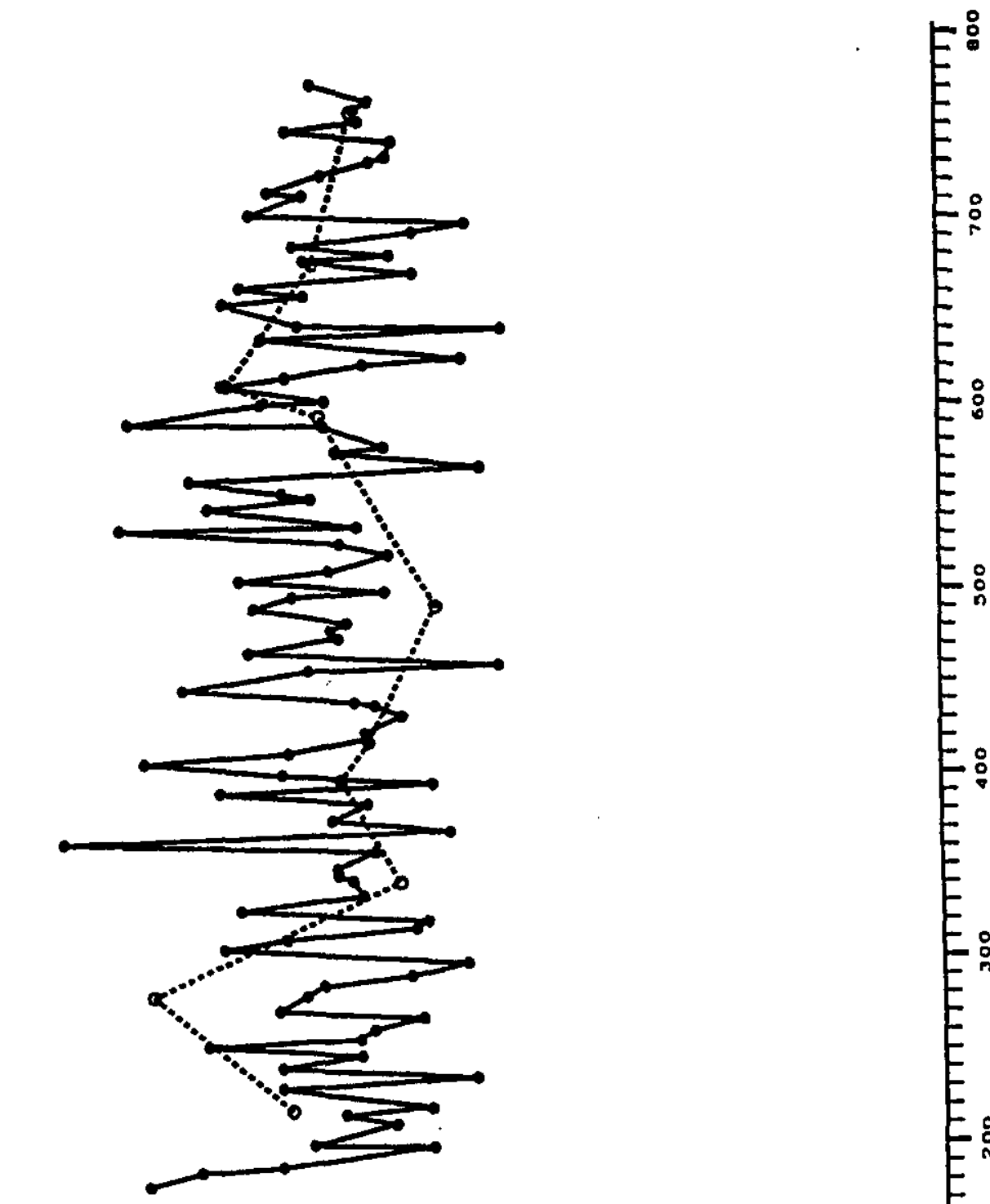

: :

E

E

- : :

资

E

- 8 :

용

- 7

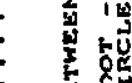

E

$E$ 。

- :

E

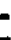

E

E。

E:

E

$E$

$E$

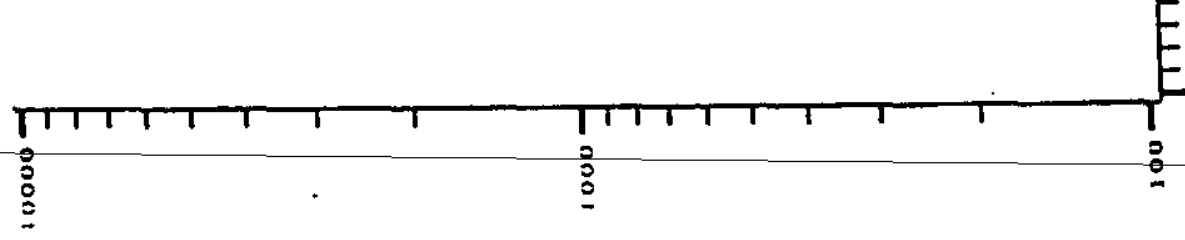

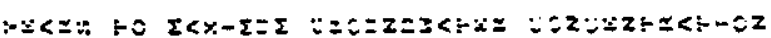



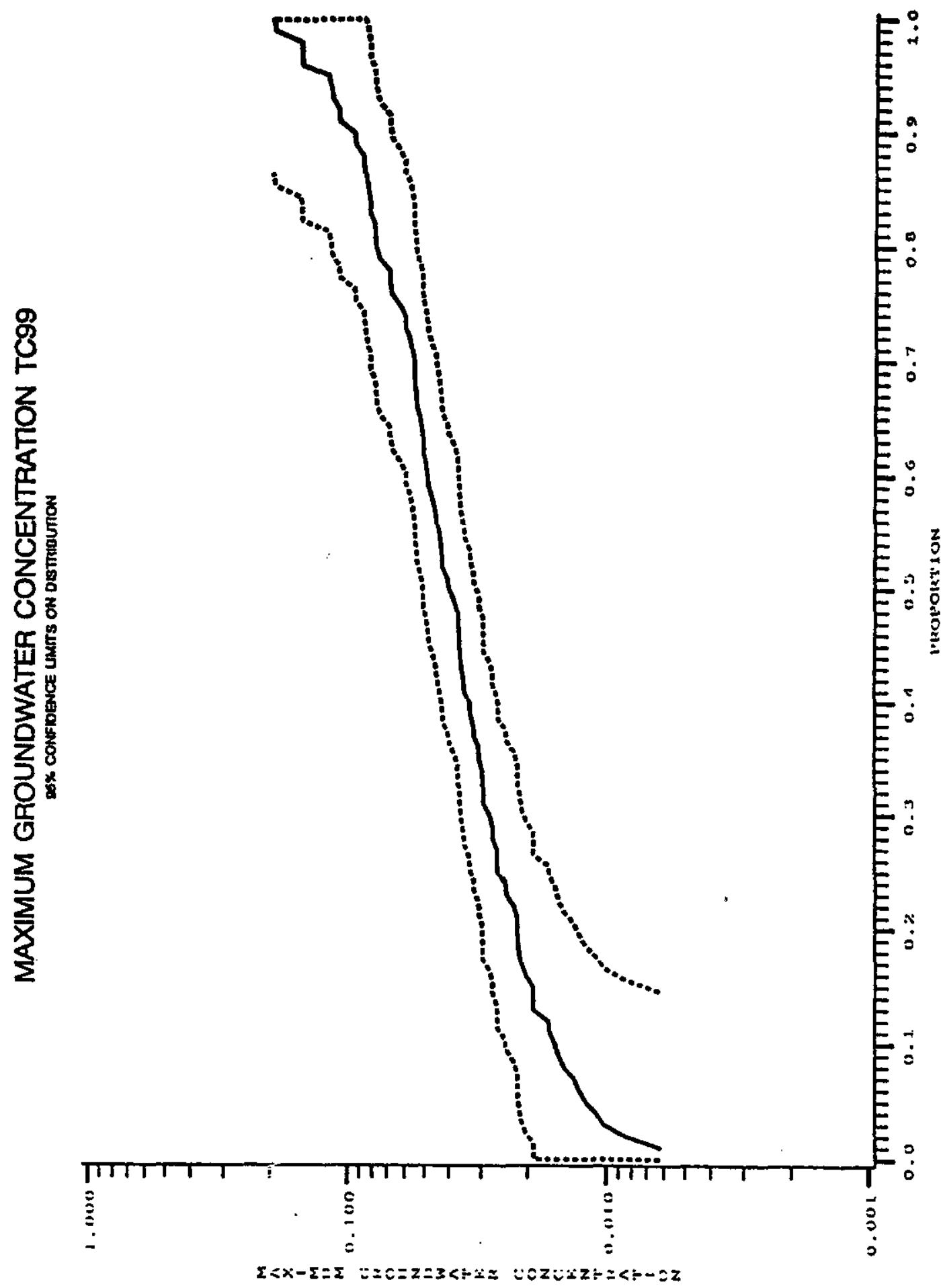


\section{APPENDIX H \\ REFERENCES}

Iman, R. L., and M. J. Shortencarier. 1984. A Fortran 77 Program and User's Guide for the Generation of Latin Hypercube and Random Samples for Use with Computer Models. NUREG/CR-3624, SAND83-2365. Sandia National Laboratory.

WSRC. 1992. Radiological Performance Assessment for the Z-Area Saltstone Disposal Facility,

WSRC-RP-92-1360. Savannah River Site, Westinghouse Savannah River Company, Aiken, SC. 


\section{Westinghouse Savannah River Company Document Approval Sheet}

\begin{tabular}{l}
\hline Title \\
Radiological Performance Assessment fo \\
\hline Primary Author/Contact (Must be WSRC) \\
James R. Cook \\
\hline Organization Code \\
L3230
\end{tabular}

for the E-Area Low-Level Waste Facility
\begin{tabular}{|l|l|}
\hline Location & $\begin{array}{l}\text { Phone No. } \\
773-43 A\end{array}$ \\
\hline $\begin{array}{l}\text { Organization (No Abbreviations) } \\
\text { Waste Processing Technology }\end{array}$ \\
\hline
\end{tabular}

\section{Other Authors}

L.McDowell-Boyer, A.D. Yu, D. C. Kocher, E.L. Wilhite, K.E. Young, H. Holmes-Burns

Document No. WSRC-RP-94R18, Rev. 1

Key Words (iist 3)

Low-Level Waste Disposal, Performance Assessment, Waste Potosition Fellow Geologist User ID T5193 Pas an invention disclosure, patent application or copyright application $\square$ Yes $\triangle$ No If yes, date submitted
been submitted related to this information?

Disclosure No. (If Known) Title

If no, do you intend to submit one? $\quad \square$ Yes $\bigotimes$ No If yes, projected date

\section{Information Product Description}

$\bigotimes$ Technical Report

$\square$ Semiannual $\square$ Annual $\triangle$ Final $\square$ Topical $\square$ Other

$\square$ Administrative Report

$\square$ Semiannual $\square$ Annual $\square$ Final $\square$ Topical $\square$ Other

$\square$ Videotape/Multimedia

$\square$ External Web Page URL

$\square_{\text {Brochure/Booklet }}$

$\square$ Procedure/User Guide

$\square$ Drawing

$\square$ Software Package

References $\checkmark$ In Public Literature $\square$ Routing Concurrently

$\square$ Journal Article Journal Name

Book/Book Chapter Book Name

$\square$ Conference Submission"

I understand that for the information (in this material to be given external distribution, approvals by both WSRC and, as appropriate, DOE-SR are required. Distribution (verbally or published) mugt in acoprdance with policies set forth in WSRC management requirements and procedures (MRP 3.25) and in DOE-SR orders, and the content of the external distritution must be limited to that actually approved. Author's Signature

$$
\frac{3 / 31 / 2000}{\text { Date }}
$$

\section{Approvals by Author's Organization}

Derivative Classifieg

Intended Distribution

$\checkmark$ Unlimited (release to public)

Explanation for Limited Dist. $\quad \square$ Corporate/University Partner

$\square$ Limited (see explanation)

$\square$ Site Use Only

$\square$ Other

Other DOE facility(ies) only

I understand and have considered whether any potential intellectual property rights (patents, copyrights, etc. in accordance with MP 1.09 and MRP 1.07) or any contractural barriers (CRADAs, Work for Others, etc.) may be involved before authorizing that this document be proposed for public relpase. If any $^{-1}$ concerns were identified, thesa have been discussed and resolved with General Counself

$\frac{\text { were identifieg these have been discussed and resolved with General Counselfotiliz }}{\text { Manager's Name (Print) }}$

Classification (Check One for Each)

Overall

$\square$ s $\square$ S $\square$ S UCN

Title $\square$ s $\square$ C UCN

WSRC Classificat a io

onssification ANALYS

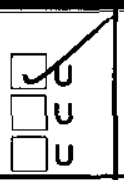

Classification Guide Topics

OPSEC $\square$

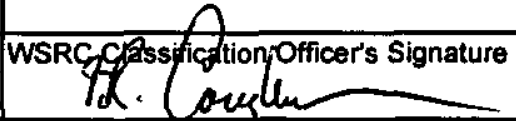

Export Control Related $\square$ Yes $\square$ No

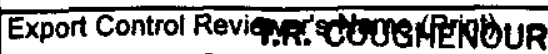

CLASSIFICATION ANALYST

Exporgonfrol heyiewer's Signature

Requested by (date)

OSTi Subj. Category No.

11

Routing

Editor/lllustrator/On-line Support

MSD Project No.

NOTE OSR 17-8 must be completed in addition to this form when submitting information for review and approval. 


$$
F[-[1,0]
$$

April 3, 2000
P.O. Box 616

Aiken, SC 29802

WSRC-RP-94-0218, Rev. 1

MSD-STI-2000-00274

Ms. W. F. Perrin, Technical Information Officer

U. S. Department of Energy - Savannah River Operations Office

Dear Ms. Perrin:

\section{REQUEST FOR APPROVAL TO RELEASE SCIENTIFIC/TECHNICAL INFORMATION}

The attached document is submitted for classification and technical approvals for the purpose of external release. Please complete Part II of this letter and return the letter to the undersigned by $5 / 16 / 2000$. The document has been reviewed for classification and export control by a WSPC Classification staff member and has been determined to be Unclassified.

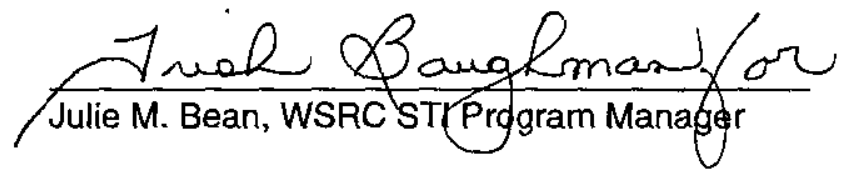

\section{DETAILS OF REQUEST FOR RELEASE}

Document Number: WSRC-RP-94-0218, Rev. 1

Author's Name: J. R. Cook

Location: $773-43 \mathrm{~A}$

Phone 5-5802

Department: Waste Processing Technology

Document Title: Radiological Performance Assessment for the E-Area Vaults Disposal Facility

Presentation/Publication: Report

Meeting/Journal:

$$
\text { Meeting Date: } \quad N / A
$$

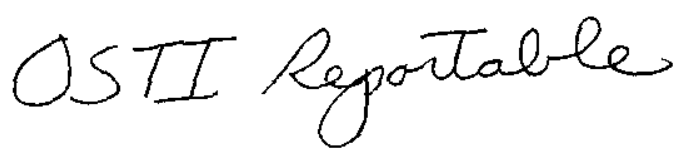

\section{DOE-SR ACTION}

$$
\text { Date Received by TIO }
$$

[X] Approved for Release Approved Upon Completion of Changes Approved with Remarks

Remarks: 
RECORD STATUS (select one):

..... New X...Revised Data ..... Tevised STI Product

Part l: STI PRODUCT DESCRIPTION

A. STI PRODUCT TYPE (select one)

X.. 1. Technical Report
a. Type: $\square$ Topical $\square$ Semiannual $\square$ Annual $\bigotimes$ Final
Other (specify)
b. Reporting Period ( $\mathrm{mm} / d d / y y y y$.
.. thru

2. Conference

a. Product Type: ...... Conference Proceedings ..... Conference Paper or Other (abstracts, excerpts, etc.)

b. Conference Information (title, location, dates)

3. Software Manual ( The actual software package should be made available simultaneously. Follow instructions provided with ESTSC F 1 and ESTSCF 2.)

4. Journal Article
a. Type: $\quad \underline{X}$ Announcement citation only
_. Preprint
Postprint
b. Journal Name
c. Volume
d. Issue
e. Serial identifier (e.g., ISSN or CODEN)

S\&T Accomplishment Report

Book

7. Patent Application

a. Date Filed $(\mathrm{mm} / \mathrm{dd} / \mathrm{yyyy})$

b. Date Priority ( $\mathrm{mm} / \mathrm{dd} / \mathrm{y} y \mathrm{y} / \mathrm{H})$

c. Patent Assignee

..... 8. Thesis/Dissertation

B. STI PRODUCT TITLE Radiological.Performance.Assessment.for.the.E.Area.Vaults.Disposal.Facility.

C. AUTHOR(s) J.,.R._. Cook

E-mail Address(es):

D. STI PRODUCT IDENTIFIER

1. Report Number(s) WSRC-RR.:94-0218,.Rex 1

2. DOE Contract Number(s) _DE-AC09-96.SR1850.0.

3. R\&D Project ID(s)

4. Other Identifying Number(s)

E. ORIGINATING RESEARCH ORGANIZATION_Savannah River Site

F. DATE OF PUBLICATION $(\mathrm{mm} / \mathrm{dd} / \mathrm{y} y \mathrm{y} y)$

G. LANGUAGE (if non-English) English

(Grantees and Awardees: Skip to Description/Abstract section at the end of Part I)

H. SPONSORING ORGANIZATION

I. PUBLISHER NAME AND LOCATION (if other than research organization)

Availability (refer requests to [if applicable])

J. SUBJECT CATEGORIES (list primary one first)

1.1.

Keywords .Computer.Modeling..Low.Lexel.Radioactive..Waste,.Pathways.Analysis.

K. DESCRIPTION/ABSTRACT

This report is the first revision to "Radiological Performance Assessment for the E-Area Vaults Disposal Facility, Revision 0", which was issued in April 1994 and received conditional DOE approval in September 1994. The title of this report has been changed to conform to the current name of the facility. The revision incorporates improved groundwater modeling methodolgy, which includes a large data base of site specific geotechnical data, and special Analyses on disposal of cement-based wasteforms and naval wastes, issued after publication of Revision 0 . 


\section{ANNOUNCEMENT OF U. S. DEPARTMENT OF ENERGY (DOE) SCIENTIFIC AND TECHNICAL INFORMATION (STI)}

\section{Part II: STI PRODUCT MEDIA/FORMAT and LOCATION/TRANSMISSION}

\section{A. MEDIAFFORMAT INFORMATION}

1. Medium of STI product is: $\quad$ X... Paper $\quad$...... Electronic document $\quad$....... Computer medium $\quad$...... Audiovisual material
2. Size of STI product

3. File format:

a. If electronic document is posted at site, indicate: $\square$ html $\square$ pdfn $\square$ sgml $\square$ xml

b. If electronic document is transmitted to OSTI, indicate: $\square$ html $\square$ pdfn $\square$ pdfi $\square$ msword

_._TIFFG4 __WP-indicate Version (5.0 or greater)

MS Word-indicate Version (5.0 or greater)

platform/operating system

4. If computer medium or audiovisual material:

a. Quantity/type (specify)

b. Machine compatibility (specify)

c. Sound:

(yes)

d. Color

(yes) e. Tables/Graphics

f. Other information about product format a user needs to know:

\section{B. LOCATION/TRANSMISSION INFORMATION}

1. STI Product is available at site: Unique URL (of specific STI Product)

2. STI Product is being transmitted to OSTI:

a.__ Electronically via FTP

b._. Via Mail or shipment (e.g., Federal Express) (Paper products, electronic documents on CD-ROM, diskettes, videocassettes, etc.)

3. Information Product Filename (of transmitted electronic format)

C. ADDITIONAL INFORMATION (concerning media/format or location/transmission; for OSTI internal use only):

(Grantees and Awardees: Skip to Contact section at the end of Part III)

Part III: STI PRODUCT REVIEW? RELEASE INFORMATION

A. ACCESS LIMITATION

X.... 1. Unlimited Announcement (available to U.S. and non-U.S. public)

2. OpenNet (use OpenNet guidance for below):

a. If additional source other than making it available through NTIS:

e. OpenNet Document Type

(1) Accession Number

f. OpenNet Document Keywords

(2) Document Location

b. Field Office Acronym

c. Declassification date (mm/dd/yyyy) _-__________

g. OpenNet Addressee

d. Declassification Status:

_- Declassified _- Sanitized _ Never classified

3. U.S. Dissemination Only

4. Copyrighted material; Are there any restrictions based on copyright?

yes no. If yes, list the restrictions

5. Small Business Innovation Research (SB/R) Release date ( $\mathrm{mm} / \mathrm{dd} / \mathrm{yyyy})$

6. Small Business Technology Transfer (STTR) Release date ( $\mathrm{mm} / \mathrm{dd} / \mathrm{yyyy}$ )

7. Proprietary/Trade Secret

8. Patent Pending

9. Protected data __ CRADA ___Other (specify)

Release date $(\mathrm{mm} / \mathrm{dd} / \mathrm{yyyy})$

10. Official Use Only (OUO)

11. Program-Directed Special Handling (specify)

12. Export Control/ITAR/EAR

13. Unclassified Controlled Nuclear Information (UCN)

14. Classified Classification Level/Categorv of:

a. This form $\mathbf{U}$.

b. The STI Product Unclassified.

15. Other information relevant to access (specify; for OSTI internal use only))

B. OTHER (information useful to include in published announcement record which is not suited for any other field on this form)

C. CONTACT AND RELEASING OFFICIAL

1.Contact (if appropriate, the organization or site contact to include in published citations who would receive any extemal questions about the content of the STI Product or the research information contained therein)

Name and/or Position

E-mail Organization Westinghouse Savannah River Company

\section{Phone (803) $725-2765$}

2. Releasing Official $\mathbf{X}$ I verify that all necessary reviews have been completed (e.g. Patent, Copyright, ECl, UCNI, etc.)

Released by (name) Julie M. Bean

Date $(m m / d d / y y y)$

E-Mail

Phone 